\title{
Die praktischen Konsequenzen des Methodenstreits : eine Aufarbeitung der Einkommensbesteuerung
}

Citation for published version (APA):

Hansen, R. (1996). Die praktischen Konsequenzen des Methodenstreits : eine Aufarbeitung der Einkommensbesteuerung. [Doctoral Thesis, Maastricht University]. Duncker \& Humblot. https://doi.org/10.26481/dis.19960620rh

Document status and date:

Published: 01/01/1996

DOI:

10.26481/dis.19960620rh

Document Version:

Publisher's PDF, also known as Version of record

\section{Please check the document version of this publication:}

- A submitted manuscript is the version of the article upon submission and before peer-review. There can be important differences between the submitted version and the official published version of record.

People interested in the research are advised to contact the author for the final version of the publication, or visit the DOI to the publisher's website.

- The final author version and the galley proof are versions of the publication after peer review.

- The final published version features the final layout of the paper including the volume, issue and page numbers.

Link to publication

\footnotetext{
General rights rights.

- You may freely distribute the URL identifying the publication in the public portal. please follow below link for the End User Agreement:

www.umlib.nl/taverne-license

Take down policy

If you believe that this document breaches copyright please contact us at:

repository@maastrichtuniversity.nl

providing details and we will investigate your claim.
}

Copyright and moral rights for the publications made accessible in the public portal are retained by the authors and/or other copyright owners and it is a condition of accessing publications that users recognise and abide by the legal requirements associated with these

- Users may download and print one copy of any publication from the public portal for the purpose of private study or research.

- You may not further distribute the material or use it for any profit-making activity or commercial gain

If the publication is distributed under the terms of Article $25 \mathrm{fa}$ of the Dutch Copyright Act, indicated by the "Taverne" license above, 


\section{DIE PRAKTISCHEN KONSEQUENZEN DES METHODENSTREITS: EINE AUFARBEITUNG DER EINKOMMENSBESTEUERUNG}

PROEFSCHRIFT

Ter verkrijging van de graad van doctor aan de Rijksuniversiteit Limburg te Maastricht, op gezag van de Rector Magnificus Prof.mr. M.J. Cohen, volgens het besluit van het College van Dekanen, in het openbaar te verdedigen op donderdag 20 juni 1996 om 16.00 uur

door

Reginald Hansen 


\section{Volkswirtschaftliche Schriften}

Begründet von Prof. Dr. Dr. h. c. J. Broermann †

Heft 457 


\title{
Die praktischen Konsequenzen des Methodenstreits
}

\author{
Eine Aufarbeitung \\ der Einkommensbesteuerung
}

Von

Reginald Hansen

Duncker \& Humblot · Berlin 
Die Deutsche Bibliothek - CIP-Einheitsaufnahme

\author{
Hansen, Reginald: \\ Die praktischen Konsequenzen des Methodenstreits : eine \\ Aufarbeitung der Einkommensbesteuerung / von Reginald \\ Hansen. - Berlin : Duncker und Humblot, 1996 \\ (Volkswirtschaftliche Schriften ; H. 457) \\ Zugl.: Maastricht, Univ., Diss., 1996 \\ ISBN 3-428-08507-8 \\ NE: GT
}

Alle Rechte vorbehalten

(c) 1996 Duncker \& Humblot GmbH. Berlin

Fotoprint: Berliner Buchdruckerei Union GmbH. Berlin

Printed in Germany

ISSN 0505.9372

ISBN 3-428-08507-8

Gedruckt auf alterungsbestlindigem (sliurefreiem) Papier entsprechend ISO 9706 (2) 


\section{Vorwort}

"Soll eine Arbeit als wissenschaftlich qualifiziert werden, so muß ihr Verfasser an erster Stelle das Material kennen und beherrschen, das die Grundlage der Arbeit bildet und zu ihrem Verstandnis erforderlich ist. ... Der Verfasser mußs mit diesem Material so vertraut sein, wie es fur den Aufseher einer Chaussee selbstverständlich ist, daß er alle Hăuser und Băume, alle schlechten und gefahrlichen Stellen an dieser Chaussee kennt."

Gustav Schmoller ${ }^{1}$

Die nachfolgende Abhandlung ist das Ergebnis meines langjăhrigen Forschungsinteresses, das sowohl von frühen Erörterungen wirtschaftlicher Fragen im Kreise bekannter Wirtschaftsfihrer im Elternhaus als auch spatter von den Beitrăgen der wissenschaftlichen Fachgelehrten der Universităt zu Köln und dann meiner langjährigen selbständigen praktischen Berufstătigkeit in der Vermögens- und Steuerberatung profitierte.

Gefragt, was mich im Laufe meines wissenschaftlichen Studiums am stärksten beeindruckte, müßte ich auf so extreme Positionen der wissenschaftstheoretischen Auseinandersetzung der 50er Jahre, die von Hans Albert und dem Einfluß der wirtschaftspolitischen Ideen Alfred Müller-Armacks und Gerhard Weissers ausgingen, hinweisen. Andererseits wärde es das Bild verfallschen, verschwiege ich die vielen Erkenntnisse, die mir in den Seminaren der profilierten Gelehrten der Universität zu Köln der 50er und 60er Jahre, und zwar in der Philosophischen Fakultăt, der Rechtswissenschaftlichen Fakultăt und der Wirtschafts- und Sozialwissenschaftlichen Fakultăt zuteil wurden.

Mein Interesse hat infolge einer naturwissenschaftlichen universitären Vorbildung während meiner Studien schwerpunktmäßig den methodologischen Auseinandersetzungen zwischen Gustav Schmoller und seinen vielen Gegnern gegolten. Die Diskussion um die wissenschaftstheoretischen Differenzen hat mich seit der Studienzeit an der KöIner Universităt fasziniert.

\footnotetext{
1 Zitiert nach seinem spāten Schaler Dr. jur. Dr. phil. Rolf Grabower; ehemals Ministerialreferent im Reichsfinanzministerium und nach 1945 Oberfinanzpräsident in Namberg in: Zur ethischen Betrachtungsweise im Abgabenrecht (Steuer und Wirtschaft 1959, Teill 1, Sp. 563).
} 
Ich habe daher Herrn Professor Dr. Jürgen G. Backhaus dafür zu danken, daß er mich im Jahr 1992 ermutigte und mir sodann zusetzte, meine Erkenntnisse über Gustav Schmollers Beiträge zur Sozialpolitik niederzuschreiben. Ich habe ihm weiter dafür Dank zu sagen, daß er mir die Anregung gab und mir Mut machte, die nun vorliegende Abhandlung zu schreiben. Dabei möchte ich darauf hinweisen, daß ich von Herrn Professor Backhaus nicht nur einige wichtige Gesichtspunkte für diese Abhandlung erhielt, sondern auch in vielen seiner von unvoreingenommenem Forschungsinteresse getragenen Seminarveranstaltungen an der Rijksuniversiteit Limburg in Maastricht/Niederlande zahllose Ratschläge erfuhr.

Auch die umfangreichen Kenntnisse über die Freiburger Schule und die Literaturhinweise von Herrn Dr. Gerrit Meijer waren für mich von großem Wert.

Für den Wahrheitsgehalt meiner Thesen habe ich freilich selbst einzustehen. Sie werden, dessen bin ich gewiß, nicht überall widerspruchsfrei bleiben.

Ich hătte zu meiner Niederschrift nicht ansetzen und sie später bestimmt nicht vollenden können, wenn mir meine Ehefrau Marlis nicht die zeitaufwendigen Tatigkeiten in meiner Steuerberatungspraxis zum großen Teil abgenommen und wenn sie nicht mit viel Geduld in ihrer Freizeit jedes Wort dieser Abhandlung niedergeschrieben hătte.

Daß ich meinem Schwiegersohn Heiner den Sieg über die Tücken der Computertechnologie verdanke und ohne die systematische Erfassung der Literatur durch meine Tochter Andrea die problemträchtigen Anmerkungen nicht hätte niederschreiben können, möchte ich erwähnen.

Hervorheben möchte ich auch noch, daß ich meine Arbeit ohne die Hilfsbereitschaf der Mitarbeiter der KöIner Üniversitätsbibliothek, aber auch derjenigen des Steuerrechtsseminars nicht hätte bewältigen können. 


\section{Inhaltsverzeichnis}

A. Warum diese Abhandlung? Die Einkommensteuer als "Konigin der Steuern" und ihre Bedeutung als "schönstes und bestes finanzpolitisches Instrument".

B. Einfuhrung in die Thematik zum besseren Verständnis der historischen $\mathrm{Zu}$ sammenhănge

C. Die Beurteilung des gütigen Einkommensteuerrechts der Bundesrepublik Deutschland im historischen Ablauf .................................................................. 28

I. Bewertung in den Fachzeitschriften ...................................................... 28

II. Beurteilung durch die höchstrichterliche Finanzrechtsprechung................ 37

D. Die von der Systematik der "deutschen Einkommensteuertype" gewahrten Möglichkeiten zur Herabsetzung beziehungsweise Vermeidung des Steuerzugriffs

I. Gestaltungsmöglichkeiten zur Vermeidung der direkten Steuern in Preußen nach den Befreiungskriegen bis 1891

II. Gestaltungsmöglichkeiten zur Herabsetzung des Steuerzugriffs in Sachsen nach der Steuerreform durch das EStG 1874/78

III. Gestaltungsmöglichkeiten in Preußen nach Einfuhnung des Einkommensteuergesetzes von 1891

IV. Die bis heute bestehenden Möglichkeiten zur Herabsetzung der Steuerbelastung in der "deutschen Einkommensteuertype" durch legale Gestaltungen zur Steuervermeidung.

E. Eigentumlichkeiten der Besteuerungswirklichkeit in der Bundesrepublik Deutschland seit 1949 - Schlaglichter auf soziale Unzutrăglichkeiten mit drohenden Konsequenzen

I. Die gesetzlichen Vorkehrungen für den Einsatz des Einkommensteuergesetzes als Instrument der Wirtschaftspolitik.

II. Steuervergüstigungen und deren Anreiz zur Steuervermeidung nach 1948

III. Die Technik der Steuervergünstigungen nach dem Einkommensteuergesetz und deren Konsequenzen

IV. Umfang der Steuerverganstigungen und Höhe der Steuervermeidung ....... 148

V. Konsequenzen einer problematischen Lastenverteilung.

F. Die kurzgefaßte Entstehungsgeschichte des Einkommensteuerrechts in Deutschland. 
I. Der geistesgeschichtliche Hintergrund der modernen Einkommensteuergesetze

1. Die wissenschaftstheoretischen Auseinandersetzungen im

19. Jahrhundert und deren Bedeutung fur die Nationalokonomie und die allgemeine Steuerlehre.

2. Die methodologische Außenseiterstellung Gustav Schmollers und dessen Besteuerungsidee

3. Die wissenschaftstheoretische Aufrassung Adolph Wagners und der ubrigen Nationalokonomen und dessen Fortsetzung der an den nachklassischen Thesen Karl-Heinrich Raus ausgerichteten Besteuerungslehren

II. Die gesetzgeberischen Konsequenzen

1. Die Entwicklung des sächsischen Einkommensteuergesetzes $1874 / 78$ aus der Besteuerungsidee Gustav Schmollers

2. Die Orientienung des preußischen Einkommensteuergesetzes 1891 an den Lehren Adolph Wagners

III. Das endgultige Verhandlungsergebnis in Preußen

G. Beurteilung der heute geltenden, von einer gespaltenen Systematik bestimmten Einkommensbesteuerung in der Bundesrepublik Deutschland unter verschiedenen modemen Gesichtspunkten.

H. Einfthrung in den weiteren Gedankengang in Form einiger Thesen.

J. Konsequenzen fur die Losung der anstehenden dringlichen Probleme bei der Finanzierung des Aufbaus nach der Wiedervereinigung mit der ehemaligen Deutschen Demokratischen Republik

I. Die Bedeutung der "sozialen Marktwirtschaf" als umfassendes Organisationsprinzip und die Konsequenzen fitr die Einkommensteuer Erfahrungen aus einem gelungenen Experiment

II. Die Eingliederung des Elesteuerungswesens in das Konzept der sozialen Marktwirtschaft - die Rolle cler Einkommensteuer beim Aufbau der Bundestepublik Deutschland

III. Die Ausdehnung des Institutionengefuges der Bundesrepublik Deutschland auf die ehemalige DDR durch den Beitritt gemäß

Art. 23 GG nach dem Einigungsvertrag vom 31. August 1990

1. Die institutionellen Ausgangsbedingungen im Beitrittsgebiet als Gnundlage für die Einfuhrung der Marktwirtschaft

2. Der Einsatz einkornmensteuerrechtlicher Gestaltungen als unter-stutzendes marktkonformes Mittel zur Förderung des Aufbaus in den fünf neưen Bundeslăndern.

a) Die ungünstigen Ausgangsbedingungen fur den erwarteten

Wirtschaftsaufschwung und die Strategie der Bundesregierung zur Problemlösung 
b) Steuerliche Verlustzuweisungsgesellschaften als Investoren Funktionswandel der Steuervergünstigung: Von der Stärkung der Wettbewerbsfahigkeit zur reinen Finanzierungshilfe durch Einsatz der Einkommensteuer als Instrument der Wirtschaftspolitik.

c) Die in der Bundesrepublik Deutschiand gemachten Erfahrungen mit Verlustzuweisungsgesellschaften und deren Eignung zur Forderung der wirtschaftlichen Infrastruktur in den neuen Bundesländern

K. Steuervergunstigungen als Subventionen - die Finanzierung von Verlustzuweisungsgesellschaften aus Steuerersparnissen zum Zweck der Investition im Fördergebiet und deren volkswirtschaftliche Bedeutung der Fiskus wurde wichtigstes Finanzierungsinstitut

L. Grenzen des Einsatzes der Einkommensteuer als Instrument der Wirtschaftspolitik

I. Die zunehmende Kompliziertheit des Besteuerungsverfahrens und die Leistungsfahigkeit der Verwaltung.

II. Ist das geltende Veranlagungsverfahren der zunehmenden wirtschaftspolitischen Verwendung der Einkommensteuer noch gewachsen?.

1. Kann von einer Fehlentwicklung des Vollzuges der Einkommensteuer gesprochen werden?

2. Fruhe Wamungen zur Einfuhrung der Einkommensteuer

3. Ergebnisse der Gesetzesanwendung in Sachsen nach Durchfuhrung der Reform in Jahr 1878

4. Die Ergebnisse der Gesetzesanwendung nach Einfuhrung des preußischen EStG 1891

5. Fortentwicklung von Gesetz und Gesetzesanwendung zur sogenannten "deutschen Type" der Einkommensbesteuerung

a) Die systemtragenden Grundgedanken des sächsischen EStG 1874/78, die Problematik der Gewinnermittlung nach Handels. recht und die Vorreiterrolle Sachsens

b) Die Gewinnermittlung nach Handelsrecht und die "preufische Type" der Einkommensteuer

c) Der Einfluß Matthias Erzhergers auf das Einkommensteuerrecht und den Gesetzesvollzug und dessen Nachwirkungen ........ 388

d) Die Fortentwicklung zum heutigen Gesetzesvollzug bei der Einkommensbesteuerung .

e) Fehlentwicklungen in der deutschen Einkommensbesteuerung durch das Zusammenwirken von Gesetz und Gesetzesvollzug .... 408

6. Unpraktikable Anforderungen an den heutigen Gesetzesvollzug die Selbstveranlagung der Steuerpflichtigen als Ausweg aus einem Dilemma

a) Der Amtsermittlungsgrundsatz und die Besteuerungswirklichkeit. 
b) Ansătze zu einer Reform der Veranlagung zur Einkommensteuer

c) Die US-amerikanische Selbstveranlagung zur Einkommensteuer aus der Sicht der Bundesirepublik Deutschland im Jahr 1994

d) Denktraditionen als Hemmnisse für einen reformierten Gesetzesvollzug.

M. Die mit dem wachsenden Einsatz der Einkommensteuer zu nichtfiskalischen Zwecken verbundenen gesellschaftspolitischen Interessen und die zu erwartenden Verteilungskămpfe

I. Thesen des Steuerrechtswissenschaftlers............................................. 449

II. Thesen des Sozialpolitikers.............................................................. 451

III. Thesen des Volkswirts und Finanzwissenschaftlers............................... 454

IV. Darstellung der Entwicklung und Rechtfertigung der Steuerpolitik durch die Finanzbehörde.

V. Der gesellschaftspolitische Hintergnund bei Entstehung der Einkommensteuer und die Beurteilung der neueren Entwicklung durch den Soziologen

N. Ergebnis: Eignung und Grenzen der aus unterschiedlichen und einander ausschließenden Besteuerungsideen entwickelten Einkommensbesteuerung der Bundesrepublik Deutschland.

Anlage 1: Einkommensteuergesetz vom 2. Juli $1878, \S \S 15$ Abs. 1, 15 Abs. 6 ,

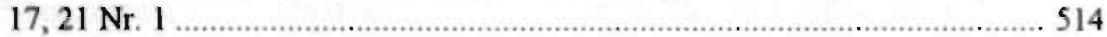

Instruction zum Einkommensteuergesetz vom 2. Juli 1878, $\$ 64 \ldots \ldots \ldots \ldots \ldots \ldots . . .515$

Anlage 2: Einkommensteuergesetz vom 24. Juni 1891, $\S \S 7,8,14,9 \ldots \ldots \ldots \ldots \ldots \ldots \ldots \ldots$

Anlage 3: Einkommensteuergesetz. Vom 29. Mărz 1920, $\S \S 4,5 \ldots \ldots \ldots \ldots \ldots \ldots \ldots \ldots . \ldots 17$

Anlage 4: Einkommensteuergesetz. Vom 10. August 1925, $\$$ 6, $7 \ldots \ldots \ldots \ldots \ldots \ldots \ldots ., 518$

Anlage 5: Gesetz zur Verminderung der Arbeitslosigkeit. Vom 1. Juni 1933 ......... 519

Anlage 5 a: Vordruck 1. Anzeige uber die Belassung alter Gegenstănde im Betrieb als Aushilfegegenstände

Anlage 6: Fôrdergebietsgesetz vom 23. September 1993, $\S \S 1,3,4,5$

Anlage 7: Geschlossene Immobilienfonds. Jahrhundertgeschenk oder Zeitbombe? Aus: Der Platow Brief Spezial, November 1994 
Anlage 9: Der "Hebeleffekt" bei Erzielung von Oberschüssen zwischen Verkauf und Kauf einer Wohnung

Anlage 10: Berechnungsbeispiel fur die Beteiligung einer $\mathrm{GmbH}$ an einer

Reederei fur den Neubau eines Schiffes

Anlage 11: Der Begriff der Abschreibungs- oder Verlustzuweisungsgesellschaft und Darstelilung der sogenannten "Hebelwirkung"

Anlage 12: Berechnungsbeispiel I fur eine Beteiligung am Immobilienfonds Ostdeutschland

Anlage 13: Berechnungsbeispiel II fur eine Beteiligung am Immobilienfonds Ostdeutschland.

Anlage 14: Die neue Schiffsbeteiligung 1994

Anlage 15: Angebot zur Beteiligung an dem MT "Donaustern"

Anlage 16: Musterberechnung fur die Steuerersparnis durch Verlustzuweisung

Anlage 17: Berechnungsbeispiel für die Beteiligung an einer Rehabilitationsklinik

Anlage 18: Berechnungsbeispiel "Steuerliche Netto-Überschußrechnung fur den Anleger"

Anlage 19: Der offentlich geförderte soziale Wohnungsbau Berlin. Ein Coberblick.. 541

Anlage 20: Berechnungsbeispiel fur die Beteiligung am ôffentlich geforderten sozialen Wohnungsbau in Berlin

Anlage 21 a: Berechnungsbeispiel ohne Refinanzierung fur eine Kommanditeinlage.

Anlage 21 b: Berechnungsbeispiel mit Refinanzierung fur eine Kommanditeinlage

Anlage 22: Beteiligungsangebot an einem Flugzeug-Leasingfonds

Anlage 23: Beteligungsangebot an einer VerwaltungsGmbH u. Co Vermietungs KG (Jenoptik)

Anlage 24: Berechnung der Vorteilhaftigkeit einer Beteiligung am Wohnungsbau in Berlin 
Anlage 25: Beispielrechnung einer Kommanditeinlage

Anlage 26: Angebot "Investieren in Berlin-Neukölln" nach dem Fördergebietsgesetz

Anlage 27: Berechnungsbeispiel Fondsbeteiligung an dem Einkaufs- und Dienstleistungszentrum Cottbus

Anlage 28: Angebot zur Beteiligung am Wiederaufbau des Hotel Adlon, Berlin 553

Anlage 29: Wirtschaftlichkeitsberechnung für den Kauf eines Zweifamilienhauses im Kreis Aachen-Neuß

Anlage 30: \& 32 d ESIG 1990 i. d. F. vom 23.6.1993

Anlage 31: Anlage E (Erwerbsbezlige) zur Einkommensteuererklärung 1994 558

Literaturverzeichnis 559

Namenregister 664 


\section{Abkürzungsverzeichnis}

\begin{tabular}{ll} 
a.F. & Alter Fassung \\
AG & Aktiengesellschaft \\
AHGB & Allgemeines Handelsgesetzbuch \\
Anm. & Anmerkung \\
AO & Abgabenordnung \\
ARSP & Archiv der Rechts- und Sozialphilosophie \\
bearb. & bearbeitet \\
BB & Betriebs-Berater (Zeitschrift) \\
betr. & betreffend \\
BewG & Bewertungsgesetz \\
BFH & Bundesfinanzhof; auch: Sarnmlung der Entscheidun- \\
& gen des BFH \\
BGB & Burgerliches Gesetzbuch \\
BGBI. & Bundesgesetzblatt \\
BGH & Bundesgerichtshof \\
BMF & Bundesminister(ium) der Finanzen \\
BpO & Allgemeine Vorschriften fur die Betriebsprufung \\
BStBl. & Bundessteuerblatt \\
BVerfG & Bundesverfassungsgericht \\
BVerfGE & Entscheidungen des Bundesverfassungsgerichts \\
DB & Der Betrieb (Zeitschrift) \\
DDR & Deutsche Demokratische Republik \\
DJZ & Deutsche Juristen-Zeitung \\
DM & Deutsche Mark \\
DMBilG & D-Markbilanzgesetz \\
DRiZ & Deutsche Richter-Zeitung \\
Drs. & Drucksache \\
DSTG & Deutsche Steuer-Gewerkschaft; auch: Zeitschrift \\
DStJG & Deutsche Steuerjuristische Gesellschaft \\
DStR & Deutsches Steuerrecht (Zeitschrift) \\
DSZ & Deutsche Steuer-Zeitung \\
EFG & Entscheidung der Finarzgerichte (Zeitschrift) \\
Einf. & Einfuhrung \\
Einl. & Einleitung \\
ErbStG & Erbschaftsteuergesetz \\
ESt & Einkommensteuer \\
EStDV & Einkommensteuer-Durchfuhrungsverordnung \\
EStG & Einkommensteuergesetz \\
& \\
\hline
\end{tabular}




\begin{tabular}{|c|c|}
\hline EStR & Einkommensteuerrichtlinien \\
\hline EStRG & Einkommensteuerreformgesetz \\
\hline F. & Fach \\
\hline FA & Finanz-Archiv; auch: Finanzarchiv (Zeitschrift) \\
\hline $\mathrm{FG}$ & Finanzgericht \\
\hline FKPK & $\begin{array}{l}\text { Gesetz zur Umsetzung des foderalen Konsolidierungs- } \\
\text { Programms }\end{array}$ \\
\hline Fn. & Fußnote \\
\hline FördG & Fördergebietsgesetz \\
\hline $\mathrm{FR}$ & Finanz-Rundschau (Zeitschrift) \\
\hline $\begin{array}{l}\text { GbR } \\
\text { gem. }\end{array}$ & $\begin{array}{l}\text { Gesellschaft bürgerlichen Rechts } \\
\text { gemäß }\end{array}$ \\
\hline GFE & $\begin{array}{l}\text { Gesellschaft zur Förderung der Entbörokratisierung } \\
\text { e. V., Bonn }\end{array}$ \\
\hline GG & Grundgesetz fur die Bundesrepublik Deutschland \\
\hline $\mathrm{GmbH}$ & Gesellschaft mit beschrănkter Haftung \\
\hline GmbHG & $\begin{array}{l}\text { Gesetz betreffend die Gesellschaften mit beschränkter } \\
\text { Haftung }\end{array}$ \\
\hline GNOFĀ & $\begin{array}{l}\text { Grundsătze zur Neuorganisation der Finanzămter und } \\
\text { zur Neuordnung der Besteuerung }\end{array}$ \\
\hline $\mathrm{GoB}$ & Grundsătze ordnungsmäßiger Buchführung \\
\hline GV & Gesetz- und Verordnungsblatt \\
\hline GVR & Geldverkehrsrechnung \\
\hline Halbbd. & Halbband \\
\hline Hansa & Hansa, Zeitschuift für Schiffahrt, Schiffbau, Hafen \\
\hline HdF & Handbuch der Finanzwissenschaft \\
\hline HdSW & Handwörterbuch der Sozialwissenschaften \\
\hline HdSt & Handwörterbuch der Staatswissenschaften \\
\hline HdWW & Handwörterbuch der Wirtschaftswissenschaften \\
\hline HFR & Höchstrichterliche Finanzrechtsprechung (Zeitschrift) \\
\hline HGB & Handelsgesetzbuch \\
\hline Hrsg. & Herausgeber \\
\hline hrsg. & herausgegeben \\
\hline h.M. & herrschende Meinung \\
\hline HwStR & Handwörterbuch des Steuerrechts \\
\hline Inf. & $\begin{array}{l}\text { Die Information aber Steuer und Wirtschaft (Zeit- } \\
\text { sehrift) }\end{array}$ \\
\hline IRC & Internal Revenue Code \\
\hline IRS & Internal Revenue Service \\
\hline i.S. & im Sinne \\
\hline i.S.d. & im Sinne des \\
\hline JbflNSt & Jahrbücher für Nationalökonomie und Statistik \\
\hline JuS & Juristische Schulung (Zeitschrift) \\
\hline JZ & Juristen-Zeitung \\
\hline KG & Kommanditgesellschaft \\
\hline
\end{tabular}


KÖSDI

KStG

LSt

m.w.N.

N.F.

NWB

NJW

n.rkr.

n.v.

o.A.

OFD

OHG

preuß.

Preuß. Jb.

RAO

Rnr.

RFH

RFHE

RGBI.

RGZ

rkr.

RStB1.

RGSt

Rz.

$\mathrm{S}$.

s.

s.a.

sächs.

Schm.Jb.

Sp.

StandOG

StÄndG

StbJb

Stpfl.

StuW/StW

$\mathrm{StVj}$

StWG

u..a.

Unt.

usw.
Kölner Steuer-Dialog (Zeitschrift)

Körperschaftsteuergesetz

Lohnsteuer

mit weiteren Nachweisen

Neue Folge

Neue Wirtschafts-Briefe (Zeitschrift)

Neue Juristische Wochenschrift (Zeitschrift)

nicht rechtskraftig

nicht veroffentlicht

ohne Autorenangabe

Oberfinanzdirektion(en)

Offene Handelsgesellschaft

preußisch(es)

Preußische Jahrbücher (Zeitschrift)

Reichsabgabenordnung

Randnummer

Reichsfinanzhof

Sammlung der Entscheidungen des Reichsfinanzhofs

Reichsgesetzblatt

Sammlung der Entscheidungen des Reichsgerichts in Zivilsachen

rechtskraftig

Reichssteuerblatt

Sammlung der Entscheidungen des Reichsgerichts in Strafsachen

Randziffer

Seite

siehe

siehe auch

$\operatorname{sảchsisch(es)~}$

Jahrbuch fur Gesetzgebung, Verwaltung und Volkswirthschaft im Deutschen Reich, Hrsg. G. Schmoller, auch: Schmollers Jahrbuch

Spalte

Standortsicherungsgesetz

Steuerånderungsgesetz.

Steuerberater-Jahrbuch

Steuerpflichtige(r)

Steuer und Wirtschaft (Zeitschrif)

Steuerliche Vierteljahresschrift (Zeitschrift)

Gesetz zur Förderung der Stabilitht und des Wachstums der Wirtschaft

und andere, auch: unter anderem

Urteil

und so weiter 
u.U.

Verw.Arch.

VfS

vo

VStG

VStR

VZR

WFA

WRV

ZfZ

ZHR

ZRP

$\mathrm{ZfgSt}$ unter Umstănden

Verwaltungsarchiv (Zeitschrift)

Verein für Socialpolitik

Verordnung

Vermögensteuergesetz

Vermōgensteuertichtlinien

Vermōgenszuwachsrechnung

Wohnungswirtschaftlicher Fachausschuß des Instituts der Wirtschaftsprafer in Deutschland e. V.

Weimarer Reichsverfassung

Zeitschrift für Zölle und Verbrauchsteuern

Zeitschrift fur das gesamte Handelsrecht und Wirtschaftsrecht

Zeitschrift für Rechtspolitik

Zeitschrift für die geșamte Staatswissenschaft 


\section{A. Warum diese Abhandlung ? Die Einkommensteuer als "Königin der Steuern" und ihre Bedeutung als "schönstes und bestes finanzpolitisches Instrument"}

Für Johannes Popizz war die Einkommensteuer die "Königin der Steuern",' für den Nationalökonomen Adolf Lampe "die Zentralsonne" unter den Abgaben. ${ }^{2}$ Joseph Schumpeter sprach von dem "schönsten und besten finanzpolitischen Instrument". ${ }^{3}$ Inzwischen tritt die volle Bedeutung dieser Aussagen für jeden erkennbar zutage: Sieht man von dem stark wachsenden Bereich der Sonderabgaben ab, so läßt sich festhalten, daß der moderne Rechtsstaat, als welcher sich die Bundesrepublik Deutschland versteht, "wesentlich ein Sozialstaat in seiner Eigenschaft als Steuerstaat ist." ${ }^{\text {4 }}$

Die Finanzierung von Bund, Ländern und Gemeinden hat nach der Verfassung aus dem Ertrag der Steuern und Finanzmonopole zu erfolgen.

Von der herausragenden Bedeutung der Einkommensteuer im Gesamtsystem der Besteuerung werden wir sogleich erfahren. Dennoch ist sie bis heute heftigst umstritten geblieben.

\footnotetext{
1 Popitz, J. (1926), S: 402.

${ }^{2}$ Lampe, A. (1934), Reine Theorie ..., S. 222.

${ }^{3}$ Schumpeter, J. (1929), S. 381. Schumpeter vertrat die bei Volkswirten herrschende Oberzeugung. die der Herausgeber des "Deutschen Volkswirt" G. Siolper 1929 in einem umfangreichen "Finanzplan" entwickelt hatte. Danach stand der Tarifzugriff der ESt von $40 \%$ in der Spitze notwendigen Investitionen im Wege. Da Schumpeter argwöhnte, eine Senkung des Tarifs und vor allem eine starkere Besteuerung der verbrauchten Einkommensteile sei nicht durchsetzbar, glaubte er, die ESt habe ihren Zenit als finanzpolitisches Instrument, als "schönste Blate der Steuerkultur" und "höchste Emungenschaft der Steuertechnik" aberschritten. Sie war nach Schumpeter "die Steuer des bärgerlichen Liberalismus" (S. 382). In einer vergleichbaren Situation glaubte 1950 G. Schmolders, das Schicksal der für die BRD für einen Wiederaufbau aus Ruinen lebensnotwendigen Investitionstatigkeit halnge von einer Herabsetzung des Tarifzugriffs und einer wirtschaftspolitischen Ausrichtung đer ESi ab. Der Umfang der Eignung der Einkommensbesteuerung als Institution zur wirtschaftspolitischen Steuerung der Volkswirtschaft durch den instrumentalen Einsatz ihrer einzelnen, Ermittlungs-, Bewertungs- und Tarifvorschriften war beiden Gelehrten noch nicht abersehbar. Siche Schumpeter, J. (1930), S. 695: Schmölders, G. (1948), S. 481; ders. (1953), S. 58, S. 68.

4 Isensee, J. (1977), S. 410; Zitat entnommen aus: Forsthoff, E. (1977). Der Sozialstaat ist nach Forsthoff "unausweichlich auf den Steuerstaal als Vehikel angewiesen". Darin kommt der ESt die gröBte Bedeutung zu.
} 
Erst kürzlich räsonierte in einer von Richtern am höchsten deutschen Finanzgericht herausgegebenen Steuerzeitschrift ein sachkundiger Autor - wenn auch scherzhaft - über eine Totalreform des deutschen Steuersystems bei Fortfall von Einkommen- und Körperschaftsteuer und deren Ersetzung durch eine geradezu atemberaubende Erhöhung der Umsatzsteuer: ${ }^{5}$ Ein bekannter Steuerrechtler wollte die Einkommensteuer gelegentlich zornig ganz abgeschafft wissen, sofern es nicht endlich gelinge, sie an den Ansprüchen gerechter und gleichmäßiger Besteuerung zu orientieren. ${ }^{6}$ Andererseits erwähnte er aber deren Qualifikation, bei den Harmonisienungsbemühungen für Europa als "geistiger Exportartikel" zu dienen, ${ }^{7}$ wobei er sofort in einer Anmerkung beiläufig einwarf: "Aber seien wir ehrlich: Das deutsche Steuerrecht ist schlechter als sein Ruf". ${ }^{8}$ Tatsăchlich wurde 1991 dessen langiähriger Assistent und Nachfolger im Lehramt vom deutschen Bundesfinanzministerium mit der Ausarbeitung eines Gesetzeswerkes zur Einkommensteuer für liberalisierte osteuropäische Republiken auf Grundlage der deutschen Erfahrungen betraut. ${ }^{9}$

So schlecht kann wohl das Steuersystem eines Landes, das nach dem letzten Krieg einen unvergleichbaren Aufschwung erlebte, nicht sein, so wird sich mancher sagen, der die unterschiedlichen Bewertungen abzuwägen sucht.

Fragen wir uns nun, für welche Problemlösungen das deutsche Einkommensteuerrecht nach seiner spezifischen Ausgestaltung geeignet ist. Kommt es gar wiederum anläßlich der Harmonisierung größerer Wirtschaftsräume als Exportartikel infrage ? Das preußische EStG von 1891, dessen Rahmenkonzeption das heute gültige EStG der Bundesrepublik Deutschland noch weitgehend bestimmt, hat tatsächlich vielen Ländern in der ganzen Welt als Muster gedient. ${ }^{10}$ Die "preußische Type" des Einkommensteuerrechts setzte am 24. Juni 1891 - wie kürzlich von Steuerrechtlern in Gedenkfeiern festgehalten

Janssen, B. (1991), S. 594.

- Tipke, K. (1980), Steuergerechtigkeit .... S. 296: "... so liegt im abrigen die Frage nahe, ob sie für unser Land, obwohl ja kein Entwicklungsland, überhaupt eine geeignete Steuer ist". Nach Tipke ist die Einkommensteuer "in ihrem gegenwärtigen Zustand ... als Kônigin der Steuern enthhront". s. Steuerrecht. 12. Autl. 1990, S. 185. S. 178; ders. (1986), Ober Steuervereinfachung .... S. 65: ders. (1988), Ober richtiges Steuerrecht .... S. 262; ders. (1979), S. 77.

Tipke, K. (1976), Öber Steuergesetzgebung .... S. 307; ders. (1990), S. 309. Ähnliche Vorstellungen aber die Eignung des preuß. ESi-Rechts als Exportartikel ãuBerte bereits 1903 Fiusting mit inhaltichen Auffassungen, die mit denen Tipkes absolut unvereinbar sind. Fuisting. B. (1903). Einkommensbesteuering .... S. I.

Tipke, K. (1976), Ober Steuergesetzgebung. S. 307. Anm. 85.

9 Lang, J. (1992), S. 3.

${ }^{10}$ Das preußische EStG war von großem EinfluB, wenn nicht gar bestimmend für den gesamten deutschen Sprachraum. Ähnlich verhielt es sich mit der spăteren AO. die z B. heute noch für Luxemburg grundlegend ist, hierzu: Tipke, K. (1976). Ober Steuergesetzgebung .... S. 307. Anm. 85. Erwảhnt werden auch Japan und China (Taiwan), s. Halfar. B., S. 397. 
wurde - bis heute, also für 100 Jahre "den Maßstab für Deutschland". "Ist das deutsche Einkommensteuerrecht gar mit den großen Gesetzeskodifikationen zur Jahrhundertwende, wie dem Strafgesetzbuch, dem Bürgerlichen Gesetzbuch, den Prozeßordnungen und anderen Regelungssystemen insoweit vergleichbar?

Hierzu vorerst einige Zahlen aus der Bundesstatistik: Die gesamten Steuereinnahmen der Gebietskörperschaften der Bundesrepublik Deutschland betragen ca. 25\% des Bruttosozialproduktes. Sie erreichten im Jahr 1993 DM 748 Mrd. Davon entfielen 44,99\%, also DM 336,5 Mrd. auf die mit der Einkommensteuer in direktem Zusammenhang stehenden einzelnen Steuerarten. ${ }^{12}$ Nach vorlăufigen Schătzungen betrugen die gesamten Steuereinnahmen im Jahr 1992 einschließlich der neuen Bundesländer noch DM 731,7 Mrd. ${ }^{13}$

Die zur Einkommensteuer zu rechnenden Abgaben sind inzwischen auf etwa DM 350 Mrd aufgelaufen. Diese Steuereinnahmen in Hohe von fast $11 \%$ des gesamten Bruttoinlandsproduktes sind mithin von der rechtlichen Ausgestaltung einer einzigen Steuerart betroffen. ${ }^{14}$

Der Tarifzugriff des heute geltenden EStG ist progressiy ausgestaltet. Er erreicht derzeit bei einem steuerpflichtigen Einkommen von DM 120.042,-- den Spitzensatz von $53 \%{ }^{15}$ Der Körperschaftsteuersatz beträgt im Regelfall $50 \%{ }^{16}$

Bei Kenntnisnahme dieser Zahlenzusammenhănge wird die Nervosităt verständlich, mit der zuständige oder betroffene Behördenleiter und verantwortliche Politiker reagieren, wenn eingefahrene Besteuenungsmodalităten in der Diskussion infrage gestellt oder gar von Finanzgerichten Novellierungen aus Verfassungsgründen angemahnt werden. Bei 29 Mio. steuerpflichtigen Arbeitnehmern sind schnell durch Abänderung gewohnter Regelungen Fehlbeträge in mehrfacher Milliardenhöhe im jährlich gesetzlich verabschiedeten Haushalt erreicht.

"Großfeld, B. (1981), S. 46: Bayer, H. W. (1991, S. 334, S. 339.

12 Aus: BMF: Der Bundeshaushalt. Unser Geld, Bonn 1994, S. 6, S. 8: ders., Der Finanzplan des Bundes 1993 bis 1997, S. 80, Bonn 1994.

13 Mitteilung des BMF in: Suddeutsche Zeitung vom 22.6.1993 und Kölnische Rundschau vom 26.2.1993.

14. Das KStG verweist in den $\$ \S 7$ und 8 fur die Ermittlung der Bemessungsgrundlage auf die Vorschriften des EStG. Die LSt ist eine Erhebungsform der ESt. Die VSt wurde als Besteuerung des fundierten Einkommens konzipiert.

15 \$ 32 a Abs. 1 Ziff. 4 EStG (1993).

16. $\$ 23$ Abs. 1 KStG 1993. 
Halten wir fest: Der Sozialstaat Bundesrepublik Deutschland wird überhaupt erst durch die Einkommensteuer in ihrer heutigen Form ermöglicht. Diese trägt aber nicht nur wesentlich zum Fundus für die Umverteilung bei. Wie wir noch sehen werden, hat sie sich inzwischen zu einem der wichtigsten Bestandteile des wirtschaftspolitischen Instrumentariums für eine arbeitsplatzsichernde und wachstumsgerichtete Globalsteuerung des Wirtschaftskreislaufs und sogar der Förderung konkreter bereichsorientierter Aufgaben entwickelt, ohne dabei die Freiheiten des Marktes antasten zu müssen.

Der Autor stellt sich die Aufgabe, durch eine Rückbesinnung auf die zur Zeit der Entstehung der "deutschen Einkommensteuertype" konkurrierenden Besteuerungsideen zu skizzieren, wo die Stärken und wo die Schwächen eines Normengefuges liegen, das es vermochte, die Verwerfungen eines bewegten Jahrhunderts unter der Herrschaft von drei verschiedenen Verfassungen, die Turbulenzen eines "totalen" Krieges und dann auch noch danach den Zeitraum eines beschwerlichen, alles umfassenden Wiederaufbaues unter völlig veränderter Wirtschaftsordnung ohne Umgestaltung des tragenden Systems zu überdauern.

Für die Fortbildung der deutschen Einkommensteuer erhält die Analyse ihrer Entwicklung und eventueller Fehlleistungen zunehmend an Bedeutung. Ihre Eignung als "geistiger Exportartikel" muß an den Ergebnissen gemessen werden. 


\section{B. Einführung in die Thematik zum besseren Verständnis der historischen Zusammenhänge}

Die leitenden Gedanken des ersten modernen deutschen Einkommensteuergesetzes wurden von Gustav Schmoller im Oktober 1862 in einem Aufsatz mit dem Titel "Die Lehre vom Einkommen in ihrem Zusammenhang mit den Grundprincipien der Steuerlehre" formuliert.' In diesem Aufsatz übernahm Schmoller die von F. B. W. Hermann 1832 benutzte Definition des Einkommens, die in dessen Lehrbuch eine Verbindung von der Produktionslehre der klassischen Nationalökonomie zu der in den Vordergrund rückenden Verteilungslehre suchte. ${ }^{2}$ Schmoller löste die Definition aus der bei Hermann noch bestehenden Einbettung in die klassische Lehre von der Produktion für den Markt, einer Lehre von der anteiligen Verteilung der Güterproduktion auf die dabei beteiligten Produktionsfaktoren. ${ }^{3}$ Damit fiel für ihn die scharfe Abgrenzung zwischen produktivem und abgeleitetem Einkommen fort, die bei Hermann noch von Bedeutung war. ${ }^{4}$ Seine Definition des Einkommens setzle nicht mehr die unmittelbare Beteiligung des Empfängers an der Gütererzeugung für den Markt voraus. ${ }^{5}$ Das war ein völliger Bruch mit dem klassischen Konzept, das im Grunde eine Lehre von der Produktion für den Markt zur Sicherung der allgemeinen Wohlstandsmehrung gewesen war. ${ }^{6}$

Schmollers Vorschlag zur Definition eines Einkommensbegriffes für die Besteuerung lautete: "Unter Einkommen verstehen wir ... die Summe von Mitteln, welche der Einzelne ohne in seinem Vermögen zurückzukommen, für sich und seine Familie ... in einer Wirtschaftsperiode verwenden kann". Im übrigen unterstellte er: "Die wenigen Fälle von Verschwendern ausgenommen, muß jede Bedürfnisbefriedigung auf einem Einkommen ruhen. Niemand kann dauernd Ausgaben für seine Persőnlichkeit machen ohne Einkommen". ${ }^{8}$

1 Schmoller, G. (1863), S. 1.

2 Schmoller, G. (1863), S. 17. u.a.; Hermann, F. B. W. (1870), S. 582.

${ }^{3}$ Schmoller, G. (1863), S. 6, S. 32.

4 Hermann, F. B. W. (1870), S. 590, S. 593.

s. Schmoller, G. (1863), S. 6, S. 32, S. 52.

- Schmoller, G. (1863), S. 32.

'Schmoller, G. (1863), S. 52.

"Schmoller, G. (1863), S. 53. 
Schmoller wußte, daß er sich mit diesem Vorschlag von den herrschenden Auffassungen völlig löste. Er schlug dannit einen Maßstab für die "Wăgung der totalen wirthschaftlichen Kraft der Persönlichkeit" vor. ${ }^{9}$

Dieser Maßstab war unabhăngig von deren Beteiligung an der Produktion für den Markt. "Das Einkommen ... ist also keine Ertragskathegorie ... kein Produkt eines beliebigen wirtschaftlichen Rechnungsexempels. ... Dies ist die wahre Grundlage unseres Einkommensbegriffes; mit dem Produktionsprozess steht er nur in mittelbarem Zusammenhang", so heißt es bei Schmoller. "Der Gegenstand der Besteuerung sollte also über das benufliche Erwerbseinkommen aus festen, der Ertragsbesteuerung unterworfenen Quellen hinausgehen, indem es so einen Maßstab fur "die ganze wirthschaftliche Kraft" des Steuerpflichtigen als Bernessungsgrundlage festlegte.

Nach Schmollers Vorstellung sollte die Einkommensteuer im Gesamtsystem der Besteuerung die Funktion übernehmen, gewissermaßen als Schlußglied eine Steuerbelastung der Bürger nach ihrer individuellen Leistungsfahigkeit zu bewirken. $\mathrm{Zu}$ diesem $\mathrm{Zweck}$ sollte sie die Abgabenlast derartig korrigieren, daß jeder Bürger ingesamt zu direkten und indirekten Steuern, etwa gemäß seiner Leistungsfăhigkeit, beiträgt. " Diese Besteuerungsidee setzte naturgemäß die aktive Mitwirkung des Steuerbürgers bei der Ermittlung der Bemessungsgrundlage durch eine sogenannte "Selbsteinschätzung" oder Deklantion des Einkommens voraus.

Nach ausgiebigen Beratungen und Einholung vieler Gutachten beschloß der săchsische Landtag am 11. November 1872 ein neuartiges Einkommensteuergesetz auf Grundlage der von Schmoller entwickelten Besteuerungsidee zu verwirklichen. ${ }^{12}$ Dasselbe trat dann am 2. Juli 1878 in Kraft. ${ }^{13}$

Die "Selbsteinschätzung" des Steuerpflichtigen wurde in Sachsen eine der wichtigsten Neuerungen dieser umfassenden Steuerreform von 1874/78. Thre Ausgestaltung wurde von dem Ziel geleitet, den zuständigen Behörden des Finanzministeriums zu ermöglichen, die Lasten des Gemeinwesens nach wirtschaftlichen Gesichtspunkten der Leistungsfähigkeit im Einklang mit den gesetzlichen Vorschriften auf die Steuerbürger zu verteilen.

\footnotetext{
Schmoller, G. (1863), S. 53.

10 Schmoller, G. (1863). S. 52

$"$ Schmoller, G. (1863), S. 54, S. 71, S. 73, S. 83

${ }^{12}$ Mittheilungen aber die Verhandlungen des Landtages im Königreich Sachsen, II. Kammer, 91. Offentliche Sitzung der zweiten Kammer, S. 3313.

${ }^{13}$ Gesetz- und Verordnungsblatt. Königreich Sachsen 1878, Nr. 45. S. 129.
} 
Für den Fall, daß die Verwaltung von der Erklărung eines Zensiten abweichen wollte, war dieser Entscheidung nach Gesetz und Verwaltungspraxis eine vorhergehende Erörterung und vor Rechtskraft eines beschwerenden Bescheides waren Abănderungen nach schlüssigen Nachweisungen und gegebenenfalls einer Eidesleistung des Steuerbürgers vorgesehen. ${ }^{14}$

Das im Königreich Sachsen im Rahmen der Steuerreform nach 1872 dann beschlossene Steuersystem wich insofern von Schmollers Vorstellungen ab, als die Einkommensteuer bestimmungsgemäß die alleinige direkte Steuer wurde, die zudem die Hauptlast der Abgaben tragen sollte. Schmoller befürwortete jedoch wiederholt ein Besteuerungssystem, das aus vielen Steuerarten bestehend und nach jeweiligen Zweckmäßigkeiten und unterschiedlichen Gesichtspunkten konzipiert sein sollte. ${ }^{15}$

Bei der Schaffung des preußischen EStG von 1891, dem wegen der Bedeutung Preußens als größtem deutschen Flächenstaat und wegen der in juristischer Hinsicht schlüssigen Rechtsprechung der mit dem Gesetz gebildeten Senate für Staatssteuersachen bei dem preufischen Oberverwaltungsgericht bald große Ausstrahlung auf den gesamten deutschen Sprachraum zukam, dienten das sächsische EStG von 1874/78 und die Erfahrungen mit dessen Reclamationscommissionen als Muster für die Gesetzgebung. ${ }^{16}$ Für dic Verhandlungen im preußischen Landtag waren zudem in Sachsen Erfahrungsberichte und eine Befragung aller Beteiligten am Besteuerungsverfahren angefertigt worden, die sehr positiv ausgefallen waren. ${ }^{17}$ Der Gesetzgeber folgte dennoch nach dreijährigen ausgiebigen Verhandlungen bei der Definition des für die gesamte Systematik grundlegenden Einkommensbegriffes zur Bestimmung des Gegenstandes der Besteuerung im zuständigen Ausschuß des Landtages im Jahre 1883 völlig anderen, nămlich wiederum den Gesichtspunkten aus der herkömmlichen Ertragsbesteuerung. ${ }^{18}$ Diese wurde vermittels der aus

${ }^{14} \S \S 42 \mathrm{ff}, \S \S 48 \mathrm{ff}$ salchs. EStG $1874 / 78 ; \S \S 23 \mathrm{ff}$ Instruction zum săchs. EStG 1874/78

1s Schmoller, G. (1863), S. 73, S. 83; ders. (1871), S. 137.

16 Obgleich die Vorschriften des preuß. EStG 1891 die technische Umsetzung einer anderen, konkurrierenden Besteuerungsidee darstellten, enthielten sie, abgesehen vom Gesamtschema, viele alhnilche oder sogar wortgleich abernommene Formulierungen aus dem neuartigen, mit der Tradition brechenden săchs. EStG 1874/78, Wagner. A. (1899), S. 107.

17 Gensel, J. (1885), 495; Böhmert, V. (1889), S. 57: Soetbeer, A. (1889), S. 426: Conrad. J. (1873), S. 228.

${ }^{18}$ Anlagen zu den stenographischen Berichten aber die Verhandlungen des Hauses der Abgeordneten wăhrend der Session der 15. Legislaturperiode 1883/4. Dritter Band. Aktenstock No. 290. S. 2500: s. a. hierzu Fuisting, B. (1902), S. 110; s. a. Bredt, V. (1912), S. 31, S. 63 u.a. Der "Entwurf eines Gesetzes betr. Die Einkommensteuer" nach den Beschlüssen der Kommission in 2. Lesung aus dem Jahr 1884 wurde zurückgezogen und von Miquel wenige Monate nach seiner Berufung zum Finanzminister im November 1890 mit kleineren Veralnderungen und Zusaltzen dem Preußischen Landtag emeut zur BeschluBfassung vorgelegt. Hierzu: Hansen, R. (1990), S. 3. S. 50. 
dem săchsischen Gesetz übernommenen neuartigen, auf die Person des Beziehers der Erträge abstellenden Merkmale zu einer Einkommensteuer fortentwickelt. Die Besteuerungsidee, die dem preuBischen EStG zugrundegelegt wurde, suchte im Einkommensbegriff die Menge von Sachgütern wertmäßig zu erfassen, die einem Steuerpflichtigen für dessen Lebensbedürfnisse aus bestehenden Produktionsquellen mit Regelmäßigkeit zufließen. ${ }^{19}$ Den drei Produktionsfaktoren, denen nach den klassischen Lehren allein eine werteschaffende Funktion zukam, wurde die entscheidende Bedeutung beigemessen. Veränderungen der Quelle, also am Stammvermögen, durften keine Berücksichtigung finden ${ }^{20} \mathrm{Im}$ Hintergrund dieser Regelung stand die Vorstellung eines regelmäßigen Früchteflusses aus produktiven gewerblichen Vorrichtungen bzw. aus der eigenen Arbeitskraft. Diese Lehren vertrat auch der mit dem Gedankengut der nachklassischen Nationalökonomie ausgebildete Adolph Wagner. Er führte die Lehrbücher von K. H. Rau, die er den Zeitströrnungen anpaßte, zu mehreren Neuauflagen ${ }^{21}$ Die strenge Unterscheidung zwischen nicht steuerbaren Vermögensmehrungen und allein steuerbaren Vorgängen der Einkommenssphäre war hier grundlegend. ${ }^{22}$ Übernommen wurden aus dem săchsischen Gesetz jedoch Organisationsprinzipien, wie die Bestimmung des Steuersubjektes, die Steuererklărungspflicht, die Gewinnermittlung der Gewerbetreibenden, die Vorschriften über die einheitliche Bemessungsgrundlage, über die Steuersătze, über das Verfahrensrecht, über den Rechtsmitteleinsatz und uber das Steuerstrafrecht. Sie wurden abgewandelt und mit der preußischen Tradition abgestimmt, teils stark entwertet, wie das Steuerstraf-

19 Fur die Auslegung des preub. EStG 1891 wurden die Auffassungen A. Wagners und B. Fuistings maßgeblich. Wagner hatte als führender Finanzwissenschaftler, Abgeordneter des Landtages und Mitglied des zustăndigen Ausschusses an den Beratungen des Gesetzgebers in den Jahren 1883 und 1884 teilgenommen. Fusing hatte in den Ausschubsizungen das Gesetz als Regierungskommissar cusammen mit dem Generalsteuerdirektor K. Burghart seit 1883 betreut und sich an den Erörterungen ubber die Ausgestaltung beteiligt. Die Eingrenzung der Besteuerung auf "Erträge dauernder Quellen der Gütererzeugung" empfahl die Aullistung steuerbarer Einnahmen in einem Enumerativkatalog. Auf diese Weise wurde sichergestellt, "unproduktive", "abgeleitete" Erträge, bei den klassischen Nationalōkonomen als "unearned Income" bezeichnet, von der Besteuerung auszunehmen, Smith, A. 2. Bd., 3. Kap.

20. Fuisting trennte daher begrifflich streng zwischen Einkommen und Vermögen, 5. Fuisting, B. (1902), S. 109: ders. (1903), Reformbedürftigkeit .... S. 231, S. 281. Diese Unterscheidung muBte dem săchs. EStG 1874/78, das einer völlig anderen Besteuerungsidee folgte, fremd bleiben. Siehe: Wachler, P. (19 12), Bem. 1 zu $\S 17$ sächs. EStG, S. 76. Eine Einteilung der Einkommenspartialen in Einkūnfte verschiedener Art war in Sachsen nur von Interesse für die Statistik. Auch Zuflüsse ohne. Rechts. anspruch waren hier steuerbar, s. Wachler. P. (1912), Bem. 1 u. 2 zu $\$ 17$ săchs. EStG; Schelcher. W. (1903), S. 69; auch: Gensel, J. (1875), Sp. 1530.

\footnotetext{
21 Wagner, A. (1875/6); ders. (1876); ders. (1880), danach ohne Namen Rau's fortgesetzt.

22 Finisting, B. (1903), Reformbedürftigkeit .... S. 232 u. a.; ders. (1902), S. 109; hierzu: Platter. J.. S. 313 , insbes. S. 322 .
} 
recht, aber auch teils wesentlich - nicht die Gleichmäßigkeit der Besteuenung fordernd - verbessert, wie im Falle des Personenrechtsschutzes. ${ }^{23}$

Die aus dem sächsischen Gesetz eingebrachte Verpflichtung zur Deklaration wurde in Preußen zu dem Beitrag des Steuerbürgers als Mitwirkungspflicht bei der amtlichen Einschătzung durch die Behörden des Innenministeriums. Die amtlich festgesetellte Bemessungsgrundlage war dabei das Einkommen, das nunmehr als Ausdruck der Leistungsfahigkeit des Zensiten einen in Gesetzesvorschriften veränderlichen positiv bestimmten Ausschnitt der wirtschaftlichen Vorgănge aus dessen Lebenswirklichkeit als steuerbar erfaßte.

Im übrigen sollte die Einkommensteuer in Preußen nach der Absicht Miquels, wenn auch nicht zur alleinigen direkten Steuer, wie in Sachsen, so jedenfalis zum "Hauptträger .... zum Eckstein" des preußischen Staatssteuersystems entwickelt werden ${ }^{24}$ Das entsprach ebenfalls nicht der Vorstellung Schmollers, der sie zur Wahrnehmung einer Ergänzungsfunktion zur Ausgleichung der jeweiligen Steuerbelastung nach der Leistungsfahigkeit des Steuerbürgers hergerichtet wissen wollte.

Das preußische EStG von 1891 blieb in Form der Novellierung von $1906^{25}$ mit einer Aussetzung des Quellenprinzips fur die Kriegszeit vom Dezember 1916 - auch Gelegenheitsgeschäfte wurden steuerbar ${ }^{26}$ - bis 1920 gültig. Dann wurde das neue Reichseinkommensteuergesetz 1920 hastig und tubereilt auf

${ }^{23}$ Anders als in Sachsen war und blieb die Einfuhrung der Deklaration in Preußen heflig umstrituen. Allgemein furchtete man hier wie bereits seit 1820 das lästige Eindringen des Staates in die Privatsphä: re. Die Steuervorschriften wurden daher traditionsgemalB als Eingriffsrecht des Staates beurteilt. Andererseits bestimmte traditionsgemâB der Amtsermittlungsgrundsatz die Veranlagung der Steuerbärger. Die Voreinschätzungskommissionen sollten daher zur Sicherstellung absoluter Unbefangenheit und. Objektivitalı nach einer Zirkularverfugung vom 20.11.1891 vor ihrer Tatigkeit keinerlei Kennums des Inhalts der Steuererklärungen der Steuerpflichtigen erhalten, s. Mitteilungen ... Preuß. Staat, Steuerjahr 1892, H. 25, S. 48. Die Erklărungen der Steuerpflichtigen dienten somit in Preußen, anders als in Sachsen, nur als zusătzliche Information zụ oder als Kontrollmaterial für die Prufung der amtlichen Einschätzungen auf Grundlage der an Amtsstelle gesammelten und in einer besonderen Personalakte zusammengefaßten Informationen ubler die Steuerzahler, hierzu: Wagner, A. (1891), S. 758, S. 767; Greim-Kuczewski, P., S. 205, S. 213. Traten bei Prüfung des Informationsmaterials zwischen Einschătzungsabsicht der Kommission und Steuererklârung, Widersprūche auf, mußte von der Behörde gem. $\S 38$ preuB. EStG 1891 bzw. $\S 37$ preuß. EStG 1906 ein umständliches und zeitraubendes Beanstandungsverfahren eingeleitet werden, sofern sie auf ihrer Festsetzung beharren wollte. Dieses Beanstandungsverfahren sollte den Steuerborger vor drohendem "Fiskatismus" schotzen, da der Steuerzugriff als lästiger Eingrifr beurteilt wurde. Der auf diese Weise aberzogene Rechtsschutz beg0instigte aber im Grunde tatsăchlich fortan den unchrlichen Steuerzahler, Greim-Kuczewski, P., 8. 226. Vor allem verhinderte er den Einsatz des Sanktionsmechanismus, Wagner. A. (1891), S, 759.

24 Stenographische Berichte ober die Verhandlungen der durch die allerhôchste Verordnung vom 21.10.1890 einberufenen beiden Hâuser des Landtages, Haus der Abgeordneten, 1. Bd., 1891, S. 20.

${ }^{25}$ PreuB. EStG 1891 i. d. F, vom 19.6.1906, abgedr. in FA, 23. Bd., Jg. 1906, S. 582.

26 Gesetz betr. dịe Ergănzung des preuB. EStG vom 30.12.1916, in: PreuB. Gesetzessammlung 1917, S. 1: s. a.: Moll, W. (1917), S. 289. 
die umfassenderen leitenden Grundgedanken des ehemaligen sächsischen Gesetzes umgestellt. ${ }^{27}$ Nach den inflationären Wirren wurde am 10. August 1925 ein neues, EStG beschlossen, das grundsätzlich keiner der alternativen Lehrmeinungen über das Wesen des Einkommens zu folgen bestimmt war. ${ }^{28}$ Tatsăchlich wurden jedoch die Grundprinzipien des preußischen EStG von 1891 - wenn auch auf Grundlage vieler vor allem im Krieg gesammelter abträglicher Erfahrungen mit dem Quellenprinzip, mit Einschränkungen versehen - wiederum für das EStG 1925 bestimmend und sind es bis heute geblieben. Hier sind zu nennen: Die grundsătzliche Einschränkung des Einkommensbegriffes auf das Markteinkommen und damit auf Einkünfte aus einer Erwerbstătigkeit und das Prinzip der enumerativ aufgezählten, im einzelnen genau definierten Einkunftsarten. ${ }^{29}$ Eine klare Entscheidung zugunsten einer zugrundeliegenden Besteuerungsidee, wie dies dem ehemaligen sächsischen bzw. mit Einschrảnkungen dem preußischen EStG eigen war, erfolgte jedoch bewußt nicht. Tatsächlich wurden dem Gesetz zusătzlich verschiedene Regelungen aus dem sảchsischen EStG 1874/78 eingefugt. So wurde für Landwirte, Gewerbetreibende und selbstăndige Berufsträger der Bestandsvergleich (bis 1969 für Landwirte und Selbständige aber eingeschränkt) zur Ermittlung der Bemessungsgrundlage vorgeschrieben. Im preußischen EStG 1891 hatte die für Gewerbetreibende nach 1878 schrittweise Konturen gewinnende "Maßgeblichkeit der Handelsbilanz" wegen der konkurrierenden normierten steuerlichen Ermittlungsvorschriften bereits eine heftig umstrittene Wirksamkeit ausgeübt. $^{30}$

Weiterhin ist hier die Einführung der aus dem sächsischen EStG 1874/78 übernommenen Besteuerung nach dem Verbrauch als Ersatztatbestand für solche Vorgänge zu nennen, in denen eine Selbsteinschätzung des Einkommens durch den Steuerpflichtigen aufgrund seines Verbrauchsverhaltens un-

27 EStG vom 20.3.1920, in: RGBI. I, S. 859; hierzu Begründung in: Verhandlungen der verfas. sungsgebenden .... Anl. Nr. 1524, S. 17.

${ }^{28}$ EStG 1925 vom 10.8.1925, in: RGBI. I, S. 189; zur Begründung s. Anlagen zur Verhandlung des Deutschen Reichstages 1924. III. Wahlperiode, Anl. Nr. 795, S. 21; s. a. Becker, E. (1940), S. 1.

29 Die Aufteilung der Ermittlungsvorschriften fur solche Steuerpflichtige, die nach Handelsrecht oder anderen Vorschriften verpflichtet sind Bücher zu führen oder ohne derartige Verpflichtung ordnungsmalßige Bucher fahren und solche Pflichtige, die hierzu nicht verpflichtet sind und auch keine Bucher fuhren, ließ letztlich de facto einen sogenarnten "dualistischen Einkommensbegriff" in der deutschen Einkommensbesteuerung nach 1925 entstehen, s. Schmölders, G. (1960), Sp. 75: Tipke, K. (1973), S. 391.

${ }^{30}$ Fuisting, B. (1896), S. 480; ders. (1903), Reformbeturftigkeit ..., S. 29; s. hierzu die amtliche Ausfuhrungsanweisung und Kommentierung aus der Feder Fuistings (1891), S. 104; S. 285; ders. (1892), S. 174; auch: Barth, K. (1955), S. 183. 
terstellt werden konnte. ${ }^{31}$ Der überkommene Quellenbegriff spieite nun nur noch eine eingeschrảnkte Rolle. Auch einmalige Gelegenheitsgeschäfte wurden seit 1925 steuerbar. Spekulationsgeschăfte wurden, ebenso wie Einkünfte aus Leistungen, in den Katalog der Einkunftsarten bei Vorliegen weiterer Tatbestandsmerkmale aufgenommen, obgleich sie dem das preußische ESIG von 1891 bestimmenden Grundgedanken wegen Fehlens einer beständigen Quelle früher nur bedingt eingliederbar waren. Die Steuerbarkeit blieb aber auf positiv normierte Tatbestandsmerkmale eines Enumerativkatalogs eingeschränkt.

Im übrigen hat die allgemein sogenannte "goldene Zeit" des deutschen Steuerrechts (nach 1925 bis 1934) zu einer gewiß vorbildlichen Durchdringung, begrifflichen Bereinigung und Systematisierung des allgemeinen deutschen Steuerrechts und speziell des Einkommensteuerrechts geführt.

31 Die in dem Aufsatz von Schmoller 1863 enthaltene These, daB der tatsalchliche Verbrauch eines Steuerbörgers in einem Besteuerungsabschnitt ein Kriterium für seine "wirthschaftliche Kraft." (S. 53) und damit seine steuerliche Leistungsfahigkeil sein kann, da "niemand (kann) dauernd Ausgaben für seine Persönlichkeit machen (kann) ohne Einkommen" (S. 53), hatte in $\$ 15$ Ziff. 6 salchs. EStG 1874/78 Berücksichtigung gefunden. Nachdem es Miquel nicht gelang die gleiche Vorschrift als $\$ 16$ preuB. EStG 1891 durchzusetzen, wurde sie von Popitz und Schlieben als \$ 49 EStG vom 10.8 .1925 durchgesetzt. In dem reformierten EStG 1934 blieb die Bestimmung als $\S 48$ erhalten, bis sie durch Beschluß des Deutschen Bundestages vom 18.8.1980 ersatzlos gestrichen wurde. Zu einer Zeit vôllig darniederliegender Investitionstatigkeit hatte sie nunmehr die wirtschaftspolitischen Anreize von Steuervergünstigungen empfindlich stören kônnen, s. hierzu Fundstellen in: Hansen. R. (1990), S. 40, S. 66 . 


\section{Die Beurteilung des gültigen Einkommensteuerrechts der Bundesrepublik Deutschland im historischen Ablauf}

\section{Bewertung in den Fachzeitschriften}

Die heute als Steuerwissenschaften zusammengefaßten Einzeldisziplinen haben sich erst um die Jahrhundertwende, dem Zuge der Zeit folgend, in Finanzwissenschaft, Steuerrechtswissenschaft und betriebliche Steuerlehre aufgefächert und in jeweils eigener Weise fortentwickelt. ${ }^{1}$ Dabei ist in der Finanzwissenschaft der eigentliche Ursprung dieser Einzelfächer zu sehen. Im deutschen Sprachraum bildete sie sich als selbständiger Ableger der im 18. Jahrhundert vorherrschenden "Cameralwissenschaften", die mit der eindringenden klassischen Nationalökonomie später verschmolzen wurden. Entsprechend finden sich in der Tübinger "Zeitschrift für die gesamte Staatswissenschaft" frühzeitig im 19. Jahrhundert kritische Aufsätze zur Besteuerungswirklichkeit. Hier crschien 1863 der bereits genannte längere Aufsatz Schmollers mit seinem Beitrag zur Definition des Besteuerungsgutes der Einkommensteuer. ${ }^{2}$ Seit 1871 verfolgten sodann die "Jahrbücher für Nationalökonomie und Statistik" kritisch die Steuerreformbestrebungen in Sachsen und die diesbezüglichen Verhandlungen im "Verein für Socialpolitik". ${ }^{3}$ Das sächsische EStG von 1874 wurde hier bei Entstehung und nach Verabschiedung positiv beurteilt. ${ }^{4} 1885$ wurde ein Bericht des Schmoller nahestehenden Referenten für die Steuerreform im sächsischen Landtag, Julius Gensel, abgedruckt, in dem der sachkundige Autor nach siebenjähriger Gültigkeit des Gesetzes aufgrund intensiver Befragungen aller Beteiligten ein positives Urteil über die gemachten Erfahrungen abgab. ${ }^{5}$

'Schmölders, G. (1981), Steuerwissenschaften ..., S. 1371: Rose, G. (1976), S. 174.

${ }^{2}$ Schmoller, G. (1863), S. 1. Ab 1850 findet sich in fast jedem Band der Zeitschrift ein langerer Aufsatz iber Fragen der Besteuenung, z. B. Kries, C. G. (1855).

${ }^{3}$ Conrad, J. (1871), Bd. 16, S. 429; ders. (1873), Bd. 20, S. 227; ders. (1875), Bd. 25, S. 279, hier S. 303 u. S. 306: ders. (1879), S. 445.

${ }^{4}$ Conrad, J. (1873), S. 227, S. 248, S. 307; ders. (1879), S. 463.

${ }^{3}$ Gensel, J. (1885), S. 489. Gensel war Rechtsanwalt in Leipzig. Zugleich war er leitender Mitarbeiter der Handelskammer. Er war Abgeordneter des săchs. Landtags und seit 1871 gewăhlter Vorsitzender des Landtagsausschusses für die Steuerreform in Sachsen. Gensel war ein einflußreiches Mitglied des "Vereins für Socialpolitik" seit dessen Gründung 1873. 
Auch in den von Georg Hirth herausgegebenen einflußreichen "Annalen des Deutschen Reichs" wurde die Entstehung des săchsischen EStG 1874 aufmerksam verfolgt. ${ }^{6}$ Der Leipziger Advokat Julius Gensel berichtete hier ausführlich über Einzelheiten der Verhandlungen des zustăndigen Landtagsausschusses und über das Endergebnis der Beschlußfassung. ' In einem längeren Aufsatz beschrieb zur selben Zeit Karl Burkart, ein bayerischer Finanzbeamter und Experte für Besteuenungswesen, die im Deutschen Reich geltenden Einkommensteuergesetze und verglich die Einzelheiten der Regelungen einschließlich - später angefuigt - der Vollzugsvorschriften. ${ }^{8}$ Dem săchsischen Gesetz bescheinigte er eine nachahmenswerte Fortschrittichkeit. ${ }^{9}$

Auch die Steuerstatistik bestätigte vereinfachend zusammengefaßt das einkalkulierte erwartete Aufkommen als zufriedenstellend und zeigte fortan befriedigende Ergebnisse von dessen Wachstum. ${ }^{10}$ Der Übergang erfolgte problemlos.

Ähnlich positive Stellungnahmen fanden sich später zum 25jährigen Jubiläum von Seiten hoher Richter und von Verwaltungsbeamten in preußischen und sächsischen Verwaltungsblăttern und spăter in der "Deutschen JuristenZeitung". "Bosse sprach 1890 von dern "sittlich erzieherischen Einfluß", den das Gesetz nach zehnjähriger Wirksamkeit ausübte. ${ }^{12}$

Gänzlich anderer Art war die Resonanz, die das preußische EStG von 1891 in Presse und Fachzeitschriften seit seiner Einführung gefunden hat. Nach Gültigkeit des Gesetzes und Auswertung nachhinkender Steuerstatistiken wurde Kritik an der ungleichmäBigen Behandlung der Steuerpflichtigen und der sozialen Unausgewogenheit der Veranlagungsergebnisse geführt. ${ }^{13}$ Das Steueraufkommen entsprach zwar etwa den Erwartungen und stieg jährlich an. Die hohe Zahl der Beanstandungsverfahren, der eingelegten Rechtsmittel und die dadurch verursachte "Hochfluth" der bei dem Oberverwaltungsgericht

${ }^{6}$ Burkart, K. (1874), Sp. 115, Sp. 988, Sp. 1682; ders. (1875), Sp. 979; Gensel, J. (1874), Sp. 1373; ders. (1875), Sp 1519.

7 Gensel, J. (1874), Sp. 1373; ders. (1875), Sp. 1519.

Burkart, K. (1876), S. 21, S. 682; ders. (1879), S. 1.

${ }^{9}$ Burkart, K. (1876), S. 21 ff, insbes, S. 49, S. 50. Sachsen strebte Burkharts !deal an.

${ }^{10}$ Bohmert, V. (1889), S. 57, S. 63; von Nostitz, H. (1903); Hoffmann, A(1906).

1 Wachler, P. (1903), Ein fünfundzwanzigjähriges ..., S. 308; ders, (1903), Erfahrungen ..., S. 312 ; Blüher (1913), S. 620; Böhmert, V. (1889), S. 57; Burkhart, K. (1876), S. 49; Wilding, Graf A. (1993) in: Harden, M., Die Zukunft, S. 211.

12 von Bosse, H. A. (1890), S. 42.

${ }^{13}$ Schanz, G. (1896), S. I; Delbrück, H. (1909), S. 166; Schmoller, G. in: Behirnauer, F. (1910), Anm. 1, S. 113; Meisel, F. (1911), S. 285; ders. (1914), S. 144; Buck, L. (1917), S. 1; Michaelis (1912), S. 65; Moll, W. (1918), S. 1; Mrozek, A. (1909), S. 259; ders. (1910), S. 101. 
anhăngigen Beschwerden gemäß $\S 44$ des preußischen EStG $1891^{14}$ machten auch dem steuerpflichtigen Laien erkennbar, daß nicht nur wegen normaler Umstellungsschwierigkeiten die Gerichte und deren Besetzung seit 1894 mehrfach verändent werden mußten, um der Überlastung Herr zu werden. ${ }^{15}$ Das Gesetz galt als außerordentlich kompliziert und für den Laien unverständlich.

Im Grunde konnten die Vorgänge die 1887 geảußerten Warnungen Vockes vor übereilter Einfühnung der Einkommensteuer durchaus bestătigen, daß "nur die Besoldeten nach dem Maße ihres wirklichen Einkommens, soweit es in Gehalt besteht, richtig besteuert sind ${ }^{16}{ }^{16}$ Bei ihnen konnten nur in den seltenen Fällen sehr hoher Bezüge Auslegungsdifferenzen bei der Einschätzung auftreten.

Unter Hinweis auf viele Ungereimtheiten wurde die trotz der juristischen Perfektion unzweckmäßige Technik der Besteuenung beklagt und die erkennbar zunehmende mangelhafte Steuermoral damit in Zusammenhang gebracht. ${ }^{17}$ Im Grunde ist das bis heute unterschwellig so geblieben. Bereits im Jahre 1896 veröffentlichte Georg Schanz in dem von ihm herausgegebenen "Finanz-Archiv" eine vehemente Kritik an dem zu engen Einkommensbegriff des preußischen EStG und an der "haarspalterischen" formaljuristischen Abgrenzung zwischen steuerbarem Einkommen und nicht steuerbarem Vermögenszugang, die auf das dem Gesetz zugrundeliegende Quellenprinzip der Einkommensbesteuerung zurückzuführen waren. ${ }^{18}$ Die sehr theoretischen Ausführungen von Schanz fanden aber erst 1919 Resonanz in der Diskussion. Viele Steuerrechtler der Zeit waren mit dem führenden Kommentator Bernhard Fuisting oder dem angesehenen Finanzwissenschaftler Adolph Wagner der Überzeugung. daß das preußische Einkommensteuergesetz 1891 sachgemäß und fortschrittlich konzipiert war. Die Kritik an den Ergebnissen des Gesetzes wurden aber vernehmlicher. ${ }^{19}$ Im Jahr 1909 beklagte Hans Delbrück

${ }^{14}$ Fusting, B. (1903), S. 5.

15 Fuisting, B. (1896), S. 326.

16 Vocke, W. (1887), S. 487.

${ }^{17}$ Meisel, F. (1911), S. 373; Michaelis (1912), S. 78; Mrozek, A. (1909), S. 276; ders. (1910), S. 105. Mrozek war Richter an einem Senat für Staatssteuersachen des preuB. OVG. Michaelis war langjährig Leiter von Veranlagungs- und Berufungskommissionen großer preuß. Bezirke, zeitweise Berlins. Seił 1903 war er stăndiger Mitarbeiter des Verwaltungsarchius als Rezensent steuerrechtlicher Versffentlichungen.

18 Schanz, G. (1896), S. I. S. 57.

19 Fuisting, B. (1903), Einkommensbesteuenung .... S. 21; ders. (1903), Reformbedarftigkeit ..., S. 229. Fuisting suchte ab 1896 fortlaufend darauf aufmerksam zu machen, daß der leitende Grundgedanke des preuB. EStG 1891 durch Einfügung ohne Inkonsequenz nicht integrierbarer Elemente aus dem săchs. EStG 187478, wie etwa die Ermittlung des "Geschăftsgewinnes" als "Einkommen aus 
in den einflußreichen Preußischen Jahrbüchern vermittels statistischer Daten über die Einkommensentwicklung und bekannt gewordene konkrete Veranlagungsergebnisse die unsozialen Auswirkungen der preußischen Einkommensbesteuerung. In der Kritik Delbrücks wurde nicht zwischen legaler Steuervermeidung und Steuerhinterziehung differenziert. Ein besonders fragliches Beispiel bot in der Beurteilung Delbrücks die Besteuerung der Landwirte. ${ }^{20}$ Sofort meldeten sich Steuerrechtler wie F. Behrnauer, später L. Waldecker und andere, die aus Erfahrung in amtlicher Tätigkeit versicherten, daß jeweils keinerlei amtliche Nachlăssigkeiten vorlăgen und die Veranlagungen gesetzmäßlig erfolgten. ${ }^{21}$ Sie glaubten daher, keinen Grund für generelle Kritik an dem Vollzug des Gesetzes erkennen zu können. Schmoller stellte sein "Jahrbuch für Gesetzgebung, Verwaltung und Volkswirtschaft im Deutschen Reich" 1910 zum Abdruck von Behrnauers Replik zur Verfugung. Dabei legte er in einer langen Fußnote dar, daß er die ablehnende Beurteilung Delbrücks nach eigener Ermittlungstătigkeit voll teile. ${ }^{22}$ Im nächsten Heft brachte er dann den berühmt gewordenen, offenbar von ihm selbst veranlaßten Aufsatz Franz Meisels mit dem Titel "Moral und Technik bei der Veranlagung der preußischen Einkommensteuer" in seinem "Jahrbuch" zum Abdruck. ${ }^{23}$ Die Feststellungen Meisels wurden von vielen sachkundigen hohen Finanzbeamten aufgegriffen und in verschiedenen Zeitschriften, wie dem "Preußischen Venwaltungs-Blatt", dessen Beilage, dem "Verwaltungs-Archiv" und anderen erörtert und jeweils bestätigt. ${ }^{24}$ Dabei wurden dann fortlaufend die sachdienlicheren săchsischen Regelungen vergleichend herangezogen oder zumindest erwähnt. Gelegentlich sah sich sogar der Senatspräsident des sächsischen Oberverwaltungsgerichts in Staatssteuersachen veranlaßt, in einem Nachruf im "Verwaltungs-Archiv" die Vorzugswürdigkeit der sächsischen Gesetzesregeln und deren Verwal-

Handel und Gewerbe" durch Bestandsvergleich und dic Einbeziehung von Spekulationsgewinnen (denen es an einer Quelle mangelte) II. a. verwilssert wurde. Er glaubte, dadurch werde eine Besteuerung nach der Leistungsfăhigkeit gefahrdet, s. Fuisting. B. (1906), Zur Besteuerung .... Sp. 1170; ders. (1903), Einkornmensbesteuerung .... S. 23. Wagner trug noch 1897 die gleichen Auffassungen vor, die er 1876. aus dem Lehrgebăude Rau's fortentwickelt hatte, s. Wagner, A. (1897), S. 66. Sogenannte "Conjunkturengewinne" sollten nach seiner Auffassung nicht von der Einkommensteuer, sondern durçh Ausbau der Verkehrssteuem erfaßt werden. Hierzu diente dann 1911 die von ihm standig geforderte Wertzuwachssteuer. s. DJZ (1910), S. 519; Hansen, R. (1990), S. 28; s. a. Bredt, V., S. 41. S. 66.

20 Delbrück. H. (1909), S. 183.

21 Behrnauer. F. (1910), S. 113; Waldecker, L. (1913), S. 61; Buck, L. (1916), S. 70

22 Schmoller, G., Anm. 1, zu Behrnauer, F. (1910), S. 113.

${ }^{2}$ Meisel, I. (1911), S. 285.

${ }^{24}$ Michaelis (1912); Wachler, P.: Meisel, F. (1914); Moll, W, (1917); Mrozek, A. (1909); ders. (1910). Die ausgelöste Diskussion hatte groBen Einfluß auf Berichte in allen Medien und hatte vor allem Auswirkungen auf die von Wagner zur Ergänzung der ESt geforderte Wertzuwachssteuer zur Heranzichung des "unverdienten" Einkommens. Dies war eine Lieblingsidee Wagners, hierzu: Gerloff, W. (1913), S. 402. 
tungspraxis zu bestătigen, aber abwiegelnd die Möglichkeit von deren Übertragung in Frage $z u$ stellen. ${ }^{25}$

Das preußische EStG von 1891 wurde im Lichte der Zeitkritik vom Gesichtspunkt der Praxis aus, den von seinen theoretischen Befürwortern Bernhard Fuisting und Adolph Wagner versprochenen Kriterien, einer Besteuerung nach der Leistungsfähigkeit zu dienen, nach der Diskussion offensichtlicli in keiner Weise gerecht. Da das preußische EStG als "preußische Einkomniensteuertype" bis heute den Rahmen für das Einkommensteuerrecht abgibt, ist es nicht verwunderlich, daf man auch heute, trotz der inzwischen eingetretenen Gewöhnung an die Gesetzeswirklichkeit, regelmäßig vergleichbarer grundsătzlicher Kritik in den neueren Fachzeitschriften begegnet. Die fortlaufenden Beanstandungen der Einkommensbesteuerung, an denen sich neben Hochschullehrern nach der Jahrhundertwende hohe Beamte aus der Finanzverivaltung und dern Richterstand, wie Schmoller, Delbrück, W. Moll, Mrozek, Buck, Maatz, Droste, Behrnauer, Meisel, Michaelis, Wachler, Waldecker, Justus. (Pseudonym) und andere beteiligten, ${ }^{26}$ lälst bei kritischen Lesern folgende Feststellung zur Gewißheit werden: Das preußische Einkommenstelergesetz von 1891 venursachte infolge seiner unzweckmäßigen Ausgestalung gegenüber den hohen, ständig neu geweckten Ansprüchen und Erwartungen, eine Besteuerung nach der Leistungsfahigkeit zu garantieren, große Frusirationen und Verärgerungen. Diese erzeugten dann eine ungewöhnlich schlechte Steuermoral. Hierfür scheinen insbesondere der bereits von Schanz, bemängelte zu enge Einkommensbegriff mit dem notwendigen Merkmal des Vorhandenseins beständig fließender Quellen der Gütererzeugung, die von Meisel und Michaelis beanstandeten und mit den sắchsischen Regelungen verglichen, streng juristisch ausgerichteten Verfahrensvorschriften und Ämterbesetzungen und nicht zuletzt das gegenüber den sächsischen Vorschriften unzulängliche preußische Steuerstrafrecht verantwortlich zu sein. Davon werden wir noch hören. Nicht der seither wiederholt unterstellte große Steuenwiderstand war in Preußen ungewöhnlich ausgeprägt, sondern die mangelhafte Steuermoral war, wie Meisel wiederholt festhielt, die Folge einer unzulänglichen Technik, die auf mangelhafte Untersuchungen des Sachgebietes durch Nationalökonomen und ideologische Voreingenommenheiten der zuständigen Finanzwissenschaftler und Steuerrechtler zurückzuführen war. ${ }^{27}$

25 Wachler, P. (1912), S. 353

${ }^{26} \mathrm{~S}$. Anm. 13 u. Arut. 24. Daß L. Buck 1911 noch völlig, andere Auffassungen zuĩ Beurteilung des preuB. EStG 1891 ats 1916 vortrug, bestatigt dic hier vertretenen Thesen, s. Buck, L. (1911), S. 46, S. 48 , S. 57; ders. (1916), S. 6.

\footnotetext{
${ }^{27}$ Meisel, F. (1914), S. 114.
} 
Da von einer "deutschen Einkommensteuertype" gesprochen werden kann, weil das Grundkonzept des heute noch geltenden Systems 1891 festgelegt wurde, ist es nicht verwunderlich, wenn wir auch heute noch in kritischen Beschwerden über das gültige Einkommensteuerrecht in Fachzeitschriften den bereits von Schanz beanstandeten Măngeln eines zu engen Einkommensbegriffes begegnen. ${ }^{28}$ Es liegt auf der Hand, daß die Konsequenzen weitreichend sind und nur wegen der eingetretenen Gewöhnung und zumeist mangellhaften Sachkompetenz und einer fehlenden historischen Aufarbeitung nicht oder nur unzureichend beanstandet werden. Denn: Das Steuerrecht ist ständig komplizierter geworden. Seine konkreten Auswirkungen sind zumeist mur noch von den unmittelbar tätigen Berufsträgern, oft auch nicht mehr von Hochschullehrern durchschaubar.

"Die Einkormmensteuergesetze von 1891 und von 1991 unterscheiden sich in der Art ihrer Rechtfertigung nicht voneinander", so hieß es kürzlich in einem Beitrag zum Gedenken an "100 Jahre modernes preußisch-deutsches Einkommensteuerrecht 24.6.1891 - 24.6.1991". ${ }^{29}$ "Beide Gesetze dienten", so der Autor, "einem wirtschaftich fiskalischen und gleichzeitig einem rechtlichen Ziel". Und: "Das EStG 1991 deckt sich darüber hinaus mit dem von 1891 auch darin, daß es dem einzelnen und zwar im Zweifel eher noch ausgeprägter als früher die Zahlung von Einkommensteuer nur in den Grenzen seiner wirtschaftlichen Leistungsfähigkeit abverlangt." ${ }^{30}$ Für den Kommentator Bernhard Fuisting hatte das preußische EStG diesen Anforderungen nur unvollkommen entsprochen. Der Ansatz von Einkünften hătte nach seiner Öberzeugung ausschließlich auf die Verbindung von Wertzuflüssen aus dauernd fließenden Quellen beschränkt bleiben müssen. Durch die Übernahme von Positionen aus dem sächsischen EStG 1874/78 hatte aber der Gesetzgeber 1891 diesen Grundsatz durchbrochen. ${ }^{31}$

${ }^{28}$ Der von Meisel verwendete Begriff einer "deutschen Type" der Einkommensbesteuerung ist enst kürzlich von Bayer wieder aufgegriffen und stichhaltig begründet worden, s. Bayer, H.-W. (1991), 100 Jahre ..., S. 333; Tipke, K. (1973), S. 391.

${ }^{29}$ Bayer, H.-W. (1991), S. 336; s. a. Halfar, B., S. 397.

${ }_{30}$ Bayer, H.-W., S. 336; hierzu auch Halfar, B., S. 397. Als "Vater" des preuB. EStG 1891 wird von Steuerjuristen regelmäBig J. von Miquel ausgegeben, obgleich dieser, wie Fuisting gelegentlich verărgert festhielt, "nur Adoptivvater" desselben sein konnte und im Grunde noch nicht einmal dies. Fâr eine Öberarbeitung des seit 1884 unter der Leitung des Finanzministers Scholz fertiggestellten Entwurfs fehlte dem erst im April 1890 berufenen Miquel bis zur Einbringung des Entwurfs im Landtag im Herbst nicht nur die Zeit. Er vertrat in den wesentlichen Bestimmungen den galnzlich am QuelIenprinzip orientierten Entwurf der Regierung, s. Fuisting, B. (1903), Einkommensbesteuerung ..., S. 2; Mauz, F. (1935), S. 176. Anm. 349, S. 116; Hansen, R. (1990), S. 3. Theisens Klage aber feststellbare "steuerhistorische Defizite" hat auch systematische Konsequenzen, s. Theisen, M. R. (1990), S. 150.

"Fuisting, B. (1903), Einkommensbesteuerung ..., S. 22. 
Der von Fuisting beklagte Systembruch lag in der vom Ausschuß des preußischen Landtages beschlossenen Abänderung der Vorschriften des Regierungsentwurfs über die Ermittlung des "Einkommens aus Handel und Gewerbe einschließlich des Bergbaues" ( $\$ 14$ Regienungsentwurf vom 3. November 1890, abgedruckt in Finanz-Archiv, 7. Jg., S. 643), der Einbeziehung vereinnahmter Gewinne aus Spekulationsgeschäften bei Verăußerung von Gegenständen des Kapitalvermögens und den Gewerbebetrieben zuzurechnenden gleichartigen Veräußerungsvorgängen. Während sämtliche Regierungsentwürfe generell die Beibehaltung der traditionsgemäßen Ermittlung der Einkünfte als Überschuß der Einnahmen aus produktiven Quellen über die verursachten Ausgaben vorsahen, hatte der preußische Landtag zur dritten Lesung des Gesetzes für die Einkunftsart Handel und Gewerbe die Einführung des Bestandsvergleichs als Ermittlungsform beschlossen. Dabei wurde in $\$ 14$ EStG 1891 , entsprechend $\S 21$ Abs. I des săchsischen EStG 1874/78, auf die Rechnungslegung nach dem AHGB und den "Gebrauch eines ordentlichen Kaufmannes" verwiesen. Fuisting sah in diesen Bestimmungen einen systemfremden Bestandieil im Gesetz, dessen Konsequenzen er fortan in allen Veröffentlichungen beklagte.

Auch für Wagner handelte es sich bei den Abweichungen vom Quellenprinzip nur um eine vorübergehende Notlősung. "Die Entstehung des Einkommens" aus dauernden "Quellen der Gütererzeugung". die "Anknüpfung an die Ertragsquellen" war für beide ein essentielles Merkmal des Einkommensbegriffes, damit des gesetzlich normierten Tatbestandes und so eine Garantie für die Besteuerung nach der Leistungsfähigkeit. ${ }^{32}$

Im Anschluß an die Terminologie von Schanz spricht man heute von einer "Reinvermögensaugangstheorie" bzw. von einer "Quellentheorie" des Einkommens. Dabei ist zu berücksichtigen, daß der Besteuerungsgegenstand des såchsischen ESıG 1874/78 keinen Eumerativkatalog der Einkünfte kannte. da hier der leitenden Besteuerungsidee entsprechend allein auf die Person und deren Leistungsfâhigkeit abgestellt wurde. Der Unterschied lag dabei nicht nur in der anderen Ermittlung des Gewinns. sondern in der anderen Besteuerungsidec, dic cin abweichendes Besteucrungsgut skizzicrte. Hier wurde auf die Person abgestellt, dort auf Einkommensquellen. Daraus ließen sich dann auch Konsequenzen für die Zuordnung des letztlich Personen zuzurechnenden Ertrages herleiten.

32 Fuisting. 13. (1902), linkommensbesteucrung .... S. 110: ders. (1903), Reformbedurrtigkeit .... S 230. Wagner hat ssine fruh entwickelten theortischen Auflassungen. die er in den Neuauflagen der Rau'schen I shrbücher niederiegte, nie revidiert oder gar aufgegeben, wenn or auch gelegentlich diesen Eindruck zu erwecken vermag (s. Anm. 19). 
Eben dieser Zusammenhang zwischen der ursprünglichen Besteuerungsidee und dem geltenden Einkommensteuerrecht soll heute nach fortlaufenden Forderungen in den Fachzeitschriften zur Ausrichtung der Besteuerung nach der Leistungsfahigkeit des Steuerpflichtigen weiter eingeschränkt werden, indem die Gewinne aus der Verâußerung von Vermögensgütern bei den Quellieneinkünften des noch geltenden EStG voll steuerbar werden, wie dies für Gewinneinkünte schon lange zutrifft. Der Einkommensbegriff soll also - wie bereits 1925 geschehen - nochmals erweitert werden.

Die Konsequenzen der unterschiedlichen Ermittiungsvorschriften für die jeweiligen Einkunftsarten sind seit 1953 wegen der beträchtlichen Belastungsdifferenzen als Folge geeigneter Gestaltungen in Fachzeitschriften ein ständiger Anknüpfungspunkt für Reformforderungen gewesen. Die Sachverstăndigenbeiräte bei dem Finanzministerium sind seit lăngerer Zeit für Abănderungen ebenso eingetreten, wie andere Gutachtergremien. ${ }^{33}$

Die Erörtenung der im EStG normierten heute geltenden unterschiedlichen Ermittlungsvorschriften für die Einkunftsarten I bis 3 nach dem Bestandsvergleich und 4 bis 7 nach dem Quellenprinzip des Überschusses der Einnahmen über die Werbungskosten ist nun in den Fachzeitschriften auch aus systematischen Gründen neu entbrannt. ${ }^{34}$ Der Gesetzgeber des EStG 1925 hatte ausdrücklich auf die Bestimmung eines übergreifenden einheitlichen Einkommensbegriffes zugunsten positiv normierter einzelner Tatbestandsmerkmaie verzichtet. Das hat in Verwaltungspraxis, Rechtsprechung und Literatur dazu geführt, von zwei konkurrierenden, sich gegenseitig ausschließenden Einkommensbegriffen im heute geltenden EStG zu sprechen ${ }^{35} \mathrm{Da}$ zur amtlichen Auslegung der Gesetzesvorschriften eine einheitliche Besteuerungsidee fehlte, haben die Finanzgerichte seither vergleichbare Sachverhalte, je nach Zurechnung zur Einkunftsart, entsprechend unterschiedlich beurteilt. Nun werden die

${ }^{33}$ Charakteristisch für viele Auffassungen: Tipke, K. (1973), S. 400: BMF (1967), S. 23

34 Typisch für viele kritische Beiträge ist: Jehner, H. (1990), S. 8.

35 Jehner, i. (1988), S. 267. Die gegebenenfalls problematische Zuordnung von Einkünften kañin nicht nur zu hohen Differenzen in der Steuerbelastung fuhren. Aus einer umstrittenen Zuordnung kann sich auch z B. mit wechselnden Entscheidungen ergeben, ob von der Staatsanwaltschaft ein Strafverfahren von Amts wegen mit der Beschuldigung der Steuerhinterziehung einzuleiten ist. Das "Einkommen" als "zentraler Begriff des offentlichen Schuldrechts" fuhrt wegen seiner Aufspaltung in zwei Gruppen von Einkûnften, die ursprünglich nur sachgerechten verschiedenartigen Ermittlungsweisen Rechnung tragen sollten, heute zunehmend zu völlig absurden Konsequenzen. Diese zeigen șich insbesondere dort, wo der Einkommensbegriff als angeblicher Maßstab für die Leistungsfahigkeit des Steuerbürgers auch als Berechnungsgrundlage fur soziale Maßnahmen geeignet sein sollte, wie z. B. im Unterhaltsrecht oder etwa für die Festsetzung von Geldstrafen. die gemäB § $40 \mathrm{Abs}, 2 \mathrm{StGB}$ vom Nettoeinkommen abhăngig gemacht werden etc, hierzu: Tipke. K. (1985), Forum S. 345, S. 35I. Jehner zeigt, daß wirtschaflich gleiche Sachverhalte infolge von reinen Zufallen andersartige steuerliche Tatbestandsmerkmale enthalten können, die dann die Entstehung vơllig unterschiedlicher Steuerbeträge verursachen können. Jehner, H. (1988), S. 270. 
mangelhafte Abstimmung und die damit verbundenen sehr erheblichen steuerlichen Auswirkungen zunehmend als Belastung einer gerechten und gleichmäBigen Besteuerung nach der Leistungsfähigkeit beurteilt. Auch führende Steuerrechtslehrer teilen diese Auffassung, wobei sie Vorstellungen verreten, die denjenigen der Schöpfer des preußischen EStG von 1891, das eine konkrete Verwirklichung dieses Prinzips zu sein vorgab, völlig zuwiderlarfen. ${ }^{36}$ Bernhard Fuisting und ebenso Adolph Wagner hatten geglaubt, eine Besteuerung nach der Leistungsfähigkeit des Steuerbürgers setze die strenge Orientierung des EStG am Quellenprinzip voraus. Führende Steuerrechtslehrer, wie etwa Klaus Tipke, vertreten aber heute den gegenteiligen Standpunkt, allein der Gesichtspunkt des Reinvermögenszugangs als systemtragendes Prinzip des Gesetzes gebe eine Garantie für eine gerechte Besteuerung. ${ }^{37}$ Einigkeit besteht allein darin, daß der dualistische Einkommensbegriff zu unerträglichen Ungerechtigkeiten fuhre. ${ }^{38}$

Angesichts der Ungereimtheiten, die durch den im Gesetz fehlenden einheitlichen Einkommensbegriff verursacht werden, hielt der als Rechtsanwalt und Notar tătige Praktiker Hansgeorg Jehner kürzlich im "Deutschen Steuerrecht" fest: "Die mit gesetzlichen Gegensätzen zwangsläufig einhergehende Möglichkeit, wirtschaftlich gleiche Vorgänge unterschiedlich besteuern lassen zu können, hat zur heutigen Bemessung der Steuerlast nach der geistigen Leistungsfahigkeit gefuhrt. ${ }^{39}$

Daß der hier erkennbare Vertrauensschwund in eine gerechte und gleichmäßige Verteilung der Lasten nach der Leistungsfähigkeit der Steuerpflichtigen wie nach 1891 wiederum negative Auswirkungen auf die Steuermoral der Beteiligten hat, ist heute dauerhaft diskutiertes Thema in vielen Fachzeitschriften. ${ }^{40}$

36 Fuisting glaubte, nur eine uneingeschralnkte Orientierung des im Gesetz festgelegten Besteueringsgegenstandes am Quellenprirzip garantiere eine Besteuerung, nach der Leistungsfähigkeit. Diese sah er wegen der Aufnahme des Bestandsvergleichs als Emittlungsvorschrif für Gewerbetreibende. und wegen der Besteuerung von Spekulationsgewinnen, bei denen es an einer früchtetragenden Quelle fehle, infrage gestellt.

37 Tipke, K. (1993), Die Sieuerrechtsordnung, S. 469. Tipke gibt hier im Grunde eine Zusammerfassung der Ergebnisse seiner früheren Beiträge in verschiedenen Fachzeitschriften, die von grolfer Wirkung auf die Meinungsbildung der Steuerrechtswissenschaft waren.

3s Tipke, K. (1985), Forum \$. 345. Tipke zeigt hier möglicherweise entstehende absurde Konsequenzen, die wegen ihrer Willkür niemand gutheißen kann. Ähnlich: Jehner, H. (1990), S. 6. Jehner erwăhnt Vorgănge aus der Alltagspraxis des Steuerberaters, in denen der Mandant erst durch sinnvolle Gestaltung der Umstände vor Willikur geschêtzt werden kann.

\footnotetext{
39 Jehner, H. (1988), S. 272.

${ }^{40}$ Streck, M. (1984), S. 2205; Tipke, K. (1983), Gerechte Steuern ..., S. 31.
} 


\section{Beurteilung durch die höchstrichterliche Finanzrechtsprechung}

Am 5. September 1892 nahm am preußischen Oberverwaltungsgericht ein neugebildeter 5. Senat, dem die Zuständigkeit für alle Steuersachen übertragen wurde, seine Tätigkeit als endgültig entscheidende Instanz in Staatssteuersachen auf. Wegen der völlig unerwartet starken Inanspruchnahme traten dann bis zur Jahrhundertwende zwei weitere Senate mit Zuständigkeit fur Staatssteuersachen hinzu. ${ }^{41}$ Die Bewältigung der Arbeitslast "durch eine Hochfluth von Beschwerden" wurde erst möglich, nachdem durch Gesetz vom 26. Mărz 1894 das Staatsministerium ermåchtigt wurde, "den bestehenden und noch zu errichtende Steuer-Senate" in Kammern einzuteilen, bei deren Beschlußfassung die Teilnahme von nur drei Richtern genügte. ${ }^{42}$

Durch Gesetz vom 29. Juli 1900 wurde in Sachsen zum 1. Januar 1901 dem 2. Senat des Königlich-Sächsischen Oberverwaltungsgerichts đie Zuständigkeit als letzte Instanz in sămtlichen Abgabensachen übertragen. ${ }^{43}$

Das war der Anbeginn selbstandiger Gerichte für Steuersachen in Deutschland. Diese hatten die Aufgabe, die richtige Auslegung der Steuergesetze, die gesetzmäßige Ausgestaltung des Veranlagungsverfahrens und die Veranlagungspraxis in konkreten Fallen zu überprüfen und zu überwachen. ${ }^{44}$

In Preußen wurde zum 1. Januar 1894 dann der ehemalige Regierungskommissar und Referent für die Reform der Einkommensteuer seit 1878, Bernhard Fuisting, Präsident des 6. Senates für Staatssteuersachen am Oberverwaltungsgericht. ${ }^{45}$ In Sachsen übernahm der ehemalige Regierungskommissar und Referent für die Reform der Einkommensteuer im Finanzministerium seit 1874, Paul Wachler, diese Aufgabe als Präsident des 2. Senats am Oberverwaltungsgericht mit Zuständigkeit für Staatssteuersachen. Beide Senatspräsidenten berichteten ab 1902 fortlaufend in der zur Förderung der Vereinheitlichung des Rechts 1896 begrindeten "Deutschen Juristen-Zeitung" iber die Entwicklung der Rechtsprechung ihrer Gerichte in Staatssteuersachen. $^{46}$

41 Gerlach, O. (1903), S. 785; Fuisting, B. (1896), S. 1, S. 324; ders. (1903), Einkommensbesteuerung ..., 8. 4; Strutz, G. (1908), S. 426.

42. Gerlach, O. (1903), S. 785; Fuisting, B. (1903), Einkommensbesteuerung ..., S. 4; ders. (1896), S. 326 .

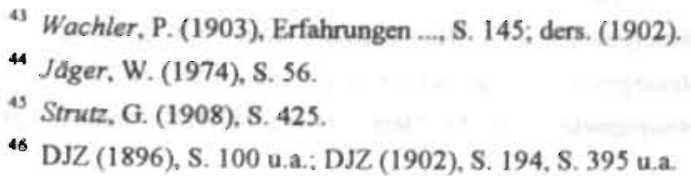


Nach einem Bericht Wachlers aus dem Jahr 1903 führte die Rechtspre:hung des săchsischen Oberverwaltungsgerichts, anders als in Preußen, nicht zu größeren Beanstandungen bei der Überprüfung der Verwaltungspraxs "in Bezug auf ihre Ubereinstimmung mit dem bestehenden Rechte" und suslegungsdifferenzen oder gar zu Kritik an den Gesetzesvorschriften. ${ }^{47}$

Das nach heutiger Terminologie an dem "Reinvermögenszugangsprnzip" orientierte sächsische EStG 1874/78 war einheitlich an diesem allgemein überzeugenden Grundgedanken ausgerichtet worden. Dies kam denn atch in der Kommentienung der Vorschriften durch Wachler in den Erläuterungen zu $\S 1$ des săchsischen EStG $1874 / 78$ klar zum Ausdruck. Es heißt dort "Die sächsische Einkommensteuer ist eine allgemeine. Hieraus folgt insbesondere, daß $\S 17$ nicht schlechterdings als eine erschőpfende Aufzăhlung det Einkommensquellen zu betrachten ist. Jedes unter die Begriffsbestimmung in $\S 15$ Ziff. I fallende, nicht von einer ausdrücklichen Befreiungsvorschrift betroffene Einkommen ist steuerpflichtig, auch wenn es nicht unmittelbar in eine Guppe des $\S 17$ eingereiht werden kann. ${ }^{48}$ Es gab hier also einen Enumerativkatalog fur die Ausnahmen von der Steuerbarkeit von Einnahmen, nicht wie spater in Preußen für die selektive Auswahl steuerbarer Einnahmen.

Der Begriff des "reinen" Einkommens umfaßte den "Gesamtbetrag desjenigen, was der einzelne Beitragspflichtige an Geld und Geldeswert nach Abzug

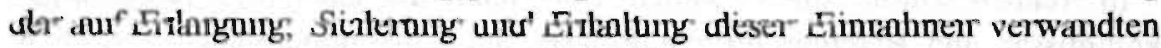
Ausgaben, ..., durch seine wirhschaftliche Thätigkeit oder sonst auf berechtigte Weise innerhalb Jahresfrist erwirbı". ${ }^{49}$ Dieser Grundgedanke durchwirkte das Gesetz und bedeutete grundsătzlich die Steuerbarkeit aller Erwerbungen, bei Ausschluß aufgeführter Erbschaften und Schenkungen und ähnlicher Vorgänge, auch wenn dieselben ohne Rechtsanspruch, aber "auf berechtigte Weise erîlgten". ${ }^{50}$

Die Konsequenzen der dem sảchsischen Gesetz zugrundeliegenden Besteuerungsidee hatten zur Entwicklung eines Besteuerungsgutes geführt, das auf alle Wertzugänge einer steuerpflichtigen Person bei Berücksichtigung dessen individueller Merkmale abstellte. Diese Beurteilung bedeutete die Belanglosigkeit der Art der Quellen, der Frage, ob ein Rechtsanspruch vorliegt oder nicht, solange Zugänge "auf berechtigte Weise" erfolgten. Gewinne aus Vermögensgeschäften zählten der Regel nach ebenso zum steuerbaren Einkom-

\footnotetext{
${ }^{47}$ Wachler. P. (1903), Erfahrungen .... S. 147.

${ }^{48}$ Wachler, P. (1912), Einkommensteuergesetz ..., S. 1. Bem. 2 zu § 1 sằchs. EStG $1874 / 78$.

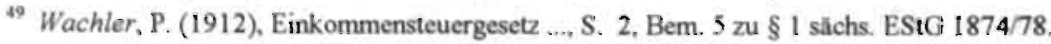

${ }^{50}$ Wachler, P. (1912).Einkonmensteuergesetz .... S. 55. Bem. I zu $\S 15$ Ziff. 1 sằchs. EStG $1874 / 78$
} 
men, wie Erzeugnisse aus eigener Wirtschaft, also verbrauchbare werthaltige Wirtschaftsgüter, die außerhalb des Marktgeschehens in die Privatsphăre des Steuerbürgers zu dessen Nutzung gelangen.

Nach einem Resümee Wachlers von 1903 regte das Gericht die Novellierung des Gesetzes zu vier Punkten von untergeordneter Bedeutung an. Damit sei "die Aufzählung der hauptsăchlichen Erfahrungen und Wünsche aus der Rechtsprechung speziel! in Abgabensachen erschöpft", st so hieß es abschlieBend. Nachhaltige Kritik ist nicht bekannt geworden.

Vollig anders verlief die Beurteilung, die das Preußische Oberverwaltungsgericht an der amtlichen Auslegung der Gesetzesvorschriften und der Uberprüfung der Veranlagungstătigkeit der Behörden in seinen Urteilen erkennen ließ. Den Eindnuck heftiger ideologischer Auseinandersetzungen bis in die Beschlußkörper des Gerichts hinein vermitteln bereits die Beiträge des Präsidenten des 6. Senats, Bernhard Fuisting, in vielen Fachzeitschriften und Buchveröffentlichungen, die durchweg in streitbarer Weise die "Reformbedürftigkeit des preußischen Einkommensteuergesetzes" bzw. "die Einkommensbesteuerung der Zukunft in Anknüpfung an das pretßische Einkommensteuergesetz ${ }^{\mathrm{n} 52}$ behandelten. Sie standen in krassem Gegensatz zu den Beurteilungen anderer Richter am Oberverwaltungsgericht.

Den Einfluß Fuistings mag man daran erkennen, daß er den spăter von Georg Strutz fortgesetzten fuhrenden Kommentar zum preußischen EStG 1891 herausgab und stellvertretender Leiter des Justizprifungsamtes für Verwaltungsbeamte war. Der Senatpräsident am Preußischen Oberverwaltungsgericht und frühere Referent im Finanzministerium, Bernhard Fuisting, wußte die Ursache des nach seiner Auffassung für die fernere Entwicklung fatalen, in das preußische EStG bei der Beschlußrassung im Landtag eingednungenen Fremdkörpers in der Verwässenung mit dem nach seiner Auffassung zu weiten Schmollerschen Einkommensbegriffs zu lokalisieren. ${ }^{53}$ Das hatte nach seiner Auffassung "in den weitesten Kreisen der Steuerpflichtigen eine stark ausgeprägte Unzufriedenheit, die vielfachen Anfeindungen in der Tagespresse, heftige Erörterungen im Landtage und eine Überfülle von Rechtsmittelangriffen gegen die Veranlagung zur Folge gehabt". ${ }^{54}$ Als Folge verfehlte, so Fui-

\footnotetext{
St Wachler. P. (1903), Erfahrungen .... S. 156.

92 Fuisting. B. (1903), Reformbedürtigkeit ...: ders. (1903)., Einkommensbesteuerung ...; Mrozek, A. (1909); ders. (1910); Strutz, G. (1908), S. 426.

s3 Fuisting. B. (1903), Einkommensbesteuerung ..., S. 21: ders. (1902), S. 110: ders. (1896), S. 328.

${ }^{34}$ Fuisting, B. (1903), Einkommensbesteuerung ..., S. 3; hierzu auch: ders. (1896), S. 326, S. 328 , S. 330 .
} 
sting 1903, das Gesetz oft das Ziel einer Besteuerung nach der Leistungsfáhigkeit und sollte durch eine Neubesinnung auf das reine Quellenprinzip reformient werden. ${ }^{55}$

In dem von Miquel zur zweiten Lesung im Preußischen Landtag eingebrachten Entwurf eines neuen Einkommensteuergesetzes im November $1890^{56}$ hatten die Ermittlungsvorschriften der Einkünfte durchgängig noch denjenigen der klassifizierten Einkommensteuer vom 1. Mai 1851 bzw. deren Novellierung von $1873^{57}$ entsprochen. Von Vertretern der Kaufmannschaft wurde aber in den Verhandlungen bei den Einkünften aus Handel und Gewerbe eine Übernahme der Vorschriften aus § 21 Abs. I des săchsischen EStG 1874/78 gefordert. Mit der Entwicklung der Bestimmungen über die Rechnungslegung nach Handelsrecht vertraute Abgeordnete wie Goldschmidt und Broemel suchten in den Verhandlungen des preußischen Landtages zur zweiten Lesung des Regierungsentwurfs zum EStG 1891 dann zu erreichen, daß die Ermittlungsvorschrift für Einkünfte aus "Handel und Gewerbe einschließlich des Bergbaues" aus dem sächsischen EStG zwar übernommen wurde, dabei soilte aber nicht auf \$ 31 AHGB verwiesen werden, sondern auf die inzwischen novellierte Vorschrift, die als lex specialis für Aktiengesellschaften den Wertansatz der Vermögensgegenstände in der Bilanz nach den neueren Erfahrungen mit Schwindelgründungen in den 70er Jahren vorschrieb. ${ }^{58}$ Nach dieser 1884 verabschiedeten Gesetzesvorschrift war in der Bilanz nicht mehr für Vermögensgegenstände undifferenziert der Zeitwert anzusetzen, sondern für Gegenstände des Umlaufsvermögens der Niederstwert und für alle übrigen Gegenstände, also das Anlagevermögen, der fortgeschriebene Höchstwert aus Anschaffungs- oder Herstellungskosten. ${ }^{59}$ Diese Regelung entsprach dem aus neuester Erfahnung entwickelten "Gebrauch eines ordentlichen Kaufmannes", auf den sich die sächsische Ermittlungsvorschrift von $1874 / 78$ bezog.

Miquel vertrat in den Verhandlungen jedoch die Regierungsseite, die ein durchgängig an der Quellentheorie orientiertes Gesetz durchzusetzen suchte, da sie anderenfalls auftretende Ungereimtheiten bei der Auslegung der Vor-

\footnotetext{
15 Fuisting, B. (1903), Einkommensbesteuerung ..., S. 25.

${ }^{56}$ Siche $\$ 14$ Entwurf eines EStG vom 3.11.1890, abgedruckt in FA, 7. Jg. 1890. S. 647.

${ }^{57} \S 30$ Ziff. 3 Gesetz, betrettend die Einfuhrung einer Klassen- und klassifizirten Einkommensteuer vom 1.5.1851, in: Gesetz-Sammlung 1851. Nr. 12. S. 193. S. 206

58 Gesetz betr. Aktiengesellschaften vom 18.7.1884, in: RGBI 1884, Nr. 22, S. 123, S. 136.

s9 Siche hierzu: Barth, K. (1955), S. 203; ders. (1953), S. 156; $\$ 185$ a der Aktienrechtsnovelle von 1884, abgedruckt in: Barth, K. (1953), S. 287. Barth weist verschiedentlich auf die große Bedeutung hin, die den Erö̀terungen im săchs. und spăter im preuß. Landtag und in den gerichtlichen Auseinandersetzungen um die Ermittlung der Einkünfte durch Bestandsvergleich für steuerliche Zwecke für die Entwicklung von Bilanz- und Bilanzsteuerrecht zukam. s. Barth. K. (1953). S. 147: ders. (1955), S. 196; s. a. Pausch. A. (1979), Von der Deklarationsberatung .... S. 449.
} 
schriften und zu geringe Gewinnausweise befurchtete. Er lehnte die Vorschläge ab und stimmte dann letztlich einem Mixtum Compositum zu. ${ }^{60}$ In der in der dritten Lesung nicht beanstandeten Fassung folgte in $\S 14$ nach einem Eingangssatz über die Ermittlung des Geschăftsgewinns gemăß den in $\S \S 6$ bis 11 vorgeschriebenen traditionellen, bereits 1851 normierten Grundsătzen der Überschußrechnung die Bestimmung, daß die Berechnung auch den Grundsătzen des AHGB für die Rechnungslegung "und dem Gebrauche eines ordentlichen Kaufmannes entspreche".61

Den hergebrachten Ermittlungsvorschriften des preußischen Einkommensteuerrechts war so die Bestimmung des săchsischen EStG 1874/78 über die steueriliche Rechnungslegung für Gewerbetreibende aufgepfropft worden. Auslegungsdifferenzen waren vorprogrammiert. Bereits frühzeitig wurde das Oberverwaltungsgericht von einem Mühlenpächter zur Entscheidung einer grundsätzlichen Frage bei Ermittlung der Einkïnfte angenufen. ${ }^{62}$ Zuständig war der 5. Senat, dem Fuisting nicht präsidierte. Zu entscheiden war, ob die noch aus der Feder Fuistings als Regierungskommissar stammenden Anweisungen des Finanzministers vom 5. August 1891 zur Ausfithrung des EStG 1891, die in den $\S \S 19$ und 24 eine Auslegung des $\S 14$ des preußischen ESiG nach der hergebrachten, mit dem Quellenprinzip vereinbarlichen Überschußrechnung vorsahen, oder der entsprechend der im AHGB zur Rechnungslegung vorgeschriebene Bestandsvergleich bei Ermittlung der Einkünfte aus Handel und Gewerbe anzuwenden sei. ${ }^{63}$ Dabei trat noch der Umstand hinzu, daß der im AHGB undifferenziert vorgesehene Wertansatz der Gegenstănde gar nicht mehr dem "Gebrauche eines ordentlichen Kaufmannes" entsprach. Die in $\S 185$ a des "Gesetzes betr. Aktiengesellschaften" vom 18. Julj 1884 normierte Vorschrift mit Niederstwert- und Höchstwertansătzen für die ver-

${ }^{60}$ Barth, K. (1955), S. 203. Barth gibt die wesentlichen Passagen der Verhandlungen im preuB. Landtag wörtlich wieder. Die Einwendungen der Abgeordneten Goldschmidt ind Broemel gegen die abwiegelnden Entwärfe Miquels zăh/en zu den wichtigsten Vorgăngen in der Ẽntwicklung des deutschen Bilanz- und Bilanzsteuerrechts, s. Stenographische Berichte ..., 34. Sitzung 16.2.1891, S. 859 bis S. 865; s. a. Walb, E. (1933), S. 6, S. 25.

${ }^{61} \S 14$ preuß. EStG 1891 . In der Novellierung vorn 19.6.1906 wurde daraus § 13. Die Vorschrif wurde aberarbeitet und Widerspruche beseitigt. Der Eingangssatz wurde getilgt.

${ }^{62}$ Siehe Urteil des OVG vom 13.12.1895, Rep. V 5/95 in: Entscheidungen des Kgl-PreuB. ..., 4. Bd. Nr. 57, S. 241.

${ }^{6}$ Fulsting, B. (1892), S. 281, hier S. 309. In der Kommentierung zu $\$ 14$ EStG 1891 heiBt es bei Fuisting: "Der zweite und dritte Satz sind Zusatzbestimmungen des Abgeordnetenhauses. ... Arı erster Stelle gelten daher die allgemeinen Bestimmungen ( $\$ \S 6$ - 11$)$; nur soweit diese keine abweichenden Vorschriften enthalten, kommen die Grundsătze des Handelsgesetzbuches aber die Aufstellung von Inventur und Bilanz zur Anwendung ...", s. S. 174. Der Kommentar erzeugte den Eindruck einer amtlichen Auslegung: 
schiedenen Gegenstănde des Vermögens gab den neuesten Stand dieser Gebrăuche wieder ${ }^{64}$ Von diesen sprach das preußische ESIG 1891 jedoch nicht.

In einer ausführlichen Besprechung hielt Droste als sachkundiger Finanze-amter die richtungweisende Entscheidung des, Oberverwaltungsgerichts vom 13. Dezember 1895 fest. $^{65}$ Seit dem Urteil des OVG vom 1. Mai 1888 waren Bilanzen für die Einkommensbesteuerung in Preußen "als völlig bedeuturgslos" eingestuft worden. Nun hatte der zuständige neugebildete 5. Senat in Staatssteuersachen "im Anfang nur zögernd und allmählich und stets in Beschränkung auf den einzelnen zu entscheidenden Fall sich der Tatsache ncht verschließen können, daß der Einkommensbegriff in seiner Abgrenzung vom Stammvermögen beim Einkommen aus Handel und Gewerbe anders beurieilt werden müsse, wie nach den allgemeinen Grundsătzen", so gab er die Entscheidung des Gerichts wieder. ${ }^{66}$ Damit war für die Zukunft unrevidierbar klargelegt, då für Einkünfte aus Handel und Gewerbe "die Trennung des, Einkommens vom Stammvermögen anders zu beurtheilen sind als bei den anderen Einkunftsarten". ${ }^{67}$

Bereits im vorausgehenden Band des "Verwaltungsarchivs" hatte Fuisting. vor Droste die Konsequenzen dieser ihm wohl vorzeitig bekannt gewordenen Entscheidung dargelegt und letztlich unüberhörbar seinen Unmut über die sogar vom Oberverwaltungsgericht bestătigte Verwăsserung der dem preußiscneen EShG zugrundeliegenden, as Quellenprinzip bezoithnotos Bastuerungsidee, die nach seiner Überzeugung allein eine Besteuerung nach der Leistungsfahigkeit garantieren konnte, bekundet. ${ }^{68}$

Zwar betraf der eingetretene Einbruch in die einheitliche Systematik des EStG 1891 nur die Einkünfte aus "Handel und Gewerbe einschließlich des Bergbaues" und Einkünfte aus Spekulationsgeschäften, richtete sich also an eine kleine Teilmenge aller Steuerpflichtigen und regelte bloß eine Ermittlungsvorschrift. Darüber hinaus wurde die Geltung der Vorschrift in der Novellierung des Gesetzes vom 19. Juni 1906 sogar auf diejenigen Steuerpflichtigen beschränkt, "welche Handelsbücher nach den Vorschriften des HGB führen". Dennoch muß man berücksichtigen, daß gerade die Steuerpflichtigen betroffen waren, auf die sich vornehmlich das besondere Interesse der Schmollerschen Besteuerungsidee gerichtet hatte: Die geringe Anzahl von

\footnotetext{
4. Siehe Anm. 59; aus $\$ 185$ a der Novelle vurde $§ 261$ HGB 1897.

${ }^{65}$ Droste (1897), S. 543.

${ }^{66}$ Droste (1897), S. 545, S. 555.

${ }^{67}$ Droste (1897), S. 556.

${ }^{6}$ Fuisting, B. (1896), S. 481, s. a. S. 328; ders (1903), Reformbedürftigkeit ..., S. 230.
} 
Empfângern höherer Einkommen sollten, anders als bis dahin, entsprechend ihrer höheren Leistungsfahigkeit zu Abgaben herangezogen werden.

Nun eröffnete aber die im 19. Jahrhundert gesteigerte Mobilităı durch die Privatautonomie eben diesen Steuerbürgern infolge der entstandenen gespaltenen Systematik der Einkünfteermittlung fortan nichı einkalkulierte weitreichende Möglichkeiten von legalen Steuervermeidungen.

Der von Wagner vertretene Besteuerungsplan, der die als sachgerecht nach dem Quellenprinzip organisierte Einkommensteuer einschloB, hatte zur Erfassung der Steuerbürger nach ihrer Leistungsfähigkeit, sofern erforderlich, den Ausbau der Verkehrssteuern zur Berücksichtigung eines eventuellen Vermögenswertzuwachses und zur Erfassung letztlich unerwünschter Spekulationsgewinne vorgesehen. ${ }^{69}$

Zu Ansătzen einer Verwirklichung dieser Planung kam es aber erst nach 1910 und zwar nun in völlig unabgestimmter und ungeeigneter Weise ohne erkennbare Systematik. ${ }^{70}$

Damit war 1895 die Grundlage für den bis heute bedeutsamen Einkommensbegriff des preußischen EStG gelegt und vom preußischen Oberverwaltungsgericht durch Auslegung des Gesetzes festgeschrieben. Das preußische EStG 1891 wurde zwar vom Quellenprinzip als Orientierungsgesichtspunki bestimmt. Es kannte jedoch bei den Ermittlungsvorschriften Ausnahmen von der Regel. Praktiker wußten fortan aus diesen Auslegungen Nutzen zu ziehen. Steuerrechtler suchten nach Lösungen, indem sie meinten, man müsse die "Dinge auch vom Rechtsstandpunkt aus genau kennen oder studieren, den Rechtsstandpunkt zu Wort kommen lassen". " Sie glaubten dabei zumeist an die richtungsweisenden Thesen Fuistings über die Orientierung des preußischen EStG 1891 an der Leistungsfähigkeit der Steuerbürger. ${ }^{12}$

Sozialpolitisch orientierte Beobachter der konkreten Besteuerungswirkungen, wie Schmoller, Delbrück. Mrozek, Meisel, Michaelis und andere, verwic-

69 Wagner, A (1887). S. 109, S. 113. Zu Wagners steuerlichem Einkommensbegrifí s. ders. (1890), S. 324, S. 325. Zur Besteuenung von Wertzuiwachs s. ders. (1890), S. 559. S. 579. Wertzuwăchse gehörten für Wagner grundslitzlich nicht zurn Einkommen, seine Ausfuhrungen hierzu waren inkonsequent, s. Bredt. V. S. 41, S. 62, \&. 66; auch: Hansen, R. (1990), S. 29 mit FundstelJen. Futsting war sehr konservativ und lehnte die Besteuerung von Wertzuwachs grundsalzlich ab, s. Fuisting (1902), S. 67, S. 71, S. 147, S. 171; hierzu: Meyer, R. (1904), S. 125. Die Besteuerung des Wertzuwachses ist ein Zentralpunkt von Wagners sozialpolitischen Anliegen an eine Steuerpolitik.

70 Gerloff, W. (1913), Die Wertzuwachssteuer ..., S. 401, hier S. 408; hierzu auch: Meisel, F. (1919/20), Wo steht .... S, 487. Der Aufsatz von Gerloff gibt viele weitere Fundstellen. Offensichtich paßte er in Schmollers Konzept und wurde daher in dessen, Jahrbuch veröffentlicht.

$"$ Waldecker, L. (1916), S. 171.

7 Waldecker. L. (1916), S. 174. 
sen bald mit Nachdruck auf die Differenzen zwischen Anspruch und Wirklichkeit.

In dem EStG vom 10. August 1925, das in systematischer Hinsicht bis heute fortgilt, griff man für das leitende Konzept wieder auf das preußische ESIG 1891 zurück.

Die in dem geltenden EStG normierte dualistische Vorschrift über die Einkommensermittlung wird von vielen kritischen Steuerrechtslehrern heute als Verstoß gegen das Verfassungsgebot der Gleichmäßigkeit der Besteuerung kritisiert. Zur Begründung wird jeweils angeführt, daß alle Bezüge eines Steaerpflichtigen, die dessen wirtschaftliche Leistungsfähigkeit erhöhen, in der Bemessungsgrundlage gleichmäßig zu erfassen seien. Die Verletzung des Gleichheitsgrundsatzes, so fuhrt Tipke aus, ist bereits in $\S 2 \mathrm{EStG}$ angelegt. In dem Dualismus dieser Vorschrift sieht er einen "Systembruch". ${ }^{73}$ Wir haben jedoch gesehen, daß der Begriff der Leistungsfähigkeit zur Zeit der Schaffung des preußischen EStG einen anderen Inhalt hatte, was auf das inzwischen fortentwickelte wirtschaftliche Umfeld zurückzuführen ist. Mit der wirtschatlichen Entwicklung hat sich die Verkehrsauffassung bis heute stark verändet. Dies gilt für die zu erfassenden Einnahmen ebenso, wie für die zur Ermittlung der individuellen Leistungsfahigkeit abzugsfähigen Aufwendungen. Letztlich ist auch bereits Fuisting, ebenso wie heute Tipke, für eine sachgerechte und konsequente Rechtsanwenctung eingetreten, woober das Prinzip der Besteuerung nach der Leistungsfahigkeit eben den für das preußische EStG von 1891 typischen Inhalt erhalten hat. ${ }^{74}$ Dieses Gesetz wurde mithin, anders als heutige Kritiker glauben, sehr wohl von einer einheitlichen übergreifenden Besteuerungsidee bestimmt, die allerdings bei Vorliegen bestimmter Tatbestandsmerkmale in Teilbereichen gewollt durchbrochen wurde.

\footnotetext{
${ }^{73}$ Tipke, K. (1973), S. 397; ders. (1972), Steuerrechtswissenschaft ..., S. 212, S. 215

7a Die heute vertretene Auffassung, daB die "Quellentheorie" des Einkommens "eine Regel sei, die außerhalb des vom Leistungsfahigkeitsprinzip beherrschten Einkommensteuersystems steht" (Lang, J., 1981, S. 228), stellt in der Verwendung Langs und Tipkes eine subjektive Wertung ohne Allgemeinverbindlichkeit dar. Es zeigt sich, daß das sogenannte "Leistungsfähigkeitsprinzip" keinen eindeutigen Inhalt bezeichnet. "Ein normatives Prinzip, das keine mogliche Verhaittensweise verbietet (Leerformel), ist in diesem Sinne gehaltlos und hat keine regulative Funktion", s. Albert, H. (1960), S. 221. Fn. 43. Auch wenn nur ein kleiner Bereich mōglicher Regelungen ausgeschlossen sein sollte, ândert dies nichts wesentliches, da noch unendlich viele Gestaltungen kompatibel sein können. Ein Wettstreil um die wahre Bedeutung des Begriffs einer Bestetierung nach der Leistungsfahigkeit kann nicht weiterhelfen. Der Begriff bedarf der Definition vor der Venwendung. Sehmoller hatte daher eine solche geliefert. Eine Erkenntnis sah er darin nicht; ein Eindruck, der gern erzeugt wird. Tipke glaubt, eine gerechte Besteuerung müsse von sachgerechten Regeln nach der Leistungsfähigkeit des Steuerbûrgers bestimmt sein. Dies erfordere die Verwendung des Reinvermögenszugangsprinzips als. Fundamentalprinzip der Besteuerung. In dem dualistischen Aufbau der Einkommensbesteuerung sieht Tipke die Verhinderung einer gerechten Besteuerung. Insofern sieht er einen Systembruch als gegeben. Tipke glaubt eine Wertentscheidung des Gesetzgebers erkennen zui können, die für den. Rechtsanwender verbindlich sei.
} 
Nun sind die Gerichte der Bundesrepublik Deutschland nach der Verfassung streng an Recht und Gesetz gebunden. Nach dem seit 1925 geltenden Einkommensteuerrecht entspricht der dualistischen Aufgliederung der darin normierten steuerbaren Einkünfte eine zweifache, unterschiedlich orientierte Regelhaftigkeit.

Weder der Bundesfinanzhof, noch das Bundesverfassungsgericht haben daheп bis heute in dem Einkünftedualismus des geltenden ESıG einen Verstoß gegen den Gleichheitsgrundsatz erkennen können. ${ }^{75}$ Denn die Bindung an Recht und Gesetz in der Verfassung beinhaltet nach der Uberprüfung durch das Bundesverfassungsgericht, "daß die Regelhaftigkeit im subjektiv teleologischen Rahmen" folgerichtig vollzogen wird. ${ }^{76}$ Jedes kodifizierte Recht, so die herrschende Meinung, enthălt Regelungslücken, auch wenn es noch so sorgfältig geschaffen wurde, da der Gesetzgeber nicht alles vorhersehen kann. Auch ist jede Rechtsordnung ein "ständig in Entwicklung begriffenes System normativer Regeln". ${ }^{77}$ Die alltăgliche Praxis ermöglicht es dem Richter, das Normengefüge jeweils zu verbessern, zu präzisieren, Lücken zu füllen und zu ergănzen und insoweit fortzubilden.

Aber die Rechtsfortbildung findet im demokratischen Rechtsstaat ihre Begrenzung im "dictum des Gesetzgebers", so die Auffassung des für die Beurteilung zustăndigen Beschlußgremiums ${ }^{78}$ Dies ist Ausdruck des "gesetzgeberisch intendierten Regelungsprogrammes" ${ }^{79}$ Sie findet ihre Grenze in der Tatigkeit des Gesetzgebers. Auch die Verwendung von Analogien ist in der Finanzrechtsprechung umstritten, da es sich bei dem Steuerrecht nach vorherrschender Auffassung um Eingriffsrecht handelt und dies zu einer Auslegung nötigt. ${ }^{80}$ Zwar hat sich in der höchstrichterlichen Finanzrechtsprechung ein allmählicher Wandel der Begriffsauslegung von Aufwandspositionen, wie etwa Betriebsausgaben und Werbungskosten, bei der Ermittlung des Einkommens,

75 BVerfG Urteil vom 9.7.69, in: BVerfGE, Bd. 26, S. 202. Feststellung dortselbst auf S. 312; BVerfG Urteil von 7.10.69, in: BVerfGE, Bd. 27, \$. 111. Feststelilung auf S. 127.

76. Lang. J. (1981), S. 228; hierzu: Larenz, K. (1991), S. 328, S. 339.

77 Weber-Grellet, H. (1991), S. 441.

7 Weber-Grellet, H. (1991), S. 445; BVerfG Urteil vom 24.1.62 1. BvR - 262/60, in: BVerfGE 1962, S. 318, S. 328.

79 Weber-Grellet (1991), S. 442.

${ }^{80}$ Die. Frage, ob Steuerrecht Eingriffsrecht oder Lastenverteilungsrecht ist, ist als zentrales Problem der Steuerrechtsanwendung bis heute umstritten, s. Feix, G. (199J), \$. 8733; Weber-Grellet, H (1991), S. 445. Nach Weber-Grellet ist das Steuerrecht "neben seiner Funktion als Eingriffisrecht vor allem auch Verteilungsrecht". Der Schwerpunkt scheint damit erkennbar. 
die zu einer größeren Gleichmäßigkeit führte, ${ }^{81}$ vollzogen. Eine dem "Gesamtplan des EStG widersprechende Unvollkommenheit", einen "Systembruch", haben jedoch weder der Bundesfinanzhof, noch das Bundesverfassungsgericht im geltenden EStG zu erkennen vermocht, da das Gesetz seit 1925 gewollt eine zweifach aufgegliederte Ausrichtung der Tatbestandsmerkmale für die Ermittlung des steuerbaren Einkommens vorsieht.

si Walz, W. R. (1986), S. 21. Walz zeige, wie der Wandel von Normalitătsvorstellungen und Verkehrsanschauungen Einfluß auf richterrechtliche Zusatzkriterien für die Entstehung einer fallrechtlichen Dogmatik aunbt, s. S. 39, S. 43. 


\section{Die von der Systematik der "deutschen Einkommensteuertype" gewährten Möglichkeiten zur Herabsetzung beziehungsweise Vermeidung des Steuerzugriffs}

Nachfolgend sollen im historischen Ablauf die Reaktionen skizziert werden, die es dem Steuerpflichtigen infolge der Ausgestaltung des jeweiligen Einkommensteuerrechts ermöglichten, den Steuerzugriff durch legale rechtliche Gestaltungen seiner Verhältnisse herabzumindern oder gar ganz zu vermeiden. Dabei soll auch kurz das durch den typischen Aufbau des geltenden Steuerrechts in einer Grauzone der Legalităt angesiedelte Verhalten der Zensiten erwähnt werden, das zu einer Verringenung oder gar Vermeidung der Steuerlast zu führen geeignet war, ohne die Gefahr steuerstrafrechtlicher Konsequenzen auszulösen.

\section{Gestaltungsmöglichkeiten zur Vermeidung der direkten Steuern in Preußen nach den Befreiungskriegen bis 1891}

Zu Beginn des 19. Jahrhunderts war die Stadt Königsberg in Ostpreußen das wichtigste Einfallstor für die neuen politischen und wirtschaftlichen Orientierungen aus England, die von dem liberalen Gedankengut Adam Smith' bestimmt waren.'

Die von der napoleonischen Besatzungsmacht auferlegten Kriegskontributionen lasteten schwer auf Preußen, dessen Regierung sich nach Ostpreußen zurückgezogen hatte. Die mit der französischen Revolution aufgekommene Forderung nach größerer Steuergerechtigkeit und vor allem das Verlangen nach einer Besteuenung der Bürger entsprechend ihrer Leistungsfahigkeit beflügelten die Erörterungen um eine gerechte Verteilung der drückenden offentlichen Lasten. So konnte die in England entstandene neuartige Einkommensteuer angesichts einer trostlosen finanziellen Situation in Preußen wie eine Verheißung in der Not erscheinen. Aber ebenso wie in England war auch in Preußen einer von Steuererklărungen der Zensiten ausgehenden und durch harte Strafandrohungen geschützten Einkommensteuer letztlich nur eine kurze

1 Mamroth. K. (1890), S. 12; s. a. Lehmann, M. (1901), S. 9, S. 21: Großfeld, B. (1981), S. 27. 
Wirksamkeit beschieden. ${ }^{2}$ Die aus England einströmenden Gedanken zur Neuordnung der politischen und wirtschaflichen Verhältnisse wurden jedenfalls enthusiastisch von der Öffentlichkeit aufgegriffen und bildeten die Grundlage für einen politischen Neuaufbau des darniederliegenden Landes. "Wenn aus unserem Staate irgend etwas werden, wenn er sich bei dem Mangel ăußerer Mittel wieder emporheben ... soll, so müssen all seine inneren Krăfte entfesselt und frei wirken, so muß jeder Eingesessene seine Intelligenz und seine Körperkraft ganz anwenden und den Nutzen davon ziehen ..."," ${ }^{3}$ so lauteten programmatische Sătze, die die Zeit bestimmten. Der Zeitgeist war aber bald nicht mehr der Einkommensteuer als dem gerechten Ausweg aus großer finanzieller Not des Staates gesonnen. Die Methoden zur Veranlagung und Einziehung der Steuer und die damit verbundenen harten Strafbestimmungen führten zu stăndigen Streitereien, die auf Dauer für einen Neuaufbau unerträglich waren. Die für đie Einkommensteuer obligatorische Steuererklärung der Zensiten und dazu die angedrohten Strafen für Steuerhinterziehung bei falschen Angaben erschienen Adel und Bürgertum gleichermaßen wegen des Eindringens in die Privatsphăre völlig inakzeptabel. ${ }^{4}$ Zugesicherte Maßnahmen zum Schutz des Vertrauens gegen einen befürchteten gehässigen Fiskalismus schafften keine Basis für die erforderliche Zuversicht. Die Methoden der Veranlagung, das sogenannte "Einschătzungsverfahren", und der dem Pflichtigen dabei gewăhrte Rechtsschutz vor einem von Bürgertum und Adel befürchteten Eindringen des Finanzbeamtentums in die Privatsphäre hat dann in Preußen bis zum 1. Weltkrieg fortan die Diskussion um die Ausgestaltung der Einkommensteuer beherrscht und belastet. ${ }^{5}$

Im Mai des Jahres 1820, als zur Einführung einer Einkommensteuer eine obligatorische Steuererklärung der Pflichtigen gar nicht mehr zur Debatte stand, einigte man sich auf die Schaffung einer "Klassensteuer", die die Bevölkerung nach einfachen äußeren Merkmalen des Wohlstandes als Zeichen der gesellschaftlichen Stellung in vier Klassen einordnete. ${ }^{6}$ Die in einer "Klassifikations-Instruction" von 1820 festgelegten Unterscheidungen waren aber äußerst fragwürdig und unpräzise. So reichten der Besitz eines größeren Landgutes, eines Handelsgeschäftes oder eines sonstigen Gewerbebetriebes, die ein Einkommen erwarten ließen, das einen unabhängigen und bequemen Lebensstil ermöglichen konnte, für die Aufnahme in die höchste Hauptklasse aus. Die

${ }^{2}$ Grabower, R. (1932), S. 195; Gropfeld, B. (1981), S. 21, S. 34

3 von Mamroth, K. (1890), S. 202, s. a. Walz, W. R. (1980), S. 34

${ }^{4}$ Großfeld, B., S. 30, S. 35; Greim-Kuczewski, P., S. 72, S. 87; Linzbach, P. (1984), S. 138.

'Großfeld, B., S. 35 .

${ }^{6}$ Greim-Kuczewski, P., S. 92; Held, A. (1872), S. 266. 
amtlichen Entscheidungskriterien erlaubten eine wenig differenzierte Beurteilung. Im Grunde stellten sie, wenn auch nach außen verborgen, auf eine Differenzienung nach der Höhe des vermuteten Einkommens als Klassifikationskriterium $a b{ }^{7}$

So kam es zu einer Einteilung, bei der im Jahr 1821 in die erste Hauptklasse $3,5 \%$, in die zweite $16 \%$, in die dritte $36 \%$ und in die vierte Hauptklasse $43 \%$ der Erwachsenen eingestuft wurden. Nur 1,5\% galten als steuerbefreit. Diese Klassifikation war bewußt als Kriterium des sozialen Status der Steuerpflichtigen ausgestaltet. ${ }^{8}$ Ernüchternd hielt jedoch Joseph A. Hill, ein amerikanischer Berichterstatter, nach Studium der Verhăltnisse 1892 in dem "Quarterly Journal of Economics" fest: "... in general, the Prussian subject, when it came to the question of taxation, did not seem to aspire to a high social position"?

Die höchst fragwürdige Form der Einschătzung der Zensiten nach willkürlichen Kriterien führte naturgemäß als Reaktion bei den Steuerpflichtigen zu einer stăndigen Verheimlichung und Verschleierung der persönlichen Einkommensverhältnisse sowie zu einer Einschrănkung des Aufwandes des - nach außen hin zumindest im Bereich der Geltung des Gesetzes - erkennbaren Lebensstils. $^{10}$

Tatsächlich verringerte sich von 1821 bis 1846 dann die Besetzung der oberen zwei Hauptklassen um 16,3\%, diejenigen der unteren beiden vermehrten sich dagegen um 10,05\% und die Gruppe der Steuerbefreiten wuchs um $6,58 \%$. Wenn auch konjunkturelle Gründe hier eine Rolle gespielt haben mögen, so ist die Tendenz jedenfalls unverkennbar. ${ }^{11}$

Von Interesse mag sein, daß es vielen wohlhabenden Landwirten offensichtlich gelang, die Einschätzungskommissionen zu erheblich zu niedrigen Veranlagungen zu motivieren: von 12.352. Rittergutsbesitzern in Preußen, denen ein jährliches Einkommen von 6.000 bis 60.000 Reichsthalern nachgesagt wurde, fanden dennoch im Jahr 1849 nach Feststellungen des Finanzministers von Rabe nur 676 Familien Aufnahme in die erste Hauptklasse. ${ }^{12}$

7 Greim-Kuczewski, P., S. 93; Held, A.. (1872), S. 276 ff Anm. 1.

"Greim-Kuczewski. P., S. 95.

${ }^{9}$ Hill, J. A. S. 211.

${ }^{10}$ Greim-Kuczewski, P., S. 95.

$"$ "Grätzer, R. (1884), S. 52; von Beckerath, E. (1912), S. 163; Greim-Kuczewskd, P., S. 95.

12 Siehe: Motive zu dem Gesetzentwurf. die Einfuhrung einer Einkommen- und Klassensteuer betreffend, in: Stenographische Berichte über die Verhandlungen der durch Allerhőchste Verordnung vom 30. Mai 1849 einberufenen Zweiten Kammer, 1. Band, Berlin, 1849, S. 576. 
Durch die geschilderten Regelungen und Umstände denaturierte die Klassensteuer immer mehr zu einer Kopfsteuer, da die unteren Klassen zunehmend die Steuerlast übernehmen mußten. ${ }^{13}$ Das tatsächliche Aufkommen entsprach dabei der Höhe nach mit geringen Differenzen dem Sollaufkommen. ${ }^{14}$

Erwähnt werden mag noch die Verfilzung der die Veranlagung durchführenden Verwaltung. Vorsitzender der Einschätzungskommission war jeweils der Landrat. Die leitenden sachbearbeitenden Beamten waren durchweg Juristen mit Befahigung zum Richteramt, denen es an wirtschaftlichen Kenntnissen mangelte. ${ }^{15}$ Im Falle einer zu hohen Einschätzung konnte der Steuerpflichtige ein Rechtsmittel einlegen und fakultativ zur Begründung eine eigene Steuererklärung zwecks Richtigstellung der Veranlagung abgeben. Nur ausnahmsweise machten Bürger von dieser Möglichkeit Gebrauch, nämlich um kein Präjudiz bezüglich der eigenen Einkünfte für die Zukunft zu schaffen. Die Behörde war daher gezwungen, die Einschătzung aus der an Amtsstelle vorhandenen amtlichen Information zu alimentieren und durchzuführen.

Vergeblich suchte die Regierung 1847 in einem strengeren Gesetzentwurf "die übermäßige Milde der Klassensteuer gegen die Reichen" abzubauen. Der Vorschlag wurde abgelehnt, obgleich bekannt gemacht wurde, "daB im Jahre 1846 nur 346 Personen den höchsten Klassensteuersatz von 144 Thalern jăhrlich zahlten und in der obersten Hauptklasse überhaupt nur 4.586 Haushaltungen waren ...". ${ }^{16}$

Während im übrigen die Bevölkerung Preußens von 1822 bis 1837 um 22\% zunahm, stieg das Klassensteueraufkommen nur um etwa 5\%. ${ }^{17}$

Was über die Wirkung des Klassensteuergesetzes vom 30 . Mai $1820 \mathrm{zu}$ sagen ist. gilt im wesentlichen auch für das "Gesetz zur Einführung einer Klassen- und klassifizirten Einkommensteuer" vom 1. Mai 1851 und dessen Novellierung im Jahr 1873 und für die Zeit bis zum 23. Mai $1891 .^{18}$

${ }^{13}$ Linzbach, P. (1984), S. 157.

14 Limzbach. P. (1984), S. 154; von Beckerath, E.. S. 11; Hofffmann, J. G., S. 173, S. 186.

15 Pausch, A. (1976), 250 Jahre ..., S. 116: Bleck. W. (1972), S. 102: S. 123; von Delbrïck, C. (1917), S. 7; Witt, P. C. (1973), S. 207.

${ }^{16}$ Held, A. (1872), S. 284

${ }^{17}$ Linzbach. P. (1984), S. 157: Held, A. (1872), S. 279

${ }^{18}$ Mauz, F. (1935), S. 26. S. 46, S. 47: Greim-Kuczewski, P... S. 130; Linzbach. P. (1984), S. 168. S. 169; Großffeld, B. (1981), S. 41. In einem Gesetzesentwurf der Regierung "wegen Abănderung einiger Bestimmungen des Gesetzes betreffend die Einführung einer Klassen- und klassifizirten Einkommensteuer vom 1.5.1851" wurde noch 1869 letztmals vorsichtig versucht, eine Verpflichtung zur Selbsteinschätzung einzufthren, wobei diese sich nur noch auf eine "Einschătzung in die Klassen" erstrecken sollte. Sogar dieser halbherzige Versuch wurde vom Landtag verworfen. Der Schwerpunkt des Entwurfs hatte sich dabei nur auf die "Ergànzung der Mittel zur richtigen Erforschung des steuer- 
Das Vorbild einer Wiedereinfuhrung der Einkommensteuer durch Peel in England im Jahr 1842 hatte die Regierung in Preußen errnutigt, $1847 \mathrm{zu}$ versuchen, die Klassensteuer aufzuheben und durch eine Einkommensteuer auf alle Einkommen über 400 Thaler zu ersetzen. ${ }^{19}$ Nach $\$ 11$ des Gesetzentwurfs sollte die Erklärungspflicht eingeführt und durch Strafandrohung für falsche oder fehlende Angaben unterstützt werden. Der Entwurf scheiterte aber an eben diesen Vorschlăgen. ${ }^{20}$ Ebensowenig Erfolg hatte dann aus denselben Gründen der Furcht vor inquisitorischen Maßnahmen der Behörden sogar der 1850 gestartete Versuch der Regierung, eine vorgesehene Erklărungspflicht in eingeschränkte Mitwirkungspflichten ${ }^{21}(\$ \S 11,13)$ der Steuerbürger beì eingegrenzten Tătigkeitsrechten der Veranlagungsbehörde umzuwandeln. ${ }^{22}$

Schließlich kam es 1851 zu der Regelung, die letztlich mit unbedeutenden Änderungen bis 1891 Bestand haben sollte. Auf eine Steuererklärung wurde verzichtet. Es blieb danach bei der Klassensteuer für die unteren 12 Stufen $(\$ \S$ 7. 9). Dieser wurde eine klassifizierte Einkommensteuer ( $\$ \S 16$ ff) mit 30 Steuerstufen aufgestülpt. ${ }^{23}$ Das steuerbare Einkommen wurde in Anlehnung an die Lehren der allgemein vertretenen klassischen Nationalokonomie selektiv definiert. Nur unmittelbar an der Güterproduktion beteiligte Einkünfte sollten danach der Einkommensteuer unterworfen werden. So lautete $\$ 19$ klassifiziertes EStG 1851: "Die Veranlagung der klassifizirten Einkommensteuer erfolg1 lediglich nach Maßgabe des Gesammt-Einkommens, welches dem Steuerpflichtigen aus Grundeigenthum, aus Kapital-Vermögen oder aus Rechten auf periodische Hebungen oder aus Vortheilen irgend welcher Art aus dem Ertra-

pflichtigen Einkommens" gerichtet. In den Motiven zu dem Entwurf wurde beklagt, đals nur die Festbesoldeten "nach ihrem vollen Einkommen besteuert werden ..." und daß es "an jedem Mittel fehlt, das Einkommen aus Kapitalbesitz in zutreffender und genauer Weise zu ergründen", zitiert nach Held, A. (1872), S. 297 - 299; s. a. Teschemacher, H. (1912), S. 68.

19 Held, A. (1872), S. 283; Großfeld, B. (1981), S. 37. \&. 38.

${ }^{20}$ Held, A. (1872), S. 285, S. 286; Großfeld, B., S. 39, Anm. 160.

21 Held, A. (1872), S. 291, S. 292; Großfeld, B., S. 40.

22 S. Rede Kahnes für den Regierungsentwurf, abgedr. in: Held, A. (1872), S. 291. Anm. 1; s. Großfeld, B., S. 40.

${ }^{23}$ Held, A. (1872), S. 293; Großfeld, B., S. 40, S. 41. Die Klassensteuer galt nur für "Einwohner in nicht mahl- und schlachtsteuerpflichtigen Orten (in Preußen 83). Sie kannte keine Eingangsstufe und betraf Einwohner, deren Jahreseinkommen 1.000 Reichsthaler nicht aberschritt $(\$ 5)$. Befreit waren u. a. "Arme, die im Wege der offentlichen Armenpflege eine fortlaufende Unterstutzung erhalten oder in öffentlichen Anstalten auf offentliche Kosten verpflegt werden" ( $\$ 6$ Buchst. e Klassensteuer vom 1.5.1851. Gesetz-Sammlung 1851, S. 195). Die 30 Steuerstufen der klassifizirten Einkommensteuer für Jahreseinkûnfte oberhalb von 1.000 Reichsthalern sahen einen Steuersatz von 3\% des jeweiligen Eingangsbetrages vor. Einkommensbetrăge über 240.000 Reichsthaler wurden nicht besteuert, da die Stufenfolge der Steuer bei 7.200 Reichsthaler endete (\$ 20). 
ge eines Gewerbes oder irgend einer Art gewinnbringender Beschäftigung zufliebt" ${ }^{24}$

Die Bemessungsgrundlage sollte von der Einschătzungskommission "ohne tieferes Eindringen in die finanzielle Situation des Steuerbürgers" geschătzt werden. ${ }^{25}$ Nur auf dessen Reklamation gegen die Festsetzung hin konnten von ihm in einem ordentlichen Gerichtsverfahren Informationen abverlangt und gegebenenfalls Zeugen einvernommen werden. Nur für diesen ausdrücklich als letztes Mittel vorgesehenen Fall waren falsche Angaben mit Geldstrafen bedroht. $^{26}$

$\mathrm{Zu}$ bedenken ist hierbei, daß es keine steuerlichen Bestimmungen über die Verpflichtung zur Führung von Aufzeichnungen gab und die globalen Vorschriften des Allgemeinen Landrechts für die Preußischen Staaten von 1794 in den $\S \S 562$ ff (IV. Abtheilung) wegen fehlender konkreter Regelungen wenig hilfreich waren. ${ }^{27}$ Teschemacher sprach von "einer Einkommensteuer, der die entscheidenden Hilfsmittel zur Erfassung des Einkommens genommen sind" ${ }^{28}$

Fragt man nach den Konsequenzen dieses bis 1891 mit geringen Änderungen gültigen Gesetzes für das Verhalten der Steuerbürger, so ergibt sich folgendes: Für die kleinen Steuerzahler gab es keine Alternativen. Eine Steuervermeidung oder gar Hinterziehung war für sie nicht möglich.

Die Zensiten der oberen Klassen konnten sich bereits vor 1851 der Klassensteuer erheblich, gegebenenfalls ganz entziehen. Sie konnten einmal durch ihr Verbrauchsverhalten im Besteuenungsbezirk durch bescheidenes Auftreten dafür sorgen, in eine niedrigere Klasse zu gelangen. Durch Nachweis der Anwesenheit in einem der 83 mahl- und schlachtsteuerbelasteten Orte (etwa Berlin) für länger als ein halbes Jahr konnten sie sodann die Klassensteuer sogar

\footnotetext{
${ }^{24}$ S. Gesetz-Sammlung für die PreuB. Staaten 1851, Nr. 12, v. 1.5.1851, S. 200.

25 Dies wurde im Gesetz ausdrücklich normiert, s. \$22 Abs. 3 und \$23 Abs. 1. klass. EStG 1851.

${ }^{26} \$ 24$ Abs. 2 klass. EStG 1851 schreibt als Regel versuchsweise den "milderen Weg" vor. Ausdrìcklich erlaubte das Gesetz nur "äuBersten Falles" die eidliche Einvernahne durch Einschaltung des Gerichts, die Befragung vọn Zeugen und Einforderung der Einsicht in Ürkunden und die Vorlage von "Handlungsbochern". Wer als Reklamant wissentlich "einen Theil seines Einkommens verschwiegen oder zu gering angegeben hat", konnte mit einer Geldstrafe in Hōhe des vierfachen Betrages der verkürzten Steuer bestraft werden, s. § 33 Abs. 1 klasss. EStG 1851. Wer das Rechtsmittel der Reklamation rechtzeitig zuruickzog, konnte entsprechend nicht bestraft werden. Der Versuch war mithin nicht strafbar. Eine ähnliche Regelung findet sich später in der Handhabung des $\S 38$ Abs. 2 i. V. m. $\S 66$ preuB. EStG 1891.

${ }^{27}$ In den Vorschriften $\$ \S 562 \mathrm{ff}$ des Allgemeinen Landrechts für die Preußischen Staaten, Zweyter Theil, Achter Titel, finden sich keinerlei Bestimmungen uber die Rechnungslegung. Zumeist handelt es sich um Fragen der Beweiskraft von Handelsbochern, wobei auf das Urteil von Sachverstlindigen hingewiesen wird, s, hierzu: Barth, K (1953), S. 66; Walb, E., S. S.
}

\footnotetext{
28 Teschemacher, H. (1912), S. 71 .
} 
gănzlich vermeiden. ${ }^{29}$ Die Mahl- und Schlachtsteuer war nämlich eine ortsgebundene Verbrauchssteuer, ${ }^{30}$ die jeweils die Entstehung der Klassensteuer ausschloß. Sie belastete die unteren Schichten im übrigen wie jede Verbrauchssteuer stärker. ${ }^{31}$

Die dann nach 1851 ab einem. Einkommen von 1.000 Thaler erhobene "klassifizirte Einkommensteuer" ließ sich ebenso leicht verringern oder gar ganz vermeiden. ${ }^{32}$ Dem bis in Einzelheiten vorgeschriebenen steuerlichen Ermitt* lungsverfahren fehlten für die Berechnung der Bemessungsgnundlage nămlich einheitliche inhaltliche Vorschriften über die Führung von Aufzeichnungen und Buchhaltungsunterlagen für steuerliche Zwecke. $\S 30$ des klassifizirten Einkommensteuergesetzes 1851 - eine Vorschrift, die bis 1891 unverăndert blieb - schrieb zwar die Aufstellung der Uberschußrechnung genau vor, darüber hinaus bestimmte jedoch bis 1891 allein das Allgemeine Preußische Landrecht in rein formalistischen Vorschriften ohne Rücksicht auf steuerrechtliche Erfordernisse, welche Art Bücher ein Bürger führen mußte. ${ }^{33}$ Konkrete inhaltliche Bestimmungen sucht man in dem Gesetzeswerk vergeblich, Wer keinerlei buchhalterische Unterlagen führte, konnte somit auch nichts falsch machen und diente eigenen Interessen. Denn für die Besteuerung fehlte somit jede Grundlage. Einkommensbeträge über 240.000 Reichsthaler waren im übrigen nach $\S 20$ klass. EStG 1851 sogar ganz steuerfrei.

Das gesetzlich vorgesehene Steuerfeststellungs- und Steuerfestsetzungsverfahren des klassifizirten EStG 1851 verhinderte wegen des Fehlens irgendwelcher praktikabler Vorschriften über die Mitwirkungspflichten des Steuerbürgers bei der Veranlagung und ebenso des Verzichts auf irgendwelche zweckmäßigen Prüfungs- und Kontrollrechte der Finanzbehörde die notwendigsten Voraussetzungen für die amtlich gebotene Wahrnehmung der Ermittlungs-

29 Mauz, F. (1935), S. 20; Linzbach, P. (1984), S. 158; Held, A. (1872), S. 279; s. Anlage zum Gesetz wegen Einfuhrung einer Klassensteuer v. 30.5.1820, in: Gesetz-Sammlung 1820, Nr. 617, S. 140.

30 Fuisting, B. (1902), S. 38.

31 Mauz, F. (1935), S. 16, S. 17; Fuisting, B. (1902), S. 38.

${ }^{32}$ Held stellte 1872 fest: "Es ist kein Wort darüber zu verlieren, daB die Einschaltzungen mit Ausnahme der einen kleinen Kategorie der vermögenslosen Beamten bei Allen zu niedrig sind; es ist dies ein öffentliches Geheimnis; zahlenmäßig laßt es sich freilich nicht nachweisen, denn ein solcher unwiderleglichet Nachweis würde das Úbel sofort entfernen" (S. 294). Den Zensiten war zu raten, auf́ die Einschătzungskommission durch das Verbrauchsverhalten einen entsprechenden Eindruck zu machen; s. Henrich, L., S. 50, S. 88.

33 Für den einfachen Bürger enthielt das Allgemeine Landrecht bis zur Verabschiedung des BGB zum 1.1.1900 die Bestimmungen über eine notwendige Rechnungslegung. Diese waren rein formal und auslegungsbedurftig. Zum 1.1.1861 wurde für Kaufleute das AHGB als Gesetz des Norddeutschen Bundes wirksam, das 1897 vom HGB abgelöst wurde, s. Barth, K. (1953), S. 68. 
pflichten. Ein Steuerstrafverfahren hatte schon aus diesen Gründen keine Grundlage. Es konnte in der Regel gar nicht erst in Gang gesetzt werden.

Die klassifizirte Einkommensteuer war somit nach der nüchternen Formulienung eines sachkundigen Zeitzeugen ein "Lug- und Trugsystem". ${ }^{34}$ Es galt dennoch bis zur Ablösung durch das preußische EStG 1891. Der Suche nach legalen Möglichkeiten zur Steuervermeidung durch Ausschöpfen rechtsgestaltender, den hergebrachten wirtschaftlichen Ablauf der Vorgänge steuernder Maßnahmen fehlte der Anreiz. Berichte darüber sind jedenfalls nicht bekannt geworden. Man konnte auf andere Weise bequemer an das Ziel gelangen, sich der Steuerlasten zu entziehen.

Als Sanktionsmechanismus zur Aufrechterhaltung einer zumindest halbwegs glaubhaften Besteuerung konnte allein die Scham und das Ehrgefühl des einzelnen Steuerbürgers vor Entdeckung der Unehrlichkeiten gegenüber den gegebenenfalls personen-, orts- und sachkundigen Mitgliedern der im ubrigen zu Stillschweigen verpflichteten Beteiligten der Einschätzungskommissionen dienen. ${ }^{35}$. Aber auch diese wichtige Schranke zur Aufrechterhaltung eines Mindestmaßes an Glaubwürdigkeit konnte versagen, wo - wie im Beispiel des Bochumer Steuerskandals von 1890 erkennbar - Verfilzungen und Vetternwirtschaft für die Einschätzung bestimmend waren. Zwar konnte das im Landtag mit hehren Worten verteidigte zersetzenden Neid und unmoralische Mißgunst in Schach haltende Steuergeheimnis einigen Schutz vor Entdeckung gewähren. ${ }^{36}$ Das soziale Gewissen journalistisch begabter Politiker und Historiker, wie Johannes Fusangels, Hans Delbrücks. Maximilian Hardens und Zeitschriften wic der "Westfälischen Volkszeitung", den "Preußischen Jahrbüchern" und der "Zukunft", deren Auflagen Enthüllungen über höchst ehrenwerte Honoratioren zuträglich waren, durfte aber nicht verharmlost werden. ${ }^{37}$

${ }^{34}$ Henrich, L. (1889), S. 58, S. 88. Henrich war Notar in Völklingen; s. a. Großfeld, B., S. 43.

${ }^{35}$ Nach der Instruction des Finanzministeriums, die Erhebung der Klassensteuer betreffend, wurden die zu führenden Steuerrollen, die das Einschătzungsergebnis abschlieBend verkündeten, zur Einsicht der Offentlichkeit bereitgehalten. Nach $\S 32$ des Gesetzes zur Einführung einer Klassen- und klassifizirten Einkomumensteuer vom 1.5.1851 war jedoch strikte Geheimhaltung der Ergebnisse der Veranlagung geboten, s. $\$ 32$ klass. EStG 1851, in: Gesetz-Sammlung 1851, Nr. 12, S. 207.

${ }^{36}$ Delbrilck, H. (1891) in: Preuß. Jahurbūcher, S. 132, S. 134: Kumpf, H. (1989), S. 180. Kumpf berichtet aber die Ereignisse, die den Bochumer Steuerskandal ausmachten. Delbrûck war zwar Inhaber eines Lehrstuhls für Zeitgeschichte. $\mathrm{Er}$ war zugleich Reichstags- und Landtagsabgeordneter. Delbrilck futhrte in seinen Jahrbuchern aus, daß sich in den Bochumer Vorgăngen die Regel der Veranlagungstätigkeit zeige. Zu niedrig besteuerte Beteiligte an dem Skandal hatten sogar noch gegen die fehlerhaften Bescheide reklamiert und so das Verfahren ausgelöst, s. Delbrück, H. (1891), 68. Bd., S. 134; Wagner, A. (1891), S. 587.

${ }^{37}$ H. Delbrilck verfugte ebenso wie M. Harden, dessen "Zukunft" 1892 in erster Auflage erschien, aber exzellente Informationskanäle. Sie brandmarkten rücksichtslos unabhängig von der Parteizugehörigkeit, was ihnen als Verstoß erșchien. Im übrigen blieb Delbrïck skeptisch, ob sich durch Einfüh- 
Demnach waren für Preußen jedenfalls bis 1891 die Klagen Helds, spăter Vockes und ähnlich W. Molls für die Besteuenungspraxis zutreffend, daß nur die Festbesoldeten des offentlichen Dienstes wegen der für diese Gruppe vorgesehenen Auskunftspflichten des Arbeitgebers richtig besiewert wurden. ${ }^{38}$ Wir müssen ergănzend hinzufügen, daß dies nur bezüglich ihrer Arbeitseinkommen richtig sein mußte. Schließlich gab es stets auch Beamte in höheren Positionen mit Nebeneinkünften aus weiteren Einkunftsanten. Die Konsequenz des Systems war: Man liefi sich zu niedrig einschätzen, fulhrte keinerilei oder nur die erst ab 186! nach Handelsrecht vorgeschriebenen unverzichtbaren Aufzeichnungen und gabı vor, die Steuergesetze nicht zu verstehen. Gegebenenfalis wurde gegen Bescheide reklamiert. Das war vőllig problemlos, da man bei Gefahr der Aufdeckung von Widersprichen die Reklamation jederzeit zurücknehmen konnte. Bei dem Bochumer Gerichtsverfahren handelte es sich nicht um Ermittlungen steuerlicher Art wegen der Beschuldigung von Steuerstrafvergehen, sondern um ein Strafverfahren gegen den Journalisten J. Fusangel wegen Beleidigung, das - als im äffentlichen Interesse liegend - von der Staatsanwaltschaft betrieben wurde. Der Steuerskandal war nur ein Nebenergebnis, das das Verhalten von hochrangigen Parteigängern des Finanzministers Miquel bloBstellte ${ }^{39}$ und den Angeklagten und späteren Zentrumsabgeordneten des Reichstages voll entlastete.

\section{Gestaltungsmöglichkeiten zur Herabsetzung des Steuerzugriffs in} Sachsen nach der Steucrreform durch das EStG 1874/78

Besteuenungsidee, Steuertechnik und wirtschaftliche Mobilität sind die wichtigsten Bestimmungsfaktoren, die über Erfolg oder Mißerfolg steuerpolitischer Absichten entscheiden. Denn Steuergläubiger müssen stets mit Steuerwiderstand durch Dispositionen der Steuerbürger zur Herabsetzung oder gar Vermeidung der ausgelösten Steuerschuld rechnen. ${ }^{40}$

Auch das Schicksal der Reform der sächsischen Besteuerung durch das EStG 1874/78 stand unter dem Verdikt der Auswirkungen dieser Faktoren.

\footnotetext{
rung der Verpflichtung des Bürgers zur Deklaration ohne nachhaltigen Ausbau eines amtlichen Prüund Kontrollapparates wesentliche Verbesserungen der viel zu geringen Veranlagungen erreichen ließen. Er sollte Recht behalten, s. Delbrick, H. (1889), Preuß. Jb., 64. Bd., S. 495.

${ }^{38}$ Held, A (1872), S. 294; Vocke, W. (1887), S. 487; Meisel, F. (1911), S. 331; Moll, W. (1918), S. 103 .

39 Delbrïck, H. (1891), S. 134; Kumpf. H. (1991), S. 183.

${ }^{40}$ Strümpel, B. (1966), Sozialőkonomischer Wandel ..., S. 442; ders. (1966), Steuermoral ..., S. 94. Strümpel skizziert und interpretiert Einstellungen zum Steuerwiderstand, die heute fur die BRD typisch sind und bringt sie in Verbindung mit den sozialen Randbedingungen.
} 
Eine Untersuchung der sozialen Randbedingungen zur Zeit der Steuerreform in Sachsen zeigt, daß eine überdurchschnittlich hohe wirtschaftliche Mobiltät der dortigen Gesellschaft der Durchsetzbarkeit einer völlig neuartigen Besteuenung nicht förderlich sein konnte. Im Vergleich mit Preußen gehörte das Königreich Sachsen nämlich nach der Jahrhundertmitte neben Württemberg und den Stadıstaaten Hamburg und Bremen zu den am stärksten industrialisierten Ländern Deutschlands mit dem höchsten Lebensstandard der Bevökerung. ${ }^{41}$ Der Übergang von einem starren Wirtschaftssystem, in dem der Agrarund Kleingewerbesektor dominierte, zu gröBeren und flexibleren Prodaktionsstrukturen war in Sachsen nach 1870 bereits weit fortgeschritten. Der terhăltnismäßig hohe Grad an Mobilität wurde obendrein von starken Wancerbewegungen der Arbeiterschaft im Halbjahresrythmus, der sogenannten "Sachsengăngerei" mit den hierdurch verursachten weitreichenden wirtschuftlichen Folgewirkungen noch unterstrichen. ${ }^{42}$

Erst die Kenntnis der leitenden Grundgedanken des Gesetzes und der zu deren praktischer Umsetzung verfolgten Besteuerungstechnik kann uns heute den Zugang zur konkreten Auslegung des im Gesetz normierten Besteuerurgsgegenstandes, des darin festgelegten Umfangs steuerbarer Vorgänge und zu der Handhabung der Veranlagung im Regelfall vermitteln.

Nachdem die säblsische Regierung nacb einem vergeblichen Reformversach von 1869 zur Verbesserung der Zustände 1871 dem Landtag einen eigenen Reformvorschlag vorgelegt hatte, ${ }^{43}$ kam es in dessen neugebildeter "außerordentlicher Deputation der Zweiten Kammer des Landtages für die Steuerreformfrage" zwar zu konkreten ablehnenden Erörterungen der Regierungsvorlage, zugleich aber zu einer mehrheitlichen Willensbildung über neue leitende zu verfolgende Reformgesichtspunkte. ${ }^{44}$ Nach Prüfung einer großen Zahl angeforderter Gutachten beschloß der Landtagsausschuß in seinem am 6. September 1872 gefertigten und am 19. November 1872 dem Landtag vorge-

"Hoffmann, W. G./Miller, J. H. (1959), S. 14, S. 87, S. 99, S. 112, S. 148; Henrich, L. (1889), S. 72, S. 84; Wilding, Graf A., S, 211. Graf Wilding war promovierter Jurist. Die Einkommensentwicklung in Sachsen kann verfolgt werden in: Heiß, C. (1893), S. 81.

${ }^{42}$ Kärger, K. (1890), S. 1, S. 3, S. 76, S. 169, hierzu: Delbrück, H., PreuB. Jb. 1890, S. 705. Zwar betraf die kontinuierliche Wanderbewegung von ca. 72.000 Arbeitskräften im Halbjahresrythmus aus Hinterpommern, Westpreußen, Posen und Schlesien im wesentlichen die zu Preußen gehörende "Provinz Sachsen", sie erstreckte sich jedoch auf den. Bereich des Kônigreichs Sachsen.

${ }^{43}$ Conrad, J. (1871), S. 428; ders. (1873), S. 229; ders. (1875), S. 304; Gensel, J. (1874), Sp. 1373, Sp. 1380; ders. (1875), Sp. 1519; Hoffmann. A. (1906), S. 74; von Nostiz, H. (1903), S. 78; Held, A. (1872), S. 321;

4 Gensel, J. (1874), Sp. 1383; s. a.: Bericht nebst Beilagen der außerordentlichen Deputation für die Steuerreformfrage, vorgelegt am 19.11.1872, in: Mittheilungen über die Verhandlungen des Land. tages, II. Kammer, 91. Oeffentl. Sitzung, Dresden, 30.11.1872, S. 3301; hierzu: Conrad, J. (1873), S. 247 ; ders. (1875), S. 304. 
legten Bericht, die von Gustav Schmoller 1863 entwickelte Besteuenungsidee zur Grundlage der săchsischen Einkommensteuerreform zu machen. ${ }^{45}$ Sie legte in dem Bericht das steuerbare Einkommen eines Bürgers fest als "die Summe von Mitteln, welche der Einzelne ohne in seinem Vermögen zurückzukommen, für sich und seine Familie, für seine geistigen und körperlichen Bedürfnisse, für seine Genūsse und Zwecke, kurz für die Steigerung seiner Persönlichkeit in einer Wirtschaftsperiode verwenden kann". ${ }^{46}$ Dabei berief sich der Beschiuß nicht nur auf Schmollers Beitrag von 1863, sondem auch auf Adolf Helds kritische Auseinandersetzung ${ }^{47}$ mit der seil 1820 eingefahrenen preußischen Besteuerungspraxis von 1872 . Held hatte sich für den in seiner Abhandiung grundlegenden Einkommensbegriff ausdrücklich auf Schmollers Beitrag von 1863 bezogen. Der Referent des Landtagsausschusses für die Einkommensteuerreform, Julius Gensel, war Mitglied des Vereins für Socialpolitik unmittelbar nach dessen Gründung. Er hatte ebenso wie Adolf Held 1872 von den Gründungsmitgliedern den Auftrag zur Anfertigung eines Gutachtens zur Reform der Einkommensteuer übernommen. Die beiden Gutachten, die von den Schmollerschen Gesichtspunkten Gebrauch machten, erschienen im März 1872 und wurden sofort von Gensel zur laufenden Erörterung eines Reformentwurís im săchsischen Landtagsausschuß eingebracht. ${ }^{48}$

Indem die Deputation in ihrem Bericht der sächsischen Regierung Auflagen zur Fertigung einer reformierten Gesetzesvorlage erteilte, gab sie auch konkrete Hilfestellungen, wobei sie skizziente, wie sie sich die praktikable Umsetzung der Schmollerschen Besteuerungsidee für ein neuartiges Einkommensteuergesetz dachte. Sie umriß das ihr vorschwebende Besteuerungsgut, das dann später von der Regierung im Besteuerungsgegenstand des Gesetzes einen endgül-

45 Schmoller, G. (1863), S. 52 und s. Bericht der außerordentl. Deputation ..., (wie Anm. 44) S. 3313

46. Bericht der außerordentl. Deputation der Zweiten Kammer für die Steuerreformfrage, in: Beilage zur dritten Abtheilung, 3. Bd. Landtags-Acten von den Jahren 1871/72, die Berichte der Zweiten Kammer enthaltend, S. 435; ebenso: wie Anm. 44, S. 3313.

${ }^{47}$ Bericht der auBerordentl. Deputation (wie Anm. 44), S. 3313; ebenso: Beilage zur dritten Abtheilung ... (wie Anm. 46), S. 435. Held war Gründungsmitglied des Vereins für Socialpolitik.

${ }^{48}$ Held, A (1872), S. 66, S. 90. Die Reform der Einkommensteuer gehörte bei Gründung des Ver. eins fur Socialpolitik zu den vordringlichen. Themen, die bereits 1873 auf der ersten Sitzung behandelt werden sollte. Die nach Schmollers Anregung gefertigten Gutachten hierzu lagen bereits im März 1873 vor. Die Behandlung, wurde jedoch auf die dritte Generalversammlung vom Oktober 1875 verschoben. Deru Knapp hielt fest: "Die Steuer ist garz verfahren, denn das hat weder Anfang noch Ende", s. Boese, F. (1939), S. 16. Siche: Die Personalbesteuerung, Gutachten auf Veranlassung der Eisenacher Versammlung zur Besprechung der sozialen. Frage, in: Schriften des Vereins fur Socialpolitik, 3. Bd. 1873; darin: Held, A. Gutachten über die Steuerfrage, S. 23, u. Gensel, J: Wie ist unsere bestehende directe Personalbesteuerung im Sinne von Gerechtigkeit und einer richtigen Wardigung der wirthschaftlichen Interessen am zweckmäBigsten zu reformieren, S. 39. Gensel brachte diese Gutachten in die Landtagsverhandlungen ein, s. Gensel, J. (1874), S. 1405. 
tigen ausformulierten Ausdruck erhalten sollte, wie folgt: "Unter dem Einkommen eines Steuerpflichtigen ist der Gesamtbetrag desjenigen zu verstehen, was derselbe an Geld oder Geldeswerth durch seine wirthschaftliche Tätigkeit oder auf sonst berechtigte Weise, nach Abzug aller Produktionskosten mit EinschluB der Schuldzinsen innerhalb Jahresfrist erwirbt und für seinen und seiner Angehörigen Unterhalt, Nutzen und Vergnügen verwendet oder zur Verbesserung seiner Vermögensverhältnisse erübrigt". ${ }^{49}$

Es schien der Deputation dabei "zur Vermeidung von Mißverstăndnissen nothwendig, solche Einnahmen, welche ihrer Natur nach als eine Vermehrung des Stammvermo̊gens betrachtet werden, ausdrücklich von dem "Einkommen" im Sinne des Steuergesetzes auszunehmen ...". ${ }^{50}$ Hierzu zăhlte sie aber erläuternd nur "Erbschaften, Vermächtnisse, Aussteuer und dergleichen"51 auf. Diese Regelung sollte garantieren, daß alle hier nicht ausdrücklich erwăhnten Vermögensmehrungen dem Besteuerungsgut zugerechnet würden. Durch diese Auflagen der Deputation des Landtages war für die Regienung der Auslegungsrahmen für die einzelnen konkreten Bestimmungen des Besteuerungsgegenstandes des sächsischen EStG 1874/78 durch dessen Entstehungsgeschichte festgeschrieben. Im Grunde blieb die hier vorgegebene einheitliche innere Regelhaftigkeit der Vorschriften bis zum Jahr 1919 ungebrochen, wenn auch gelegentlich als Folge der von der preußischen Finanzrechtsprechung später ausgehenden zunehmenden Einflüsse zu einer Vereinheitlichung der Begriffsauslegungen Unsicherheiten und später auch Einbriiche in die sächsische Besteuenungspraxis feststellbar sind. ${ }^{52}$ Die völlig unterschiedliche Auslegung einiger grundlegender gleichlautender Begriffe des späteren preußischen Steu-

40 Bericht der auferordentl. Deputation ... (wie Arum. 46), S. 436, S. 437

30 Bericht der auBerordentl. Deputation ... (wie Anm. 46), S. 436

31 Bericht Jer auBerordenti. Deputation ... (wie Aum. 46), S. 437

32 Hierzi mag folgendes Beispiel diener; Obgleich die Aufzahlung der nicht steuerbaren außerordentlichen Einnahmen abgeschlossen sein sollte, wurden spăter z. B. Lotteriegewinne und ebenșo wegen $\$ 762$ BGB nicht einklagbare Gewinne aus Differenzgeschäten und Spiel- und Wetigewinne ats nicht steuerbare außerordentliche Einnahmen behandelt, $\mathrm{s}$. Wachler, P. (1912). Bern. 15 zu $\$ 15$ săchs, EStG 1874/78, S. 60 . Nach dem preuß. EStG mangelte es an der Subsumierbarkeit unter $\S 7$ preuB EStG 1891, da keine beständigen Quellen der Güterproduktion den Einnahmen zugrunde Jagen. Die Zuflusse waren daher nicht steuerbar. Es konnte nicht ausbleiben, daB bei gleichlautenden Begriffen die politisch filhrende Rolle Preußens für die Auslegung bedeutsam wurde, zumal B. Fuisting, spater sein Nachfolger G. Strutz; und P. Wachler uber die Rechtsprechung der Finanzgerichte ihrer Lander in der DJZ kontinuierlich berichteten. Die Zeitschrift war $1896 \mathrm{zu}$ eben diesem Zweck von Laband begrindet worden (DJZ 1896, S. 1). Die zunehmende Bedeutung Preußens bei der Auslegung von steuerlichen Begriffen wurde öfters als Gängeiei heftig beklagt, s. Pistoriụs, T. (1919), Unser Steuerrecht ..., S. 78. Pistorius beklagt den "EinfluB Fuistingschen Geistes" in der Finanzrechtsprechung. Vernichtende Kritik fand Meyer, R. (1903), S. 125, S. 126, wenn er den Einfluß des preuß. OVG bedauert. Ähnliches findet sich vorsichtiger bei Wachler (1912), S. 355, und Meisel, F. (1911), S. 349; ders. (1914), S. 149 , 
errechts gegenüber der săchsischen Besteuerungspraxis konnten jedenfalls vorerst nicht übersehen werden.

Nicht nur die Besteuerungsidee, die dem sächsischen EStG 1874/78 zugrunde lag, ließ einen völligen Bruch mit der herkömmlichen Besteuerungspraxis erkennen; auch die Steuertechnik, die Umsetzung des Gesetzes, folgte neuartigen Gesichtspunkten. Die Besteuerungsidee Schmollers setzte die aktive Mitwirkung in Form der sogenannten "Selbsteinschătzung" oder heute "Steuererklärung" der Zensiten voraus. Diese wurde ein Kernstūck der Reform. Nach dem Gesetz und den dazu erteilten Verwaltungsanweisungen war die Finanzbehörde zwar in der Regel verpflichtet, bei der amtlichen Veranlagung den abgegebenen Deklarationen nach Ausräumung auftretender Zweifelsfragen in Erörterungen mit dem Steuerbürger zu folgen ${ }^{53}$ Bei substantiierten und unaufgelösten Bedenken durfte sie jedoch bei der Veranlagung "auf Grund ihrer eigenen Kenntnis der Verhältnisse" ${ }^{54}$ von den Angaben in der Erklärung des Steuerpflichtigen im Interesse einer gleichmäßigen Lastenverteilung abweichen. Dem Steuerpflichtigen blieb dann aber nach dem Gesetz die Möglichkeit, durch Einlegung eines Rechtsbehelfs eine neue Entscheidung uber die Veranlagung nach ausgiebiger Erörterung der Zweifelsfragen, gegebenenfalls nach Vorlage von Büchern, Aufzeichnungen und Urkunden, nach gerichtlicher Einvernahme von Zeugen und Sachverständigen und sogar bei Verlangen nach Eidesleistung herbeizuführen oder dieselbe gegebenenfalls nach Einlegung eines Rechtsmittels vom Gericht berichtigen zu lassen. ${ }^{55}$ Die weiterge-

93 § 43 Abs. 3 săchs. EStG 1874/78; hierzu: Instruction vom 7.12.1878, in: Gesetz- u. Verordnungsblatt 1878, S. 532; s. auch: Gensel, J. (1874), Sp 1480.

s4 $\S 43$ Abs. 4 săchs. EStG 1874/78.

5s Der Rechtsbehelf war an đie Einschătzungskornmission, die den angefochtenen Bescheid erteilt hatte, zu richten ( $\$ 46 \mathrm{i}$. V. m. $\S 48$ ). Die Kommission durfte die Einschătzung abăndern, sofern das ihr vom Pflichtigen freiwillig vorgelegte Beweismaterial die Fehlerhaftigkeit der angefochtenen Festsetzung schlusssig darlegte ( $\$ 56$ Abs. 2). Gelangte sie jedoch zu der Überzeugung, daß đie Entscheidung von der Abgabe einer eidesstattlichen Versicherung oder der Vorlage von freiwillig nicht zur Einsicht angebotenen Geschåftsbüchern und Urkunden abhängig gemacht werden müsse, so hatte sie das Verfahren an die Reclamationscommission abzugeben ( $\$ 56$ Abs. 3). Dieses desgleichen aus einem Beamten des Finanzministeriums als Vorsitzendem und sechs weiteren Mitgliedern gebildete BeschluBgremium durfte dann Zeugen und Sachverständige anhören und, sofern erforderlich, vom Gericht eidlich vernehmen lassen, von dem Steuerpflichtigen Auskünfle und gegebenenfalls mit Ëidesleistung die Vorlage von Geschäftsbūchern und Urkunden verlangen $(\$ 62)$. In $\S 6$ der Instruction zum sắchs, ESıG $1874 / 78$ v. 7.12 .1878 (Gesetz- u. Verordnungsblatt 1878, S. 526) wurde den Einschâtzungscommissionen "eine ganz besondere Sorgfalt" beim Umgang mit den Deklarationen und, wenn erforderlich. eine rûcksichtsvolle Erledigung der Veranlagung durch Erôrterung von Unklarheiten angeordnet. Eine der sachgerechien Bearbeitung nicht dienliche Ubernahme der späteren preußischen Bestimmung eines einzuleitenden schriftlichen formalistischen Beanstandungsverfahrens, dessen Auswirkungen aus der Veranlagung regelmäBig ein quasiforensisches streitiges Verfahren entstehen ließen, hat Sachsen trotz offensichtlichen Drucks nach 1891 ständig abgewehrt, s. Wachler, P. (1912), Das KöniglichSăchsische .... Bem. 4 zu $\S 42$ săchs. EStG 1874/78, S, 136. Verschiedene Åußerungen Fuistings, Waldeckers und Wachlers lassen erkennen, daB Sachsen in dieser Hinsicht sich in einer Abwehrhal- 
henden Kontroll- und Prüfungsbefugnisse der Verwaltung waren mithin dadurch gewährleistet, daß diese bei Auftreten vom Steuerbürger nicht ausgeräumter Bedenken und Zweifel von der Erklärung nach eigenem Ermessen durch Schătzung abweichen durfte und dem Steuerpflichtigen dadurch zur Berichtigung der Veranlagung bei undurchsichtigen Vorgängen eine erhöhte Beweislast durch eine nachgeschobene intensive Prüfung des Sachverhalts aufgebürdet werden konnte. ${ }^{56}$

Im übrigen sorgte ein streng gehandhabter gesetzlich geregelter Sanktionsmechanismus durch empfindliche Geldstrafen für die Beachtung der Gesetzesvorschriften. $^{57}$

Eine vertrauenschaffende Besteuerungsidee und eine abgestimmte, auf gleichmäßige Lastenverteilung ausgerichtete Steuertechnik ermöglichten in Sachsen trotz Übergangsschwierigkeiten und den Steuerwiderstand begünstigender hoher sozialer Mobilităt zusammen mit einem streng gehandhabten Steuerstrafrecht eine fortan reibungslos ablaufende Besteuerungspraxis mit einem - wie man der Berichterstattung entnehmen muß - zufriedenstellenden Steuerklima. ${ }^{58}$ In einer Fachzeitschrift erfuhr man nach Inkraftreten des Gesetzes, daß der Gesetzgeber den "Anschauungen des Abgeordneten Dr. Gensel gefolgt (sei), der sich die Ergebnisse der neuen wissenschaftlichen Forschung zu eigen gemacht hat". ${ }^{59}$

Das sächsische EStG 1874/78 enthielt, der zugrundeliegenden Besteuerungsidee entsprechend, eine Generalklausel, was als steuerbares Einkommen

tung befand. Gernäß $\S 64$ săchs. EStG i. đ. F. des Gesetzes von 1900 konnte Berufung gegen die Entscheidung der Reclamationscommission bei dem săchss. OVG eingelegt werdeñ.

s6 Dieses Verfahren âhnelt der in England eingeschlagenen, bis heute üblichen Vorgehensweise. Sobald der Steuerpllichtige auftretende sachlich berechtigte Zweifel gegeṇ̄ber der erōrternden Behôrde nicht ausrăumt und sein Begehren durch Eidesleistung in sachlicher Hinsicht nicht nachweist, darf die Finanzverwaltung die Bemessungsgrundlage schătzen und den Zensiten auf diese Weise zum schlissigen Nachweis zwingen, hierzu: Beichelt, B. (1969), S. 21. In Großbritannien werden umfangreichere Steuerhinterziehungen durch die Gefahi einer Schătzung der Bemessungsgrundlage von der Behörde in Schach gehalten. Hinzu kommt das gegenọber der BRD andere Berufsrechts der "public accountants". Diese ersetzen dic deutsche Betrięsprüfung der Finanzverwaltung und nehmen durch die Form ihrer institutionellen Eingliederung eine Mittlerstellung zwischen Finanzverwaltung und Steuerpflichtigen ein, s. Beichelt, B. u. a. (1969), S. 21.

$37 \S \S 68$ Af. săchs. EStG 1874/78; $\$ 27$ Instruction v. 7.12.1878, in: Gesetz- und Verordnungsblatt 1878, S. 540. Das Reichsgericht als lețֵte Instanz in Strafsachen bestătigie spăter die für die Zeitverhăltnisse rigorose salchsische Handhabung des Steuerstrafrechts, s. hierzu: Urteile des Reichsgerichts in Strafsachen U. IV 301/09 v. 15.6.1909, in: ERGSt 42. Bd. 1909, S. 376, u. U IV 509/07 v. 8.10.1907, in: ERGSi 40. Bd. 1907, S. 305. Die Ôffentlichkeit hatte offenbar für die rigorose Spruchpraxis Verstalndnis, s. Wilding, Graf A., S. 211. Wilding war Richter am OVG, s. Justus, J., S. 71.

58 Gensel, J. (1885), S. 502; Henrich, L. (1889), S. 81; Wachler, P. (1903), Ein fünfundzwanzigjăhriges ..., S. 508; Blaher (1913), S. 623; Wilding, Graf A. (1893), S. 211.

s9 Conrad, J. (1879), S. 465, S. 449. 
im Sinne des Gesetzes "gilt". ${ }^{60}$ Nur zur statistischen Erfassung und als Beispiele wurden aufgegliederte Einkunftsarten aufgeführt. In einem Enumerativkatalog wurden bestimmte Wertzugänge als Ausnahmen von der Besteuenung ausgenommen. ${ }^{61}$

Grundsătzlich war alles steuerbar, was ein Steuerbürger in einem Kalenderjahr bei gleichem Vernögensstand hinzu erwarb, also aufsparte oder für sich und seine Angehörigen verbrauchte oder hătte verbrauchen kőnnen. Enisprechend war auch nach dem Grundgedanken des Gesetzes ein nach kaufmănnischen Gesichtspunkten aufzustellender Bestandsvergleich für die Ermittlung der Bemessungsgrundlage für den Steuerzugriff entscheidend. In dem Verhandlungsbericht der Kommission für die Reform der Einkommensteuer war entsprechend 1872 festgehalten worden, "vom fiskalischen Standpunkt könne man in der That nur wünschen, daß jeder Steuerbürger verpflichtet wäre, in kaufmännischer Weise Bücher zu führen und sein Einkommen alljährlich festzustellen". ${ }^{62}$ Wenn aus Gründen der Praktikabilităt jedoch der Bestandsvergleich als Ermittlungsvorschrift nur für buchfühnngspflichtige Kaufleute vorgeschrieben $(\$ 21)$ und in anderen Fällen die hergebrachte Überschußrechnung vorgesehen wurde, so blieb der Grundgedanken der Besteuerungsidee jedenfalls stets verbindlich. ${ }^{63}$

So gehörte es in Sachsen der Regel nach zur ståndigen Spruchpraxis von Reclamationscommissionen und des später geschaffenen Senats für Staatssteuersachen bei dem sächsischen Oberverwaltungsgericht, daß realisierte Vermögenszuwächse als Veräußerungsgewinne bei allen Einkunftsarten insoweit steuerbar waren, als sie bei einem fiktiven Bestandsvergleich als Vermögenszugang verbrauchbar erscheinen konnten. ${ }^{64}$

Nicht realisierte Vermögenszuwächse waren dagegen nach den Bestimmungen im Gesetz nur steuerbar, insoweit die "Gebräuche eines ordentlichen

${ }^{50} \S 15$ săchs. EStG $1874 / 78$, s. Anlage 1.

61 \$ 15 Abs. 2 săchs. EStG 1874/78, s. Anlage 1.

62. Gensel, J. (1874), Sp. 1462; hierzu: Mittheilungen über die Verhandlungen ...(wie Anm. 44), S. 3326.

${ }^{63} \S 21$ Abs. 1 săchs. EStG 1874/78, s. Anlage 1.; $\$ 64$ Instruction v. 7.12.1878, s. Anlage i. Die hier gefundene Vorschirift entspricht den noch heule in $\$ 4$ Abs. 3 EStG 1993 normierten Regelungen.

64 Wachler, P. (1912), Das Künigl-Săchs. ..., Bem. 14 zu $\$ 15$ săchs, EStG 1874/78, S. 59, S. 60. Hier gibt Wachler die Generalregel wider, s. hierzu: Uirteile des OVG in Staatssteuersachen $v$. 20.5.1912 und v. 26.4.1906 (zitiert nach Wachler). S. a.: Verordnung den Betrieb von Borsengeschalften für eigene Rechnung betreffend, in: Mittheilungen aus der Verwaltung der directen Steuern im Königreich Sachsen v. 24.12.1883, Bd. 1, S. 134. 
Kaufmannes" einen Gewinnausweis für Kaufleute zuließen und dieser in die Handelsbilanz auch eingestellt war. ${ }^{65}$

Nach dem Besteuerungskonzept waren auch alle werthaltigen Entnahmen aus einer eigenen Wirtschaft für private Zwecke als Einkommensteile steuerbar. ${ }^{66}$

Wichtig erscheint auch, daß jeder realisierte Wertezugang steuerbar war, unabhångig davon, ob ihm ein Rechtsanspruch zugrundelag, oder nicht. ${ }^{67}$

Die für die gănzlich anderen Problemstellungen der klassischen Nationalbkonomie wichtige Unterscheidung zwischen "produktivem" und "unproduktivem" "abgeleitetem Einkommen", die bis heute in der Differenzierung von steuerbarem "Markt-" bzw. "Erwerbseinkommen" und nicht steuerbaren privaten Vermögensmehrungen in der Diskussion Bedeutung für die Besteuerung behalten hat, ${ }^{68}$ fand in dem săchsischen EStG $1874 / 78$ keinerlei Funktion. Insoweit folgte das Gesetz streng der Schmollerschen Besteuerungsidee mit dem ihr eigenen Maßstab für Leistungsfähigkeit.

In seiner Definition dieses Maßstabes für die Leistungsfähigkeit eines Steuerbürgers und damit für eine überzeugende Bemessungsgrundlage der Besteuerung hatte Schmoller dem tatsächlichen getätigten Verbrauch die Rolle eines zusătzlichen Kriteriums gegeben. ${ }^{69}$ Das sächsische EStG 1874/78 schuf aus diesem Gesichtspunkt den Ersatztatbestand einer Besteuerung nach dem Verbrauch, sofern die Aufwendungen eines Steuerbürgers sein rechnerisch ermitteltes Einkommen überschreiten. ${ }^{70}$

Jastrow sprach daher später in einem Vergleich des preußischen EStG 1891 mit dem sächssischen Vorbild von dem letzteren als "einer kombinierten Einkommen- und Verbrauchssteuer". Dies hing gewiß damit zusammen, daß der

69 \$ 19 Abs. 1 săchs. EStG $1874 / 78 ; \S 18$ sächs. EStG $1874 / 78$ i. V. m. $\$ \$ 57,59$ Instruction v. 7.12 .1878 .

66 $\S 15$ Abs. 1 sächs. EStG 1874/78. Zur Auslegung s. Wachler, P. (1912), Bem. 2 u. 5 zu $\S 1$ sächs. EStG 1874/78.

${ }^{67}$ Wachler, P. (1912), Das Königl.-Săchs. ..., Bem. 1 zu § 15 Ziff. I săchs. EStG 1874/78 und die angegebene Finanzrechtsprechung.

ss S. hierzu: Smith, A., 5. Aufl. 1789. Wohlstand der Nationen. Eine Untersuchung seiner Natur und seiner Ursachen, ubersetzt von C. Recktenwald, Munchen 1974, 2. Buch, 3. Kap., S. 272, insbes. S. 274 ; s. a. Rau, K. H. (1864), S. 404, S. 405; ders. (1865), S. 193; Roesler, H. (1868), S. 302.

65 Schmoller, G. (1863), S. 53, S. 54. Bei Schmoller heißt es: "Die wenigen Falle von Verschwendern ausgenommen, muß jede Bedürfnisbefriedigung auf einem Einkommen beruhen; Niemand kann dauernd Ausgaben für seine Persōnlichkeit machen, ohne Einkommen". Diese. Feststellung war Ausfluß von Schmollers Definition eines Maßstabes für die Leistungsfähigkeit einer Person als Bemessungsgrundiage für die Einkommensteuer.

${ }^{70 .}$ § 15 Ziff. 6 săchs. EStG $1874 / 78$, s. Anlage I. 
Besteuerung nach dem Verbrauch in der Praxis in Sachsen große Bedeutung zukam. ${ }^{71}$

Fragen wir nach Erörterung der Gesetzessystematik nach legalen Möglichkeiten der Steuervermeidung, so richtet sich die Aufmerksamkeit auf die möglichen wirtschaftlichen Dispositionen des Steuerbürgers bezüglich der erwarteten Wertezugänge. Dabei wollen wir von Steuerentlastungen absehen, die durch Verlagerungen von Wohnsitz und Belegenheit des Unternehmens oder durch doppelte Wohnsitze in verschiedenen Lăndern erreichbar waren. ${ }^{72}$ Ebenso wollen wif die zur Steuervermeidung betriebenen Dispositionen von Aktiengeseilschaften und anderen juristischen Personen des Handelsrechts bei der Bemessung von ausgeschütteten Dividenden, Investitionen und Gestaltung der Abschreibungen und sonsțigen Betriebsausgaben ersı später in die Erörterung einschließsen. ${ }^{73}$ Die hier eröffneten Moglichkeiten betrafen nur einen sehr kleinen, wenn auch maßgeblichen Kreis von Steuerbürgern.

In dem skizzierten Besteuerungssystem nahmen bei der Veranlagung nicht, wie spăter in Preußen, die Prüfung von Definitionen und rechtlichen Zusammenhängen, sondern wirtschaftliche Fragen, wie Schătzungen von Vermōgenszuwăchsen, Aufstellungen ortsspezifischer Preisbewegungen, Kosten-, Ēlös- und Umsatzrelationen, Vergleiche von Märkten, Mengenberechnungen, Bewertungen von Wirtschaftsgütern, Aufstellungen über die Lebensdauer von Wirtschaftsgütern des Anlagevermögens, die Anfertigung von Richtsatzsammlungen etc. große Aufmerksamkeit in Anspruch. Die Finanzbeamten, die die Einschătzungskommissionen leiteten, erhielten - anders als in Preußen - eine entsprechend wirtschaftlich ausgerichtete Ausbildung. ${ }^{74}$ Die das săchsische Gesetz beherrschende, den Steuergegenstand - mit wenigen aufgezahlten Ausnahmen - als Summe aller dem Steuerbürger zuwachsenden werthaltigen

71 Jastrow, J. (1891), \$. 744. Die vielen Entscheidungen der Reclamationscommission und des spăteren OVG in Staatssteuersachen wegen einer Besteuerung nach dem Verbrauch zeigen, daßs dieser Regelung, in Sachsen eine große Bedeutung zukam, s. z. B. Mittheilungen aus der Verwaltung .... Bd. V 190G, Sammlung Wachler, P./Naundorf, E., Sammlung Schelcher, $\dot{W}$.

${ }^{72} \S 2$ Abs, 2, §5, $\S 8$ săchs. EStG $1874 / 78$.

${ }^{73} \S 4$ Abs. 2 săchs. ESiG 1874/78.

74 Hierzu: Kirsch, L., S. 73, \&. 76 und Blaher (1913), S. 621; Wachler, P. (1912), Moral und Technik ..., S. 353, S. 354. S. 355; für Preußen: Michaelis (1912), S. 98; Pausch, A. (1976), S. 116, S. 117; Delbrück, C. von (1917). Nach Blüher waren die Bezirkssteuerinspectoren, die nach dem Gesetz vom Finanzministerium zur Leitung der Einschatzungscommissionen berufen wurden, nur ausnahmsweise ausgebildete Juristen. Sie erhielten vom Ministerium, eine wirtschaftlich und steuerlich ausgerichtete Spezialausbildung. Auch Schmoller hatte eine vergleichbare Ausbildung erhalten, die er im November 1862: mit dem Assessorexamen abschloB. S. a.: Buck, L. (1919), S. 559, S. 566, S. 577. Der Aufsatz stammt aus dem Jahr 1917, s. S. 551. Buck trat trotz seiner Eigenschaft als hoher, mit der Veranlagungspraxis vertrauter preuBischer Finanzbeamter fur den wirtschaftlich ausgerichteten salchsischen Ausbildungsgang der Finanzbeamten auch in Preußen ein. 
Wirtschaftsgüter bestimmende Generalklausel, machte die Suche nach Schlupflöchern im System für den normalen Steuerbürger überflüssig. Die Regelung verschob das Interesse von der Durchprüfung des Normengefüges auf eine Suche nach Schwachstellen im praktischen Abrechnungswesen. Denn der Schwerpunkt der Veranlagung lag nicht mehr, wie in Preußen bis 1891 und noch darüber hinaus, in der Reclamationsinstanz, sondern in der Selbsteinschătzung. Für den Steuerbürger war es zur Herabsetzung des Steuerzugriffs daher empfehlenswert, sich über die einzelnen ihm zuteil gewordenen steuerbaren Wertzugänge rechnungsmäßig Klarheit zu verschaffen, sei es als Unterlage für die Selbsteinschătzung, sei es als Verteidigungsmaterial gegen Uberschätzung von Seiten der sachkundigen Finanzbehörde. ${ }^{75}$

Das Abrechnungswesen und insbesondere Bilanzlehre und Bewertungsfragen fanden daher in Sachsen frühzeitig vor allem an der Universităt Leipzig und zur Jahrhundertwende an der dortigen Handelshochschule ein geistiges Zentrum. ${ }^{76}$ Durch die in dem EStG $1874 / 78$ normierte "Maßgeblichkeit der Handelsbilanz" führten die Differenzen zwischen den unterschiedlichen Interessen bei Aufstellung von Handels- bzw. Steuerbilanzen bald zu Meilensteinen in đer Entwicklung von "Grundsătzen ordnungsmäßiger Buchführung" (GoB), die auch für das Steuerrecht verbindlich waren. ${ }^{77}$ Entsprechend hoch war der Ausbildungsstand der Finanzbeamten, die schwerpunktmäßig eine wirtschaftlich praktische und nicht formal juristische Ausbildung erhielten und - vom Finanzministerium berufen - den Einschätzungskommissionen vorstanden. ${ }^{78}$ Zur Entscheidung von Rechtsbehelfen und Rechtsmitteln waren im ersten Instanzenzug das Finanzministerium und dortselbst ebenfalls nicht Juristen, son-

${ }^{75}$ Howard, H. (1889), S. 37, S. 38. Howard war Inhaber eines Lehrstuhls fur landwirtschaftliches Rechunungswesen an der Universitat. Leipzig. Er entwickelte bereits sehr fruhzeitig (1872) Vorlagen für die Erfassung von Vorgängen in der Landwirtschaf, die als Aufzeichnungen zur Erstellung einer noch heute als modern bezeichneten doppelten Buchfuhrung zur Eriolgsermittlung, aber auch zur rationalen Betriebssteuerung geeignet war. Seine Empfehlungen zeigen jedenfalls, daß er den Schwerpunkt der Ermittlung dei steuerlichen Bemessungsgrundlage im Rechnungswesen sah.

${ }^{76}$ Hierzu: Pausch, A. (1979), Von der Einkommensteuer ..., S. 449; Hansen, R. (1990), S. 24. In Leipzig entstand die erste deutsche Handelshochschule, an der nach 1898 die fuhrenden deutschen $\mathrm{Be}-$ triebswirte wie E. Schmalenbach. F. Fischer. H. Nicklisch und W. Prion das Diplom erwarben. Bereits 1873 entwickelte der bereits genannte H. Howard Schemata für landwirtschaftliche Rentabilitattsberechnungen (1873), ebenso befaßte er sich mit dem nach Steuerrecht zu erfassenden "Werth der zum Haushalte verbrauchten Erzeugnisse der eigenen Wirthschaft" (§ 15 Abs. 1 Satz I săchs. EStG 1874/78), s. Howard, H. (1889), S. 33.

7 Hierzu: Barth, K. (1953), S. 215: Pausch, A. (1979), Von der Einkommensteuer ..., S. 448.

7 \$ $\$ 25$ săchs. EStG $1874 / 78$. Die Einschătzungscommissionen bestanden aus vier bis sieben Mitgliedem. Den Vorsitz fuhrte der vom Finanzministerium bestimmte Bezirkssteuerinspector. Er war Beamter des Finanzministeriums. Erforderlichenfalls wurde ihm vom Finanzministerium ein Stellvertreter zur Seite gestellt, s. $\S 3$ Instruction v. 7.12.1878. 
dern wirtschaftlich ausgebildete Sachkundige zustăndig. ${ }^{79}$ In den spăter als Beschwerdeinstanz eingerichteten Senaten für Staatsstenersachen am săchsischen Oberverwaltungsgericht waren dann ausschlieBlich Volljuristen als Richter mit der Entscheidung befaßt.

$\mathrm{Da}$ ßer Grundgedanke der såchsischen Einkommensteuer bis in die Einzelregelungen der "Instructionen" hinein konsequent zur Garantie einer nach der Schmollerschen Definition von Leistungsfahigkeit orientierten Lastenverteilung eingearbeitet war, ergeben beispielhaft die Regelungen für den Betrieb einer Landwirtschaft. ${ }^{80}$ Eben hier zeigte sich besonders drastisch der für die Zeitspanne so charakteristische, große Verärgerung schaffende hohe Lebensstandard einzelner Begüteter, die jedoch nie anteilig zu einer angemessenen Beteiligung an den Steuerlasten herangezogen wurden. Nicht nur "der Wert der zum Haushalt verbrauchten Erzeugnisse der eigenen Wirtschaft" gehörte in Sachsen fortan zum steuerbaren Einkommen, sondern ebenso der Mietwert der eigenen Wohnrăume einschlieBlich derjenigen für das zum privaten Haushalt gehörenden Personals, der "Stallungen für Luxuspierde und Wagenremisen für Kutschwagen" ${ }^{81}$ etc. Schließlich wurde auch die Ausübung des Jagdrechts durch den Eigentümer - anders, als spåter in der in Preußen gefunden Regelung (Liebhaberei) - ebenso als ein entnehmbares bewertungsfahiges Wirtschaftsgut beurteilt, das bei Eigennutzung in Hohe des marktublichen Nutzungsentgelts nach den Grundgedanken des Gesetzes zum steuerbaren Einkommen gehörte. ${ }^{82}$

791 S. $\S 60$ săchs. EStG 1874/78. Der Vorsitzende det Reclamationscommission muBte Beamter des Finanzministerium sein. Von den sechs weiteren Mitgliedern muBten zwei vom Finanuministerium, die übrigen vom Kreisausschuß gewahlt werden. Die Vorbildung der Finanzbeamten war im cinzelnen vom Gesetzgeber nicht vorgeschrieben. Sie wurde vom Finanzministerium nach dessen Bedürfnissen bestimmt, s. Blizher (1913), S. 621: Kirsch, L. (1883). S. 76.

${ }^{501} \S 18$ sâchs. EStG 1874/78, dazu auch $\$ 21$ Abs. 4 sächs. EStG 1874/78; $\S 50$ - 59 Instruction v. 7.12.1878, hier $\$ 51$.

\$1 52 Ziff. 4 Instruction; s. a. den beispielhaft, ausdruoklich vorgeschriebenen Ansatz eines Nutzungswertes für Parks, Lustgărten, Schlosser, Land- und Gartenhăuschen, die zur Unterkunft im Sommer verwendet wurden und ahnliches mehr. Als Wert war stets der marktmaBig vorsichtig ermit. telte Mietwert maßgeblich, wobei angeordnet wurde, daB auf das "übrige. Einkommen" des Zensiten Rücksicht zu nehmen sei ( $\$ 58$ Instruction).

n2 S. hierzu die Kommentierung zur Emittlung des Einkornmens beirn Fehlen ziffermmâliger Unterlagen gem. $\$ 49$ der novellierten Instruction i. d. F. v. 24.7.1900. Nach der "Generalvdg" des Finanzministeriums v. 21.8.1908, abgedr. in: Mittheilungen aus der Verwaltung der directen Steuern im Königreich Sachsen. Bd. 9. S. 188 und v. 6.11.1908, Bd. 9. S. 385 gehörte auch die Ausobung đes Jagdrechts auf eigenem Land zum steuerbaren Einkommen gem. $\S 18$ sllohs. EStG 1874/78. Die Ausübung des Rechts war in Hŏhe der Jagdpachtgelder für vergleichbare Reviere anzusetzen, hierzu: Wachler, P. (1912), Das Königlich-Sächsische ..., S. 318. Die cigentümliche Konstruktion des instituts. der "Liebhaberei", die vorn preuB. OVG durch Urteil vorn 14.12.1894 (Rep. V 16/94 - OVGE, 3. Bd. 1895, S. 150) festgeschrieben wurde und die damit gegebene Freistellung von Einnahmen und Ausgaben der Jagdausabung war ein typisches Ergebnis der vollig andersartigen, von dem Quellenprinzip des. preuB. EStG 1891 bestimmten Denkweise. Diese Regelung führt bis heute dazu, daB einen hohen 
Der Grundgedanke des săchsischen EStG 1874/78 war die Ausrichtung des Steuerzugriffs an der Leistungsfähigkeit des Zensiten, die Schmoller in der Möglichkeit des Verbrauchs ohne Vermögensminderung als Maßstab der wirtschaftlichen Kraft einer Person erblickte. Die rechnerische Entwicklıng dieser Bernessungsgrundlage aus Bestandsvergleich oder eventuell ergånzter Überschußrechnung konnte zwar in der Regel zuverlässig sein, sie mußte es aber im Einzelfall nicht sein ${ }^{83}$ Als Beteiligte an Körperschaften des Handelsrechts konnten Zensiten durch einen geeigneten vorsichtigen Gewinnausweis, durch überhöhte Abschreibungen und hohe Investitionen ihr steuerbares Einkommen gering halten, damit ihr Vermögen beständig zunahm, ohne tine Besteuerung auszulösen. Aber auch Unternehmer des Mittelstandes konten unter gewissen Umstånden, etwa durch überhöhte Abschreibungen der Mirtschaftsgüter ihrer Betriebe und weitere hohe fragliche Betriebsausgaben ein steuerbares Einkommen ausweisen, das die tatsächlichen wirtschaftlichen Vermögensmehrung den Umstănden nach nicht berücksichtigte.

Nur Festbesoldeten ist dieser Weg der Steuervermeidung, wie die Erörterang des Gesetzes im Landtag wiederholt ergab, grundsåtzlich verschlossen. Das sächsische ESıG 1874/78 sah daher für vergleichbare Fälle vorsorglich vor, $\mathrm{daB}$ der Aufwand für die Lebensführung des Zensiten dann als Maßstab für die Bemessungsgrundlage der Einkommensteuer anzunehmen sei, wenn dieser jeweils im konkreten Fall das rein rechnerisch ermittelte Einkommen übersteigt und das eventuell zur Finanzierung des Lebensaufwands durch eine erfolgsneutrale Kreditaufnahme ermöglichte Verbrauchsverhalten des Steuerpflichtigen letztlich eine Selbsteinschätzung seines tatsăchlichen Einkommens erkennen laßbt. ${ }^{84}$ Die Entscheidungssammlungen zeigen, daß die Finanz-

Lebensstandard erlaubende Aufwandspositionen durch fehlende Steuerbarkeit der zugrunde liegenden Vorgånge steuerlich begunstigt werden, da nicht nur die Einnahmen, sondern auch die Entnahmen mangels varhandeñei Gewinnabsicht unberücksichtigt bleiben können.

*3. Schmoller hatte den steuerlichen Einkommensbegriff für seine Zwecke aus der herkômmlichen güterwirtschaftichen Denkweise, die noch bei Hermann vorherrschte. herausgelōst. Das Einkommen war entsprechend filr Schmoller "keine Eirtragskategorie". "kein Produkt eines beliebigen wirthschaftlichen Rechnungsexempels", "es stand für ihn im unmittelbaren Zusarnmenhang mit der Bedurfnisbefriedigung". Das Einkommen hatte für Schmoller nur aus Grùnden der Praktikabilität, der ErfaBbarkeit "buchhalterische Existenz". Wenn es jedoch gelegentlich auf diese Weise nicht aberzeugend erfaßt werden kann, so empfichlt es sich, auf die "durch die Persônlichkeit und ihre Bedûrfnisbefriedigung sehr bestimmte Realität" zurückzugreifen. Schmoller. G. (1863), S. 54. Das war einer der tragenden Grundgedanken des in der Besteuerungspraxis ausgebildeten Wartternbergischen Finanzassessors G. Schmoller.

"n In $\$ \$ 23$ bis 27 Instruction v. 7.12.1878 waren für die Finanzverwaltung sehr sorgfaltig die Kriterien herausgearbeitet worden. dic als Grundlage für eine Selbsteinschătzung đes Einkommens des Steuerpflichtigen durch seinen lebensaufwand, sein Verbrauchsverhalten, angesehen werden konnten. Wachler bemalngelte 1903 in einew Rechenschaftsbericht, daß Einzelheiten der Instruction in das Gesetz aufigenommen werden sollten. Eirst dann, so führte or aus, lägen für die Rechtsprechung Gesetzesvorschriften vor, da die Gerichte nicht an Verwaltungsanweisungen gebunden seien. $7 \mathrm{u}$ inhaltlicher 
behörden und Gerichte von dieser Vorschrift sehr regen Gebrauch machten. ${ }^{85}$ Da die Regelung allgemein überzeugte, ist sie offenbar offentlich nie in Frage gestellt worden. $^{86}$

Als Konsequenz, dieser institutionellen Ausgestaltung zeigt sich, daß legale Dispositionen zur Vermeidung des Einkommensteuerzugriffs in Sachsen zwar nicht ganz ausgeschlossen, aber sehr beschwerlich, eingeschränkt, wenn nicht gar unmöglich gemacht wurden und zumindest einen noch vertretbaren Rahmen nicht überschreiten konnten. Es war die Absicht der Mehrheit der Abgeordneten im săchsischen Landtag gewesen, die Einkommensteuer zu reformieren und den Steuerzugriff an der Leistungsfähigkeit der Steuerbürger auszurichten. Dabei wurde der Begriff der Leistungsfahigkeit gewollt an der Definition ausgerichtet, die Schmoller in seinem 1862 gefertigten Aufsatz vorgeschlagen hatte. Der Referent des Landtagsausschusses für die Steuerreform, Julius Gensel, hatte die 1873 erstellten Gutachten für den Verein für Socialpolitik zu dem Problemkreis in die Verhandlungen des Landtages eingebracht, worin er selbst die Schmollersche Besteuenungsidee vertrat. Steuerliches Ermittlungsverfahren, Festsetzungsverfahren, außergerichtliches Rechtsbehelfsverfahren und nicht zuletzt das wichtige Steuerstrafverfahren waren unter dem Gesichtspunkt der Zweckmäßigkeit zur Erreichung des Ziels einer allgemein überzeugenden Besteuerung aufeinander abgestimmt.

Denn das săchsische EStG 1874/78 schuf aus dieser Besteuerungsidee ein Normengefüge, das technologisch durchdacht dem Steuerwiderstand nur wenige Schwachpunkte und damit geringe Chancen bot. Jedenfalls hat sich die Steuervermeidung - wie es scheint - wohl in einem vertretbaren Rahmen gehalten.

$\mathrm{Da}$ es eine gewisse Unzufriedenheit gab, zeigt sich naturgemaß ge!egentlich. Aber diese richtete sich offenbar weniger gegen das Gesetz, als gegen den Umstand der korrekten Besteuerung in Sachsen im Vergleich mit den laschen preußischen Verhältnissen. Nach Lektüre der Thronrede bei Eröffnung der 17. Legislaturperiode des preußischen Landtags vom 14. Januar $1889 \mathrm{mit}$ der Ankündigung der preußischen Einkommensteuerreform beruhigte der Lehr-

Kritik an den Verwaltungsanweisungen sah er keinen AvlaB, s. Wachler. P.. Ein fünfundawanzigjthriges, .... S. 509.

${ }^{85}$ Die Aufzalhlungen in den alphabetischen Sachregistern der verschiedenen Veröffentlichungen von Entscheidungen der Verwaltung und des Finarzgerichts unter dem Stichwort "Besteuerung nach dem Verbrauch" geben stets eine große Anzahl von Hinweisen, s. beispielsweise: Mittheilungen aus der Verwaltung der directen Steuerm .... Bd. V, S. 448; Schelcher, W. (1907), Hauptregister, S. 253.

4. Hierz: Gensel, J. (1885), S. 502; Bčhmert, V. (1889), S. 70: Henrich, L. (1889), S. 81: Wachler, P. (1903), Ein funfundzwanzigjăhriges .... S. 508; Wilding. Graf A (1894), S. 211 . Kritik findet sich unmittelbar nach Einfíhnung nur bei Conrad, J. (1879), S. 466; Blaher (1913), S. 613. 
stuhlinhaber für landwirtschaftliches Rechnungswesen an der Leipziger Universität in einer als Ratgeber zur Einkommensbesteuenung der sächsischen Landwirte verfaßten Broschüre 1889 seine Leser, indem er ausführte: "Man kann wohl sagen, daß die Bevölkerung sich jetzt daran gewöhnt hat, und daß die Hoch- und Höchstbesteuerten auch den letzten Groll dagegen noch überwinden werden, wenn die Nachbarstaaten in gleicher Weise das Einkommen rückhaltlos nach Maßgabe seiner Höhe zu den Staatslasten heranzichen". "Ja", so fuhr er fort, "es ist das wohl auch zur Zeit die größte Härte des sächsischen Einkommensteuergesetzes gewesen, daß Sachsens wohlhabende Einwohner denselben Einwohnern anderer Staaten, besonders Preußens gegenüber, allerdings unverhältnismäßig hoch besteuert gewesen sind". ${ }^{87}$ Howards Erwartungen sollten sich jedoch nicht erfüllen.

Offenbar herrschte in Sachsen nach den zu erwartenden Umstellungsschwierigkeiten und einer vierjăhrigen Übergangsphase ${ }^{88}$ ein befriedigendes Steuerklima, jedenfalls eine die antagonistischen Interessen ausgleichende Steuerkultur. Die Absichten des Gesetzgebers wurden im wesentlichen erreicht.

Erwăhnt werden mag auch noch, daß das EStG 1874/78 auf den wirtschaftlichen Fortschritt keinen negativen Einfluß ausübte. Sachsen blieb fortan unter den deutschen Landern an der Spitze des wirtschaftlichen Fortschritts. So lautete jedenfalls auch die Überzeugung sachkundiger Zeitgenossen. ${ }^{89}$

\section{Gestaltungsmöglichkeiten in Preußen nach Einführung des Einkommensteuergesetzes von 1891}

Das sächsische EStG 1874/78 hatte eine große Ausstrahlungskraft vor allem auf die deutschen Mittelstaaten. Adolph Wagner führte 1899 aus, "daß sich Sachsen den Ruhm des Pioniers des steuerpolitischen und steuertechnischen Fortschritts auf diesem Gebiete der directen Besteuerung in Deutschland" erwarb. ${ }^{90}$ Später sprach er dann mit verhaltenem Stolz von der großen Bedeu-

37 Howard, H. (1889), S. 7.

S. hierzu Bericht in: Conrad, J. (1879), S. 448.

"Hoffmann, W. G.MMaller, J. H. (1959), S. 87, S. 99 u. a.; Wilding, Graf A., S. 211; hierzu auch: Heiß, C. (1893), S. 82. Die salchs. Steuerstatistik der Zeitspanne zeigt eine kleine Verminderung der Anzahl der Steuerpflichtigen mit kleinen Einkommen, verbunden mit einer großen Zunahme der großen Einkommen. Das weist auf die hohe Zunahne der Industrialisierung hin und zeigt, dal die Besteuerung nach dem Einkornmen keine Behinderung des Wachstums mit sich brachte; s. hierru such: Tabacovici, N. (1913), S. 26.

90 Wagner, A. (1899), S. 107. 
tung Preußens bei Inangriffnahme der eigenen Einkommensteuerreform von 1891, die zwar "nach dem Muster anderer Staaten" vorgehend, danach aber sofort durch Übernahme einer Führungsrolle "auf diesem Gebiete durch seine neue Gesetzgebung nun auch wieder auf die übrigen deutschen Staaten einwirken und da und dort weitere bezügliche Reformen anregen wird". "So stellte er 1899 befriedigt fest, daß Sachsen "jetzt die Stelle an der Spitze des Fortschritts in der Reform der directen Besteuerung wieder verloren und an Preußen abgetreten" habe. ${ }^{92}$

Demzufolge wird denn auch die preußische Reform der Einkommensteuer in der Berichterstattung regelmäBig als eine gradlinige Fortentwicklung der Besteuenungspraxis beurteilt, in der "Sachsen zum Vorreiter eines modernen Steuersystems in Deutschland" wurde. ${ }^{93}$

\footnotetext{
"Wagner, A. (1891), S, 599.

2 Wagner, A. (1899), S. 109.
}

${ }^{3}$ Groffeld, B. (1891), S. 44. Der Eindruck von einer gradlinigen Fortentwicklung der preußischen ESt seit 1820 bis hin zum heute galtigen ESt-Recht wird in allen bekanntgewordenen Abhandlungen erzeugt. Neuerlich wurde diese Darstellung in einem weit verbreiteten EStG-Kommentar, der von fuhrenden Steuerrechtlern herausgegeben wird und zu dem 35 aus Finanzrechtsprechung. Finanzverwaltung. Prüfungswesen und Steuerberatung ausgewiesene Fachleute und Hochschullehrer als Mitarbeiter beitragen, wiederum festgeschrieben. Nach Auffassung P. Kirchhofs war das salchs. EStG 1874/78 "auf der Grundlage der Quellentheorie" aufgebaut und hat "das slichs. Quellenkonzept ... später des preuß. EStG von 1891 beeinfluBt", s. Kirchhof, P./Söhn, H. (1992), Bd. 1, S. 143, Rdurr. A 407. Die vallige Vergessenheit, in die die Lehren Schmollers und damit auch die Bedeutung des Vereins für Socialpolitik für die Entstehung des săehs. EStG 1874/78 gerieten, hat zugelassen, daß das preuB. EStG 1891 und darüber hinaus die Entwicklung des deutschen ESt-Rechts von der Aura eines beständigen Wachstums zu höherer Sachgerechtigkeit umgeben wurde. Alternativen wurden daher ausgeblendet jedenfalls nicht zureichend bearbeitet. So fanden die kritischen Beitralge von Schanz, Meisel u. a. nur geringe Beachtung und wurden 1919 nur kurzfristig von Bedeutung. Eine fehlerhafte Auslegung des Einkommensbegriffs des sdehs. EStG $1874 / 78$ zugleich mit einer unzutseffenden Einordnung der diesem zugrundeliegenden Lehren Schmollers stehen im Zusammenhang mit wissenschaftstheorttischen Auseinandersetzungen, die den deutschen Sprachraum im 19. Jahrhundert bewegton, s. hiern: Hansen, R. (1990). S. 24, S. 25; ders. (1993), S. 114. Fûr die wissenschaftstheoretische Ausrichtung Schmollers fehlte und fehlt bis heute zumeist das Verständnis. Daher konnte eine von $\mathrm{K}$. Diehl vorgetragene Typeneinteilung zur Grundlage verfehlter Interpretationen der Lehren Schmollers für mehrere Generationen dienen, s. Diehl, K. (1929), S. 4; ähnliche Auffassungen in einer Dissertation bei Kellner, F. (1928), S. 19. Die Typenbildung Diehls wurde unoberpruft in eine einflußreiche Abhandlung von Barth übernommen, s. Barth, $K$. (1953), S. 93. Ebenso ist die fehierhafte Auslegung in viele Lehrbûcher und Beitrlge eingeflossen und gilt heute als herrschende Meinung.Tipke verweist auf die Dissertation Kellners und fîhrt die sog. "Reinvermögenszugangstheorie" auf Schanz zuräck, s. Tipke, K. (1973), S. 393. Allein Lang erkannte, daß Schanz 1896 für seine Kritik am preuß. EStG 1891 den Einkommensbegriff Schmollers verwendete, s. Lang, J. (1981). S. 38. Auch die Verbindung. die Kirchhof von der Quellentheoric zu Schmollers Einkommensbegriff zieht, wird den tatsächlichen historischen Gegebenheiten nicht gerecht, s. Kirchhof, P./Söhn, H. (1992), Bd. 1, S. 114, Rdns. A 315. S. 107, Rdnr. A 293, S. 108, Rdnr. 297. Die mangelhafte Aufarbeitung der Vergangenheit hat weitreichende Konsequenzen: Wenn Tipke bei Wurdigung der Bedeutung Miquels von "besonderen legislatorischen Leistungen ohne steuerwissenschaftliche Grundlage" berichtet und diesen zusammen mit Erzberger als die großen Reformatoren des Einkommensteuerrechts ausgibt, so muß erwakhnt werden, daß beiden Politikem jeweils alternative Muster vorgegeben waren, s. Tipke, K. (1991), Die Entwicklung .... S. 211. 
Tatsăchlich kann sich einem Laien nach oberflächlicher Lektüre der Bestimmungen des sächsischen EStG 1874/78 und Vergleiches derselben nit denjenigen des preuBischen EStG 1891 leicht die Überzeugung aufdrängen, bei den erkennbaren Abweichungen in den beiden Regelungssystemen handele es sich um vernachlässigbare Geringügigkeiten. Der Fachmann mag ohne Einblicknahme in die Kommentierungen und ohne Kenntnis der amtlichen Interpretation der Vorschriften im Lichte der zugrundeliegenden Besteuerungsidee ăhnliche Vorstellungen entwickeln. Denn das preußische EStG 1891 enthălt nicht nur viele wortgleiche, teils aus dem sächsischen Muster übernommene Passagen, es benutzte gleichlautende Begriffe, hatte einen gleichen Ablauf der Regelungen, eine vergleichbare Paragraphenfolge, einen vergleichbaren Umfang des Regelungsgehaltes und nicht zuletzt sollte es arch gleichen Absichten des Gesetzgebers dienen. ${ }^{94}$

Diese rein åußerliche Vergleichbarkeit bedeutete aber nicht, daß die als Steuertechnik bezeichnete Ausgestaltung des preußischen Regelungsgefüges in sich ebenso abgestimmt war, wie im sächsischen EStG 1874/78, so daß Steuerwiderstand und Steuervermeidung auf einem unvermeidbaren niedrigen Niveau gehalten werden konnten, um die Absichten des Gesetzgebers nicht durchkreuzt zu sehen.

Wer von einem Erfoỉg der refonmierten Eimkommensteuer in Preußen spvach oder heute noch spricht, hătte sich mit den Argumenten kompetenter Fachleute auseinandersetzen müssen, die eine Verfehlung der Absichten des Gesetzgebers beklagten. Auf die Fehlleistungen der Lastenverteilung des preußischen EStG 1891, gemessen an den erklärten sozialen Absichten des Gesetzgebers, wurde nämlich frühzeitig hingewiesen, wenn auch stets zugleich eine Verbesserung gegenüber dem früheren Zustand eingeräumt wurde. Bei Abwägung

94 Wegen der äuß̉erlichen Ähnlichkeit der Gesetzeswerke berichten führende Steuerrechtler, das săchs. EStG 1874/78 stehe auf der "Gundlage der Quellentheorie", s. Kirchhof. P./Sōhn, H. (1992). Bd. 1, Rdns. A 407, und es kenne vier Hauptquellen der Einkuntsarten wie das preuB. EStG 1891, s. Kirchhof, P./Sóhn. H. (1992), Bd. 1, Rdnr. A 407. Dabei wird Obersehen, daßs die Einkunftsarten im sächs. EStG 1874/78 ausdrücklich nicht erschöpfend aufgezalhlt wurden, wie im preuß. EStG 1891, hierzu: Gensel, J. (1875), Sp. 1520; ebenso: Wachler, P. (1912). Das Königlich slichsische ..., S. 76, Bem. 1; auch: $\S 7$ preuß. EStG 1891 bzw. $\S 6$ preuB. EStG 1906 (s. Anlage 2); dazu Fuisting. B. 1902), Grundzoge ..., S. 83, S. 109. S. 133; ders. (1894), S. 55, Bern. 4; ders. (1896), S. 440. Die Aufzllhlung in $\$ 17$ slschs. EStG $1874 / 78$ hatte nur Bedeutung furr die statistische Erfassung (s. hierzu Anlage 1). Obersehen wird in den Darstellungen auch stets, daß nach dem sächs. EStG $1874 / 78$ der Vermo̊genszugang als solcher den Inhalt des Steuergegenstandes bestimmte und da $\$$ hier ein Enumerativkatalog Ausnahmen von der Steuerbarkeit auffuhrte. In Preußen dagegen bestimmte umgekehrt ein Enumerativkatalog von Einkunftsarten die allein steuerbaren Vermőgenszugange. Das preuß. EStG 1891 trennte dabei streng zwischen Einkommens- und Vermögenssphäre. Nur die Früchte aus bestehenden und beständigen Quellen waren in Preußen steuerbar und ebenso war für Ausgaben der Bestand einer Einkommensquelle Voraussetzung, hierzu: Schanz, G. (1896), S. 51; Fuisting, B./Strutz, G. (1904), S. 55, Bem. 4; Fuisting. B./Strutz, G. (1917), S. 139, S. 141; Fuisting, B./Strutz, G. (1915), S. 163, S. 218. 
der Kritik mit vielen später bekanntgewordenen überprüfbaren Auswirkungen wird man das preußische EStG gegenüber dem salchsischen Muster bei einem Vergleich mit den erklărten Zielen des Gesetzes gewiß nicht als Fortschritt bezeichnen können.

Adolph Wagner, der an der Schaffung beteiligt war, war stets vordringlich an rechtsdogmatischen Problemstellungen interessiert. Mit der praxisorientierten Kritik an den Auswirkungen des Gesetzes hat er sich nach dessen Einfuhrung nicht auseinandergesetzt. ${ }^{95}$ Die beklagte mangelhafte Besteuerung von der Einkommensteuer nicht erfaßter Vermögensmehrungen suchte er, seiner Besteuerungsidee entsprechend, durch Ausbau der Verkehrssteuern zu kompensieren. Spăter wurde er daher wegen seines Eintretens für eine soziale Ergănzung der Einkommensteuer als "Bannerträger" der Wertzuwachssteuer gefeiert. ${ }^{96}$ Fuisting hatte frühzeitig die praktischen Schwachstellen des preußischen EStG in der Übernahme unvereinbarlicher Elemente aus dem sächsischen Muster erkannt. Er setzte sich fortan vergeblich für eine Reform durch Eliminierung dieser Fremdkörper und eine durchgăngige strenge idealtypische Ausrichtung nach dem Quellenprinzip ein. ${ }^{97}$ Dabei wollte er aber die Einkommensteuer aus sozialen Gründen durch Erhöhung der Freibeträge auf die höheren Einkommen begrenzt sehen. ${ }^{98}$

Ein Überblick über die mangelhafte Durchsetzung der erklärtermaßen mit dem preußischen EStG 1891 verfolgten sozialen Absichten macht eine Untersuchung des gegenüber dem sächsischen Muster eingeschränkten Besteuerungsgegenstandes, der mangelhaften Abstimmung der einzelnen Vorschriften, als Steuertechnik bezeichnet, und der unzweckmäßigen Überwachungsmöglichkeiten notwendig. Letztlich forderte das Regelungsgefüge nămlich wegen seiner perfektionistischen Konstruktion die Zensiten geradezu zur Steuervermeidung durch völlig legale Dispositionen zu einer vorteilhaften Gestaltung der Tatbestandsmerkmale heraus und es ermőglichte daruiber hinaus we-

95 Nach Abstimmung mit Miquel übernahm in PreuBen A Wagner die Aufgabe, im "Finanzarchiv" ausgiebig über die Einzelheiten der Verhandlungen zur Entsiehung des preuB. EStG 1891 und die vom Gesetzgeber verfolgten Absichten zu berichten. Der Aufsatz ist demjenigen von J. Gensel aber die Entstehung des săchs. EStG 1874/78 in den "Annalen đes Deutschen Reichs" vergleichbar, Wagner, A. (1891), S. 551; Gensel, J. (1874), Sp. 1373; ders. (1875), Sp. 1519; hierz: Rubner, H. (1878), S. 268, Anm. 3.

${ }^{9}$ DJZ, 15. Jg. 1910, Sp. 519; Bauckner. A. (1919), S. 27; Hansen, R. (1990), S. 28.

97 Fuisting, B. (1894), S. 104, Bem. 14; ders. (1896), S. 327: ders. (1903), Einkommiensbesteuerung ..., S. I. S. 9 u.a.; ders. (1902), Grundzage .... S. 264; ders. (1903), Reformbed0rftigkeit .... S. 230; s. a. Fuisting, B./Strutz, G. (1915), §13 preuB. EStG, Bem. 22, Bem. 27, S. 582, S. 594. 275 .

${ }^{98}$ Fuisting, B. (1902), Grundzuge ..., S. 270 - S. 275; ders. (1903), Einkommensbesteuemg ..., S. 
gen Fehlens erforderlicher Kontrollen durch die Finanzverwaltung, fast gefahrlos gesetzwidrige Steuerverkürzungen zu begehen.

Die Auslegung der Gesetzesvorschriften ergibt sich erst aus einer Darstellung der ursprünglichen zugrundeliegenden Besteuerungsidee.

Adolph Wagner war der eigentliche geistige Vater des preußischen EStG 1891. Er lieferte als allgemein anerkannter Wissenschaftler der Berliner Universităt in seinen in drei Auflagen weit verbreiteten Beiträgen zur politischen Ökonomie und zur Finanzwissenschaft, die die Lehren des von der nachklassischen Nationalökonomie beeinflußten K. H. Rau fortfuhrten, ${ }^{99}$ die Besteuerungsidee fur die preußische Reform der Einkommensteuer von 1891 . $^{100} \mathrm{Gene}$ ralsteuerdirektor Burghart und B. Fuisting waren die Gesetzestechniker, die als Regierungskommissare den im preußischen Landtag heftig umstrittenen Besteuerungsgegenstand endgültig ausformulierten. ${ }^{101} \mathrm{~J}$. von Miquel war nach 1890 als Finanzminister der Geburtshelfer, der durch sein mit Durchsetzungsvermögen gepaartes Verhandlungsgeschick und seine - von Fuisting bedauerte - große Kompromißbereitschaft das Gesetz nach schwierigen streitigen Erorterungen 1891 zur endgültigen Beschlußfassung im Landtag brachte. ${ }^{102}$

Nach Wagners Fortfuhtrung der Lehren Rau's war "Einkommen ... diejenige Summe wirthschaftlicher Güter, welche derselben (einer Person, d. V.) in gewissen Perioden ... regelmäßig und daher mit der Făhigkeit der regelmäßigen Wiederholung als Reinerträge einer festen Erwerbsquelle neu als Vermögen hinzuwachsen". ${ }^{103}$ Unter Hinweis auf Schmollers Beitrag von 1863 führte Wagner als zum Einkommen gehörig auch zusätzlich noch "Genüsse (Nutzungen) oder selbst nur Genußmöglichkeiten aus dem Nutzvermögen einer Person" an. ${ }^{104}$ Die letzteren Wertzuflüsse erhielten jedoch bei Wagner nur eine

${ }^{9}$ Zur Bedeutung der Lehren K. H. Raus für die 2. Jahrhunderthâlfte s.: Gerlach, O. (1908), S. 25 : Wagner fthrte die Lehrbücher von Rau in mehreren Neuauflagen fort, indem er den Lehrinhalt Jen modernen Anforderungen anpâte, s. Wagner, A. (1876), S. V: ders. (1879), S. V: ders. (1880), S. VI.

${ }^{100}$ Die Grundgedanken von Rau zur Definition von Einkommen und zur Verwendung des Begriffs für steuerliche Zwecke wurden von Wagner abernommen und fortentwickelt, s. Rani, K. H. (1855), § 70. S. 89: ders, (1864), $\S \S 258$ bis 262. S. 404; ders. (1865), §§ 398, 399. S. 183, § 400a, S. 193; vergleiche damit: Wagner, A. (1875/76), S. 96; ders. (1879), S. 114, S. 11 ; ders. (1890), S. 255, S. 256; ders. (1890), S. 324, S. 325; ders. (1892), S. 405, S. 406. Wagner ergănzte die Definitionen Raus durch Zusitze, die er unter ausdrüklichem Hinweis aus Schmollers Aufsatz von 1863 übernahm, denen er aber nur mindere Bedeutung beigelegt wissen wollte

101 Stenographische Berichte über die Verhandlungen des preuB. Landtages, Haus der Abgeordneter, 17. Sitzung vom 15.12.1882, S. 326. Als Minister war A. von Scholz zuständig, als Regienıngskommissar diente Fuisting, B. (1903), Einkommensbesteuerung ..., S. 2; Scholz, A. von (1922), S. I1; Mave, F., S. 112; Hansen, R. (1990), S. 3.

\footnotetext{
${ }^{102}$ Fuisting, B. (1903), Einkommensbesteuerung .... S. 2, S. 3.

103. Wagner, A. (1876), s. 96.

19. Wagner, A. (1876), 3.97.
} 
Lückenbüßerfunktion. Sie wurden fortan nur selten erwähnt und letztlich im Gesetz höchst unvollkommen und unsystematisch berücksichtigt. ${ }^{105}$ Anders als Schmoller, der den aus der klassischen Nationalökonomie stammenden und für deren Produktions- und Preislehre gefertigten Einkommensbegriff für steuerliche Zwecke als zu eng verwarf, ${ }^{106}$ wollte Wagner vornehmlich das Ergebnis der Gütererzeugung für den Markt zum Besteuenungsgut gerechnet wis$\operatorname{sen}^{107}$

Fuisting umriß, Wagner folgend, in seinem Lehrbuch das der Einkommensteuer zu unterwerfende Besteuenungsgut als "Gesamtheit der Sachgüter, welche in einer bestimmten Periode (Jahr) den Einzelnen als Ertrăge dauernder Quellen der Gütererzeugung zur Bestreitung der persönlichen Bedürf̂nisse für sich und für die ... gesetzlich angewiesenen Personen (Familie) zur Verfügung steht". ${ }^{108}$ Dabei suchte Fuisting den Unterschied zu dem viel umfassenderen Einkommensbegriff Schmollers herauszustellen und auf diese Weise die grundlegende Besteuerungsidee des "preußischen Types" der Einkommensteuer systematisch von dem weitergehenden sächsischen Regelungssystem abzugrenzen. Der Schmollersche Einkommensbegriff berücksichtigt "nur den Zweck, nicht aber die Entstehung des Einkommens ...", so stellte er den Unterschied richtig heraus. ${ }^{109}$ Das Woher, die Entstehung des Wertezuflusses, der aus einer bestăndigen Quelle der Gütererzeugung stammen mußte, bestimmte in Preußen fortan die Steuerbarkeit als Selektion einer Teilmenge von Vor-

${ }^{105}$ Wilke, G. (1921), S. 98. Im übrigen unterschied Wagner wie Fuisting zwischen einem wissenschaftlichen und somit richtigen Einkommensbegriff und einem solchen aus bloBen ZweckmalBigkeitsgrunden, der von den herrschenden Zeitumstanden diktiert wurde. In dem letzteren sah er eine befristete Übergangslösung. Hierzu rechnete er letżlich auch ebenso wie Fuisting die Besteuerung von Vermọ̆gensmehrungen durch "Conjuncturengewinne" infolge eines zu weiten, lebtlich auf Schmollers Definition zurickgehenden Einkommensbegrifts. Vermōgensmehrungen sollten nach Wagners $\mathrm{Be}$ steuerungsidee dem Besteuerungsgut der Verkehrssteuen in Form von Wertzuwachssteuem zugewiesen werden. Dieser Leitidee Wagners folgte man denn auch zunehmend nach 1908, s. Wagner, A. (1880), S. 257; ders. (1892), S. 405 bis 407 ; Bredt, V., S. 41, S. 42; Gemperli, A. (1923), S. 20. S. 21, S. 51, S. 94; Hansen, R. (1990), S. 27. S. 28. Die Ausführungen Wagners zul diesem Problemkreis sind nicht ohne Widerspruche, s. Hansen. R. (1990), S. 33, S. 64.

106 Schmoller, G. (1863), S. 6, S. 7, S. 32 u. a.

${ }^{107}$ Darin setzte Wagner Rau's Lehren fort. Danach kamen für den Steuerzugriff nur Einkünfte infrage, die als Ertrïge produktiver Quellen nach der klassischen Tradition als "ursprüngliches Einkommen" bezeichnet werden, s. Rau, K. H. (1855), $\S 70$, S. 89; ders. (1864), $\$ \S 251$ bis 262, S. 404; ders. (1865), $\S \S 398,399$, S. $183, \S 400$ a. S. 193 . Gegen eben diese letztlich aus der Produktionslehre der klassischen Nationalokkonomie entnommene und für die Verteilungslehre aufbereitete Auffassung hatte Schmoller sich 1863 als ungeeignet ausgesprochen, Schmoller, G. (1863), S. 6, S. 7, S. 32 u. a. Austrücklich bemăngelte Schmoller, daß nach den Lehren von A Smith das erbaute Haus nach Fertigstellung und Beginn der Selbstnutzung aufhört, "einkommengewâhrendes Kapital zu sein", Schmoller, G. (1863), S. 6, S. 7; Smith. A. (1789), 2. Buch, 1. Kapitel, S. 231.

\footnotetext{
${ }^{108}$ Fuisting, B. (1902), Grundzüge ..., S. 110.

109 Fuisting, B. (1902), Grundzũge ..., S. 110.
} 
găngen aus den gesamten Positionen der Vermögensmehrungen. Eine güterwirtschaftliche Betrachtungsweise der Produktion für den Markt lag hier zugrunde, der als Muster die Beobachtung der Früchtereifung und deren Ernte in der Natur diente. Nach den Lehren von Adam Smith sollte auf diese Weise durch Beschränkung der Verteilung das Wachstum der Produktion für den Markt garantiert werden. ${ }^{110}$ Aus dieser Betrachtungsweise folgte jedenfalls die strenge Unterscheidung der zum Stammvermögen gerechneten Quelle, der Aufwendungen für deren Erwerb, deren Verbesserung und ebenso der Wertezugănge bei deren Veräußerung einerseits von dem Früchtebezug aus der Quelle als Überschuß der Vermögensmehrungen über die laufenden Aufwendungen zur Erhaltung und zum Betrieb der Quelle andererseits.

Veränderungen der Quelle mußten nach dieser Vorstellung steuerlich irrelevant bleiben, damit der Steuerzugriff sich nur auf den ohne Beeinträchtigung der Güterproduktion verfügbaren Teil des Überschusses bezieht und daher das Wachstum des Wohlstandes nicht beeinträchtigt wird.

Der Steuergegenstand des preußischen EStG 1891 suchte das skizzierte Besteuerungsgut entsprechend in einer abgeschlossenen Aufzählung von vier Einkunftsarten zu erfassen. Er wich somit wesentlich von den Bestimmungen des săchsischen Musters ab. ${ }^{111}$

Indem die Ermittlungsvorschrift für Einkünfte aus HandeI und Gewerbe in den Verhandlungen des Landtages dann jedoch derjenigen des sächsischen Musters angepaßt wurde, erhielt das Gesamtgefüge einen schwer integrierbaren Fremdkörper. Dadurch wurde der äußerliche Eindruck der Vergleichbarkeit mit dem sächsischen Muster aber noch verstärkt.

Die ohnehin zugunsten rechtsdogmatischer Erörterungen vernachlässigte Abstimmung der einzelnen Regelungen des preußischen EStG 1891 im Hinblick auf die praktischen Erfordernisse zur Verfolgung der sozialen Absichten des Gesetzes ${ }^{1 / 2}$ mußten bald zum starken Anschwellen des Steuerwiderstandes

${ }^{110}$ Nach A Smith stamunt des private Einkommen des Bürgers, das allein for die Besteuerung zur Verfugung steht, "aus drei voneinander verschiedenen Quellen, aus Rente, Gewinn und Lohr", s. Smith, A. (1789), 5. Buch, 2. Kapitel, 2. Teil, S. 703. Nur Zuflosse aus produktiven Quellen konumen; fur eine Einkommensbesteuerung infrage, Smith, A. (1789), 2. Buch, S. 227, S. 278. S. 279: hierzu: Kelber, M. (1933), S. 161, S. 165, S. 177, S. 189, S. 190; Roesler, H. (1868), S. 303, S. 306; s. hierzu: Fuisting, B. (1894), S. 55, S. 56.

III $\$ 7$ preuß. EStG 1891 bzw. $\S 6$ pretuB. EStG 1906 (s. Anlage 2).

112. In đer amtlichen Denkschrift und in den Begründungen zu den Entwūrien đer Steuerreformgesetze hieB es, da $B$ "ein den Anforderungen der Gerechtigkeit und Billigkeit entsprechendes System der direcien Staatssteuem ... nur auf der Grundlage der persōnlichen Leistungsfahigkeit aufbauen kann", s. Die preußischen Steuergesetzentwur rfe von 1892 nebst Denkschrift und Begründung, Berlin 1892, S. 13, S. 14. Das preuB. EStG 1891 war bestimmungsgemal auf dieses Ziel hin konzipiert worden, s. Denkschrift 1892, S. 13. 
führen. Dabei trat belastend hinzu, daß in Preußen eine rechtsdogmatischformalistische Beurteilung der Vorgănge die Aufmerksamkeit stets mehr beanspruchte als die konkreten praktischen Auswirkungen. Die Besteuerung wurde hier nicht, wie in Sachsen, als offentlich-rechtliche Lastenverteilung, sondern, die Tradition seit 1820 fortsetzend, als obrigkeitliches Eingriffsrecht beurteilt, dem der Steuerbürger nicht schutzlos ausgeliefert sein durfte.

Nach dem Steuergegenstand des preußischen EStG 1891 war ein Reinertrag nur steuerbar, wenn er unter eine der vier durch Tatbestandsmerkmale kodifizierten Einkunftsarten subsumierbar war. Dabei konnie die Zuordnung zu einer konkreten Einkunftsart wegen der unterschiedlichen Ermittlungsweise eventuell von großer Bedeutung sein. Wenn der Zensit mithin durch vertragliche Gestaltungen erreichte, daß die Herkunft einer Bereicherung nicht unter eine der vier Einkunftsarten subsumierbar war, weil eventuell keine dauerhafte Quelle der Gütererzeugung zugrunde lag, so waren die Reinerträge nicht steuerbar. Gelang es ihm, etwa Bereicherungen aus Handel und Gewerbe durch geeignete Dispositionen in Erträge einer Einkunftsart der Überschußeinkùnfte umzuwandeln, so waren realisierte Gewinne aus dem Stammvermögen steuerfrei. Verträge unterschiedlichster Art, wie Pacht- oder Mietverträge, die Schaffung von dinglichen oder obligatorischen Nießbrauchsrechten ${ }^{1 / 3}$ und andere Konstruktionen, wie Gründung von Gesellschaften mit zeitlich und sachlich begrenztem Zweck. Kündigungen von Darlehen, Umgründungen, Unterbrechung von Dienstverhältnissen etc. etc., eigneten sich fortan vorzüglich zur völlig legalen Stcuervermeidung. Anders als in Sachsen wurde die Besteuerung ja nicht von der Bereicherung des Zensiten bestimmt, sondern allein von dem Vorhandensein normierter, rein formaler Tatbestandsmerkmale im Sachverhalt, ${ }^{14}$ so daß gegebenenfalls der tatsächlich Bereicherte durch

113. Nach $\S 13$ Abs. 3 preuB. ESIG 1891 bzw. § 12 Abs. 3 preuB. EStG 1906 war der NieBbraucher dem Eigentumer einer Einkommensquelle gleichgestellt. Dieses Rechtsinstitut eignete sich daher besonders zur legalen Minderung des Steuerzugrifts durch eine zweckmaBige vertragliche Gestaltung der Rechtsverhalltnisse. Durch eine in der Vermügenssphäre angesiedelte entgeltliche oder unentgeltliche zeitlich geregelte Ûbertragung abstrakter objektiver Rechtspositionen konnten die formalen gesetzlich norrnierten Indikatoren für die Entstehung der Steuerschuld so verlagert werden, daß eine wirtschafliche Bereicherung beim Übertragenden, weil in der Vermōgenssphäre effolgt, keine Besteuerung auszuJōsen vermochte. Das Nießbrauchsrecht gehōrte zu den Personalservituten, die bereits frühzeitig aus dem römischen in die versehiedenen deutschen Rechtssysteme recipiert, allgemeine Wirksamkeit erhielten und zwar, wie es bei Puchta heißt, "durch die Macht wissenschaftlicher Öberzeugung". Dem Bedürnis im Rechtsverkehr entsprechend hatte das Rechtsinstitut im Allgemeinen Landrecht für die Preubischen Staaten im 21. Titel des 1. Theils in den $\$ \S 1$ bis 185 umfassende Regelungen gefunden. Das BGB ûbernahm die Bestimmungen im wesentlichen in den $\S \S 1030$ bis 1085 . Das preuB. EStG 1891 konnte das Interesse an diesem Rechtsinstitut noch verstârken, s. Puchta, G. P. (1856), $\$ \S 179$ bis 182, S. 269, S. 1: Allgenneines Landrecht für die Preußischen Staaten, S. 310 bis S. 315.

114 In der Öfentlichkeit bestand für die von formalen Tatbestandsmerkmalen allein ohne Berucksichtigung der wirtschaftlichen Zusammenhănge und der Vermōgensmehrung ausgelöste Besteuerung 
Verlustausweise steuerlich sogar noch begünstigt wurde, während der formell Bereicherte die ihm infolge intelligenter Dispositionen zuzurechnenden steuerbaren Erträge mit eigenen Verlusten saldieren konnte. ${ }^{115}$

Das preußische EStG 1891 war von vornherein eine Arena für intelligente Konstruktionen zur Vermeidung der Besteuerung. Freilich galt dies nur für den kleinen Kreis vermögender Sachkundiger, die gute Gründe hatten, ihr Wissen zumeist für sich zu behalten. ${ }^{116}$

Ohne hier eine systematische oder gar erschöpfende Darstellung aufzeigen zu können, lassen sich vielleicht für eine Erörterung der durch das preußische Gesetz dem Steuerpflichtigen gewăhrten Gestaltungsmöglichkeiten zur steuerlichen Entlastung folgende typische Regelungsbereiche von Wichtigkeit auflisten:

a) Der der Aufstellung im såchsischen EStG 1874/78 vergleichbare Katalog der Einkünfte im preußischen EStG 1891 wich insoweit von dem sächsischen Muster ab, als es sich um einen Enumerativkatalog mit vier Einkunftsarten handelte. In der Formulierung kommt dies nicht klar genug zum Ausdruck. ${ }^{11}$ ?

b) Zum Einkommen rechnete nur, was aus bestăndig fließenden Quellen der Güterproduktion oder der Benufstätigkeit stammte. Dies ist allerdings erst der Novellierung des Gesetzes im Jahr 1906 textlich klar zu entnehmen, da nun

oft kein Verstandnis, hierzu: Fuisting, B. (1906), Zur Besteuerung ..., Sp. 1172; als Beispiel: Urteil des OVG in Staatssteuersachen, in: Entscheidungen, 12. Bd. 1906, S. 79 bis S. 86.

115 Des Rechtsinstitut des in Anm. 113 angefuhrten NieBbrauchs eignete sich vorzüglich für bûr. gerlich-rechtliche Vertragsgestaltungen zur legalen Vermeidung der Steuerenistehung. Letztlich bestanden hierfür keinerlei komplizierte oder hemmende Formvorschriften. Es war sogar möglich, das Recht auf den Bezug der Frichte aus einem Recht, einer Sache oder einem Vermoggen auf den Niebbraucher, unabhängig von der Verpflichtung zur Bestreitung der Aufwendungen für die Aufrechterhaltung des Früchteflusses zu übertragen. Daß von diesen Möglichkeiten mit steuerlicher Wirkung frühzeitig ausgiebig Gebrauch gemacht wurde, ergeben die umfangreiche Kommentierung und Rechtsprechung seit 1893, s. Fuisting. B. (1894), Bem. 8a; ders. (1894), S. 145, Bem. 3; Fuisting, B./Strutz, G. (1917), S. 132, Bem. 73a. Das Register in B. Fuisting (1915) zeigt, wie umfangreich die Rechtsprechung in Anspruch genommen wurde. For die Abzugsfahigkeit von Werbungskosten und die Steuerbarkeit der Einnahmen war das weitere Bestehen einer Einkommensquelle, unabhăngig von erzietten Einnahmen, erforderlich, Fuisting, B./Sirutz, G. (1915), S. 218, S. 219.

"16 Die Kenntnis des Steuerrechts wurde schnell eine solide Grundlage für den neuartigen Dienstleistungsbereich der Steuerberatung, s. Pausch, A. (1979), S. 448, S. 449.

117 Zur Zeit der Einfulurung und Geltung des preuß̂. EStG 189 ! stand die Beschränkung der Einkunftsarten außer Frage. Anders als in Sachsen, wo die Ertragsteuem von der Einkommensteuer ersetzt wurde, stelte letztere in Preußen eine Fortentwicklung der Ertragsbesteuerung durch deren Bezug auf den einzelnen Steuerpflichtigen dar. Fuisting betonte dies wiederholt, Fuisting, B. (1902), Grundzuge ..., S. 83. Auch Wagners Empfehlung einer stäkeren Auffàcherung der Einkunftsarten änderten an diesem Grundgedanken einer Beschränkung nichts, Wagner, A. (1891), S. 698. 
erst der Terminus "Einkommensquellen" in das Gesetz aufgenommen wurde. ${ }^{118}$

Als Ausnahme wurde die Besteuenung von Spekulationsgewinnen in das Gesetz eingefügt, obgleich in diesen Fällen keine bestăndig fließende Quelle unterstellt werden konnte. ${ }^{119}$

c) In Preußen wurde 1891 - auf Intervention des Handelsstandes hin erst in letzter Lesung des Gesetzes - für buchführende Kaufleute die Handelsbilanz zur Grundlage der Einkunftsermittlung gemacht. ${ }^{120}$ Der ausgewiesene "Geschăftsgewinn" war jedoch nach den für alle Steuerpflichtigen verbindlichen Ermittlungsvorschriften der $\S \S 6$ bis 11 des preußischen EStG 1891 vorerst umzurechnen. Erst die Rechisprechung des OVG fuhrte zur Auslegung im Sinne eines dualistischen Ermittlungsvorschrift. Fernerhin blieb eine spitzfindige Kasuistik bezüglich der Steuerbarkeit von Veräußerungsgewinnen unvermeidbar. ${ }^{121}$

d) Im Grundsatz war nach dem Gesetz das steuerbare Einkommen auf das Markt- oder Erwerbseinkommen beschränkt. Als Ausnahme wurde der Mietwert der Wohnung im eigenen Haus als steuerbar aufgefuhrt. ${ }^{122}$

Die Entnahme von Gütern aus der eigenen Landwirtschaft konnte daher erst durch die Finanzrechtsprechung des Oberverwaltungsgerichtes durch Auslegung des Begriffs einer "Einkommensquelle" in der Landwirtschaft für steuerbar erklärt werden. ${ }^{123}$

118 \$ 8 Abs. 1 und $\S 9$ Abs. 1 preuß. EStG 1906.

119 \$ 12 Abs. 2 d und $\S 14$ Abs. 3 preuB. EStG 1891.

${ }^{120} \$ 14$ Abs. 1 preuB. EStG 1891 baw. $\$ 13$ Abs. 1 preuB. EStG 1906.

121 Von großer Bedeutung wurde num, ob Gewinne bei Verăußerung von Wirtschaftsgotern steuerbare Gewinne aus unternehmerischer Tătigkeit waren oder Vorgange in der nicht steuerbaren Vermọgens- oder Privatsphăre des oder der Untemehmer darstellten. hierzu: Fiisting, B. (1894), S. 103, S. 104; Fuisting, B./Strutz, G. (1917), S. 218, Bern. 16.

${ }^{122} \$ 13$ Abs. 3 preuB. EStG 1891 bzw. $\$ 12$ Abs. 3 preuB. EStG 1906.

123 Wăhrend nach dem slichs. EStG $1874 / 78$ dem Grundgedanken entsprechend der "Werth der zum Haushalte verbrauchten Erzeugnisse der eigenen Wirthschaft und des eigenen Gewerbebetriebes" (§ 15 Ahs. 1) zum steuerbaren. Eirikommen rechnete, war im anders orientierten preuB. EStG 1891 aber die Anrechnung des Selbstverbrauchs als Einkommen keinerlei Bestimmung getroffen. Daftr waren die "zur Bestreitung des Haushalts der Steuerpflichtigen ... gemachten Ausgaben" bei Ermittlung des steuerbaren Einkommens ausdröcklich vom Abrug ausgeschlossen ( $\$ 9$ Abs. 2 Ziff. 2 preuß . EStG 1891 bzw. $\$ 8$ Albs. 3 Ziff. 2 preuB. EStG 1906). Erst die Auslegung des Begriffs der landwirtschaftlichen Einkommensquelle als systematisch ausgerichtet auf die Produktion von Erzeugnissen zur Ertragserzielung durch Selbstverbrauch und zur Bestreitung des Unterhalts durch Verlußerung am Markt und deren Abgrenzung von der unsystematisch betriebenen Liebhaberei führte zur Steuerbarkeit des Geldwertes des Selbstverbrauchs, s. Fuisting, B. (1902), Grundzage ..., S. 112; Fuisting, B./Strutz, G. (1915), S. 537, S. 538; zu $\S 12$ preuB. EStG 1906, S. 336, S. 337 zu $\S 8$ Abs. 3 Ziff. 2 preuB. EStG 1906. May wies darauf hin, daß in Preußen Landwirte der Tradition gemäB nur das als Jahresverdienst betrachteten, was sie nach Jahresende auf die Bank bringen konnten. Dieser Meinung waren, 
e) Da nur die Früchte aus bestăndig fließenden, der Gütererzeugung dienenden Quellen als steuerbar galten, wurde eine spitzfindige Unterscheidung von Wertmehrungen des Stammvermögens und Einkommen bedeutungsvoll. Für die Einkommensteuer durften hiemach - sofern es sich nicht um Einkünfte bilanzierender Kaufleute handelte - nur die Früchte des Stammvermögens, nicht jedoch die Verändenungen des Wertes, der Quellen selbst, bei Verăußerungen erfaßt werden. ${ }^{124}$

Dies ergab sich aus den systemtragenden Prinzipien, die das ganze Gesetz durchzogen, und es galt unter Umständen auch bei den durch Bestandsvergleich für Kaufleute ermittelten Gewinnen, die dann durch Umrechnung zu bereinigen waren, ${ }^{125}$ da sie zu deren Privatsphäre gehörten.

f) Besteuert wurde das gegenwärtige Einkommen nach dem Ergebnis des abgelaufenen Steuerjahres. Maßgeblich für die Besteuenung war jeweils der Bestand der Einkommensquellen am 1. April, dem Beginn des Steuerjahres. ${ }^{126}$

g) Der Versuch vieler gutsituierter Steuerpflichtiger, Aufwendungen für ein standesgemäßes Steckenpferd, etwa đie Jagdausübung, mit positiven Einkünften zu saldieren, führte in der Finanzrechtsprechung des Oberverwaltungsgerichtes zur Entwicklung des Rechtsinstitutes der "Liebhaberei". Die Finanzrechtsprechung betonte die strenge Beschränkung der Besteuerung auf das Markt- oder Erwerbseinkommen und schloß den Verlustausgleich durch Auslegung der "Einkommensquelle" in der Landwirtschaft aus. ${ }^{127}$ Anders als in Sachsen waren nunmehr in Preußen auch die Entnahmen von "Erzeugnissen der eigenen Wirthschaft" in diesen Fällen nicht mehr steuerbar, was bei geeigneter Gestaltung erhebliche Steuervorteile ermöglichen konnte, eine Gestaltung, die offenbar auch reichlich in Anspruch genommen wurde. Ein hoher Lebensaufwand konnte so, anders als in Sachsen, kostengünstig finanziert werden, ohne Steuern auszulösen. ${ }^{128}$

so deutete er an, auch viele Mitglieder der Einschälzungscommissionen, May, R. E. (1903), S. 123; ders. (1909), Volksvermōgen .... S. 148.

124 Siche: OVG in Staatssteuersachen, U. v. 19.6.08 IN VII-C-487-Rep. VII C - 395/07, in: E.OVG, 13. Bd., S. 137, hier S. 146, S. 147; s. Zirkularverfügung vom 10.12.91, in: Mitteilungen ..., Nr. 25, Jg. 1892, S. 4; s. Mitteilungen ... Nr. 40, Jg. 1900, S. 7.

125 Fuisting, B. (1894), S. 103 bis S. 106; Fuisting, B./Strutz, G. (1915), S. 597 bis 601: ders. (1917), S. 217, Bem. 14 und die angeführte Rechtsprechung.

${ }^{126} \S 10$ preuB. EStG 1891 bzw. $\S 9$ preuB. EStG 1906; s. hierzu: Fuisting, B. (1894), S. 84, Bem. 1-15; Fuisting, B./Strutz, G. (1917), S. 139, Bem. 3; s. insbes, Buck, L. (1909), S. 814.

${ }^{127}$ OVG in Staatssteuersachen, U. v. 14.12.1894, V. Senat, Rep. V 16/94, in: E.OVG, 3. Bd., S. 150, S. 153; OVG in Staatssteuersachen, U. v. 30.12.1905, V. Senat, Z.J.N DX 68 - Rep. DX 41/05, in:

E.OVG, 12. Bd., S. 101.

128 Im Falle der Liebhaberei waren Einnahmen nicht steuerbar und Ausgaben nicht abzugsfahig, da es an einer beständigen Einkommensquelle mangelte. Dazu fehlte die erkennbare nachhaltige Absicht 
h) Die obligatorisch abzugebende Steuererklärung - bei Versăumnis drohte eine Benachteiligung - war nicht die wesentliche Grundlage des Einschälzungsverfahrens. Sie war nur ein Indiz unter vielen der durch die Behörde zu sammelnden und amtlich zu bearbeitenden Informationen über das steuerbare Einkommen. ${ }^{129}$ Durch das in $\S 38$ Abs. 2 preußisches EStG 1891 vorgeschriebene Beanstandungsverfahren wurde die Bedeutung der.Einkommensteuererklärung de facto stark entwertet. ${ }^{130}$

i) Das Steuerstrafrecht sah für die Abgabe falscher Erklärungen im Unterschied zu dem sächsischen Muster eine Geldstrafe nur vor, wenn tatsächlich bewußt Steuern verkürzt worden waren. ${ }^{131}$ Das Reichsgericht bestätigte gelegentlich als Beschwerdeinstanz diese gravierende, die Systematik entwertende Differenz zu dem săchsischen Muster, ${ }^{132}$ Es handelte sich beim preußischen Steuerstrafrecht ohnehin um Verwaltungsstrafrecht. Bestraft wurde die Nichtbeachtung von Vorschriften, nicht der Betrug gegenüber der Gemeinschaft der Steuerzahler durch Herbeiführung einer ungesetzlichen Lastenverteilung. ${ }^{133}$

j) Abweichungen in den Veranlagungen gegenüber den Erklärungen von Seiten der Einschätzungscommissionen setzten ein von der Verwaltung durchzufiuhrendes, spitzfindig geregeltes, formales und langwieriges "Beanstandungsverfahren" voraus. Dies mußte formgerecht eröffnet und durchgezogen werden. ${ }^{134}$ Es gab den Steuerpflichtigen die Möglichkeit, die Steuererklärung absolut gefahrlos wie einen "Schleiertanz" vor der Behörde zu handhaben und

zur Erzielung von Erträgen, sei es zum Hausverbrauch oder zur Erzielung von Unterhaltsmitteln. Letatlich konnte diese Beurteilung von Steuerpflichtigen, planvoll berücksichtigt, zu erheblicher Verbilligung von Luxusaufwendungen verwendet werden. Dies geschah und geschieht bis heute forlaufend. Demgegenüber konnte in Sachsen die Ausübung einer Liebhaberei, z. B. des Jagdrechts, als steuerbare Entnahme aus der eigenen Wirtschaft zum marktublichen Preis der Jagdpacht besteuert werden. Im Falle einer Besteuerung nach dem Verbrauch konnte die Austiłung als Indiz for die Leistungsfahigkeit die Bemessungsgnundlage erhöhen.

129 Zirkularverfugung Nr. 37 v. 20.11 .1891 , in: Mitteilungen ..., Jg. 25, S. 48; Wagner, A. (1891) S. 767. Fuisting, B. (1896), S. 562; ders. (1903), Reformbedarfligkeit ..., S. 381; s. auntl. Begrethdung von $\$ \S 24$ und 25 preuß. EStG 1891 , in: FA. 7. Jg. 1890. S. 688.

${ }^{130}$ Meisel, F. (1911), S. 353. S. 360; Michaelis (1912), S. 83; Wachler, P. (1912), S. 353; Meyer, R. (1903), S. 127.

${ }^{131} \S 66$ Abs. 1 preuß. EStG 1891 bzw. $\$ 72$ Abs. 1 preuß. EStG 1906; vgl. hiermit $\$ 68$ Abs. 1 und $\$ 70$ sãchs. EStCi $1874 / 78$.

132 RGSt. U. v. 25.6 .1909 g. v. W. IV $301 / 09$, in: E.RGSt, 42. Bd. 1909 s. 376, S. 378, s. a. Fuisting. B. (1903), Einkommensbesteuerung ... \&. 266; Meisel beklagte die geringe Elfizienz der Vorschriften zum Strafrecht als Prävention, s. Meisel, F. (1911). S. 349; Michaelis bestatigte Meisels Auffassung, aus praktischer Erfahrung Michaelis (1912), S.91.

133 Schneider, V., S. 45: Die steuerstrafrechtlichen Bestimmungen dienten, anders, als in Sachsen, allein dem Anspruch des Staates auf Beachtung der Vorsehriften; Pollack, F. (1911), S. 73.

134 $\$ 38$ Abs. 2 preuB. EStG 1891 bzw. $\$ 37$ Abs. 2 preuB. EStG 1906; hierzu: Art. 55 Ausfuh rungsanweisungen v. 5.8.1891, in: Futsting, B. (1894), S. 358; dazu Formular-Muster XI und XII, S. 471. 
zu versuchen, die Behörde bei der amtlichen Ermittlungstätigkeit zu tăuschen, indenn der geschickt formuliert erklärte Sachverhalt dazu diente, die Tatsachen des wahren Sachverhalts zu verbergen. ${ }^{135}$

Falsche Überzeugungen der Behörde konnten für den Steuerpflichtigen von immensem Nutzen sein. Im Falle einer drohenden Entdeckung war de facto stets eine Richtigstellung straffrei möglich. Die Praxis machte von diesen Schwachstellen offenbar einen regen und fast risikolosen Gebrauch. ${ }^{136}$

k) Die Leiter der Einschătzungs- und der Berufungskommissionen waren durchweg Juristen mit der Qualifikation zum Richteramt. Ihnen mangelten infolge ihrer Ausbildung die praktischen wirtschaftlichen Kenntnisse. Über diese verfugiten oft nur die Mitarbeiter des Büropersonals, die zumeist als inkompetente "Subalternbeamte" beurteilt wurden. Die Vorstellung des "judex non calculat" beherrschte vielfach auch die Denkweise der Finanzbehörde. ${ }^{137}$

1) Leiter der Einschătzungskommission war obendrein jeweils der Landrat, der mit den Bürgern durch politische Interessen verfilzt und überfordert war. Dies stand im Gegensatz zu den săchsischen Verhăltnissen, wo wirtschaftlich geschulte unabhăngige Finanzbeamte die Tătigkeiten ausübten.

Die für die Veranlagungstătigkeit tragenden juristischen Gesichtspunkte waren zum großen Teil auf die Aktivitäten Fuistings zurückzuführen, der, in die Tradition der preußischen Einkommensbesteuenung eingebunden, fest glaubte, der Rechtsschutz der Steuerpflichtigen sei erweiterungsbedürftig, denn der Steuerzugriff sei nach eingriffsrechtlichen Gesichtspunkten zu beurteilen. ${ }^{138}$

135 Hierzu: Meisel, F. (1911), S. 363, S. 370; Michaelis (1912), S. 80, Mrozek, A. (1909), S. 267 u. a.

136. Meisel, F. (1911), S. 340, S. 341 ; s. Mitteilungen ..., Nr. 40, S. 88 ; s. hierzu die in den Mitteilungen veröffentlichten Aufstellungen 0̈ber Beanstandungs- und Strafverfahren.

${ }^{137}$ Fuisting, B. (1894), S. 174, S. 175, Bem. 1 u. 2 zu \$ 37 preuB. EStG 1891 . Aus dem Begriff "Holfsbeanter" in $\$ 37$ preuB. EStG 1891 (\$38 preuB. ESiG 1906) wurde in den Konmentierungen abfatiig. "Subalternbeanter", vermutlich, weil ihnen die Qualifikation zum Volljuristen mangelte. Es wurde in Konmentienungen darauf hingewiesen, daB den "subaltemen Hulfskrafften" keinerlei, auch nicht geringste Entscheidungsbefugnisse zustanden. Durch Urieil des OVG v. 20.3 .1902 wurde sogar festgeschrieber, daß diese offenbar gelegentlich als. Folge ihrer zumeist wirtschaflich ausgerichteten, durch Berechnungen, Vergleiche und Kalkulationen einzig sachkundigen Hülfsbeamten niemals als sachverstandige Gutachter eingesetzt werden dörtten, hierzu: Fuisting, B. (1894), S. 174, S. 175; Fuisting, B./Strutz, G. (1915), S. 896, Anm. 2 u. 3; ders. (1917), S. 337; Mrozek, A. (1909), S. 260. Gelegentlich wurde beklagt daß Vorsitzende der Einschätzungscommission vom Büropersonal atr hilingig waren und die Mitarbeiter Entscheidungen treffen ließen, s. hierzu: Zirkularverfugung Nr. 30 v. 23.8.91, in: Mitteilungen ..., Nr. 25, S. 35, mit dem Tenor "Zuweisung staatlicher Subalternbeamten".

138 Fuisting, B. (1896), S. 293, insbes. S. 564. Meisel wies darauf hin, daB das von Fuisting perfektionierte und durch Urteile des OVG bestatigte Beanstandungsverfahren die Stellung der Finanzbehörde als Partei bei Wahmehrnung ihrer Aufgabe gegenaber dem Steuerpflichtigen so schwächte, daß sie ihren gesetrilichen Verpflichtungen nicht mehr entsprechen konnte, Meisel, F. (1911), S. 352; s. a. Buck, L. (1911), S. 79, S. 80; ders. (1916), S. 82, Justus (1897), S. 62. Hinzu kam, dab die zeich- 
Hohe Finanzbeamte und Hochschullehrer, wie Gustav Schmoller, Hans Dellbrück, Franz Meisel, Watter Moll, Alfons Mrozek, Michaelis und viele andere, haben vergeblich unter Hinweis auf konkrete Vorgânge die sozialen Unzuträglichkeiten bei der Veranlagung zur preußischen Einkommensteuer beklagt. Dabei zeigt sich in der Berichterstattung die Eigentümlichkeit, daß ständig auf eine angeblich fragwürdige Beratungstätigkeit durch Sachkundige und Buchführungsstellen hingewiesen wurde. Gelegentlich wurde von absurden Differenzen zwischen dem von den Steuerpflichtigen selbst geschătzten und dem vom Sachverstăndigen als erklărungspflichtig bezeichneten Einkommen berichtet. ${ }^{139}$ Trotz abfalliger Bemerkungen ist jedoch nie von nachgewiesenen Verfehlungen oder gar von Strafverfahren gegen sachkundige Berufsträger berichtet worden. In den Darstellungen wird auch nicht zwischen legaler Steuervermeidung dienenden Dispositionen und unterschwellig angedeuteter Steuerhinterziehung unterschieden. Offensichtlich machten Berater in ihren Empfehlungen von den Gesetzesbestimmungen einen zulăssigen Gebrauch. Daß sie Konjunktur erlebten, ist daher wohl verstandlich. Dies konnte aber allgemein zu aufgestauten Verärgerungen führen, da es nur wenigen Sachkundigen gestattet war, an der Konstruktion des preußischen EStG vorsichtige Kritik zu üben. $^{140}$

Viele Beiträge sachkundiger Berichterstatter hinterlassen jedenfalls den Eindruck eines tiefen Mißtrauens in die soziale Ausgewogenheit des preußischen EStG von 1891, das nach ständigen amtlichen Bekundungen an dem Prinzip einer Besteuerung nach der Leistungsfähigkeit ausgerichtet war. ${ }^{141}$ "Wie dem im übrigen sein mag, gegenwärtig werden im Rahmen der Einkommensteuer eigentlich nur die Lohnarbeiter und Festbesoldete ziffernmäßig genau belastet", so führte der Direktor der Berliner Veranlagungskommission und langjähriger leitender Mitarbeiter in der Finanzverwaltung nach über 20jăhriger Geltung des Gesetzes aus. ${ }^{142}$ Obendrein beklagte er - selbst hoher Beamter und

nungsberechtigten Finanzbeamten eine juristische Ausbildung abgeschlossen haben muBten, s. Cuno (1902), Gesetzentwurf aber die Befahigung für den höheren Verwaltungsdienst, in: PreuB. Verw.Blatt, S. 529.

${ }^{139}$ Delbrick, H. (1909). 136. Bd., S. 169; Michaelis (1912), S. 76; Mrozek, A. (1909), S. 268. Mrozek zeigt sich verärgert, daß das Klientel der Steucrbüros schnell anwuchs, da ihre Tătigkeit die Mandanten sehr befriedigen konnte.

140 Unter dem Pseudonym "Justus" übte im "Finanzarchiv" 1897 ein hoher preußischer Finanzbamter durch zynische Formulierungen und durch Vergleiche der hehren Absichten des Gesetzgebers mit den feststellbaren Konsequenzen des EStG 1891 in der Realităt harte sachliche Kritik. Offenbar sah Justus Grunde, sein Pseudonym zu wahren, s. Justus (1897), S. 58 Anm.

141 Siehe: Die preuB. Steuergesetzentwürfe .... S. 13, S. 14; s. a.: Begründung zum Entwurf eines EStG v. 3.11.1890, Aktenstūck Nr. 5, abgedr. In: FA, Bd. 7 1890, S. 264.

142 Moll, W. (1918), S. 103. Diese unzumutbare Mehrbelastung von Mittelstand und Festbesoldeten als Folge von Steuervermeidungen, die er offenbar als unvermeidlich beurteilte, hatte Fuisting vorher-

6 Hansen 
Jurist mit Qualifikation zum Richteramt - ebenso wie Clemens Delbrück die rein juristische, anstelle einer wirtschaftichen Ausbildung der Finanzbeamten in Preußen, die den anstehenden Problemen bei den Veranlagungen einfach nicht gewachsen seien. ${ }^{143}$

Ein bekannter Steuerrechtslehrer hat zur Feier des 100jährigen Geburtstages des preußischen EStG von 1891 einen anonymen Kritiker des Gesetzes aus dem Jahr 1897 zitien, der von dem "trefflichen Aufbau" des Normengefüges sprach. $^{144}$ Dabei hat er jedoch übersehen, daß die Bemerkung des Autors zy. nisch gemeint war. Der Autor, ein hoher Finanzbeamter, beklagte anonym in seinem Beitrag die unsozialen Auswirkungen des von strenger Systematik geprägten Gesetzes. ${ }^{145}$

Das Gesetz mit dem "trefflichen Aufbau" und die "kunstvolle Mosaikarbeit der von deutscher Gründlichkeit erfültten zugehörigen ministeriellen Anweisung" vermochte Sachkenner gewiß nicht zu erschrecken. Bereits die Lektüre von Aufsătzen leitender Ministerialbeamten. Finanzbeamten und Richtern in den Fachzeitschriften reichte zu, die gesetzlich vorgesehenen Steuerbelasturgen durch formaljuristisch spitzfindige Konstruktionen so zu umgehen, das der gestaltete Sachverhalt sich nicht unter die "trefllich" ausgefeilten Tatbestandsmerkmale subsumieren lieB. ${ }^{146}$

Hier einige Beispiele zur Erläuterung:

Schon Gustav Schmoller hatte warnend festgehalten: "Wollte man auf das, was aus dem Tauschverkehr der Volkswirtschaft in die Privatsphäre herein-

gesehen und nach langerer Erfahrung als Gerichtsherr beaobachtet. Er trat daher 1903 für eine Reform des preuß. EStG 1891 cin. Verstāndnis fand er für seine Kritik nicht, s. Fuisting, B. (1903). Einkommensteuer .... S. 9; ders. (1902), Grundzuge .... S. 270, S. 304; von Mayr, G. (1904), S. 19I; Strutz, G. (1908), S. 427: Fusting, B. (1906), Zeit- und Streitfragen, S. 1, S. 2.

${ }^{143}$ Moll, W. (1918). S. 99; Delbrück, C. von (1917), S. 11: Michaelis (1912), S. 84, S. 85, S. 98; Mrozek, A. (1909), S. 274.

146 Bayer. H. W. (1991), S. 336

14 Justus (1897), S. 536: S. 544.

146 Das preul. ESIG 1891 hatte insofern einen "trefllichen Aulbau", als es den von Rau aber Wagner aus dem Gedankengul der klassischen Nationalǒkonomie herausdestilierten Grundgedlanken für die Definition steuerbaren Einkommens streng fortgeführt systematisiente. Der die Systematik störenđe Fremdkörper einer regelwidrigen, aus dem sāchs. Muster übernommenen Fimittlungsvorschrift für Einkunfte aus Handel und Gewerbe konnte zusammen mit der fragwürdigen Orientierung des Gesetzes dem Laien bezüglich der Folgewirkungen verborgen bleiben, zumal alles; "vom theoretischen Standpunkt aus betrachtet recht hübsch" gestaltet war, Justus (1897), S. 61. Annı. 1. Für Wagner und Fuisting hatten nicht, Uberlegungen empririsch @̈berprüter Zweckmãßigkeit, sonđern rechtsdogmatische Richtigkeit im Vordergrund gestanden. Ein fachkundiger Kritiker hielt 1904 fest, daB Fuisting "der deduktiven Geistesarbeit ein größeres Maß̣ von Einfluß auf seine Entscheidungen einrăumt, ais nach der tatsăchlichen Lage der Verhältnisse und insbesondere nach Maßgabe besonderer Erwägungen vernünftiger Steuerpolitik gerechtfertigt ist", von Mayr, G. (1904), S. 192. 
kommt, den Einkommensbegriff beschränken, so würde damit dem reichen Hofbauer, der auf eigener Scholle reichlich lebt aber wenig kauft und verkauft, ein kleineres Einkommen zugesprochen, als dem armen von seinem Gehalt lebenden Schulmeisterlein, der mit dem fünften Teil auskommen soll". ${ }^{147}$ Die grundsătzliche Beschrănkung der Besteuenung auf das Markteinkommen war eines der systemtragenden Prinzipien für den Einkommensbegriff des preußischen EStG und ist es bis heute geblieben. Eben zu Schmollers umfassenderem Einkommensbegriff hatte Adolph Wagner wie Fuisting in seinen Lehrbüchern stets in Fußnoten Widerspruch angemeldet. ${ }^{148}$ Sehen wir uns die Konsequenzen an:

Ein Rittergutsbesitzer in Preußen legte im Normalfall Wert darauf, nur insoweit am Marktgeschehen durch Kăufe und Verkăufe teilzunehmen, wie es die notwendig aufzubringenden Kosten für den Betrieb des Gutes und die durch Geldausgaben zu bestreitende Lebenshaltung erforderten. Letztlich waren auch die Aufwendungen für einen repräsentativen Lebensstil, wie Kutsche, Reitpferd, Bewirtungen etc., ohnehin durch nicht steuerbare Naturalentnahmen gesicher. ${ }^{149}$ Aufwendungen für teure Luxusliebhabereien, wie Spielschulden in Monaco (sic!), Ausstattung der heiratenden Tochter oder des Sohnes als unterbezahltem Kavallerieoffizier (von Delbrück erwähnt), konnten etwa zum Beispiel durch einen außergewöhnlichen Holzeinschlag, den Verkauf von Herdbuchvieh oder eines Hengstes oder auf ähnliche Weise finanziert werden. ${ }^{150}$ Bei geschickter Durchführung war dies problemlos steuerfrei móglich,

${ }^{147}$ Zitiert nach: Wilbrandt, R. (1908), S. 27.

148 Wagner, A. (1876), S. 97; ders. (1879), S. 115; ders. (1892), S. 405, S. 406

149 Der in $\$ 7$ preuB. EStG 1891 bzw. $\$ 6$ preuB. EStG 1906 aufgeführte Katalog fulurte abschlieBend auf, was allein steuerbar war. Anders, als nach dem sächs. EStG 1874/78, waren entsprechend dem Grundgedanken des Gesetzes "zum Haushalt verbrauchte Erzeugnisse der eigenen Wirthschaft" (\$ 15 Abs, 1 săchs. EStG 1874/78) nicht steuerbar, da nicht ausdrücklich aufgefulhrt. Allerdings durften andererseits nach $\S 9$ Abs. 2 Ziff. 2 preuB. EStG 1891 bzw. $\$ 8$ Abs. 3 Ziff. 2 preuß. EStG 1906 die "zum Unterhalt gemachten Ausgaben einschließlich des Geldwerthes der ... verbrauchten Erzeugnisse und Waaren des eigenen landwirthschaflichen oder gewerblichen Betriebes" bei Ermittlung der Bemessungsgrundlage nicht in Abzug gebracht werden. Der Unterschied der beiden Regelungsmuster war erheblich, da viele Naturalien, wie etwa das erlegte Wildbret oder nicht systematisch gezüchtetes Kleinvich, bei Bedarf in Gewässem gefangene Fische etc. keinerlei Einsatz von Aufwendunge benötigen, wohl aber ein Indiz für Leistungsfahigkeit darstellen. Fôr die Besteuerung der Landwirte gab der ḋem preuß EStG 1891 innewohnende Grundgedanke. der im Besteuerungsgegenstand des Gesetzes keinerlei Konkretisienung gefunden hatte. keine geeignete Grundlage. Die Auslegung des Begriffs einer bestehenden "Einkommensquelle" konnte nicht weiterhelfen, s. Art. 11 der Ausfuhrungsanweisungen...; s. Fuisting. B. (1896), S. 479; s. Buck, L. (1917), S. 70. Dem Großgrundbesitzer konnte es daher leichtfallen, sich der Besteuerung fast gănzlich zu entziehen. Dem kleinen Bauem mit vielen Kindern konnte dies nicht gelingen, wie Fusting aufzeigte; Fuisting. B. (1896), S. 479. S. 480.

So konnte z. B. ein Holzeinschlag mit erklärter Absicht des Verzichts der Wiederaufforstung etwa wegen einer Umwandlung des Gelăndes in eine andere Nutzungsart zu steuerfreien Eriōsen füren, s. U. OVG XIII b 10 v. 31.5.1902, in: DJZ, III. Jg. 1903, S. 34. Nach stândiger Rechtsprechung haben Holzverkãufe als Folge von Windbruch ebenso zu Steuerfreiheit gefụhrt, đa unterstellt 
da es sich bei geeigneter Darstellung um die nicht steuerbare Veräußerung von Wirtschaftsgütern des Stammvermögens handelte. Dies ist wiederholt in Urteilen bestătigt worden. Der Argwohn Delbrücks gegen dieser Art Vorgănge, der 1909 in den "Preußischen Jahrbüchern" offensichtlich ohne zureichende Sachkenntnis der gesetzlichen Zusammenhänge nach Ausdruck suchte, betraf im Grunde die Besteuerungssystematik. Ehrenrührige Verdächtigungen gegen Gutsbesitzer wurden von ihm auch nicht unmittelbar geăußert. Der Vorsitzende einer großen Einschătzungskommission verteidigte die Landwirte mit groBem Pathos, von statistischen Aufstellungen unterstützt, in "Schmollers Jahrbuch" 1910 völlig zu recht vor diskriminierenden Vorwürfen, ${ }^{151}$ wobei Schmoller in einer langen Anmerkung seine sozialen Bedenken gegen die Systematik des preußischen EStG 1891 einbrachte. ${ }^{152}$ In Sachsen liefen die Uhren offensichtlich völlig anders, wie sich aus der oben zitierten Äußerung des Lehrstuhlinhabers für landwirtschaftliches Abrechnungswesen der Universităt Leipzig ergibt. ${ }^{153}$

Weitere Beispiele: In Preußen waren nur die Früchte aus einer fortdauernd fließenden Quelle der Gütererzeugung steuerbar. Daher fielen einmalige Gelegenheitsgeschăfte nicht unter die Besteuerung. Nun lassen sich aber im Grunde fast alle Vereinbarungen zu Gelegenheitsgeschäften - falls opportun - in eine "ad hoc"-Gesellschaft umfunktionieren. ${ }^{154}$ Die Besteuerung für das laufende Jahr erfolgte jeweils nach eben den Tatbestandsmerkmalen zum 1. April entsprechend der Bemessungsgrundlage des abgelaufenen Steuerjahres. Unternehmen konnten als Quellen der Gütererzeugung aber vor dem 1. April des laufenden Jahres aufgelost, umgegründet oder durch einen Beteiligungswechsel so verăndert werden, daß die für die Gesetzesauslegung zustanndigen Juristen von einer Beendigung der alten Quelle sprachen. ${ }^{155}$ Das Ende der Quelle

wurde, daß es sich um Stammvermōgen handele, s. Fuisting. B./Strutz, G. (1915), S. 544, S. 545 ; s.U. OVG v. 2.5.1899, J. N. VI/35/V23 - RP VI 12/97, in: EOVG, 8. Bd., S. 49; s. Vfg. V. 2.5.1899, in: Mitteilungen .... Heft 40, S. 7.

191 Behrnauer, F. (1910), Konservative .... S. 675, S. 679.

152 Schmoller, G. (1910), Anm. zu Behrnauer, F. (1910). Schmollers Jb., S. 1581, S. 1582.

158. Howard, H. (1889), S. 7; s. Anm. 87.

134 Fur die Entstehung von ESt war das Bestehen einer Einkonmensquelle in Sime des Katalogs der Einkunftsarten des $\$ 7$ preuB. EStG 1891 bzw. $\$ 6$ preuB. EStG 1906 erforderlich. Gleiches galt für die Geltendmachung von abragsfahigen Ausgaben gernäß $\$ 9$ preuB. EStG 1891 bzw. $\$ 8$ preuB. EStG 1906. Dabei muBte es sich um Quellen haudeln, aus denen ein bestândiger Früchteflu $B$ zu erwarten war, s. Dröge (1908). S. 46: Weißenborn, H., S 705; s. a. Fuisting, B./Strutz, G. (1915), S. 162, S. 163, S. 187.

15s Nur das Bestehen einer bestandigen Einkunftsquelle am 1.4. eines Jahres fuhrte jeweils zu einer Besteuerung. Einkunftsque!len, die vorher beendet wurden, fanden keine Berücksichtigung. Bei einem preußischen Beamten des höheren Dienstes galt das ihm übertragene "Kommissarium" (Amt) als Einkommensquelle. Wurde er als Gerichtsassessor z B. erst am 2.4. eines Jahres mit einem Amt betraut, so ging \& mithin steuerfrei aus. Es war daher sinnvoll, Einkommensquellen vor dem 1 . April 
zum Stichtag bedeutete dann, daß der Ansatz des Gewinns bei der Besteuerung zu Recht unterblieb. Nach den Vorstellungen Wagners und Fuistings waren derartige kurze Zeit wăhrende oder gar einmalige Wertzugănge ex definitione kein Indiz für Leistungsfähigkeit und somit nicht steuerbar. Grobe Vermōgen entstanden auf diese Weise im Krieg.

Bei Beamten war nach der Rechtsprechung die Quelle in der Berufung in das konkrete Amtsverhăltnis zu sehen. ${ }^{156}$ Auch hier konnte man durch geschickte Veränderungen des Termins der Öbertragung der amtlichen Funktion daher den Nichtansatz der Früchte aus der Quelle bei der laufenden Besteuerung bewirken. Für Beamte des höheren Dienstes konnte sich die Lektüre des "Preußischen Verwaltungs-Blattes" somit als sehr nützlich erweisen.

Bei Einkūnften aus Kapitalvermögen war nach Auslegung des Gesetzes jedes einzelne Darlehens- oder Dividendenguthaben an einer Gesellschaft oder die einzelne konkrete Hypothekenforderung durch Uirteil als separate Quelle bestimmt worden. Fälligkeit, eine Kündigung oder eine sonstige Disposition vor dem 1. April und gegebenenfalls eine Wiederanlage eigneten sich vorzüglich für interessante Gestaltungen zur Steuerersparnis. Robert Meyer beklagte die zugrundeliegende Regelung bereits 1903 nach Übernahme des preußischen EStG 1891 in Österreich. Zu Konsequenzen fuhrte die Kritik, die die Systematik betraf, nicht. ${ }^{157}$

Spekulationsgeschäfte waren gegen den Rat Fuistings als steuerbare Vorgănge in den Gesetzestext aufgenommen worden. Dabei wurde die innere, interpersonell nicht überprüfbare Intention des Steuerpflichtigen in dem gesetzlichen Tatbestand als notwendiges Merkmal festgelegt. ${ }^{158}$ Die Konsequenz war, daß nur bei Verlusten diese zur Verärgerung Fuistings regelmäßig von den Steuerpflichtigen in die Erklärungen aufgenommen wurden, so daß sie mit positiven Einkünften aus den übrigen Einkunftsarten saldiert werden konn-

eines Jahres auslaufen zu lassen, s. Dröge (1908), S. 46; Buck, L. (1909), S. 814; s. a. $\$ 9$ Abs. 1 preuB. EStG 1906; s. a. OVG, U, v. 13.10.1906, in: DJZ XII. Jg. (1907), Sp. 887.

156 Hierzu: Weißenborn, H. (1907), S. 706, S. 707; s. a. Fuisting, B./Strutz, G. (1915). S. 162, S. 163.

157 Meyer hatte bei Wagner und Schmoller in Berlin studiert. Als Sektionschef war er zur Zeit der Einführung der Personalsteuer in Osterreich der zustlandige Referent im Wiener Finanuministerium. Als Praktiker sah er frùhzeitig die Schwächen des preuB. EStG 1891, s. Meyer, R. (1901), S. 692; ders. (1903), S. 125. Ab 1917 wurde eine Änderung für die Kriegszeit eingeführt.

${ }^{158}$ Hierzu: $\S 12$ Abs. 2 Ziff. 3 u. $\S 14$ Abs. 2 Ziff. 3 preuB. EStG 1891 bzw. $\S 11$ Abs. 2 Buchst. d) u. $\$ 13$ Abs. 2 Ziff. 4 preuB EStG 1906; hierzu: Wagner, A. 1891), S. 692; ders. (1892), S. 67. Wagners Einstellung ist widersprüchlich und unsicher, Fuisting, B. (1903), Reformbedarftigkeit ..... S. 232; Friedberg (1903), S. 570; Witthoef? (1893), S. 207. 
ten. ${ }^{159}$ Die Erklärung von positiven Einkünften wurde jedoch durchweg unterlassen. Das Vorhandensein oder Fehlen der im Gesetz normierten Tatbestandsmerkmale, hier der Intention zur Spekulation im Sachverhalt, konnte vom Finanzamt letztlich nur durch Befragung der Pflichtigen überpnüf werden, was stets zum selben Ergebnis führte und sehr verständlich ist. Die Zensiten wußten ihre Interessen jeweils gut zu vertreten. Ohne positiven Nachweis eines konkreten Investments als Quelle durfte aber die Verwaltung nach ständiger Rechtsprechung keinen Zufluß schätzen. ${ }^{160}$

Angesichts gerade dieser Umstănde war es nicht abwegig. wenn der spăter sehr einflußreiche, Wagners Denkansă̈tze fortführende Schüler F. J. Neumanns, Alexander Hoffmann, im Jahr 1920 blauăugig die Fortschrittlichkeit des preußischen EStG von 1891 gegenüber dem săchsischen EStG mit dem Argument hervorhob, daß darin auch die Besteuerung von Spekulationsgewinnen gewăhrleistet sei. ${ }^{161}$ Ihm blieb offenbar verborgen, daß Wertzuflüsse nach dem săchsischen EStG 1874/78 unabhängig von der Herkunf bei Realisation grundsătzlich steuerbar waren. Nur formell hatte er daher recht. Hoffmann benutzte das Argument in seiner erfolgreichen Philippika gegen die 1919 wegen der sozialen Unausgewogenheiten in Angriff genommene Umstellung des preußischen EStG von 1891 auf ein von den Schmollerschen systemtragenden Prinzipien geprägtes Reichseinkommensteuergesetz 1920 durch Matthias Erzberger. $^{162}$

Obwohl die Finanzverwaltung zwar die Höhe der Einkünfte aus Kapitalvermögen vermittels bekanntgewordener steuererheblicher Randumstände nach der Rechtsprechung hochschätzen durfte ${ }^{163}$ haben die Einschảtzungskommissionen grundsătzlich davon absehen müssen, bei mangelnden Angaben des Steuerpflichtigen das Bestehen von Quellen ohne konkreten positiven Nachweis von Einzelheiten zu unterstellen und damit Einkünfte aus Kapitalvermögen durch Schätzung festzusetzen. Das führte automatisch dazu, daß das Veranlagungsverfahren bei begüterten Steuerpflichtigen, die sich von Fachleuten beraten ließen, quasiforensische Züge erhielt. ${ }^{164}$

159 Mrozek, A. (1909), S. 266. S. 276: Fuisting, B. (1903), Reformbedürfligkeit .... S. 232: ders. (1906) Sp. 1170.

${ }^{160}$ Michaelis (1912), S. 70; Fuisting, B. (1903), Einkommensbesteuerung .... S. 383: ders. (1896), Rechtsschuiz ..., S. 383, S. 459, S. 462.

${ }^{161}$ Hoffmann, A. (1919), S. 8 .

${ }^{162}$ Hoffmann, A. (1919). S. 7.

${ }^{163} \S 38$ Abs. 3 preuB. EStG 1891 bzw. $\S 40$ Abs. 5 preuf. EStG 1906; dazu: Art. 58 Ausfuhrungsanweisung v. 5.8.189!, in: Fuisting, B. (1894), S. 365, S. 366; ders. (1896), S. 459, S. 568; Fuisting, B./Strutz, G. (1915), S. 918 , Anm. 7.

${ }^{104}$ Meisel, F. (1911), S. 352, S. 361, S. 362; ders. (1914), S. 637; Waldecker, L. (1914), S. 61. 
Zu erwăhnen sind noch die Gestaltungsmöglichkeiten. die das Recht zur entgeltlichen oder unentgeltlichen, befristeten oder sonstwie zeitlich geregelten, von Formvorschriften nicht behinderten Ubertragung des Nießbrauchs an Rechten, Sachen oder Sachinbegriffen (ususfructus, quasiususfructus) ${ }^{165}$ gewăhrte. Da nach dem preußischen EStG nur auf die formelle Rechtsposition des Steuerbürgers abzustellen war, konnte dieses Rechtsinstitut insbesondere zur steuerfreien Tilgung von Schulden, etwa Unterhaltsverpflichtung, Ausbildung des Sohnes, Aussteuer der Tochter etc., Verwendung finden. Dabei waren für den Zensiten zusätzlich günstige Regelungen bezüglich der mit den Bezugsrechten notwendig verbundenen Aufwendungen möglich. Das war erreichbar, weil die Bemessungsgrundlage des preußischen EStG nach dessen Auslegung nicht, wie in Sachsen, auf die wirtschaftiche Bereicherung des

165 Das bis zur Einfuhrung des BGB gultige Allgemeine Landrecht fur die PreuBischen Staaten bot in seinen Bestimmungen des 21 . Titel des ersten Theils in den $\$ \S 1$ bis 183 die Grundlage fur einen breiten Flacher von steuerlich interessanten privatrechtlichen Gestaltungsmöglichkeiten zur Losung konkreter Vorgalnge. Von der gewalhrten Privatautonomie wurde mit wachsendem Wohlstand als Folge der Industrialisierung zunehmend Gebrauch gemacht. Die neuartige Einkommensteuerbelastung konnte hier zusaltzliche Anreize schaffen. Viele der in impressionistischen Darstellungen der Tagespresse als skandalōs hochgespielte Berichte uber das erkllirte geringe steuerbare Einkommen hochbeguterter Zeitgenossen - eine Fundgrube fur Politiker zur Diffasnierung politischer Gegner - verlieren bei Berücksichtigung der gesetzlich gegebenen und in Anspruch genommenen Gestaltungsmöglichkeiten für den Fachmann ihren als illegal ausgegebenen, weil unsozial, ja sogar gegebenenfalls kriminellen Beigeschmack (ein gutes Beispiel ist die Darstellung, die Gerlach 1910 von seiner Tatigkeit als Regierungsassessor bei der Veranlagung Bismarcks festhielt; sie hat vielen Historikern als Beleg für ideologisch vorgeprägte und dogmatisch vertretene Beurteilungen gedient, s. von Gerlach, H. (1910), S. 48, S. 49. Die Orientierung der preuB. EStG stellte nach der ihr vorgegebenen Rechtsdogmatik allein auf rein formalistische Tatbestandsmerkmale im Sachverhalt ab, die jeweils in der Praxis durchweg unabhängig von den gegebenen wirtschaftlichen Bereicherungen auf Vertragsbasis gestaltbar waren. So vermochte ein begateter Steuerpflichtiger in Preußen, anders als in Sachsen, ohne sein Vermōgen und seinen Lebensaufwand zu verändem, Regelungen mit steuerlichen Auswirkungen zu vereinbaren, die, nach seiner neuen steuerlichen Bemessungsgrundlage beurteilt, den fur Laien verwirrenden Eindruck erzeugen mußten, er nage am Hungertuch, hierzu: Maatz (1905), S. 309. Verschiedene der von Delbrück 1909 skizzierten gewiß problematischen Beispiele zur Besteuerungspraxis lassen sich dadurch erklăren, đaß vôllig legale Gestaltungen zu den in sozialer Hinsicht fragwürdigen Veranlagungen fuhrten. Behrnauer gab sich 1910 vergebliche Mahe zu versichem, daB Landwirte nach seiner Prufung der Vorzănge durchweg bei Anwendung des gettenden Steuerrechts gesetzlich korrekt veranlagt wurden, s. Behrnauer, F. (1910), S. 679 u.a.). Meisel hatte nach Erfahrungen mit der aus Preußen 1897 nach Ôsterreich importierten "Type" der Einkommensbesteuerung als Freund der Schmollerschen Sozialpolitik die amtliche Statistik zur Beurteilung der Ergebnisse der Besteuerungspraxis in dem Musterland Preußen verwendet. Da die rechisdogmatische Beurteilung ihn weniger interessierte, lenkte er seine Aufmerksamkeit auf die Veranlagungstechnik der "preußischen Type". Hier glaubte er den wesentlichen Grund für die vielfachen Măngel zu lokalisieren. Änderungen bewirkte Meisel durch seine Beitrage nicht, sondern ärgerliche Kritik. Denn letztlich konnte der Festbesoldete aus eigener Erfahrung bestätigen, was mit Einfuhrung des preuBischen ESIG als Absicht des Gesetzgebers versprochen wurde: wer höhere Bezäge erhielt, zahlte auch höhere Steuern, da er leistungsfahiger war. Sobald aber - und das entzog sich der Ubersicht des Normalbürgers - eine gewisse Einkommenshōhe erreicht wurde oder weitere Einkunitsarten hinzutraten, mußte diese Charakteristik für die "preußische Type" der Einkommensbesteuerung nicht mehr stimmen. Unabhängig von diesen Zusammenhangen eignete sich jedoch das Argument von der Einkommensteuer als einer Besteuerung nach der Leistungsahigkeit in Preußen vorzäglich dazu, das dic Begüterten einseitig begünstigende Besteuerungssystem in den A.ugen der Mehrheiten zu rechtfertigen und aufrecht zu erhalten. 
Steuerbürgers abstellte, sondern rein formal auf die Inhaberschaft an eine beständigen Einkommensquelle und dies sowohl für Wertzugänge (nach $\S$ EStG 1891 bzw. §ु 6 EStG 1906), als auch für abzugsfähige Ausgaben (gernä § 9 EStG 1891 bzw. § 8 EStG 1906). Die Berücksichtigungsfähigkeit wurd wesentlich von dem Bestand der Einkommensquelle bestimmt. ${ }^{166}$

Als besonders interessant und vorteilhaft für die Steuerbelastung entpuppt sich für weniger skrupelbefangene Steuerpflichtige die Veränderung, die da preußische EStG von 1891 an der ansonsten fast wörtlich übernommene sächsischen Vorschrift zum Steuerstrafrecht brachte. Diese entwertete gerade zu den Präventivschutz der Strafbewehrung im Zusammenhang mit der Ein führung des amtlich unabdingbaren, vor Abweichung von der eingereichte: Erklărung einzuleitenden Beanstandungsverfahrens. ${ }^{167}$

Wer eine falsche oder unvollständige Einkommensteuererklärung einreichte konnte damit rechnen, daß die Verwaltung vor Veranlagung bei beabsichtigte Abweichung von der Erklänung verpflichtet war, das formelle und umständli che Beanstandungsverfahren einzuleiten. Darin mußte die Absicht und di genau spezifizierte Begründung der Abweichung dem Steuerpflichtiges schriftlich zur Stellungnahme mitgeteilt werden. ${ }^{168}$ Drohte das Beanstan dungsverfahren trotz der Möglichkeit der Widerlegung durch Urkunden etc zu Ungunsten des Zensiten auszugehen, so konnte sich dieser stets noch ent schließen, die ursprünglich fehlerhafte Erklärung ohne Auslösung einer Strafe zu berichtigen. Konsequenzen gab es nicht, zumal die Verwaltung zufrieden war, einen Vorgang abschließen zu können. ${ }^{169}$

Diese Liste der Möglichkeiten, die Steuerbelastung zu verringern, könnte noch erheblich ausgeweitet werden. Es stand jedem Steuerpflichtigen offen, durch Lektüre der Aufsătze von führenden Finanzbeamten, wie Fuisting. Maatzen, Buck, Moll, Wilmowsky, Mrozek, Michaelis, Dröge. Rohde. Friedberg. Droste, Weißenborn und anderer, in der "Deutschen Juristenzeitung", dem "Verwaltungsarchiv", dem "Preußischen Verwaltungs-Blatt", ab 1912 der "Deutschen Steuer-Zeitung", dem "Finanz-Archiv" etc. sein Wissen um die ihm gegebenen juristisch spitzfindigen Dispositionsmöglichkeiten zu einer

\footnotetext{
${ }^{106}$ Hierzu: Fusting. B. (1894), S. 55; Fusting, B./Strutz, G. (1915), S. 304, S. 399.

${ }^{167}$ Hierzu: Meisel, F. (1911), S. 353, S. 370: ders. (1914), S. 638, S. 639; Justus (1897). S. 62: Wachler, P. (1912), S. 355, S. 356: Buck, L. (1916), S. 56, S. 57, S. 82.

${ }^{158} \$ 38$ Abs, 2 preuß. EStG 1891 bzw. $\$ 39$ Abs. 1 preuBl. EStG 1906; hierzu: Fuisting, B. (1906), Finanzpolitische .... S. 38, S 39. ders. (1894), S. 357; s. Art. 55 Ausführungsanweisung und Anlage Muster 11 und 12, in: Fuisting (1894), S. 471. S. 472; Fuisting, B./Strutz, G. (1915), S. 903, S. 911 , Anm. 6 bis 10 .

${ }^{169} \mathrm{~S}$. Beanstandung der Steuererklärung, in: Mitteilungen ..., Hef 40, Jg. 1900, S. 25 und S. 88, S. 89; Mrozek (1909), S. 264; Droste (1904), S. 349; Pollack, F. (1911), S. 98.
} 
legalen Herabsetzung der Einkommensteuerlast zu nutzen oder jedenfalls die Gefahr der Entdeckung von Hinterziehungen und deren strafrechtlichen Folgen abzuschătzen.

Es wurde bereits erwăhnt, daß der ehemals zustăndige Regienungskommissar, bei dem die Fäden der Verhandlungen bei der Beschlußfassung zum preußischen ESıG 1891 zusammenliefen und der später als Senatspräsident am preußischen OVG in Staatssteuersachen die allgemein benutzte Kommentierung zum Gesetz lieferte, ${ }^{170}$ mit dem Ergebnis des nach einigen Kompromissen verabschiedeten Gesetzeswerkes bald nicht mehr zufrieden war und dies zur Verärgerung konservativer Kreise vernehmlich vortrug. Der scharfsinnige Jurist erkannte offenbar als Folge der als Gerichtsherr gemachten Erfahrungen zunehmend die im Gegensatz zu den erklärten Absichten des Gesetzgebers bewirkten Konsequenzen, die er jedoch nur unscharf zu skizzieren vermochte. ${ }^{171}$ So trat er als Steuerpolitiker bereits kurz nach der Jahrhundertwende wegen der durch die Besteuerungspraxis verursachten, als ungerecht empfundenen höheren Steuerbelastung der mittleren Gewerbetreibenden und kleinen Landwirte, also des Mittelstandes, in aufsehenerregenden Veröffentlichungen für eine Beschränkung der Einkommensteuer auf die hohen Einkommensempfänger ein. Neben der Besteuerung nach der Leistungsfahigkeit sollte nach seiner Auffassung als Kompensat für Ausfalle eine Besteuerung nach dem Interesseprinzip durch Reorganisation der Ertragsteuern verstärkt werden. ${ }^{172}$

Von den rechtsdogmatisch als sachgerecht beurteilten Grundprinzipien des preußischen EStG überzeugt, wollte Fuisting in einer Reform das 1891 entstandene Gesetz von den durch Kompromisse aus dem săchsischen Muster eingedrungenen, das Konzept störenden Fremdkörpern bereinigt sehen. ${ }^{173}$ Ein früher Tod beendete seine Bemühungen. ${ }^{174}$

Fuistings Kritik an dem bestehenden preußischen EStG führte zu heftigen Kontroversen in konservativen Kreisen, wobei auch die von dem Verstorbenen

${ }^{170}$ Strutz. G. (1910), S. 659. Strutz bezeichnet Fuisting als den "Vater einer wissenschaftlichen Kommentierung der Steuergesetzgebung".

171 Fuisting, B. (1902), Grundsätze ..., S. 127 bis S. 130 und S. 304; ders. (1903), Einkommensbesteuerung ..., S. 9.

172. Fuisting, B. (1902), Grundsâtze ..., S. 304, S. 399.

${ }^{173}$ Fuisting. B. (1903), Einkommensbesteuerung ..., S. 9, S. 21; ders. (1903), Reformbedurftigkeit .... S. 229, S. 281, S. 380, S. 409; ders. (1902), Grundsătze ..., S. 110.

174 Strutz, G. (1908), S. 425: ders. (1903), S. 475; s. a. DJZ (1908), S. 295. 
ständig wiederholte und übernommene Ablehnung des andersartig orientierten ursprünglichen sächsischen Musters noch lange von Bedeutung blieb. ${ }^{175}$

In Preußen wurde fortan die Beurteilung des preußischen EStG 1891 als soziale, an der Gerechtigkeit orientierte Leistung herausgekehrt, die dem Reformwerk zugrundeliegende Gesinnung gewürdigt, unbequeme Kritik an den Ergebnissen der Besteuerungspraxis verharmlost und die Erörterung möglicher alternativer Gestaltungen als gegen die Natur der Sache verstoßend abgewürgt. Auf diese Weise konnten unliebsame Problemlösungen, wie bereits zur Jahrhundertmitte in Preußen, "ad calendas graecas" aufgeschoben werden. $^{176}$

Dennoch wurde stăndig in vielen Abhandlungen der soziale Gedanke als treibende Kraft der Entwicklung des modernen preußischen Einkommensteuerrechts positiv hervorgehoben. ${ }^{177}$

Dabei standen dann die Auseinandersetzungen um die fernere Ausgestaltung des Gesetzes durch Erhőhung der steuerfreien Eingangsstufe - kurz als Existenzminimum bezeichnet -, Freibeträge für Familienangehörige, Abzüge von der Bemessungsgnundlage für die Altersvorsorge, für Versichenungen, Erörterungen der Tarifprogression und berücksichtigungsfahige Belastungen für besondere Lebensumstănde und Notralle zur Diskussion. ${ }^{178}$

Die Bestimmung des als Einkommen bezeichneten Besteuerungsgutes, das in Preußen durch die restriktive Definition des Einkommensbegriffs vom săchsischen, nach Fuistings Auffassung "unrichtigen" Muster abgegrenzt worden war oder gar die völlig unzulängliche "Technik" der Besteuerung hat in

${ }^{175}$ Fristing, B. (1906), Zeit- und Streitfragen, S. 1, S. 2; Strutz, G. (1910), S. 657, S. 658 . DaB die streng konservative "Kreuzzeitung" ihr negatives Urteil über Fuisting ausgerechnet in einer abfalligen Bemerkung des săchsischen Finanzministers bestätigt fand, bewirkte bei Sirutz großle Verărgerung. Ein dagegen von der SPD im săchs. Landtag (Opposition) für Fuisting ausgesprochenes Lob für den Verstorbenen, den Befürworter einer Reform der preußs. ESt von 1891, muBte die Verărgerung von Strut noch verstärken.

176 Held, A. (1872), S. 288.

${ }^{177}$ Ein Beispiel fur viele ist die Dissertation von G. Kornfeld (1913) mit dem Titel "Der sozialpolitische Nebenzweck in der Besteuerung". Diese Abhandlung sucht die Einführung der die ESt nach der Idee Wagners ergänzenden Wertzuwachssteuter als Ziel der Entwicklung darzustellen, s. a. Schneider, P. (1938).

178 Wagner, A. (1899), S. 37, S. 110, S. 152, S. 222. Die Vorliebe Wagners für systematische Frageh und Rechtsdogmatik und dessen geringes Interesse für die konkreten Vorglnge und Konsequenzen durch empirische Oberprufung hat bereits Schmoller wiederholt kritisiert. Dies gilt noch stärker für Schmollers Mitarbeiter Wilhelm Hasbach, der ein Schuler Wagners gewesen war. sich aber aus methodologischen Gründen von diesern lossagte, s. hierzu: Hansen, R. (1990), S. 25, S. 26, S. 59, S. 60; ders. (1993), S. 125, S. 126. 
der Diskussion unter sozialen Aspekten jedoch keinerlei Aufmerksamkeit gefunden. $^{179}$

Finanzwissenschaftler beurteilten das preußische EStG 1891 als wissenschaftlichen Forderungen entsprechend und haben die bewirkten sozialen Konsequenzen jedenfalls nicht weiter beachtet. Adolph Wagner hat trotz der von Schanz 1896 aufgezeigten Eigentümlichkeiten des preußischen EStG 1891 deren praktische Folgewirkungen und die Differenzen zu dem săchsischen Modell schlichtweg verdrăngt. ${ }^{180}$ Er trug noch zur Jahrhundertwende seinen Studenten seine begrifflich streng gefügten rechtsdogmatischen Auffassungen vor und verwies dabei in Veröffentlichungen, um Vollständigkeit bemüht, kommentarlos auf die Kritik von Georg Schanz. ${ }^{18 !}$

Ursprünglich als Jurist ausgebildet und als "Manchestermann" ausgerichtet, glaubte er wie Fuisting ein "richtiges" Einkommensteuerrecht zu vertreten. ${ }^{182}$

So wird verständlich, daß nicht nur die der sogenannten "Kreuzzeitung" nahestehenden konservativen Gruppierungen, sondern mit ihnen auch die Mehrzahl der Steuenwissenschaftler das preußische EStG 1891 für richtig und verteidigungswert beurteilten. Daß es letztlich dem Begüterten ermöglichte, sogar z. B. anfallende Unterhaltsleistungen oder Scheidungsfolgeaufwendungen vermittels einfacher obligatorischer Verträge oder der Ubertragung befristeter Nießbrauchsrechte durch Reduktion der Steuer von der Allgemeinheit mittragen zu lassen, wurde übersehen. Daß die konkrete Steuerbelastung in der Praxis für Höherverdienende nicht von der wirtschaftlichen Leistungsfähigkeit bestimmt wurde, sondern von gestaltbaren, rein formalen Merkmalen im Sachverhalt, wurde als der Natur der Sache entsprechend und unvermeidbar

${ }^{179}$ Far Fuisting durfte ebenso wie far Wagner die ESt keine Vermögensrnehrung besteuern. Dafur waren rechtsdogmatische Gründe allein maBgeblich. Wăhrend Fusiing in diesern Punkt konsequent blieb, war Wagner bereit vorubergehend Gesichtspunkten der Zweckmäßigkeit Konzessionen zu machen, s. Wagner, A. (1891), S. 691; ders. (1892), S. 66; ders. (1897), speziell in: Schönberg, Handbuch (1897), S. 423; Hansen, R. (1990). S. 29, S. 30; Bredt. V., S. 41. S. 42; Fuisting. B. (1902). Grundruge ..., S. 110; ders. (1903), Einkommensbesteuerung .... S. 22.

${ }^{180}$ Wagner, A. (1899), S. 111. Wagner betonte sogar, jeweils nicht an den Einzelheiten interessiert zu sein, sondern nur an den "characteristischen Hauptpunkten" des Gesetzes, S. 110. Diese erkannite er aber nicht, S. 111. Neumann beurteilte das preuB. EStG 1891 trotz der sich meldenden Kritik 1896 als Muster für Württembergs Steuerreform, s. Neumann, F. J. (1896), S. 173.

181 Wagner, A (1897), Universitats-Vorlesung. S. 65, S. 66.

${ }^{182}$ Dies kam in zahllosen Wendungen zum Ausdruck: Wagner, A. (1880), S. 239, S. 256, S. 257, S. 405; Fuisting, B. (1902), Grundsätze .... S. 110, u. a.. Strutz konnte enwăhnen, daB "das Miquel'sche Steuersystem im großen und ganzen mit den herrschenden Auffassungen der Wissenschaft im Einklang steht", s. Strutz, G. (1903), in: Verwaltungsarchiv, 11. Bd., S. 474, S. 475. Neumann bestattigte 1896, daß die Regierungsvorlage Württembergs zur Reform der ESt, die dem preuB. EStG 1891 entsprach, mit "dem, was Theorie und Praxis jetzt in solchen Dingen an die Hand zu geben vermōgen". übereinstimmte, Neumann, F. J. (1896), S. 173. 
beurteilt. ${ }^{183}$ Bei rechtlicher Beratung konnte es dem gutsituierten Zensiten sogar gelingen, im oben erwähnten Beispiel die mit dem übertragenen Bezugsrecht ursächlich verbundenen Aufwendungen weiterhin von der eigenen steuerlichen Bemessungsgrundlage abzusetzen; dies war dann möglich, wenn der Steuerpflichtige im Auge behielt, daß die "Einkommensquelle" im Sinne des Gesetzes als solche bestehen bleiben mußte. ${ }^{184}$ Dies war durch eine geeignete Vertragsgestaltung leicht erreichbar.

Ein bißchen sprachliches Geschick bei rein begrifflichen Erörterungen und einige elementare Rechtskenntnisse vermochten den Begüterten zu helfen, ihre Besteuerungshőhe selbst zu bestimmen; denn: "Jus vigilantibus scriptum est".

Die vorstehenden Ausführungen zeigen, welche Möglichkeiten das preußische EStG ab 1891 einigen Gruppen von Steuerbürgern zur legalen Steuervermeidung und zur fast gefahrlosen illegalen Steuerverkürzung gewährte. Es ergibt sich daraus jedoch nicht, daß von diesen Möglichkeiten auch Gebrauch gemacht wurde, zumal die Ergebnisse der Steuereingănge sich wegen der wachsenden Wirtschaft zumeist sehr zufriedenstellend entwickelten.

Eine wachsende allgemeine Unzufriedenheit mit der als ungerecht empfundenen Einkommensbesteuerung, zu der viele bekanntgewordene unverständliche konkrete Vorgänge und Belastungsvergleiche in der Tagespresse beitnugen, ${ }^{185}$ führte um 1908 zur Bildung von steuerlichen Interessengemeinschaften im einflußreichen "Bund der Landwirte", demgegenüber zur Gründung und Stärkung eines "Hansa Bundes" und vor allem eines "Bundes der Festbesoldeten". ${ }^{186}$ Der Historiker, Herausgeber der "Preußischen Jahrbücher" und politisch profilierte nationalliberale Abgeordnete des preußischen Landtages Hans Delbrück suchte unter diesem Eindruck 1909 die Ergebnisse der Besteuerung in Preußen vermittels der Zahlenangaben von Verbänden und aus der amtlichen Statistik zu verproben. ${ }^{187}$ Er ermittelte als Ergebnis seiner Berechnung,

${ }^{183}$ Fuisting, B./Strutz, Q. (1915), S. 273, Anm. 36. Der Abzug von Abschreibungen stand in der Regel dem Eigentîmer, der von detn "Substanzverlust der Quelle" getroffen wird, zu, nicht dem NieBbraucher, hierzu Aum. 175 und die dort angegebenen Fundstellen; s. a. Preub. OVG U. XIIIa 6 v. 25.1.06, in: D.JZ 1906, Sp. 1154; U. JN.XIIIa 28 v. 19.1.05; U. NN VIIIa 56 v. 11.10.05; U. JN VIIIb 81 v. 22.10.04 in: E. PreuB. OVG in St., 12. Bd., S. 50 bis 53. Anders als dies heute erscheinen mag (Nevermann, K. 1994, S. 72), konute das seiner Zeit nicht als "sittenwidrige Steuerumgehung" gewertet werden.

184 Fuisting, B. /Strutz, G. (1915), S. 218, Anm. 3 b, S. 219, Anm. 4. Für den Abzug von Werbungskosten multe ebenso dern Grundgedanken des Gesetzes entsprechend "eine Einkommensquelle vorhanden sein, innerhalb deren sie entstanden sind". Das gait auch bei Verlusten, s. Buck, L (1911), S. 604; Fuisting, B. (1902), Grundeuge ..., S. 143.

\footnotetext{
tos Delbriack, H. (1909), 136. Bd., S. 180; s. a Meisel, F. (1914), S. 640, S. 641.

${ }^{186}$ Delbrück, H. (1909), 138. Bd., S. 555, S. 556.

in Delbrick, H. (1909), 136. Bd., S. 176.
} 
daß die Vermőgensteuer tatsăchlich eine Veranlagungslücke von $35,2 \%$ ausweise, ${ }^{188}$ woraus er dann für die Einkommensteuer eine Fehlrelation von $50 \%$ bis $66,6 \%$ schătzte. ${ }^{189}$ Obgleich der Hamburger Statistiker R. E. May in einem vorher für "Schmollers Jahrbuch" gefertigten Aufsatz, den er für Delbrücks, "Jahrbuch" überarbeitete, die Steuerausfalle in Preußen in der Einkommensteuer nur auf $22 \%$ bis $25 \%$, also nicht unerheblich niedriger ermittelte, ${ }^{190}$ blieb Delbrück unter Angabe guter Gründe bei seiner Hochrechnung.

Delbrück suchte durch seine Berechnungen einen Anstoß zu geben, daß die Einkommensteuer glaubwürdiger an den Absichten des Gesetzgebers orientiert würde. ${ }^{191}$ Seine Ausfuhrungen fanden weite Beachtung, aber er ließ vobllig offen, inwieweit es sich bei den Steuerverkürzungen um gesetzlich zulăssige, aber unerwünschte Steuervermeidungen und inwieweit um gesetzlich unzulässige Unterveranlagungen handelte.

Nachdem Behrnauer 1910 in der "Konservativen Monatsschrift" als verantwortlicher Finanzbeamter auf Grundlage einer Oberprüfung der Veranlagungen auf die Gesetzmäßigkeit der Besteuenung der Landwirte hingewiesen hatte, ${ }^{192}$ suchte auf Veranlassung Schmollers Meisel dann 1911 in seinem längeren Beitrag die in Preußen eingerissene schlechte Steuermoral als Konsequenz. einer unzweckmäßigen Ausgestaltung der "preußischen Type" der Einkommensbesteuerung, als Besteuerungstechnik bezeichnet, nachzuweisen. Durch Aufbereitung der in der preußischen Steuerstatistik erfaßten Angaben über die Anzahl von Veranlagungen, Beanstandungsverfahren, Berichtigungen von Veranlagungen, Steuerstrafverfahren und deren Trends im Zeitablauf glaubte er die Vermutungen Delbrücks belegt. ${ }^{193}$ Auch leitende Finanzbeamte bestätigten in der Folgezeit ausdrücklich Meisels Thesen vermittels ihrer langjährigen praktischen Erfahrungen ${ }^{194}$ als Leiter von Berufungscommissionen.

Meisel stellte fest, daß "die Technik der preußischen Einkommensteuer ... in den wichtigen Mitteln die primitive der Vorgăngerin, der klassifizierten Einkommensteuer," blieb. Er sprach von dem "großen Irrtum der Einkommen-

${ }^{188}$ Delbrïck, H. (1909), 136. Bd., S. 177.

${ }^{189}$ Delbrück, H. (1909), 138. Bd., S. 559.

${ }^{190}$ May, R. E. (1909), S. 146.

${ }^{191}$ Delbrïlk, H. (1909), 138. Bd., S. 564.

${ }^{192}$ Behrnauer, F. (1910), Konservatives ..., S. 675.

${ }^{193}$ Meisel, F. (1911), S. 293, S. 321; ders. (1914), S. 145.

194 Michaelis (1912), S. 65; ders. (1913), Rezensionen, in: Verwaltungsarchiv, 21. Bd., S. 162 bis 165, S. 488, S. 489; Moll, W. (1918), S. 2, Anm. 1; Buck, L. (1916), S. 58, S. 82; Maatz in: DJZ 17. Jg. (1912), Sp. 587. 
steuergesetze des preußischen Typs". ${ }^{195}$ Hierfür machte der gelernte Jurist mit Erfahrungen in der praktischen Veranlagungstătigkeit mit dem nach Österreich importierten preußischen EStG 1891 das Versagen der Finanzwissenschaften zur Jahrhundertwende verantwortlich, die "nach einer kurzen herrlichen Blüteperiode mitten im vollen Wachstum plötzlich stehen geblieben" sei. ${ }^{196}$ Zunehmend nahmen fortan Steuerjuristen deren Stelle ein.

Unverständlich ist, daß das preußische EStG 1891 nach Auffassung von Bernhard Fuisting und ebenso von heutigen Steuerrechtslehrern als Fortschritt zu einer Besteuerung nach der Leistungsfahigkeit beurteilt wurde bzw. wird. ${ }^{197}$ Die Möglichkeiten für begüterte Steuerbürger zur Steuervermeidung standen einer sozialen Ausgewogenheit im Wege. Dabei sollte man den Steuerzugriff nicht bagatellisieren. $\mathrm{Zu}$ den $4 \%$ Einkommensteuer kam ein Gemeindeaufschlag von bis zu 450 Prozentpunkte hinzu, so daß eine Gesamtbelastung von bis zu $22 \%$ in den großeren Städten infrage stand. ${ }^{198}$

Die von dem preußischen EStG 1891 durch die oben aufgezeigten sozialen Unzuträglichkeiten geschaffene Atmosphäre des Mißtrauens war gewiß für die

${ }^{193}$ Meisel, F. (1920), S. 16, S. 17. Wie ausgeprägt die hohen im Spiel stehenden Interessen verfolgt wurden, zeigt folgender Umstand: Schmollers weitergehender Einkommensbegriff, 1863 als Maßstab der Leistungsfahigkeit für Besteuerungszwecke konzipiert, hatte offensichtlich beständig einen Stobfaktor für die Rechtfertigung des angeblich rechtsdogmatisch "richtig" entwickelten preuB. EStG dargestellt. Fusting hielt es daher für notwendig, die Auslegung des grundlegenden Einkommensbegriffs des preub. EStG 1891 und auch eines zu reformierenden emeuerten EStG streng von dem als unrichtig kritisierten zu weiten Schmollerschen Begriff abzugrenzen, Fuisting, B. (1902), Grundzüge ..., S. 110; ders. (1903). Einkommensbesteuerung ..., S. 21, S. 22. Als Schmoller dann 1904 in dem 2. Bd. Seines "Grundrisses" für die Behandlung von Problemen der Einkommens- und Vermôgensverteilung in der Ciesellschaft die allgemein abliche Definition des Begriffs für Einkommen verwendete, wurde dies von Fuisting und spater von Srrutz registriert und in den Neuauflagen der Kommentierung zum preuB. EStG 1891 zur zusătzlichen Bestattigung von dessen Einkommensbegriffs als "richtig" in einem langeren Abschnitt dem Text eingefigt. Fuisting, B./Strutz, G. (1915), S. 163. Fortan wurde dadurch der Eindruck unterstütat, Schmoller seien gegenüber 1863 bessere Einsichten zuteil geworden. Tatsăchlich waren Begriffe für Schmoller nur Werkzeuge. Ein EStG wollte er als Institution wie eine zweckmäBig konstruierte Maschine gewertet wissen. Dabei lagen die Zwecke allgemein akzeptiert offen zutage. Begriffe waren für Schmoller ohne Wahrheitsgehalt. An einer Uhr werkelt man nicht mit einer groben Zange herum, man bedient sich einer Pinzette, so etwa Iaßt sich Schmollers oftmals dargelegte Wissenschaftsauffassung. die ihm viele Feinde eintrug, darstellen, hierza: Hansen, R. $(1990)_{n}$ S. 16, S. 55; ders. (1993), S. 116.

${ }^{196}$ Meisel, F. (1920). S. 35. S. 36. Meisel bedauerte es, dab die Finanzwissenschaft zur Jahrhundertwende versagte und daß̉ nur Schanz, Vocke und Fuisting, die "Radikalfehler" erkannten.

197 Wagner, A (1892), S. 8. S. 47; ders. (1899), S. 48, S. 109; Fuisting, B. (1902), Grundzüge .... S. 264; Kirchhof, P. (19912), Einkornmensteuergesetz ..., Rdnr. 396; Bayer. H. W. (1991), S. 336. Für Tipke ist die "legislatorische Leistung" der Miquel'schen Einkonumensteuerreform ohne "steuerrechtswissenschaftliche Grundlage" der Beginn dieser Disziplin, zu "deren Aufgaben die Entwicklung einer Steuergerechtigkeitslehre" gehört, Tipke, K. (1993), Steuerrechtsordnung. S. 31, S. 16. Lang läßt eine modern ausgestaltete ESt mit dem preuB. EStG 1891 beginnen, er bedauert das vorhandene "Traditionsdefizit", Lang, J. (1987), S. 3, S. 6.

${ }^{198}$ Meisel, F. (1911), S. 298, Anm. 1. 
Steuerehrlichkeit weiter Bevölkerungskreise nicht förderlich. Delbrück, May und Meisel schătzten auf Grundlage statistischer Erhebungen, daß dem preuBischen Staat jährlich durch Unterveranlagungen über $25 \%$ des eigentlichen Steuersolls verlorengehe. ${ }^{199}$ Dabei kamen für diese Steuervermeidung obendrein nur die Empfänger höherer Einkommen in Frage, die unter 4\% der Gesamtzahl der Steuerzahler ausmachten. Meisel stellte 1913 fest: "Die Moral ist also nach 22jähriger Geltung des Gesetzes nicht nur nicht besser, sondern schlechter geworden ...". ${ }^{200}$ Paul Jostock hat 1943 die Mutmaßungen bestätigt $^{201}$.

Die Ausführungen haben gezeigt, daß das preußische EStG 1891 einen weiten Spielraum für legale Steuervermeidung durch privatrechtliche Gestaltungen und darüber hinaus für fast gefahrlose Verkürzungen infolge von Mängeln bei der amtlichen Ermittlung und Festsetzung der Besteuenungsgrundlagen ermöglichte. Das lag nun einmal in der Tradition der preußischen Einkommensbesteuerung angelegt, indem diese seit 1820 stets unter eingriffsrechtlichen Gesichtspunkten beurteilt und ausgestaltet worden war.

Bereits die ersten Veranlagungen nach dem EStG 1891 zeigten eine unerwartet hohe Quote von Beanstandungsverfahren, die sich dann auf über 30\% einpendelte. ${ }^{202}$ Die nicht vorausgesehene Zahl der Rechtsbehelfsverfahren zwang zur Vergrößerung der Verwaltung und die Explosion der eingelegten Rechtsmittel konnte nur nach Schaffung weiterer Senate im OVG und Änderungen der Richterbesetzung in deren Beschlußkörpern bewältigt werden. Die Einkommensstatistik machte erkennbar, daß große Teile des steuerbaren Einkommens in den Erklärungen der Zensiten nicht erfaßt wurden und der Besteuerung vorenthalten blieben.

Angesichts dieser Umstănde muß die höchst positive Beurteilung, die Adolph Wagner 1892 von der Bedeutung des Gesetzes für "die soziale Seite der Finanz- und Steuerpolitik" vor einer qualifizierten Leserschaft entwarf, eigentümlich erscheinen. ${ }^{203}$ Eine größere Fehlleistung ist kaum vorstellbar,

199 Meisel, F. (1911), S. 305; ders. (1914), S. 145. Im Jahr 1913 führen die Beanstandungen der Steuererklăsungen durch die Behörde zu einer Erhbhung der eingenommenen ESt von $35,4 \%$, s. Mitteilungen ... (1913), angefuhrt bei Meisel, F. (1925), S. 130; s. hierzu auch Delbrück, H. (1909), S. 184; s. a. Böhmert, V. (1898). Nach Böhmert bleiben in Preußen $45 \%$ des Gesamteinkomnens unversteuert. Diese Ziffer ist in diesem Zusammenhang irreführend, weil sie auf der Steuerstatistik aufbaut.

${ }^{200}$ Meisel, F. (1925), S. 130: ders. (1920), S. 405; s. hierzu: Hauptergehnisse ... (1894), S. 177; Meisel, F. (1914), S. 144.

201 Jostock, P. (1940). S. 49. S. 50.

${ }^{202}$ S. hierzu: Mitteilungen ... ab Heft Nr. 25; s. a. Zusammenstellung bei Meisel (1911), S. 2913 bis S. 299; ders. (1914), S. 145; ders. (1920), S. 13 bis S. 15.

203 Wagner, A. (1892), S. 1 
mehr praktische İnkompetenz kaum nachvollziehbar, als in Wagners von Pathos erfülter Prognose zum Ausdruck kam. Er glaubte voraussagen zu können, daß die bisher begünstigten höheren "industriellen, merkantilen, großgrundbesitzlichen, die Zins-Spekulations- und Konjunkturengewinneinkünfte" fortan endlich höher belastet würden und daß damit "die Vermögensbildung der höher belasteten Personen" zu Gunsten der bisher Minderbemittelten verschoben und somit eine soziale Umschichtung der Vermögensbildung erfolgen könne. ${ }^{204}$

Während Schmoller durch seine Interessen an empirischer Aufarbeitung der Statistiken zur Durchleuchtung der tatsächlichen Einkommensverteilung im Interesse einer sozial akzeptablen Steuenung der Institutionen vermittels der erkennbaren Auswirkungen bei Interessenverbănden und politischen Gegnern stündig Unruhe auslöste, ${ }^{205}$ fand Wagner mit seiner offensichtlichen Schönfärberei in allen Schichten und insbesondere auch in streng konservativen Kreisen, denen sein Staatssozialismus ohnehin entgegenkam, eine große Anhăngerschaft. ${ }^{206}$

Die zur Jahrhundertwende wachsende Außenseiterstellung Schmollers kommt in dem Umstand zum Ausdruck, daß die Mängel der Besteuenungspraxis, obgleich in seinem weit verbreiteten und meinungsbildenden, als Speerspitze der Sozialpolitik bekannten "Jahrbuch" allgemein publik gemacht, nie zu einer nachhaltigen kritischen, die Systematik betreffenden Erörtenung oder gar zu Abänderungsentwürfen des preußischen EStG 1891 führten. Die Auswirkungen des Gesetzes auf die soziale Realität kamen nämlich nach vorherrschender Überzeugung von Wissenschaftlern und Steuerexperten als regulative Instanz für die Korrektur des Gesetzeswerkes, das nach deren Auffassung in rechtsdogmatischer Hinsicht richtig entwickelt worden war. nicht infrage. Die von Delbrück 1909 skizzierten Ungereimtheiten und die von Schanz 1896 und Meisel 1911 aufgezeigten Mängel in der Systematik und der Technik der Veranlagungsvorschriften des Gesetzes - Schanz und Meisel bekannten beide. zu ihrer Kritik an dem Regelungsgefüge von Schmoller ent-

\footnotetext{
${ }^{204}$ Wagner, A (1892), S. 58; s. Kritik von Oldenberg, K. (1893). S. 458.

${ }^{205}$ Die Einkommensverteilung war ein zentrales Thema Schmollerscher Sozialpolitik. Für ihn stand die zu beseitigende Klassenspaftung in engem Zusammenhang mit der Einkommensverteilung. Nach 1890 verstärkte Schmoller seine diesbezüglichen Interessen. 1893 schätzte er den jullhrlichen Vermögenszuwachs in der Börsen-Ënquete. Danach veröffentliche er etwa im Vierjahresrythmus Untersuchungen zu diesenn Thema von R. E. May., der Mitglied des Vereins fur Socialpolitilk war, s. BörsenEnquete-Kommission ... (1893), S. XX]; Schmoller, G. 1895, S. 27; ders. (1904), S. 728, S. 778, S. 1070; May, R. E. (1903), S. 195; ders. (1909), S. 1459; ders. (1899), S. 271.

${ }^{206}$ Herzfeld gibt in seiner Darstellung der Entstehung der preuß. ESt von 1891 ein Bild von dem hohen Ansehen A. Wagners, s. Herzfeld, H. (1938), Bd. I, S. 486; Pausch, A. (1992), S. 30; s. DJZ (1915), Sp. 399.
} 
scheidende Gesichtspunkte bezogen zu haben - ${ }^{207}$ wurden zwar im preußischen Landtag erörtert, aber ohne daß eine nachhaltige Untersuchung eingeleitet wurde. ${ }^{208}$

Die aus der Tătigkeit als Senatspräsident am preußischen OVG gespeiste Erfahrung hatte den eher theoretisch interessierten Fuisting seit 1902 dazu bestimmt, für eine Reform des EStG 1891 einzutreten. ${ }^{209}$ Von der Sachgerechtigkeit des aus fundamentalen Prinzipien einer Besteuerung nach der wirtschaftlichen Leistungsfähigkeit des Steuerbürgers entwickelten ESIG 1891 überzeugt, setzte er sich bis 1906 dafür ein, die bestimmenden Konstruktionselemente in einer Novellierung stårker hervortreten zu lassen. ${ }^{210}$ Seine 1902 und 1903 skizzierte Zielvorstellungen, das Gesetz von den aus dem săchsischen Muster eingednungenen Fremdkörpern zu bereinigen und die Grundfreibeträge wesentlich zu erhöhen, um den Mittelstand von der ihn überhöht belastenden Steuerlast zu befreien, war nicht durchsetzbar, ja nicht einmal vertretbar.

Erst die finanzielle Notlage im Krieg führte dann nach heftiger Kritik letzlendlich zu einer auf die Kriegszeit zeitlich und inhaltlich begrenzten Aussetzung des Quellenprinzips in der sogenannten "lex Schweckendieck" vom 30. Dezember 1916. ${ }^{211}$

Nachdem das preußische Modell der Einkommensbesteuerung 1897 auch in Österreich im Zuge der dort vordringenden Orientierung an den Zielen der im Verein für Socialpolitik angestrebten gesellschaftlichen Vorgaben maßgeblich geworden war, ${ }^{212}$ zeichnete sich auch dort bald emsthafte Kritik an der übernommenen Besteuerungsform bei Vergleich mit den erkennbaren Ergebnissen $a b^{213}$ Franz Meisel, von Ausbildung her Jurist und als Beamter in der öster-

${ }^{207}$ Schanz, G. (1896), S. 6, insbes. Anm. 3. Schanz zeigt hier, daB er Schmollers Revolutionierung des steuerlichen Einkommensbegriffs erkannt hatte und sich diesen für die nachfolgenden Ausführun* gen zu eigen machte; Meisel, F. (1911, S. 287. Meisel begann seinen zuerst in "Schmollers Jahrbuch" abgedruckten Aufsatz unter Hinweis auf Schmollers Auffassungen.

${ }^{208}$ Haus der Abgeordneten, Sitrungsprotokolle vom 5. u. 6.2.1912.

${ }^{209}$ Fusting, B. (1902), Gundsatze ..., $\$ \S 127$ bis 129, S. 270; ders. (1903), Einkommensbesteuerung .... S. 9, S. 35 .

${ }^{2 ! 0}$ Fuisting, B. (1906), S. 1.

${ }^{2 i \mathrm{i}}$ PreuB. Gesetzsammlung, Jg. 1917. S. 1; s. as Moll, W. (1917), S. 289.

212 Gesetz v. 25.10.1896, betreffend die directen Personalsteuem, in RGBI., S. 673. darin Personaleinkommensteuer. $\S \S 153 \mathrm{E}, \mathrm{S} .70$.

${ }^{213}$ Das osterreichische Personaleinkommensteuergesetz ubernahm aus dem sâchs. EStG 1874/78, das Preußen als Muster gedient hatte, wörtlich in $\$ 159$ die grundlegende Definition des weitgefaßten steuerbaren Einkommens ( $\$ 15$ Abs. 1 und 2 săchs. EStG $1874 / 78$ ) und in $\$ 214$ den im săchs. EStG vorgesehenen Ersatztatbestand einer Besteuerung nach dem Verbrauch $(\S 15 \mathrm{Abs}$. 6 săchs. EStG 1874/78). In $\$ \$ 163$ bis 171 wurden die in $\$ 7$ preuB. EStG 1891 abschließend aufgefuhrten vier Einkunftsarten, in $§ 202$ die Verpflichtung der Zensiten zur Abgabe von "Bekenntnissen" und andore 
reichischen Besteuerungspraxis tătig, suchte dann 1911 die Măngel der Veranlagung zur Einkommensteuer in der als Muster dienenden "preußischen Type" der Einkommensbesteuerung, deren Technik er für ungeeignet hielt und die er fur die soziale Fehlentwicklung zu einer wachsenden problematischen Steuermoral verantwortlich machte. ${ }^{214}$

\title{
IV. Die bis heute bestehenden Möglichkeiten zur Herabsetzung der Steuerbelastung in der "deutschen Einkommensteuertype" durch legale Gestaltungen zur Steuervermeidung
}

\author{
Wie bereits mehrfach angeführ wurde, ist das noch heute geltende Einkom- \\ mensteuerrecht der Bundesrepublik Deutschland aus dem preußischen EStG \\ 1891 fortentwickelt worden. Nachdem das Reichseinkommensteuergesetz vom
}

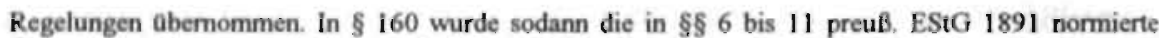
Oberschußrechnung als einzige verbindliche Ermitulungsweise vorgeschrieben. Die Vorschriften waren mithin aus unterschiedlichen (Sachsen bzw. Preußen) Rechtssystemen ubernommen worden und, im Zusammenhang beurteilt, nicht miteinander abgestimmt, s. Kleinwächter, F. (1896), S. 11; Schanz, G. (1897), in: FA 1897, S. 434. Schon deshalb war einer zusammenfassenden Auslegung nach der von Fuisting geschaffenen, för die preuBische Einkommensbesteuerung maBgeblichen Kommentierung eine ausschlaggebende Bedeutung zugekommen, s. Sieghart, R. (1897), S. 10; s. a. Mataja, V., S. 374, S. 405; Rewesch, R. (1897) S. 177. Der Einkamonenshegriff, der das Besteuenungsgut hestimmt wurde in keiner Erörterung behandelt, sondern stets als problemlos bekannt unterstellt. Das Gesetz fand nach einigen Jahren Wirksamkeit wie in Preußen in den herrschenden Kreisen Zuspruch und positive Befürworter, s. hierzu: Leitner, F., S. 1, S. 2. Das allgemeine Wirtschaftswachstum als Folge der Industrialisierung gab dem Steueraufkormmen auch hier ohnehin eine unerwartet erfreuliche Entwicklung. Beruflich mit der Veranlagungspraxis befaßte Beamte, wie der fruh verstorbene Sektionschef Meyer und ebenso Meisel, sahen jedoch frihzeitig, Ihnlich wie in Preußen Fuisting, eine zunchmend unerträglicher werdende unsoziale Lastenverteilung als Ergebnis der Veraulagungspraxis. Sie erkannten, wenn auch jeweils mit der Forderung nach anderen Konsequenzen verbunden. die Ursache für die Mängel in der Ubernahme grundlegender Systemelemente aus der "preuBischen Type" der Einkommensbesteuerung. Der Grazer Professor für Statistik und Finanzwissenschaften Mischler hielt 1907 fest, da $B$ dịe Personaleinkommensteuer "aus Gewerbe und Handel ... in keinem meB̈barea Verhăltris zu dem Einkommen (stehe) und letzteres ... unbekannt" hleibe, s. Mischler. E. (1907). Rezension, S. 960; auch: X́leinwächrer. F. (1922), S. 174. Anrn. Die wahren Größen des Einkommens mü̉ten deshalb nach $M$ ischler unbekannt bleiben, weil nicht veranlagtes Einkommen nun einnal in einer noch so gut aulbereiteten Steuerstatistik gar nicht erfaßt wird. Dies nichi zu erkennen warf er denjenigen Autoren wie Leitner vor, die die österreichische Einkommensbesteuerung durch Aufbereitung der Steuerstatistik positiv würdigten. s. Mischler, E.. S. 958. So wurde nach Mischler das Einkommen der bãuerlichen Wirtschaiten uberhaupt nicht einbezogen, da die. Besteuerung und damit die Steuerstatistik nach dem preuB. Muster auf die Tauschwirtschaft allein abstellte, s. Mischler. E., S. 958. Gegenüber den auftretenđen Fragen der Besteuerung zeigten Nationalökonomen wie Friedrich von Wieser und andere, gemessen an der Fragwürdigkeil herausgestellter Konsequenzen, eigentümliche Hilflosigkeit, s. von Wieser, F. (1901); s. a. Menger, C. (1902), Lit. Centralbi., S. 18.

214 Meiset, F. (1914), S. 164, S. 166, S. 167; s. a. Michaelis (1912), S. 69 bis 72, S. 91 bis 93 ; ders. (1913), in: Verwaltungsarchiv, Bd. 21, Rezensionen, S. 162 bis 185, S. 488, S. 489. Michaelis war seil 15 Jahren Vorsitzender groBer Berufungscommissionen und seit 20 Jahren Mitarbeiter im Verwaltungsarchiv. Er beklagte "die Unkenntnis der wirklich bestehenden Verhältnisse bei unseren Parlamentariern bzw. die Abneigung aus den Verhăltnissen, wo sie etwa bekannt sind, die greifbaren Folgerungen zu ziehen", s. S. 163 


\section{Mărz 1920 nach dessen Begründung an den systemtragenden Prinzipien} des săchsischen EStG 1874/78 - nach Schanz als "Reinvermögenszugangsprinzip" bezeichnet - orientiert wurde, ${ }^{215}$ ist der Gesamtrahmen des Einkommensteuergesetzes vom 18. August 1925 in der Schlieben/ Popitzschen Reform wieder ganz auf die tragenden Gesichtspunkte des preußischen Einkommensteuergesetzes von 1891 umgestellt worden. ${ }^{216}$ In der Gesetzesbegründung heißt es zwar, daß das Gesetz keiner der konkurrierenden finanzwissenschaftlichen Lehrmeinungen folge, ${ }^{217}$ tatsächlich wurde es jedoch mit geringen Einschränkungen inhaltlich von der charakteristischen systematischen Sinneinheit des preußischen Einkommensteuergesetzes 1891 geprägt.

Wăhrend das Reichseinkommensteuergesetz 1920 konsequent dem aus dem ursprünglichen sächsischen Muster bezogenen Grundgedanken zu folgen suchte, nämlich daß Einkommensteuerrecht Lastenventeilungsrecht sei - Erzberger sprach von der "kräftigen Klammer", die das Steuerrecht in der Zeit der Not nach dem verlorenen Krieg für das Deutsche Reich bereiten sollte ${ }^{218}$ - war

215 Verhandlungen der Verfassungsgebenden Deutschen Nationalversammlung. Bd. 340, Anlagen zu den Stenographischen Berichten. Nr. 15324 - 1558, Berlin 1920, S. 17 - 23, hier S. 24; s. a. Begründung zu einem Reichseinkommensteuergesetzentwurf, in FA, 37. Jg. 1920, S. 593; hierzu: Schanz, G. (1896), S. 23 u. a. Daß es sich bei dem Beitrag von Schanz, der massive Kritik an Grundgedanken des preuB. EStG 1891 enthiclt, um eine Fortuhrung der Gesichtspunkte handelte, nach denen Schmoller 1863 einen Maßstab für wirtschaftliche Leistungsfahigkeit festzulegen suchte und den dieser zur Orientierung der Einkommensbesteuerung als Drehpunkt der gesamten Abgaben vor-schlug, ist nicht zu übersehen. Schanz übernahm sogar die Terminologie seines fruheren Lehrers ( $\mathrm{z}$. B. S. 5). Dies wird neuerdings richtig erwähnt, s. Biergans, E./Stockinger, R. (1982), S. 2; Lang, I, (1988), S. 38; Hansen, R. (1990), S. 33. Die Ausrichtung der von thm ständig als fortschrittlich erwảhnten săchsischen Regelungen an dem Schmollerschen Einkommensbegriff mochte Schanz offensichtlich 1896 nicht klar hervorheben, obgleich sich dies aus seinen Ausführungen entnehmen läßt, s. Schanz, G. (1896), S. 43, S. 47; ders. (1887), S. 508. Schanz vertrat andere methodische Auffassungen als Schmoller und war offensichtlich in dem für ihn als Herausgeber des FA besonders ernpfindlichen Spannungs.feld zwischen Wagner und Schmoller um gleichmä.iigen Abstand bernüh, hiersu: Hansen, R. (1990), S. 10, S. 25, S. 48 u.a: s. a. Vogel, H. (1910), S. 100 - 103. Schmoller hatte nach vielen Jahren praktischer Erfahrung und einem abgeschlossenen theoretischen Studium des Besteuerungswesens - \$. Hansen, R. (1990), S. 8 - einen konkreten und praktischen Maßstab für Leistungsfahigkeit zu definieren versucht, den er als Orientierung für die Verteilung der Belastung durch Abgaben für den zentralen Einkommensbegriff vorschlug. Während Schmoller jede Fom von Begrifisrealismus ablehnte, suchte Schanz nach einem "richtigen" Einkommensbegriff, Hansen. R. (1993), S. 116

216 Verhandlungen des Deutschen Reichstages 1924, III. Wahlperiode, Anlagen Nr. 795, Begründung zum Entwurf eines EStG. S. 21 - 23; s. a. Krohn, C. D. (1974). S. 148. S. 179. Auch wer Krohns politische Wertungen nicht teilt muß zugeben, daß er die Konsequenzen richtig darstellt. Neumarks Kritik ist für die Erkenntnis der Zusammenhänge nicht hilfreich, s. Neumark, F. (1976), S. 362.

217 Begründung zum Entwurf eines EStG (wie Anm. 216), S. 21. Rutschl sprach 1929 davon, daB das neue EStG 1925 eine "Synthese" der beiden vorherigen Systeme darstelle. Diese Beurteilung hat sich weithin durchgesetzt. Er glaubte. daß die Umstellung zu dem EStG 1925 ein erster Schritt zu einem "wirtschaftlichen Steuersystem" und zu einer Besteuerung "im Verhältnis zur Leistungsfahigkeit" sei. Auch diese Auffassung wurde zur herrschenden Meinung, s. Ritschl, H. (1930), S. 286. S. 288, S. 276; ders. (1929), S. 354, S. 356.

${ }^{218}$ Erzberger, M. (1919), S. 113. In den Verhandlungen des săchs. Landtages wegen der Reform der ESt nach 1891 hatte die Forderung nach einer gerechten Lastenverteilung entsprechend der wirt- 
mit der nachfolgenden Umstellung durch das Einkommensteuergesetz 1925 wieder eine Rückbesinnung auf die in der preußischen Tradition fortgefürte, von Verwaltungsjuristen entwickelte eingriffsrechtliche Auslegung des Einkommensteuerrechts verbunden. ${ }^{219}$

So erhielt das Einkommensteuergesetz 1925 als Besteuerungsgegenstand wiederum einen Enumerativkatalog steuerbarer Einkünfte, der auf acht, nach 1934 auf sieben Einkunftsarten erweitert wurde. Es übernahm aus dem preußischen Einkommensteuergesetz 1891 auch wieder die dualistische Ermittlungsvorschrift für die Berechnung der Einkünfte. 220

Für die Einkunftsarten 1 bis 3, das waren Einkünfte aus dem Betriebe von Landwirtschaft, aus Gewerbebetrieb und aus selbständiger Berufstätigkeit, war der Gewinn zu ermitteln. ${ }^{221}$ Dieser ergab sich aus einem Bestandsvergleich, der nur bezüglich des Wertes des Grundbesitzes eingeschränkt wurde. ${ }^{222}$ Speziell fur die Gewinnermittlung der buchfühungspflichtigen Gewerbetreibenden wurden die fortentwickelten Grundsătze ordnungsmäßiger Buchführung maßgeblich und im übrigen ebenso das Bilanzsteuerrecht verbindlich.

schaftlichen Leistungsfahigkeit der Steuerbärger beständig im Vordergrund gestanden, s. Mittheilung aber die Verhandlungen des Landtages, II. Kammer, 91. Sitzung v. 30.11.1872; desgl. 56. Sitzung v. 11.5.1874 und 57. Sitzung v. 19.5.1874; desgl. 27. Sitzung v. 18. bis 19.12.1877 und 58. Sitzung vom 18.2.1878; s. hierzu: Gensel, J. (1874), Sp. 1380; ders. (1875), Sp. 1520; s. a. Conrad, J. (1871), S. 429; ders. (1873), S. 227. Wie wir noch sehen werden (Anm. 228), hatte Erzberger sich bereits nach 1897 intensiv bernüht, tragende Gesichtspunkte des săchs. EStG 1874/78 in die Verhandlungen zur Steuerreform im Württembergischen Landtag einzubringen.

${ }^{219}$ Für das Steuerrecht als Bestandteil des Verwaltungsrechts waren in Preußen die Auffassungen aber den Rechtsstaat bezüglich der Handhabung der Staatsgebote durch die Verwaltung H. R. von Gneists nach 1860 maBgeblich. Gneist verlangte auch für das offentliche Recht Garantien eines rechtlichen Verfahrens, wie sie im Privatrecht zum Schutz von Personen und Eigentum errungen worden waren. Aufgabe der ordentlichen Gerichte war der Schutz der individuellen Rechte gegenüber staatlichen Họeitsrechten, s. Pausch, A. (1976), 250 Jahre ..., S. 216; s. a. Hatscheck, j. (1899), Gneist, H. R, in: ADB, Bd. 49, S. 405, S. 406. Gneist war viele Jahre hindurch Prăsident des Deutschen Juristentages. Als Mitbegründer und erster Vorsitzender des Vereins für Socialpolitik stellte sich sofort heraus, daß seine Auflassung mit den Zielen der Mitgründer zur Bewirkung gerechterer Einkommensverteilungen und Belastungen nicht vereinbar waren. So wurde er nach den ersten Sitzungen zum Rücktritt veranlaßt, s. Boese, F. (1939), S. 22. Die Auffassungen Gineisis bestimmten auch spăter noch die Beurteilung des Einkommensteuerrechts durch den jüngeren Mitarbeiter Fuistings, G. Strutz, der 1928 von diesem Rechtsgebiet als dem "neben der jetzt weggefallenen Wehrpflicht einschneidensten Eingriffsrecht des Staates in die Sphlire des Einze!nen" sprach, Strutz, G. (1928), S. 233; s. hierzu auch: Tipke, K. (1993), Die Steuerrechtsordnung, S. 151; ders. (1982), Grenzen .... Einfürung, S. 3.

${ }^{220} \S 6$ EStG 1925 lautete eingangs: "Der Besteuerung des Einkommens unterliegen nur: ...". Es folgte sodann die Aufzăhlung von acht Einkunftsarten. § 7 EStG 1925 ist als Anlage 3 wiedergegeben. Die Erweiterung des Katalogs auf acht Einkunftsarten in $\S 6$ entsprach einer Empfehlung von Wagner, der hierin eine fortschrittliche Entwicklung sah, s. Wagner, A. (1891), S. 698.

221 \$12 Abs. 1, Satz 2 EStG 1925, in: RStBI. 1, S. 191.

$222 \S \S 12$ und 13 EStG 1925, in: RStBI. I, S. 191, S. 192. 
Die Ermittlungsvorschrift für die Einkunftsarten 4 bis 8 sah die herkömmliche Überschuibrechnung vor. ${ }^{223}$

Damit wurde für die Einkunftsarten 1 bis 3 vorgeschrieben, was wir nach dem Urteil des preußischen OVG in Staatssteuersachen vom 13. Dezember 1895 als verbindliche Auslegung des preußischen Einkommensteuergesetzes 1891 kennenlernten und was letztlich zu dem heute sogenannten "dualistischen" Einkommensbegriff fuhrte. ${ }^{224}$ Diese Auslegung, die erst in der Novellierung von 1906 eine textlich klare Bestätigung gefunden hatte, verfestigte als Konsequenz die strenge Trennung des Gesetzes zwischen Vermögens- oder Privatsphäre und der allein steuerlich relevanten Einkommenssphäre. Vermehrung oder Verminderung des Stammvermögens gehörten regelmäßig nicht zum steuerbaren Einkommen des Steuerbürgers, der nur ausnahmsweise bei Einkünften aus Handel, Gewerbe und Bergbau den nach den Grundsätzen für die Aufstellung von Inventar und Bilanz gemäß HGB berechneten Gewinn ( $\S$ 13 preuß. EStG 1906) zu versteuern hatte. Diese Regelung wurde in umstandlichen Formulierungen zum Inhalt der $\S \S 7,12$ und 13 EStG 1925 gemacht.

Wenn der langjährige einflußreiche Senatspräsident beim Reichsfinanzhof und Schöpfer der Reichsabgabenordung, Enno Becker, zur Rechtfertigung des resuitierenden zweigespaltenen Aufbaus des Einkommensbegriffs wiederholi bestritt, "daß die Lehre der Finanzwissenschaft unmittelbar für den steuerrechtlichen Begriff des Einkommens verwendbar sei" und ausführte, daß "der Gang der Dinge" gelehrt habe, "daß der Begriff des Einkommens nach den Bedürfnissen des Lebens und unserer Zeit entwickelt und festgelegt wurde", ${ }^{225}$ so verwirrte er damit die Zusammenhänge. Erst die bewußt oder unbewußt dem Gesetz zugrunde gelegte "Belastungsidee" - nach der von uns verwendeten Terminologie "Besteuerungsidee" - bestimmt die Auslegung des gesetzlich vorgeschriebenen Besteuerungsgegenstandes, worauf der Steuerrechislehrer und Verfassungsrichter Kirchhof nachdrücklich hinweist. ${ }^{226}$ Gerade die Kombination von zwei unterschiedlichen finanzwissenschaftlichen Besteuerungsideen zur Orientienung der Ermittlungsvorschriften hatte letztlich bereits in Preußen die Vermengung von zwei unterschiedlich umfangreichen Besteue-

\footnotetext{
${ }^{223}$ § 14 i. V. m. $\S \S 15$ bis 17 EStG 1925, in: RStBI. I. S. 192.

224 Schmoldiers; G. (1960), Sp. 75; Tipke, K. (1973), S. 391; Tipke, K/Lang, J. (1991), S. 200; Tipke, K. (1993). Die Stetuerrechtsordnung, S. 563.

${ }^{225}$ Becker, E. (1940), S. 1; s. a. \$ 172, S. 214 und ders. (1925), in: SimW (1935), Sp. 4, Sp. 8.

${ }^{226}$ Kirchhof, P. (1985), S. 320, S. 321; Tipke, K. (1976), Steuergesetzgebung ..., S. 301, S. 304. spricht von einer "systematischen Sinneinheit". Gelegentlich spricht Tipke von einem "inneren System", das die wertungsmäBige Einheit des Gesetzes durch die "systerntragenden Prinzipien oder Wertungen" bewahurt und den Steuerbürgern vor "Verletzung des Gleichheitssatzes der Verfassung Schutz verleiht", s. Tipke, K. (1975), S. 407; ders. (1972), S. 214.
} 
rungsgegenständen zur Folge gehabt. Das wiederholte sich 1925. Die Denkfiguren des preußischen EStG 1891 bestimmten somit auch die Auslegung des EStG 1925, das letztlich von Beamten geschaffen wurde (Popitz, Schlieben), die - anders als Erzberger - ihre Laufbahn am preußischen OVG in Staatssteuersachen begannen und beim Reichsschatzamt fortsetzten.

Dieser Umstand hatte fortan wiedenum erhebliche Auswirkungen auf die Besteuerungspraxis und übte einen tiefgreifenden Einfluß auf das Wirtschaftsleben bis heute aus.

In diesem Zusammenhang ist zu erwăhnen, daß das bis heute geltende Einkommensteuerrecht seit der Erzbergerschen Reform von 1920, insbesondere in den sogenannten "goldenen Jahren" des deutsche Steuerrechts 1924 bis $1930,{ }^{227}$ mit subtilem Fleiß durchdacht, begrifflich fortentwickelt und abgestimmt wurde. Der bereits seit 1900 von der Schmollerschen Besteuerungsidee beeindruckte Erzberger - seit dieser Zeit vorerst Mitarbeiter des Ausschußvorsitzenden für die Steuerreform des Württembergischen Landtages - war ein harter Kritiker der preußischen Besteuerungspraxis gewesen. ${ }^{228}$ Er legte 1919 eine neue Zielrichtung für die erforderlichen Reformen unter Anlehnung an die Kritik Meisels und das săchsische Muster für die Zukunft fest. Zusătzlich wurden diejenigen Teile des preußischen EStG, die nicht das Steuerchuldverhältnis betrafen, 1919 in systematisch fortgebildete eigene Gesetzeswerke, wie die Reichsabgabenordnung, das Körperschaftsteuergesetz, das Kapitalertragsteuergesetz und andere, ausgelagert. ${ }^{229}$ Dann wurde z. B. zur Eindämmung der Steuervermeidung in der Abgabenordnung ein Umgehungstatbestand

${ }^{227}$ Vogel, K. (1962), S. 437. Zu dieser Zeit löste sich das Steuerrecht als aigenes Rechtsgebiet aus dem allgemeinen Verwaltungsrech, s. Vogel, K. (1962), S. 435, S. 436; s. a. Henning, F. W. (1973), S. 293; auch: Tipke, K. (1993). Die Steuerrechtsordnung, S. 49.

${ }^{228}$ Epstein berichtete von Erzbergers intensiver Tatigkeit fur den Vorsitzenden des Ausschusses des Württembergischen Landtages für đie Einkommensteuerreform ab 1897. A. Gröber, von Berufs wegen Richter, war als Mitglied des Württembergischen Landtags Gründer und Vorsizender der dortigen Zentrumspartei. Desgleichen war er Mitzlied des Deutschen Reichstags, in den Erzberger 1904 als jüngstes Mitglied einzog. Erzberger bearbeitete für Gröber đie Entwürfe und Verhandlungen zur Einfuhrung eines modemen EStG. Beide versuchten die tragenden Grundgedanken des sächsischen EStG 1874/78 als Leitidee in das württembergische EStG einzubringen, was ihnen nur bezüglich einiger Verhandlungspunkte gelang, s. Pistorius, T. (1903), S. 67 - 69; ders. in: Ministerielle Denkschrift vom 19.3.1909, S. 400; s. a. Pausch, A. (1965), S. 11; ders. (1992), S. 32; Epstein, K. (1959), S. 32, S. 328; Eschenburg, A. (1973), S. 10; s. a. Erzberger; M. (1903), S. 380.

229 Epstein, K. (1959), S. 338; Bayer, H. W. (1991), S. 335; Pausch, A. (1992), S. 35; s. a. Leidel, H. (1964), S. 105 . 
normiert, der bis heute, wenn auch verändert, beibehalten wurde und stăndig umstritten blieb. ${ }^{230}$

Das Steuerstrafrecht, dessen sowohl mangelhafte, als auch unabgestimmte Ausgestaltung Meisel beklagt hatte, wurde in der Abgabenordnung ausgebaut und den notwendigsten Bedürfnissen der Finanzverwaltung, soweit durchsetzbar, angepaßt. ${ }^{231}$

Viele der in der Kritik von Meisel und anderen gerügten Măngel der Steuertechnik wurden um 1919 endgültig beseitigt. Dazu gehörte auch die von Schanz 1896 beklagte, für das preußische EStG 1891 grundlegende Bedeutung des Begriffs der "Einkommensquelle", die bereits für die restliche Dauer des Krieges durch die "lex Schweckendieck" 1916 eingeschränkt worden war. Der fortdauernde Bestand einer Einkommensquelle verlor fortan für die Besteuenung seine bisherige essentielle Geltung. ${ }^{232}$ Die Rolle einer Einkommensquelle als Inbegriff der normierten Tatbestandsmerkmale zur Auslosung steuerbarer Einkünte und zugleich Regelungsinstanz für deren Zurechnung blieb jedoch als notwendiger Bestandteil des Enumerativkatalogs (mit Einschränkungen) bis heute erhalten. ${ }^{233}$ Auch die von Meyer bereits 1901 empfohlene Umstel-

230 § 5 RAO 1919, in: RStBI. I, S. 1994, spater § 42 AO 1977. Nach Hensel war $\$ 5$ RAO als "Generalumgehungsklausel" ... "ein unbestimmter Steuertatbestand, dessen Voraussetzungen und Folgen sich erst aus dem Einzelfall ergeben", s. Hensel, A. (1923).

${ }^{231}$ S. Meisel, F. (1911), S. 330 - 352; ders. (1920), S. 9; s. a. Erzbergers Beurteilung und diejenige des hohen preuß. Finanzbeamten Michaelis (1913), Rezension, in: Verwaltungsarchiv, 21. Bd.., S. 488, S. 489; s, a. Becker, E. (1927), Sp. 710; Trapp, P., Sp. 863. Für Meisel gewährieistete auch das in der RAO 1919 normierte Steuerstrafrecht noch keinen zweckmäßigen Sanktionsmechanismus.

232 $\mathrm{Zu}$ den Wesensmerkmalen des Begriffs der "Einkommensquelle" nach dem preuB. EStG s. Fuisting, B. (1894), S. 58, Bem. 7; ders. (1902), Grundzüge ..., S. 109. S. 133, S. 150; ders. (1903), Einkommensbesteuerung, S. 9, S. 35; Fuisting, B./Sirutz. G. (1915), S. 186, S. 187, Bem. 15, 16 u. a. Zur Suspendierung der Bestandsvoraussetzung der Quellentheorie für die restliche Dauer des Weltkrieges s. Gesetz. betr. die Ergânzang des preuß. EStG v. 30.12.1916, in: PreußB. Gesetzessammlung 1917, S. 1; s. a. Moll . W. (1917), S. 289. Nach der erst von Schanz, dann von Delbrîck und Meisel nach 1909 in Gang gesetzten Diskussion um die mangelnde Eignung und spåter die problematischen Auswirkungen des preuB. EStG und insbesondere dessen Quellenbegriff, aber ebenso des Besteuerungsabschnittes, letrlich die ganze Besteuerungstechnik, hat es an Kritik nicht gemangett. Erst durch Erzbergers Reformen konnten die hôehst unsozialen Konsequenzen der Quellentheorie eingeschränkt und eine Besteuerung nach der Vergangenheit eingeführt werden, hiera: Moll, W. (1914), S. 384, S. 385; ders. (1912), S. 275; ăhnliche Kritik bereits bei Meyer, R. (1901), S. 17, S. 34 u. a.

${ }^{233}$ Zur Frage der Zurechnung von Einkünften bei Emittlung der Einkünfle nach dem Vermögenszugangsprinzip bzw. Quellenprinzip s. Biergans, E./Stockinger, R. (1982), S. 26, S. 30. An die Stelle des Begriffs der "Einkommensquelle" des preuß. EStG 1891 ( 8 Abs. 1 preuß. EStGi 1906); Futsting, B. (1894), S. 53, S. 54: $\$ 17$ Abs. 1 săchs. EStG 1874/78 (das săchs. EStG kannte nur "Hauptquellen") ist heute in Rechtsprechung und Literatur die "Einkunftsquelle" getreten. Fä die Vorstellung von "Einkommensquellen" war in Preußen bereits 1808 in dem "Reglement für das Kriegs-SchuldenWesen ..." die Plattform gelegt worden, die dann über das preuß. "Gesetz betreffend die Einfuhrung einet Klassen- und klassifizirten Einkommensteuer" vom 1.5.1851 ( $\$ 27$ bis 30), das EStG 1891 ( 7) bis zum EStG 1925 (\$§ 6.7) fortentwickelt wurde, s. Grabower, R. (1932). Preußens Steuem, S. 641, Anl. 2. S. 644, S. 236. Bereits in $\$ 2$ der "Deklaration des Kriegsschuldenreglements vom 22.3.1810 wird dann von "verschiedenartigen Quellen" des Einkommens gesprochen. Das "Regle- 
lung der Bemessungsgrundlage auf die Erfassung der Einkünfte eines abgelaufenen Kalenderjahres als Besteuerungsabschnitt fand nach 1919 Berücksichtigung.

Zu erwähnen ist noch, daß trotz der großen Finanznot nach Ende des verlorenen Krieges, ăhnlich wie in dem als Muster benutzten sächsischen EStG 1874/78, gemäß §§ 4 und 5 EStG 1920 der Regel nach alle, also auch einmalige Vermögensanfälle - unabhăngig von dem "rechtlichen oder tatsächlichen Grunde" - zu der steuerlichen Bemessungsgrundlage hinzuzurechnen wa-

ment" von 1808 befaßte sich intensiv mit den sogenannte "Fonds" ( $\$ 35)$, die zu "verschiedenen Arten des Einkommens" (\$§ 23, 24, 27, 30, 31) bzw, zu "Eink0̈nften" (\$ 34) fuhrten. Das Gesetz normierte unterschiedliche Tarife fũ Einkönfte, je nachdem, ob der Bezug derselben auf Eigentumsrechten des Steuerbürgers beruhte, oder ob Rechtspositionen schuldrechtlicher An den Zuflussen zugrunde lagen. Fur die Zuordnung des Besteuerungsgutes zu einem Steuerpflichtigen war dabei allein das Zivilrech! maßgeblich, das auswies, aus welcher Art objektiven oder obligatorischen Rechtspositionen die Zuflüsse stammten (§ 35a bzw. § 35b), s. Sammlung der für die Kgl.-Preuß. Staaten ...(1822), S. 193, S. 673. Das sächs. EStG 1874/78 setzte insofern eine völlig neue Entwicklung in Gang, als die Herkunft der Einkanfle ihre zentrale Bedeutung für die Entstehung und Zuordnung des Besteuerungsgutes verlor, Die in \$ 17 slichs. EStG 1874/78, erwalhnten "Hauptquellen" des Einkommens erfulliten nămlich, anders als vorher und später im preuB. EStG 1891, keinerlei systematische Funktion. Sie hatten nur einteilende statistische Bedeutung, s. Gensel, J. (1875), Sp. 1520; Wachler, P. (1912), S. 76. Die Zurechnung von Einkünften bestimmte sich hier nicht nach den zugnunde liegenden zivilrechtlichen. sondem nach wirtschaftlichen Merkmalen des Sachverhalts. Das hatte Folgen: Sowohl Ausbildung der Beamten als auch Behördenaufbau wurden entsprechend anders ausgerichtet als in Preußen, s. Kirsch, L. (1887), S. 73, S. 76; s. a. Blaher (1913), Sp. 623. Das preuB. EStG 1891 führte dann den 1808 gefundenen Grundgedanken wieder fort, indem die Inhaberschaft an einer Einkommensquelle vorı den zivilrechtlichen Merkmalen allein bestimmt wurde. Danach waren dern Inhaber eines dinglichen objektiven Rechts, z. B. Eigentum. NieBbrauch, Autorenrecht, Wohnrechte etc., bzw. einer schuldrechtlichen Rechtsposition, z. B. Pacht, Miete, Lizenzverträge, obligatorische Nutzungsrechte etc., die ihm zufließenden Einkünfte zuzuordnen. Nunmelur war weiterhin streng auf die zivilrechtliche formale Regelung abzustellen. Ausbildung der Beaunten und Aufbau der Behörde folgte den Anforderungen an juristische Verkenntnisse. Die bei Einfthrung der ESt in Preußen 1808 erkemnbare Gedankenfuhnung wurde als Tradition für die Reform von 1891 und den Neuaufbau im Deutschen Reich von 1925 und somit bis heute hin bestimmend. Das brachte das Primat des Zivilrechts mit sich. Dem Steuerrecht wurde die Funktion als Folgerecht zugewiesen. Enno Becker suchte in den 20er Jahren durch seine Forderung nach wirtschaftlicher Auslegung des Steuerrechts und nach eigenen steuerrechtlichen $\mathrm{Be}-$ griffen mit schwankenden Ergebnissen den Konsequenzen dadurch ermöglichter mißßbrăuchlicher zivilrechtlicher Gestaltungen für die Einkommensbesteuenung ohne Änderungen an dem Grundkonzept entgegenzuwirken. Die Vorliebe für rechtsdogmatische Perfektion füurte dazu, daß in der BRD lange Zeit hindurch geschickte Vertragsgestaltungen selbst unter pflichtteilsberechtigten nahen Angehörigen Versorgungszahlungen und ăhnliche Leistungen beim Verpflichteten der Besteuerung entzogen werden konnten. Dies entsprach oftmals den preuß. Verhältnissen, die zu großem Unmut gefulhrt hatten. Fut= sting, B. (1894), Anm. $4 \mathrm{zu} \S 7$ EStG, S. 56, Art. 23 Abs. 2 u. 3 der Ausführungs-Anweisung, S. 296 , S. 297. Erst die Finanzrechtsprechung schrănkte zu Ende der 70er Jahre die ausufernden Möglichkeiten zur Steuervermeidung wegen der Zurückhaltung des Gesetzgebers ein, vgl. Jansen, R/Wrede. F.. 3. Aufl. 1970 mit der 9 . Aufl. 1986; s. a. Schulze zur Wiesche, D. (1979). Sie tat dies, indem sie den Begriff der bisher einkunftsartbezogenen "Einkommensquelle", nunnchr "Einkunftsquelle", rechtsfortbildend einen gegenüber der bisherigen Auslegung anderen, eingeschrànkten wirtschaftsbezogenen Inhalt verlich. Da den Urteilen nur sektorale Bedeutung zukommen konnte, zeigen sich seither deutlich die Grenzen der Wagner-Fiuistingschen Besteuerungsidee in der Vielzahl von Erlassen und Verfugungen der Verwaltung zur Eindämmung von Mißbrãuchen, hierzu: Söffing, G. (1981), S. 200. 
ren, ${ }^{234}$ wobei in einem spezifizierten Enumerativkatalog von 13 Positionen nichtsteuerbare Ausnahmen aufgelistet waren. ${ }^{235}$

Diese Vorschrift wurde spăter von wissenschaftlichen Gegnern - und wird heute noch - zu dem Charakteristikum einer realitätsfremden, angeblich nicht an der Leistungsfahigkeit der Steuerbürger orientierten Reinvermögenszugangstheorie aufgebauscht. ${ }^{236}$

Rechtsdogmatisch orientierte Steuerjuristen verweisen noch heute auf den Ausnahmekatalog, um zu bemăngeln, daß durch diesen "der Durchbruch zu einer Rechtstheorie nicht geschaffl war", oder daß die Reinvermögenszugangstheorie durch diese Einschränkungen "ihre rechtsdogmatisch nachweisbaren Konturen verlor". ${ }^{237}$

In der Vernachlăssigung der praktischen Konsequenzen der Einschrånkungen zeigt sich die Abneigung gegen eventuell empirisch erprobte und bewährie Problemlösungen, die jedoch dem Ideal eines rein begrifflich "richtigen", dogmatisch widerspruchsfreien Rechtsgebăudes aus ästhetischen Gründen nicht genügen können.

Zur Zeit der Geltung des EStG 1920, das wegen der großen Finanznot in mehreren Novellierungen Einschränkungen erfuhr, war dessen Grundgedanken, wie bereits in Preußen, ständiger Kritik ausgesetzt.

In $\S 6$ Abs. 3 EStG 1925 wurden dann daher ausdrücklich "einmalige Vermögensanfälle" von der Besteuerung ausgenommen, obgleich der nunmehr im Gesetz wiederbelebte Enumerativkatalog steuerbarer Einkünfte deren Besteuerung ohnehin ausschloß. Erst bei Novellierung des Gesetzes vom 16.Oktober 1934 wurde diese Passage als überflüssig ersatzlos gestrichen.

Im übrigen sollten seit dieser Zeit die Tatbestandsbeschreibungen der Steuergesetze nach den unbefriedigenden Erfahrungen in der Vergangenheit wirtschaftliche Vorgänge und Zustănde und nicht nur formale Merkmale steuerlich erfassen. Vor allem sollten nach ihrer wirtschaftlichen Leistungsfähigkeit gleiche Fälle auch steuerlich gleich behandelt werden. Daher konnte das Anknüpfen des gesetzlichen Tatbestandes an die normierten formalen zivilrechtlichen Merkmale im Sachverhalt nicht ohne Einschränkung als zweifelsfreies Kriterium für die Entstehung des Steuerschuldverhältnisses ausreichen. Ohne

S. Anlage 3.

${ }^{315}$ S. hierzu $\$ 12$ Abs. 1 EStG 1920, in: RStBI. 1, S. 363

${ }^{266}$ Bereits bei Ritschl findet sich diese Bewertung, s. Ritschl, H. (1930), S. 267, S. 271, S. 281, S 286 Eine sachliche Darstellung geben Kirchhof, P./Söhn, H. (1992), Rđnr. A 424.

37 Lang, J. (1988), S. 39. Nach Lang führt § 12 EStG 1920 33. Ausnahmepositionen aut, tatsăch. lich sind es nur 13 Positionen, ūber die in übrigen bei Dưrchsicht kaum Streit entstehen könnte. 
Preisgabe des nun einmal aus dem preußischen EStG fortentwickelten Systems suchte man daher nach 1925 in zwei Richtungen den Ansprüchen an eine gleichmäßige Besteuerung zu genügen, damit die wirtschaftlichen Wertzugănge erfaßbar wurden: ${ }^{238}$ Einmal wurden für das Steuerrecht eigene steuerrechtliche Begriffe entwickelt, die zur Erfassung der spezifischen wirtschaftlichen Vorgänge geeigneter waren. ${ }^{239}$ Zusätzlich führte das Bedürfnis nach Gleichbehandlung von Vorgängen gleicher wirtschaftlicher Leistungsfähigkeit zur Fordenung nach einer die Măngel rein zivilrechtlicher Typisierung ergånzenden "wirtschaftlichen Betrachtungsweise" des steuerrechtlich relevanten Sachverhalts, wofür insbesondere Enno Becker frühzeitig eintrat. ${ }^{240}$

Die wirtschaftliche Beurteilung von Sachverhalten sollte danach durch eine entsprechende Auslegung der Vorschriften zur steuerrechtlichen Beurteilung werden, wie sich dies auch im Handelsrecht zunehmend durchsetzte.

Im Anschluß an die Finanzrechtsprechung wurden auf diese Weise nach 1925 durch Ausweitung der Interpretation die normierten formalen Tatbestandsmerkmale des Gesetzes zur Beurteilung ähnlicher wirtschaftlicher Vorgånge im Sachverhalt verwendet. Durch "eine freiere Interpretation von Rechtsbegriffen" oder "einen dehnbaren Sprachgebrauch" wurde so versucht, wirtschaftlich gleiche Gestaltungen ebenso auch steuerlich gleichmäßig mit zu erfassen. ${ }^{241}$ Auf diese Weise wurde durch Inanspruchnahme der Finanzrechtsprechung zur Regelung typischer Einzelfälle und Herleitung amtlicher Richtlinien das Einkommensteuerrecht außerordentlich kompliziert. Viele ärgerliche Gesetzeslücken konnten jedenfalls geschlossen werden. Die Privatautonomie erlaubte jedoch weiterhin eine schier unerschöpfliche Gestaltungsvielfalt, die dann nach 1925 stets wieder zu neuen Lücken im Besteuerungssystem fürte. Dennoch wurde der einmal eingeschlagene Weg ständig weiter beschritten.

238 Becker, E. (1934), Steuerrecht ..., Sp. 300. Nach Becker sollte das Steuerrecht "ein selbständiger Teil eines einheitlichen deutschen Rechts" werden. Die Tatbestandsverwirklichung sollte daher nicht nur auf Grund der privatrechtlichen Gestaltung beurteilt werden (Sp. 301). Dazu wurde von Becker gefordert, die wirtschaftliche Bedeutung "des Tatbestandes, auf den er das Recht anwenden will" und "Zweck und wirtschaftliche Bedeutung des Gesetzes" zu berücksichtigen, Becker. E. (1931), Sp. 25; s. a. Beisse, H. (1981), S. 136.

239. Henning, F. W. (1973), S. 295; Becker, E. (1934), Sp. 299, Sp. 306; ders. (1924). Sp. 166; ders: (1931), Sp. 24; ders. (1939), Sp. 745; Ball, K. (1925), Sp. 177; Beisse, H. (1981), S. 136; s. a Maunz, Th. (1940), S. 344.

${ }^{240}$ Becker, E. (1924), Zur Auslegung ..., Sp. 145, Sp. 146. Becker suchte ein "lebensnahes, fortschrittliches, wirtschaftlich orientiertes Steuerrecht" dem "lebensfremden, formalen rückständigen, begriffserstarten Zivilrecht" gegenüberzustellen. Zu dieser Kritik s. Maunz, Th. (1940), S. 348; s. a. Tipke, K. (1993), Steuerrechtsordnung, S. 1295.

241 Becker, E. (1924), Sp. 147; Beisse, H. (1981), S. 136. 
Viele der kritisierten, Steuervermeidungen erlaubende Schwachstellen der "preußischen Type" der Einkommensbesteuerung waren so bei der erneuten Umstellung durch Einführung des EStG 1925 bereits beseitigt und konnten in einer "deutschen Type" nicht neu belebt werden, was der Besteuerungspraxis zugute kam.

Die in dem systemtragenden Grundkonzept des preußischen EStG 1891 angelegten, von Schanz 1896 als wesentliche Mängel bewerteten Eigentümlichkeiten des zu engen Einkommensbegriffs und der strengen Trennung von Einkommen und Vermögensmehrung mit den störenden Folgewirkungen fanden aber nach Einführung des EStG 1925 eine heute oftmals von Sachkennern beklagte Neubelebung von großer Tragweite. ${ }^{242}$

Aus Vorsicht war zur möglichen Korrektur befürchteter unerwünschter Steuervermeidungen als $\$ 49 \mathrm{EStG} 1925$ in das Gesetz die nach dem săchsischen EStG 1874/78 erfolgreich angewendete Vorschrift über eine ersatzweise normierte Besteuerung nach dem Verbrauch aufgenommen worden. ${ }^{243}$ In der wiederum nach eingriffsrechtlichen Gesichtspunkten ausgerichteten Einkommensbesteuerung der "deutschen Type" blieb diese Regelung in der Öffentlichkeit stets heftig umstritten und wurde als Fremdkörper beurteilt, da die Grundgedanken der das sächsische EStG $1874 / 78$ als Ausgangsmuster tragenden Besteuerungsidee Schmollers in Vergessenheit geraten war bzw. Verständnislosigkeit erzeugte. ${ }^{244}$ Die als Ermessensvorschrift ausgestaltete Bestimmung,

${ }^{242}$ Schmolders, G. (1960), S. 75; Tipke, K. (1973), S. 394; Jehner, H. (1988), S. 267; ders. (1990), S. 8. Schmölders sprach von dem fehlenden Einkommensbegriff, was der Sache nicht ganz gerecht wird. Er stellte jedoch auf dasselbe Problem ab.

${ }^{243}$ Zur Aufnahme der Vorschrift in das EStG 1925 s. Strutz, G. (1930), Kommentar zum EStG 1925, IV. Besteuerung nach dem Verbrauch, \$ 49. I. Entstehungsgeschichte, Begruindung und Inhalt. S. 790, insbes. S. 807. Der Grundgedanke wurde bereits in $\$ 11$ der Zweiten SteuernolVO vom 19.12.1923, RGBI. I. S. 1207, zur Bemessung der Vorauszahlungen verwendet. Es sollte sichergestellt werden, da $B$ der Steuerbürger seinen Lebensunterhalt aus versteuerten Mitteln bestreitet.

244 Jastrow hat 1891 das såchs. EStG $1874 / 78$ im Vergleich als "eine kombinierte Einkomunen. und Verbrauchssteuer" bezeichnet, da die Vorschrift in Sachsen sehr oft angewendet wurde. Er hielt die Regelung dem preuB. EStG 1891, das dem sächs. Muster nicht gefolgt war, entgegen, s. Jastrow, J. (1891), S. 744. Der Verbrauch sollte jedoch nur als Kriterium fur die Selbsteinschaltzung des Steuerbûrgers dienen, er war als Ersatztatbestand für die Bemessungsgrundlage konzipiert. Das Finanzamt sollte von ihr Gebrauch machen können, sobald der Verdacht einer Verschleierung der Einkommensverhāitnisse nicht auszuschließen war. Aus finanzpsychologischen Gronden legte die Verwaltung auf die Vorschrift, die eine Emessensvorschrift war. großen Wert, s. Thieme, Verbrauchsbesteuerung, in: FR 1960, S. 539; s. a. FR (1979), S. 534. Mit den seit Ende der 60er Jahre ausufernden Steuerver. gûnstigungen stellte sich zunehmend die Frage, ob ein Steuerbürger mit hohem regelmäßigem Lebensaufwand, der jedoch kein nennenswertes Einkommen versteuert, zur Abwehr einer Besteuerung nach den Kriterien des Verbrauchs, (\$ 48 EStG) mit Erfolg auf' die gesetzlich gewalhrte Inanspruchnahme von Steuervergünstigungen verweisen kann. Eine Untersuchung vertrat als Ergebnis, da $\mathbf{B}$ die Vorschrift gegen Art. $3 \mathrm{GG}$ verstoBe, da sie den gewandelten Verhältnissen nicht angepaBt wurde und infolge der gesetzlich gewăhirten Steuervergünstigungen zu willkürlichen Ergebnissen gelangen könne, s. Gerstein, E. (1970), S. 119. Fortan schwankende Finanzrechtsprechung bestătigte die gespaltene 
die mehrfach von Strutz ausgiebig kommentiert wurde, ${ }^{245}$ ist jedoch in konkreten Fätlen von der Finanzrechtsprechung zumeist anerkannt worden. ${ }^{246}$ Die Vorschrift wurde, anders als seiner Zeit in Sachsen, aber selten angewendet und später trotz Bestätigung durch den Bundesfinanzhof noch im Jahr 1972 schließlich 1980 als angeblich überflüssig ersatzlos - nunmehr § $48 \mathrm{EStG}$ gestrichen. ${ }^{247}$

Im ubrigen behielten die für die "preußische Type" charakteristischen Regelungselemente ihre nach dem preußischen EStG 1891 vorgesehene Funktion. So blieb es bei der Deklarationspflicht zugleich mit dem für die Behörde bei der amtlichen Veranlagung 1891 vorgeschriebenen Untersuchungsgnundsatz und der entsprechend eingeschränkten Bindung der Behörde an die Erklärung. In dieser Kombination mit den weiteren Regelungen des ungeeigneten Steuerstrafrechts und mangelhafter Prüfungsmöglichkeiten der Behörde hatte Meisel Unvereinbarlichkeit gesehen und er hatte sie unter anderen Umständen als charakteristische Elemente der "preußischen Type" der Einkommensbesteuerung beurteilt. ${ }^{248}$

Trotz der eingangs erwähnten Beseitigung vieler Schwachstellen sind nun bis heute die von Schanz und Meisel beklagten schwerwiegenden Măngel mit Übernahme der systemtragenden Grundgedanken in der von letzterem sogenannten "deutschen Type" der Einkommensteuer erhalten geblieben. Sie ha-

Beurteilung. Die Verwaltung wendete die Vorschrift seit 1970 nicht mehr an. Sie hătte durch Anwendung die Ziele der aus wirtschaftspolitischen Gründen gewährten und zur Zeit erheblicher Schwäche des Kapitalmarkts erwünschten Inanspruchnahme von Steuervergünstigungen durch die Steuerzahler empfindlich stören kōnnen. Die Vorschrift wurde 1980 mit einer Begrindung, die der Realitait erkennbar nicht entsprach, vorn Gesetzgeber ersatzlos ohne Gegenstimmen gestrichen. Für ihre Anwendung war das offfentliche Verständnis abhanden gekornmen, s. FR 1979, S. 533; s. Deutscher Bundestag, 8. Wahlperiode, Drs. 8/3688, S. 20 u. Drs. 8/4007, S. 6. Nach Tipke hob $\$ 48$ EStG "die Harmonie zwischen Destination der Steuer und Bemessung" auf und war daher nicht zu rechtfertigen, $s$. Tipke, K. (1971), S. 17. Der Rechtsdogmatiker steht den praktischen Auswirkungen fem, obgleich er vehement für eine Besteuenung nach der Leistungsfähigkeit eintritt.

245. Strutz war 1912 unter dem Eindruck der Kritik an den sozialen Auswirkungen des preuß. EStG 1906 nachhaltig futr die Aufnahme dieser aus dem sächs. Muster stammenden Vorschrift im Falle von Unklarheiten bei Ermittlung der Bemessungsgrundlage eingetreten, Strutz, G. (1912), S. 224. Nun trat er als Gegner der Vorschrift auf, Strutz, G. (1925), Sp. 606; ders. (1925), Sp. 1952; ders. (1927), Sp. 406, Sp. 764; s. a. Becker, E. (1927), Sp. 718; ders. (1933), Handkonmentar .... § 49, S. 1931; ders. (1934), Sp. 225 .

${ }^{246}$ Hierzu: BFH, U. v. 9.8.68 VI R. 220/66, in: BStBI. II, S. 5; BFH I R 231/70 v. 10.5.72, in: BStBI. II 72, S. 900; s. a. Rechtsprechung, in: Becker, E. (1933), Handkommentar ... II, 3. Teil, dort zu $\$ 49$ angegebene Rechtsprechung des RFH.

247 Die Vorschrift wurde mit Zustimmung aller Parteien getilgt, s. Deutscher Bundestag. 8. Wahlperiode, 218. Sitzung, Verhandlungen, S. 14539; s. a. Drs. 8/3688.

248. Meisel, F. (1911), S. 352. Meisel beklagte, "wie wenig die Kenntnis der Steuertechnik in die Finanzwissenschaft eingedrungen ist", S. 359. Die Feststellungen Meisels decken sich mit den Darstellungen zur selben Zeit des preuB. Steuerbeamten L. Buck, die negativen Bewertungen blieben bei Buck freilich nur angedeutet, s. Buck, L. (1911), S. 95, S. 99; s. Neckels, P. (1994), S. 15. 
ben wegen der Konsequenzen die Verwaltung bis heute zum Aufbau zahlloser Verteidigungslinien gegen einen inzwischen mit der hohen Steuerprogression einhergehenden ausufernden Steuerwiderstand durch eine umfassende Kasuistik von Verwaltungsrichtlinien, Erlassen und letztich auch Novellienungen durch Einschalten des Gesetzgebers gezwungen und so zi schwer beherrschbarer Kompliziertheit des Einkommensieuerrechis geführt.

So bringt es der Enumerativkatalog der acht, nach 1934 sieben Einkunftsarten, wie bereits in Preußen mit sich, đaß Wertzugănge, die nicht unter die konkret normierten positiv festgelegten Tatbestandsmerkmale subsumierbar sind, keine Besteuerung auslösen. Dieser Umstand läßt sich gegebenenfalls durch vertragliche Gestaltungen zur Steuervermeidung aber leicht erreichen. Die Frage, ob in einem konkreten Fall ein Veräußerungsgewinn steuerbar ist, hăngt nămlich z. B. oftmals von đer Zuordnung zu đer Einkunftsant ab. Eben diese Zuordnung ist aber zumeist rechtzeitig gestaltbar.

Das EStG 1925 und die Novellierungen bis heute stellen ebenso wie das preußische EStG 1891 grundsätzlich mit wenigen Ausnahmen entsprechend dem eingeschränkten Einkommensbegriff auf das sogenannte Markteinkommen ab, da dieses, wie es oft heißt, angeblich der beste Indikator der Leistungsfähigkeit sei. ${ }^{249}$ Zur Vermeidung einer mißbräuchlichen fortlaufenden Saldierung hoher Verluste für Aufwendungen von Steuerbürgern, die in den Bereich eines Hobbys fallen, der eigentlich Lebensaufwand darstellt, mit steuerbaren positiven Einkünften hatten Verwaltung und Finanzrechtsprechung 1895 das Rechtsinstitut der sogenannten "Liebhaberei" entwickelt. Die hierzu in Preußen gefundene Regelung und die bereits dargelegten Konsequenzen gelten mit unwesentlichen Abstrichen bis heute fort. ${ }^{250}$ Die sächsische Lösung

${ }^{249}$ Becker, E. (1931), S. 26: "Das Gesetz will das Einkommen = einkommen besteuern, also doch wohl was einkornmt ...". Tipke, K. (1993), Steuerrechtsordnung. S. 560; Lang, J. (1988), Die Bemessungsgrundlage .... S. 104; Bayer, H. W. (1991), S. 525; Kurchhof, P. (1988), S. F 23, S. F 91 . Nach Kirchhof sollten nur steuerbar sein "die Einnahmen, die aus einer den Zugang zum Marki vermittelnden Erwerbsgrundlage erzielt worden sind". ... "Die Einkommensteuer belastet das vom Markt abgeleitete Einkommen", so die Konzeption Kirchhofs.

${ }^{250}$ Becker, E. (1925), Sp. 357; ders. (1935), Sp. 9; ders. (1940), S. 396 - 405; Lang, J. (1981), Liebhaberei ..., S. 223. Lang kommt zu dem Ergebnis, daß Liebhabereieinkunfte nach Auslegung des dem Worttext zugrundeliegenden Sinnzusammehangs nicht steuerbas sind. Das entspricht der preub. Regelung (S. 234). Zum selben Ergebnis gelangt Weber-Grellet, H. (1992), S. 561, S. 602. Für den Praktiker, der groBe Steuerzahler steuerlich betreut, scheint die von Steuerjuristen vertretene rechtsdogmatisch vorgegebene Beurteilung mit einer zumeist von denselben Autoren geforderten Besteuerung nach der Leistungsfahigkeit nicht vereinbar zu sein. Die fortgefuhrte preuß. Regelung ist eine Fundgrube für Hochverdienende zur Einsparung, von Aufwendungen der Lebensführung. Die noch heute üblichen, aus, der Wagnerschen Besteuerungsidee hergeleiteten Konsequenzen für die steuerliche Behandlung der Liebhaberei zeigen eine erstaunliche praxisferne Hilflosigkeit rechtsdogmatisch orientierter Steuerjuristen, s. a. vom praktischen Interesse der Steuerpllichtigen ausgehend Streck, M./ Rainer, T. (1980), 2/80, S. 3638 und 3/80, S. 3656; Kupfer, G. (1993), S. 9212; Schuhmann, H. (1994), S. 245; s. aL Reinhardt, F. (1943), S. 464. 
sah völlig anders aus und brachte viele oft unliebsame, aber eher überzeugende Ergebnisse.

Die Versteuerung von Einkünften aus Kapitalvermögen führte in dern preuBischen EStG 1891 zu der früher erwăhnten unerfreulichen Erscheinung von Grauzonen, die die illegale Verkürzung von Steuern begünstigte. Die hier gegebenen Möglichkeiten werden auch heute noch in großem Umfang infolge eines außergewöhnlich hohen Steuerwiderstands zur Steuerverkürzung ausgenutzt. ${ }^{251}$ Auch das hăngt mit der Charakteristik der "preußischen" bzw. "deutschen Type" der Einkommensbesteuerung eng zusammen. Diese ist nach wie vor schwerpunktmäßig nach eingriffsrechtlichen Gesichtspunkten organisiert. Sie trennt streng zwischen Einkommens- und Privatsphäre und legt die veranlagende Verwaltung auf den Untersuchungsgrundsatz fest, ohne ihr dabei ein geeignetes Prüfungsrecht zu gewähren. Dennoch ist diese aber nicht an den Inhalt der obligatorischen Einkommensteuererklärung des Zensiten gebunden. Auch die im AnschluB an die Erzbergersche Steuerreform eingefuhrte Betriebsprüfung kann hier bis heute nicht weiterhelfen, da ihre Tätigkeit ebenso nach eingriffsrechtlichen Gesichtspunkten streng eingegrenzt ist. ${ }^{252}$ Bereits Meisel hielt für die preußischen Verhăltnisse fest, daß von der veranlagenden Behörde "Allwissenheit" erwartet wird. ${ }^{253}$ So ist es heute noch.

Auf diese Weise wird die illegale Verkürzung gerade der Einkünte aus Kapitalvermögen nach wie vor durch geringes Entdeckungsrisiko leicht gemacht, und der Unehrliche wird, wie zuvor schon in Preußen, weiterhin belohnt. ${ }^{254}$

251 Streck, M. (1984), S. 2205; Tipke, K. (1986), Ungleichmäßigkeiten ..., S. 601; ders. (1989), Die rechtliche Misere ..., S. 157. Neumark schătzte 1984, daß 70\% der Zinsertrăge in Deutschland steuerlich nicht erfaßt würden, s. Frankfurter Rundschau v. 31.10.84, S. 3.

${ }^{252}$ Nach $\$ 193$ AO 1977 erstreckt sich die Zulässigkeit der BP im wesentlichen auf den betrieblichen Bereich, also auf Einkünfte der Einkunftsarten 1 - 3. Daraber hinaus ist eine BP nur zulässig, "wenn die für die Besteuerung erheblichen Verhâltnisse der AufkJärung bedörfen und eine Prûfung an Amtsstelle nach Art und Umfang des zu prüfenden Sachverhahtes nicht rweckmäßig ist", $\$ 193$ Abs. 2 Ziff. 2 AO 1977. s. Geimer, R. (1988), S. 134. Dazu kommt, daß zur Zeit Mittelbetriebe etwa nur nach neuneinhalb, Kleinbetriebe alle 19,3 und Kleinstbetriebe alle 50 Jahre gepraft werden. Daß die BP dern Schutz des steuerehrlichen Bürgers dient und schon daher eine Schutzvorrichtung der Demokratie ist, war seit ihrer Einfuhrung nach 1921 nur schwer vermittelbar. Tipke erweckt in einer Abhandlung den Eindruck, er mulsse die BP gegen allmăchtige Feinde verteidigen, Tipke, K. (1968), S. 135. Ober die Möglichkeiten ihres Einsatzes zur Kontrolle der Steuerchrlichkeit durch intelligente Verprobungsweisen erfihrt man aus der Feder rechtsdogmatisch orientierter Juristen nichts.

${ }^{253}$ Meisel, F. (1911), S. 360.

254 Insbesondere der BankenerlaB von 1949 zum Schutz des Kapitalmarkts ist hier zu nennen. Zwar anderte der Bankenerla\& vom 2.8.1945 nichts an der in §175 AO 1957 normierten Auskunftspflicht Dritter in Interesse einer gesetzmaBigen Besteuerung, s. Mattern, G./Meßmer, K. (1968), S. 322, Anm. 1149. Die vorgeschriebene praktische Handhabung von Auskunftsersuchen an Banken, Sparkassen und Kreditinstitute erschwerte jedoch die Tatigkeit der Verwaltung zur Wahmehmung der Steueraufsicht, da jeweils die Voraussetzungen des $\S 209$ AO 1931 i. d. F. v. 22.10.1957 gegeben sein mußten. Im abrigen ist der Schutz des Bankkunden durch Gesetz vom 25.7.1988 inzwischen als $§ 30 \mathrm{a}$ 
Die Finanzverwaltung ist bis heute wegen der vielen Möglichkeiten zu Steuervermeidungen und Steuenumgehungen đaher auch hier stăndig gezwungen, Verteidigungslinien gegen Mißbrăuche aufzubauen.

Dabei haben die hohen Tarifsătze von insgesamt bis zu $61 \%$ in der Spitzenbelastung das Interesse an der Steuervermeidung außerordentlich vermehrt.

Drei Gestaltungsbereiche zur legalen Stenervermeidung sind heute allgemein von besonderem Interesse: Einmal lassen sich viele Verăußerungsgeschăfte infolge des "dualistischen" Einkommensbegriffs bei geschickter Gestaltung des Sachverhalts ebenso wie nach dem preußischen ESIG 1891 steuerfrei in der Privatsphäre abwickeln. Ein großer Teil wirtschaftlicher Vorgănge, der zu Vermögensmehrungen führt, löst auf diese Weise keine Einkommensteuer aus. Dann lassen sich Einkünfte bzw. Einnahmen und gegebenenfalls getrennt davon ebenso die zugehörigen Aufwendungen đurch geeignete Vereinbarungen wie früher leicht verlagern. Dazu kommen noch neuartige Möglichkeiten zur legalen Steuervermeidung, die heute von der noch zu erwăhnenden Einführung besonderer nichtfiskalischer Vergünstigungsnormen bereitgehalten werden.

Das Interesse, Verảßerungsgewinne als Folge von Wertzuwächsen betrieblich genutzter langlebiger Wirtschaftsgüter nicht versteuern zu müssen, hat z. B. zu Betriebsaufspaltungen in bloß vermögensverwaltende Besitzgesellschaften und gewerblich tätige Betriebsgesellschaften geführt. Hier hat die Verwaltung durch Erlasse für Einschränkungen gesorgt. So wurde von ihr die sogenannte "Geprägetheorie" entwickelt. Diese wurde von der Finanzrechtsprechung verworfen, was dann wieder zu einer Gesetzesnovellierung führte. ${ }^{255}$

Die Behörden sind seither beständig gehalten, Indizien zum Nachweis einer tatsächlichen gewerblichen Tätigkeit zu suchen, während vermögensverwăltende Verrichtungen in der Privatsphäre erklärt wurden. Das Interesse kann wegen der hohen Progressionssätze erheblich sein. Die Veranlagung wird auf diese Weise wie in Preußen zum quasiforensischen Verfahren. Die Konsequenzen dieser Umstände können sich im übrigen zumeist mit großer Verspä-

in die AO 1977 übernommen und weiter ausgebaut worden. Die Tatigkeit der Finanzverwaltung zur Garantie der Gleichheit der Besteuenung ist dadurch weiter erschwert worden.

${ }^{25 s}$ Blencke, H. (1979), S. 41; Wendt, R. (1978), Betriebsaufspaltung, in: StKongr.Rep., S. 219; Schmidt, L. (1979), S. 671, S. 699; Felix, G. (1979), Betriebsaufspaltung, Attraktion mit Túcken, in: Wirtschaftswoche Special, S. 26; Schmidt, L. (1994), EStG-Kommentar, § 15, Anm. 140 - 151, S. $1381 ;$ s. a. Donath, R. (1991), S. 16. 
tung bis in das Steuerstrafrecht auswirken, das auf diese Weise seine Präventivwirkung einbüßen muß. ${ }^{256}$

Infolge des seit 1949 bestảndig zwischen $53 \%$ und $56 \%$ in der Spitze angesiedelten progressiv ausgestalteten und bereits bei $20 \%$ einsetzenden Tarifzugriffs - wobei noch Ergänzungsabgaben, Kirchensteuer und eventuell Gewerbesteuer einzukalkulieren sind - ist es seither von großem Interesse, durch vertragliche Gestaltungen Einkünfte so zu verlagern, daß insgesamt eine Steuerersparnis bei dem geringe Steuern zahlenden Übertragungsberechtigten gegenüber dem in hoher Progression eingebundenen Verfügenden entsteht. Durch das Gefalle kann es dann jeweils gelingen, die Allgemeinheit durch Steuerersparnis an Aufwendungen zu beteiligen, die Angehörigen, aber nicht nur diesen, freiwillig oder auf Verpflichtungen beruhend, gewährt werden. Dem Bürger mit der höchsten Steuerbelastung entstehen auf diese Weise wirtschaftliche Vorteile durch Einsparung von Einkommensteuer von heute immerhin bis zu $61,5 \%$ der Zahlungen.

Mit der Höhe der ausgelösten Progression wächst das Interesse an gegebenenfalls komplizierten vertraglichen Konstruktionen zur Erlangung derartiger Vorteille.

Auf dieser Grundlage wird verstăndlich, daß Vereinbarungen der verschiedensten Art und vor allem intelligente Kombinationen verschiedener Vertragstypen mit nahen Angehörigen heute zum alltäglichen Repertoire eines jeden Beratungsgesprächs in Steuerkanzleien gehören. ${ }^{257}$

Besonders erwähnenswert ist hierbei wiederum das bereits früher angeführte Rechtsinstitut des Nießbrauchs und nicht zuletzt verwandter Dienstbarkeiten, wie etwa des Wohnrechts, die in den $\$ \S 1030$ bis 1093 BGB geregelt sind. Sie erlauben eine wegen der formal objektive Rechtsstellungen einnehmenden Position des Berechtigten eine steuerlich wirksame Verfügung über Erträge ohne Aufgabe des Eigentums durch den Verfügenden.

Mit steuerlicher Wirkung sind derartige nicht formgebundene entgeltliche, unentgeltliche, befristete oder unbefristete, kündbare oder unkündbare Vereinbarungen anzuerkennen, insoweit sie nicht den Tatbestand der Steuerumge-

256 Tipke zeigt die strafrechtlichen Konsequenzen im AnschluB an eine langwierige komplizierte finaragerichtliche Entscheidung. Da die endgültige Rechtskraft eines Vorgangs nach Ausschöpfung der Rechtsmittel derzeit etwa acht Jahre beansprucht, ergibt sich erst mit dieser Verspātung die Feststellung, ob eine strafbewehrte Verkürzung vorlag. Das kann zu absurden Konsequenzen fuhren. Bis zum Aufgreifen eines Steuerstrafverfahrens verstreichen nach Erfahrungen des Autors heute bis zur Vernehmung durch die Strafsachenstellen etwa drei Jahre, s. hierzu: Tipke, K. (1985), Juristische Schulung, S. 347.

257 Zur Stellung des Steuerberaters zu seinem Mandanten s. Spitaler, A. (1949), in: FA, Sonderheft, S. 26, S. 27; s. a. Blencke, H. (1979), S. 25 . 
hung durch "Mißbrauch von rechtlichen Gestaltungsmöglichkeiten" gemäß § $42 \mathrm{AO} 1977$ erfullen.

Einkünte werden in der Regel bei demjenigen erfaßt, der formal in seiner Person die gesetzlichen Voraussetzungen der jeweiligen Einkunftsart der noch heute maßgeblichen Besteuerungsidee entsprechend erfült. Dabei muß es sich jedoch nicht um die auch wirtschaftlich begünstigte Person handeln. Allein das Vorhandensein der normierten formalen Tatbestandsmerkmale im Sachverhalt ist entscheidend. ${ }^{258}$

Gerade dieses Institut des Nießbrauchs war lange Zeit hindurch als Folge rein formaler steuerlicher Beurteilungen gemä $B$ der "deutschen Type" eine Fundgrube für spitzfindige Konstruktionen zur Steuerersparnis, bis die höchstrichterliche Finanzrechtsprechung $1976^{259}$ und dann $1980^{260}$ durch veränderte Auslegungen bei Zurechnung von Einkünften endlich die Anerkennung von rein formalen zivilrechtlichen Merkmalen auf wirtschaftiche Kriterien des Sachverhalts umstellte und die Verwaltung durch zwei Erlasse ${ }^{261}$ der bis dahin sogar auf Vertragsgrundlage formlos möglichen unterschiedlichen Zuordnung von Einnahmen und verursachten Aufwendungen die steuerliche Anerkennung versagte $e^{262}$.

258 Lange Zeit hindurch war die Einräumung eines NieBbrauchs an einem Wertpapierdepot zu Gunsten unterhaltsberechtigter Kinder (und/oder sonstiger Angehöriger oder Nahestehender), die dann sogar eventuell von dem unterhaltsverpflichteten Elternteil zu deren Unterhalt verwendet wurden, ein weit verbreitetes Mittel, Steuern zu sparen. Auch als Verăußerungsgeschăfte, Darlehensabsprachen oder åhnlich getarnte obligatorische Versorgungsverträge konnten durch abgestimmte Einzelheiten zu gleichen steuerlichen Ergebnissen füren. In Abschn. 123 Abs. 1 ESTR 1968 wurde zwar unter Hinweis auf das BFH-Urteil VI R $274 / 66$ v. 24.11.67, BStBI. I 1968, S. 260, angeordnet, daß̉ Einkünfte aus Kapitalvermogen bei befristeter NieBbrauchsbestellung von unter füf Jahren dem Eigentümer weiterhin zuzurechnen seien, diese Verwaltungsanweisung blieb jedoch umstritten und konnte im abrigen vertraglich problemlos ausgeschaltet werden, s. hiera: Jansen, R./Hoffmann, M. (1977), 2. Auf., S. 55; s. a. Schulze zur Wiesche. D. (1979), S. 101, Bem. $249-255$.

${ }^{259}$ BFH-Urteil VIII R I 146/73 v. 14.12.1976, in: BStBI. II 1977, S. 115; hierzu: Schulze zur Wie. sche, D. (1979), S. 100, Bem. 247 und S. 101, Bem. 248.

${ }^{260}$ Drei Urteile des BFH v. 13.5.1980 in: BStBI. II 1981, S. 295, S. 297, S. 299; BFH-Urteil VIII R 75/79; BFH-Urteil VIII R 128/78.

${ }^{261}$ 1. NieBbrauchserlaB: Schreiben des BMF v. 23.11.1983 IV B 1 - S $2253-90 / 83$, in: BStBI. I 1983 , S. 508 (Einkormmensteuerrechtliche Behandlung des NieBbrauchs bei Einkünften aus Vermietung und Verpachtung und aus Kapitalvermögen). 2. NieBbrauchserlaB: Schreiben des BMF v. 15.11.1984 IV B 1 - S 2253 - 139/84, in: BStBI. I, S. 561 (Einkommensteuerliche Behandlung des, Nießbrauchs und anderer Nutzungsrechte bei Einkünften aus Vermietung und Verpachtung). Der zweite Erlaß wurde notwendig zur Berucksichtigung der in der Zwischenzeit ergangenen BFH-Urteile VIII R $215 / 79$ und VIII R 184/83, in: BStBI. II 1984, S. 366, S. 371.

${ }^{262}$ S. Brandenberg, B. (1985), S. 66, Bem. $85-105$, ders. S. 78, Bem. $106-111$; s. a. Setithel (1985), S. 70. 
Der seit 1949 von hohen Steuersătzen extrem angeheizte Steuerwiderstand ließ das NieBbrauchsrecht geradezu zur "Nagelprobe" für das Verhältnis zwischen Steuerrecht und Zivilrecht werden. ${ }^{263}$

Im bürgerlichen Recht als eines von vier vergleichbaren sachenrechtlichen Nutzungsrechten ausgestattet, verdrängt der Nießbrauch als umfassendes Rechtsinstitut den Eigentümer sowohl aus der Nutzung, als auch aus dem Besitz der Sache. Der Nießbrauch zieht mithin nach dem von strengem Typenzwang beherrschten Sachenrecht die Früchte einer Sache oder Gesamtheit von Rechten und Sachen kraft eigenen Rechts. ${ }^{264}$

Da die Rechtsordnung dieses normierte Rechtsinstitut zur Verfügung stellt, darf auch der Steuerbürger es für seine Steuerplanung in Dienst stellen. Insoweit herrschte stets Einigkeit. ${ }^{265}$

Wăhrend der Vorbehaltsnießbrauch im deutschen Sprachraum von Alters her in einer băuerlich strukturierten Gesellschaft vornehmlich zur Altersversorgung und im Erbrecht Verwendung fand, konnte mit Einführung der Einkommensteuer bald dem Zuwendungsnießbrauch besondere Aufmerksamkeit wegen seiner Eignung zur Erzielung von Steuerentlastungen insbesondere, aber nicht nur, unter Angehörigen zuwachsen.

Bereits in dem săchsischen EStG $1874(\S 3)$ und in dem spăteren preußischen EStG 1891 ( $\$ 13$ Abs. 3 bzw. $\S 12$ Abs. 3 EStG 1906) hatte der Nießbrauch bzw. der Nutznießer Erwähnung gefunden. Zur Zeit der Geltung des preußischen EStG 1891 konnte die Kenntnis der Folgen eines Zuwendungsnießbrauchs und insbesondere des Quotennießbrauchs wegen der Aufrechterhaltung einer bestehenden Einkommensquelle für den besserverdienenden Steuerbürger ein Geheimtip für legale Steuerentlastungen sein. ${ }^{266}$

Viele der von Delbrïck 1909 geh̆ußerten, gegen vermögende Großgrundbesitzer gerichtete Verdächtigungen der ungesetzlichen Steuerverkürzung finden bei Berücksichtigung der vom Nießbrauchsrecht - aber nicht nur diesem - ge-

263 Felix, G. (1981), Der NieBbrauch in Steuer und Recht, 26. Kölner Trainingstagung vom 22.29.6.1981. Arbeitsunterlage für Tagungsteilnchmer. S. S.

${ }^{264}$ Baur. F. (1989), Lehrbuch des Sachenrechts, 15. Aufl., S. 295: "Der Eigentûmer wird in seinem Nutzungs- und Besitzrecht depossediert": s. Promberger, B. in: Staudinger, Komm. z BGB 1981 , Vorbem. 5 zu $\S 1030$, Bem. 4 zu $\S 1036$.

265 Jansen. R./Hoffmann, M. (1977), 2. Aufl., S. 45.

206 Nach dem preuß. EStG 1891 war fur die Geltendmachung von Werbungskosten der Bestand einer Einkommensquelle Voraussetzung. Vorweggenommene Werbungskosten ließ diese formalistische Voraussetzung nicht zu. s. Fuisting, B. (1894), S. 71. Anm. 2; Fuisting, B./Strutz, G. (1915), S. 218. Anm. 31a. 
währten Möglichkeiten steuerrechtlicher Gestaltungen eine dem Laien und vielen Historikern schwer verstăndliche Auflösung. ${ }^{26 ?}$

Durch Schaffung eines Zuwendungsnießbrauchs vermochte man nämlich das in $\S 9$ Abs. 2 Ziff. 2 des preußischen EStG 1891 vorgeschriebene Abzugsverbot von "Ausgaben zur Bestreitung des Haushaltes der Steuerpflichtigen und der zum Unterhalte ihrer Angehörigen gemachten Ausgaben" bei Ermittlung der steuerlichen Bemessungsgnundlage als Folge des Primats des Zivilrechts elegant zu überspielen. ${ }^{268}$

Nach dem sächsischen EStG 1874/78 wurde die Einkommensteuer dagegen nicht von der Inhaberschaft einer Einkommensquelle als wesentlichem Merkmal für die Zurechnung der Einkünfte im Sachverhalt ausgelöst, sondern von der wirtschaftlichen Bereicherung eines Steuerbürgers, unabhăngig von der Herkunft oder dem Rechtsgrund der Vermögenszugănge. ${ }^{269}$ Daher ergab sich hier die Obliegenheit, auch Vermögensmehrungen durch Dispositionen des Steuerbürgers zur Tilgung von gesetzlichen oder freiwillig übernommenen Verpflichtungen in einer der Besteuerung zugrunde zu legenden fiktiven Vermögenszuwachsrechnung zu erfassen. Diese auf wirtschaftliche Merkmale des Sachverhalts abstellende Beurteilung blieb der "preußischen Type" der Einkommensbesteuerung fremd. ${ }^{270}$

267 Die in die Darstellung der maßgeblichen Historiker aufgenommenen Thesen ober dic Steuerunehrlichkeit der preuB. GroBgrundbesitzer wurden, wie Behrnauer 1910 zeigte, unüberprüft als. Vorurteile übernommen. Die meisten Gutsbesitzer waren hoch verschuldet. Sie waren nicht unehrlicher, als die Industriellen, sie schöpften nur die ihnen steuerlich gegebenen Möglichkeiten aus. Darin unterschieden sie sich nicht von anderen Gruppen, s. Behrnauer, F. (1910), S. 675; Witt, P. (1973), S. 210; Buck, L. (1916), S. 70. Auch Tipke übernimmt die Auffassung unäberprift, Tipke, K. (1993). Steuerrechtsordnung, S 319.

268 Der NieBbraucher war nach dem preuB. ESIG bezüglich der Einnahmen wie ein Eigentümer als Inhaber der Quelle zu behandeln. Um den Bestand der Quelle für eventuelle Werbungskosten aufrecht. zu erhalten, empfahl sich für den Eigentümer, gegebenenfalls einen entsprechenden Quotennießbrauch zu bestellen, s. Fuisting, B. (1902), Grundzûge ..., S. 125, S. 143, S. 158; Fuisting, B./Strutz, G. (1915), S. 186, Anm. 15, S. 513, Anm. 3; Fuisting, B. (1894), S. 33., Anm. 8, S. 14. Anm. 3. S. 73. Anm. 14.

269 Wachler, P. (1912), Das Königlich-Săchs.... S. 55, Bem. I zu $\$ 15$. Fuisting verwies wiederholt darauf, daß der Einkommensbegriff des preuB. EStG, den er für richtig hielt, in diesem Punkt von dem Schmollerschen Begriff abwich, Fuisting. B. (1902), Grundzüge ..., S. 110, S. 147; ders. (1903). Die Einkommensbesteuerung ..., S. 21.

${ }^{270}$ Fuisting hatte dem Rechtsschutz des Steuerbürgers im Besteuerungsverfahren uneingeschränkic Prioritat zugeordnet, s. Fuisting, B. (1896), S. 293 ff, hier S. 437. Der überspannte Rechtsschutz brachte mit sich, daB die positive Kenntnis der einzelnen zivilrechtlich vorgegebenen Einkommensquellen des Steuerpflichtigen bei der Veranlagung fur die Finanzbehörde erforderlich war (\$. 440), wobei z. B. jede einzelne Kapitalforderung als Einkommensquelle zăhlte (S. 462). Die Annahme einer Quelle durch Schătzung war unzulässig (S. 459). Eine zweifelsfreie Ermittlung der Quellen war daher Voraussetzung fùr die Tătigkeil der Veranlagungsbehôrden (S. 457). Die Veranlagungstătigkeit muBte sich auf juristische Beurteilungen des Sachverhalts konzentrieren. Da eine Veranlagung nur von bekannten Einkommensquellen ausgehen konnte: lagen mit. deren Kenntnis stets auch konkrete Avhalts- 
Nach der Auslegung des deutschen Einkommensteuergesetzes durch den führenden Kommentator Enno Becker kam dem $\S 18$ Abs. 1 Ziff. 2 EStG 1925 - nach der späteren Novellierung § 12 Ziff. 2 EStG 1934 und noch heute $\S 12$ Ziff. 1 und 2 EStG 1990 -, der den Abzug von Aufwendungen "zur Bestreitung des Haushalts des Steuerpflichtigen und zum Unterhalte seiner Familienangehörigen" bei Ermittlung der steuerlichen Bemessungsgrundlage verbot, nach den gemachten Erfahrungen die Rolle als vorrangiger "Kerngedanke" des Gesetzes zu. ${ }^{271}$ Dies war eine Konsequenz der von Becker nachhaltig geforderten wirtschaftlichen Betrachtungsweise. Auf diese Weise vermochte er die legale aber mißbräuchliche Steuervermeidung durch Zuwendungsnießbrauch und obligatorische Vertragsgestaltungen zu verhindern.

In rechtsdogmatischer Hinsicht waren die von Becker hergeleiteten Auslegungen, die das Primat des Zivilrechts für das Steuerrecht infrage stellen mußten, für viele Steuerrechtler inakzeptabel. In bezug auf die Bedeutung des ZuwendungsnieBbrauchs waren eine schwankende Rechtsprechung und mangelnde Rechtssicherheit die Folge. ${ }^{272}$

Nach 1964 wurde dann erst einmal der entgeltlich eingerăumte Nießbrauch als Quellenübertragung ohne Prüfung der Angemessenheit der Gegenleistung anerkannt. ${ }^{273}$ Rechtssicherheit war aber erst wieder gegeben, als nach 1966 die

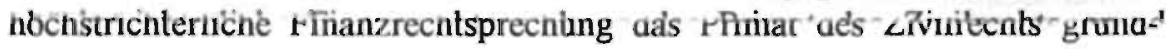

punkte fûr eine Schătzung der Einkûnfte vor (S. 451). Für eine Vermőgenszuwachsrechnung, seì es als Schätzungsmethode oder als Hilfsmittel zur Verprobung von Angaben des Steuerpflichtigen fehlte nach dem Besteuerungsverfahren ohne konkreten Nachweis von Quellen des Einkommens die Grundlage. Die Veranlagungstätigkeit lag entsprechend in Händen von Volljuristen, die komplizierte zivilrechtliche Rechtsfragen, die zugleich die Steuerbarkeit und Zurechnung von Wertzugängen bestimmten, zu beurteilen vermochten. Die Vorbereitungsarbeiten fuhrten dabei nicht systematisch ausgebildete sogenannte Subalternbeamte ohne Entscheidungsbefugnisse aus. Bei dem Juristenprivileg ist es bezungfich der Ausbildung der verantwortlichen Beannten des höheren Dienstes mit unbedeutenden Ausnahmen bis heute geblieben, s. Pausch, A. (1976), S. 123. Vermōgenszuwachs- und Gelúverkehrsrechnung. auf die eine sieuerliche Betriebsprüfung heute als Verprobungs- und Schäzungsmethode nicht verzichten kann, sind noch immer unterbewertete Hilfsmittel des gehobenen Dienstes. Zwar wurden sie inzwischen als Schätzungsmethode von der höchstrichterlichen Finanzrechtsprechung anerkannt (BFH IV $142,311 / 63$ v. 20.10 .67 , in: BStBI. III $67, S .201$; BFH X R 178/87 v. 8.11.89, in: BStBI. II $90, S$. 268), sie sind jedoch nur Hilfsmittel der BP, deren Einsatz wesentlich auf den Bereich der Gewinneinkünfte (Arten 1 bis 3) eingeschrănkt ist ( $(193 \mathrm{AO})$ und die seit längerer Zeit nicht mehr routinemäBig. erfolgen kann. Zwar ist die Privatsphăre für die BP heute nicht mehr tabu, der Einsatz ist aber fast unaberwindbar erschwerh, s. Assmann, E. (1989), Rechte ..., S. 854; ders. (1989), Geldverkehrsrechnung ..., S. 257, S. 269; ders. (1990), S. 5; s. a. Sauer, O. (1991), S. 250; Geimer, R. (1988), S. 134.

271 Becker, E. (1940), S. 24. Für Becker handelte es sich um "Vorausverfügungen ûber künftige Einnahmen", die steuerlich unbeachtlich bleiben muBten, s. S. 22.

${ }^{272}$ Soffing, G. (1981), S. 200, stellt in Anm. 5 die seit dem 31.7.1941 in dieser Sache ergangenen. Grundsatzurteile des RFH und des spăteren $\mathrm{BFH}$ chronologisch zusammen.

${ }^{273}$ BFH-Urteil VI 165/63 U v. 7.8.64, in: BStBI. III, S. 576. Zur Änderung der höchstrichterlichen Finanzrechtsprechung und zu der Bedeutung des Privatrechts for das Steuerrecht seit 1949 s. Blencke, H. (1979), S. 20. 
sătzlich billigte, indem bestätigt wurde, daß allein die Inhaberschaft an einer Einkommensquelle die Zurechnıng der Einkünfte ais Früchte aus der Quelle bestimme. ${ }^{274}$

Somit bestand nun eine Vertrauensgrundlage für sehr unterschiedliche bürgerlich-rechtliche Dispositionen unter Einschluß entgeltlicher oder unentgeltlicher Übertragungen der Einkommensquelle mit weitgehenden steuerlichen Auswirkungen. Fortan wurden oft eigentümliche komplizierte Veriragskonstruktionen zwischen Fremden und Angehörigen geschaffen, die zu hohen Steuerentlastungen führten. So konnte etwa der Erwerb eines sanierungsbedürftigen Hauses von Angehörigen vereinbart werden, wobei als Gegenleistung ein lebenslanges Wohnrecht in demselben und indexorientierte Unterhaltsleistungen für die Veräuß̉erer zugleich mit einer Renovienung und Sanierung des Anwesens zugesagt wurden. Die Beurteilung der Einkommensteuer als vom Zivilrecht bestimmtes Folgerecht konnte dabei ungewöhnliche Steuerentlastungen schaffen. Der Wert des eingeräumten Wohnrechts konnte zusammen mit den Sanierungsaufwendungen zu Sonderabschreibungen fuhren ( $\$ 7$ b EStG), die indexorientierte Leibrente konnte als voll abzugsfihige "dauernde Last" ( $\$ 10$ Ziff. 1 EStG) und die Hypothekenzinsen sowie die laufenden Erhaltungsaufwendungen konnten als Werbungskosten ( $99 \mathrm{EStG})$ beim Erwerber voli abgesetzt werden. Fiktive Einnahmen aus dem Vorbehalts- oder Zuwendungsnießbrauch oder Wohnrecht waren dann beim Veräußerer zu versteuern, was zumeist zu keinen Steuern führte. ${ }^{275}$

Sogar pflichtteilsberechtigte Angehörige konnten auf diese oder ăhnliche Weise durch Wohnung und Unterhalt steuergünstig versorgt werden und die Finanzierung von Sanierungsmaßnahmen konnte infolge der zusătzlichen Steuervergünstigungen durch Sonderabschreibungen vom Enwerber ais Eigentümer leicht sichergestellt werden. Die Besteuerungshöhe wurde für Besserverdienende zum Intelligenztest. Ihr Vermögen konnte auf geheimnisvolle Weise durch Steuererspamisse kontinuierlich anwachsen.

${ }^{274}$ BFH-Urteil VI 124/65 v. 6.7 .66 , in: BStBI. III, S. 584. Das Gericht steltte ausdrûcklich heraus, dafs es an đen Rechtsgrundsătzen đes Uírteils VI $27 / 56$ v. 8.2 .57 , in: BStBI. III. S. 207, nicht mehr festhalte. § 12 Nr. 2 EStG finde deshalb keine Anwendung, weil die Einkunfte dem NieBbraucher aus. eigenem Recht zufließen.

275 Hierzu: Jansen, R./Hoffmann, M. (1977), 2. Aun., S. 68; auch Schulze zur Wiesche, D. (1979); Lammsfüß/Rinne (1981), Vereinbarungen mit nahen Angehörigen und Ersparnis von Ertragsteuern. Unterlage zur 25. Arbeits- und Diskussionstagung vom 12.6.1981. Manuskript des Studienwerks der Steuerberater in NRW e. V., Kōln. Zu "Dauemden Lasten" s. Jansen, R./Wrede, F. (1970), 3. Aufl., S. 50; hierz. BFH-Urteil IV $67 / 61$ v. 16.9.65, in: BStBI. III, S. 706; BFH-Urteil 153/77 v. 30.5.80, in: BFHE, Bd. 130, S. 24, S. 25; als Beispiel s. Lang, 1. (1979), Steuern sparen mit Kindern, in: Wirtschafts Woche Special, S. 15, 
In zahllosen Fällen machten Steuerbürger von diesen oder åhnlichen Möglichkeiten Gebrauch, wobei gelegentlich dann bis zu drei Generationen vertraglich verbunden wurden. Der steuerlichen Anerkennung des Nießbrauchsrechts kam dabei regelmäßig eine Schlüsselstellung zu.

Einen mit der Steuerprogression des Erwerbers wachsenden Anteil der Aufwendungen für den ausbedungenen Unterhalt und für die Sanierungs- und laufenden Erhaltungsaufwendungen zahlte dann die Solidargemeinschaft der Steuerzahler in Form hoher Steuerentlastungen beim Erwerber.

Berater hochverdienender Steuerbürger mußten in der Zeit nach 1967 Skepsis entwickeln, ob die oftmals geradezu absurden steuerlichen Konsequenzen dieser rechtsdogmatisch folgerichtig von dem Grundschema der Wagner/ Fuistingschen Besteuerungsidee zugelassenen Gestaltungsmöglichkeiten der "deutschen Type" der Besteuerungspraxis für lange Zeit Bestand haben könnten.

Nachdem ein großes Kölner Privatbankhaus sogar die Kundschaft in Handzetteln mit praktischen Empfehlungen anregte, zur legalen Steuervermeidung die Einräumung eines quotalen Zuwendungsnießbrauchs zugunsten der Angehörigen an dem eigenen Wertpapierdepot - obendrein als Bruttonießbrauch ausgestaltet - vorzusehen, setzte erneut nachhaltig eine offentliche Diskussion um die Fragwürdigkeit der disponibelen Belastungsverteilung ein.

Ein bei dem BFH anhängiges Verfahren zu einer vergleichbaren Rechtsfrage schuf in der Folge erneut Rechtsunsicherheit über die Problematik des Primats des Zivilrechts. In dem sogenannten "Wertpapier-Urteil" vom 14. Dezember 1976 kam das Gericht zu dem bereits von Enno Becker vertretenen Ergebnis, daß es sich beim Zuwendungsnießbrauch an Wertpapieren "wirtschaftlich lediglich um eine Vorausabtretung dieser Erträge" handele. ${ }^{276}$

Damit war der Vorrang des Zivilrechts erneut infrage gestellt. Entgeltlicher und auch unentgeltlicher Zuwendungsnießbrauch an Einkünften aus Kapitalvermögen verloren ihre steuerliche Bedeutung. Beim unentgeltlichen Zuwendungsnießbrauch waren die Einkünfte fortan in der Regel weiterhin dem Eigentümer zuzurechnen. Dabei ist es bis heute geblieben. ${ }^{277}$

${ }^{276}$ BFH-Urteil VIII R 146/73 v 14.12.76, in: BStBI. II 77, S. 115; s. hierzu Becker, E. (1940), S. 24. In dem Musterfall waren alle fornalen sachenrechttichen Vorschriften des BGB beachtet worden. Da đer NieBbrauch als BruttonieBbrauch ausgestattet war, erhielten die minderjährigen Kinder nur rechtliche Vorteile, $\$ 181 \mathrm{BGB}$ kam somit nicht zum Zuge.

277 Seithel, R. (1985), S. 68; s. Schreiben des BMF v. 23.11.1983 - IV B 1 - S 2253 - 90/83, in: BSIBI. I, S. 508 , dort Tz. 55 . 
$\mathrm{Zu}$ einem ăhnlichen Ergebnis gelangte der BFH in drei Urteilen vom 13. Mai 1980 bezüglich des Zuwendungsnießbrauchs bei den Einkünften aus Vermietung und Verpachtung. ${ }^{278}$

Mit diesen Urteilen hat der BFH die Wagner/Fuistingsche Besteuerungsidee als Grundlage des geltenden Besteuerungssystems bei Behandlung des Nießbrauchsrechts rechtsfortbildend entscheidend verlassen. ${ }^{279}$

Der Nießbrauch war de facto zum Prüfstein der dogmatischen Weiterentwicklung der das bisherige Steuersystem tragenden einheitsstiftenden Konzeption geworden. ${ }^{280}$

Die seit Einführung der Einkommensteuer in Preußen fortentwickelte Vorstellung von Einkommensquellen hatte bis dahin als wesentliches Element im Konzept auch als Indiz für die Zurechnung der Einkünfte nach der zivilrechtlichen Inhaberschaft gedient. ${ }^{281}$ Dabei war zwar der folgerichtigen rechtsdogmatischen Entwicklung und Abstimmung des Einkommensteuerrechts innerhalb der Rechtsordnung Aufmerksamkeit gewidmet worden, die von den Regelungen gewăhrten geradezu ausufernden Möglichkeiten zur legalen Steuervermeidung wurden jedoch, wie bereits in Preußen, regelmäßig völlig vernachlässigt.

Nunmehr erfolgte die Zurechnung von Einkünten nach der Finanzrechtsprechung nicht mehr beim Inhaber einer Einkommensquelle, sondern sie wurde rechtsfortbildend an die aktive Teilnahme des Zensiten am Marktgeschehen, etwa durch die tatsächliche Ausübung der Vermieterposition, geheftet. 282

${ }^{278}$ BFH-Unteil VIII R 63/79 y. 13.5.80, in: BStBI. 81, S. 295; BFH-Urteil VIII R 75/79, in: BStBI. II 81, S. 297; BFH-Urteil VIII R 128/78, in: BStBI. II 81. S. 299.

279 Das Gericht gelangte zu dem Ergebnis, daß unter einer "Einkunftsquelle" das dem Eigentum innewohnende Recht zu verstehen sei, das den Inhaber in die Lage versetze, die Nutzungen aus dem Wirtschaftsgut zu ziehen. Der BFH geht nunmehr einschränkend davon aus, daß eine Einkunftsquelle die Möglichkeit zu einer aktiven disponierenden Teilnahme am Marktgeschehen beinhaltet. Das Gericht stellte jetat auf das Disponierenkōnnen des Inhabers der Einkunftsquelle als notwendiges Merkmal ab. Das brachte gegenüber der bisherigen eine eingeschränkte Auslegung der Inhaberschaft einer Einkunftsquelle, verglichen mit der ursprünglichen im "PreuB. Reglement" von 1808 verwendeten Bedeutung mit sich.

${ }^{280}$ Hierzu Felix; G. (1981), Der NieBbrauch ..., wie Anm. 263, S. 8.

281 Siehe zum Vergleich Anm. 233; s, a. Söffing, G. (1981), S. 202, der vor nunmehr auftretenden Widersprùchen im System wamt; s. a. Soffing, G. (1978), S. 139.

282 BFH-Urteile VIII R $63 / 79$ v. 13.5.80, in: BStBI. 81, S. 295 u. VIII R 75/79 v. 13.5.80, in: BStB31. 81, S. 297: Wie Söffing zeigte, setżen sich die Urteile durch die verânderte Auslegung in Widerspruch zur vorhergehenden Rechtsprechungstradition. Sie wasen auch mit grundlegenden Positionen der das EStG tragenden Konstruktionselementen nicht vereinbar. Eben hierzu gehörte die bis dahin übliche Auslegung des Begriffs der Einkommensquelle. Die Urteile dienten offenkundig dem 
Die Abkoppelung der steuerlichen Beurteilung von der zivilrechtlichen Regelung des Zuwendungsnießbrauchs brachte das Verbot des Werbungskostenabzuges beim Eigentümer einschließlich der als Steuervergünstigungen gewăhrten Sonderabschreibungen mit sich. Das war um 1980 auch der erkennbare Grund für die neuartige Interpretation der tragenden Idee des seit 1891 unveränderten gesetzlich vorgegebenen Besteuerungsgegenstandes.

Damit war die bis zum 13. Mai 1980 unbestrittene steuerliche Bedeutung des ZuwendungsnieBbrauchs auch bei den Einkünften aus Vermietung und Verpachtung zerstôrt.

Diese hatte gerade darin gelegen, daß trotz der Zurechnung der Einnahmen beim Nießbraucher der Eigentümer die von ihm getragenen oder nach dispositivem Recht zu tragenden, mit den Einnahmen verbundenen Werbungskosten einschließlich der zumeist hohen Sonderabschreibungen absetzen konnte.

Der steuerlichen Bedeutung des Zuwendungsnießbrauchs war mit der Ablehnung des Abzuges von Werbungskosten durch den Eigentümer jedenfalls die Grundlage insoweit entzogen, als Steuerentlastungen gesucht wurden. ${ }^{283}$

In komplizierten Übergangsregelungen gewährte die Finanzverwaltung in Form von Erlassen Erleichtenungen zur Anpassung von Altfällen. ${ }^{284}$

Jedenfalls brachten zwei Nießbrauchserlasse der Finanzverwaltung Rechtssicherheit für die Zukunft.

Wenn durch die Erlasse den ausufernden Möglichkeiten zur legalen Steuervermeidung als Folge vertraglicher Gestaltungen durch Nießbrauchsbestellung eine Schranke gesetzt wurde, so geschah dies zu einem hohen Preis.

Die höchstrichterliche Finanzrechtsprechung war für einen Teilbereich jenseits der Auslegung nach dem historisch fortentwickelten Sinnzusammenhang des geltenden EStG rechtsfortbildend tătig geworden. Die Übertragung von Einkunftsquellen und nicht zuletzt auch deren Definition wurden zu einem wichtigen kontrovers diskutierten Thema unter Steuerrechtlern. Die Suche nach einer allgemein überzeugenden Regelung der vom Nießbrauchsrecht auf-

Zweck, Gestattungen des Sachverhalts zu verhindern, deren Folgen mit dem allgemeinen Empfinden für Gerechtigkeit der Besteuenung nicht mehr vereinbas waren.

${ }^{283}$ Das BFH-Urteil VIII R $128 / 78$ v. 13.5.80, in: BStBI. 81, S. 299, erkannte fur Recht, daB der Besteller des Nießbrauchs keinen Werbungskostenabzug (auch nichl als vorweggenommene Werbungskosten) geltend machen kōnne; s. hierzu: Seithel, R. (1985), S. 70.

${ }^{294}$ S. Stephan, R. (1985), S. 22; Schr. d. BMF y. 15.11.1984, in: BStBI. 1 84, S. 561, hier Tz. 60, abgedr, in: Seithel, R. (1985), S. 75; s. a. Brandenberg, B.JPetzold, R. (1984). 


\title{
geworfenen Fragen war zum Prüfstein einer dogmatischen Weiterentwicklung
} der Systematik des Einkommensteuerrechts angewachsen. ${ }^{285}$

\author{
Ebenso wurden "Grenzen der Rechtsfortbildung durch Rechtsprechung und \\ Verwaltungsvorschriften im Steuerrecht" fortan nachhaltig kontrovers erörtert \\ und mit ausländischen Gepflogenheiten verglichen. ${ }^{286}$
}

ass Felix, G. (1981), Der NieBbrauch ..., S. 8, Tz. 32; s. a. Tipke, K. (1978), Obertragung .... Die Verhandlungen der Deutschen Steuerjuristischen Gesellschaft am 16/17.11.1977 ergaben, daß eine Mehrheit der Steuerjuristen den seit 1808 für das preuB. Einkommensteuerrecht grundlegenden Begriff der "Einkommensquelle" neuartig ausgelegt und verwendet wissen wollte, Tipke, K. (1978), S. 229. Für Wagner sowie Fuisting war der Bestand einer Einkommensquelle, mit der man seit 1808 (s. Anm. 233) in Preußen die dinglichen oder obligatorischen Rechtspositionen unterschiedlichster Art, die zu Einkünten fuhrten, bezeichnete, ein zentraler Begriff des EStG. Als steuerbares Finkommen sollte nach $\S 7$ preuß. EStG 1891 nur "gelten", was dem Empfinger als Erträge aus den vier enumerativ aufgeführten Einkunftsarten zufloB. "Abgeleitetes Einkommen" war folgerichtig "in der Hand dessen, der es bekommt, nur dann steuerpflichtig, wenn er ein Recht darauf hat", s. Fuisting, B. (1894), S. 55 , Anm. 4, wenn eine eigene neue Quelle entstanden war, als deren Inhaber er gelten konnte. in dem Erfordernis eines Rechtsanspruchs fur die Steuerbarkeit von Wertzugalngen lag die Differenz zu dem salchs. Besteuerungssystem, auf die Fuisting wiederholt hinwies, s. Fuisting, B. (1902), Grundsatze ...., S. 110 u. a.; ders. (1894), $\$ 7$ preuB. EStG, Anm. 4, S. 55, S. 56. Die Einkommensquelle folgte mithin dem zivilrechtlichen Anspruch auf Auskehrung der Früchte aus einer vorgegebenen Rechtsposition. Um der unentgeltlichen Öbertragung von Einkunftsquellen zum Zweck der legalen Steuervermeidung die steuerliche Beachtung zu nehmen, hat der BFH in dem sog. Wertpapier-Urteil v, 14.12.76 von der Tradition abweichend diesen heute noch zentralen Begriff des ESt-Rechts enger ausgelegt. Nach diesem Urteil war die Übertragung des bloßen Erträgnisanspruchs ohne vollzogenen Ubergang des zugrundeliegenden Rollenspiels des Oberlassers von Kapitalvermögen zur Nutzung gegen Entgelt fur die steuerliche Anerkennung der Entstehung einer neuen Einkunftsquelle bei dem Bezugsberechtigten der Erträge nicht mehr ausreichend. Der NieBbrauchsbesteller durfte die Erträge, die ihm nicht mehr zustanden, daher nach dem Urteil folgerichtig nicht von der Bemessungsgrundlage abziehen, bei dem Empfanger waren sie andererseits wegen Fehlens einer bestehenden Quelle nicht steuerbar. Fur Ruppe und gleichgesinnte Steuerjuristen war das entscheidende zusătzliche Merkmal einer Einkunftsquelle "die entgeltliche Verwertung von Leistungen (Wirtschaftsgütern oder Dienstleistungen)", also eine disponierende Beteiligung an Marktvorgängen, s. Ruppe, G. (1978), S. 16. Öber die große Tragweite der Auslegungsanderung waren sich Steuerrechtler bewuße. Tipke sprach von einem "fundamentalen Konfliktschwerpunkt" zur Verbesscrung des Steuerrechts, s. Tipke, K. (1978), Obertragung .... S. 2, S. 230.

286 Tipke, K. (1982), Grenzen ... Auf der Veranstaltung der Deutschen Steuerjuristischen Gesellschaf vom 5./6.10.1981 wurde offen von einer "Misere" des deutschen Steuerrechis gesprochen, zu deren Beseitigung sehr kontroverse Meinungen bestanden. Das Dilernma des ESt-Rechts war in dem Umstand za sehen, daß das noch geltende Wagner-Fuistingsche Modell infolge des Primats des Zivilrechts durch viele steuervermeidende Gestaltungsmöglichkeiten bei den Anforderungen an GleichmăBigkeit und Gerechtigkeit der Besteuerung nach derzeitiger Bewertung der bekanntgewordenen Auswirkungen an natürliche Grenzen geriet. Diese wurden zumeist als Regelungslücken im Gesetz beurteilt, die es durch verănderte Auslegungen oder durch Analogie zu schließen gelte. For das aus standesstaatlichem liberalem Gedankengut als Bewilligungsrecht entstandene Steuerrecht sind jedoch steuerverschărfende Auslegungen der Steuergesetze zur Schließung von Läcken durch rechtsergănzende Analogie umstritten, s. Woerner, L. (1982), S. 29. Aus demokratisch konstitutioneflen und rechtsstaatlichen Grùnden gilt daher der mōgliche "Wortsinn" der jeweiligen Vorschrift als "Scheidelinie" zwischen zulässiger und unzulässiger rechtserglinzender oder sogar rechtsfortbildender Auslegung, s. Friauf, K.-H. (1982), S. 60. In den Erörterungen der Steuerjuristen deutete sich trotz des Meinungsstreits 1982 Einigkeit bei einer Mehrheit daruber an, daB eine steuerverschărfende Rechtsfortbildung infolge Untātigkeit des Gesetzgebers in begrenztem Rahmen möglich sein mûsse, um sachgerechte Regelungen zu gewährleisten, s. Tipke, K. (1982), S. 413. Einigkeit herrschte darüber, daß das Dictum des Gesetzgebers, der "Wortsinn der Gesetze", nicht allen Problemen gerecht werden kann, s. Friauf, 
Die beigetragenen differierenden Theorien zur Begründung und zugleich Rechtfertigung der Zurechnung von Einkünften bei Einräumung von Nießbrauchsrechten bewertete ein Richter am BFH gelegentlich wohl zu Recht als "vollkommenes Chaos" einer rechtsdogmatischen Beurteilung. ${ }^{287}$

Wie bereits Meisel beklagte, fehlten seit der Jahrhundertwende in der Diskussion Beiträge von Finanzwissenschaftlern zu einer konzeptionellen Neuorganisation der Einkommensbesteuenung. ${ }^{288}$ Mehr noch: eine mißverständliche Beurteilung der Entwicklung setzte sich durch. ${ }^{289}$ Die Erörterungen blieben unter der Regie von Steuerrechtlern, die einseitig nach rechtsdogmatischer Vorgehensweise unter Abstimmung mit der gesamten Rechtsordnung und insbesondere des Verfassungsrechts nach Lösungen suchten. Man bemühte sich unter Steuerjuristen wie, bereits zu Wagners und Fuistings Zeiten, um die Weiterentwicklung eines folgerichtigen und widerspruchsfreien Ordnungsgefüges. Die konkreten praktischen Auswirkungen der verschiedenen Konzeptionen auf die Belastungsverteilung konnten, obgleich letztlich von entscheidender Bedeutung, in dem jeweiligen Begründungszusammenhang der diffe-

K.-H. (1982), S. 149. Der Finanzverwaltung mussen daher, so die vorherrschende Meinung, die gleichen Möglichkeiten und Grenzen der Rechtsfortbildung gewalhrt werden, wie den Gerichten, s. Tipke, K. (1982), S. 413. Die Beitrăge zeigten, daB auch das Ausland keine Patentlósung kennt, s. Tipke, K. (1982), S. 412. Ob die hergebrachte Form der Rechtsfortbildung in Deutschland als Problemlösung für die Rechtsanwendung weniger geeignet erscheint, als die elastischere, undogmatisch historisch pragmatisch orientierte verwaltungsfreundlicher wirkende Rechtsanwendungspraxis der USA, blieb unerörtert, s. Walz, W. R. (1982) in: Tipke, K. , Grenzen ..., S. 381; ders. (1982), S. 1. Konturen einer Neuordnung des ESt-Rechts, die den oft wiederhotten, als Prinzipien ausgegebenen Worthülsen, wie Besteuerung nach Gerechtigkeit, Gleichmaßigkeit, Leistungsfahigkeit etc., konkreten Gehalt gegeben haltten, wurden in Beitrăgen und Diskussion infolge der Bandbreite der Interpretationsspielräume nicht sichtbar, s. Kelsen, H. (1953), S. 19: Topitsch, E. (1960), S. 263, S. 264; Myrdal, G. (1963), S. 153. For den Praktiker ergeben Beitralge und Erörterungen die Empfehlung, stiliker als bisher auf konkrete Regelungen durch die jeweils regional zustăndigen Behōrden und Ausiegungen der Finanzgerichte zu achten. Die offene Inkaufnahme einer rechtsfortbildenden Gesetzesanwendung durch die Verwaltung seitens der Mehrheit der Steuerjuristen vermag das Vertrauen in die Rechtssicherheit jedenfalls zu beeinträchtigen.

287 Soffing, G. (1981), Einführung und Grundsatzfragen, in: Felix, G., Der NieBbrauch ..., S. 11, Tz. 20. Das entstandene Dilemma wurde von Söffing erörtert in: ders. (1981), Der Nießbrauch ..., S. 199. Tipke stellte zu dem Wertpapier-Urteil fest: "Uberhaupt scheiden sich an diesem Urteil die Geister", s. Tipke, K. (1978), Übertragung …, S. 233.

${ }^{283}$ Meisel, F. (1920), S. 35.

${ }^{289}$ So enthielt Ritschls für die Konferenz der Friedrich-List-Gesellschatt vorn 26. -28.10 .1929 in Bad Eilsen mit dem Thema "Kapitalbildung und Steuersystem" gefertigtes Gutachten zu der Frage der "Wandlungen des deutschen Steuersystems von 1913 bis 1928 in ihrem EinfluB auf die Kapitalbildung" als roten Faden die These, daß der Schanzsche Einkonmensbegriff einer "verfehiten Maxime der Besteuerung im Verhảltris zur Leistungsfahigkeit" entspreche und einem "wirtschaftlichen Steuersystem" entgegenstand. Ritschl vertrat die Auffassung, das EStG 1925 sei eine "Synthese" des vorhergehenden preuB. EStG 1891 mit dem Schanzschen EStG 1920, s. Colm, G./Neisser, H. (1930), 2. Teil, S. 286, s. a. S. 267 , S. 271 . S. 281; ahnliche Auffassungen Ritschls in: Lotz, W. (1929), S. 345, hier S. 354. 
rierenden Lehrgebäude aber keine systematische selektierende Funktion übernehmen. ${ }^{290}$

So bleiben fur den Praktiker infolge der auftretenden Widersprüche weiterhin genügend Lücken im System, da empirisch orientierte Beitrăge von Finanzwissenschaftlern fehlen und Steuerjuristen sich obendrein zumeist über die Niedrigkeiten des praktischen Vollzugs und seiner Möglichkeiten hinwegsetzen.

Da die Behandlung des NieBbrauchs im Einkommensteuerrecht nur als begrenztes Problem verhandelt worden war, blieben im übrigen das traditionelle einheitsstiftende Konzept, die zugrundeliegende Besteuerungsidee des EStG und damit die vielen übrigen vorhandenen Möglichkeiten zur Steuervermeidung weitgehend erhalten.

Das Ziel der skizzierten vielgestaltigen Vertrăge ist es weiterhin stets, Einkünfte bzw. Ausgaben zur Steuerersparnis so zu verlagern, daß unabhángig von dem Anfall der wirtschaftlichen Bereicherung der Steuerzugriff auf das ubertragene Besteuerungsgut einen Steuerpflichtigen in niedrigerer Progression trifft und derselbe auch den rein formalen Tatbestand der Einkünfteerzielung tatsächlich erfültt. Denn die Entstehung der Einkommensteuer ist streng an das Vorhandensein der normierten Tatbestandsmerkmale im Sachverhalt geknüpft.

Die gezeichneten Regelungen haben dazu geführt, daß zur Steuervermeidung z. B. Landwirte, Gewerbetreibende und Freiberufler heute, soweit sinnvoll möglich, das Eigentum an langlebigen Wirtschaftsgütern ihres Betriebes, etwa Grundstücken, in der Privatsphäre anzusiedeln suchen. Dabei kommen hierfür Angehörige oder Lebensgefährten infrage. So betreiben viele Freiberufler oder Gewerbetreibende ihre Praxis oder den Betrieb in von der Eihefrau oder von einer Besitzgesellschaft gemieteten Räumen selbst dann, wenn eigene Mittel für den Erwerb aufgewendet wurden und kombinierte Schenkungs-, Darlehens- und Mietverträge zusammengebunden werden müssen, um das Ziel zu erreichen. Gründe zur betriebswirtschaftlichen Rechtfertigung der Gestaltung lassen sich dann zur Neutralisienung der Umgehungsvorschrift des $\S 42 \mathrm{AO}$ leicht formulieren.

290 Hiernu ist L. Waldecker zu nennen, der sich als Schûler Fuistings bekannte und bereits 1913 eine engagierte Kritik der Thesen Meisels, von rechtsdogmatischen Gesichtspunkten ausgehend, zur Verteidigung der preuB. Einkommensbesteuerung lieferte. Waldecker nahm dann weiterhin mehrfach von seinem rechtsdogmatischen Standpunkt aus in polemischer Weise gegen Meisels Beurteilungen und vor allem gegen das săchs. Modell der Einkommensbesteuerung Stellung. Waldecker wurde 1915 zurn Begründer steuerrechtswissenschaftlicher Lehrstühle an der Universităt Berlin und danach Kōnigsberg. s. Waldecker, L. (1913), S. 53; ders. 1917, S. 155, insbes. S. 169; ders. (1918), S. 83, insbes. S. 87; ders. (1925), S. 69. 
Beil Aufgabe oder Veräußerung des Betriebes oder der Praxis macht sich dann spătestens die Mühe durch erhebliche Steuerersparnis bezahlt.

Bauunternehmer suchen zu erreichen, daß durch geeignete Entnahme- oder Veräußerungsvorgănge die Wertsteigenung nach Marktfåhigkeit der Baulichkeit zum eigenen Vorteil steuerfrei in der Privatsphäre realisient wird, Hauseigentümer wandeln Mietwohnungen in Sondereigentum und achten streng darauf, daß der Vorgang bis zur Veräußerung einzelner Objekte als reine Vermögensumwandlung in der Privatsphăre erfolgt, was dann zu steuerfreier Realisierung der Vermögensmehrung führen kann. ${ }^{291}$

in vielen vergleichbaren und andersartigen Sachverhalten füren geschickte vertragliche Regelungen mit unterhaltsberechtigten Angehörigen zu leicht erzielbaren Steuervorteilen đurch Verlagerung von Anteilen des Besteuerungsgutes und dadurch Beteiligung der Allgemeinheit an Unterhaltsaufwendungen, Scheidungsfolgekosten, Ausbildungskosten der Kinder etc..

Die Versuche, den in allzu phantasiereichen Steuervermeidungen ausufernden Steuerwiderstand einzugrenzen, haben Verwaltung und Gesetzgeber zu Erlassen, Richtlinien und Gesetzesänderungen geführt, die das Einkommensteuerrecht an den Rand der Praktikabilität brachten. Die Undurchsichtigkeit des Regelungsgefüges dient wiederum vielen Steuerbürgern zur fragwürdigen Rechtfertigung gesetzeswidriger Steuervermeidungen. Viele kleine Steuerzahler halten sich auf diese Weise für die von ihnen nicht zu unrecht vermutete Übervorteilung durch das System schadlos. ${ }^{292}$

Ein großer Teil der skizzierten Möglichkeiten, die gesetzliche Steuerentstehung zu vermeiden, gehen auf die Eigentümlichkeiten des aus dem preußischen System fortgefürten Regelungsgefugges zurück, die Meisel als "preußische Type" bzw. "deutsche Type" der Einkommensteuer bezeichnete und deren Technik er als mangelhaft beurteilte. Ohne Anspruch auf Vollständigkeit wurden von Schanz und Meisel folgende Problembereiche genannt:

Der durch einen Enumerativkatalog von Einkommensquellen eingeschränkte Einkommensbegriff, die dualistische Ermittlungsvorschrift der Einkünfte, die strenge Trennung zwischen Einkommens- und Vermögenssphäre, die amtliche Veranlagung mit der Verpflichtung der Behörde zur Untersuchung des Sachverhalts ohne zureichende Prüfungsrechte. die Deklarationspflicht der Steuerbürger und das damit unabgestimmte, zur Prävention wenig geeignete

${ }^{291}$ S. Schmidt, L. (1994), § 15, Anm. 10-18, S. 1223; Gosch, D. (1990), S. 585; s. a. BStBI. I (1990), S. 884.

${ }^{292}$ Streck, M. (1984), S. 2205. Diese Ausfuhrungen fuhrten zu großen Verärgerungen und zugleich zu vielen Zustimmungen, s. a. Dakke, K. H., in: Der Steuerzahler (1995), Heft 2, S. 18. 
Steuerstrafrecht. Dazu kam noch die rein formalistische eingriffsrechtliche Betrachtungsweise des Einkommensteuerrechts, der die wirtschaftlichen $\mathrm{Zu}$ sammenhänge zumeist fremd blieben. ${ }^{293}$

Hinzu traten noch folgende heute ausschlaggebende Umstände: Nach Geltung des 1925 auf der alten Grundlage neu geschaffenen Regelungsgefüges wurden nur kurze Zeit später im Zuge des Einsatzes von in Art. 48 der Weimarer Reichsverfassung vorgesehenen Notverordnungen nichtfiskalischen, wirtschaftspolitischen Zwecken dienende steuerliche Bestimmungen von Bedeutung, ${ }^{294}$ die inzwischen das heute geltende Einkommensteuerrecht durchziehen. Im Jahr 1933 noch in zusătzlichen Sonderbestimmungen außerhalb des EStG 1925 mit zeitlicher Begrenzung eingefuhrt sind vergleichbare Vorschriften inzwischen seit 1949 feste Bestandteile des EStG geworden. ${ }^{295}$ Diese

293 Tipke erwăhnt eine dem Steuerrecht innewohnende, auf das ursprüngliche Steuerbewilligungsrecht der Stalnde zuräkgehende positivistische Tradition als unsalchlich. Diese legte den Schwerpunkt auf die wortwôrtliche Beachtung det Gesetzesvorschriften und ließ Auslegungen ebensowenig wie Ausweitungen der Vorschritten durch Analogie zu. Die vorherrschende Meinung setzte nach dem 2. Weltkrieg nicht zuletz unter dem Eindruck ausufemder Tarifzugriffe diese Tradition fort. Nach der Lehre des anerkannten Systematikers Hensel war ein durch AnalogieschluB hergeleiteter Rechtssatz auf dem Gebiet des Steuerrechts "ebensowenig als Rechtsnorm anzuerkennen, wie auf dem Gebiete des Strafrechts". Soweit der Staat nicht tâtig wird, hat er diese Bereiche "selbst zu seinem Nachteil als Freiheitssphäre der ihm Rechtsunterstellten anzuerkennen", s. Hensel, A. (1923), Bonner Festgabe für E. Zitelmann, S. 246. Zur Begründung des "steuerverschărfenden Analegieverbotes" berufen sich dessen Vertreter zumeist auf rein formale Prinzipien, s. Tipke, K. (1993), Steuerrechtsordnung, S. 212, s. a. Anm. 286. Die Konsequenzen einer einseitigen Berücksichtigung dieser Prinzipien auf die resulticrende Steuerlastverteilung sind von rechtsdogmatisch orientierten Steuerjuristen erst verspattet unter dem Eindruck offentlicher Kritik beachtet worden. Seither herrscht offener Meinungsstreit über Prioritäten, s. Tipke, K. (1993), Steuerrechtsordnung. S. 217.

294 Durch verschiedene Notverordnungen des Reichsprâsidenten mit Gesetzeskrafl, zu der Art. 48 Abs. 2 der Weimarer Reichsverfassung die Rechtsgrundlage bot, suchte man, beginnend am 1.12 .1930, "zur Behebung finanzieller, wirtschaftlicher und sozialer Notstände" die ausgebrochene Wirtschaftskrise zu meistem. Zu Ende 1932 wurden dann die allgemeinen Sparnaßnahmen in eine "AntiDeflationspolitik" übergeleitet und die Finanxpolitik wurde zur Wirtschaflspolitik umgestaltet, s. Terhalle, F. (1950), S. 310, S. 313. Als Rechtsgrundlage fur weitere Verordnungen mit Gesetzeskraft diente dann fortan das "Gesetz zur Behebung der Not von Volk und Reich" v. 24.3.1933 (sog, Er. måchtigungsgesetz). Abschn. II des darauf beruhenden "Gesetzes zur Verminderung der Arbeitslosigkeit" v. 1.6.1933 eröffnete umfangreiche Steuerbefreiungen bei Ersatzbeschaffungen, s. hierzu die Wiedergabe in Anlage 5. Die Geltung der Vorschrif war auf die Zeit vom 1.1.1933 bis zum 1.1.1935 befristet.

${ }^{295}$ Das EStG v. 10.8.1948, das bis heute nur fortentwickelt wurde, ûbernahm den Gesetzestext v. 28.2.1939. Es fügte diesem abweichende begûnstigende Ermittlungsvorschriften für den Fall erwuinschter Tatbestandsmerkmale im Sachverhalt in Form einer Erweiterung der in der Regel wirtschaftlich bestimmten Abschreibungen durch $\S \S 7 \mathrm{a}$ bis $7 \mathrm{e}$ an. Dies war die Keimzelle fur die bis heute fortwuchernde Verfälschung der Ermittlungsvorschriften von ihror ursprünglich wirtschaftichen Bestimmung. Das ab 1.1.1995 gültige EStG enthăht als Ausnahmen von der Norm die §̧§ 7 Abs. 5, 5a, $7 \mathrm{a}$ bis $7 \mathrm{k}$. Hinzu tritt aus systematischen Gründen $\S 10 \mathrm{e}$ als korrespondierende Vorschrift für Eigentumer eigengenutzter Wohnobjekte. Dazu kommen noch die Sonderabschrcibungen det $\$ \S 82 \mathrm{a}$ bis $82 \mathrm{k}$ EStDV, die auf der Gesetzesermächtigung des $§ 51 \mathrm{EStG}$ aufruhen. Weiterhin ist hier noch das Fördergebietsgesetz i. d. F. v. 23.9.1993 anzuführen, dessen wesentliche Vorschriften in Anlage 7 wiedergegeben sind. Allein die zu $\S \S 7$ bis $7 \mathrm{k}$ v. 7.9 .1990 rechnenden Bestimmungen uber Abschreibungen in der ab 1.1.1995 gultigen Fassung erstrecken sich ûber 607 Textzeilen. Dazu kommen noch 601 
zur Förderung wirtschaftlicher Ziele eingefügten gesetzlichen Steuervergünstigungen, die zumeist als Sonderabschreibungen vorübergehend in den Ermittlungsvorschriften des EStG vorgesehen wurden, konnten durch die charakteristische Gestaltung der "deutschen Type" der Einkommensbesteuerung dem Regelungsgefüge problemlos integriert werden. ${ }^{296}$ Was in dem sächsischen Muster der Einkornmensteuer wegen dessen auf die periodengerechte Ermittlung der Vermögensmehrung eines Steuerbürgers abstellenden Orientierung zu unauflösbaren Widersprüchen mit dem systemtragenden Grundgedanken hătte führen müssen, konnte in der "deutschen Type" ohne weiteres eingefügt werden: Da als Einkommen nach dem EStG 1925 nur steuerbar war, was in dem Gesetz ausdrücklich positiv aufgefürt wurde, lag es in dieser Systematik nahe, falls als zweckmäßig beurteilt, auch die Ermittlungsvorschriften zur Bemessungsgrundlage bei den einzelnen Einkünften nach anderen, als rein wirtschaftlichen Gesichtspunkten positiv zu regeln. Sie konnten auf diese Weise als neuartiges, leicht hantierbares und weitgehend verborgenes Instrument fur wirtschaftspolitische Ziele von ihrer ursprünglichen systematischen Aufgabe entfremdet eingesetzt werden. Die rein formalistische Ausrichtung des Gesetzes machte dabei schwer erkennbar, daß es seiner eigentlichen ursprünglichen Bestimmung, nămlich der Ermittlung der wirtschaftlichen Leistungsfahigkeit eines Steuerpflichtigen nicht mehr entsprechen mußtc. Die Interessenlage tat ein übriges.

"Was Einkommen im Sinne des Einkommen- und Körperschaftsteuergesetzes ist, muß aus diesen Gesetzen selbst entnommen werden, nicht aus der Lehre der Finanzwissenschaft", so führte Enno Becker zur Charakterisierung des EStG 1925 wiederholt aus. ${ }^{297}$ Das konnte gewiß ebenso für die Ermittlungsvorschriften gelten. Diese Auffassung eines führenden Steuerjuristen und einflußreichen Kommentators der Zeit gibt jedenfalls die formale Auslegung der "deutschen Type" bis heute wider. Sie hat ebenso Popitz letztlich vorgeschwebt.

So wurden seit 1932 vorerst zusätzlich zeitlich begrenzte Regelungen zu den Ermittlungsvorschriften eingefürt und später nach 1949 ähnliche neuartige Ermittlungsvorschriften in die Systematik des EStG integriert, die unter der "Tarnfarbe der Grundstruktur der Besteuenung" ${ }^{298}$ anderen, nämlich nichtfis-

\footnotetext{
Zeilen der Vorschriften $\$ \$ 10$ e bis $10 \mathrm{~h} \mathrm{Zu}$ bericksichtigen sind bei Anwendung noch die vielen amtlichen Anweisungen in Form von Richtlinien, denen zumeist Finanzgerichtsurteile zugrunde liegen, s. NWB, Fach 3, S. 4408.

${ }^{296}$ Tipke spricht in diesem Zusammenhang neuerdings von "steuergesetzlichem Wirtschaftsrechi", s. Tipke, K./Lang, J. (1991), 13. Aufl., S. 644.

${ }^{297}$ Becker, E. (1940), S. I.

29. Zitzelsberger, H. (1985), S. 206 u. a.
} 
kalischen Zwecken zu dienen bestimmt waren. Die Vorschriften über Sonderabschreibungen waren unter anderem dafür vorgesehen, politische und wirtschaftspolitische Ziele zu befördern. Die Steuerbürger wurden auf diese Weise dann nach Entdeckung der großen Effizienz der Maßnahmen zunehmend zum festen Bestandteil und unmittelbaren Instrument politischer Zielvorgaben. ${ }^{299}$ Die Steuerpolitik wurde bald zum eigentlichen Taktgeber der Wirtschaftspolitik, die erst hierdurch ihr heutiges Durchsetzungsvermögen erhielt. Mit der Zeit wuchsen der Finanzverwaltung auf diese Weise, wie wir noch sehen werden "entscheidende bankähnliche Funktionen zu. ${ }^{300}$

Während Steuerjuristen seit den 20er Jahren an einer fehlenden einheitsstiftenden Rechtsdogmatik des Steuerrechts und deren Abstimmung mit dem Zivilrecht Interesse zeigten, suchten Volkswirte, ausgehend von einer Epoche großer finanzieller Not nach dem verlorenen Weltkrieg, "den Zusammenhang zwischen Kapitalbildung und Besteuerung" aufzuhellen. Das Ergebnis war zumeist die Uberzeugung, daß die Höhe der Steuer, also deren Tarif, der Kapitalbildung entgegenwirke. Daher wurde als Problemlösung bereits seit 1924 wiederholt eine Herabsetzung des Höchstsatzes des Steuertarifs von $40 \%$ auf $25 \%$ und Einführung gespaltener Tarife für verbrauchte bzw. investierte Einkommensteile angeregt. ${ }^{301}$

Die Praxis beschritt jedoch - wie wir noch sehen werden - nach 1930 mit Erfolg andere Wege.

Tatsächlich wird sich noch zeigen, daß die weit verbreitete undifferenzierte Überzeugung von den Auswirkungen der Besteuerung als Behinderung der Investition falsch ist. ${ }^{302}$

Ein hoher Steuerzugriff in Verbindung mit abgestimmten Steuervergünstigungen als Anreiz für erwünschtes Investitionsverhalten beseitigt schnell beklagte wirtschaftspolitische Engpässe, die sich bei ungelenktem Sparverhalten und freiem Kapitalmarkt nur sehr zeitaufwendig auflosen können.

299 Schmolders, G. (1968), S. 137. S. 138.

300 Die Beurteilung der Finanzverwaltung als neuartiges Bankinstitut verdankt der Autor einer Erörterung der Zusammenhänge mit Jürgen Backhaus.

301 Ritschi, H. (1929), S. 354; ders. (1930), S. 291; Stolper, W. (1929), S. 1323, S. 1363, S. 1399. Stolper trat für die ErmäBigung des hōchsten Tarifzugriffs von $40 \%$ auf $25 \%$ und erhöhte Verbrauchssteuern ein; ahnlich Schumpeter, A. (1929), Was vermag ..., S. 79; ders. (1929), Wenn die ..., S. 695; Grau, W. (1929), S. 239. Zu ähnlichen Ergebnissen gelangten die volkswirtschaftlichen Experten nach dem 2. Weltkrieg in einer vergleichbaren Veranstaltung des Vereins für Socialpolitik vom Oktober 1952, s., Wolf, E. (1952), S. 118: Schmölders, G. (1952), in: Albrecht, G./Arndt, H., S. 194: Wessels, T. (1952), S. 198; Gerloff, W. (1952), S. 84, S. 85; Neumark, F. (1952), S. 65

${ }^{302}$ Diese abwegige Auffassung wird etwa heute von M. Rose für Modellentwürfe vertreten, s. C. Schürte, in: Wirtschafiswoche v. 22.4.94, S. 26. 
Diese neue Entwicklung der Steuerpolitik hat die Möglichkeiten der skizzierten legalen Steuervermeidungen inzwischen geradezu potenziert. Die vorstehend gezeichneten Gestaltungen zur legalen Steuervermeidung lassen sich nämlich heute zusätzlich durch Zeichnung von Anteilen an sogenannten Abschreibungs- oder Verlustzuweisungsgesellschaften in fast beliebigen LosgröBen auf einem inzwischen entstandenen Nebenkapitalmarkt in vielfacher Weise mit den bereits skizzierten Mőglichkeiten zur Steuervermeidung kombinieren, um die Steuerersparnis dadurch noch wesentlich zu erhöhen. Auf das Ausmaß der Vergünstigungen werden wir noch einzugehen haben.

$\mathrm{Zu}$ berücksichtigen ist dabei für potentielle Investoren wegen der dem Investment noiwendig zugrundeliegenden langfristigen Laufzeiten das Risiko, dalß in der Zwischenzeit eine durchgreifende Systemänderung des geltenden EStG die auf den bisherigen Bestimmungen aufruhenden Kalkulationen wertlos macht.

Wie wir noch sehen werden, ist dieses Risiko derzeit aber als äußerst gering zu beurteilen.

Tatsăchlich schwindet nămlich diese Besorgnis, sobald man bedenkt, daß der Einnahmenpolitik der Finanzwirtschaft eine neuartige, inzwischen unentbehrliche Rollo zugowachsen ist. Großs, durch Krieg und nachfolgende politische Wirnungen entstandene, Naturkatastrophen vergleichbare Ereignisse erfordern noch heute zu einer allgemein als vordringlich erstrebten zeitaufwendigen Entspannung der Notlage umfangreiche Investitionen, deren Finanzierung sicherzustellen ist. Die Steuerpolitik hat dabei vorerst notgedrungen und sodann als Folge ihrer beeindruckenden Effektivität und nicht zuletzt wegen ihrer formalen marktwirtschaftlichen Kompatibilität zunehmend die Rolle der pretialen Lenkung beim Wiederaufbau nach den Kriegszerstörungen und heute bei den Kriegsfolgen im Ostteil Deutschlands übernommen. Weitere erstrebte wirtschaftspolitische Ziele traten inzwischen hinzu.

Die konkreten unterschiedlichen Wirkungsmöglichkeiten der beiden verschiedenartigen Besteuerungsideen werden von Finanzwissenschaftlern und Steuerjuristen nie angemessen aufgearbeitet. Daher gelten - wenn man von gesellschaftspolitisch motivierten Vergïnstigungen, wie etwa zur Vermögensbildung, zum Wohnungsbau etc. einmal absieht - noch heute Tarifprogression, Pauschalierungen, Freibeträge und die seit etwa 1880 in der Diskussion oft als Existenzminimum bezeichnete steuerfreie Eingangsstufe des Tarifs als die wesentlichen Kriterien für die soziale Ausgestaltung der Einkommensteuer. ${ }^{303}$

\footnotetext{
303. Zwar wird die Bedeutung unterschiedlicher Einkommensdefinitionen zumeist erwähnt, aber mit wenigen Worten abgehandelt und ausgeklamunert. Hierzu als Beispiel: Findling, M. (1992), S. 72. Tatsăchlich können die hier angesprochenen Wirkungszusammenhänge ohne intensive Zusammenar-
} 
Für deren Anhebung in einem jeweils umstrittenen vertretbaren Umfang machen sich oft fast alle Gruppierungen unterschiedslos stark.

Hochverdienende, zu denen heute gerade die Meinungsbildner der einflußreichen Medien - heute oftmals als "vierte Gewalt" bezeichnet - rechnen, können im herrschenden Steuersystem jeweils bei Verbesserung der so verstandenen sozialen Ausgestaltung noch gröBere Steuerbeträge in Vermögen umwandeln. Die Interessenlage erschwert eine sachliche Aufhellung der Zusammenhănge.

Auch kleinere Steuerzahler erwarten von derartigen Maßnahmen eine steuerliche Entlastung. Tatsächlich provoziert das Ergebnis jedoch letztlich durch die notwendig werdende Tarifanpassung nur eine neue Verteilung des Haushaltsbedarfs mit der Folge einer stärkeren Belastung des Mittelstandes, für den sich die Verwandlung von Steuern in Vermögen durch Beteiligung an steuerbegünstigten Investitionen nicht mehr rechnet.

Eine Änderung dieser Zusammenhänge und der Konsequenzen ist nicht in Sicht. Wir werden davon noch hören.

Seit 1949 können, wie wir noch sehen werden, bestimmte Gruppen von Steuerbürgern entstehende Steuern auf diese Weise in Vermögen umzuwandeln. Ja, dies ist sogar politisch erwünscht. Die Vermögensbildung kann sogar bei sinnvoller Auswahl des Investments höher ausfallen, als der zur Steuervermeidung eingesetzte Betrag des Einkommens. Das mag absurd klingen, entspricht jedoch der Wahrheit, wie wir sogleich sehen werden. ${ }^{304}$

beit von Juristen und Okonomen nicht erfolgreich bearbeitet werden. Dies bat J. Backhaus erkannt, wern er an die Tradition G. Schmollers anzuknupfen sucht und eine "okonomische Rechtsanalsyse" als Institution fordert. "Rechtsfolgenanalyse", "Funktionsanalyse" und "normative Analyse" kônnten zur Aufhellung der Zusammenhalnge zwischen den verschiedenen Bercichen entscheidend beitragen, $s$. Backhaus, J. (1991), S. 149. Wagner, Fuisting, Waldecker u. a. folgten einseitig rechtsdogmatischen Vorgehensweisen. Das wurde fùr die Entwicklung richtungsweisend.

304 Das Erscheinungsbild der Finanzinter im offentlichen Bewußtsein war seit 1949 groß̈en Wandlungen unterworfen. Es ist heute noch als verworren zu bezeichner. Dem Besucher des Finarzamtes Düsseldorf-Nord konnte dies um 1980 besonders deutlich werden. Der Vorsteher der Behôrde, ein Freund des exaltierten, in seinem Amt zur ESt veranlagten Düsseldorfer Kunstprofessors Joseph Beuys, hatte das Amtsgebăude äuBerlich durch Plakate und Aufschriften mit veriockend wirkenden Angeboten von Steuervergünstigungen, Pauschbeträgen, Freibeträgen, Pauschalen etc. so herrichten lassen, als handele es sich un eine für die Óffentlichkeit zur Verteilung von Wohltaten errichtete Wohlfahrtseinrichtung. Dem Besucher bot sich dann bei Betreten ein anderes, eher ernâchterndes Bild. Die eindrucksvolle hohe Empfangshalle des Amtes wurde von einem von der Decke herabbaumelnden grobflächigen, verrottet wirkenden alten Fischemetz verunzient, das durch eine nicht abersehbare Notiz symbolisch als "soziale Hängematte" kenntlich gemacht war. Zu FüBen des Netzes stand ein Katheder, auf dem, von Halogenlampen grell angestrahlt, eine Ausfertigung des Bundessteuerblatts mit dem jeweils gültigen EStO aufgeschlagen zur Lektüre bereitlag Viele Amtsbedienstete und Besucher der Behôrde empfanden diese Aufmachung als surrealistische, vôllig unsubstantiierte Provokation. Die Frage, wer den realistischen Durchblick behielt, scheint jedoch so leicht nicht lōsbar. War es der junge Veranlagungsbeamte, der seiner Ausbildung entsp̣rechend den Steuerpflichtigen zur Erörterung ihrer 
Branchenkenner schätzen das im Jahr 1994 allein von geschlossenen Immobilienfonds durch Inanspruchnahme von Steuervergünstigungen auf diese Weise zusammengebrachte Investitionsvolumen auf ca. $25 \mathrm{Mrd}^{305} \mathrm{DM}$. Daß hierzu noch die ohne Einschaltung eines Nebenkapitalmarktes ebenso durch Steuervergünstigungen ausgelöste Investitionsleistung von vielen kleinen und mittleren Uinternehmern und Privatleuten, die durchweg von freiberuflichen Berufsträgern betreut werden, hinzutritt, ist anzuführen. Wegen der zahllosen Renovierungs-, Sanierungs- und Aufbauvorhaben in den neuen Bundesländern mag sie betragsmăßig mindestens in gleicher Höhe anzusetzen sein.

Zur selben Zeit berichtet die Deutsche Steuergewerkschaft, daß nach ihren statistischen Unterlagen die Neigung, die persünliche Vermögenssituation durch steuerstrafrechtlich relevante Manipulationen auf Kosten der Allgemeinheit zu verbessern, wächst. Danach betrug 1992 das Hinterziehungsvolumen allein in den alten Elundesländern über 130 Mrd. DM. ${ }^{306}$ Dieser Betrag entspricht in etwa den durch die sogenannte Wiedervereinigung der Bundesrepublik Deutschland seit 1991 jährlich von den alten Bundesiändern aufgebrachten Transferleistungen.

steuerlichen Obliegenheiten zur Verfügung stand? War es der überspannte, realitätsfeme Künstler Beuys, der das "Werk" schuf, oder war es der Finanamisworsteher, der zwischen ẩerlichem Eindruck und innerer Ausgestaltung zu trennen wußle?

${ }^{365}$ Der Platow-Brief Special, November 1994, S. I; s. a. Cash, 13. Jg., 1995. S. 121.

${ }^{306}$ Die Stetier-Gewerkschaff, 12. Jg. Dez. 1993, S. 151, S. 152; ebenso 13. Jg. 1994. S. 71; s. a. Grïn, W. H. (1994), der stellveztretender Finanzantsworsteher ist. Tatsächlich bestlitigen Mitarbeiter der BP verschiedener Äunter im Kölner Raum, daß die von Grün skizzierten Steuervergehen mit hohern kriminellem Engagernent bereits in den meisten Amtsbezirken vorkamen; s. hierzu auch: Däke; K. H. in: Der Steuerzahler, 2/1995, S. 18. 


\title{
E. Eigentümlichkeiten der Besteuerungswirklichkeit in der Bundesrepublik Deutschland seit 1949
}

\author{
Schlaglichter auf soziale Unzuträglichkeiten mit \\ drohenden Konsequenzen
}

\section{Die gesetzlichen Vorkehrungen für den Einsatz des Einkommensteuergesetzes als Instrument der Wirtschaftspolitik}

Mit Einführung des EStG 1948 vom 22. Juni1948' und dann des EStG 1949 vom 20. April $1949^{2}$ durch den der "Militärregienung Deutschland" untergeordneten "Wirtschaftsrat des Vereinigten Wirtschaftsgebietes" wurde die Einkommensbesteuerung systematisch und fortan in zunehmendem Umfang für verschiedenartigste politische Zwecke verwendet. Das ESIG 1948 "zur vorläufigen Neuordnung von Steuern" - und gleiches gilt für das EStG 1949 und die nachfolgenden Einkommensteuergesetze - bestand aus vorerst wenigen "Änderungen und Ergänzungen" zu dem EStG vom 27. Februar 1939, die aber bereits den Trend der ferneren Entwicklung festlegten.

Nach den großen Zerstörungen durch den zweiten Weltkrieg suchten die westlichen Besatzungsmächte durch progressiv ausgestaltete hohe Steuertarife zur eigenen Entlastung beizutragen. ${ }^{4}$ Indem sie durch Steuervergünstigungen Anreize $\mathrm{zu}$ unvermeidbar notwendigen Wiederaufbaumaßnahmen zur Linderung der vorherrschenden Verelendung schufen, suchten sie möglichst schnell

1 Beilage Nr. $4 \mathrm{zum}$ Gesetz- und Verordnungsblatt des Wirtschaftsrates des Vereinigten Wirtschaftsgebietes. Militărregierung Deutschland. Geseţ, Nr. 64 v. 20.6.1948, S. 2, und Verordnung zur Änderung der EStDV vom 16.10.1948 in: Gesetzblatt der Verwaltung des Vereinigten Wirtschaftsgebietes 1948 , Nr. 26 v. 28.12.1948, \$. 139.

2 Zweites Gesetz. zur vorläufigen Neuordnung von Steuern vom 20.4.1949, in: Verordnungsblatt für die Britische Zone. Amtliches Organ zur Verkundung von Rechtsverordnungen der Zentralverwaltungen, Hamburg, v. 31.5.1949, Nr. 27, S. 168; für viele Einzelheilen s. Drei/3ig, W. (1984), S. 175; hierzu auch: Schweigert, E. (1970).

${ }^{3}$ EStG v. 27.2.1939, in: RGB!. I 1939, S. 297. Das EStG 1939 entsprach in den hier behandelten Passagen demjenigen v. 16.10.1934, in: RGBI. I 1934, S. 1006.

${ }^{4}$ Es wurden viele Gründe für hohe Tarife geltend gemacht. Die Tarifprogression erreichte im EStG ab 1948 cinen Grenzsteuersatz von 95\%, s. Gesetzblatt 1948, S. 166; s. a Dreißig, W., S. 182. 
zugleich eine gewisse finanzielle Unabhängigkeit des besetzten Landes von einseitigen drückenden eigenen Unterhaltsleistungen $z u$ erreichen. ${ }^{5}$

Maßnahmen, die bei Einführung als heftig umstrittene vorübergehende Übergangsregelung zur zügigen Beseitigung dringendster Notzustånde in Fachkreisen als noch akzeptabel erschienen, wurden bald nach Schaffung der Bundesrepublik Deutschland mit eigener Gesetzeskompetenz infolge Entdekkung der großen Effektivităt bei Erreichung der Zielvorgaben zum festen Bestandteil der Einkommensbesteuerung. ${ }^{6}$

Das von erdrückend hohen Tarifsätzen gekennzeichnete Einkommensteuerrecht der Militărregierung Deutschland erzeugte einen entsprechend hohen Steuerwiderstand, der dann wie ein Motor mit Selbstzündung als Folge der den Steuerzugriff zurückführenden geföderten Investitionen zusammen mit der Einfuhrung marktwirtschaftlicher Organisationsstrukturen gesteigerte, selbst Fachleute überraschende wirtschaftliche Aktivităten freisetzte. ${ }^{7}$

Die Einkommensbesteuerung wurde dann allmăhlich zum unentbehrlichen Instrument der Wirtschaftspolitik. Wăhrend in einer ersten Periode die von Kriegseinwirkungen dezimierte Wohnungsversorgung, der Wiederaufbau kriegszerstörter Produktionsstătten und die Eingliederung ehemals politisch Verfolgter und Heimatvertriobener Vorrang bei steuerlichen Förderungsmaßnahmen zukam, folgte eine Zeitspanne, in der die Vollbeschäftigung als Orientierung das Primat der Maßnahmen bestimmte. ${ }^{8}$

Nach 1966 traten dann Strukturpolitik, Verteilungs- und Konjunkturpolitik in den Vordergrund. Danach verschob sich das Interesse auf die stärkere Be-

\footnotetext{
${ }^{5}$ Die Alliierte Hohe Kommission legte noch nach Gründung der BRD und nach Wirksamkeit des sogenannten Generalvertrages an 21.4.1950 iftr Veto gegen den GesetzesbeschluB des Deutschen Bundestages zur Herabsetzung der Stettertarife v. 30.3.1950 ein. Sie begründete ihren Einspruch mit der eventuellen "Notwendigkeit, auslāndische Hilfe für Deutschland zu verschärfen und Deutschlands Devisenbedarf zu erhöhen", s. Alliierte Hohe Kommission fur Deutschland. Der Rat. Schreiben an den Kanzler der Bundesrepublik Deutschland v. 21.4.1950, abgedr. in: Deutscher Bundestag, 1. Wahlperiode 1949, Drucksachen Nr. 854, S. 2.

6 S. Dreißig, W. (1984), S. 196. S. a. Wörtliche Berichte und Drucksachen des Wirtschaftsrates des Vereinigten Wirtschaftsgebietes 1947 - 1949, hrsg. v. Institut furr Zeitgeschichte und dem Deutschen Bundestag, Wissenschaftliche Dienste, Bd. 3, 23 - 40 Vollversammlung, München 1977, darin Beitrag. des Berichterstatters Blicher u. a., S. 1453. Hierz: auch: Fischer, C. (1949) in: StuW, Sp. 581, und Spitaler, A., (1949), in: StuW, Sp. 760.

'Schmólders, G. (1968), Der Staatsbürger ..., S. 137. Schmölders hat zu dem großen Kreis von Finanzwissenschaftlern gehồt, die den Einsatz steuerpolitischer Maßnahmen zưr Investitionsförderung. ablehriten. Er hat gegen diese Verwendung stets am heftigsten polemisiert und fragwürdige Beispiele als Nachweis von angeblichen Fehlinvestitionen angeführt. Andere Finanzwissenschaftler wie Neumark äußerten sich eher ambivalent und unsicher, ja oft widersprüchlich, hierzu: Albrecht, A/ Arndt, H. (1952), Kapitalbildung ..., S. 56, S. 76, S. 119, S. 194, S. 198 u.a.

s. Muscheid, J. (1986), S. 16.
} 
achtung einer gleichmäßigeren Vermögensverteilung, auf Maßnahmen zur Konjunkturstabilisierung und neuartig aufkommende Zielvorstellungen, wie den Umweltschutz und dessen technische Erfordernisse.

Auf diese Weise wurden durch Maßnahmenbündel, deren wirkungsvollster Bestandteil die steuerliche Förderung durch Sonderabschreibungen darstellte, der Wohnungsbau, die Eingliederung ehemals politisch Verfolgter und Heimatvertriebener, die Schaffung neuer Produktionsstătten, Energiegewinnung, Schiffssau und Schiffsverkehr, Hochseefischerei, die Luftahrt, Stădtesanicrungen, rational geplante Gewerbeansiedlungen, Vermőgensbildung der Arbeitnehmer, Regelungen zur Konjunkturstabilisierung, allgemeiner Urmweltschutz, Immissionsminderung der Industrie, Anlagen zur Abwåsserreinigung und ebenso zur Energiegewinnung aus natürlichen Ressourcen, Einrichtungen zur Lărm- und Wărmedămmung von Gebăuden, Maßnahmen zum Denkmalschutz, Erhaltungsaufwendungen für Bauwerke, abnutzbare Wirtschaftsgüter der Krankenanstalten, Zweckbauten und besondere Einrichtungen der Landund Forstwirtschaft, mittlere und kleine Betriebe und vieles mehr durch Steuervergünstigungen bei der Einkommensbesteuerung bis heute unterstützt. ${ }^{10}$

Wie wir noch sehen werden, war es das Ziel der steuerlichen Förderung, die Finanzierung von Neugründungen zu erleichtern, die Ertragskraft bestehender Unternehmen durch neuartige Möglichkeiten zur Selbstfinanzierung zu stărken bzw. Privatleuten Anreize zu einer Beteiligung an der Erneuerung einer erwünschten, breit gefächerten verbesserten Infrastruktur zu bieten.

Fast vierzig Jahre spăter liegt der Schwerpunkt der steuerlichen Förderung im Wiederaufbau und einer geeigneten Eingliederung der neuen Bundesländer in die Bundesrepublik. ${ }^{11}$

Die Anreize folgten dem nachstehend skizzierten Rezept: Die Förderung erfolgte und erfolgt heute noch dadurch, daB im System des EStG 1939 verstreut Bestimmungen integriert wurden, die die Steuerbarkeit von gewissen

\footnotetext{
${ }^{9}$ S. Muscheid, J. (1986), S. 16.

i0 Die $\S \S 7$ und 7a bis 7k EStGi v. 7.9.1990, in: BGBI. I, S. 1899, geben bei Berücksichtigung spăterer Änderungen und Erganzungen bis zum 28.10.1994 durch 27 Einzelgesetze einen Eindruck von der Unzahl spitzfindiger, nichtfiskalischen Zwecken dienender Ausnahmeregelungen als sogenannten Lenkungsıormen. Dabei enthălt § 7 EStG nunmehr 94 Zeilen und die $\S \S 7 \mathrm{a}$ bis $7 \mathrm{k}$ sind aul 513 Zeilen angeschwollen, s. NWB Gesetzestexte, F. 3, S. 4408. Dazu sind noch die Vorschriften in $\$ \S 82$ bis $82 \mathrm{k}$ EStDV hinzuzurechnen. Der ursprüngliche $\$ 7$ EStG v. 27.2.1939, der die Verteilung des Aufwands für abnutzbare Wirtschaftsgûter auf die Besteuerungsabschnitte regelte, hatte noch 18 Zeilen beansprucht.

"I Fördergebietsgesetz in der letzten Fassung v. 23.9.1993, BGBI. I, S. 1655. Nach dieser Vorschrift kônnen Aufwendungen für nachträgliche Herstellungsarbeiten und Anschaffungskosten, die auf ModemisierungsnnaBnahmen und andere nachträgliche Herstellungsarbeiten entfallen, in zehn Jahren zul 100\% als Sonderabschreibungen bei Ennittlung des Gewinns oder Ôberschusses abgesetzt werden.
} 
Wertzugängen einschränkten bzw. bei Ermittlung der Bemessungsgrundlage für den Tarifzugriff bei Vorliegen besonderer ausgewählter Tatbestandsmerkmale im Sachverhalt Umfang und Höhe der ursprünglich nach wirtschaftlichen Kriterien zu berücksichtigenden Abzugspositionen erweiterten ${ }^{12}$ Oftmals wurden zusätzlich auch die Tarifvorschriften selbst in die Fördenung einbezogen. $^{13}$

Als besonders wirksam erwies sich eine gewährte Durchbrechung des Prinzips der periodengerechten Besteuerung. Hierzu gehörte u. a. die Befugnis, Sonderabschreibungen in gewissen Grenzen beliebig auf verschiedene Jahre zu verteilen. ${ }^{14}$

Die Freistellung bestimmter sozial indizierter Leistungen, wie Abfindungen oder die Steuerfreiheit besonderer Zinserträge von Wertpapieren zur Finanzierung aufwendiger langlebiger Investitionen zur Energieerzeugung sind hier ebenso zu erwăhnen. ${ }^{15}$ Auch die Steuerfreiheit von Zuschlägen zum Arbeitslohn und die Begünstigung von Nebeneinkünften sind zu nennen.

Fruhzeitig wurden bis heute Sonderabschreibungen für unbewegliche und bewegliche abnutzbare Wirtschaftsgüter als wichtigstes Steuerungsinstrument in den Kreis der Betriebsausgaben bzw. Werbungskosten aufgenommen. ${ }^{16}$

Investitionszuschüsse und Investitionszulagen, die nicht unmittelbar in das EStG integriert wurden, sind hier gleichfalls anzuführen. Sie mußten abgestimmt werden. ${ }^{17}$

${ }^{12}$ Als Beispiel mag folgendes dienen: Nach $\S 9$ Ziff. 4 EStG 1939 und ebenso noch nach $\S 9$ Ziff. 4 EStG 1953 waren nur "notweridige Aufwendungen des Steuerpflichtigen fur Fahrten zwischen Wohnung und Arbeitsstäte" bei Emittlung der steuerlichen Bemessungsgrundlage als Werbungskosten abzugsfahig. Aus wirtschafllichen Grùnden wurden ab EStC 1955 v. 21.12.1954 für die Benutzung eines PKW zu diesen Zwecken Pauschbetrăge pro gefahrenen Kilometer erheblich überschritten, die bis heute laufend fortgeschrieben wurden.

13. Eirstes Gesetz zur Änderung des EStG i. d. F. v. 12.12.1954, das KStG i. d. F. v. 12.12 .54 und das Gesetz zur Erhebung einer Abgabe: "Notopfer Berlin" v. 4.7.55 (Steuererleichterungsgesetz), in: BStBI. I 1955, S. 384.

${ }^{14}$ \& 7b Abs. 4 EStG v. 10.12.1965, BGBI. I, S. 1901. Diese Erlaubnis, den versảumten Ansatz von Sonderabschreibungen in den ersten vier Jahren bis zur Höchstgrenze nachzuholen, wurde später im BerlinfG und danı im FördG noch erweitert, indem auch Anzahlungen für Investitionen als Grundlage fur. Abschreibungen dienen durften, s. $\$ 4$ Abs. 2 FördG.

15. $\$ \$ 3,3 \mathrm{a} \mathrm{EStG} \mathrm{v.} 21.12 .1954$; s. a. BGBI. I 1952, \&. 793.

16 Bei Abschreibungen handelt es sich um die Berucksichtigung von Aufwendungen für die Anschaffing bzw. Hersteliung von abnutzbaren Wirtschaftsgutern, deren Lebensdauer eine Abrechnungsperiode sberdauern. zur Ermittlung des periodengerechten Gewinns oder Verlustes. Nach dem in $\$ 9$ EStG 1939 formulierten Grundsatz war der Anschaffungs. oder Herstellungsaufwand fur ein Wirtschaftsgut auf dessen betriebsgewohnliche Nutzungsdauer systematisch zu verteilen. Sonderabschreibungen erlaubten die in Anm. 10 aufgezählten Ausnahmen von dem Grundsatz nach außerfiskalischen Gesichtspunkten. 
Zeitweise durften Teile des nichtentnommenen Gewinns unter die Positionen der in einem Enumerativkatalog aufgezăhlten absetzbaren Sonderausgaben eingestellt werden. ${ }^{18}$

Bei Ermittlung des Gewinns durch Bestandsvergleich durfte sodann im Falle des Vorliegens normierter Tatbestandsmerkmale im Sachverhatt von Bewertungsfreiheiten für bestimmte Wirtschaftsgüter Gebrauch gemacht werden. ${ }^{19}$

Schließlich brachte die Einfuhrung des Verlustvortrages bzw. -rücktrages die Möglichkeit zu dessen Berücksichtigung ohne Beachtung des Verursachungsabschnitts mit sich. ${ }^{20}$

Von größter Bedeutung wurde folgendes: Bereits in das EStG vom 15. Sep-tember 1953 war eine neuartige Gesetzesermăchtigung als $\S 51$ eingefuhn worden, von der die Bundesregierung mit Zustimmung des Bundesrates Gebrauch machen durfte. ${ }^{21}$ Ab dem EStG vom 21. Dezember 1954 wurde und wird diese Möglichkeit bis heute durch die Bestimmungen der $\$ \$ 75$ bis 78 und später bis $\S 82 \mathrm{k}$ EStDV ausgiebig für Steuervergünstigungen als Ausnahmeregelungen genutzt. ${ }^{22}$ Diese Ermăchtigung hat zwar die Eingrenzungen des Art. 80 der Verfassung der Bundesrepublik Deutschland zu beachten, vereinfacht es der Regierung aber, in weitreichendem Umfang die Wirtschaft im Wege von Verordnungen, Erlassen und Richtlinien durch Einführung, Einschränkung oder Streichung von Vergünstigungen zu steuern.

Die Wirksamkeit der vorstehend nicht abschließend aufgeführten gesetzlichen Regelungsbereiche erstreckte sich auf alle natürlichen und als Folge des in $\S 8 \mathrm{KStG}$ normierten Gesetzesverweises auf die Ermittlungsvorschriften des

17 Ein Investitionszulagengesetz (letzte gülige Fassung v. 23.9.1993, BStB1. I, 5. 1651) und das Finanzreformgesetz v. 12.5 .1969 i. d. F. v. 31.7.1970 regeln die Vergabe von Zulagen und als notwendige regionale Gemeinschaftsaufgaben zur Verbesserung der Wirtschaftsstruktur gestattete Zusagen von Zuschüssen zu Investitionen. Hierbei handelte es sich dann um offerse veriorene stasiliche Subventionen.

${ }^{18}$ Dem EStG 1939 war diese Vergünstigung unbekannt. Durch das Änderungsgesetz v. 29.41.1950. BGBI. I, S. 98, wurde \$10a ESIG der Systematik eingefugt. Die Vorsciurift wurde im EStG v. 28.12.1950, BGBI. I, S. 7, beibthalten. Sie findet sich noch im ESIG v. 15.9.1953, BGBI. I, S. 1364, im EStG v. 21.12.1954, BGBI. I, S. 449, und im EStG v. 13.11.1957, BGBI. I, \$. 1802.

${ }^{12} \S \S 74,75$ ESIDV 1954, BGB1. I, S. 772. Die Vorschrift blieb bis heute erhalten.

20 § 10d EStG v. 15.8.1974, BGiBI. I, S. 1993, gewährte diese Moglichkeil für die Gewinneinkunftsarten 1 bis 3. Durch $\S$ 10d EStC v. 20.4.1976, BGBI. I, S. 1054, wurde die Geliung auf alle Einkunftsarten ausgedehnt.

21 \& 51 EStG v. 15.9.1953, BGBl. I, S. 1355, hier S. 1377. Diese Vorschrift wurde 1953 erstmals eingefuhrt. Sie bestand 1953 aus, 72 Zeilen Gesetzestext, inzwischen ist $\$ 51$ in dem ab 1.1.1995 gültigen EStG auf 488 Zeilen angewachsen, s. NWB, F. G 3, S. 4518.

22. EStG 1955 v. 16.12 .1954 i. d. F. v. 2!.12.1954, BGBI. I, S. 441, und EStDV 1955 i. d. F. v. 7.2.1958, BGBI. I, S. 70; heute EStDV 1990 i. d. F. v. 25.10 .1994 , BGBI. I, S. 3082. 
EStG, soweit anwendbar, auch auf alle juristischen Personen mit Einkünften in der Bundesrepublik.

Weiterhin sind hier noch die Vorschriften zu nennen, die als lex specialis zu den Bestimmungen des EStG zu werten sind, wie die verschiedenen seit 1950 beschlossenen Gesetze zur Fördenung der Wirtschaft von Berlin, die dann 1964 durch das. Berlinhilfegesetz ersetzt wurden, ${ }^{23}$ dem späteren Fördergebietsgesetz u. a. $\mathbf{m}^{24}$

\section{IL. Steuervergünstigungen und deren Anreiz zur Steuervermeidung nach 1948}

Diese Regelungen brachten es mit sich, daß ein großer Teil der Tätigkeit steuerberatender Berufsträger frühzeitig darauf gerichtet werden mußte, angesichts der gewaltigen Zerstörungen durch den Krieg Mandanten bei der Inanspruchnahme von Steuervergünstigungen für den Wiederaufbau der Betriebe, bei Saniening ihrer Wohngebäude und Festigung ihrer gewerblichen und beruflichen Existenz zu beraten und zu vertreten.

Das sogenannte "Wirtschaftswunder" der Bundesrepublik Deutschland, zu dem nicht zuletzt auch die Schaffung der modernen Infrastruktur zu rechnen ist, kann als sichtbares Ergebnis dieser umfassenden Inanspruchnahme der gewährten zielgerichteten Steuererleichterungen durch Privatleute, Einzelfirmen, kleine und mittlere Gemeinschaften bürgerlichen Rechts, Personengesellschaften und den übrigen Gesellschaften des Handelsrechts im Zuge des Wiederaufbaus gesehen werden, mag dieser Gesichtspunkt nach erstem Anschein auch als ungewöhnlich erscheinen. ${ }^{25}$

Bei den Folgeschäden des Krieges, die beseitigt wurden, handelte es sich stets um Schäden am Eigentum natürlicher oder juristischer Personen oder

23 Die Rechtsentwicklung des BerlinFG setzte mit dem Gesetz zū̃ Förderung der Wirtschaft von Grob Berlin (West) v. 7.3.1950, BGBI. 1, S. 41, ein. Es wurde sodann $17 \mathrm{mal}$ ergànzt und verändert, bis das Berlinhilfegesetz v. 19.8.1964, BGBBI. I, S. 674, an die Stelle trat. Dieses wurde dann ebenso 27 malk verändert und ergänzt, bis es 1992 von dem FördG in der heute geltenden dritten Fassung nach der Wiedervereinigung abgelöst wurde, s. hierzu die Zusammenstellung bis 1980 in: Hecker, C. (1982), Anhang, S. I.

24 FördG v. 23.9.1993, BGBI. I. S. 1655. In $\$ \S 3$ und 4 werden Sonderabschreibungen bis zu $100 \%$ der Anschaffungs- bz.w. Herstellungskosten in zehn Jahren vorgesehen, s. Anlage 6.

25 In einem Rückblick gelangte ein bekannter Zeitzeuge 1966 zu der Erkenntnis, daß die konsequent durchgehaltene Steuerpolitik "das Wunder von zwei Jahrzehnten deutschen Wiederaufstiegs" bewirkte. Die umfassende steuerliche Begünstigung der Eigenfinanzierung und die hohe steuerliche Förderung vonı Investitionen bei Einführung einer marktwirtschaftlichen Gesamtordnung schufen nicht nur notwendige Voraussetzungen, sondern verursachten das, was allgemein als "Wirtschaftswunder" bezeichnet wird, s. Zischka, A. (1966), S. 519, S. 531, S. 553 u. a. 
öffentlich-rechtlicher Körperschaften. Eine Beseitigung der Zerstörungen und der Neuaufbau notwendiger Vorrichtungen war bei Einsatz von steuerlichen Vergünstigungen als Anreiz unvermeidbar verbunden mit einer Vermögensmehrung der jeweiligen Eigentümer.

Steuervergünstigungen brachten es daher mit sich, daß andere Steuerbürger solidarisch die steuerliche Entlastung der Eigentümer bei der Lastenverteilung der offentlich-rechtlichen Abgaben mit übernehmen mußten.

Nachdem dem von Schrnoller konzipierten Grundgedanken für die Orientierung der Einkommensteuer seit 1891 und dann seit 1925 nur noch als Ermittlungsvorschrift für einzelne Einkunftsarten Bedeutung zukam, traten Bedenken gegen eine fragwürdige steuerliche Lastenverteilung nicht hervor. Die von einer Steigerung des Sozialprodukts erwartete allgemeine Wohlstandsmehrung ließ die steuerlichen Maßnahınen unter dem Eindruck der Zerstörungen ohnehin als fraglos im allgenneinen Interesse liegend erscheinen.

Wer nach 1950 keine Möglichkeit hatte, von den gewährten Steuervergünstigungen direkten Gebrauch zu machen, konnte sich, sofern seine einkommensmäßigen Voraussetzungen dies zuließen, mit anderen Steuerbürgern zu einer Zweckgemeinschaft verbinden. Mit allgemein steigenden Einkommen entstanden deshalb bald neuartige Formen ertragsorientierter steuerbegünstigter Kapitalanlagen. Denn: was von einzelnen Steuerbürgern als Privatmann, Landwirt, Gewerbetreibender oder Freibenfler in Anspruch genommen werden konnte, durfte zweifellos auch ebenso von Gemeinschaften und Gesellschaften und in anderen Größenordnungen beansprucht werden.

Das Zivilrecht hält eine reichhaltige Palette möglicher Rechtskleider für geeignete steuerliche Mitunternehmerschaften bereit, die ein breites Spektrum verschiedenartigster Interessen abzudecken vermögen. Dieser Ürnstand brachte als Konsequenz mit sich, daß es Hochverdienenden seit 1950 bis heute leichtgemacht wurde, die Einkommensteuerbelastung trotz hoher Steuerprogression stets in erträglichen Grenzen zu halten.

Dazu werden wir noch Einzelheiten erfahren.

Die nach Wiedereinfühnung marktwirtschaftlicher Prinzipien gewährleistete Privatautonomie bewirkte bald nach 1950, daß die durch hohe Anreize begünstigte Realisierung vieler kleiner, aber auch großer Investitionsvorhaben mit entsprechend umfangreichem Bedarf an Finanzierungsmitteln schon wegen einer zweckmäßigen Risikoverteilung zur Inanspruchnahme steuerlicher Vergünstigungen durch Bildung von neuartigen, bis dahin ungebräuchlichen zweckbestimmten Gemeinschaften unterschiedlicher Größen und Konstruktio- 
nen fuhrte. Diese wurden jeweils von einer abgeschlossenen Anzahl von Beteiligten zu dem Zweck begründet, ein konkretes Investment zu verwirklichen.

Die Einkommensbesteuerung erhielt im Zuge dieser Entwicklung eine neuartige Funktion, die bislang die Domảne von Banken gewesen war. Für die Anregung von Investitionen und zu deren Finanzierung wurden nämlich die normierten Tatbestandsmerkmale der Steuervergünstigungen ausschlaggebend.

Das Ausma des bald sichtbaren Erfolgs dieser steuerpolitischen Maßnahmen war, wie bereits zuvor nach 1932, überraschend.

Damals hatten vergleichbare steuerpolitische Maßnahmen einerseits eine schnelle Erlösung aus wirtschaftlicher Not und ein Ende der hohen Arbeitsiosigkeit mit sich gebracht. Gerade diese Eriolge hatten auf Grundlage der Zeitumstănde jedoch andererseits die politische Balance der Demokratie zerfallen lassen.

Ein Rückblick auf die Zusammenhănge mag die Bedeutung von Vergünstigungen bei der Einkommensteuer zur Meisterung von Krisensituationen bestaltigen:

Die Arbeitslosigkeit hatte im Zuge der Weltwirtschaftskrise im Februar 1932 den Stand von 6.128.429 erreicht. Im Februar 1933 hatte sie noch 6.013 .000 betragen, was über $30 \%$ der arbeitenden Bevölkerung ausmachte. ${ }^{26}$ In den USA nahm man zur selben Zeit Zuflucht zu der als "New Deal" bezeichneten Wirtschaftspolitik vermittels eines eher zusammenhanglosen Konglomerats von weitgehend unabhängigen Teilregelungen. Roosevelt legte dabei das Hauptgewicht beschäftigungspolitischer Maßnahmen in den Bereich öffentlicher Arbeiten, zugleich in eine Erhöhung der Einkommensteuerprogression und eine expansive Geld- und Kreditpolitik. ${ }^{27}$

Das Reichsfinanzministerium hatte schon länger an Plänen für eine allgemeine Wirtschaftsbelebung durch Finanz- bzw. steuerpolitische Maßnahmen vorgearbeitet. $^{28}$

Popitz wies als Staatssekretăr des Ministeriums 1929 darauf hin, daß Konzepte zur Förderung von Kapitalmarkt und Investition zur Ankurbelung der

\footnotetext{
${ }^{26}$ Stat. Jh. f. d. Deutsche Reich 1934, S. 308; s. a. Wirtschaft und Statistik 1935, S. 32.

27 Fritsch, B. (1963), S. 519.

28. Der dt. Volksw. 1933, S. 1010, S. 1469 u. a.; s. a. Schwerin von Krosigk, Graf L. (1974), S. 207; ders. (1977), S. 163.
} 
Produktion ausgearbeitet würden und daß man amtlicherseits auf einen durchsetzungsfähigen Politiker zu deren Verwirklichung warte. ${ }^{29}$

Vorerst konnten nur im Wege von Notverordnungen gem. Art. 48 Abs. 2 WRV - zuletzt am 18. Mărz 1933 - notwendigste Maßnahmen zur Linderung der Not als Folge der Weltwirtschaftskrise durchgesetzt werden. Da die Parteien sich nicht zu einer gemeinsamen Willensbildung durchzuringen vermochten, war die parlamentarische Demokratie nach 1930 de facto in eine Prisidialdemokratie übergeglitten. Am 24. Mărz 1933 ließ sich die Reichsregierung zum Erlaß von Reichsgesetzen ohne Einschaltung des Parlaments zugleich zur legislativen Instanz ermächtigen, um - wie es hieß - die Politik zur "Behebung der Not von Volk und Reich" des Reichspräsidenten konsequent fortzusetzen. $^{30}$

Die nunmehr sofort in Gang gesetzte, bereits theoretisch durchdachte AntiDeflationspolitik zur Beseitigung der Arbeitslosigkeit sah offentliche Investitionen, die Verbesserung der Rentabilităt privater Investitionen und eine Hebung der Kaufkraft der Verbraucher vor. ${ }^{31}$

Als wichtigste Initiative zur Ankurbelung der gewerblichen Wirtschaft waren in diesem abgestimmten Maßnahmenbündel Steuererleichterungen bei der Einkommensteuer vorgesehen, $\mathrm{zu}$ denen noch unterstützend verlorene $\mathrm{Zu}$ schüsse und Kreditverbilligungen aus öffentlichen Mitteln hinzutraten. ${ }^{32}$

Die Vergünstigungen bei der Einkommensteuer als Teil der Ankurbelungsmaßnahmen finden in der Berichterstattung der Vorgänge von 1933 zumeist nur kurze Erwähnung; ihre die Wirtschaftsbelebung auslösende Bedeutung wurde nie erkannt, da bei der Art der Vergünstigungen unmittelbare Aufwendungen nicht anfallen, desgleichen die Ergebnisse sich einer einfachen statistischen Ermittlung entziehen und einige steuerliche Kenntnisse vorausgesetzt werden müssen. Hardach räumt jedenfalls ein, ${ }^{33}$ daß die öffentlichen Maßnahmen den frühen zügigen Abbau der Arbeitslosigkeit im Jahr 1933 letztlich nicht erklären können. Er läßt diese Frage der Auslösung einer bisher unerklärten Initialzündung unbestimmt.

\footnotetext{
29 Colm, G./Neisser, H. (1929), S. 147.

${ }^{30}$ RGBI. I 1933, S. 141; DAZ v. 25.3.1933, S. 1, S. 2.

${ }^{31}$ Mackenroth, G. (1934), S. 56.

32 ders., S. 60.

${ }^{33}$ Hardach, K. (1976), S. 71.
} 
1974 hielt Ortlieb fest, daß nach 1949 selbst Erhard von dem rasanten wirtschaftichen Fortschritt nach dem Einsatz vergleichbarer Maßnahmen überrascht wurde. ${ }^{34}$

Die Suspendierung grundlegender Ermittlungsvorschriften des EStG als auslösendes Moment für eine Initialzündung zur Wirtschaftsbelebung wurde jedenfalls nicht nachhaltig erörtert.

$\mathrm{Daß}$ es sich 1933 bei der wichtigsten gewährten Steuervergünstigung um eine Ersetzung des zeitanteiligen Ansatzes von Aufwendungen für langlebige abnutzbare Wirtschaftsgüter in den Ermittlungsvorschriften durch Sonderabschreibungen von $100 \%$ handelte, wurde nur in Fachzeitschriften vermerkt. ${ }^{35}$

In der Reichsregienung waren zu der Zeit Wirtschafts- und Finanzminister, der Präsident der Reichsbank und ebenso viele Fachleute der Überzeugung, daß vorerst der Förderung der Eigenkräfte der gewerblichen Wirtschaft unbedingt Priorităt zukommen müsse, um inflationäre Entwicklungen durch zu hohe Ausweitungen des Kreditrahmens der offentlichen Haushalte auszuschließen. ${ }^{36}$

Die zeitweilige Abändenıng der Ermittlungsvorschriften des EStG wirkten jedenfalls, schon wegen des befristeten Einsatzes, sofort. Die anlaufenden Staatsausgaben konnten erst mit der unvermeidlichen Verzögerung unterstützend greifen und den bereits gestarteten Wirtschaftsaufschwung stabilisieren. ${ }^{37}$

\footnotetext{
34 Ortlieb, H. D. (1974), S. 126.

${ }^{35}$ StW 1933, S. 770.
}

${ }^{36}$ Hierzu Schacht, H. 1953, S. 352, S. 400; ders. (1968), S. 77; Schmitt, K. in: Der dt. Volksw. v. 1.9.1933, S. 1371: Nassen, P. in: Der dt. Volksw. (1933), S. 1310; Rittershausen, H., in: Der dt. Volksw. (1933), S. 1282; F.R. in: Der dt. Volksw. (1933), S. 1275.

${ }^{37}$ Die leitenden Ermittlungsworschriften des EStG wurden nămlich nur kurzwährend ab 30.6.1933 his zum 31.12.1934 durch Gewalhrung extrem hoher Sonderabschreibungen von 100\% als Ausnahmevorschrift und durch hohe Tarifbegünstigungen abgeănderh, wobei nach Ablauf dieser Frist noch ein zweijähriger Verlustwortrag zur Verfügung stand, s. StW 1933, S. 770. Dies wirkte auf die gewerbliche Wirtschaft ankurbelnd, bis Ende 1936 die Arbeitslosigkeit endgultig beseitigt war, s. Schacht, H. (1968), S. 105. Das Horten von Geldbeträgen in bar und auf Girokonten endete sofort; Untemehmer nutzten die steuerlichen Anreize zur Durchführungen von Ersatzinvestitionen, sie fanden sich bereit, dieselben durch Querzeichnung von Akzepten zu finanzieren, wobei die Banken großzügige Prolongationen zusagten. Landwirte errichteten neue Wirtschaftsgebăude, die mit bis zu dreißig, Wechseln finanziert wurden, deren Prolongation kontinuierlich von Seiten der Bank erfolgte. Grundlagen dieser Vorgänge waren: Gesetz zur Verminderung der Arbeitslosigkeit v. 1.6.1933, RGBI. I, S. 324, S. 1074 , S. 1075, s. Anlage 5. Dies ließ den Abzug von Aufwendungen für Anschaffung oder Herstellung von abnutzbaren Gegenstånden des Anlagevermögens, die als Ersatz für gleichartige Gegenstânde zu dienen bestimmt waren, im Rurnpjjahr ab 30.6.1933 und im Jahr 1934 in voller Hōhe ohne Begrenzung wie Betriebsatusgaben bei Ermittlung der steuerlichen Bemessungsgrundlage zu. Hinzu traten noch "SteuerermäBigungen für Instandsetzungen und Erganzungen an Betriebsgebăuden", s. RGBI. I, S. 491. Auch hier war keine Begrenzung vorgesehen. Für beide Steuervergunstigungen galt, daß die Vorgănge vor dem 1.1.1935 abgeschlossen sein muBten, so daß für alle Dispositionen Eile geboten war. Der Tarif 1934 sah in der hőchsten Progressionsstufe eine Durchschnittsbelastung von $48 \%$ vor. 


\section{Die Technik der Steuervergünstigungen nach dem Einkommensteuergesetz und deren Konsequenzen}

Zwar sollten die in das EStG seit 1948 eingefügten Steuervergünstigungen, zu denen spăter noch direkte Förderungsmaßnahmen, wie Investitionszulagen und Investitionszuschüsse aus unterschiedlichen Gründen hinzutraten, schwerpunktmäßig Kriegsschäden beseitigen, Produktionsstrukturen verbessern, Liquiditătsengpässe verringern etc., um die Unternehmen in dem harten, plötzlich entstandenen weltweiten Konkurrenzkampf zu stärken. Zugleich sollte durch Begünstigung der Selbstfinanzierung die Existenzfahigkeit bei engem Kapitalmarkt erleichtert und es sollten Anreize zur Investition in Neugründungen von Unternehmen gegeben werden. ${ }^{38}$

Demgegenüber konnten jedoch die steuerlichen Vergünstigungen aus Gründen ihrer systematischen Eingliederung in die Ermittlungsvorschriften der Bemessungsgrundlage zur Einkommensbesteuerung nur von den formalrechtlichen Inhabern der Einkunftsquelle, unabhängig von den zugrundeliegenden betrieblichen Vorgăngen und obendrein nur indirekt in einer Einkommensteuererklärung geltend gemacht werden. Die Vergünstigung konnte dann nur in der nach Veranlagung erfolgenden Steuerentlastung von dem Anteilseigner vereinnahmt werden.

Eben dieser Umstand hatte sehr weitreichende Konsequenzen: Denn nach dem geltenden deutschen Einkommensteuerrecht handelt es sich bei den zur Realisienung von Investitionen gebildeten Bruchteilsgemeinschaften und Gesamthandsgemeinschaften nach bürgerlichem Recht oder nach Handelsrecht um später zumeist als sogenannte "geschlossene Investmentfonds" begründete, oftmals seit etwa 1970 auch abfälig als "Abschreibungsgesellschaften" oder "Verlustzuweisungsgesellschaften" charakterisierte Zusammenschlüsse vieler kleiner und mittlerer Investoren. Bei diesen gelten steuerrechtlich die einzelnen Beteiligten als eigenständige Unternehmer oder besser Mitunternehmer der wirtschaftlichen Aktivitäten.

Dies konnte, wie wir noch sehen werden, die neuartige Finanzienungsweise entstehen lassen, die den vorerst noch funktionsuntüchtigen nachkriegsbedingt engen Markt für die Zeichnung von haftendem Eigenkapital zu erzeugen oder später gar bereichsweise zu ersetzen vermochte.

Hinzu kamen noch Maßnahmen, die die Beschåfligung von Arbeitnehmern verbilligten und die Verlängerung von Steuererleichterungen für neu errichtete Wohngebăude, s. RGBll. 1, S. 493. Die Maßnahmen setzten die Verteilung der Steuerbelastung nach der Leistungsfahigkeit außer Kraft. Die Auswirkungen abertrafen die Erwartungen; s. a. Hardach, K. (1976), S. 71.

${ }^{38}$ Dreißig, W., S. 194. 
Die im Zuge der Entwicklung entstandenen geschlossenen Fondsgesellschaften $^{39}$ zeigten bald schon wegen der oftmals großen Zahl von Beteiligten und der ohnehin angestrebten Haftungsbegrenzung trotz ihrer Konstruktion als Gemeinschaften nach BGB oder Personengesellschaften nach HGB die für große Publikumsgesellschaften wie die Aktiengesellschaft typischen Symptome. ${ }^{40}$ In diesen verbindet nur das Interesse an der Dividende und gegebenenfalls noch am Kurswert der Aktie die Anteilseigner mit dem Unternehmen, dessen Eigentümer sie letztlich mittelbar sind. Trotz der Ähnlichkeit ihrer Haltung mit derjenigen von Aktionären der als eigenstăndige juristische Personen ausgestalteten Körperschaften sind und bleiben die Zeichner von Anteilen an geschlossenen Investmentfonds steuerrechtlich als Mitglieder einer Gemeinschaft oder Personengesellschaft, jedoch anteilige Inhaber einer Einkunftsquelle und somit als Mitunternehmer Subjekte der Einkommensbesteuerung der gesellschaftlichen Aktivitäten. Sie sind somit ebenso alleinige Bezugsberechtigte der als wirtschaftspolitisches Fördenungsinstrument verwendeten Steuervergünstigungen.

Mit wachsendem Einkommen zeigen die Zeichner von Anteilen an geschlossenen Investmentfonds ublicherweise sogar nur noch Interesse an eben diesen im Ausgabeprospekt zugesagten Steuervergünstigungen in Form möglichst hoher Verlustzuweisungen. Daneben und oft erst in zweiter Linie richten sich die Erwartungen von Zeichnern auf laufende Erträge und einen möglichst frühzeitig erzielbaren liquiden Veräußerungserlös für das erworbene Wirtschaftsgut. Der Absatz steuerorientierter Fondsanteile verdrängt jedenfalls mit steigendem Einkommen der Zeichner denjenigen der ertragsorientierten Modelle.

Vorsorglich wird heute darauf geachtet, daß es sich beim Anteilserwerb möglichst um vermögensverwaltende, nichtgewerbliche Einkünfte mit hoher Verlustzuweisung handelt und später ein Verkauf steuerfrei in der Privatsphäre erfolgt. In Angebotsprospekten wird hierzu von den Initiatoren stets Stellung genommen. ${ }^{41}$

Anteilen an derartigen geschlossenen Investmentfonds, die zumeist als Bruchteilsgemeinschaften ( $\$$ $\$ 41$ ff $\mathrm{BGB}$ ), Gesellschaften bürgerlichen

${ }^{39}$ Die ersten größ̣eren geschlossenen Investmentfonds, die in der BRD öffentlich Beteiligungen anboten, betrafen Immobilien-Investments. Mellerowicz suchte diese 1963 bekannt zu machen, s. Mellerowicz, K. (1963), S. 181, S. 186.

${ }^{40}$ S. Zybon, A. (1973), S. 419. Zybon hielt die Publikums-KG für eine Entartungserscheinung, die ein Tătigwerden des Gesetzgebers empfiehlt. Die inzwischen allgemein akzeptierte Verwendung der KG als Verlustzuschreibungsgesellschaft im Zusammenhang mit der Finanzierung des Anteilserwerbs aus Verlusten hielt Zybon noch 1973 firr "schizophren", S. 420; auch: Raupach, A. (1973), S. 46.

${ }^{41}$ Hierzi BdF-Schr. IV B 2 - S 2240 - 61/90, in: BStBI. I 1990, S. 884. 
Rechts ( $\S 705 \mathrm{ff}$ BGB) oder als Kommanditgesellschaften ( $\$ \S 161 \mathrm{ff}$ HGB) organisiert sind, wurde bereits in den spăten 50er Jahren aus der Sicht des Sparers die Bezeichnung "steuerbegünstigte Kapitalanlagen" beigelegt. Die steuerliche Orientierung auf hohe Verlustzuweisungen verdrängte mit wachsenden Einkommen allmăhlich die vorerst noch dominierende Ertragsorientienung. ${ }^{42}$

Die erworbenen Miteigentumsanteile sind infolge der sehr unterschiedlichen Beteiligungsobjekte und der verschiedenartigen Gesellschaftsverträge wenig fungibel. Da sie nicht vertretbare Wirtschaftsgüter darstellen, sind sie anders als börsenfahige, in Wertpapieren verbriefte Rechte nicht leicht veräußerbar. Man spricht in diesem Zusammenhang von einem "Nebenkapitalmarkt", in dem freibenufliche Berater ebenso, wie sogenannte gewerblich tătige Vermögensberater, heute oft "Allfinanzberater" genannt, inzwischen aber auch Banken und Versicherungen eingebunden sind. ${ }^{43}$

Bereits ab Ende der 60er Jahre wurde auf diese Weise jährlich mehr haftendes Eigenkapital für Investitionen gezeichnet, als durch Neuemissionen von Aktien über die amtlichen deutschen Börsen zusammenkam. Der Trend hat bis heute ståndig zugenommen. ${ }^{44}$

${ }^{42}$ Mellerowicz behandelte 1963 die "neuartige Form des Immobilien-Investments" noch allein unter demı Gesichtspunkt der Ertragsorientierung. Er wog das For und Wider ab und sah die steuerlichen Vergünstiguingen nur als angenehme, bald ûberlebte und beseitigte Beigabe, s. Mellerowicz, K. (1963), S. 181, S. 186; s. hierzu Anlage 7 aus: Platow Brief Spezial, Nov. 1994, S. 1; s. a. Herrmann. H. J. (1989), S. 97.

${ }^{43}$ Die von der wirtschaftichen Entwicklung geschaffenen neuen Formen von "ertragsorientierten Kapitalanlagen" mit steuerlichen Anreizen bzw. "steuerorientierten Kapitalanlagen", deren positive Erträge von untergeordneter Bedeutung sind, setzen bei dem Vertrieb der Anteilsrechte nicht nur Kenntnisse des Kapitalmarkts, der Versicherungswirtschaft und der staatlichen und betrieblichen Altersversorgung voraus; gute Kenntnisse des ESt-Rechts sind ebenso unerlälich, wie Rechtskenntnisse und Kenntnisse des beruflichen Haftungsrechts. Insbesondere der Gesamtverband der deutschen Versicherungswirtschaft versuchie bisher vergeblich, durch sein Berufsbildungswerk einen Ausbildungsgang festzulegen. Nachdem zunehmend auch Banken und Versichenungen geschlossene Fonds auflegen und das Versicherungsaufsichtsamt diesen Anlagen Deckungsstockfihigkeit verleiht, besteht ein erhöhtes Interesse an einem funktionsfahigen Nebenkapitalmarkt. Die große Bedeutung, die Steu= erkerntnissen für die Beratung der Kunden beim Ẽwerb zukommt, kommi darin zum Ausdruck, daß Banken mit Vorliebe Finanzbeamte für diese Zwecke abwerben. Dies zeigt die neuartige Funktion der Finanzverwaltung, s. hicrzu Cash, Beilage Nr. 6/93 v. Nov. 1993; ebenso Cash, März 1993, S. 24; s. a. Kölnische Rundschau v. 24.5.1995, S. 6; s. Capital $10 / 93$.

4 Bereits fur 1971 wurde der Absatz von Anteilen an Abschreibungsgesellschaften auf aber 4 Mrd. DM geschä̌tz. Der Absatz. đieser Kapitalanlagen überschritu damit bereits zu dieser Zeil die Kapitalzu. fuhrung an deutsche Aktiengesellschaften über đie Börse mit 2,7 Mrd. DM ganz erheblich. Die Differenz hat sich dann im Zusammenhang mit dem Wiederaufbau Berlins schnell vervielfacht, s. FAZ v. 28.12 .1971 ; s. a. FAZ v. 4.473, S. 19, u. v. 5.4.73, S. 13; Rạdler, A. J., in: Rạdler, A. J./Raupach, A. (1973), S. 32. Im Jahr 1994 setzten allein die 99 bekanntesten Fondsinitiatoren ein Investitionsvolumen von 26,6 Mrd. DM um, s. Cash 3/95, S. 45. 329 weitere Initiatoren machten keine Angaben. Kleinere, nicht professionelie Gründungen durch Architekten und Berater kommen noch hinzu. Man kann den Umsatz ohne Bedenken auf die doppelte Hôhe hochschăłzen. 
Zur Gründung eines geschlossenen Investmentfonds wird zumeist in einem Prospekt dem Zeichner eine seiner Progressionsstufe entsprechende "steuerorientierte Rentabilităt" seiner Einlage versprochen. Diese errechnet sich nicht nur aus der in den üblichen Angeboten zugesagten, durch die amtliche Veranlagung der Fondsgesellschaft festgesetzten anteiligen Verlustzuschreibung an den Anteilseigner als Mitinhaber der Einkunftsquelle. Die steuerorientierte Rentabilităt des Anteils ist bei dieser Anlageform ebenso abhängig von der vorgegebenen Höhe des Einkommens des jeweiligen Anteilseigners. Die Höhe des Steuersatzes wird in Prospekten zumeist mit über $50 \%$ unterstellt. ${ }^{45}$

Die Rentabilităt ergibt sich immer erst aus der amtlichen Veranlagung des Investors, in der die anteilige Verlustzuweisung zu der angestrebten Steuerentlastung führt. Zwei Finanzärnter müssen zur Erzielung der steuerorientierten Rentabilităt tătig werden: das Belegenheitsfinanzamt der Verwaltung der Fondsgeselischaft, das die Verluste der Mitunternehmergemeinschaft durch Bescheid mit Bindungswirkung amtlich feststellt und anteilig den Mitinhabern der Einkunftsquelle zuordnet, und das Wohnsitzfinanzamt des anteiligen Investors, das diesen zur Einkommensteuer veranlagt.

Für steuerorientierte geschlossene Investmentfonds sind aus diesen Gründen zur Erhöhung des Anreizes zum Anteilserwerb hohe vorverlegte Betriebsausgaben oder Werbungskosten zur frühen Erzielung hoher Verlustzuweisungen bereits in der Anlaufphase der Investition typisch geworden. Auf diesen Umstand wird in den Prospekten stets werbewirksam hingewiesen. ${ }^{46}$

Positive Erträge treten in den Hintergrund. Oft sind sie nur zur Abgrenzung des Investments von Liebhaberei von Interesse.

Durch Vorverlagerung von Aufwandspositionen - Zinsen der Laufzeit von Fremdmitteln, als "Damnum" bezeichnet, können z. B. ebenso wie Aufwendungen für verschiedene Dienstleistungen mit steuerlicher Wirkung vorab bezahlt werden - können auf diese Weise hohe Anlaufverluste erreicht werden, was den Interessen der Anteilszeichner infolge frühzeitiger hoher Verlustzuweisungen entgegenkommt.

Denn hohe Verlustzuweisungen bereits im selben Jahr des Anteilserwerbs können die vom Zeichner zu entrichtende Bareinlage so mindern, daß der Beitritt mit geringer oder eventuell gar keiner liquiden Beanspruchung verbunden ist. Hâtte er den Anteil nicht gezeichnet, wäre ohnehin der gesetzlich entstandene ungeminderte Steuerbetrag an das Finanzamt zu entrichten gewesen.

\footnotetext{
$45 \mathrm{~S}$. Anlagen 11 bis 13 und 15 bis 25 .

${ }^{46} \mathrm{~S}$. Aniagen; $14,15,16,17,19,23,24$.
} 
Aus diesen Gründen werden von den Initiatoren derartiger geschlossener Fondsgesellschaften die Verlustzuweisungen durch geeignete Dispositionen gerade für das Beitrittsjahr so gestaltet, daß die für den Anteilserwerb erforderliche, eventuell ratenweise fällige Barzahlung des Investors kurzfristig durch Steuereinspanungen voll kompensiert oder sogar ein Liquiditätsüberschuß̉ ausgelöst wird.

Von den İnitiatoren der Fondsgesellschaften werden jedenfalls werbewirksam bereits im Zeichnungsprospekt Einzahlungsverpflichtungen der potentiellen Investoren so mit den vorausbestimmbaren Verlustzuweisungen abgestimmt und terminiert, dab jeweils - wenn überhaupt - nur eine sehr geringe und jedenfalls kurzfristige liquide Beanspruchung des Beitretenden bewirkt wird. $^{47}$

$\mathrm{Daß}$ durch den Beitritt eines Steuerpflichtigen zu einem geschlossenen Investmentfonds infolge der ausgelosten Steuerprogression eventuell Steuererstattungen oder Steuereinsparungen bewirkt werden, die die entrichtete Bareinlage oder deren falligen Teilbetrag übersteigen können, vermag beim Normalbürger als Laien zumeist Verstăndnislosigkeit auszulösen.

Dieser Umstand ist nicht zuletzt auf den Aufbau des Einkommensteuertarifs zurückzuführen, der der Form einer Parabel angenähert, für einen Ledigen ab $5.616,--$ DM in zwei Stufen steil ansteigt und derzeit ab 120.084,-- DM bei $53 \%$ verharrt. Die Durchschnittsbelastung weicht dadurch bis zu Einkommen von $120.084,--D M$ stark von der Grenzsteuerbelastung ab, um sich danach allmählich der Grenzbelastung von $53 \%$ zu nähern. ${ }^{48}$

Da die von Schmoller formulierten, für die Entstehung der modernen Einkommensteuer grundlegenden Gesichtspunkte völlig vernachlässigt wurden, fehlte in der Öffentlichkeit im Grunde bis in die 80er Jahre zumeist ein kritisches Bewußtsein, das diese steuerbegünstigenden Regelungen als notgeborene Ausnahmen beurteilt hätte.

Unabhängig von ideologischen oder sozialkritischen Grundhaltungen wurde zur Zeit einer sozial-liberalen Koalition in den 70er Jahren in der Bundesrepublik Deutschland vom Bundesministerium für Wirtschaft sogar der Werbeslogan "aus Steuern Vermögen schaffen" ersonnen, ${ }^{49}$ der zweifellos fortan das ungute Steuerklima verstärkte, aber seither wegen seiner eingängigen Formulierung in Werbeprospekten und Medien, durch Interessenverbände und Maklerfirmen millionenfach Verbreitung fand. Zur Zeit völlig darniederliegender

\footnotetext{
${ }^{47}$ Als Beispiel s. Anlage 16, 19, 24.

${ }^{48}$ § 32a Abs. I EStG v. 7.9.1990 i. d. F. v. 28.10 .1990

49 Kreile, R., S. 283. Kreile war Vorsitzender des Finanzausschusses des Dt. Bundestages.
} 
Kapitalbildung über Börsenemissionen sorgten Steuervergünstigungen - wie wir noch sehen werden - für ausgleichende Kompensation der Sparlücke und lenkten vor allem die Investitionen in zurückgebliebene Sektoren. ${ }^{50}$

Tatsächlich führt der genannte Werbeslogan bei vielen Steuerbürgern bis heute fortlaufend zu ärgerlichen Mißverständnissen: Verlustzuweisungen können sich nămlich jeweils zur Rechtfertigung eines Investments nur dann der Höhe nach genügend steuermindernd auswirken, wenn der Anleger über ausreichend hohe saldierungsfahige Einkünte aus anderen Quellen verfügt. Denn unabänderlich gilt: nur mit steigendem anderweitig verdientem Einkommen, also mit zunehmender Steuerprogression, gewinnt die Verlustzuweisung überhaupt an Bedeutung.

Als Faustregel gilt: Das zu versteuernde Einkommen des Investors sollte im konkreten Fall nach Abzug der Verlustzuweisung der Höhe nach noch einer marginalen Steuerbelastung von mindestens $40 \%$ unterworfen sein, um das Investment rentabel zu erhalten. Für Steuerpflichtige, bei denen die Spitzenbelastung des zu versteuernden Einkommens einem niedrigeren Grenzsteuersatz als $50 \%$ unterworfen ist, rechnet sich im Normalfall die steuerorientierte Kapitalanlage nămlich nicht mehr. Sie belastet den Investor sogar zumeist zusătzlich durch Entzug von Liquidităt, wie sich leicht errechnen laßßt. Die mit verminderter Höhe des zu versteuernden Einkommens schnell absinkende Progression hat dann den Effekt, daß die Renditerechnung infolge sinkender Steuerentlastung im Vergleich mit einer konventionellen Anlage, etwa durch Erwerb festverzinslicher Wertschriften, wegen der entzogenen Liquidität negativ ausfallt. $^{51}$

Die Betriebsausgaben bzw. Werbungskosten, die die Höhe der begehrten Verlustzuweisung eines Engagements in geschlossenen Investmentfonds wesentlich bestimmen, lassen sich grob in Aufwendungen für die Dienstleistungen des Initiators, für Mietgarantien, für Bürgschaften zur Beschaffung des Fremdkapitals, für Treuhandgebühren, für Beurkundungen einerseits und für die Verzinsung des Fremdkapitals und Abschreibungen einschließlich Sonderabschreibungen andererseits aufgliedern.

Die erstgenannten Positionen. die Dienstleistungen der Verwaltung enthalten. betreffen Kosten. die bei einem Direkterwerb oder eigener Herstellung des Objekts nur sehr verminder entstehen würden. Fachleute nennen diese Aufwendungen, mit denen sich die Verwaltungen entgelten lassen. "weiche Kosten".

${ }^{50}$ Dies gilt für die Zeit bis um 1980. Gemeint ist haftendes Eigenkapita!.

"1. Zur Anlagestrategie s. Wirtschaftswoche 1995, S. 120. 
Die Finanzverwaltung anerkennt sie als anteilig zurechenbare Betriebsausgaben oder Werbungskosten nach ergangenen Erlassen nur bis zu einer Höhe von $25 \%$ des Gesamtengagements. Ein Überschußbetrag wird als überhőht anteilig den abschreibungsfahigen Anschaffungskosten zugerechnet. ${ }^{52}$

$\mathrm{Zu}$ den für die Hőhe der Verlustzuweisungen wichtigen Aufwendungen gehören die Zinsen für die aufgenommenen Darlehen als Fremdmittel der Finanzierung, zu denen auch ein eventuell vereinbartes Damnum zu rechnen ist. Als wichtigste Aufwandsposition sind die Abschreibungen und die als Sonderabschreibungen gewăhrten Steuervergünstigungen zu bezeichnen. Diese sind zumeist der Hohe nach vom Gesetzgeber sachlich, răumlich und zeitlich differenziert vorgesehen, wobei obendrein innerhalb eines Zeitrahmens von der periodengerechten Zuordnung abgesehen werden darf. ${ }^{53}$

Für die konkrete Höhe der anteiligen Verlustzuweisung an die Investoren ist die Relation der aufgenommenen Fremdmittel zu den Aufwendungen für die gesamten Anschaffungs- oder Herstellungskosten des abnutzbaren Investmentobjekts von ausschlaggebender Bedeutung. In diesem Zusammenhang spricht man von der "Hebelwirkung" des Fremdmitteleinsatzes. Denn: Die Abschreibung auf ein abnutzbares Objekt findet zwar eine Grenze in den Anschaffungs- oder Herstellungskosten; ein Unternehmen, das eine Investition teilweise fremdfinanziert - und das ist die Regel - kann jedoch für dieses Wirtschaftsgut, bezogen auf den Einsatz von Eigenmitteln, entsprechende Buchverluste von über $100 \%$ der Einlagen geltend machen ${ }^{54}$ Das hat große Auswirkungen, die dem Laien leicht verborgen bleiben können.

Die Höhe der auf das Eigenkapital entfallenden prozentualen Verlustanteile ist nämlich abhängig von der Relation des Betrages der Gesamtfinanzienung zu dem Eigenkapitalanteil an demselben.

Besonders wichtig ist es zu berücksichtigen, daß jeder Anteilszeichner bei Verfolgung seiner steuerlichen Interessen nach Abstimmung mit der Fondsverwaltung durch eine Refinanzierung seiner übernommenen Bareinlage von der skizzierten Hebelwirkung in sehr weit gespannten Grenzen zusätzlich

${ }^{32}$ BdF-Schr. v. 31.8.1990 - IV B 3 - 2253- 49/90, in: BStBI. 1, S. 366; BFH U. v. 1.11.1994 IX R 82/91, in: DStR 1994, S. 931.

${ }^{33}$ Nach $\S 7 \mathrm{~b}$ Abs. 3 EStG und $\S 10$ e Abs. 3 EStG kōnnen die gewlihrten Sonderabschreibungen bis. zum 4. Jahr nach Fertigstellung oder Anschaffung des Objekts nachgeholt werden. Nach $\S 4$ Abs. 2 FördG kőnnen die Sonderabschreibungen innerhalb der ersten 5 Jahre der Herstellung oder Anschaffung beliebig verteilt und unter Umstānden sogar bereits im Jahr der Anzahlung geltend gemacht. werden.

s4 Zur sogenannten "Hebelwirkung" s. Anlagen 9, 11. 
nochmals Gebrauch machen kann. Im Grunde kann er daher die Höhe der Verlustzuweisung weitgehend selbst bestimmen. ${ }^{55}$

Diese Möglichkeit ergibt sich schon aus dem Umstand, daß jeder Anteilszeichner steuerrechtlich als selbständiger Mitunternehmer gilt.

Gegebenenfa!ls sind seine spezifischen Beteiligungsdaten auf einem Sonderkapitalkonto einer Sonderbilanz der Gesamthandsgemeinschaft buchmäßig zu erfassen oder in deren Aufzeichnungen zu vermerken. ${ }^{56}$

Gegen Gestaltungen, die zu übertriebenen Verlustzuweisungen ohne Aussicht auf einen letztendlichen Totalüberschuß des Investments führen bzw. gegen solche Konstruktionen, die dem Anteilszeichner ermöglichen, saldierungsfahige Verlustanteile bis zur Beendigung der Mitgliedschaft durch eine steuerbegünstigte oder gar steuerfreie Veräußerung der Beteiligung zu erzielen, hat die Finanzverwaltung durch Erlasse im Anschluß an ergangene Finanzrechtsprechung Barrieren zu errichten versucht. In einer Richtlinie wird der Grundgedanke der steuerlich als nicht relevant beurteilten Liebhaberei zur Eindămmung von Mißbräuchen als Regelungsgesichtspunkt herangezogen. Darauf werden wir noch eingehen. ${ }^{57}$

\section{Umfang der Steuervergünstigungen und Höhe der Steuervermeidung}

Seit 1950 haben sich zahllose Investoren zu kleinen und größeren Gemeinschaften zusammengeschlossen. Ihre Organisationsformen reichen von losen Formen nach bürgerlichem Recht bis zu spitzfindigen Konstruktionen nach Handelsrecht. Aus verschiedenen Gründen erfreute sich die Kommanditgesellschaft besonderer Beliebtheit, wobei als Komplementärin eine $\mathrm{GmbH}$ vorgèsehen wird. ${ }^{58}$

Steuervergünstigungen kam für Investitionen von geschlossenen Investmentfonds in den versehiedensten Sektoren der Wirtschaft eine entscheidende Rolle zu. Darüber hinaus bildeten sich jedoch auch viele Gemeinschaften zur Ausnutzung allgemeiner steuerlicher Vorschriften, denen kein eigentlicher Fördenungscharakter eigen war.

\footnotetext{
5s $\mathrm{S}$, hierzu die Anregungen in den Anlagen $14,15,21$; $\mathrm{s}$. a. Anlage 11.

56. BFH U. v. 14.5.91 VIII R 31/88, in: BStBI. II, S. 167; danu: BdF-Schv. v. 20.2.92 - IV B 2 - S $2241 \mathrm{a}-8 / 92$, in: BSIBI. 192, S. 123.

57 BdF-Schr. v. 23.7.92 - IV B 3 - S 2253 - 29/92, in: BStBI. I 199/2, S. 434.

* Raupach in: Rädler, A. J/Raupach, A. (1973), S. 47.
} 
Dabei ist den Gerneinschaften zur Errichtung von Baulichkeiten als sogenannten geschlossenen Immobilienfonds mit sehr unterschiedlichen Konzeptionen zumeist steuerlich eine Sonderstellung eingerăumt worden.

Bei Inanspruchnahme von Steuervergünstigungen standen zumeist folgende Zwecke im Vordergrund: Die Errichtung von Mietwohngrundstücken, von Eigentumswohnungen, von Eigenheimen, von Hotelneubauten, von Krankenhăusern, von Rehabilitationskliniken, von Gewerbebauten, von Gewerbeparks, von Einkaufszentren, von Schiffsneubauten und vielen weiteren Branchengruppen.

Hinzugetreten sind gegen Ende der 70er Jahre geschlossene Investmentfonds, die sich der bloßen Finanzierung von konkreten Objekten durch Immobilien- oder Mobilienleasing an einen Leasingnehmer als Betreiber widmeten und dabei als Eigentümergemeinschaften die Sieuervergünstigungen in Anspruch nehmen konnten. ${ }^{59}$

Hierbei handelt es sich etwa um Anschaffung bzw. Hersiellung und Verieasen von Frachtcontainern, von Containerlinienschiffen, von Maschinenanlagen, Baugerätschaften, Bürogebäuden etc:

Private Steuervergünstigungen in Anspruch nehmende sogenannte $A b$ schreibungs- oder Verlustruweisungsgesellschaften finanzieren neuerdings als Immobilien-Leasingfonds sogar öffentlich-rechtliche Amtsgebăude, wie etwa Dienststellen der Bundesanstalt für Arbeit (BA Neuruppin, Magdeburg und Riesa bei Dresden), eine Justizvollzugsanstalt (Berlin-Wilmersdorf), ein Kulturzentrum (München-Gasteig), ein Finanzamt (Neuwied), je ein Rathaus in Erfurt und Glochau, das Polizeirevier Leipzig-West, das Amtsgericht in Halle, das zentrale Mahngericht des Landes NRW in Hagen, das Finanzamt Altenburg/Thüringen und in Esslingen, das Landgericht in Sachsen-Anhalt, offentliche Abwăsserentsorgungsanlagen im Havelgebiet, öfentliche Heizkraftwerke und Energicerzeugungsprojekte in den neuen Ländern. Trink- und Abwasseranlagen des Zweckverbandes Beilrode Arzberg bei Torgau und vieles mehr. Bei einem einzigen Initiator liegen noch Anfragen von Gemeinden und Städten mit einem Gesamtvolumen von über $500 \mathrm{Mio}$. DM für Infrastrukturfonds vor. ${ }^{60}$

Sogar über einen Mobilien-Leasing-Fonds zur Finanzierung eines kompletten Intercity-Expreß zum Betrieb durch die Deutsche Bahn AG wird derzeit nachgedacht, nachdem gute Erfahrungen mit dem steuerbegünstigten Verlea-

59 Paulus, H., Immobilien-Leasing. Referat anläBlich der Fachtagung der Steuerberater am 13.11.1979 im Industrie-Club, Disseldorf, Manuskript S. 51; s. a. Bordewin, A. (1989), S. 975.

${ }^{60}$ Hierzu: Cash Nr. 3, Mai 1995, S. 124 u. Nr. 6, S. 151; auch: Wirtschaftswoche Nr. 9/95, S. 19. 
sen von Airbus-Fluggeräten an eine Tochtergesellschaft der Deutschen Lufthansa AG gemacht wurden. ${ }^{61}$

Die Deutsche Lufthansa AG gründete inzwischen eine Tochtergesellschaft als GmbH mit der Bestimmung, geschlossene Mobilien-Leasingsfond zu entwickeln und als Komplementärin zu betreuen, um die Finanzierung von Flugzeugen für den eigenen Betrieb zu erleichtern. ${ }^{62}$

Zweck dieser Konzerntochter ist es, geschlossene Fonds in der Rechtsform von Kommanditgesellschaften zu gründen und als Komplementärin mit beschränkter Haftung zu verwalten, um nach erfolgter Zeichnung des vorgesehenen haftenden Eigenkapitals durch anlagesuchende Kommanditisten bei Aufnahme von weiteren Bankdarlehen durch die Gesamthandsgesellschaft ein Airbus-Fluggerảt zu erwerben und sodann unter Ausnutzung der ausgelösten Hebelwirkung des Einsatzes von Fremdkapital kostengünstig an die Deutsche Lufthansa $A G$ verleasen zu können.

Dabei ergibt sich für die Anteilszeichner als die formellen Miteigentümer des verleasten Wirtschaftsgutes einerseits und die Deutsche Lufthansa AG andererseits wegen der in $\S 82 \mathrm{k}$ EStDV normierten Sonderabschreibungen als Steuervergünstigungen eine wirtschaftliche Symbiose: Eine weit über dem Marktzins liegende Rentabilität der Bareinlage der Mitinhaber der Einkunftsquelle kann bei vernachlässigbarem Risiko mit äußerst kostengünstigen Leasingraten der Leasingnehmerin bei Verbesserung von deren Liquidität und Bilanzstruktur kombiniert werden.

Der Zeichner erwirbt dabei eine ertragsorientierte steuerbegünstigte Kapitalanlage. Obgleich nicht Eigentümerin von Gegenständen ihres im Grunde betriebsnotwendigen Anlagevermögens vermag die Fluggesellschaft als Leasingnehmerin andererseits, sich indirekt Anteile an den Steuervergünstigungen der nur formalen Miteigentümer des Leasinggutes in Form von hohen Verlustzuschreibungen und Steuerersparnissen durch preisgünstige niedrige Leasingraten nutzbar zu machen.

Die Abwicklung der Gründungs- und Anlaufphase eines größeren geschlossenen Investmentfonds, auch "Abschreibungs- oder Verlustzuweisungsgesellschaft" genannt, erfolgt zumeist etwa nach folgendem Schema:

Initiatoren konkreter Investmentvorhaben, zu denen heute oftmals auch Banken und Versicherungen rechnen, entwerfen die Satzung einer Bruchteils-

${ }^{61}$ Wirtschaftswoche Nĩ. 21 v. 20.5.94, S. 117; Cash Nr 3/1994, S. 116; Welt am Sonntag v. 12.2 .95$, S. 36; s. Bordewin, A. (1989), S. 975.

${ }^{62}$ Cash Nr. 3/1994, S. 117; Beteiligungsangebot an einem Flugzeug-Leasingfonds der Lufthansa Leasing GmbH \& Co. Charlie-Echo KG-Fondsgesellschaf, Anlage 22. 
gemeinschaft, Gesamthandsgemeinschaft nach BGB oder einer Kommanditgesellschaft, stellen den Komplementăr und/oder Geschăftsfürer und fertigen Prospekte mit Musterberechnungen der wirtschaftichen Daten des vorgesehenen Investments.

Diese enthalten die wesentlichen Angaben, wie Firma und Sitz des Initiators und der gegruindeten Fondsgesellschaft, desgleichen des Plazierers, Angaben zur Branche des vorgesehenen Fonds, Daten zum geplanten Investitions- und Plazierungsvolumen, Mitteilungen zur Beteiligungsform, zur Mindestbeteiligung sowie Auskünfte über erwartete Ausschüttungen und vor allem über zu erwartende Verlustzuweisungen und deren zeitlichen Rahmen. ${ }^{63}$

Die Initiatoren führen dann zumeist als abzurechnende Dienstleistung durch eine Tochter-GmbH, gegebenenfalls als Komplementărin mit geringstmőglichem Eigenkapitaleinsatz, die Geschăfte der Fondsgesellschaft.

Prospekte für Zeichner von Anteilen mit Aufforderungen zum Beitritt werden dann an einen eigenen Vertiebsapparat (Strukturvertrieb) abgegeben und/ oder über Banken, Versicherungen, steuerberatende Benufe, Anlageberater, über Zeitungsanzeigen und sonstige Medien in Umlauf gebracht.

Als Beispiel zur Erlăuterung des geweckten Interesses bei den Zeichnern soll nachfolgend als Beispiel ein kirchensteuerpflichtiges Ehepaar mit einem zu versteuernden Einkommen von $480.000,--$ DM unterstellt werden, das einen Fondsanteil von 100.000,-- DM zeichnet. Die in dem Prospekt vorausgesagte Verlustzuweisung soll für die ersten drei Veranlagungsjahre insgesamt $240 \%$ betragen, wobei der Schwerpunkt wie üblich im ersten Rumpfjahr der Zeichnung zu erwarten ist. Die gezeichnete Bareinlage von 100.000,-- soll in zwei Raten in den Jahren 1995 und 1996 zu zahlen sein.

Folgendes Ergebnis laßßt sich dann bezüglich der Einkommensteuer der unterstellten Eheleute für die Folgejahre ab dem 1.1.1995 voraussagen:

Insoweit das zu versteuernde Einkommen 240.084,-- DM übersteigt, entsteht nach dem ab 1.1.1995 gültigen Gesetzestext gemäß $\$ 32$ a Abs. 1 Ziff. 4 EStG ein Steuerzugriff von $53 \%$. Hinzu kommen noch gemäß $\$ 4$ i. V. m. $\S 3$ SolzG ein Zuschlag von $0.075 \times 0,53 \%$ und dazu noch die Kirchensteuer nach den Vorschriften der Länder von $0,09 \times 0.53 \%$. Insgesamt besteht mithin in unserem Beispiel eine Steuerbelastung der letzten $240.000,--$ DM des zu versteuemden Einkommens in Höhe von $61,745 \%$, also ca. $61 \%$. Das führt zu folgender Steuerentlastung nach Zeichnung:

\footnotetext{
${ }^{63}$ In der Fachzeitschrift Cash werden die Initiatoren jeweils mit diesen Angaben der einzeinen aufgelegten Fonds aufgelistet, s. z. B. Cash, Heft 6/94, S. 110.
} 
Für die Zeichner des Anteils in Höhe von 100.000,- DM errechnet sich für die ersten drei Kalenderjahre ab 1995 als Besteuerungsabschnitten eine Verlustzuweisung von $240 \%$ von $100.000,-$ DM, also von $240.000,-$ DM. Dieser anteilige fiktive Verlusit aus dem Investment führt für das unterstellte Ehepaar zu einer Ersparnis von 240.000,-- DM x 0,61 = 146.400,-- DM. Das heißt, die Investoren erhalten in den ersten drei Jahren, also in der Anlaufphase des Investments, durch Steuereinsparungen bei der Einkommensteuer, beim Solidaritătszuschlag und bei der Kirchensteuer $46.400,--$ DM mehr, als die eingezahlte Bareinlage, von ihrem zustăndigen Wohnsitzfinanzamt durch Anrechnung oder in bar erstattet.

Ihr Vermögen wurde mithin in der Privatsphäre um 146.400,-- DM vermehrt, da bei Unterlassen des Beitritts der Betrag von 100.000,-- DM als von Gesetzes wegen entstandene Steuern an das Wohnsitzfinanzarnt hătte abgeführt werden müssen.

Die gezeichnete Bareinlage, die oftmals erst in Raten innerhalb von zwei Besteuerungsabschnitten zur Zahlung fallig wird, fließt im Beispielsfall also innerhalb desselben Zeitraums wieder an die Zeichner zurück, so daß eine effektive liquide Belastung nicht oder nur geringfügig und - wenn überhaupt nur kurzfristig gegeben ist.

Im übrigen wurden die Zeichner in dem vorstehenden Beispiel anteilige Miteigentümer eines Wirtschaftsgutes, das später als Einkunftsquelle zu Erträgen und darïber hinaus einmal zu einem Veräußenungserlös führen wird.

Dabei ist noch zu berücksichtigen, daß ein späterer Veräußenungsgewinn, der auch eine Abfindung sein kann, sofern der Anteil in der Privatsphäre des Beteiligten gehalten wurde, steuerfrei vereinnahmt wird, wenn es sich nicht um Einkünfte aus dem Betrieb eines Gewerbes handelt. In diesem letzteren Fall greift eine Ermäßigungsvorschrift, die eine Besteuerung zum halben Tarifsatz vorsieht. ${ }^{64}$

Im übrigen wird von den Fondsverwaltungen stets Vorsorge getroffen, daß die Zeichner nach Entrichtung ihrer Bareinlage - wenn überhaupt - nur geringfuigig zur Liquidităt des Unternehmens beitragen müssen, daß also die

64 Die Fondsinitiatoren achten darauf, dafi die Fonds möglichst als rechttiche und wirtschaflliche Eigentümer ausschlieblich vermögensverwaltend tătig werden. Da die Finkünfte in diesern Fall als Öberschuß $\mathbf{B}$ der Einnahmen uber die Werbungskosten und nicht durch Bestandsvergleich zu ermitteln sind, ist ein anfallender Verăußetungsgewinn in der Vermōgenssphăre der Miturternehmer angesiedelt. Er gehōrt dann nach $\$ 2$ Abs. 2 Ziff. 2 EStG nicht zum steuerbaren Einkornmen. Ist das nicht erreich. bar, da die Gemeinschaft Einkünfte aus Gewerbebetrieb erzielt, kormm die Tarifbegünstigung nach $\S$ 34 Abs. 1 EStG infrage. 
Annuitäten für den Fremdmitteleinsatz und die sonstigen Aufwendungen nach Ende der Investitionsphase durch laufende Einnahmen gedeckt werden. ${ }^{65}$

Zusătzlich achten die Fondsverwaltungen auch darauf, daß in den vorgelegten Kalkulationen zur Rentabilităt des Investments die Vorausberechnungen "ein positives Gesamtergebnis der voraussichtlichen Vermögensnutzung durch den Steuerpflichtigen und seinen Gesamtrechtsnachfolger oder einen unentgeltlichen Einzelrechtsnachfolger" erkennen lassen. ${ }^{66}$ Nach Verwaltungsrichtlinien ist dabei von einer tatsăchlichen Nutzungsdauer von 100 Jahren bei Einkünften aus Vermietung und Verpachtung auszugehen. Anders als bei Einkünften aus Gewerbebetrieb ist dabei ein Verăußenungsgewinn nicht zu berücksichtigen.

Ist die Vorauskalkulation in dieser Hinsicht nicht zufriedenstellend, kann die Finanzverwaitung nach ergangenen Erlassen Liebhaberei unterstellen. Verluste und auch Gewinne können dann von der Verwaltung steuerlich als irrelevant behandelt werden.

Für die Finanzverwaltung soll bei der Prüung jeweils der "Beweis des ersten Anscheins" genügen. ${ }^{67}$ Initiatoren begnügen sich daher zumeist mit einer Übersicht, die zehn Jahre nicht überschreitet. Nur sofern eine Autgabe der Beteiligung zweifellos als bereits zu einem Zeitpunkt eingeplant ist, "zu dem ein Überschuß der Einnahmen über die Werbungskosten eindeutig noch nicht erreicht sein wird", darf die Finanzverwaltung nach dem Erlaß Liebhaberei unterstellen, da eine Absicht zur Einkunftserzielung dann klar ersichtlich fehlt und das Investment nur fiktive Verluste produzieren soll. ${ }^{68}$

Es ist leicht zu durchschauen, daß die Finanzverwaltung mit der praktischen Überwachung dieser Verwaltungsanweisungen völlig überfordert wird, zumal viele spitzfindige juristische Einwendungen wegen des Umstandes, daß unüberprüfbare mentale Dispositionen zum Tatbestandsmerkmal gemacht werden, möglich sind. Wer weiß schon im voraus, wie hoch Mieten in zehn Jahren anzusetzen sind. Letztlich darf sich der Steuerbürger irren.

Daher werden viele Fondsgesellschaften zur Errichtung von Mietwohngrundstücken oder deren Sanierung heute stillschweigend so konzipiert, daß der Gebäudekomplex zu dem Zeitpunkt des Endes von Verlustzuweisungen durch Errichtung eines von vornherein vorgesehenen Aufteilungsplans in Eigentumswohnungen und Teileigentum umgewandelt werden kann.

${ }^{65}$ Hierzu Anlagen 16, 19, 23 und 24.

${ }^{66}$ BdF-Schr. v. 23.7.92 - IV B 3 - 2253 - 29/82, in: BStBI. I, S. 434.

${ }^{67}$ BFH-U. v. 25.7.84, in: BStBI. II 1984, S. 751; wie Anm. 66.

BdF-Schr. v. 23.7.92 - IV B 3 - 2253 - 29/82, in: BStBl. I, S. 434. 
Die Anteile der Beteiligten sollen dann nach stillschweigendern Einverständnis in Sondereigentum eingetauscht werden, wobei unterschiedliche Beteiligungswerte durch Barausgleich verrechnet werden.

Dieser Vorgang wird sich dann in der Vermögenssphäre der Beteiligten, also steuerfrei abwickeln. Die besondere Marktfahigkeit von Eigentumswohnungen bringt dann ganz erhebliche steuerfreie Vermögensmehrungen mit sich.

Eine Überwachung der Abgrenzung zur Liebhaberei durch die Finanzverwaltung scheitert bereits daran, daß nach Ende der Verlustzuweisungen passende Teilbetrăge der Fremdmittel vom Zeichner zurückgezahlt werden kőnnen. Sie haben ihre Aufgabe, als Hebelwirkung zu dienen, erfullt. Durch Gesamtrechtsnachfolge oder durch eine unentgeltliche Zuwendung kann dann eine Anteilsubbertragung erfolgen, die Sachverhalt und Zustândigkeit der Behörde veråndert. Der Zeitablauf tritt hinzu und begünstigt ein einträgliches Verwirrspiel. Das Finanzamt kann die Zusammenhänge schwerlich aufklären und hat wegen Beachtung der Verjährungsvorschriften kaum Handhaben zur steuerlichen Richtigstellung.

Dabei ist festzustellen, daß die in unserem Beispiel unterstellte Verlustzu-

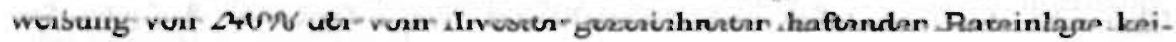
neswegs ein utopisches, nicht repräsentatives Beispiel darstellt. Letztendlich kann dieser Sachverhalt auch unabhängig von Prospektangaben von dem einzelnen Zeichner durch eine Refinanzierung des übernommenen Anteils geschaffen werden. ${ }^{69}$ Der Zeichner muß nur darauf achten, daß er dabei nicht überzieht und dadurch für die Finanzverwaltung unwiderlegbar den Eindruck entstehen läßt, daß der für die Abgrenzung zur steuerlich nicht relevanten Liebhaberei geforderte Totalüberschuß der Einnahmen über die Aufwendungen während der Lebensdauer des Investments erkennbar nicht eintreten kann.

Zwar überwiegen in den Fachzeitschriften Angebote zur Zeichnung von Anteilen an geschlossenen Immobilienfonds, die Verlustzuschreibungen von unter $200 \%$, ja auch vielfach unter $100 \%$, bezogen auf die Bareinlage, zusichern, für die Vielzahl der tatsächlichen Vorgänge sind diese Objekte jedoch nicht typisch. ${ }^{70}$

69 Initiatoren von Investmentfonds bieten of ihre Vermittlungsdienste für derartige Refinanzierungen von Anteilen bei Zeichnem an. Der Prospekt wirt dann in der Regel eine AJternativrechnung mit đen hōheren Verlustzuschreibungen aus. Bei den finanzierenden Kreditinstituten handelt es sich oft um Banken, die das Investment vorgepruft haben. Gelegentlich wird sogar vorgesehen, das refinanzierende Darlehen durch eine Hypothek an dem Objekt abzusichem. Ein derartiges Beispiell werden wir noch kennenlernen. Das Darlehen bleibt trotz der Absicherung eine private Verpflichtung des Zeichners, für das die Gesamthand nur haftet, 3. hierzu Anlage 14, 15, 21 b, 24.

70 Hierzu die Aufstellung in Cash Nr. 6/94, S. 110 , in der 142 Beteiligungsobjekte vergleichsweise aufgelistet werden. Die in Spalte 10 aufgefuhrten Verlustzuweisungen zeigen zwar zumeist das Ange- 
Denn bei diesen Aufstellungen geschlossener Fonds, die steuersparende Kapitalanlagen offerieren, handelt es sich durchweg um professionelle Anbieter, die Beteiligungen an Plazienungsvolumen von bis zu 1,8 Mrd. DM mit Investitionsvolumen von gleicher Höhe bei einem breiten Publikum unterbringen wollen. Die Initiatoren richten sich dabei an eine Öffentlichkeit mit laienhaften Kenntnissen des Steuerrechts, die täglich von superklugen mißverständlichen Informationen über steuersparende Investitionen überschüttet wird. $^{71}$

Das Investitionsvolumen der einzelnen offfentlich angepriesenen Fonds liegt selten unter 15 Mio. DM. So ist es verständlich, daß es sich zumeist um Investments handelt, die sich gut vorzeigen lassen und bei denen die Initiatoren durch ansehnliche Anschaffungspreise, stattliche "weiche Kosten" und die Abrechnung weiterer reichlich dotierter eigener Routinedienstleistungen und zusätzlich noch in jedem Einzelvorgang wegen der Größenordnung überhohten eigenen Aufwand und hohe Gewinne einkalkulieren können.

Diese von Verwaltungsaufwand aufgeblăhte Grundbelastung begrenzt zur Aufrechterhaltung einer nach Abschluß der Verlustphase später erforderlichen Rentabilität des Investments die Höhe des Einsatzes von Fremdmitteln und damit die den Anleger durch die erhöhte Verlustzuweisung begünstigende Hebelwirkung. $^{72}$

Wenn dennoch der Absatz dieser Fondsanteile sehr hoch ist, so zumeist weniger aus rational nachvollziehbaren Gründen. Es ist zum Statussymbol geworden, steuersparende Kapitalanlagen zu erwerben, selbst dann, wenn sich der Erwerb im Vergleich mit dem Kauf von Effekten nicht rechnet. Viele schichten dafür sogar ihr Kapitalvermögen um und wollen nicht glauben, daß sie sich dabei verschlechtern. Der Steuerberater tut gut daran, nicht allzu nachhaltig auf diesen Umstand aufmerksam zu machen, um keinen Mandanten zu verlieren. Es macht nun einmal viele zumeist qualifizierte Anleger

bot von Anteilen als ertragsorientierte Kapitalanlagen; der Zeichner vermag aber durch eine entsprechende Refinanzierung aus dem Engagement ein steuerorientiertes Investment zu machen. Dabei sind nur einige steuerliche Besonderheiten zu beachten.

"Aufstellung in Cash, Nov. 94, S. 110: "142 Fonds zum Steuersparen". Wenn die Zeitschrift in dieser Aufstellung des Investitionsvolumen der genannten Initiatoren für 1994 auf 12,3 Mrd. DM schatzte, so berichtigte sie im Heft 3/95, S. 45, die Angabe dahingehend, daB im Jahr 1994 allein die bekanntesten 100 Initiatoren $26,6 \mathrm{Mrd}$. DM umsetzien.

72 Dabi die Zeichnung von Beteiligungen gerade an diesen zumeist sehr großen ertragsorientierten Fonds erstaunlich hoch ist, kommentiert der kritische Platow-Brief mit der Bemerkung, daB viele Vertriebe offenbar "über ein hinreichend diunliches Publikum verfügen", s. Platow-Brief Spezial, Nov. 1994, S. 10. Das ist gewiB übertrieben. Viele Burger suchen eine breite Vermōgensstreuung. Sie sehen im Miteigentum an Sachvermōgen über eine Gesamthandsbeteiligung, wie bereits Mellerowicz, einen Schutz von inflationären Entwicklungen, s. Mellerowicz, K. (1963), S. 184; aber: Capital 10/93. 
stolz, kleiner Miteigentümer eines wieder aufgebauten Hotels zu sein, in dem Kaiser Wilhelm II. verkehrte und das höchsten internationalen Ruf genoB, Eitelkeit hat ihren Preis. Dafür verzichtel mancher gern auf herkömmliche ertragbringende und fungible A.nlagetitel mit marktüblicher Rentabilität. ${ }^{73}$

Repräsentativ sind für die hier verfolgten Gesichtspunkte die unzähligen, nicht offentlich werbenden, völlig unbekannt bleibenden kleinen und mittleren Gemeinschaften, die sich durch andere Absatzkanăle in vielen Beratungspraxen konstituieren und auf diese Weise ohne überreizten Kostenapparat auskommen. Sie bleiben der Öffentlichkeit verborgen, da sie allein aus den Akten der zur Verschwiegenheit verpilichteten wirtschafts-, rechts- und steuerberatenden Berufsträger ersichtlich sind. Statistiken gibt es hierzu nicht. ${ }^{74}$

Bei diesen Investitionen, die von Gemeinschaften, aber auch von Einzelpersonen getătigt werden, ergeben sich Verlustzuweisungen, die sich in der Anlaufphase oft auf weit über $400 \%$ der Bareinlage oder der eingeflossenen Eigenmittel kumulieren. ${ }^{75}$

Die Verluste lassen sich als Folge der gesetzlich gestatteten Vorwegnahme der Sonderabschreibungen dabei so verlagern, daß bereits spätestens im zweiten Besteuerungsabschnitt die Bareinlage von der eingefahrenen Steuerersparnis erheblich überschritten wird. Dann werden bei Ende des Ansatzes von Sonderabschreibungen, also nach 10 Jahren, infolge guter zu erwartender Erträge steuerliche Überschüsse erzielbar. ${ }^{76}$

Zumeist handelt es sich bei diesen Objekten um Sanierungsvorhaben von alten Mietwohngrundstïcken und Gewerbebauten in Berlin und den neuen Bundesländern. Wegen ihrer Lage in der Nähe von Industriezentren und guter verkehrsmäßiger Anbindung stellen diese nach Erneuerung eine gesicherte

${ }^{73}$ Der vom größten deutschen Initiator mit einem Kommanditkapital vom 425 Mio. DM zum Wiederaufbau des Hotel Adlon am Brandenburger Tor in Berlin aufgelegte geschlossene Investmentfonds wird bei Verlustzuschreibungen von $38.45 \%$ des Zeichnungsbetrages als "hochrentable und vor allem sichere" Immobilienanlage angeboten. Platows nûchieme und überprüfbare Zahlenangaben weisen entgegen vielen Gutachtem und Prüfsiegeln uberzeugend das Gegenteil aus. Letzilich befordert das klug einkalkulierte Interesse an Statussymbolen das Geschäft und zugleich auch den Wiederaufbau, s. Platow Brief Spezial, Nov. 94, S. 11: s. a. Cash 1/95, S. 123; s. Anlage 28.

74 Hierzu: Anlage 24. Es handelt sich bei dem Beispie! um das Angebot zur Beleiligung an einem kleinen Fonds, der den Erwerb und die umfassende Modemisierung eines 1905 errichteten Mietwohngnundstûcks guter Bausubstanz, in Berlin-Wedding, zum Zweck hat. Initiator ist ein Bauingenieur: Treuhalnderischer Verwalter ist eine Steuerberatungsgesellschaft. Weiche Kosten sind vernachlässigbar.

73 Im Falle des vorstehenden Beispiels betrăgt das Investitionsvolumen nur 11,15 Mio. DM. Fûr große Initiatoren rechnet sich das nicht. Die Verlustzuweisungen betragen $443,85 \%$.

${ }^{76}$ In dem Beispielsfall (Anlage 24) ist, wie sich ergibt, nur kurzfristig mit einer Liquiditātseinbuße von $11.325,-$ DM bei Unterstellung einer Steuerbelastung von insgesamt $55 \%$ zu rechnen. 
und wirtschaftlich gute Kapitalanlage dar, mag man das den Objekten auch nicht ansehen.

Nach Angaben des Berliner Senats aus dem Jahr 1994 gibt es allein im Bereich der Stadt Berlin 250.000 derartige sanierungsbedürftige Wohneinheiten. Das lăßt Schlüsse auf die Größenordnung des Erneuerungsbedarfs in allen neuen Bundeslăndern zu. ${ }^{17}$

Dazu kommt noch, daß der gesamte Bestand der sogenannten Plattenbauten zur Sicherstellung heutiger Wohnansprüche vor frühzeitigem Verschleiß durch eine einmalige Sanierungsaktion gerettet werden muß. Pro Wohneinheit sehen die Maßnahmen Instandsetzungen von durchschnittlich ca. 87.000,-DM vor. ${ }^{78}$

Aus diesen Objekten, bei denen das erforderliche Investitionsvolumen jeweils zumeist unter 15 Mio. DM liegend, sich zur Sanierung durch große professionelle Initiatoren vermittels Gründung von Immobilienfonds nicht eignet, besteht der Großteil der Wohnsubstanz in den neuen Bundeslăndern.

Das geltende Einkommensteuerrecht sieht fur diese Objekte folgende $\mathrm{Ab}$ schreibungsmöglichkeiten vor: Zu den Regelabschreibungen für Baulichkeiten gemäß $§ 7$ Abs. 4 EStG können zusätzlich die Sonderabschreibungen gemäß $§$ 4 FördG in Höhe von 50\% der Anschaffungs- oder Herstellungskosten und insbesondere der Aufwendungen für nachträgliche Modernisierungen in Ansatz gebracht werden. Diese können beliebig auf die ersten fünf Jahre verteilt werden. Zusätzlich können ab dem fünften Jahr Modernisierungsmaßnahmen und nachträgliche Herstellungskosten der restlichen 50\% der Aufwendungen in fünf gleichbleibenden Jahresraten zum Abzug gelangen. Eine Höchstgrenze oder Beschränkung der Anzahl der Objekte ist nicht vorgesehen. Nach zehn Jahren sind also die Objekte zu $100 \%$ abgeschrieben.

Die Finanzierung eines Investments in ein derartiges Objekt kann mithin vollständig aus Steuerersparnissen erfolgen. Dabei kommt fast der gesamte Bestand an Bauwerken in den neuen Ländern für die begünstigten Maßnahmen infrage und der Gestaltungsvielfalt sind kaum Grenzen gesetzt.

Wenn auf der von einer führenden Fachzeitschrift jährlich veranstalteten Konferenz zu dem Titel "Geld und Kapital" zwei fachkundige Referenten im

77 Diese Angaber machte RA und StB H. W. Jehl in dem Referat mit dem Thema "SteuersparTrends 1994" auf dern KongreB "Geld und Kapital" am 4.9.1994 in Hamburg, s. Cash, Beilage zu Heft 6/94, S. 84. Die Angaben entnahm der Autor der von dem Cash-Vertrieb angebotenen Audiocassette des Referates.

${ }^{78} \mathrm{Jehl}$, H. W., wie Anm. 76. Jehl ist maBgeblich bei der Konzeption von geschlossenen InvestmentFonds beratend tătig. 
September 1994 von der "wundersamen Eigentumsvermehrung" durch "Fonds zum Nulltarif" bzw. von der Möglichkeit zu "gigantischen Steuervorteilen" sprachen, so lagen diesen Ausführungen die soeben erwähnten Sanierungsobjekte zugrunde. ${ }^{79}$

Nach Einsichten des Verfassers stellen diese Modelle heute den gebräuchlichsten Fall steuerorientierter Kapitalanlagen dar. Hierbei handelt es sich obendrein um die Zielgruppe, auf die sich die Förderungsmaßnahmen richten. Die Träger sind meist kleine Gemeinschaften oder gar Einzelpersonen, die sich überschaubarer Risiken annehmen und auf diese Weise die Infrastruktur in den neuen Bundesländern zügig wieder normalisieren werden. Sie treten weder in den Medien in Erscheinung, noch sind sie statistisch leicht erfaßbar.

Die fachkundigen Referenten auf dem genannten Kongreß warnten jedoch das Publikum, daß "Immobilien zum Nulltarif" nur von demjenigen erworben werden können, der "eine hohe Steuerlast trägt" und daher "die Erwerbskraft hat, in eine solche Steuerlast hineinzukommen". Dem Steuerbürger, dessen Einkommen nicht hoch genug ist, bleibt diese lukrative Mőglichkeit der Vermögensbildung aus Steuern verschlossen. Hălt er sich nicht an diese Warnung. drohen ihm ungenehme Überraschungen. ${ }^{80}$

Im übrigen bietet das heutige Angebot von Anteilen an steuersparenden Kapitalanlagen eine breite Palette von Möglichkeiten. Dabei steht oft nicht nur die Steuerersparnis im Vordergrund, sondern auch Risikostreuung oder der Schutz vor inflationären Entwicklungen oder der säkularen Geldentwertung. Dafür wird die mangelnde Fungibilität der Anteile von Zeichnern willig in Kauf genommen.

Eine mögliche Aufsplitterung der Anteile in kleine Einheiten von 5.000,-DM kommt of den Bedürfnissen der Anleger entgegen.

Die größten steuerlichen Vergünstigungen und damit steuerfreien Vermögensmehrungen sind derzeit im Bereich der Renovierung von Bauwerken, insbesondere von Gewerbebauten und Sanienungsmaßnahmen im Wohnungs-

79 S. Ausfohrungen von T. Engels zu dem Thema: "Geschlossene Fonds zum Nulltarif" und H. W. Jehl zu "Steuerspar-Trend "94", in: Cash, Beilage zu Heft 6/94, S. 46, S. 84.

so Aus der Wiedergabe der Ausfuhrungen in Diskussion und Referaten auf den von Cash beziehbaren Audiocassetten ergibt sich, daB die Referenten in berufsrechtlich verantwortungsbewuBter Weise vor den Gefaliren warnten, s. Audiocassetten Nr. 7 mit einer Diskussion und Nr. 14 mit dern Referat "Geschlossene Fonds zum Nulltarif" der Veranstaltung "Geld und Kapital" vonn 4.9.94 in Hamburg. Cash-Verlag. 
bau in đen neuen Bundesländern und ebenso im Containerschiffsbau erzielbar. $^{81}$

Besonderes Interesse finden in letzter Zeit wiederum die bereits erwahnten steuersparenden Kapitalanlagen, die als Immobilien- und ebenso MobilienLeasing-Fonds konzipiert sind. In diesen geschlossenen Investmentgesellschaften, die reinen Finanzierungszwecken dienen, zeigt sich idealtypisch die neuartige bankăhnliche Funktion, in die die Finanzverwaltung durch die Steuervergünstigungen des $\mathrm{EStG}$ seit 1949 hineingewachsen ist.

Obendrein ist zugleich mit der Zunahme der übernationalen Bedeutung der Leasinggesellschaften im europäischen Binnenmarkt mit einem weiteren Wachstum dieser Fonds bei Berücksichtigung steuerbegünstigter Gestaltungselemente zu rechnen. ${ }^{82}$

Durch einen geeigneten rechtlichen Zuschnitt der Leasingverträge läßt sich nämlich weitgehend bestimmen, wer das geleaste Objekt als formaler Eigentümer oder wirtschaftlicher Eigentümer in seiner Bilanz zu aktivieren oder jedenfalls in sein Vermögensverzeichnis aufzunehmen hat, wem es gemăß $39 \mathrm{AO}$ zuzurechnen ist.

Da Steuervergünstigungen in der Regel durch die Befugnis zu Sonderabschreibungen der Wirtschaftsgüter gewährt werden und daher nur dem Inhaber der Einkunftsquelle zustehen, ist diese Zurechnung notwendige Voraussetzung für deren Inanspruchnahme. Und: Die mit dem Leasing verbundenen Vorzüge, wie objektgebundene Vollfinanzierung der Gegenstände des Vermögens und Verbesserung der Liquidität bei weitgehender Schonung des Eigenkapitals des Leasingnehmers, sind in Verbindung mit der Möglichkeit, Steuervergünstigungen in die Finanzierung, wenn auch indirekt, einzubinden, besonders begehrenswert.

Das Immobilien-Leasing ist daher inzwischen zu einem gern benutzten Instrument zur Lösung von Finanzierungsproblemen der öffentlichen Hand geworden, indem es auch für die Mobilisierung privaten Kapitals und privater Initiativen zur Erfüllung staatlicher Aufgaben verwertet wird.

Tatsächlich werden auf diese Weise - wie der Bundesrechnungshof inzwischen rügte - sogar Finanzierungskosten öffentlich-rechtlicher Dienstleistun-

\footnotetext{
${ }^{8 i}$ Ein Blick in die Anzeigen, konkurrierenden Angebote zu Beteiligungen und Auflistungen in jedem Heft von Cash. Das Exklusive Kapitalanlage-Magazin, Hamburg. bestatigt diese Aussage; s. Anlagen 14, 18, 24.

${ }^{82}$ Figge, H. (1990), S. 49.
} 
gen aus den Haushalten der Gebietsköıperschaften verlagert und die Verschuldung obendrein verschleiert ${ }^{83}$

Nachfolgend soll an einem konkreten praktischen Beispiel aus dem Jahr 1994 abschließend die vielseitige Verwendbarkeit der Leasing-Fonds zu steuerbegünstigten Finanzierungszwecken aufgezeigt werden. Vor allem sollen dabei die steuerlichen Vorteile fur Erwerber steuerorientienter Kapitalanlagen und die Konsequenzen für die Allgerneinheit beleuchtet werden:

Im Jahr 1994 regte eine zu 100\% im Besitz eines der neuen Bundesländer stehende, aus "volkseigenem Vermögen" von der Treuhandanstalt gebildete Konzerngesellschaft die Begründung eines Immobilien-Leasing-Fonds zur Finanzierung eines konzerneigenen modernen Dienstleistungszentrums an. ${ }^{84}$

Es sollten im Zentrum der Stadt Jena auf eigenem Gelände moderne Büround Ladenflăchen von $16.500 \mathrm{qm}$ zuzüglich notwendiger Tiefgaragen zur eigenen Nutzung entstehen.

Plăne zur Renovierung und zum Ausbau des alten Verwaltungsgebảudes auf dem konzerneigenen Grund und Boden waren bereits von einer Konzerntochter als Projektplanungsgesellschat nach den mit dem Firmenkonzept abgestimmten Vorgaben der Konzernmutter fertiggestellt worden. Ein verbindliches Angebot zur kompletten Bauausführung von einer ebenso konzerneigenen Bauunternehmung lag gleichfalls vor. Es warf einen verbindlichen Festpreis von 65,8 Mio. DM für die Durchführung des Bauauftrages durch den Generalübernehmer aus. ${ }^{85}$

Auch die Baugenehmigung der Stadt Jena war von der Konzerngesellschaft, der Firma Jenoptik GmbH, bereits erwirkt worden. Die Firma Jenoptik GmbH hatte sich selbst so ein auf ihre Bedürfnisse genau abgestimmtes Maßkleid geschneidert, das auch von eigenen Regiebetrieben gefertigt werden sollte.

Da die umfangreichen Baupläne mit geringster Beanspruchung der eigenen Liquidität abgewickelt werden sollten, suchte man nach einer Finanzierung durch Einschaltung eines Leasingmodells.

Um die verlockenden Steuervergünstigungen der $\S \S 3$ und 4 FördG und dabei insbesondere die Erweiterung des $\$ 4$ Abs. 2 FördG optimal in die Finanzierung zur eigenen Kostenentlastung einzubinden, bot sich an, das Grund-

Wirtschaftswoche 1995, Nr. 9, S. 19.

* Zu folgenden Ausfïhrungen s. Berichte über die Firma Jenoptik, in: Handelsblatt vom 6.10 .94 und ebenso in Süddeutsche Zeitung, v. 6.10.94, S. 30.

35. Zahlenangaben und Einzelheiten des Investmentangebots wurden dem ausführlichen Prospekt des Beteiligungsangebots mit vorbereiteten Viertragsformularen, Ergebnisübersichten und Darstellung der steuerrechtlichen, wirtschaflichen Beurteilung und der vorhandenen Risiken entnommen. 
stück. mit einem denkmalgeschützten erneuenungsbedürftigen alten Baukörper im derzeitigen Zustand an eine geschlossene Fondsgesellschaft zu verăuß̉ern, so daß diese formalrechtlich als Eigentümerin und Bauherrin des vorgesehenen Bauvorhabens fungieren konnte. ${ }^{86}$

Durch Schaffung eines Erbbaurechts mit einem Heimfallrecht und einem Recht zur Kaufoption nach 30 Jahren, Verkauf des Grundstücks mit Altbaukörper bei Vereinbarung von weitgehenden Verpflichtungen des Käufers zum Eintritt in die vorgefertigten Verträge zu Sanierung und Bebauung und zur Uberlassung des Besitzes nach Fertigstellung konnte das Ziel verwirklicht werden.

Nach Verăußerung des Erbbaurechts des bebauten Grundstücks an die Fondsgesellschaft konnte diese als formale Eigentümerin und Bauherrin die Steuervergünstigungen durch Sonderabschreibungen in Anspruch nehmen, wobei sie sich in einem Leasingvertrag verpflichten mußte, der Verkäuferin nach Fertigstellung des Bauwerks den langfristigen Besitz an dem Grundstück für deren betriebliche $Z$ wecke zu garantieren.

Auf diese Weise wurde es der Firma Jenoptik GmbH ermöglicht, die bei der Treuhandanstalt bei Ausgliederung aus dem volkseigenen Vermógen zusătzlich gewährte liquide Mitgift von $600 \mathrm{Mio}$. DM für andere Zwecke, nämlich für die Arondierung der vorhandenen Unternehmenspalette zu verwenden. ${ }^{87}$

Die Liquidität des Unternehmens wurde auf diese Weise trotz des aufrechterhaltenen Besitzzustandes an dem betriebsnotwendigen Dienstleistungszentrum obendrein um den vereinnahmten Kaufpreis für die Veräußerung des erbbaurechtlich belasteten Grundstücks mit Altbau von 7,3 Mio. DM noch verbessert. Dabei wurden die nach Sanierung und Erweiterung des Baukörpers zu zahlenden Leasingraten dann fortan voll abzugsfähige Betriebsausgaben.

Auf Grundlage dieser Gesichtspunkte wurde eine Problemlösung entwickelt, die zum 15. Oktober 1994 verwirklicht wurde, nachdem das haftende Eigenkapital des Leasing-Fonds sehr schnell gezeichnet worden war ${ }^{88}$

Ein renommierter Initiator begründete eine geschlossene Immobilien-Lealsing-Fondsgesellschaft als vermögensverwaltende Kommanditgesellschaft. Die Bareinlagen des Fonds wurden auf ca. 33 Mio. DM begrenzt. Dazu kam eine

${ }^{86}$ S. 11 des ausfürrlichen Beteiligungsangebots, Pos. Erbbaurechtsvertrag.

${ }^{87}$ Bericht von A. Oldag in: Stuttgarter Zeitung v. 10.10.1994, S. 7 (Wirtschaf).

Eine Kurzfassung des Beteiligungsangebots mit abgerundeten Angaben der wesentlichen Positionen für Kunden einer deutschen Großbank findet sich in Anlage 23. 
finanzierte Einlage der Zeichner von ca. 42 Mio. DM, die grundbuchlich gesichert wurde, und ein weiteres Bankdarlehen an die KG von 15 Mio. DM. ${ }^{89}$

Die von jedem Anleger zu leistende haftende Bareinlage betrug 978.000,-DM oder ein vielfaches, also mindestens $3 \%$ von insgesamt ca. 33 Mio. DM. Die finanziente weitere Einlage betrug ca. 1,3 Mio. DM. Die Einzahlungen erfolgten zum 15. Oktober 1994.

Die Leasing KG erwarb am 31. Oktober 1994 die Liegenschaft im Zentrum Jenas auf erbbaurechtlicher Basis auf 66 Jahre zum Kaufpreis von 7,3 Mio. DM.

Die Leasing KG schloß als Leasinggeberin mit der Jenoptik als Leasingnehmerin zum selben Datum einen ab 1. Oktober 1995 einsetzenden, von starken Steigerungsraten indexbestimmten Leasingvertrag bezüglich des bis dahin sanierten und erweiterten Girundstücks mit der Firma Jenoptik GmbH uber 30 Jahre. Sie übernahm die Verpflichtung, bis zum 30. September 1995 das vom Leasinggeber vorgeplante Bauwerk fertigzustellen.

Zugleich schiloß die Fonds-Gesellschaft mit der Jenoptik-BauentwicklungsGmbH Jena einen Generalübernehmervertrag zu dem Festpreis von 6.5,8 Mio. DM. Der Betrag wurde gleichzeitig fällig und sofort entrichtet. Weitere Einzelheiten können wir übergehen.

Für den Zeichner eines Anteils in Höhe von 978.000,-- DM führt das Investment zu folgendem zu erwartendem Ergebnis: ${ }^{90}$

Nach dem sehr ausführlichen und den Grundsátzen des Fachgutachtens des Instituts der Wirtschaftsprüfer in jeder Hinsicht entsprechenden Beteiligungsangebots zum Beitritt als Gesellschafter der Firma einer Immobilien-LeasingFonds KG in München werden für die Zeichner während der zehnjăhrigen Periode der Sonderabschreibungen insgesamt Verlustzuweisungen in Höhe von $234,15 \%$ anfallen. ${ }^{9 !}$

Da sich die Fonds-Gesellschaft verpflichtete, bereits zum 30. Oktober 1994 das gesamte Entgelt für die Bauleistungen in Höhe von 65,8 Mio. DM an den Generalübernehmer, die Firma Jenoptik-Bauentwicklungs GmbH, zu entrichten, konnte sie nach $\S 4$ Abs. 2 FördG i. V. m. $\$ 1$ Satz 2 FördG bereits für das

so Diese abgerundeten Zahlenangaben wurden dem Bankprospekt des Beteiligungsangebots entnommen. s. Anlage 23

90 Der Zeichnungsbetrag, von 978.000,-- DM ergibt sich. aus dem ausfürlichen Prospekt. Von einem zusătzlichen Disagio findet sich keine Erwăhnung,

9! Der ausfuhrliche Prospekt entspricht den in einem Fachgutachten L/1983 vom Institut der Wirtschaftsprüfer in Deutschland e. V.. Dosseldorf, niedergelegten "Grundsătzen ordlnungsmäBiger Durchführung von Prospektprüfungen". 
Jahr der Anzahlung, das ist das Rumpfquartal 1994, die gesamten Sonderabschreibungen auf die Herstellungsaufwendungen in Höhe von $50 \%$ von 65,8 Mio. DM geltend machen und dementsprechende anteilige hohe Verluste den Beteiligten sofort zuordnen. Tatsăchlich ist es möglich und vorgesehen, den Zeichnern in den ersten drei Jahren fiktive anteilige Verluste von $164,78 \%$ der Bareinlage eines Anteils gutzuschreiben. ${ }^{92}$

Bei Berücksichtigung der Belastung mit Kirchensteuer und Solidaritătszuschlag hat der Investor somit, sofern er die Voraussetzungen durch ein entsprechend hohes Einkommen erfullt, bereits mit Ablauf des Jahres 1996 eine Steuerersparnis bewirkt, die den Betrag, der als Steuern ohne den Beitritt vom Investor hătte entrichtet werden müssen, un ca. 5.000,-- DM übersteigt. Er konnte bereits zum 10. Dezember 1994 eine Steuerersparnis von $862.000,--$ durch Verrechnung zurückerhalten, so daß nur eine sehr geringe kurzfristige liquide Belastung in Hobhe von 116.000,-- DM erfolgte. ${ }^{93}$

Der Zeichner hat mithin bereits nach etwa zwei Jahren und zwei Monaten Steuerschulden in Höhe von 983.000,-- DM in Privatvermoggen umgewandelt. Außer 5.000,-- DM an zusătzlichen Barmitteln besitzt er nunmehr einen Fondsanteil, dessen Wert durch sachenrechtliche Absicherung als erbbaurechtliches Miteigentum zur gesamten Hand gewiß in Höhe der Anschaffungskosten wertbeständig bleiben wird.

Ab dem vierten Jahr erhält der Investor dann weiterhin zusătzlich zu der inzwischen erfolgten Erstattung der Aufwendungen für die Bareinlage 27 Jahre hindurch Ausschüttungen, die infolge der Tilgung von Fremdmitteln sehr niedrig beginnend im Gesamtdurchschnitt jăhrlich über $6,8 \%$ der Bareinlage von $978.000,--$ DM betragen.

Im 30. Jahr wird er dann im Falle der Ausübung des Optionsrechts durch den Leasingnehmer eine steuerfreie Abfindung von 214.000,-- DM erhalten, sofern er, wie ausdrücklich empfohlen, den Anteil als Privatmann erwarb.

92 Diese vorgesehenen Verlustzuweisungen wurden dem ausfuhrlichen Prospekt entnommen. GemäB $\$ 4$ Abs. 2 i. V. m. $\$ 1$ Abs. 1 \$atz 2 FördG kơnnen $50 \%$ des bei Vertragsschlubi am 30.10 .94 von der Forndsgemeinschaft im voraus an den Generalübernehmer, die Fìma Jenoptik Bauentwicklungs$\mathrm{GmbH}$, zu zahlenden Festpreises für die Bauleistungen in Hôhe von $65.8 \mathrm{Mio}$. DM nọch im selben Jahr als Sonderabschreibungen wie Werbungskosten bei Ermitulung des Verlustes angesetzı werden, da der Betrag im năchsten Besteuerungsabschnitt vertaut sein wird (Zweifelsfragenerlaß zum FördG).

${ }^{93}$ Diese Ziffern ergeben sich aus Spalte 8 der dem Prospektangebot beigefüten Ergebnisvorschau als Kapitalbindung. Die im Prospekt angegebenen Beträge von 228.895,- DM als Kapitalkindung, fur das erste und 172.175,- DM für das zweite Jahr wurden umgerechnet in 115.643.- DM per Ende 1994 und 53.20,-- DM per Ende 1995. Dies geschah deshalb, weil in dem Prospekt ausdrucklich eine Gesamtbelastung mit ESt von nur 53\% ohne KiSt und SolZ zugrunde gelegt wurde. Die hier vorgenommene Rechnung berücksichtigt den derzeitigen Rechtszustand, in dem der SolZ für 1994 und 1995 berücksichtigt wirdi. Im ũbrigen wird auch KiSt eingeschlossen. 
Diese Ablősungssumme ist ein Nettobetrag, da die Leasingnehmerin alle Fremdmitte! kontinuierlich zu tilgen verpflichtet ist.

Der Investor kann also bei Außerachtlassung von Zinsen 27 Jahre hindurch mit Ausschüttungen von durchschnittlich jährlich ca. 69.000,-- DM nach Bedienung der Annuităten rechnen. Das sind insgesamt im Laufe der Jahre etwa 1,9 Mio. DM zuzüglich einer Abfindung von ca. 214.000,-- DM im 30. Jahr nach Ausübung der Option durch den Leasingnehmer, nachdem dieser alle Fremdmittel tilgte. ${ }^{94}$

Tatsăchlich eröff́net dieses Beispiel steuergesetzlicher Wirtschaftsforderung für den Investor aber noch viel weitergehende wohltuende Möglichkeiten, sich einer gleichmå̊igen Lastenverteilung nach der wirtschaftichen Leistungsfähigkeit durch Zeichnung einer steuerbeguinstigten Kapitaleinlage - hier in Form eines Anteils an einem Leasing-Fonds - zu entziehen:

Ziel zukünftiger Dispositionen der Zeichner wird es nämlich sein, die Verlustzuweisungen durch eine geeignete Gestaltung jeweils nach Zeichnung bei demjenigen Steuerbürger anzusiedeln, der mit hohem Einkommen und mit dem entsprechend höchsten Progressionszugriff der Steuer belastet ist. Für die zehn Jahre der Wirksamkeit der Sonderabschreibungen wird das vermutlich stets der Zeichner selbst bleiben.

Sobald nach zehn Jahren die Sonderabschreibungen des FördG von 100\% der Herstellungsaufwendungen verbraucht sind und nun steigende zu versteuernde Gewinnzuschreibungen erfolgen, wird der Zeichner gewiß den Anteil unentgeltlich an einen in niedrigerer Progressionsstufe stehenden, eventuell unterhaltsberechtigten Angehörigen übertragen.

Das fuihrt in dem konkreten Fall dann zu folgendem Ergebnis: Der Zeichner wird von 1994 bis zum Jahr 2005 Verlustzuweisungen von insgesamt $978.000,--$ DM x 2,3415 $=2.290 .000,--$ DM erhalten. Das wird bei Fortführung der derzeit herrschenden und vorgesehenen Steuersätze dem Investor Steuerersparnisse von insgesarnt ca. 1.375.000,-- DM einbringen. Dabei wird ab 1997 die Einstellung des Solidaritätszuschlags unterstellt. ${ }^{95}$

Ab dem Jahr 2006 wird dann nach Übertragung des Anteils ein weniger hoch besteuerter unterhaltsberechtigter angehöriger Schenknehmer 20 Jahre

\footnotetext{
94 Die Gesamtziffer ist niedriger als in der Ẽrgebnisvorschau des Prospekts (2.106.511,-- DM), da wegen der KiSt eine hōhere Steuerbelastung unterstellt wurde. Von der Möglichkeit der Kappung wurde abgesehen.

95 Auch diese Berechnung erfolgte auf Grundlage der Engebnisvorschau des Prospekts. Erst für den Schenknehmer wird eine durchschnittliche Steuerbelastung mit ESt von $28 \%$ unterstellt, was z B. den Lebensverhalltnissen eines Beamten mit mittlerem Einkommen entspricht.
} 
hindurch Ausschüttungen erhalten, die nach Steuern insgesamt etwa 1.755.000,-- DM ausmachen. Dabei wurde für die steuerbaren Anteile ein durchschnittlicher Steuersatz von $28 \%$ zugrunde gelegt, was für ein mittleres Einkommen heute realistisch ist.

Der Schenknehmer erhălt mithin 20 Jahre hinđurch im Durchschnilt jăhrlich Unterhaltsmittel nach Steuern von über 85.000,-- DM.

Dieser Art laufende Bezugsrechte eignen sich, wie man sieht, vorzüglich zur steuerlich günstigen Abgeltung von Unterhalts- bzw. Ausbildungsaufwendungen abhängiger Angehöriger, zur Bestreitung von Scheidungsfolgekosten, als Unterhaltsmittel für Lebensgefahrten etc., also zur unentgeltlichen Übertragung an Personen, denen infolge geringen oder fehlenden Einkommens durch die Schenkung nur eine geringe steuerliche Kürzung der Einkünfte aus Vermietung und Verpachtung bevorsteht.

Da infolge des hohen, nur allmählich abgebauten Einsatzes von Fremdmitteln die Bemessungsgrundlage für die Schenkungssteuer noch zum Zeitpunkt der Schenkung im Jahr 2005 rechnerisch vermutlich negativ ausfallt, empfiehlt sich auch unter diesem Gesichtspunkt der Ausgleich von Verpflichtungen durch eine derartige unentgeltliche Zuwendung.

Es liegt auf der Hand, daß diese Einnahmen in Höhe von insgesamt über 3,1 Mio. DM, die in einem Zeitraum von 32 Jahren dem Investor und seinen Angehörigen zufließen werden und die dadurch ausgelöst werden, daß bei einer zusätzlichen, nur kurzfristigen Kapitalbindung von 115.700,-- DM ein Betrag von 978.000,-- DM nicht an die Kasse des Finanzamts, sondern als Bareinlage an einen Leasing-Fonds entrichtet wurde, nicht auf allgemeines Verstandnis stößt. Schließlich erhält der Zeichner als Belohnung allein für den Umstand einer Umdisposition von Steuermitteln in Höhe von 978.000,-- DM 32 Jahre hindurch eine durchschnittliche jährliche Bereichenung nach Steuern von über 96.000,-- DM. Das addiert sich zu einem Betrag, der etwa zweimal soviel ausmacht wie das Lebenseinkommen eines fleißigen Aufstiegsbeamten des gehobenen Dienstes der Finanzverwaltung.

Ein Senatspräsident am BFH hielt zwar zu Ende der 70er Jahre zu diesen Vorgängen fest: "Steuererleichterungen sind kein einseitiges Geschenk des Staates für reiche Kapitalanleger, sondern die Gegenleistung für ein bestimmtes, volkswirtschaftlich erwünschtes Verhalten seiner Bürger" ${ }^{96}$

${ }^{9}$ Hart, W. (1980), zitiert aus Vorwort zu: Hecker, C. (1982). Ähnliche Ausführungen konnte man in den 70er Jahren von vielen hohen Finanzrichtern und Finanzbeamten, bis hin zum pensionierten Prāsidenten des Bundesamtes für Finanzen und desgleichen vielen Professoren der Nationalōkonomie in Eingangsreferaten auf Veranstaltungen großer Initiatoren von Abschreibungsgesellschaften hōren. Oftmals erhielt man als Steuerberater den Eindruck, die Zeichnung von Anteilen an Abschreibungsge- 
Wenn mit dieser öfters zitierten Feststellung eines einflußreichen leitenden Richters am höchsten Finanzgericht der Bundesrepublik Deutschland der Eindruck erweckt wird, es handele sich bei dieser Art Steuervergünstigungen um einen angemessenen oder gar gerechten Leistungsaustausch, so ist demgegenüber festzuhalten, daß die Gegenleistung als Privileg auf Großverdiener beschränkt ist und in keiner sinnvollen Relation zur Leistung des Investors steht.

Viele Mitarbeiter der Finanzverwaltung vermögen die hier vorgetragenen Zusammenhänge aus der Aktenkenntnis nachzurechnen. Sie bemalngeln, daß die Gegenleistung in der gezeigten Höhe für das Ausklinken einer kleinen Gruppe von hochverdienenden Zeichnern derartiger Anteile aus der Solidargemeinschaft der Steuerzahler zu Lasten derjenigen Bürger erfolgt, für die sich der Erwerb steuerbegünstigter Kapitalanteile nicht rechnet. Das ist der gesamte Mittelstand, der die entsprechend höheren Steuerleistungen zu Lasten einer Bildung von eigenen Ersparnissen übernehmen muß.

Daltons Beurteilung der Psychologie der Steuerzahler ist keineswegs abwegig, wenn er für empfehlenswert hallt, "that the rich should pay more taxation

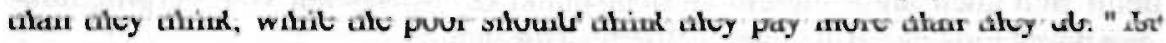
dieser Glaube, "this double illusion", erschüttert, können sich unerwünschte Folgen für die Allgemeinheit einstellen. ${ }^{97}$

Wegen der erkennbaren Unausgewogenheit von Leistungsaustausch, Vermögensbildung und Lastenverteilung ist es wichtig festzuhalten, daß die dem Land Thüringen gehörende Firma Jenoptik GmbH ihre Baupläne auch auf konventionelle herkömmliche Weise durch Aufnahme von Hypothekendarlehen hătte verfolgen können. Durch Investitionszulagen, Investitionszuschüsse und verbilligte Kredite hätte das Vorhaben aus öffentlichen Mitteln wie in vergleichbaren Fällen ausreichend gefördert werden können. Da das Unternehmen in fünf Jahren durch Ausgabe von börsenfähigen Aktien privatisiert werden soll, wäre dieser Weg vielleicht überzeugender gewesen.

Wegen gegebenenfalls auftretender Kritik an den Konsequenzen ausgefallener Gestaltungen ist ein Berater gehalten, der Frage eventuell drohender Gefahren bei der vorliegenden Konstruktion nachzugehen. Denn: Die Einkommensteuer ist eine Abschnittsbesteuerung. Der Sachverhalt kann vom Finanzamt jeweils bei jeder Veranlagung erneut in bezug auf die gesetzlichen Tatbe-

sellschaften sei eine uneigennųuige gut Tat; sie stehe moralisch höherwertig gegenaber der Steuerzahlung an das Finanzamt. Hierin kam die zeitgemllbe gesellschaftliche Bewertung zum Ausdruck, die unreflektiert konkreten Wiederaufbauleistungen Vorrang vor Verteilungsgesichtspunkten zuerkannt wissen wollte.

${ }^{97}$ Dalton, H. (1946), S. 49. 
standsmerkmale im Sachverhalt abgeklopft werden. Ratsam wăre es daher, für den vorliegenden Sachverhalt eine verbindliche Auskunft der Finanzverwaltung zu verlangen. Hierzu besteht jedoch im geltenden Steuerrecht keine verbindliche Anspruchsgrundlage.

Voraussetzung der skizzierten Konstruktion ist der Umstand, daß der Leasingnehmer nicht als wirtschaftlicher Eigentümer des sanierten und erweiterten Dienstleistungszentrums beurteilt wird. Ansonsten könnte der Leasinggeber seinerseits keine Sonderabschreibungen geltend machen.

Tatsächlich führten nach der bisherigen Rechtsprechung beim ImmobilienLeasing die besonderen Bedürfnisse des Leasingnehmers, Planung und konkrete Ausführung eines Leasing-Objekts letztlich zu bestimmen, regelmäßig nicht zur Ansiedlung des wirtschaftlichen Eigentums beim Leasingnehmer.

Im vorliegenden Fall kann jedoch von einem zumeist als entscheidend unterstellten Interesse des Leasinggebers ein möglichst vielseitig fungibles $\mathrm{Ob}$ jekt zu Eigentum zu besitzen, das gegebenenfalls auch anderweitig verwendbar ist, überhaupt nicht mehr gesprochen werden. Ist er in diesem Fall dennoch Inhaber einer Einkunftsquelle durch seine erbbaurechtliche formale Eigentümerstellung ohne wesentliche unmittelbare Verfügungsrechte geworden?

Tatsächlich schneiderte sich der spätere Leasingnehmer bereits als Eigentümer frühzeitig einen Maßanzug.

Die dingliche Rechtsposition des Leasinggebers dient hier erkennbar nur seinen Gläubigerschutzinteressen bei der Finanzierung. Die gesamte Konstruktion soll durch Einbindung von Steuervergünstigungen nur günstig kalkulierte Finanzierungsmodalitäten ermöglichen.

$\mathrm{Ob}$ hier die formelle Eigentümerposition steuerlich bestimmend bleibt oder die wirtschaftlichen Verhältnisse maßgeblich sein sollen, könnte von der Finanzverwaltung durchaus unter den Gesichtspunkten der Vorschriften über den Mißbrauch rechtlicher Gestaltungsformen erörtert werden. ${ }^{98}$ Dabei müßte dann eine Abwägung der wirtschaftlichen Nutzungsstellung und der Verfügungsbefugnisse des Leasingnehmers gegenüber der formalrechtlichen Eigentümerposition des Leasinggebers erfolgen.

Auch die Grundgedanken der 1976 und 1980/81 ergangenen Rechtsprechung des BFH zur steuerlichen Anerkennung der formaldinglichen Übertragung von Einkunftsquellen - denn darum handelt es sich hier auch - durch

98 § 42 AO regelt den Steueranspruch bei Mißbrauch von rechtlichen Gestaltungsmöglichkeiten. Sofern die Finanzverwaltung den Leasingnehmer als wirtschaftlichen Eigentümer beurteili, entstehen bei dem Leasinggeber keine fiktiven Verluste durch den Ansatz von Sonderabschreibungen nach \$4 FördG und/oder $\S 7$ EStG. Die formale Regelung weicht dann der wirtschaftlichen Beurteilung. 
Einräumung von Nießbrauchsrechten könnten von der Finanzverwaltung im vorliegenden Fall herangezogen werden. ${ }^{99}$

Hier setzte sich die Finanzverwaltung über das Primat des Zivilrechts bei Verwendung ăhnlicher sachenrechtlicher dinglicher Dispositionen, wie wir sahen, hinweg. Der BFH bestătigte die Entscheidung. ${ }^{100}$

Diese Bedenken, mit denen sich ein verantwortungsbewußter Berater vor der Zeichnung von Anteilen an dem erwähnten Leasingfonds durch seinen Mandanten auseinandersetzen muß, da sie Unsicherheiten bezüglich der Inanspruchnahme von Sonderabschreibungen und damit der ausschlaggebenden Verlustzuweisung erzeugen, entpuppen sich jedoch als unrealistisch, sobald man folgendes berücksichtigt:

Eigentümerin der Leasingnehmerin ist zu $100 \%$ das Land Thüringen. Die Landesregierung hat angekündigt, daß das Unternehmen in fünf Jahren durch Ausgabe börsenfahiger Aktien privatisien werden soll. Dazu wird die Firma Jenoptik GmbH lebensfahig ausgestattet sein müssen.

Zuständig für die Erteilung der Bescheide zur gesonderten und einheitlichen Feststellung der Einkünfte aus Vermietung und Verpachtung mit Bindungswirkung für die Wohnsitzfinanzämter der Anteilseigner des Leasing-Fonds ist das für die Verwaltung desselben zustăndige Finanzamt in München.

Mit einer Verwerfung der steuerlichen Anerkennung der Inanspruchnahme von Sonderabschreibungen ist von dieser Behörde nicht zu rechnen. Anderenfalls kann die Zustândigkeit des Finanzamts für die wenig aufwendige Verwaltung des Fonds sofort durch einen satzungsändernden Beschluß der 33 Zeichner nach Thüringen verlegt werden. Dort sind die Finanzämter den Weisungen desselben Finanzministers unterworfen, der als Vertreter der Landesregierung die Eigentumsrechte an der Firma Jenoptik GmbH wahrzunehmen hat.

Die Interessenlage tritt offen zutage. Nur die Behörde könnte als Klägerin vor dem Finanzgericht auftreten. Für eine Eingabe an das Bundesverfassungsgericht ist ein aktivlegitimierter beschwerter Kläger nicht in Sicht. ${ }^{101}$

99 Bei Beurteilung der Einrâumung von NieBbrauchsrechten war die Finanzverwaltung, als die Inanspruchunahme auszuufern begann, unvermittelt nach 1977 den Thesen Ruppes zur Oblertragung von Einkunftsquellen gefolgt, s. Ruppe (1978), S. 25; s. a. Kapitel D, Anm. 279 und Anm. 282; s. BFH v. 26.1.1970, in: BStBI. II. S. 264.

${ }^{100}$ Die unterschiedliche Zuordnung von Einkünften infolge gewandelter Auffassungen uber die anzawendende Definition der Einkunftsquelle führte nach Soffing zu einem "Chaos" grundlegender Konstruktionselemente des EStG, s. Kapitel D, Anm. 287.

101 Ein anhängiges finanzgerichtliches Verfahren würde die vorgesehene Privatisierung der Firma Jenoptik innerhalb des vorgesehenen Rahmens von fünf Jahren erschweren, wenn nicht gar unmöglich machen. 
Nach derzeitiger vorherrschender Rechtsauffassung vermietet und verwaltet die Leasinggeberin also als rechtliche Eigentumerin ausschließlich eigenen Grundbesitz. Sie ist daher eine vermögensverwaltende Kommanditgesellschaft. Ihr sind die Sonderabschreibungen gemäß $\S \S 3$ und 4 FördG zuzurechnen.

Die Gesellschafter beziehen als anteilige Mitinhaber einer Einkunftsquelle Einkünfte aus Vermietung und Verpachtung und erfullen rechtlich somit den Tatbestand der Einkünfteerzielung.

Naturgemäß können diese Einkünfte auch negativ ausfallen. Eben das ist letztlich der ganze Sinn der Konstruktion. Wichtig ist, daß es sich bei den Mitinhabern der Einkunftsquelle um deren Privatvermögen handelt.

Ein Restrisiko mag verbleiben, ist aber als gering einzustufen. Im ganzen gesehen handelt es sich um ein empfehlenswertes Geschäf.

Aber: Erst die hohen Steuersătze, über die allenthalben gestöhnt wird, machen es lukrativ, wenn auch nicht für jedermann, sondern nur für eine kleine, zumeist meinungsbildende Elite. Sie vermag die Hōhe ihrer Besteuerung weitgehend selbst zu bestimmen. Die ausfallenden Steuerzahlungen übernimmt der Mittelstand als Solidargemeinschaft.

\section{Konsequenzen einer problematischen Lastenverteilung}

Das deutsche Einkommensteuerrecht hat seit Einführung des săchsischen EStG 1874/78, das fortan in Deutschland als Musterentwurf diente, eine Entwicklung genommen, die es seiner Grundidee einer Besteuerung des Bürgers nach "der wirthschaftlichen Kraft der Persönlichkeit"102 zunehmend entfremdete.

Johannes von Miquel hatte in der Begründung zum "Entwurf eines Einkommensteuergesetzes vom 3 . November $1890^{\prime \prime}$ zwar engagiert vertreten, daß mit der Vorlage "das Verlangen einer thunlichsten Übereinstimmung der Steuerlast mit der Leistungsfähigkeit ihres Trägers zu immer unbestrittenerer Herrschaft gelangt ist". ${ }^{103}$

Von Steuerjuristen hört man heute noch gelegentlich die Auffassung, daß das geltende EStG jedenfalls in seiner Grundstruktur gerecht sei, indem es "dem einzelnen und zwar im Zweifel eher noch ausgeprägter als früher die

${ }^{102}$ Schmoller, G. (1863), S. 53 u. a.

${ }^{103}$ So Miquel in der Begrùndung zu. dem am 3.11.1890 im Preuß. Landtag eingebrachten Entwurf eines EStG, s. FA. 7. Jg. 1890, S. 666. 
Zahlung von Einkommensteuer nur in den Grenzen seiner wirtschaftlichen Leistungsfahigkeit abverlangt". ${ }^{104}$

Die Gesetzesvorschrift und die von ihnen ausgelöste Besteuerungswirklichkeit standen jedoch bereits seit 1891 in unauflösbarem Kontrast zu diesen schönfärbenden Beurteilungen, die das Gesetz fortan begleiteten.

Heute bemißt sich im krassen Gegensatz dazu die Möglichkeit, "aus Steuern Vermögen (zu) schaffen", ursprünglich sogar vom Bundeswirtschaftsministerium vorformuliert und derzeit noch von vielen erfolgreichen Anlageberatern ständig werbend herausgestrichen oder in anderer neuerer Terminologie "Immobilien zum Nulltarif" zu erwerben, nach eben dieser "Erwerbskraft" des Steuerbürgers. ${ }^{105}$

Dabei werden diese flotten Sprüche obendrein heute von verantwortungsbewußten Anlageberatern warmend vorgetragen, um kleine Steuerzahler davon abzuhalten, sich zu übernehmen. Denn, so der Kern ihrer Thesen, deren Mißachtung sehr teuer werden kann: Quod licet Jovi non licet bovi.

So kann man heute mit gewissen Einschränkungen sagen, daß die Schmollersche Anregung zu einer allgernein akzeptablen Lastenverteilung in seinem Beitrag zur Definition einer steuerliche Bemessungsgnundlage von 1863 de facto durch nichtfiskalische Einfügungen in das EStG inzwischen glatt ins Gegenteil verkehrt wurde.

Dabei sind die auftretenden sachlichen Zusammenhänge und die Konsequenzen der Durchsetzung des EStG mit den unterschiedlichsten Steuervergünstigungen zwar fortlaufend registriert und wegen der ausgelösten zunehmenden Komplikation heftig beklagt worden, die konkreten Wirkungen wurden von den zuständigen Steuerwissenschaften jedoch nicht genügend aufgehellt. ${ }^{106}$ Das Für und Wider des Einsatzes der Steuervergünstigungen, die zu berücksichtigenden Aspekte, wurden nicht gegeneinander abgewogen und so aus der Diskussion ausgeblendet. Sie sind im öffentlichen Bewußtsein daher heute verblaßt. Auf diese Weise wurden sie zum mehr oder weniger verborgenen Aktionsfeld von Fachleuten in Regierung und Verwaltung und pressure groups in parlamentarischen Ausschüssen.

Die Folgen dieses Umstandes zeigen sich nicht zuletzt in der Verständnislosigkeit der Öffentlichkeit für die entstandene Kompliziertheit des EStG, die mit der Kombination von gezielten Steuervergünstigungen und der Unterdrük-

\footnotetext{
${ }^{104}$ Bayer, H. W. (1991), S. 336.

${ }^{109}$ Engels, T. (1994) Fonds zum Nulltarif, in: Cash, Beilage zu Heft 6/94, S. 46. Die Audiocassette Nr. 14 gibt weitere Einzelheiten wider, s. a. Cash, Heft 6/95, S. 151 u. Beilage S. 44.

106 Zitzelsberger, H. (1985), S. 197; Tipke, K. (1989), Uber Steuervergùnstigungen ..., S. 186.
} 
kung von Mißbrăuchen durch eine Vielzahl amtlicher Erlasse notwendig einhergeht. Das führte inzwischen zu steigendem Steuerwiderstand. ${ }^{107}$

Die positive Seite des instrumentalen Einsatzes der Einkommensbesteuerung durch Beseitigung von Notzustănden und Erleichterung auftretender wirtschaftspolitischer Engpåsse als zeitlich befristete Ausnahmeregelungen hat ebenfalls in den Steuerwissenschaften nicht die Aufmerksamkeit gefunden, die seiner Wirksamkeit als effizientes und rasch wirkendes Steuenungselement entspricht.

Auch der viel beklagte Wildwuchs, der of Disharmonien bei verfolgten Zielen erkennen lăßt, ist ein Eirgebnis dieser Versäumnisse.

Daher droht den Steuervergünstigungen als steuerrechtlich verkleidetem Wirtschaftsrecht heute, ginge es nach dem Votum vieler Steuerjuristen und Finanzwissenschaftler, die schnelle und totale Verbannung aus dem Arsenal wirtschaftspolitischer Instrumente trotz wohlstandssteigernder Ergebnisse bei geeigneter Verschreibung und Dosierung. ${ }^{108}$

Frühzeitig ist dabei von Steuerjuristen zur Rechtfertigung der Steuervergünstigungen durch Einfügung nichtfiskalischer Normen in das EStG zum Investitionsanreiz auf den wichtigen Vorteil hingewiesen worden, der diese gegenüber direkten Subventionen wie Investionszulagen und -zuschüssen auszeichnet. Sie seien, so hieß es noch 1975, aufkommende Kritik aus der ideologisch neuausgerichteten Finanzverwaltung auffangend, das "marktwirtschaftlichere Mittel", das obendrein kurzfristigere Reaktionszeiten als Steuerungselement benötige. ${ }^{109}$

107 Streck. M. (1984), S. 2205.

${ }^{108}$ Durch Unteil vom 25.9 .92 hat das BVerfC den Gesetzgeber angewiesen, den in $\S 32$ a Abs. 1 EStG berücksichtigten Grundfreibetrag durch Gesetzesalnderung so anzuheben, daß "Erwerbsbezage" bis zur Hōhe der im Sozialrecht festgelegten Regelsatze des, Existerżminimums (\$ 2I SHG) steuerfrei belassen bleiben. Die dadurch erforderliche Abstimmung des nach dem deutsche ESt-Rechit entwickelten Einkommensbegriffs mit dem auf abweichende Zwecke ausgerichteten Erwerbsbegriff des SHG füren unvermeidbar zu einer weiteren großen Komplizierung des ESt-Rechts. Daruber hinaus erfordern die zu erwartenden hohen Steuerausfalle, die kaum von einer Verminderung der Sozialhilfelasten aufgewogen werden düften, zum Ausgleich eine Neuverteilung der arforderlichen Steuerlast entweder durch höhere Belastung der verbliebenen Steuerzahler oder eine sofortige Beseitigung von Steuervergünstigungen durch Ausmerzung vieler kostspieliger Lenkungsnormen. Das einerseits das letztere zun erheblichen Umschichtungen bei der Wirtschaftsfordenung fuhren muß und kurzfristig nicht zi Entlastungswirkungen führen kann und das Gericht andererseits nicht nur auf eine Vereinfachung des Steuerrechts abstellte, sondern auch eine Fortentwicklung einer unterstellten Zielrichtung der sozialen Traditionen des ESt-Rechts beracksichtigt wissen wollte, gleicht die Auflage einer Anordnung, die Quadratur des Kreises zu vollziehen. Sozial befriedigende Folgen kann der Vollzug der Auflage, wie. immer die Lossung aussehen mag, nicht bringen, s. hierzu Kapitel M IV Nr. 15; s. a. Wirtschaftswoche v. 30.3 .95 , S. 24 und v. 16.3.95, S. 32; Der Spiegel v. 27.2.95, S. 82.

${ }^{109}$ Geiger, K. (1977), S. 300. 
Tatsăchlich beläßt diese Art von Investitionsförderung dem Markt, anders als direkte Preise und Kosten lenkende Eingriffe, die Signalfunktion zur Auslösung wirtschaftlicher Entscheidungen. Das ist von großem Wert, da die Marktwirtschaft als solche durch die richtige Weiterleitung der Knappheitsverhăltnisse über die Preisbildung am Markt bereits eine wichtige soziale Funktion erfullt. ${ }^{110}$

Den ordnungspolitischen Leitideen der für die Bundesrepublik maßgeblichen "sozialen Marktwirtschaft" kann die rein formale Ausrichtung an einem "marktkonformen Mittel" bei Verzicht auf Abstimmung der Folgewirkungen mit einer angestrebten Entwicklung der Wirtschaft zu einer sozial ausgeglichenen Lebenswelt nach vorherrschender Überzeugung jedoch nicht ausreichen. Trotz ihrer Eignung als marktkonform bleiben die nichtfiskalischen Normen ein bloßes Werkzeug, dessen Einsatz jeweils mit dem Gesamtkonzept der sozialen Marktwirtschaft und deren Zielen auch bezüglich der zu erwartenden Nebenwirkungen abzustimmen ist. ${ }^{11 !}$

Es genügt den Prinzipien der sozialen Marktwirtschaft nicht, Enthaltsamkeit von direkten Eingriffen in das Marktgeschehen zu üben, wobei unkontrollierte Entwicklungen sich durchsetzen dürfen, sofern diese nur auf den äußeren Datenkranz, die Randbedingungen der Wirtschaft zurückzuführen sind.

Zwar unterscheidet sich diese Wirtschaftsordnung durch ihr Instrumentarium marktkonformer Mittel, durch Einflußnahme auf das Wirtschaftsgeschehen vermittels Einwirkungen auf und Gestaltungen des Institutionengefüges gegenüber Lenkung der Märkte durch direkte Eingriffe in die Preisbildung. Die richtungsweisende übergreifende Zielvorgabe der marktkonformen Maßnahmen ist es demgegenüber in dieser Wirtschaftsordnung, "sozialen Fortschritt" anzustreben. ${ }^{112}$

Dieses Ziel wird nach übereinstimmender Auffassung von Vertretern dieser Ordnung darin gesehen, "breitesten Schichten der Verbraucher eine wesentliche Verbesserung ihrer Lebenswelt" zu sichern. ${ }^{113}$

${ }^{110}$ Maller-Armack, A. (1948), S. 93, 94. Nichtfiskalische steuerliche Lenkungsnomen sind danach ein marktkonformes Steuerungsmittel, sofern "wesentliche wirtschaftliche Daten grundlegend geăndert werden" (S. 93), ohne dabei die Spielregelin des Marktes zu stören (S. 108).

111 Die marktwirtschaftliche Ordnung ist nach Maller-Armack "nur ein überaus zweckmãßiges Organisationsmittel" ... "und es wăre ein verhalngnisvoller Irrtum der Automatik des Marktes die Aufgabe zuzumuten, eine letztgätige soziale Ordnung zu schaffen ... Es bedarf vielmehr einer bewuBten Einstellung der marktwirtschaftlichen Ordnung in eine abergreifende Lebensordnung", also letztlich einer zielgerichteten korrigierenden und lenkenden Instanz, s. Maller-Armack, A. (1948), S. 85.

${ }^{112}$ Miller-Armack, A. (1948), S. 105; ders. (1956), S. 391.

113 Mriller-Armack, A (1948), S. 85; ders. (1956), S. 391. 
Insofern bedeutet soziale Marktwirtschaft "keineswegs den Verzicht auf eine wirksame Sozialpolitik", sie ist die richtige, weil sachgerechte Form deren Verwirklichung. ${ }^{114}$

Das Ziel der sozialen Marktwirtschaft besteht daher nicht allein darin, eine Politik der Vermehrung der Güterproduktion, gemeinhin als "Sozialprodukt" bezeichnet, zu betreiben; sie setzt zugleich deren sozial ausgeglichene und verantwortete Verteilung voraus, ohne deren überwiegend als gerechtfertigt empfundene Regelungen Wohlstandsmehrung nicht definiert werden kann. Dies gilt jedenfalls heute in der Nationlökonomie als vorherrschende Auffassung.

Damit wird eine Tradition fortgesetzt, die in Deutschland mit der Gründung des Vereins für Socialpolitik einsetzte und eng mit der Entstehung der modernen Einkommensbesteuerung verbunden war. ${ }^{115}$

Der Kritik an der Einkommens- und Vermögensverteilung kam sofort eine wichtige Rolle zu. Einer Reform der Einkommensteuer wurde daher bereits 1872 Priorităt für die anstehenden Veranstaltungen beigemessen. Die noch zu Ende 1872 erstellten Gutachten der Gründungsmitglieder des Vereins für Socialpolitik, Gensel und Held, wurden zusammen mit dem Aufsatz Schmollers aus dem Jahr 1863 dann die Grundlage, auf denen das erste moderne EStG im deutschen Sprachraum 1874 entstand. ${ }^{116}$

Einkommens- und Vermögensverteilung beanspruchten weiterhin Schmollers Aufmerksamkeit. Insbesondere nach Einführung des preußischen EStG 1891 verfolgte er ihre Entwicklungen in kürzeren Zeitabständen. Hier sah er einen wichtigen Maßstab für die soziale Balance der Gesellschaft, die er mit seiner Vorstellung von "Gerechtigkeit in der Volkswirtschaft" in Verbindung brachte. ${ }^{117}$

"14 Muller-Armack, A. (1948), S. 108, S. 110; âhnlich Lampert, H. (1988), S. 42.

"1" Hansen, R. (1993), S. 158.

116 Siehe Kapitel D, Anm. 48; s. Schmoller, G. (1900), S. 122.

${ }^{117}$ Schmoller, G. (1881), S. 19. Gerechtigkeit war für Schmoller keine Frage der richtigen Herleitung von Rechtsanwendungen aus einem Prinzip (S. 21). Es war eine "Idealvorstellung", keine Erkenntnis oder "Offenbarung" (S. 53) im Sinne objektiver Richtigkeit (S. 22). Die "konventionellen MaBstäbe sind der historische Niederschlag des Gerechtigkeitsgefuhls..." (S. 30). Dieser ist Folge von "Kampfen unterschiedlicher Beurteilungsmaßstabe" (S. 31), wobei dic Oberzeugungskraft im Lichte fortschreitender Kenntnisse die Auswahl bestimmt (S. 32). Die Verteilung des Einkummens ist eine Konsequenz mens.chlicher Institutionen (S. 36). Im Zuge der Entwicklung führen Erfahrungen über die Folgen zur steten Verbesserung der Institutionen und zu einer korrigierten Zweckerfullung (S. 45). Die Gestaltung der Institutionen ist danach "das Mittel, die (so verstandene) Gerechtigkeit aber der Zweck des Rechts" (S. 46). Die Konsequenz dieser Auffassung ist, dab dic Gestaltung der Institutionen kontinuierlich so berichtigt werden muB, daB die sachlichen Folgen "mit denjenigen Idealvorstellungen der Gerechtigkeit in Einklang; bleiben, welche auf Grund unserer sittlichen und religiösen Vorstelifungen die heute herrschenden oder zur Herrschaft gelangenden sind" (S. 49). Diese soziale Balance zu errei. 
Die von Schmoller nach 1900 forcierten statistischen Untersuchungen der Einkommens- und Vermoggensverteilung sollten wie ein Thermometer der Rechtfertigung von Regelungen zur Aufrechterhaltung des gesellschaftlichen Gleichgewichts etwa durch institutionelle Maßnahmen zum weiteren Abbau der Klassenspaltung dienen. ${ }^{118}$

Schmollers und Meisels Kritik am preußischen EStG 1891 konnte sich allerdings nicht mehr durchsetzen. Wagners Besteuerungskonzept wurde um 1910 verstärkt wirksam.

Solange nach 1949 die Einfügungen nichtfiskalischer Lenkungsnormen in das herkömmliche ESıG 1939 in der Offentlichkeit als sachlich notwendige und zeitlich befristete Ausnahmen zum Investitionsanreiz beurteilt wurden, blieb die Kritik an dem geltenden Einkommensteuerrecht verhalten und war auf Wissenschaftler beschränkt. Wachsender Wohlstand, sozialpolitische Umverteilungen und vielerlei abgestimmte vermögensbildende Maßnahmen für kleine Steuerzahler sorgten als Gegengewicht gegenüber großen Vermögensmehrungen aus Steuerersparnissen von Investoren für die Aufrechterhaltung einer sozialen Balance und verdrängten jedenfalls systematische Kritik an der Einkommensbesteuerung. ${ }^{119}$

Ein von Juristen vertretener formaler, grundsätzliche Widersprüche aufdekkender rechtsdogmatischer Perfektionismus vermochte gegenüber dem in der Offentlichkeit allgemein als wichtiger empfundenen Interesse an einer fortschreitenden Wohlstandsmehrung durch forcierte Investitionen als nachrangig erscheinen.

Diese Voraussetzungen sind seit Ende der 70er Jahre allmählich verblaßt. Auch die als Folge der Wiedervereinigung entstandenen wirtschaftlichen Not-

chen und im Laufe der Entwicklung im Interesse einer "vertheilenden Gerechtigkeit" (S. 33) aufrecht zu erhalten und zu verbessern sah Schmoller als Ziel seiner Tätigkei, zu der auch sein früher Beitrag zur allgemeinen Steuerlehre zählte. Die Entwicklung der preußischen ESt hat einen anderen Weg eingeschlagen, der bis heute bestimmend blieb. Steuerrechtswissenschaft gilt nach vorherrschender Auffassung als "Steuergerechtigkeitswissenschaft", s. Vogel, K. (1993), Juristen-Zeitung, 48. Jg., S. 1121. Gesucht wird ein System sachgerechter steuerlicher Prinzipien, aus dem sich "gerechte" Steuern herleiten lassen, s. Tipke, K. (1993), Steuerrechtsordnung, S. 470 u. a.; s. a. Kirchhof (1985), S. 323. Kirchhof glaubt, die Gerechtigkeitsforderungen an das System des EStG sogar bis hin zu sehr konkreten Einzelheiten aus den in den Art. 3 und 14 GG festgeschriebenen Grundrechten herleiten zu kōnnen, S. 323; ders. (1988), S. F30; s. a. Tipke, K. (1988), Fundamentalrevision ..., S. 2091.

11 Z Zu der wichtigen Rolle, die der Statistik im Lehrgebăude Schmollers zukann s. Hansen, R. (1993), S. 117, S. 140. Schmollers Interessen entsprachen dem, was heute als Rechtstatsachenforschung bezeichnet wird. Zur Bedeutung der Einkommensverteilung s. Lindenlaub, D. (1969), S. 274.

119 Im Jahr 1961 konnte die verfolgte Steuerpolitik noch die Zustimmung der Gewerkschaften erhalten, weil sie als "Mittel einer Politik des Einkommens- und Vermōgensausgleichs" beurteilt wurde, s. Pehl, G. (1962), S. 79, S. 85. Der stellvertretende Vorsitzende des Deutschen Gewerkschaftsbundes schrieb ein anerkennendes Vorwort. 
wendigkeiten haben diese Grundeinstellung in der Öffentlichkeit nicht neu entstehen lassen.

Seit Mitte der 80er Jahre wird nun zunehmend das ganze System des EStG als ein angebliches "Chaos" oder ein "prinzipienloses Konglomerat" infrage gestellt. $^{120}$

Diese abwertende Terminologie stammt von einem Steuerjuristen aus den 70er Jahren, als die wirtschaftlichen Erfordernisse zu Ausnahmeregelungen infolge der erreichten Wohlstandsmehrung langsam zuricktraten.

An dieser grundlegenden Kritik an dem geltenden EStG beteiligen sich seither Steuerjuristen ebenso, wie Finanzwissenschaftler und Nationalökonomen und - diesen folgend - eine breite Öffentlichkeit.

Bezüglich der vorgebrachten Fordenungen an ein neues Einkommensteuersystem herrscht heute im wesentlichen Einverständnis bei fast allen Wissenschaftlem mit einer breiten Öffentlichkeit, die sich nur in wenigen Formulierungen und Nuancen unterscheidet:

Es soll endlich ein Gerechtigkeitssystem werden, zugleich soll es die Besteuerung der Bürger nach der individuellen Leistungsfähigkeit garantieren, dabei Beitrảge zum Wirtschaftswachstum belohnen, einer marktwirtschaftlichen Ordnung der Wirtschaft entsprechen, sich rechtsdogmatisch in die hierarchisch geordnete, von der Verfassung überwölbte Rechtsordnung widerspruchsfrei einpassen und nicht zuletzt einfach und für jedermann verständlich sein und obendrein niedrige Steuerzugriffe enthalten.

Das sind viele hehre Gesichtspunkte, die ohne Berücksichtigung ursprünglicher quasigesetzlicher Zusammenhänge der sozialen Realităt und die konkreten ausgelösten Rechtsfolgen Forderungen ohne Chancen zur Realisierung bleiben müssen.

So fragt sich vorab einmal, ob die Konsequenzen der einzelnen Forderungen, zu Normen umgesetzt, überhaupt miteinander ohne entwertende Abstriche kompatibel sind.

Denn hinter den Begriffen des Forderungskatalogs verbergen sich letztlich sehr unterschiedliche konkrete, zum Teil widersprüchliche, sich gegenseitig ausschließende Inhalte.

Nur dadurch wird eine Einigung auf die Prinzipien überhaupt erst ermogglicht. Heftige Streitigkeiten über Inhalt und Rangfolge der Prinzipien entpup-

${ }^{120}$ Tipke, K. (1971), S. 2. 
pen sich dabei zumeist als Erörterung von Definitionen, die beanspruchen, Erkenntnisse über Begriffe, denen Realitätsrang beigelegt wird, zu vermitteln.

Inhaltliche Übereinstimmung in bezug auf ein konkretes, allgernein überzeugendes Regelungssystem sind vorerst jedenfalls nicht erkennbar.

Die Öffentlichkeit zieht aus der vorherrschenden globalen systematischen Kritik an dem geltenden Steuersystem inzwischen Konsequenzen, die sich in dem stark anwachsenden Steuerwiderstand niederschlagen und steuerberatenden Blerufsträgern die übernommenen Mitwirkungspflichten und den Mitarbeitern in der Finanzverwaltung die gesetzliche Veranlagungstätigkeit übermäßig erschweren. $^{121}$

Derzeit werden in den USA erörterte neuere Reformvorschläge und ein konkreter deutscher Reformentwurf als eine Art Patentlösung der als Misere beurteilten Situation herausgestellt: sie sehen eine Beschränkung des steuerpflichtigen Einkommens auf den konsumierten Teil des steuerbaren Einkommens vor. ${ }^{122}$ Auf diese Weise kőnnte, so glauben Vertreter dieser Neuregelung, auf die lästigen und von Steuerjuristen als "steuergesetzliches Wirtschaftsrecht" beklagten, als nicht recht integrierbare Fremdkörper beurteilten nichtiskalischen Einschübe in das EStG-Normengefüge gänzlich verzichtet werden, ohne die inzwischen als unerläßlich erkannte empfindliche Investitionstätigkeit abzuwürgen. Konsumverzicht, Ersparnisse und deren Investition sollen nach diesem Konzept steuerbefreit sein und erst später bei Verbrauch durch den Verfügungsberechtigten der früher investierten Mittel der Besteuerung unterworfen werden. Die Problemlossungen würden auf diese Weise verlagert.

Mag dieser Vorschlag im Denkmodell auch zu einer Erleichterung rentabler Investitionen bei vorhandenen Engpässen führen, was sich in der Realität noch als praktikabel erweisen müßte, so wäre mit dieser Regelung grundsätzlich der endgültige Verzicht auf eine Besteuerung des Bürgers nach seiner Leistungsfahigkeit verbunden. Die investierte Vermögensmehrung wäre fortan von Gesetzes wegen steuerbefreit.

Auf diese Weise wären jedenfalls die Vielzahl der Steuervergünstigungen, die die Ermittlungsvorschriften des gegenwärtigen EStG durchwuchern, jedoch noch erkennbar nur zeitlich limitierten Ausnahmecharakter haben, im Gesetz zu einer leicht faßbaren Norm erhoben und somit endgültig zementiert.

Zwar mögen derartige Entwürfe den ästhetischen und rechtsdogmatischen Ansprüchen von Steuerjuristen entgegenkommen; mit den Zielvorstellungen

${ }^{121}$ Metzger, U./Weingarten, J. (1989), S. 85; Weingarten, J. (1993), S. 356 u. a.

${ }^{122}$ Rose, M. (1989), S. 191; ders. (1990), S. 88; ders. (1990), Proceedings ...; Lang, J. (1992). 
der sozialen Marktwirtschaft lassen sich diese Modelle der Einkommensbesteuerung wegen der erkennbaren Nebenwirkungen nicht vereinbaren. Darauf wird noch einzugehen sein. ${ }^{123}$

Letztlich ist es eine kleine, oftmals meinungsbildende Minderheit, die die Voraussetzingen für gewăhrte Vermögensbildungen aus ersparten Einkommensteuern ständig erfullt. Dabei handelt es sich heute zumeist um Steuerbürger aus den alten Bundesländern, deren Vermögensmehrung durch die Vielzahl von Sanierungsobjekten in den neuen Ländern steuerlich noch zusătzlich erleichtert wird. Das Ost-West-Gefalle wird auf diese Weise obendrein vorerst noch verstărkt.

Problematische soziale Begleiterscheinungen der mehrere Jahrzehnte hindurch fü̇ das Gemeinwesen als Ganzes wohlstandsmehrend gewăhrten Steuervergünstigungen konnten im Zeitablauf nicht ausbleiben. Sie zeigen sich heute bereits in großen Differenzen in der Einkommens- und Vermögensverteilung.

Verschiedene Institutionen warnen neuerdings bereits vor den erkennbaren Folgen zunehmender Notfaile von Bürgern und verweisen auf die anwachsende Zahl völlig überschuldeter Haushalte, die auf $4,2 \%$ des Gesamtbestands gestiegen ist. ${ }^{124}$ Der Wohltätigkeit verpflichtete gemeinnützige Verbände berichten neuerdings von alarmierender Steigerung echter Armut. Sie betonen die Gefahr zunehmender Belastungen des Mittelstandes, der schwerpunktmăBig die zusätzlichen Bürden der Solidargemeinschaft durch eine problematische Lastenverteilung zu tragen hat. Sie warnen vor den zunehmenden Notlagen, die diese an den Rand des Absturzes in die Armut bringt. Die steuerliche Förderung von Neugründungen vermag demgegenüber heute oft als verantwortungslos zu gelten. ${ }^{125}$

Der Trend eines Auseinanderdriftens der Einkommens- und Vermögensverteilung war nach Schmoller ein Maßstab für das Erfordernis, die bestehenden. Institutionen in geeigneter Weise unter Zusammenfassung volkswirtschaftilicher, finanzwissenschaftlicher, rechtswissenschaftlicher und richt zuleizt

123 Falthauser, K., Statt des Einkommens đen Konsum besteuern? in: Die Welt v. 29.3.95, S. 7 (Forum). Falthauser ist. Staatssekretăr im Bundesfinanzministerium; s. a. ders., Radikale Reform des. Steuersystems, in: Focus v. 27.3.95, S. 86; s. a. Kapitel MI V, Nr. 17.

124 S. Deutscher Sparkassen- und Giroverband: Zur Oberschuldung privater Haushalte. Eine Bestandsaufnahme v. 15.3.95, S. 3; hierzu auch Ortlieb, H. D. (1974), S. 126 u. a.

125 S. Hanesch, W. (1994), S. 32, S. 268; Döring, D./Hanesch, W./Huster, E. (1990), S. 113; Student, D./Böhmer, R. (1994), Aufsatzreihe "Neue Armut", in: Wirtschaftswoche Nr. 13 bis Nr. 16. Student weist in vielen Beispielen darauf hin, daB der soziale Abstieg den Mittelstand erreicht habe und der erzwungene Ausweg in die Selbständigkeit keine Dauerlösung biete, s. Wirtschaftswoche Nr. 13 v. 25.3 .94$, S. 32 , Nr. 14 v. 1.4.94, S. 34 , Nr. 16 v. 15.4 .94 , S. 35 , v. 8.7 .94$, S. 21. 
soziologischer Erkenntnisse zu reformieren, um die verlorene soziale Balance in der Gesellschaft wieder herzustellen und aufrecht zu erhalten. Hierauf werden wir noch zurückkommen.

Für einen revolutionăren Systemwechsel, von dem offenbar einige Steuerjuristen und Finanzwissenschaftler trăumen, fehlt derzeit die Voraussetzung einer allgemein uberzeugenden alternativen Besteuerungsidee. Unzufriedenheit mit und Kritik an dem bestehenden System, mag sie sachlich noch so berechtigt sein, vermag die erkennbaren Mänge! noch nicht zu ersetzen.

Ein völliger Systemwechsel würde im übrigen derzeit angesichts des noch lange nicht beseitigten Investitionsbedarfs in den neuen Bundesländern unübersehbare Auswirkungen auf die erforderliche Planungssicherheit für die weitere Entwicklung haben. ${ }^{126}$

Es erscheint daher geboten, das bestehende System vorerst fortlaufend vermittels stăndiger Durchforstung von überlebten Bestandteilen zu bereinigen. Das kann durch die Kenntnis der Entstehungsgeschichte des Normengefüges und der jeweiligen Folgewirkungen gefordert werden.

Der steuerpolitische Einsatz des EStG zur Unterstützung der Wirtschaftspolitik ist, wie wir noch an einzelnen Beispielen sehen werden, jedenfalls ein sehr wichtiges, weil wirksames Steuerungsmittel geworden, dessen Verzicht vorerst nur schrittweise verantwortet werden kann.

Ihre Verwendbarkeit zu wirtschaftspolitischen Zwecken bei Vermeidung oder Einschränkung unerwünschter Nebenwirkungen könnte durch geeigmete Untersuchungen gesteigert werden. Weder eine anzustrebende einseitige Verbannung aus dem Arsenal wirtschaftspolitischer Instrumente, noch ein leichtfertiger, aber bequemer Einsatz von Steuervergünstigungen des EStG vermag letztlich heute nach den gemachten Erfahrungen zu befriedigen.

$\mathrm{Da}$ der Einsatz von Steuervergünstigungen ausuferte, ist offensichtlich auch eine Folge unzureichender Aufhellung der sozialen Verursachungszusammenhänge.

${ }^{126}$ Falthauser, K, wie Anm. 123. 


\title{
F. Die kurzgefaßte Entstehungsgeschichte des Einkommensteuerrechts in Deutschland
}

\section{Der geistesgeschichtliche Hintergrund der modernen Einkommensteuergesetze}

\author{
1. Die wissenschaftstheoretischen Auseinandersetzungen \\ im 19. Jahrhundert und deren Bedeutung für die Nationalökonomie \\ und die allgemeine Steuerlehre
}

Wie wir gesehen haben, ist die Systematik des sächsischen EStG 1874/78 aus der im Oktober 1862 niedergeschriebenen Besteuerungsidee Gustav Schmollers hervorgegangen.

Die innere Organisation des preußischen EStG 1891, die den wichtigsten Teil der Miquelschen Steuerreform ausmachte und der das Ergebnis einer über zehnjährigen praktischen Erfahrung mit dem sächsischen EStG 1874/78 vorherging, wurde bereits 1882 in Ausschußverhandlungen des preußischen Landtags nach einem anderen Strickmuster gefertigt, das der wissenschaftlichen Grundansicht von Adolph Wagner entsprach.

Man mag sich fragen: warum ist es zu so divergierenden Gestaltungen zwischen Preußen und Sachsen gekommen? Dabei stellt sich zusătzlich die Frage, warum diese unterschiedlichen Baupläne trotz der ungewöhnlich weitgehenden Konsequenzen bis heute der historischen Berichterstattung verborgen bleiben konnten.

Die Beantwortung der ersten Frage führt uns zu dem Umstand, daß Gustav Schmoller als Heranwachsender den Umbruch der wissenschaftstheoretischen Grundauffassungen zur Jahrhundertmitte unmittelbar im Elternhaus miterlebte. ${ }^{1}$ Er wollte dann ebenso spăter auch in der Nationalökonomie die dort noch immer vorherrschenden methodologischen, an überholten naturrechtlichen Überzeugungen von einer normativen Wirklichkeit absoluten Charakters geprägten dogmatischen Lehren durch eine neuartige, kritische, an der Vorge-

Hierzu: Hansen, R. (1993), S. 111. Die dort skizzierten Zusammenhänge und die Fundstellen sollten zur Ergänzung der Ausführungen herangezogen werden; s. a.: Hansen, R. (1990), S. 1 und ders. (1968), S. 137; s. a. Lindenlaub, D. (1967), S. 110. 
hensweise der erfolgreichen Naturwissenschaften orientierte, empirisch ausgerichtete Wissenschaftsauffassung ersetzt wissen.

Mit der Ubernahme der Herausgeberschaft suchte Schmoller nach seinem Einfuhrungsaufsatz das "Jahrbuch für Gesetzgebung, Verwaltung und Volkswirtschaft im Deutschen Reich" 1881 einer Aufklărungstätigkeit mit dieser Zielrichtung zu widmen. ${ }^{2}$

Nach seinen einführenden Worten glaubte Schmoller insbesondere bei der Finanzwissenschaft eine Neuorientierung unerläßlich: "Auf diesen Gebieten herrscht noch ziemlich unbeschränkt das metaphysische Zeitalter", so führte er aus. $^{3}$

Noch deutlicher wurde Schmoller sodann im năchsten Band von 1882 des von ihm herausgegebenen "Jahrbuchs" in einer Rezension des "Handbuches der politischen Ökonomie", das von Schönberg besorgt worden war und zu dem sein Berliner Kollege Adolph Wagner, der bereits als führender Finanzwissenschaftler galt, vier Beiträge geliefert hatte. ${ }^{4}$

Schmoller sah in diesem "Handbuch" einen Rückschritt in Richtung auf die rein begrifflich ausgerichtete überholte alte "dogmatische Nationalökonomie". Das "Rau'sche System" der Nationalökonomie müsse wegen der unbrauchbaren dogmatischen Orientierung einem völligen Neuanfang Platz machen, so führte er aus. ${ }^{5}$

${ }^{2}$ Schmoller, G. (1881), Über Zwecke und Ziele des Jahrbuchs vom Herausgeber, in: Schm. Jb. NF, 5. Jg., S. 1. Das "Jahrbuch" sollte die "schwebenden gesetzgeberischen Aufgaben" mit "überwiegend praktischer Tendenz" auf wissenschaftlicher Grundlage so behandeln, da $B$ weite Leserkreise erreicht werden. Auf diese Weise sollte es meinungsbildende Wirkungen entfalten. Daneben sollte ergânzend die von Schmoller desgleichen bereits 1878 obernommene Schriftenreihe der "staats- und sozialwissenschaftlichen Forschungen" durch streng wissenschaftliche Bearbeitung abgegrenzter überschaubarer Bereiche tiefergehenden, weniger publikumswirksamen Anspruchen genügen (S. 2)

3 Schmoller, G. (1881), Uber Zwecke .... S. 7. Schmoller sah die gesamten Staatswissenschaften nach dem von Auguste Comte unterstellten "Dreistadiengesetz" noch tief verstrickt in eine fruhe Entwicklungsepoche, die systematisch von überholten metaphysischen Erklärungen des realen Geschehens ausgeht (S. 3). Schmoller glaubte, daß nur langsam und auf einzelne abgegrenzte Gebiete, begrenzt durch "Detailforschungen", zunehmend ein Öbergang zu dem Ziel einer "exakten Wissenschaft" möglich sei. Der Weg hierzu, glaubte er, führe äber "strenge wissenschaftliche Forschung, die freilich zunalchst nicht mehr ist, als Materialsammlung" (S. 7). "Für die Finanzwissenschaft fehlt eigentlich noch der erste Beginn einer exakten Behandlung", so glaubte er ( $\mathrm{S}$. 7). Von einem allmăhlichen Wandel zeigte Schmoller sich uberzeugt. Zu Schmollers Forschungsziel s. Hansen, R. (1993), S. 173, Anm. 78; s. a. Brief Schmollers an Brentano v. 2.11.1878, in: Archiv für Kulturgeschichte, XXX. Bd. 1941, S. 206. Wagner beklagte sich gegenuber Stieda bereits 1877 dahingehend, daB Schmoller einen "Methodenstreit" provoziere, s. Schreiben an Stieda v. 13.4.1877, in: Rubner. H. (1978), S. 144.

4 Handbuch der politischen Ôkonomie (1882), Hrsg. Schönberg, G.; dieses Werk erschien in vier Auflagen, die letzte in Jahr 1897.

${ }^{3}$ Schmoller, G. (1882), Rezension in Schm. J6., NF, 6. Jg., S. 1379, hier S. 1380 - 1383. Wagners lingster Beitrag im 2. Bd. v. 123 Seiten hatte die direkten Steuern, insbes. Einkornmen- und Vermö- 
Nun hatte gerade zu dieser Zeit Wagner die umfangreichen Rau'schen Lehrbücher für Nationalökonomie und zur. Finanzwissenșchaft überaibeitet und in zwei verbesserten Neuauflagen zu einem allgemein benutzten Sammelwerk gemacht ${ }^{6}$ Obendrein war Wagner seit 1882 als allgemein anerkannter Fachmann und Abgeordneter des preußischen Landtags Mitglied der Kommission für die von dem Minister Scholz in Gang gesetzte preußische Einkommensteuerreform?

Dieser Ausschuß einigte sich um 1883 in einer Resolution auf die systematischen Grundlagen, die dann erst sieben Jahre spăter in das preußische EStG 1891 übernommen wurden. In den Verhandlungen des Landtags fuhrte Wagner aus, daß Teile der Resolution von ihm selbst formuliert wurden. ${ }^{8}$

Zur Verteidigung seiner Reputation wehrte sich Wagner in einer "Antikritik" 1883 gegen Schmollers Abwertung der Rau'schen Nationalokkonomie als einer "überlebten systematischen Dogmatik", deren Inhalt aus überholten begrifflichen Ausfuhrungen und einer rein sprachlichen Durchdringung sozialer Phănomene ohne Erkenntniswert bestehe. ${ }^{9}$ Er bekannte sich selbst zu der Methode, die soziale Realităt durch Definitionen zu erklären.

In einer weiteren Rezension einer Schrift von Cohn legte er dann 1886 in offener Gegnerschaft zu Schmoller ein kurzgefaßtes wissenschaftstheoretisches Bekenntnis zu seiner "systematischen Nationalökonomie" ab. ${ }^{10}$ Die von

gensteuer, behandelt. Der Aufsatz erschien noch in der 4. Aufl. von 1897, nunmehr in Bd. 3 in gleicher Weise auf 217 Seiten durch Ergänzungen ausgeweitet.

${ }^{6}$ Wagner, A. (1876), Lehrbuch der politischen Oekonomie von Karl-Heinrich Rau, vollstündig neu bearbeitet von Dr. Adolph Wagner und Dr. Erwin Nasse, Leipzig und Heidelberg. Allgemeine oder theoretische Volkswirthschaftslehre, mit Benutzung von Rau's Grundsatzen der Volkswirhschaftslehre von Adolph Wagner, zugleich 9. Ausgabe der Rau'schen Volkswirthschaftsleture. Erster Theil, Grundlegung Leipzig und Heidelberg 1876. Es erfolgte sodann eine zweite, vielfach verbesserte und stark vermehrte Ausgabe mit leicht verändertem Titel, ebenso als "Grundlegung" bezeichnet, im Jahr 1879. Im Jahr 1880 erschien dann: Wagner, A, Finanzwissenschaft (zugleich als sechste bzw. siebente Ausgabe von Rau's Finanzwissenschaft), Zweiter Theil, Gebūhren und allgemeine Steuerlehre, Leipzig und Heidelberg.

7 Hierzu Anlagen zu den stenographischen Berichten uber die Verhandlungen des Hauses der Abgeordneten wăhrend der 2. Session der 15. Legislatur-Periode 1883/4, Vierter Bd, Aktenstūck Nr. 290, S. 2499, Berlin 1884, hierzu auch: Scholz, A. (1922), S. 34; s. a. Mauz, F. (1935), S. 112, hier S. 123.

- Hierzi: Preußischer Landtag, Haus der Abgeordneten, Verhandlungen der 27. Sitzung vom 17.1.1884, S. 747, hier S. 777; s. a. Grabower, R. (1962), S. 459; Geiger, W. (1934), S. 22; Herzfeld, H. (1938), Bd. 2, S. 227.

'Wagner, A. (1883), Rezension (Antikritik), in: Zeitschrift für die gesamte Staatswissenschaft, 39. Bd., S. 259, insbes. S. 263, S. 266, S. 271.

10 Wagner, A. (1886), Rezension: "Systematische Nationaloekonomie", in: Jahrbucher für Nationaloekonomie und Statistik, NF., 12. Bd, S. 197, S. 206, S. 245 u. a. Das hier von Wagner formulierte wissenschaftstheoretische Bekenntnis ist dann bis $1892 \mathrm{zu}$ einem ausfuhrlichen methodologischen Vorspann der Neuauflage der "Grundlegung" als Bestandteil seiner allgemeinen Volkswirtschaftslehre integriert worden. Wagner sprach nun von "Grundlagen" der Volkswirtschaft, s. (1892), Titelseite. Zur 
Schmoller geforderte "Verwandlung der sogenannten politischen Ökonomie in Sozialwissenschaft" lehnte Wagner darin grundsätzlich ab. " Er bekannte sich zu der alten "abstrakt dogmatischen" Nationalökonomie, wobei er seine Übereinstimmung mit der 1883 profiliert vorgetragenen traditionellen Richtung Carl Mengers und deren sogenannter "deduktiver Methode" bekundete.

Tatsăchlich gehört diese Auseinandersetzung zu den Vorgängen, die als "alterer Methodenstreit" in die Geschichte der Disziplin eingegangen ist. Der Schlagabtausch der beiden Berliner Kollegen erfolgte aber indirekt in Rezensionen durch vorsichtig eingestreute Einschübe. Daß letztlich die Verankenung der Nationalökonomie und insbesondere der Finanzwissenschaft in einer metaphysisch-dogmatischen Wissenschaftsauffassung, die den Ansprüchen Schmollers an eine wissenschaftliche Erklärung sozialer Zusammenhảnge nicht genügte, den offenen Streit ausiōste und daß dies große praktische Konsequenzen mit sich bringen mußte, blieb bis heute verborgen. ${ }^{13}$

selben Zeit erubeitete Schmoller einen Methodenaufsatz als wissenschaftstheoretisches Bekenntnis. Hierbei handelte es sich um den lußerlichen Abschluß des sogenannten Methođenstreits; s. Schmoller, G. (1894), Volkswirthschaft ..., S. 527. Schmoller und Wagner respektierten fortan ihre Standpunkte als unvereinbar, s. Schmoller, G. (1908), Reden ..., S. 2, S. 11.

1 Wagner, A. (1886), in: Jahrbücher fur Nationalockonomie und Statistik, N. F., 12. Bd., S. 198, insbes. S. 245 u. a.

12 Wagner, A (1886), Rezension: "Systematische Nationaloekonomie", in: Jahrbücher für Nationaloekonomie und Statistik, N. F., 12. Bd., S. 237. S. 245 u. a.; auch: Wagner, A. (1892), Grundlagen ..., S. VIII, S. 143, S. 166, S. 188 u. a.; auch: Lindenlaub, D. (1967), S. 111.

${ }^{13}$ Hohe Begabung. Gelehrtheit und vor allem die Fahigkeit zu publikumswirksamen Formulienungen des Berliner Finanzwissenschaftlers waren nach Berichten von Zeitgenossen gepaart mit überstejgerter Selbsteinschätzung, mimosenha.fter Empfindlichkeit und zägellosem Temperament, s. Brentano, L (1931), S. 71: Brief Schmollers an Brentano v. 21.4.1878, in: Goetz, W. (194I), S. 188, S. 190; s. a. Rubner, H. (1978), S. 428. Daß Ausfuhrungen Schmollers und seines Mitarbeiters Hasbach in zahllosen Rezensionen Wagners seherische Fähigkeiten respektlos in Frage stellien und an seiner wissenschaftlichen Autorität kratzten, konnte niemand ôbersehen. Ohne Erwiderung hätte er uni seine wissenschaftliche Reputation besorgt sein müssen. Hasbach und Schnnoller streuten in viele Rezensionen, gegen Wagner gerichtet, abfallige, dessen Lehren infrage stellende Bemerkungen ein. Gemeinsamer Kern der Wendungen wir, dafi universelle Hypothesen, sofern sie überhaupt sachlich gehaitvolle Aussagen darstellten, bezüglich ihrer Wahrheit einer Bestätigung durch Experiment oder ersatzweise vergleichender historischer Forschung bedütten, um als sogenannte Gesetze der empirischen Realităt anerkannt zu werden. Der Verweis auf die Autorităt einer Person allein so argwōhnten viele Bemerkungen, kōnne diese Anforderung nicht arsetzen. Inn Gegensatz zur "empirischen Methode" Schmollers beruhten die kritisierten Gesetze der "abstrakten" oder "dogmatischen Methode", auf Wagners Autoritat als Wissenschafter, auf die er sich gern berief, s. hierzu etwa: \$chm. Jb. (1885), S. 553; Schm. Jb. (1886), S. 991; Schm. Jb. (1887), S. 587, S. 593; Schm. Jb. (1888), S. 731; Schm. Jb. (1890), S. 709; Schm. Jb. (1895), S. 661; Schm. Jb. (1895), S. 783 u. a. Die vorsichtige, unmittelbar nach dessen Berufung auf den vakant gewordenen Lehrstuhl Helds durch Brief an Schmoller v. 23.5.1881 gerichtete Bitte um Zuruckhaltung bei seiner Kritik respektierte Schmoller offenbar durch gewundene Formulierungen, die die Differenzen noch stärker hervortreten lieBen, s. Rubner, H. (1978), S. 198. Kar! Diehl berichtete, daB die Studierenden der Berliner Universităt sich um 1882 in zwei Lager spalteten, die "Schmollerianer und die Wagnerianer", s. Diehl, K. (1924), S. 61. Anders als Schmoller mit seiner nuchternen Vortragsweise vermochte Wagner in den Studierenden Emotionen zu wecken, sie mitzureiBen; S Grabower, R. (1959), Sp. 565; Stucken, R. (1961), in: HdSW, 11. Bd., S. 470; Rubner, H. 
Bereits 1875 hatte der Wiener Nationalökonom Carl Menger die grundlegende Bedeutung der Rau'schen Lehrbücher, auf denen er seine Habilitationsschrift von 1871 aufbaute, herausgestellt. Er hatte dabei bedauert, daß durch die Neuauflagen der Sammlung und insbesondere der "Grundsătze der Finanzwissenschaft" durch Adolph Wagner diese eine Auslegung in Richtung auf die Reformbestrebungen des Vereins für Socialpolitik erhielten. Dieser Richtungswandel paßte nicht mehr in das Gesamtkonzept seiner Ausbildung.

Im Jahr 1883 rezensierte dann Schmoller eine methodologische Abhandlung dieses Wiener Nationalokonomen, der die von ihm als tiberholt beurteilte traditionelle dogmatische Wissenschaftsauffassung besonders nachhaltig als richtig rechtfertigte und dem angestrebten Richtungswandel insgesamt entschieden entgegentrat. ${ }^{14}$ Der Autor wehrte sich gegen Schmoller in ausfallender Weise. Menger war jedoch nur ein Ersatzgegner, der - anders als Wagner nicht durch Veröffentlichungen von unmittelbarer sozialer Relevanz hervorgetreten war. Die Ausführungen Wagners führten dagegen schon wegen ihrer konkreten aktuellen sozialen Konsequenzen zur Zeit großer Reformvorhaben zu vielen ăhnlichen weiteren Kritiken Schmollers und seines Mitarbeiters Hasbach, die beide in Rezensionen zumeist finanzwissenschaftliche Beiträge Wagners kritisierten und deren rein begriffliche Ausrichtung, die in unterstellten Strukturen verborgenen Wertungen und die dogmatische Rechtfertigung derselben bemängelten. ${ }^{15}$

Dabei ist zu berücksichtigen, daß zu dieser Zeit bis 1916 noch keine separaten steuerrechtlichen Vorlesungen an Universitäten eingerichtet waren. Diese

(1978), S. 1, S. 430; Pausch, A. (1992), S. 30; Herzfeld, H. (1938), Bd. 2, S. 212; Simon, H., (1914), in: Die Zukunf, Bd. 86, S. 122; s. a. Lindenlaub, D. (1967), S. 110; Hansen, R. (1968), S. 138; ders. (1990), S. 24, S. 59; ders. (1993), S. 111; s. a. Pesch, H. (1924), S. 197.

${ }^{14}$ S. Menger, C. (1875), Besprechung der Neuauflage von Rau's Lehrbuch, in: Wiener Abendpost, Beilage zur Wiener Zeitung v. 23.11.1875; s. Schmoller, G. (1883), Rezension, in: Schm. Jb., Bd. 7, S. 975. Eine Diskussion oder gar einen Streit zwischen Carl Menger und Gustav Schmoller hat es nie gegeben. Schmoller hielt "das ganze methedologische Fundament" der Richtung Mengers "für heute nicht mehr berechtigt", s. hierzu im einzelnen; Hansen, R. (1968), \$. 138; zum Hintergrund s. Hansen, R. (1993), S. 11!. Menger war in seinem Studium mit einer Wissenschaftsauffassung ausgebildet worden, die mit den Thunschen Hochschulreformen in Osterreich einsetzte und gegen die sich Schmollers Ablehnung richtete, s. Hansen, R. (1993), S. 122.

15 Menger hatte bis 1883 nur eine einzige Veroffentlichung in Buchform aufzuweisen, an der der Rezensent J. Conrad 1872 bemăngelte, daß der Titel vorgebe, ein Lehrbuch der allgemeinen Volkswirtschaft zu sein, "whlhrend er doch nur die mechanische Aneinanderreihung von Studien aber die. Begriffe Gut, Werth, Tausch, Preis, Geld ist". Eir biete keine sachlichen Erkenntnisse, s. Conrad, J. (1872), Rezension, in: Jahrbücher für Nationalôkonomie und Statistik, 18. Bd. S. 343. Diese Kritik. wurde jedoch dem Unstand nicht gerecht, daB Mengers Ausfuhrungen als Theorien zu verstehen waren; sie erfullten eine normativ-explikative Doppelfunktion. Die von einer vergleichbaren Wissenschaftsauffassung mit anderen Inhalten ausgehenden Lehren Wagners muBten dagegen im Zusammenhang mit den anstehenden sozialen Reformen der Zeit nach 1880 in Preußen von erheblicher praktischer Relevanz werden, s. Hansen, R. (1968), S. 162; ders. (1993), S. 122. 
Funktion von zunehmender Dringlichkeit erfüllten bis dahin zugleich Nationalökonomen in ihrer Rolle als Finanzwissenschaftler. ${ }^{16}$

Im übrigen wandte Schmoller sich in vielen Rezensionen ebenso gegen andere ideologische Lehrmeinungen, Strömungen und politische Auffassungen, die etwa, wie der Sozialdarwinismus, insofern von sozialer Bedeutung werden konnten, als der Handlungsspielraum der Gesetzgebung durch sie unzweckmäßig eingeschränkt zu werden vermochte. Stets suchte er dabei zwischen empirisch bestätigten Naturgesetzen und dogmatisch vertretenen Glaubensgewißheiten, "welche die Naturforscher wie Historiker aufstellen", zu scheiden. $^{1 ?}$

Wie Meisel spăter festhielt, blieb die Finanzwissenschaft für Schmoller stăndig von besonderem Interesse. ${ }^{18}$ Die Einkommens- und Vermőgensverteilung beanspruchte nămlich seine stăndige Aufmerksamkeit. Dies wird durch eine kontinuierliche Veröftentlichungstătigkeit dokumentiert.

Wie ein roter Faden zieht sich durch die Beiträge Schmollers als leitendes Erkenntnisinteresse die Frage nach der zweckmäßigen Gestaltung von Institutionen zum Schutz der Schwachen und zur Aufrechterhaltung einer "sozialen Balance" zwischen "den oberen und den unteren Klassen". Auch das Steuerrecht war hier einbezogen.

Im Jahr 1874 hatte Schmoller in einem weit beachteten längeren, in den "Jahrbüchern für Nationalökonomie und Statistik" veröffentlichten sogenannten "offenen Sendschreiben" an Heinrich von Treitschke dessen naturrechtlich-dogmatische Rechtfertigung konservativer politischer Leitbilder - von diesem als natürliche Ordnung oder "Naturordnung" bezeichnet - als willkürliche und wissenschaftlich unverbindliche Voreingenommenheiten zurückgewiesen. ${ }^{19}$ Dabei hatte er beklagt, daß dieserlei Lehren geeignet seien, jeden Freiraum für Problemlösungen zur Förderung sozialen Fortschritts abzuwürgen.

Nun wandte sich Schmoller in vergleichbarer, wenn auch vorsichtiger Weise gegen die als dogmatische Erkenntnisse unterstellten fatalistischen Eingebungen Wagners. Diese rechtfertigten, wenn auch mit anderer inhaltlicher Zielrichtung, die Ausgestaltung von Rechtsinstitutionen nach begrifflich erläuterten, als dogmatische Erkenntnisse ausgegebenen einseitigen Mustern ebenso

\footnotetext{
${ }^{16}$ Waldecker, L. (1917), S. 175; Wagners "GrundriB" (1897) diente diesem Zweck.

17 Schmoller, G. (1895), Rezension, in: Schm. Jb., S. 1044; s. a. S. 1039; ders. (1896), S. 303 u. a.

${ }^{18}$ Meisel, F. (1918), S. 358.

19 Schmoller, G. (1874): "Offenes Sendschreiben", in Jahrb. f. Nationalokkonomie u. Statistik, 23.
} Bd., S. 225, hier S. 240. S. 256, S. 279. Fü die Zeit nach 1910 vgl. "Widmungen", in: Liebmann, O. (1910), S. 194, S. 196. 
als natürlich vorgegeben. Sie engten damit für Schmoller den Handlungsspielraum zur Lősung anstehender Probleme willkürlich ein.

"Es gibt keine rein natürliche Einkommensverteilung", so lautete Schmollers Feststellung, die auch Wagners Grundvorstellungen zuwiderlaufen mußte. ${ }^{20}$

Im übrigen verhielt es sich im sogenannten spăteren Werturteilsstreit in der Nationalökonomie ăhnlich. Auch für die hier angesprochenen Vorgănge kam Fragen um die Besteuerung unter anderen Umstănden eine auslösende Funktion zu. Auch in diesem Fall setzten sich die Gegner Schmollers voll durch ${ }^{21}$

Schmoller sah in Institutionen, zu denen er auch das Rechtsgefüge des Einkommensteuerrechts zăhlte, das wichtigste Insirument zu einer aktiven Gestaltung der "Lebensordnung" in Richtung auf den von der Mehrheit der Bürger angesichts einer durch ungestüme Industrialisierungen entstandenen "socialen Frage" erwünschten sozialen Fortschritt. ${ }^{22}$

Möglichkeiten zur Versöhnung der Klassengegensătze durch stăndige Verbesserung der Institutionen auf Grundlage der durch begleitende Erfahrungen kontinuierlich vermehrten Kenntnisse über relevante Wirkungszusammenhänge der sozialen Realität zu erforschen, sah er als wichtige Aufgabenstellung von Nationalökonomie und Finanzwissenschaften.

"Die Form des Rechts ist das Mittel, die Gerechtigkeit aber der Zweck des Rechts", so umschrieb er seine aktivistische Grundhaltung und seine Offenheit für soziale Problemlösungen 1881 in seinem ersten programmatischen Aufsatz des "Jahrbuchs", den er spăter als einen seiner wichtigsten Beiträge bezeichnete. ${ }^{23}$

20 S. Anm. 19, S. 263, S. 257, S. 264.

21 S. hierzu Kapitel M, Abschn. V, Nr. 8; s. a. Hansen, R. (1968), S. 156; ders, (1993), S. 154. Lindenlaub, D. (1967), S. 436.

22. Die Kritik Schmollers an den Lehren der klassischen Nationalokonomie zentrierte um die Feststellung, das die Bedeutung von Rechtsinstitutionen verkannt werúe. Das Regelstudium der Nationalökonomie hatte ihn nach seiner Ausbildung im Kameralamt wenig interessiert. An Stelle dessen bemūhte er sich intensiv um Philosophie, Naturwissenschaften, Jurispnudenz und Geschichte, s. Schmoller, G. (1908), Reden ..., S. 47; ders. (1918), Meine Heilbronner .... S. 59. S. 60. Sein stăndiges Interesse galt von Beginn an detn Einsatz von Institutionen in einem weiten Sinn zu Problem!ösungen im Zusammenhang mit einer befriedeten Entwicklung der Gesellschaft bei Aufreclrterhaltung eines konkurrenzwirtschaftlichen Gesamtrahmens. Auch Regelungen, die eine allgemein als akzeptabel beurteilte Besteuerung garantieren konnten, gehōrten dazu, s. Schmoller, G. (1872), Arbeitseinstellung, S. 26; ders. (1874), Offenes Sendschreiben .... S. 318; ders. (1875), S. 81; s. a. Schmoller, G. (1883), Rezension von Mengers "Untersuchungen ...", in: Schm. Jb., 7. Jg, S. 983.

${ }^{23}$ Schmoller, G. (1881), Gerechtigkeit ..., S. 19. Dieser Aufsatz erschien als erster Beitrag in dem ersten Heft nach Obernahme der Herausgeberschaft des Jahrbuchs; der handschriftliche Entwurf und mehrere korrigierende Abschriften im Teilnachlaß Schmollers im Hessischen Hauptstaatsarchiv zeigen die große Bedeutung, die der Autor den einzelnen Passagen des Aufsatzes beimaB. 
Dabei wollte Schmoller - anders als alle seine Gegner - keineswegs dem Begriff der Gerechtigkeit die Qualităt objektiver Erkenntnis beigemessen wissen. Die "Idealvorstellung" der Gerechtigkeit beurteilte er vielmehr als das historische Ergebnis laufender gesellschaftlicher Auseinandersetzungen. ${ }^{24}$

Er bekampfte daher fortlaufend alle Versuche und Thesen, "aus irgendeinem Princip heraus, als logische Folge desselben eine Formel (zu) entwickeln, deren strikte Anwendung überall das Gerechte ergäbe ${ }^{n} .{ }^{25}$ Den hinter derartigen Axiomen und Floskeln erkennbaren epistemologischen Dogmatismus jeder Form wies er entschieden als unbegründet zurück.

Eben von der hier erkennbaren Einstellung hob sich die in der Tradition des am nachkantischen philosophischen deutschen Idealismus des 19. Jahrhunderts orientierte vorherrschende wissenschaftstheoretische Grundhaltung Wagners in einer Weise ab, die zu stăndigen, nur mühsam überbrückten Differenzen der beiden Berliner Professoren führte. ${ }^{26}$

Nach der eher kontemplativ gestimmten Wissenschaftsauffassung Wagners wurde die soziale Realităt nămlich von vorgegebenen, den Erscheinungen zugrundeliegenden Wesenheiten geformt und dabei von einem Entwicklungsgesetz beherrscht.

In seiner "Grundlegung" fuihrte Wagner die Lehren von Rau und deren begriffliche Verarbeitung und Durchdringung der sozialen Realität unter diesen

\footnotetext{
${ }^{24}$ Schmoller, G. (1881), Gerechtigkeit ..., S. 22, S. 30, S. 36, S. 53. u. a.

${ }^{25}$ Schmoller, G. (1881), Gerechtigkeit ..., S. 21. Ein gutes Beispiel fur die beherrschende Rolle von "Principien" in dem von Schmoller abgelehnten Wissenschaftskonzept Wagners und Mengers ergibt sich beispielsweise aus der Rezension, die letzterer \$cheels Vorschlag der Einführung einer Erbschaftssteuer 1875 zuteil werden lieB. Er bemalngelte, daB Scheel nicht einmal den Versuch unternornmen hatte, diese Besteuerungsart aus gültigen "Principien" rechtsdogmatisch herzuleiten, was für deren Berechtigung als Voraussatzang zu gelten hătte, s. Menger, C. (1875), Die Erbstewer, in: Wiener Abendpost, Beilage zur Wiener Zeitung v. 6.10.1875, S. 4. Ähnlich muß man Mengers Ablehnung des Kathedersozialismus verstehen. Das paite nicht in das ihm vermittelte begrifflich festgezurrte, von der geeignet ausgelegten herkōmmlichen klassischen Wissenschaftslehre rechtfertigte konservative Weltbild, s. Menger, C. (1873), in: Wiener Abendpost v. 2. und 3.1.1873.

${ }^{26}$ Diese Differenzen zeigten sich bei allen Gelegenheiten, zu denen beide Gelehrte Stellungnahmen abgeben muBten, so etwa Rubner, H. (1978), S. 330. S. 332, sie finden sich auch noch zwanzig Jahre, nachdem sie ihr aloweichendes wissenschaftstheoretisches Credo veröftentlicht hatten. Ein gutes Beispiel zeigen die sich unmittelbar folgenden Widmungen in der Festgabe der DJZ zur Jahrhundertfeier der Juristischen Fakultât der Berliner Universităt, s. Liebmann, O. (Hrsg), (1910), S. 194, S. 196. Wenn Wagner seinen Studenten die Belehrung erteilte, daB "der Jurist (muB) auch Nationalôkonom sein" mußs und die Universităt ihn demgemäB auszubilden hat, s. Pausch, A. (1992), S. 113, so war das in dem von Schmoller abgelehnten Sinn zu verstehen. Danach hatte das ESt-Recht den grundlegenden Besteuerungsgegenstand aus den "Grundlagen der Volkswirtschaft" rechtsdogmatisch zu abernehinen.
} 
Gesichtspunkten mit neuartiger Ausrichtung ais "soziale Finanzauffassung" fort. $^{27}$

Die als Strukturen der Realităt ausgegebenen Definitionen konnten nach Wagners Wissenschaftsauffassung aus den Erscheinungen durch Abstraktion auf einen unterstellten Kerngehalt herausdestilliert werden. Sein Lehrbuch dex politischen Ökonomie gab dann das Ergebnis systematisch zusammengestellt wieder. Die Fähigkeit hierzu blieb nach Wagner nur dem Wissenschaftler vorbehalten.

Die so gefundenen Definitionen beurteilte er spăter als "Grundlagen der Volkswirtschaft". Sie bildeten für ihn die Ausgangsbasis für die Lösung von "Organisationsfragen" und "prinzipieller Fragen der Rechtsgrundlagen der Volkswirtschaft" ${ }^{28}$ So hat Wagner etwa in seiner Finanzwissenschaft für die Definition "Einkommen" stets auf seine "Grundlegung" von 1879 oder seine "Grundlagen" von 1892 verwiesen, auch wenn er die steuerliche Bemessungsgrundlage behandelte. ${ }^{29}$

Für Rechtsinstitutionen fanden sich demgemäß in dem der historischen Ideenlehre entlehnten Entwicklungsmodell Wagners eine jeweils zeitangepaßte Definition der wesentlichen Begriffsinhalte.

Wagner glaubte fest daran, daß sich ihm insofern eine gesetzlich vorgegebene Struktur der Realität und deren Entwicklung in Begriffen offenbarte.

Nach diesem Konzept konnten richtige soziale Problemlösungen allein von dem besonders qualifizierten Wissenschaftler in den vorgegebenen, in Entwicklung befindlichen normativen Strukturen der sozialen Realităt erkannt werden. Diese offenbarten sich durch begriffliche Isolierung und Ausdeutung der den Erscheinungen innewohnenden treibenden Krăfte.

\footnotetext{
${ }^{27}$ In der Einleitung zu seiner "Neubearbeitung" des umfangreichen Rau'schen "Lehrbuchs der politischen Okonomie" und insbesondere in dessen der Finanzwissenschaft gewidmetem Teil fuhrte Wagner aus, er habe sich, von seiner "innersten Uberzeugung getrieben", inzwischen "von Rau ganz. emancipiert". Die starke Erweiterung der begrifflichen Gliederung und eine umfangreichere Darstellung änderten jedoch nichts an dem epistemologischen Grundansatz. Nach wie vor verweist. Wagner im ubrigen an entscheidenden Stellen zur Erlätenung auf Rau's Lehrbuch, s. Wagner, A. (1876), S. Vi: ders. (1880), S. VI, s. hierzu Anm. 29; s. a. Brief Wagners an Bucher v, 8.5.1892, in: Rubner, $\mathrm{H}$. (1978), S. 269.

28 Wagner, A (1886), Systematische Nationalōkonomie, in: Jahrb. f. Nationalōkonomic u. Statistik, N. F., Bd. 12, S. 213.

29 S. Wagner, A. (1880), Finanzwissenschaft, S. 250, S. 255. Wagner verweist auf §ु 84 seiner "Grundlegung" von 1876, (S. 96), bzw. seiner "Grundlegung" von 1879 (S. 114), s. a. Wagner, A. (1890), Finanzwissenschaft, § 135, S. 324, S. 330. § 84 der "Grundlegung" wurde nunmehr $\S 173$ der "Grundlagen" von 1892, S. 405. Fortlaufend bezieht sich Wagner weiterhin auf die Lehren Rau's in dessen "Grundsaltzen der Finanzwissenschaft, 5. Aufl., 1. Abtheilung, Leipzig 1864, § 73, S, 89, S. 143, S. 163 , und 2. Abtheilung, Leipzig $1865, \S \S 254$ bis 261 , S. 396 bis S. 405 .
} 
Die Rechtsinstitutionen richtig zu konzipieren und eine systemkonforme konkrete Rechtsanwendung vorzubereiten ist dann die wichtige Aufgabe des rechtsdogmatisch vorgehenden Juristen.

Daß dieser Art angebliche Erkenntnisse, auf die Wagner seine Empfehlungen stützte, auf "dogmatischen" Einsichten beruhten, die sich einer empirischen Kontrolle vermittels Überprüfung an der sozialen Realităt als regulativer Instanz entzogen, diente Schmoller immerfort als Argument für ablehnende Kritik $^{30}$

Wagner hatte erst nach Ausbildung zum Juristen den Weg zur Nationalökonomie gefunden. Die DIZ feierte ihn bei Jubilăen stets als Mitglied der Zunft, eine Ehrung, die Schmoller nicht zuteil werden konnte. ${ }^{31}$

Nicht zu unrecht wurde Schmoller demgegenüber gelegentlich abfallig als "Sozialingenieur" bezeichnet. Da er Institutionen nicht als richtig oder unzulăssig, sondern als zweckmäßig oder ungeeignet für die Verwirklichung konkreier sozialer Zielvorgaben beurteilte und sie sogar gelegentlich mit Maschinen verglich, gab er selbst für diese Einschảtzung genügend Anlaß.

Für die Beurteilung der Gedankenführung mußte im übrigen von Bedeutung sein, daß beide Gelehrten in ihrer Jugend im Elternhaus in enger Berührung mit naturwissenschaftlichen Lehrmeinungen und Forschungstätigkeiten heranwuchsen und bei Gelegenheit bestätigten, von diesen wesentlich geformt worden zu sein.

Da das wissenschaftstheoretische Anliegen Schmollers bis heute Mißverständnissen begegnete, konnte sich die Auffassung festsetzen, ihm hätten methodologische Kenntnisse gefehlt. Diese Beurteilung blieb sogar erhalten, obgleich Schmoller in den Jahren von 1888 bis 1890 seine Überzeugungen in einem längeren Aufsatz fïr das "Handwörterbuch der Staatswissenschaften" niederlegte und dieses Konzept bis um die Mitte des 20. Jahrhunderts richtungweisend hătte sein können. Es wurde jedoch nie beachtet. ${ }^{32}$

${ }^{30}$ Fundstellen hierzu in: Hansen, R. (1990), S. 58 bis S. 60; ders. (1993), S. 116; s. a. Lindenlaub, D. (1967), S. 98 ; s. a. Schmoller, G. (1894), Volkswirtschaft ..., S. 546.

31 Heilmann, M. (1980), S. 126. Wagner wăre gern Mitglied einer juristischen Fakultăt geworden, da er sich hier zugehörig fuhlte, s. Rubner, H. (1978), S. 415; DJZ 30. Jg. 1915, Sp. 399; s. a. Wagner, A (1910), Beitrag in: Festgabe der DIZ, S. 194.

${ }^{32}$ Schmoller, G. (1894), S. 527. Der Aufsatz entstand in den Jahren 1888 bis 1890, s. Schmoller; G. (1911), S. 497. Das Handwörterbuch der Staatswissenschaften war von Schmoller gefordert worden, da er Schönbergs Haadbuch seit Erscheinen im Jahr 1882 wegen der aberholten wissenschaftstheoretischen Auffassungen der meisten Mitarbeiter für ungeeignet. hielt. In seinem Methodenaufsatz suchte Schmoller die Differenzen zu den Auffassungen seiner Kollegen zu skizzieren. Entsprechend behandelte er die wesentlichen Elemente dessen, was die Naturwissenschaften nach der Jahrhundertmitte von denjenigen zu Jahrhundertbeginn unterschied. Eine der wichtigsten Erörterungen nahm darin 
Es scheint daher wichtig, den Hintergrund Schmollers stärker auszuleuchten als denjenigen Wagners.

Gustav Schmoller war Sohn des Kameralverwalters von Heilbronn. Er selbst war längere Zeit in diesem Kameralamt unter Leitung des Vaters und fur das Finanzministerium in Stuttgart tătig. ${ }^{33}$ Als er im Oktober 1862 den Aufsatz mit dem Titel "Die Lehre vom Einkommen in ihrem Zusammenhang mit den Grundprincipien der Steuerlehre" verfaßte, bereitete er sich auf das Assessorexamen für den höheren Finanzdienst vor. ${ }^{34}$

In einem mutterlosen Haushalt aufwachsend verbrachte er seine gesamte freie Zeit beim Großvater Carl-Friedrich Gärtner, einem Arzt und Botaniker, der im Alter bis zu seinem Tode sein Vermőgen und seine gesamte Zeit der Hybridisierungsforschung widmete. ${ }^{35}$ Hier erhielt Gustav Schmoller, wie er später berichtete, die ersten Eindrücke von seriöser wissenschaftlicher Gelehrtentätigkeit. In den Gewächshäusern des Großvaters in Calw wurden in 9000 laufenden Versuchsreihen die Erkenntnisse erarbeitet, die praktisch das Ende der spekulativen Aristotelisch-Schelling'schen Botanik und vor allem der romantischen Biologie mit sich brachten ${ }^{36}$ Bei der Ausbildung zum Arzt in wissenschaftlicher Hinsicht noch nach den Ideen der zu dieser Zeit ihr Ende findenden Humoralpathologie ausgebildet, interessierte sich Gärtner besonders für die nach den Erkenntnissen Antoine Laurent de Lavoisiers, die zur Ablösung der Phlogistonlehre und zur Entdeckung des Sauerstoffs führten, sich neu

die Behandlung der Rolle von Begriffen und Klassifikationen fur die wissenschafliche Erkenntnis ein. Hier bekannte er sich ausdräcklich zu der Auffassung William Whewells, der sich mit der Typenbildung des Urgroßvaters von Schmoller und den Lehren des Grobvaters auseinandergesetzt hatte, s. Schmoller, G. (1894), S. 527, hier S. 546. Zu Einzelheiten und Fundstellen s. Hansen, R. (1993), S. 116, S. 129; ders. (1968), S. 151 u. a. Whewell hatte den Ansalz zu seinem Kampf gegen die traditionelle aristotelische Wissenschaftslehre von seinem Versuch aus gefunden, die Lehre Ricardos zu systematisieren und mit der empirischen Realităt in cine sinnvolle Verbindung zu bringen. Das konnte Schmoller nicht verborgen bleiben, da sein Großvater die Diskussionen verfolgte, s. Hansen, R. (1993), S. 112 u. a. Die hier skizzierten wissenschaftshistorischen Zusammenhalnge kŏnnen dem Forschenden zu ersten vagen Vermutungen werden, wenn er entdeckt, daß Titel Whewells aus der "Bibliotheca Regia Monacensis" die handschriftliche Widmung des umtriebigen Autors an seinen Freund und philosophischen Gegner F. W. J. Schelling enthalten. Viele gezielte Verprobungen und Kontrollen lassen erste unklare Vermutungen dann zur GewiBheit werden. Hier kōnnen nur Ergebnisse skizzenhaft dargelegt werden, soweit sie unmittelbar relevant erscheinen.

33 Schmoller, G. (1918), Meine Heilbronner ..., S. 56, S. 57; ders. (1908), Reden ..., S. 49.

${ }^{34}$ Schreiben Schmollers an W. Roscher v. 3.11.1862, in: Biermann, E. (Hrsg.) (1922). Briefwechsel zwischen Wilhelm Roscher und Gustav Schmoller, Greifswald, S. 5, S. 6; s. a. Schmoller, G. (1918), Meine Heilbnonner ..., S. 60.

${ }^{35}$ S. Allgemeine deutsche Biographie, Bd. 8, Leipzig 1890, S. 382; s. Schmoller, G. (1918), Meine Heilbronner ..., S. 55; ders. (1908), Reden ..., S. 48.

${ }^{36}$ Schmoller, G. (1908), Reden ..., S. 48; ders. (1918), Meine Heilbronner ..., S. 55; s. hierzu: Nordenskgobld, E. (1926), S. 475, S. 597; s. a. Mayr, E. (1984), S. 519; Sachs, J. (1875), S. 474, S. 596; Stubbe, H. (1963), S. 91; Jahn, J./Senglaub, K. (1985), S. 414; hierzu: Hansen, R. (1993), S. 112. 
entwickelnde moderne wissenschaftliche Chemie. ${ }^{37}$ Mit einigen später berühmt gewordenen Vertretern der antiphlogistischen Chemie war er zeitlebens in Freundschaft und wissenschaftlicher Korrespondenz verbunden. Er selbst experimentierte mit Harnstoffen und erprobte selbstentwickelte Heilstoffe als Medikamente, bildete Hypothesen über chemische Vorgănge, die er dann experimentell zu überprüfen suchte. Seine Forschungen standen ganz in der Linie der sich zu Ende des 18. Jahrhunderts entwickelnden modernen wissenschaftlichen Chemie. ${ }^{38}$ So war er auch korrespondierendes Mitglied vieler wissenschaftlicher Gesellschaften und Akademien des In- und Auslandes. Auf einer seinen wissenschaftlichen Interessen dienenden Reise lernte er auch die leitenden Mitglieder der Royal Society in London kennen. Danach stand er mit Darwin wegen seiner Forschungsergebnisse zur Hybridisierung in Briefwechsel. Spăter wandte er sich dann der Botanik zu und entwickelte in einer Preisschrift der holländischen Akademie der Wissenschaften den schlüssigen Nachweis über die Geschlechtlichkeit der Pflanzen, wobei er die Grundlage für die später von Gregor Mendel entdeckte Gleichmäßigkeit in der ziffernmäßigen Verteilung von Merkmalen legte. ${ }^{39}$ Die im Erbgut spăter isolierten Verursacher erbielten um die Jahrhundertwende dann den Namen Gene und die Entdeckung Mendels wird heute oft mit derjenigen des Wirkungsquantums in der Physik verglichen. Letztlich entwickelte sich hieraus die moderne Mikrobiologie und das weite Feld der heutigen von der physikalischen Chemie weitergeführten Gentechnik.

Der Großvater Schmollers, Carl-Friedrich Gärtner, trug durch seine von großem Fleiß begleitete Forschungstätigkeit entscheidend zur Ablösung der noch um 1830 vorherrschenden aristotelischen Biologie bei. ${ }^{40}$ Durch die Ergebnisse seiner Hybridisierungsforschung konnte zugleich ein Schlußstrich unter bis dahin dogmatisch vertretene grundlegende Thesen der Biologie gesetzt und zugleich ein neuer Forschungsbereich über Anpassung und Veränderung alter bzw. Züchtung völlig neuer Pflanzenarten eröffnet werden. ${ }^{41}$

${ }^{37}$ Hierzu und zu folgenden kurzgefaîten Ausführungen s. Graepel, H. (1978), S. 232 - 241, S. 244 - S. 253. Diese Dissertation eines Pharmakologen, als Apothekersohn aus der Heimatstadt von Schmollers Grolivater stammend, wurde dem Verfasser erst 1991 bekarnt, als dessen Aufsatz uber Schmoller von 1993 bereits abgesetzt war. Er findet dadurch seine bereits seit 1966 vertretenen Thesen voll bestătigt, Hansen, R. (1968), S. 140.

${ }^{38}$ Graepel, H. (1978), S. 80; s. a. Hennemann, G. (1959), S. 85 u. a.

39 Graepel, H. (1978), S. 2, S. 114 , S. 148, S. 215 , S. 327, S. 331 , S. 335, S. 338.

${ }^{40}$ Graepel, H. (1978), S. 224, S. 252 u. a.; s. Wolf, K. (1983), Die Gene, S. 12.

${ }^{41}$ S. Gärtner, C. F. (1849), S. 663. Hier wurde nicht nur die Züchtung neuer Arten, sondern auch die Bewirkung neuer Eigenschaften experimentell eingeleitet, s. Hansen, R. (1993), S. 134. 
Hier erhielt der Enkel Gustav Schmoller erste Eindrücke von solider empirischer Forschungstătigkeit vermittels Verprobung und Bestătigung oder Falsifizierung von Vermutungen und Ausmerzung falscher Hypothesen. Und was noch wichtiger war: Er erhielt hier einen bleibenden Eindruck von Möglichkeiten und Grenzen, gestaltend in den Ablauf der Natur einzugreifen, indem man sich die Kenntnisse hierzu durch sinnvolle Einrichtung und Organisation empirischer Forschungstătigkeit zunutze macht. ${ }^{42}$

Es mag von Bedeutung sein zu erwähnen, daß Carl-Friedrich Gärtner sich auch intensiv mit den höchst spekulativen umfangreichen Beiträgen Hegels zur Chemie, den Beiträgen Schelvers, Goethes und der übrigen zum nachkantischen Idealismus gerechneten und der Machart der romantischen Naturlehren anhängenden Gelehrten auseinandersetzte. ${ }^{43}$

Gewiß hat Gustav Schmoller hier die bei ihm of vernehmbare kritische Einstellung zu einer überholten traditionellen spekulativen Wissenschaitsauffassung erfahren, die mit der neuartigen Weltansicht der jungen Naturwissenschaftler der Zeit einherging. Man kann hier von einem Paradigmawechsel im Sinne von Th. S. Kuhn sprechen. Mit der neuartigen Weltansicht dieser jungen Wissenschaftler der Zeit war der Übergang von einem kontemplativen Denkstil zu einer aktivistischen, am Experiment orientierten Vorgehensweise, vom passiven Beobachten natürlicher Abläufe einer unberührten Natur zum aktiven Registrieren von gleichförmigen Antworten der Natur auf gleichförmige Eingriffe verbunden. Ein neuartiger Typ von Theorien, für deren Ergebnisse eine Bestätigung an der empirischen Realităt als regulativer Instanz diente, war die Folge. Auf ihm beruhte die technische Revolution im 19. Jahrhundert. ${ }^{44}$

${ }^{42}$ S. Graepel, H. (1978), S. 115. Sichmollers Tante Emma Gärtner fuhrte den 13jährigen Heranwachsenden nach dem Tode Güriners in Einzelheiter des Nachlasses des bedeutenden Gelehrter ein. Gärners lebenslanger Kampf gegen dogmatische naturphilosophische Principien als angebliche Erkenntnisse, aus denen die Zusammenhänge der Natur a priơi erschlossen werden könnter, wurde spăter von G. Schmoller auf die Sozjalwissenschaften übertragen, s. Graepel, H. (1978) „, S. 234 u. a.

43 In einer heute noch wegen der Klaren Gedankenfuhrung eindrucksvollen kleinen Abhandlung zeigte Gărtner, daß die voin seinem wissenschaftlichen Gegner F. J. Schelver zur Erklärung einer. Erscheinung verwendeten "naturphilosophischen Principien a priori" zwas weder widerlegt wurden, noch widerlegt werden konnten. Er forderte daher den Gegner auf, nach Mōglichkeiten zur Bestătigung von deren Wahrheit durch geeignete Experimente zu suchen. Ein fehlgeschlagener Versuch m0sse als Falsifikation der angeblichen Erkenntnis als Hypothese gewertet. werden. Diesen Gedankengang der Bestãtigung bzw. Falsifikation als Kriterium für gehaltvolle Hypothesen zur Erklărung der Realităt begegnen wir in Schmollers Methodenaufsatz von 1894 wieder, s. hierzu; Gärtner, C. F. (1813), Rezension von Schelver, F. J.: Kritik der Lehre von den Geschlechtern, in: Jenaische Allgemeine Literatur-Zeitung. Jg. 10, Bd. 1, Sp. 321 - 328, hier Sp. 323 und Sp. 328; s. hierzu: Schmoller, G. (1894), Volkswirtschaft ...., S. 547, S. 554. Schelver war Schuler F. W. J. Schellings.

${ }^{44}$ Hierza: Hansen, R. (1993), S. 115; s. 117, Anm. 30, S. 133, Anm. 78. 
So entsprachen Denkweise und Wissenschaftsauffassung Schmollers etwa den heutigen wissenschaftstheoretischen Vorstellungen unserer modernen $\mathrm{Na}$ turwissenschaften.

Schmoller lernte hier, den Begriffsrealismus abzulehnen, er schloß teleologische Konstruktionen als Erkenntnisse aus. Wesenseinsichten, die nicht in der Realităt durch Beobachtung und Experiment überprüfbar waren und scheitern können, gehörten für ihn nicht in das Gebăude wissenschaftlicher Aussagen. ${ }^{45}$

Das hatte weitreichende praktische Konsequenzen: So wie die antiphlogistischen Chemiker, zi denen auch Großvater Gärtner zählte, den Sauerstoff als Element durch den Einsatz künstlicher Meßgerăte, wie Präzisionswaagen, fanden und dann erst zu isolieren vermochten, sich hierzu theoretischer Begriffe als Dispositionsbegriffe bedienten, ${ }^{46}$ suchte Schmoller 1862 analog einen einheitlichen Begriff für die Messung von "Leistungsfähigkeit" als einen geeigneten, theoretisch festzulegenden Begriff für die Zwecke der Besteuerung zu konzipieren. Denn er hatte gelernt: auch Hitze oder Kälte oder die schwere Masse kann man nicht unmittelbar skalieren, sondern für theoretische Zwecke nur messen, indem man dem Phănomen der inneren Erlebniswelt einen sinnvoll definierten künstlich geschaffenen, interpersonell überprüfbaren Maßstab zuordnet: ${ }^{47}$ Etwa die Ausdehnung einer Quecksilbersăule mit einer metrisch unterteilten Skala zur Messung dessen, was wir als Wărme oder Temperatur empfinden, oder die durch Druck oder Zug bewirkte Längendehnung einer Feder bei Beschwer durch ein Gewicht für das, was wir schwere Masse nennen.

45 Der Methodenaufsatz, der im Handworrterbuch von 1894 Schmollers Wissenschaftsauffassung zusammenzufassen suchte, begegnete bei Geisteswissenschaftlem Verștändnislosigkeit. Schmoller war seiner Zeit weit vorausgeeilt. Die aus dem Wissenschaftskonzept Whewells übernommene Vorstellung von Begriffen als nûtzlichen Instrumenten für Problemīőungen, der andersartige Gesetzesbegriff und die Rolle der empirischen Realität als regulativer Instane wurden von den nach dem humanistischen Bildungsideal mit der klassischen Philosophie als Wissenschaftslehre ausgebildeten Geisteswissenschaftlem als Zeichen von Bildungamangel interpretiert. Die spalteren Beitrige Max Webers zur Wissenschaftslehre zeigen eindrueksvoll die Schwierigkeit, sich nach Aushildung zum Rechtswissienschaftler und Historiker von der durch die aristotelische Philoșophie vorgeprägten Denkweise freizumachen, s. Baumgarten, E. (1973), Einleitung zu: Max Weber, Soziologie. Universalgeschichtliche Analysen. Politik, S. XIX; Hansen, R. (1993). S. 153.

${ }^{46}$ Lavoisier erschutterte die Phlogistontheorie durch den mit Hilfe von Präzisionswaagen gefuhrten Nachweis, JaB ein Verbrennungsprodukt stets schwerer ist, als der verbrannte Kôrper. Er schloB daraus, daß bei der Verbrennung ein Bestandteil der umgebenden Luft mit dem verhrannten Kôrper eine Verbindung einging. Er benannte ihn mit Oxigene. Die Anerkennung der Theorie durch die Pariser Akademie setzte lange Kămpfe voraus, bis die Lehre vom Phlogiston als einen geheimnisvollen Agens aufgegeben wurde, s. Bugge, G. (1955), Das Buch der großen Chemiker, Weinheim, S. 326.

47 Zum Problen des Messens, und zur Bildung, von Maßstäben in empirischen Wissenschaften $\mathrm{s}$. Hempel, C. G. (1952), Fundamentals of Concept Formation, in: Empirial Science, Chicago, S. 58, S. 62; s. a. Bohnen, A. (1964), Die utilitaristische Ethik als Grundlage der modernen Wohlfahrtsőkonomik, Gottingen, S. 24, S. 28 . 
Unter diesen Umstănden wird es verständlich, daß Schmoller als Folge seines Werdeganges und der erhaltenen neuartigen Sichtweise Anregungen zu sozialen Reformen vertrat, die mit den Wissenschaftsauffassungen konservativ gestimmter Kollegen nicht zu vereinbaren waren, ja tiefe Skepsis erzeugten. Das zeigte sich besonders nachhaltig nach seiner Berufung an die Berliner Universităt im Jahr 1882.

Um bezüglich der andauernden unerquicklichen. Differenzen und persönlichen Reibereien bei Promotionen, Habilitationen, Berufungen und der Beurteilung von Veröffentlichungen klare Frontstellungen zu schaffen, sahen offenbar sowohl Schmoller, als auch Wagner nach 1888 das dringliche Erfordernis, ihre differenten wissenschaftstheoretischen Überzeugungen systematisch zusammengefaßt niederzulegen.

Daher fertigte Wagner 1886 bis 1892 eine lăngere Einleitung von insgesamt 285 Seiten für seine 1879 als zweite Auflage verofffentlichte, aus Rau's "Lehrbuch" fortentwickelte "Grundlegung der politischen Oekonomie". 48

Diese erhielt nunmehr einen als "Ginundlagen der Volkswirtschaft" bezeichneten umfangreichen methodologischen Vorspann, der sich eng an die hergebrachte, von Menger 1883 verteidigte dogmatisch-naturrechtliche Wissenschaftsauffassung anschloB.

Wagner gliederte darin die Aufgabe der Wissenschaften in 1. "die Fesistellung (Ermittlung) der Erscheinungen", 2. die "Ermittlung des Typischen darin" und 3. "die Zielstellung für ihre Entwicklung, die Wegweisung zu diesem Entwicklungsziel". 49

Die Beantwortung der Frage des "Was soll sein?" wurde somit von Wagner wie bei Menger ausdrücklich als dogmatische Erkenntnis der die Erscheinung steuemden inneren Gesetzmäßigkeit der empirischen Realităt beurteilt. ${ }^{50}$ Auch eine richtige Finanz- oder Steuerpolitik mußte sich nach diesen Erkenntnissen ausrichten.

Der von Hasbach und Schmoller in vielen für Wagner ärgerlichen Rezensionen oftmals in beißender Form wiederholten Kritik an kryptonormativen Realdefinitionen, an dem diesen zugrundeliegenden herkömmlichen Gesetzesbegriff und der damit einhergehenden, insbesondere für die Finanzwissenschaften bemängelten fortlaufenden Vermengung von "lex lata" und "lex ferenda" wurde so die Spitze genommen.

48 Wagner, A. (1892), Grundlegung der politischen Oekonomie. Erster Theil. Grundlagen der Volkswirtschaft, S. 1 - S. 285 , insbes. S. 16.

49 Wagner, A. (1892), Girundlegung ...., S. 144.

so Wagner, A. (1892), Grundlegung ..., S. 146. 
Denn Wagners von Schmoller als nicht mehr zeitgemäß und dogmatischspekulativ kritisierte Ausfuhrungen waren nunmehr Ausfluß einer konsequent vorgetragenen, in sich konsistenten Wissenschaftsauffassung.

Schmoller unterwarf sich seinerseits gleichzeitig von 1888 bis 1891 intensiver Arbeit zur Abfassung seines Beitrages zur Methodologie. ${ }^{51}$

Das Ergebnis bemăngelte er zwar als infolge Zeitdrucks von unbefriedigender Qualităt. Dennoch brachte er den Aufsatz in der ersten Auflage des "Handwörterbuchs der Staatswissenschaften" unter, das - von Conrad bearbeitet - das 1882 von Schmoller als überholt beurteilte "Handbuch der politischen Öko-

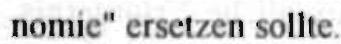

Schmollers Beitrag enthielt eine grundlegende Kritik an der in Natur- und Geisteswissenschaften bis nach der Jahrhundertmitte vorherrschenden dogmatisch-spekulativen, vordringlich an Begriffen ausgerichteten Wissenschaftsauffassung. ${ }^{52}$

Beide Berliner Gelehrien fanden sich fortan mit der Unvereinbarkeit ihrer Auffassungen und deren praktischen Konsequenzen $a b$.

Sic arrangierten sich. wenn auch von vielen Reibungspunkten unterbrochen, entsprechend. ${ }^{53}$ Das konnte wegen der grundlegenden Differenzen nicht leichtfallen. Während Wagner fortlaufend vortrug, daß Rechtsinstitutionen wie das Steuerrecht an vorgegebenen volkswirtschaftlichen begrifflichen Erkenntnissen zu orientieren seien und deshalb Jurisprudenz und Nationalökonomie engste Verbindungen eingehen müßten, ${ }^{54}$ suchte Schmoller ständig Richtigstellungen anzumahnen. Er wollte der Gestaltung von Institutionen, zu denen auch das Steuerrecht zählte, konkrete Ziele gesetzt sehen, solche, die sich aus politischen Vorgaben bei Kenntnis der empirischen Wirkungszusammenhänge der sozialen Realität herleiten lassen.

Bei den politischen Zielvorgaben hatte für Schmoller ausdrücklich die Erhaltung einer sozialen Balance Priorität. ${ }^{55}$ Im übrigen sah er, daß für eine

31 Schmoller. 6. (191 i), Volkswirtschaft .... S. 497.

32 Schmoller, G. (1894). Volkswirtschaft .... S. 527, hier S. 534.

${ }^{53}$ Brief Wagners an Schmoller vom Herbst 1892 (ohne Dalum). abgedr. in: Rubner. H. (1978), S. 271. Wagner kündigte Schmoller die Zusendung eines Exemplars seiner "Girundlagen" mil seinem methodologischen Bekenntnis an. Er fügte die Bemerkung hinzu, daß es sich bei seiner Veröffentli. chung um eine Antwort auf "Wendungen und Angriffe" handele, "dic ich wenigstens auf mich bezieherı konnte".

4 Wagner. A (1880), Finanzwissenschaft. S. 255, S. 256; ders. (1890), S. 323, S. 324; ders. (1910), Widmung, in: Liebmann, O.. S. 194. u. a.

"Schmoller. (i. (1874), Oflenes Sendschreiben .... S. 290. S. 324. S. 345: ders. (1875), Offenes Sendschreiben .... S, 91 u. a.: derx. (1881), Gierechtigkeit .... S. 52: ders. (1910), Widmung .... S. 196. 
politische Lenkung dieser Art durch Gestaltung der Institutionen ein noch nicht vorhandener neuartiger Theorietypus erforderlich sei. ${ }^{56}$

Wagner hatte jedoch bis 1890 das Gebiet der Finanzwissenschaften erobert und er verwaltete es, von allen bis heute respektiert, als seine Domanne.Die unterschiedlichen Wissenschaftsauffassungen mußten bei Gesetzesvorhaben notwendig weiterhin zu differierenden Problemlösungen führen.

Das traf insbesondere bezüglich der seit 1882 im preußischen Landtag zur Zeit đer Durchsetzung allgemeiner sozialpolitischer Reformen auch erörterten Reform der Einkommensteuer zu.

Schmollers Vorschlag zu einer Neuorientierung lag seit 1863 vor. Aus sei* ner Besteuerungsidee war das săchsische EStG 1874/78 entstanden, das sich bewährt hatte. Die darin verarbeitete neuartige Definition des Besteueningsgutes setzte seine andere Beurteilung der Funktion von Begriffen und damit den Bruch mit vorherrschenden Auffassungen der Zeit voraus.

Wagner suchte hiergegen den Steuergegenstand eines reformierten preußischen EStG weiterhin an dem "richtigen" Einkommensbegriff zu orientieren. Dieser entsprach den von ihm unterstellten verborgenen Strukturen der Realität, die in seiner "Grundlegung" nachgezeichnet wurden. ${ }^{57}$ Diese Sammlung von Begriffen diente ihm dabei als Hilfsmittel für Problemlösungen. Gegen ständige Kritik von Schmoller behielt er diese Grundvorstellung bei. Sie blieb weiterhin für Nationalökonomie und Finanzwissenschaften die vorherrschende Wissenschaftsauffassung.

\section{Die methodologische Außenseiterstellung Gustav Schmollers und dessen Besteuerungsidee}

Für die Entstehung und weitere Ausgestaltung der Einkommensteuer galt die im 19. Jahrhundert aufkommende Forderung nach einer Besteucrung der

\footnotetext{
${ }^{36}$ Schmoller, G. (1894), S. 546. Schmoller schlug vor, die Historie unter volkswirtschaftlichen und sozialpolitischen Gesichtspunkien zu untersuchen. Vergleichende historische Untersuchungen glaubte er als Ersatz fur Experimente zur Gewinnung von Erkenntnissen verwenden zu können. Dies trug ihm zu Recht den Vorwurf ein, seine historischen Untersuchungen hătten einen "Laboratoriumsbeigeschmack" an sich. s. Meinecke, F. (1922) in: HZ. Bd. 125, S. 251: s. a. Hasbach, W. (1902), Rezension, in: Jb. f. Nationalökonomie u. Statistik, 23. Bd., S. 55; s. Schmoller, G. (1894), Volkswirtschaft .... S. 395; Hansen, R. (1993), S. 133, Anm. 78. Die von Schmoller betreute. Schriftenreihe der "staats. und sozialwissenschaflichen Forschungen" sollten diesem Zweck dienen. Darin sollten in sogenannten "Detailuntersuchungen" sozialpolitische relevante Fragen uberschaubarer Bereiche durch Herausarbeiten der ursăchlichen Wirkungszusammenhănge zur Schaffung vợ Grundlagen für institutionelle Regelungen mit erwünschten Folgen behandelt werden.
}

57 Wagner, A. (1890), Finanzwissenschaft ..., S. 255. 
Bürger gemảß ihrer Leistungsfähigkeit als grundlegend. Von der konkreten Definition dieses Begriffs mußten Art und Umfang des Besteuerungsgutes abhängen.

Schmoller hatte 1862 in seinem ersten aus rein wissenschaftlichem Interesse geschriebenen Aufsatz der Öffentlichkeit einen Maßstab zur Messung dessen vorgelegt, was er unter steuerlicher Leistungsfähigkeit verstanden wissen wollte und empfohlen, diesen als Besteuenungsidee einem modernen Steuersystem für die Bemessung der Beitragspflicht der Steuerbürger zugrunde zu legen. Die allgemein übliche Erörterung eines derartigen Begriffs ohne gleichzeitige operationale Definition bezeichnete er als "müßige Begriffsspielerei", da es eben "richtige" oder "wissenschaftliche" Begriffe - in der Terminologie Adolph Wagners - nicht gibt und dieser Art Erörterungen auch zu keinerlei Erkenntnissen führen kőnnen. ${ }^{58}$ Begriffe waren für Schmoller, anders als für Wagner, bloße Instrumente zu Problemlösungen, mehr nicht, jedenfalls keine Erkenntnisse der Realităt. Ohne zureichende Definition bleiben sie - so seine Wissenschaftsauffassung - unbestimmt, grenzen mögliche Zuordnungen nicht genügend ein und können daher nicht für konkrete Problemlösungen als zweckmäßig ausgewählt bzw. als unzweckmäßig verworfen werden. ${ }^{59}$

Das Einkommen als Bemessungsgrundlage für die Besteuerung wurde von Schmoller daher 1862 durch einen Maßstab für die Leistungsfahigkeit vermittels einer theoretischen Definition festgelegt. Diesen bestimmte er als "die Summe von Mitteln, welche der Einzelne, ohne in seinem Vermögen zurückzukommen, für sich und seine Familie, für seine geistigen und körperlichen Bedürfnisse, für seine Genüsse und Zwecke, kurz für (die) Steigerung seiner Persönlichkeit in einer Wirtschaftsperiode verwenden kann". ${ }^{60}$

Gesucht werden letztlich nach dieser Besteuerungsidee Ziffern, die die Leistungsfähigkeit des einzelnen Steuerbürgers auswerfen und so ermöglichen sollen, die jeweils anteilige konkrete Steuerbelastung aus dem Verhältnis der Ziffern als Relationen zu ermitteln und auf die Mitbürger aufzuteilen. Dies durchzuführen war der Zweck der Veranlagung. Der Einkommensbegriff war in diesem System im Grunde nur die Bezeichnung für eine Relationsgröße. Dessen absolute Höhe als solche hatte keine unabhăngige separate Bedeutung. Der Begriff "Einkommen" bezeichnete für Schmoller nicht mehr etwas Vorgegebenes, dessen richtige Definition einer ungetrübten Erkenntnis "durch Abstraktion aus der Fülle des überwältigenden konkreten Einzelnen" bedarf, wie

58 Schmoller; G. (1863), S. 57; ders. (1894). S. 546; s. a. ders.: viele Rezensionen, wie in: Schm. Jb. (1888), \&. 731 ; ders. (1863), S. 5. S. 26.

59. Schmoller, G. (1894), S. 548. Hierfur benft er sich auf W. Whewell.

${ }^{60}$ Schmoller, G. (1863), 5. 52. 
es bei Wagner hieß. Es handelte sich um eine nach Gesichtspunkten der Zweckmäßigkeit gefertigte Definition zur Lösung der Aufgabe, eine überzeugende Lastenverteilung unter den Steuerbürgern zu gewährleisten. ${ }^{61}$

Der Technik der kaufmănnischen Gewinnermittlung durch Bestandsvergleich kam in diesem Konzept Schmollers eine wichtige und für die Besteuerung neuartige Rolle zu. Dort hatte man bis dahin nur die Überschußrechnung als Ermittlungsweise gekannt. ${ }^{62}$

Schmoller hat sich nach 1862 an einer Diskussion über den Begriff der Leistungsfăhigkeit, der Steuerfăhigkeit, der Opfergröße und ăhnlichen Erörterungen nicht beteiligt. Wenn er etwa den Begriff "Einkommen" in seinem "GrundriB" um 1900 verwendete, so hat er ihm einen anderen Inhalt gegeben, als in dem Aufsatz von 1862, weil er nun damit Überlegungen für die statistische Einkommensverteilung innerhalb der Gesellschaft verband und nicht Beitragspflichten von Steuerbürgern.

Wer ihm, wie etwa Carl Menger, Friedrich-Julius Neumann, Georg Schanz, aber auch Walter Eucken und viele andere, vorwarf, eine unscharfe Begriffsbildung zuzulassen, Begriffe jeweils mit unterschiedlichen Inhalten zu definieren, muß sich vorhalten lassen, daß Schmoller erklärtermaßen kein Begriffsrealist war, und dies eben im Unterschied zu seinen Kritikern. Seine Verwendungsweise von Begriffen machte in dem von ihm abgelehnten Wissenschaftskonzept keinen Sinn. Für Schmoller gab es so etwas nicht, wie einen "richtigen" oder "wissenschaftlichen" Begriff des Einkommens, wie für Wagner. Insbesondere die vielen Gegner Schmollers, die diesem gern mangelhafte Kenntnisse der Methodenlehre attestierten, hätten dies erwägen müssen.

Genau hier lag das Trennende zwischen den beiden Berliner Gelehrten. Schmoller hat wiederholt auf die völlig andere Denkweise Wagners, aber auch Brentanos und anderer hingewiesen.

Für die Festlegung eines steuerlichen Einkommensbegriffs. der den Bedürfnissen der Zeit zur Jahrhundertmitte nach einer Besteuerung der Bürger entsprechend ihrer Leistungsfahigkeit genügen konnte, kamen Schmoller die Erfahrungen einer mehrjährigen praktischen Tätigkeit im Dienste der Finanzverwaltung zustatten. Hier hatte er konkrete Vorstellungen von einem Maßstab zur Bestimmung der Leistungsfähigkeit der Steuerbürger gewinnen können. In

${ }^{61}$ S. Wagner, A. (1910), in: Liebmann, O., S. 194; Schmoller, G. 1863), S. 32, S. 36, S. 53, S. 54 , S. 56, S. 57. Schmoller betont fortlaufend, daB er nur einen MaBstab für die Verteilung suche. Er fragt: "Ist wirklich der fiktive Theil des National-Einkommens, aus welchem die: Steuern gezahlt werden, nothwendig auch der arithmetische Maassstab, nach welchem, sie umzulegen sind?" Dieser letzteren Relation sollte die Steuerzahlung entsprechen (S. 32). Seine Antwort: Nein.

${ }^{62}$ S. Hierzu die gute Zusammenstellung in: Barth. K. (1955), Bd. II, Anhang. S. 4. 
vielen Verhandlungen mit aufstrebenden Untemehmern des Heilbronner Raumes hatte er Anwendungsfalle für die erst spăter im Studium von F, W. B. Hermann erworbenen Kenntnisse gefunden. ${ }^{63}$ Dabei hatte er den Einkommensbegriff aus der Verbindung mit dem aus der klassischen Nationalökonomie übernommenen Gedankengut herausgelöst und abgewandelt. ${ }^{64}$ Den Begriff der Leistungsfahigkeit suchte er, vereinfachend gesagt, an dem Geldwert dessen zu orientieren, was ein Mitbürger in einem Jahr insgesamt an Aufwand für Verbrauch oder Vermögensmehrung betreiben kann, ohne sein Vermögen anzugreifen. Die Schmollersche Besteuerungsidee suchte dann den Einkommensbegriff als Bemessungsgrundlage für die Verteilung der Steuerlasten an der so definierten Leistungsfähigkeit der Bürger auszurichten. Tatsăchlicher Aufwand in einem sehr weiten Sinne und Vermögensmehrung bestimmten mithin danach die Leistungsfahigkeit der Zensiten.

Adolph Wagner beurteilte die Zusammenhänge, wie wir noch sehen werden, grundlegend anders.

Für ihn bestand die Aufgabe des Wissenschaftlers darin, den Forderungen der Zeit nach einer Besteuerung der Bürger entsprechend ihrer Leistungsfahigkeit durch Herleitung eines richtig definierten Einkommensbegriffs zu entsprechen. Der richtige Einkommensbegriff, der die einzelnen Einkünfte auflistete und addierte, konnte dann nach Wagners Vorstellung zugleich einen Maßstab für die Leistungsfähigkeit des Zensiten abgeben. Der Begriff der Leistungsfähigkeit wurde auf diese Weise durch den Begriff des Einkommens definiert und nicht umgekehrt. Der unter Mitarbeit von Wagner entwickelte Steuergegenstand des preußischen EStG 1891 zeigte später die juristische Fortentwicklung dieses Denkansatzes. Demgegenüber hatte das sächsische EStG $1874 / 78$ die von Schmoller skizzierte Besteuerungsidee in praktikable juristische Gesetzesvorschriften durch Definition eines einheitlichen wirtschaftlichen Steuergegenstandes in Anlehnung an Schmollers Maßstab für Leistungsfähigkeit zu kleiden gesucht.

Schmoller, G. (1918), S. 57; ders. (1908), Reden ..., S. 49.

44 Schmoller, G. (1863), S. 6, S. 7. S. 27; hierzu: Roesler, H. (1968), S. 302, S. 307. Roesler ubernahm die Beurteilung von Schmoller, s. a. Hansen, R. (1990), S. 8. 


\section{Die wissenschaftstheoretische Auffassung Adolph Wagners und der übrigen Nationalökonomen und dessen Fortsetzung der an den nachklassischen Thesen Karl-Heinrich Raus ausgerichteien \\ Besteuerungslehren}

Rudolph Wagner, der Vater des Nationalökonomen Adolph Wagner, war ein theoretisch interessierter Physiologe von Weltruf, der mit führenden Wissenschaftlern, wie etwa Carl-Friedrich Gauß in Göttingen, wo er als Lehrstuhlinhaber der Physiologie tätig war, und mit vielen anderen berühmiten Naturwissenschaftlern grundlegende wissenschaftstheoretische Fragen erörterte. ${ }^{65}$ Er kannte die wissenschaftstheoretischen Standpunkte der Induktionslehren von John Stuart Mill und William Whewell, blieb jedoch Zeit seines Lebens Vertreter heute merkwürdig klingender zeitgemäßer spiritualistischer Denkweisen und der dem nachkantischen Idealismus der romantischen Naturlehren eigenen Wissenschaftsauffassungen streng verbunden. ${ }^{66}$

Wenn Wagner sich zu der Wissenschaftsauffassung seines Vaters bekannte, so gab es dafür gute Gründe. Schließlich führten, ebenso wie bei Entdeckungen seines Vaters, viele hochspekulative Erklärungsweisen der Naturwissenschaftler der Zeit der Romantik zu bedeutenden Erkenntnissen, die erst später empirische Bestătigung fanden. ${ }^{67}$

Ein Ausläufer dieser zur romantischen Denkweise gehörigen Lehren von schulebildender Kraft waren für die Geisteswissenschaften die historischen Ideenlehren. Ihre wichtigsten Vertreter, Leopold von Ranke, Johann Gustav Droysen und Wilhelm von Humboldt und deren Schüler und Enkelschüler Treitschke, Below und viele andere, glaubten, die Aufgabe des Historikers sei, die "Darstellung des Strebens einer Idee, Dasein in der Wirklichkeit zu gewinnen" ${ }^{68}$ Die Idee, so diese Lehren, ist danach der "zugnundeliegende Kern", "das Wesen", "das innere Prinzip", "die ewige Form der Erscheinungen" und "äußerlichen bloßen Ereignisse". Der Historiker hat danach die Aufgabe, die

${ }^{65}$ Hierzu: Pagel (1896), in: Allgemeine Deutsche Biographie, 40. Bd., Neudruck der 1. Aufl. v. 1896, Berlin 1971, S. 573; s. a. Hansen, R. (1993), S. 125. Anm. 50, S. 121. Anm. 39

${ }^{66}$ Hiezzu: Hansen. R. (1993), S. 120, dortselbst umfangreiche Fundstellen.

${ }^{67}$ S. Wagner, A. (1864), "Dem Andenken meines theueren Vaters, des Physiologen Rudolph Wagner", Vorwort und Widmung zu: Die GesetzmäBigkeill der scheinbar willkörlichen menschlichen Handlungen vom Standpunkte der Statistik. S. VII. S. XII. S. XIII, S. 3: ders. (1864), Nekrolog, in: Nachrichten von der Königl. Gesellschaft der Wissenschaften und der G. A. Universită1 zu Göttingen, Nr. 14. S. 375; s. hierzu Hennemann, G. (1959), S. 48, S. 33 u. a.

68 Humboldt, W. (1827), Ober die Aufgabe des Geschichtsschreibers, abgedr. in: Fitner, A. (1956), Willhelm von Humboldt. Schriften zur Anthropologie und Bildungslehre, S. 109; hierzu auch: Rothacker, E. (Hrsg.) (1925), Leopold von Ranke, Das Politische Gespralch und andere Schriften zur Wissenschaftslehre, S. X, S. XIV; auch: Droysen, J. G. (1867), Grundriss der Historik. 
"leitenden Tendenzen, das innere stillwirkende Gesetz der jeweiligen Epoche" als herrschende Idee zu beschreiben. Dabei sind die Formen wie "erschaffende Kräfte von entelechialer Essenz" zu verstehen, die als inneres Wesen der Abláufe den bloßen Erscheinungen als Stoff den Stempel aufdrïcken. ${ }^{69}$ Dies war im ubrigen nach der Jahrhundertmitte die herrschende Denkweise in den Geisteswissenschaften, die Schmoller ständig kritisierte. Dabei kannte er die Theoriestruklur dieser Richtung genau, hatte er doch die Enkelin eines der Begründer der deutschen historischen Rechtsschule geheiratet und war mit führenden Rechtsgelehrten und Historikem zeitlebens ebenso eng befreundet, wie mit Naturwissenschaftlern von internationalem Rang. Adolph Wagner bekannte demgegenüber wiederholt, daß er die in romantischen Vorstellungen wurzelnde Wissenschaftsauffassung seines Vaters vollinhaltlich teile.

Aber nicht nur Adolph Wagner ließ sich von derartigen zeitgemäßen Glaubensgewißheiten leiten, sondern unter anderen ebenso etwa Lujo Brentano, wern auch mit anderen politischen Konsequenzen. Dieser hielt Schmoller gelegentlich sogar vor, selbst historischer und damit theoretischer zu denken als err und bemängelte an Schmoller, nicht zu erkennen, daß die von Adolph Wagner vertretenen Thesen über die allgemeine gesetzliche Entwicklung zum Staatssozialismus in der Realität erkennbar falsch seien. ${ }^{70}$ Schmoller antwortete, daß sein Briefpartner im Gnunde das gleiche spekulative dogmatische methodische Konzept der historischen Ideenlehre vertrete, wie Adolph Wagner, nur daß bei ihm die Entwicklung zum Liberalismus die Stelle des Staatssozialismus als teleologisches Endziel der Geschichte und zugleich als Erkenntnisobjekt des Wissenschaftlers einnehme. Diese Wissenschaftskonzeption sei ebenso dogmatisch spekulativ und für seine kritische Denkweise unhaltbar. Von einem gesetzlichen Ablauf könne man nicht sprechen. $\mathrm{Zu}$ empirisch überprïfbaren, strukturell relativierten Hypothesen umformuliert, so fügte er an, seien viele Äußerungen Wagners über die Bedeutung und möglichen Aufgaben des Staates für die Sozialpolitik jedoch diskussionswürdig und sehr wichtig. ${ }^{11}$ Dies führte zu großer Verärgerung Brentanos. ${ }^{72}$ Eine gewisse Isolie-

${ }^{69}$ Die Wendungen wurde den Beiträgen W. von Humboldts, Rankes und Droysens zur Wissenschaftslehre in verstreuten Aufsatzen entnommen, Die Beiträge sowohl W. von Humboldts, als auch Rankes und Droysens stūtzten sich in wișsenșchaftstheoretischer Hinsicht ausdrücklich auf die StoffForm-Metaphysik von Aristoteles, s. hierzu: Ranke, L. (1832), wie Anm. 68, S. 7. S. 8, S. 14, S. 17. S. 24, S. 45, S. 46 u. a.; insbes. Humboldt, W. von (1827), Ober die Aufgabe ...., (wie Anm. 68), S. 102 , S. 104 - S. 106; s. a. Tónnies. F. (1918), Adolph Wagner, in: Deutsche Rundschau, Bd. 174. S. 110 S. 114; s. a. Wagner, A. (1892), Grundlegung ..., S. 146 u. a.

${ }^{70}$ Brief Brentanos an Schmoller v. 27.10.1878, abgedr. in; Goetz, W. (1941), XXX. Bd., S. 199

"Brief Schmollers an Brentano v. 2.11.1878, in: Goets, W. (1941), XXX. Bd., S. 202 - S. 205.

72 S. Brentano, L. (1931), S. 98; Briefwechsel zwischen Brentano und Schmoller, wie Anm. 71, S. 186 - S. 207. 
rung Schmollers nach allen Richtungen, auch im "Verein für Socialpolitk", war eine Folge der vorherrschenden wissenschaftstheoretischen Grundhaltung, die kein rechtes Verstăndnis für dergleichen Kritik an dogmatisch unterstellten teleologischen Konstruktionen zuließ.

So glaubte Wagner an einheitliche, begrifflich beschreibbare, innere stillwirkende entelechiale Kräfte in der Geschichte. Speziell für unsere Disziplin glaubte er an "leitende Ideen der Epoche", an "Ideen, welche hier, wie ebenfalls stets, wieder in Einklang mit politischen, sittlichen, volkswirtschaftlichen Anschauungen der Zeit sind". ${ }^{73}$ Dabei unterstellte er für seine Zeit den Ubergang von einer "staatsbürgerlich liberalen Epoche" zu einer "sozialen Epoche". ${ }^{74}$ Die Aufgabe des Wissenschaftlers sah er in der Ausübung der Geburtshelferfunktion, konkret auf die Finanzwissenschaften bezogen, für "Umänderungen des Finanzrechts" tảig zu werden, "welche nur die Konsequenz. der in der Volkswirtschaft und Gesellschaft sich unaufhaltsam vollziehenden Entwicklung" sind ${ }^{75}$ Die leitenden Ideen der Epoche bestimmen somit in Theorie und Praxis durch "immanente Logik" die Entwicklung der Besteuerung. Und: "Der Begriff der Gerechtigkeit" - und hinzuzufügen sind alle finanzpolitisch wichtigen Principien wie Leistungsfähigkeit, Gleichmäßigkeit, Allgemeinheit, Bestimmtheit, etc. etc. (d. V.) - "verändert sich und offenbart sich damit überhaupt wieder als historischer Begriff" ${ }^{76}$

Wagner glaubte, die Entwicklung auf dem Wege zum Staatssozialismus sei durch geheimnisvolle, nur dem Wissenschafter erkennbare innere stillwirkende Kräfte oder Ideen unaufhaltbar vorgeschrieben, eine Vorstellung, die Schmoller als spekulative unwissenschaftliche Prophetie ablehnte und als fatalistisch bekämpfte. ${ }^{77}$ Entsprechend entwarf Wagner abgestimmte Forderungen, die von Verbesserung der Produktionsordnung, Steigerung der Löhne, Sicherung des Arbeitsplatzes etc. etc., bis zu fiskalischen Eingriffen, wie Abschöpfung sogenannter Renteneinkommen, einer Umverteilungszielsetzung für Vermögen und Einkommen und regulierenden Eingriffen in den Konsum reichten. Auch die Wertzuwachsbesteuerung, für die Wagner ständig eingetreten ist, gehört hier erwăhnt. ${ }^{78}$

73 Wagner, A. (1890), Lehr- und Handbuch der politischen Oekonomie. Vięrte Hauptabtheilung. Finanzwissenschaft. Zweiter Theil. Theorie der Besteuerung, Gebahrenlehre und allgemeine Steueriehre., S. 376.

${ }^{74}$ Wagner, A. (1890), wie Anm. 73, S. 376. Ziel der Entwicklung war die "ștaatssozialistische Lösung" der sozialen Frage.

${ }^{75}$ Wagner, A. (1890), wie Anm. 73, S. 377, S. 384.

76 Wagner, A. (1890), wie Anm. 73, S. 386.

77 Schmoller, G. (1894), S. 558.

${ }^{78}$ Heilmann, M. (1980), S. 25. 
Wagner war der Meinung, daß die Steuerpolitik sich besonders für die Überleitung zur "sozialen Epoche" eigne. Mit konkreten Einzelheiten darüber, wie die Institutionen des Steuerrechts dies umsetzen sollten, hielt er sich freilich zurück. Seine Ausführungen hierzu auf der 5. Tagung des "Vereins für Socialpolitik" zur "Communalsteuerfrage" trugen ihm eine zeitlebens währende Entfremdung zu den übrigen Mitgliedern ein. Als ausgewiesener Fachmann konnte er Zweifel an seiner Autorităt und der Wissenschaftlichkeit seiner dogmatischen angeblichen Erkenntnisse schlecht ertragen. ${ }^{79}$

Die Auffassungen Wagners ließen die rechtsdogmatische Herleitung neuartiger Abgaben aus "Principien" zu, wie etwa die Erbschaftsteuer, die Vermögenssteuer, eine Wertzuwachssteuer, eine Vermögenszuwachssteuer und weitere bis dahin unbekannte Steuerformen. Diese letzteren suchte Wagner in seiner Systematik bei den Verkehrssteuern einzugliedern. ${ }^{80}$

Daß der Gesichtspunkt einer Besteuerung nach der Leistungsfähigkeit bei deren praktischer Ausgestaltung nicht überzeugend berücksichtigt werden konnte, wurde später gelegentlich hervorgehoben. ${ }^{8 !}$

Das von Wagner aus der Rau'schen Volkswirtschaftslehre fortentwickelte Begriffsgebäude diente jedenfalls weniger der Erklärung der Zusammenhänge der ökonomischen Realităt, denn der Skizzierung einer unterstellten natürlich vorgegebenen Ordnung zur Rechtfertigung diese stabilisierender staatlicher Eingriffe - als "Volkswirtschaftspflege" ${ }^{82}$ bezeichnet - oder als "Wegweiung $^{\text {"83 }}$ für abgabenrechtliche Maßnahmen.

Ein Begriffehimmel wies dem Finanzpolitiker ebenso den Weg, wie der Sternenhimmel dem Kapităn auf hoher See.

Tiefgreifenden sozialpolitischen Eingriffen durch steuerrechtliche Reformen stand jedoch bei diesem zum Manchestermann ausgebildeten und erst spät nach der Berührung mit Rodbertus und Schäfle zum Staatssozialisten konvertierten, im Grunde konservativen, tief religiösen Gelehrten eben dieser

"Boese, F. (1939), S. 28; s. a Schritten des Vereins für Socialpolitik, Bd. XIV, Verhandlungen von 1877, Leipzig 1878, S. 5, hier S. 21: s. a. Bericht Helds (1877), in: Schm. Jb. N. F., 1. Jg. S. 792.

${ }^{80}$ Wagner, A. (1890), Finanzwissenschaft... S. 455. hier insbes. S. 466: ders. (1890). Finanzwissenschaft ..., S. 566, hier S. 579, S. 581, S. 679.

si Bauckner, A. (1915), Die Wertzuwachsbesteuerung in Deutschland, Diss. Würzburg, S. 27, S. 29.

82 Menger verwendete diesen von Sonnenfels abernommenen Begriff der Volkswirtschaftspllege, s. etwa: Wiener Abendpost v. 23.11.1875; s. a. Menger. C. (1883), Untersuchungen über die Methode, S. 245; ders. (1889), Grundzüge ..., S. 13 u. a.; Hansen, R. (1993). S. 139, Anm. 93.

83 Für Wagner bestand die Aufgabe des Wissenschaftlers ebenso nicht nur in der Erkenntnis der "Ziel-Aufstellung", sondern auch in der praktischen "Wegweisung", zu diesem Ziel. Er verwies hierzu auch auf Mengers Methodenschrift, s. Wagner. A. (1892), Gundlagen ...., S. 144, S. 146, S. 164. 
dogmatisch-philosophische Begriffsrealismus im Wege. Er glaubte - und dies entsprach der herrschenden Wissenschaftsauffassung - wie alle Nationalökonomen seiner Zeit, es sei Aufgabe der Wissenschaft, richtige Begriffe aus der Realităt zu "abstrahieren". Diese Überzeugung entsprach auch den Vorstellungen der Vertreter der deutschen historischen Ideenlehren. Allein Schmoller entwickelte gänzlich andere Vorstellungen.

So wurde der herkömmliche Einkommensbegriff von Wagner letztlich aus den klassischen Lehren in Fortruhrung der Interpretation Rau's übernommen, die die Auffassungen seiner Zeit inhaltlich bestimmten. Er entsprach etwa dem Begriff des "Gesammt-Einkommens" in $\S 19$ der "klassifizirten Einkommensteuer" von $1851 .{ }^{84} \mathrm{Er}$ entsprach auch der Lehre von den allein werteschaffenden Produktionsfaktoren.

Er stammte letztendlich aus dem römischen Zivilrecht. Dort bezeichnete er den Früchtefluß aus einer gütererzeugenden, an der Regelung der Eigentumsverhältnisse orientierten Quelle und wurde von den klassischen Nationalokonomen auf die Zuordnung der aus Gewerbefleiß erzeugten Güter auf die drei Produktionsfaktoren zugeschnitten.

Schmoller verwarf bereits 1862 in seinem angeführten Aufsatz diesen aus der Smith'schen Preis- und Produktionslehre fortgebildeten Begriff als brauchbare Grundlage für die Einkommensbesteuerung, wie er auch letztlich die Annahme von drei Produktionsfaktoren als angeblich sachlichen Gehalt der Realität für Besteuerungszwecke ablehnte. ${ }^{85}$

Wagner konnte jedoch aus den genannten Gründen seiner weltanschaulichen Voreingenommenheiten von den vorgegebenen Begriffen als angeblich "richtig" bzw. "wissenschaftlich" und für rechtliche Gestaltungen rechtsdogmatisch maßgeblich nicht loskommen.

\section{Die gesetzgeberischen Konsequenzen}

1. Die Entwicklung des sächsischen Einkommensteuergesetzes 1874/78 aus der Besteuerungsidee Gustav Schmollers

Die Konsequenzen dieser Differenzen um die Entstehung der beiden im Grunde unvereinbarlichen Besteuerungssysteme, das nach rein wirtschaftlichen Gesichtspunkten ausgerichtete sächsische EStG von 1878 einerseits und

\footnotetext{
84 Gesetz-Sarmmlung für die Königll. PreuB. Staaten, Nr. 12 v. 10.5.1851, S. 200.

${ }^{85}$ Schmoller, G. (1863), S. 32; ders. (1894), S. 547 u. a.
} 
das an rein abstrakt-juristisch begrifflichen Bestimmungen orientierte preußische EStG von 1891 andererseits, waren von großer Tragweite. Zur Zeit der Erörterung des preußischen Gesetzentwurfes nach 1882 war Wagner Abgeordneter im preußischen Landtag für Osthavelland. Er war Mitglied des 1882 gebildeten zuständigen Ausschusses für die Reform des preußischen EStG. Zu dieser Zeit erschienen Wagners wichtigste Veröffentlichungen, das "Lehrbuch der Politischen Oekonomie" und die "Finanzwissenschaft" überarbeitet auf dem Markt. Von Schmoller und seinem Schüler Wilhelm Hasbach wurden sie wegen ihres umfanglichen, rein begrifflich dogmatischen Aufbaus in "SchmolIers Jahrbuch" hefig kritisient.

Etwa zu dieser Zeit wurde auch der von Gensel fü die preußische Regierung gefertigte Erfahrungsbericht über die Auswirkungen des sächsischen Experiments bekannt. ${ }^{87}$ Wagner ist auf das Ergebnis nie eingegangen.

Ähnlich günstige Voraussetzungen waren bei Entstchung des sächsischen EStG 1874/78 nicht gegeben. Das war für den Bruch mit der Tradition allerdings von Vorteil gewesen.

Schmoller hatte 1862 in der dargestellten Bemessungsgrundlage für die Besteuerung einen Maßstab für die Verteilung der Lasten des Gemeinwesens durch - in seiner Sprache - "die Wägung der ganzen wirthschaftlichen Schwere, die Messung der totalen wirthschaftlichen Kraft der Persönlichkeit" festzulegen gesucht. Der Schmoller nahestehende Julius Gensel, Mitglied des "Vereins für Socialpolitik", in Leipzig als Rechtsanwalt tätig. war Vorsitzender des zuständigen Ausschusses im sächsischen Landtag für die Reform des EStG und betreute dann die ausgiebige Diskussion der Vorschriften bis zu deren endgültiger Verabschiedung.

Anders als für Wagner, der den aus der klassischen Nationalökonomie in die Ertragsbesteuerung übernommenen Begriff des Einkommens nur ausbaute, stand das Einkommen für Schmoller "mit dem Produktionsprozess nur in mittelbarem Zusammenhang". Es war "keine Ertragskathegorie, kein Produkt eines beliebigen wirthschaftichen Rechnungsexempels". ${ }^{88}$ Im Vordergrund der Gesichtspunkte stand für ihn "die ganze wirthschaftliche Kraft des Individuums ... in ihrem Zusammenhang mit der Bedürfnisbefriedigung". Für Schmoller waren mithin im Grundsatz, mit wenigen Ausnahmen, alle Wertzugănge eines Besteuerungsabschnitts zu berücksichtigen, insoweit der Steu-

so S. hierzu die in Anm. 13 aufgefuhrten Rezensionen Schmollers und Hasbachs. Insbesondere Hasbachs Aufsatz in Schm. Jb. von 1887 und Schmollers angefügter Nachruf richteten sich gegen Wagners dogmatisch aufgebaute Finanzwissenschaft, s. Schm. Jb., 11. Jg. 1887, S. 587.

s7 Gensel, J. (1885), S. 489.

${ }^{88}$ Schmoller, G. (1863), S. 52. 
erbürger sie verbrauchen oder auf andere Weise für sich verwenden kann, ohne sein Vermögen anzugreifen. Zu den Genüssen gehörte für Schmoller auch die Möglichkeit des Müßigganges des reichen Kapitalbesitzers, der infolge seiner hohen Einkünfte aus Kapitalvermögen ohne eigenen Arbeitseinsatz auskommen kann. ${ }^{89}$ Dieser Gedanke führte zur Schaffung einer Vermögensteuer, die in Sachsen erst später verwirklicht wurde. ${ }^{90}$

Darüber hinaus gehörte nach Schmollers Maßstab für Leistungsfăhigkeit jeder "Verbrauch, der ein Bedürfnis befriedigt", bei Ermittlung der Bemessungsgrundlage berücksichtigt. Daher rechnete er den Wert eines selbstbewohnten Hauses ebenso hinzu, wie die ohnehin angerechneten Einküntte aus einem vermieteten Objekt. Die Besteuerung griff mithin in der Regel über die im Tauschverkehr marktmäßig erzielten Erträge hinaus. ${ }^{\text {91 }}$

Auch der Genuß der Nutzung von ungewöhnlichen Luxusgütern jeder Art war mithin steuerbar. Bezüglich des Wertansatzes wies Schmoller darauf hin, daß er in der Höhe erfolgen sollte, die den Erträgen aus dem Veräußerungserlös des Nutzvermögens bei marktmäßiger verzinslicher Anlage desselben entsprechen würde; denn soviel - so glaubte er - muß es dem Nutzer wert sein, das Eigentum an dem Luxusgut aufrecht zu erhalten. ${ }^{92}$ Das war eine überzeugende Folgerung aus dem mit der Besteuenungsidee verbundenen Maßstab für die Lastenverteilung.

Die aus der Finanzrechtsprechung in Preußen zur Unterbindung von mißbräuchlichen Gestaltungen 1894 entstandenen Regelungen für die steuerliche Behandlung von Einnahmen und Aufwendungen aus einer Liebhaberei waren somit nach der zugrundeliegenden Besteuerungsidee in Sachsen entbehrlich. $\mathrm{Da}$ es keine Beschränkung der Einkommensbesteuerung auf Vorgänge des marktmäßigen Tauschverkehrs gab, konnte die bis heute nach der preußischen und später "deutschen Type" der Besteuerung bei intelligentem Einsatz der

89 Schmoller, G. (1863), S. 59, S. 77 u. a.

${ }^{20}$ In Preußen war die Einfuhrung einer Vermỏgensteuer Bestandteil der Miquelschen Steuerreform der Jahre 1891 bis 1893. Deshalb hielt Wagner Preußen für fortschrittlicher als Sachsen, Wagnër, A. (1899), S. 109. In Sachsen wurde eine Vermōgensteuer erst durch Gesetz v. 2.7.1902 als Ergănzungssteuer eingeführt, s. hierzu: Hoffmann. A. (1906), S. 206.

91 Schmoller, G. (1863), S. 66. S. 76 u. a., "Erwerb und Genuß sind Ein und Dasselbe, nur von verschiedenen Seiten oder in verschiedenen Momenten angesehen und darum verschiedene Form zeigend. Es ist dieselbe Werthmenge, die erworben werden muB um sie durch unmittelbaren Verbrauch oder Kapitalanhäufung zu genießen. Jeder Genuß muß auf einem Erwerb beruhen", S. 66, S. 67.

92 Schmoller, G. (1863), S. 76. 
Liebhaberei erreichbare Annehmlichkeit, die Steuerbarkeit von Vermögenszugängen zu unterlaufen, nicht durchgesetzt werden. ${ }^{93}$

Schmollers Maßstab für Leistungsfähigkeit, der die Verteilung der Lasten in der Gesellschaft der Regel nach bestimmte, bezog sich somit auf die ganze Person und nicht nur auf den Teil des Steuerbürgers, der in den marktmäßigen Tauschverkehr hineinragte.

Uberhaupt bestimmte in dem aus dieser Besteuerungsidee entwickelten Steuersystem der tatsächlich getåtigte Verbrauch der Regel nach die unterste Grenze der Besteuerung; dies jedenfalls, insoweit er als verläßliches Indiz für eine Selbsteinschătzung des Einkommens durch den Steuerbürger gelten konnte. $^{94}$

Gewiß entwickelte Schmoller in dieser Besteuerungsidee einen Maßstab für die Belastungsverteilung, der zur Ermittlung des steuerbaren "Total-Einkommens" der Steuerbürger in der Praxis einige theoretische Umrechnungen erforderlich machte. ${ }^{95}$ Diese sind aber ohne größere ungewöhnliche Schwierigkeiten auch bei Massenverfahren durchführbar. In Sachsen führte die daraus entwickelte Einkommensbesteuerung nicht zu bekanntgewordenen Beanstandungen.

"Unvollkommenheiten" bleiben bei der Anwendung bestehen; den "theoretischen Forderungen" kann man sich in der Besteuerungspraxis stets nur nähern, so hielt der durch die praktische Veranlagung von Steuerbürgern erfahrene junge Finanzassessor fest. Aber: "Sollen wir den einzigen Anker, den wir

93 Die Beschrănkung der. ESt auf die im Besteuerungsgegenstand des preü̈. EStG in einem Enumerativkatalog aufgelisteten Einkunftsarten hat die strenge Trennung von nicht steuerbaren Vorgängen in der Privatsphăre von steuerbaren Vorgängen in der Marktsphäre entstehen lassen. Zur Verhinderung erôftneter großer Möglichkeiten der Steuervermeidung durch intelligente Gestaltungen durch Vermengung von Berufs- und Privatsphlise hat das preuB. OVG im Urteil v. 14.12.1894 Gesichtspunkte formulieren müssen, die einer steuerlichen Anerkennung in Wege stehen. Diese wurden unter dem Schlagwort "Liebhaberei" zusammengefaßtt. Tatsăchlich können aber nur grobe Fälle der Steuervermeidung verhindert werden. Hier liegt nun einmal ein Spezifikum der preuß. oder "deutschen Type" der Einkommensbesteuerung, s. hierzu Kapitel D, Anm. 127, 128 und 250.

94 Schmoller hielt 1862 fest: "Niernand kann dauernd Ausgaben für seine Persönlichkeit machen ohne Einkommen", Schmoller, G. (1863), S. 53. Diese Feststeliung führte im sáchs. EStG 1874/78 zu dem in $\$ 15$ Ziff. 6 normierten alternativen Ansatz des Verbrauchs als Bernessungsgnundlage für die ESt. Die Regelung wurde spater als § 49 EStG 1925 und dann § 48 EStG 1934 in das ESt-Recht übernommen. Nachdem $\$ 48$ im Jahr 1980 ersatzlos gestrichen wurde, wird der zugrundeliegende Gedanke von der höchstrichterlichen Finanzrechtsprechung noch heute gelegentlich als Indiz für die Bemessung der Leistungsfahigkeit eines Stpfl. herangezogen.

95 Das "Total-Einkommen" als steuerliche Bemessungrgrundlage schliebt die wirklichen und die mŏglichen Ertrăge und Genüsse ein, s. Schmoller, G. (1863), S. 76, S. 77. Zui praktischen Umsetzung s. von Myrbach, F. (1898), in: Schm. Jb., 22. Jg, S. 103, S. 104. 
haben, über Bord werfen, und uns Wind und Wellen überlassen, weill der Anker auch schon versagte?" ${ }^{\text {"96 }}$

Diesen Maßstab für die Leistungsfahigkeit und damit für die Besteuerung eines Mitbürgers konnte man nach Schmoller übernehmen oder verwerfen. Man konnte ihn auch übernehmen und einzelne konkrete Ausnahmen und Auslegungsregeln vorsehen, wie dies in Sachsen geschah. Allein, seine Richtigkeit in wissenschaftlicher Hinsicht kann man weder behaupten, noch bestreiten, so glaubte Schmoller, da es für die Verwendung gute Grinde, aber kein Wahrheitskriterium geben kann.

Eine Erörterung des Begriffes der Besteuenung nach der Leistungsfähigkeit ohne konkrete Definition desselben lehnte Schmoller im übrigen als leere, unverbindliche Begriffsspielerei, als Trăumerei, wiederholt ab. Hiermit kritisierte er 1862 insbesondere Schäffle, der behauptete, man könne den Begriff gar nicht endgültig definieren und zugleich in Veröffentlichungen viele Seiten über seine große Bedeutung fulltte, ohne sich darüber klar zu werden, worüber er konkret redete. ${ }^{97}$

Im übrigen glaubte Schmoller, daß der Einkommensteuer im System der Besteuerung eine Korrekturfunktion zur Orientierung der gesamten Steuerbelastung an der Leistungsfähigkeit des Steuerpflichtigen zukommen solle.

Die Schmollersche Definition wurde etwa 10 Jahre nach Formulierung als Grundlage der Besteuerung im gesamten deutschen Sprachraum zur Neuorganisation dieser Besteuerungsart erörtert und allgemein empfohlen ${ }^{98}$ Auf der 2. Tagung des "Vereins für Socialpolitik" war diese Besteuerungsidee von den Schmoller nahestehenden Referenten Julius Gensel und Adolph Held - freilich ohne Namensnennung Schmollers - vertreten und allgemein befürwortet worden.

Tatsächlich wurde die Definition Schmollers ausdrücklich die Grundlage des ersten modernen deutschen Einkommensteuergesetzes in Sachsen. Grundgedanken daraus wurden später unter anderen Ländern in Preußen, in Österreich, in der Schweiz und um 1900 in Württemberg übernommen.

Nach rein wirtschaftlichen Gesichtspunkten ausgerichtet, erhielt das sächsische EStG 1878 allgemein eine Vorbildfunktion für viele Teile des späteren preußischen EStG von 1891.

\footnotetext{
${ }^{96}$ Schmoller, G. (1863). S. 57.

${ }^{97}$ Schmoller. G. (1863), S. 57. S. 62.
}

${ }^{98}$ Burkhart, K. (1876). Die bestehenden Einkommensteuern. Eine vergleichende Darstellung, im Auftrage des deutschen Steuer=Reformvereins bearbeitet, in: Annalen des Deutschen Reichs, S. 50; s. a. Hansen, R. (1990), S. 23. 


\section{Die Orientierung des preußischen Einkommensteuergesetzes 1891 an den Lehren Adolph Wagners}

Es konnte nicht ausbleiben, daß dem sächsischen EStG 1874/78, das stets eine positive Beurteilung fand, für das preußische EStG 1891 eine Vorbildfunktion zukam. Jedenfalls galt dies für wesentliche Elemente, wie etwa den Gesamtaufbau und die Paragraphenfolge, die einheitliche Bemessungsgrundlage für alle Einkünfte, die lange Zeit hindurch in Preußen heftig umstrittene Selbsideklaration und eher eingeschränkt für das Steuerstrafrecht und ebenso für das Rechtsbehelfsverfahren.

Die Gesichtspunkte für die Bestimmung des Besteuenungsgutes, die zugleich für die Gesamtauslegung des Gesetzes Bedeutung haben mußten, konnten jedoch in Preußen nicht übernommen werden.

Wie sah nun đie Grundlage für das preußische, aus Wagners Lehren entwikkelie Einkommensteuergesetz aus?

Bereits 1875 hatte Wagner klar herausgestellt, daß die Einkommensteuer nur Einkünfte aus einer "festen Erwerbsquelle" erfassen kann. Das entsprach den aus Rau's Lehrbuch übernommenen und in seiner "Grundlegung" (1876 und 1879) und später den "Grundlagen" (1892) fortentwickelten begrifflichen "Erkenntnissen". Wagner sprach von Einkünften aus der "Wirtschaftsführung", aus einzelnen "wirtschaftlichen Tätigkeiten", aus "Forderungsrechten" und aus "Genußmöglichkeiten" aus dem "Nutzvermögen einer Person". ${ }^{99}$ Diese letztere Position, die Wagner nach einem Hinweis aus dem Aufsatz Schmollers von 1863 übernommen hatte, blieb in dem System der Regel nach ein Fremdkörper und wurde nicht weiter berücksichtigt. ${ }^{100}$

99 Wagner, A (1876), Allgemeine oder theoretische Volkswirthschaftslehre. Mit Benutzung von Rau's Grundsätzen der Volkswirthschaftslehre. Zugleich als 9. Ausgabe der Rau'schen Volkswirthschaftslehre. Theil 1, Gnundlegung, Leipzig u. Heidelberg 1875/76 (Karl-Heinrich Rau, Lehrbuch der politischen Oekonomie), Bd. I, S. 96. Die hier wiedergegebene Definition wurde mit geringfügigen Ergănzungen in die Neuauflage von 1879 abernommen, s. dort S. 115. In der Neuauflage, als "Grundlagen" bezeichnet, finden wir die Definition auf S. 405. Fär die hinzugefügten "GenuBmōglichkeiten aus dem Nutzvermōgen einer Person" vervies Wagner darauf, diesen Zusatz aus Schmollers Aufsatz yon 1863 abernommen zu haben (s. Anmerkung). Er wiederholte dies in sămtlichen Auflagen. Tatsächlich vernachlässigte er điese Forrn von Einküntten als Fremdkörper in seinern System jedoch vôllig. In seiner Definition des Einkommens in den "Grundlagen" des Jahres 1892 unterschied er plotzlich zwischen einem "wesentlichen" Einkornmensbegriff und einer Erweiterung desselben aus Grüunden der ZweckmäBigkeit, s. "Grundlagen" (1892), S. 407 und Finanzwissenschaft (1890), S. 325.

${ }^{100}$ Diese letztlich nach Wagners Anmerkungen aus Schmollers Beitrag von 1863 übernommenen "Genußmōglichkeiten aus dem Nutzvermoogen einer Person" wurden volllig vernachlăssigt. Sie stellten in Wagners System einen Fremdkōrper dar. Bereits Schmoller hatte festgehalten, daß đie herkömmliche Einkommenslehre ein Nebenprodukt der klassischen Preis- und Produktionslehre war und fertigerzeugten Investitionsgütern nach Abschlub der Produktion keine Funktion zukam, s. Schmoller, G. (1863), S. 6, S. 7; s. a. Wilke, G. (1921), S. 98; s. Wagner. A. (1897), Handbuch, S. 434, Anm. 289. 
Schon seit 1871 beklagte Wagner, daß eine Einkommensteuer außerordentliche, "unverdiente Einkünfte", entstehend aus den außerhalb der durch regelmäßige, beruflich bedingte Erwerbstätigkeit anfallenden Zuflüssen, grundsătzlich ungeschoren lassen muß. Diese Feststellung hat Wagner 1871 getroffen und er hat sie weiterhin in seinen von 1875 bis 1880 verfaßten Lehrbüchern und in deren späteren Auflagen um 1890 sowie in seinem Referat auf der Generalversammlung des "Vereins für Socialpolitik" über die "Communalsteuerfrage" im Jahre 1877 sowie in zahllosen Vortrăgen wiederholt. Unter den Begriff des Einkommens waren derartige Wertzugänge nicht subsumierbar und daher ex definitione kein Einkommen. Wenn er noch 1890 Schmoller die Definition des Einkommensbegriffes nach Gesichtspunkten der Zweckmaßigkeit vorwarf, so kommt hier die im "Methodenstreit" aufgeworfene wissenschaftstheoretische Differenz kurz vor dem sogenannten "Sieg" auf einem der "Schlachtfelder" zum Ausdnuck. ${ }^{10 !}$

Seit seiner Untersuchung des Reichsfinanzwesens im Jahr 1871 empfahl Wagner, das von einer Einkommensteuer nach seinen Vorstellungen nicht steuerbare, in seiner Größenordnung wachsende Besteuerungsgut der außerordentlichen Erträge einer Steuer zu unterwerfen. Seine Besteuerungsidee für die direkte Besteuerung sah hierfür einen Ausbau der Verkehrssteuern vor. ${ }^{102}$ Auf seine Anregung hin lieferte dann später 1878 sein Schüler Robert Friedberg eine Systematik des Besteuenungsgutes für die erforderliche Erfassung. ${ }^{103}$ Diese Besteuerungsidee hat Wagner noch in seinen Vorlesungen 1897 vorgetragen. Für einen Ausbau der Verkehrssteuern hat er sich noch im hohen Alter eingesetzt. ${ }^{104}$ Die auf sein Drängen entstandene preußische Wertzuwachssteuer von 1910, die er hierzu rechnete, begrüßte er.

${ }^{101}$ Diese agonale Denkweise hat Schumperer in die Berichterstattung der wissenschaftstheoretischen Ŝtreitigkeiten eingefuhrt. Für ihn endete der Methodenstreit, weil es an eigentlichen wesentlichen Differenzen mangelte. Es war "ein Kampf zwischen Leuten verschiedenen geistigen Habitus, die um Luftraum oder Herrschaft stritten", s. Schumpeter, J. A. (1914), Epochen der Dogmen- und Methodengeschichte, in: Grundriß der Sozialoekonomik, 1. Abteilung. Wirtschaft und Wirtschaftswissenschaf, Tübingen, S. 104; ăhnlich Schumpeter (1954), History of Ecanomic Analysis, New York, S. 814; ders. (1965), Geschichte ..., S. 994; s. hierzu: Hansen, R (1968), S. 170.

102 Hierzu: Wagner, A (1871), Reichsfinanzwesen, in: Jahubuch fur Gesetzgebung, Verwaltung und Rechtspflege im Deutschen Reich, 1. Jg, S. 624 und desgl. 3. Jg. 1874, S. 208 - S. 210; s. a. Wagner. A. (1877), Referat über die Communalsteuerfrage, in: Verhandlungen der 5. Generalversamnlung des Vereins für Socialpolitik, am 8.9. und 10.10.1877 (Schriften des VfS, Bd. 14), Leipzig 1878, S. 5, S. 9, S. 22; hierzu auch: Held, A. (1877), in: Jahrb. f Gesetzgebung, Verwaltung und Volkswirt. schaft im Deutschen Reich, N. F., 1. Jg., S. 791.

${ }^{153}$ Friedberg, R. (1878), Zur Theorie der Stempelsteuem, in: Jahut. f. Nationaloekonomie und Statistik, Bd. 31, S. 69, hier S. 79 - S. 85; s. a. Heckel, M. von (1890), Zur Lehre von den Verkehrssteuem, in: FA. 7. Jg., S. 401, hier S. 411 ; s. a. Wagner, A (1890), § 228, S. 557 - S. 559.

${ }^{104}$ Wagner, A. (1897), Grundriß ..., S. 65 - S. 69; s. a. DJZ, XV Jg. 1910, Sp. 519. 
Wenn Wagner gern von einer Besteuenung nach der "Leistungsfähigkeit" sprach, so muß festgehalten werden, $\mathrm{da}$ er nur in wenigen Bemerkungen eine mit seinem System konforme Definition dieses Begriffes formulierte. ${ }^{105}$ Der Begriff der Leistungsfähigkeit wurde von Wagner auf diese Weise letztlich stets vermittels des Einkommensbegriffs bestimmt. Er wurde bei Wagner, Fuisting, Bredt und den spăteren Vertretern der preußischen Einkommensbesteuerung nur noch als epitheton ornans benutzt, da sie auf eine unabhängige Definition des Begriffs verzichteten. Das blieb bis heute so.

Der von der Kommission des preußischen Abgeordnetenhauses mit der Regierung 1890 endgültig beschlossene Entwurf eines Einkommensteuergesetzes folgte zu dieser Zeit streng der in Rau's Lehrbüchern nach Fortführung durch Wagner entwickelten, von Schmoller 1863 als ungeeignet bekảmpften Systematik. Wie das Einkommen als Besteuerungsobjekt zu bestimmen ist, habe danach die. Finanzwissenschaft aus der herkömmlichen theoretischen Nationalökonomie zu entnehmen, so heißt es bei Wagner. ${ }^{106}$ Hierzu waren die Definitionen in seiner "Grundlegung" (1876) bzw. in den späteren "Grundlagen" (1892), die Wagner als theoretische Lehrbücher der Volkswirtschaftslehre verstanden wissen wollte, maßgeblich. ${ }^{107}$ Begriffe waren für Wagner Theorien. Ausgangspunkt für die volkswirtschaftlichen Steuerquellen ist nach diesen Lehren das Nationaleinkommen, aus dem das Privateinkommen als Beziehung der Einnahmen oder Erträge auf die Person, welche sie empfängt, entwickelt wird. Die Produktions- und Verteilungsinteressen haben in der Volkswirtschaft nach Wagner ausdrücklich Priorităt. ${ }^{108}$ Das Einkommen besteht danach aus dem Reinertrag der "wahren Ertragsquellen", ist also ein Resultat der Güterproduktion für den Markt. ${ }^{109}$ Die Güterquellen selbst sind mit ihren konjunkturbedingten Wertschwankungen als Besitz oder Vermögen im Interesse der Wohlstandsmehrung streng von der Besteuerung auszunehmen. Diese darf nưr die Früchte aus bestehenden, regelmäßig fließenden Quellen erfassen. Von den nachklassischen Theoretikern war jedes sogenannte "Renteneinkommen" als "unearned increment" unproduktiv und daher als Folge und nicht als Ursache der Preisbildung beurteilt worden. Derartige Einkünfte waren wissenschaftlich nicht zu rechtertigen, da sie nicht notwendig mit einer

\footnotetext{
${ }^{105}$ Wagner. A. (1880). Finanzwissenschaft .... S. 350; ders. (1890), S. 444.

106 Wagner. A. (1880), Finanzwissenschaft .... S. 256.

107 Wagner. A. (1879), Grundlegung .... S. 114; ders. (1892), Grundlagen ..., S. 405; hierzu: Besprechung von Wagners Schriften durch M. v. Heckel (1900), in: Jb. f. Nationalōkonomie u. Statistik, 19. Bd., S. 862, hier S, 868 .

${ }^{108}$ Wagner, A. (1876), Grundlegurig ..., S. 98; ders. (1879), Grundlegung ..., S. 114; ders. (1880), Finanzwissenschaft, S. 239.

109 Wagner, A. (1880), Finanzwissenschaft .... S. 249. S. 371 u. a.
} 
Güterproduktion verknüpft waren. Entsprechend erfaite und belastete ein aus diesen Thesen für Besteuerungszwecke entwickeltes Normensystem vorzugsweise das Ergebnis des Fleißes der in der Güterproduktion tätigen Inhaber sogenannter Produktionsfaktoren. Vermögenszuwächse, ob durch Spekulation, durch konjunkturelle Entwicklungen oder gar geschickte steuerrechtliche Gestaltungen erzielt, ebenso unregelmäbige Zuflüsse, die nicht einer bestehenden produktiven, der Gütererzeugung dienenden Quelle zurechenbar sind, gehörten daher nach Wagner nicht zum Einkommen. Da es sich aber hierbei um ein stetig wachsendes Besteuerungsgut handelt, "welches durchaus nicht als Steuerquelle völlig ungenutzt gelassen werden kann", wie Wagner gelegentlich ausführte, legte er nahe, Vermögensmehrungen als "Wertzuwachs ohne eigene personnliche wirtschaftliche Leistung", also "unverdientes Einkommen", wie er es auch nannte, steuerlich besonders, nămlich bei den Verkehrssteuern zu berücksichtigen. ${ }^{110}$

In seinem berühmt gewordenen Aufsatz mit dem Titel "Finanzwissenschaft und Staatssozialismus" wies Wagner 1887 gelegentlich starker Konjunkturschwankungen auf die mit der Industrialisierung zunehmende Bedeutung der außerhalb der Güterproduktion entstehenden erheblichen Kapitalanhäufungen hin. ${ }^{111}$ Er sprach dabei von einem Erfordernis "der Verhütung der Ausnutzung der wirtschaftlichen Konjunkturen durch die einen auf Kosten der anderen" und wollte der Spekulation Dämpfer aufgesetzt wissen. ${ }^{112}$ Sein feststehendes, aus den nachklassischen Lehren mit dem ihm inhaltlich vorgegebenen Einkommensbegriff rechtsdogmatisch entwickeltes Konzept für die Einkommensbesteuerung wurde jedoch von diesen Gedanken nicht berührt. Diese Feststellung gilt im Grunde für die Zeit bis zu seinem Tode, wenngleich er sich später gelegentlich schwankend zeigte und in Widersprüche verwickelte. Im übrigen überschätzte Wagner um 1879 die großen Schwierigkeiten einer Einkommensteuerreform und bevorzugte - der Bismarckschen Politik nachfolgend - anstelle dieser Reform vorsichtig eine Erhöhung der indirekten Steuern. ${ }^{113}$

In der im "Finanz-Archiv" abgedruckten detaillierten Besprechung des neuen preußischen EStG von 1891 nach dessen Verabschiedung durch Wagner finden sich zu diesem Problemkreis nur wenige kritische Passagen. Im Widerspruch zu seinen bisherigen Auffassungen und Lehren trat Wagner jetzt plötzlich unvermittelt für die Erweiterung des gesetzlichen Einkommensbegriffs um "außerordentliche" Einkünfte - nun plötzlich sogar inklusive nicht reali-

\footnotetext{
${ }^{110}$ Hierzu s. Anm. 101 und Anm. 102.

111 Wagner, A. (1887), Statssozialismus ..., S. 37.

112 Wagner, A. (1887), Stuatssozialismus ..., S. 109, S. 113.

"1s Wagner, A. (1879), Ober die schwebenden ..., S. 98.
} 
sierter Wertsteigerungen - unter Gesichtspunkten der reinen Zweckmäßigkeit ein, solange dieses Besteuerungsgut nicht bereits anderweitig erfaßt wird. Die unveränderte "wissenschaftliche" Definition des Einkommensbegriffes sollte nun zeitbedingt und nur behelfsweise der Zweckmäßigkeit Vorrang einräumen. ${ }^{114}$

Zweifellos kommt dem großen Fleiß, mit dem Wagner die von Rau aufgebaute Finanzwissenschaft fortentwickelte und begrifflich verarbeitete, für das moderne Besteuerungswesen dennoch große Bedeutung $\mathrm{zu}$.

Wie wurden die Gedanken Wagners zum preußischen Einkommensteuergesetz fortentwickelt?

Der großte Flächenstaat Deutschlands definierte in dem preußischen EStG von 1891 Einkommen als den Gesamtbetrag aller Vermögenszugänge aus vier năher bezeichneten, an den herkömmlichen Produktionsfaktoren ausgerichteten, aus der Ertragsbesteuenung übernommenen Einkunftsquellen, "insoweit sie in ihrer Gesamtheit als Erträge dauernder Quellen der Gütererzeugung zur Bestreitung der persönlichen Bedürfnisse zur Verfügung stehen ...". ${ }^{115}$ Dabei setzte dle Steuerpflicht einschränkend obendrein spăter durch die Begriffsauslegung eine auf Gewinn gerichtete Tätigkeit, oder besser: die Absicht der Überschußerzielung, voraus. Diese Einschränkung ist von großer, einem Laien zumeist nicht erkennbarer Tragweite. Darüber hinaus mußte die Einkunftsquelle regelmäßig fließen und zu Beginn eines Steuerjahres bereits bestanden haben.

Gegenüber dem auf den "Werthezufluß einschließlich realisiertem Werthezuwachs einer Person" abstellenden sächsischen Maßstab für die Bemessungsgrundlage trat hier in Preußen die Beurteilung des "Woher des Werthezuflusses", ${ }^{116}$ der aus bestehenden, regelmäßig fließenden Produktionsquellen von Gütern stammen mußte. Daher die Bezeichnung "Quellenprinzip" der Einkommensbesteuerung. Der Wertezuwachs der Quelle wurde nur im Falle der nachweisbaren Spekulationsabsicht, also als Ausnahme, steuerlich von Bedeutung. Der in England 1803 von Henry Addington aus Gründen der ZweckmäBigkeit verfolgte Gedanke einer Erhebung der Einkommensteuer durch "stop-

I' Wagner, A. (1891), Die Reform .... S. 551, hier insbes. S. 692; s. a Gemperl, A. (1923), Finanztheoretischer und finanzpolitischer Einkommensbegriff, Diss. Freiburg. S. 20, S. 51, S. 94. Gemperli stellte heraus, daß fur Wagner die Erfassung dieser "unverdienten" Einkünfte nur so lange aus ZweckmaBigkeit bei der Einkommensbesteuerung erfolgen sollte, wie eine Besteuerung nicht auf andere Weise bei den Verkehrssteuern angemessen sichergestellt ist. Es handehte sich hierbei gewissermaß̉en um eine Notlōsung, die mit der Besteuerungsidee Wagners nicht in Einklang stand, s. hierzu auch: Wagner, A. (1890), Finanzwissenschat, S. 444.

${ }^{11}$ S. Fuisting, B. (1902), Gnundzäge ..., S. 110.

"16 Fuisting, B. (1902), Grundzùge ..., S. 110. 
page at source" hatte im preußischen EStG eine essentialistische Auslegung gefunden.

Die Feststellung der Einkünfte erfolgte durch Ermittlung des Überschusses der steuerbaren Einnahmen über die mit diesen in Verursachungszusammenhang stehenden Ausgaben, den sogenannten Werbungskosten $(\S 9$ preußisches EStG 1891).

Spitzfindigen, rein begrifflichen Abgrenzungen von Einkommen und Vermögenszugang kam fortan - wie wir an anderen Stellen erfahren - für die Bcsteuerung entscheidende Bedeutung zu. ${ }^{117}$ Das Markteinkommen wurde der Regel nach zum Maßstab der Leistungsfähigkeit bestimmt.

Das hatte weitgehende Konsequenzen für die Gesetzesvorschriften, deren Auslegung und die Organisation der Besteuerung.

Vor allem die noch heute für die "deutsche Type" der Einkommensbesteuerung charakteristische, betont eingriffsrechtliche Beurteilung des Einkommensteuerrechts findet in der auf Wagner zurückgehenden streng begrifflichen Orientienung eine Grundlage, die nie abgestreift wurde: Der heute eingefahrene steuerliche Einkommensbegriff hat trotz der inzwischen allen erkennbaren offensichtlichen Fragwürdigkeit als Kriterium für die Belastungsverteilung gegenüber demjenigen des allgemeinen Sprachgebrauchs, der Wagnerschen Denkweise folgend, dennoch seine Bedeutung behalten, mehr zu beinhalten, als eine bloße zweckmäßige Rechengröße zu einer sinnvollen Lastenverteilung.

Wie die von Wagner in seinen "Grundlagen" zusammengetragenen Begriffe wird er von Steuerjuristen heute noch wie eine hinter den Erscheinungen stehende Entităt behandelt, indem das Einkommen zur Abwehr unzulässiger Eingriffe mit objektiven Grundrechten der Verfassung abgestimmt wird.

Als reine Berechnungsgröße für die Lastenverteilung könnte der steuerliche Einkommensbegriff sonst kaum aus Art. 14 Abs. 2 GG bzw. Art. 12 Abs. 1 GG hergeleitet werden, wie dies von einem einflußreichen Steuerjuristen heute vertreten wird. ${ }^{118}$

${ }^{117}$ S. Schanz, G. (1896), S. 57.

${ }^{118}$ S. Kirchhof, P. (1988), Empfiehlt es sich ..., S. 14. Kirchhof glaubt, vermittels Interpretation der. Art. 14 Abs. 2 und 12 Abs. $1 \mathrm{GG}$ begründen zu können, daß nur marktabhângige "Erwerbseinnahmen, ... die aus einer den Zugang zum Markt vermittelnden Erwerbsgrundlage erzielt werden", steuerbar sind (S. F 21). "Die Einkommensteuer ist keine Bereicherungssteuer, sondern staatliche Teilhabe am Erfolg individuellen marktabhăngigen Verhaltens", so fuhrte er 1988 in einem Gutachten für den 57. Deutschen Juristentag aus (S. F 20). Entsprechend stellt Kirchhofs Belastungsidee auf eine eingeschrânkte, "durch die Gemeinschaft vernittelte individuelle Leistungsfahigkeit" ab, die in seinem Einkommensbegriff konkretisiert wird (S. F 21). Die Erwerbsgrundlage der sachlichen Einkommens- 
Im übrigen war die Aufzählung der Tatbestandsmerkmale des Einkommensbegriffs im preußischen EStG 1891 nach der zugrundeliegenden Besteuerungsidee erschöpfend. Für eine ausweitende Auslegung des Einkommensbegriffs durch eine wirtschaftliche Interpretation als Vermōgenszugänge fand sich im Gesetz kein Ansatzpunkt. Die Vorstellung von sittenwidrigen Steuerumgehungen war jedenfalls bis zur Schaffung des $\S 5$ RAO durch die Reformen von 1919 abwegig. ${ }^{119}$ Was als Einkommen zu verstehen war, lag nun einmal begrifflich vorgegeben fest. Daß Steuervermeidungen durch geeignete rechtliche Gestaltungen leicht möglich waren, war der praktische Schwachpunkt des Systems, der von Wagner nicht gesehen wurde, weil er nach einem "richtigen" Einkommensbegriff in einem abstrakten Sinne suchte. Einer Rechtstatsachenforschung konnte daher in dem zugrundeliegenden Denkansatz keine systematische Funktion zukommen.

Meisel hielt 1919 ernüchternd fest: "Es ist doch bezeichnend, daß der Streit um die Veranlagung der preußischen Einkommensteuer ein sachverständiges Urteil über die sächsische Einkommensteuer veranlaßt hat, das (dort d. V.) friedliche Verhältnisse und günstige Ergebnisse bei der Veranlagung feststellt. ${ }^{\text {"120 }}$

Erst auf dieser Grundlage kann die vorsichtige Kritik verständlich werden, die Schmoller in seine Gedenkrede anläßlich des Todes seines langjährigen Freundes und Mitglieds des Vereins für Socialpolitik, Johannes von Miquel,

quellen und die Erwerbsgnundlage der Berufstătigkeit sind nach dieser Auslegung gem. Art. 14 Abs. 2 bzw. Art. 12 Abs. 1 GG von einer Sozialpflichtigkeit ausgenommen, die nur deren Gebrauch ein. schlieBt. Nach diesem Gedankenmodell würden spitzindige Abgrenzungen die Beschränkung des Steuerzugriffs auf ein Markteinkommen garantieren, der bei intelligenter praktischer Gestaltung des Sachverhalts stets nur ein Teil dessen als steuerbar umfassen dürfte, was der Bürger nach allgemeiner Sprachabung unter Einkommen versteht und was er sich letztlich als Mittel zur Erhaltung und Mehrung seines Lebensaufwands verfügbar machen will. Kirchhof sucht offenbar nicht einen Verteilungsschlossel für eine aberzeugende Lastenverteilung entsprechend der Leistungsfahigkeit der Steuerbürger festzulegen, er sucht einen rechtsdogmatisch richtigen Einkommensbegriff zu definieren. Schmoller verfolgte 1863 mit seinem Ausbrechen aus der Tradition ein anderes Ziel. Merkwürdig ist, daB Kirchhof für seine Konstruktion auch Schmoller zitiert (S. F 22). Kirchhof ist als Bundesverfassungsrichter Mitglied des für Steuerșachen zustalndigen Senats.

119 Nevermann, K. (1994), S. 70, S. 71, spricht von den in preuß. EStG 1891 gewährten Möglichkeiten zur Steuervermeidung als "Ungereimtheiten". Das wird den historischen Gegebenheiten nicht gerecht. Es handelte sich "bei Verträgen der angefuhrten Art nicht um neue Gestaltungen zur Steuervermeidung, die bald zur Aufrnerksarnkeit der Behörden und Gerichte" gelangten. Das Verhalten stellte vielmehr eine allgemein benutzte legale Form der Steuervermeidung durch vertragliche Gestalfung dar, die mit dem begrifflichen Aufbau des Gesetzes unvermeidbar verbunden war und deshalh vorerst nur von kritischen Beobachtern wie Meisel, Schmoller, Delbrück, Michaelis und weiteren an sozialpolitischen Gesichtspunkten orientierten Fachleuten beanstandet wurde. Anders verhielt es sich bei den Vorgängen, die zu der Beurteilung als steuerlich nicht relevanter Liebhaberei fuhrten. Hier war jeweils vom Steuerpflichtigen zumeist eine Intention vorgetauscht worden, die nach dem objektiv vorliegenden Sachverhalt nicht glaubwirdig aufrecht erhalten werden konnte.

${ }^{120}$ S. Meisel, F. (1910), S. 406; ders. (1914), S. 649. 
anf der Generalversammilung am 23. September 1901 bei Würdigung von dessen Lebenswerk einflocht. Er bedauerte zwar Teile der konkreten Ausgestaltung als Problemlósung, rief aber die mit dem Gesetz verfolgte, jahrelang währende gemeinsame soziale Interessenrichtung in Erinnerung. ${ }^{121}$

Auch die zweite eingangs formulierte Fragestellung erscheint somit beantwortet: Die Steuenwissenschaften haben versăumt, die Entstehung der Einkommensbesteuerung in Deutschland kritisch aufzuarteiten. ${ }^{122}$

\section{Das endgültige Verhandlungsergebnis in Preußen}

Einer Reform des gesamten Besteuerungswesens, insbesondere dem Stellenwert der direkten Steuern und speziell der Funktion und Ausgestaltung der Einkommensteuer, war bereits bei Gründung des Vereins für Socialpolitik im

${ }^{121}$ Schmoller, G. (1902) in: Schriften des Vereins fur Socialpolitik. Bd. 98, S. 13/14, abgedr. in: ders. (1913), Charakterbilder, S. 93. Schmoller erwahnte in der Gedenkrede, daß die preuß. Finanzreform der Jahre 1891 bis 1893 "nicht ausschließlich ein Werk sozialer Gerechtigkeit" war. "... sie hat manche Bestandteile, die man vom sozialen Standpunkt vielleicht angreifen kann ...". Mit dem verfolgten "Grundzug" einer "Entlastung der unteren Klassen" identifizierte er sich jedoch.

${ }^{122}$ Die Finanzwissenschaften wurden von A. Wagner maBgeblich gepragt, indem er ihre Aufgabenstellung und die methodische Vorgehensweise festlegte. Noch 1932 konnte der Schüler und jüngere Freund E. Seligmans, G. Myrdal, bemanngeln, was Schmoller bereits 1881 beklagt hatte und was den sogenannten Methodenstreit in der Nationalökonomie auslöste: Das "Räsonnieren" von metaphysischen, inhaltlich nicht festgelegten "Principien" stehe noch immer im Mittelpunkt der Finanzwissenschaft, s. Myrdal, G. (1963), S. 153. Die Untersuchung der Wirkungen móglicher Besteuerungssysteme und "die Aufgabe, die Wirkungen altemativer Maßnahmen festzustellen, so da B politische Entscheidungen aufgrund einer richtigen Wirklichkeitserkenntnis getroffen werden können", wurde nach Myrdals Beurteilung von den Finanzwissenschaften vollig vernachlăssigt, S. Myrdal, G. (1963), S. 179. Steuerrechtswissenschaftler beklagen heute ein angeblich vorhandenes "Traditionsdefizit" bezuglich der Einkommensbesteuerung. Sie lassen das moderne ESt-Recht mit der grundlegenden Reform Miquels entstehen und bewundern dessen "besondere legislatorische Leistungen ohne steuerrechtswissenschaftliche Grundlagen", s. Lang. J. (1987), S. 6; Tipke, K. (1993), Steuerrechtsordnung, S. 39. Nationalökonomen haben andererseits den Methodenstreit in der Disziplin als "Kampf um Luftraum oder Herrschaft" bagatellisiert, wobei in Vergessenheit geriet, daß er 1881 durch Schmollers Klage âber die metaphysische Ausrichtung der Finanzwissenschaft ausgelőst wurde und daß̉ die Reform der ESt zu den wichtigsten Programmpunkten bei Gründung des VIS zählte. Ebenso blieb unbekannt, daß die Streitigkeiten um die Methode zwischen den Berliner Professoren Schmoller und Wagner ausgetragen wurden, zu deren Lebzeiten nicht endeten und letztlich fur die Ausgestaltung der ESt von konkreter praktischer Bedeutung wurden, s. hierzu: Schumpeter, J. A. (1914), S. 104; s. a. Hansen, R. (1968), S. 170; ders. (1990), S. 24. Die Einteilung in Schulen und politische Richtungen hat die Aufarbeitung der Auseinandersetzung in den Steuerwissenschaften erschwert. Wenn heute von einer "neuen deutschen wirtschaftswissenschaflichen Denkrichtung", die in Berlin zur Jahrhundertwende aufkam, gesprochen wird, sollte endlich berücksichtigt werden, daß Nationa!økonomie und Finanzwissenschaften dort nach deren eigener Beurteilung von Gelehrten vertreten wurde, die methodologisch und inhaltlich als Antipoden durch Welten getrennt waren, s. hierzu: Streißler, E. (1990), S. 185; s. Schmoller, G. (1905), Zum 70. Geburtstag von Adolph Wagner, in: Schm. Jb., 19. Jg., S. 6; s. a. Schmoller, G. (1908), Reden ..., S. 2. Eine einheitliche "Denkrichtung" gab es in Berlin nicht. 
Jahr 1872 eine zeitgemäße Priorität bei Auswahl der zu verhandelnden Themen zugekommen. ${ }^{123}$

Tatsăchlich wurden die in Sachsen bereits in Gang gesetzten, vorerst zerfahrenen Reformbestrebungen ${ }^{124}$ ab 1872 durch Beiträge von Gründungsmitgliedern des Vereins für Socialpolitik in Bahnen gelenkt, die 1874 und dann endgültig 1878 in einem modernen Einkommensteuergesetz einen Abschluß fanden. ${ }^{125}$ Das săchsische EStG $1874 / 78$ blieb dann nach einer Novellierung am 10. Mărz 1894 ohne Änderung der systemtragenden Grundgedanken bis 1919 gültig. ${ }^{126}$

Wăhrend dieses Gesetz mithin aus Erörterungen im Verein für Socialpolitik leitende Strukturelemente erhielt und im wesentlichen den von Schmoller und anderen "Kathedersozialisten" empfohlenen sozialpolitischen Reformgesichtspunkten entgegenkam - wobei praktische Erwägungen Berücksichtigung finden mußten -, beruhte die spätere Entwicklung der Steuerpolitik in Preußen auf der Denkrichtung, die seit 1875 von Wagner ausging.

Seit den umfassenden Beiträgen Rau's, dessen Lehrbücher Wagner auf Bitten des inzwischen verstorbenen Autors fortführte, hatte sich die Finanzwissenschaft aus der ursprünglichen Umklammerung durch die Volkswirtschaftspolitik gelöst. Den charakteristischen Anspruch, gültige "Principien" der Finanzpolitik aufzustellen, zu lehren, was nach finanzwissenschaftlichen Erkenntnissen sein sollte, hatte sie jedoch aufrecht erhalten. ${ }^{127}$

Wagners Bedeutung kann man nun darin sehen, daß er der "Aufstellung von Zielpunkten"128 der Steuerpolitik in der Rau'schen Finanzwissenschaft neue, zeitgemäße soziale Inhalte mit Gültigkeitsanspruch eingab und diese dann auch zur allgemeinen Überzeugung der Öffentlichkeit gemacht hat.

${ }^{123}$ S. Boese, F. (1939), S. 16; s. a. Schriften des VfS, Bd. III, Die Personalbesteuerung, Gutachten auf Veranlassung der Eisenacher Versammlung zur Besprechung der socialen Frage, Leipzig 1873; s. a. Schriftenreihe Bd. VIII. Die progressive Einkommensteuer im Staats- und Gemeindehaushalt. Gutachten 00ber Personalbesteuerung, abgegeben von F. J. Neumann (1874).

124 Gensel, J. (1874), Sp. 1380; Nostitz, H. von (1903), s. 81.

123 Gensel, J. (1874), Sp. 1398; Hoffmann, A. (1906), S. 84.

${ }^{126}$ S. Gesetz- und Verordnungsblatt fũr das Kõnigreich Sachsen (1894), S. 53; hierzu: Schanz, G. (1895), Die Novelle zum săchs. Einkommensteuergesetz vom 10. März 1894, in: FA. 12. Jg., S. 751. $\mathrm{Zu}$ erwăhnen ist, daß die Auslegung der sächs. Bestimmungen durch die zunchmende Bedeutung, die der Rechtsprechung des preuB. OVG in Staatssteuersachen beigemessen wurde und durch die Vereinheitlichungsbestrebungen einem allmählichen Wandel unterworfen waren. Das wurde gelegentiich beklagt.

127 Altmann, P. (1911), Das Problem der Gerechtigkeit der Besteuerung in: Archiv für Sozialwissenschaft, und Sozialpolitik, XXXIII. Bd., S. 77.

128 Altmann, P. (1911), wie Anm. 127, S. 79; Wagner, A. (1892), Grundlegung ..., S. 144. 
Jedenfalls verlagerte Wagner nach 1877 durch seine unermüdliche Agitation in zahllosen Beitrăgen neben seinen Neuauflagen der Rau'schen Lehrbücher die steuerpolitischen Erörtenungen aus den Gremien des Vereins für Socialpolitik, wo er wegen seiner Forderungen nach einem durchgreifenden außerfiskalischen Einsatz der Besteuerung für sozialpolitische Zwecke einer Vermögensumverteilung Widerspruch ausgelöst hatte, ${ }^{129}$ auf seine Person.

Wagner gelang es dann, den Grundsătzen der Finanzwissenschaft durch die Übernahme von Strukturelementen der historischen Ideenlehre konkrete zeitgemäße sozialpolitische Inhalte einzupflanzen. ${ }^{130}$

So wurden die der sozialen Realităt als vorgegeben und bestimmend unterstellten normativen Principien der überkommenen Finanzlehre für Wagner als finanzpolitische, volkswirtschaftliche und administrative Grundsätze zu jeweils zeitbedingten historischen, aber dennoch objektiv gültigen Kategorien. Mochten sich mit ihnen auch unterschiedliche, auf die jeweilige Epoche bezogene Inhalte verbinden, das zugnundeliegende Denkschema wurde durch Wagners Überzeugungskraft zum - wenn auch umstrittenen - Allgemeingut der herrschenden Auffassungen.

Jedenfalls bestimmten ab etwa 1882, als in Preußen Steuerreformen unvermeidbar wurden, die Auffassungen des Berliner Professors weitgehend die Reformdiskussion. Indem er dem Besteuerungswesen eine von unterstellten Entwicklungsgesetzen vorgegebene Rolle bei dem Übergang zu einer neuen "sozialen Epoche" zuwies, suchte er den aus liberalistischem Denken entwikkelten "Nachtwächterstaat" durch Einsatz der Steuerpolitik grundlegend zu verändern.

Wagner konnte zwar nicht vermeiden, die intellektuellen Führungsschichten in zwei Lager zu spalten. Da er aber auf elementare Bedürfnisse der Bürger und deren Hoffnungen auf die Entwicklung der Verhältnisse zu einer neuen, von sozialer Gerechtigkeit geprägten Epoche abstellte, verhieß er mit seinen Forderungen insbesondere vielen gläubigen evangelischen Christen die Lösung der "sozialen Frage" durch die Beendigung vieler als unerträglich beurteilter sozialer Zustände. ${ }^{[3]}$

\footnotetext{
129 S. Boese, F. (1939), S. 27; s. a. Schriften des V:S (1878), XIV. Bd., Verhandlungen der fünften Generalversammlung des: VfS, S. 5 - S. 26 u. S. 75 - S. 105.

${ }^{130}$ Tónnies, F. (1918), Adolph Wagner, in: Deutsche Rundschau, Bd. 174, S. 113; s. a. Wagner, A. (1892), Finanzwissenschaft ..., S. 146; ders. (1887), S. 104, S. 121 u. a.

${ }^{131}$ von Heckel, M. (1900), Die finanzwissenschaftichen Schriften Adolf Wagners, in: Jahrb. f. Naltionalōkonomie u. Statistik, III. F., 19. Bd., S. 862, hier S. 865.
} 
Dabei betrachtete Wagner den Marxisrnus als größten Feind und glaubte, daß unvermeidlich dem Staat der Zukunft neuartige präventive Aufgaben zuwachsen würden. ${ }^{132}$

Diese politische Einstellung und insbesondere die Rolle des Staates in seinem System brachten Wagner viele Sympathisanten in allen politischen Lagern ein.

Trotz vieler Gemeinsamkeiten in bezug auf alle Problembereiche, die mit der Verbesserung der Lebensbedingungen der minderbemittelten Schichten verbunden waren, bestimmten aber unüberbrückbare Differenzen das Verhältnis zwischen Wagner und Schmoller, sobald es um konkrete Problemlösungen zur "sozialen Frage" ging.

GröBere Antipoden als der aus einer Familie streng religiöser evangelischer Theologen und konservativer Naturforscher abstammende Adolph Wagner einerseits und der bei fortschrittlichen Naturwissenschaftlem und leitenden Finanzbeamten aufgewachsene Gustav Schmoller andererseits waren kaum denkbar.

Jedenfalls sah sich infolge Erziehung in einer Umgebung wissenschaftlicher Gelehrtentätigkeit von Weltrang keiner von beiden veranlaßt, für die Läuterung der eigenen vertretenen wissenschaftstheoretischen Position auf die Hilfestellung Dritter zurückzugreifen. Die praxisfernen Lehren des Wiener Gelehrten Carl Menger konnten für sie keine Bedeutung erhalten. ${ }^{133}$

Für die an herkömmlichen Wissenschaftsauffassungen orientierten Wirtschaftslehren galt "jedes staatliche Eingreifen ... nicht nur als unzulässig, sondern als fruchtlos". ${ }^{134}$ Für Wagner stand jedoch diese natürliche Ordnung, die letztlich den Ablauf der Erscheinungen der Realität bestimmte, unter einem vorgegebenen Entwicklungsgesetz. Dieses zu erkennen und aus ihm "Wegweisungen"135 für eine geeignete, dem Geschehen entsprechende Organi-

132 Heilmann, M. (1980), S. 41, S. 46.

13 Damit kann keine abwertende Beurteilung verbunden werden, denn Mengers berahmt gewordene Methodenschrift zeigte umfassende Kenntnisse einer seit der Jahrhundertmitte äberholten Wissensehaftsauffassung. Wenn Schmoller und Hasbach auch zeigen konnten, daB Menger verfehlte Vorste!hungen von der Vorgehensweise der Naturwissenschaften vertrat, so blieb die Durchdringung der Probleme und die gefundene Systematik beeindruckend. Denn Menger hatte keine Lehrer auf diesem neuartigen Wissensgebiet. Dagegen hatten sowohl Wagner als auch Schmoller durch Bezugspersonen in der eigenen Fanilie Verbindung zu dem zur Jahrhundertmitte mit Heftigkeit ausgetragenen "Philosophenstreit". Obendrein waren sie bereits in aufnahmefähigem Alter, hiernu s. Vorländer, K. (1903), Geschichte der Philosophie, 2. Bd., S. 428; s. Ausfuhrungen bei Hansen, R. (1993), S. 120; zur Aus* bildung Mengers s. Hansen, R. (1968), S. 162. Mengers Wissenschaftslehre wurde von dem in Österreich erwünschten Rechtfertigungscharakter gepralgt s. Hansen, R. (1993), S. 122.

${ }^{134}$ Herzfeld, H. (1938), Bd. I. S. 102.

135 Wagner, A. (1892), Grundlegung ..., S. 114. 
sation der Institutionen herzuleiten, sah Wagner als Aufgabe des Wissenschaftlers und speziell des Finanzwissenschaftlers, nämlich anläßlich des Übergangs der Epochen als Geburtshelfer tätig zu werden. ${ }^{136}$

Tatsächlich bestanden bezüglich der Forderungen zu einer Verlagerung des Schwergewichts der Besteuerung auf die direkten Steuern und deren sozialer Ausrichtung als solcher zwischen Schmoller, den übrigen Kathedersozialisten und Wagner keine unüberbrückbaren Differenzen. ${ }^{137}$ Bei der konkreten Ausgestaltung war dies dann wieder anders.

Als Miquel als langjähriges Mitglied des Vereins für Socialpolitik im Februar 1890 das Amt des Finanzministers übernahm, griff er für die Steuerreform auf den von seinem Vorgänger Adolf von Scholz unter früher Mitarbeit von Wagner fertiggestellten Einkommensteuerentwurf zurück. Er bestimmte sogleich Wagner zu seinem Gutachter und machte ihn zum dauernden Gesprächspartner für die anstehende Steuerreform. ${ }^{138}$

Sieht man von den unterschiedlichen, das Besteuerungsgut bestimmenden Grundgedanken $a b$, dann bestanden zwischen der sozialen Ausgestaltung des sächsischen EStG 1874/78 und demjenigen des unter Minister von Scholz 1889 fertiggestellten und von Miquel übernommenen und im preußischen Landtag eingebrachten Einkommensteuerentwurfs nur unbedeutende Differenzen. $^{139}$

Das sächsische EStG 1874/78 sah für den Regelfall einen Steuerzugriff von $3 \%$ vor. Für Einkommen unter 5.400 Mark wurde dieser Zugriff degressiv bis auf $0,17 \%$ abgesenkt. Die Besteuerung der untersten Stufe setzte bei 300 Mark, ab 1895 bei 400 Mark ein. Der Eingangssatz betrug 0,50 Mark.

Der unter Minister von Scholz ausgearbeitete und von Miquel übernommene Entwurf sah desgleichen einen Regelsatz für den Steuerzugriff von 3\% vor. Dieser sollte bei einem Einkommen von 9.500 Mark einsetzen. Der Zugriff wurde ebenso für niedrigere Einkommen bis auf 0,67\% abgesenkt. Die unterste Stufe begann bei 900 Mark und war mit 6 Mark belastet. Dieser Satz entsprach dem sächsischen Gesetz.

\footnotetext{
${ }^{136}$ Wagner, A. (1887), Staatssozialismus ..., S. 121.

137 Schmoller, G. (1881), Theorie und Praxis, ..., S. 437.

${ }^{138}$ Herzfeld, H. (1938), Bd. 1, S. 486; ders. Bd. II, S. 207; s. a. ders. S. 195, S. 212, S. 227 . S. 231. Miquel war in frühen Jahren Marxist gewesen; die von konservativer Grundhaltung getragenen Auffassungen des Staatssozialismus Wagners hatten starke Beruhrungspunkte mit seinen nationalliberalen Öberzeugungen. Wagner suchte eine "staatssozialistische Lösung der sozialen Frage", s. Höuser, K. (1991), S. 10.

139 Schanz, G. (1895), Die Novelle ..., S. 751; für die folgenden Ausführungen s. dortselbst S. 756 S. 761 mit Vergleichen.
} 
Wesentliche Unterschiede bestanden mithin nur bezüglich des Grundfreibetrages, der in Sachsen bis 1895 bei 300 Mark und dann bei 400 Mark endete, und dem Betrag, bei dem der Regelsatz von 3\% einsetzte. In Preußen betrug der Grundfreibetrag 900 Mark.

Vergleichbare Mildenungen des Steuerzugriffs waren zur Berücksichtigung von Familienangehörigen und für außergewöhnliche Belastungen in beiden Gesetzen vorgesehen. ${ }^{140}$ Dabei ist zu berücksichtigen, daß das săchsische EStG keine Haushaltsbesteuerung, sondern Einzelveranlagungen vorsah. ${ }^{41}$

Die maximalen, aber nicht durchsetzbaren Forderungen Wagners von 1901 sahen einen Regelsteuersatz von $6 \%$ ab 100.000 Mark vor. ${ }^{142}$ Auch Wagner berücksichtigte im übrigen, daß eine weitere Erhöhung der steuerfreien Eingangsstufe aus Gründen der Haushaltsdeckung nicht machbar war. ${ }^{143}$

In Gesprächen mit Miquel gelang es ihm jedoch, den dann in das Gesetz aufgenommenen Regelsatz von $3 \%$ auf $4 \%{ }^{144}$ zu erhöhen. Miquel scheint überhaupt alle wesentlichen Positionen des Gesetzes mit Wagner vor Einbringung abgestimmt zu haben, um sich vorsorglich vorher die Zustimmung des allgemein anerkannten Finanzwissenschaftlers zu sichern.

Im übrigen wurde in der Novellierung des sächsischen EStG 1874/78 vom 10. März 1894 der Regelsatz desgleichen auf $4 \%$ angehoben, so daß der Tarifzugriff beider Gesetze ab 1895 in etwa übereinstimmte. ${ }^{145}$

Miquel erteilte Wagner den Auftrag zur Erstellung eines ausführlichen Berichts über die Verhandlungen im preußischen Landtag zur Entstehung des preußischen EStG 1891. Die hierzu erforderlichen Unterlagen stellte das Finanzministerium zur Einsichtnahme zur Verfügung. ${ }^{146}$

Dieser Vorgang entsprach ebenso dem sächsischen Vorbild. Julius Gensel hatte 1874 und 1875 in den "Annalen des Deutschen Reichs" ausgiebig über die Entstehung des sảchsischen EStG 1874 berichtet. $^{147}$

\footnotetext{
${ }^{140} \S 13$ săchs. EStG 1874/78; $§ \S 18,19$ preuß. EStG 1891.

141 \$\$2,3 săchs. EStG 1874/78; anders $\$ 11$ Abs. 1 preuß. EStG 1891.

142 Herzfeld, H. (1938), Bd. 2, S. 249.

${ }^{143}$ Herzfeld, H. (1938), Bd. 2, S. 217, Anm.

${ }^{144}$ Herzfeld, H. (1938), Bd. 2, S. 249.

l4s $\S 12$ Abs. 2 săchs. EStG $1874 / 8$ i. d. F. v. 10.3 .1894 , abgedr. in: FA, 12. Jg. 1895, S. 767. Der Steuersatz betrug bis 25.000 Mark 3\%, von 25.000 Mark ab $4 \%$. Diese Sătze waren mit dem preuß. EStG 1891 abgestimmt worden, s. Schanz, G. (1895), Die Novelle ..., S. 760, dort Vergleichsaufstellungen; s. a. Vergleich in PreuB. Verw. Bl., 31. Jg. 1909. S. 202.

${ }^{146}$ Herzfeld, H. (1938), Bd. 2, S. 231. Anm; s. hierzu Brief Wagners an die Cotta'sche Buchhandlung Nachf. v. 8.5.1892, in: Rubner, H. (1978), S. 268, Anm. 3.

147 Gensel, J. (1874), Sp. 1373; ders. (1875), Sp. 1519.
} 
Wenn Wagner sich mit dem Ergebnis der Steuerreform, von seiner "sozialen Finanzauffassung" ausgehend, nicht zufrieden zeigte und von einem ersten Schritt sprach, so lag das nicht nur daran, da $\$$ er den Steuerzugriff bei $6 \%$ festgesetzt sehen wollte. Soweit sich aus Ausführungen und Andeutungen ergibt, ging er von umfangreichen Zielvorgaben aus, die vor allem die Erfassung sogenannter unverdienter Wertzuwächse betrafen und die seinen Belastungs- und Umverteilungsvorstellungen entsprachen. ${ }^{148}$

Für die Einkommensteuer beschrănkte sich seine Kritik, wie es scheint, aber auf den zu niedrigen Tarifzugriff, den er bei $6 \%$ angesetzt sehen wollte. Die tragenden Strukturelemente erschienen ihm offenbar auch nach Kenntnisnahme der später einsetzenden Kritik realitătsgerecht zu sein.

Jedenfalls stellte Wagner das preußische EStG 1891 als "Krönung" der Steuerreform der Jahre 1891 bis 1893 dar. ${ }^{149}$ Diese Beurteilung wurde dann allgemein übernommen. Sie wird im Grunde noch heute vertreten.

Nachdem im Rahmen der Reformen von 1891 bis 1893 auch eine in Sachsen schon länger vorhandene Erbschaftsteuer, eine neuartige Vermögensteuer, eingefuhrt und eine Anpassung der Gewerbesteuer abgeschlossen worden waren, wurde allgemein von einem auf die Erfassung der Leistungsfähigkeit ausgerichteten Maßnahmenpaket gesprochen.

Wagners Besteuerungsidee sah zusätzlich noch die Heranziehung der von der Einkommensteuer nicht erfaßbaren unverdienten Wertzuwächse durch den Ausbau der Verkehrssteuern vor. ${ }^{150}$ Er glaubte auf diese Weise für eine als gerecht beurteilte soziale Umverteilung eine prinzipielle Grundlage gelegt zu haben. Er hatte "Wegweisungen" eröffnet, für deren Realisierung er zeitlebens noch tätig blieb. ${ }^{151}$

Die Auffassungen Wagners, daß es sich bei dem EStG 1891 um einen Meilenstein zu einem nach Kriterien der "sozialen Epoche" gerechten und an der Leistungsfähigkeit der Bürger orientierten Gesetz handele, hat sich sofort als allgemeine Überzeugung durchgesetzt. Sie ist erhalten geblieben. Wer anderer Auffassung war, befand sich in einer Außenseiterposition.

\footnotetext{
${ }^{148}$ Herzfeld, H. (1938), S. 248; s. a. Wagner, A. (1890), Finanzwissenschaft ..., S. 466 - S. 593.

149 Herzfeld, H. (1938), S. 248; s. a. Pausch, A. (1992), S. 18.

150 Wagner, A. (197), Gundriß ..., S. 73; ders. (1890), Finanzwissenschaft ..., S. 566 - S. 593.

151 Bauckner, A. (1913), S. 27 - S. 29; s. DJZ (1910), 15. Jg., S. 510.
} 
Als ein höherer Finanzbeamter sich 1897 mit nachhaltiger Kritik im "Finanzarchiv" zu Wort meldete, tat er dies vorsichtshalber unter einem Pseudonym. $^{152}$

Wenn Georg Schanz 1896 Kritik an dem systemtragenden, den Umfang des Besteuerungsgutes bestimmenden Einkommensbegriff vortrug, so geschah dies in vorsichtigen Wendungen und sparte die Konsequenzen der Regelungen weitgehend aus. ${ }^{153}$ Eine weitere Erörterung unterblieb vorerst völlig.

Wagner nahm die Kritik nur zur Kenntnis und fügte Hinweise zur Vervollståndigung der Anmerkungen seinen Beitrảgen ohne Kommentar hinzu. ${ }^{154}$

Schanz scheute sich im übrigen, das sächsische EStG $1874 / 78$ als vorzugswürdig zu bewerten, obgleich verschiedene Bemerkungen in Text und Anmerkungen darauf hinauslaufen. ${ }^{155}$

In der Rezension eines bekannten Beitrages zur Finanzwissenschaft hatte Schanz 1892 dem sächsischen EStG $1874 / 78$ jedoch die bestandene "Feuerprobe" eines neuartigen Gesetzeswerkes bescheinigt. ${ }^{156}$

Die Zurückhaltung Schmollers zu den Vorgängen entsprach seiner Wissenschaftsauffassung, eine Beurteilung vom Erhalt verwertbarer empirischer Ergebnisse abhängig zu machen. Auffällig ist, daß er ab den 90er Jahren periodisch statistische Untersuchungen über die Vermögens- und Einkommensverteilung anregte, die Ergebnisse in seinem "Jahrbuch" veröffentlichte und für Verbreitung sorgte. ${ }^{157}$

\footnotetext{
192 Justus (Pseudonym) (1897), S. 58.

${ }^{153}$ Schanz, G. (1896), S. 1; s. a. Brief Wagners an Althoff v. 12.2.1884, in: Rubner, H. (1978), S. 217.

194 Wagner, A. (1897), Handbuch ..., Anm. 4, S. 434, Anm. 289; ders. (1897), GrundriB ..., S. 63.

15s Schanz, G. (1896), S. 42, S. 43, S. 48 - S. 50.

156 Schanz, G. (1892), Rezension von Vocke, W. (1887), Die Abgaben ..., S. 508.

is Einkommens- und Vermógensverteilung und ihre Verïnderungen waren für Schmoller stets von
} zentralen Interesse, zumal er die bekämpte Klassenbildung mit diesen Vorgången in Zusanmenhang brachte. Nach 1890 finden wir dann von ihm Beiträge zu diesem Komplex in verschiedenen Aufsätzen seines "Jahrbuchs" und sonstigen Abhandlungen. Zu Aufsäzen mit relevantem Inhalt zog er für sein "Jahrbuch" den Nationalökonomen und Statistiker Victor Böhmerl und nach 1899 den vielseitigen Hamburger Nationalökonornen und Statistiker Emst R. May heran, der auch Mitglied des VfS wurde. Gañz offensichtlich hat die von Schmoller systematisch geforderte Aufhellung der Zusammenhănge um Einkommens- und Vermögensverteilung zu der urn 1909 von Delbrilck eröffneten Kritik an der Einkommensbesteuerung durch Hochrechnen statistischer Daten und deren versuchter Verprobung mit der ESt-Statistik gefuhri May beteiligte sich an den Verprobungen, indem er Delbrîck 1909 unter dem Titel "Volksvermögen und Steuerdeklaration" (PreuB. Jb., 138. Bd., S. 95 - S. 148) abgewogenes Material lieferte, auf das er gleichzeitig in einem korrespondierenden Aufsatz mit ăhnlichem Thema in Schm. Jb. hinwies (1909), 33. Jg, S. 1500, Anm. 2 u. S. 1509), s. hierzu: Schmoller, G. (1893), Börsen-Enquete-Kommission, Statistische Anlagen, Einteilung S. XXI; s. Schm. Jb., 19. Jg. 1895, S. 665 u. S. 1067; 20. Jg. 1896, S. 1227; 23. Jg. 1899, S. 271; 27, Jg. 1903, S. 511 , S. 889; 33. Jg. 
Bereits 1893 veröffentlichte Schmoller in seinem "Jahrbuch" einen Aufsatz seines langjährigen wissenschaftlichen Assistenten Karl Oldenberg, der die völlig andere Denkweise seiner engeren Umgebung wiedergibt: Oldenberg zeigte, ${ }^{158} \mathrm{daB}$ man die preußische Besteuerungspraxis unter volkswirtschaftlichen Gesichtspunkten trotz einer problematischen Lastenverteilung neuartig und ungewohnt auch als soziale Steuerpolitik beurteilen konnte. Nicht die sozialpolitische Richtigkeit war Gegenstand der Untersuchung; Oldenberg stellte auf die von dem Regelungssystem verursachten Wirkungszusammenhănge ab.

Wăhrend dem Wagnerschen Konzept für die Einkommensteuer auch die fraglose Gewißheit zugrundelag, daß eine durch progressiv ausgestaltete Steuereingriffe geförderte gleichmäßigere Verteilung der Einkommen zugunsten der unteren Schichten das Sparaufkommen insgesamt fördern und allmählich eine Umstrukturierung der Vermögen bewirken werde, ${ }^{159}$ stellte Oldenberg diese Annahme als offensichtlich fehlerhaft heraus. ${ }^{160}$ Er zeigte, daß die problematische preußische Besteuenungspraxis der Vergangenheit letztlich praktisch eine soziale Funktion erfült hatte, indem sie durch die Förderung einer ungleichen Einkommensverteilung Kapitalbildung und Investition begünstigte und damit sogar eine Erhöhung des Wohlstandes, durch Verbesserung der Kapitalausstattung $\mathrm{zu}$ beschleunigen vermochte. ${ }^{161}$ Oldenberg verwies darauf, daß zu Zeiten großer Kapitalarmut die Öffentlichkeit wegen der vordergründigen allgemeinen wirtschaftlichen Interessen stets zuließ, daß "der Fiskus ein Auge zu(drückte) bei der stillschweigenden Umbildung der Steuern zu Gunsten der freiwilligen Kapitalbildner". Erst "die beginnende Săttigung der Volkswirtschaft mit Kapital bringt den gesunden Menschenverstand wieder zu seinem Recht, wobei sociale Empfindungen mitspielen", ${ }^{162}$ so Oldenberg.

Hier zeigte sich die gegenüber der Wagnerschen Denkweise völlig andere Beurteilung der Besteuerungspraxis, die insbesondere auf Wirkungszusammenhänge der sozialen Realität als Kriterium für Beurteilung und Gestaltung

1909, S. 1459: 34. Jg. 1910, S. 319. Zu erwähnen sind noch die Darstellung und Verarbeitung der Statistiken in: Schmoller, G. (1904), GrundriB ..., Bd. II, S. 147 - S. 149, S. 188, S. 197, S. 491. Das ganze 3. Buch von über 500 Seiten ist dem Thema der Einkommens- und Vermōgensverteilung gewidmet. Die Verwendung, der zusammengetragenen statistischen Angaben zur Verprobung und Konvolle der Daten der Steuerstatistik lag nahe.

${ }^{158}$ Oldenberg, K. (1893), S. 450. Zu Oldenbergs, sehr engem Verhältnis zu Schmoller s. Schmoller, G. (1908), Reden .... S. 28.

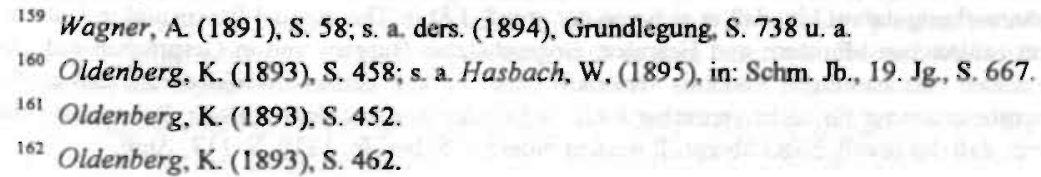


abstellte, wobei der Eignung zur Erreichung konkreter Ziele bei Gewährleistung erwünschter Randumstănde allein Bedeutung zukam.

Derartige Gesichtspunkte waren in die Wissenschaftsauffassung Wagners nicht recht integrierbar. Die Ergebnisse der Besteuenungspraxis in der empirischen Realität konnten hier grundsătzlich nicht zur Kritik der Eignung eines aus richtigen Principien rechtsdogmatisch entwickelten Besteuerungssystems dienen. Das war nun einmal ein Grundgedanke der Wagnerschen Methodenlehre, die letztlich auf der "Stoff-Form-Metaphysik" der klassischen Philosophie aufbaute. ${ }^{163}$ Dies nicht erkennen zu können zeigte, so die Konsequenz, die mangelnde philosophische Bildung seiner Gegner.

Eine Abstimmung erkennbarer sachlicher Konsequenzen des Gesetzes mit erwünschten positiv festgelegten Zielvorgaben nach Gesichtspunkten der Zweckmäßigkeit war, auch insoweit unvermeidbar, jedenfalls von nachrangiger Bedeutung.

Solange die kontinuierlich verfolgte Einkommens- und Vermögensverteilung keine sozial problematische Entwicklung auswies, sah man in Kreis um Schmoller keinen Anlaß für nachhaltige systematische Kritik.

Dies sollte sich jedoch ändern, als nach der Jahrhundertwende die Statistiken Anzeichen für eine höchst fragwürdige Besteuerungswirklichkeit ergaben und die ansetzende öffentliche Erörtenung die "sociale Balance" zu stören drohte.

Schmoller stellte nach 1909 sein "Jahrbuch" wie bei früheren Gelegenheiten zur Aufhellung der Zusammenhänge zur Verfügung, ${ }^{164}$ wobei er in einer eigenen Stellungnahme Position bezog, indem er Zweifel an der Eignung der tragenden Strukturelemente des preußischen EStG 1891 vortrug. ${ }^{165}$

So erschien im "Jahrbuch" von 1911 nach dem einführenden Aufsatz des hohen Finanzbeamten im nächsten Heft der Beitrag Franz Meisels mit dem Titel "Moral und Technik bei der Veranlagung der preußischen Einkommen-

\footnotetext{
${ }^{163}$ Hansen, R. (1993), S. 115 ; s. a. ders. (1968), S. 172 u. a.

${ }^{164}$ Behrnauer, F. (1910), S. 113.

163 Der Aufsatz rechtfertigte đie Verwaltungstätigkeit der Behōrden; er ging aber insofern darüber hinaus, als er die Besteuerung insbesondere der Landwirte als richtig hinstellte. Schmoller wies in einer langeren Anmerkung darauf hin. dals er sich von der preuB. ESt in Theorie und Praxis und in Unterredungen mit zahlreichen Ministern und Beamten, eingeschatzten Bärgern und in Gesprikchen mit Miquel von dessen Anschauungen Kenntnis verschaff habe. Er ließ keinen Zweifel daran, daB er die Einkommensbesteuerung furr nicht vertretbar hielt. Schmoller zog aus dem Aufsatz Behrnauers die Konsequenz, daß das preuB. EStG aberprüft werden mulsse, s. Schm. Jb. 1910, S. 113, Anm.
} 
steuer". ${ }^{166}$ Dieser Aufsatz hat bis heute eine gewisse Aktualităt behalten und wird noch immer bei Gelegenheit zitiert.

Tatsächlich war aber bei Erscheinen des Beitrags die Überzeugung von der sozialen Ausgestaltung und der Orientierung der preußischen Einkommensbesteuerung an der Leistungsfähigkeit der Steuerbürger und darüber hinaus die Gewiß̉heit der erfolgten Bestätigung des preulßischen EStG von einem wissenschaftlichen Standpunkt aus stäiker als jede nur von empirischen Dăten. ausgehende Kritik von Fachleuten. ${ }^{167}$

Als am 5. und 6. Februar 1912 der preußische Landtag über einen "Gesetzentwurf, betreffend die Abänderung des Einkommensteuergesetzes und des Ergänzungssteuergesetzes" ${ }^{168}$ beriet, griff keiner der Abgeordneten die Gedanken aus der inzwischen in mehreren führenden Fachzeitschriften erörterten Kritik in geeigneter Weise auf. Zum Einkommensbegriff gab es nur positive Stellungnahmen von Finanzminister Lentze und den Abgeordneten. ${ }^{169}$ Sowohl freikonservative Abgeordnete, unter ihnen der Professor fur Staats- und Verwaltungsrecht, J. V. Bredt, als auch der Vertreter der sozialdemokratischen Partei beriefen sich, offensichtlich für sehr unterschiedliche Vorstellungen eintretend, gleichermaßen auf die Autorität Adolph Wagners als Finanzwissenschaftler. ${ }^{170}$ Wagners Denkweise hatte sich als herrschende Meinung voll durchgesetzt.

\footnotetext{
16. Meisel, F. (1911), S. 285.
}

167 Insbesondere der langjąhrige Mitarbeiter Fuistings. G. Strutz, Mitautor und nach 1908 alleiniger Autor des führenden Kommentars zum preuB. EStG 1891/1906, verbreitete den Standpunkt, das preuB. EStG und vor allem "das Miquel'sche System (stehe) im großen und ganzen mit den herrschenden Anschauungen der Wissenschaft in Einklang", s. z. B. Sirutz. G. (1908), Rezension, in: Verwaltungsarchiv, 11. Bd., S. 475. Preußen besitze "das relativ beste und gerechteste Steuersystem" uberhaupt, etc., s. Strutz, G. (1910), PreuB. Verw.-Bl. XXX. Jg., S. 658, S. 659. Nach Erscheinen des 2. Bandes von Schmollers "GrundriB" fügte Sirurz der Kommentierung des Einkommensbegriffs zu $\$ 6$ preuB. EStG $1906 \mathrm{zu}$ dessen wissenschaflicher Bestätigung eine Bemerkung an, nach der der Autor nunmehr seine Definition des Einkommens (die Grundlage des săchs. EStG 1874/78 wurde) grundlegend - wohl kraft besserer Einsicht - geăndert haben mußtc, s. Schmoller, G. (1902), Grundriß ..., 2. Bd. S. 229; s. Strutz, G. (1915), Anm. 2 zu $\$ 6$ preuB. EStG, S. 163. Strutz sah hierin cine Rechtertigung, s. hierzu Anm. 45,61 u. 95. DaB der ultrakonservativen "Kreuzzeitung" das preuB. EStG 1891 in der ursprünglichen Form trotz der Uheberschaft des "Kathedersozialisten" A. Wagner richtig und verteidigungswert war, bedarf wohl keiner näheren Begründung, s. Preuß. Verw. BI. XXXI, 1910, S. 657.

168 S. Stenographische Berichte über die Verhandlungen des PreuB. Hauses der Abgeordneten, 21. Legislaturperiode. V. Session 1912/13, 1. Bd., Sp. 1 bis Sp. 356, hier Sp. 325.

169 Finanzminister Dr. Lenze in: Stenographische Berichte (wie Anm. 168), Sp. 334. Lentze wies darauf hin, da $B$ alle Änderungsvorschlagge zum Einkommensbegriff sich als "gesetzgeberisch nicht verwertbar" ergeben hätten. Bredr bestätigte sodarn, $\mathrm{daB}$ an dem "aḷten preuBischen Einkommensbegriff" festgehalten werden müsse (Sp. 345).

${ }^{170}$ Der Abgeordnete Dewitz von der freikonservativen Partei berief sich desgleichen wie der Abgeordnete Hirsch von den Sozialdemokraten auf die wissenschaftliche Autorität Adolph Wagners (Sp. 
Das săchsische EStG 1874/8 in der Fassung vom 10. März 1894 und das preußische EStG 1891 hatten, wie wir sahen, eine fast gleiche soziale Ausgestaltung, beide wichen nur durch die verschiedenartigen systemtragenden Grundgedanken bezüglich des Besteuerungsgutes voneinander ab. Dies konnte obendrein wegen der gleichermaßen verwendeten Begriffe leicht verborgen bleiben.

Schmoller erwähnte 1909, daß die Finanzwissenschaft bis zur Gegenwart hinter der Volkswirtschaftslehre zurückgeblieben sei. ${ }^{171}$ Meisel bedauerte dann 1920 in einem Rückblick, daß die deutsche Finanzwissenschaft zur Jahrhundertwende "plötzlich stehen geblieben" sei. Man erkannte die "technischen Radikalfehler" nicht, ${ }^{172}$ so führte er aus.

Wagner hatte die finanzwissenschaftliche Steuerlehre endgültig zu einer rechtsdogmatischen Disziplin gemacht. Als Gegenstandsbereich für unbehinderte sozialpolitische Aktivităten kam sie infolge Herleitung ihrer Erkenntnisse aus vorgegebenen normativen "Principien" nicht mehr infrage.

Tatsächlich haben seit dieser Zeit, wie Meisel zu beklagen wußte, Juristen Meisel selbst gehörte zu den Juristen - die Funktionen der finanzwissenschaftlichen Steuerlehre übernommen.

Die in "Schmollers Jahrbuch" veroffentlichten Statistiken, Kalkulationen und Hochrechnungen, die in den "Preußischen Jahrbüchern" ausgebreiteten Verprobungen und die eigenen zum Teil im "Finanzarchiv" 1914 entfalteten Berechnungen führten Meisel zu einem harten Urteil über das preußische EStG 1891: "Eine neue gerechte Einkommensteuer sollte sie werden! Die Mittel zur Erreichung des schönen Ziels hat sie nicht gebracht". ${ }^{173}$

Die von Schmoller in Gang gesetzte Kritik nach 1909 führte jedoch. wie wir gesehen haben, nicht zu einer Revision der systemtragenden Grundgedanken des preußischen EStG 1891. Im Gegenteil, sie führte zu einem verstärkten Ausbau der Wagnerschen Besteuerungsidee.

Sie führte dazu, daß die herausgestellten hohen Vermögensmehrungen, die von der preußischen Type der Einkommensbesteuerung nicht erfaßt werden

388 u. Sp. 435). Dewitz setzte sich sogar für das Lieblingskind Wagners, die Wertzwwachsbesteuerung, ein (Sp. 438).

${ }^{17}$ Schmoller, G. (1909), Historische Betrachtungen aber Staatenbildung und Finanzentwicklung. in: Schm. Jb., 33. Jg. S. 8.

${ }^{172}$ Meisel, F. (1920), S. 35, S. 36.

${ }^{173}$ Meisel, F. (1920), S. 17. 
konnten, nunmehr als zusätzliches Besteuerungsgut durch Wertzuwachssteuern mit neuartigem Besteuerungsgegenstand belastet werden sollten. ${ }^{174}$

\section{Die Besteuerungsidee Wagners blieb das vom Gesetzgeber vorgesehene Or- ganisationsprinzip.}

Trotz vieler Hinweise Meisels auf deren große Bedeutung gerieten Schmollers Beiträge zur Steuerlehre in völlige Vergessenheit. ${ }^{175}$

Meisel kam zu dem Ergebnis: "Wo die preußische Type gilt, ist der Zustand geradezu unerträglich, mit der primitiven Technik und Unergiebigkeit der Ertrags-, Einkommen-, Ergånzungs- und Erbschaftsteuer ungerecht und unzweckmäßig, ein guter Gradmesser des Verfalls unserer Steuerkultur". ${ }^{176}$

174 Gerloff zeigte in Schm. Љ. 1913, daß die Diskussion um die Einfuhrung der Wertzuwachssteuer als Gemeindesteuer bzw. Reichszuwachssteuer zu einer Prufung und tiefergehenden Kritik der von Wagner ausgehenden Steuersystematik hätte führen müssen. Er führte die umfassende Literatur zu dieser Besteuerungsform an und bedauerte die Entwicklung, s. Gerloff, W. (1913), Die Wertzuwachs-

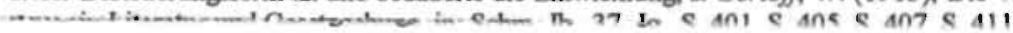

${ }^{173}$ Meisel, selbst Jurist, suchte wiederholt vergeblich die Bedeutung Schmollers für die Finanzwissenschaft und speziell als Brennpunkt für die finanzwissenschafliche Steuerlehre hervorzukehren. Er bedauerte gelegentlich auch vorwurfsvoll, daB Schmollers Interessenahme trotz laufender aktueller wertvoller Beiträge schwerpunktmäBig andere Ziele verfolgte, s. Meisel, F. (1911), S. 287; ders. (1918), S. 358; ders. (1925), S. 63; ders. (1926), S. 258. Eine jüngere Generation brachte Schmollers sozialpolitischen Zielen ab 1909 kein Verständnis mehr entgegen. Eine Gruppe um Julius Wolf suchte sogar zu erreichen, daB "die von ihm vertretenen Ziele aufhorren, für weite Kreise als Erkenntnisse, als Ergebnisse wirklich wissenschaftlicher Forschung zu getten", Wolf, J. (1912), in: Schlesische Zeitung, Nr. 694, zit. nach Tonnies, F. (1912), in: Schm. Jb., 36. Jg., S. 6. Diese Erklärung war verworren und enthielt unzutreffende Behauptungen, wurde jedoch im Zusammenhang mit dem Wertfreiheitspostulat Max Webers von den vielen Gegnern Schmollers sehr erfolgreich benutzt, seine Lehren in Verruf zu bringen, s. a. Schmoller, G. (1912), in: Schm. Jb., 36. Jg, S. 1. Das Ergebnis war, daB sowohl Person, als auch Ziele und Lehren Schmollers in Vergessenheit gerieten. So lernen angehende leitende Beaumte der Finanzverwaltung heute aus Darstellungen, s. Pausch, A. (1976), Finanzbeamte ..., von der Bedeutung der "Finanzbeamten als Mitgestalter der Kameral-Finanz- und Steuerwissenschaften", beginnend mit Caspar Klocks Verdienst, "Praxis und Wissenschaft zu verbinden"( S. 181, hier S. 186), sie lemen, daB Adam Smith Finanzbeamter war, s. Pausch, A. (1976), 200 Jahre ..., S. 303, sie erfahren, daß Grillparzer als Jurist eine leitende Stellung im österreichischen Finanzdienst versah; sie srfahren von den Verdiensten Friedrich Lists, von Malchus und von H. L. Hoffmann etc., etc., s. Pausch, A. (1976), 250 Jahre .... S. 88; von Gustav Schmoller, der vor Beginn seines Studiums eine intensive Ausbildung im gehobenen und dann im höheren Dienst der Finanzverwaltung mit AbschluB der zweiten Staatsprüfung absolvierte, hören die angehenden leitenden Beanten nichts. Auch von "Persónlichkeiten der Steuerkultur", streng nach Anciennität rangmäBig geordnet, wird berichtet, wobei, angeführt von J. v. Miquel und gefolgt von A. Wagner (er war 7 Jahre jûnger), die wichtigsten Steuerjuristen und Politiker genannt werden, Pausch, A. (1992), Persőnlichkeiten .... Der Autor war als Ministerialrat lange Jahre Dozent für Finanzgeschichte an der Bundesfinanzakademic, einer Einrichtung zur Ausbildung der Finanzbeamten im höheren Dienst. Der Name Schmollers wird nicht angeführ, ob-gleich er in den Akten der Weimarer Nationalversammlung im Zusammenhang mit der Steuerreform von 1919 verzeichnet ist. Min der Person sind auch die Gesichtspunkte Schmollers in Vergessenheit geraten, S. Hansen, R. (1990), S. 48; ders. (1993), S. 153; s. a. Lindenlaub. D. (1967), S. 441.

${ }^{176}$ Meisel, F. (1919), Wo steht die deutsche Finanzwissenschaft?, in: Zeitschr. f. d. ges. Staatswissenschaft, 74. Jg., S. 395. 
Was Meisel allerdings nicht in seine Beurteilung einbezog, waren Fragen der Eignung des Wagnerschen Systems für eine volkswirtschaftlich erwünschte Kapitalbildung, ein Aspekt, auf den Oldenberg 1893 aufmerksam gemacht hatte.

Wir werden darauf noch wiederholt einzugehen haben. 


\section{G. Beurteilung der heute geltenden, von einer gespaltenen Systematik bestimmten Einkommensbesteuerung in der Bundesrepublik Deutschland unter verschiedenen modernen Gesichtspunkten}

Wie wir erfahren haben, boten die systemtragenden Elemente des preußischen EStG 1891 dem Steuerpflichtigen ein sehr reichhaltiges Repertoire nicht zu beanstandender Möglichkeiten, den Steuerzugriff zu vermindern oder sogar gänzlich zu vermeiden.

Auf diese Weise konnten gutsituierte Bürger mit höherem Einkommen die durch sehr hohe Zuschlagsteuern der Gemeinden entstehende Gesamtbelastung von bis zu $22 \%$ der Bemessungsgrundlage, oder jedenfalls Anteile davon, einsparen.

An erster Stelle ist hier anzuführen, was seit 1973 unter dem "dualistischen" oder "gespaltenen" Einkommensbegriff des heute noch geltenden EStG verstanden wird. ${ }^{1}$ Die Übernahme der in dem sächsischen EStG $1874 / 78$ als Regel vorgesehenen Ermittlungsweise der Bemessungsgrundlage durch Bestandsvergleich für Einkünfte aus dem Betrieb eines Gewerbes, ab 1925 auf Einkünfte aus Landwirtschaft und freiberuflicher Tätigkeit ausgedehnt, einerseits, und demgegenüber die Ermittlung der übrigen Einkünfte als Überschuß der steuerbaren Einnahmen über die Werbungskosten andererseits, bevortcilte zivilrechtliche Gestaltungen des Sachverhalts, die eine Besteuerung nach der Leistungsfähigkeit im Sinne der üblichen Sprachregelung glatt verhindern konnten.

Ähnliches galt, wie wir gesehen haben, bezüglich anderer Eigentümlichkeiten der preußischen und später "deutschen Type" der Einkommensbesteucrung.

Hierzu zählen die strenge Trennung zwischen der steuerlich irrelevanten Privatsphäre und der Einkommens- bzw. Berufssphäre, die Steuerersparnisse

1 Tipke, K. (1973), S. 391, sprach davon, daß de facto bei Beracksichtigung der Ermittlungsvorschritten mehrere Einkornmensbegriffe im EStG vorliegen (S. 396). Er beurteilte die sich ergebenden Möglichkeiten zur Steuervermeidung als Lacken im System des EStG, deren Oberbrückung, er dem Verfassungsgericht empfehlen wollte. Tatsăchlich handełt es sich nicht um Läcken, sondern um Eigentümlichkeiten. Das ESt-Recht ist auch kein Chaos, wie er vortrug, s. Tipke, K. (1971). 
durch sogenannte Liebhabereieinkünfte und die durch eine sehr unzweckmäBige Steuertechnik genảhrte Grauzone gesetzwidrigen Verhaltens, die Steuerverkürzungen leichtmachte.

Die Kombination dieser Umstände machte es wohlhabenden Steuerbürgern möglich, die entstehende Steuerschuld in weitgehendem Umfang durch geeignete zivilrechtliche Gestaltungen selbst zu bestimmen.

$\mathrm{Daß}$ viele dieser Möglichkeiten, wenn auch durch spitzfindige Abgrenzungsund komplizierte Abwehrvorschriften eingeschränkt, erhalten blieben, wird an anderen Stellen gezeigt.

Wichtiger ist heute, daß die fortgeschriebene Grundkonzeption des preußischen EStG 1891 durch sehr unterschiedlich auslegbare Begriffe und deren vom Gesetzgeber in Anspruch genommene inhaltliche Festlegung nach zeitgernăßen wirtschaftspolitischen Bedürfnissen ein sehr flexibles und anpassungsfahiges Abgabengefüge hat entstehen lassen, ohne in demselben Unordnung oder gar innere Widersprüche auszulosen. Dieser Umstand hat das EStG inzwischen zu einem hilfreichen politischen Steuerungsinstrument fortentwikkelt.

Vor allem ließ es sich, wie wir gesehen haben, ohne grundlegende Änderung der inneren Systematik widerspruchsfrei zur Unterstützung wirtschaftspolitischer und sogar allgemein politischer Ziele einsetzen, die von der Fördenung von Investitionen konkreter Bereiche der Wirtschaft über die Stabilisierung konjunktureller Zielvorgaben bis zu der begünstigten Eingliederung ehemals politisch Verfolgter reichte.

Hochschätzungen der auf diese Weise seit 1949 jährlich geförderten Investitionen ergeben jeweils einen Umfang, der trotz hoher Schwankungen in einzelnen Jahren einen ansehnlichen Prozentsatz der gesamten Steuereinnahmen ausmachte.

Daß die verursachte steuerliche Belastungsverteilung den üblichen Gerechtigkeitsvorstellungen nicht mehr entsprechen kann, liegt auf der Hand.

Eine Wägung der Steuerverteilung nach Gesichtspunkten des Nutzens für die Entwicklung des Wohlstands der Gemeinschaft kann aber demgegenüber zu einer konträren positiven Beurteilung führen:

So konnte, wie wir erfuhren, die deutsche Einkommensbesteuerung 1933 ebenso wie 1949 ohne Änderung systemtragender Strukturelemente durch eine geeignete Festlegung wichtiger Begriffe wie Abschreibungen, Sonderausgaben 
und Werbungskosten bei Verbesserung allgemeiner großer Notzustånde wichtige Funktionen zu aktuellen Problemlösungen übernehmen. ${ }^{2}$

Das konnte naturgemäß nur auf Kosten eines Verzichts auf Beachtung des in Art. 134 WRV angeführten Gebots einer Besteuerung nach der Leistungsfăhigkeit des Steuerbürgers geschehen. Abzuwăgen war demgegenüber, daß die Maßnahmen dem Nutzen der Allgemeinheit durch Anreiz für Selbstheilungskrä.fte und Verminderung des Elends in Notlagen dienten. Das sogenannte Ermächtigungsgesetz vom 24. März 1933 erlaubte nach Art. 2 insoweit ein Abweichen von der Reichsverfassung. ${ }^{3}$

In der Berichterstattung über den völlig unerwarteten schnellen Wiederaufbau Westdeutschlands nach der Vernichtung des deutschen Staatsgefüges durch die Siegermächte des zweiten Weltkrieges im Jahr 1945 zu einem "Trümmerhaufen" wurde bereits 1953 von einem "Wunder" gesprochen, das erst durch Wiedereinführung der Marktwirtschaft erklärbar werde. ${ }^{4}$

Der insbesonders von Beobachtern im Ausland als "Wirtschaftswunder" bezeichnete überraschend schnelle wirtschaftliche Wiederaufbau Westdeutschlands wurde sofort als Ergebnis der als "soziale Marktwirtschaft" hervorgehobenen verfolgten neuen ordnungspolitischen Leitidee gewürdigt. ${ }^{5}$ Das war zur Zeit des aufbrechenden "kalten Krieges" und der einhergehenden strengen Trennung der Welt in zwei ideologisch abgegrenzte Blöcke gewiß verständlich. Dabei wird aber bis heute regelmäßig der Eindruck erweckı, es handele sich bei dieser Leitidee für die "ordnungspolitische Fundierung der Marktwirtschaft" in Westdeutschland auch um die wesentliche ursächliche Voraussetzung für den schnellen Wiederaufbau, der gegenüber andere Maßnahmen nur eine Nebenrolle als nachrangig unterstützende Hilfestellung ausfüllten. $\mathrm{Zu}$ diesen Hilfen werden dann auch "Abschreibungs- und Steuererleichterungen" gerechnet, die nach diesen Darstellungen "zur Zeit der Aufbauphase" unter

2 Gesetz zur Verminderung der Arbeitslosigkeit v. 1.6.1933, in: RGBl. I Nr. 60 v. 2.6.1933, S. 323 ; s. a. Gesetz uber Steuererleichterungen v. 15.7.1933, in: RGBI. I v. 19.7.1933, \&. 491 und weitere Vorschriften in Kap. E III., Anm. 37.

${ }^{3}$ Die Zahl der Arteitslosen verminderte sich vom 1.3.1933 bis Ende Dezember 193.4 (Ende der Sonderabsetzungen) von 6.001 Mio. auf 2,604 Mio., also um 3,4 Mio. ins Wirtschaftsleben eingegliederte Arbeitslose, s. hierzu Entwicklung der Arbeitslosigkeit, in: Statistik der Frankfurter Zeitung v. 12.11.1935, wiedergegeben in: Forsthoff. E. (1943), Deutsche Geschichte von 1918 bis 1938 in Dokumenten, Stuttgart, Kröners Taschenausgabe, Bd. 113, S. 251.

${ }^{4}$ Rueff, J. (1953), S. 204, hier S. 222.

${ }^{5}$ Rilstow, A. (1953), Soziale Marktwirtschaft .., S. 97, hier S. 116 u. a.; Röpke, W. (1965), Wort und Wirkung. S. 53, S. 177 u. a. 
anderen wachstumspolitischen Maßnahmen "als regulierende (prozesspolitische) Eingriffe des Staates" angeführt werden. ${ }^{6}$

Diese Beurteilung gibt die offensichtliche Bedeutung der Steuervergünstigungen als wirtschaftspolitsches Steuerungsmittel nicht richtig wieder.

Es erscheint wichtig zu erkennen, daß die übliche Art der Darstellung für die Praxis zu falschen Erwartungen führen muß. Sie läßt die tatsächlichen Wirkungszusammenhănge von Gestaltungen der Institutionen und Eingriffen in ihr Regelungsgefüge zugunsten einer Beschreibung und fragwürdigen Einschatzung der Gedankenelemente der Ordnungsidee als letztlicher Ursache unerkannt.

Tatsächlich wird die Steuerpolitik bei Darstellung der fortentwickelten Marktwirtschaft zur sogenannten "sozialen Marktwirtschaft" stets nur insoweit als Bestandteil des Instrumentariums erwähnt, als eine zumeist steuerbegünstigte sozialpolitisch motivierte Umverteilung von Einkommensteilen zur Vermögensbildung durch Gewinnbeteiligung, durch Lohnpolitik und durch allgemeine Sparförderung von Arbeitnehmern infrage steht. ${ }^{7}$ Dabei handelt es sich um Maßnahmen, die, dem sozialen Ausgleich dienend, das Charakteristikum der "sozialen Marktwirtschaft" darstellen.

Die Einflußnahme von Steuervergünstigungen auf die Wirtschaftsdaten und deren Konsequenzen werden dagegen regelmäßig ausgeblendet.

Jedenfalls muß auf diese Weise übersehen werden, daß die übliche These über die Auslösung des sogenannten "Wirtschaftswunders" durch Einführung der "sozialen Marktwirtschaft" nach 1948 in Form der üblichen Formulierung falsch ist.

Tatsăchlich haben nämlich Steuervergünstigungen durch hohe Sonderabschreibungen für abnutzbare Wirtschaftsgüter bereits in den Jahren 1933 und 1934 bei Geltung einer von zunehmend lenkenden, marktwirtschaftliche Ordnungselemente ersetzenden wirtschaftspolitischen Aktivitäten einen ebenso unerwarteten und ebenso allgemein bewunderten seinerzeit politisch verklärten Wirtschaftsaufschwung ausgelöst. ${ }^{8}$

- Hamel, H. (1994), Soziale Marktwirtschaft ..., S. 116. Bei anderen Autoren, wie etwa Röpke, Rueff oder Rilstow werden diese Maßnahrnen nicht einmal als wichtige Hilfsmittel in einem Nebensatz erwathnt.

'Paraskewopoulos, S. (1976), Sozialordnung, in: Wirtschaltsverfassung, S. 201 bis S. 206.

${ }^{8}$ Zwar hieß es in der Regierungserklărung des Reichskanzlers v. 23.3.1933, die zugleich Begrûndung des eingebrachten sogenannten Ermalchtigungsgesetzes war, daß "die Regierung die Wahmeh-. mung der wirtschaftlichen Interessen des deutschen Volkes nicht über den Umweg einer staatlich zu organisienenden Wirtschaftsbürokratie betreiben, sondern durch stärkste Förderung der privaten Initia-tive unter Anerkennung des Privateigentums" verfolgen werde, s. Deutsche Allgemeine Zeitung. Nr. 
Wenn auch richtig sein mag, daß der allmähliche Übergang zu einer von sozialen, marktkonformen Korrekturen ergänzten und durch eine große Mehrheit gewünschten marktwirtschaftlichen Ordnung nach 1948 wegen des ausgelösten Vertrauenszustands zu einer Stabilisierung und Verbreiterung eines bereits eingeleiteten Wirtschaftsaufschwungs wesentlich beitrug und dann auf Dauer unverzichtbar wurde, so ist zugleich folgendes festzuhalten: Die historischen Zusammenhănge waren wesentlich komplizierter, als es in den systematischen Ausführungen der Vertreter einer "sozialen Marktwirtschaft" über die Wirkungszusammenhänge zumeist allzu vereinfacht zum Ausdruck gelangt. In der vereinfachend vorgetragenen Form ist die Aussage über die Verursachung eines "Wirtschaftswunders" jedenfalls falsch. ${ }^{9}$

141 v. 24.3.1933, Beibl. S. 1, Sp. 4; s. a. Forsthoff. E. (1943), S. 306. Zu dieser Zeit wurden die vorherrschenden Oberzeugungen von fuhrenden Nationalökonomen und Zeitkritikem aber von Vorstellungen vom "Ende des Kapitalismus" und von "antikapitalistischen", an Autarkiemodellen und Lenkungsdenken orientierten Leitideen bestimmt. Sie waren von wachsendem Einfluß auf die Wirtschaftspolitik. Selbst J. M. Keynes trat in Schm. Jb. für "nationale Selbstgenügsamkeit" ein, s. Schm. Jb. 1933, 57. Jg., S. 561. Darin hieB es: "Der dekadente internationale, aber individualistische Kapitalismus ... hat zu keinem Erfolg geführt. Er ist nicht klug, nicht schön, nicht gerecht und nicht sittlich und er liefert nur unzulängliche Güter" , S. 565. Edgar Salin setzte sich mit vielen anderen Zeitkritikern als Mitbegründer des "Tat-Kreises" gleichermaßen für antikapitalistische Ersatzmodelle der Wirtschaftsordnung ein, s. Salin, E. (1933), S. 192. Auch Sombart ist hier zu nennen. Dennoch führten die Steuervergünstigungen, deren wichtigste Maßnahme eine befristete Sonderabschreibung von $100 \%$ darstellte (s. Anm. 3), in kurzer Zeit zu einer wirtschaftlichen Initialzundung, die trotz Devisenbewirtschaftung und einsetzendem AuBenhandelsboykott die Erholung in anderen Industrieländern bei weitem übertraf. Diese allgemein wie ein Wunder begrüßte Leistung, die de facto schon länger von kenntnisreichen Beamten des Reichsfinanzministeriums vorbereitet worden war, wurde jedoch in verhängnisvoller Weise von Politikem mißbraucht, die Gestalt Adolf Hitlers zu verklären, mit einer gūtigen Vorsehung in Verbindung zu bringen und zum Erretter aus gröbter Not aufrubauen. Der am 4.4.1933 emannte Staatssekretär im Reichsfinanzministerium Fritz Reinhardt war als autodidaktischer Steuerexperte zugleich Leiter der "Reichsrednerschulung" und sorgte sofort wirkungsvoll für den Vertrauenszustand, der einen Weg in den Abgnund überhaupt erst ermōglichte. Der Verfasser erinnert sich, als Heranwachsender an vielen Gesprächen des Vaters, eines Berliner Bankiers, mit fuhrenden Bankiers und anderen Personen aus der Wirtschaft im kleinen Kreis auf dem heimischen Gut in Mecklenburg 1934 teilgenommen zu haben, in denen die fatale politische Manipulation durchschaubarer wirtschaftlicher Zusammenhänge mit unabsehbaren Folgewirkungen beklagt wurde. Man geht nicht zu weit, wenn man festhälth $\mathrm{daB}$ erst die durchschlagende Wirkung der steuerpolitischen MaBnahmen ab Juni 1933 und darin insbesondere der Abschreibungsvergunstigung, indem die großen Leistungen des Finanzressorts zu einer "Verherrlichung Hitlers" mißbraucht wurden, eine Entwicklung, ermöglichte, die mit der Zerstörung des historisch gewachsenen deutschen Staatsgefüges endete, s. hierzu zur Stellung Salins und Sombarts in: Hock, W. (1960), S. 50; zu den Auseinandersetzungen s. Krohn, D. (1981), S. 167: zur Figur F. Reinhardts s. Pausch, A. (1987), S. 349, hier S. 356; s. a. BDSt (Hrsg.) (1970), Fünfig Jahre deutsche Steuerfachverwaltung, S. 110; s. a. Hāuser, K. (1966), Das dritte Reich und der zweite Weltkrieg, in: Stolper, G. (1966), Deutsche Wirtschaft seit 1870, 2. Aufl., Tũbingen, S. 162; s. a. Blaich, F. (1976), Die Grundsătze nationalsozialistischer Steuerpolitik und ihre Verwirklichung, in: Henning, T. W. (Hrsg.) (1976), Probleme der nationalsozialistischen Wirtschaftspolitik, Berlin, S. 100; Reinhardt, F. (1936), Die neuen Steuergesetze, Berlin, S. 3; Terhalle, F. (1952), S. 290; s. a. Schwerin von Krosigk, Graf L. (1974), S. 205.

"In Darstellungen wird zumeist von einem "Wunder" oder "Wirtschaftswunder" gesprochen, dessen "natürliche Erklărung" sich aus einer Erläuterung der "sozialen Marktwirtschaft" als eines "Zaubermittels" ergibt. Im Ausland war der Wiederaufstieg der deutschen Wirtschaft für viele Beobachter so 
Zwar wurden unmittelbar nach Durchführung der Währungsreform in einem eigenmächtigen Schritt am 25. Juni 1948 die meisten noch vorhandenen Preisbindungen für Verbrauchsgüter aufgehoben, später am 30. Juni 1950 die Bewirtschaftungs-Notgesetze beseitigt und am 30. April 1952 die deutsche Einfuhr liberalisiert. ${ }^{10}$ Der Markt erhielt weitgehend wieder eine regulierende Funktion und wirkte selektierend und stimulierend auf die Produktion. Die Deutsche Mark war fortan der einzige Bezugsschein für knappe Güter.

Weite wichtige Bereiche der Wirtschaft blieben jedoch noch lange Preisvorschriften unterworfen und die Preise der freigegebenen Güter zogen sofort stark an. Es folgte eine große, als strukturell beurteilte Arbeitslosigkeit. Erst die Anforderungen des Korea-Krieges führten zu größerer Entspannung. ${ }^{11}$

Dagegen ist festzuhalten: Gegenüber den vorherrschenden Zuständen mußten den von der Militärregierung seit 1948 vorgeschriebenen exorbitant hohen progressiv ausgestalteten Steuertarifen, die schnell bis zu $95 \%$ anstiegen und somit jede wirtschaftliche Initiative erstickten, ${ }^{12}$ zusammen mit Steuervergünstigungen bei erwünschten wirtschaftlichen Dispositionen seit eben dieser

unvorstelibar, daB selbst Wissenschafler auf historische Legenden zurückgriffen, Rueff, J. (1953), S. 205, S. 206; Ristow, A. (1953), S. 111; Ropke, W. (1953), S. 66; ders. (1965), S. 136, S. 177, S. 207 u. a.: Gutmann, G. (1976), S. 5: Zischka, A (1966), S. 543 u. a.. Inzwischen haben die vom Zusammenbruch des Sozialismus betroffenen Ostblockstaaten leidvolle Erfahrungen darüber gemacht, daß auch bei Schaffung von Grundvoraussetzungen, wie Privateigentum und zweistufigem Banksystem ein marktwirtschafliches Regelungsgefüge nicht die fehlenden Ressourcen verfügbar machen kann. Regein zur Wettbewerbssicherung, zur Geldwertstabilitht und zum sozialen Ausgleich reichen desgleichen nicht zur Wohlstandsbildung aus. Offenbar wird aber inzwischen erkannt, daB die Forschung bei Erôrterungen "ordnungs- und wirtschaftspolitischer Grundlagen sozialer Marktwirtschaft" nichı verharren darf, s. Watrin, C. (1994), S. 16 u. a.. Da die konkreten Wirkungen der einzelnen Regelsysteme, wie das ESt-Recht, nicht genügend Aufmerksamkeit erhielten, kann heute auch über "konzeptionelle Malngel der Sozialen Marktwirtschaft" geklagt werden, die "den Weg von der sozialen Marktwirschaft zum Wohlfahrtsstaat" geebnet haben, Hamel, H. (1994), S. 117; thhnlich Paraskewopoulos, S. (1994), S. 212.

10 Zischka, A. (1966), S. 545; hierzu: Verordnungsblatt für die Britische Zone v. 13.7.1948, S. 201; s. desgl. Ausgabe Nr. 38 v. 23.8.1948, S. 244; s. Sammelblatt für Gesetze, Verordnungen und Bekanntmachungen des Bundes, der Länder und der Besatzungsmăchte, Nr. 5 v. 3.2.1950, S. 61; desgl. Nr. 32 v. 2.7.1950, S. 691; desgl. Nr. 44 v. 17.10.1950, S. 995. Die Liste der Waren wurde eingeschralnkt, bis eine weitere Verlangerung nach dem 31.12.1950 unterblieb.

$"$ Hierzu s. Muscheid, J., (1986), S. 32. Muscheid weist auf die vielen vorhandenen EinfluBfaktoren hin und zeight da $\mathbf{B}$ keineswegs ein problemloser mehrjahriger Wirtschaftsboom ausgelöst wurde, $s$. Zischka, A. (1966), S. 553, S. 554; als Beispiel s. a: Anordnung uber Preisbildung und Preisuberwachung nach der Walhnungsreform v. 25.6.1948, in: Verordnungsblatt fur die Britische Zone, Nr. 33 v. 13.7.1948, S. 201. Die Bestimmung war auf einen aufgefuhrten Katalog beschralnkt. Zugleich erfolgten Anordnungen zur weiteren Öberwachung, s. S. 203, S. 204.

12 Hierzu s. Verordnungsblatt fur die Britische Zone v. 2.7.1948, S. 189; EStG v. 29.4.1950, in: BStBI. 1950, S. 104 u. S. 169; EStG v. 28.12.1950, in: BStBI. I 51, S. 1, hier S. 20; EStG v. 17.1.1952, in: BStBI. I 52, S. 33, hier S. 52; EStG v. 10.12.1952, in: BStBI. I, S. 789, hier BStBL. I 53, S. 811 u. S. 837; EStG v. 15.9.1953, in: BStBI. I, S. 1355; EStG v. 16.12.1954, in: BStBI. I, S. 373, hier S. 412; erst hiernach pendelte sich die höchste Progressionsstufe auf 53\% bis $56 \%$ ein. 
Zeit für das, was allgemein als "Wirtschaftswunder" bezeichnet wird, eine entscheidende Rolle zukommen.

Der Wille von Unternehmern angesichts der vorhandenen hohen Arbeitslosigkeit, der zum Teil ruinösen, von der Militărregienung erlassenen Bilanzierungsvorschriften und der extrem früh einsetzenden Steuerprogression zu überleben, machte nämlich die Erzielung von Steuervergünstigungen durch Beteiligung an begünstigten Investitionen und damit eine erwünschte Wirtschaftsankurbelung zur einzigen sinnvollen Alternative.

Gewiß hat die zunehmende Ersetzung einer obrigkeitlich, von Bezugsscheinen gelenkten Wirtschaft durch eine marktwirtschaftliche Ordnung bei Berücksichtigung der heute selbstverständlich gewordenen sozialen Korrekturen den für den Wiederaufbau bei allen politischen Gruppienungen notwendigen Vertrauenszustand unterstützt. Zu der erforderlichen nachhaltigen Initialzündung, zu der notwendigen Wirtschaftsbelebung konnte sie jedoch vorerst nicht beitragen. Die wirtschaftliche Entwicklung zeigte sich bis 1951 vorersi schwankend. ${ }^{13}$

Wer - wie der Verfasser - die "soziale Marktwirtschaft" als entwicklungsfähige und vor allem verteidigungswerte, ja wichtigste Leitidee der Volkswirtschaft beurteilt, wird gut beraten sein, sich auch mit den Eigentümlichkeiten des geltenden deutschen Einkommensteuerrechts und den unterschiedlich zu beurteilenden Wirkungen der Steuervergünstigungen auseinanderzusetzen.

Dem deutschen EStG liegen nun einmal, wie wir sahen, zwei unterschiedliche Baupläne zugrunde, denen jeweils eine unterschiedliche innere Zweckmäßigkeit eigen ist und die daher unterschiedlichen Zielvorgaben also Problemlösungen zu dienen vermögen. Eine einseitige bzw. mangelhafte Aufarbeitung der Entstehungsgeschichte der Einkommensbesteuerung hat den Fortschritt dieser Erkenntnis verzögert. ${ }^{14}$

13 S. die Darstellung bei Muscheid, J. (1986), S. 32. Wallich gibt dem Beginn des Korea-Krieges für die positive Fortentwicklung der Wirtschaft entscheidende Bedeutung, s. Wallich, H. (1955), S. 84.

${ }^{14}$ In ihrer sehr subtilen Darstellung der Ereignisse und Zusammenhänge nach 1945 weist Muscheid auch der Kombination von "Steuervergünstigungen bei hohem Tarif" und der Tatsache, daß die Steuergesetze seit 1948 im wesentlichen von deutschen Institutionen gefertigt wurden, groBe Bedeutung zu, s. Muscheid, J. (1986), S. 44. Der Direktor der Verwaltung der Finanzen des "Vereinigten Wirtschaftsgebietes" war tatsächlich ein ehemaliget Ministerialdirigent des Reichsfinanaministeriums, dem eт von 1925 bis 1935 angehōrt hatte. Er knüpfte offensichtlich an die in diesen Krisenjahren bei dieșer Behörde gesammelten praktischen Erfahrungen an, s. hierzu Kapitel M IV, Nr. 7; s, BDSt (Hrsg.) (1970), Fünfzig Jahre ..., S. 99. Muscheid bestätigt, daB die Diskussion der Vorschriflen des EStG in Fachkreisen um 1948 sich wesentlich nur den verteilungspolitischen Aspekten widmete, s. Muscheid, J. (1986), S. 45, S. 46. Hier war man der Auffassung daß eine TarifermaBigung Sparquote und Wachstum fördern würden, s. hierzu Littmann, K. (1981), in: Handb. d. Finanzwissenschaf, 3. Aufl., Bd. IV, S. 1028. Die These Muscheids, daß die Gesetze der Militäregierung wesentlich von deutschen Mitarbeitern ausgingen und die Besatzungsmacht sich zumeist auf ein Vetorecht beschränkte ș. Mul- 
So kommt es, daß die Forderungen nach gerechten, gleichmäßigen und an der Leistungsfahigkeit orientierten Steuern nicht nur in der Öffentlichkeit stets auf die Erhöhung der Tarifprogression und die weitere Einfügung und Erhöhung von Freibeträgen, auf Pauschalienungen, Typisierungen und Schematisierungen beschränkt und konzentriert werden. ${ }^{15}$ Je höher - und nach Volkes Meinung damit sozialer - diese genannten Positionen ausgestaltet werden, um so stărker wird aber automatisch die Verlagerung der notwendigen Steuerbelastung auf weniger Schultern, um so höher ist die Belohnung bei legaler Steuervermeidung und damit die Umverteilung von unten nach oben. Die mit dem dualistischen Aufbau der Ermittlungsvorschriften des deutschen EStG verbundenen Ungereimtheiten sind erst spät von Fachleuten überhaupt wahrgenommen worden, nachdem sie lange Zeit hindurch ausschließlich zum Handwerkszeug von Praktikern zăhlten. Die Inanspruchnahme zur steuerfreien Vermögensmehrung uferte in den 60er Jahren derart aus, daß die Medien darin ein Ärgernis sahen. Der Bundesfinanzminister beauftragte den Wissenschaftlichen Beirat mit der Anfertigung eines Gutachtens zur Reform der direkten Steuern. ${ }^{16}$

scheid, J. (1986), S. 44, kann der Verfasser aus eigener Kenntnis als ehemals ieitender Angestellier dieser Einrichtung bestatigen.

${ }^{13}$ In den letzten 45 Jahren hat es vier als organische große, ja sogar 1975 als Jahrhundertwerk angekündigte einkommensteuerliche Gesetzeswerke gegeben (1954/55, 1965, 1975 und 1990). Dazu kommen noch zahllose kleine Gesetzeslinderungen. Regelmåig wurden alle als mutige Systemănderungen mit dem Ziel gröBerer Gerechtigkeit und Steuervereinfachung angekündigt. Stets handelte es sich nur um Anpassungen des irrefuhrend seit 1883 sogenannten steuerfreien Existenzminimums, die Einfuhrung, Kürzung, Streichung oder Anpassung von Abschreibungen, Freibeträgen, Pauschbeträgen, Pauschalen, Absetzungen für Sonderausgaben und außergewöhnliche Belastungen und Änderungen im Verlauf der Tarifprogression. Entgegen anderslautenden Andeutungen ist von Seiten der Steuerwissenschatten in dieser Zeit keine aberzeugende realisierbare systemveraindernde Alternative entwickelt worden. Noch heute wird in Reformvorschlagen insbesondere von Steuerjuristen die strenge Trennung zwischen steuerlich relevanter Einkommens- und nichtrelevanter Privatsphalre vertreten, die für die Wagner-Fuistingsche Besteuenungsidee grundlegend war. Dazu werden heute zur Begründung geeig. nete Auslegungen in die Verfassung hineininterpretiert, s. Kirchhof, P. (1988), S. F 14; s. Beschlũsse des 57. Deutschen Juristentages 1988, in: NJW 1988, S. 3006 u. a. Ärderungen bei Steuervergùnstigungen durch Sonderabschreibungen folgten seit 1949 jeweils den Begünstigungsschwerpunkten, die die Zeitumstlınde zu Motiven verdichteten und die von Wachstumsförderung öber Konjunkturstabili. sierung bis zu Einkommensnivellierung, Umweltpolitik und fiskalischen Zielen reichen, s. Muscheid, J. (1986); Findling, M. (1992), Franke, S. F. (1981), S. 105. Die Steuerpolitik übernahm so neben ilhrer Bedarfsdeckungsfunktion, die wegen der Ausgahen der öffentlichen Haushalte strukturverăndernd wirken kann, die Aufgabe, die Wirtschafts-, Sozial- und Gesellschaftspolitik unmittelbar zu unterstuitzen

${ }^{16}$ Gutachten zur Reform der direkten Steuern v. 11.2.1967, erstattet vom wissenschaftlichen Beirat beim Bundesministerium der Finanzen, in: Schriftenreihe des BMF, Heft 9, Bonn. Die Vorgänge fulhrten dazu, daß in dem Gutachten angeregt wurde, große Verăußerungsgewinne gleichmäßig zu, besteuern, sofern Freigrenzen überschritten wurden. Das. Gutachten sprach von "Lücken" im "System" und einer unbefriedigenden Erfassung von Wertsteigerungen (S. 23 - S. 25). In dem Bericht der Einkommensteuerkommission von 1964, die 1958 von dem damaligen Bundesfinanzminister eingesetzt worden war, fehlen noch vergleichbare Ausführungen, s. Untersuchungen zum Einkommensteuerrecht, in: Schriftenreihe des BMF 1964, Heft. 7. 
Wollen wir zu einem abgewogen bewertenden Urteil über die Vermengung der beiden Besteuerungsweisen im Einkommensteuerrecht der Bundesrepublik Deutschland seit 1949 gelangen, so werden wir uns der Ausführungen Karl Oldenbergs aus dem Jahr 1893 entsinnen müssen und auch deren Auswirkungen auf die Finanzierung des Wiederaufbaues und damit die Vermehrung des Wohlstandes und die positive Entwicklung der allgemeinen Einkommensverhältnisse nicht außer acht lassen đürfen.

Die Vermischung der beiden unterschiedlichen Organisationsweisen der Besteuerung hat letztlich ohne Zweifel eine gewaltige Mobilisierung von haftendem Kapital für Aufbaumaßnahmen ermöglicht. Der Wiederaufbau des kriegszerstörten Westdeutschlands und vor allem West-Berlins verdankt diesem Umstand entscheidende Impulse. Hierauf werden wir noch zurückkommen.

Dies gilt es jedenfalls erläuternd festzuhalten, wenn vereinfachend erwähnt wird, die Ursache für den Wiederaufbau der Bundesrepublik Deutschland nach 1949 sei im wesentlichen der Einfuhrung der Marktwirtschaft gutzubringen.

Richtig ist, daß in den 50er Jahren die sozialen Folgen, die mit der unterschiedlichen Finanzierung des Wiederaufbaues verbunden waren, nachhaltig öffentlich erörtert wurden. Die marktwirtschaftliche Preisbildung wurde dabei jeweils als rein formales Organisationsprinzip gesehen, welches vielfacher Lenkung durch marktgerechte Eingriffe zugänglich ist und solche auch zur Garantie eines funktionsfahigen Wettbewerbs und zum sozialen Ausgleich erfordert. So wurden korrigierende Eingriffe marktkonformer Art durchaus als notwendig beurteilt. Die Selbstfinanzierung der Wiederaufbauinvestitionen durch Kapitalbildung und Investitionen über Verkaufspreise wurde wegen der damit verbundenen überhöhten Preisbildung stets als sozial höchst unbefriedigende, weil ungerechte, wenn auch vorerst unvermeidbare Übergangsregelung beurteilt. ${ }^{17}$ Gesucht wurde nach einer vertretbaren Balance der Interessen.

Aus diesen Gründen wurde nachhaltig empfohlen, im normativen Teil des Handelsrechts Bewertungs-, Abschreibungs- und Gewinnvorschriften so abzuändern, daß die Produktionskosten jeweils im Preissystem richtig wiedergege-

17 Die Möglichkeit zur Selbstfinanzierung hatte schon immer für Konfliktstoff zwischen Aktionären, Vorstand und Aufsichtsrat bei Aktiengesellschaften gesorgt. Nun sah man eine wichtige Aufgabe des Staates darin, Zwang auf alle Gesellschaften zugunsten von deren Wettbewerbsverhalten auszu. üben. Die Gesellschaften sollten veranlaßt werden, alle Preisvorteile weiterzugeben und so eine Mengenkonjunktur auszulōsen. Bilanzrecht und Bilanzsteuerrecht wurden auf dieses Ziel hin neu ausgerichtet. Auch der gespaltene Körperschaftsteuertarif gehôrt hier erwăhnt. Die "dynamische" Bilanzauffassung Schmalenbachs verdrängte weitgehend die "statische" Bilanzlehre, von der die auf Giäubiger. schutz abstellenden Normen des Handelsrechts meist geprägt waren, s. Jecht, H. (1957), S. 420, hier S. 431 . 
ben werden und das Wertrechnungssystem nicht zugunsten einer überhöhten Bildung von Eigenkapital über Verbraucherpreise verfälscht wird. ${ }^{18}$ Im Mittelpunkt von Investitionsentscheidungen sollte ein nach Gesichtspunkten des Wettbewerbs organisierter Kapitalmarkt stehen. Nur auf diese Weise, so glaubte man, komme dem Verbraucher die entscheidende Funktion bei der Lenkung der Produktion über die Preisbildung zu. ${ }^{19}$ Das war aber genaugenommen auch mit dirigistischen Lenkungen der Investitionsströme über Eingriffe in die Besteuerung im Grunde ebenfalls nicht zu vereinbaren.

Die kleine und dann die große Aktienrechtsreform und die Änderung der Bewertungs-, Abschreibungs- und Gewinnvorschriften des Handelsrechts und die dadurch ausgelöste Anpassung der Grundsätze ordnungsmäßiger Buchführung $(\mathrm{GoB})$ für Kaufleute suchten in den sechziger Jahren dann diesem ordnungspolitischen Ziel zu dienen. ${ }^{20}$ Auch die offene Finanzierung sozialer Forderungen aus Steuermitteln wurde in dem System der "sozialen Marktwirtschaft" grundsătzlich als marktkonforme Maßnahme beurteilt. ${ }^{21}$

Die Finanzierung von Investitionen durch Sondervorschriften über steuerliche Vermögensvorteile, also durch eine verborgene und daher einfach durchzuführende Steuerumverteilung in Form von Sonderabschreibungen wurde jedoch selten nachhaltig erörtert. Dazu fehlten wohl zumeist die Kenntnisse des

${ }_{18}$ Hierzu: Oettle, K. (1964), Selbstfinanzierungsmöglichkeiten und Investitionsentscheidungen, in: Schmalenbachs Zeitschrift fur betriebswirtschaftliche Forschung, 16. Jg., S. 381, hier S. 394; s. Gutenberg, E. (1963), Ober den Einfluß der Gewinnverwendung auf das Wachstum der Unternehmung, in: Zeitschrift fur Bletriebswirtschaf, 33. Jg., S. 193, hier S. 206 - S. 208; Ballerstedt, K. (1965), Bilanzrecht und Unternehmensform, in: Zeitschrif für Betriebswirtschaf, 35. Jg., S. 1, hier S. 8; Gutenberg, E. (1965), in: Zeitschrift für Betriebswirtschaft, 35, Jg., S. 13 - S. 20.

19 Hierzu: Gesetz gegen Wettbewerbsbeschränkungen (GWB) v. 27.7.1957, in: BGBI. I, S. 1081. Die Einzelheiten des Gesetzes und die Frage, ob dem Verbots- oder dem MiBbrauchsgesichtspunkt zu folgen sei, wurde lange Zeit offenilich diskutiert. Kartellverbot, Fusionskontrolle und Kontrolle des MiBbrauchs von Marktmacht kennzeichneten seither die Tätigkeit zur Aufrechterhaltung der Funktionsfthigkeit des Wettbewerbs.

20 Das Gesetz aber die Kapitalerhöhung aus Gesellschaftsmitteln und über die Gewinn- und Verlustrechnung v. 23.12.1959. in: BGBI. I, S. 789, und Maßnahmegesetz v. 30.12.1959, in: BGBI. I S. 834, suchte die unkontrollierbare Selbstfinanzierung durch Bildung stiller Rücklagen einzuschrainken, indem Normativbestimmungen über die Gliederung der Gewinn- und Verlustrechnung fur bessere Publizithit der Betriebs- und Unternehmensergebnisse sorgten. Die große Aktienrechtsreform vom 6.9.1965 (BGBI. I Nr. 48, S. 1089, hier insbes. $\$ \S 148$ - 178, S. 1124 - S. 1135) suchte durch Normativbestimmungen zur Rechnungslegung vermittels neuer Gliederungs- und Bewertungsvorschriften demselben Zweck zu dienen. Gesichtspunkte aus der dynamischen Bilanzauffassung Schmalenbachs zur richtigen Ermittlung des periodengerechten Gewinns verdrångten Regelungen, die stärker auf den Gläubigerschutz abgestellt hatten. Dies kam auch den Forderungen der Finanzverwaltung entgegen, s. Littmann, E. (1966), Die aktienrechtlichen Rechnungslegungsvorschriften, in: DStR, S. 233; s. Dóllerer, G. (1965), Rechnungslegung nach dem neuen Aktiengesetz, in: BB, S. 1409.

${ }^{21}$ Maller-Armack, A. (1948), S. 109. Ähnlich beurteilt Mïller-Armack ein System von Beihilfen in sozial gebotenen Fallen, das die Preisbildung und deren Lenkungsfunktion nicht behindert, als marktkonforme Maßnahune, s. Mriller-Armack, A. (1956), S. 391. 
Steuerrechts, aber auch das Interesse. Wenn Erörtenıngen über Kapitalmarkı und Steuersystem stattfanden, so wurden dirigistische Eingriffe streng verworfen und interventionistische Maßnahmen vorsichtig als unzweckmäßig abgelehnt. Die Ausfiihrungen blieben jedoch stets programmatisch und unkonkret. Die Begriffe wurden unscharí definiert. ${ }^{22}$

Jedenfalls wurde in der Folgezeit die systematische Bedeutung des Steuerrechts für die konkrete Ausgestaltung der Marktwirtschaft vernachlässigt. So wurde vorerst die Ausrichtung steuerlicher Vorschriften zur Verfolgung nichtfiskalischer Ziele als Eingriff in den Datenkranz des marktwirischaftichen Gefüges und somit letztlich formell als marktkonforme Maßnahme beurteilt. ${ }^{23}$ Das hat bei einigen Finanzwissenschaftlern frühzeitig Besorgnis geweckt und Ablehnung hervorgerufen, die aber nicht weiter verfolgt wurde. ${ }^{24}$

Die erfreulichen Wachstumsraten der Wirtschaft und die sich jeweils artikulierende Interessenlage standen einer Kritik ohnehin entgegen.

Vernehmbare offentliche Kritik regte sich, wie wir noch sehen werden, erst nach Beendigung der ersten Phase des Wiederaufbaus zu Ende der 50er Jahre und zwar nachhaltig bei den Steuerrechtlern, denen die "Wandlungen im Steuerrecht" in systematischer Hinsicht wegen der zunehmenden Kompliziertheit und Kurzlebigkeit der steuernden nichtfiskalischen Vorschriften zunehmend Schwierigkeiten bereiteten. ${ }^{25}$ Danach kam es auch bei Finanzwissenschaftlern zu lebhaften Erörterungen über die Kompatibilität nichtfiskalischer steuerrechtlicher Gesetzesvorschriften mit der Idee der "sozialen Marktwirtschaft", eine Diskussion, die mit der Verabschiedung des Stabilitătsgesetzes einen gewissen Höhepunkt, wenn auch ohne Abschluß, erreichte. ${ }^{26}$ Seither ist

22 S. Neumark, F. (1970), S. 224 - S. 230; s. a. ders. (1957), S. 450, hier S. 452 - S. 457.

${ }^{23}$ S. Geiger, K. (1977), S. 300. Die instrumentale Seite einer Maßnahme war nach Müller-Armack von grōBter Bedeutung, da der ProzeB einer die Knappheiten wiedergebenden Preisbildung nicht durch direkte Eingriffe gestôrt werden durfte, Müller-Armack, A (1956), S. 391. Dabei war "das regulative Prinzip sozialer Intervention" in der Marktwirtschaft ... ihre Verträglichkeit mit dem Funktionieren einer marktwirtschaftichen Produktion und der ihr entsprechenden Einkommensbildung", MülerArmack, A. (1956), S. 391.

24 Schmólders, G. (1958), Allgemeine Steuerlehre, 3. Aufl., S. 54. Schmólders suchte zwar eine tolerante Grundhaltung zu entwickeln; seine ablehnende Skepsis gegenüber einer Vorherrschaft der Wirtschaftspolitik über die Steuerpolitik schlug jedoch ständig durch, s. a. Schmolders, G. (1970), Die Steuer als Instrument der Währungspolitik, Tübingen, S. 253, S. 273, S. 289 u. a.

2s Spitaler, A. (1960), Wandlungen im Steuerrecht, S. 379, hier S. 422; s. Falk. L. (1962), S. 27. hier S. 44. Klagen über eine zunehmende, nicht mehr verkraftbare Kompliziertheit steuerlicher Bestimmungen und Forderungen zu deren Vereinfachung sind von allen Steuerwissenschaftlem seit $W$. Roscher über B. Fuisting bis heute kontinuierlich vorgebracht worden.

20 S. Neumark, F. (1966), S. 477; ders. (1969), S. 100; ders. (1970), S. 224. Das Gesetz zur Förderung der Stabilität und des Wachstums der Wirtschaft vom 8.6.1967 (BGBI. I, S. 527) stellte einen Wendepunkt in der deutschen Finanz- und Wirtschaftspolitik dar, indem es der Bundesregjerung einen 
das Steuerrecht in der politischen Praxis offenbar zunehmend in das Arsenal marktkonformer Steuerungsinstrumente aufgenommen worden.

Zwar wird den Gesetzen der marktwirtschaftlichen Ordnung auf diese Weise heute in formaler Hinsicht noch Genüge getan: Die pretiale Lenkung des wirtschaftlichen Geschehens, die Weitergabe der Knappheitsverhältnisse des Marktes durch den Preismechanismus an die Produktion in Form von Signalen der Rentabilităt ist aber vielfach mit vorerst nicht übersehbaren Konsequenzen zunehmend in eine de facto im vorparlamentarischen Raum ausgehandelte fiskalische Steuerung des Wirtschaftsgefüges übergeglitten.

Und: Viele Investitionen werden heute getătigt, obgleich ihre Rentabilität für die Zukunft auch rechnerisch unsicher ist. Oftmals dient dabei eine kalkulierte steuerfreie Vermögensmehrung allein als ausreichender Anreiz. Überschüsse werden dann, insoweit dies steuerlich machbar ist, gar nicht mehr angestrebt. Das wichtige Ziel der Markiwirtschaft, eine richtige Weitergabe der Kosten-/Preisverhältnisse an die Produktion zu gewährleisten, wird dabei glatt überspielt. Das marktwirtschaftliche Wertrechnungssystem gerät so in Unordnung. ${ }^{2 ?}$

Auch die sozialpolitischen Korrekturen des marktwirtschaftichen Prozesses konnten im Lauf der Zeit überspannt werden. Dies konnte verborgen bleiben und zu dem Sachverhalt führen, daß oftmals nicht mehr Marktpreise, sondern steuerfreie Vermögensvorteile lenkende Funktionen ausüben mußten.

Der Preis der seit 1949 gegebenen Möglichkeit zur legalen Steuervermeidung, die die Progressionsbelastung bei höherem Einkommen glatt aufhebt, ist eine gewaltige unkontrollierte Umverteilung der Einkommen von unten nach oben. Dies ist gelegentlich gesehen, aber bezüglich seiner Tragweite nicht weiter erörtert worden. Wenn auch im Laufe der Zeit bei den Steuerpflichtigen erhebliche Verdrossenheit über das Einkommensteuersystem erkennbar wurde, so ist diese jedenfalls durch den Ausbau des sozialen Netzes und andere Maß-

Lenkungs- und Interventionsauftrag zur Regulierung der gesantwirtschaftlichen Entwicklung erteilte, s. Strickrodt, G. (1981), Stabilitătsgesetz, in: Handwörterbuch des Steuerrechts, S. 1245.

${ }^{27}$ Zur Eriâuterung s. in Anlage 29 das Angebot zum Erwerb eines Zweifamilienhauses, das am 30.6.1995 einem auslăndischen Mandanten unterbreitet wurde. Wenn von notwendigen Erganzungen und. Berichtigungen in der Kalkulation abgesehen wird, ergibt sich, daB hohe Steuerersparnisse jeweils als fiktive Einnahmen das wesentliche Kriterium fur die wirtschaftliche Entscheidung darstellen. Da das Objekt zwischen Neuß und Aachen belegen ist, liegen der Berechnung keineswegs Steuervergünstigungen nach dem Fördergebietsgesetz zugrunde, sondern die "normale" gewăhrte "degressive" Afa gemaß $\S 7$ Abs. 5 EStG. DaB auf diese Weise ein von Partnern abgesprochener Erwerb und die gegenseitige Vermietung der Objekte zu geeignet kalkulierten, die Steuerersparnis hochtreibenden Bedingungen gefördert wird, mag am Rande erwalhnt sein. Partnerschaftliches Vertrauen kann sich vermōgensbildend bewăhren, freilich nur, wenn das zu versteuernde Einkommen der Eheleute aber ca. $250.000,-\mathrm{DM}$ beträgt. 
nahmen, wie etwa Vorschriften zurn Investivlohn, zur Vermögensbildung in Arbeitnehmerhand und weitere, wiederum mit steuerlichen Begünstigungen versehene Regelungen, voll aufgefangen worden. ${ }^{28}$ Mit Abschluß der Aufbauphase stellte sich die Problematik seit etwa 1980 jedoch allmählich anders dar.

Halten wir fest: Die auf Gustav Schmoller zunickgehende Systematik einer Einkornmensbesteuerung hătte die Finanzienungsform durch steuerliche Entlastungen in dem vorstehend geschilderten Ausmaß nicht zugetassen. Anderenfalls wăre die innere Ordnung des Systems mit vorerst unvorhersehbaren Konsequenzen zerstört worden. Einige in unser geltendes Einkommensteuerrecht aus dem săchsischen System übernommene Regelungen sind denn auch 1980, insoweit sie eine übermäßige, nichtfiskalischen Zwecken dienende Steuerentlastung stören konnten, geschickt entfernt worden. Dies geschah zur Zeit, als die Bildung von "Verlustzuweisungsgesellschaften" einen Höhepunkt erlebten und die übrige Nettokapitalbildung zusammengebrochen war. ${ }^{29}$

Die heute noch in dem geltenden Einkommensteuergesetz nachweisbaren Regelungen aus dem alten sächsischen EStG von 1878 geben dem Gesetz dennoch weiterhin den Anschein einer Besteuerung nach der Leistungsfähigkeit. Die aus der Wagnerschen Denkweise stammende Orientierung am Quellenprinzip hat dem geltenden EStG aber erst die Flexibilität zu einem nichtfiskalischen Einsatz. gegeben, nämlich als größtes Finanzierungsinstrument in Zeiten immenser Anstrengungen zum Wiederaufbau verwendbar zu sein, und das sogar in einem demokratischen Gefüge, in dem die Bewilligung von Haushaltsmitteln für diese Zwecke erhebliche Interessenkonflikte herauszulocken vermag.

Die Wiedervereinigung mit den Ländern der ehemaligen DDR hat nach 1990 erneut Anlaß gegeben, die Bedeutung des geltenden EStG für eine Finanzienung des Wiederaufbaues im deutschen Osten auf die Probe zu stellen.

Gewaltige Investitionen durch private Kapitalbereitstellungen werden seit 1989 durch den Einsatz des geltenden EStG vermittels des Fördergebietsgesetzes für Wirtschaft und Infrastruktur in dem Beitrittsgebiet ausgelöst.

Adolph Wagner hat die Grundlage für ein Einkommensteuersystem geschaffen, das mit seinen Vorstellungen über die aufkommende "soziale Epoche" nur sehr bedingt in Einklang zu bringen ist. Sein Begriffsrealismus stand dem eigenen aktivistischen Sendungsbewußtsein, der "Geburtshelfer" einer von

${ }^{28}$ S. Paraskewopoulos, S. (1976), Die Wirtschaftsverfassung .... S. 201 - S. 202.

${ }^{23}$ Hierzu s. Deutscher Bundestag. Drucksache $8 / 3688$ zu Nr. 18. S. 20; s. a. Thieme (1960), Verbrauchsbesteuerung, in: FR, S. 539 und FR 1979, S. 533: s. a. Hansen, R. (1990), S. 40. 
ihm als Wissenschaftler prophezeiten Geschichtsentwicklung zu sein, entgegen. Seine wichtigsten Veröffentlichungen schließen ab mit einer Erörterung der "socialoekonomischen Behandlung und Construction der Enteignung" als Gang der Entwicklung. Wagner gab bisher der Entwicklung in der Praxis jedoch eine andere, entgegengesetzte Richtung.

Als besonders bedenklich ist auf die feststellbare allgemeine Verdrossenheit hinzuweisen, die durch die unvermeidbare Undurchsichtigkeit des entstandenen Normengefuges und nicht nur seine tragende Systematik erzeugt wird. ${ }^{31}$ $\mathrm{Da \beta}$ hiervon Konsequenzen auf die Steuermoral ausgehen, ist nicht mehr zu übersehen. Weiterhin muß darauf aufmerksam gemacht werden, daß es der Finanzverwaltung wegen der inzwischen erreichten Kompliziertheit des Normengebăudes zunehmend unmöglich wird, den im Gesetz vorgeschriebenen Bestimmungen über die Veranlagungstätigkeit nachzukommen. ${ }^{32}$ Infolge der Überforderung insbesondere der Mitarbeiter im mittleren Dienst durch Aufgaben von grołer Tragweite, wird zur Bewältigung des Arbeitsanfalles zumeist nur noch nach den abgegebenen Steuererklärungen veranlagt.

Diese Umstände führen - zusammen mit der Verwendung der Einkommensbesteuerung zu nichtfiskalischen Zwecken - zu einer beängstigenden Vermögenskonzentration in wenigen Hănden, einer besorgniserregenden Umverteilung. Im Grunde wird Wohlstand heute infolge der hohen Steuerbelastung nicht mehr durch fleißige Arbeit, sondern durch Verwandlung entstehender Steuerschulden in Vermögen gebildet. Die Einkommensteuer hat sich zum größten Finanzierungsinstrument bei der Vermögensbildung entwickelt.

Wegen der entstandenen Kompliziertheit des Normengefüges wird heute sogar gelegentlich nachhaltig vor einem Zusammenbruch der Finanzverwaltung gewarnt.

Wenn heute von exponienten Vertretern der "sozialen Marktwirtschaft" über ein allmähliches Abgieiten der Wirtschaftsverfassung der Bundesrepublik Deutschland zu wohlfahrtsstaatlichen Regelungselementen mit problematischen Konsequenzen für die weitere Entwicklung des allgemeinen Wohlstands geklagt wird. ${ }^{33}$ dann ist für diese Abweichung vom ursprünglichen Weg der

30 Wagner, A. (1894), Grundlegung der politischen Oekonomie, 3. Aufl.. Zweiter Theil. Volkswirthschaft und Recht, oder Freiheit und Eigentum in volkswirthschaftlicher Betrachtung. S. 532. hier insbes. S. 551 .

31 S. Wirrwarr im deutschen Steuerrecht. Wildwuchs und Willkar. in: Der Spiegel, Heft 20 v. 16.5.1994, S. 104. hier insbes. S. 105, S. 106: Der Steuerzahler. Jg. 1993. S. 105, S. 107.

${ }^{32}$ S. Jenetzky, J. (1982), S. 273, hier S. 260 u. a.; s. a. Der Steuerzahler, Jg. 1993, S. 105, S. 107; s. a. Mitteilungsblatt der Steuerberaterkammer Köln v. Juni 1993, S. 3.

33 Hamel, II. (1994), S. 117. hier S. 121. Hamel sieht die Ursache der Entwicklung in dem Nachlassen der Wettbewerbsorientierung und der allmalhlichen Verdrängung eines sozialen Ausgleichs ver- 
weitergeführte langwährende kontinuierliche Einsatz von Steuervergünstigungen ohne wirklich dringliches Erfordernis nicht ohne Bedeutung. Er hat den Richtungswechsel nămlich zumindest erst ermöglicht.

Steuervergünstigungen stimulieren wirtschaftliche Aktivităten nun einmal auch dann, wenn das Wertrechnungssystem des Marktes die hierzu notwendigen Signale wegen fehlender Anpassungsvorgănge blockiert.

Steuervergünstigungen sollten daher nur zurückhaltend bei feststehender Indikation zeitlich befristet und restriktiv dosiert eingesetzt werden.

Auf Dauer verschrieben wirken sie als Stimulans wie eine Droge, die die Empfindlichkeiten des Organismus für Signale überspielt und so dessen Oberlebensfähigkeit gefährdet. Vor allem können sie den Patienten süchtig machen. Dennoch darf der Arzt auf ihren Einsatz nicht durch dogmatisch begründete Entfernung aus dem Arzneimittelschrank verzichten. Er sollte aber jedenfalls die Wirkungen und Nebenwirkungen kennen, um eine zweckmäßige Verschreibung abwăgen zu können.

Die weiteren Ausführungen versuchen durch Einblicke in die Wirkungsweise des deutschen Einkommensteuerrechts hierzu beizutragen. Dabei mag sich auch ergeben, ob bzw. welche Strukturelemente als funktionsuntüchtig reformbedürftig sind.

mittels Umverteilungen nach dem Subsidiaritätsprinzip durch Einrichtung einer staatlich organisierten Solidarität. s. a. Hamm. W. (1994), Marsch in den Wohlfahrtsstaal, in: FAZ Nr. 33 v. 28.3.1994. S. I1; s. a. Paraskewopoulos, S. (1994), Sozialpolitik ..., S. 202; s. a. Schüller, A. (1994), Umverteilungschaos im Versorgungsstaat, in: Ausgewählte Vortrăge Nr. 24 v. 11/12.3.1994 (BKU), S. 6. Die Wirkungen der Strukturelemente der geltenden Einkommensbesteuerung werden nirgends behandelt, sie sind seit Schmollers Tod offenbar Volkswirten nicht mehr von Interesse. 


\section{H. Einführung in den weiteren Gedankengang in Form einiger Thesen}

Die Fortentwicklung der Besteuerungsidee Adolph Wagners zu dem heutigen Einkommensteuersystem und dessen kontinuierliche Anreicherung mit Bestandteilen aus dem ehemaligen sächsischen EStG von 1874/78 nach rein pragmatischen Gesichtspunkten der Zweckmäßigkeit zu dem heutigen dual aufgebauten deutschen Einkommensteuerrecht hat ein Regelungsgefüge geschaffen, das die unterschiedlichsten Aufgaben zu erfüllen vermag. Die nachfolgenden Thesen mögen dazu dienen, den weiteren Gedankengang zu erleichtern:

a) Das Einkommensteuergesetz der Bundesrepublik Deutschland erbringt ein außèrordentlich hohes Steueraufkommen, auf das der Sozialstaat angewiesen ist.

b) Es eignet sich wegen der auf einem Enumerativkatalog steuerbarer Einkünfte aufbauenden Systematik vorzüglich zur Unterstützung erstens wirtschaftspolitischer Globalsteuerung der Volkswirtschaft durch Einflußnahme auf die steuerliche Belastung der Zahlungsströme und zweitens zur wirtschaftspolitischen Feinsteuerung der das Marktgeschehen weitgehend beeinflussenden Investitionsvorgänge durch steuerliche Belastungen bzw. gezielte, tatsächlich und der Hőhe nach verborgen bleibende Vergünstigungen.

c) Dabei erstickt das Einkommensteuergesetz trotz der im Grunde konfiskatorischen Progressionssătze die Investitionstätigkeit nicht, vielmehr ist die Finanzverwaltung, wie wir noch sehen werden, in der Lage. Investitionen mit steigender Progression interessanter zu machen und durch administrative Maßnahmen in gewünschte Bahnen zu lenken.

d) Die jeweilige Regienung erhält durch ihre Einwirkung auf die Finanzverwaltung ein weitreichendes Instrument wirtschaftspolitischer Steuerungsmöglichkeiten ohne die Einschaltung eines langwierigen, von parlamentarischen Auseinandersetzungen in den Ausschüssen begleiteten Gesetzgebungsverfahrens. Das Instrumentarium kann - wie die Vergangenheit zeigte - nicht einmal durch Inanspruchnahme der Finanzgerichtsbarkeit wesentlich behindert werden. 
e) Interventionistische und dirigistische Eingriffe bleiben schon wegen der Kompliziertheit der Systematik im wesentlichen verborgen. Die von Lenkungsnormen gebotenen steuerlichen Vorteile von großer Tragweite werden im übrigen üblicherweise gerade von den Kreisen in Anspruch genommen, die als potentielle Kritiker infrage kommen. Das wirkt sich positiv aus. Dieser Umstand erhöht die Bedeutung wissenschaftlicher Aufhellung der Wirkungszusammenhănge.

f) Durch moderne unternehmensrechtliche Gestaltungen ist im Zusammenwirken einer hohen progressiven Tarifbelastung mit den hergebrachten Steuervergünstigungsvorschriften des Einkommensteuerrechts ein Wirkungszusammenhang entstanden, der sich als gewichtiges Finanzierungsinsirument steuern läßt.

g) Diese Umstände sind ebenso als Grundlage für das derzeit wichtigste finanzpolitische Instrument zum Wiederaufbau der Länder der ehemaligen Deutschen Demokratischen Republik und deren Eingliederung in die Bundesrepublik Deutschland geeignet.

h) Die mit jeder eingefügten Lenkungsnorm und den dazu jeweils erteilten notwendigen Richtlinien und Anweisungen zur Abwehr mißbrảuchlicher Inanspruchnahme von Steuervergünstigungen verbundene Komplikation führt sicherlich nicht $\mathrm{zu}$ einem gelegentlich vorhergesagten Zusammenbruch der Finanzverwaltung, aber zu einer nicht mehr zu verkraftenden Belastung der Verwaltungstătigkeit. Diese erzeugt dann als Konsequenz bei den Beteiligten das Gefühl, bei der Besteuerung der Willkür ausgeliefert zu sein. Der entstehende Steuerwiderstand zwingt zur Erhöhung der Steuer bei den Hilflosen. Harte Verteilungskämpfe sind die unausweichliche Folge. Hierdurch wird die Begrenzung des instrumentalen Einsatzes der Besteuerung bei pragmatischer Berücksichtigung der von Schmoller geprägten Besteuerungsidec als ständig notwendiges ergänzendes Prinzip zur jeweiligen Erhaltung der Glaubwürdigkeit des Systems in der heute geltenden deutschen Einkommensbesteuerung abgesteckt.

i) Verbesserungen sind vorerst nur durch Veränderungen im Besteuerungsverfahren erzielbar. Als wichtigstes Reformziel ist ein Übergang zur Selbstveranlagung zu beurteilen, eine Entwicklung, die bereits in der săchsischen Einkommensbesteuerung angelegt war. 


\title{
J. Konsequenzen für die Lösung der anstehenden dringlichen Probleme bei der Finanzierung des Aufbaus nach der Wiedervereinigung mit der ehemaligen Deutschen Demokratischen Republik
}

\author{
I. Die Bedeutung der "sozialen Marktwirtschaft" \\ als umfassendes Organisationsprinzip und die Konsequenzen \\ für die Einkommensteuer - \\ Erfahrungen aus einem gelungenen Experiment
}

Die "soziale Marktwirtschaft" wird als eine ordnungspolitische Idee verstanden, die die Vorteile einer auf freier Initiative aufbauenden Wettbewerbswirtschaft durch geeignete Institutionen mit dem gesellschaftlichen und sozialen Fortschritt zu verbinden sucht. Nach Beendigung des Krieges war das aus zentralen Eingriffen in den Wirtschaftskosmos bestehende System der staatlichen Wirtschaftslenkung Deutschlands für alle erkennbar nicht in der Lage, den vielfaltigen politischen und wirtschaftlichen Erfordernissen des Wiederaufbaus zu genügen. Es wurde von einer marktwirtschaftlichen Konzeption abgelöst, deren Vertreter die Gründe für das Versagen der hergebrachten liberalen Wirtschaftsordnung erkannt hatten und forderten, diese durch eine zur Aufrechterhaltung ihrer Funktionsfähigkeit gesteuerte neuartige Gestaltung zu reformieren. Dabei wurden die zentralen Bereiche, die der Liberalismus der Selbstregulierung überlassen hatte und die zu ständigen Wettbewerbsverzerrungen und Krankheitssymptomen neigten, einer aktiven Wettbewerbspolitik des Staates anempfohlen. Während die Vertreter der sogenannten Freiburger Schule die Aufmerksamkeit der staatlichen Wirtschaftspolitik schwerpunktmäßig auf die Aufrechterhaltung einer konkurrenzwirtschaftlich umfassenden Marktordnung, also auf Ordnungspolitik konzentrierten, unterstrich die Richtung um Müller-Armack und Erhard die Aufgabe des Staates, eine weitergehende, die marktwirtschaftliche Ordnung "übergreifende Lebensordnung" zu garantieren.'

Miller-Armack, A (1948), S. 85; ders. (1966), S. 171, S. 231, S. 243; hierzu s. Grossekettler. H. (1987), S. 2, S. 32 und Literaturhinweise. 
Beides lief letztlich darauf hinaus, einer aktiven Wirtschaftspolitik durch die Schaffung geeigneter Institutionen die Aufsicht über die Funktionsfähigkeit des Wettbewerbs und der davon abhängigen Wirtschaftsstniktur, der Preisgestaltung, einer aktiven Sozialpolitik, der Ordnung von Bau- und Wohnungswirtschaft, der Betriebsstruktur, der Abwicklung des Außenhandels, der Geldund Konjunkturprobleme etc., zuzuweisen. Wettbewerbsbeschränkungen sollten unter Kontrolle stehen, Monopole, Oligopole und Kartelle sollten durch institutionelle Regelungen möglichst völlig vermieden oder jedenfalls zur Aufgabe ihrer wettbewerbsbehindernden Praxis genōtigt werden.

Grundsătzlich war eine Rückkehr zur liberalen Marktwirtschaft angesagt, aber es bestand die Überzeugung, daß die Wirtschaftspolitik ohne eine klare Entscheidung für ein vom Staat zu setzendes Koordinationsprinzip und laufende Überwachung der Funktionsfahigkeit nicht erfolgreich geführt werden könne. $^{2}$

Diese bewußt gestaltete, auf einem System des freien Wettbewerbs als regulativem Prinzip aufruhende "marktwirtschaftiche Gesamiordnung" wurde nach einer Wortschöpfung Müller-Armacks "soziale Marktwirtschaft" genannt. In ihr, so die Grundvorstellung, sollte der Wettbewerb "die Funktion einer variabel gehandhabten Wertrechnung" garantieren, die Preise sollten die Knappheitsverhältnisse der Güter widerspiegeln, die Produktion auf diese Weise lenken und so ein "höchst rationales System wirtschaftlicher Rechenhaftigkeit" entstehen lassen. ${ }^{3}$ Das wirtschaftliche Geschehen sollte damit der Ausfluß einer freiheitlichen, von allgemeiner Durchlässigkeit und vom Wettbewerb bestimmten umfassenden Lebensordnung sein. ${ }^{4}$

Die staatlichen Interventionen, die im Grunde nur eine Garantiefunktion für diese "Rahmenordnung" wahrnehmen sollten, durften auf keinen Fall störend in die Marktparameter eingreifen und eine freie Preisbildung durch Wettbewerb behindern. Sie sollten nach der von Müller-Armack geschaffenen Sprachregelung "marktkonform" erfolgen. Hierzu wurde ein reichhaltiges Instrumentarium von Maßnahmen entwickelt. "Das regulative Prinzip sozialer Interventionen in der Marktwirtschaft ist (hierbei) ihre Verträglichkeit mit dem Funktionieren einer marktwirtschaftichen Produktion und der ihr entsprechenden Einkommensbildung", ${ }^{5}$ so hieß es bei Müller-Armack. Diese

${ }^{2}$ Mũller-Armack, A. (1949), S. 57; Bohm, F. (1946), S. 144: ders. (1950), Wirtschaftsordnung .... S. 68; ders. (1933), S. 369; Eucken. W. (1948). S. 13; ders. (1948). Die Wirtschaftsordnung. S. 77.

${ }^{3}$ Muller-Armack. A. (1948), S. 71 , S. 93 u. a.

${ }^{4}$ Müller-Armack, A. (1948), S. 85; ders. (1981), S. 174.

${ }^{5}$ Müller-Armack, A. (1956), S. 390; ders. (1966), S. 246. 
ordnungspolitischen Auffassungen mußten letztlich auch für die Ausrichtung des Steuerrechts Konsequenzen mit sich bringen.

Die Einführung der vorstehend skizzierten Grundgedanken einer sozial eingebundenen Marktwirtschaft in die Praxis und deren problemorientierte Fortentwicklung wurde nach allgemeiner Überzeugung die Grundlage für die Entfaltung der Bundesrepublik Deutschland zu einer wohlhabenden Industrienation, die aus einer Trümmerlandschaft hervorgegangen ist.

\section{Die Eingliederung des Besteuerungswesens}

in das Konzept der "sozialen Marktwirtschaft" - die Rolle der Einkommensteuer beim Aufbau der Bundesrepublik Deutschland

Eine Fülle von gesetzgeberischen, mit dem Ziel der Verwirklichung einer unbehinderten "sozialen Marktwirtschaft" koordinierten Maßnahmen wurde seit der Einführung der neuen wirtschaftspolitischen Ära nach 1949 in Deutschland erörtert und verwirklicht. Alle für die wirtschaftliche Entwicklung wichtigen Institutionen wurden auf ihre Eignung zur Garantie einer nur vom unbehinderten Wettbewerb bestimmten Marktwirtschaft hin untersucht und gegebenenfalls umstrukturiert. Hierbei ergaben sich - anders, als dies heute nach Einführung marktwirtschafticher Prinzipien als bestimmende Struktur nach der Wiedervereinigung mit der Bundesrepublik Deutschland in den Lăndern der ehemaligen DDR erkennbar wird, - keine grundsätzlichen Schwierigkeiten. Die unentbehrlichen Grundlagen der vormaligen alten Ordnung waren, wenn auch stark durch staatliche Lenkungsmaßnahmen behindert und überwuchert, jedenfalls noch insgesamt vorhanden. Auf ihnen konnte ungehindert aufgebaut werden. Darauf werden wir noch zurückkommen. Jedenfalls waren die Eigentumsverhăltnisse intakt geblieben. Das Privateigentum war nicht infrage gestellt worden. Ansprüche auf Rückübertragung ehemaligen zu Unrecht in der Zeitspanne von 1933 bis 1945 enteigneten Besitzes waren Ausnahmen von der Regel. Es herrschte in dieser Beziehung Rechtssicherheit. Weiterhin war das zweistufige Bankensystem erhalten geblieben. Eine Währungsreform beseitigte am 21. Juni 1948 den vorhandenen Geldüberhang und schuf die Voraussetzung für eine an den Grundpreisen orientierte und den Bedürfnissen entsprechende Geldversorgung der Wirtschaft.

Es bedarf keiner weiteren Begründung dafür, daß auch das Besteuerungswesen bereits frühzeitig in bezug auf Kompatibilităt der einzelnen Gesetzeswerke mit den Grundprinzipien marktwirtschaftlicher Regelungen hin abgeklopfi wurde. Das geschah bereits im Jahr 1953 durch den Finanzwissenschaftler Günter Schmölders, der die "Notwendigkeit einer organischen Steuerreform" 
unterstrich, nachdem er bereits seit 1948 für ein "rationales Steuersystem" eingetreten war, in dem die einzelnen Steuern "aufeinander und die insgesamt mit der Besteuerung verfolgten zeitgemäßen Zwecke fiskalischer und außerfiskalischer Art ... abgestimnt" sind.?

Zur Förderung eines funktionsfăhigen Kapitalmarktes, zur Vermeidung doppelter Besteuerung und zur Unterstützung und Erleichterung einer kostenorientierten Preisbildung entsprechend den marktwirtschaftlichen Zielvorstellungen einer preisorientierten Produktion wurden bald Reformen im Einkommensteuer-, im Körperschaftsteuer- und im Umsatzsteuerrecht zur Koordinierung eines rationalen Steuerrechts mit der neuen Wirtschaftspolitik empfohlen. Die Senkung der Tarife war zwar eine wichtige, aber im Gesamtrahmen nicht die entscheidende Anregung. Die hohe Progression der Stenertarife hatte nach Schmölders eine besonders nachteilige Wirkung auf ein marktwirtschaflich organisiertes Gefüge. Da auch nicht ausgeschüttete, der Investition dienende Gewinne dem hohen Steuersatz unterworfen waren, konnte jede steuernde Anpassung der Produktion an den Markt erstickt werden. Aus einer Personalsteuer wurde so nach Schmölders eine Objektbesteuerung. ${ }^{8}$ Die Lenkungsfunktion des Marktes war zerstört.

Wir erörterten bereits, daß der Einkommensteuer in der nach 1891 als sogenannte "deutsche Type" entwickelten Form nicht nur der Vorteil enormer fiskalischer Ergiebigkeit, sondern auch hoher Elastizität zur Realisierung wirtschafts- und sozialpolitischer Zielvorhaben zukommt. Diese Eignung konnte

${ }^{6}$ Schmolders, G. (1953), Die Notwendigkeit ..., S. 21; ders. (1953), Organische ..., S. 9.

${ }^{7}$ Schmôlders, G. (1948), S. 480; ders, (1953), Die Notwendigkeit ..., S. 22, Anm. 1; ders. (1949), Leitsătze ...; der Gedanke einer Abstimmung der gesamten Steuerarten unter dem Gesichtspunkt der Belastung des einzelnen Stpfl. nach seiner individuellen Leistungsfahigkeit wurde bereits von Schmoller vorgebracht, s. Schmoller, G. (1863), S. 54. Der preuB. Finanzminister Scholz fordert 1882 im preuB. Landtag eine organische Steuerreform durch Abstimmung der einzelnen Steuern, $\mathrm{s}$. Verhandlungen Haus der Abgeordneten, 15. Legislatur-Periode, 16. Sitzung v. 15.12.1882, S. 332. Schmolders imte wenn er glaubte, neuartige Forderungen Wagners fortzufühen.

${ }^{8}$ Schmölders, G. (1953), Organische .... S. 49. Schmölders trat für Herabsetzung des Tarifs und Erleichterung der Selbstfinanzierung bei Reduzierung der Steuervergünstigungen durch Sonderabschreibungen ein, s. S. 58 , S. 68. S. 159. Vor allem trat er für eine "Ǔbereinstimmung zwischen Finanzsystem und Wirtschaftsordnung" ein, s. ders. (1953), Notwendigkeit ..., S. 22, S. 24, ohne zu erlāutern, was damit gemeint war. Besonders originell mufte im Jahr 1953 der Vorschlag von Schmölders wirken, ein einheitliches Betriebssteuergesetz zu schaffen, dem alle wirtschaftiichen Geschäftsbetriebe unterworfen sein sollten, die den Rahmen einer Vermögensverwaltung überschreiten (S. 188), S. a. StW (1949), 26. Jg., Sp. 1022 - 1031. Die Gewinnermittlung dieser Vorschriften betonte die Bedeutung der $\mathrm{GoB} z \mathrm{u}$ Lasten des Ausweises eines periodengerechten Gewinns und war geeignet, die Selbstfinanzierungsmöglichkeiten zu stärken, s. Gesetzentwürfe, S. 183, S. 188. Der Vorschlag richtete sich gegen das, was Schmölders als "Doppelbelastung der Gewinne" bei Körperschaften verstand. Der Gedanke fand in den 70er Jahren in der KSt-Reform Berücksichtigung. Zur Kritik der Vorschläge von Schmōlders, die als Empfehlungen vom Wissenschaftlichen Beirat bei dem BMF ūbernommen wurden, s. Spitaler, A. (1953), Sp. 693. 
zu politischen Planspielen verlocken, eine Versuchung, die ståndig groß gewesen ist. "... eine Abgabe, die eine so hervorragende fiskalische Bedeutung besitzt wie die Einkommensteuer, eignet sich zugleich als Mittel zur Realisicnung nichtfiskalischer Zwecke", hielt bereits 1947 Fritz. Neumark fest. ${ }^{9}$ Die Einkommensteuer in der Bundesrepublik Deutschland geriet denn auch mit wachsendem Wohlstand tatsåchlich bald zunehmend zur finanziellen Grundlage eines modernen Sozialstaates und zugleich zum effizientesten Instrument politischer Zielvorstellungen. Vorschriften zur Ermittlung der Einkünfte und andere Bestimmungen des EStG wurden seit 1949 mit Steuervergünstigungen als Belohnung bei Vorliegen erwünschter Merkmale im Sachverhalt angereichert, von deren Ausmaß wir bereits an früherer Stelle erfuhren.

Es war das Verdienst von Franz Böhm, angesichts des Zusammenbruchs des Deutschen Reichs nach 1945 den Wettbewerbsgedanken zum entscheidenden Gesichtspunkt der Wirtschaftsverfassung gemacht zu haben. Dem Staat sollte fortan "eine wichtige Rolle als Garant einer herrschaftsfreien Wirtschaftsordnung" zukommen.

Wettbewerb und Markt erhielten durch Böhms vielfaltige Diskussionsbeiträge und darüber hinaus durch seine konkreten Gesetzesvorschläge eine Bedeutung "von verfassungspolitischer und verfassungsrechtlicher Qualität". ${ }^{10}$

Ludwig Erhard bestätigte gelegentlich den richtungsweisenden Einfluß Böhms für die Entwicklung der Bundesrepublik Deutschland. "

Fragen wir, wie das uns interessierende Einkommensteuerrecht nach 1945 in eine neuartig ausgerichtete und veränderte Gesamtrechtsordnung eingefügt wurde, so ergibt sich folgendes Bild:

In sieben Jahren Referententătigkeit in der Kartellabteilung des Reichswirtschaftsministeriums hatte Böhm seit 1925 Erfahrungen mit Kartellen über die "ökonomische Eigengesetzlichkeit", den "rein naturgesetzlichen Automatismus eines Kampfverlaufes" und die "gleichsam naturgesetzlichen Zwangsläufigkeiten" des Wettbewerbs in der "freien Verkehrs- und Konkurrenzwirschaft" gesammelt. ${ }^{12}$

Er glaubte, so sein Ergebnis, "Symptome eines Systemverfalles" zu erkennen, die zur "Zerrittung des freien Wirtschaftssystems" durch die Entstehung von Gebilden verschiedenster privatrechtlicher Formen führten und die wirt-

\footnotetext{
Neumark, F. (1947), S. 96; ders. (1953), S. 39 u. a.

${ }^{10}$ Nörr. W. K. (1995), S. 62; s. etwa auch: Böhms Entwurf eines Gesetzes gegen Wettbewerbsbeschrănkungen, in: Deutscher Bundestag, 2. Wahlperiode 1953, Drș. 1269.

"Erhard, L. (1975), S. 15; Schlecht, O. (1995), S. 7.

${ }^{12}$ Hollerbach, A. (1988), S. 82, S. 83; Böhm, F. (1960), S. 158; ders. (1948), S. 197.
} 
schaftliche Macht mißbräuchlich gegen die İnteressen der Allgemeinheit auszuüben vermögen. ${ }^{13}$

Zur Problemlösung suchte Böhm Rat in den Beitrăgen der Nationalökonomie, wobei er das "Lehrgebăude der klassischen Wirtschaftsphilosophie" ${ }^{14}$ für seine Analyse der sachlichen Zusammenhänge als Erkenntnisquelle für die Abwehr von "Entartungsprozessen" des "freien Wirtschaftssystems" nutzte. ${ }^{15}$

Ähnlich wie die Begründer der klassischen Nationalökonomie sah auch Böhm in einer "natürlichen, göttlichen Gesetzmäßigkeit einer freien, vom Leistungskampf organisienten Wirtschaft" ein "kămpferisches Ordnungsprinzip" als Naturgesetz am Werk, in dem das private Erwerbsstreben "- immer unter der Einwirkung der Konkurrenz - eine prăstabilisierte Harmonie zwischen dem Vorteil des einzelnen und dem Nutzen des Ganzen herstellt." sehen wir denn", so Böhm 1933, "wie sich in einer sich selbst tiberlassenen, befreiten, aber von der Kampfregel der Leistungskonkurrenz beherrschten Wirtschaft aus sich selbst eine Ordnung von höherer Vollkommenheit entwikkelt, als es bewußter menschlicher Wirtschaftslenkung mőglich sein würde" ." Nach diesem Muster sah Böhm im übrigen in allen wirtschaftlich entwickelten Staaten der Welt die "Befreiung der Wirtschaft" vorangetragen. ${ }^{18}$

Die "Lehre der klassischen Wirtschaftsphilosophie" hatte jedoch unterstellt, so erkannte Böhm, daß das Interesse eines Produzenten stets allein auf die Interessen der Konsumenten abstellte, sich also nur hiervon ableitete. Daher mußte in der Darstellung der Klassiker "die Rechts- und Sittenordnung ...

13 B $\mathrm{hm}$, F. (1933), S. 369 u. a.. Von weitergehendem Interesse dürfte sein, daß Böhm für seine Erkenntnisse auf die Darstellung und Beurteilung der klassischen Nationalökonomie in zwei Abhandlungen von W. Hasbach zurackgriff, s. Bohm, F. (1933), S. 249, S. 326, S. 327, S. 330, S. 335, S. 336, S. 370. Hasbach ist der meistzitierte Autor Böhms. Hasbachs Untersuchungen erschienen in Schmollers Staats- und sozialwissenschaflichen Forschungen und wurden von Schmoller aysfuhrlich positiv rezensient, s. Schm. Jb. (1891). S. 921; Schm. Jh. (1892), S. 287. Hasbach war der engste wissenschaftstheoretische Mitarbeiter Schmollers und hatte sich dieserhalb von A. Wagner abgesetzt. Diese Umstānde und die ausgiebige Erōrtenung, die Schmoller der Kartell- und Trustfrage zukommeni ließ, zeigen die Fragwürdigkeit der Kritik Euckens an Schmollers Beiträgen, die spāter in Mode kam. s. Schm. Jb. ab 1891, insbes. Schmoller, G. (1905), S. 1581; ders. (1923), GrundriB ... I, S. 537, II S. 470; Eucken, W. (1940), Wissenschaft im Stile Schmollers, in: WA 52, S. 493; ders. (1938), Die Ūberwindung des Historismus, in: Schm. Jb., 62. Jg., S. 205; Hansen, R. (1993), S. 138. Schmollers Lösungsvorstellungen der gleichartig beurteilten Mängel sahen zeitbedingt ăhnlich aus, wie diejenigen Böhms.

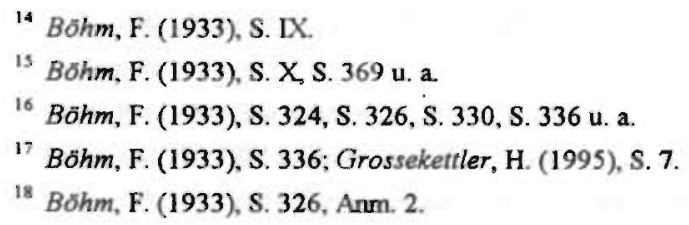


wirksame rechtliche und moralische Gegengewichte gegen die Überwucherung des Erwerbsstrebens" bereithalten. ${ }^{19}$

Inzwischen isı nach Böhm aber die von den klassischen Nationalökonomen unterstellte Einbindung des Ertragsstrebens der miteinander am Markt um die Gunst der Kăufer konkurrierenden Anbieter an ein natürlich vorgegebenes Leistungsprinzip in der freien Verkehrswirtschaft verloren gegangen. Die Institution der freien Konkurrenz wurde durch einen nicht mehr leistungsorientierten Wettbewerb sogar zu einer ernsten Gefahr für die Allgemeinheit. Kollektive Zusammenschlüsse verschiedenster Art, sei es auf freiwilliger Basis oder als gesetzlich vorgeschriebene Zwangskartelle, ermöglichen, so beklagte er, eine mißbäuchliche Ausübung wirtschaftlicher Macht zum Schaden der Gemeinschaft. ${ }^{20}$

Wenn "die Ordnung der Verkehrswirtschaft eine Ordnung bleiben soll", so Böhm 1933, ist es "die Aufgabe des Rechts, den Wettbewerb in sich selbst gegen Entartung zu schützen". ${ }^{21}$ Er empfahl daher, "das Lehrgebäude der klassischen Wirtschaftsphilosophie aus der Sprache der Nationalökonomie in

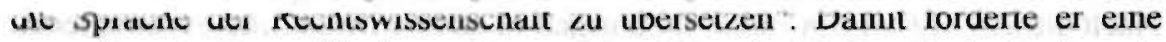
neuartig orientierte "Rechtsverfassung des Wirtschaftslebens" als Rechtsordnung im positiv verfassungsrechtlichen Sinne zu schaffen, um eine freie Verkehrswirtschaft vor Zerfallserscheinungen durch mißbräuchliche Machtausübung abzusichern. ${ }^{22}$ Es ging ihm darum, Macht zu beschränken, um deren wirtschaftlichen Mißbrauch im Marktprozeß zu verhindern. Zugleich zeigte sich die weitergehende Bedeutung der Machtbeschränkung für die politische Verfassung überhaupt.

Dazu war zum Schutz von Wettbewerbsbeschränkungen die Ausschließung eines "Nichtleistungskampfes" ${ }^{23}$ in einem entsprechenden Gesetz durch angemessene Sanktionsmechanismen allein nicht ausreichend, da die gesante Rechtsordnung mit dieser Orientierung abgestimmt werden mußte.

Das Privatrecht erhielt daher durch Böhms EinfluB nach 1945 neben der dogmatischen eine zweite, durch die Nationalökonomie empirisch bestimmte Grundlage, indem hergebrachte Prinzipien der "Institution Wettbewerb untergeordnet wurden". ${ }^{24}$

\footnotetext{
t9 Bסhm, F. (1933), S. 327, S 336

${ }^{20}$ Bohm, F. (1933), S. 329.

${ }^{21}$ Bohm. F. (1933), S. 105.

${ }^{22}$ Bo hm, F. (1933), S. IX

${ }^{23}$ Bohm, F. (1933), S. 193, S. 250 u. a.

${ }^{24}$ Norr, W. K. (1995), S. 69.
} 
Auch Walter Eucken, mit Franz Böhm und weiteren Gelehrten Mitbegründer der sogenannten "Freiburger Schule", vertrat vergleichbare Auffassungen. $^{25}$

Die "soziale Frage des 20. Jahrhunderts" sei nur lösbar, wenn ein marktwirtschaftliches Ordnungsgefüge durchgesetzt wird, so glaubte Eucken ${ }^{26}$ Dabei wies er dem Staat - ebenso wie Böhm - die Sicherstellung der Funktionsfahigkeit des Marktes als umfassender wettbewerbsorientierter Regelungsinstanz zu. Mit der "Lenkung des alltäglichen Wirtschaftsprozesses" muß der Staat scheitern, denn nur in der freien Verkehrswirtschaft wird die Koordination der unzähligen Einzelplăne durch den Mechanismus befriedigend sichergestellt, so hören wir. ${ }^{27}$

Diese Vorstellung einer "preisgesteuerten Marktwirtschaft", in der der einzelne Preis das Ergebnis "Hunderter und Tausender von Wirtschaftsplănen der Marktbeteiligten" ist und der einzelne Preis "sozusagen die Gesamtheit aller Wirtschaftspläne ... wie ein Kristall" widerspiegelt, ${ }^{28}$ war die gemeinsame Gestaltungsidee Böhms, Euckens und ebenso Müller-Armacks nach 1945. Der Marktmechanismus sollte die Zentralinstanz des "Regelsystems einer freiheitlich marktwirtschaftlichen Ordnung" sein, die eine umfassende Wohlstandssteigerung in einem demokratischen Gemeinwesen verspreche. ${ }^{29}$

So verweisen denn auch die Vertreter dieser Richtung seither gern darauf, $\mathrm{da} B$ die die Wirtschaftsordnung der sozialen Marktwirtschaft festlegenden Bestimmungen der Wirtschaftsverfassung des Privatrechts seit 1948 den Wiederaufbau und zugleich mehr Gerechtigkeit und Wohlstand geschaffen haben. ${ }^{30}$

Diese und ähnliche Hypothesen mögen allgemein als zutreffend empfunden werden. Dennoch sind sie erläuterungsbedürftig und nötigen zu Einschränkungen. Die Ursachen sind unvollständig wiedergegeben.

Zwar ist es richtig, daß die Institutionen des Privatrechts und des öffentlichen Rechts, die in ihrer Gesamtheit von Normen den Regelungsbestand der Wirtschaftsverfassung abstecken, wie etwa Wettbewerbsrecht, Handelsrecht, Berufsrecht, Gewerbeordnung, Betriebsverfassungsrecht, Kreditwesenrecht etc., bezüglich der verursachten Rechtsfolgen mit den Zielvorgaben der Be-

\footnotetext{
${ }^{25}$ Nörr, W. K. (1995), S. 65; Grossekettler, H. (1987), S. 2; Böhm, F. (1960), Reden .... S. 172.

${ }^{26}$ Eucken, W. (1948), S. 113, S. 116, S. 1120.

${ }^{27}$ Eucken, W. (1948), S. 130.

${ }^{28}$ Böhm, F. (1950), Wirtschaftsordnung ..., S. 17.

${ }^{29}$ Willgerodt, H. (1985), Die Sachlogik ..., S. 14.

${ }^{30}$ Willgerodt, H. (1985), Die Sachlogik ..., S. 32; Erhard, L.Maller-Armack, A. (1972), S. 110.
} 
hinderung von Wettbewerbsbeschränkungen und des Mißbrauchs wirtschaftlicher Machtstellungen nach 1948 abgestimmt wurden. Dabei mußten Prinzipien des Privatrechts Erkenntnissen der Nationalökonomie untergeordnet werden, indem etwa freie Verfügungsrechte Einschrảnkungen erfuhren. Die Wirtschaftsordnung mußte in der Wirtschaftsverfassung nun einmal Berücksichtigung finden. ${ }^{31}$

Allein das Steuerrecht wurde hier aber ausgenommen. Zwar lenkte Böhm gelegentlich nach Einführung des Gesetzes gegen Wettbewerbsbeschränkungen die Aufmerksamkeit auf die Verbindung zwischen Wettbewerbsgesetzgebung und der Gestaltung des Steuersystems, indem er die konzentrationsfreundliche, aber bequeme Technik der alten Brutto-Allphasen-Umsatzsteuer beklagte. ${ }^{32}$ Einige Jahre spăter wurde die Umsatzsteuer dann durch das Mehrwertsteuerprinzip reformiert. Bezüglich des Einkommensteuerrechts gab man sich aber damit zufrieden, daß von nichtfiskalischen Normen keine unmittelbaren Auswirkungen auf die Preisbildung ausgingen. Die Einflußnahme auf Marktprozesse erfolgt marktkonform. Änderungen der nichtfiskalischen Lenkungsnormen stellen Eingriffe in die vnn Eucken sngenannte "rechtliche und soziale Organisation" dar. ${ }^{33}$ Sie verändern den Datenkranz und wirken sich daher nur mittelbar auf das Marktgeschehen aus. Das wurde gelegentlich zur Rechtfertigung vorgebracht.

Für Müller-Armack setzte "die marktwirtschaftiche Ordnung ..., sofern sie von Dauer sein soll, gewisse Elemente einer zentralen Steuerung geradezu voraus". ${ }^{34}$ Diese durfte aber nur "ohne Störung des Marktapparates", also "marktkonform" erfolgen und es mußte die erwünschte Anreizstruktur im Preissystem erhalten bleiben. Ein direkter "Eingriff in den Preisapparat" war auszuschließen. ${ }^{35}$ Die Steuervergünstigungen des Einkommensteuergesetzes erfüllten diese Bedingungen in idealer Weise.

Der Staat verzichtete fortan keineswegs auf die konkrete Ausübung von Wirtschaftslenkung. Er beschrånkte sich also nicht auf die ihm zugewiesene Funktion der Garantie eines freien Wettbewerbs. Die Lenkung erfolgte jedoch fortan in neuartiger, nämlich marktkonformer, indirekter Weise, nämlich

31 Norr, W. K. (1995), S. 68.

32 Bōhm, K., zitiert in: Schmölders, G. (1961), S. 495. Im übrigen trat Schmōlders fortlaufend für Wettbewerbsneutralitat der Besteuerung ein, s. S, 503, S. 505.

33 Eucken, W. (1950), Grindlagen .... S. 133.

${ }^{4}$ Maller-Armack, A. (1948), Die Wirtschaftsordnung sozial gesehen, in: Ordo, 1. Bd., abgedr. in: ders. (1966), S. 171, hier S. 197; ders. (1975), S. 449, S. 450.

33 Miller-Armack, A. (1966), S. 197. 
durch Einflußnahme auf das Belohnungssystem der Wirtschaft. Hierzu diente das Einkommensteuerrecht als wichtigstes Instrument.

Nicht "the invisible hand of Adam Smith" bewirkte die allgemein bewunderten Aufbauleistungen; tatsächlich war es "the smooth and hidden hand of a sophisticated and efficient government administration", ${ }^{36}$ genauer: tax administration.

Auch die Vorstellung einer erreichten, nicht von staatlichen Interventionen gelenkten und insoweit machtfreien Verkehrswirtschaft wird durch die fortlaufend geübte steuerpolitische Einflußnahme auf die Wirtschaftsprozesse durch Änderungen der Normen des geltenden Einkommensteuerrechts seit 1948 ad absurdum gefuihnt.

$\mathrm{Da}$ das Grundkonzept des aus der Wagnerschen Besteuerungsidee fortentwickelten Systems des geltenden Einkommensteuergesetzes durch Erweiterung des Normeninhalts und durch inhaltliche Fixierung der Sätze für Abschreibungen, Werbungskosten, der Tarifvorschriften und der Höhe des Steuerzugriffs etc., ohne innere Widersprüche zu erzeugen, ${ }^{37}$ eigentümliche und leicht veränderbare und eventuell sehr weitgehende wirtschaftliche Anreizstrukturen entstehen läßt, ist nicht zu übersehen. Die These von einer pretialen Lenkung der Wirtschaftsprozesse durch ein marktwirtschaftliches Regelwerk der Preisbildung, das allein aus einer am Leistungswettbewerb orientierten Vielzahl von Plänen freier Wirtschaftssubjekte spontan entsteht, bedarf daher der Korrektur.

Die von Schmoller 1863 entwickelte, zu seinen frühen sozialpolitischen Zielvorgaben gehörende Besteuerungsidee hätte, wie wir mehrfach gesehen haben, diese verborgene Lenkung der Wirtschaft von leichter Hand mit weitgehenden Wirkungen ohne Aufgabe der Regelungsfunktion des Marktes als Ordnungselement nicht zugelassen, ohne unlösbare innere Widersprüche aufzuwerfen.

Die Konsequenzen eines Verzichts auf diese staatliche Lenkungsmöglichkeit werden uns im nächsten Abschnitt noch erkennbar werden. $\mathrm{DaB}$ viclc Ausführungen Böhms und in Festvorträgen ständig wiederholte Thesen über Zusammenhänge von Lenkung. Demokratie, Machtausübung, Leistungswettbewerb, Wohlstandsmehrung und Marktpreisbildung in den üblichen überspitzten

\footnotetext{
30 Hierzu s. Reuss, F. G. (1963), S. 28.

37 Falk, L. (1962). S. 46; Geiger, K. (1977), S. 300.
} 
Formulierungen oft widersprüchlich und weltfremd sind, kann hier nur angedeutet werden. ${ }^{38}$

Festzuhalten ist, daß eine Vernachlässigung der Erörtenung der angesprochenen Zusammenhänge dazu geführt hat, daß der steuerpolitische Einsatz des Einkommensteuerrechts als Bestandteil der Wirtschaftsverfassung eine Arena für Praktiker in Regierung, Parlament und Verbänden wurde und diese Arena keineswegs geschlossen wurde, als die Erfordernisse des Wiederaufbaues nach dem Krieg beseitigt waren.

Die Erörterungen der Steuerwissenschaftler blieben im übrigen nach 1948 zumeist dogmatischen Bekenntnissen ohne Abwägung konkreter Sachverhalte verhaftet. Dabei erhielten Fragen rein formeller Art, wie Definitionen und Abgrenzungen interventionistischer und dirigistischer steuerpolitischer Eingriffe, der wirtschaftspolitischen Neutralität der Besteuerung, der Verfassungsmäßigkeit nichtfiskalischer Steuernormen und andere Gesichtspunkte größere Aufmerksamkeit.

Vier verschiedene Richtungen bestimmten die Diskussion um die Abstimmung steuerlicher Eingriffe mit dem Konzept der "sozialen Marktwirtschaft" und die Auseinandersetzung bis heute. Dabei lassen sich idealtypisch zwei kontroverse Stellungnahmen hervorkehren: Fritz Neumark beurteilte zwar grundsätzlich eine nichtfiskalische Verwendung der Besteuerung und speziell der Einkommensteuer als ein äußerst wirksames Instrument der Wirtschaftspolitik. Eine im klassischen Sinn "neutrale" Finanz- und Steuerpolitik war für ihn "weder notwendig noch nützlich für die Aufrechterhaltung der Wirtschaftsordnung". "Es besteht", so glaubte er, "kein vernünftiger Grund (dafür), lediglich die Steuer aus dem Arsenal der wirtschaftspolitischen Mittel auszuschließen". ${ }^{39}$ Er unterschied dabei zwischen "interventionistischen" und "dirigistischen", "punktuellen" steuerlichen Eingriffen in das Wirtschaftsgeschehen. Entscheidend für die Beurteilung sollte allein sein. ob die Maßnahme "relativ und absolut geeignet ist, der Verwirklichung der angestrebten Ziele zu

38 Hierzu als Beispiel s.: Biedenkopf, K. (1995), S. 15. Biedenkopf bezeichnei șich als Schüler Bohms und Mestmäckers. Trotz nachhaltiger Forderung nach ordnungspolitischer Erneuerung marktwirtschaftlicher Steuerungsprozesse vermittelt er eher das Gefuhl der Kritik an der Ausrichtung und Kompliziertheit der Lenkung durch Steuersubventionen, als an dieser Form als soicher (S. 30); Schlecht, O. (1995), S. 11: zu Recht werden von Schlecht die KornpromiBiahigkeit des spāteren Bóhms und der beigelegte Ausnahmecharakter positiv gewulrdigt "Solange der Gundvorgang der Wirtschaft einheitlich, also marktwirtschaftlich, bleibt, ist es möglich, auch andere Prinzipien im bestimmtem Umfange zu tolerieren", so Maller-Armack (1959); ders. (1966), S. 258; s. Nipperdey, H. C. $(1961)$, S. 40 .

39 Neumark, F. (1961), Wirtschafts- und Finanzprobleme ..., S. 281. 
dienen" ${ }^{40}$ Neumark bekannte sich dabei aber in einer Weise entschieden zu den Zielen der "sozialen Marktwirtschaft", die in dem "Steuerinterventionismus" ein besonders geeignetes marktkonformes Mittel zur Beeinflussung der wirtschaftlichen Globalgrößen zur Erreichung erwünschter Ziele sah. Den von ihm nie klar abgegrenzten "Steuerdirigismus" wollte er sogar einschrànkend nur insoweit als unzulässig beurteilen, als er "die Steuerverfassung mit Bestimmungen durchsetzt" und so die Ausrichtung der Wettbewerbswirtschaft verfalscht, "ohne an irgendeinem rationalen Prinzip ausgerichtet zu sein", ${ }^{41}$ so mußte man jedenfalls seine Ausführungen verstehen. Eine Bewertung kỏnne jeweils nur im Einzelfall abgegeben werden. Zumeist richtete Neumark seine Aufmerksamkeit aber nur auf die Sicherung einer stabilen wirtschaftlichen Entwicklung. Seine Beurteilung schlo $B$ dabei ausdrücklich die Ergebnisse von Lenkungs- und Kontrollvorschriften von erheblicher Tragweite und dabei ohne Einschaltung des Parlaments, etwa durch Bewirkung hoher versteckter Subventionen, ein. Sie galt wohl auch für den Fall, daß dieselben bei Offenlegung auf massive Ablehnung hätte stoßen müssen. ${ }^{42}$ Die Eignung von Sieuervergünstigungen zur Erreichung eines Ziels allein war jedenfalls erkläriermaßen für ihn entscheidend. Tatsächlich muß aber festgehalten werden, daß Neumarks Ausführungen, die große sprachliche Begabung zeigten, eine sehr widersprüchliche Grundhaltung erkennen ließen. Davon werden wir noch hören. Die eigentümliche, rein instrumentale Betrachtungsweise hat Neumark jedenfalls später den Ruf eingebracht, der geistige Vater des 1967 verabschiedeten Stabilitätsgesetzes geworden zu sein. Im übrigen ist seine Auffassung sofort auf Widerstand bei Finanzwissenschaftlern wie Schmölders und bei vielen Steuerrechtslehrern gestoßen. ${ }^{43}$

Als gegnerische Position mag hier - beispielhaft für viele - die Auffassung Schmölders angeführt werden, der nachhaltig auf die beträchtlichen Gefahren eines leichtfertigen Umgangs mit nichtfiskalischen Zwecken dienenden steuerlichen Vorschriften aufmerksam machte, mochte er auch deren Einsatz in Ausnahmefallen ebenfalls vorsichtig bejahen. Die Gewichte wollte er jedenfalls anders gelegt sehen. Schmölders hielt es für vordringlich, jeweils im Einzelfall erst konkret zu prüfen, ob bei dem Einsatz steuerlicher Mittel mit unerwünschten Nebenwirkungen zu rechnen sei, die den erstrebten Erfolg durchkreuzen oder durch andere unvorhergesehene Nachteile aufwiegen könn-

10 Neumark, F. (1957), S. 452; ders. (1961), Wirtschafts- und Finanzprobleme ..., S. 131, S. 147. S. 281 .

4 Neumark, F. (1957), S. 287

${ }^{42}$ Neumark, F. (1961), Wirtschafts- und Finanzprobleme ..., S. 283; ders. (1952), S. 587.

43. Neumark, F. (1966), S. 477; ders. (1953), S. 39; Paulick, H. (1970), S. 204 u. a. 
ten. ${ }^{44}$ Die Komplikation der sozialen Zusammenhänge mache die Ergebnisse unbedachter Eingriffe in den wirtschaftlichen Kosmos meist unvorhersehbar, so glaubte er. Insoweit beurteilte Schmölders auch den Einsatz der sogenannten "fiscal policy" zur Steuerung der Globalgrößen der Volkswirtschaft vermittels steuer- bzw. haushaltsrechtlicher Maßnahmen, anders als Neumark, mit Besorgnis, sofern die längerfristigen Konsequenzen nicht klar erkennbar sind, was fast nie möglich ist. Im übrigen warnte Schmölders auch vor unübersehbaren Fernwirkungen sowie vor Verschiebung der steuerlichen Belastungen zwischen den Steuerpflichtigen, weil durch die Einbindung von Lenkungsnormen eine Besteuenung nach der Leistungsfähigkeit auf der Strecke bleiben müsse. Er befürchtete einen vermehrten Steuerwiderstand und nachlassende Steuermoral mit größerer Kompliziertheit des Systems. ${ }^{45}$ Er wies auch auf die Folgewirkungen der zeitlichen Verzögerung der gewünschten Wirksamkeit steuerlicher Vorschriften hin.

Die Vertreter des Konzepts der "sozialen Marktwirtschaft", wie MüllerArmack. trugen ähnliche Bedenken zu einer Instrumentalisierung des Einkommensteuerrechts für nichtfiskalische Zwecke aber nur sehr zurückhaltend vor. Entscheidend war für den letzteren bei allen Eingriffen in das Wirtschaftsgefüge. daß "das Rechnungssystem wirtschaftlicher Leistungen" unbehelligt bleibt. In einem vergleichbaren Fall wollte Müller-Armack direkten Subventionen wegen der möglichen Kontrolle durch die Öffentlichkeit vor steuerlichen, verborgenen Lenkungsmaßnahmen jedenfalls den Vorzug eingeräumt wissen. ${ }^{46}$

Auch Steuerrechtslehrer standen den nichtfiskalischen Zwecken dienenden Normen in Form von Steuervergünstigungen zumeist - wenn auch aus anderen Gründen - ablehnend gegenüber. Dabei wurden zumeist Verfassungsprinzipien herangerogen und die nichtfiskalischen Steuerbestimmungen grundsătzlich infrage gestellt. ${ }^{\text {? }}$

Unabhängig von dieser kontrovers geführten Diskussion war aber bereits seil 1949, beginnend von Seiten der wesilichen Besatzungsmächte und nach Bildung der Bundesrepublik durch Finanzverwaltung und Politik in Form von Gesetzesnovellierungen eine große Zahl von Vergünstigungsnormen. als "Bewertungsfreiheit", "erhöhte Absetzung" oder "Steuerbegünstigung des nicht entnommenen Gewinnes" bezeichnet. in die Bestimmungen des EStG über die

\footnotetext{
4h Schmolders. G. (1970), S. 263.

4s Schmölders, G. (1970), S. 289. S. 290.

${ }^{40}$ Maller-drmack: A. (1948), S. 109: Watrin, C. (1988), S. 56.

${ }^{47}$ Paulick, II. (1970), S. 210.
} 
Gewinnermittlung bzw. als "Sonderausgaben" und 1952 noch die Steuerbefreiung bestimmter Zinsen zur Förderung des Kapitalmarktes integriert worden. Zusătzlich wurde dabei dem Gesetz 1952 eine Ermăchtigung eingefügt, unter Mitwirkung des Bundesrates Rechtsverordnungen zu erlassen, die später noch von immenser Bedeutung werden sollte. Diese inzwischen zur längsten Vorschrift des EStG fortentwickelte Bestimmung ist nach der letzten amtlichen Ergänzung des Gesetzestextes von 1992 von 67 auf 488 Zeilen angeschwollen. ${ }^{48}$

Seit 1960 hat sich dann allmăhlich zunehmend ein Wandel in der Beurteilung der Funktion des Steuerrechts vollzogen. Die Besteuerung nach der Leistungsfahigkeit, die noch in Art. 134 der Weimarer Reichsverfassung vom 11 . August 1919 fest verankert war und die von vielen Steuerrechtslehrem auch als systemtragendes Prinzip des noch geltenden Einkommensteuerrechts beurteilt wurde, konnte bald durch die neuere Rechtsprechung des Bundesverfassungsgerichts zu $\S \perp$ Reichsabgabenordnung 1931 infrage gestellt werden. Denn Steuervergünstigungen im Einkommensteuerrecht stehen einer Besteuerung nach der Leistungsfahigkeit nun einmal entgegen. Das Bundesverfassungsgericht ließ aber nun in mehreren hochgespielten Verfahren steuerliche Lenkungsnormen als verfassungskonform zu. Die Einführung des "Stabilitätsgesetzes" im Jahr 1967 hat die Position der Gegner einer Lenkung der Marktwirtschaft durch nichtfiskalischen Einsatz der Einkommensteuer zusätzlich entscheidend geschwächt. Letztendlich wurde dann in $\$ 3$ der neu kodifizierten Abgabenordnung vom 16. März 1976 sogar bcstimmt, daß "die Erzielung von Einnahmen Nebenzweck" einer steuerlichen Norm sein darf.

Gegen Ende der 60er Jahre wurde dann die Vermögensverteilung Gegenstand heftiger sozialer Auseinandersetzungen. ${ }^{49}$ Die in anfechtbaren Berechnungen ermittelte ungleiche Verteilung und der nicht erkennbare Trend zu ausgewogeneren Besitzverhältnissen wurden nun in einen unmittelbaren Verursachungszusammenhang mit Privateigentumsordnung und Marktwirtschaft gebracht. Einsetzende harte Verteilungskämpfe führten zu Kostenexplosionen durch Steigenungen von Löhnen, Lohnnebenkosten und Sozialabgaben. Der Kostendruck führte bei unternehmerischen Tätigkeiten zu einer unbefriedigenden Entwicklung. Eine "sozial-liberale" Regierung setzte nun neuc Schwerpunkte für die Wirtschaftspolitik. Bis zum Beginn der 80er Jahre büßıe die Börse im Zuge der eingeleiteten Entwicklung ihre marktwirtschaftliche Funktion, als Leitstelle für anlagesuchendes Kapital zu dienen. weitgehend

${ }^{48}$ \$ 51 EStG 1952, in: BGBI. I, S. 33: für \$ 51 EStG 1995 s. NWB. Fach 3. v. 30.1.1995. S 4518:

${ }^{49}$ Krelle, W./Schunck, J./Siebke, J. (1968); Willgerodt, H./Bartel, K/Schillert, U.(1971). 
ein. An deren Stelle traten nun wieder vermehrt die bei Vertretern der Marktwirtschaft unerwünschte Selbstfinanzienung mit Hilfe überhöhter Preise und ein unübersichtlicher Nebenkapitalmarkt von Angeboten zur Zeichnung von Anteilen an steuersparenden geschlossenen Investmentgesellschaften.

Wenn der Wachstumspfad des Wohlstandes auch während dieser der Selbststeuerung der Wirtschaft durch die ungebundenen Marktkräfte kritischer gegenüberstehenden Zeitspanne zwischen 1970 und 1980 nicht wesentlich verlassen wurde, so lag das daran, daß die Bildung des erforderlichen Risikokapitals für die den Fortschritt tragenden Nettoinvestitionen nun zunehmend aus anderen, mit der Börse konkurrierenden Quellen gespeist wurde. Investmentgesellschaften in der Rechtsform von großen Gesellschaften bürgerlichen Rechts und Kommanditgesellschaften übernahmen die führende Funktion bei Kapitalanlagen. Mit ihrer Hilfe konnte die Aufgabe der Borse in vielfacher Hinsicht ergănzt oder teilweise sogar ersetzt werden.

Ebenso wie im Falle von Investitionen durch Aufforderungen zur Zeichnung von Inhaberpapieren über die Börse konnte das Gesamtengagement durch Gründung von Kommanditgesellschaften in vergleichbarer Weise auf viele mittlere Anleger verteilt und die Haftung der Mitunternehmer durch Aufnahme entsprechender Bestimmungen in die Satzung der Trägergesellschaft fast beliebig begrenzt werden. Im Brennpunkt dieser so gebildeten Gesellschaften stand jedoch nicht mehr eine erwartete Ausschüttung von Erträgen, sondern die zugesagte Verlustzuweisung durch kundige Ausschöpfung aller vom EStG gewährten steuerlichen Vergünstigungen. Dies wirkte sich dann vorteilhaft bei der Veranlagung zur Einkommensteuer aus.

Da die Kommanditgesellschaft eine Personengesellschaft mit einer Haftungsbegrenzung für die Zeichner von Anteilen als Mitunternehmer ist, führte das durch Steuervergünstigungen verursachte Auseinanderfallen von wirtschaftlichem und steuerlichem Gewinn dazu, daß die Anteilseigner durch eine Gewinn- bzw. Verlustzuweisung unmittelbare Nutznießer der im Einkommensteterrecht versteckten staatlichen Vergünstigungen infolge von privilegierten Investitionen wurden.

Das mochte die den Anteilsrechien von Natur her im Vergleich zu börsenfahigen Inhaberpapieren eigene mangelhafte Fungibilität infolge der Schwerfalligkeit einer Veräußerung aufwiegen, zumal sie oftmals in voller Höhe aus Steuerersparnissen erworben worden waren.

Diese Art Verlustzuweisungsgesellschaften bestimmten von etwa 1970 bis in die frühen $80 \mathrm{er}$ Jahre weitgehend den Markt für risikobehaftete Kapitalanlagen. Die Werbung in den Angeboten zur Beteiligung an Investitionsprojekten 
zentrierte stets um die Aussicht, nach Zeichnung von Anteilen aus Verlustzuweisungen Vermögen zu bilden. Dabei konnte sich der Zeichner je nach Höhe der mit den zu erwartenden Verlustzuweisunigen zu saldierenden eigenen positiven Einkünften und der dadurch ausgelösten Steuerprogression eine teilweise Deckung, eine gleich hohe Erstattung oder gar eine Überdeckung der zu leistenden Zahlung für den Anteilserwerb errechnen und seine Entscheidung davon entsprechend abhängig machen. Wegen dier ausgelösten Folgeprobleme, der Kompliziertheit der praktischen Vorgănge um die Erzeugung rentabler Anteilsrechte und sogar eventueller zusătzlicher Vermögenswerte ohne eigenen Mitteleinsatz brachten auch Fachorgane die Abschreibungsgesellschaften gelegentlich in Zusammenhang mit dem, was sie "Hexeneinmaleins" nannten.

Um den Anschein sozialer Ausgewogenheit aufrecht zu erhalten, wurden während der Regierungszeit der "sozial-liberalen Koalition" forciert Gesetze zur Vermögensbildung in Arbeitnehmerhand verabschiedet, die wiederum in komplizierter Weise steuerbegünstigt bzw. mit einem steuerlich alimentierten Prämiensystem verbunden waren. ${ }^{50}$ Dabei handelte es sich aber für den einzelnen Berechtigten um vergleichsweise bescheidene Größenordnungen, die sich in den Haushaltsplänen der Gebietskörperschaften jedoch zu hohen Beträgen addierten.

Es liegt auf der Hand, daß der Investitionen und Anlageformen durch Steuerbegünstigungen lenkende Steuerdirigismus bald zu beträchtlichen Komplikationen, zu unerwünschten steuerlichen Mehrfachbegünstigungen und letztlich zur Undurchsichtigkeit des Steuersystems führen mußte. Die gegen Mißbräuche ausgelösten Abwehrmaßnahmen der Verwaltung durch Erlasse. Richtlinien und sonstige ministerielle Anweisungen an die nachgeordneten Behörden schufen bald ein schwer durchdringbares, oftmals sogar widersprüchliches Dickicht von Bestimmungen, das zum Teil bis heute fortbesteht. ${ }^{51}$

In den frühen 80er Jahren wurden dann durch einige Gesetzesănderungen, aber im wesentlichen durch Ausschöpfung der Maßnahmen des Verwaltungsrechts, die Möglichkeiten steuerbegünstigter Investitionen beschnitien und konzentriert. Die Börse wurde dabei vorerst wieder zum Zentrum eincr marktwirtschaftlichen Lenkung der Investitionsströme gemacht.

50 3. VermBG v. 27.6.1970, in: BGBI. I S. 930. Das Gesetz sah eine wesentliche Erweiterung und Emōhung der bereits vorhandenen Förderung vor, s. 1. VermBG v. 12.7.1961, in: BGB1. I S. 909, das durch Einfuihnung des SpPG und des WoPG zum 2. VermBG v. 1.10.1969. in: BGBI. I S. 1853. ausgebaut wurde. Man nannte es auch kurz "312-DM-Gesetz".

st Falk, L. (1962), S. 44. Falk beklagte bereits 1962 die Unubersichtlichkeit des ESt-Rechts als Folge der vielen verfolgten nichtfiskalischen Zwecke. Falk war Leiter der Steuerabteilung im BMF. 
Es ergibt sich aus dieser skizzenhaften Darstellung, daß die jeweilige Regierung durch dic Finanzverwaltung bis heute über ein nachhaltiges Instrument verfügt, das Marktgeschehen dirigistisch in marktkonformer Weise zu lenken und Investitionen in gewünschte Richtungen zu bündeln, ohne dafür den schwerfalligen Gesetzgeber bemühen zu müssen. ${ }^{52}$

Den verschiedenartigen Konsequenzen eines nie eingeplanten, zunehmend ausufernden Arbeitsanfalles bei den die Einkommensteuer veranlagenden Finanzämtern werden wir noch nachgehen müssen.

\section{Die Ausdehnung des Institutionengefüges der Bundesrepublik Deutschland auf die ehemalige DDR durch den Beitritt gemäß Art. 23 GG nach dem Einigungsvertrag vom 31. August $1990^{53}$}

\section{Die institutionellen Ausgangsbedingungen im Beitrittsgebiet als Grundlage für die Einführung der Marktwirtschaft}

Anders, als bei dem Aufbau einer sozial eingebundenen Marktwirtschaft als neuer Wirtschaftsordnung in der Bundesrepublik Deutschland nach 1949 mußten in der ehemaligen DDR die unverzichtbaren Voraussetzungen eines auf Privatautonomie aufruhenden wirtschaftlichen Tătigwerdens überhaupt erst geschaffen werden.

Die ehemalige DDR war ein sozialistischer Staat. Das sogenannte "Volkseigentum an den Produktionsmitteln" war über 40 Jahre die herrschende Eigentumsform. Nach seiner Bestimmung war es "die höhste Form des sozialistischen Eigentums und Grundlage des persönlichen Eigentums der Bürger" überhaupt. ${ }^{54}$ Dabei existierte das sozialistische Eigentum in drei Formen, nämlich als "Volkseigentum". "genossenschaftliches Eigentum" und als "Eigentum

52 Der Markt fur die Zeichnung von Anteilen an offenen Investmentfonds ist sehr leicht durch die Finanzverwaltung auf dem Erlaßwege steuerbar. Sobald die Verlustzuweisungen fraglich sind, finden sich keine Zeichner mehr, s. hierzu die streitigen Erörterungen der 70er Jahre, z. B.: Uelner, A. (1979), S. 93; Friedemann, J., Der Tod einer Branche, in: Die Zeit v. 30.6.1978, S. 25; s. Kappe, H. (1976). in: BB, S. 457; s. a. Lipps, W. (1977), S. 5.

33 Der Autor bringt in diesem Abschnit konkrete berufliche Erfahrungen in den Gedankengang ein. Einmal gehört er zu dem Personenkreis der von der russischen Besatzungsmacht zwischen 1945 und 1949 enteigneten Grundbesitzer. Daruber hinaus hat er in mehreren Fallen Bewohnern der ehemaligen DDR bei der Grundung von Gewerbebetrieben mittlerer GröBe Hilfestellung gegeben. Die Niederschrift dieses Abschnitts erfolgte bereits 1993. Fortentwicklungen wurden nicht berücksichtigt.

${ }^{4}$ Rechtslexikon, hrsg. vom Staatsverlag der Deutschen Demokratischen Republik. Berlin 1988, S. 84. Stichwort "Eigentum": s. a. $\$ 17$ ZGB, $\$ 22$ ff ZGB. 
gesellschaftlicher Organisationen" ${ }^{55}$ Nur der Befriedigung "materieller und kultureller Bedürfnisse der Verbraucher" diente dann das "persönliche Eigentum der Bürger", das allein aus "Arbeitșeinkommen" hergeleitet werden konnte. ${ }^{56}$ Dem "sozialistischen Eigentum an den Produktionsmitteln" stand somit das "persönliche Eigentum der Bürger" an den aus der "Arbeitstătigkeit in volkseigenen Betrieben, staatlichen Einrichtungen, sozialistischen Genossenschaften und geseilschaftichen Organisationen" entstandenen Konsumgutern, zu denen auch Eigenheime, Kraftfahrzeuge und sonstige langlebige Produkte des persönlichen Bedarfs gehörten, gegenüber. ${ }^{57}$

Nach $\S 24$ Zivilgesetzbuch (ZGB) DDR gewährte das Eigentumsrecht dem Inhaber zwar die umfassende Befugnis, über eine Sache zu veriugen, jedoch betraf dies im Grundsatz nur den Bereich der Konsumgüter und - als Ausnahmen - Produktionsmittel einiger kleinerer Betriebe. Und: In der ehemaligen DDR galt der strenge "Grundsatz der Planung und Leitung der Volkswirschaft sowie aller anderen gesellschaftichen Bereiche". Es herrschte eine zentrale Planwirischaft. ${ }^{58}$

Das ökonomische System des Sozialismus verband die zentrale staatliche Planung und Leitung der gesellschaftlichen Entwicklung mit der Eigenverantwortung der sozialistischen Warenproduzenten und der örtlichen Staatsorgane. Diese bestimmten jeweils die Rechtsträger zur Ausübung der erforderlichen Dispositionsbefugnisse an dem Volkseigentum in der Form von Produktionsmitteln. Auch "die Festlegung des Wähnungs- und Finanzsystems war Sache des sozialistischen Staates". 59

So unterlagen alle wichtigen wirtschaftichen Prozesse in der ehemaligen DDR einer umfassenden zentralen Planung durch staatliche Wirtschaftsverwaltungsbehörden. Dies schlo $\beta$ - anders, als in der Marktwirtschaft. - eine zentrale Festsetzung aller Preise ein. Dabei wurde sowohl der Einsatz aller Produktionsfaktoren, als auch die Verwendung aller Erzeugnisse und zugleich die Einkommensverteilung staatlich kontrolliert und geregelt. Lebensnotwen-

"9 Art. 10 der Verfassung der Deutschen Demokratischen Republik v. 6.4.1968, in: GBI. I 68. S. 199; s. Rechtlexikon ... (wie Anm. 53), S. 331, Stichwort "sozialistisches Eigentum". Nach § 24 ZGB gewăhrte zwar das Eigentum die umfassende Befugnis. über eine Sache zu verfügen, jedoch erstreckte sich die Befugnis nur auf Verbrauchsguter.

${ }^{56}$ s. Rechtslexikon ... (wie Anm. 53). S. 267. Stichwort "persônliches Eigentum"; § 22 Zivilgesetzbuch der DDR (Z.GB) v. 19.6.1975, in: GBI. I I975. S. 465.

"7. R. Rechtslexikon ... (wie Anm. 53). S. 267; § 22 Abs. I ZGB; Autorenkollektiv der Akademie für Staats- und Rechtswissenschaft (Hrsg.) (1974): Gesellschaft. Staat, Bürger. Potsdam u. a., S. 53: $\S 23 \mathrm{ZGB}$.

58 Art. 9 Abs. 3 Verfassung der DDR.

59 Art. 9 Abs. 4 Verfassung der DDR. 
dige Waren und Dienste, wie etwa Grundnahrungsmittel, wurden entsprechend der planerisch zugewiesenen Kaufkraft subventioniert und Erzeugnisse des gehobenen Bedarfs wiederum wurden mit zusätzlichen Verbrauchsabgaben belastet, um überschüssige Kaufkraft abzuschöpfen und die umlaufenden Mittel im Gleichgewicht zu halten. Auch der eingliedrige Bankenapparat war in das sozialistische Wirtschaftsgefüge planerisch eingegliedert. ${ }^{60}$ Den dem staatlichen Apparat oder dem sozialistischen Genossenschaftswesen zuzurechnenden Kreditinstituten der DDR war allein die Abwicklung des Zahlungsverkehrs, die Einrichtung von Sparkonten für die Bevölkerung und die Einräumung von Krediten zur Finanzierung langlebiger Konsumgüter vorbehalten. Die Geldströme folgten so ohne Einwirkung systemfremder Faktoren allein den global festgelegten Planvorgaben. ${ }^{61}$

Für den Beitritt der ehemaligen DDR zur Bundesrepublik Deutschland und vor Schaffung einer Währungsunion mußten völlig neue institutionelle Voraussetzungen für die einzuführende Wirtschaftsordnung geschaffen werden.

In $\S 1$ Abs. 3 des Staatsvertrages vom 18. Mai 1990 wurde daher vereinbart, daß die Grundlage der vorgesehenen Wirtschaftsunion die "soziale Marktwirtschaft" der Bundesrepublik sein sollte. Dabei verpflichtete sich die DDR vor der Errichtung einer Währungsunion, alle wesentlichen in der Bundesrepublik gültigen, die marktwirtschaftliche Ordnung tragenden Gesetzesvorschriften mit wenigen enumerativ aufgeführten Ausnahmen - in Kraft zu setzen.

Bereits am 1. und 7. Mărz 1990 hatte die DDR in Reformen eingewilligt und die Treuhandanstalt zur treuhänderischen Verwaltung des Volkseigentums geschaffen. Deren Aufgabe sollte es sein, die Privatisierung der DDRWirtschaft vorzubereiten und das Eigentum an Produktionsmitteln in Privatbesizz zu überführen.

Die DDR hat dann tatsächlich bis zum 21. Juli 1990 die für die Währungsunion unverzichtbaren Gesetze der Bundesrepublik wortgleich übernommen. so daß die Wăhrungsunion zeitgerecht wirksam werden konnte. Auch die Bestimmungen der Bundesrepublik zur Haushaits- und Finanzpolitik wurden dabei in Kraft gesetzt. wobei die Steuergesetze der Bundesrepublik wegen der besonderen technischen Schwierigkeiten mit Zeitverzögerung erst ab 1. Januar 1991 Gültigkeit erlangten. Grundsätzlich waren nach Geltung des Einigungsvertrages Vorschriten der ehemaligen DDR, die noch der sozialistischen Gesellschaftsordnung entsprachen. nicht mehr anzuwenden. ${ }^{62}$ Aber Anlage I

\footnotetext{
${ }^{60}$ Kitterer. B. H. J. (1990), S. 9. S. 10.

${ }^{61}$ Rechtslexikon (wie Anu. 53), S. 204, Stichwort "Kredit - Kreditinstitute".

62 Art. 8 Abs. 1 EVertr. v. 31.8. 1990, in: BGBI. II. S. 889
} 
Kap. III $\S 9$ zum Einigungsvertrag (EVertr) bestimmte, daß das im Zeitpunkt der Unterzeichnung geltende alte Recht der DDR - wie Landesrecht beurteilt gültig bleiben solle, soweit dies mit den Vorschriften der Bundesrepublik vereinbar sei. Die am 3. Oktober 1990 mit dem Beitritt noch bestehenden alten Rechtsverhăltnisse der Vergangenheit sollten, sofern sie nach altem Recht unanfechtbar zustande gekommen waren, mithin für die Zukunft wirksam bleiben.

Nun mögen diese Verträge und alle weiteren Bestimmungen, die mit der für Westdeutsche und ebenso für Ostdeutsche gleichermaßen typischen Gründlichkeit ausgearbeitel wurden, ein Muster von Perfektion darstellen. Die als sozialistisches Musterland in den Wirtschaftsraum des Ostblocks eingegliederte ehemalige DDR übernahm - das muß festgehalten werden - innerhalb weniger Monate unvermittelt und ohne Vorbereitung die die Wirtschaftsordnung der Bundesrepublik tragenden, in 40 Jahren aus Erfahrung fortentwickelien Gesetzeswerke. Behördenaufbau und Abrechnungswesen hatten bis zum 30 . Juni 1990 den Anforderungen an eine zentrale Planung entsprochen. Die Abrechnungen, die den Räten der jeweiligen Kreise vorgelegt werden mußten, hatten Abschöpfungsbeträge bei Rechnungslegung für Luxusgüter und Stützungsbeträge bei lebensnotwendigen Gebrauchsgütern als auszugleichende Differenzen zu den Planvorgaben ausgeworfen. Den mit dieser Art Rechnungslegung vertrauten ehemaligen Mitarbeitern aus den Abteilungen für Finanzen bei den früheren Räten der Kreise begegnete und begegnet man noch heute wegen ihrer Qualifikation, mit Zahlen umgehen zu können, als Sachbearbeitern in den neu entstandenen Finanzämtern, in den Sparkassen und Banken, in den Zweigniederlassungen der Landeszentralbank, in den Kreditabteilungen der bäuerlichen Handelsgenossenschaften, bei den Industrie- und Handelskammern und in den Amtsstuben der jeweiligen Bewilligungsbehörden. Die allgemein bekannten Konsequenzen dieses Umstandes erübrigen eine Erörterung darüber, daß selbst großes Engagement ein Mindestmaß an Sachkenntnis nicht ersetzen kann. Der Wissenstransfer schreitet nur ganz langsam voran. Er ist das Nadelöhr des sozialen Fortschritts im Beitrittsgebiet und bestimmt ebenfalls die praktische Wirksamkeit der von der Bundesrepublik übernommenen Gesetze. Eine kleine Schar engagierter Beamter und Mitarbeiter aus den alten Bundesländern vermag die mangelnden Kenntnisse von dem Vollzug der Vorgänge eines modernen Wirtschaftsgefüges in den neuen Bundesländern nicht aufzuwiegen.

Nun hatte die in wirtschaftlicher Hinsicht ungeeignete Organisation der obrigkeitlichen Steuerung von Produktion und Preisen in der DDR einen desolaten Zustand der wirtschaftlichen Ausstattung entstehen lassen. Nach zeitnahen Schätzungen des deutschen Instituts der Wirtschaft hätten um 1990 25\% 
aller Produktionsanlagen allein wegen Umweltbelastung und zu hohen Energieverbrauchs stillgelegt werden müssen. Der technische Rückstand der DDR und die Überalterung der Produktionsanlagen gegenüber westlichen Standards sowie die Unzulänglichkeiten von Verkehrseinrichtungen und allgemeiner Bausubstanz war offenkundig. Der Produktivitätsrïckstand lag nach Schätzungen Sachkundiger etwa bei $50 \%$ des Westniveaus. ${ }^{63}$ Zudem war die Arbeitsmotivation systembedingt niedrig. Diese Umstände machen verständlich, daß eine bloße Änderung der systemtragenden Gesetzesvorschriften innerhalb weniger Jahre keine wesentlichen Wandlungen zu bewirken vermochten, zumal Infrastruktur und sachkundiges Personal fehlten und heute noch fehlen.

Mit Durchführung der Wirtschaftsunion wurden die unverzichtbaren Voraussetzungen einer auf Privatautonomie gründenden liberalen Wirtschaftsordnung geschaffen oder zumindest auf den Weg gebracht: die Wiedereinsetzung des Geldwesens in die dieser in einer liberalen Wirtschaftsordnung eigenen Funktionen und die Wiederherstellung eigentumsrechtlicher Verhältnisse in Händen von frei verfügungsberechtigten Bürgern.

Das Geld, das zur Zeit der DDR nur ein passives "Instrument der Plangestaltung und Planrealisierung" in "einem Bilanzsystem, das in Mengeneinheiten und Planpreisen rechnete", gespielt hatte, wurde durch die Währungsunion am 1. Juli 1990 mit einer aktiven, durch das Kreditwesengesetz geregelten Funktionen ausgestattet, als Bezugsschein für alle in dem Gemeinwesen produzierten und gehandelten knappen Güter zu dienen. Die Kreditinstitute der ehemaligen DDR wurden zum 1. Juli 1990 in das zweigliedrige Bankensystem der Bundesrepublik eingefügt. Für die Versorgung der Bevölkerung mit neuen Banknoten und Geldmünzen und für die Ausstattung der Geschäftsbanken mit Mitteln zur Bewältigung ihrer neuen Aufgaben diente das Grundkonzept der Wăhrungsreform vom 20. Juni 1948 in Westdeutschland und die bis heute damit gemachten Erfahrungen als Blaupause. ${ }^{64}$ Die Ausgabe des neuen Geldes und die Umtauschverhältnisse, die 1948 an einer Aufrechterhaltung des bestehenden Preisniveaus lebensnotwendiger Güter orientiert wurden, sind diesmal schwerpunktmäßig nach sozialen Kriterien und daher 1990 eher zu üppig ausgefallen.

Ähnlich wie die westlichen Geschăftsbanken 1948 durften zum 1. Juli 1990 die Bankinstitute der neuen Bundesländer bei zusătzlicher Berücksichtigung von $4 \%$ der Bilanzsumme für fehlendes Eigenkapital Ausgleichsforderungen zur Abdeckung der Unterdeckung in die Eröffnungsbilanz einstellen. ${ }^{65}$ Diese

\footnotetext{
${ }^{63}$ Hierzu s. Kitterer, B. H.J. (1990), S. 13.

${ }^{64}$ Hierzu s. Hăuser, K. (1992), S. 7; s. a. Moller, H. (1989), S. 55.

6s Hôser, K. (1993), S. 13.
} 
gegen die Gebietskörperschaften gerichteten Forderungen erhielten sogar die Qualităt börsenfähiger Wertpap̣iere, nämlich den Charakter von Teilschuldverschreibungen mit vierteljährlicher, den Marktverhältnissen variabel angepafier Verzinsung durch den Bund und die Treuhandanstalt als K.orperschaft des offentlichen Rechts. ${ }^{66}$ Die Ausgleichsforderungen, die bis Ende 1994 durch endgültig bestătigte Eröffnungsbilanzen angefordert sein müssen, werden dann nach Vorausschätzungen einen Umfang von ca. 100 Mrd. DM erreichen.

Für die Bewältigung der im Beitrittsgebiet anstehenden Probleme des wirtschaftlichen Aufbaues ist mithin seit dem 1. Juli 1990 die formelle Seite der Schaffung geeigneter Wăhrungsverhăltnisse und der bankmäßigen Finanzierung und Betreuung von Investitionsvorhaben nach neuestem Kenntnisstand aus Erfahrungen der Bundesrepublik ausreichend geregelt. Wenn dennoch Engagements in den neuen Bundesländern nach der Wiedervereinigung am 3. Oktober 1990 nur åußerst zögerlich und unter größten Schwierigkeiten zustande kommen, so liegt dies im wesentlichen an dem Umstand, daß die über 40jährige Zentralverwaltungswirtschaft, zusammen mit einem marxistisch geprägten Schul- und Berufsbildungssystem, Randbedingungen haben entstehen lassen, die erst in einigen Jahren mühsamer Ausbildungstätigkeit ausgeräumt sein können.

Bezüglich weiterer Voraussetzungen für die Transformation der in der ehemaligen DDR praktizierten Zentralverwaltungswirtschaft in eine sozial überformte Marktwirtschaft gilt ähnliches: Während in der Bundesrepublik nach dem letzten Krieg die Eigentumsverhältnisse an den Produktionsmitteln in der Regel noch problemlos fortbestanden und in den Fällen eines aus politischen Gründen vorgesehenen Restitutionsanspruchs schnell Rechtssicherheit hergestellt werden konnte, herrscht in den neuen Bundesländern bis heute ein $\mathrm{Zu}$ stand, den man als Chaos bezeichnen muß. Alte Grundbücher wurden zum Teil ausgelagert, unlesbar gemacht oder gar vernichtet. Neu angelegte Blätter wurden wie Kladden von Subalternbeamten bei den Räten der Kreise geführt und gelegentlich fortgeschrieben. Oft sind sie unleserlich oder gar nicht auffindbar und nicht zeitnah bearbeitet worden.

Und: Obgleich das Bodennutzungsrecht in der ehemaligen DDR sehr konsequent durchdachten gesetzlichen Regelungen unterworfen war, ${ }^{67}$ wurden diese

\footnotetext{
66 Häuser, K. (1993), S. 14.

${ }^{67}$ BodennutzungsVo v. 26.2.1981, in: GBI. I Nr. 9, S. 97; VO über den Kauf und Verkauf volks. eigener unbeweglicher Grundmittel durch Betriebe der volkseigenen Wirtschaft, in: GBI. II 1968, S. 797; Anordnung über die Rechtstrăgerschaft an volkseigenen Grundstacken, in: GBI. 1969 II, S. 433; Anordnung über das Verfahren bei Änderung der Rechtstrăgerschaft v. 21.8.1956, in: GBL. 1, S. 702.
} 
nur selten korrekt beachtet. Nach dem sogenannten "sozialistischen Gang der Dinge" galt jeweils derjenige als Nutzungsberechtigter, in dessen Bilanz das Wirtschaftsgut geführt wurde. Hierbei spielten Parteizugehörigkeit und Nepotismus eine gewichtige Rolle. ${ }^{68}$ Grund und Boden und Produktionsbetriebe wurden in der Regel als Volkseigentum verwaltet, wobei das Nutzungsrecht vom Rat des Kreises jeweils einem sogenannten "Rechtsträger" zugewiesen war. ${ }^{69}$ Im Falle noch vorhandenen, nicht aufgehobenen Privateigentums an handwerklichen Kleinbetrieben, kleinen landwirtschaftlich genutzten Flăchen oder nur Wohnzwecken dienenden Grundstücken lagen jeweils gesetzliche Nutzungsbeschränkungen vor. ${ }^{70} \mathrm{Da}$ in einer zentralen Planwirtschaft genaue Regelungen über Nutzungsrechte am Volkseigentum erforderlich sind, gab es in der ehemaligen DDR, deutscher Gründlichkeit entsprechend, spitzfindige Vorschriften über die zur Nutzung berechtigende Rechtsträgerschaft, über vertragliche Gestaltungen und über die amtliche Übertragung von Nutzungsrechten. Zu ihrer offentlich-rechtlichen Wirksamkeit bedurften derlei Rechtsgeschäfte der Genehmigung durch Beschluß des Kreisrates und der abschlieBenden Eintragung in eine amtliche Rechtsträgerkartei. ${ }^{\text {71 }}$ Auch in den Grundbüchern war ein Rechtsträgerwechsel zu vermerken. Dabei kam den Grundbüchern jedoch kein öffentlicher Glaube - vergleichbar mit $§ 829$ BGB - zu. Dariber hinaus wurden die Verfügungsrechte oftmals praktisch von einflußreichen Machthabern mit Abneigung gegen formalistische Bestimmungen ausgeübt, so daß der tatsächliche Sachverhalt eventuell erheblich von dem gesetzmåßigen Tatbestand abwich. Nun normierte Anlage I Kap. III $\S 7$ zum Einigungsvertrag vom 31. August 1990, daß die Bestimmungen des BGB erst mit Wirksamkeit des Beitritts, also mit dem 3. Oktober 1990, Gültigkeit erlangen sollten. Dabei sollen die vor dem Beitritt geltenden Rechtsvorschriften der ehemaligen DDR, also dic $\S \S 26$ ff $Z G B$, fortgelten, wenn der Antrag auf Eintragung der Ändenung in das Grundbuch noch vor diesem Datum rechts-

\footnotetext{
${ }^{68}$ Nach konkreten Erfahrungen des Verfassers standen auch die mit der Qualifikation zum Richteramt ausgezeichneten Diplom-Juristen als Rechtsvertreter der Treuhandanstalt auf dem Standpunkt, daB Auführung in der Bilanz die Eigentumsposition festlege. Als Opfern "des sozialistischen Gangs der Dinge" muBte man ihnen erst nach Lektûre der Bestimmungen des Eigentumsrechts und der Bodennutzungs VO der DDR die Konsequenzen der im EVertr vorgesehenen Fortgeltung richtig ausgelegter alter Gesetzesbestimmungen entgegenhalten. Die Fortgeltung von. Schlamperei und Nepotismus war nicht vereinbart worden, was gelegentlich Unverstândnis erzeugte.

69 Hierzu \&. Anordnung über die Rechtsträgerschaft an volkseigenen Grundstûcken, in: GBI. II v. 15.8.1969, S. 433 ff; s. a. Autorenkollektiv (Hrsg.) (1989), Bodenrecht, S. 80 .

${ }^{70}$ Hierzu s. $\$ \S 26 \mathrm{ff} . \mathrm{ZGB}$.

${ }^{n} \S 5$ Anordnung ... (wie Anm. 68), S. 434.
} 
wirksam gestellt wurde. ${ }^{12}$ Ein großer Teil der bestehenden Eigentumsverhăltnisse kann daher nach den Erfahrungen des Verfassers vor heute zuständigen Gerichten nach altem DDR-Recht uberprüf werden, da Nichtberechtigte nach altem Recht kein Eigentum übertragen konnten und ein öffentlicher Glaube an die Richtigkeit des Grundbuchs nicht bestand. Zudem läßı Anlage 1 Kap. III $\S 8$ zum EVertr vom 31. August 1990 auch Bereicherungsansprüche gemäß $\S 459$ ZBG DDR fortgelten und es gab nach weichendem Recht die Möglichkeit zu separatem Eigentum an aufstehenden Gebäuden, die dann abweichend von der Regel nicht wesentlicher Bestandteil des Grund und Bodens waren. ${ }^{73}$ Die Konsequenzen dieser und weiterer Bestimmungen belasten die Möglichkeit der Schaffung von Pfandrechten an Grund und Boden als übliche Kreditunterlage für Investitionen und darüber hinaus den Eigentumserwerb als solchen.

Hinzu kommt noch, daß das Gesetz zur Regelung offener Vermögensfragen vom 28. September 1990 normiert, daß grundsătzlich eine Rückgabe von Rechtsgütern an widerrechtlich enteignete frühere Eigentümer Vorrang vor einer Entschädigung hat. Die seit über 40 Jahren in der ehemaligen DDR mit oder ohne Entschädigung enteigneten, gegebenenfalls republikflüchtigen Bürger können mithin - mit Ausnahme der von der sowjetischen Besatzungsmacht zwischen 1945 und 1949 enteigneten ehemaligen Großgrundbesitzer (ab 100 ha) - einen die Rechtssicherheit beeinträchtigenden Antrag auf Naturalrestitution stellen. An die Stelle der früheren Eigentümer sind zumeist inzwischen deren Erben getreten, die ihre Rechte erst einzuschätzen suchen, was der Rechtssicherheit abträglich ist.

Naturgemäß vermag man unter den dargestellten Umständen zumeist nicht innerhalb angemessener Frist potentiellen Investoren mit absoluter Sicherheit originäres Eigentum zu verschaffen. Daran änderte bisher auch das "Gesetz zur Vermeidung von Hemmnissen bei der Privatisierung von Unternehmen und zur Förderung von Investitionen" vom 22. März $1991^{74}$ nicht viel. Komplizierte, dem Investitionsklima nicht förderliche Vertragskonstruktionen, die das Risiko verschieben, müssen oft gewählt werden, um ein kapitalintensives Projekt auf den Weg zu bringen.

\footnotetext{
${ }^{72} \mathrm{Da}$ Grundbŭcher und Rechtsträgerkarteien, die beim Rat des Kreises zu führen waren, die - wenn überhaupt - wie Kladden sporadisch fortgeschrieben wurden, entstehen hier Probleme von grober Tragweite.

${ }^{73}$ Grundsätzlich galt nach $\S 467$ Abs. 2 ZGB auch für die DDR das aufstehende Gebåude als wesentlicher Bestandteil des Grundstūcks. Gegebenenfalls ist infolge Fortfalls der Geschāftsgrundlage ein Bereicherungsanspruch gem. $\$ 357$ ZGB entstanden, s. OG v. 26.11.1985 - OZK 30/85.

${ }^{74}$ BGBI. I 1991, S. 1486.
} 
Der "Hauptprozeß der Systemtransformation", nämlich die Umwandlung der Eigentumsverhältnisse an den Unternehmen, gestaltet sich mühsam und zeitaufwendig. "So wenig, wie eine zentrale Planwirtschaft auf der Basis von Privateigenturn an den Produktionsfaktoren gestaltbar war, so wenig ist nunmehr umgekehrt eine funktionierende Marktwirtschaft ohne Privateigentum realisierbar ...". ${ }^{75}$ Es wird noch viel Zeit verstreichen, bis auf dem für Finanzienungszwecke so wichtigen Gebiet des Eigentums an Grund und Boden Rechtssicherheit vorherrscht.

Der Unternehmensverkauf durch die Treuhandanstalt als Privatisienungsmethode zwecks schneller Herbeiführung des Aufschwungs, der Ähnlichkeiten mit einem Totalausverkauf hat, verläuft nicht nur schleppend, sondern wirft auch erhebliche soziale Probleme auf, die Aufmerksamkeit verdienen:

Die ehemalige DDR hatte die Treuhandanstalt am 1. März 1990 mit dem Ziel geschaffen, über das Volkseigentum zugunsten der Bürger durch Schaffung von Privateigentum unter Berücksichtigung der wirtschaftlichen Prioritäten schnell und wirksam zu verfügen.

Tatsăchlich zeichnet sich jedoch ein schleppender Ausverkauf des ostdeutschen Kapitalstocks an den Westen ohne den erwarteten Wirtschaftsaufschwung $a b .{ }^{76}$ Daher wurde inzwischen vorgeschlagen, treuhänderisch für die Bürger der neuen Bundesländer Beteiligungsgesellschaften zu bilden, in denen potentielle Investoren zwar die Mehrheitsbeteiligung und damit Stimmenmehrheit halten, im wesentlichen aber nur ihr technisches Wissen und die Verpflichtung zu Investitionen und zur Beschäftigung der Mitarbeiter einbringen, wobei dies auf den eventuell zu stundenden Kaufpreis anrechenbar sein soll. $^{73}$

Es mag dahingestellt bleiben, ob diese Lösung angesichts des im Beitrittsgebiet vorhandenen Wissensstandes und der allgemeinen Interessenlage letztlich zu schnelleren, gerechteren und bestandskräftigen Ergebnissen des notwendigen Systemtransfers sowie der erwünschten Eingliederung nebst Wirtschaftsaufschwung zu führen vermag und ob sie überhaupt praktikabel ist.

\footnotetext{
73 Busch, U.SSchmidt, H. (1991), S. 176.

76. Hierzu s. Sinn, G./ Sinn. H. W. (1993), S. 107; Gutachten des Wiss. Beirats beim BMWi v. 16.2.1991, in: Bundesanzeiger Nr. 53 v. 16.3.1991, S. 1873.

7 Sinn, G. Sinn, H. W. (1993), S. 157, s. a. ders. (1991), S. 78. Die Autoren unterschătzen die Bedeutung der Motivationsstruktur, der Ausbildungsvoraussetzungen und der Umstellungsschwierigkeiten in der Bevölkerung der neuen Bundesländer. Sie gehen von falschen Voraussetzungen aus.
} 
Fụ̂r das Ingangbringen einzelner besonderer Projekte scheint die Anregung jedenfalis erwăgenswert zu sein und sie wurde von der Treuhandanstalt inzwischen auch aufgegriffen und - soweit möglich - verwertet.

\section{Der Einsatz einkommensteuerrechtlicher Gestaltungen als unterstützendes marktkonformes Mittel zur Förderung des Aufbaus in den fünf neuen Bundesländern}

a) Die ungünstigen Ausgangsbedingungen für den erwarteten Wirtschaftsaufschwung und die Strategie der Bundesregierung zur Problemlösung

Wie wir aus dem vorherigen Abschnitt erfuhren, kann die Transformation der abgewirtschafteten Zentralplanwirtschaft der ehemaligen DDR in ein marktwirtschaftliches Ordnungsgefüge und die erforderlichen Anpassungsvorgănge zur vollen Eingliederung der neuen Bundesländer in die Gemeinschaft der Bundesrepublik nach der Wiedervereinigung aus verschiedenen Gründen nur langsam und schrittweise vorankommen. Dabei gab es gute Gründe für die Annahme, daß Ostdeutschland den Lebensstandard des Westens kurzfristig erreichen werde und daß schmerzliche Anpassungsprozesse jedenfalls schneller überstanden sein würden, als in allen anderen liberalisierten Ländern des ehemaligen Ostblocks. So glaubte man, daß der Vorteil des Beitritts gerade darin zu sehen sei, daß der gegebene stabile rechtliche und institutionelle Rahmen wegen des von einer wirtschaftsfreundlichen Politik gewährten Schutzes einen hervorragenden Anreiz auf Investoren aus Europa und Übersee ausüben werde. Man glaubte auch, die niedrige Produktivität der veralteten Betriebsausstattungen könne durch die Motivation und den Ausbildungsstand der Mitarbeiter aufgewogen werden, zumal die Treuhandanstalt den Auftrag erhielt, "die früheren volkseigenen Betriebe wettbewerblich zu strukturieren und zu privatisieren". ${ }^{78}$ In der allgemeinen Hochstimmung der Zeit entstand der Eindruck, die Beseitigung des Wohlstandsgefälles zwischen Ost und West werde innerhalb von vier Jahren gelungen sein.

Die Entwicklung verlief dann aber sehr unterschiedlich zu dem Aufschwung, den die Bundesrepublik nach 1949 erlebte.

Die industrielle Arbeitsproduktivität in der ehemaligen DDR hatte bei etwa $40-50 \%$ der westdeutschen Werte gelegen. ${ }^{79}$ Löhne gehören zu den wichtig-

\footnotetext{
${ }^{8}$ Art. 25 Abs. 1 EVertr. v. 31 1.1990.

${ }^{79}$ Kitterer, B. H. J. (1990), S. 13; Sinn, G/ Sinn. H. W. (1993), S. 22, S. 18; DIW (Deutsches Institut für Wirtschaftsforschung), Wochenbericht $\mathrm{Nr}$. 14/90 v. 5.4.1990.
} 
sten Preisen einer marktwirtschaftlich organisierten Volkswirtschaft. Da Preise in einer Marktwirtschaft das zentrale, die Effizienz besorgende Steuerungsinstrument sind, sind sie - gegebenenfalls verbunden mit Arbeitslosigkeit - als falsche Signale geeignet, den Transformationsprozeß empfindlich zu stören und sogar zu blockieren. Dazu ist es infolge einer zu schnellen Anpassung der Löhne an das westliche Niveau gekommen.

Die unvermittelte Eingliederung der neuen Länder in das politische Institutionengefüge der Bundesrepublik hat angesichts der Ausgangslage zu erheblichen Anpassungsschwierigkeiten geführt. Von der nach dem liberalen Staatsverständnis der Bundesrepublik in der Verfassung verankerten Tariffreiheit wurde bisher jeweils ein Ausgleich der widerstreitenden Belange in einer gegebenen kontroversen Interessenlage zwischen Arbeitgebern und Arbeitnehmern am ehesten erwartet. Nun war bei dem Aushandeln der ersten Tarifvertrăge im Beitrittsgebiet die Arbeitgeberseite aber gar nicht vertreten. Es gab sie noch nicht. Die Tarifverträge wurden auf Seite der Arbeitnehmer 1990 von straff geführten Ostgewerkschaften, die von westdeutschen Dachverbänden beraten wurden, und auf der anderen Seite von den bisherigen Leitern der astdeutschen Betriebe, also Angestellten der Treuhandanstalt, vereinbart. Auch die letzteren folgten ohne eigenes verantwortliches Interesse der allgemeinen Überzeugung, daß das Wohlstandsgefalle innerhalb von vier Jahren beseitigt sein werde. So wurden die Weichen - von der Öffentlichkeit wenig beachtet bereits unmittelbar nach dem Beitritt am 3. Oktober 1990 falsch gestellt, zumal die Löhne, die bis dahin in wertniedriger Ost-Mark gezahlt wurden, nun in derselben Höhe in DM fortgezahlt werden mußten.

Die aggressive Lohnpolitik der Ostgewerkschaften, die von den um die Höhe der im Westen herrschenden Tarife besorgten westlichen Dachverbänden beraten wurden, bewirkte ohne wesentlichen Widerstand - auch die mögliche Abwanderung von Fachkräften nach dem Westen mußte berücksichtigt werden - eine schicksalhafte Erhöhung der Produktionskosten, die die Existenz. ganzer Industrien zerstören mußte.

Im Zuge der Hochstimmung hatte die ostdeutsche Arbeitnehmerschaft bereits vor Schaffung der Währungsunion Lohnerhöhungen in der Industrie von durchschnittlich $17 \%$ durchgesetzt. ${ }^{80}$ Nach der Währungsunion führten dann die ersten Tarifivereinbarungen zu nochmaligen Lohnerhöhungen um $25 \%$ bis $60 \%$ und zu der Festlegung von Stufenplänen mit einer schrittweisen Angleichung der Ost- an die Westlöhne bis zum Jahr 1995, ohne Rücksicht auf die Entwicklung der geringen, stagnierenden Produktivităt der Betriebe. ${ }^{81}$ Der

\footnotetext{
${ }^{80} \operatorname{Sinn}$, G./ Sinn, H. W. (1993), S. 195.

si Sinn, G.Sinn. H. W. (1993), S. 79, S. 196.
} 
Wunsch nach schneller Angleichung der Lebensverhältnisse hat eine Explosion der Ansprüche bewirkt, denen mit steigenden Transferleistungen begegnet werden mußte.

Die durchschnittlichen Lohnstückkosten der Industrieproduktion entwickelten sich seit der Zeit der Auflösung der politischen Strukturen der DDR und deren Beitritt zur Bundesrepublik auf die Höhe der westdeutschen Werte, die inzwischen sogar gelegentlich schon überschritten wurden. Ohne westdeutsche Hilfe kann die ostdeutsche Industrie wegen ihrer mangelhaften Produktivităt jedoch nicht überleben. Verschiedene große westdeutsche Unternehmen, die sich - der allgemeinen Euphorie folgend - am Aufbau im Osten beteiligten, suchen sich heute von den als Tochterunternehmen übernommenen Firmen abzunabeln und durch Anmeldung zum Gesamtvollstreckungsverfahren zu entledigen, um nicht selbst an den Folgen des Auseinanderklaffens von Lohnaufwand und Arbeitsproduktivităt zugrunde zu gehen. ${ }^{82}$

Die Löhne in Ungarn und der Tschechoslowakei, die bei Auflösung des Ostblocks vor gleichartigen Problemen standen wie die DDR, sind inzwischen bis heute auf $10 \%$ der Westlöhne stehen geblieben, da ihnen die Möglichkeit fehlte, in ein westliches Wirtschaftsgefüge aufgenommen zu werden. Das kann nicht ohne eine Verlagerung von Produktionen und entsprechende Folgewirkungen auf Ostdeutschland bleiben. ${ }^{83}$

Anpassungsvorgänge, die für die Transformation der abgewirtschafteten Planwirtschaft in ein marktwirtschaftliches Ordnungsgefüge nicht zu vermeiden sind, werden vorerst im Beitrittsgebiet infolge der mit der Wiedervereinigung übernommenen Sozialgesetzgebung und der im horizontalen und vertikalen Finanzausgleich vom Osten zum Ausgleich beanspruchten Transferleistungen verhindert. Die Aussicht auf ausreichend dotiertes Arbeitslosengeld, auf Sozialleistungen, auf Fördenung durch Arbeitsbeschaffungsmaßnahmen oder Beschäftigungsgesellschaften u. a. m. haben den Arbeitnehmern schnell die Sorge vor einem Konkurs ihres Arbeitgebers genommen. Mit gesetzlich

82 Ein Beispiel fũr viele geben die Erfahrungen, die die Firma FAG Kugelfischer Georg Schäfer $\mathrm{KGaA}$ nach der Wiedervereinigung infolge ihres Engagements in Sachsen machen mußte. Der größte deutsche Fabrikant von Kugellagern mit einem Aktienkapital von 224 Mio. DM hatte von der Treuhandanstalt die in Leipzig beheimateten Deutsche Kugellagerfabriken GmbH erworben. Nach Investitionen von insgesamt 420 Mio. DM sah der Erwerber die Grenze der Belastbarkeit erreicht, ohne daß eine kostendeckende Produktion erkennbar wurde. Rationalisierungsmaßnahmen widerselzte sich die Belegschaft und spertte die Betriebsleitung aus. Die DKFL in Leipzig mußte das Gesamtvollstrekkungsverfahren eröffnen. Die FAG Kugelfischer mußte in einem Sanierungsverfahren Verluste in Hōhe von 439 Mio. DM durch Auflösung aller stillen Reserven zur Sicherung des Überlebens auflösen. Sie arbeitet heute in fremden angemieteten Râumen, s.: Grenze der Finanzbelastung ist erreicht, in: FAZ v. 4.6.1993, S. 22; s. Geschäftsberichte 1990 bis 1994.

83 Die Autoren Sinn/Sinn sprechen 1993, S. 204, davon, daß die Tarifvereinbarungen für Ostdeutschland einem "Beschäftigungsverbot" in diesem Landesteil gleichkommen. 
abgesicherten Lohnersatzleistungen ausgestattet, ziehen viele ein ruhiges Dasein mit einer kleineren steuerfreien Nebentätigkeit der aufreibenden zeitlich eingebundenen Benufstätigkeit vor. So ist es trotz hoher gemeldeter Arbeitslosigkeit, z. B. in Mecklenburg und dort im ärmsten Kreis dieses ärmsten der neuen Bundesländer, fast unmöglich, motivierte Arbeitskräfte mit Hilfe des Arbeitsamtes zu finden. ${ }^{84}$

Ein Vergleich dieser Umstände mit den zur Zeit nach dem letzten Krieg in den Altländern herrschenden Zuständen zeigt, daß hier völlig andere Verhältnisse gegeben waren. Die zum Wirtschaftsaufschwung führenden Anpassungsschwierigkeiten wurden nach 1949 von einer langen Zeit tariflicher Zurïckhaltung und einem durch erhebliche Unterbewertung der DM hervorgerufenen maßvollen Lebensstandard der Bürger begleitet. ${ }^{85}$

Zusammenfassend kann festgehalten werden, was der Wissenschaftliche Beirat bei dem Bundesministerium für Wirtschaft in seinem von 26 Mitgliedern unterzeichneten Bericht vom 15. Juli 1991 über die "Lohn- und Arbeitsmarktprobleme in den neuen Bundesländern" feststellte und was heute noch unverdindert fortgill: "Die hohe Arbeitslosigkeit, die rasche Angleichung der sozialen Sicherung an das westdeutsche System, der Bedarf an Infrastrukturinvestitionen, die Subventionstätigkeit der Treuhandanstalt, Umweltlasten und nicht zuletzt die geringe Steuerkraft in den neuen Bundesländern können bewirken, daß die jährlichen Transfers von öffentlichen Mitteln (einschließlich der Leistungen der Sozialversicherung) vorläufig nicht abnehmen, ja eher noch steigen werden". ${ }^{86}$ Die hohen Steigerungsraten der Geld- und Reallöhne im Zusammenhang mit der Auflösung der DDR hat inzwischen einen massiven Einbruch von Produktion und Beschättigung hervorgerufen. Wegen der aggressiven Lohnpolitik der Gewerkschaften hielt der Beirat es 1991 für nicht verantwortbar. Lohnsubventionen als Förderungsmittel zu befürworten. Denn die Verwertungsmöglichkeiten des vorhandenen alten Sachkapitals erschien dem Beirat nur noch als Standort für völlig neue Investitionen vertretbar. Die Anpassung an neue zukunftsträchtige Investitionen hielt er daher für vordringlich. ${ }^{87}$

Die Vorschläge der Gewerkschaften, zur Überwindung der wirtschaftlichen Probleme der Krisenbetriebe "das Instrument selektiver Lohnkostenzuschüsse

\footnotetext{
34 Der Verfasser hat diese Erfahrungen in den Jahren 1992 und 1993 im Kreis Rōbel/Mọritz gemacht.

${ }^{85}$ Hierzu s. Moller. H. (1989), Exkurs, in: Hampe, P., S. 34: ebenso Pfleiderer, O. (1989), Bedingungen des Erfolges, in: Hampe, P.. S. 30.

so In: Bundesanzeiger v. 17.8.1991. Nr. 153. Jg. 43. S. 1

"Wie Anm. 85, S. 6.
} 
und -subventionen" einzusetzen, wurden als unzweckmäßig zurückgewiesen. Die von dieser Seite angeregte komplizierte Differenzienung einer Finanzhilfe nach Branchen, Betrieben und Beschăftigungsgruppen mit aufwendiger Erarbeitung von Voraussetzungen vermittels eines erst noch festzulegenden "Kriterienkataloges" zur Berücksichtigung der Unternehmenskonzepte und Produktionsprogramme bei Nachweis von Stückkosten, marktüblichen Wettbewerbspreisen und Weiterbeschäftigungsgarantie für die Belegschaft nach Beendigung der Lohnsubventionen, konnte als Relikt aus der abgewirtschafteten zentralen Planwirtschaft nicht als empfehlenswert erscheinen. ${ }^{88}$ Der Vorschlag der Gewerkschaften, "die Lohnsubventionen sollten zeitlich befristet und degressiv ausgestaltet sein, konnte nicht als Problemlösung überzeugen, da die Notwendigkeit zu schmerziichen Anpassungsvorgăngen auf diese Weise nur in die Zukunft verlagert, aber nicht vermieden, sondern eher beschwert würde. $^{89}$

Lohnsubventionen würden das Beschăftigungsrisiko nach Auffassung des Gremiums auf die Allgemeinheit abwallzen und auf diese Weise die notleidende Differenz zwischen Arbeitskosten und erwirtschaftetem Ergebnis der Beschäftigten zementieren. Lohnsubventionen würden die Tarifparteien auch aus ihrer beschäftigungspolitischen Verantwortung entlassen und den Zwang beseitigen, eine falsche Lohnpolitik wieder zu verlassen. Der Versuch der Gewerkschaften, durch hohe, an das Westniveau angepaßte Lohnfordenungen produktivitätssteigernde Investitionen politisch zu erzwingen, ist nach Auffassung des Beirats ohne nachhaltige Schäden für die Gemeinschaft nicht zu verwirklichen. ${ }^{90}$

Zwar sei, so meinte das Gremium, eine "sozialverträgliche Abfederung" der Krise bei Schonung der unmittelbar Betroffenen notwendig, im übrigen sollte diesen aber durch zeitweilige Mitarbeit an den vielen erkennbaren erforderlichen Arbeiten in den neuen Ländern in Beschäftigungsgesellschaften aus öffentlichen Mitteln der Übergang in neue sinnvolle Tătigkeiten für den Markt erleichtert werden.

Der Wissenschaftliche Beirat betonte im übrigen im Juli 1991, daß das mittlerweile vorhandene umfangreiche Fördenungsprogramm zur Umstruktu-

\footnotetext{
${ }^{83}$ Wie Anm. 85, S. 8.

${ }^{89}$ Wie Anm. 85, S. 8.
}

90 Die Grewerkschaften forderten die Einführung "selektiver Lohnkostenzuschüsse bzw, -subventionen", ... "die nach Branchen, Betrieben und Beschäftigungsgruppen differenziert für begrenzte Zeit gezahlt werden", s. hierzu Kittner, M. (Hrsig.) (1993), Gewerkschafts-Jahrbuch 1993. Daten - Fakten Analysen, Köln, S. 193. Die Bundesregierung lehnte diesen Vorschlag ab, da er "die Tarifparteien aus ihrer beschäfligungspolitischen Verantwortung entlassen" würde, s. Bundesanzeiger (wie Anm. 85), S. 8 . 
rierung der östlichen Wirtschaft, das staatliche Hilfe durch Steuervergünstigungen von weit mehr als der Hälfte der jeweiligen Investition vorsieht, auf einem Niveau angesiedelt wurde, das sinnvollerweise nicht mehr steigenungsfähig sei. Die wichtige Aufgabe, die erforderlichen Anpassungsprozesse durchzusetzen, müsse nunmehr dem Zwang überlassen bleiben, der von den Märkten ausgehe. 9 !

Damit liegt die Strategie für die Erreichung eines Wirtschaftsaufschwungs im Osten fest: die Anpassungsvorgänge müssen vom Wettbewerb der Marktwirtschaft erzwungen werden. Die lenkenden Eingriffe des Staates sollen auf Stărkung der Autorităt der Marktkräfte vermittels verbilligter Kredite, einmaligen Investitionszuschüssen und Investitionszulagen und auf Steuerbegünstigungen für Investoren beschränkt werden. Dieser Art steuernde Interventionen hatten sich bereits bei dem Wiederaufbau der Bundesrepublik und insbesondere Berlins bewährt. Wegen ihres formell marktkonformen Charakters war ihnen eine tragende Rolle zugekommen. Darüber hinaus belassen sie ein Höchstmaß marktwirtschaftlicher Kontrollen als verbindlich. Eine andere Strategie ist bei Berücksichtigung der politischen Vorgegebenheiten - etwa durch Einführung hoher offener Subventionen - auch nicht recht erkennbar, sofern eine marktwirtschaftliche Ordnung angestrebt wird.

Die zu erwartenden sozialen Konsequenzen dieser Strategie, die vorerst als nachrangig beurteilt werden mögen, werden unsere Aufmerksamkeit noch in Anspruch nehmen müssen.

\section{b) Steuerliche Verlustzuweisungsgesellschaften} als Investoren - Funktionswandel der Steuervergünstigung:

Von der Stärkung der Wettbewerbsfahigkeit zur reinen Finanzierungshilfe durch Einsatz der Einkommenstewer als Instrument der Wirtschaftspolitik

Bereits in dem ersten Einkommensteuergesetz der Bundesrepublik Deutschland vom 29. April 1950 waren nichtfiskalischen wirtschaftspolitischen Zwekken dienende Steuervergünstigungen in die Bestimmungen über Abschreibungen ( $\S \S 7$ a bis 7 e EStG) bzw. bei den Sonderausgaben ( $\$ 10$ Abs. 1 Ziff. 3 EStG) und in den Tarifvorschriften ( $\$ 32$ a EStG) integriert. Diese in die

91 Wie Anm. 85, S, 9. Der Beirat hielt fest, daß gesetzliche Hilfen vorgesehen sind, die bis zur Halfte der vorgenonmenen Investition betragen. Sinnvoller Weise konnten sie nicht mehr erhōht werden. Tatsăchlich bestehen die Hilfen aus Investitionszulagen, Investitionszuschüssen und den. Sonderabschreibungen des FördG. Diese letztere Position stellt den wichtigsten Bestandteil der Förderung dar. 
Ermittlungsvorschriften des letzten gültigen Reichseinkommensteuergesetzes vom 27. Februar 1939 eingefügten Steuervergünstigungen hatte bereits die "Militărregierung Deutschland" als Besatzungsmacht in dem von ihr für das "Vereinigte Wirtschaftsgebiet" erlassenen Einkommensteuergesetz vom 20. April 1949 vorgesehen. Die alten Bestimmungen des letztlich aus dem Jahr 1925 stammenden Gesetzes waren nur übernommen, angepaßt und weiter ausgebaut worden. ${ }^{92}$ Im übrigen bedurften im Jahr 1950 vorerst noch Ändenungen von dem von der Militärregierung Deutschland auf Grundlage des Gesetzes Nr. 64 vom 20. Juni 1946 im Zusammenhang mit der Wăhrungsreform fuir das "Vereinigte Wirtschaftsgebiet" erlassenen EStG vom 22, Juni 1948 in der Fassung vom 20. April 1949 noch der ausdrücklichen Genehmigung durch die "Alliierte Hohe Kommission". Diese wollte die "innere finanzielle Stabilität" bei Verringerung auslăndischer Hilfe für die Zukunt schneí sichergestellt wissen und verwarf daher am 21. April 1950 das ihr vom Deutschen Bundestag am 30. März 1950 zur Genehmigung zugeleitete "Gesetz zur Änderung des Einkommensteuergesetzes" vom 20. April 1949 nach reiflicher Prüfung. ${ }^{93}$

Die Steuervergünstigungen erschienen der Alliierten Hohen Kommission nach wie vor zweckmäßig. Sie widersetzte sich nur den vorgesehenen pauschalen Tarifsenkungen in dem vom Deutschen Bundestag beschlossenen Entwurf.

Der Gesetzgeber suchte auf diese Weise dann weiterhin - und ab 1953 in völliger Souveränität - die Selbstfinanzierung der zum Aufbau und zur Erhaltung ihrer Wettbewerbsfähigkeit zu erheblichen Investitionen gezwungenen Unternehmen zu stärken. Vor allem sollte es den Unternehmen erleichtert werden, die infolge der Währungsumstellung den Anforderungen nicht mehr genügende Kapitalstruktur den Erfordernissen der Wettbewerbswirtschaft anzupassen. ${ }^{94}$

Der Gewinn als Bestandteil der Einkünfte, deren Summe den Ausgangsbetrag für die Ermittlung des steuerbaren Einkommens darstellt, wurde auf diese Weise normabweichend für den Fall bestimmter im Sachverhalt vorliegender

${ }^{52} \S 1$ des EStG v. 20.4.1949 lautet: "Das Einkommensteuergeset? vom 27.2.1939 (RGBI. I S. 297) in der Fassung des Artikels I des Anhanges zum Gesez Nr. 64 zur vorläufigen Neuordnung von Steuern vom 22. Juni 1948 wird wie folgt geändert:..." . Nachfolgend wurden u. a. $\S \S 7$ a bis 7 e neu eingefügt, s. Gesetzblatt der Verwaltung des Vereinigten Wirtsehaftsgebietes, Nr. 15 v. 25.5.1949, S. 69.

93. Alliierte Hohe Kommission für Deutschland. Der Rat: Schreiben vom 21.44.1950, in: Deutscher Bundestag, 1. Wahlperiode 1949, Drs. 854, S. 2.

${ }^{94}$ Dreifig. W. (1984), S. 193, S. 195; Muscheid, J. (1986), S. 42, S. 47; Verhandlungen des Deutschen Bundestages, 1. Wahlperiode 1949, Stenographische Berichte, Bd 2, von der 26. Sitzung am 11.1.1950 bis zur 47. Sitzung am 16.3.1950. Verhandlung v. 24.2.1950, S. 1401. 
Tatbestandsmerkmale verfalscht: Denn nach dem tragenden Grundgedanken des Gesetzes sollte eigentlich das nach betriebswirtschaftlichen Grundsätzen ermittelte periodengerechte Ergebnis der Rechnungslegung jeweils Grundlage für die Feststellung der Leistungsfähigkeit sein und damit die Bemessungsgrundlage für die Besteuerung bestimmen. Nach dieser Vorstellung sind Abschreibungen nur nach Verteilung des Anschaffungs- bzw. Herstellungsaufwands eines Wirtschaftsgutes auf die betriebsgewöhnliche Nutzungsdauer, also zeitanteilig, berücksichtigungsfahig. Bei dem Ansatz zusätzlicher Abzüge als Sonderausgaben, die in Wirklichkeit Gewinnbestandteile betrafen, verhielt es sich ähnlich. Bei dem Ansatz von Sonderausgaben hätten nur sozial indizierte, enumerativ aufgeführte Positionen Berücksichtigung finden dürfen. Zur Stärkung der Wirtschaftskraft durch die steuerfreie Bildung von Eigenkapital zwecks Verbessenung der Kapitalstruktur der Unternehmungen durften jedoch bei Vorliegen bestimmter Voraussetzungen ausnahmsweise Teile des Gewinns als Sonderausgaben der Besteuerung vorenthalten bleiben.

Dieser einmal eingeschlagene Weg - vorerst eingeführt, um den notleidenden Unternehmen angesichts der Kriegsfolgen und der Währungsreform durch steuerliche, versteckte Subventionen den Wiederaufbau unter internationalem Wettbewerbsdruck zu erleichtern - wurde später beibehalten und für andere Zwecke immer weiter ausgebaut. Die Beeinflussung der Investitionsentscheidungen privater Unternehmen erfolgte fortan durch steuerliche Maßnahmen zur Verbessenung der Kapitalstruktur, der Rentabilităt und der Liquidität. Als Mittel hierzu dienten bald nicht nur Sonderabschreibungen, sondern ebenso die Steuerfreiheit bestimmter Zinseinnahmen, Bewertungsfreiheiten für aufgeführte Wirtschaftsgüter, die Bildung steuerfreier Rücklagen, die Übertragung stiller Rücklagen auf andere Wirtschaftsgüter bei Vermeidung von Veräußerungsgewinnen, die Einführung des steuerlichen Verlustrücktrages und die Gewähnung von Investitionszulagen und Zuschüssen aus offentlichen Mitteln. Durch jeweilige Verändenungen dieser Maßnahmen und durch die gelegentliche Einfuhrung einer Investitionssteuer sowie von Konjunktur- und Stabilitätszuschlägen zur Einkommensteuer konnte bald durch Einflußnahme auf unternehmerische Entscheidungen und Einwirkung auf Kaufkraft, Konsumund Sparneigung der privaten Haushalte ein steuerpolitisches Instrumentarium geschaffen werden, das wirtschafts-, konjuniktur- und dariber hinaus auch gesellschaftspolitischen Zielen zu dienen vermochte. Es war vielseitig einsetzbar. $^{95}$

${ }^{95}$ Zur Rechtfertigung der "Steuem als Mittel der Wirtschaftspolitik" und zur Systematisierung der Ziele und Zusammenstellung und Systematisierung der steuergesetzlichen Mittel s, a. Wöhe, G. (1975), S. 169, S. 176, S. 179. 
Die 1925 festgelegte Gesetzessystematik in der Înterpretation, die ihr von Johannes Popitz und Enno Becker mitgegeben worden war, stand einer entsprechenden Anwendung nicht entgegen. Einzelbestimmungen, die aus dem am Reinvermögenszugangsprinzip orientierten sächsischen ESıG 1874/78 übernommen worden waren, wie $\S 48 \mathrm{EStG}$, wurden bald als nicht integrierbarer Fremdkörper empfunden und schließlich getilgt.

Die in der Nachkriegszeit herrschende Kapitalknappheit zwang Handel und Produktion vorerst zur Selbstfinanzienung über die Preise, solange die Leistungsfăhigkeit des Kapitalmarktes der größte Engpaß für erforderliche Finanzierungen war. Die Börse als wichtigstes Finanzierungsinstrument einer marktwirtschaftlichen Ordnung fand erst viel später ihre Rolle als großte Kapitalsarnmelstelle. "Die Selbstfinanzierung ist in den ersten Jahren nach 1948 das Kernproblem der betrieblichen Kapitalbeschaffung geworden", hielt Mellerowicz noch 1958 fest. ${ }^{96}$ Die Steuergesetzgebung hat sich auf diesen Umstand durch geeignete Förderungsmaßnahmen eingestellt.

Bereits 1958 entwickelten sich dadurch zusătzlich zur Börse bis dahin unbekannte Formen der Finanzierung des Wiederaufbaus durch sogenannte "Immobilien-Investmentgesellschaften". Diese hatten zumeist die Rechtsform von Kommanditgesellschaften, die zur Durchführung jeweils größerer Investitionsprojekte gegründet wurden, wobei das risikobehaftete Eigenkapital von einer Vielzahl kleiner und mittlerer Sparer als Kommanditeinlage eingebracht wurde. Je nach der Satzung der Gesellschaften wurde dann zumeist ein Bankinstitut als Treuhandkommanditistin eingesetzt. ${ }^{97}$

Diese als Personengesellschaften organisierten Unternehmen kamen auch vielen Wünschen eines nach sicherer Anlage der Ersparnisse suchenden breit gestreuten Publikums mit höherem Einkommen entgegen. Als wichtigste Vorteile dieser Gesellschaften beurteilte man, daß

1. die Zertifikatinhaber Miteigentümer der errichteten oder erworbenen Liegenschaften wurden und der Wert des Anteils somit vor inflationärer Entwicklung gesichert zu sein schien,

2. die Beteiligung in fast beliebig kleine Anteile gesplittet werden konnte,

3. die Zeichner an den Steuervergünstigungen teilhatten, wobei durch den Fremdmitteleinsatz der Gesellschaft infolge der Hebelwirkung eine günstige Rentabilität des gezeichneten Kapitaleinsatzes zugesagt werden konnte.

\footnotetext{
${ }^{96}$ Mellerowicz, K. (1958), Die Problematik der Industriefinanzienung, in: Zeitschr. f. d. gesamte Kreditwesen, S. 122.

${ }^{97}$ Mellerowicz, K. (1963). S. 179, S. 184.
} 
4. die Haftung auf den Zeichnungsbetrag beschränkt war und nicht zuletzt

5. eine angesehene Bank als Treuhandkommanditistin tätig wurde. ${ }^{98}$

Die mangelhafte Fungibilität der Anteile stand selten im Vordergrund der Überlegungen. $\mathrm{DaB}$ die für die Beteiligten an dieser Art neu entstandener Publikumsgesellschaften ausgegebenen Zeichnungsscheine oder Zertifikate keinerlei Wertpapiercharakter verbrieften, wurde nie recht verstanden und spielte in Beratungsgesprächen nur eine untergeordnete Rolle. ${ }^{99}$

Bereits 1963 sah Konrad Mellerowicz als Folge dieses neuartigen Finanzierungsweges die allmähliche Entstehung eines Nebenkapitalmarktes für die beschriebenen inflationsgesicherten Beteiligungsrechte voraus. Dazu ist es dann, trotz der sehr verschiedenartigen Ausstattung der einzelnen Beteiligungsrechte und deren nicht gegebener Vertretbarkeit, auch gekommen. Vor allem sah Mellerowicz das wachsende Interesse an dieser Art Kapitalanlage mit Erhöhung der Einkommensteuerprogression wegen der Bedeutung der Steuervergünstigungen für die Inhaber.

Die fernere Entwicklung eines Nebenkapitalmarktes war eng verwoben mit dem inhaltlichen Funktionswandel der Vergünstigungsvorschriften des Einkommensteuerrechts. Diese hatten ursprünglich dem Zweck gegolten, Investitionen in fördenungswürdigen Wirtschaftszweigen und in unterentwickelten Gebieten zu begünstigen, um die Konkurrenzfähigkeit der Betriebe zu verbessern. Dabei war vornehmlich auf bereits bestehende Unternehmen abgestellt worden, die durch Verbesserung von Anlagevermögen und Kapitalstruktur widerstandsfähiger gemacht werden sollten.

Dann entdeckte man zur Mitte der 60er Jahre die Möglichkeit, die Weitergabe der Steuervergünstigungen an die Zeichner von Beteiligungsrechten an Personengesellschaften vermittels Zuordnung der einheitlich festgestellten steuerlichen Verluste als werbewirksames Argument allgemein für die Beschaffung von Eigenkapital bei Neugründungen zu verwenden. So waren schon die erwähnten "Immobilien-Investmentgesellschaften" zur Beschaffung. von Risikokapital verfahren. Neugründungen wurden bald auf gewerbliche Vorhaben ausgedehnt und schließlich machten später sogar Gemeinden von

\footnotetext{
* Áhnliche Prioritaten bei Mellerowicz, K. (1963), S. 180.

99 Sofern die Initiatoren đen Inhabern der Anteilsrechte Urkunden ûber ihre Beteiligung ausgeben, handelt es sich bei denselben, soferm sie uberhaupt Wertpapiercharakter haben, um Rektapapiere, also Beweisurkunden. Eine große Initiatorfirma im Kölner Raum verwaltet heute allein Anteilsrechte in Hôhe von über 8 Mrd. DM. Für eine bekannte große Berliner Firma kommı die gleiche GröBenordnung infrage. Eine Hochrechnung ergibt, daß ein großer Teil des Volksvermōgens inzwischen aus Anteilsrechten an geschlossenen Fonds besteht. Es zeigt sich ein offentliches Bedürnis, den Handel mit. diesen Rechten institutionell nach Wettbewerbsgesichtspunkten zu regeln, s. hierzu Cash. Mai 1995.
} 
den Steuervergünstigungen für notwendige Investitionen in großem Umfang Gebrauch. Sie übertrugen Bau und Finanzienung städtischer Einrichtungen auf zu diesem Zweck gegriindete private Investmentgesellschaften, die rechtlich auf die öffentlichen Bedürfnisse zugeschnitten waren. ${ }^{100}$

Die Vorgehensweise erfaßte nun alle Branchen. Die investitionsfordernde Wirkung der steuerbegünstigenden Vorschriften des EStG blieb bei diesem Funktionswandel erhalten. Man wird sogar festhalten können, daf̧ die Investitionstätigkeit sich weiterhin positiv fortentwickelte. Die Unterstützung durch das Gesetz veriagerte sich jedoch von der Stärkung der Wettbewerbskraft bestehender Unternehmungen auf Subventionen für neue Zeichner von Risikokapital, also auf die Finanzierung neuer Unternehmen.

Es bildete sich allmăhlich ein verwirrender, unkontrollienter, stetig wachsender, vorhergesehener Nebenkapitalmarkt heraus, der von der Werbung in den Tageszeitungen, von einem neu entstandenen Berufsstand der Anlageberater, in Rechtsanwalts-, Steuerberater- und Wirtschaftsprüferpraxen sowie in gezielten Aktionen von Promotern geschlossener Anlagefonds verschiedenster Branchen und Aktionen auf dem Postweg für ein breites, besser verdienendes Publikum versehen wurde. Bereits in den Jahren von 1970 bis etwa 1980 wurden auf diesem Nebenkapitalmarkt höhere Ersparnisse als Risikokapital investiert, als an den Aktienbörsen durch Neuemissionen. ${ }^{101}$

Betreiber von Investitionsvorhaben verschiedenster Art und Größenordnung suchten diese durch Bildung geschlossener Fonds in Form von Kommanditgesellschaften, Gesellschaften bürgerlichen Rechts, stillen Gesellschaften, einer AG \& Co., einer GmbH \& Co. oder sogar doppelstöckiger Konstruktionen voranzutreiben. Geworben wurde jeweils mit Verlustzuweisungen, die möglichst zeitnah nach der Gründung eine teilweise, eine vollständige oder sogar eine Überdeckung des Zeichnungs- und zugleich Haftungsbetrages aus Steuerersparnissen versprachen.

Bei den so entstandenen Fondsgesellschaften handelte es sich um Rechtsgebilde, die als Publikumsgesellschaften bezeichnet werden müssen und die jedenfalls einer Aktiengesellschaft ähnlicher waren als einer Personengesellschaft, in der im Gegensatz zu juristischen Personen der Unternehmer oder die

:00 Die Entwicklung begann bereits zu Ende der 60er Jahre, nachdem die Gesetzgebung, entspre= chende Steuervergünstigungen im "Städtebauforderungsgesetz" vorsah. Sogar gutsituierte Gemeinden, wie z. B. die Stadt Leverkusen, machten von den Möglichkeiten Gebrauch, s. hierzu FAZ v. 28.12.1971, S. 13; Monatsbericht Deutsche Bundesbank, Januar 1975; Friedemann, J.: Abschreiben im Rathaus, in: Die Zeit v. 9.1.1976, S. 17; Cash, Mai 1995, S. 124.

101 FAZ v. 28.12.1971, S. 13: "Mehr Kornmanditanteile als Aktien abgesetat". Nach einer Schătzung waren bereits um 1970 allein in sechs Jahren aber 20 Mrd. DM Kommanditanteile von Publikums-Gesellschaften gezeichnet worden, s. Zybon, A. (1973), S. 422; FAZ v. 3.4.1973, S. 13. 
Mitunternehmer oder die nach Steuerrecht bzw. bürgerlichem Recht beteiligten Gesellschafter mit "ihrem" Betrieb steuerrechtlich als unternehmerische Einheit zu beurteilen sind. Zumeist handelte es sich um Gesellschaften mit einer GmbH als haftendem Komplementär und einer großen Zahl auf die gezeichnete Einlage beschränkt haftender Kommanditisten. Die Stärkung der Eigenmittel der Anteilszeichner durch Steuerersparnisse war zwar als Anreiz. zur Zeichnung und Hergabe von Mitteln als Eigenkapital geeignet, die Kapitalstruktur der neu gegründeten Fondsgesellschaft konnte davon jedoch unberührt bleiben, da der Einheit von Betrieb und Unternehmer die hohe Zahl Beteiligter und die Satzungsbestimmungen entgegenstanden. Nach Gründung bestand zwischen Verlustzuweisungen und Leistungsfähigkeit des Betriebes keine Verbindung mehr. ${ }^{102}$ Mehr noch: Das Interesse der Zeichner stand nur in unmittelbarem Zusammenhang mit der zugesagten Verlustzuweisung und damit wegen der mehrfach bereits erwähnten sogenannten "Hebelwirkung" mit einem hohen Einsatz von Darlehensmitteln und einer geringen Ausstattung der Neugründung mit haftendem Eigenkapital. ${ }^{103}$

Die ursprünglich nach der Währungsreform im Jahr 1949 zur Verbesserung der wirtschaftlichen Leistungsfähigkeit durch Entspannung der Kapitalstruktur und Erleichterung der Liquiditätsverhältnisse in das Einkommensteuerrecht eingestellten Vergünstigungen erhielten zur Mitte der 60er Jahre auf diese Weise die neuartige Funktion, jeweils nur als Anreiz für die Aufbringung des Mindestbetrages für das erforderliche Eigenkapital bei Neugründung geschlossener Anlagefonds zu dienen. Die gesetzlich gewährte Steuervergünstigung wurde im Grunde zweckentfremdet.

Bereits 1964 sorgte der Bau des "Europa Center" an der Berliner Gedächtniskirche als in den Medien breit erörtertes schulemachendes Beispiel für diese neuartige Anschubfinanzierung von Projekten aller Größenordnungen auf Kosten des Fiskus bei gleichzeitiger Entstehung dessen, was im "Handelsblatt" als "Steuergewinne" bezeichnet wurde ${ }^{104}$ Diese erreichten für die Zeichner, wie der Leser erfuhr, in kürzester Frist Steuerersparnisse und Gewinne, die sogar ein Vielfaches des eingesetzten Zeichnungsbetrages ausmachten.

\footnotetext{
${ }^{102}$ Hierzu s.: Zybon, A. (1973), S. 418, hier S. 421. Zybon spricht von einer Perversion der handelsrechtlich vorgesehenen Gestaltungsform.

10s. Hierzu s. Anlage 9 und Anlage 11.

${ }^{104}$ Bolke, P. (1973). S. 27. Sieht man vom sozialkritischen Gehabe des 'Titels und den fragwürdigen Bewertungen ab, so enthalt er viele richtige und nachprufbare Informationen. Daß, zum Wieder. aufbau Berlins angesichts der politischen Unsicherheiten hohe steuerliche Anreize gewalhrt werden muBten, war gewiß unvermeidlich. Daß đie Allgemeinheit von den Auswirkungen profitiert hat, dûrfte heute ohne Zweifel feststehen, s. Handelsblatt v. 27.9 .1978 , Nr. 180, S. 9; s. a. Wirtschaftswoche v. 23.9.1972, S. 90.
} 
Obendrein war in dem genannten und in vielen anderen Fällen die Zeichnung völlig risikolos, da eine offentlich-rechtliche Verbürgung für die eingesetzten Darlehen aus ERP-Mitteln vorlag. Freilich darf man bei Beurteilung dieses und vergleichbarer Fâlle die das Investitionsklima in Berlin in den 60er Jahre belastenden Auswirkungen des "kalten Krieges" nicht übersehen. Der Umstand, daß der Anreiz zu einer Beteiligung an einem geschlossenen Anlagefonds von dem vom zuständigen Betriebsstättenfinanzamt zu erteilenden Bescheid über die Verlustbeteiligung abhängig ist, zeigt die Pervertierung des ursprünglich vorgesehenen Wirkungszusammenhanges auf: Je höher die zugesagte Verlustzuweisung und je höher die Steuerprogression des Zeichners, desto stärker ist die Motivation zur Zeichnung eines Anteils. Sogar eine gegebenenfalls unsolide Finanzierung wurde mithin aus Steuermitteln belohnt.

Ja sogar ein eingeplanter Konkurs der Beteiligungsgesellschaft infolge unseriöser Finanzierung, unwirtschaftlicher Geschăftsführung oder gar vorliegender Betrugsabsicht vermochte lange Zeit hindurch an diesem Zusammenhang nichts zu ändern. ${ }^{105}$ Eine intensive Prüfung des Projektes durch den Zeichner war mithin nachrangig. Eine eventuell aus Steuerersparnissen rechtskräftig vereinnahmte Überdeckung der Zahllast konnte die Zeichnung als solche endgültig sinnvoll erscheinen lassen.

Diese Verknüpfung ist es, die von Fachleuten später zynisch als Berliner "Abschreibungswunder" oder gar als geheimnisvolles "Hexeneinmaleins" bezeichnet wurde. ${ }^{106}$ Es gibt wohl nur wenige Angehörige der steuerberatenden Berufe, die nicht gern gelegentlich in der Zeit zwischen 1970 und 1980 einwilligten, auf Kosten einer Trägergesellschaft kostenlos Berliner Abschreibungsprojekte $z u$ besichtigen und die während des dortigen Aufenthaltes mit Ehepartner zu Lasten der Projekte im besten Hotel am Kurfürstendamm logierten. Die Kosten für diese Berlin-Aufenthalte wurden von der Trägergesellschaft letztlich den Anteilszeichnern belastet, die dafür eine höhere Steuerreduktion erhielten.

Es ist verständlich, daß diese Vorgänge in einer breiten Öffentlichkeit zur Kritik anregten. Dem Druck der öffentlichen Diskussion folgend setzte etwa seit 1970 die Finanzverwaltung ohne langwierige gesetzliche Neuregelungen Maßnahmen durch, die mißbräuchliche Auswüchse auszutrocknen vermochten. ${ }^{107}$ Auch betrügerische Gründungen, mißbräuchliche Gestaltungen und bisweilen bekanntgewordene unwirtschaftliche Geschäftsführungen trugen

los Schneider. D. (1974), S. 405.

${ }^{106}$ Brestel, H. (1972): Das Abschreibungs-Ärgemis, in: FAZ v. 10.2.1972.

107 Handelsblatt v. 27.9.1978, S. 9; Wirtschaftswoche Special 1979, Steuem. S. 93; Kappe, H. (1976), BB, S. 457; DB v. 21.3.1975, S. 518; DB v. 4.4.1980, S. 657; Lipps, W. (1977), in: BB, S. 5. 
dazu bei. Sie gaben $A n l a ß$ für Einschränkungen und Erschwerungen vieler anfangs problemlos gegebener Möglichkeiten, das Steuerrecht zur Finanzierung ideenreicher Konstruktionen in Anspruch zu nehmen. Die Zahl verunglückter Fälle oder mißbräuchlicher Inanspruchnahmen hielt sich jedoch in Grenzen, auch wenn in den Medien oft andere Eindrücke erzeugt wurden. Dafür sorgten wohl die finanzierenden Banken, die ungern Verluste einfahren, und das Kreditwesengesetz mit seinen strengen Vorschriften zur Kreditprüfung.

Erwähnenswert ist jedenfalls, daß allen schnellen Gesetzesänderungen der Einfluß der begünstigten Gruppen mit höheren Einkommen, die "Steuern in Vermögen umwandeln" wollten, entgegenstand. Dazu rechnete vor allem der stattliche Kreis der sozialen Aufsteiger - besonders in den Medien -, die wegen der von der Steuerprogression bestimmten unterschiedlichen Steuerentlastung aus sozialen Gründen keine Bedenken anmeldeten, wenn z. B. eine allzu geringe Erhöhung der Kinderfreibeträge oder der Werbungskosten- bzw. Sonderausgabenpauschale zur Diskussion stand ${ }^{108}$ Eine als soziale Maßnahme begrüBte Anhebung der Steuerprogression vermochte dann ebenso wenig WV: derstand zu finden, da man sich bei der Umwandlung von Steuern in Vermögen ohnehin schadlos halten konnte. SchlieBlich traf die zusätzliche Belastung ohnehin nur die kleinen Steuerzahler, für die sich die Zeichnung von Anteilen an Steuersparmodellen nicht rechnet. Aber - wer vermag diese komplizierten Zusammenhänge schon zu verstehen?

\section{c) Die in der Bundesrepublik gemachten Erfahrungen mit Verlustzuweisungsgesellschaften und deren Eignung zur Förderung der wirtschaftlichen Infrastruktur in den neuen Bundes!ändern}

Der Übergang zu einer marktwirtschaftlichen Ordnung hat in Ostdeutschland Anpassungsprozesse eingeleitet, die teilweise mit den Schwierigkeiten anderer liberalisierter osteurophischer Länder vergleichbar sind, zu einem großen Teil jedoch auf die viel glücklicheren Ausgangsbedingungen der neuen Bundesländer zurückzuführen sind. Die DDR vermochte der zu den wohlhabenden Ländern der westlichen Welt zugerechneten Bundesrepublik Deutsch-

10 Die fohlerhafte Darstellung und fragwôndige Bewertung steuerlicher Vorgănge in aflets Medien ist fur das Gros der Sieuerfachleute ein ständiges Ärgernis. Die uberdurchschnittlich hohen Einkünfte des Personals des Zweiten Deutschers Fernsehens wurden vom Landesrechnungshof Rheinland-Pfalz in dem Prufungsbericht für die Jahre 1990 bis 1992 besonders beanstandet, s. hierzu Bild am Sonntag v. 28.11.1993, S. 14, und Bild am Sonntag v. 23.10.1994, S. 22. 
land beizutreten. Diese gewährt den betroffenen Bürgern immense wirtschattliche Erleichterungen. Sie hat aber zugleich neuartige, in vergleichbaren Ländern unbekannte Anpassungsschwierigkeiten geschaffen.

Der Versuch, im Beitrittsgebiet einen sich selbst tragenden wirtschaftlichen Aufschwung, vergleichbar mit der Entwicklung der Bundesrepublik nach 1948 , in Gang zu setzen, ist bisher entgegen vielen Hoffnungen und Voraussagen nicht gelungen. Die inzwischen verstummte Euphorie hat eine Vielzahl von Schwierigkeiten unterschätzt. Es bedarf heute offensichtlich ungewöhnlicher "Strategien für den Aufschwung", ${ }^{109}$ um die von einer marktwirtschaftlichen Ordnung üblichenweise bereitgehaltenen empfindlichen Zwănge zu ersetzen. Dabei hatte die Einführung der marktwirtschaftichen Ordnung in der Bundesrepublik nach 1949 als Muster für die Transformation der Planwirtschaft der DDR gedient. Für die Wăhrungsunion wurde die Wăhrungsreform vom 20. Juni 1948 als Blaupause verwendet. ${ }^{110}$ Die noch von der Regierung der DDR gegründete Treuhandanstalt erhielt den Auftrag, durch eine zügige Privatisierung und die Schaffung wettbewerbsfähiger Unternehmenseinheiten die Voraussetzungen für das notwendige Investitionsklima zu schaffen. Die nur langsam voranschreitende Privatisienung der Produktionsmittel und das vorhandene Defizit an Ausbildung vermögen allein die feststellbar erheblichen Rückschläge im Transformationsprozeß jedoch nicht zu erklären. Im Unterschied zu den Abläufen nach 1949 kommt den Lohnvorgängen im Beitrittsgebiet eine wichtige, bisher stark unterschätzte Bedeutung zu. Im Verteilungskampf um das Sozialprodukt haben die Vertreter der Arbeitnehmer - anders, als dies in den anderen Ländern des früheren Ostblocks möglich war - die Löhne in den an der Spitze der Produktivität im Weltvergleich stehenden alten Bundesländern als Bezugsgröße für die Löhne in den neuen Bundesländern eingeführt. Sie suchten eine schnelle Anpassung der Lohnverhältnisse an den Westen, obgleich die Arbeitsproduktivität nur rund 50\% derjenigen der Bezugsländer erreicht. ${ }^{111}$

Als Argument diente ihnen die ernste Gefahr der Abwanderung von Fachkräften in den Westen und die Notwendigkeit, auf diese Weise hohe Investitionen im Osten politisch ohne Lohnreduktionen zu erzwingen, um vermittels der entstehenden größeren Arbeitsproduktivität Löhne und Arbeitsintensităt auf höherer Basis in Einklang zu bringen. ${ }^{12}$ An früherer Stelle sind wir auf diese Probleme eingegangen.

\footnotetext{
$109 \operatorname{Sinn}$, G./Sinn, H. W. (1993), S. 179.

${ }^{110}$ Möller, H. (1948), S. 58; Häuser, K. (1993), S. 4.

in $\operatorname{Sinn}$, G./Sinn, H. W. (1993), S. 23.

${ }^{112}$ Kittner, M. (1993), S. 191.
} 
Der Wissenschaftliche Beirat bei dem Bundeswirtschaftsministerium hat am 15. Juli 1991 überzeugend darauf hingewiesen, daß dieser Weg zu keiner befriedigenden Lösung führen kann. Er hat auf die hohen steuerlichen Vergünstigungen und die weiteren offenen Subventionen als wesentliche Förderungsmaßnahmen aufmerksam gemacht, die Investoren in den neuen Bundesländern gesetzlich zustehen und deren Höhe nicht mehr steigerungsfähig erscheint. Staatliche Lohnsubventionen lehnte der Beirat mit guten Gründen ab. $^{113}$

Nach den Ausführungen des Beirates kommt den steuerlichen Vergünstigungen in Form von Sonderabschreibungen, Investitionszulagen und -zuschüssen, verbilligten Krediten und Eigenkapitalhilfen die tragende Rolle bei dem Transformationsprozeß zu. ${ }^{14}$

Wie ist nun der wiederum nach dem Muster des Wirtschaftsaufschwungs nach 1949 in den alten Bundesländern erfolgende, durch nichtfiskalische Normen des Einkommensteuerrechts verborgen bleibende Einsatz hoher Subventionen zur Ingangsetzung eines sich selbst tragenden Wirtschaftsaufschwungs in đen neuen Lāndern zu beurteilen?

Tatsăchlich haben sich verschiedene große Kapitalgesellschaften - zumeist ohne nennenswerten Erfolg - durch Investitionen in den neuen Bundesländern angesiedelt. Die zum Teil erheblichen Anlaufverluste der dortigen Tochterunternehmen können mit den Gewinnen der Mutterunternehmen saldiert werden. Gleiches gilt für Personengesellschaften, die von den Sonderabschreibungsmöglichkeiten bei Investitionen in den neuen Ländern Gebrauch machen. Auf diese Weise sind die Anlaufverluste - insbesondere auch durch Rückstellungen nach dem DDR-Investitionsgesetz vom 26. Juni $1990^{115}$ - leichter zu verkraften, da sie vor- und rücktragbar mit Gewinnen saldierbar sind. Unternehmer und Privatleute aus den neuen Ländern sind jedoch zumeist vorläufig und für die nähere Zukunft ohne höhere steuerbare Einkünfte, die bei Investitionen mit Sonderabschreibungen saldiert werden können. Ihr Beitrag zum Wirtschaftsaufschwung bleibt ohne den großen Anreiz, der den Gebietsfremden Entscheidungen erleichtert. Sie sind allein auf Investitionszuschüsse und -zulagen, Eigenkapitalhilfen und verbilligte Darlehensmittel angewiesen. Hier verbirgt sich ein gesellschaftspolitisches Problem, auf das wir noch zurückkommen werden.

\footnotetext{
113 Siehe Anmerkungen 86 bis 89 .

114 Siehe Anmerkung 90.

its BStBI. 1990 I, S. 1143.
} 
In dieser Situation mag man eine wichtige Hilfe darin erblicken, zur Schaffung einer geeigneten Infrastruktur in den neuen Ländern die Erfahrungen mit dem Einsatz von Abschreibungsgesellschaften in der Bundesrepublik in den frühen 70er Jahren zu Rate zu ziehen. Wie wir noch sehen werden, vermochten diese durch Aufforderung zur Zeichnung von Beteiligungen an Verlusizuweisungsgesellschaften große Mengen von Risikokapital in Verwendungen zu lenken, die Investitionslücken zu schließen erlaubten.

Durch Gründung geschlossener Fonds zur Durchführung konkreter Projekte kōnnen Măngel der Entwicklung durch die Finanzierung von Gewerbe- und Einkaufszentren, Wohnanlagen, Betriebseinrichtungen, Stadtentwicklungen, Versorgungseinrichtungen, Kraftwerksanlagen, Kläranlagen, Trinkwasseraufbereitungsvorrichtungen, Heizkraftwerke, Bürohăuser für Behörden etc. beseitigt werden. ${ }^{116}$ Heute kommen vergleichbare Gründungen und deren Förderung einer "Strategie für den Aufschwung" entgegen, nămlich durch Verbesserungen der Infrastruktur und insbesondere der Ausstattung der Arbeitsplătze im Beitrittsgebiet zum notwendigen Anstieg der Arbeitsproduktivităt beizutragen und so die durch überhöhte Löhne entstandenen Differenzen zu lindern. Mag es auch sein, daß von einem marktwirtschaftlichen Gesichtspunkt aus erhebliche Bedenken gegen dieser Art versteckter Subventionen sprechen und daß erhebliche gesellschaftspolitische Zweifel an deren Zweckmäßigkeit unausräumbar sind: unmittelbare Eingriffe in das Regelungsgefuge des Marktes entstehen jedenfalls nicht und dieser Art Investitionstätigkeit kommt der derzeitigen Strategie zur Erhöhung der Arbeitsproduktivität als vordringliches Ziel entgegen. Die Schaffung einer entsprechenden Anreizstruktur durch geeignete Steuervergünstigungen kann zu einer wesentlichen Verkleinerung der Scherenöffnung zwischen Produktivität und Lohnhöhe beitragen.

Bekannt gewordene Alternativen scheinen mit einer marktwirtschaftlichen Ordnung jedenfalls nicht kompatibel zu sein. Sie waren bisher erfolglos.

Tatsächlich entsteht zur Zeit wieder als Folge der neuen Bestimmungen des Fördergebietsgesetzes ein reichhaltiges Angebot von Anteilen an geschlossenen Fonds, die ein abgegrenztes Investitionsprojekt in den neuen Bundesländern betreiben. Steuerberatungspraxen werden hierfür wieder zunehmend mit Prospektmaterial versehen. Die wirtschaftliche Belebung der Branche zeigt, daß genügend Phantasie auf der Angebotsseite vorhanden ist. Die Diskussion von Steuererhöhungen wird die Nachfrageseite beleben, denn der Wunsch, Steuern zu sparen, scheint tatsåchlich alle anderen Bedürfnisse zu übertreffen.

\footnotetext{
${ }^{116}$ Hierzu s. Cash Nr. 3/Mai 1995, S. 124. Viele derartige geschlossene Fonds wurden inzwischen begründet. Die Anlagen sind zum Teil bereits in Betrieb.
} 
Nun gibt es bezüglich der Bedeutung der Verlustzuweisungsgesellschaften Eriahrungsberichte, die heute von großem Wert sein können:

Die nachfolgenden Ausführungen versuchen, aus der Tătigkeit der Verlustzuweisungsgesellschaften in Berlin einige für unsere Erörterungen wichtig erscheinende Erfahrungen vereinfachend herauszustellen.

Aus mehreren Gründen empfiehlt es sich, die Vorgänge um den Wiederaufbau des zerstörten Berlins als Beispiel heranzuziehen: Einmal liegt für Berlin zu dem Problemkreis eine abgeschlossene Untersuchung über einen längeren Zeitraum vor, die die verschiedenen Aspekte der steuerlichen Förderung einer kritischen, gut dokumentierten Prüfung unterwirf. Dazu kommt, daß die Steuervergünstigungen in Berlin besonders hoch waren.

Mit dem Änderungsgesetz zur Förderung der Wirtschaft von Berlin (West) vom 25. März $1959^{17}$ wurden, nachdem bereits seit $195250 \%$ ige Sonderabschreibungen vorgesehen waren, beliebig verschiebbare erhöhte Absetzungen für Abnutzung für bestimmte abnutzbare Wirtschaftsgüter des Anlagevermögens in Höhe von $75 \%$ eingeführt. Die Änderung des Berlinhilfegesetzes vom 19. Juli $1968^{178}$ hat dann noch zusätzlich eine Abschreibungsmöglichkeit von $50 \%$ für den freifinanzierten Wohnungsbau festgesetzt. Daneben wurden hohe Investitionszulagen normiert und viele Einzelheiten, wie etwa die sehr wirksame steuerliche Behandlung von Vorschußzahlungen, großzügig geregelt. ${ }^{119}$ Die Zinsen für die stets hohen Darlehensschulden wurden dabei zumeist aus offentlichen Mitteln subventioniert und of sogar zusätzlich bankmäßig verbürgt, so daß keinerlei Risiko entstand. Daher fielen die sogenannten "Steuergewinne" im Falle der Zeichnung von Anteilen an Berliner Projekten besonders hoch aus. Die durch den "kalten Krieg" verursachten politischen Unsicherheiten, der hohe Zerstörungsgrad und die Berliner Mauer rechtfertigten dennoch die Zweckmäßigkeit der zugrundeliegenden politischen Entscheidung. Zeichnungen von Beteiligungen erfolgten wegen der beargwöhnten Unsicherheiten zu Beginn trotz der hohen in Aussicht gestellten Gewinne jedoch erst einmal nur schleppend.

Auslöser einer kritischen Erörtenung der Investitionen in Berlin betreffenden Abschreibungsgesellschaften waren die bekanntgewordenen Vorgänge um ein großes Berliner Bauvorhaben des Jahres 1964. Die in den Medien hochgespielten "Geschäfte mit Berlin", die in kurzer Frist zu erheblichen steuerfreien

\footnotetext{
117 BGBI. I 1959, S. 160.

118 BGBI. I 1968, S. 833.

119 Art. I, $\S 14$ Abs. 4 Drittes Gesetz zur Ānderung des Berlinhilfegesetzes v. 19.7.1968, in: BGB1. I, S. 833, hier S. 834 .
} 
Gewinnen bei hohen steuerbaren Einkommen der Zeichner führen konnten, haben seit Mitte der 60er Jahre ür stăndige Kritik an dem Berlinhilfegesetz bzw. dem spăteren Berlinförderungsgesetz gesorgt. ${ }^{120}$ Spektakulăre Konkursfalle Berliner Großprojekte, die von Verlustzuweisungsgesellschaften betreut worden waren, verstärkten die Entstehung einer Art "Makeltheorie" der gesamten Branche. Diese geriet schon wegen des außergewöhnlich großen Umfangs der Vorhaben schnell in den Medien in den Ruf, am Rande des gesetzlich Erlaubłen zu operieren. ${ }^{121}$

Höchste politische Gremien mit Kompetenz zur Gesetzesinitiative ebenso, wie Mitglieder von Strafverfolgungsbehörden und selbst sachkundige Journalisten der Fachpresse prägten ein abwertendes Bild und sorgten fir Mißtrauen. Trotz des Eindrucks, der gelegentlich entstehen mußte, waren diese Beteiligungsgesellschaften aber in keiner Weise privilegiert. Sie utbten Tätigkeiten aus, die jedem Bürger offenstanden und die auch in Anspruch genommen wurden. Die meisten Zeichner von Beteiligungsrechten können sich aber nur in verhältnismäßig kleinen Sparbeiträgen binden. Obendrein wollen sie ihr Risiko streuen. Auch die aufgetretenen Behauptungen, Abschreibungsgesellschaften würden Kapital fehlleiten, sie stellten auf die Erzielung von Verlusten und nicht Gewinne ab, sie dienten der Umgehung des Steuerrechts, sie liefen marktwirtschaftlichen Prinzipien entgegen und ständen der Wirtschaftskriminalităt nahe, können - wie wir noch am Beispiel Berlins sehen werden - in dieser Allgemeinheit nicht behauptet werden. ${ }^{122}$

Im übrigen mußten und müssen Abschreibungsgesellschaften zum Erhalt der für ihre Investitionen erforderlichen hohen Fremdmittel den beleihenden Banken nach dem Kreditwesengesetz die vorgeschriebenen und überprüfbaren Unterlagen zur Ermittlung der Rentabilität vorlegen. Eine nicht überzeugende Rechnungslegung wird eine Bank wegen des drohenden Verlustes und der Regreßmöglichkeiten nicht honorieren. ${ }^{123}$ Die hochgespielten Konkursfalle in Berlin betrafen zumeist mit öffentlich-rechtlichen Bürgschafteñ versehene

${ }^{120}$ Bölke, P. (1973), S. 153. Die Darstellung in diesem Titel richtete sich gegen die unerwünschten Auswirkungen der Steuetpräferenzen, die darin gesehen wurden, daß die "Vermögensbildung der Vermögenden" gefördert wird (S. 169). Der Titel, der groBe Verbreitung fand, vernachlässigt die Erörterung der Auswirkungen auf Wohnungsversorgung, die Stärkung der gewerblichen Wirtschaft und die Infrastruktur Berlins, die der Allgemeinheit diente und zu Recht Prăferenz ethielt.

${ }^{121}$ Die Tátigkeit der Abschreibungsgesellschaften effolgte in Öbereinstimmung mit den steuergesetzlichen Vorschriften, s. Bolke, P. (1973), S. 30, S. 171; s. a. Costede, J. (1978), S. 23 u. a.

${ }^{122}$ Hierzu s. Hecker, C. (1982), S. 223 - S. 234.

${ }^{123} \S 18 \mathrm{KWG}$. Banken setzen ihre eigene Existenz aufs Spiel, wenn sie die Unterlagen für eine Kreditgewährung nicht ordnungsmäBig prüfen. Sobald privilegierte Zinskonditionen in Frage stehen, hat, der Staat über die Kreditanstalt fur Wiederaufbau und die Deutsche Ausgleichsbank weitere Prufungsmöglichkeiten zur Einhaltung marktgerechter Konditionen. 
Objekte, die aus politischen Gründen protegiert worden waren. Zumeist handelte es sich um die Folgen verfehlter gesetzgeberischer Maßnahmen. ${ }^{124}$

Die Konkursquote der Abschreibungsgesellschaften in Berlin in den Jahren 1967 bis 1976 lag mit 15,3\% zwar höher als diejenige der Nicht-Abschreibungsgesellschaften. Sie zeigte sich jedoch stark konjunkturabhängig und stand offenbar zum Teil mit den zu hohen Begünstigungen von Investitionen nach der Anderung des Berlinhilfegesetzes vom 19. Juli 1968 in direktem Zusammenhang. Einzelheiten dazu können hier nicht dargelegt werden. ${ }^{125}$

Jedenfalls entstand um 1970 ein extrem ungutes steuerpolitisches Klima bezüglich der Abschreibungsgesellschaften. "Exekutive und Legislative wollten plötzlich entdeckt haben, daß die steuerlichen Vergünstigungen in zunehmendem Maße von Großverdienern in Anspruch genommen würden. Obwohl dies ganz natürlich war, kam man plötzlich auf die Idee, die steuersparenden Beteiligungen seien mit Mitteln angeschafft worden, die diese Großverdiener eigentlich dem Staat und der Allgemeinheit schuldeten". Das Bundestinanzministerium suchte etwa. seit 1971 Verlustzuweisungsgesellschaften zunehmend zu behindern und fertigte schlieillich sogar fur nachgeordnete Behorden eine "Zusammenstellung über Maßnahmen gegen den Mißbrauch von Steuervorteilen" an. Fast zur selben Zeit hatte seit 1972 aber das Bundeswirtschaftsministerium den zur Zeichnung, von Anteilen an Abschreibungsgesellschaften auffordernden Slogan "mit Steuern Vermögen schaffen" herausgegeben. ${ }^{126}$ Die Investitionstätigkeit in Berlin wollte man regierungsseitig wegen der politischen Bedrohung der Stadt auf keinen Fall verringert sehen. Zu den Zeichnern zählten insbesondere alle in eine höhere Einkommensteuerprogression aufrückende Steuerpflichtige ohne Investitionsmöglichkeiten in eigenen Betrieben, wie z. B. Selbständige, hoch verdienende Angestellte, Facharbeiter und nicht zuletzt Beamte, insbesondere bei zwei verdienenden beamteten Ehegatten, die ihre liquiden Mittel ahne Rücklagen für Notzeiten insgesamt fest anlegen können.

Zwar wollte man in den 70er Jahiren von Seiten der Verwaltung die sieuer. begünstigten Gesetzesvorschriften, die den erîlgreich tătigen Verlustzuweisungsgesellschaften gerade in Berlin kolossalen Auftrieb gewährten, schon deshalb nicht abschaffen, weil sic bis 1981 das Rückgrat der Risikokapitalbildung überhaupt darstellten. In einer Reihe von Erlassen und Anweisungen, die als Verwaltungsvorschriften zwar nur nachgeordnete Behörden verpflichten

\footnotetext{
124 Hecker, C. (1982), S. 203. Hecker zeigt Beispiele für unzweckmäBige Regelungent.

125 Hecker, C. (1982), S, 181, S. 229.

126 Kreile, R. (1976), S. 283. Kreile war Vorsitzender des Finanzausschusses des Deutschen Bundestages.
} 
konnten, da es sich nicht um konkret anfechtbare Verwaltungsakte, wie z. B. Steuerbescheide, handelte, drückte der Bundesfinanzminister nach einiger Zeit letztlich aber seinen Gestaltungswillen durch. Sogar der Vorwurf, durch Sonderrechtsbildungen gegen bilanzsteuerrechtliche Gesichtspunkte zu verstoßen, konnte die Finanzverwaltung nicht von ihrem Ziel abhalten, unerwünschte Branchen und als mißbräuchlich beurteilte Konstruktionen für die Einfuhrung auf dem Nebenkapitalmarkt zu problematisieren und letztlich bis zur Einstellung der Geschäftstätigkeit zu behindern. Eine Förderung der Investitionen in Berlin wurde jedoch mit großer Vorsicht von möglichen Behinderungen ausgespart. Selbst die steuerliche Beschränkung der Bildung eines negativen Kapitalkontos durch eine neue Gesetzesvorschriff wurde hier - anders, als außerhalb Berlins - vermieden. ${ }^{127}$

Die nervöse Aufmerksamkeit und argwöhnische Beobachtung der Entwicklung der Abschreibungsgesellschaften hatte gewiß auch positive Effekte: Die Trägergesellschaften entschlossen sich, zur Vertrauensbildung selbstbeschränkenden Richtlinien bei der A.nfertigung von Prospekten zur Zeichnung von Anteilen im Interesse des Publikums zu folgen. Der Prototyp der PublikumsKG als Abschreibungsgesellschaft war die GmbH \& Co. KG. Wegen der eingeschränkten Haftung des Komplementärs wurde diese Konstruktion vielfach als mißbräuchliche Rechtsgestaltung beurteilt, wobei die große Zahl der Kommanditisten diesen Standpunkt noch verstärkte.

Das Institut der Wirtschaftsprüfer in Deutschland e. V. entwickelte später als Folge der in Gang gesetzten kritischen Erörterung von problematischen Beteiligungsangeboten "Grundsätze ordnungsmäßiger Durchführung von Prospektprüfungen", denen sich seither führende Initiatoren von geschlossenen steuerbegünstigten Fondsgesellschaften bezüglich der wichtigsten Prüfungskriterien vor Veröffentlichung der Prospekte freiwillig unterwerfen. ${ }^{128}$

Vorerst hatte die Bundesregierung keinen Handlungsbedarf zum Schutz der Anleger vor Übervorteilung gesehen, bis das Bundesjustizministerium im Jahr 1974 unter dem Druck der öffentlichen Meinung eine Gutachterkommission zur Bekämpfung der Wirtschaftskriminalität einsetzte und festlegte, daß die Problematik der Abschreibungsgesellschaften unter dem einheitlichen Gesichtspunkt des Publikumsschutzes bei Vermögensanlagen beurteilt werden solle.

\footnotetext{
${ }^{127}$ Fundstellen bei Hecker. C. (1982), S. 208 - S. 211.

${ }^{128}$ Hierzu s. Kapitel K, Anmerkung 52. Die weite Auslegung, die $\S 45$ BörsGi in der Rechtsprechung fand, der neu in das Strafrecht eingefuhrte Tatbestand des Kapitalanlagebetruges $(\S 264$ a StGB) und nicht zuletż die Ergânzung der Gewerbeordnung durch ẹine Makler- und BauträgerVO haben tiefgreifende Wirkungen gezeigt.
} 
Wegen der Schwierigkeit einer Typisienung der Abschreibungsgesellschaften, die sich durch kaum mögliche Vergleichbarkeit der Beteiligungsangebote auszeichnen, neigte die Kommission im Ergebnis zu einer Kapitalmarktlösung, einer Schaffung von Markttransparenz durch Normierung eines umfassenden Prospektzwanges. ${ }^{129}$ Eine gesellschaftsrechtliche Lösung wurde verworfen. Gerichte haben inzwischen die leitenden Gedanken der Vorschriften des Börsengesetzes über Börsenprospekte bei Zulassung von Wertpapieren zum amtlichen Handel allgemein für die Beurteilung der Haftung der Trảgergesellschaften bei Beteiligungsangeboten verwendet. Die Anbieter unterwerfen sich mittlerweile zumeist freiwillig den Anforderungen an die Prospektwahrheit, deren Auslegung von den strengen amerikanischen Vorschriften des "Securities Act" von 1933 und des "Securities Exchange Act" von 1934 beeinflußt wurde. ${ }^{130} \mathrm{Zu}$ einer gesetzlichen Regelung ist es bisher nicht gekommen. Nur das Strafgesetzbuch wurde 1986 zur Bekämpfung der Wirtschaftskriminalität durch Einfügung einer Vorschrift über "Kapitalanlagebetrug" erweitert, nachdem bereits früher die Gewerbeordnung durch die "Makler- und Bauträgerverordnung" ergănzt und das Recht der Gesellschaft mit beschränkter Haftung reformiert worden waren.

Wenn nun nachfolgend Zahlenangaben über die Bedeutung der Verlustzuweisungsgesellschaften für den Aufbau Berlins nach 1962 vorgetragen werden sollen, so muß auf die Schwierigkeit ihrer Erfassung aufmerksam gemacht werden. Es gibt kein statistisches Grundlagenmaterial über Abschreibungsgesellschaften. Die Zahlenangaben wurden von dem Autor einer 1982 veröffentlichten Untersuchung, die alle öffentlichen amtlichen Register auswertete und darüber hinaus Angaben verschiedener Berliner Behörden und Spezialbanken zusammentrug, übernommen. Außerdem wurden einschlägige Prospektangebote, Branchenzeitschriften sowie Brancheninformationen und Angebotskataloge für Steuerberater ausgewertet. ${ }^{131}$

Das Ergebnis waren feststellbare Minimalwerte, die teilweise bei Beriicksichtigung der wirtschaftichen Zusammenhänge auf die vermuteten tatsächlichen Werte hochgerechnet werden mußten.

Den nachstehenden Ausführungen wird die im Jahr 1982 abgeschlossene Untersuchung der Berliner Entwicklung von 1962 bis 1974 zugrunde gelegt.

129 FAZ v, 17.9.1976, S 12. Auf dem 51. Deutschen Juristentag setzte sich die Forderung nach einer "Kapitalmarktlōsung" durch.

${ }^{130}$ Hierzu s.: Saage, G., DB v. 10.7.1973, S. 485; Luckau, E., DB v. 7.8.1970, S. 1449; Loss, L. (1967), S. 197.

${ }^{131}$ Hecker, C. (1982), S. 6. 
Danach ergibt sich, daß in Berliner Abschreibungsgesellschaften insgesamt 43.850 Kommanditisten von Abschreibungsgesellschaften eingeiragen wurden. Die tatsächliche Zahl wird wesentlich höher gelegen haben, da in vielen Fällen Treuhandkommanditisten verzeichnet wurden. ${ }^{132}$ Das Gesamtinvestitionsvolumen der Verlustzuweisungsgesellschaften in Berlin mag maximal bis zum Jahr 1974 bei ca. 75 Mrd. DM gelegen haben. ${ }^{133}$ Das entspricht fast dem Summenwert der "reinen Ist-Ausgaben" der ordentlichen Haushalte von Berlin in derselben Zeitspanne, die sich zu insgesamt 79,745 Mrd. DM aufaddieren. ${ }^{134}$ Die geschätzten steuerbegünstigten Gesamteinlagen der Kommanditisten für die allein in Berlin registrierten Gesellschaften betrugen für die Zeit zwischen 1962 und 1974 nach Erfahrungswerten etwa 7,5 Mrd. DM. Das sind $29,7 \%$ aller Zufuhrungen von nominellem Aktienkapital an alle deutschen Aktiengesellschaften in derselben Zeitspanne. ${ }^{135}$ Dabei bedarí der Betrag von 7,5 Mrd. DM der Hochrechnung mit unbekanntem Faktor. Auch anderen Ortes registrierte Verlustzuweisungsgesellschaften investierten nămlich in Berlin und ebenso die vielen nicht registrierungspflichtigen Gesellschaften bürgerlichen Rechts. Den Zahlenangaben konnten lediglich die im Handelsregister als $\mathrm{GmbH} \& \mathrm{Co}$. KG oder als $\mathrm{AG} \& \mathrm{Co}$. KG eingetragenen Rechtsgebilde zugrunde gelegt werden. Nur diese waren jeweils als Abschreibungsgesellschaften aus amtlichen Unterlagen erkennbar. Tatsächlich war der Kreis dieser Verlustzuweisungsgesellschaften jedoch, wie die steuerberatenden Berufsträger aus ihrer Praxis wissen, erheblich umfangreicher.

Im übrigen waren die Abschreibungsgesellschaften in dieser Zeitspanne im Durchschnitt bei steigender Tendenz mit $1,6 \%$ an der Bruttowertschöpfung in Berlin (West) beteiligt. ${ }^{136}$ Sie stellten darüber hinaus in der Phase nach 1971 trotz verwirrender Zahlenangaben erkennbar "einen stabilisierenden Faktor" am West-Berliner Arbeitsmarkt dar. "Ohne die Abschreibungsgesellschaften", so hieß das Ergebnis Heckers, "wären die Arbeitslosenzahlen in Berlin in den Jahren 1974 bis 1978 um $81 \%, 35 \%$ und $21 \%$ höher gewesen". ${ }^{137} 2,4 \%$ aller Wohneinheiten, die im sozialen Wohnungsbau Berlins errichtet wurden, bis zu $80 \%$ der im steuerbegünstigten Wohnungsbau (im Mittel 33,5\%) hergestellten Wohneinheiten der Jahre 1962 bis 1978 und 22\% der in den Jahren 1960 bis

\footnotetext{
${ }^{132}$ Hecker, C. (1982), Anhang, S. 13 - S. 78.

133 Hecker. C. (1982), S. 76

${ }^{134}$ Hierzu s. Anlage 8; s. a. Hecker, C. (1982), S. 72, S. 79.

${ }^{135}$ Hecker, C. (1982), S. 76.

${ }^{136}$ Hecker, C. (1982), S. 88 - S. 126, hier S. 125.

137 Hecker, C. (1982), S. 142.
} 
1970 errichteten freifinanzierten Wohnungseinheiten wurden von Abschreibungsgesellschaften gebaut. ${ }^{138}$

In diesen Zahlen sind jeweils nur die für Berlin auf Grundlage verschiedener amtlicher Quellen ermittelten Angaben dargelegt oder mit Erfahrungsfaktoren hochgerechnet worden. Außerdem wurden nur die Jahre 1964 bis 1974 in die Untersuchung eingebunden. Es muß hinzugefügt werden, daß gerade in der Zeit von 1975 bis 1981 Investitionen in Berlin durch Abschreibungsgesellschaften besonders erfolgreich waren, wie sich in der Angebotsfülle zeigte.

Die durchgeführten Bauvorhaben im Rahmen des Wiederaufbaus von Berlin (West) zeigen eindrucksvoll, daß von Kapitalfehlleitungen als Regelfall jedenfalls nicht gesprochen werden kann. Da die zum Teil sehr hohen, vom Berlinhilfegesetz ab 1959 in seinen verschiedenen Fassungen ermöglichten Investitionen in den unterschiedlichen Branchen nach Abschluß der Anlaufphase der Projekte von einer Erzielung von Überschüssen abgelöst werden und die Erhaltung der Liquidität planerisch stets gewährleistet sein mußte ${ }^{139}$ und da nach einer vereinbarten Schonzeit die von Geschäftsbanken bereitgestellten beträchtlichen Fremdmittel systematisch zu tilgen waren, hätten Fehlplanungen inzwischen längst zu einer Kette von Konkursverfahren führen müssen. Davon wurde jedenfalls in Berlin bisher nichts bekannt. Die These, daß Abschreibungsgesellschaften ihre Tătigkeit vornehmlich auf die Erzielung von Verlusten abstellen und somit in der Regel den Grundsätzen der Marktwirtschaft widersprechen, muß etwa 30 Jahre nach deren erstmaligem Einsatz zu Investitionszwecken in dem fast vollständig kriegszerstörten, von einer Mauer eingeschlossenen West-Berlin als falsch zurückgewiesen werden.

Nun hat sich das Interesse an Abschreibungsgesellschaften seit dem neuen Fördergebietsgesetz vom 24. Juni 1991 zur Einbindung der neuen Bundesländer wieder stark belebt. Die geplanten und durch Prospekte zur Zeichnung vorliegenden Investitionsvorhaben, die zunächst Wohnanlagen und Gewerbezentren in den neuen Bundesländern und im Großraum Berlin betreffen, haben sich vervielfacht.

Waren die Umsätze der 98 führenden großen Trägergesellschaften im Jahr 1985 auf 1.9 Mrd. DM zusammengeschmolzen, so teilten sie für das Jahr 1992 ein Investitionsvolumen von $25,2 \mathrm{Mrd}$. DM mit ${ }^{140}$ Wir stehen mithin nach Erlaß des neuen Fördergebietsgesetzes vor einer Wiederbelebung der Füh-

138 Hecker, C. (1982), 3. 167.

119 Hecker, C. (1982), S. 223, S. 228. Von Konkursverfahren unter Abschreibungsgesellschaften in Berlin ist in den beruflichen Mitteilungen der Steuerberater nichts Ungewōhnliches berichtet worden.

${ }^{140}$ Cash, Januar 1993, S. 30. Die Zahlenangaben schwanken stark, da der größere Teil der Initiatoren keine Angaben macht und Hochrechnungen erforderlich sind. 
rungsrolle dieser Spar- und Finanzierungsform. Wenn nicht alles tăuscht, kann man davon ausgehen, daß sie genau so effizient verlaufen wird, wie dies für Berlin in den Jahren seit 1964 nachvollziehbar ist. Da die Abschreibungssätze durch das Fördergebietsgesetz einheitlich auf $50 \%$ festgesetzt wurden undi da die Investitionszulage in dem neuen Investitionszulagengeseiz vom 28. August 1991 auf $12 \%$ bzw. $8 \%$ begrenzt wurde, können Fehlleistungen der Vergünstigungen des Gesetzes, wie sie für einige fragwürdige Vorgänge in Berlin ursăchlich waren, wohl vermieden werden. Nach den beim Aufbau Berlins gemachten Erfahrungen wird man wohl davon ausgehen können, daß die Steuervergünstigungen ausreichend dotiert wurden und sich die Wirkungen vieler mittlerer, aber wichtiger Investitionsleistungen nun zunehmend einstellen werden.

Für die geplanten, zur Verbesserung der Infrastruktur in den neuen Bundeslăndern führenden Projekte, deren haftendes Kapital infolge der enwarteten Steuererspamis von einer Vielzahl in hoher Progression stehender Zeichner von Kommanditanteilen aufgebracht wird, sind die bisher angeführten Hindernisse eines zügigen Aufschwungs belanglos. Die ungesichenen Eigentumsverhăltnisse und das überhöhte Lohnniveau tangieren im wesentlichen nur Unternehmer, die dortige Betriebe übernehmen und weiterführen bzw. neue Betriebe gründen und einrichten wollen.

Auch die Frage der Prospektgestaltung scheint inzwischen durch die freiwillige Prüfungskontrolle und durch eine ausgiebige Rechtsprechung sinnvoll geregelt.

Des weiteren ist darauf hinzuweisen, daß ein Großteil der umfangreichen Kredite aus staatlichen Mitteln der Kreditanstalt für Wiederaufbau bzw. der Deutschen Ausgleichsbank stammen. Hier sind empfindliche, mißbräuchlichen Gestaltungen vorbeugende bankmäßige Lenkungsmaßnahmen möglich.

Der Einsatz von Steuervergünstigungen des Einkommensteuerrechts kann als technisch außerordentlich geeignetes und formell marktkonformes Instrument zur Förderung der wirtschaftlichen Eingliederung der neuen Länder bezeichnet werden.

$\mathrm{Daß}$ dieser Art steuerpolitische Maßnahmen, die hohe wirtschaftliche Anreize an konkrete Sachverhalte nach räumlichen und bereichsbezogenen Kriterien binden, herkömmlichen Prinzipien der Besteuerung entgegenstehen, ist unbestritten.

Wer die tragenden Grundgedanken der "sozialen Marktwirtschaft" letztlich auf gesellschaftichen Fortschritt ausgerichtet sicht. wird wohl nie ohne cine realitätsbezogene, jeweils politisch zu verantwortende Güterabwägung aus- 
kommen. Diese nötigt zu Kompromißlösungen, die aber als Ausnahmen zu gelten haben. ${ }^{141}$

Eine nicht nur formale, sondern auch inhaltliche Beschränkung der Staatstătigkeit auf die Garantie der Funktionsfähigkeit des Wettbewerbs zum Schutz vor der von Böhm befürchteten Selbstzerstörung durch Machtverfilzung reicht als Direktive nicht mehr aus.

Die Einkommensbesteuerung erhielt daher inzwischen in dem Regelungsgefüge eine wichtige Funktion, mag diese auch zeitlich und sonstwie im Einzelfall begrenzt werden müssen.

Wiederum zeigt sich, was G. Wöhe zur Zeit des intensiven Wiederaufbaues von Berlin 1975 vor Steuerberatern - um Verständnis für die entstandene Kompliziertheit des Steuerrechts werbend - festhielt: "Die Steuerpolitik ist heute ein notwendiger Bestandteil des wirtschaftspolitischen Instrumentariums. Sie wird es aller Voraussicht nach auch in Zukunft bleiben müssen. Die steuerpolitischen Instrumente sollten jedoch nur in sorgfältiger Abstimmung mit anderen wirtschaftspolitischen Mitteln und unter Beachtung der allgemein anerkannten Grundsätze der Besteuerung angewendet werden". ${ }^{142}$

Tatsăchlich gelang es bisher mit Hilfe der Steuervergünstigungen des Einkommensteuerrechts, die Folgen der entstandenen Unelastizität der MarktgröBen, die zu Fehlsteuerung und sogar zu Steuerungsausfällen der Produktionsfaktoren führen, durch geeignete Anreizstrukturen zu überspielen, ohne die Funktionen der Marktwirtschaft außer Kraft zu setzen.

Der Preis für diesen Mechanismus muß allerdings durch den sozialen Ausgleich entrichtet werden, den die "soziale Marktwirtschaft" bestimmungsgemäß verspricht.

141 Schlecht, O. (1995), S. 11.

142 Wohe, G. (1975), S 195. 


\section{K. Steuervergünstigungen als Subventionen - die Finanzierung von Verlustzuweisungsgesellschaften aus Steuerersparnissen zum Zweck der Investition im Fördergebiet und deren volkswirtschaftliche Bedeutung - der Fiskus wurde wichtigstes Finanzierungsinstitut}

Subventionen gehören zum "unverzichtbaren Instrumentarium einer interventionistischen Wirtschaftspolitik". Nach ublicher Definition sind sie "Geldbeträge, die der Staat oder ein anderes offentliches Organ Unternehmungen (offentlichen oder privaten) oder Unternehmensgruppen ohne marktwirtschaftliches Entgelt zuleitet." Der Staat sucht durch sie "die Stellung von Einzelwirtschaften in der Volkswirtschaft" so zu verändern, wie es der allgemeinen wirtschaftlichen Zielrichtung entspricht. ${ }^{\prime}$

Grundsätzlich ist die Wirtschafts- und Finanzpolitik der Bundesrepublik Deutschland an dem Leitbild der "sozialen Marktwirtschaft" ausgerichtet. Subventionen sollen daher das Ergebnis des nationalen und internationalen Wettbewerbs dem Grundsatz nach nicht verzerren, da der Markt nach geltender Vorstellung die Lenkungsfunktionen wirtschaftlicher Vorgånge besser erfüllen kann.

Dem Staat darf hiernach nur in besonderen Ausnahmesituationen gestattet sein, durch Subventionen die Scharfrichtertätigkeit des Wettbewerbs außer Kraft zu setzen. Hilfen, die nur darauf angelegt sind, in bestimmten konkreten Fällen und dabei zeitlich begrenzt einen notwendigen Strukturwandel zu fördern oder zu erleichtern, "regionale Disparitäten" abzubauen und die damit verbundenen sozialen Härten auszugleichen, bleiben als Erfordernis der sozialen Einbindung stets Ausnahmen von dem tragenden Prinzip der Marktwirtschaft. $^{2}$

Was dem Grundsatz des marktmäßigen Ausgleichs von Leistung und entgeltender Gegenleistung widerspricht, bedarf als Ausnahme der besonderen

'Wessels, T. (1960), Subventionen ..., Sp. 5321; s. a. Hansmeyer, K. H. (1963), Subventionen ..., S. 323; Ziegler, G. (1955), Diss. Köln; s. a. von Arnim, H. (1986), Subventionen. Von der Schwierigkeit der Subventionskontrolle, in: FA, 44. Bid., S. 81.

2 Stichwort "Subventionen", in: Enzylklopådisches Lexikon für das Geld-, Banken- und Börsenwesen, 3. Aufl., Stuttgart 1968, Bd. 2, S. i577; Wessels, T. (1960), Sp. 5321. 
Rechtfertigung. Müller-Armack zeigte überzeugend, daß die durchgängige Beachtung dieses Grundsatzes gegenüber direkten Eingriffen in das Marktgefüge letztlich zu sozialeren Ergebnissen zu führen vermag. ${ }^{3}$

Gelegentlich erscheint der Einsatz von Subventionen für eine "Zielrealisierung gegen den Wettbewerbsmechanismus" aber unvermeidbar, um als vorrangig empfundene soziale oder allgemeine staatspolitische Zielvorstellungen zu realisieren. ${ }^{4}$

Die Regierung der Bundesrepublik Deutschland ist dann nach $\S 12$ des Stabilităts- und Wachstumsgesetzes von 1967 verpflichtet, über "Bundesmittel, die für bestimmte Zwecke an Stellen außerhalb der Bundesverwaltung gegeben werden," ... "alle zwei Jahre eine zahlenmäßige Übersicht vorzulegen". Darin sind "Finanzhilfen und eine Übersicht über die Steuervergünstigungen", in die die Subventionen amtlich untergliedert werden, getrennt einzeln aufzuführen. Die Positionen dieser Aufstellung sind jeweils in "Erhaltungs-, Anpassungsund Produktivitătshilfen" zu untergliedern und mit ihrer Begründung, ihrer erstmaligen Einführung und ihrer Befristung kenntlich zu machen. ${ }^{5}$ Der zu-

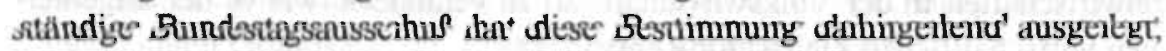
daß auf Subventionen aller Art (nicht nur solche an Wirtschaftsunternehmen, sondern auch an Teilgruppen von Bürgern) abzustellen sei, soweit diese nicht bereits im jährlichen Sozialbericht der Bundesregierung aufgenommen sind. ${ }^{6}$ Die amtlichen Veröffentlichungen sollen dem Zweck dienen, die Be-

${ }^{3}$ Maller-Armack, A (1948), S. 109 u. a.. Entscheidend bleibt, da@ der Wettbewerb als stimulierende Kraft des "marktwirtschaftlichen Wertrechnungssystems" erhalten bleibt; s. ders. (19.48), S. 70, S. 96 u. a.; s. a. ders. (1949), S. 63.

"Stichwort "Subventionen", in: Enzyklopădisches Lexikon für das Geld-, Banken- und Börsenwesen, 3. Aufl., Stuttgart 1968, S. 1577. Nach Hansmeyer gilt: "... in einer konfliktempfindlichen Wohlstandsgesellschaft kōnnen Subventionen als das Ôl angesehen werden, das den empfindlichen Motor "Marktwirtschaft" kurzfristig am Heißlaufen hindert", Dies gilt für Hansmeyer, obgleich sie in dem Konzept der Marktwirtschaft als unakzeptabel beurteilt werden, s. Hansmeyer, K-H. (1963), S. 19, S. 27 u a.; Neumark, F. (1933), Subventionen, in: Hwb des Bankwesens, I. Aufl., S. 548; Meinhold, W. (1954), Subventionen, in: HdSW, V. Bd., S. 236; Strickroth, G. (1981), Subventionen, in: HwStR, Bd. 2, S. 1389 .

${ }^{3}$ S. $\$ 12$ Abs. 2 StWG v. 8.6.1967, in: BGBI. I S. 583, hier S. 585, Zur näheren Auslegung des Begriffs "Finanzhilfen" s. Schriftlicher Bericht des Ausschusses für Wirtschafts- und Mittelstandsfragen (15. Ausschuß) aber den von der Bundesregierung eingebrachten Entwurf eines Gesetzes zur Förderung der wirtschaftlichen Stabilitat, in: Deutscher Bundestag. Drs. V/890, V/1678, dort Bericht des Abg. Elbrächter, S. 5/6 zu $\S 2$.

' Bericht des Bundestagsausschusses für Wirtschafts- und Mittelstandsfragen v. 2.5.1967 zu Bundestagsdrucksache V/1678; s. hierzu: Bericht der Bundesregierung aber die Entwicklung der Finanzhilfen des Bundes und der Steuervergunstigungen für die Jahre 1973 bis 1976 gemäB § 12 des StWG v. 8.6.1967 (fünfter Subventionsbericht) v. 22.10.1975, in: Deutscher Bundestag. Drs. 7/4203, S. 5; s. desgleichen 13. Subventionsbericht v. 11.11.1991, S. 8. 
herrschbarkeit von Subventionen, die allzu leicht eine Eigendynamik mit unerwünschten Folgewirkungen entwickeln, zu gewăhrleisten.

Entsprechend werden die einzelnen Positionen der Finanzhilfe und der Steuervergünstigungen im zweijăhrigen Rhythmus im Subventionsbericht mit Einzelheiten über Zielsetzung, Einfuhrung, Befristung und erlăuternder Stellungnahme der Verwaltung aufgelistet.

Die in den Bericht eingestellten Steuerausfalle für die Inanspruchnahme einzelner Steuervergünstigungen vermögen jedoch nur ein unvollkommenes und teilweise unzutreffendes Bild von der effektiven Belastung des Haushalts sowie der Zweckmäßigkeit und Bedeutung der Maßnahmen zu vermitteln. Taisăchlich wird nämlich, wie wir noch sehen werden, eine Veränderung des Subventionscharakters verschiedener Steuervergünstigungen zur Belohnung an Kapitalgeber für Neugründungen, insbesondere von Verlustzuweisungsgesellschaften zur Ingangsetzung erwünschter Investitionen, erkennbar. Die Vorgänge ähneln dann den Geschäften, die nach unserem Wirtschaftsaufbau den Banken vorbehalten sind.

Bereits unmittelbar nach Gründung der Bundesrepublik Deutschland zeigte sich die infolge einer von der Besatzungsmacht verordneten hohen Progression des Einkommensteuertarifs außerordentliche Bedeutung des Wunsches, Steuern zu sparen für die Finanzierung der zum Wiederaufbau erforderlichen Investitionsprojekte.

Der gesteigerte Anreiz, den Steuerzugriff zu verringem, ließ sich, wie frühzeitig erkannt wurde, für die Förderung des Wiederaufbaus in Dienst stellen. Steuervergünstigungen eigneten sich hervorragend als Ansporn für Finanzicrungszwecke und damit zur Auslösung eines sich selbst tragenden Wirtschaftsaufschwungs. Hinzu kam der Umstand, daß sie nicht zu inneren Widersprüchen in der Systematik des geltenden Einkommensteuerrechts führten und als marktkonformes Hilfsmittel mit der Wirtschaftsordnung vereinbar waren. Zur Darstellung der eigentümlichen Funktionen, die Steuervergünstigungen auszuüben vermögen, kann als Beispiel die Ingangsetzung des Wiederaufbaues der im Krieg vernichteten, bzw. nach 1945 zu Reparationszwekken ausgelieferten deutschen Handelsflotte dienen:

Nach Gründung der Bundesrepublik erhielt der für den lebensnotwendigen Außenhandel erforderliche Aufbau einer leistungsfähigen Handelsflotte höch-

Hansmeyer, K.-H. (1963). Subventionen, S. 27. Fûr Hansmeyer ist die Ôffentlichkeit das wirksamste Mittel zur Sicherstellung der Beherrschbarkeit von Subventionen gegenüber der Neigung zur Eigendynamik. In dem ersten Subventionsbericht v. 20.9.1966 sprach die Bundesregierung noch von "sichtbaren und unsichtbaren Finanzhilfen" bzw. "unsichtbaren Begünstigungen im Rahmen des Steuerrechts", s. Deutscher Bundestag, V. Wahlperiode, Drs. V/931, S. 1, S. 18. 
ste Bedeutung. Die vorhandenen Reedereien, die Krieg und Währungsreform überstanden hatten, verfügten nicht mehr über nennenswerte Eigenmittel. Forderungen an das Deutsche Reich, die sich aus Leistungen im Krieg angesammelt hatten, durften nach Anordnungen der Besatzungsmacht, die die Regierungsgewalt ausübte, grundsätzlich nicht in Bilanzen eingestellt werden. ${ }^{8}$ Der größte Posten der Aktivseite der Eröffnungsbilanzen nach DMBG, der oftmals bis zu $90 \%$ der Bilanzsumme der Reedereien ausmachte (Hapag und Lloyd $\mathrm{ca} .82 \%$ ) war daher ein sogenannies "Kapitalentwertungskonto", das nach $\S \S 36$ und 37 DMBG eingestellt werden durfte, um ein Konkursverfahren vermeidbar zu machen. ${ }^{9}$ Der eigentliche Wert der Unternehmen bestand im Grunde nur noch in einem inneren Firmenwert, der aber als solcher, da originåren Ursprungs, nicht aktivierbar war. Der Finanzierung des Wiederaufbaus der Flotten durch Inanspruchnahme des Kapitalmarktes stand ohnehin dessen lang anhaltende Funktionsuntüchtigkeit entgegen. Überhöhte Steuertarife wirkten sich zusătzlich hemmend aus. Der höchste Progressionssatz der Einkommensteuer lag bis Ende 1954 bei $95 \% .^{10}$ Der Tarifsatz der Körperschaftsteuer lag durchgängig noch vorerst bei $60 \%{ }^{11}$ Dazu kan die Gewerbesteuer mit weiteren etwa $10 \%$ und gegebenenfalls waren noch die Kirchensteuern zu berücksichtigen. Eine Finanzierung des Neubaus von Schiffstonnage durch Selbstfinanzierung kam mangels fehlender Umsätze aus vorhandener funktionsfähiger Schiffahrt nicht infrage.

Das "Gesetz über Darlehen zum Bau und Erwerb von Handelsschiffen" vom 27. September 1950, das eigenkapitalersetzende Mittel zu günstigen, eventuell aussetzbaren Zinskonditionen in Höhe von $\mathbf{4 0} \%$ der Herstellungs- oder Anschaffungskosten eines Schiffes zusagte, brachte zwar Erleichterungen, konnte aber keine schnelle Besserung der Verhältnisse herbeiführen. ${ }^{12}$

Das war jedoch das åußerste, was offentlich-rechtliche Haushalte hergeben konnten. Ersatz der fehlenden eigenen Mittel durch Entschädigungen wie nach dem ersten Weltkrieg war angesichts des totalen Zusammenbruchs nicht zu verwirklichen.

s S. $\$ 21$ Gesetz aber die. Eröffnungsbilanz in Deutscher Mark und die Kapitalfestsetzung y. 21.8. 1949, in: Gesetzbl. der Verwaltung des Vereinigten Wirtschaftsgebietes v. 30.8.1949, S. 279, hier S. 282 .

Rogowsky, J. (1954), S. 25, S. 26.

10 EStG 1950 v. 29.4 .1950 , in: BStBI. 1, S. 95, hier S. 169; EStG v. 15.9.1953, in: BGBI. I, S. 834. AB 1.1.1955 betrug der hōchste Tarifsatz dann 55\%, s. EStG v. 17.12.1954, in: BGBI. I, S. 412 .

"t Der Tarif der KSt lag im Normalfall ab 1.1.1951 gemaB $\S 19$ KStG y. 28.12 .1950 bei $50 \%$ s. BGBI. 1 1951, S. 37.

${ }^{12}$ BGBI. I 1950, S. 684. 
In dieser Situation gab die Bundesregienung dem Aufbau einer neuen Handelsflotte hohe Priorităt. ${ }^{13}$ Tatsăchlich wurden dann von Mitte 1951 bis zum Ende des Jahres 1954 insgesamt 587 Neubauten mit einem Umfang von insgesamt 1.793.153 Bruttoregistertonnen abgewickelt, die Baukosten von über 2,748 Mrd. DM erforderten. Dies wurde möglich, ohne den noch funktionsuntüchtigen Kapitalmarkt durch weitere dirigistische Eingriffe in Anspruch zu nehmen. Bewirkt wurde das verblüffende Ergebnis im wesentlichen von einer am 29. April 1950 verabschiedeten, dem Laien unbedeutend erscheinenden Steuervergünstigung, die 1950 dem Einkommensteuergesetz als $\S 7$ d Abs. 2 angefugt wurde. ${ }^{14}$ Dieser Zusatz, der $\S 7 \mathrm{c} \mathrm{EStG}$ nachgebildet war, bestimnte, daß ein Steuerpflichtiger die an einen Darlehensnehmer zum Bau eines von ihm zu Eigentum zu übernehmenden und zu betreibenden Schiffes zinsios gegebenen Dariehen und ebenso verlorenen Zuschüsse bei Ermittlung der eigenen steuerlichen Bemessungsgrundlage wie Betriebsausgaben absetzen durfte. ${ }^{15}$ Die zu einem späteren Zeitpunkt eingenommenen Tilgungsbeträge waren dann vom Darlehensgeber wie Betriebseinnahmen zu versteuern. Dieser Abweichung von den gesetzlichen Ermittlungsvorschriften für die steuerbaren Einkünfte kam nun trotz des äußerlichen Anscheins nur eingeschränkt der Charakter einer Subvention des Wiederaufbaus der Handelsflotte zu. Die Reeder erhielten ja gar keine staatlichen Finanzhilfen. Die Steuervergünstigung für die Darlehensgeber bestand darin, daß die steuerliche Abzugsfähigkeit der hingegebenen Darlehen und die spätere Versteuerung der kleineren ratenweise rückfließenden Teilbeträge - nicht zuletzt auch wegen der erwarteten Herabsetzung der Tarife - zu erheblichen Steuerersparnissen führte. Die hohen Steuertarife bewirkten, daß eine Körperschaft bei Hergabe eines Darlehens oder des verlorenen Zuschusses höchstens auf $34 \%$ an Liquidität, die obendrein fremdfinanziert werden konnte, verzichtete. Für selbständige Unternehner lag der Betrag im Regelfall noch niedriger. Hinzu trat ein eventueltes Interesse an

${ }^{13}$ Hierau s.: Aufruf der Bundesregierung und führender Personen der Wirtschaft, im eirzelnen von K. Adenauer, F. Blücher, H. C. Seebohm, L. Erhard, F. Berg. R. Stödter, T. Strecker, H. Agatz, G. Schnadel, im Dezemberheft der "Hansa" 1951.

${ }^{14}$ S. Hoeth, P. (1956), S. 1274.

15 Art. I Ziff. 7 des Gesetzes zur Änderung des EStG und des KStG v. 29.4.1950 (BGBI. I, S. 97) lautete: "Dem $\$ 7 \mathrm{~d}$ wird folgender Absatz 2 angefügt: "(2) Steuerpflichtige, die den Gewinn auf Grund ordnungsınāßiger Buchfuhrung, ermitteln, körunen Zuschüsse oder unverzinsliche Darlehęı zur Förderung des Schiffbaues, sonstige Steuerpflichtige kônnen Zuschûsse zur Fôrderung des Schiffbaues im Jahr der Hingabe als Betriebsausgaben oder Werbungskosten absetzen, wenn die Zuschüsse oder Darlehen einem Unternehmer für den Bau eines von ihm bei einer Werf im Bundesgebiet in Auftrag gegebenen, zum Erwerb durch die Schiffahrt dienenden Schiffes gegeben werden und dieses Schiff nach Fertigstellung in sein Eigentum übergeht". Von diesem Zusatz unabhangig blieb $\S 7 \mathrm{~d} \mathrm{Abs.} 1$ EStG bestehen, wonach zusätzlich zur normalen Afa bei Anschaffung, Herstellung oder Wiederherstellung eines Schiffes im ersten und zweiten Jahr eine Sonderabschreibung in Höhe von jeweils $15 \%$ der Aufwendungen bei Ermittlung der Bemessungsgrundlage abgesetzt werden konnte. 
dem Betrieb einer bestehenden Reederei, an dem Neubau eines Schiffes, an der Neugründung einer Partenreederei oder der Beteiligung an einer Neugründung, was vermittels der Hingabe verlorener Zuschüsse günstig möglich wurde. $^{16}$

Tatsăchlich war die Auswirkung dieses Zusatzes von $\S 7$ d Abs. 2 EStG enorm. So verwendete beispielsweise eine Aktiengesellschaft ihren gesamten Jahresgewinn von 60 Mio. DM zur Vergabe derartiger abzugsfähiger zinsloser Darlehen bzw. verlorener Zuschüsse. ${ }^{17}$

Der Subventionscharakter der in $\S 7 \mathrm{~d}$ Abs. 2 EStG normierten Steuervergünstigung ist mit guten Gründen stets zu Recht bestritten worden. ${ }^{18} \mathrm{Die} \mathrm{Be}$ griffe "Subventionsgeber" und "Subventionsnehmer" lassen sich ohne erläuternde Definitionsstützen im Grunde gar nicht verwenden. Die Kassenlage des Bundes hätte zu dieser Zeit die Hingabe von zusätzlichen Finanzmitteln auch gar nicht erlaubt.

Als Ergebnis ist festzuhalten, daß die deutsche Schiffstonnage, die im Jahr 1949 aus 102 völlig veralteten Einheiten bestehend, auf 68.399 BRT zusammengeschrumpft war, bereits bis Ende 1954 durch moderne Neubauten von 1.793.153 BRT wieder die Hăltte des Vorkriegsbestandes erreicht hatte. ${ }^{19}$

In dieser kurzen Zeitspanne waren 587 Schiffseinheiten mit Baukosten von insgesamt ca. 2,75 Mrd. DM fertiggestellt oder jedenfalls bereits genehmigt worden. ${ }^{20}$ Die nach $\S 7 \mathrm{~d}$ Abs. 2 EStG 1950 zinslos gegebenen Darlehen hatten eine Höhe von ca. 1,53 Mrd. DM erreicht, ein für die damalige Zeit bei dem gegebenen Geldwert und der Marktenge völlig unerwarteter Betrag. Die verlorenen Zuschüsse betrugen 5,8\% der gesamten Mittel. Darlehen und $\mathrm{Zu}$ schüsse trugen im Durchschnitt einen Anteil von 54,5\% und für einen Teil der Schiffe sogar $75 \%$ der Herstellungskosten bei. ${ }^{21}$

${ }^{16}$ Buassgen, H. R. (1963), S. 63, S. 67. Ober den erzielbaren Vermōgenszuwachs beim Investor gibt Anlage 10 in einem konkreten Beispiel AufschluB. Das Beispiel stammt von dem WP K. Langer und ist ungekürzt abgedruckt in: Der Wirtschaftsprüfer, Zeitschrift für das Deutsche Pruafungs- und Bilanzwesen, 5. Jg. 1952, S. 33. Das Beispiel ist stark vereinfacht; ein Fehler Langers, die Bemessungsgrundlage der Afa nicht gem. $\S 11$ a i, V.m. $\$ 11$ Abs. 2 EStDV um den verlorenen Zuschuß zu kürzen, wurde in Anlage 10 richtiggestellt, s. a. Rogowsky, J. (1954), S. 75.

${ }^{17}$ Bussgen, H. R. (1963), S. 77, Anm. Nr. 50.

18 Büssgen, H. R. (1963), S. 63, S. 67, S. 68; s. Seebohm, H. C., Bundesminister für Verkehr. (1954), in: Verhandlungen des Deutschen Bundestages, 2. Wahlperiode 1953, Stenograph. Berichte, Bd. 19, S. 838, Sitzung v. 7.4.1954; Rogowsky, J. (1954), S. 92.

\footnotetext{
${ }^{19}$ Rogowsky, J. (1954), S. 22; Hoeth, P. (1956), S. 1275; Bussgen, H. R. (1963), S. 57.

${ }^{20}$ Hoeth, P. (1956), S. 1275; Buissgen, H. R. (1963), S. 70.

${ }^{21}$ Hoeth, P. (1956), S. 1274-1276; Büssgen, H. R. (1963), S. 69.
} 
Diese überaus erfolgreiche Maßnahme hatte erreicht, daß der Schiffahrt mehr oder weniger fremd gegenüberstehende Geldgeber Darlehen an investitionsfreudige Unternehmer in der Schiffahr gaben und Unternehmer (Reeder) andererseits zu Ausgründungen aber auch eigenen Investitionen in Schiffsbauten angeregt wurden. ${ }^{22}$ Der eingefugte $\S 7 \mathrm{~d} \mathrm{Abs.} 2$ EStG war aber nur eine mittelbare Hilfe für die Schiffahrt. Er belohnte direkt, wie man beachten muB, die wohlhabenden Finanzierer, nicht die notleidenden Reederfirmen, und forderte gewiß nicht, wie intendiert, deren Eigenkapitalstruktur zur Verbesserung der Wettbewerbsfahigkeit durch "Erhaitungs-, Anpassungs- und Produktivitătshilfen", wie es seit 1967 im Stabilitătsgesetz lautet. ${ }^{23}$

Bei den Darlehensgebern handeite es sich vielmehr nur um Steuerpflichtige, die in einer hohen Einkommensteuerprogression angesiedelt waren. Der Staat hatte keine Finanzhilfen gegeben. Er motivierte durch Steuervergünstigungen einen größeren Kreis von Darlehensgebern, die oftmals weniger am Wiederaufbau einer deutschen Handelsflotte interessiert waren, als an einer günstigen Kapitalanlage durch große steuerliche Vorteile, die jeweils durch Neugründungen vermittelt wurden. ${ }^{24}$ Mit dem, was üblicherweise unter "Steuergerechtigkeit" verstanden wird, war diese Maßnahme gewiß unvereinbar.

Bei diesem Verfahren stundete der Staat im übertragenen Sinne durch eine vom Steuerpflichtigen in Anspruch genommene Ausnahmeregelung zinslos die von Gesetzes wegen entstandene Steuer zugunsten einer erst nach jeweiligem Rückfluß der Tilgungsraten entstehenden Steuerschuld. Je nach Tarifentwicklung und Stand des Einkommens konnte die später durch Veranlagung falliggestellte Steuerforderung höher oder niedriger ausfallen. Zur Zeit der Einfügung des $\S 7 \mathrm{~d}$ Abs. 2 EStG und bis 1954 war eine Tarifreduktion der Besteuerung fortlaufend im Gespräch, was das Interesse noch verstärkte. Auch ein verlorener Zuschuß konnte im übrigen mit einiger gestalterischen Phantasie zu einem einträglichen Geschäft für den Geber werden, was für den Laien unverständlich klingen mag. Sie konnte nämlich später einer eigenen Beteiligung durch Umwandlung des Darlehens werterhöhend zugute kommen. ${ }^{25}$

${ }^{22}$ Büssgen, H. R. (1963), S. 68, S. 69; Hoeth, P. (1956), S. 1274.

${ }^{23}$ Büssgen, H. R. (1963), S. 68; Rogowsky, J. (1954), S. 74; Hoeth, P. (1956), S. 1570. Hierzu s. $\S 12$ StWG v. 8.6.1967, in: BGBI. I, S. 583; s. a. Stichwort "Stabilitătsgesetz" in: Handwörterbuch fùr das Gelü-. Banken- und Bōrsenwesen, 10. Aufl. Wiesbaden, S. 1933; Büssgen, H. R. (1963), S. 76.

${ }^{24}$ Büssgen, H. R. (1963), S. 68, S. 72; Rogowsky, J. (1954), S. 73 mit weiteren Hinweisen.

25 Nach einem Erlaß des Senators für Finanzen der Hansestadt Hamburg v. 18.10.1951 wurde ein Optionsrecht auf die spâtere Umwandlung eines zinslosen Darlehens in eine Beteiligung grundsătzlich für zulässig erachtet. Für diesen Fall galt dann das Darlehen als zurückgeflossen. Das lieB intelligente Gestaltungen zu, s. hierzu: Der Wirtschaftspirufer, Zeitschr. f. d. dt. Prufungs- und Bilanzwesen, 5. Jg. 1952, S. 35 Hinweis der Redaktion; s. a. Korff. H. C. (1953), S. 262. 
Man fragt sich, ob hier überhaupt von einer "Subvention" gesprochen werden sollte. Unter das, was in akademischen Abhandlungen in begrifflicher Feinarbeit etwa mit "Subventionen als Instrument der Lenkung und Koordination" dargelegt wird, ist dieser äußerst erfolgreiche Vorgang aus der Praxis nur schwer einzuordnen. ${ }^{26}$ Meist führte die Steuervergünstigung zu Neugründungen von Partenreedereien in Form von Gesellschaften mit beschränkter Haftung und dabei zu erheblichen Vermögenszuwächsen. Das gesetzlich vorgeschriebene Verhaltensmuster des Fiskus ähnelte der Tătigkeit einer Bank, die kurzfristig fallige Forderungen durch Prolongation in langfristige, bei Eintritt einer vereinbarten Bedingung fallige Darlehen umwandelt. Ein solches Geschäft ist üblicherweise mit Zinseinnahmen der Bank verbunden, die als Resultat der Teilnahme an der Wertmehrung des Kunden in die Ergebnisrechnung des Instituts eingehen. Beide Parteien, Bank und Kunde, profitieren von derartiger Kreditgewährung, was beim Darlehensnehmer im voraus zur Rechtfertigung der Investition in einer Wirtschaftlichkeitsrechnung festgehalten wird. Im vorliegenden Fall ist es aber eine im Gesetz nicht erwähnte Grundvoraussetzung, daß der Darlehensgeber ein hohes Einkommen hat (oder haben wird - auch diese Fälle gab es wegen des möglichen Verlustvortrages -) und daher in obersten Progressionsstufen angesiedelt ist. Steuertarifänderungen, ja bereits entsprechende Erwartungen, vermögen das Interesse stark zu beeinflussen. Im übrigen profitiert der Fiskus zusătzlich von dem höheren Steueraufkommen aus dem durch die späteren Dienstleistungen der Schiffsbauten gewachsenem Sozialprodukt. Daß diese Form von Kreditgewährung nicht aus einem Sondervermögen des Bundes erfolgt, verleiht der Betrachtungsweise etwas Ungewohntes. Denn man kann den sehr unbestimmten Sammelbegriff "Fiskus" nicht für ein Bankinstitut verwenden. ${ }^{27}$

Sind für eine Bank gemăß $\S 18$ Kreditwesengesetz Umsatz und Vermögen des Darlehensnehmers die wesentlichen Bezugsgrößen für die Darlehenszusage und der durch eine entsprechende Ausbildung legitimierte Kreditvermittler die Hilfsperson, die die Verbindung, zum Kunden schaff, so ist für die Auswahl der vom Fiskus Begünstigten deren steuerliche Bemessungsgrundlage entscheidend und der Steuerberater sorgt für die Voraussetzang, die gesetzlich festgelegten Steuerminderungen in Anspruch nehmen zu können. So kommt es, daß Steuerberater seither von gutsituierten Mandanten gelegentlich freudig

${ }^{26}$ Kirchhof, G. (1973). Die hier behandelten Steuervergünstigungen gleichen eher Aquisitionskosten oder Provisionen, als dem Vorgang, den Kirchhof als Subvention definiert.

27 Den dargestellten kreditähnlichen. Steuervergünstigungen für erwùnschte Investitionen liegen die Steuergesetzgebung und die relevanten Verwaltungsanweisungen zugrunde, aber keine Leistungen aus einern Sondervermōgen des Bundes, s. Schlauwitz, W. (1966), Der Bund als Finanzier. ERP-Sondervermōgen, Sondervermōgen fïr berufliche Leistungsforderung, Bad Godesberg. 
mit "Sie sind meine zweite Einnahmequelle" begrüßt werden. Inzwischen entsteht, von großen Versicherungsgesellschaften gefördert, ein neues Berufsbild des Vermögensberaters, der als "Allfinanzberater" dem Bedarf nach einer umfassenden, branchenübergreifenden Betreuung "unter Ausschöpfung aller staatlichen Förderungen" nachzukommen sucht. Hierin zeigt sich deutlich die völlig neue Rolle, in die der Fiskus inzwischen hineingewachsen ist. ${ }^{28}$

Beim Fiskus muß eine Vergünstigungsvorschrift nach Art § 7 d Abs. 2 ESiG 1950 nach dem Gesetz über Stabilität und Wachstum der Wirtschaft seit 1967 dennoch in den jeweils aufzustellenden Subventionsbericht unter Angabe hochgerechneter Mindereinnahmen aufgenommen und bei der obligatorischen Steuerschätzung im jährlichen Finanzbericht berücksichtigt werden. ${ }^{29}$ Dadurch allein wird aus dem Vorgang aber noch keine Subvention im Sinne der hergebrachten Sprachregelung.

Der ungewöhnlich erfolgreiche Wirtschaftsaufschwung der Bundesrepublik nach 1949 dürfte nicht zuletzt in erheblichem $\mathrm{Maß}$ auf die Folgen der in das Steuerrecht eingefügten verschiedenen vergleichbaren Steuervergünstigungen,

28. Der neu entstandene Bedarf an umfassender Beratung auf diesem sehr unübersichtlichen Gebiet, die Dispositionen bezüglich Kapitalanlagen, Versicherungen, Altersversorgung etc. mit den ausge!ōsten steuerlichen Folgewirkungen zusammenfaßt, hat in den Medien erhebliche Beachtung gefunden. Es ist zur Gründung vieler neuartiger Dienstleistungsunternehmen gekommen, die einen breiten Făcher von Finanzanlagen anbieten. Nach Pressemitteilungen schätzen Branchenkenner das Heer der freien Finanzdienstleistenden bundesweit inzwischen auf 400.000 bis 500.000 , von denen nur ein Bruchteil eine fundierte Ausbildung erhielten, s. Welt am Sonntag v. 6.8.1995, S. 39; hierzu a. Cash, 11. Jg., Nr. 4, Juli 1993, S. 110; s. a. Kölnische Rundschau v. 24.4.1995 (Wirtschaft).

29 Im 13. Subventionsbericht der Bundesregierung v. 11.11.1991 über die Entwicklung der Finanzhilfen des Bundes und der Steuervergünstigungen für die Jahre 1989 bis 1992, in: Deutscher Bundestag, Drs. 12/1525, S. 176, werden bspw. folgende Steuermindereinnahmen als Folge von $\S \S 2$ und 3 FördG v. 24.11.1991 ausgewiesen: Für 1991 Steuermindereinnahmen von 1.450 Mio. DM und für 19921.505 Mio. DM. Dazu kommen noch Steuermindereinnahmen für neue Gebãude im Privatvermögen im Beitrittsgebiet gem. § 3 FördG für 1991 von 105 Mio. DM und für 1992 von 310 Mio. DM. Insgesamt betrugen die ausgewiesenen Mindereinnahmen dieser Position des EStG mithin für $19911.555 \mathrm{Mio}$. DM und für 19921.815 Mio. DM. Nach Mitteilung des zuständigen Referenten im BMF dienten als Grundlage für diese Hochrechnungen die Meldungen ûber die Inanspruchnahme für Investitionszulagen nach dem Investitionszulagengesetz. In $\S 6 \mathrm{Abs}$. 1 InvZulG wird als Ausschlußfrist für die Beantragung der Finanzhilfen der 30.9. des der Anschaffung folgenden Jahres festgelegt. Da die gesetzlichen Bemessungsgrundlagen nicht deckungsgleich sind, werden jedoch nicht afle Vorgănge erfalłt. Und wichtiger: Die Ermittlung der Steuermindereinnahmen bezieht sich nur auf rechnerische fiktive Primäreffekte. So muB man sich fragen, welchen Wert etwa der Ausweis eines Minderbetrages von 1.815 Mio. DM für 1992 haben mag, da allgemein bekannt wurde, daß sowohl ESt als auch USt in den Altländern im selben Abschnitt tatsăchliche hohe Zuwächse als Folge der von derselben Maß. nahme ausgelösten Konjunktur auswiesen. Im übrigen gibt es, anders als im Fall des Schiffbaues, keine amtlichen Angaben über Initiatoren von geschlossenen Investmentfonds und die gebildeten Geselischaften. Eine Evidenzzentrale oder Meldestelle ist nicht vorgesehen. Die deutsche Bundesbank gab bereits 1970 den Versuch auf, einen Überblick über geschlossene Fonds zu schaffen. Im Februar 1992 sprach die Deutsche Bundesbank in đer Wertpapierstatistik von einer ats "vorlāufig" bezeichneten Anzahl von 123.183 Anlegern. Auch diese Ziffern, wie Angaben über die Hōhe von Fondsvermögen, sind reine Spekulationen ohne nachvollziehbare Grundlage, da es keinerlei Statistiken hierzu gibt, s. Cash, 11. Jg., Jan. 1993, S. 30; s. Uhlmann, R.: "Kuddelmuddel", in: Handelsblatt v. 1.9.1995, S. 5. 
vor allem in Verbindung mit der zur Verfügung gestellten Inanspruchnahme von Sonderabschreibungen bei erwünschten Investitionen, zurückzuführen sein.

Da Finanzwissenschaftler und Nationalökonomen sich durchweg grundsätzlich gegen diese Form der Finanzierung des Wiederaufbaues aussprachen, haben sie die sich dabei anbietenden technischen Möglichkeiten vernachlässigt und die großen Erfolge und Ergebnisse aus ihren Erörterungen ausgeblendet.

Sie haben daher die Gestaltung dieser Maßnahmen weitgehend den Praktikern aus Regierung und Finanzwelt überlassen und die Auswirkungen nicht genügend aufgearbeitet.

Steuerrechtler haben zumeist nur die entstehende Kompliziertheit des Einkommensteuerrechts wahrgenommen und dann die Frage der Verfassungsmäßigkeit erörtert. Erst sehr spät wurde von ihnen unter dem Eindruck aufkommender starker Kritik in den Medien die Frage der Verteilungsgerechtigkeit der Steuern zum Problem gemacht. Daß sich dabei Anlaß zu harter Kritik ergab, muß nicht dargelegt werden.

Zusammenfassend ist festzuhalten: Der Wille des Gesetzgebers bei Einführung des $\$ 7 \mathrm{~d}$ Abs. 2 EStG lief darauf hinaus, den Wiederaufbau der deutschen Handelsflotte durch Verbesserung der Kapitalausstattung zu fördern. Tatsächlich richtete sich die Steuervergünstigung jedoch an potentielle hochverdienende Darlehensgeber. Den anvisierten Reedern als Darlehensnehmern kam die staatliche Hilfe zwar entscheidend, aber nur mittelbar zugute. Der Staat unterstützte in erster Linie also nicht die Schiffahrt, sondern die Geldgeber, "die dem Flottenbau nicht unbedingt eng verbunden zu sein brauchten". Dies bewirkte jedenfalls eine Initialzündung zum Vorteil aller Beteiligten. Es war ein gelungenes Experiment, das aus dem Insinumentarium einer praxisorientierten Finanzpolitik hervorgegangen ist und in der gegebenen Ausnahmesituation bei Abwägung der Interessen wohl positiv beurteilt werden kann. Diese Form finanzpolitischer Eingriffe zur Förderung des Wiederaulbaues war 1919 bei ăhnlich gelagertem Sachverhalt noch unbekannt. Die am HermannSchmollerschen Muster orientierte Erzbergersche Reform der Einkommensteuer hätte sie auch wegen der entstehenden Widersprüche im System gar nicht zulassen können.

Die Förderung des Schiffbaues wurde nach Vorankündigung einer heftig diskutierien sogenannten "organischen Steuerreform" im Deutschen Bundestag am 16. Januar 1953 durch das neue EStG vom 24. April 1954 und die dann erfolgte Bestätigung in der großen Steuerreform vom !6. Dezember 1954

Büssgen, H. R. (1963), S. 68. 
für die Zeit ab 1. Januar 1955 durch völlige Streichung des $\S 7$ d Abs. 2 EStG gegen starken Widerstand der Verbănde wieder beseitigt. ${ }^{31}$ Spăter wurde dann auch $\S 7 \mathrm{~d}$ Abs. 1 EStG, der Sonderabschreibungen für die Schiffahrt vorsah, völlig gestrichen. Diesen Anschein konnte die Gesetzesänderung aber nur beim Laien erwecken. Die Förderung wurde, da offenbar vorerst unverzichtbar, in verborgener Weise, freilich eingeschränkt, fortgefuihrt.

Nachdem das Ziel der Schaffung einer angemessenen Grundausstattung für die Fischerei- und Frachtschiffahrt erreicht war, sollte nach herrschender Auffassung die fernere Investitionstătigkeit wieder den Prinzipien rein marktwirtschaftlicher Steuerung durch den Kapitalmarkt überlassen bleiben. Wegen dessen langanhaltender Funktionsunfähigkeit bezweifelte der zuständige Minister in den Erörterungen 1954 im Bundestag, daß dies gelingen könnte, vermochte sich jedoch den allgemein vertretenen ordnungspolitischen Vorstellungen nicht zu verschließen, zumal die steuerlichen Förderungsmaßnahmen gerade von Finanzwissenschaftlern heftig kritisiert worden waren. ${ }^{32}$ Um der Schiffahrt den weiterhin notwendigen Aufbau zu internationaler Wettbewerbsfahigkeit dennoch zu erhalten, kam es dann dazu, daß die Regierung bald von einer in § 51 EStG vorgesehenen Ermächtigungsvorschrift Gebrauch machte, Steuervergünstigungen für die Schiffahrt in $\S 82 \mathrm{f}$ EStDV verborgen, ohne Mitwirkung des Parlaments, wieder vorzusehen. Bis Ende 1989 sorgten weitere befristete, inzwischen bis Ende 1999 verlängerte, verborgen gebliebene Steuervergünstigungen für die weitere ständige Anpassung der Schiffahrt an den internationalen Wettbewerb. ${ }^{33}$

${ }^{31}$ Hierzu: Jecht, H. (1955), S. 31. Nach Jecht waren die Steuervergünstigungen im EStG die Konsequenz der exorbitanten Tarifsalze. die noch von den alliierten Siegemächten verordnet worden waren. Mit deren Milderung könnten sie wieder bescitigt werden, s. S. 37, so lautete jederffalls dic vorherrschende Auffassung, s. hierzu Schmölders. G. (1953), Organische Steucrteform .... S. 59, S. 100. Schmolders trat für Streichung von $\$ 7$ d Abs. 2 EStG ein, s. \$. 184; anders das von Verwaltungsseite vorgelegte sog. Tröger-Gutachten, s. Tröger. H. (1953), Diskussionsbeiträge .... S. 29: anders auch Spitaler, A. (1953).

32 Beitrag des Bundesministers für Verkehr. C. Seebohm. in: Verhandlungen des Deutschen Bundestages v. 7.4.1954, Stenograph. Berichte. Bd. 19. 2. Wahlperiode, 1953. 5. 837. In der Iruhzeitigen Beseitigung des besonders wirksamen $\$ 7$ d Abs. 2 EStG im lahr 1994 zeigte sich, daß die Vergünstigung finanzpolitisch beherrschbar blieb. Nachdem die notwendige moderne Grundausstattung der Handelsflotte neu erstellt war. konnte eine stärker marktwirtschaftlich orientierte Steuerung der Weiterentwicklung nur vorteilhaft sein. Für diese Erkenntnis sorgten die öffentliche Wirksamkeit von Warnungen der Nationalökonomen und die Erörterungen đer Finanzberichte der Regierung. Bereits vor Einführung des StWG im Jahr 1967 wurde regelmãßig von der Bundesregierung Offenlegung der Subventionen in Anfragen im Parlament verlangt. wobei zwischen "sichtbaren Begüstigungen im Haushalısplan" und "unsichtbaren Begünstigungen im Rahmen des Steuerrechts" unterschieden wurde. 5. als Beispiel: Deutscher Bundestag. 3. Wahlperiode, Drs, 3/1229. S. 11. S. 15.

${ }^{3} \S 7$ d Abs. I EStG, der zusâtzlich zu der Regelafa für zwei Jahre Sonderabschreibungen von jeweils 15\% der Ansehaffungs-, Herstellungs- oder Wiederherstellungskosten vorsah. blieb bis 1958 gûltig. Erst für Anschaffungen nach dem 10.6.1958 war die Begûnstigung nicht. mehr anwendbar. $s$. StÄndG v. 18.7.1958. BGBl. I. \$. 473. Auf Grundlage der Ermächtigungsvorschrift des $\S 5$ i Ahs. I 
Mehrfach erkannten wir, daß dieser Art steuerliche Vergünstigungen, zu denen auch $\S 7$ d EStG 1950 zählte, von dem Gesichtspunkt einer gerechten Lastenverteilung aus beurteilt, als höchst problematisch $\mathrm{zu}$ bewerten sind. Wägt man diesen Umstand jedoch - wie dies 1893 von Oldenberg geschah mit den erreichten wirtschaftlichen Vorteilen für das Gemeinwesen und dem dadurch ermöglichten sozialen Fortschritt ab, so erscheinen die Maßnahmen in einem anderen Licht. Politische Entscheidungen werden nachvollziehbar.

Das Deutsche Reich war 1945 untergegangen. Für Entschädigungen der durch Kriegseinwirkungen vernichteten Wirtschaftsgüter gab es, anders als nach dem 1. Weltkrieg 1919, keinen Anspruchsgegner. ${ }^{34}$ Für den Wiederaufbau fehlte zur Finanzierung auch ein funktionsfähiger Kapitalmarkt. Fehlende laufende Umsätze bei sofort einsetzendem starken Konkurrenzdruck des Weltmarktes ließen die Finanzierung von Neubauten aus Abschreibungen in der Schiffahrt utopisch erscheinen.

Das 1948 übernommene, aus der Steuerreform von 1925 stammende fortentwickelte EStG ließ sich ohne Gefahr der Verwicklung in innere Widersprücrie als frinanzierungsinstrument zum Wiederautbau einer deutschen Handelsflotte und ohne abenteuerliche Belastung des Haushalts in die Wirtschaftsordnung der sozialen Marktwirtschaft integrieren. Direkte steuernde Eingriffe in das Marktgeschehen konnten unterbleiben. Die Lenkung erfolgte marktkonform.

Als Folge einer ausufernden Tarifprogression des EStG schufen die eingefügten Steuervergünstigungen einen starken Anreiz zur Vermögensmehrung, die die Investitionen in notleidenden Sektoren der Wirtschaft bündelten und so der Fördenung des allgemeinen Wohlstands dienten.

Wenn auch die Berücksichtigung der Verteilungsgerechtigkeit vernachlässigt wurde. so ist jedenfalls durch die Verbessenung der investierten Kapitalstruktur der Gemeinschaft die Grundlage für den zügigen "sozialen Fortschritt" geschaffen worden, dessen Ergebnisse heute selbstverständlich erscheinen mögen. Denn alles, was zur Kräftigung des Wirtschaftswachstums geschah, diente gleichzeitig der Festigung des "Netzes der sozialen Sicherheit".

Ziff: 2 w EStG wurde die Vergunstigung als $\S 82 \mathrm{fEStDV}$ mit Gultigkeit ab 1.1.1965 wieder eingeführt. Die befristete Galtigkeit wurde dann laufend verlängert, zuletzt in Art. 8 StandDG, so daB die Wirksamkeit erst zum 1.1.2000 auslăuft. Dabei wurde die Sonderafa auf $40 \%$ erhōht und inzwischen wurden Luftahrzeuge eingeschlossen. Zur wirtschaftlichen Bedeutung für Anleger s. Wirtschaftswoche v. 9.7.1993. S. 62. Die Europaische Kommission der EG hat Bedenken wegen dieser Finanzierungshilfen inzwischen fallenlassen, s. Cash, 13. Jg. 1995, S. 14.

${ }^{34}$ Hierzu: Heeckt, H./ Stender, H. (1954), S. 44; Becker, Erich (1933), S. 61. 
Es mag von Interesse sein zu erfahren, welchen Gebrauch die Finanzwissenschaften von điesem eindrucksvollen Experiment des Wiederaufbaus der deutschen Handelsschiffahrt gemacht haben:

Zur Zeit der Geltung der erfolgreichen Steuervergünstigung wurde auf der Salzburger Tagung des einflußreichen "Vereins für Socialpolitik" vom 2. bis 5. Oktober 1952 das Thema "Kapitalbildung und Kapitaiverwendung" verhandelt. ${ }^{35}$ Hier spielte in den wichtigsten Beiträgen - anders, als in einer vergleichbaren Veranstaltung im Jahr 1929 - die Frage der Lenkung der Volkswirtschaft durch nichtfiskalische Steuernormen eine wichtige Rolle. Fritz Neumark, Helmut Meinhold und einige weitere Mitglieder, wie auch Karl Schiller, vertraten ausdrücklich den Standpunkt einer "interventionistischen Wirtschaftsordnung". Neumark hob hervor, daß die Steuer, "obwohl ein machtvolles Instrument der modernen Finanz- und Wirtschaftspolitik, nur eines und nicht das wirksamste Mittel" sei, um dem Kapitalmarkt als der für die Lenkung von Investitionsentscheidungen in der Marktwirtschaft zustăndigen Institution eine sozial erwünschte Richtung zu geben. ${ }^{36}$ Aber selbst dieses vage Bekenntnis zu einer nichtfiskalischen Verwendung der Besteuerung ging der Mehrheit der anwesenden führenden Nationalökonomen und Finanzwissenschaftler noch zu weit.

Wilhelm Gerloff, Günter Schmölders, Theodor Wessels und andere brachten ihre grundsätzliche Ablehnung eines Einsatzes der Besteuerung als Lenkungsinstrument in gleichermaßen vorsichtiger Diktion, das Mitglied des Direktoriums der Bank deutscher Länder, Eduard Wolf, aber mit Entschiedenheit zum Ausdruck. Schmölders sah in dem nichtfiskalischen Einsatz speziell der Einkommensteuer ein allzu "grob wirkendes Mittel" und warnte vor unerwünschten sozialen Konsequenzen und vor der Unbeherrschbarkeit der einmal in Gang gesetzten Eingriffe. ${ }^{37}$

Im Mittelpunkt der Erörterungen standen offensichtlich dogmatische Voreingenommenheiten auf beiden Seiten. Es war und blieb ein Streit ohne Analyse der konkreten Konsequenzen. Es gab keine Erörterung von Zielen und alternativen Lösungsvorschlägen für wirtschaftlich brisante, von der Schwäche des Kapitalmarktes verursachte Engpässe, ähnlich wie in der erwähnten Konferenz von 1929, an der auch zwei ehemalige Reichsfinanzminister und der zuständige Staatssekretär J. Popitz aktiv teilnahmen, keine Diskussion möglicher konkurrierender Finanzhilfen oder Steuervergünstigungen zur Ingangset-

35 Albrecht, G./ Arndt. H. (1953).

36. Neumark, F. (1953), Möglichkeiten einer finanzpolitischen Beeinflussung von Kapitalbildung und Kapitalverwendung, in: Albrecht, G./Arndt, H. (1953), S. 75.

${ }^{37}$ Albrecht, G./Arndt, H. (1953), S. 82, S. 86, S. 169, S. 194, S. 197, S. 201. 
zung dringender Problemlösungen, und dies, obgleich nunmehr die Zeitumstände und die Berichte genügend Beispiele für Untersuchungen auf empirischer Grundlage bereithielten.

Schmölders suchte sogar die Wirkungen der damals geltenden Steuervergünstigungen nach $\S 7 \mathrm{~d}$ Abs. 2 EStG als Beweis für die Gefahr von Fehlinvestitionen als Folge eines nichtfiskalischen Einsatzes des Einkommensteuerrechts zu verwenden. Ihm bekannt gewordene Zusammenhänge eines Einzelfalles, in dem sich die zu hohen Erwartungen eines Investors nicht erfült hatten, verwendete er als Beweis für den unterstellten Regelfall, daß es sich um Fehlinvestitionen gehandelt habe. ${ }^{38}$ Trotz grundsätzlichen Eintretens für eine nichtfiskalische Verwendung des Steuerrechts verharrte auch Neumark in bloßen Lippenbekenntnissen mit Schwerpunkt auf begrifflichen Erörterungen und Abgrenzungen ohne Untersuchungen mit empirisch überprüfbaren Thesen von praktischer Relevanz. Dabei hat seine positive Würdigung eines interventionistischen Einsatzes des Steuerrechts, den er hart gegen streng abgelehnte "dirigistische", "punktuelle" Begünstigungsnormen abgrenzte, die spätere Diskussion geprägt.

Zwar war Neumark der Auffassung, daß "kein vernünttiger Grund dafür besteht, lediglich die Steuer aus dem Arsenal der wirtschaftspolitischen Mittel prinzipiell auszuschließen", ${ }^{39}$ aber das, was er "Fiskaldirigismus" nannte, war seiner Meinung nach grundsătzlich mit der als "erhaltungswürdig unterstellten Wirtschaftsordnung unvereinbar". ${ }^{40}$ Dirigistische Eingriffe in die Besteuerungsvorschriften beurteilte er undifferenziert als "irrational", "ungerecht", zu "wirtschaftlicher Rückständigkeit" und "suboptimaler Recourcenallokation" führend etc. ${ }^{41}$ und brachte sie in unmittelbaren Zusammenhang mit der abfällig bewerteten Tätigkeit politischer "pressure groups". Neumark verwickelte sich in diesen. Thesen in vielerlei Widersprüche, wenn er etwa einleitend bekannte, daß er Werturteile aus der Wissenschaft ausschließen wolle, ${ }^{42}$ und für die Rationalität "nichtfiskalisch motivierter Besteuerungsmaßnahmen" nur entseheidend sein könne, "ob diese absolut und relativ geeignet sind, der Verwirklichung der angestrebten Ziele zu dienen". ${ }^{43}$

\footnotetext{
38 Diskussionsbeitrag v. Schmōlders, G. in: Albrecht, G./Arndt, H. (1953), S. 195.

39. Neumark, F. (1957), Interventionistische ..., in: Beckerath, E. von/Meyer, F.Muller-Armack, A. (1957), S. 452.

${ }^{40}$ Neumark, F. (1970), Grundsătze der Besteuerung ..., S. 50.

41 Neumark, F. (1970), Grundsaltze der Besteuerung .... S. 40, S. 51; ders. (1970), Grundsalzze gerechter Besteuerung ..., S. 227.

${ }^{42}$ Neumark. F. (1970), Grundsătze gerechter Besteuerung ...., S. 16.

4. Neumark. F. (1957), Interventionistische .... S. 452.
} 
Dirigistische Eingriffe definierte Neumark folgendermaßen: "Steuerdirigismus ist dadurch charakterisiert, ... daß̊ die einzelnen Maßnahmen primăr darauf abzielen, einzelne Wirtschaftsgruppen, Erzeugungszweige, Konsumarten, Kapitalbildungs- und Verwendungsformen und dergleichen mehr aus nichtökonomischen Gründen ... relativ zu begünstigen oder zu benachteiligen". ${ }^{44}$ Dabei schloB Neumark offenbar alle - mit Ausnahme des von ihm erwähnten sozialen Wohnungsbaues - im EStG von den Grundnormen abweichende Begünstigungen, so etwa zur Förderung des allgemeinen Wohnungsbaues sowie des Schiffbaues, aber auch normabweichende Gewinnermittlungsvorschriften diese als marktinkonform bezeichnet - als gegen die Wirtschaftsordnung verstoßend ein. ${ }^{45}$ Sein Eintreten fur ein interventionistisches Steuerrecht richtete sich allein auf eine Globalsteuerung der Volkswirtschaft, die dann später 1967 im Stabilitătsgesetz ihr Handwerkszeug finden sollte.

Der schnelle Wiederaufbau der deutschen Handelsflotte wăre nach dem Votum deutscher führender Finanzwissenschaftler und Nationalökonomen unterblieben. Der Einsatz der Einkommensbesteuenung zur Problem!ösung wurde von Schmölders aus grundsătzlichen Erwägungen wegen des Verstoßes gegen marktwirtschaftliche Prinzipien mit der Folge drohender Fehlinvestitionen verworfen. Neumark lehnte eine derartige Verwendung von Steuernormen als "dirigistisch" ebenso grundsätzlich ab. Der zügige Wiederaufbau einer deutschen Handelsflotte als Folge der Einführung eines $\$ 7 \mathrm{~d}$ Abs. 2 EStG ist von ihnen daher auch nicht weiter verfolgt worden.

Da die Integration unterschiedlicher Besteuerungsideen in dem geltenden deutschen EStG unbekannt blieb, war die Frage der von Steuervergünstigungen ausgelösten Lastenverteilung dabei nur von untergeordneter Bedeutung. Die Frage der Verteilungsgerechtigkeit wurde erst zum öffentlich erörterten Problem, als der Einsatz von Steuervergünstigungen später ausuferte.

Die Einstellung Neumarks, die in weiten Bereichen Zustimmung fand. hat zumeist die Haltung der Finanzwissenschaften bestimmt. ${ }^{46}$ Die "dirigistischen", "punktuellen" Regelungen zugerechneten Vergünstigungsnormen, zu denen auch undifferenziert die Sonderabschreibungen nach dem Berlinforde-

${ }^{4}$ Neumark, F. (1970), Grundsätze der Besteuerung .... S. 50, S. 51.

4s Neumark. F. (1961), S. 147; s. a. Napp-Zinn. A. F. (1955). Rezension. in: FA. S. 538

${ }^{46}$ Neumark trat als Befũrworter einer interventionistischen Steuerpolitik auf und verlagerte durch seinen EinfluB das Schwergewicht der Wirtschaftssteuerung als Globalsteuerung von der Ausgabenauf die Einnahmenseite des Haushalts, s. Matthöfer, H. (1980), Fritz Neumark wird achtzig in: Die Zeit, Nr. 30, v. 18.7.1980. Neumark wurde zumeist als "Nestor der deutschen Finanzwissenschaft" gefeien, s. Penzlin, H., in: Die Welt v. 18.7.1980; FAZ v. 19.7.1980. Andererseits wurde der "Neumark-Effekt" beklagt, nämlich, daB an seinem Werk alles gemessen und "der Tatendrang" jüngerer Finanzwissenschaftler gelăhmt werde, FAZ, v. 13.10.1982. 
rungsgesetz und dem heutigen Fördergebietsgesetz gehören, fanden daher beì Finanzwissenschaftlern nicht die Aufmerksamkeit, die ihnen nach ihrer volkswirtschaftlichen Bedeutung hätte zukommen müssen.

Nun drängen gegenwärtig wiederum nach der Wiedervereinigung der Bundesrepublik Deutschland mit der ehemaligen DDR eine Vielzahl von Angeboten mit Aufforderungen zur Zeichnung von Anteilen an geschlossenen steuerbegünstigten Investmentfonds auf den Markt. Diese machen Gebrauch von den Abschreibungsfreiheiten, die nach dem neuen Fördergebietsgesetz für Aufbauleistungen im Großraum Berlin und in den neuen Bundesländern gewährt werden. ${ }^{47}$ Der wissenschaftliche Beirat bei dem Bundesministerium für Wirtschaft hat - wie wir bereits gesehen haben - auf die immense Bedeutung dieser Förderungsmaßnahmen für die strukturellen Anpassungen und die Eingliederung Ostdeutschlands in einer ungewöhnlichen Situation hingewiesen ${ }^{48}$

Die Inanspruchnahme der vielen durch Steuervergünstigungen gegebenen Möglichkeiten mit unterschiedlichen Risiken setzt für die angesprochenen Steuerbürger einen Überblick und neuartige Kenntnisse voraus.

Die steuerfinanzierten Kapitalanlagen werden daher von einem neu entstandenen und umfassender ausgebildeten Berufsstand, der in eigenen Praxen oder bei Banken und in Versicherungen tätigen Vermögensberatern, die sich Kenntnisse des Handels- und Steuerrechts erwarben. für Dispositionen der Sparer angeboten. ${ }^{49}$ Die Bildung großer Publikumsgesellschaften, die sich zum

47 Im Posteingang einer in amtlichen Verzeichnissen aufgeführten Steuerberatungspraxis finden sich heute wiederum fast täglich Angebote zur Zeichnung von Anteilen an geschlossenen Investmentfonds, die mit Steuervorteilen nach dem FördG werben, s. hierzu als Beispiel die aufgelisteten Angebote in der Fachzeitschrift Cash oder dem Anzeigenteil der überregionalen Tageszeitungen. Viele Betreiberfimen unterwerfen ihre Angebote freiwillig einer Analyse der Chancen und Risiken durch ausge. wiesene Fachleute, s, bspw. Cash. 13. Jg. Nr. 5 v. Sept. 1995. S. 139; ungekürzte Gutachten kōnnen bei Interesse angefordert werden.

48 Gutachten des Wissenschaftlichen Beirats beim Bundesministerium für Wirtschaft v. 15.7.1991. abgedr. in: Bundesanzeiger, 43. Jg. Nr. 153, v. 17.8.1991, hier Pos. IV Nr. 7. Das Gutachtergremium bejahte mehrheitlich das angelaufene "umfangreiche Förderungsprogramm" durch "Standortsubven. tionen", zu denen als wichtigste Maßnahme das FördG rechnet. Den Terminus "Sonderabschreibungen" vermied das Gutachten freilich.

49. Unter den Beratem gibt es oft unqualifizierte Mitarbeiter. Verschiedene Verbànde versuchten. bisher vergeblich, für den neuartigen Berufsstand Mindestausbildungsvoraussetzungen einzufuhren. Einige initiierten sogar erfolglos den Aufbau eines "Zentralregisters unabhăngiger Finanzdienstleister" (Zefi). Der Gesamtverband der deutschen Versicherungswirtschaft (GDV) suchte ergebnislos sein ausgebautes Berufsbildungswerk zur Sicherstellung einer notwendigen Mindestausbildung einzusetzen. Inzwischen findet zur Schaffung von Markttransparenz jährlich ein KongreB der Branche zu dem. Thema "Geld und Kapital" fur Alfinanzberater statt. Vor kurzer Zeit wurde von der Fernuniversitāt Hagen ein Studiengang "Finanzdienstleistungen" mit den Bereichen Kredit- und Finanzwirtschaft, Steuern, Rechtswissenschaft und Marketing mit einem Abschlußdiplom (MBA) geschaffen, s. Allfinanz-Report, I. Jg. 1993, Ausgabe 1. S. 2; s. a. Stahl, A. Streit ums Gütesiegel für seriöse Berater, in: Kölnische Rundschau v. 24.5.1995; Die Zukunft der Allfinanz. Beilage zu Cash Special 6/93: Lockruf des Geldes, in: Capital 3/95, S. 86; Steinreicher Scharlatan, in: Der Spiegel Nr. 23/95 v. 5.6. 1995; s. a. 
Ziel gesetzt haben, konkrete Investitionen zur Anreicherung der Infrastruktur im Beitrittsgebiet vorzunehmen, ist in Gang gekommen. In den Aufforderungen, Anteile an geschlossenen Fondsgesellschaften zu erwerben, wird oft offen darauf hingewiesen, daß der eigene Einsatz von Sparmitteln nur vorübergehend nötig bzw. ganz geringfügig sei. Da der Zeichnungsbetrag ganz oder zum großen Teil zeitgerecht aus ersparten Steuern gezahlt werden kann, wird sogar gelegentlich vorgeschlagen, gar keine Eigenmittel einzusetzen, sondern einen Bankkredit in offener Rechnung einzurichten, der gewissermaßen ohne liquide Belastung des Zeichners vom Fiskus durch Steuererstattungen getilgt wird. ${ }^{50}$ So tritt auch nach außen erkennbar der Fiskus an die Stelle einer Bank. Freilich geht diese Rechnung nur auf, wenn der Anteilszeichner infolge hoher Einkünfte einer entsprechend hohen Tarifprogression unterworfen ist. Im übrigen ist die liquide Belastung und die spätere Tilgung der Fremdmittel kalkuliert und im Regelfall aus den Einnahmen bestreitbar. Wie im Berliner sogenannten "Hexeneinmaleins" 51 erhallen Zeichner mit hohem Einkommen später wiederum Renditen und einen Verkaufserlös aus dem Nichts, ermöglicht durch die Finanzierungshilfe des Fiskus. Tatsächlich sind die Angebote heute durchweg sauber durchkalkuliert, die Prospekte sind zumeist von namhaften Treuhandfirmen geprüft und entsprechen dann den vom Institut der Wirtschaftsprüfer in Deutschland erarbeiteten Kriterien. ${ }^{52}$

Auch die von den Fondsgesellschaften verwendeten Musterverträge wurden offenbar seit den Anfängen der steuerbegünstigten Publikumsgesellschaften zur Mitte der 50er Jahre zweckentsprechend fortentwickelt. Dabei werden von

Lodermann, W., Berater für kleiner Vermōgen groB im Geschäft, in: Kölnische Rundschau v. 26.7.1993, S. 6; s. a. Wardenbach, H., Das Vermõgen erhalten, in: Welt am Sonntag v. 10. 9. 1995, S. 51.

${ }^{50}$ Hiera Kapitel E, Abschn. III und IV, dort auch Anlagen 16, 19, 24 u. a.

s1 Noch 1972 beurteilte der zustandige Redakteur der FAZ, Heinz Brestel, den Umstand, daß einem Anleger durch Zeichnung eines Kapitalanteils eine Verlustzuweisung zugerechnet wurde, deren Hôhe es dem Zeichner ermöglichte, die Kapitalhergabe für die Anlage ganz aus der Steuerersparnis zu bezahlen, in einem Leitartikel als "Abschreibungs-Ärgemis". Er meinte: "Das gleicht dem Hexeneinmaleins: Aus eins mach keins", s. FAZ v. 10.2.1972, S. 1. Er glaubte, die Zeit sei reif, "die ZweckmallBigkeit der Sonderabschreibungen als Instrument der Wirtschaîs- und Sirukturpolitik zu überprufen". Als Alternative wußte er jedoch nur hochmoralische fromme Wünsche beizutragen. Offenbar hatte er vôllig übersehen, was zu dieser Zeit offenkundig wurde und mit dem verstärkten Wiederaufbau Berlins nach dem Mauerbau eingesetz hatte: Die Zeichnungsbeträge von Anteilen an Abschreibungsgesellschaften aberstiegen die Zeichnung von neu aufgelegtem Beteiligungskapital über die deutschen Börsen, s. FAZ v. 28.12.1971, S. 13; Wirtschaftswoche v. 23.9.1972, S. 90; Die Zeit v. 5.12.1969, S. 39; s. a. Fleischer, E., Die Abschreibungs-KG - ein Hexeneinmaleins, in: StLex 3, 51-54, S. 17.

${ }^{52}$ WFA (1987), Grundsătze ordnungsmäBiger Durchführung von Prospektprūfungen. Das Gutachten stellt grundsătzliche Gesichtspunkte zusammen, die sich auf viele Prüfungsbereiche übertragen lassen; wichtig erscheint die Forderung (B Abs. 2), daß die Prospektprüfung dem Anleger eine Grundlage zu "der eigenen Beurteilung der Risiken und Chancen der dargestellten Tatsachen. Ausnahmen und Folgerungen" ermōglichen soll. 
den Initiatoren Gebilde des bürgerlichen Rechts (GbR) ebenso, wie Rechtsfiguren des Handelsrechts (Kommanditgesellschaft, Stille Gesellschaft, GmbH) wegen der unterschiedlichen steuerrechtlichen Konsequenzen für geeignete Gesellschaftskonstruktionen zur Verwirklichung konkreter Projekte verwendet. $^{53}$ Ziel der Initiatoren war stets, den Zeichnern von Gesellschaftsanteilen eine hohe Verlustzuweisung zuordnen zu können, dabei die Haftung der Gesellschafter möglichst auf die Einlage zu begrenzen, abzusichern, daß die Einnahmen und Ausgaben der Gesellschaft nach Beendigung der Anlaufphase ausgeglichen sind, sicherzustellen, daB die Fremdmittel aus den liquiden Überschüssen der Gesellschaft - wenn auch langsam - getilgt werden können und für den Zeichner jedenfalls nach Einzahlung der Einlage keine weitere liquide Belastung mehr entstehen kann. Denn den steuerlichen Vorschriften liegt die Vorstellung der Einheit von Anteilseigner und Betrieb zugrunde, was zur sogenannte "Bilanzbündeltheorie" führte. Im Falle steuersparender Kapitalanlagen sind diese Voraussetzungen im Innenverhältnis tatsächlich jedoch gar nicht gegeben. Weitere Zahlungsverpflichtungen des Zeichners nach der Anlaufphase würden das Interesse an der Anlage in der Regel empfindlich stören. ${ }^{54}$

Für vermögensverwaltende Abschreibungsgesellschaften sind wiederum andere vertragliche Gestaltungen zu beachten, als fuir eine als Gewerbebetrieb beurteilte Mitunternehmerschaft. ${ }^{55}$ Die in $\$ 15$ a EStG normierten und auch in $\S 21 \mathrm{EStG}$ angeführten Beschränkungen einer Berücksichtigung von Verlusten der Zeichner auf die Hőhe der Haftungssumme als Gesellschafter - eine Bestimmung, von der sofort Ausnahmen vorgesehen wurden - hat Rechtskonstruktionen entstehen lassen, die den unterschiedlichen Bedürfnissen des einzelnen Falles zu entsprechen suchen. Letztlich kann auch eine Refinanzierung des Anteilserwerbs oder eine Finanzierung von Teilbeträgen durch Dritte für

sil S. Böger, M./Raupach, A. (1973), Gesellschaftsformen und gesellschaftsrechtliche Probleme bei Abschreibungsgesellschaften, in: Radler, A. J./ Raupach, A., S. 43; s. hierzu: Schrōder, B. (1972), Gesetzliche Regelung für geschlossene Anlagefonds? in: Zeitschr. f. d. ges. Kreditwesen, 14. Jg., 1972, S. 640. Der Autor war der zustăndige Referent im BMF.

"W Nach Hueck, A. (1972), Gesellschaftsrecht, 16. Aufl., S. 94, ist die KG eine "Abart der OHG". Whahrend in der OHG als handelsrechtlicher Fortentwicklung der Gesellschaft nach BGB $(\$ 705 \mathrm{ff}$ BGB) alle Beteiligten im Grundsatz voll haften, gibt es bei der KG nur noch bestimmte Vollhafter und im abrigen Teilhafter. In den für Zwecke der geschlossenen Investmentfonds fortentwickelten Publikumsgesellschaften mit unbegrenzter Anzahl Beteiligter ist die im Prototyp der Personengesellschaft unterstellte und abliche persōnliche und geschäfliche Verbundenheit zerstōrt und nicht herstellbar, ja nicht cinmall gewollt. Die Beteiligung eines Teilhaftenden athnelt im Grunde eher derjenigen eines Aktionărs, s. hierzu Zybon, A. (1973), S. 418. Zybon spricht von Entartung. Die angepriesene Verlustzuweisung als Anreiz zum Beitritt beurteilte er als "schizophren".

5s. Hierzu: Costede, J. (1978), S. 23, hier S. 27; Bareis, H. P. (1981), S. 31. 
die Höhe der Haftung, die in eine Sonderbilanz eingestellt werden muß, von Bedeutung sein. ${ }^{56}$

Auch die Anforderungen an die Satzung für eine steuerliche Anerkennung als Mitunternehmerschaft hat in Finanzgerichtsurteilen inzwischen eine gewisse Klărung gefunden. Dies mag sich auf das Vertrauen in die Vertragsgestaltungen positiv auswirken.

Bei den uns interessierenden Abschreibungsgesellschaften ist die $\mathrm{GmbH}$ \& Co. KG die gebräuchlichste Vertragsgestaltung. Das in den $60 \mathrm{er}$ Jahren dieser Typenmischung entgegengebrachte Mißtrauen konnte inzwischen weitgehend ausgeräumt werden.

Die Prüfung der Prospekte mit Aufforderungen zur Zeichnung von Anteilen an Verlustzuweisunsgesellschaften ist zeitaufwendig und stellt infolge der stets notwendigen und unterschiedlichen fallbezogenen Komplikationen und nicht zuletzt wegen der Prifung der steuer- und zivilrechtlichen Konsequenzen hohe Anforderungen an den Zeichnungswilligen bzw. dessen Berater. Schon aus diesen Gründen profiliert sich seit einiger Zeit eine Gruppe von Fachleuten als sogenannte "Allfinanzberater". Sie vereinigen Kenntnisse über den Kapitalmarkt mit Erfahrungen auf steuer- und gesellschaftsrechtlichem Gebiet. Es handelt sich zumeist um ehemalige Mitglieder der rechts- und steuerberatenden Berufe oder um erfahrene Bank- oder Versicherungskaufleute, die oftmals in enger Verbindung zu Banken und Versicherungen tảtig werden.

Als Zeichner kommen, wie schon wiederholt ausgeführt, nur anlagesuchende Personen mit höherem Einkommen infrage, über deren Schutzbedürftigkeit unterschiedliche Auffassungen bestehen mögen. Letztlich können sie alle Zeichnungsunterlagen prüfen oder prüfen lassen und sich so Klarheit über das enthaltene Risiko verschaffen.

Seit dem 13. Subventionsbericht der Bundesregierung vom 11. November 1991 werden die steuerlichen Mindereinnahmen durch Inanspruchnahme der in $\S \S 2$ und 3 Fördergebietsgesetz normierten Steuervergünstigungen durch zusătzliche Sonderabschreibungen von $50 \%$ der Anschaffungs- oder Herstellungskosten als "flankierende Maßnahme zur zusätzlichen Investitionsförderung im Beitrittsgebiet" bezeichnet. Sie wurden für das Jahr 1991, wie wir bereits erfuhren, mit 1,450 Mrd. DM und für 1992 mit 1,505 Mrd. DM angesetzt. $^{5 ?}$

${ }^{56}$ Hierzu: Kapitel E, Abschnitt III, dort Anm. 55.

${ }^{57}$ Bericht der Bundesregierung über die Entwicklung der Finanzhilfen des Bundes und der Steuervergünstigungen für die Jahre 1989 bis 1992 (dreizehnter Subventionsbericht), hrsg. v. BMF 1991, Drs. $12 / 25$, S. 14, S. 176. 
Die entsprechenden Titel in dem 7. Subventionsbericht für die Jahre 1973 bis 1976 vom 22. Oktober 1975 hatten noch eine andere amtliche Begründung angeführt, nämlich "Stärkung der Wettbewerbsfähigkeit und Schaffung von Arbeitsplätzen in Berlin". 58

$\mathrm{Zu}$ dieser Zeit um 1976 bekämpfte die Finanzverwaltung die Abschreibungsgesellschaften noch unter der Bezeichnung "mißbräuchlicher Ausnutzung von Steuervorteilen". ${ }^{59}$ Inzwischen hat sich eine andere Beurteilung durchgesetzt. Manche Gemeinde und Gebietskörperschaft öffentlichen Rechts macht heute gern von der Möglichkeit Gebrauch, die Hilfe von Initiatoren von Abschreibungsgesellschaften zur Beseitigung von Wohnraumproblemen, zur Sanierung ganzer Stadtviertel, zum Bau von Amtsgebäuden, Versorgungseinrichtungen etc., in Anspruch zu nehmen. Gemeindezentren großer Städte wurden auf diese Weise bereits aus "steuerfinanzierten Kapitalanlagen" alimentiert. Damit nimmt die Gemeinde oder überhaupt die öffentliche Hand den Fiskus, an dessen Ertragshoheit sie selbst über Steuern teilnimmt, zur Finanzierung ihrer Strukturinvestitionen wie eine Bank in Anspruch. Die Regierung schätzt offenbar den Wandel des Charakters der Steuervergünstigungen inzwischen richtig ein. ${ }^{60}$

Es würde von Interesse sein, Einzelheiten über die Vorgehensweise bei Schătzung der Höhe des eingestellten Minderungsbetrages im Subventionsbericht zu erfahren. Zwischen den von Abschreibungsgesellschaften in Berlin in den 70er Jahren nachweislich vereinnahmten Kapitaleinlagen und den im 7. Subventionsbericht eingestellten Beträgen für Steuerminderungen zu $\S \S 14$ und 14 a BerlinFG läßt sich aber keine erklärende Beziehung finden. Gleiches ist über die in den 13. Subventionsbericht für die Jahre 1991 und 1992 eingestellten Mindereinnahmen zu sagen. ${ }^{61}$

3t Bericht der Bundesregierung aber die Entwicklung der Finanzhilfen des Bundes und der Steuerverganstigungen für die Jahre 1973 bis 1976 gemäß $\S 12$ des Gesetzes zur Förderung der Stabilităt und des Wachstums der Wirtschaft (StWG) v. 8.6 .1967 (fünfter Subventionsbericht) v. 22.10.1975, Dr. Bundestag, 7. Wahlperiode, Drs. 7/4203, S. 193.

59 Aktuelle Beiträge zur Wirtschafts- und Finanzpolitik v. 29.4.1976, Nr. 103, hrsg. v. Presse- und Informationsamt der Bundesregienung; s. a. Friedemann, J., Der Tod einer Branche, in: Die Zeit v. 30.6 .1978 , S. 25 ; s. a. BB (1976), S. 450; BB (1976), S. 1649; BB (1977), S. 576; BB (1977), S. 930, S. 1534.

*o Friedemann, J., Abschreiben im Rathaus, Geldmangel zwingt die Kommunen zu ungewōhnli. chen Finanzierungsmethoden, in: Die Zeit v. 9.1.1976, S. 17: s. a. Cash, 11. Jg. Nr. 4, Juli 1993, S. 61; Cash, 13. Jg. Nr. 3, Mai 1995, S. 124; Wirtschaftswoche, Nr. 9/95, S. 19.

"1" Die fragwürdige Aussagekraft des Subventionsberichts gibt regelmäig Anlaß zu kritischen Ausfuhrungen, s. Uhlmann, R. "Kuddelmuddel", in: Handelsblatt v. 1.9.1995, S. 5. Im 5. Subventionsbericht der Bundesregierung v. 22.10.1975 wurden für die Jahre 1973 bis 1976 Steuermindereinnahmen wegen $\$ 14$ BerlinFG von 310 Mio. DM, 340 Mio. DM, 290 Mio. DM und 290 Mio. DM aufgeführt; diejenigen wegen $\S 14$ a wurden auf 25 Mio. DM, 30 Mio. DM, 20 Mio. DM und 20 Mio. DM festgelegt. Insgesamt ergab das für diese Zeitspanne Steuermindereinnahmen von 1.325 Mio. DM. Der 
Eine Befragung von nư 98 geschăftsmäBig tătigen Initiatoren von Kapitalanlagen durch Beteiligung an Abschreibungsgesellschaften hat für das Jahr 1992 ergeben, daß Zeichnungen von Anteilien an steuerinanzierten Kapitalanlagen in Höhe von über 10 Mrd. DM erfolgten. Die zugrundeliegenden Projekte betrafen im wesentlichen Investitionen in den neuen Bundesländern. Dabei stellten die Angaben der 98 Unternehmen, die die Nachfrage einer Fachzeitschrift der Branche beantworteten, nur eine Teilgruppe von 304 bekannt gewordenen, als "Kapitalanlageinitiatoren" tătigen Unternehmen dar. ${ }^{62}$ Hinzu kommen viele kleine Gemeinschaften in unterschiedlicher Rechtsform und Einzelpersonen, die von der Vergünstigung Gebrauch machen und bereits 1992 Investitionsausgaben im Rahmen eines Projektes im Fördergebiet tätigten. Die genannten 98 größeren initiatoren planten nach der angestellten Befragung im Jahr 1992 Investitionen in Hohe von ca. 25 Mrd. DM. ${ }^{63}$ Dieser Betrag dürfte ebenso als Mindestsumme einzusetzen sein, wie die von uns früher im Falle Berlins hochgerechneten Zahlen Mindestbetrăge waren. Viele vergleichbare steuerbegünstigte Investitionen werden nicht von gewerbsmäßig auf diesem Gebiet tătigen Interessenten vorgenommen.

In den etwa 100.000 Kanzleien der rechts- und steuerberatenden Berufe in der Bundesrepublik gehen heute wiederum täglich Prospekte mit Aufforderungen zur Zeichnung von Anteilen an geschlossenen Fondsgesellschaften ein, die größere Investitionsvorhaben betreffen. Wiedenum wird, wie in den 70er Jahren, von den Betreibern um Vermittlung von Interessenten gebeten, die die wirtschaftlichen Voraussetzungen für eine Beteiligung erfüllen.

Fragen wir uns nach der Größenordnung von potentiellen Zeichnern derartiger steuerfinanzierter Anteile an Fondsgesellschaften, so ergibt sich, daß alle Steuerpflichtigen infrage kommen, deren Einkommen 100.000.-- DM pro Jahr übersteigt. Nach der letzten amtlichen Steuerstatistik für das Jahr $198 \overline{8}$ gibt es in der Bundesrepublik (Altländer) etwa 790.000 Personen mit lohnsteuerpflichtigen Bezügen von über $100.000,-$ DM und zusătzlich über 920.000

errechnete Betrag fût die während dieser Zeit gezeichneten Anteile an geschlossenen Fonds in Form von im Handelsregister erfaßten Publikumsgesellschaften mit Investments nach $\S \S 14$. 14a BerlinFG betrug allein 2.7 Mrd. DM. Dazu kommen noch die Investitionen, die nicht uber den grauen Kapitalmarkt finanziert wurden. Diese Investments haben in vielfacher Hōhe zu vereinnahmten Lohn-, Einkommen-, Umsatz-, Gewerbe-, Kồperschafisteuem etc. gẹührt. Darüber hinaus wurde Arbeitslosenunterstützung und Sozialhilfe eingespart.

${ }^{62}$ Aufaddient ergeben die allein von 98 Gesellschaften gemeldeten Beträge für gezeichnete Anteile privater Anlager 1991 insgesamt 14.637 Mrd. DM. Vorsichtshalber wurde bei der Ermittlung unterstellt, daß nur $2 / 3$ davon, also 10 Mrd. DM, das Fördergebiet betreffen, s. hierzu Cash, 11. Jg. Nr. 6 v. Juli I993. S. 40.

${ }^{63}$ Cash, 11. Jg., Nr. 6 v. Juli 1993, S. 28, S. 40. 
Steuerpflichtige mit einem Gesamtbetrag der Einkünfte in gleicher Höhe. ${ }^{64}$ Diese etwa 1,7 Mio. Personen können infolge ihrer Einkommensverhältnisse ohne oder mit nur geringer Einbuße an Liquidität die Kosten des Erwerbs eines Anteils - bei Abstimmung des Beteiligungsbetrages mit den eigenen Liquiditătsverhältnissen - vom Fiskus aufgrund einer steuerlichen Verlustzuweisung durch Einsparung von Einkommen-, Kirchensteuer und eventuell Gewerbesteuer und derzeit Stabilitätszuschlag zurückerhalten. Im übrigen müssen die Zahlen infolge der zeitlichen Veränderungen von 1988 auf 1992 hochgerechnet werden.

Nach $\S 32$ a EStG beträgt heute der höchste Tarifsatz 53\%, der bei einem Einkommen von 120.034,-- DM erreicht wird. Hinzu kommt die Kirchensteuer mit 8\% oder 9\% des Einkommensteuerbetrages (ohne Kappung). Ab 1995 wird ein zusätzlicher Solidaritätszuschlag von $7,5 \%$ erhoben. $^{65}$

Im Falle der vermögensverwaltenden Personengesellschaften kann bei Veräußerung des Anteils je nach Gestaltung auch noch ein steuerfreier Liquidationsüberschuß erzielt werden.

Vermögensberater, die sich selbst heute als "Allfinanzberater" verstehen, sehen neuerlich sogar Veranlassung, den Kunden cine völlige Umschichtung ihres Vermoggens anzuraten: Die privaten Haushalte verfügen über Vermögenswerte in Höhe von ca. 7.000 Mrd. DM. Darin ist das Netto-Geldvermögen mit 3.250 Mrd. DM enthalten. 500 Mrd. DM werden heute noch auf Sparkonten mit gesetzlicher Kündigungsfrist gehalten. Die hinzugekommenen Sparleistungen betrugen im Jahr $1992 \mathrm{ca} .250 \mathrm{Mrd}$. DM. ${ }^{66}$ Angesichts dieser GröBenordnungen wird verständlich, daß ein erfolgversprechender Anreiz darin besteht, hochverdienenden Steuerpflichtigen den Erwerb steuerfinanzierter Anteile an Vermögenswerten, eventuell durch bloße Vermögensumschichtung, anzuraten, die infolge der Verschaffung, von Miteigentum an Sachwerten vor Preisverfall geschützt erscheinen und deren Anschaffung obendrein nur wenn überhaupt - geringe Liquiditätseinbußen verursachen. Soweit erkennbar ist, wird von diesem Angebot, an dem vor allem die Berater großes Interesse haben, umfangreich Gebrauch gemacht.

\footnotetext{
G4 Statistisches Jahrbuch 1994 für die BRD, S. 545. Die Ziffern betreffen die Auswertung der Steuerstatistik des Jahres 1988. Diese liegt wegen der Veranlagungsvorgănge immer erst ca. 6 Jahre spăter vor.

os Von den Initiatoren geschlossener steuerorientierter Investmentfonds wurde und wird die Einfuhrung des Solidaritătszuschlages als geschäftsfordernd begrüBt und sofort werbemäBig fûr die Angebote zur Zeichnung von Anteilen an geschlossenen Investmentfonds benutzt, s. Cash 2/95, S. 119 u. a.

${ }^{66}$ Die Zahlen wurden dem Einleitungsreferat von Prof. H. Jïrgensen anläBlich der Eröffnung des Kongresses der Allfinanzberater mit dem Thema "Geld und Kapital" in Hamburg am 19.3.1993 entnommen, s. Cash, 11. Jg., Heft 6 v. Juli 1993, S. 114; s. a. Referat von K. Jäger, dortselbst, S. 110.
} 
Die Konsequenzen der 1949 in das Einkommensteuergesetz eingefügten $\mathrm{Ab}$ schreibungsvergïnstigungen sind inzwischen weitreichend. Von Neumark und anderen führenden Finanzwissenschaftlern als "dirigistisch", "nicht marktkonform", "ungerecht" und "irrational" gnundsätzlich abgelehnt, haben diese Bestimunungen eine Bedeutung erlangt, die zumindest in Zeiten starker Umbrïche eine - volkswirtschaftlich beurteilt - wichtige Rolle übernahmen und noch übernehmen werden. Der im Beitrittsgebiet gerade auch von der Treuhandanstalt als größtes Investitionshenmmis bezeichnete Mangel an geeigneten gewerblich nutzbaren Räumen, fehlenden Gewerbe- und Wohnzentren nebst den erforderlichen städtischen. Einrichtungen, die Unmöglichkeit, notwendige Vorrichtungen auf Zeitbasis zu leasen und vieles mehr, sind Engpăsse, die im Laufe der Zeit durch Verlustzuweisungsgesellschaften beseitigt oder jedenfalls gemildert werden können.

Durch Förderung der Gründung dieser An Gesellschaften ist der Fiskus in eine völlig neuartige Rolle hinübergeglitten. Vergünstigungen durch Sonderabschreibungen können nicht mehr als Subventionen bezeichnet werden. Sie gehören in einem übertragenen Sinne zu bankähnlichen Geschäften des Fiskus, die in der Bankbetriebslehre als "Aktivgeschäft" bezeichnet werden. Die Zunahme des Sozialproduktes führt zu höheren Steuereinnahmen und dies entspricht den Zinseinnahmen der Banken für die hingegebenen Darlehen. Sonderabschreibungen vermögen die Wirtschaft bei sinnvoller Steuerung in großem Ausmaß zu beleben. Unter Subventionen sind diese Maßnahmen fehlerhaft eingeordnet. ${ }^{6 ?}$

Die Finanzwissenschaften haben die hier auftretenden Fragen wegen ihrer ablehnenden Grundhaltung zu sogenannten "dirigistischen" steuerlichen Maßnahmen nicht weiter verfolgt. Anstelle pauschaler positiver Bewertung oder Ablehnung von Steuervergünstigungen als solchen sollten sie sich vermehrt

\footnotetext{
67 Zügige Vorbereitung. Planverwirklichung und Kalkulationssicherheit bei Einsatz privater Gesellschaften als Bauträger von Infrastrukturinvestitionen nach einem Fondsleasingmodell sind von hohem Reiz gegenüber der Ingangsetzung einer schwerfälligen Verwaltung. Aber: Erst die regelabweichende Abgabenvergünstigung durch die intertermporale Verschiebung des Besteuerungsgutes als Folge der gewährten Sonderabschreibungen im EStG beim Leasinggeber (s. Kapitel E IV) bereitet die winschaftliche Grundlage für diese Finanzierungsform. Dabei wirkt sich die Verpflichtung zu einer Ablösungszahlung bei Ablauf der Finanzierungsphase wie ein Fälligkeitstermin für Darlehensschulden aus und bedarf der Berücksichtigung in der öffentlichen Finanzplanung der Gebietskörperschaften, s. Art. 110 Abs. I S. 1 GG: s. von Arnim. H. H. (1992), S. 192. Die Finanzministerin des strukturell benachteiligten Bundeslandes Mecklenburg-Vorpommern übernahm inzwischen eine Pionierrolle bei der Entwicklung neuartiger Ausweismöglichkeiten im Landeshaushalt zur Gewährleistung der verfassungsmäBigen Funktion des Haushaltsrechts bei privatwirtschaftlicher Finanzierung unumgănglicher staailicher Baumaßnahmen durch Fondsleasingmodelle, wie z. B. die JVA Warnemūnde und das LBA Neustrelitz, s. Kleedehn, B. (1996); s. a. Büschgen, H. E./ Ergenzinger, T. (1993), S. 77, S. 99; s. a. Cash 6/95, S. 151 u. Beilage, S. 44.
} 
der Untersuchung der Wirkungen alternativer Besteuerungsvorgänge und deren zieladăquater $Z$ weckmäßigkeit widmen. ${ }^{68}$

Inzwischen bahnt sich nämlich eine Entwicklung an, in der dem Fiskus eine völlig neuartige Rolle zuwächst.

Im Falle der Fortsetzung würde dies für die Zukunft umwälzende, noch nicht absehbare wirtschaftliche Auswirkungen mit sich bringen. Der Fiskus würde dann die dargestellten Funktionen bei der Finanzierung von Investitionen gegen andere Dienlichkeiten eintauschen.

Auch hierin zeigt sich wiederum die Flexibilität, die ein Besteuerungskonzept, ohne in innere Widersprüche zu geraten, in sich birgt, dessen wichtige Bestimmung der steuerlichen Bemessungsgrundlage nicht an einem explizit und unabhångig definierten Begriff für Leistungsfähigkeit festgelegt ist, wobei diesem nach Auffassung führender Steuerrechtslehrer jedoch systemtragende Bedeutung von Verfassungsrang beigemessen wird. ${ }^{69}$

${ }^{o 8}$ In modernen Lehrbidchern der Finanzwissenschaft werden zwar die Wirkungen steuerpolitischer Malnahmen behandelt, die Ausfuhrungen beschranken sich jedoch auf formale modelltheoretische Darstellungen ohne konkreten Realitătsbezug, wobei obendrein die Aufmerksamkeit allein der Stabilisienung der wirtschaflichen Globalgroßßen gewidmet wird, s. etwa Brûmmerhoff, D., S. 391, S. 421; Gaddum, W. (1980); Andel, N. (1983), S. 250; von Arnim, H. H. (1985), S. 156, S. 188; Woll, A. (1992); Peters, H. R. (1995); Peters, H. R., M. E. (1991); Molitor, B. (1995), S. 120, S. 215, S. 260. Das Versilumnis, den wirtschaftspolitischen Einsatz von Einkommensteuervergunstigungen in theoretische Abhandlungen einzubeziehen, grenzte bisher die Frage, "was kann der Staat in einer Marktwirtschaft wirklich leisten?" so Willgerodt, H. (1984), S. 60 unnōtig ein. Der praktische Wert der Beiträge und Lehrbücher herausragender wissenschafticher Vertreter der "sozialen Marktwirtschaft" Ieidet unter diesem Mangel. Auch in den diesbezäglichen Gutachten der Wissenschaftlichen Beirâte beim BMWi und BMF, deren Mitglieder zu den fuhrenden Rechtswissenschaflen, Nationalökonomen, Finanzwissenschaftlem, Sozial- und Wirtschaftspolitiken zahlen, sucht man vergeblich nach zweckdien!ichen Ausführungen aber deu Einsatz von Abgabenvergünstigungen als marktkonformern Hilfsmittel "staatlicher Interventionen in einer Markiwirtschaft", s. Gutachten v. 15./16.12.1978, in: Der wissenschaftliche Beirat beim BMFi, 10. Bd. 1980, S. 895, hier S. 948: desgl. Gutachten v. 17./18.12.1989, 13. Bd., S. 1481; s. a.: Der wissenschafliche Beirat beim BMFi v. 14.2.1953 und v. 11.2.1967, in: Gutachten und Stellungnahmen $1949-1973$, Bd. 1, S. 54, S. 326. Unter fünf aufgefụhrten "Prămissen gesamtdeutscher Wirtschaftspolitik" erwähnte 1990 der Vorsizzende des Wisserschatilichen Beirats beim BMWi regionalpolitische Maßnahmen in Form von "Steuervergûnstigungen oder offentlichen Zuschüssen zur Investition" noch in abwertender Weise, wobei er einralumte, da B "Investitionsprämien unter den gegebenen Umstănden am ehesten tolerabel" seien, Watrin, C. (1990). S. 3, S. 6. Der Wissenschaftliche Beirat muBte dann im Gutachten v. 15.7.1991 die Bedeutung der im wesentlichen aus Steuervergunstigungen bestehenden staatlichen Investitionshilfen in den neuen Lândern aber als wichtigstes, "nicht mehr steigerungsflhiges wirtschaftspolitisches Hilfsmittel" zur Problembewaltigung herausstellen, s. Bundesanzeiger Nr. 153, 1991, S. 5554. Es bleibt abzuwarten, ob der Beirat in dem derzeit bearbeiteten neuerlichen Gutachten zur Lohnentwicklung trotz der Bedenken zui den Vorschlägen stärker sektoral, regional und zeitlich differenzierter Einkommensteuervergünstigungen Stellung nimmt. Auch Giersch bezieht Steuervergûnstigungen, als "Datenvariation" bezeichnet, nicht in seine der "Konjunktur- und Wachtstumspolitik in der offenen Gesellschaft" dienenden "grundsătzlichen Oberlegungen zur Verstetigungspolitik" ein, Giersch, H. (1977), S. 145; s. a. Pohmer. D. (1993), S. 586.

69 Hierzu Kirchhof, P. (1985), S. 319, hier S. 323, S. 324; ders. (1988), S. F 19, S. F 23; ders. (1982), S. 309. Es ist zu bericksichtigen, daB die Verfassung der BRD die in Art. 134 WRV enthalte- 
Die Änderung, die uns nachfolgend interessieren muß, ist die in das EStG neu eingefügte Tarifvorschrift des $\$ 32 \mathrm{~d} \mathrm{EStG}$ als. Folge des Urteils des Bundesverfassungsgerichts vom 25 . September $1992{ }^{70}$

Die Ausgestaltung der Bundesrepublik zu dem in Art. 20 Abs. 1 GG vorgeschriebenen "demokratischen und sozialen Bundesstaat" hat im Zusammenhang mit der in Art. 1 Abs. 1 GG festgeschriebenen Unantastbarkeit der Würde des Menschen bei Fortentwicklung des erreichten Wohlstandes zu dem Aufbau einer unübersichtlichen Vielzahl voneinander getrennter, mit Rechtsansprüchen versehener, zu einem neuartigen Sozialrecht rechnender Leistungsgesetze geführt. Die darin normierten Transferleistungen werden jeweils von unterschiedlichen Bundes-, Landes- oder Gemeindebehörden verwaltet und abgewickelt.

Zumeist wird in diesem Zusammenhang von einem "sozialen Netz" gesprochen, das als Eirgănzung zur Marktwirtschaft für den notwendig werdenden "sozialen Ausgleich" sorgt und die "soziale Marktwirtschaft" auszeichnet.

Nach diesem Ausbau erfolgten bald von Seiten der Finanzrechtsprechung zur harmonisierenden Auslegung vergleichbarer Begriffe der Steuernormen mit denen des Sozialrechts Rückgriffe auf dessen zeitnahe Festsetzungen.

So wurden etwa für Ausbildungsfreibeträge ( $\$ 33$ a EStG) Bestimmungen des Sozialrechts wie eine "negative Einkommensteuer" bei Ermittlung der Bemessungsgrundlage oder der Höhe des Tarifzugriffs durch Progressionsvorbehalt ( $\$ 32$ b EStG z. B. im Falle von Arbeitslosengeld) beurteilt und mußten jeweils bei der Veranlagung berücksichtigt werden. ${ }^{71}$

Die Notwendigkeit für die einzelnen voneinander unabhängigen verschiedenen Transfers, eine sachgerechte Ermittlungsweise vorzuschreiben, hat zu einer Vielzahl verschiedener unvergleichbarer Bemessungsgnundlagen des

\footnotetext{
ne Bestimmung nicht ûbernommen hat. Da die mit der WRV verbundenen Erfahrungen die Ausgangsgrundlage für das GG v. 23.5. 1949 bildeten. mäBte man wegen des Schweigens des Verfassungsgesetzgebers $z u$ diesem Punkt gewiB mit formell größerer Berechtigung aus den wenigen Sătzen des Verfassungstextes genau entgegenstehende Folgerungen ziehen, zumat bei Schaffung desselben andere Priorităten im Vordergrund standen. P. Kirchhof ist Steuerrechtslehrer und Richter am 2. Senat des BVerfG; s. Tipke, K. (1993), Steuerrechtsordnung, S. 490; Kirchhof, P /Sōhn , H. (1992), § 2 RdNr. A 68.

${ }^{70}$ Urteil des BVerfG 2 BvL 5, 8, 14/91 v. 25.9.1992, in: BVerfGE $87 \mathrm{Nr}$. 10, S. 153; $\$ 32 \mathrm{~d} \mathrm{EStG}$ 1993 ist wiedergegeben in Anlage 30.

${ }^{71}$ S. Buob, H. (1988), S, 170.
} 
Sozialrechts als Ausgangspunkt für die Ermittlung des jeweils vorgeschriebenen Leistungssolls geführt. ${ }^{72}$

Ein übergeordneter einheitlicher Einkommensbegriff für die Berechnung ergänzender, dem einzelnen Bürger das Existenzminimum garantierender öffentlich-rechtlicher Unterstützungsmittel als Ausgangsgröße bietet sich schon wegen der unterschiedlichen Leistungsziele nicht an. ${ }^{73}$

Obgleich die Bemessungsgrundlage des EStG als Grundmuster diente, erscheint eine weitere Harmonisierung von Einkommensteuer- und Sozialrecht schwer durchführbar. Tatsächlich müssen die einzelnen sozialen Leistungsgesetze nämlich unterschiedlichsten sozialpolitischen Zielsetzungen genügen. ${ }^{74}$

Örtliche und persönliche Merkmale, wie Gemeindegröße, Vermögensbesitz und dessen Art und Verkehrsfähigkeit, vorgegebene bestehende Unterhaltspflichten oder Unterhaltsrechte. Gesundheit und körperliche Fähigkeiten, Ausbildung und Familiengröße des Hilfsbedürftigen und im Einzelfall vieles mehr kommen neben der Höhe der Erwerbsbezüge als Indizes für die Bemessungsgrundlage des Ergänzungsbedarfs nach den einzelnen sozialen Leistungsgesetzen infrage. ${ }^{75}$

Hierin zeigt sich die zur Abwehr wachsender mißbräuchlicher Bewirkung öffentlicher Unterstützungen streng am Subsidiaritätsprinzip orientierte Organisation des Sozialrechts.

Die für das Einkommensteuerrecht maßgebliche Bemessungsgrundlage berücksichtigt demgegenüber wegen der Ausrichtung am Gleichmäßigkeitsprinzip allein dic Verwirklichung der im Gesetz aufgeführten Tatbestandsmerkmale im Sachverhalt. Soziale Indizes, die zu Freibeträgen oder Tarifbegünstigungen führen. bezichen sich dabei nur auf allgemeine. vergleichbare persönliche Merkmale des Steuerpflichtigen und berücksichtigen in der Regel nur die tatsächlichen Wertaugänge des steuerbaren Einkommens eines Kalenderjahres, da auf die Solidarität der Steuerbürger in bezug auf diesen Abschnitt abgestellt wird.

Zeppernick, R. (1986), S. 17; s. a. Institut Finanzen und Steuern (1985): hier werden die Eirkommensbegrifte von 16 teistungsgesetzen gegenubergestellt, das Wohngeldgesetz kennt 32 Einnahmearten, die außer Betracht bleiben.

"Zeppernik: R. (1986), S. 18.

${ }^{24}$ Uelner. A. (1995), darin S. 4. S. 5: 7um Verhaltnis Finkommensteuerrecht/Sozialrecht. Uelner war lange Jahn Abteilungsleiter der Steuerabteilung im BMF.

" Ilisrzu: Dentsche Stener-(iewerkschaft (1995). Finaryamt auf dem Weg zum Transferamt. in: DSTG, Juni 1995, S 84. 
Die Menge der unterschiedlichen Bemessungsgrundlagen und ihre verschiedenen. Zielen dienenden Konzeptionen stehen einer einfachen Transparenz und einer Harmonisierung der Ansătze daher unvermeidlich im Wege.

Dennoch übt auf viele Finanzwissenschaftler und Politiker seit lăngerer Zeit die Idee einer Vereinheitlichung und Zusammenfassung der zuständigen Behörden unter einem Dach und die Ausgestaltung der Finanzămter zu neuartigen "sozialen Transferämtern" eine hohe Faszination und Zugkraft aus. ${ }^{76}$

Viele Politiker sehen die Lösung zur Vereinfachung der unübersichtlichen, zersplitterten und sich jeweils ergänzenden Transferleistungen in einer grundlegenden Reform der direkten Steuern und persönlichen Unterhaltshilfen zu einem integrierten Personalsteuer- und Subventionssystem, das nach einem Gedankenexperiment durch Umbau der Finanzämter zu "sozialen Transferämtern" geschaffen werden könnte. ${ }^{77}$

Wegen der unterschiedlichen Bemessungsgrundlagen der zum Sozialrecht zăhlenden Gesetze wird es dabei aber erforderlich, bei niedrigeren Einkommen zusătzlich die Summe der gesamten, dem Lebensunterhalt dienenden "Erwerbsbezüge" des Steuerbürgers zu ermitteln und nicht nur das eingeschränkte, gemäß EStG steuerbare Einkommen. ${ }^{78}$

Erreichen die Erwerbsbezüge bei der Veranlagung dann nicht den im Sozialrecht amtlich festgelegten Regelbedarf des Existenzminimums, soll vom Finanzamt als Transferamt ein sogenanntes "Bürgergeld" die Summe der personenbezogenen monetären Teilleistungen sämtlicher bisher zersplitterter Sozialbehörden, wie z. B. Kindergeld. Wohngeld, Ausbildungsförderung. Sozialhilfe, sonstige wirtschaftliche Hilfen der Jugend-. Versorgungs- und Gesundheitsämter sowie die redistributiven Geldleistungen der gesetzlichen Sozialversicherungen und diverser Objektförderungen ergänzend zur Verfügung gestellt werden. ${ }^{79}$

Dabei müßten dann auch neben dem Familienstand mit gestaffeltem Gnundbetrag Zuschläge für besondere Bedürfnislagen, wie Umschulung. Ausbildung, Invalidität, Krankheit oder Unterkunftsnotlagen Berücksichtigung finden. ${ }^{80}$

${ }^{76}$ DSTG (1988), S. 168.

"Mitschke, J. (1978), Umverteilung. Politiker im Normengestrüpp. in: Wirtschaftswoche Nr. $48 \mathrm{v}$. 24.11.1978, S. 84, S. 113, S. 117; s. a. Molitor. B. (1995), S. 268.

77. Der Begriff "Erwerbsbezüge" muBte neu in das Einkornmensteuerrecht als umfassender Terminus, der zu den steuerbaren auch bestimmte nicht steuerbare Zuflusse einschließt. eingefügt werden. um Korrekturen bei Anwendung des Tarifs durchführen zu kōnnen, wenn Transferleistungen zu berũcksichtigen sind, s. Anlage 30; s. Art. 19 Abs. 3 FKPG v. 23.6.1993, in: BGBI. 1. S. 944.

${ }^{79}$ Mitschke, J. (1978), wie Anm. 77. S. 111:DSTG, wie Anm. 73. S. 59. S. 83.

89. DSTG (1995), Finanzamt auf dem Weg zum Transferamt, in: DSTG Juni 1995, S. 84. 
Als Gedankenmodell eignet sich eine solche Problemlösung vorzüglich zur Vereinfachung vorhandener Regelungen. Ob hieraus eine praktikable Lösung für Massenverfahren, mit denen das Steuerrecht zu tun hat, entwickelt werden kann, muß vorerst jedoch offen bleiben. Skepsis ist jedenfalls angebracht.

Einzelne durchaus realistische Politiker lockt auch die Möglichkeit, den Finarzämtern heute bereits die Auszahlung eines "Bürgergeldes" als negativer Einkommensteuer zur Entlastung des Arbeitsmarktes aufzuerlegen. ${ }^{81}$

Dabei soll ein "Bürgergeld" die Lücke zwischen dem Lohn, den ein Arbeitsplatz tragen kann, und dem Einkommen, für das der Bürger zu arbeiten überhaupt erst willig ist, schließen. Diese Politiker glauben sogar, das für die Gesamtausrichtung der Fördenungsmaßnahmen zu beachtende Subsidiaritätsprinzip werde auf diese Weise gestärkt, "wenn das Bürgergeldsystem durch Arbeitsplätze die Chancen für eigenverantwortliches Leben wieder erhöht" ${ }^{12}$

Vielfach wird heute sogar von qualifizierten Fachleuten die Auffassung vertreten, eine derartige Umstellung der Finanzämter zu neuartigen sozialen Transferbehörden führe zu mehr Transparenz, zur Vereinfachung der Verwaltung und damit zu Einsparungen und vor allem zu mehr Gerechtigkeit. Im Konzept können diese Gedankenexperimente bestechend sein.

Nach der Theorie könnten die Ersparnisse dann obendrein in den Haushalten der Sozialverwaltungen sogar die als negative Einkommensteuer oder kurz "Negativsteuer" an Bürger ausbezahlten Betrăge voll ausgleichen.

Nun hat das Bundesverfassungsgericht in dem erwähnten Urteil vom 25. September 1992 derartigen Spekulationen neuen Auftrieb gegeben. Wegen der großen Tragweite des Urteils müssen wir hier darauf eingehen.

Das Gericht hat nämlich für Recht erkannt, daß die tariflichen Grundfreibeträge des EStG den Regelsătzen des Sozialrechts für das Existenzminimum entsprechen müssen. Seit Verdrängung des sogenannten Manchester-Liberalismus und Zurücktreten des Glaubens an das aus dessen theoretischer Grundlage hergeleitete "eherne Lohngesetz" nach 1850 durch eine aufkommende "ethische Nationalökonomie" und eine sich bildende sozialpolitische Richtung im deutschen Sprachraum hatte die bis dahin vorherrschende Überzeugung von dem Zusammenhang zwischen Existenzminimum und Besteuerung ihre

\footnotetext{
3i Lambsdorff. Graf O. (1994), Bürgergeld schafft Anreize für reguläre Erwerbsarbeit, in: Handelsblatt v. 3./4.6.1994, S. 3: s. a. Mitschke, J. in: FAZ v. 16.12.1995, S. 17.

${ }^{82}$ Hierzu s, die Kritik von H. Siebert: Bürgergeld - ein Fehlanreiz, in: FAZ v. 14.1.1995, S. 11: s. a. in: Handelsblatt v. 27.5.1994, Nr. 104, S. 2. Siebert weist uberzeugend auf die Konsequenzen einer Veränderung der Anreizstruktur durch das Belohnungssystem für die gesamte Volkswirtschaft hin, s. ders, in: Wirtschaftswoche v. 13.5.1994, S. 26.
} 
Bedeutung verloren. Deren theoretische Grundlage wurde als überholt verworfen. $^{83}$

Die maßgeblichen, im "Verein für Socialpolitik" verbundenen Nationalôkonomen traten nun für die Zulassung von Gewerkschaften, für Lohnerhöhungen, für die Einfuhrung und soziale Ausgestaltung des Versicherungswesens, für Gewinnbeteiligung der Arbeiter, für eine Besteuenung nach der Leistungsfăhigkeit und nicht zuletzt für Ausbau und moderne Ausgestaltung der Armengesetzgebung ein. Aus Arbeitern des dritten Standes sollten gleichberechtigte Bürger eines Staates mit gleichen Rechten und Pflichten werden.

Folgerichtig vertraten führende Nationalökonomen den Standpunkt, daß jeder Bürger - soweit erhebungstechnisch vertretbar - in die Einkommensbesteuerung durch einen eventuell unbedeutsamen kleinen Beitrag eines degressiv ausgestalteten Tarifs (in Sachsen 1 Mark) eingebunden werden sollte. ${ }^{84}$

Ab etwa 1885 wurde dann zunehmend der schon aus erhebungstechnischen Gründen in allen Einkommensteuergesetzen vorgesehene niedrige Grundfreibetrag - meist auf polemischem Hintergrund - mit dem Terminus "Existenzminimum" belegt, was mißverständlich war und zu einem mehrdeutigen "Schlagwort" wurde. ${ }^{85}$

Das Verfassungsgericht hat nunmehr den Gesetzgeber verpflichtet, die Grundfreibeträge des EStG bis 1996 mit den Regelsätzen des Sozialhilfegesetzes abzustimmen. Dabei sind auch Kinderfreibeträge den Bestimmungen des Sozialrechts anzupassen. ${ }^{86}$

${ }^{83}$ Hierzu s. Cohn, G. (1889), S. 272; s. a. Nothhardt, J. (1901), S. 115; s. Helfi. E. (1908), S. 214.

*4 Vertreter dieser Auffassung waren G. Schmoller, G. Cohn, A. Held. E. Nasse, K. von Rotiek, K. von Gneist, s. hierzu: Helft, E. (1908), S. 215; Schanz, G. (1926), S. 911 ; Schmoller. G. (1863), S. 37, S. 83 u. a.: s. a die Erörterungen im sächs. Landtag um die Anpassung des Grundfreibetrages der untersten KJasse, die mit 1 Mark belastet war, Schanz. G. (1895), S. 756. S. 760.

${ }^{85}$ Noch in seinem Kommentar zum preußB. EStG 1891 von 1894 brachte Fuisting. B. S. 43, den Grundfreibetrag nur in losen Zusammenhang mit dem Existenzminimum. Er wies darauf hin, daß er auch Nichtbedürttigen und Aktiengesellschaften gleichermaßen zukomme. Nach den mit dem Gesetz. gemachten Erfahrungen wollte er dieses später auf Hochverdienende beschriankt sehen, Fuisting, B. (1902), S. 270. Daher trat er für eine starke Erhohung dessen ein, was er jetzt als Existenzminimum bezeichnete. Fuisting, B. (1902), S. 220, S. 273.: ders. (1903), S. 261. Schanz: verwendete nun fortlaufend seit 1900 den Begriff Existenzminimum, auch wenn er Grundfreibeträge behandelte, s. Schanz, G. (1900 und 1926). Nachdem die Entwicklung der Sozialpolitik nach 1900 zum Stillstand gelangt war, konnte spăter die Auffassung viele Vertreter finden. der Grundfreibetrag müsse dem Existenzminimum entsprechen, obgleich bezùglich dessen Höhe und dem örtlich und den persônlich bedingten Umfang unterschiedlichste Auffassungen bestanden, s. Helft. E. (1908), S. 217: Nothhardt. I. (1901), S. 140 .

${ }^{86}$ Urteil des BVerfG 2 BvL 5,8,14/91 v. 25.9.19912, in: BVerfGE 87, 1992, S. 164, S. 171. 
Ein entstehendes Haushaltsdefizit - so das Gericht entgegen einem Urteil des BFH vom 8. Juni $1990^{87}$ - könne eine niedrigere Dotierung aus Verfassungsgründen nicht mehr rechtfertigen. Gegebenenfalls seien zur Deckung des Haushaltsbedarfs vorrangig Steuervergünstigungen abzubauen oder sogar ganz zu streichen. ${ }^{88}$

Das Verfassungsgericht hat im übrigen eindeutig eine neuartige Rangordnung für die Funktionen des Einkommensteuerrechts gesetzt: Das EStG hat sich danach vorrangig am Sozialrecht auszurichten. Während nämlich das Urteil zusätzliche Sozialzwecknormen zu einem integralen Bestandteil der Bemessungsgnundlage des EStG bestimmt, will es die oftmals als "steuergesetzliches Wirtschaftsrecht" bezeichneten Steuervergünstigungen als nachrangigen Fremdkörper abgebaut sehen. ${ }^{89}$

Das Gericht glaubt sogar aus den in Art. 1 Abs. 1 GG und Art. 20 Abs. 1 GG verwendeten Begriffen herauslesen zu können, daß eine Steuerentstehung grundsătzlich dann rechtswidrig ist, wenn der aufgrund von Steuergesetzen entstandene Steuerbetrag nach Gesetzesvorschriften des Sozialrechts dem Steuerbürger zur Ergänzung seiner Unterhaltsmittel auf das Existenzminimum als Regelbedarf von der ergänzungspflichtigen Sozialbehörde wieder erstattet werden muB. ${ }^{90}$ Die dem Bürger verfügbare gleiche Höhe von Unterhaltsmitteln durch die nach Sozialhilferecht wieder erstatteten Mittel ist allein mithin für die Beurteilung der Richtigkeit oder Gerechtigkeit nicht entscheidend.

Dem Steuerbürger steht vielmehr sein erworbenes steuerbares Markteinkommen stets wie ein objektives Gundrecht insoweit ungeschmälert zu. als die aus einer gesonderten Berechnung ermittelten Erwerbsbezüge den Regelbedarf als Existenzminimum nicht überschreiten. ${ }^{91}$

Das steuerbare Markteinkommen ist dabei eine Teilklasse des umfangreicheren Begriffs der Erwerbsbezüge, die auch alle übrigen nach der deutschen Type der Einkommensbesteuerung nicht steuerbaren, aber zum Unterhalt ver-

${ }^{87}$ BFH v. 8.6.1990 - III R 14-16/90, in: BStBI. II S. 969, hier S. 972; s. EFG (1990), S. 249.

$=$ BVerfG -U. v. 25.9.1992, in: BVerfGE 87, 1992, S. 172; Kirchhof, P. (1988), S. F 80.

89 Das weit verbreitete, als systematischer Grundriß des Steuerrechts verwendete Lehrbuch Tipkes behandelt bis zur 10. Auflage von 1985 in $\S 16$ des besonderen Teils "steuergesetzliches: Wirtschaftsrecht und Spendenabzugsrecht". In späteren Auflagen finden sich dann die Titel "Steuervergünstigungen als Sozialzwecknormen" bzw. "wirtschaftslenkende Steuervergünstigungen", s. Tipke, K. (1985), Steuerrecht, 10. Aufl., S. 560.

${ }^{90}$ BVerfGE 87, 1992, S. 172.

91 BVerfGE 87, 1992, S. 172. Nach dem Urteil "ist' das Existenzminimum (allerdings) so zi bemessen, daß es in mōglichst allen Fallen den existenznotwendigen Bedarf abdeckt, kein. Steuerpflichtiger also infolge einer Besteuerung seines Einkommens darauf verwiesen wird, seinen existenznotwendigen Bedarf durch Inanspruchnahme von Staatsleistungen zu decken". 
wendbaren Wertzugănge eines Steuerbürgers in einem Abschnitt einschließen sollen.

Nach dem Urteil muß das Finanzamt mithin zukünttig zusätzlich für Kleinverdiener eine weitere Veranlagung mit einer neuartigen, dem EStG bisher fremden Bemessungsgrundlage durchführen. Die Steuerpflichtigen mit geringem steuerbaren Einkommen müssen dazu eine sehr komplizierte Erklârung ihrer nicht steuerbaren Erwerbsbezüge abgeben. ${ }^{92}$

Das Verfassungsgericht gibt für seine Entscheidung explizit bzw. implizit drei Gründe an, nămlich erstens, daß̉ dem deutschen Einkommensteuerrechi seit seiner Einfuhrung im 19. Jahrhundert die Tendenz innewohne, das Existenzminimum freizustellen, daß zweitens diese Regelung rechtsdogmatisch richtig und gerecht sei und drittens die Regelung zu einer Vereinfachung des Steuerrechts füre, indem der Gesetzgeber zu einer Überarbeitung und Entschlackung der Normenvielfalt gezwungen werde. ${ }^{93}$

Tatsächlich kann keine dieser Begründungen einer Überprüfung standhalten.

Die erste These geht von fehlerhaften Überzeugungen von der Entwicklung der Einkommensbesteuerung im deutschen Sprachraum aus. ${ }^{94}$

92. 46 Abs. 2 Ziff. 7 EStG. Eine Veranlagung wird erforderlich, da beim Lohnsteuereinbehalt dem Steuerpflichtigen zugeflossene Erwerbsbezüge nicht berücksichtigt werden können. Ähnlich verhălt es sich mit der neuen Regelung der Kinderfreibetrige. Das vorgesehene Wahlrecht bereitet ungewöhnliche Erschwernisse, s. hierzu: Merkblatt zur Steuerfreistellung des Existenzminimums, abgedr. in: BStBI. I 1992. S. 736.

93. BVerfGE 87, 1992, S. 153, S. 169, S. 173. Das Gericht verweist ausdrücklich auf die Möglichkeit. "verfassungsrechtlich nicht gebotene steuerliche Entlastungen oder Vergünstigungen" ... "bei wachsendem staatlichem Finanzbedarf" abzubauen. Die gesetzgebenden Gremien sehen sich gezwungen. zur Gegenfinanzierung des höheren Gnundfreibetrages nach $\$ 32 \mathrm{~d} \mathrm{EStC}$ die $\$ \S 7 \mathrm{~g}$ und $7 \mathrm{fEStG}$. die den Mittelstand förderten, zu streichen, s. NWB Nr. 33 v. 14.8. 1995. Aktuelles, S. 2629.

"9 Das BVerfG vernachlässigt den Umstand, daß in den Beiträgen der Autoren des 19. Jahrhunderts das Existenzminimum höchst unterschiedlich bestimmt wurde. Die Forderungen des vom Gericht erwathnten weltfremden ehemaligen Archivars Karl Murhard aus dem Jahr 1834 entsprach in den Folgerungen den zeitgenössischen Uberzeugungen von der Gültigkeit des "ehemen Lohngesetzes", das in den Empfehlungen Biersacks zur Besteuerung den konsequentesten Ausdruck erhielt. s. Biersack. H.L. (I850) S. 149 - S. 152. In den spateren Diskussionen stritt man zumeist darum. den Grindfreibetrag auf eine Höhe anzuheben. die einem "notwendigen Existenzbedan" entsprechen konnte. wobei aber für viele Ökonomen anteilige Beiträge zu den Staatsausgaben einzubegreifen waren. Für einen Grundfreibetrag wurden jeweils. Haushaltsbedarf. steuertechnische Momente, die konkrete Ausgestaltung des Systems und soziale Gesichtspunkte malgeblich. s. Helfi. E. (1908), S. 219. Wenn das BVerfG heute die Auffassung Nothhardts von 1901 fortfuhurt daB es auf "Thorheit". "Gelegenheits. oder ZweckmäBigkeitsargumente" hinauslaufe, wenn dem Bürger von der Amenpflege zurückgegeben werde, was ihm vorher von der Besteuerung genommen wurde, so ist wohl darauf aufmerksam zu machen, da B aus der unzulänglichen Armenhilfe des 19. Jahrhunderts inzwischen, dem Programm des VfS entsprechenc. ein mit Rechtsansprïchen des Bûrgers ausgestaltetes umfassendes Sozialrecht entwickelt wurde. Dies kann dem personenbezogenen unterschiedlichen Bedarf nach Garantie des 
Im übrigen folgte das Gericht bei seiner Fiktion des richtigen Einkommensbegriffs und dessen Konsequenzen den theoretischen Vorstellungen, die bereits für Adolph Wagner charakteristisch waren und die von uns an anderer Stelle dargestellt und beurteilt wurden. Für konkrete zu erwartende Folgewirkungen war in der Begründung des Urteils vom 25. September 1992 kein systematischer Raum, da das Gericht nach einer "richtigen" rechtsdogmatischen Eingliederung der Einkommensteuer in die Gesamtrechtsordnung nach seinem Verfassungsverstăndnis suchte.

Seitdem um 1970 die sehr unterschiedlichen steuerlichen Konsequenzen der dualistischen Ermittlungsvorschriften des EStG Aufmerksamkeit erhielten, haben einige einflußreiche Steuerrechtslehrer die Rede vorn "Chaos oder Konglomerat" ${ }^{195}$ des Gesetzes verbreitet. Dabei handelt es sich um willkürliche und unsachliche Bewertungen, die zur damaligen Zeit aus der Verständnislosigkeit für die doppelte Regelhaftigkeit des EStG herrührten.

Das deutsche Einkommensteuerrecht leidet nicht an einem Mangel an Ordnung, an erratischer Zusammenhanglosigkeit, an zu wenig Regelung; es krankt an einer Überfrachtung mit Regelungsinhalten. Dadurch ist es an die Grenze der Beherrschbarkeit, der Praktikabilităt geraten.

Es kann jedoch kaum infrage gestellt werden, daß die zahllosen, für Außenstehende überkomplizierten und für Berufspraktiker in Beratungswesen und Verwaltung höchst zeitaufwendigen und ärgerlichen steuerlichen Regelungen im geltenden EStG eine nie erwartete beispiellose allgemeine Wohlstandsmehrung bewirkt, gefordert oder zumindest nicht verhindert haben. ${ }^{96}$

Existenzminimums heute sachgerecht entsprechen, was dem anderen Zwecken dienenden Steuerrecht nicht mọglich ist, hierzu: Nothhardi, J. (19011), S. 122; Helft, E. (1908), S. 217.

"9s Tipke, K. (1971), S. 2.

96 Die vielen Stetuervergünstigungen des EStG haben erst die Anreize geschaffen, deren Ergebnisse durch einen hervorragenden Wohnungsbestand, zweckmäßig gestaltete Wohnșiedlungen, sinnvoli ausgestaltete Dienst!eistungszentren, vorbildliche Einkaufsparks. modeme Entsorgungseinrichtungen, energiesparende Heizungsanlagen, wärmeisolierende Hauserneuerungen, Anschiüsse an Kanalisation und zentrale Kläranlagen etc. eic. đen uns selbstverständlichen hohen Lebensstandard in Deutschland ausmachen. So hat etwa als Beispiel $\S 7$ e EStG 1990, der zum 31.12.1995 endgültig (bisher bereits zum 31.12.1993) auslăuf, längere Zeit den entscheidenden Anreiz furr Herstellung zusătzlich hochwertiger Wohnungen in bestehenden Gebăuden geschaffen und den Markt entspannt Gewịß haben die vielen zugrundeliegenden Förderungsmaßnahmen das Gesetz kompliziert gemacht. Die streng forma• tistischen, weniger auf wirtschaftliche denn juristische Tatbestandsmerkmale im Sachverhalt abstellenden Eigenarten der deutschen Veranlagungspraxis reizen zi vermeidungsstrategischen Gestaltungen heraus, um in den GenuB von Steuervergünstigungen zu gelangen, ohne die wirtschaftichen Voraussetzungen zu erfullen. Das wiederum fuhrt zu Abwehmmaßnahmen von Gesetzgeber und Verwaltung in Gesetz und Richtlinien gegen Mißbrăuche, die alles noch komplizierter machen. Vor allem führte dies bei den einzelnen Steuerbürgern zu dem stăndigen Gefühl, von anderen abervorteilt zu werden und sich durch eigene Steuerunehrlichkeit schadlos halten zu dürfen. Es würde den Rahmen sprengen, hier neueste Beispiele anzufuhren, etwa, wie man derzeit durch den Erwerb von Anteilen an Abschreibungsgesellschaften, Gründung einer $\mathrm{GmbH}$ \& $\mathrm{Co}$. GbR, Einbringung der Anteile und dabei erreichte 
Das Unteil des Verfassungsgerichts macht nun durch seine Konsequenzen die Tätigkeit der Berufsträger in Steuerberatung und in der Verwaliung noch wesentlich komplizierter, ais sie bereits war. Im Grunde ist für viele Steuerbürger mit kleinem Einkommen ein weiterer am Sozialrecht ausgerichteter Einkommensbegriff zu berücksichtigen. Viele neue Pflichtveranlagungsfalle erschweren nun noch zusätzlich die Besteuerungstătigkeit der Verwaltung. ${ }^{97}$

$\mathrm{Daß}$ die Entwicklung zu spitzfindigen Regelungen seit längerer Zeit ausuferte, ist unbestreitbar. Steuerrechtlern, die bereits seit 1971 fortlaufend von Chaos reden, fehlt jedoch zumeist die Geduld, die vielen Ziele der in sich jeweils sinnvollen, überbordenden Einzelregelungen wahrzunehmen. Vom freiberuflichen Praktiker wird dies tăglich erwartet und geleistet, ebenso wie vom Veranlagungsbeamten.

Gewiß muß eingerăumt werden: Nachdem sich die wirtschaftiichen Verhältnisse im Laufe von über 100 Jahren entscheidend veränderten, ist es nur natürlich, daß das im Jahr 1882 von Adolph Wagner konzipierte Gnundgerüst des noch geltenden EStG der Überarbeitung bedarf. So ist heute nicht mehr zeitgemäß, daß z. B. Inhaber moderner Institute für medizinische Diagnostik mit hohem Kapitaleinsatz und vielen angelernten Mitarbeitern Einkünfte aus freiberuflicher Tätigkeit beziehen, während es sich bei einem allein von seinen handwerklichen Fähigkeiten lebenden Kunstschmied oder bei einem Heilmasseur mit erheblichen steuerlichen Konsequenzen um solche aus Gewerbebetrieb handelt (es sei denn, der Heilmasseur verabreiche "Fangopackungen"). ${ }^{98}$ Die Bedeutung von Einkunftsarten und deren steuerliche Abgrenzung erscheinen heute völlig überholt, die Konsequenzen für die Ermittlung der Bemessungsgrundlage willkürlich. Grundfreibeträge, Kinderlastenausgleich, Versorgungsaufwendungen, außergewöhnliche Belastungen und viele weitere Regelungen sollten neu durchdacht werden, mag die allem zugnundeliegende Besteuerungsidee auch als ordnende Kraft bestehen bleiben.

Die derzeitige, infolge der Wiedervereinigung unvermeidliche Beanspruchung des Haushalts steht aber größeren Experimenten mit weitreichenden Änderungen - ähnlich, wie nach 1948 - vorerst entgegen.

formlose Verschiebung der Geschäftsführungsbefugnis wegen $\S 15$ Abs. 3 Ziff. 2 EStG geradezu atemberaubende Möglichkeiten eröffnet, in großem Ausmaß die Entstehung von ESt, VSt und Schenkungsteuern legal zu vermeiden.

${ }^{97}$ Hierzu s. Rendels. H. J. (1993), S. 895; s. $§ 4$ Abs. 2 Nr. 7 EStG; Rendels ist der zustăndige Referent im BMF.

S. BFH-Urteil v. 24.1.1985. IV R 249/82, in: BStBI. II, S. 676. Das Urteil bestătigt die Gewerbesteuerpflicht für den ohne wesentlichen Kapitaleinsatz tătigen, von Handfertigkeit lebenden Kunstschmied und Heilpraktiker, wāhrend für den mit sehr erheblichen Kapitaleinsatz arbeitenden, von teuren Geräten und Aslernkräiten unterstũtzten Facharzt Gewerbesteuerfreiheit fraglos ist. 
Die ständig seit über 100 Jahren wiederholte Forderung nach einer einfachen und gerechten Einkommensbesteuerung dient einem hehren Ziel. Da in der Praxis Interessenkonflikte auf einen gemeinsamen Nenner zu bringen sind, gibt es hierfür aber kein Patentrezept, das aus reinem Denken entstehen könnte, mögen die Thesen vieler Steuerrechtslehrer diesen Eindruck auch erwecken. Aus Prinzipien läßt sich kein System materiell gehaltvoller Steuernormen herleiten. Hinzu kommt, daß an Universitäten die kritische Öffentlichkeit fehlt, die in Parlamentsausschüssen, zumeist aus Fachleuten bestehend, die vorhersehbaren praktischen Auswirkungen zum Angelpunkt verantworteter Entscheidungen macht. Assistenten und Studenten an Universitäten sind wohlberaten, Kathederwertungen nicht zu widersprechen.

Lex lata und lex ferrenda gehen im Steuerrecht wiederum, wie nach 1882 von Hasbach und Schmoller kritisiert, in vielen Lehrveranstaltungen nahtlos ineinander über. ${ }^{99}$

Das Bundesverfassungsgericht hat nun im Urteil vom 25. September 1992 die enge Verknüpfung von Einkommensteuer und Sozialhilfe gefordert, ohne selbst die Konsequenzen zu beachten, die in einer weitergehenden organisatorischen Zusammenfassung von Einkommensteuer und sozialen Transferleistungen liegen. Diese Entwicklung wurde durch das Urteil damit jedoch höchst wirkungsvoll und schwer revidierbar eingeleitet.

Offenbar hat das Gericht infolge der Praxisferne nur die Clearingfunktion der Transferleistungen im Auge gehabt und die Schwierigkeiten unterschätzt, die darin liegen, daß die Übernahme von Funktionen des Sozialamtes - auch

${ }^{99}$ Gegen die Ôberzeugung Wagners, eine auch das Steuerrecht bindende, in Entwicklung begriffene normative Wirklichkeit absoluten Charakters erkennen zu können, hatten Schmoller und Hasbach nach 1882 heflig polemisiert, was - wie wit sahen - wegen der weitgehenden Konsequenzen die methodologischen Streitigkeiten in der Nationalokononie ausloste, hierzu 5. Kapitel F, Abschnitt I. Anm. 13; s. Hansen, R. (1988), S. 60, Anñ. 106. Dabei stōrte den eine empirisch soziologische Richtung vertretenden Schmoller die Einengung des Spielraums für notwendige gesetzgeberische Gestaltungen durch Wagners juristisch-dogmatische Denkweise. Die von Wagner vertretene dogmatische normative Struktur des Denkens ist von Steuerrechtlern offenbar zumeist fortgefuhrt worden. Als Quelle der Erkenntris gilt hette auch fur das Steuerrecht die Bezugnahme auf eine umfangreiche Auslegung der Verfassung, wobei der Rechtsprechung des BVerfG eine wichtige Rolle zukommt. Viele kritische Rechtslehrer bemalngeln jedoch, daß "die unter dem Etikett der Verfassungsauslegung in Wahrheit erfolgende Rechtsetzung - die sogar dazu fuhrt, daß das Gericht neue Grundrechte erfindet, deren Einfuhrung eine Zweidrittelmehrheit im Bundestag benôtigen würde -" darauf hinauslăuft. "daß sich das Gericht zu einem Gesetzgebungsorgan mit = mangels parlamentarischer Struktur - autorităren Zügen entwickelt hat", s. Hirsch. H. J., in: FAZ v. 6.9.1995, S. 10. Dabei wird dann beklagt, daß die Konsequenzen einer Entscheidung von dem Gericht nicht mitbedacht werden, s. Scholz. R., in: Welt an Sontag v. 13.8.1995, S. 33; s. a. Vielain, H., in: Welt am Sonntag v. 20.8.1995, S. 4; s. a. Rathers, B., in: Wirtschaftswoche Nr. 41 v. 5.10.1995, S. 29; Weidenfeld, U/ Wolf-Doetlinchem, L dortselbst. GewiB ist hier festzuhalten, daB eine diskutierende Öffentlichkeit, Transparenz und Meinungsfreiheit wichtige mittragende Elemente unseres Rechtsstaates sind, s. Felux, G. (1995), in: KOSDI, S. 10143. 
wenn es sich nur um Teilfunktionen handelt - die zeitaufwendige und ausbildungsintensive Beratungsfunktion umfassen muß, die $\S 89 \mathrm{AO}$ fraglos unterstellt, ohne daß die Finanzverwaltung der normierten Verpflichtung schon bisher je hătte entsprechen kōnnen.

Die Finanzämter sind als Sozialămter ungeeignet. Sie werden es bleiben. Eine völlig andere Spezialausbildung der Mitarbeiter müßte anderenfalls eingeführt sein.

Denn: "Die Aufgabe des Sozialamtes erschöpft sich nicht in der Ermittlung des Familieneinkommens und der Auszahlung der Sozialhilfe. Vielmehr finden darüber hinaus Betreuung, Beratung und Hilfe zur Selbsthilfe statt. Dabei kommt zwar auch, aber nicht nur die Übernahme von Kosten durch das Sozialamt in Betracht (z. B. Altenhilfe, Hilfe zur Überwindung besonderer sozialer Schwierigkeiten, Hilfe zur Arbeit). Diese Beratungstătigkeit setzt neben einer besonderen Qualifikation auch eine răumliche Nähe zu den betreuten Menschen voraus. Steuerbeamte und Finanzämter erfüllen diese Voraussetzungen nicht und sollten deshalb auch nicht mit solchen Tätigkeiten betraut werden". 100

Die hohen Erwartungen, die von dem als soziale Wohltat in den Medien gepriesenen Verfassungsgerichtsurteil ausgingen, ergeben sich aus der wohlklingenden Auflage an den Gesetzgeber, den Grundfreibetrag des EStG auf das vom Sozialrecht festgelegten Betrag des Existenzminimums anzuheben und den Kinderlastenausgleich anzupassen.

Tatsächlich stellt sich aber große Enttäuschung heraus, sobald die vorhersehbaren Konsequenzen bekannt werden. ${ }^{101}$

Der Begriff des Existenzminimums wird durch den für dic Bemessungsgrundlage der Sozialhilfe maßgeblichen Regelbedarf definiert. Diese Bestimmung wird nun als Minimum für die Erwerbsbezüge in das EStG aufgenommen. ${ }^{102}$

Die betroffenen Kleinverdiener müssen daher nunmehr zusätzlich nach diesem neuartigen, in Anlehnung an das Sozialrecht geschaffenen Kriterium für Leistungsfähigkeit veranlagt werden. Zur Wahrnehmung ihrer Interessen bedürfen sie dabei gebührenpflichtiger Beratung. Das von der Finanzverwaltung

100 DSTG Juni 1995, S. 84. Welcher Art Probleme sich bei Ermittlung des personenbezogenen Existenzminimurns stellen, zeigt Kummer, J.: 4767 Mark Sozialhilfe pro Monat für eine Familie, in: Welt am Sonntag, Nr. 1 v. 1.1.1995, S. 4.

${ }^{101}$ Hierzu s. Woring, S. (1992), Zur Steuerfreistellung des Existenzminimums durch das Bundesverfassungsgericht, in: KOSDI 1992, S. 9162, S. 9132.

102. § 22 BSHG. 
entworfene komplizierte, nunmehr obligatorische und unverzichtbare Formblatt zur Ermittlung der Erwerbsbezüge vermag kaum ein Steuerbürger ohne Hilfe auszufüllen. ${ }^{103}$ Die Erläuterungen dazu in der Anleitung zur Einkommensteuererklärung oder das Merkblatt zur Anwendung der Zusatztabelle zur Lohnsteuer- bzw. Einkommensteuertabelle kann kaum ein Steuerbürger verstehen, ohne die Hilfe eines Steuerberaters in Anspruch zu nehmen. Weder die Finanzverwaltung (aus Mangel an Personal), noch das Sozialamt (infolge mangelnder Sachkenntnis) vermögen dabei za helfen.

Inzwischen zeigt sich den Angehörigen des Mittelstandes, daß sie zum Ausgleich eines geringeren Steueraufkommens als Folge der Neuregelung durch Streichung verschiedener Freibeträge höher besteuert werden, um die Haushaltsdeckung zu gewährleisten. ${ }^{104}$

Profitierende der Regelung sind Gruppen von Steuerbürgern mit Vermögen, aber geringen steuerbaren Einkünften. Während sie früher wegen vorhandenen Vermögens trotz niedriger Erwerbsbezüge keine Ergänzung zur Sozialhilfe beanspruchen konnten, beziehen sie nunmehr ihr Einkommen bis zur Höhe des Existenzminimums steuerfrei.

Eine materielle Besserstellung der tatsăchlich Bedürftigen geht im übrigen von dem Urteil des Bundesverfassungsgerichts vom 25. September 1992 deshalb nicht aus, weil jeder Bürger bereits bisher einen Ergänzungsanspruch auf Sozialhilfe bis zur Höhe des Existenzminimums beim Sozialamt geltend machen konnte.

Wenn in dem Pro und Contra zu dem Urteil diese Mängel vielleicht bagatellisiert werden mögen, so geben andere Konsequenzen, die bisher nicht erörtert wurden, Anlaß zu größerer Besorgnis: Es sind dies - sieht man von der weiteren Komplikation der Besteuerung, die vereinfacht werden sollte, ab - die veränderten Anreizstrukturen, die durch die Entwicklung der Finanzämter zur Übernahme von Funktionen der Sozialämter in Gang gesetzt wurden.

${ }^{103} \mathrm{~S}$. Anlage 31 . Im ubrigen handelt es sich bei dem Katalog des $\S 32 \mathrm{~d}$ Abs. 2 EStG und der dar. aus entwickelten Anlage E urn eine abgeschlossene Aufzählung, s. NWB, Fach $3 \mathrm{~b}, \mathrm{~S} .4471$. Die Gestaltungsfreiheit wird nach den ständig zu machenden Erfahrungen bald zu notwendigen Ergänzun. gen fuhren, denn die Erfindungsgabe bei der Suche nach Schlupflóshern scheint grenzenlos zu sein. Obendrein wird der Erfolg wie ein sportliches Ereignis bewertet.

104 Das BMF rechnet nach dem von Regierung und Opposition bezüglich des Jahressteuergesetzes 1996 ausgehandelten Kompromisses wegen der vom BVerfG geforderten Erhöhung des Grundfreibetrages auf das Existenzminimum des Sozialrechts und der gefundenen Kindergeldregelung mit Steuerausfallen von 19 Mrd. DM. Zur Gegenfinanzierung werden u. a. Steuerfreibeträge und Steuervergûnstigungen ( $\$ \S 7 \mathrm{f}, 7 \mathrm{~g}$ EStG) vorzeitig abgebaut, die beide den berufstatigen Mittelstand betreffen, s. NWB Nr. 33 v. 14.8.1995. Aktuelles, S 2629. 
Die Sozialhilfe ist bisher streng nach dem Subsidiaritătsprinzip organisien. Sie setzt erst dann ein, wenn die eigenen Unterhaltsmittel und diejenigen der Unterhaitsverpflichteten nicht ausreichen und auch kein nennenswertes verwertbares eigenes Vermögen einschließlich Immobilienvermögen vorhanden ist. Die Sozialhilfe hat insofern eine andere Bemessungsgnundlage für die eigene Leistungsfähigkeit des Bedürftigen, als diejenige der Besteuerung. Sie sucht nach einem auf eine konkrete Person bezogenen bedarfsgerechten Existenzminimum.

Da der neu eingeführte Grundfreibetrag zur Garantie des Existenzminimums, als Tarifvorschrift in $\S 32 \mathrm{~d}$ ESıG eingefugt, nicht auf das zu versteuernde Einkommen, sondern - dem Urteil entsprechend - auf die Höhe der Erwerbsbezüge abstellt, ist es schwierig zu überblicken, wer von der neuen Regelung profitiert. Leichter fallt die Feststellung, daß̄ es sich nur um eine Umverteilung der Steuerbelastung zu Ungunsten des für die Entstehung des Sozialproduktes unentbehrlichen Mittelstandes handelt, der aus optischen Gründen zwar nicht einem höheren Tarifzugriff ausgesetzt wird, sondern die Kürzung verschiedener Steuervergünstigungen, Freibeträge und sonstiger Abzugspositionen hinnehmen muß, was letztlich auf dasselbe hinausläuft.

Leichter erkennbar ist auch, daß Rentner und Pensionäre, die aus dem Berufsleben ausgeschieden sind, bei niedrigen Einkünften bessergestellt werden. Eine Ergänzung der Unterhaltsmittel auf die Höhe des Existenzminimums kam bisher für diese Gruppe zumeist wegen der vorhandenen Ersparnisse und des sonstigen vorhandenen Vermögens nicht infrage.

Anders als bei der Sozialhilfe spielt nunmehr das Vorhandensein von Vermögen für die Steuerfreiheit des Existenzminimums bei der Einkommensbesteuerung für sie keine Rolle mehr, auch dann nicht, wenn Vermögensteuer zu zahlen ist.

Da das Einkommensteuerrecht nicht nach dem Subsidiaritätsprinzip organisiert ist und daher auch gesetzliche Unterhaltsansprüche nicht $z$ u den im Katalog des $\$ 32$ d Abs. 2 EStG abschließend aufgeführten Hinzurcchnungen bei Ermittlung der Erwerbsbczüge gehören, werden im übrigen Gicstaltungen zur Ausschöpfung der hohen Freibeträge bei Einkünften aus Kapitalvermögen bald ein Knotenpunkt intelligenter Dispositionen im Zusammenhang mit unterhaltsberechtigten Abkömmlingen sein. Begünstigt sind dabei wiederum Steuerbürger mit höheren Einkünften aus Kapitalvermögen.

Dem Praktiker muß es angesichts dieser Überlegungen schwerfallen zu verstehen, inwiefern das Urteil des BVerfG vom 25. September 1992 der Gerechtigkeit und der Vereinfachung der Besteuerungspraxis dienen soll. ${ }^{105}$ 
Es ist kaum zu übersehen, daß diese Neuregelung nach dem Urteil des Bundesverfassungsgerichts vom 25. September 1992 im Zusammenhang mit einem eventuell geforderten beschleunigten Abbau der bisher gewährten Steuervergünstigungen, die letztlich stets notwendig an tatsächlich durchgeführte Investitionen als Tatbestandsmerkmal gekoppelt sind, völlig veränderte Anreizstnukturen in der Volkswirtschaft mit sich bringen wird. Dennoch wird diesem Umstand, der von großer Bedeutung werden kann. keinerlei Beachtung geschenkt.

Eine resultierende, schnell ansteigende Belastung des die Hauptbürde der Steuern tragenden beruflichen Mittelstandes muß das bereits starke Interesse zum Ausweichen in die ohnehin schon haussierende Schattenwirtschaft noch erhöhen.

Die bereits als ausufernd beklagte Schattenwirtschaft trägt jedoch wesentlich zum Sozialprodukt nur durch Dienstleistungen bei. In der Regel ist von ihr eine Vermehrung des Produktivvermögens schon wegen des notwendigen Verzichts auf jedwede Rechnungslegung nicht zu erwarten.

Hinzu kommt noch, daß eine gesetzwidrige Inanspnuchnahme der Steuerfreiheit durch sehr schwer kontrollierbare falsche Angaben über die Erwerbsbezüge leicht bewirkt werden kann. Die Finanzämter stehen vor einer schwierigen Aufgabe, zusătzliche Massenverfahren bewältigen zu müssen. Kontrollen sind wegen des entstehenden Aufwandes kaum noch möglich. Das Bundesdatenschutzgesetz erleichtert die zusätzlich erforderliche Tätigkeit der Finanzverwaltung nicht. ${ }^{106}$

Festzuhalten ist, daß eine Neuorientierung der wirtschaftspolitischen Ausrichtung des EStG im Ansatz erkennbar wird. Es resultieren veränderte, auf unterstellte "Verteilungsgerechtigkeit" abstellende Anreizstrukturen. Daß hierbei Mißßbrăuchen Tür und Tor geöffnet wird, bestătigt dem Praktiker die tảgliche Erfahrung.

In Zukunft könnten im Zuge dieser Entwicklung an die Stelle zeitlich begrenzter nichtfiskalischer Normen zur Begünstigung wohlstandsfördernder Iñvestitionen Sozialzwecknormen treten, die eine Umverteilung der Einkommensteuer zugunsten von Gruppen vorsehen, die zum Sozialprodukt weniger

\footnotetext{
105 Hierzu s, Bilsdorfer, P. (1992), S. 1423. Bilsdorfer ist Richter am Finanzgericht.

106. Nach dem Ergebnis verschiedener Untersuchungen wurden im Jahr 1992 die Steuerhinterziehungen, bezogen allein auf die alten Bundeslānder, auf aber $130 \mathrm{Mrd}$. DM geschătżt, s. DSTG 12/93, S. 152. Offenbar ist das Volumen heute sehr viel höher anzusetzen, \&. DSTG 7-8/95, Beilage "Blickpunkt", S. 4.
} 
beitragen und dies auch gar nicht wollen und nicht müssen, da die Ausrichtung der Sozialhilfe nach dem Subsidiaritătsprinzip zurücktritt. Der verborgene Hilfsmotor des Wirtschaftswunders würde - da gegen Verteilungsgerechtigkeit verstoßend - entsorgt. Das System würde dann vornehmlich den Aussteiger belohnen, der seine Interessen intelligent zu verfolgen weiß.

Die Eigentümlichkeiten der deutschen Type der Einkommensteuer mit ihrer heute wiederum stark betonten Differenzierung zwischen nicht steuerbarer Privat- und steuerbarer Einkommenssphäre und der eigenartigen Regelung für Liebhabereieinkünfte würde eine wirtschaftlich für das Gemeinwesen problematische Entwicklung noch erheblich verstärken. ${ }^{107}$

Im Gegensatz zur Schmollerschen Besteuenungsidee, nach der auch der von einem Steuerbürger geübte Müßiggang und Verbrauch unter Umständen als Kriterium für Leistungsfảhigkeit zur Bemessungsgrundlage der Besteuerung gehörte, setzt die auf Wagners Gedankenwelt zurückgehende strenge Abtrennung nichtsteuerbarer Vorgănge der Privat- oder Vermögenssphäre nămlich schwer überwindbare Hürden für eine überzeugende Besteuerungspraxis. ${ }^{108}$

Weder ist die Frage der Auswirkungen des Urteils des Bundesverfassungsgerichts vom 25. September 1992 für die fernere Lastenverteilung in der Öffentlichkeit oder gar in der Urteilsbegründung erörtert worden, noch die Frage der Konsequenzen für die zukünftigen Investitionserfordernisse, für die Beschäftigung und für die weitere Wohlstandsmehnung oder dessen Erhalt. Die vorzusehenden Gesetzesänderungen haben jedoch große Bedeutung für den sozialen Fortschritt der Gesellschaft, an dem alle Mitglieder des Gemeinwesens teilhaben.

Wenn bisher die marktwirtschaftliche Organisation der Wirtschaft zusammen mit einem jeweils abgestimmten marktkonformen Hilfsmotor die Wohlstandsbildung vorantrieben, so sorgte das differenziert nach Subsidiaritätsgesichtspunkten umfassend ausgebaute Sozialrecht und viele Einzelmaßnahmen in Gesetzesform als Ausgleich für das soziale Netz, dessen Stützpfeiler von dem erreichten Wohlstand getragen werden konnten.

\footnotetext{
1097 Diese charakteristischen Eigenarten des preuß. EStG 1891 sind bis in das heute gültige EStRecht erhaltei geblieben. Sie heben die preußische bzw. "deutsche Type" des: Besteuerungsrechts als eigentumliche Besonderhei von dem aus Schmollers Besteuerungsidee entwickelten săchsischen Muster ab. Dic Charakteristika finden sich auch in heutigen Reformvorschlăgen, die sich daher nur unwesentlich von dem preuBischen Ausgangsnnodell unterscheiden, s. Lang, J. (1985). Reformentwurf .... S. 31. Kirchhof leitet dic Abgrenzung aus der Verfassung her. s. (1988), S. F 24, S. F 29.
}

${ }^{198}$ Hierzu s. Kapitel D. Abschnitt 4; Kapitel E. Abschnitt II, Nr. 1, 2 u. a. 
Zwar mögen Steuervergünstigungen der Verteilungsgerechtigkeit entgegenstehen. Dafür stimulieren sie die Vermögensbildung durch Wertschöpfung der Wirtschaft. Aus der Kapitalbildung der Unternehmen "profitieren Arbeitnehmer durch Löhne und Gehälter, der Staat durch Steuern und die Kapitaleigner durch die verbleibenden Erträge und Gewinne". ${ }^{109}$ So lange der Wiederaufbau im deutschen Osten Priorität behält, wird man dies bedenken müssen.

Das Urteil des BVerfG vom 25. September 1992 überspannt insoweit die soziale Einbindung der Bundesrepublik.

Die modernen Definitionen von Armut unterstellen als wesentliches Kriterium einen "Mangel an Mitteln zur Teilnahme am normalen gesellschaftlichen Leben". 110

Obgleich eine ausgeglichene Vermögensverteilung ein langfristig anzustrebendes unverzichtbares Ziel einer prosperierenden Demokratie ist, hat derzeit die Beseitigung vorhandener Einkommensarmut Priorität. Bisher scheint es jedenfalls gelungen zu sein, trotz angestiegener Zahl von Sozialhilfeempfängern das Phănomen einer "festen Klasse von Armen" durch forcierten sozialen Ausgleich vermittels eines umfassenden Bündels von Sozialleistungen so zu steuern, daß die "soziale Mobilitảt" der Benachteiligten jedenfalls erhalten blieb. Das Problenn einer Dauerarmut mit einer Spaltung der Gesellschaft ist trotz angestiegener Sozialhilfefälle nicht typisch geworden. ${ }^{111}$

Die Aufrechterhaltung des Systems der sozialen Sicherung ist jedoch vom Sozialhaushalt und damit von der weiteren Vermögensbildung und dem Wachstum der Wirtschaft durch Kapitalbildung abhängig. Diese geraten in Gefahr, wenn eine stăndig abnehmende Zahl von Erwerbstätigen für eine immer größer werdende Zahl von Sozialleistungsempfängern arbeiten muß. ${ }^{1 / 2}$

Vorerst erhöht die steuerliche Förderung der Kapitalbildung das Sozialprodukt der Zukunft und erweitert damit die Höhe der möglichen Abgaben für soziale Zwecke. ${ }^{113}$

Als Gegengewicht wird man jedoch zur Unterstützung einer breiteren Vermögenstreuung im Zusammenhang mit dem gesamten System des sozialen Ausgleichs weiterhin beweglich bleiben müssen.

\footnotetext{
${ }^{109}$ Hierzu s. Abs, H. J. (1980), S. 26.

${ }^{110}$ Berger, P. A. (1994), S. 21.

III Zwick, M. (1994), S. 182.

112 Abs., H. J. (1980), S. 31.

113 Willgerodt, H. (1980), S. 43.
} 
Daher ist es jedenfalls nicht empfehlenswert, auf das erfolgreiche Instrument steuerpolitischer Wirtschaftsforderung in der Zukunft gänzlich zu verzichten, welches Ziel die eingeschlagene Entwicklung derzeit verfolgt.

Es besteht heute die Gefahr, daß die empfindliche soziale Balance durch den volligen Abbau des bisher verborgenen, wenn auch nicht unproblematischen Hilfsmotors verlorengeht, da die Statik des Gesamtsystems nicht aufgearbeitet wurde.

Solite die bisherige bankähnliche Funktion dem Fiskus genommen werden, so müßte vermutlich eine neu zu schaffende Institution, sei es als Subventionsbehörde, sei es als "q̣ualifiziertes Sparinstitut",114 die Aufgabe übernehmen. Worin der Vorteil einer derartigen Regelung liegt, ist bisher noch nicht überzeugend dargelegt worden. Der Glaube an gerechtere Lösungen hat die Frage nach den konkreten Auswirkungen offenbar verdrăngi.

Die bisherige Funktion des Fiskus als gröBtes Finanzienungsinstitut mag mit Ungerechtigkeiten bei der Lastenverteilung verbunden sein. Aber die Wohlstandsmehrung verlangte offenbar ihren Preis.

Die Suche nach einer vertretbaren Balance, einem sozialen Ausgleich, setzt jedenfalls - worauf Oldenberg aufmerksam machte - die Kenntnis der Zusammenhänge voraus. Zu diesem Ziel sollen die weiteren Ausführungen beitragen, indem wir uns der Veranlagungspraxis zuwenden.

${ }^{114}$ Lang, J. (1993). $\$ 123$ u. $\$ 832$ des Entwurfs eines Steuergesetrobuches ..., S. 144, S. 221; hierzu s. Kapitel M, Abschnitt V. Nr. 17. Der "Mißbrauch des Steuerrechts als Vehikel der Wirtschaftsienkung". Lang, J. (1993), S. 6, hatte jedenfalls bisher große Erfolge aufzuweisen, die zumeist fehilerhaft allein der "sozialen Marktwirtschaft" zugerechnet werden. 


\section{Grenzen des Einsatzes der Einkommensteuer als Instrument der Wirtschaftspolitik}

\section{Die zunehmende Kompliziertheit des Besteuerungsverfahrens und die Leistungsfähigkeit der Verwaltung}

Seit langer Zeit stehen die Finanzämter der Bundesrepublik Deutschland im Zentrum offentlicher Kritik. Seit 1992 mehren sich Hinweise mit Warnungen uber aufziehende bedrohliche Entwicklungen. So sprach der Leitartikel eines weitverbreiteten norddeutschen Nachrichtenmagazins von dem "Bürgerschīeck Finanzamt".' Die süddeutsche Konkurrenz berichtete über "Chaos im Finanzamt". 2 Das als Mitgliederzeitschrift des Bundes der Steuerzahler fungierende Fachorgan "Der Steuerzahler" erörterte zur selben Zeit mit Hinweisen auf konkrete Vorgänge das Thema "Steuerchaos und Steuerstaat". ${ }^{3}$ Der Präsident der Bundessteuerberaterkammer referierte auf dem Deutschen Steuerberaterkongreß 1993 in Bremen über "Steuerchaos in Deutschland ?". ${ }^{4}$ Zur selben Zeit wurde sogar eine Entschließung aller 21 Oberfinanzpräsidenten vom 18. Mai 1993 veröffentlicht, in der es heißt, daß die Komplizierung des Steuerrechts und die Hektik der Steuergesetzgebung (haben) ein Ausmaß erreicht" haben, "das die Finanzämter, die Steuerbürger und ihre Berater nicht mehr verkraften können". ${ }^{5}$ Eben auf diese Umstănde hatte bereits im November 1992 die Standesvertretung der Finanzbeamten, die "Dcutsche Steuergewerkschaf ${ }^{n}$. in einer eigens hierzu anberaumten Pressekonferenz warnend hingewiesen. ${ }^{6}$

Nụn mögen derartige Hiobsbotschaften in der modernen Medienlandschaft nicht ungewohnlich sein. ${ }^{7}$ Für manche aullageninteressierte Journalisten sind

' Der Spiegel. 46. Jg. Nr. 2 v. 6.1.1992, S. I. S. 36

2 Focus, Nr. 25 v. 27.6 .1993 , S. I.S. 122

3 Der Steuerzahler, Heft 7/93, S. 105, S. 107.

${ }^{4}$ Mitteilungshlatt der Steucrheraterkammer Köln . Juni 1993, S. 3.

'Mitteilungsblatt đer Steuerheraterkammer Köln. Juni 1993, S. 3.

"Deutsche Steuer-Gewerkschaft. Pressckonferenz des DSTG-13undesvorsitzenden E. Gieyer vom 9.11.92. in: Bundespressck onferenz-1Druckschritt. S. 2

Der Abteilungsleiter im BMF stellte gelegentlich den joumalistischen ! Irsprung dieser einprägsamen Bildersprache bloB, s. Uelner, A. (1985), S. 179 
nur schlechte Nachrichten mit Panikhintergrund wirklich gute Nachrichten. Besorgniserregend ist jedoch die Nachhaltigkeit, mit der sogar fachkompetente Gremien Horrorterminologien verwenden und die in den Mitteilungen angeführten Zahlen und Trends, mit denen Schreckensbilder untermalt werden.

Der Leser mag sich fragen:

- welche konkreten problematischen Umstănde können solch düstere Vorhersagen auslösen,

- wo sind die Ursachen für ein derartig bedrohliches Ereignis zu suchen,

- mit welchen negativen unerwünschten Folgewirkungen ist zu rechnen und - welche Maßnahmen sind geeignet, eventuell drohende soziale Konsequenzen zu verhindern?

Nachfolgend soll eine Beantwortung dieser Fragen versucht werden, wobei die Reihenfolge nicht immer eingehalten wird.

Vorerst mögen einige Zahlenangaben die als allgemein nicht mehr verkraftbar beklagte Steigerung der Belastung der Finanzverwaltung deutlich machen: Gab es im Jahr 1961 noch 3,27 Mio. veranlagte Steuerpflichtige, so stieg die Anzahl bis zum Jahr 1968 auf 4,84 Mio. und bis 1986 auf 13,86 Mio. Sie: dürfte heute vermutlich aber bei $20 \mathrm{Mio}^{8}$ liegen. Hinzu kommen die Steigerungen bei den zu erteilenden Feststellungsbescheiden für Gemeinschaften und die vielen neugegründeten Gesellschaften sowie die ständig steigende Zahl von Körperschaftsteuerveranlagungen. Waren um 1965 von jedem Bediensteten bei der Einkommensteuer noch ca. 750 bis 800 Veranlagungen jährlich zu bearbeiten, so waren es im Jahr 1978 bereits 1200. Inzwischen ist die Zahl heute auf 1.800 bis 2.000 und darüber - genannt werden sogar schon bis zu 3.000 - angewachsen. ${ }^{9}$ Gelegentlich werden die Finanzämter dieserhalb von Fachleuten bereits abfällig als "Steuerbescheidfabriken" bezeichnet. ${ }^{10}$

Dabei ist jeder einzelne Veranlagungsfall heute obendrein unvergleichbar komplizierter geworden. Die Anzahl der zu beachtenden Gesetze. Verordnungen, Erlasse, sonstigen Anweisungen und Richtlinien hat sich inzwischen vervielfacht. Es sind heute etwa 120 verschiedene Steuergesetze zu beachten. Jährlich müssen etwa 40 Erlasse des Bundesfinanzministers und ungefahr dic

\footnotetext{
${ }^{8}$ Statistisches Jahrbuch für die Bundesrepublik Deutschland (1975), S. 416: dass. (1992). S. 542.

'Weingarten, J. (1993), S. 135; Tipke, K./Lang, J. (1989), Steuerrecht ..., 12. Aufl., S. 658. Dic angegebenen Zahlen stammen aus Rückisprachen mit Sachgebietsleitern in den gröBten Finanzàmtern des Kölner Raums seit 1961. Die Zahl von 1.800 Veranlagungen im Jahır wurde aus der Statistik eines groben Finanzamtes im Bonner Raum ermittelt. Die dort veranlagten Steuerpflichtigen mit Einkünften. aus nichtselbstāndiger Arbeit sind besonders zeitintensiv. Es sind oft. doppeiverdienende Ehepaarc aus der Ministerialbürokratie, deren Veranlagungen mit. zeitaufwendigen komplizierten Berechnungen verbunden sind.
}

${ }^{10}$ Jenetzky. J. (1982), S. 278, S. 285. 
gleiche Anzahl aus dem Landesfinanzministerium berücksichtigt werden." Zusătzlich sind jährlich etwa 200 Urteile des Bundesfinanzhofes zu Auslegungs- und Anwendungsfragen und ca. 3.000 Urteile nachgeordneter Finanzgerichte mit sehr spitzfindigen Ergebnissen zu verarbeiten. Dafür, daß dies auch geschieht, sorgen argwöhnische Steuerpflichtige mit ihren Beratern. Etwa 1000 neue Durchführungsverordnungen pro Jahr beanspruchen zeitaufwendige Kenntnisnahme. Allein zu der Frage, was als Betriebsausgaben anzuerkennen ist, liegen 31 Verwaltungsanweisungen vor. Hinzu kommen etwa 2370 Gerichtsurteile, deren Zahl jährlich steigt. Wegen der zu beachtenden Stetigkeit der Rechtsanwendung sind Geltungszeiten und Fristen streng zu befolgen.

Da die Verarbeitung und die Übersicht über ständig neue Regelungen nicht mehr vom einzelnen Sachbearbeiter erwartet werden kann, gibt es in jedem Finanzamt für die verschiedenen Steuerarten einen sogenannten "Hauptsachbearbeiter" und einen "Hauptsachgebietsleiter", die vornehmlich den Überblick in bezug auf das ihnen übertragene Gebiet zu bewahren suchen, als Ansprechpartner den übrigen Bediensteten zur Verfügung stehen und so für die einheitliche Bearbeitung der Veranlagungsfalle sorgen. Fällt etwa der Hauptsachbearbeiter wegen Krankheit oder Urlaub aus, so sind eine Fülle von Komplikationen, bis hin zum Anwachsen der Rechtsbehelfe vorprogrammiert; und dies geschieht häufig genug.

$\mathrm{Zu}$ berücksichtigen ist bei der Arbeitstätigkeit der Ämter noch, daß durchweg 30 bis $40 \%$ der Arbeitszeit durch Publikumsverkehr und langwierige, oft redundante Telefonate von Steuerbürgern beansprucht wird. Trotz vielfältiger Versuche der Finanzämter will es nicht gelingen, den Publikumsverkehr einzuschränken und durch die schriftliche Abgabe von Erklärungen zu ersetzen.

Die immerfort zunehmende Komplizienung und Anreicherung der Vorschriften durch entlastende normabweichende Vergünstigungen oder die Einführung von Bestimmungen zur Abwehr mißbräuchlicher Inanspruchnahmen von steuerlichen Vorteilen bringen unvermeidlich wegen des hohen Geldwertes der Privilegien stăndige persönliche oder nervöse telefonische Nachfragen und Beschwerden bei den für die Veranlagung zustăndigen Sachbearbeitern mit sich. Das rechtliche Gehör kann den Steuerpflichtigen nach geltenden rechtsstaatlichen Prinzipien nicht versagt werden und mancher Steuerpflichtige macht gern und unbelehrbar, langwierig und lautstark von seinen Rechten Gebrauch.

11 Focus, Nr. 25 v. 21.6.93, S. 124 
Ảnderungen von Gesetzesvorschriften - und zwar auch von solchen, die nicht durch die vorgesehene schnellfristige Anwendung des Stabilitätsgeset$z e s^{12}$ geboten erscheinen und daher unvorhersehbar zur Anwendung gelangen kōnnen - sind gelegentlich von unvermuteten Zeitpunkten ab, etwa nach bekanntgemachten Kabinettsbeschlüssen, zu berücksichtigen. Es handelt sich dann um einen Termin, der innerhalb des Besteuerungsabschnittes liegt. Das bringt zusătzliche, umfangreiche und umständliche Abgrenzungen innerhalb des Ermittlungsabschnittes für den Steuerpflichtigen mit sich. Es bedeutet obendrein ebenso Überprüfungsarbeiten der sachlichen Richtigkeit auf Seiten des Finanzamtes bei der Veranlagung, wobei hohe geldliche Interessen im Spiel sein können. ${ }^{13}$ Allein das Berlinforderungsgesetz, das als lex specialis den Vorschriften des EStG vorrangig war - und das nach unseren früheren Feststellungen für große Steuerzahler von erheblichem Wert sein konnte -, erlebte in dem Zeitraum vom 7. Mărz 1950 bis zum 20. August 1980 innerhalb von 30 Jahren 44 zum Teil umfangreiche Änderungen. ${ }^{14}$ Inzwischen wurde es bis heute weiter mehrfach fortgeschrieben, bis es nunmehr in das Fördergebietsgesetz aufgenommen wurde. ${ }^{15}$ Wer die seit 1949 zu $\S 7$ b EStG zur Wohnungsbauförderung ergangenen Vorschriften mit denjenigen zu $\S 7$ Abs. $4 \mathrm{f}, \S 10$ e und $\S 21$ a EStG zusammenstellt, wird auf eine ähnliche Anzahl von Änderungen in der Behandlung vergleichbarer Sachverhalte eine verwirrende Fülle von Daten für Anwendungsbeginn und -ende sowie auf vergleichbare verwirrende Komplikationen stoßen. ${ }^{16}$

Lange Zeit hindurch kam z. B. dem Zeitpunkt des Anirages auf Baugenehmigung eine entscheidende Rolle für die Steuervergünstigungen beim Wohnungseigentum zu. Das galt dann auch für Novellierungen des Gesetzes mit Änderungen der Vergünstigungen. Wie war nun zu entscheiden, wenn der Bauantrag zurückgezogen und wenn er dann bei günstigerer Gelegenheit neu gestellt wurde oder wenn er durch Ergänzung der Bauplanung vorher leicht oder stark verändert worden war? War die Vergünstigung verwirkt? Ab wann

${ }^{12} \S 15$ Gesetz, zur Förderung der Stabilitat und des Wachstums der Wirtschaf (StabG) v. 6.6.1967

${ }^{13}$ Als Beispiel mag Abschn. 52 Abs. 1 Ziff. 3 EStR 1978 dienen. In dieser Verwaltungsvorschrift wird zwischen Erwerbsvorgängen vor dem 15.7.77 und solchen nach diesem Termin unterschieden. Ähnliche Ānderungen der Ermittlungsvorschriften innerhalb eines Jahres gab es mehrfach für die Anwendung von Pauschalen für Reisekosten, Umzugsaufwendungen etc. Die verursachten Differenzen sind oft betrăchtlich.

${ }^{14}$ Zusammenstellung hierzu in: Hecker, C., S. 1.

1s Fördergebietsgesetz v. 24.6.91: § 1 Abs. 2 FördGG. Das Gesetz schließt Berlin ein. Es ist am 28.6 .91 in Kraft getreten. In $\S 8 \mathrm{Abs} .1$ Zift. 2 befindet sich eine Überleitungsvorschrift.

${ }^{16}$ Von 1987 bis 1992 wurden im Einkommensteuerrecht insgesamt 218 Ānderungen von unterschiedlicher Tragweite normiert. Hierzu: Die Steuer-Gewerkschaft, Juli/August 1993. S. 121 - 136. Dort sind die Bestimmungen einzeln aufgefuhrt. 
lag ein völlig neuer Bauantrag vor? Diese und ähnliche Fragen mußten in großer Zahl fortlaufend von Sachbearbeitern und Sachgebietsleitern, wenn auch nicht endgültig. so doch vorläufig entschieden und Ablehnungen stichhaltig begründet werden. ${ }^{17}$ Wegen des hohen finanziellen Interesses kam dabei oft eine geradezu ausufernde gestalterische Phantasie der Steuerpflichtigen und deren Berater ins Spiel.

Auf die völlige Überfrachtung des Normengefüges des Einkommensteuergesetzes mit unterschiedlichsten Zwecken dienenden Steuervergünstigungen, die technisch in den verschiedensten Bereichen der Ermittlungsvorschriften der Systematik untergebracht sind, haben wir wiederholt hingewiesen. Viele Steuerrechtslehrer treten inzwischen für eine Eliminierung aller mit Vorteilen für das erwinschte Verhalten verbundenen Lenkungsnormen, also für ein System reiner Fiskalzwecknormen ein, um das Steuerrecht wieder mit der Besteuerung nach der Leistungsfähigkeit in Einklang zu bringen. ${ }^{18}$ Es mag hier dahingestellt bleiben, ob dies auf diese Weise erreicht werden könnte.

Zur Beurteilung der Bedeutung dieser Umstände mag folgendes dienen:

Die gewerkschaftiche Vertretung der Steuerbeamten beklagt derzeit einen Personalfehlbestand von 20\%. ${ }^{19}$ Die Gesamtzahl der Bediensteten der Finanzverwaltung beträgt zur Zeit etwa $120.000{ }^{20}$ Aus der Finanzverwaltung hör man, bei Beibehaltung der vom Gesetz normierten Bearbeitungsstandards müsse das in der Steuerveranlagung tătige Personal glatt verdoppelt werden. ${ }^{21}$

17 Anl. 4 a zu Abschn. 52 Abs. 3 EStR 1978; $\$ \$ 7 b, 52$ Abs. 10, 54 EStG 1978.

18. Bereits A. Spitaler warnte fruhzeitig vor den Wandlungen im Steuerrecht. Die Ausbreitung wirtschafts- und sozialpolitischer Zielsetzungen im Steuerrecht beurteilte er dennoch als im Zuge der Zeit liegend unvermeidbar. Die Konsequenzen befurchtete er in der nicht mehr leicht beherischbaren Komplikation , die "die Grundsătze gerechter Besteuerung sprengen, die Rechtssicherheit schwinden lassen, die Steuerumgehung ermōglichen und so die Steuermoral untergraben" werde. Die Steuerum. gelsung wurde fur Spitaler zum "Denksport". Spitaler, A. (1959), S. 418. Als beispielhaft für die heute vorherrschende Meinung unter Steuerjuristen mag gelten: Tipke, K. (1991) und (1993). Bei der Beurteilung durch Steuerjuristen spielt die Verärgenung daraber eine große Rolle, dafl das Steuerrecht nicht mehr nebenher als ein Rechtsgebiet wie andere betrieben werden kann. Es benötigt die volle und ungeteilte dauernde Aufmerksamkeit. Daher ist es auch zunchmend zur ausschlieBlichen Domăne der Steuerberater geworden, was erheblichen Unmut bei Rechtsanwallten erzeugt. Erfahrungsgemäß sehen die Mitarbeiter der Finanzverwaltung, sich lieber Steuerberatern gegenüber. Eine Begrūndung für diesen Umstand gibt Tipke (1993), Die Steuerrechtsordnung, S. 1366, der sich verwundert zeigt, als: junger Finanzrichter Steuerberater nicht als "Rechtspflegel" (i. S. v. "Dreschpflegel"), sondern als gesetzeskundig und verstaindnisvoll erlebt zu haben.

${ }^{19}$ Weingarten, J. (1993), S. 139: auch: Deutsche Steuergewerkschaft. Manuskript zur Pressekonforenz des DSTG-Vorsitzenden E. Geyer v. 19.11.92, S. 7. Die Gewerkschaft spricht von fehlenden 25.000 in den alten und 17.000 Mitarbeitern in den neuen Bundesländern.

${ }^{20}$ Focus, S. 123; Weingarten, J. (1993), S. 476; Aufstellungen der DSTG (1992, S. 2.

${ }^{21}$ Von dem Erfordernis einer Verdoppelung der in der Veranlagung taltigen Mitarbeiter bei Beachtung der vom Gesetz vorgeschriebenen Normen sprach Jenetzky bereits 1982, S. 276. Inzwischen sind die Zahlen qualifizierter Mitarbeiter rücklăufig, die Anzahl der Veranlagungsfalle ist geradezu explo- 
Da man aus der Berufstätigkeit als Steuerberater den Eindiruck erhalten kann, daß der Stellenkegel im höheren Dienst der Finanzverwaltung durchaus ausreichend besetzt ist, ergibt sich die Vermutung, daß die Personalfehlbestände tatsächlich im wesentlichen den mittleren und gehobenen Dienst, also die unmittelbar mit der Veranlagungstătigkeit befaßten Bediensteten betreffen. Diese Vermutung wird von den jährlich veröffentlichten Zahlen über ausgeschiedene Angehörige der Finanzverwaltung bestätigt. In den letzten sechs Jahren schieden 10.790 Mitarbeiter vorzeitig aus der Verwaltung aus. ${ }^{22}$ Da die Ausbildungszeit zum gehobenen Dienst jeweils drei Jahre in Anspruch nimmt und etwa 85.000 Personen im mittleren und gehobenen Dienst tattig sind, ${ }^{23}$ bedeutet dies im dreijährigen Rhythmus einen Personalverlust ${ }^{24}$ der durch die in Ausbildung stehenden Anwärter nicht wettgemacht wird, wobei es sich um Mitarbeiter für die Veranlagung handelt. ${ }^{25}$

Nach allgemeiner Oberzeugung ist die Ursache für diesen bedrohlich gewordenen Personalnotstand in der Überforderung der Bediensteten der Finanzämter durch die Explosion der Veranlagungsfälle zu suchen. Man muß in diesem Zusammenhang wohl festhalten. daß der Personalbedarí der Finanzverwaltung auf der Grundlage langjähriger Erfahrungen verhältnismäßig leicht kalkulierbar sein müßte und die Ergebnisse von Einschätzungen rechtzeitig zu anpassenden Dispositionen hätten verwendet werden können. Auch bei Gesetzesänderungen oder Ergänzungen könnten die Mehrbelastungen als Folgewirkungen ohne größere Schwierigkeiten einkalkuliert und für begleitende Anpassungen der Dienstleistungskapazitäten dienen. ${ }^{26}$

Tatsächlich ist aber das hier seit vielen Jahren herangereifte Problem darauf zurückzuführen, daß die Arbeit der Finanzverwaltung und vor allem die mit dem Gesetzesvollzug in Zusammenhang stehenden Erfordernisse stets vernachlässigt worden sind. Das ist seit Einführung der Einkommensteuer in Preußen bereits so gewesen. ${ }^{27}$

dient und die Normdichte hat in 12 Jahren erheblich zugenommen, zumal der Beitritt der DDR zusatzliche Komplikationen brachte.

${ }^{22}$ BMF, übernommen aus Focus, S. 123. Die Zahl für 1992 wurde nach den Angaben vom Ministerium geschătat.

${ }^{23}$ Hierzu die Aufstellungen von Weingarten, d. (1993). S. 111.

24 Das es Landesverwaltung ist. fehlen Angaben.

${ }^{25}$ Der mittlere Dienst wird zunehmend für Veranlagung zustăndig.

26. Tatsāchlich gibt es seit etwa 30 Jahren eine Personalbedarfsrechnung der Zoll- und Finanzverwaltung auf Landesebene. die um eine angemessene Stellenverteilung bemüht. war. Es fehlt eine bundeseinheitliche Personalbedarfsrechnung, die mit der Gesetzesinitiative abgestimmt wird, Weingarten, J. (1993), S. 101. insbes. S. 132.

27. Das amtliche Einschâtzungsverfahren nach ãußerlichen Kriterien bei Verbot des Iãstigen Eindringens in die Privatsphäre und verbunden mit fakultativer Deklaration auf rein freiwilliger Basis 
Wie wir gesehen haben, hat der Einsatz des Einkommensteuergesetzes zu nichtfiskalischen Zwecken heute die problematischen Mehrbelastungen potenziert. Einige der zu Finanzierungszwecken in das Gesetz eingefügten Steuervergünstigungen sind, wie wir gesehen haben, mit bankmäßigen Geschäften vergleichbar. Wir haben Beispiele für die Bedeutung erörtert, die dem Einsatz des Einkommensteuergesetzes als Lenkungsinstrument bei dem Wiederaufbau der Bundesrepublik nach den Zerstörungen des Krieges zukam. Wir erwähnten dabei auch, daß die Finanzierung dieses Wiederaufbaues mit erheblichen zusåtzlich notwendigen öffentlich-rechtlichen Dienstleistungen bei der Veranlagungstätigkeit verbunden war. ${ }^{28}$ Ein Kreditinstitut hätte jedenfalls entsprechende Vorkehnungen für die zügige Bearbeitung der von der Zunahme der Kreditgewährungen verursachten zusätzlichen Vorgänge getroffen. Die vorhandenen Bearbeitungskapazitäten der Finanzämter und deren Anpassung an ungewöhnliche Ausweitungen des Gesetzesvollzuges sind jedoch nicht nachhaltig, jedenfalls nicht bei den Beratungen über die Einbringung von Steuervergünstigungen auf Ebene der politischen Beschlußkörper erörtert worden. $\mathrm{Da}$ hier eine Begrenzung für den instrumentalen Einsatz des Steuerrechts vorliegen könnte, ist erst recht kein Thema gewesen.

Zwar finden sich in Lehrbüchern gelegentlich Beiträge zur Frage der Praktikabilität steuerlicher Vorschriften ${ }^{29}$ Die Erörterungen sind jedoch zumeist deshalb nicht hilfreich, weil es sich nur um formale Untersuchungen handelt, denen keine überprüfbaren realen Ergebnisse zugrunde liegen. Durch die Bezeichnung "praktikabel" wird dabei dann unterschwellig bevorzugten Regelungen der Anschein empirisch legitimierter Sachgerechtigkeit verlichen. Die enwünschte Regelung wird als die einzige gegebene Alternative dargestellt, die Einrichtung und Verfahrensweise der Veranlagung und die Ausbildungsvoraussetzungen der Bediensteten werden als unabänderlich vorgegeben unterstellt und die Notwendigkeiten des Vollzuges neuartiger gesetzlicher Voraussetzungen werden vernachlässigt oder gar nicht erst behandelt. ${ }^{30}$

Diese Maingel haben bereits Franz Meisel zu seiner Kritik an der preußischen und später reichsdeutschen Type der Einkommensbesteuenung animiert

verlieh der preuBischen Klassensteuer von 1820 ebenso wie der klassifizirten Einkommensteuer einen Charakier der Willkir, Greim-Kuczewski, P. (1989), S, 88, S. 123: auch: Linzbach, P. (1984), S. 167.

${ }^{28}$ S. hierzu Kapitel J III b) und Kapitel K.

29 So heißt es bei Tipke (1993). Die Steuerrechtsordnung, S. 370: "Steuergesetze dûrfen nicht mit Lenk kungsnormen durchsetzt werden, die für den gedachten Zweck nicht geeignet oder erforderlich oder unverhăitnismäBig sind". Das sind allgemeine Forderungen, die der Konkretisierung bedurfen.

30 Jenetzky (1982), S. 278, beklagt das Vorauseilen des Gesetzgebers ohne Rücksicht auf genügende Berücksichtigung der Belastung im Vollzug; auch: Metzger, (1./Weingarten, J. (1989), S. 266 
und ihm als Gegenstand streitiger Auseinandersetzungen mit seinen juristischen Widersachern, wie Waldecker und Behrnauer, gedient. ${ }^{31}$

Bereits zu Ende der 50er Jahre wurde die Personalknappheit an den Finanzämtern angesichts des sprunghaften Anstiegs der zu bearbeitenden steuerlichen Vorgänge beklagt. So wuchsen beispielsweise die Anträge auf Durchführung eines Lohnsteuerjahresausgleichs in der Bundesrepublik von 1960 bis 1969 von 1,7 Mio. auf 3,6 Mio. jährlich an. ${ }^{32}$ Alle übrigen Zahlen zeigten zusammen mit dem Wirtschaftswachstum ähnliche Steigerungen. Bereits damals wurde deshalb die Forderung nach einem Abbau aller Sieuervergünstigungen sowie nach moderner technischer Ausstattung und Neuorganisation der Steuerverwaltung erhoben. ${ }^{33}$ Der Bundesrechnungshof mahnte sogar 1968 eine Modernisierung des Besteuenungsverfahrens an, die auch dem Steuerpflichtigen Verbesserungen bringen sollte. ${ }^{34}$

Die Landesfinanzministerkonferenz entschied sich im Jahr 1971 fü die Einführung, einer von einem hierzu berufenen Ausschuß erarbeiteten neuartigen Organisation der Finanzämter und einer den wachsenden Anforderungen angepaßten Verfahrensweise. Die "Grundsätze zur Neuorganisation der Finanzämter" (GNOFÄ) suchten soweit wie möglich, die elektronische Datenverarbeitung für das Besteuerungsverfahren einzuführen. ${ }^{35}$ Die Finanzämter wurden ab Herbst 1976 auf dieses neue Verfahren, das dann noch mehrfach leicht verändert und ergänzt wurde, umgestellt. In der Folge sind dann das Veranlagungsverfahren und vor allem die gesamte Abrechnung automatisiert worden.

Ohne Zweifel hat diese Umstellung eine große Entlastung gebracht. Aber sie blieb ein Basteln an den Symptomen und keine Heilung durch Gesundung der Ursachen. Anregungen zu grundlegenden Änderungen lagen bereits seit 1960 vor. Davon werden wir später noch erfahren. Daher sind heute die Finanzămter wiederum wegen der fortschreitenden Überlastung nur schleppend in der

${ }^{31}$ Meisel, F. (1911), S. 285; der Kempunkt der Kritik Meisels war, daß die mangelhafte Technik der Veranlagung in Preußen bei bestimmten Gruppen von Pflichtigen zu offenkundig viel zu niedrigen Steuerm führte. Behrnauer und Waldecker, L. (1913), S. 53, widersprachen diesen Thesen. Replik Meisels (1914), S. 632

${ }^{32}$ Weiss, E. (1972), S. 163; Manke, K. (1976), S. 83.

${ }^{33}$ Spitaler, A. (1956), S. 253, S. 254.

${ }^{34}$ Metzger, U./Weingarien, J. (1989), S. 266.

${ }^{35}$ Jenetzky, J. (1982). S. 273, spricht von einer vom Gesetzgeber verursachten glatten Fehlentwicklung, die zum Teil auf die Reform der $A O$ von 1977 zurückgeht (S. 277). Bereits in den späteren 60er Jahren war diese Entwicklung erkennbar. Sie war mehrfach Gegenstand von Seminaren von $G$. Schmölders unter Teilnahme des Vorsitzenden der DSTG. H. Fredersdorf; auch: Hartmann, J. (1967), S. 9. 
Lage, den notwendigsten Erfordernissen der Veranlagungstätigkeit zu entsprechen. ${ }^{36}$ Die Ursachen sind neben dem fortschreitenden Wirtschaftswachstum die hektische und rastlose Tätigkeit des Gesetzgebers auf dem Gebiet des Steuerrechts. Die Entlastung währte mithin nur kurze Zeit. Die Überforderung ist heute noch besorgniserregender als zuvor. ${ }^{37}$

Fragt man nach den konkreten Ursachen für die Überlastung der Finanzämter, so lassen sich dafür viele Einzelheiten vortragen. Vor allem lassen sich die Symptome nach bestimmten Kriterien in Klassen und Unterklassen gruppieren. Es lassen sich interessante Zusammenhänge in der Entstehung der Überlastung zwischen Sachbearbeitern, Steuerpflichtigen und ihren Beratern etc. aufzeigen. Das geschieht denn auch in weit ausholenden Untersuchungen. Im Grunde werden durch dieser Art Untersuchungen die Kenntnisse über die Symptome unendlich vertieft. Für Reformen ergeben sich kaum Einsichten, mögen sie auch als fleißige Bestandsaufnahme gewertet werden. ${ }^{38}$

Unbestreitbar gibt es drei Problemkreise, bei denen zur Suche nach Lösungen der Hebel angesetzt werden könnte:

Der Arbeitsanfall ist für die Anzahl der derzeit tätigen Bediensteten mit dem vorgegebenen guten Ausbildungsstand bei der vorgeschriebenen Organisation des Verfahrens mit der vorhandenen Ausstattung der Finanzämter zu hoch. Sieht man von einer völligen Neuordnung des Veranlagungsverfahrens ab, so könnte man daran denken, Arbeitsanfall oder die Anzahl der derzeit tătigen Bediensteten und Ausbildungsstand sowie Ausstattung der Finanzämter zu verändern.

Es ist offenkundig, daß kurzfristig in der gegebenen Situation nur geringe Abhilfe möglich erscheint. Der vorhandene Arbeitsanfall ist vorerst unabwendbar von der Gesetzeswirklichkeit vorgegeben. Er hat sich bereits, wie vorhersehbar, ab Beginn des Jahres 1994 wiederum vergrößert, da mit Inkrafttreten des bereits verabschiedeten Standortsichenungsgesetzes und des Gesetzes zur Umsetzung des Föderalen Konsolidienungsprogrammes neue zusätzliche Differenzienungen für den Zeitraum ab 1. Januar 1994 in das EStG eingefügt wurden. ${ }^{39}$ Die Eliminierung auch nur einiger arbeitsaufwendiger Steuer-

36 DSTG (1992), S. 2.

37 Weingarten J. (1993), diese Abhandlung gibt eine umfassende Diagnose der Symptome; âhnlich: Metzger, U./ Weingarten J. (1989).

38 Die Bestandsaufnahmen von U. Merzger/J, Weingarten sind umfassend. Die Frage des Zusammenhangs der Arbeitsbelastung mit der steuerlichen Systematik wird nicht behandelt.

39 Gesetz zur Umsetzung des Foderalen Konsolidierungsprogrammes vom 23.6.93, darin Ãnderungen zu $\S 10$ e EStG, zu $\S 22 \mathrm{Nr} .1$ Satz 3 a) EStG, zu $\S 32$ e Abs. 1 EStG. Ebenso das am 1.1.94 in Kraft getretene Standortsicherungsgesetz. Danach wird in einer vollig neuartigen Vorschrift $(\$ 7 \mathrm{~g}$ Abs. 3 bis 6 EStG) eine Ansparabschreibung zur Förderung kleiner und mittlerer Unternehmen im 
vergünstigungen würde kurzfristig ohnehin wegen des nach rechtsstaatlichen Prinzipien gebotenen alimählichen Auslaufens der Vorschriften keine große Entlastung bringen. Höchst unerwünschte wirtschaftliche und soziale Folgen wăren unvermeidbar. ${ }^{40}$ Die Wiederherstellung einer lebenswichtigen deutschen Handelsflotte nach Kriegsende, der Wiederaufbau Berlins, die wirtschaftiche Förderung strukturschwacher Gebiete, die Förderung des sozialen Wohnungsbaus und andere Maßnahmen entsprachen zu ihrer Zeit ebenso allgemein anerkannten Prioritäten, wie die heute im Fördergebietsgesetz vorgesehene Unterstützung des "Wiederaufbaus Ost". Das Einkommensteuergesetz hat sich nun einmal seit 1949 und in den Jahren nach 1970 sogar ständig zunehmend als wichtigstes, weil wirksames Instrument der Wirtschafts- und Sozialpolitik entwickelt, ohne daß dadurch das Einkommensteuer- oder überhaupt das Steueraufkommen beeinträchtigt worden wäre. Vermutlich haben gerade diese Steuervergünstigungen sogar zu dem sehr lebhaften Wirtschaftswachstum wesentlich beigetragen und dadurch zu den wachsenden Steuereinnahmen geführt. ${ }^{41}$ Sie sind mithin als zweckmäßige Maßnahmen ausgewiesen und können aus guten Gründen positiv bewertet werden. Die Ausführungen hierzu im Subventionsbericht sind höchst einseitig und erwecken falsche Eindrücke.

Wegen der Langzeitwirkung der steuerlichen Vergünstigungen, die zumeist in das Gesetz technisch als Abschreibungsfreiheiten eingefügt wurden, würde eine kurzfristige Beseitigung vorerst nicht einmal entlastend wirken.

Der Personalbestand in den Finanzämtern ist ebenso eine nur sehr langsam veränderbare Größe. Die Befähigung der Bediensteten setzt nämlich eine gute Ausbildung voraus. Diese währt für die gehobene Laufbahn, auf der das Schwergewicht der Veranlagungstätigkeit ruht, drei Jahre. Derzeit verlassen jährlich in der Bundesrepublik etwa 3.500 Inspektorenanwärter $^{42}$ und Angehörige des mittleren Dienstes die Fachhochschulen für Finanzen und die Landesfinanzschulen der einzelnen Bundesländer und werden zur Tătigkeit in die Finanzämter übernommen. In den letzten Jahren traten nun jährlich durchschnittlich ca. 4.000 Bedienstete $^{43}$ in den Ruhestand. Zusätzlich verließen im

\footnotetext{
Fördergebiet eingeführt. Darüber hinaus sieht das Gesetz eine Begrenzung des Höchstsatzes fưr die Tarifprogression bei Einkünten aus Gewerbebetrieb von $47 \%$ vor. Dadurch wird eine Besteuerung der Einkünfte aus den verschiedenen Einkunftsarten in nunmehr unterschiedlicher Höhe eingeführ. Die Abgrenzung der verschiedenen Einkünfte erhält eine neuartige Bedeutung.

${ }^{40}$ Uelner, A. (1977), S. 122; ders. (1985), S. 175; Matthăus-Meier, I. Diskussionsbeitrag in: Raupach, A/Tipke, K./Uelner, A. (1985), Niedergang ..., S. 198; Wöhe, G. (1975), S. 119.

4 Beispielhaft hierzu: Hecker, C. (1982), S. 82, S. 127, S. 145.

${ }^{42}$ Die Zahl mußte geschătzt werden, da es Landesverwaltung ist.

43 Wie Anmerkung 42.
} 
Mittel 2.400 Inspektoren und Mitarbeiter aufgrund eines freiwilligen Entschlusses die Finanzverwaltung. ${ }^{44}$ Das geschah zumeist, weil die Anforderungen und Belastungen als in einem krassen Mißverhältnis zu der Besoldung stehend beurteilt wurden. Auch in diesem Bereich kann das Mißverhältnis zwischen der Arbeitsbelastung und der Leistungsfähigkeit der Verwaltung nur langsam beseitigt werden.

Was nun die innere Organisation und die technische Ausstattung der Finanzämter betrifft, so kann man aus dem täglichen Umgang mit diesen Behörden den Eindruck gewinnen, daß seit Neugestaltung der Finanzwerwaltung nach den "Grundsätzen zur Neuorganisation der Finanzämter und zur Neuordnung des Besteuerungsverfahrens" nach 1976 der dringende technische Nachholbedarf aufgeholt wurde. Es mag sein, daß vieles in der Einrichtung der Finanzverwaltung auch heute wiederum verbesserungsbedürftig ist und daß die Ausstattung noch weiter modernisiert werden könnte. Jedoch ist von derartigen Maßnahmen keine nachhaltige Entlastung der mengenmäßigen Überforderung der Bediensteten zu erwarten. Wie wir später noch sehen werden, kann nach diesseitiger Auffassung nur eine grundlegende Neuorganisation des Besteuerungsverfahrens weiterhelfen.

Nun findet man heute in vielen Medien die erwăhnten warnenden Ankündigungen von einem drohenden Chaos und/oder dem Zusammenbruch der Finanzverwaltung. Was ist von derartigen Hiobsbotschaften zu halten?

Die Vorstellung, der "Fiskus (stehe) vor dem Kollaps" ${ }^{45}$ und werde plötzlich unerwartet im Chaos zusammenbrechen, ist absurd. Derartige Thesen wurden dennoch zumeist von Politikern seit den 50er Jahren ofters vorgebracht. Wie wir gesehen haben, hat sich seit der Zeit der Aufstellung solcher Thesen die Fallbelastung der Mitarbeiter vervielfacht und der Personalbestand hat sich, bezogen auf den Tätigkeitsumfang, in derselben Zeitspanne ganz erheblich verringert. Dabei ist der Schwierigkeitsgrad der zu bearbeitenden Vorgănge schon infolge der Überfrachtung des EStG mit nichtfiskalischen Lenkungsnormen unverhăltnismäßig angewachsen.

Allen apokalyptischen Vorauswarnungen zum Trotz ist bisher nichts zusammengebrochen. Tatsächlich sind - für jeden aus den Medien vernehmbar die Erträge aus der Einkommensteuer sogar gerade in den letzten Jahren erheblich angestiegen. ${ }^{46}$ Sie haben regelmäßig sämtliche amtlichen Voraus-

${ }^{44}$ Focus Nr. 25 v. 21.6 .93 , S. 123.

45 "Chaos im Finanzamt" in: Focus Nr. 25, S. 123.

16 BMF, Referat Offentlichkeitsarbeit: Der Bundeshaushalt. Unser Geld, Bonn 1991, S. 8. Von 1970 bis 1990 (ohne chemalige DDR) stiegen die zum Bereich der ESt zu rechnenden Einnahmen von. DM 74,8 Mrd. Auf DM 289.3 Mrd., das ist das 3,87-fache. Bis einschließlich 1992 hat sich die ver- 
schătzungen noch übertroffen. Zur selben Zeit ist infolge besserer organisatorischer und computermäßiger Unterstützung der Verwaltungstătigkeit die durchschnittliche Veranlagungsdauer sogar verkürzt worden. Die Veranlagungen erfolgen heute in der Regel zügig. Dabei sind obendrein bei Steuernachzahlungen oder -rückerstattungen inzwischen von Gesetzes wegen unter bestimmten Voraussetzungen sogar zeitaufwendige Zinsabrechnungen zu berücksichtigen. ${ }^{47}$ Wie ist dies zu erklären und mit den Horrorgemălden und dem Gerede von einem drohenden Chaos in Einklang zu bringen?

Wie der amerikanische Finanzwissenschaftler Carl S. Shoup 1970 festhielt, kann das übliche Gerede uber den drohenden Zusammenbruch eines reformbedürftigen Steuersystems nur metaphorisch verstanden werden. ${ }^{48}$ Die Vorstellung von der notwendigen Neugestaltung wird immer allgemeiner, aber die eigentlichen Grüinde für die Reformbedürftigkeit bleiben dem Laien, dem die heute von einer Gesetzesflut gekennzeichneten geltenden Vorschriften und deren Wirkungen im einzelnen unbekannt sind und der auch nicht über Vergleichsmaßstäbe verfügt, verborgen. Andererseits kann der Steuerberater jeweils mit dem konkreten Ergebnis seiner beruflichen Tätigkeit bei dem bestehenden Zustand zufrieden sein, ebenso der normale unkritische Bürger als Steuerpflichtiger. Eine genaue Prüfung der in den Erklärungen dargestellten Sachverhalte in bezug auf die gesetzlich relevanten Tatbestandsmerkmale findet nämlich nur noch sehr oberflächlich, wenn überhaupt statt. Die Veranlagung erfolgt heute in der Regel unüberprüft nach den abgegebenen Erklärungen. $\mathrm{Daß}$ dies unbefriedigend ist und nicht der Gleichmäßigkeit der Besteuerung dienen kann, ist leicht erkennbar. Auch die Veranlagung "unter dem Vorbehalt der Nachprüfung" - ein Rechtsinstitut, das in der auf die Neuorganisation der Finanzämter zugeschnittenen modernisierten Abgabenordnung 1977 "der Beschleunigung der ersten Steuerfestsetzung" dienen sollte, ${ }^{49}$ um eine Überprüfung bestimmter Veranlagungen ohne Zeitdruck innerhalb von vier Jahren nachholen zu können - hat die Entwicklung zu den heutigen

einnahmte LSt wiederum um 15.5\% erhőht Betrugen dic Einnahmen 1990 noch ohne DDR DM 177,6 Mrd. so sind sie 1992 mit den neuen Ländern auf DM 247,3 Mrd. angewachsen.

47 Nach den Exfahrungen des Verfassers mil Mandanten im gesamten Bundesgebiet erfolgte die Veranlagungstătigkeit der Finanzămnter für 1992 im Jahr 1993 sehr zügig. Klagen sind jedenfalls unangebracht. Die Veranlagungen des Jahres 1993 im Jahr 1994 erfolgen geringfügig schleppender. Auch hier besteht kein Grund zu Klagen.

${ }^{48}$ Shoup, C. (1970), S. 252: "The tax will not become quite unworkable; it will not 'collapse', but it will perhaps eventually so disillusion the public that its roll in the tax system will gradually be reduced."

49 Begruindung des Regierungsentwurfs zu $\S 164$ AO 1977, abgedruckt in AO 1977. Materialien zusammengestellt und bearbeitet von K.-H. Mittelsteiner/H. Schaumburg, Kōln 1976, S. 211. 
Verhältnissen nicht aufhalten können. Ein praktisches Beispiel mag das verdeutlichen:

Es ist nicht recht nachvollziehbar, wie in bestimmten Ballungsräumen Vorgånge durch erforderliche und gesetzlich gebotene zeitaufwendige Überprüfungen und Erörterungen herausfallender Problemfälle von den Steuerpflichtigen durch Glaubhaftmachung oder bei ungewöhnlichen Konstruktionen durch Nachweisungen der dargelegten Sachverhalte noch veranlagungsreif gemacht werden sollen. Hier treten allein aus räumlichen Gründen, die auch die örtliche Sachkenntnis der veranlagenden Sachbearbeiter beeinträchtigen müssen, unüberbrückbare Schwierigkeiten auf. Für die infolge Personalmangels überforderten Finanzämter Münchens werden nämlich zum Teil die ländlichen Åmter in Deggendorf, Straubing, Passau und Ingolstadt tätig. ${ }^{50} \mathrm{da}$ Besoldungsverhältnisse und Überlastung den stärkeren Einsatz der Ämter in der teueren Landeshauptstadt unmöglich machen. Für andere Räume ist ähnliches zu erwarten.

Die für die Veranlagung zuĩ Einkommensteuer zuständigen Sachbearbeiter haben an ihrem Arbeitsplatz in den letzten Jahren mit der wie ein Naturereignis unaufhaltbaren Normen- und Fallexplosion fertig werden müssen. Inzwischen hat diese "doppelte Überlastung der Steuerverwaltung durch Rechtsstoffüberflutung und Fallüberlastung" zu einer Entwicklung von Strategien am Arbeitsplatz gefüht, "die formal eine einigermaßen reibungslose Erledigung der Arbeitsmenge sicherstellen und den Anschein einer hinreichenden Sachverhaltsermittlung und dogmatisch sauberen Rechtsanwendung aufrechterhalten" kann. ${ }^{51}$ Jenetzky, ein der Praxis offenbar nahestehender Dozent an der Fachhochschule für Finanzen Baden-Württembergs, nannte bereits 1982 folgenden nicht abgeschlossenen Katalog von tatshichlich praktizierten Bewăltigungsmethoden: "Die typisierende Betrachtungsweise, den Verzicht auf Rückfragen, den Verzicht auf Verprobungsrechnungen und Schlüssigkeitsprüûngen, die Überdehnung des Beweises des ersten Anscheins, die Unterstellung typischer Geschehensabläufe, die Bereitschaft, offensichtliche aber nicht offenkundige Falschdarstellungen der Steuerbürger hinzunehmen, dem quengelnden Steuerpflichtigen nachzugeben und den Folgsamen zu belasten, und dergleichen mehr" ${ }^{52}$ Diese mit der nach pflichtgemäßem Ermessen auszuübenden Ermittlungstätigkeit nicht vereinbarlichen Verfahrensweisen, so Jenetzky, wurden angesichts des explodierenden Arbeitsanfalles aus der Nol geboren. Inzwischen wurden sie mangels Alternativen durch Finanz-

50. Focus Nr. 25 v. 21.6 .93$, S. 125.

31 Jenetzky, J. (1982), S. 276.

S2 Jenetzky, J. (1982), S. 276. 
gerichte und Rechtslehre legalisiert. Die Notwendigkeit der Arbeitsbewalltigung hat es danach mit sich gebracht, daß das primăre Ziel der Finanzverwaltung von der Rechtswahrung des Steuerpflichtigen zu der "Sicherung des Steueraufkommens" übergeglitten ist. ${ }^{53}$ An die Stelle der vom Gesetz gebotenen amtlichen Ermittlungspflicht ist daher weitgehend der Opportunitătsgrundsatz getreten. ${ }^{54}$ Die lästigen, periodisch von den Sachbearbeitern für die Aufsichtsbehörden zu fertigenden Statistiken über den Stand der Veranlagungstätigkeit, die die Zahlen über die Produktion von Steuerbescheiden begleiten und die Veranlagungsriickstände für Dispositionszwecke des Haushaltes auswerfen, spielen unter den gegebenen Sachzwängen eine entscheidende Rolle. Offenbar sind diese Meldungen für die Behördenleitungen zusammen mit den Mitteilungen über das erzielte Steueraufkommen von größerer Wichtigkeit, als die erkennbaren Măngel bei der Beachtung des Grundsatzes der Gesetzmäßigkeit der Verwaltungstätigkeit mit der normierten Verpflichtung zur Sachverhaltsermittlung und steuerrechtuichen Beurteilung des konkreten Falles durch Herausfilterung der steuerbaren Tatbestandsmerkmale. Für den Regelfall bedeutet dies, daß die Finanzämter derzeit den Veranlagungen ohne Prüfung, sofern die erklärten Sachverhalte nicht völlig unglaubwürdig sind, die abgegebenen Steuererklärungen zugrunde legen. Nur im Falle offensichtlicher Ungereimtheiten, innerer Widersprüche in den Erklärungen oder im Fall des Vorliegens widersprechender Kontrollmitteilungen wird der Veranlagung eine gebotene Erörterung vorgeschoben, um die Akte nach Bearbeitung prüfungsfähig zu machen. So haben die Finanzämter Strategien dieser Art gegen die ständige Überforderung durch Politik und Erwartung der Steuerbürger entwickelt, die Jenetzky als "finanzamtsadäquate Rechtsverbiegung und Rechtsbildung" bei Anwendung des Steuerrechts nennt und die "eine Rechtsvereinfachung des Sachbearbeiters, der kapazitätsmäßig überfordert ist", darstellt und der daher bis zur "Tatbestandsverbiegung" der gesetzlich normierten Ermittlungspflicht auszuweichen sucht. ${ }^{55}$

Steuerberater erleben gelegentlich, daß ein junger, die Ermittlungsmaxime genau handhabender Sachgebietsleiter zum Problembeamten des Finanzamtes wurde, da die unerledigten Akten seine Tischplatten fültten und zu Engpăssen im Betriebsablauf führten, bis er sich endlich an die lässigere Wahrnehmung seiner Dienstgeschäfte gewöhnt hatte und vor Abzeichnung der Vorgänge nur noch auf offenkundige Widersprüche in den Erklärungen achtete, um dann zum. Schluß nur bei den von den Sachbearbeitern seines Bezirkes nach typi-

\footnotetext{
5s Jenetzky, J. (1982), S. 279.

34 Jenetzky. J. (1982), S. 280, S. 282.

35 Jenetzky. J. (1982), S. 280.
} 
sierten Anweisungen gefundenen steuerrechtlichen Beurteilungen bei Fertigung der Bescheide als "Unterschriftsmaschine" zu dienen.

Von einem drohenden Zusammenbruch der Finanzverwaltung kann mithin keine Rede sein. Die Veranlagungstätigkeit erfolgt zügig. Bei Auftreten von Auslegungsdifferenzen neigt die Verwaltung heute dazu, bei Entscheidungen ständig zugunsten des unbequemen Steuerpflichtigen oder dessen Beraters einzulenken, um längerwährenden Rechtsmitteln aus dem Weg zu gehen, zumal die Finanzgerichte der ersten Instanz bereits eine Bearbeitungszeit von fünf Jahren benötigen ${ }^{56}$ und die Bearbeitung das Finanzamt zusätzlich belastet. Das alles kann den Steuerbürgern und ihren Beratern nur recht sein. Das Steueraufkommen entwickelte sich schon wegen der jährlichen Lohnsteigerungen und der dadurch ausgelösten Progression höchst zufriedenstellend. Auf der Seite der Steuerpflichtigen setzt sich stets derjenige durch, der sich rigoros verhålt. So kann man durchaus von einer Gemeinsamkeit der Interessen sprechen, die allerdings zu Lasten derjenigen geht, die sich gegen höhere Steuerzugriffe nicht zu wehren vermögen. Das ist die große Zahl der hilflosen Steuerpflichtigen, die nicht in der höchsten Progressionsstufe angesiedelt sind. Davon werden wir noch hören.

Die Verfahrensweise der Finanzämter hat auch Rückwirkungen auf das Verhalten der steuerberatenden Berufe. Steuerpflichtige erwarten von ihren Beratern, daß diese die Steuererklärungen, die den zu erteilenden Bescheiden als Grundlage dienen, von vornherein so fertigen, daß sich eine für sie günstigere Veranlagung ergeben kann. "Nicht das Finanzamt ist das Problem, Sie sind offenbar mein Gegner!" muß man sich heute als Steuerberater von manchem Mandanten sagen lassen, wenn man Erklärungen korrekt nach den Gesetzesvorschriften anfertigt. Daher werden steuerlich ungünstige Sachverhalte dann oft in phantasiereichen, aber irrefihrenden Konstruktionen in der Hoffnung verpackt, die Finanzämter als steuerrechtskundige Behörde zu günstigen und sogar falschen Beurteilungen zu verleiten - zu "linken" -, freilich ohne gelogen zu haben. Die Verwaltung als Herr des Besteuerungsverfahrens soll sich irren.

Wenn auch von einem angeblich drohenden Zusammenbruch der Finanzverwaltung keine Rede sein kann, solange "die Produktion von Steuerbescheiden auf Hochtouren läuft", ${ }^{57}$ zeigen sich doch allmählich unverrückbare Grenzen der Belastung, wenn etwa - wie in München - gebietsfremde ländliche

36 Raupach, A. in: Raupach, A./Tipke, K./Ueiner, A. (1985), S. 59.

"Jenerzky, J. (1982), S. 285. 
Finanzàmter zur Aufarbeitung des Arbeitsanfalls eingeschaltet werden müssen.

Das Ergebnis der Veranlagung mag somit in formeller Hinsicht befriedigend sein. Immer mehr Steuerpflichtige erhalten jedoch den Eindruck, daß von einer Besteuerung nach der Leistungsfahigkeit gar nicht mehr gesprochen werden kann, mag dies auch unter dem Mantel der Kompliziertheit verborgen bleiben und vom Laien nicht recht aufweisbar sein. Bereits 1982 hielt Jenetzky warnend fest, daß altbewăhrte Praktiker aus der Finanzverwaltung "in vertrauten Gesprăch von der Überzeugung ausgehen, daß die Komplizierung des Steuerrechts von interessierten Gruppen gewünscht werde und nur deshalb jede echte Steuervereinfachung scheitere" ${ }^{58}$ Der Gedanke kann keineswegs als völlig abwegig abgetan werden. "Die betroffenen Beamten unterstellen dem Gesetzgeber nicht einmal mehr die subjektive Lauterkeit des Bemühens", so Jenetzky. Der derzeitige Unrechtszustand könne nur dadurch beseitigt werden, so führt dieser Dozent für Steuerrecht an der die Beamten des gehobenen Dienstes ausbildenden Fachhochschule Baden-Württembergs aus, daß die leitenden Beamten der obersten vorgesetzten Behörden die Verbindung zu den Erfahrungen der Sachbearbeiterbesprechungen bei den Ämtern und der Hauptsachgebietsleiterkonferenzen bei den Oberfinanzdirektionen suchen. ${ }^{59}$ Die sich hier zeigende Problematik, die dem instrumentalen Einsatz des Einkommensteuerrechts bei Vermeidung unerwünschter Folgewirkungen Grenzen setzt, liegt mithin in der Unabgestimmtheit der Gesetzesvorschriften und des explodierenden Arbeitsanfalls mit der vorgegebenen Leistungsfähigkeit der Verwaltung bei den gegebenen Anforderungen an den Gesetzesvollzug. Das gesetzlich vorgeschriebene Veranlagungsverfahren ist nach der Reform von 1976 trotz der Explosion der Vorgänge nur geringfügig verändert worden. Der Verwaltung obliegt noch heute die Ermittlung und die amtliche Feststellung der steuerlichen Bemessungsgrundlage und die Festsetzung der Fälligkeit der

\footnotetext{
98

\$8 Jenerzky. J. (1982), S. 285.

39 Jenetzky, J. (1982), S. 285. Diese Feststellung des Regierungsdirektors und Professors an der Fachhochschule für die Ausbildung der Finanzbeamten im gehobenen Dienst des Landes BadenWartiemberg ist beãngstigend, zumal man davon ausgehen kann, daB er guten Kontakt zu den die praktische Veranlagungstätigkeit verrichtenden Beamten in den Finanzämtern hat. Diese durchschauen sehr wohl, daß derjenige, der für höhere Steuern eintritt, seine eigene Vermōgens.- und Einkommensposition verbessert, wenn der Gesetzgeber seinem Begehren entspricht, sofern er bei seiner eigenen Einkommensbesteuerung in höherer Progressionsstufe angesiedeli ist. Bei đem allgemein als sozial eingestuften Eintreten für Eshoshung der Progression kann mithin bei Berucksichtigung der Besteuerungswirklichkeit getarnt ein höchst eigensüchtiges Interesse zugrunde liegen. Ein Finanzbeamter vermag resignierend $z u$ äbersehen, $\mathrm{daB}$ zur Gruppe der Begrinstigten nicht nur alle Abgeordneten, sondern alle Moderatoren der Medien und Meinungsinacher von Presse und Funk gehören. Wer hoch in der Steuerprogression angesiedelt ist, den kann eventuell eine Steuererhőhung, die als soziale Maßnahme verkauft wird, nicht schrecken, solange das Systern ihm gegebenenfalls mit Hilfe seines Steuerberaters erlaubt, Steuem in Vermōgen umzuwandeln.
} 
von Gesetzes wegen entstandenen Steuerschuld. ${ }^{60}$ Diesen Aufgaben vermag die Verwaltung jedoch heute infolge des Arbeitsanfalls in der gebotenen Weise nicht mehr nachzukommen.

In einem weiteren Abschnitt soll überlegt werden, ob eine Reform des Veranlagungsverfahrens gegenüber den modernen Anforderungen eine Entlastung bringen kann.

\section{Ist das geltende Veranlagungsverfahren der zunehmenden wirtschaftspolitischen Verwendung der Einkommensteuer noch gewachsen?}

\section{Kann von einer Fehlentwicklung des Vollzuges der Einkommensteuer gesprochen werden?}

Johannes Jenetzky sprach 1982 warnend in einer dem Steuer- und Wirtschaftsrecht gewidmeten Zeitschrift von einer "Fehlentwicklung der Steuerverwaltung", da es der Gesetzgeber versăumt habe, "die Bedingungen in den Finanzämtern an die neuen Belastungsfaktoren anzupassen". Als ursächlich für diese Entwicklung nannte er "das expansive Wachstum der Steuerrechtsnormen", "den raschen Wechsel gesetzlicher Regelungen", "den Einsatz des Steuerrechts als wirtschaftliches Lenkungsmittel", "die Überkomplizienung der Normsetzung, die in Widerspruch zu verbindenden und klärenden systematischen Grundlagen des, Steuerrechts tritt" und das "Hineinwachsen weiter Bevölkerungskreise in das Veranlagungs- oder auch Lohnsteuerjahresausgleichsverfahren" ${ }^{61}$ Die Auswirkungen dieser Fehlentwicklung lassen sich, wie wir noch später sehen werden, nur langfristig und nur durch umfassende Änderungen des Veranlagungsverlahrens und des gesamten Gesetzesvollzuges eindămmen oder gar beseitigen.

Diesen Zusammenhang hatte wohl auch Jenetzky bereits bei Niederschrift seines Aufsatzes 1982 im Auge. wenn er zu den Ünterlassungssünden des Gesetzgebers auch "rigide" Ändenungen in der neuen Abgabenordnung 1977 mit einer eriorderlichen Verlagerung des Schwergewichts der Besteuenungsaufgaben der Verwaltung in einen personell aufgestockten Außendienst anmahnte. $^{62}$

\footnotetext{
60 $\S 85$ und $\S 88$ i. V. m. $\S 155$ AO; Tipke, K./Lang, J. (1991). Steuerrecht .... 13. Aufl., S. 684.

6 Jenerzky, J. (1982), S. 278.

${ }^{62}$ Jenerzky, J. (1982), S. 278.
} 
In der gegebenen Situation ist es - wie wir noch sehen werden - nützlich, den ausgiebigen Auseinandersetzungen um die Einfuhrung der modernen Einkommensteuer und vor allem ihrer institutionellen Ausgestaltung zu der sogenannten "deutschen Type" gegen Ende des 19. Jahrhunderts nachzugehen.

Wirft man einen Blick auf die frühen Ansătze des Gesetzesvollzuges zur Einkommensbesteuerung, so gewinnt nämlich das Bild von einer fehlerhaften und unabgestimmten Entwicklung schärfere Konturen. Offenbar wurden die Weichen fruhzzeitig in eine unzweckmäßige Richtung gestellt, die uns später als "deutsche Type" geläufig wurde. Franz Meisel hat dies bereits 1911 bemăngelt und spăter wiederholt kritisiert. ${ }^{63}$ Dabei ist zu bedenken, daß Gesetz und Gesetzesvollzug für den Bürger eine Einheit darstellen. Der Vollzug fügt sich den leitenden Gesichtspunkten der zugnundeliegenden Besteuerungsidee ein; er ist deren praktische Verwirklichung.

Den Untersuchungen Meisels kommt für uns auch heute noch Bedeutung zu Der Grund ist darin za sehen, daß das preußische EStG von 1891 zwar den âußeren Aufbau und die sprachliche Ausgestaltung des sächsischen EStG 1874/78 im wesentlichen übernahm, diesem jedoch - wie wir bereits sahen mit weitreichenden Konsequenzen eine andere Besteuerungsidee zugnundelegte. Franz Meisel sprach bei der praktischen Ausgestaltung der Besteuerungsidee in diesem Zusammenhang von der "Steuertechnik", die er definierte als "dic Kunst, einen Steuergedanken in die Tat umzusetzen". ${ }^{64}$

Bereits 1911 hat er die Technik der Besteuerung des preußischen EStG, von ihm als "preußische Type" bezeichnet, grundsätzlich wegen der erkennbar bewirkten fragwürdigen Lastenverteilung hart kritisiert. ${ }^{65}$ Seine Einwendungen bekräftigte er 1914 gegen Angriffe von führenden Steuerjuristen wie Waldecker und andere, die glaubten, zur Abwehr genügten der Nachweis der formaljuristischen Gesetzmäßigkeit der Veranlagungstătigkeit und Zweifel an der Glaubwürdigkeit der von Meisel verwendeten Statistik. ${ }^{66}$ Im Jahr 1925 suchte Meisel dann das, was er nun "deutsche Type" nannte, mit der britischen Einkommensbesteuenung zu vergleichen. Die vielen Erkenntnisse Meisels über unterschiedliche Steuertechniken der beiden Typen, die sie begleitende Steuermoral und vor allem seine vorsichtige Bevorzugung des britischen Systems lassen sich zu einer Feststellung komprimieren, die den gesamten Gedankengang seiner Ausführungen durchzieht: "Die britische Veranlagung ist eine

\footnotetext{
${ }^{63}$ Meisel, F. (1925), S. 116.

Meisel, F. (1956), S. 358

${ }^{55}$ Meisel, F. (1911), S. 298, S. 304, S. 358 u. a.

${ }^{66}$ Behrnauer. F. (1910), S. 138; Waldecker, L. (1913), S. 61, S. 92.
} 
wirtschaftliche, keine juristische", so führte er aus. Und: "Das Steuerbeamtentum erscheint (in England, d. V.) den Gelehrten, Politikern und Publizisten schlechthin als die Sachverständigen". ${ }^{6 ?}$

Diesen Ausführungen Meisels kommt nach der hier vertretenen Überzeugung noch heute Bedeutung zu. Dies deshalb, weil aus der nach wirtschaftlichen Gesichtspunkten ausgerichteten Einkommensbesteuerung Sachsens das an formaljuristischen Tatbestandsmerkmalen aufgebaute preußische EStG 1891 entstand. Es hatte als Grundlage für die Reform in Preußen gedient. Die Leiter der Einschätzungscommissionen in Sachsen waren durchweg in wirtschaftlicher Hinsicht ausgebildete Beamte des Finanzministeriums. ${ }^{68}$ Die Einschătzungscommissionen in Preußen unterstanden dem Landrat als Vorsitzendem, der sich zumeist von einem Regienungsassessor vertreten ließ. Sie waren als Juristen des Verwaltungsrechts ausgebildet. Ihr Vorgesetzter war der Innenminister. ${ }^{69}$

Zur Beurteilung möglicher Fehlentwicklungen im heutigen Gesetzesvollzug und vor allem zur Erkenntnis möglicher Abhilfen mögen uns die Warnungen von fachkundiger Seite vor Einführung der neuen Besteuerungsform zu Ende des 19. Jahrhunderts weiterhelfen. Bei den nachfolgend genannten Zeitzeugen handelt es sich um entschiedene und engagierte Vertreter der Einkommensbesteuerung als dem Ideal der Beteiligung des Bürgers an den allgemeinen Lasten der Gemeinschaft nach ihrer jeweils individuellen Leistungsfähigkeit.

\section{Frühe Warnungen zur Einführung der Einkommensteuer}

Gustav Schmoller hatte eine praktische und theoretische Ausbildung zum Finanzbeamten im höheren Dienst durchlaufen, bevor er 1862 seinen für die fernere Entwicklung grundlegenden Aufsatz über den Einkommensbegriff lieferte. ${ }^{70}$ Wilhelm Vocke war lebenslang im wirtschaftlichen Prüfungs- und

\footnotetext{
${ }^{67}$ Meisel, F. (1925), S. 458.

Wachler, P. (1912), S. 353; Bóhmert, V. (1885), S. 38; ders. (1889), S. 57; ders. (1891), S. 3; Blither (1913), Sp. 621.

69 Delbrick von, C. (1817), S. 12; Witt, P.-C. (1973), S. 213 u. a.; Pausch, A. (1976), S. 114; Wachler, P. (1912), S. 354; Blaher (1913), Sp. 621. Die Darștellung vonı Witt weișt nach, daB Landrảte und Regierungsassessoren den Aufgaben der Verwaltungstătigkeì ausbildungsmäßig nicht. gewachsen waren. Wenn Witr herleitet, daß die Großgrundbesitzer in Preußen in großem Umfang steuer * unehrlich waren, so abernimmt er ungepröft die Argumente politischer Gruppierungen, die um Machterweiterung kămpften. Die Veranlagungsbeamten standen Gewerbetreibenden noch hilfloser gegenüber. und diese waren keineswegs steuerehrlicher. Die Bochumer Prozesse von 1891 sind' hierfür als Beweismittel geeignet. Hierzu: Delbrick, H. (1891), S. 132.
}

70 Schmoller, G. (1918), S. 55. 
Besteuerungswesen als leitender Beamter tätig. Er hatte sich bereits 1866 durch seine umfangreiche "Geschichte der Steuern des britischen Reiches" mit ausführlichen Untersuchungen des Gesetzesvollzuges einen Namen als Finanzwissenschaftler gemacht. ${ }^{71}$ Adolph Wagner hatte seit 1876 die einfluỉreiche Schriftenreihe von Karl-Heinrich Rau fortgesetzt. Er hatte im Finanzamsschuß des preußischen Landtages als Wissenschaftler zur Entwicklung des 1883 in zweiter Lesung vorgelegten und dann erst sechs Jahre spăter unter Johannes von Miquel mit einigen unbedeutenden Änderungen durchgebrachten Entwurfs zum preußischen EStG 1891 entscheidend beigetragen. ${ }^{72}$ Sowohl Schmoller als auch Vocke betonten, vor hochfliegenden Erwartungen warnend, daß ein Erfolg der Einkommensbesteuerung von einer akuiven und vor allem sachkundigen Mitwirkung der Zensiten abhăngig sei. ${ }^{73}$ Die Einkommensteuer ist nach Vocke zur "Durchführung einer Radikalkur im Steuerwesen" ungeeignet. "... ohne daß die unabweisbaren Vorbedingungen, die nötige Bildung der Steuerpflichtigen und der Einschătzer erfullt sind, würde das allerdings zur Folge haben, daß sie eine Strafe für die Ehrlichen und eine Prämie für die Gewissenlosen würde", ${ }^{74}$ so führte er vier Jahre vor der endgültigen Verabschiedung des preußischen EStG 1891 aus. In seiner 1887 veröffentlichten umfangreichen Abhandlung erörterte er das Für und Wider dieser Besteuerungsform. Er erlăuterte, warum eine amtliche Einschätzung der Bemessungsgnundlage ohne Deklaration des Steuerbürgers, wie es derzeit in Preußen noch geboten war und sogar beibehalten werden sollte, "eine Begünstigung der Wohlhabenden auf Kosten der Ärmeren" verursache. ${ }^{75}$ Gemessen an den hochtrabenden Erwartungen "ist die Einkommensteuer", so Vocke, dann "nur eine große Lüge". Denn nur die Festbesoldeten werden in diesem Falle richtig besteuert. ${ }^{76}$

Aber nicht nur die Steuerbürger, auch die Finanzbehörde müsse, so unterstreicht Vocke dann 1894 in einem weiteren Beitrag zur Finanzwissenschaft, den bildungsmäßigen Anforderungen, die das Abrechnungswesen zur ordnungsmäßigen Ermittlung der Bemessungsgrundlage zur Einkommensteuer mit sich bringt, genügen. ${ }^{77}$ Vocke wies etwa darauf hin, daß das Einschătzungsverfahren nicht unter die Leitung gewählter, fachlich nicht ausgewiese-

\footnotetext{
"Vocke, W. (1866).

${ }^{72}$ Hansen, R. (1990), S. 3, S. 50 Anm. 7, 8, 9, S. 62, Anm. 133, 135.

${ }^{73}$ Vocke, W. (1887), S. 500; ders. (1894), S. 352; Schmoller, G. (1871), S. 138.

74 Vocke, W. (1887), S. 353.

7 Vocke, W. (1887), S. 501.

${ }^{76}$ Vocke, W. (1887), S. 487.

7 Vocke, W. (1894), S. 353.
} 
ner Gemeindevertreter gehöre (wie in Preußen auch noch nach der Reform von 1891), sondern von wirtschaftlich ausgebildeten Beamten der Finanzbehörde betrieben werden müsse, wobei dann gewählte Laien als Vertreter der Gemeinde zu den Beschlußkörpern gehören könnten. Ohne wirtschaftliche Sachkunde der Beteiligten jedoch erfüllt diese Besteuerungsform ihre Ziele nicht, so etwa Vocke. ${ }^{78}$

Ähnliches hatte bereits Schmoller 1871 in seinem Gutachten zur Einführung der Einkommensteuer in Sachsen für die Königlich-Sächsische Regierung vorgetragen, wenn er auf die noch fehlenden, aber zum Gelingen des Experimentes erforderlichen ausbildungsmäßigen Voraussetzungen aufmerksam machte. ${ }^{79}$ In dem zur selben Zeit unter seiner Mitwirkung begründeten "Verein für Socialpolitik" wurde die Einkommensteuer daher sofort mit Vordring. lichkeit diskutiert.

Bereits seit längerer Zeit zählte die Forderung nach lastengerechter Besteuerung zu den vordringlich erörterten Themen. Die Auffassungen waren kontrovers: Der für die Liberalen einflußreiche John Stuart Mill hatte den Standpunkt vertreten, daß Deklarationspflicht der Zensiten zu einer unerträglichen Begünstigung der Skrupellosen auf Kosten der Ehrlichen führen müsse. ${ }^{80} \mathrm{Er}$ lehnte aus diesem Grund die Einkommensteuer nundweg ab. Der angesehene Leipziger Nationalokonom Wilhelm Roscher hatte aus den Thesen Mills hergeleitet, daß bei Deklarationspflicht der Zensiten eine Einkommensteuer den Ehrlichen gegenüber dem Gewissenlosen stets benachteiligt. Er hatte mit dieser Begründung in seinem für die sächsische Regierung gefertigten Gutachten 1871 gegen die Einfühnung einer Einkommensteuer erhebliche Bedenken geltend gemacht und empfohlen, es auch in Sachsen bei einer dem preußischen Vorbild von 1851, der "klassifizienten Einkommensteuer" nachgebildeten System, zu belassen, das ein amtliches Einschätzungsverfahren nach âuBerlichen Wohlstandskriterien ohne Deklaration kannte. Die Fragwürdigkeit der Lastenverteilung stellte für ihn das geringere Übel dar. ${ }^{81}$ Eine Einkommensbesteuerung modernen Zuschnitts auf der Grundlage von Deklarationen glaubte er nur für "eine hochkultivierte und darum sehr complizierte Volkswirtschaft ... aushilfsweise ... in ungewöhnlichen Notfallen" empfehlen zu können. ${ }^{82}$ Dabei standen ihm die Zustände in England nach 1800 und in PreuBen nach 1808 vor Augen.

\footnotetext{
7. Vocke, W. (1887), S. 484; ders. (1894), S. 352.

Th' Schmoller, O. (1871), S. 138.

${ }^{80}$ Mill, J. St., S. 508.

st Roscher, W. (1871) S. 130.

s2 Roscher, W. (1871), S. 131.
} 
Diesen Auffassungen, die auch in den Debatten des Landtages in Sachsen und später in Preußen wiederholt zitiert wurden, standen die grundsătzlich anderen Überzeugungen Schmollers und Vockes entgegen. Sie beurteilten die Einkommensteuer als Besteuerungsform der Zukunft, obgleich sie die technischen Schwierigkeiten ihrer zureichenden Ausgestaltung erkannten. ${ }^{83}$ In seiner Abhandlung aus dem Jahr 1887 erwăhnte Vocke in einer lăngeren Fußnote das săchsische Experiment von. 1878, das den Schritt zur Einfuhrung einer auf Deklarationen der Steuerpflichtigen beruhenden Einkommensteuer nach dem Schmollerschen Modell gewagt hatte. ${ }^{84}$ Vocke würdigte auch die positiven Aspekte dieses Entschlusses, hielt jedoch den Zeitablauf seit Einführung für zu gering, um ein abschließendes Urteil abgeben zu können.

\section{Ergebnisse der Gesetzesanwendung in Sachsen nach Durchführung der Reform im Jahr 1878}

Tatsächlich hatte man in Sachsen nach 1872, wie wir bereits erfuhren, Pionierarbeit geleistet. Dies wurde von Adolph Wagner wiederholt bestätigt. ${ }^{85}$ Der im preußischen Landtag 1883 gebildete Ausschuß zur Beschlußfassung über den von der Regierung unter dem Finanzminister Friedrich von Scholz vorgelegten Entwurf eines reformierten Einkommensteuergesetzes benutzte das sächsische EStG 1874/78 als Muster und man setzte sich mit einem erbetenen Erfahrungsbericht auseinander. ${ }^{86}$ Die neue Einkommensteuer war in Sachsen nach langen und ausgiebigen Erörterungen in beiden Hausern des Landtages unter Teilnahme einer breiten Öffentlichkeit bei Verwendung von neun wissenschaftlichen Gutachten renommierter Gelehrter unter Verarbeitung von 182 Petitionen und Stellungnahmen von Wirtschaftsverbänden und vor allen nach zwei Probeläufen des Gesetzes in den Jahren 1875 und 1876 sowie einer Übergangsregelung furr 1877 ab 1. Januar 1879 endgültig eingeführt worden. ${ }^{87}$ Die für die Veranlagungen vorgesehenen Bediensteten waren rechtzeitig entsprechend den neuen Anforderungen ausgebildet und auf ihre Tätigkeit vorbereitet worden. Im übrigen rechnete man wegen der praktischen

\footnotetext{
83 Vocke, W. (1887), S. 490; Schmoller, G. (1863), S. 56. S. 73; ders. (1874), S. 131; ders. (1881), S. 875 (Schm. J.).

us Vocke, W. (1887), S. 486.

Bs Wagner, A (1899), S. 107.

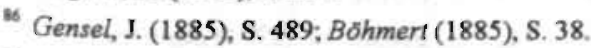

${ }^{n}$ Hoffmann, A. (1906), S. 84; von Nostiz, H. (1903), S. 91, S. 93.
} 
Erfüllung der gesetzlichen Anforderungen mit der automatischen Einleitung der erforderlichen Lernprozesse bei den Steuerpflichtigen. ${ }^{83}$

In Sachsen hatte man, wie bereits ausgeführt, nach dem Beschluß des zuständigen Ausschusses des Landtages die von Schmoller formulierte Besteuerungsidee zur tragenden Grundlage des Einkommensteuersystems gemacht. ${ }^{89}$ Zur Ermittlung der Bemessungsgrundlage waren wirtschaftliche Größen, nămlich Vermögensmehrungen und tatsăchliche bzw. mögliche Aufwendungen der Steuerpflichtigen festzustellen. Gegebenenfalls waren nach dem Gesetz, den hierzu ergangenen Verordnungen und den "Instructionen" vereinfachte Einnahmen-Überschußrechnungen anzufertigen. ${ }^{90}$ Zugrunde lag dem Gesetz somit ein wirtschaftlicher Einkommensbegriff, der auf die "wirthschaftliche Kraft" des Steuerpflichtigen abstellte. Zur Skizzierung der neuartigen Bemessungsgrundlage hielt der Berichterstatter des Ausschusses in seinem Protokoll über die Erörterungen im Landtag gelegentlich fest: "Vom fiskalischen Standpunkte könnte man in der That nur wünschen, daß jeder Staatsbürger verpflichtet wäre, in kaufmännischer Weise Bücher zu führen und sein Einkommen jährlich festzustellen". Wenn erforderlich, sollten hierzu Sachverständige Hilfestellung leisten."

Das săchsische EStG 1874/78 setzte gegenüber den abgelösten Regelungen fortschrittliche Kenntnisse im kaufmännischen Abrechnungswesen bei den erklärungspflichtigen Zensiten und bei den Vertretern der als Leiter der Einschătzungscommission tätigen Beamten und ihren Mitarbeitern voraus. Dies galt auch dann, wenn in kleinen Besteuerungsfallen das Einkommen aus Vereinfachungsgründen nach den Instructionen durch eine simple Überschußrechnung zu ermitteln war.

In seinem für die sächsische Regierung erstellten Gutachten war Schmoller 1871 skeptisch gewesen, ob man einen abrupten Übergang ohne Sicherstellung genügender Steuereinnahmen wegen der noch mangelhaften bildungsmäßigen Voraussetzungen der Steuerpflichtigen wagen könne. ${ }^{92}$

Bei den Verhandlungen im sächsischen Landtag nach 1872 waren sich die Abgeordneten aber bewußt. daß ein befriedigender Vollzug der Einkommensbesteuerung nach dem von Schmoller formulierten Prinzip die "Selbstein-

Gensel, J. (1875), S. 1462.

* Mittheilungen aber die Verhandlung des ordentlichen Landtages im Königreich Sachsen, II. Kammer, 1872, S. 3313.

${ }^{90} \S \S 64 \mathrm{f}$ der Instruction zum EStG v, 2.7.1878, in: Gesetz- und Verordnungsblatt für das Königreich Sachsen, 18. Stück vom Jahre 1878, S. 561.

" Gensel, J. (1874), S. 1462.

${ }^{92}$ Schmoller, G. (1871), S. 136 b. 
schătzung" des Steuerbürgers voraussetzt und dies viele Zensiten überfordern und daher zu praktischen Schwierigkeiten führen mußte. Die Mehrheit der 2. Kammer des săchsischen Landtages hielt dennoch bereits 1871 "die allgemeine Deklarationspflicht für ein vortreffliches und sehr wirksames Mittel (erachtet), um die Bevölkerung dazu zu erziehen, daß sie Buch und Rechnung führen und sich dem Stande ihrer wirthschaftlichen Verhăltnisse Rechenschaft geben lerne". ${ }^{93}$ Die Majorităt im Landtag, so hieß es im Protokoll, hălt es "ebenfalls vom pädagogischen Gesichtspunkt aus für richtiger, die Forderung nicht höher zu spannen, als daß sie wenigstens von der Mehrheit Derer an welche sie gestellt wird ... auch erfullt werden kann" ${ }^{194}$ Entsprechend fanden einige, den Grundgedanken verbergende Vereinfachungsvorschriften Eingang in den Gesetzestext und die vom Landtag beschlossenen "Instructionen" zur Verwaltungstätigkeit. Wichtiger noch waren die Anforderungen, die der für die Verandagungstătigkeit vorgesehenen Bchörde gestellt wurden. In den Verhandlungen des Landtages wurde hierzu deutlich gemacht, daß die Majorităt eine Stärkung der Autorităt der Einschätzungscommission befürwortete und $\mathrm{da}$ man zur Vermeidung der Überforderung der Finanzbeamten willkürlichen Einschătzungen auf diese Weise entschieden vorzubeugen suchte. ${ }^{95}$ Die Angaben der Steuerpflichtigen sollten jedenfalls, "sofern sie nicht zu begründeten Zweifeln gegen ihre Richtigkeit Anlaß geben, bei der Einschätzung berücksichtigt werden", so die einstimmige Meinung der Abgeordneten. ${ }^{96}$ Hierzu waren Erörterungen mit den Steuerpflichtigen vorgeschrieben. Die Einschätzungscommissionen sollten sogar befugt werden, die Zensiten zur Eidesleistung aufzufordern. ${ }^{97}$ Wer sich hartnäckig weigerte Erklärungen abzugeben, konnte das Reclamationsrecht verlieren. Damit rückte man in Sachsen nach eingehender Erörterung ausdrücklich von der in Preußen seit 1820 geübten Praxis ab, Angaben der Zensiten in abgegebenen Deklarationen nur "als schătzbares Material für die Commission" neben anderen Informationen zu werten. ${ }^{98}$ Im übrigen herrschte im Landtag aus denselben Gründen Einmütigkeit bezüglich harter Strafen für diejenigen, die durch falsche Erklärungen Steuern hinterziehen bzw. nur den mißglückten Versuch hierzu unternehmen. Selbst die Einführung von Gefängnisstrafen für Steuerhinterziehung wurde diskutiert, aber von der Mehrheit verworfen. ${ }^{95}$ Das sächsische EStG 1874/78

\footnotetext{
${ }^{93}$ Gensel, J. (1874), S. 1462; Mittheilungen (1872), 91. Sitzung, S. 3325.

94 Mittheilungen (1872), 91 . Sitzung, S. 3326.

${ }^{95}$ Mittheilungen (1872), 91. Sitzung, S. 3326.

96 Mitheilungen (1872), 91. Sitzung, S. 3326.

${ }^{97}$ Mittheilungen (1872), 91. Sitzung, S. 3326.

${ }^{98}$ Mittheilungen (1872), 91. Sitzung, S. 3329; Mittheilungen (1878), 60. Sitzung, S. 1272

"Mittheilungen (1872), 91. Sitzung, S. 3327.
} 
war vor Einführung im Landtag und in der Öffentlichkeit seit 1872 im einzelnen und später auf Grundlage der Probeläufe in den Jahren 1875 und 1876 sowie der Übergangsregelung für 1877 ausgiebig erörtert worden. Es hatte in Sachsen, das zu jener Zeit bereits wesentlich stärker industrialisiert war, als andere deutsche Länder, das Besteuerungswesen revolutioniert.

Die Neuartigkeit dieses Experiments war nicht nur darin zu sehen, daß ein einheitlicher ungewohnter Maßstab für die Leistungsfähigkeit des Steuerpflichtigen als Summe der Einkünfte aus einer Vielzahl von Einkunftsarten fortan - später als "synthetische Methode" bezeichnet - die einkommensteuerliche Bemessungsgrundlage bildete, sie lag auch an der vorgeschriebenen Pflicht zur Abgabe von Deklarationen durch die Zensiten, die die Grundlage für die Veranlagung, bildeten und nicht zuletzt an der Bedeutung, die den Fassionen von Amts wegen beizumessen war.

Neuartig war auch der auf die Leistungsfähigkeit des Steuerbürgers abstellende Einkommensbegriff Schmollers, der dem EStG Sachsens zugrundegelegt wurde. Er versuchte der Intention nach die "Messung der totalen wirthschaftlichen Kraft" des Pflichtigen zu ermöglichen. Schmoller hatte die Auffassung vertreten, daß das "Einkommen kein Produkt eines beliebigen wirthschaftlichen Rechnungsexempels (sei), sondern ein lebendiges Ganzes, wie es aus dem Begriff der Persönlichkeit in ihrem Zusammenhang mit der Bedürfnisbefriedigung hervorgeht". ${ }^{100}$ In Schmollers Terminologie hieß das, daß der Einkommensbegriff "mit dem Productionsprozess (steht er) nur in mittelbarem Zusammenhang" steht. ${ }^{101}$ Eben gegen diese mit der klassischen Tradition brechenden Definition hat Adolph Wagner sich in jeder Auflage seiner Lehrbücher ausgesprochen. ${ }^{102}$ Wagners Auffassung hat sich durchgesetzt und ist bis heute, insbesondere bei Steuerjuristen, erhalten geblieben.

Gnundsătzlich war nach Schmollers Definition in einem Besteuerungsabschnitt alles stenerbar, was verbraucht wurde oder hätte verbraucht werden können, ohne das Vermögen anzugreifen. In dem sächsischen EStG 1874/78 gab entsprechend ein knapper Katalog die wenigen Ausnahmen von dieser allgemeinen Regel an. Leistungsfihigkeit bezog sich auf die ganze Person des

${ }^{100}$ Schmoller, G. (1863), S. 52.

101 Schmoller, G. (1863), S. 57. Leistungsfahigkeit wurde von Schmoller als Maßstab unabhăngig vom Markteinkommen und von sozialen Merkmalen definiert. DaB diese dann bei der Besteuerung berisksichtigt werden sollten, war fulr ihn ein anderes Problem.

102 Wagner, A (1876), S. 96, Anm. 8; ders. (1879), S. 115, Anm. 6; ders. (1880), S. 256; ders. (1890), S. 324; ders. (1892), S. 407; ders. (1890), S. 443. An der Feststellung andert sich dadurch nichts, daB Wagner unter Venweis auf Schmollers Aufsatz von 1863 ab 1890 einen erweiterten und einen engeren Begriff der Leistungsfahigkeit einfürt. Für die ESt zog er keine Konsequenzen. Andere Steuerarten solthen die Lacke schließen. 
Zensiten, nicht auf einen eingeschränkten Teilbereich von Unterhaltsmitteln. Eine sirenge Trennung zwischen steuerbarem Markteinkommen und nicht steuerbarer Privatsphäre kannte das Gesetz, anders als spăter in Preußen, nicht.

In Preußen sollte dann ein anderer Grundgedanken in ähnlich lautenden Vorschriften verankert werden. Der Einkommensbegriff war hier in bezug auf seinen Umfang durch die unterstellte "richtige" Erkenntnis der Realităt vorgegeben. Er war für Wagner, anders als für Schmoller, kein Ergebnis konventionell festgelegter Zweckmäßigkeit. Einkommen war hier stets "Markteinkommen". Markteinkommen und Stammvermögen waren begrifflich streng getrennt. Der Maßstab für die Leistungsfähigkeit wurde für Fuisting und Wagner durch das Markteinkommen definiert, nicht umgekehrt. In Sachsen, wurde ein Maßstab für Leistungsfahigkeit dem Einkommensbegriff zugrunde gelegt. Zur Sicherstellung vor ungesetzlichen Ausweitungen der Besteuerung in das Starnmvermögen sorgte im preußischen Gesetz der Enumerativkatalog steuerbarer Einkünfte. Das Einkommensteuerrecht wurde in Preußen konsequent von vornherein formaljuristisch als Eingriffsrecht nicht unter wirtschaftlichen Gesichtspunkten als bloße Lastenverteilung beurteilt. Der Rechtsschutz des Bürgers lag eben daher Fuisting besonders am Herzen. Bis heute blieb diese Auffassung bei Steuerjuristen zumindest vorherrschend.

Das sächsische EStG 1874/78 hat trotz des revolutionären Charakters des in ihm als Steuergegenstand definierten Besteuerungsgutes und des gesetzlich vorgeschriebenen Vollzuges in der Alltagspraxis sowohl bei Fachleuten und Politikern, aber auch bei den Steuerpflichtigen Anerkennung bzw. Akzeptanz erfahren. Sogar der Vorsitzende des Leipziger Arbeiterbildungsvereins und zusammen mit Wilhelm Liebknecht - Mitbegründers der Sozialdemokratischen Arbeiterpartei, August Bebel, der ab 1881 Mitglied des sảchsischen Landtages war und sich aktiv an Erörterungen zu Ergänzungen des Gesetzes beteiligte, nannte es "eines der besten Gesetze, welche das Land besitzt". ${ }^{103} \mathrm{Er}$ stimmte mit der Mehrheit der Abgeordneten gegen eine Änderung. Aber auch von fachlich kompetenter Seite kamen, sowohl von Juristen, als auch von Finanzwissenschaftlem, positive Beurteilungen. Sogar Steuerzahler wußten anders als nach 1891 in Preußen - keine nachhaltige Kritik vorzubringen. ${ }^{104}$

Fragt man sich angesichts der ungewohnten und drückenden Belastungswirkung, die von diesem Gesetz letztlich ausging, woran dies gelegen haben mag.

${ }^{103}$ Gensel, J. (1885), S. 502; Böhmert, V. (1885), S. 40.

104 Blither (1913), Sp. 623. Blither war als Oberverwaltungsgerichtsrat Richter in einem Senat fur Staatssteuersachen am Oberverwaltungsgericht in Dresden. 
so legt die Durchsicht der Stellungnahmen und Beiträge aus dem Munde von Fachleuten die Antwort nahe:

Das nach Schmollers Besteuerungsidee gefertigte, nach langwierigen, nämlich sechs Jahre währenden Erörterungen und Verhandlungen im Landtag am 22. Dezember 1874 in erster und dann nach Probeläufen am 3. Juli 1878 in endgültiger Fassung verabschiedete Einkommensteuergesetz entsprach nach allgemeiner Überzeugung den Anforderungen an eine sachgerechte Problemlösung, die eine in der Öffentlichkeit verstandene einheitliche teleologische Orientierung erkennen ließ. Es vereinigte die Bestimmungen über die Steuerpflicht, das Steuerschuldrecht, die Vorschriften über die Veranlagung, ebenso diejenigen über den Behördenaufbau, den Gesetzesvollzug und die Steuererhebung bis hin zu den Bestimmungen über Bestandskraft, die Einlegung von Rechtsbehelfen und die Normen zum Steuerstrafrecht - als "Zuwiderhandlung und deren Folgen" bezeichnet ${ }^{105}$ - als Vollgesetz unter einem gemeinsamen Dach. Gesetz, Gesetzesvollzug und Besteuerungswirklichkeit - von Meisel als "Steuertechnik" bezeichnet - waren für jeden erkennbar aus einem einheitlichen Guß. Das Gesetz wurde wohI daher allgemein akzeptiert. Eine andere Erklärung gibt es für das merkwürdige Phänomen der allgemeinen Zufriedenheit mit dieser drückenden steuerlichen Belastung nicht. Dieser Umstand blieb offeribar allen Kritikem des preußischen EStG 1891 stets überraschend. Ernsthaft zu nennende systematische Kritik sucht man jedenfalls vergeblich.

Eine systematische gedankliche Einheit bestimmten ebenso die kurz nach Verabschiedung des Gesetzes beschlossenen umfangreichen "Instructionen" vom 11. Oktober und vom 7. Dezember 1878 zu dem Gesetz, die mit unseren heutigen amtlichen Einkommensteuerrichtlinien vergleichbar sind. Hierin wurden Anweisungen zur Vereinheitlichung und Vereinfachung der Verwaltungstätigkeit erteilt, die weitreichende Vorschriften vorsahen, ohne den Sinn des Gesetzes zu beeinträchtigen.

Die Öffentlichkeit, einschließlich vieler maßgeblicher Fachleute außerhalb Sachsens, war offenbar davon überzeugt, daß es sich um ein Regelungsgefüge handele, das einer gleichmäßigen und zugleich gerechten Besteuerung diente, daß̉ es jedenfalls den Ansprichen an Belastungsgerechtigkeit in etwa nahekomme. Für spitzfindige Gestaltungen zur Steuervermeidung gab das Gesetz, wie wir an früherer Stelle zeigten, keine rechten Ansatzpunkte. Von der Besteuerung waren nur einige enumerativ aufgelistete "außergewöhnliche Einnahmen" ausgenommen. Über den Begriffsumfang mochte man streiten, etwa, ob auch Gewinne als Folge obrigkeitlicher Enteignungen darunter fielen oder

105 VIII. Abschn. Sachs. EStG vom 2.7.78, bestehend aus $\$ \S 68$ bis 77 , siehe Gesetz- und Verordnungsblatt ... (1878), S. 150. 
nicht. Erst das Oberverwaltungsgericht bejahte im übrigen diese Frage. ${ }^{106}$ Das, was man heute "loopholes" nennt, konnte man hier nicht finden. Die Zuordnung von Einkünften zu aufgezählten Einkunftsarten hatte in dem System nur statistische, keine konstitutive Bedeutung. Für die Steuerbarkeit war dies ohne weitreichendere Folgen.

Die im Landtag lange erörterte "Selbsteinschătzung" wurde zur wesentlichen Grundlage der Veranlagung bestimmt. Falsche Steuererklărungen wurden daher mit empfindlichen Strafen auch für den Fall belegt, daß es durch sie zu einer Steuerverkürzung nicht gekommen war. Das Reichsgericht in Leipzig als einheitliche Berufungsinstanz in Strafsachen für alle Lănder des Reiches bestătigte die strengen Regelungen des săchsischen Steuerstrafrechts in konkreten Fällen und stellte sie gelegentlich den den sächsischen Bestimmungen nachgebildeten, aber entschärften und daher unwirksamen preußischen Vorschriften vergleichend gegenüber. ${ }^{107}$

Die Veranlagung erfolgte in Sachsen vor allem unter der Leitung wirtschaftlich geschulter, vom Finanzministerium ernannter Beamten unter Mitwirkung von gewählten Vertretern der Gemeinde.

In Leipzig entstand unter dem Einfluß des fortschrittlichen Besteuerungswesens bald das Mekka der deutschen Betriebswirtschaftslehre an der dortigen Handelshochschule. Das hoch entwickelte Abrechnungswesen förderte die Behandlung von Fragen der Bilanzlehre, des Bewertungsrechts und der Bedeutung der Gewinnermittlung unter steuer- und handelsrechtlichen Gesichtspunkten. $^{108}$

Die Zugehörigkeit der in Sachsen mit der Veranlagung befaßten Beamten zum Finanzministerium, ihre wirtschaftliche Ausbildung und ihr schwerpunktmäßiger Einsatz zu Prüfungstätigkeiten kommt in vielen Berichten der Zeit zum Ausdruck. Dies mag uns heute selbstverständlich erscheinen, war es aber zu der fraglichen Zeit, wie wir noch sehen werden, keineswegs. Bereits in der herben Kritik Franz Meisels an "Moral und Technik bei der Veranlagung

\footnotetext{
${ }^{106}$ Rechtsgrundsătze (1905), 1. Bd., S. 46 (Nr. 46 zu \& 15 Ziff. 2 EStG). Das Urteil vom 6.9.1902. zeigt die Ausnahme von der Regel, die den Bestimnnungen des preuB. EStG 189 i und deren Auslegung Jurch das preuB. OVG in Staatssteuersachen zuwiderlief. Das Prinzip ist festgehalten in: Wachler, P. (1912), S. 59, Bem. Nr. 14 zu $\$ 15$ Ziff. 2 - 5 săchs. EStG 1878 mit Fundstellen.

107 Das Reichsgericht war für das Deutsche Reich Revisionsinstanz in Strafsachen. Es hatte dazu das Strafrecht der Lånder anzuwenden; siche Entscheidungen: ERGSt., 42. Bd., Nr. 119 v. 25.6.1909, S. 376, S. 378; siehe auch: ERGSt, 42. Bd., S. 397; ERGSt, 39. Bd., S. 62; ERGSt, 40. Bd., S. 309; ERGSt, 40. Bd., S. 305; ERGSt 30. Bd., S. 14. In den Erörterungen des săchs, Landtages ist für Steuervergehen sogar Gefängnisstrafe gefordert worden, was sich nicht durchsetże, In Preußen war dies nicht nachvollziehbar, hierzu: Wagner, A. (1.899), S. 112.
}

${ }^{108}$ Pausch, A. (1979), Von der Einkommensteuer ...., S. 448: 
der preußischen Einkommensteuer" wird wiederholt verlangt, daß diese und weitere in Sachsen geltende Regelungen in Preußen eingeführt werden sollten. ${ }^{109}$ Der Vorsitzende der Einschätzungscommission unterstand in Preußen noch bis 1919 dem Innenministerium. ${ }^{110}$

In einer långeren Replik auf Ludwig Waldeckers ablehnende Rezension seiner Beanstandungen verwies Meisel dann im Jahr 1914 zur Bestätigung seiner Ausführungen und Beurteilung offen auf die besseren sächsischen Besteuerungseinrichtungen. Die vielen anerkennenden Feststellungen zu Sachsen waren ihm jedoch offenbar nicht ganz geheuer. Er suchte sie daher vermittels der verfügbaren Statistiken zu verproben. Das Ergebnis vermochte ihn nicht voll zu überzeugen, so muß allerdings wegen der mit dem preußischen EStG 1891 vergleichbaren, als zu niedrig empfundenen Eingangsstufe angefügt werden. ${ }^{111}$ Meisel gab aber wohl dem Umstand zu geringe Bedeutung, daß in Sachsen eine Einzelveranlagung jeder steuerpflichtigen Person vorgeschrieben war, und nicht - wie in Preußen - Haushaltsbesteuerung des Familienvorstands.

Vergleichbares hören wir in einer Stellungnahme des langjährigen beamteten Leiters von steuerlichen Berufungscommissionen im Dienste der preußischen Finanzverwaltung, Michaelis. Er bestätigte ausdrücklich unwidersprochen die Auffassungen Meisels. Nach seinen praktischen Erfahrungen waren die preußischen Vorschriften zum Gesetzesvollzug - aber nicht nur diese ungeeignet. Sie standen einer Besteuerung nach der Leistungsfähigkeit in der üblichen Wortbedeutung entgegen. Als Ergebnis langjähriger Tätigkeit im Dienste des Finanzministeriums bestätigte er die Richtigkeit der Warnungen Vockes, daß in Preußen nur Festbesoldete angemessen besteuert werden. ${ }^{112}$ Wir müssen nach unseren Kenntnissen der Materie aber hinzufügen, daß dies nur für Mitglieder der unteren Einkommensgruppen galt, die ihr Einkommen nicht zu gestalten vermochten, wozu höhere Beamte in Preußen oftmals in der Lage waren.

In einer Nachschrift zu dem längeren Aufsatz von Michaelis mit dem gleichen Titel wie demjenigen Meisels meldete sich der Präsident des Senates für

${ }^{109}$ Meisel, F. (1911), S. 307, S. 349, S. 353, S. 361, S. 370; ders. (1914), S. 648. Meisel kritisiert die preuß. Regelungen ständig vermittels der besseren săchs. Bestimmungen. Dabei vermeidet er, soweit irgend möglich, Sachsen ausdrücklich zu erwăhnen. Wo ihm dies nicht möglich ist, sucht er Skepsis zu Sachsen zu bewahren, siehe: Meisel, F. (1914), S. 656; ăhnliches galt für Miquel, s. Böhmert, V. (1891), S. 3

${ }^{110}$ Bleek, W. (1972), S. 175; Pausch, A (1976), Im Dienste der GleichmäBigkeit ..., S. 113.

111 Meisel, F. (1914), Anm. 108, S. 649, insbes. S. 650.

${ }^{112}$ Michaelis (1912), S. 96 u.a.; auch: Moll, W. (1918), S. 103. Zur Frage der Ausbildung siehe: Moll, W. (1918), S. 99. 
Staatssteuersachen am sächsischen Oberverwaltungsgericht in Dresden, Wachler, im preußischen "Verwaltungs-Archiv" zu Wort. Wachler hatte bei der Erörterung des Gesetzes im săchsischen Landtag 1878 als Referent des Finanzministeriums gedient. Er bestătigte die Zweckmäßigkeit des săchsischen Gesetzesvollzuges im Vergleich mit den preußischen Verhältnissen. Vor allem bekräftigte er die im Vergleich mit den preußischen Bestimmungen wirtschaftiiche Ausrichtung des săchsischen EStG, der dortigen Beamtenschaft und des Gesetzesvollzuges, einer Technik also, die Meisel dringend empfohlen hatte. Er âußerte allerdings Skepsis bezüglich der Frage, ob die săchsischen Regelungen auf Preußen übertragbar seien. ${ }^{113}$ Eine Begründung für diese Beurteilung fügte er leider nicht an.

Der Leiter des săchsischen statistischen Amtes, Victor Böhmert, hielt 1889 fest, daß "die Einschătzung zur Einkommensteuer (ist) für eine große Anzahl von Steuerpflichtigen eine jăhrlich wiederkehrende heilsame Aufforderung zur Prüfung ihrer finanziellen Lage und eine Mahnung an die büchermäßige Aufzeichnung der Einnahmen und Ausgaben aller wichtigen Vorgănge im Hause und Beruf ..." seien. Er brachte die steigenden Steuereinnahmen nicht nur mit dem gestiegenen Volkseinkommen, "sondern auch mit der größeren Gewissenhaftigkeit der Steuerzahler ... sowie der häufigeren Anwendung des Nachzahlungs- und Strafverfahrens bei Hinterziehungen ..." in Sachsen in direkten Zusammenhang. ${ }^{114}$ Der Richter in Staatssteuersachen, Blüher, langjähriges Mitglied von sächsischen Einschätzungs- und Reclamationscommissionen, berichtete 1913 aus Dresden in der "Deutschen Juristen-Zeitung", daß "der Apparat zur Zufriedenheit arbeite". Und: "Auch in den Kreisen der Steuerzahler besteht - natürlich keine volle Zufriedenheit, wo wäre dies möglich? aber kein Wunsch nach einer anderen Einrichtung". Die gerade im Abrechnungswesen gute wirtschaftliche Ausbildung der unter unparteiischer Aufsicht des Finanzministeriums tätigen, mit ausreichendem Ermessensspielraum ausgestatteten sächsischen Bezirkssteuerinspektoren und ihrer Mitarbeiter hielt Blüher 1913 in der "Deutschen Juristen-Zeitung" den von ihm bemängelten unbefriedigenden preußischen Verhältnissen entgegen, wobei er das dortige auf Fuisting zurückgehende ausufernde Beanstandungsverfahren - offenbar wie Michaelis - als in jeder Hinsicht ungeeignet verwarf. ${ }^{115}$

\footnotetext{
113. Wachler, P. (1912), S. 354.

114. Bōhmert, V. (1889), S. 57.

115. Blüher (1913), Sp. 623; hierzu auch S. 620; Michaelis (1912), S. 87. Michaelis war als hoher Beanter seit 19 Jahren verantwortlicher Leiter von Veranlagungs- und Berufungskommissionen für die direkte Besteuerung. Siehe auch: Moll, W. (1918), S. 2, S. 15-27, S. 65, S. 76, S. 99. Zu der andersartigen Ausbildung der Finanzbeamten: Kirsch, L. (1887), S. 73, S. 76.
} 
Ähnliche Auffassungen hatte bereits 1912, Meisels Thesen bestätigend, Michaelis bekundet.

Im Jahr 1916 wiederholte ein langjähriger Leiter preußischer Berufungscommissionen, S. Buck, eben diese Feststellungen in einem längeren kritischen Aufsatz im "Finanz-Archiv". ${ }^{116}$

Der sächsische Senatspräsident Wachler hatte in den bezeichneten anderen Einrichtungen des Gesetzesvollzuges sogar "das Geheimnis des Erfolges" der sächsischen Besteuerung im Vergleich mit der ständig vernichtender Kritik ausgesetzten preußischen Einkommensbesteuerung gesehen. ${ }^{117}$

Auch Skeptiker werden bei Lektüre dieser von Fachleuten stammenden Beurteilung zugeben müssen, daß die im sächsischen Landtag im Deputationsbericht zur Steuerreform 1872 aufgeführte Überzeugung der Majorität des Hauses von den positiven, die Steuerehrlichkeit fördernden Wirkungen der Verpflichtung der Bürger zur periodischen Abgabe von Einkommensteuererklärungen als Grundlage für eine befriedigende Veranlagung bestätigt wurden. Darin war als Überzeugung der gesamten Deputation festgehalten worden, "da $\beta$ der Staat in der Gegenwart von seinen Bürgern ein gereifteres Bewußtsein von den Pflichten voraussetzen dürfe, welche sie ihm gegenüber zu erfüllen haben, als dies in den ersten Jahren nach Einfuihrung der Verfassung zulässig erschien". "Sie (die Deputation, d. V.) erachtet die Selbsteinschätzung so wenig sie sich die damit verknüpften Schwierigkeiten verhehlt für auf die Dauer unentbehrlich im Interesse gerechter Besteuerung und zugleich für einen wesentlichen Hebel der politischen Erziehung des Volkes". ${ }^{118}$ Bereits 1890 bestătigte dann der Steuerexperte $H$. A. von Bosse den erkennbaren "sittlich-erzieherischen Einfluß" der Einkommensteuerreform in Sachsen von 1878. ${ }^{119}$

Bei Durchsicht der infrage kommenden Fachzeitschriften und der veröffentlichten Literatur der Zeit findet sich im Gegensatz zu der Berichterstattung über Preußen nirgends ein Hinweis auf eine negative Beurteilung von Gesetz und Praxis der sächsischen Einkommensbesteuerung, dem man nachgehen könnte. Wenn Waldecker 1916 gegen Meisels positive Beurteilung der săchsischen Besteuenung im Vergleich mit der preußischen in einer Randbemerkung auf Măngel in dem dortigen Personenrechtsschutz hinwies, ${ }^{120}$ so ist dazu zu

\footnotetext{
${ }^{116}$ Buck, L. (1916), S. 28, S. 39, S. 55, S. 82.

117 Wachler, P. (1912), S. 355.

118 Mittheilungen (1872), 91. Sitzung, S. 3326.

119 Bosse von, H.-R. (1890), Die Gemeindebesteuerung in Sachsen, Leipzig, S. 42.

${ }^{120}$ Waldecker, L. (1917), S. 169.
} 
sagen, daß der săchsische Gesetzesvollzug die in Preußen entstandene quasiforensische Form der Veranlagung mit Frontstellungen zwischen Zensit und Fiskus nicht kannte. Die Veranlagung erfolgte hier nicht in Form erstarrter Auseinandersetzungen, sondern bei Meinungsverschiedenheiten nach Erörterung und Abwägung der Interessenlage mit dem Steuerpflichtigen in sachlicher Weise, wobei der zweistufige Rechtsmittelzug in der Regel gewährleistet blieb.

Schon die Person des Prăsidenten der 2. Kammer des Landtages zur Zeit der Entstehung des Gesetzes, Wilhelm Schaffrath, bot eine Garantie für ein auf strenge Rechtsstaatlichkeit hin überprüftes Gesetz. ${ }^{121}$

Schaffrath, aus mittelloser Familie stammend, brachte es vom einfachen Hirtenjungen zum angesehenen Rechtsanwalt und Vorsitzenden der 2. Kammer des săchsischen Landtages. Mit Robert Blunn befreundet war er Mitbegründer und Vorstandsmitglied des deutschen Anwaltsvereins und blieb in Dresden der Vertrauensanwalt der Hilffosen. ${ }^{122}$

Da der einflußreiche Autor eines Werkes über das săchsische EStG 1974/78, der Finanzwissenschaftler Alexander Hoffmann, in einer vielfach zitierten Abhandlung über die Steuerreform in Sachsen gelegentlich abfallig von dem "sozialdemokratischen Land Sachsen" spricht, dessen Einkommensbesteuerung er aber positiv beurteilte, ${ }^{123}$ kann die Bemerkung Waldeckers nicht überzeugen, zumal die Verhandlungen im Landtag zur Einführung der neuartigen Einkommensteuer sachlicher, als diejenige im preußischen Landtag und weniger ideologiedurchsetzt ausgetragen wurde.

\section{Die Ergebnisse der Gesetzesanwendung nach Einführung des preußischen EStG 1891}

Höchst eigentümlich ist der Umstand, daß die positiven Berichte über das săchsische EStG 1874/78 völlig in Vergessenheit gerieten und auch Fachkundigen heute unbekannt blieben. Anders verhält es sich mit dem preußischen EStG von 1891. Die höchst negative Beurteilung. die das preußische EStG 1891 frühzeitig in einer breiten Öffentlichkeit fand und die sogar von vielen fachkundigen Bediensteten des Finanzministeriums in den führenden Zeitschriften mit konkreten Hinweisen auf die Schwachstellen bestätigt wurde, blieb indessen unbeachtet. Mehr noch: Das Gesetz wird noch heute von vielen

\footnotetext{
${ }^{121}$ Weißler, A. (1905), S. 476.

122 Weißler, A (1905), S. 466.

${ }^{12}$ Hoffmann, A., S. 133. 
Steuerrechtlern, aber auch Finanzwissenschaftlern als Beginn einer Besteuerung nach der Leistungsfähigkeit gefeiert und wegen seiner Systematik hoch gelobt. ${ }^{124}$ Nach Adolph Wagner erwarb Sachsen sich "den Ruhm des steuerpolitischen und steuertechnischen Fortschrittes auf diesem Gebiet der directen Besteuerung in Deutschland". Wagner sprach von Sachsen zwar als einem "Pionier", zugleich sprach er aber von der "noch großartigeren preußischen Reform dieser Besteuerung", die "von dem sächsischen Vorläufer mit beeinflusst" ... "doch erst ein halbes Menschenalter später erfolgt" ist. ${ }^{125}$

So ist es inzwischen zur herrschenden Überzeugung geworden, daß das sächsische Modell ein noch nicht ausgereifter Keimling einer vollentwickelten reifen Frucht gewesen sei, zu der sich erst das preußische EStG 1891 entwikkelte.

Auf diesem Hintergnund muß die negative Beurteilung, die das preußische EStG 1891 in einer breiten Öffentlichkeit, einschließlich fachkundiger Bediensteter des Finanzministeriums fand, und die sich im Krieg bis zu seiner Ablösung 1919 noch verstärkte, verwundern.

Tatsächlich hatte die Regierung unter Finanzminister Adolf von Scholz dem preußischen Landtag 1883 den Entwurf eines reformierten Einkommensteuergesetzes vorgelegt. Als "Regienungscommissar und geheimer Finanzrath" war neben dem Leiter der Steuerabteilung des Finanzministeriums der später einflußreiche Kommentator des preußischen EStG 1891 und Senatspräsident am Oberverwaltungsgericht. Bernhard Fuisting, bei den Beratungen des Landtages zugegen. ${ }^{126}$ Der 1883 von Regierungsseite vorgelegte Gesetzesentwurf stellte eine Fortentwicklung der klassifizirten preußischen Einkommensteuer von 1851/73 dar, in dem die unteren Klassensteuern abgeschmolzen worden waren. Die tragenden Elemente waren gleich. Dieser zeigte im Vergleich mit dem sächsischen EStG 1874/78 eine andere innere Systematik.

Bezuiglich des Steuergegenstandes verblicb es darin nämlich, ebenso wie bei den Ermittlungsvorschriften, bei den alten Regelungen der Ertragsbesteuerung, wenn auch für buchführende Kaufleute. wie in Sachsen, die Handelsbilanz auf Intervention des Handelsstandes hin nach der zweiten Lesung des Gesetzes als Grundlage für die Ermittlung des Steuerbetrages dienen sollte. ${ }^{127}$

\footnotetext{
124 Bayer. H. W. (199i), S. 336.

123 Wagner. A. (1899), S. 107.

126 Fiusting nahm bereits an den ersten Verhandlungen des Landtages über die Gesetzesreform am 15.12.1882 als Regierungskommissar teil, s. Stenographische Berichte der Verhandlungen Haus der Abgeordneten. 16. Sitzung vom 15.12.1882. S. 349.

127 Gesetzesentwurf mit den Beschlössen der Kommission in zweiter Lesung vom Februar 1884. hierzu: /lansen, R. (1990), S. 50, Anm. 9.
} 
Gesetzesaufbau und Textgestaltung wurden zwar dem săchsischen Muster weitgehend entnommen, das Gesamtergebnis verriet jedoch einen anderen Bauplan.

Wagner hatte die Ertragssteuern durch Einbau moderner Elemente zu Einkommensteuern fortentwickeln wollen, was mit den Vorstellungen des Regierungskommissars Fuisting und denen des preußischen Generalsteuerdirektors Burghart vereinbar war. Entsprechend muß man das letztlich 1891 endgültig verabschiedete Ergebnis denn auch charakterisieren. ${ }^{128}$

An die Stelle des an den umfassenden Wertzugăngen einer Person mit einem knappen Katalog von einzelnen aufgefürten Ausnahmen nicht steuerbarer Zugănge eines Jahres orientierten Einkommensbegriffs in Sachsen trat in Preußen eine Definition, die Einkommen selektiv auf vier enumerativ aufgeführte Einkunftsarten als Früchte aus beständig fließ̉enden Erıragsquellen begrenzte. In spitzfindigen, später von Georg Schanz als juristische "Haarspalterei" bezeichneten Sprachregelungen wurde von Fuisting dabei zwischen steuerbaren Zuflüssen der Einkommenssphäre und nicht steuerbaren Veränderungen der Privat- oder Vermögenssphäre streng unterschieden und so in Gesetz und amtlichen Anweisungen ein in sich geschlossenes System zur Ermittlung des Einkommens errichtet. An die Stelle der Deklaration der Zensiten als Grundlage der Veranlagung trat das Selbstbekenntnis als "Mitwirkungspflicht" und damit zusätzliches Hilfsmittel für die amtliche Veranlagungstätigkeit.

Verwunderlich ist allenfalls, daß die Öffentlichkeit und insbesondere Fachleute sich später über höchst eigenartige Zustände in der Besteuerungswirklichkeit wunderten und ereiferten. Die amtlichen Ausführungsanweisungen vom 5. August 1891 und die Erläuterungen Fuistings dazu aus demselben Jahr und ebenso in späteren Auflagen gaben eine nur für den Fachmann überschaubare Information darüber, welche Tatbestandsmerkmale im Sachverhalt gegeben sein müßten, damit "Einkommen" im Sinne des Gesetzes überhaupt vorlag und ein Steuerzugriff erfolgen konnte. Die Einschätzungscommissionen waren gewiß durch verwirrende und zum Teil durch die Prüfung von Intentionen der Zensiten vorschreibende Vollzugsvorschriften als Tatbestandsmerkmal überfordert.

\footnotetext{
${ }^{128}$ Bredi, V., S. 27. Fûr Wagner war das Einkommen der eigentliche Maßstab für die Leistungsfahigkeit. Fuisting definierte Einkommen als "Frucht der Quelle" (1902), S. 133. Nicht aus dauernden Quellen der Gutererzeugung entspringende Erwerbungen vermehrten nach Fuisting die Leistungsfahigkeit nicht, Bredt, S. 66. Wagner konstruierte eine Verlegenheitslösung, in dem er die Erwerbungen aus ZweckmäBigkeit zur Bemessungsgrundlage zuließ, obgleich dies nicht richtig war, hierzu:

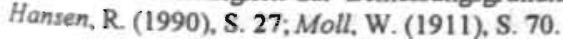


Da man zu dieser Zeit noch nicht - weder in der Öffentlichkeit, noch in der Verwaltung - zwischen legaler Steuervermeidung und Steuerhinterziehung zu differenzieren vermochte, konnte die Einkommensbesteuerung zu letztlich unüberprüfbaren und daher willkürlichen Beschuldigungen politischer ungenehmer und bekämpfter wirtschaftlicher Gruppierungen verwendet werden, denn durch geeignete Gestaltungen war es allen vermögenden Steuerpflichtigen in großem Umfang möglich, die gesetzmäßige Besteuerung zu vermeiden. "Buchführungsstellen" und "Rechnungskontore" erlebten Konjunktur und nicht nur Hans Delbrück berichtete in der früher angeführten Polemik gegen den Vollzug, daß Zensiten mit klaren Vorstellungen von ihrem hohen Einkommen verwundert die niedrigen Ziffern zur Kenntnis nahmen, die ein Rechnungskontor interessewahrend ermittelt hatte und der Deklaration zugrundelegte. $^{129}$

Erst das Abklopfen der Sachverhalte des Steuerpflichtigen in bezug auf deren Subsumierbarkeit unter gesetzlich festgelegte Tatbestandsmerkmale konnte die Steuerbarkeit erweisen. Dies bewirkte eine völlig andere Funktion von wesentlichen Elementen des Besteuerungsverfahrens und damit dessen, was Meisel als "Technik" der Besteucrung bezeichnete, gegenüber dem sächsischen Ausgangsmodell. Nicht nur war der Einkommensbegriff und damit auch das steuerbare Einkommen auf Vorgänge der Beteiligung am Marktverkehr mit Erwerbsabsicht eingeschränkt worden, was Fuisting und Wagner stets für richtig hielten; die Mitwirkungspflichten der Zensiten, die Aufgaben der Einschătzungs- und Berufungscommissionen und nicht zuletzt das Steuerstrafrecht erhielten - was leicht übersehen werden kann - entscheidend andere Zielsetzungen.

Wagner hatte zwar 1883 nur gegen heftigen Widerstand im Landtag die Deklarationspflicht der Zensiten in $\$ 21 \mathrm{c}$ der Beschlüsse der Kommission nach dem săchsischen Muster zu $\$ 21$ der Regierungsvorlage, die diese Verpflichtung noch als lästiges Eindringen in die Privatsphăre ablehnte, durchgesetzt. ${ }^{130}$ Fuisting hielt diese Vorschrift wegen einer befürchteten Uberforderung der Zensiten, den Besteuerungsgegenstand richtig zu ermitteln, für unzumutbar. ${ }^{131}$ Er vermißte im Gesetz die durchgångige Anknüpfung des Einkommensbegriffs an den herkömmlichen Ertragsbegriff und beklagte die damit einhergehende verwăsserte Unterscheidung zwischen Einkommen und

129 Delbrilck, H. (1909), S. 179; Meisel, F. (1911), S. 358; ders. (1914), S. 155; Michaelis (1912), S. 76: Buck, L. (1916), S. 70. Buck verweist darauf, daB das Ausnutzen der "vom Gesetz absichtlich geschaffener Schwalchen keine Steuerhinterziehung" sein kann; Mrozek, A. (1909), S. 268.

${ }^{130}$ Gesetzentwurf (wie Anm. 127), S. 2508; hierzu: Mauz, F., S. 120.

${ }^{131}$ Fuisting. B. (1903), Reformbedurftigkeit ..., S. 283. 
Vermögen. Die "Übergehung des Ertragsbegriffs" im Gesetz müsse zu großen Verwirrungen und zum Verlust der Orientierung am Gesichtspunkt der Leistungsfahigkeit der Zensiten führen, so glaubte er. ${ }^{132}$ Die Besteuerung von Spekulationsgewinnen, die Bedeutung, die Vermögensbilanzen zur Einkünfteermittlung anstelle von Einnahmen-Überschußrechnungen beigelegt werde, und weitere Abweichungen von dem Prinzip der Besteuerung von Früchten aus dauerhaften Quellen der Gütererzeugung beurteilte er als "eine künstliche Ausdehnung des Einkommensbegriffes", die Steuerpflichtige bei Fertigung ihrer Deklaration überfordern müsse. ${ }^{133}$ Hierbei muß erläuternd berücksichtigt werden, daß das preußische EStG 1891 für die Ermittlung der Einkünfte aus gewerblichen Vorgängen dem sächsischen Muster entsprechend auf die Vorschriften über die Rechnungslegung nach dem AHGB und deren Auslegung nach dem "Gebrauch eines ordentlichen Kaufmannes" verwies. Die im AHGB und dem spăteren HGB normierten Wertansätze der Gegenstände in den Bilanzen für Einzelkaufleute und Personengesellschaften waren frühzeitig heftig umstritten und führten bald zu einer abweichenden Praxis, die erst später als "Grundsătze ordnungsmäßiger Buchfürung" in überarbeiteten handels- und steuerrechtlichen Vorschriften einen Niederschlag fanden. ${ }^{134}$

Die Ermittlung dessen, was zum steuerbaren Einkommen gehört, kann dem Steuerpflichtigen wegen der Kompliziertheit der Materie nicht mehr zugemutet werden, so glaubte Fuisting. Und: "Eine Gesetzgebung, welche auf der einen Seite die Pflichtigen zur Abgabe von Steuererklärungen unter Versicherung der Richtigkeit 'nach bestem Wissen und Gewissen' nötigt und unrichtige, selbst auf ganz unschuldigem Rechtsirrtum beruhende Angaben unter Strafe stellt ( $\$ 66)$, auf der anderen Seite aber Vorschriften enthält, welche die gröBte Rechtsunsicherheit erzeugen, schafft hiermit einen Rechtszustand, der auf die Dauer nicht erträglich ist". ${ }^{135}$ Er sah es daher für unvermeidbar an, die Bedeutung der herkömmlichen staatlichen Ermittlungstätigkeit zu unterstreichen "und dem gesetzlichen Grundprinzip der amtlichen Ermittlungspflicht unter teils obligatorischer, teils fakultativer Mitwirkung der Pflichtigen Anerkennung zu verschaffen". ${ }^{36}$ Die Funktion der Deklaration wurde entsprechend in Preußen gegenüber dem săchsischen Muster anders festgelegt: "Die Steuererklärung ist demnach nur ein Veranlagungsmittel". so Fuisting, "ein in der Mitwirkung des Steuerpflichtigen bestehendes Hilfsmittel zur Erforschung

\footnotetext{
${ }^{132}$ Fuisting, B. (1896), S. 480; ders. (1906), S. 1172; ders. (1903), Reformbedarftigkeil..., S. 229.

133 Fuisting, B. (1903), Reformbedürftigkeit ..., S. 232.

${ }^{13}$ Barth, K. (1955), S. 196.

us Fuisting, B. (1903), Reformbedûrfligkeit ..., S. 283.

${ }^{136}$ Fuisting, B. (1896), S. 561; ders. (1903), Reformbedürftigkeit ..., S. 380.
} 
des steuerpflichtigen Einkommens". ${ }^{137}$ Sie war mithin nicht, wie in Sachsen, die Grundlage für die Einschätzung. Diese Auffassung setzte sich durch und wurde später nach einer Gesetzesnovellierung sogar verstärkt. Im Grunde gilt sie bis heute.

Auch andere Rechtsfiguren erhielten eine vom Muster abweichende Funktion: "Wenn das Gesetz die Steuererklarung unter Androhung von Rechtsnachtheilen als Pflicht erfordert", so muß nach Fuisting diesem Zwangseingriff "auch ein Recht des Steuerpflichtigen auf gewissenhafte Beachtung seiner Angaben und auf vorsichtige Behandlung bei Anzweifelungen seitens der Steuerbehörde gegenüberstehen. ${ }^{138}$ Denn: "Eine Gesetzgebung, die den Deklarationszwang vorschreibt, aber die Abgabe richtiger Steuererklärungen selbst sehr erschwert, hiermit ein Übermaß an Beanstandungen hervorruft und die Pflichtigen in Masse zur Anwendung von Rechtmitteln nötigt, ist auf die Dauer nicht erträglich". ${ }^{139}$ Zur Eingrenzung dessen, was er als Tendenz zum "Fiskalismus" beklagte, verwandte sich Fuisting erfolgreich für ein umfängliches formell geregeltes sogenanntes Beanstandungsverfahren, das in Preußen dann die Stelle der einfachen, zwanglosen Erörterung und Aufklärung des Sachverhaltes zwischen Zensit und Steuerbehörde nach wirtschaftlichen Gesichtspunkten des sächsischen Modells im Falle unterschiedlicher Beurteilung von Vorgängen einnahm. ${ }^{140}$

Anders als in Sachsen war es in Preußen die Funktion der Deklaration, nicht als Grundlage, sondern als eine unter vielen Informationsquellen für die amtliche Veranlagung zu dienen. Dem Amtsprinzip kam bei der Veranlagung in jeder Weise Vorrang zu. Dieses Prinzip hat die Besteuerungstechnik in der sogenannten "deutschen Type" bis heute bestimmt.

Ähnlich verhielt es sich in Preußen mit dem Steuerstrafrecht im Gegensatz zu Sachsen. Unrichtige Angaben in der Steuererklärung waren nur strafbar, "wenn eine Verkürzung stattgefunden hat" und an die Stelle dieser Strafe trat sogar eine kleine Geldstrafe, wenn die fragliche Angabe in der Erklärung zwar wissentlich, "aber nicht in der Absicht der Steuerhinterzichung erfolgt ist". ${ }^{41}$ Dies nachzuweisen war Aufgabe der Behörde. Das Steuerstrafrecht blieb, der Organisation der Einkommensbesteuerung in Preußen entsprechend, von den

\footnotetext{
137 Fuisting, B. (1896), S. 562.

138 Fuisting, B. (1896), S. 563.

139 Fuisting, B. (1903), Reformbedurftigkeit .... S. 381

${ }^{140}$ Fristing, B. (1896), S. 559; ders. (1903), Reformbedurftigkeit ..., S. 382; Wachler, P. (1903). S. 509, betont đie formlose Vorgehensweise in Sachsen als vorzugswürdig gegenaber dem preußischen Beanstandungsverfahren.

${ }^{141} \S 66$ Abs. 2 preuß. EStG 1891; hierzu: ERGSt 42. Bd. 1909, S. 378.
} 
Prinzipien des Verwaltungsstrafrechts bestimmt. ${ }^{142}$ Nicht die Schädigung der Allgemeinheit durch Bewirkung einer ungesetzlichen Lastenverteilung wurde bestraft, sondern die Mißachtung hoheitlicher Verwaltungsvorschriften.

Auch dies war die Konsequenz eines selektiven Einkommensbegriffs, der von dem Steuerpflichtigen erwartet, daB er den Sachverhalt nach Art von Juristen auf das Vorhandensein von normierten Tatbestandsmerkmalen zu untersuchen vermag und nicht nach kaufmännischen Gesichtspunkten einer eventuell vereinfachten Vermögens- und Aufwandsrechnung Rechenschaft legt.

Der weitergehende Wirkungszusammenhang dieser Faktoren im Veranlagungsverfahren konnte unter Berücksichtigung der Folgen der Quellentheorie für die Besteuerungswirklichkeit in Preußen zu fatalen Konsequenzen führen, die eine Besteuerung nach der Leistungsfahigkeit völlig infrage stellen mußten.

Wo nicht Zuflüsse und Wertermittlungen durch Abwägung nach kaufmännischen Gesichtspunkten Entstehung und Höhe der Steuerschuld bestimmten, sondern das Vorhandensein von formalen Tatbestandsmerkmalen im Sachverhalt allein Aufmerksamkeit beanspruchte. standen Schätzungen durch die Veranlagungsbehörden auf schwankendem Boden. Die Unterstellung von Ertragsquellen schied in Preußen nach Auslegung des Gesetzes durch das Oberverwaltungsgericht für die Einschätzungscommissionen "ganz und gar aus dem Schảtzungsbereiche aus". ${ }^{143}$ Nur der Ertrag einer positiv nachgewiesenen Quelle konnte als Grundlage einer Schätzung dienen, wobei jede einzelne Kapitalforderung als solche eine eigene ursprüngliche Quelle darstellte. ${ }^{144}$ Das von der Behörde vor Abweichung von den Angaben einer Steuererklärung bei der Veranlagung streng zu beachtende Beanstandungsverfahren und das entschärfte Steuerstrafrecht verschoben im Zusammenwirken die Beweislast auf diese Weise allzusehr zu Lasten der Einschätzungsorgane.

\footnotetext{
${ }^{142}$ Peres, W. (1973), S. 28, stellt fest, daß das Schwergewicht des arntlichen Umgangs mit steuerlichem Fehiverhalten nicht auf dem Strafverfahren der Verwaltung, sondern auf dem Beanstandungsverfahren beruhte ( $\$ 38$ preuB. EStG 1891 ). Dabèi wurde das Unrecht in der Regel korrigiert. Im abrigen blieb das Steuerstrafrecht in PreuBen Verwaltungsstrafrecht. Nicht die Schädigung des. Fiskus oder der Allgemeinheit galt es zu ahnden, sondem die Kontre!lvorschvifter, der Steueryerwaltung, Schneider, V. (1987), S. 45. Hier lag ein wesentelicher Unterschied zu den Vorschriften zum Steuerstrafrecht in săchs. EStG 1874/78; s. auch Stenglein, W. (1897), S. 233

14! Fuisting, B. (1897), S. 437, S. 443, S. 446, S. 459; ders. (1902), S. 233; ders. (1903) Reformbedarftigkeit .... S. 383.

${ }^{14}$ Weißenborn, H., S. 706; Fuisting, B. (1902), S. 233; ders. (1906), Entwurf ..., S. 73; ders. (1897), S. 462.
} 
So entarteten die Mitwirkungspflichten des Steuerbürgers infolge einer Abwehrhaltung gegen das, was er als Eingriffsrechte des Staates verstand, zu einem quasiforensischen Veranlagungsverfahren. Solange nämlich der Stand des Kapitalvermögens durch Auflistung der einzelnen Kapitalforderungen von der Behörde nicht positiv nachgewiesen werden konnte, mußte den Angaben in der Fassion gefolgt werden, so lautete auch die von Fuisting gegen den "Fiskalismus" vertretene halbamtliche Auffassung. Eine hilfsweise Besteuerung der Zensiten nach dem Lebensaufwand war in das preußische aus dem sächsischen Gesetz trotz des Versuchs von Miquel nicht übernommen worden.

Robert Meyer, der bei der Reform der österreichischen Personaleinkommensteuer um 1900 eine Fuisting vergleichbare leitende Stellung im Wiener Finanzministerium innehatte, beurteilte die preußische Einkommensbesteuerung, die Auffassungen Meisels um etwa zehn Jahre vorwegnehmend, wie folgt: "Diese ... Rechtsanschauungen ... führen in ihrem praktischen Resultate doch wohl unvermeidlich zu einer weitgehenden Steuerentlastung der Einkünfte des mobilen Kapitals überhaupt und ganz besonders des Einkommens

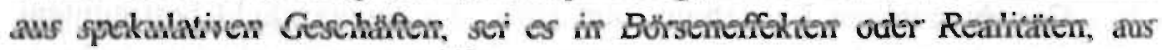
Provisionsgeschăften u.s.w." ${ }^{145}$ Seit 1902 warnte Meyer, in dieser Weise fast zehn Jahre vor Meisels kritischem Aufsatz über die preußische Besteuerungstechnik vor der Anwendung der in Osterreich von Preußen übernommenen Vorschriften zur Einkommensbesteuerung.

So kann es nicht verwundern, wenn Franz Meisel die preußische Steuerstatistik dazu verwendete, die in den Erklärungen offensichtlich versuchten Steuerverkürzungen der Jahre um 1905 als zwischen $30,3 \%$ und $38 \%$ des gesamten steuerpflichtigen Einkommens liegend zu errechnen. ${ }^{146}$ Da zu dieser Zeit noch nicht zwischen legaler Steuervermeidung, zu der bei Fehlen eines im Gesetz vorgesehenen ersatzweisen Umgehungstatbestandes auch höchst problematische steuerentlastende Gestaltungen des Sachverhaltes gehörten, und Steuerhinterziehungen unterschieden wurde, mag man daruber spekulieren, welche Höhe die gesamte erzielte Steuerentlastung wohl tatsăchlich erreicht haben mag.

Daß Meisels Hinweise auf den Zusammenhang vieler Einzelheiten zur schlechten Steuermoral in Preußen von erheblicher Tragweite waren, wird von folgenden Ergebnissen der Steuerstatistik unterstrichen: Im Jahr 1907 trugen 96,79\% der Steuerpllichtigen in Preußen mit einem zu versteuernden Ein-

14s Meyer. R. (1903), S. 126, hat die praktischen Konsequenzen des preuB. EStG bereits 1903 richtig erkannt. Er studierte bei Schmoller und Wagner in Berlin, s. Vogel, H. (1915), S. 77

${ }^{146}$ Meisel, F. (1911), S. 305. 
kommen von unter 6.500 Mark $48,31 \%$ zu der veranlagten Steuer bei. ${ }^{147} \mathrm{Da}$ der Höchstsatz der Einkommensteuer - von den Zuschlägen der Gemeinden zur Einkommensteuer von bis zu $250 \%$, ja gelegentlich bis zu $400 \%$, muß hier abgesehen werden - zu dieser Zeit 4\% nicht überschritt, erhălt man eine ìmpression von dem Auseinanderklaffen der Einkommensverteilung.

\section{Fortentwicklung von Gesetz und Gesetzesanwendung zur sogenannten "deutschen Type" der Einkommensbesteuerung}

\section{a) Die systemiragenden Grundgedanken des sächsischen}

EStG 1874/78, die Problematik der Gewinnermitilung nach Handelsrecht und die Vorreiterrolle Sachsens

"Es gibt keine demokratischere und keine humanere und keine sozialere Steuer als die Einkommensteuer", ${ }^{148}$ so lautete 1925 das Urteil Franz Meisels in seinem noch heute aufschlußreichen Vergleich von "Moral und Technik" im Bereich der von ihm sogenannten "deutschen Steuertype" mit der "britischen Steuertype". Und: "Der scharfe Einkommensbegriff, das Verhăltnis von Ertrag und Einkommen war der deutschen Theorie seit den Arbeiten von Hermann und Schmoller klar". Aber: "Die Erfaßbarkeit des Wirtschaftsergebnisses in der Form der Einkommensteuer war der Theorie ein Punkt der Steuerlehre, aber noch nicht das Problem", so bedauerte Meisel 1925. ${ }^{149}$ Die Entwicklung lief nach Meisel in Deutschland dann gegen Ende des Jahrhunderts aus dem Ruder. Denn: "Die Entwürfe der Gesetze und die Motive dazu behandelten die frühere Hauptsache nebenher, ein paar lose, allgemeine, überall fast die gleichen Bestimmungen, das war alles! "150

Es fehlte nach Meisel an einem konkret durchdachten Konzept, einer zusammenhängenden Formulierung und vor allem darauf abgestimmten Vorschriften für den Gesetzesvollzug. Er bedauerte die Beiträge vieler Wissenschaftler zu der Entwicklung der konkreten Gesetzgebung als ungeeignet. Die Finanzwissenschaft zeigte sich nicht mehr in der Lage, die Idee der Einkommensteuer fortzuentwickeln. In Deutschland entglitt den Finanzwissenschaftlern dann die Diskussion um die Organisation der Einkommensteuer völlig. Juristen nahmen ihre Stellung ein und gaben der Einkommensteuer bald eine andere, an praxisfernen rein formalistischen Prinzipien orientierte Richtung.

\footnotetext{
${ }^{147}$ Mittheilungen aus der Verwaltung ... (1907), S. 132 - 134.

${ }^{148}$ Meisel, F. (1925), S. 438.

${ }^{149}$ Meisel, F. (1925), S. 63.

${ }^{150}$ Meisel, F. (1925), S. 63.
} 
Tatsächlich waren die textlichen Ausgestaltungen der deutschen Einkommensteuergesetze der verschiedenen Länder in den wesentlichen Passagen oftmals fast identisch. Das lag daran, daß Sachsen für die Kodifikation in den einzelnen deutschen Ländern 1874 als Vorreiter Pionierdienste geleistet hatte. Allein, den Gesetzesformulierungen konnten ohne Rückgriff auf die aus den Auseinandersetzungen im Landtag hervorgegangenen "Motive" der gesetzlichen Regelungen, der innere Bauplan, die tragenden Prinzipien nicht entnommen werden. Sie konnten den Steuerjuristen, die nach Vervollkommnung der die Besteuerung auslösenden Tatbestandsmerkmale suchten, sogar leicht verborgen bleiben. ${ }^{151}$

Von Meisel sind die Gesichtspunkte zur Definition des Einkommensbegriffs, die von Schanz in seiner Kritik an dem preußischen System 1896 herausgearbeitet wurden, zwar gesehen und erwähnt worden. Trotz ihrer Tragweite wurden sie jedoch von ihm nur unbefriedigend behandelt und zugunsten seiner Aufmerksamkeit für den Gesetzesvollzug vernachlässigt. Auch Robert Meyers 1900 vorgetragene grundsätzliche Kritik an dem preußischen EStG war ihm ai's Land'smann bekannt, zumal' er in aèr osterreichiscren Finanzverwaltung, in der Meyer zuständiger Sektionschef war. Veranlagungskommissionen leitete. Dennoch zog er die von beiden aufgezeigten Mängel gegenüber den vom Gesetz erzeugten Erwartungen nicht zum Nachweis der Unzulănglichkeiten heran. Er erwahhnte sie nur gelegentlich und konzentrierte seine Kritik auf die Schwachstellen des Gesetzesvollzuges als wichtigstem Auslöser der von ihm mit Ziffernangaben unterlegten Unterstellung einer sich laufend verschlechternden Steuermoral in Preußen. Nur in dieser Hinsicht wurden von Meisel denn auch 1925 die Regelungen im Bereich der "britischen Steuertype" als vorzugswürdig hingestellt. Daß die Einkommensteuergesetze als solche allgemein verbesseningswùrdig waren, wurde von Meisel ständig erwähnt. In seiner harten Kritik an den Beiträgen Fuistings zum Gesetzesvollzug unterschătzte Meisel aber wohl die Bedeutung, die der von Meyer und Schanz erkannten Unzweckmäßigkeit der preußischen Gesetzessystematik gerade auch für den Gesetzesvollzug innewohnte und für den er bessere Lösungen forderte.

Nachfolgend soll dies genauer gezeigt werden, weil es die Entwicklung der "deutschen Type" bis heute bestimmt:

131 Die Tatsache, đaß̉ die Aufzahlung der Einkunftsarten des slichs. EStG 1874/78 nur Bedeutung fur die statistische Erfassung der Daten hatte und keinen abgeschlossenen Katalog darstellte, konnte dem, Text des Gesetzes nicht entnommen werden. Aus der Formulierung des preuB. EStG 1891 konnte man desgleichen nicht entnehmen, daB die Aufzahlung der Einkunftsarten als Enumerativkatalog zu verstehen war, u. a. m. So konnte Steuerjuristen stets unverständlich bleiben, was Meisel meinte, wenn er betont festhielt: "Der Begriff des Einkommens ist ein wirtschaftlicher, kein rechtlicher", hierzu: Moll, W. (1918), S. 2, S. 20. 
Das sächsische EStG 1874/78 hatte, wie mehrfach erwähnt, einen einheitlichen Bauplan. Dessen Grundprinzip kam in den Vorschriften zur Ermittlung der Einkünfte aus "Handel, Gewerbe einschließlich des Betriebs der Landwirthschaft auf fremden Grundstücken und jede andere Erwerbsthătigkeit" zum Ausdruck.

Im săchsischen EStG 1874/78 war in dem systemtragenden Grundgedanken entsprechend bestimmt, den "Reingewinn nach den Grundsătzen zu berechnen, wie solche für die Inventur und Bilanz durch das Handelsgesetzbuch vorgeschrieben sind und sonst dem Gebrauche eines ordentlichen Kaufmannes entsprechen". Insbesondere sollte dies "vom Zuwachs und andererseits von der Abnutzung des Anlagecapitals, sowie von Forderungen und Schulden und deren Zinsen" gelten. ${ }^{152}$

Nun waren die Vorschriften über die Rechnungslegung im AHGB 1861 vornehmlich nach Gesichtspunkten des Gläubigerschutzes konzipiert worden. Der Gedanke einer periodengerechten Gewinnermittlung wurde fur das Handelsrecht noch nicht als regelungsbedürftig beurteilt. So waren seit 1861 Einzelkaufleute und Personengesellschaften zur Aufstellung einer Bilanz verpflichtet, in der die Vermögensgegenstände ohne Differenzierung nach deren Funktion im Unternehmen zum Zeitwert anzusetzen waren ( $\$ \S 31$ ff AHGB). Das war die generelle gesetzliche Regel. Für verschiedene Körperschaften folgte das Handelsrecht dann aber bereits 1880 und noch entschiedener 1884 in Spezialvorschriften verbesserten leitenden Gesichtspunkten. ${ }^{153}$ Nun wurden aus Gründen der Erfahrung mit Schwindelgründungen der frühen 70er Jahre Gliederungsvorschriften eingeführt, die für die Bewertung der Gegenstände des Anlagevermögens mit Anschaffungs- oder Herstellungskosten das Höchstwert- und für Gegenstände des Umlaufvermögens das Niederstwertprinzip vorsahen. ${ }^{154}$

Die hier zum Ausdruck gelangenden Grundgedanken, die erst in den verbesserten Vorschriften für Körperschaften des AHGB einen noch unvollkommenen Ausdruck finden sollten, bestimmten aber bereits bei Schaffung des săchsischen EStG 1874/78 zunehmend den Inhalt der "Grundsătze, die dem Gebrauche eines ordentlichen Kaufmannes entsprechen". Nach 1880 hat das

\footnotetext{
${ }^{152} \S 21$ Abs. I sẳchs. EStG 1874/78 in: GVoBl. 1878, S. 137.
}

${ }^{153}$ § 31 AHGB von 1861, abgedr. in: Barth, K. (1953), S. 281; für Aktiengesellschaften waren nach der Aktienrechtsnovelle vom 18.7.1884, RGBI. S. 123, die Vorschriften $\$ 31$ AHGB nach MaBgabe des Art. 185 a anzuwenden, hierzu: Barth, K. (1953), S. 114, S. 139. S. 147, S. 281, S. 287.

194 Art. 185 a Aktienrechtsnovelle vom 18.7.1884. Diese war fortan gem. Art. 239 b Bestandteil des AHGB als Spezialvorschrift fur die Bilanzaufstellung der $\mathrm{AG}$. Sie zeigte den neuesten Stand der Prinzipien fur die Rechnungslegung eines verantwortungsbewuBten ordentlichen Kaufmannes, s. RGBI. 1884, S. 123. 
später sogenannte "Imparitätsprinzip" in die neueren Teile des Gesetzes Eingang gefunden. Es beherrschte bereits zu dieser Zeit die Diskussion um das Abrechnungswesen nach Gesichtspunkten, die heute als "Grundsätze einer ordnungsmäßigen Buchführung" ( $\mathrm{GoB})$ die feste Grundlage für alle Rechnungslegungen abgeben. ${ }^{155}$

Die Anordnung über den Ansatz des Zeitwertes in den Bilanzen der Personengesellschaften nach $\S \S 31$ ff AHGB - Vorschriften, die später unverändert in die nach 1900 geltenden $\$ \S 38$ ff HGB übernommen wurden - führte gelegentlich dazu, daß entgegen den die Praxis bestimmenden Grundsätzen, "die dem Gebrauche eines ordentlichen Kaufmannes entsprechen", nichtrealisierte Gewinne durch Bewertung von Gegenständen des Anlagevermögens zum gestiegenen Zeitwert bei Ermittlung der steuerlichen Einkünfte aus Gewerbebetrieb von Gerichten zugeschlagen wurden. ${ }^{156}$ Diese Urteile der Oberverwaltungsgerichte in Staatssteuersachen, die sich streng an den Text des AHGB oder später HGB - hielten, blieben in der Diskussion schon wegen der anderen Bewertungsvorschriften für Körperschaften umstritten. Die Entscheidungen des preußischen Oberverwaltungsgerichtes erhielten jedoch für den deutschen Sprachraum zunchmend eine leitende Funktion. ${ }^{157}$ Insbesondere dann, wenn es sich um den Wertansatz für Grundstücke handelte, bestand bei den Gerichten zumeist die Neigung, unabhängig davon, ob es sich um Gegenstände des Anlage- oder Umlaufvermögens handelte, den Zeitwert als Wertansatz vorzusehen. Dies lag deshalb nahe, weil Spekulationsgeschäfte in Grund und Boden mit der zunehmenden Industrialisienung ein ständiges Ärgernis bildeten, das sich bereits bei den Erörterungen des Gesetzes im Landtag wegen der sozialen Konsequenzen der florierenden Grundstücksspekulationen mehrfach entladen hatte. Erst nach 1913 setzte sich auch in Gerichtsurteilen des preußischen

155 Es handelt sich bei den GoB um einen Sammelbegriff für alle Regeln über Inhalt und Form zur Aufstellung von Bilanzen und vergleichbaren Rechenwerken, damit sie die mit ihnen verfolgten Zwekke (Rechenschaftsłegung) erfillen können, s. Handwōrterbuch des Steuerrechts, 1. Bd., S. 714.

156 S. hierzu die geschichtliche Darstellung der Entwicklung der Praxis der Rechnungstegung in Auseinandersetrung mit den Vorschriften des ESt-Rechts bei Barth, K. (1955), S. 211; ders. (1953), S. 62; Pausch, A. (1979), Von der Einkommensteuer .... S. 447.

197 Das Bedurfnis nach Schaffung einheitlicher Grundlagen für Rechtsleben und Wortentwicklung des Rechts wurde gegen Ende des Jahrhunderts groß. Die von P. Laband begründete DJZ suchte dieses Bedurfinis ab $1896 \mathrm{zu}$ befriedigen. Hier berichteten dann die Senatpräsidenten B. Fusting aus Berlin und P. Wachler aus Dresden regelmaßBig Qber die hōchstrichterliche Rechtsprechung in Staatssteuersachen in Preußen bzw. Sachsen. Obgleich die von Fuisting maßgeblich bestimmte preuß. Rechtsprechung sehr umstritten war, übemahm diese doch allmalhlich eine Führungsrolle zur Auslegung der leitenden Begriffe und Gesichtspunkte des ESt-Rechts, hierzu etwa: Meyer, R. (1901), S. 134; ders. (1903), S. 122; Pistorins, T. (1919), S. 78; Wachler, P. (1903), Gesetzesjubilăum ..., S. 509; ders. (1912) slichs. EStG, Bem. $1 \mathrm{zu} \S 15$, Bem. 1 zu $\$ 17$, hier werden vorsichtig grundlegende Abweichungen von der Fuistingschen und spater Strutzschen Auslegung des preuB. EStG 1891 festgeschricben. 
Oberverwaltungsgerichtes die Auffassung durch, daß das Verbot des Ausweises nichtrealisierter Gewinne in der Bilanz zu den wichtigsten Gundsätzen gehöre, die dem "Gebrauche eines ordentlichen Kaufmannes" entsprechen. ${ }^{158}$

Das săchsische ESıG war ausdrücklich auf den Schmoller-Hermannschen Einkommensbegriff hin ausgerichtet worden. Als Besteuerungsgut suchte man das realisierte Vermoögenswachstum sowie den Verbrauch des Pflichtigen im Besteuerungsabschnitt, also alles, was ein Steuerbürger verbrauchte bzw. verbrauchen konnte, ohne sein Vermögen anzugreifen, als Bemessungsgrundlage zu erfassen. Die Einschränkung des Steuerzugriffs auf realisierte Vermögensmehrungen hatte im Gesetz und in Verwaltungsanweisungen, soweit zweckmäßig, Berücksichtigung gefunden. ${ }^{159}$ Im Falle der Einkünfte aus Handel und Gewerbe war die Entstehung der Steuerschuld aber von den Grundsătzen der Rechnungslegung der Kaufleute abhängig gernacht worden. So zeigte das Gesetz einen einheitlichen Bauplan, berücksichtigte aber die Beurteilung okonomischer Notwendigkeiten durch den Berufsstand. Nicht realisierte Gewinne sollten dem Grundsatz nach nicht versteuert werden. Diesem Prinzip wurde gerade auch der umstrittene Ersatztatbestand einer Besteuerung nach dem Verbrauch gerecht, dessen Einbindung der Regierungskommissar Diller in den Verhandlungen des Landtages 1878 mit überzeugenden Argumenten zu begründen wußte. $^{160}$

\section{b) Die Gewinnermittlung nach Handelsrecht und die "preußische Type" der Einkommensteuer}

Die fast wörtliche Übernahme der Bestimmungen über die Gewinnermittlung für Gewerbetreibende aus dem săchsischen EStG 1874/78 in das preußische EStG 1891 stellte hier jedoch einen Fremdkörper in der an dem Quellenprinzip orientierten Systematik dar, mochte es sich auch um eine bloße Ermittlungsvorschrift für eine einzelne Einkunftsart handeln. Bereits der Landtagsausschuß von 1883 hatte die Übernahme dieser Position dem von der alten

\footnotetext{
199 Hierzu: Urteil Nr. 45 in: Mittheilungen ... Kőnigreich Sachsen, Bd. III, 1888, S. 157; ebenso: Bd. IV, 1893, Urteil Nr. 200, S. 500. Das sächs. OVG lehnte sich gegen 1900 in einigen Fragen an die Rechtsprechung des preuß. OVG in Staatssteuersachen an, s. Barth, K. (1955), S. 213, Anm. 68. Grund war das Ärgernis aber hohe Grundstacksspekulationen. Spatter wurden dann die Bewertungsgebote der Aktienrechtsnovelle von 1884 zur steuerlichen Gewsinnermittlung als maßgeblich beurteilt, s. slchs. OVG, Urteil v. 12.12.1912, zitiert in: Barth, K. (1955), S. 218.

1.99 Mittheilungen ... Königreich Sachsen, Bd. I (1884), S. 134; ebenso Bd. V (1900), S. 210; Wachler, P. (1912), săchs. EStG, Bem. 14 zu § 15; auch: Schanz, G. (1896), S. 43, Anm 2.

${ }^{160}$ Mittheilungen ..., Sitzung vom 19.12.1878, S. 1217.
} 
Systematik ausgehenden Regierungsentwurf entgegengesetzt. ${ }^{161}$ Erst in der zweiten Lesung des Gesetzes im Landtag hatte der Handelsstand dann 1890 auf der Einfügung bestanden, um nicht $\mathrm{zu}$ zwei unterschiedlichen Rechnungslegungen verpflichtet zu sein. ${ }^{162}$ Vor dieser Systemspaltung hatte Fuisting jedoch stăndig gewarnt. Er erkannte in der Übernahme der Vorschrift und ebenso in der Einfügung einer Bestimmung über die Besteuerung von Spekulationsgewinnen - in dem sächsischen System eine unnötige Bestimmung - die Verquickung von zwei unterschiedlichen Besteuerungsgütern im Besteuerungsgegenstand. In umfangreichen Darlegungen suchte er zu überzeugen, daß es sich um eine Besteuerung von Vermögenssubstanz handele, die der gesuchten Besteuerung nach der Leistungsfähigkeit, zu der er sich mit Wagner bekannte, widerspreche und die somit eine Durchbrechung der einheitlichen Ausrichtung des Bauplanes des Einkommensteuergesetzes darstelle. ${ }^{163}$ Aus diesem Grund hatte er auch in den ersten Verwaltungsanweisungen und Kommentierungen $\S 14$ des preußischen EStG 1891 in einer Weise ausgelegt, daß die Vorschriften $\S \S 6$ bis 11 des preußisches EStG 1891 auch für die Ermittlung der Einkünfte aus Handel und Gewerbe maßgeblich blieben, bis das preußische Oberverwaltungsgericht in Staatssteuersachen 1894 zu einem anderen Ergebnis gelangte. ${ }^{164}$

Im Grunde stand auch Adolph Wagner dieser Auffassung Fuistings nahe, indem er ebenso streng zwischen Besteuenung der Einkommens- bzw. der Vermögenssphäre trennte. Nur aus Gründen der reinen Zweckmäßigkeit sollte

181 Stenographische Berichte, Haus der Abgeordneten. Anlagen zur 15. Legislatur-Periode 1883/4. Nr. 42 der Drucksachen: \$11 der Regienungsvorlage. Zum Vergleich: $\$ 11$ der Beschlußemupfehlungen der Kommission der Abgeordneten; dazu: Entwurf eines ESiG vom 3.11.1890, abgedr. In FA VII. Jg. 1890, S. 643. Noch dieser Regienungsentwurf für die 2. Lesung war durchgängig nach dem Quellenprinzip gestaltet und sah zur Emnittlung der Bernessungsgoundage die Einnahmen-DherschuBrechnung vor. Die Vorschriften entsprachen denjenigen von $\$ \$ 30 \mathrm{ff}$ des preuB. EStG 1851 . Sieht man von dem Gesamtschema ab, so warem inhalilich nut das Institut der Selbstdeklaration (\$\$ 24 If) und die dann gestrichene ersatzweise Besteuerung nach dem Verbrauch aus dem săchs. EStG $1874 / 78$ ubernonmen worden.

162 $\mathrm{Zu}$ \& 16 des Regierungsentwurfs vom 3.11.1890 zur 2. Lesung siehe FA VII, Jg. 1890, S. 648; auch Begrundung hierzu S. 681; auch: Manz, F., S. 117.

163 Barth, K. (1955), S. 198: Von Fuisting ist die Unvereinbarkeit der ubernonmenen sâchs. Ermittlungsvorschrif mit der aus dem Grundgedanken der Ertragsbesteuerung fortentwickelten Systematik des preuB. EStO 1891 sofort erkannit worden. Stenographische Berichte .... Anl. 3, Session 1890/91, 7. Legislatur-Periode, Bd. 2, Nr. 75, S. 1265.

164 Fuisting; B. (1903), S. 232; ders. (1897), S. 480. Fuisting versuchte in dem halbamtlichen Kommentar zum preuB. EStG 1891 durch gecignete Auslegungen die aften Regelungen durchzusetzen, Fuisting, B. (1892), Anm. 3 zu $\$ 14$, S. 104; ders. (1894), Anrn. 9 zu $\$ 14$ EStG, S. 114. Erst das preuB. OVG verwarf die Auslegung Fuistings durch Urteil vom 13.12.1895 zu Gunsten der salchs. Regelungen. Entscheidungen ..., 5. Bd., S. 241; auch: Droste (1897), S. 556. 
nach seiner 189! vorgetragenen Meinung vorübergehend von dem eigentlich sachlich Gebotenen abgewichen werden dürfen. ${ }^{165}$

Fuisting sah als konsequent denkender scharfsinniger Jurist hier infolge der Verwerfungen durch zwei unvereinbarliche Bauplăne die entscheidenden Gründe für die von ihm fortlaufend beklagte Überforderung der Zensiten, eine richtige Einkornmensteuererklänung anzufertigen. Von hier versteht sich die hohe Bedeutung, die er dem der Veranlagung vorgeschalteten umfainglichen Beanstandungsverfahren beimaB. Das Amtsprinzip mußte seiner Auffassung nach betont werden, die Einschätzungskommission mußte Herr des Besteuerungsverfahrens bleiben, aber durch formale Beanstandungsmöglichkeiten mußte der Steuerpflichtige gegen möglichen Fiskalismus vor Willkïr geschützı werden. Die Bedeutung der Steuererklärung mußte gegenüber dem sächsischen Modell herabgestuft werden. Die Behörde war verpflichtet, für und wider die Interessen des Steuerbürgers zu ermitteln und entsprechend zu veranlagen. In der Praxis konnte das für die Verwaltung umständliche, formalistisch ausgestaltete Verfahren jedoch von den Zensiten leicht für eigennützige Zwecke mißbraucht werden.

Für Meisel wurde auf diese Weise in Preußen die Einkommensbesteuerung zu einer Bestătigung der frühen Warnungen Vockes. Die Behörden wurden infolge der unzweckmäßigen Organisation des Gesetzesvollzuges nach seiner Auffassung nicht in die Lage versetzt, "die materielle Wahrheit über das Einkommen zu ermitteln". "Die Einkommensteuer beruht für die größeren Einkommen auf dem Prinzip der Selbstbekenntnisse. Diese sind aber zu einem großen Teile unrichtig", ${ }^{166}$ so Meisel. Vorgånge in der Privat- oder Vermögenssphäre werden der Veranlagungsbehörde aber ausschließlich durch Fassionen überhaupt erst bekannt.

Das größte und entscheidende Hemmnis zur amtlichen Feststellung einer richtigen Bemessungsgrundlage zur Einkommensteuer sah Meisel aus diesen Gründen in dem von Fuisting auf die Spitze getriebenen formalistischen Beanstandungsverfahren. Hier glaubte er auch die Ursache für den nach seinen Einsichten zunehmenden Steuerwiderstand in Preußen erkennen zu müssen. Dabei hatte Meisel seinen Untersuchungen obendrein das 1906 nach 15 jăhriger Erfahrung novellierte preußische EStG, in dem - dem săchsischen Muster entsprechend - inzwischen eine Schwachstelle, durch die der Behörde neu zugewachsenen Befugnis, auf Antrag des Zensiten hin Buchhaltungsunter-

\footnotetext{
165 Wagners Grundauffassung machte es ihm erforderlich, sich für einen Ausbau der Verkehrssteu$\mathrm{em}$ einzusetzen, um sozialen Forderungen nachzukommen. Insbesondere exorbitante steuerlich unbelastete Wertmehrungen von Grundstocken führten zu starker Kritik; hierzu: Bredt, V., S. 41.

${ }^{106}$ Meisel, F. (1911), S. 373.
} 
lagen einzusehen, beseitigt worden war, zugrunde gelegt. Als Beginn einer amtlichen Steueraufsicht - ein Eindruck, der gelegentlich erzeugt wird konnte die Aufnahme dieser Bestimmung aber nicht dienen. ${ }^{167}$

Den Steuererklärungen der Zensiten haftete infolge der amtlich unterstellten Kompliziertheit der Tatbestandsmerkmale von vornherein das Omen an, fehlerhaft zu sein. Allein die Behörde, vertreten durch den Vorsitzenden der Berufungscommission, und das preußische Oberverwaltungsgericht in Staatssteuersachen waren von Gesetzes wegen steuerrechtskundig. So machte es durchaus Sinn, daß nach den Tatbestandsmerkmalen des preußischen Steuerstrafrechts, anders als in Sachsen, ein Steuerbürger nur dann für falsche Fassionen bestraft werden konnte, wenn nach einem längeren formalen Ermittlungsverfahren eine Verkürzung tatsächlich auch stattgefunden hatte und dann sogar nur eine kleinere Geldstrafe infrage kam, wenn die falsche Erklärung "zwar wissentlich, aber nicht in der Absicht der Steuerhinterziehung erfolgt ist". ${ }^{168}$ Derart mentale Tatbestandsmerkmale positiv nachzuweisen konnte ohnehin nur in Ausnahmefällen möglich sein. Die Verwaltung machte wegen dieser allgemein bekannten Insuffizienz, wie Meisel beklagte, nur in besonderen Ausnahmefallen von den unbrauchbaren Vorschriften des Steuerstrafrechts Gebrauch. Ebenso verhielt es sich mit dem Beanstandungsverfahren, das die Verwaltung, wenn irgend möglich, durch Nachgiebigkeit zu meiden suchte. ${ }^{169}$

Vom Steuerbürger wurden in Preußen Kenntnisse der steuerlichen Tatbestandsmerkmale nicht erwartet, obgleich Leiter von Berufungskommissionen und Richter zuständiger Senate am Oberverwaltungsgericht bald zynisch vermerkten, daß dieselben als hilflos angesehenen Steuerpflichtigen ihre Geschäfte jedenfalls höchst intelligent in der auf diese Weise entstandenen Grauzone zwischen Legalităt und Illegalităt an der Steuer vorbeizuführen verstanden. ${ }^{170}$

Die wichtigsten Hemmnisse einer fortschrittlichen Technik des Einkommensteuerrechts in Preußen sah Meisel in der nachrangigen Bedeutung, die den Steuererklärungen beigemessen wurde, dem ungeeigneten Beanstandungsverfahren, fehlenden amtlichen Kontrollmöglichkeiten und dem untauglichen Steuerstrafrecht. "Die Zukunft der Einkommensbesteuerung liegt nicht in der Beschränkung der beschränkten staatlichen Macht", die in der "preußischen Type" nach 1906 Urständ feierte. "Die Zukunft liegt", so führte

67 Tipke, K. (1968), S. 7.

${ }^{16} \S 72$ Abs. 2 preuB. EStG 1891: Meisel, F. (1911), S. 349, verweist auf die ärgerliche Belastung und die jeweils vorausgesehene Ergebnislosigkeit der zeitaufwendigen Verwaltungstätigkeit und das Ausbleiben einer notwendigen Pràventivwirkung.

169 Meisel, F. (1911), S. 331, S. 348, S. 353, S. 358; dazu: Wachler, P. (1912), S. 355.

${ }^{170}$ Mrozek, A., S. 265; S. 276; Michaelis (1912), S. 80. 
er aus, "in den friedlichen gesunden Verhältnissen und Beziehungen zwischen Staats- und Privatwirtschaft. Der Friede kann nur einkehren, wenn das gegenseitige Mißtrauen schwindet". Aber "dazu brauchen wir eine andere Moral und eine andere Technik". ${ }^{171}$

Obwohl selbst von Hause aus Jurist, glaubte er, daß eine Verbesserung der Verhăltnisse nicht von einer stärkeren juristischen Durchdringung des Einkommensteuergesetzes zu erwarten sei, sondern nur von einer Forführung der grundsätzlichen organisatorischen Gedankengänge, die der Besteuerungsidee ursprünglich zugrunde lag. Besonders eindringlich forderte er die dieser Besteuerungsidee fundamentale Beachtung des Rechtsschutzes des ehrlichen Steuerzahlers durch eine überzeugende Lastenverteilung, die er der dogmatischen, eingeengten Fixierung der Juristen auf die Beurteilung der Einkommensteuer nach Kriterien des Eingriffsrechts entgegensetzte. Diese verbesserte Technik, die er forderte, mußte aber neben dem überarbeiteten Gesetzesvollzug, mit dem er sich intensiv auseinandersetzte, auch eine von ihm vernachlässigte geeignetere Gesetzessystematik einschließen.

Auffällig, aber nicht ungewöhnlich ist für den Leser seiner Ausführungen, $\mathrm{da}$ er bei seiner umfassenden Kritik an den preußischen Verhalttnissen vielfach sächsische Regelungen, freilich ohne Verweis auf deren Ursprung, heranzog. ${ }^{172}$

Darin folgte er dem Beispiel von Mrozek, Michaelis, Buck, Wachler, Burkart, Maatz, Böhmert, W. Moll, Schanz und vielen anderen hohen Finanzbeamten, Richtern in Staatssteuersachen, Kommentatoren, Statistikern, Professoren, Autoren und sonstigen Fachkundigen.

Viele Umstände zeigen auf, daß es zu dieser Zeit ein "tabu" gewesen ist, sächsische Institutionen gar als beispielhaft für preußische Einrichtungen darzustellen. Der Name Sachsens wurde offenkundig in diesem Zusammenhang zumeist unterdrückt oder jedenfalls heruntergespielt. Selbst der sächsische Senatspräsident am dortigen Oberverwaltungsgericht in Staatssteuersa-

\footnotetext{
${ }^{171}$ Meisel, F. (1911), S. 373.

${ }^{172}$ Meisel, F. (1911), S. 361, S. 349, S. 353; ders. (1914), S. 160. Aufschlußreich ist die Beurteilung der Bedeutung der săchs. Regelungen für die. Besteuerung, gewerblicher Gewinne durch Barth, K. (1955), S. 61. Er bezeichnet sie als "bahnbrechend" und revolutionierend. Da Barth die fruhen Verhandlungen im săchs. Landtag und den Aufsatz Schmollers von 1863 nicht heranzog, konnte ihm entgehen, daß dem săchs. EStG 1874/78 der Hermann-Schmollersche Einkommensbegriff zugrundegelegt wurde. Indem er sich auf die fehlerhaften Auffassungen Diehls (Barth, K., 1955, S. 93) stûtzt, verzeichnet er die historischen Zusammenhānge, Diehl, K. (1929), S. 5. Daher kommt Barth zu einer fehlerhaften Darstellung der Selbsteinschătzung durchı den zuständigen Ausschuss im salchs. Landtag (Barth, K., 1955, S. 188). Bei unvoreingenommener Wordigung der Darstellung Barths zeigt sich, daB der Fortschritt der Rechnungslegung aus Sachsen kam und das preuB. EStG 1891 ein hemmender Rûckschritt war, Barth, K. (1955), S. 183.
} 
chen vollzog in einer Veröffentlichung im einflußreichen "Verwaltungsarchiv" eigentümliche Verrenkungen, als er die sächsische Einkommensbesteuerung als beispielhaft lobte, aber trotz vorsichtiger Bestätigung einer im Grunde vernichtenden Kritik in einem Vorheft desselben Jahrgangs dennoch die săchsischen Institutionen nicht offen als Vorbild für Preußens unzweckmäßige Regelungen bezeichnen mochte. ${ }^{173}$ Ähnliche Feststellungen gelten auch für Georg Schanz. Gegen Vockes offensichtliche Skepsis zu positiven Feststellungen über die sächsische revolutionierte Einkommensbesteuerung von 1878 gerichtet, die dieser in seinem viel zitierten 1888 erschienenen Lehrbuch in eine längere Fußnote verbannt hatte, bekannte er sich in der Rezension des Titels in seinem "Finanz-Archiv" zu dem sächsischen Gesetzeswerk und erklärte kurz und bündig, daß das sächsische Experiment nach achtjähriger Probezeit die "Feuertaufe" zufriedenstellend bestanden habe. ${ }^{174}$ Weitere, ausdrücklich positive Erwähnungen sucht man bei ihm vergeblich, obgleich er die dortigen Regelungen zur Kritik der preußischen Vorschriften benutzte.

Die Zusammenhänge werden klarer, wenn man berücksichtigt, daß das

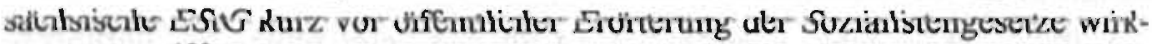
sam wurde. ${ }^{175}$ Das hohe Lob, das dem Gesetz im sáchsischen Landtag in den frïhen 80er Jahren von August Bebel zuteil wurde, hat gewiß viele erschreckt und muß hier erwähnt werden. ${ }^{176}$ Von dem Schüler F. J. Neumanns, dem Wagners Auffassungen zuzurechnenden A. Hoffmann, wurde denn 1906 auch offen in einer ausführlichen Darstellung der Steuerreform von 1874/78 von dem "sozialdemokratischen Land Sachsen" gesprochen. ${ }^{177}$ Er wurde dann der stärkste Gegner der späteren Umstellung des Reichseinkommensteuergesetzes von 1919 auf die Grundprinzipien des sächsischen Modells durch Matthias Erzberger. ${ }^{178}$

\footnotetext{
173 Wachler. P. (1912), S. 353.

${ }^{174}$ Schanz, G. (1888), S. 508 .
}

${ }^{175}$ Am 20.5.1878 wurde vom Reichskanzler der "Entwurf eines Gesetzes zur Ahwehr sozialdemokratischer Ausschreitungen" dern Reichstag vorgelegt. Die "Annalen des Deutschen Reichs" berichten dariber unmittelbar im AnschluB an die umfassende Darstellung der bestehenden ESi-Gesetze, deren Schlußglied das soeben verabschiedete săchs. ESiG $1874 / 78$ war, s. Gareis, C. (1979), S. 284.

176. Dem Vorsizenden des nach der Anlage zum Sozialistengesetz verbotenen Leipziger Arbeiterbildungsvereins drohte seit 1875 ständig die Verhaftung wegen Landfriedensbruchs, Hochverrats etc. Er hatte wegen der im săchs. ESiG $1874 / 78$ normierten Einzelveranlagung sein gesamtes Vermögen vorsorglich seiner Ehefrau zu deren Schutz abertragen. Da er den nach der Wahlgesetzgebung erforderlichen Mindestbetrag von 30,-- Mark für ESt nicht zahlen mußte, besaß er im Grunde nicht das passive Wahlrecht. Der săchs. Justizminister von Nostiz rûhmte sich fortan, das Wahigesetz durch Einbezug der ESt-Zahlung der Ehefrau zu Gunsten von A. Bebel großzügig ausgelegt zu haben, um diesem die Übernahme des Abgeordnetenmandats zu ermōglichen, s. Bebel, A. (1914), S. 186.

\footnotetext{
17 Hoffmann, A. (1906), S. 133; s. a. Czok, K. (1989), "Rotes Königreich".

17\% Hoffmann, A. (1921), S. 7.
} 
Das săchsische EStG spiegelte idealtypisch die soziologisch-wirtschaftliche Denkweise Schmollers ebenso wider, wie das preußische EStG 1891 von dem begrifflich-juristischen Denken Wagners, der sich zu einer dogmatischen Wissenschaftsauffassung bekannte, wesentlich geprägt worden war. Die Haßliebe, die die beiden Gelehrten seit 1873 personnlich verband und die letztlich die deutsche Sozialpolitik unendlich befruchtete, findet in der Kritik an dem preußischen EStG und dessen verborgener Wägung im Vergleich mit dem săchsischen Vorläufer eine adăquate Übereinstimmung. Das săchsische Experiment ist jedoch bis heute infolge der zunehmenden politischen Vorherrschaft Preußens und der ferneren schicksalhaften Entwicklung Deutschlands völlig in Vergessenheit geraten. ${ }^{179}$ Seine systematische Bedeutung wurde jedenfalls vollig verkannt.

Ludwig Waldecker, der heftige Widersacher Meisels und erste deutsche hochschulmäßige Vertreter des neu geschaffenen Lehrfaches "Finanz- und Steuerrecht" als juristischer Disziplin an der Universităt Königsberg, gab bereits frühzeitig die Stichworte für die weitere Entwicklung der Einkommensteuer zur späteren Reichseinkommensteuer von 1925, indem er die Auffassungen des früh verstorbenen Fuistings weiterfuhrte: Einem theoretischen Idealzustand hinsichtlich Steuermoral und -technik können wir uns nur annăhern, wennn wir "die Dinge auch vom Rechtsstandpunkt aus genau kennen oder studieren, den Rechtsstandpunkt zu Wort kommen lassen", so führte er 1916 aus. ${ }^{180}$ Er plädierte fernerhin für eine formalistische Verbesserung des geltenden Steuerrechts, dessen konkrete Beachtung und vor allem dessen widerspruchsfreie Eingliederung in die gesamte Rechtsordnung, wie dies bereits früher von Fuisting. Behrnauer und anderen Juristen geforden worden war. Waldecker suchte offenbar die von Wagner und Fuisting gegründeten Ansätze fortzuentwickeln. Hierin wurde er von einer großen Zahl von Schülern dieser Richtung, wie letztlich F. J. Neumann ebenso, wie dessen Schüler und Enkelschüler, zu denen Alexander Hoffmann, Wilhelm Gerloff und später Fritz Neumark als Finanzwissenschaftler rechnen, unterstützt. So bestimmte die strenge begrifflich-rechtliche Ausgestaltung des von Wagner und Fuisting geschaffenen Systems das fernere Geschehen sowohl bezüglich der Grundlagen der Gesetzessystematik, als auch, wie wir noch sehen werden, des Gesetzesvollzuges.

18 hierzu: Hansen, R. (1990), S. 40, S. 66 Anm. 173.

tio Waldecker, L. (1917), S. 171. 


\section{c) Der Einfluß Matthias Erzbergers auf das Einkommensteuerrecht und den Gesetzesvollzug und dessen Nachwirkungen}

Die von Meisel als "preußische Steuertype" bezeichnete charakteristische Ausgestaltung läßt sich so, trotz der umfassenden, von Matthias Erzberger in Gang gesetzten umwälzenden Reformen im Anschluß an die Beendigung des 1. Weltkriegs nach dessen frühem gewaltsamen Tod in der dann erfolgten Umstellung auch in der präzisierenden begrifflichen Verbesserung und Fortentwicklung als EStG 1925 noch bis heute verfolgen.

Erzberger hatte sich bereits 1899 und dann seit 1904 als Mitglied des Haushaltsausschusses des Reichstages durch nachhaltiges Eintreten für steuerliche ReformmaBnahmen qualifiziert. Er hatte sich dabei die von Schanz und später von Meisel ausgehende Kritik der Veranlagungstätigkeit zur preußischen Einkommensteuer zu eigen gemacht. Erzbergers politische Fähigkeiten waren von Adolf Gröber, dem Berichterstatter für die Steuerreform der Kammer der Abgeordneten des Württembergischen Landtages entdeckt worden. Der Reformentwurf der württembergischen Regierung war für Gröber von Erzberger bearbeitet worden. Bezeichnenderweise suchte Gröber im Landtag nach 1895, dem neuen EStG den Schmollerschen Einkommensbegriff zugrunde zu legen. Die Anträge drangen zwar nicht durch, das württembergische EStG 1903 folgte dann aber in einigen Positionen nicht dem preußischen Muster, sondern den Gedankengången des săchsischen Gesetzes. ${ }^{181}$ Nun suchte Erzberger 1919 die problematischen sozialen Konsequenzen der Einkommensbesteuerung und die ungenügende Steuermoral durch eine völlige Neugestaltung von Gesetz, Gesetzesvollzug und Erhebungsapparat auf der Ebene des Deutschen Reiches in den Griff zu bekommen. "Der Schutz des Ehrlichen gegenüber dem Unehrlichen ist eine der Hauptaufgaben dieser Reform", so führte er am 3. Dezember 1919 vor der Nationalversammlung in Weimar anläßlich der Erörtenungen der eingebrachten Reichsabgabenordnung aus. ${ }^{182}$ Unter dem Druck großer finanzieller Not nach dem verlorenen Weltkrieg gelang es Erzberger als Reichsfinanzminister, in 16 Einzelgesetzen vom 19. September 1919 bis zum 30. Mărz 1920 eine vollståndige Neugestaltung des Abgabenwesens durchzusetzen, wobei die gesamte Finanzverfassung mit den drei Bestandteilen, dem

19 Pistorius, T. (1904), S. 68. Sowohl Grobber, als auch sein Assistent Erzberger sympathisierten mit dem kritischen Aufsatz von Schanz aus dem Jahr I896. Sie vertraten ausdrücklich den HermannSchmollerschen Einkommensbegriff. So wird auch die Rolle Erzbergers als Mitglied und Leiter des Finanzausschusses des Deutschen Reichstages ab 1903 verständlich. Erzberger erkannte die Schwilchen des preuB. EStG 1891. Er qualifizierte sich als Abgeordneter letztlich durch seine Beiträge zur Steuerreform in Warttemberg um 1898, siehe: Erzberger, M. (1903), S. 380; ders. (1904), S. 685: Pausch, A. (1992), Persőnlichkeiten ..., S. 32; Buck, L. (1916), S. 115; Epstein, K., S. 16.

in: Erzberger. M. (1919), S. 120. 
Steuerrecht, der Finanzverwaltung und dem Finanzausgleich, neu geregelt wurden. Dabei fanden das allgemeine Steuerrecht, das Einkommen- und das Körperschaftsteuer- mit dem Kapitalertragsteuerrecht, die bisher als eigene Rechtsmaterien in den Einkommensteuergesetzen der einzelnen Länder mit enthalten waren, eigene reichseinheitliche Kodifikationen. "Reichsverfassung und Steuereinheit" sollen "in Zukunft die beiden kräftigen Klammern bilden, die das deutsche Volk zu einer starken Einheit zusammenfassen", so lautete das politische Programm des tatkräftigen und kenntnisreichen Finanzministers. ${ }^{183}$

Der Uberzeugungskraft und dem unermüdlichen Einsatz Erzbergers in der verfassungsgebenden Nationalversammlung gelang nicht nur die Verabschiedung einer institutionellen Neuordnung der Finanzverfassung des Deutschen Reiches. Erzberger vermochte auch inhaltlich den Gesetzen durch veränderte systemtragende Grundgedanken eine auf der Erfahrung mit dem preußischen Einkommensteuergesetz und dessen Kritik durch Georg Schanz und Franz Meisel aufbauende neue Orientierung zu geben. So wurden von ihm die uns bereits aus Meisels Beiträgen bekannten Problemfelder in der Gesetzgebung systematisch angegangen. $\mathrm{Zu}$ nennen sind hier das Quellenprinzip des Einkommensbegriffs und der damit zusammenhängende gespaltene Aufbau der Ermittlungsvorschriften, die dadurch geförderte problemlose Möglichkeit, die Entstehung der die Steuer auslösenden Tatbestandsmerkmale durch geeignete Gestaltungen legal zu vermeiden, unzweckmäßige Ermittlungs- und Veranlagungsvorschriften und der ungeeignete preußische Verwaltungsaufbau, das unpraktikable Recht der Verwaltung. Buchunterlagen der Steuerpflichtigen einzusehen, um erforderliche Kontrollmöglichkeiten für die nötige Steueraufsicht wahrzunehmen, sowie ein geeignetes, den ehrlichen Steuerbürger vor Übervorteilung durch den Unehrlichen schützendes Steuerstrafrecht.

So wurde bereits am 29. März 1920 ein eilig gefertigtes neuartiges Reichseinkommensteuergesetz verabschiedet, dessen Besteuerungsgut ausdrücklich nach der Gesetzesbegründung ebenso wie das săchsische EStG 1874/78 dem Hermann-Schmollerschen Einkommensbegriff entsprechen sollte und demge-

iss Erzberger, M. (1919), S. i13. Erzberger hatte nicht nur seil 1895 die Vorarbeiten für den Vorsitzenden des Ausschusses des Würtembergischen Landtages für die Reform der ESt, den L.andgerichtsrat Gröber, geleistet. Er war 16 Jahre hindurch Mitglied und Vorsitzender des Haushaltsausschusses des Deutschen Reichstages. Im abrigen hat das Württembergische EStG 1903 Gesichtspunkte der Schmollerschen Besteuenungsidee abernommen, da Grobber in den Verhandlungen die Auffassungen Fuistings heftig kritisierte, siehe: Pistorius, T. (1904), S. 72, S. 185; Ministerielle Denkschrift (1909), S. 439. S. 454, S. 474. Demgegenüber hatte der der Richtung Wagners und Fuistings nahestchende renommierte J. F. Neumann den Gesetzesentwurf der Regierung von 1895, der von Gröber und Erzberger abgelehnt wurde, positiv beurteilt, hierzu: Neumann, F. J. (1896), S. 173. 
mäß auszulegen war. ${ }^{184}$ Erzberger war von Haus aus kein Jurist, sondern Volksschullehrer. Es war ihm, zusammen mit seinem Landsmann, dem Staatssekretär Mösle, nicht nur gelungen, die Nationalversammlung zu überzeugen, sondern auch seinen Willen den einfluBreichen und sachkundigen Referenten des Ministeriums aufzuerlegen. Damit hatte das Programm Erzbergers die üblichen Reformhürden bezwungen und die wesentlichen Schwachstellen des preußischen Einkommensteuerrechts abgesteckt. Vor allem war nach dem völlig umgestellten Reichseinkommensteuergesetz 1920 die für Steuervermeidungen so geeignete, von der preußischen Systematik vorgegebene strenge Trennung zwischen Einkommens- und Privat- oder Vermögenssphäre entfallen.

Wie wir an anderer Stelle bereits erfuhren, erfolgte die Einführung des neuartigen Einkommensteuergesetzes 1920 jedoch zur Zeit größten fiskalischen Bedarfs und einer zunehmend inflationären Entwicklung. Die unter dem Druck der Zeitumstände festgesetzten völlig überhöhten Sätze des progressiv ausgestalteten Tarifs waren geeignet, die Reform in der Berichterstattung zu diskreditieren. Das in Eile gefertigte Gesetz, das bereíts vier Monate spăter zum ersten und dann im Mărz 1921 zum zweiten Male novelliert werden mußte, wurde bald infolge der Ereignisse außer Kraft gesetzt. Die den Grundgedanken des Gesetzes verständnislos gegenüberstehenden Finanzwissenschaftler und Juristen, clurchweg Schüler Wagners oder Neumanns und später auch Waldeckers, bekämpften zumeist die tragende Systematik. ${ }^{185}$ Nach dem gewaltsamen Tod Erzbergers am 26. August 1921 - wegen der heftigen gegen seine Person gerichteten Agitationen und Verleumdungen war er bereits im Mäırz 1920 zwecks Wahrnehmung seiner später erfolgreichen Verteidigung vor Gericht von seinem Amt zurückgetreten - blieben die neuen systemtragenden Prinzipien des Reichseinkommensteuergesetzes vom 29. März 1920 nach dessen Einführung fast 50 Jahre vergessen. Das im wesentlichen bis heute fortgeltende neu geschaffene EStG vom 10. August 1925 folgte nunmehr wiederum in seinen systemtragenden Prinzipien dem preußischen Modell vom 24. Juni 1891.

Mit der am 13. Dezember 1919 von Erzberger durchgesetzten Reichsabgabenordnung wurde eine beståndige reichseinheitliche Steuerrechtsordnung geschaffen. Ermittlungsverfahren, Steueraufsicht, Vorschriften über Fristen, Vertretung, Verjăhrung, Haftung, Mitwirkung des Steuerpflichtigen, Säumnisfolgen, Beitreibung und Steuerstrafrecht - Rechtsinstituten die, soweit bis

194 Verhandlungen ... Nationalversammlung Anlagen 1920 Nr. 1524, Begrûndung des REStG 1920, S. $17-24$.

183 Hoffmann, A. (1921), S. 5; s. a. Krohn, C. D. (1974), S. 148; Newmark, F. (1976), S. 362. 
dahin überhaupt geregelt - in den Gesetzen der einzelnen Länder angesiedelt waren, wurden hier zusammengefaßt. Die Reichsabgabenordnung wurde so zum "tragenden Fundament der rechtsstaatlichen Entwicklung im Steuenvesen". ${ }^{186}$

Der mit dem Entwurf betraute Enno Becker suchte neuartige "Befugnisse und Maßnahmen zur wirklichen Durchsetzung der Besteuerung" und "Pflichten der Beteiligten, ihrer Vertreter und Gehilfen, von Auskunftspersonen (Banken) und Staats- und Gemeindebehörden" festzulegen, "die bis dahin in Deutschland unmöglich gewesen wären". ${ }^{187}$

Zusătzlich suchte Becker nach den in Preußen stăndig beklagten Erfahrungen die Folgen der routinemäDigen Umgehung der Besteuerung auf Kosten des Fiskus als Folge einer geschickten Gestaltung des Sachverhaltes durch Meidung der konkreten steuerbegründenden Tatbestandsmerkmale zu neutralisieren: "Durch Mißbrauch von Formen und Gestaltungsmöglichkeiten des bürgerlichen Rechts", so bestimmte § 5 RAO 1919, "kann die Steuerpflicht nicht umgangen werden". Der Mißbrauch wurde in drei Fallgruppen tatbestandsmäßig umrissen und deren Auslegung und Zuordnung den Finanzgerichten überlassen. Der Reichsfinanzhof, dessen Präsident der Schöpfer der RAO wurde, unterstellte eine mißbrâuchliche Rechtsgestaltung zumeist, sobald diese erkennbar aus steuerlichen Gründen gewählt worden war. Bei Neugestaltung der heute gültigen, nicht wesentlich veränderten Abgabenordnung 1977 vom 16. März 1976 wurde diese Vorschrift in leicht überarbeiteter Formulierung in $\S 42$ übernommen. Sie erlaubt noch heute der Finanzverwaltung bei Feststellung einer als fehlsam beurteilten vollzogenen Rechtsgestaltung des Sachverhalts denselben quasi durch einen "Akt legislatorischer Analogie" unter die umgangene Rechtsnorm zu subsumieren. so da $\bar{B}$ die mit der vermiedenen Gestaltung als Rechtsfolge verbundene Steuer trotz der vergeblichen Bemühungen der Beteiligien von Gesetzes wegen entstanden ist. ${ }^{188}$ Freilich reicht heute nach der Rechtsprechung der Zweck der Steuervermeidung nicht mehr zur Beurteilung als rechtsmißbräuchlich aus.

Im sächsischen EStG 1874/78 wăren diese Bestimmungen aus rein systematischen Gründen ohne größere erkennbare Relevanz gewesen. Das preußische EStG 189 ! hatte jedoch ohne eine derartige Vorschrift seine wesentliche Aufgabe einer allgemein überzeugenden Lastenverteilung infolge seiner Systematik von vornherein verfehlt.

\footnotetext{
IM6 Pausch, A. (1992), Persönlichkeiten ..., S. 37

in Grabower, R. (1963), Sp. 41.

Tipke, K/Lang. J. (1991), S. 115
} 
Noch viel umstrittener, aber auch wirkungsvoller, sollten die in die RAO aufgenommenen, der allgemeinen Steueraufsicht dienenden Abschnitte werden.

In der Diskussion kamen bald nach 1919 Anregungen zur Sprache, eine gleichmäßige Besteuerung durch vorgeschriebene Prüfungen der Buchführung der Steuerpflichtigen sicherzustellen. Dabei kam das Beispiel Englands mit seinem traditionsbedingt hoch angesehenen Berufsstand der verbandsmäßig organisierten Buchprüfer ins Gespräch, deren Bestătigungsvermerken auf Abrechnungen und Steuerdeklarationen in der Regel, aber nicht unbedingt, von dortigen Behörden Vertrauen geschenkt wird. ${ }^{189}$ In der Folge kam es jedoch, noch der Linie Erzbergers entsprechend, bereits 1921 zum Aufbau eines zusammengefaßten "Buch- und Betriebsprüfungsdienstes" (BB) im Reichsfinanzministerium. ${ }^{190}$ In einer Denkschrift aus der Zeit hieß es, daß nur durch den Einsatz der Buch- und Betriebsprüfung der allgemeinen Steuerumgehung wirkungsvoll entgegengetreten und nur auf diese Weise Verluste hoher Steuerbetrăge vermieden werden könnten und vor allem, daß es zum Rechtsschutz der kleinen Steuerzahier, die an der Quelle korrekt erfaßt würden, unerläßlich sei, durch Verbesserung der Steueraufsicht die richtige Besteuerung sicherzustellen. ${ }^{191}$ Eben diese Bestimmung einer überzeugenden Lastenverteilung war der in Meisels kritischen Beiträgen ständig wiederholte Grundgedanke zur Rechtfertigung einer Einkommensteuer überhaupt. Dies entsprach ebenso dem politischen Programm Erzbergers.

Für Enno Becker sollte der BB, die dann 1927 in einer allgemeinen Verwaltungsanweisung - nunmehr kurz Betriebsprüfung (BP) genannt - ihre bis heute in wesentlichen Zügen gültige Gestalt erhielt, "nicht nur für die Besteuerung des gepriften Betriebes, sondern für die gesamte Besteuerung ein gewaltiges Erziehungsmittel zur Steuerehrlichkeit sein". ${ }^{192}$ Auf diese Weise wollte Becker einen starken Druck zur Erzeugung von Steuerehrlichkeit herstellen. Anders, als ehemals in Sachsen, wo die Mitwirkung der Steuerbürger unter Androhung harter Strafen im Falle des aufgedeckten Vertrauensmißbrauchs gesucht wurde, sollte im Deutschen Reich der unmittelbare Zwang die Steuerehrlichkeit bewirken. "Das Ziel, die Steuerehrlichkeit durch Zwang zu heben, wird ganz anders und viel nachdrücklicher erreicht, wenn sich alle, die bei Großbetrieben ... als Lieferer, Abnehmer oder sonst als Kunden beteiligt sind, sagen müssen,

\footnotetext{
185 Der Deutsche Volkswirt, 1. Jg. (1926), S. 391.

190 Habschmann/Hepp/Spitaler. Anm. 7 zu $§ 193$ AO, Geschichte der Außenprufung.

191 Grabower, R. (1963), Sp. 50; hierzu: Loffler, O., S. 193.

${ }^{192}$ Becker, E. (1927), Sp. 194
} 
$\mathrm{da} ß$ diese Beziehungen zur Kenntnis der Behörde gelangen können". ${ }^{193}$ So wurde der BB wegen des von ihm von vornherein ausgehenden Zwanges zur Steuermoral bereits seit 1921 von Becker gröBte Bedeutung beigemessen.

Die Funktionsfahigkeit des Vollzuges der deutschen Einkommensteuer wird heute noch maßgeblich von der inzwischen zweckdienlich ausgebauten und mit rechtsstaatlichen Prinzipien abgestimmten Betriebsprüfung sowie vor allem von den durch sie ermöglichten sogenannten "Kontrollmitteilungen" gewährleistet. Gerade die Mőglichkeit, anläßlich einer Betriebsprüfung Unterlagen über kontrollierbare Vorgånge bei anderen Steuerpflichtigen zu fertigen, hat für die Steuermoral ohne Zweifel eine enwartete stabilisierende Wirkung ausgeübt.

Die Grundlage dieser Institution zur Steueraufsicht war im Rahmen der Erzbergerschen Steuerreformen in den $\S \S 162$ bis 203 der RAO 1919 normiert worden. Es bedurfte aber des ganzen Einflusses Erzbergers, sie in der Öffentlichkeit zu rechtfertigen und vor allem Enno Beckers, sie dann nicht zuletzt vor dem 32. Deutschen Juristentag 1922 gegen verständnislose Invektiven zu verteidigen. Sie blieb für deutsche Vorstellungen ein unzulässiger Fremdkörper. Nicht Lastengerechtigkeit bestimmte die Denkweise, sondern Sorge vor mißbräuchlichen Eingriffen. ${ }^{194}$

Eine Einsichtnahme in Urkunden und Geschäftsbücher der Zensiten durch die Behörde war bereits in $\S 57$ Abs. 2 des sächsischen EStG 1874/78 im Rechtsbehelfsverfahren, zusammen mit sehr weitgehenden Rechten, Dritte einzuvernehmen, vorgesehen. Ebenso konnten von den Zensiten selbst, Sachverständigen und sonstigen Auskunftspersonen auch eidliche Versicherungen verlangt werden. Das fügte sich nahtlos in das nach wirtschaftlichen Gesichtspunkten einer gerechten Lastenverteilung gefertigte săchsische EStG 1874/78 ein. In das an der Besorgnis vor "fiskalischen Eingriffen in die Privatsphäre" orientierte, schwerpunktmäßig auf Beachtung "richtiger" juristischer Tatbestandsmerkmale fixierte und als Eingriffsrecht beurteilte preußische EStG 1891 waren diese Bestimmungen nicht, oder nur teilweise oder zusammenhanglos übernommen worden. Sie hatten hier daher stets einen Fremdkörper dargestellt. Unter dem Eindruck der heftigen Kritik an dem Gesetz wurde erst 1906, entgegen den Vorschlägen Fuistings, das Recht der Einsichtnahme in

${ }^{193}$ Becker: E. (1925), Sp. 394.

${ }^{194}$ Verhandlungen des 32. Deutschen Juristentages 1922, S. 230. Die Empfehlungen von G. Strutz, dem fruheren Mitarbeiter und Nachfolger Fuistings, liefen darauf hinaus, der Verwaltung alle Mơglichkeiten einer befriedigenden Erfullung der gesetzlich gebotenen Amtspflicht zu nehmen. Der Antifiskalismus Fuistings beherrschte noch die Diskussion. Sogar auf die Verpflichtung zur Eidesleistung sollte von Seiten der Verwaltung verzichtet werden. Es ging nicht um die Suche nach einer gerechten Lastenverteilung Die Besteuerung als solche wurde nach eingriffsrechtlichen Kriterien beurteilt. 
die Buchhaltung in der Regel auf Antrag des Steuerpflichtigen im Beanstandungsverfahren als $\S 40$ Abs. 4 in das novellierte EStG von 1891 eingebracht.

So konnte es kaum verwundern, daß Becker auf dem 32. Deutschen Juristentag keine Schmeicheleien dargebracht wurden. ${ }^{195}$

Ähnlich verhielt es sich mit dem Steuerstrafrecht. Auch hier wurden unter dem Einfluß Erzbergers 1919 Bestimmungen in die RAO aufgenommen, die mit den unwirksamen preußischen, als Verwaltungsstrafrecht konzipierten Vorschriften brachen. Wenn Meisel bereits 1920 beklagte, daß die neuen Steuerstrafvorschriften die der "preußischen Type" anhaftenden Mängel nicht abzustreifen vermochten, so sollte man die erkennbaren Verbesserungen jedenfalls nicht übersehen. Nunmehr war im Deutschen Reich auch, wie im ehemaligen Sachsen, der Versuch der mißglückten Steuerhinterziehung ohne Einschränkungen strafbar. Die intelligente Steuervermeidung blieb jedoch, sofern sie als Steuerhinterziehung beurteilt worden war, weiterhin - und dies, wie der Referatsleiter Rolf Grabower später berichtete, sogar für leitende Beamte des Reichsfinanzministeriums - ein sogenanntes "Kavaliersdelikt", ${ }^{196}$ als welches es früher in Preußen stets gegolten hatte.

Erst die neue Abgabenordnung 1977 genügt heute in dieser Hinsicht eher aber auch nicht vollstăndig - den von Meisel gesetzten Ansprüchen.

Nach einem Bericht Einno Beckers wurde nach 1919 allgemein von dem in die Reichsabgabenordnung aufgenommenen Pflichtenkatalog der Steuerbürger als von "Gifzzăhnen" des Gesetzes gesprochen. ${ }^{197}$ Ein abgewogenes Urteil über die Tragweite dieser Bestimmungen ist erst möglich, wenn wir uns die Konsequenzen der einzelnen Vorschriften für die Steuerbürger vor Augen halten. Waren die Vorschriften für den gedachten Zweck geeignet, nämlich mehr Steuerehrlichkeit und damit eine gerechtere Lastenverteilung zu bewirken?

In $\$ 163$ der Reichsabgabenordnung 1919 wurde vorgeschrieben, daß diejenigen Steuerpflichtigen, die nach anderen Gesetzen "Bücher und Aufzeichnungen" führen müssen, "die für die Besteuerung von Bedeutung sind", diese. Verpflichtung auch nach Steuergesetzen zu erfullen haben. $\$ 162$ Abs. 9 RAO 1919 verlieh dem Finanzamt dann das Privileg zu prüfen, ob diese Verpflichtung auch "fortlaufend, vollstăndig und formell und sachlich richtig" erfüllt wurde, um steuerlichen Ansprüchen zu genügen. In § 196 RAO 1919 wurde

\footnotetext{
${ }^{193}$ Das Protokoll der Verhandlungen gibt Invektiven nicht wieder, obgleich es nach Berichten daran nicht mangelte. Der Begriff des "Finanzmilitarismus" wurde gem zur Verunglimpfung der Venvaltung benutzt.

${ }^{196}$ Grabower, R. (1963), S. 42; ders. (1956), S. 610. Es handelte sich nur um Verwaltungsstrafrecht.

197 Grabower, R. (1963), Sp. 41
} 
dem Finanzamt zur Erfullung einer Verpflichtung zur Steueraufsicht das Recht zur "Nachschau" verliehen. In der Neufassung der RAO von 1931 wurde dann in $\$ 160$ der Umfang der nach Zivilrecht zur Führung von Büchern oder Aufzeichnungen Verpflichteten um diejenigen Unternehmer und Unternehmen erweitert, deren Umsatz, Gewerbeertrag, Reineinkünfte oder Betriebsvermögen bestimmte Beträge überschritten. Dadurch wurde der Umfang der Rechte und Pflichten der Finanzămter zur Steueraufsicht festgelegt. Dann wurden nach Größenklassen gestaffelte und zeitlich geregelte routinemäßige Betriebsprüfungen gesetzlich vorgeschrieben. Die Betriebsprüung erhielt ihre heute noch wirksame Gestalt. Nach $\S 1$ der "Verordnung zur Durchführung von Buch- und Betriebsprüfungen" vom 9. November 1925 galten diese Vorschriften dem "Zwecke einer Nachpnüfung von Verhăltnissen, ... die für die Besteuerung oder für ein Steuerstrafverfahren von Bedeutung sein können". 198 So ist "... die richtige Ermittlung und Beurteilung der steuerlich bedeutsamen Sachverhalte" auch heute noch nach $\S 193$ AO 1977 bei Steuerpflichtigen, "die einen land- und forstwirtschaftlichen, einen gewerblichen Betrieb unterhalten oder freiberuflich tätig sind" oder in anderen Fällen "die für die Besteuerung erheblichen Verhältnisse der Aufklärung bedürfen" der erklärte Zweck der Betriebsprüfung. ${ }^{199}$ Dabei soll die auf konkrete Verdächtigungen eingegrenzte Steuerfahndungsprüfung streng von der Betriebsprüfung getrennt sein, da die letztere eine routinemäßige Maßnahme der Steueraufsicht bleiben soll. Auch der Ermittlungstätigkeit soll sie nach dem Gesetz nur hilfsweise zur Verfügung stehen. Im Jahr 1931 kamen noch Maßnahmen hinzu, die inzwischen allgemein als Lohnsteueraußenprüfung bekannt sind und die insoweit Schwierigkeiten bereiteten, als die Prüfung sich nicht auf die Pflichten des Steuerschuldners selbst, sondern auf dessen treuhänderisch tätigen Arbeitgeber erstreckte. Es läßt sich im übrigen zeigen, daß nach den erwähnten Vorschriften die Steueraufsicht der Finanzverwaltung den Bereich der Gewinneinkünfte seit 1927 durch eine ständig zunehmende Dichte der Steuerkontrollen abdeckte.

Ohne Zweifel ist das Steuerkontrollsystem, das ursprünglich nur unterstützend durch Zwang zur Steuerehrlichkeit erzieherischen Zwecken dienen sollte, inzwischen geradezu reißbrettartig perfektioniert worden. Soeben hat wiederum eine neue "Mitteilungsverordnung" vom 7. September 1993 das System der Ūberwachung noch weiter ausgebaut. ${ }^{200}$

RStBl. 1925, S. 209; hierzu: Koppe (1928), S. 406.

199 \$193 Abs. 2 Ziff. 2 AO; weitere Voraussetzung ist, daB eine Prafung an Amtsstelle nach Art und Umfang des zu profenden Sachverhalts nicht zweckmäBig ist.

${ }^{200}$ Mitteilungsverordnung vom 7.9.1993, BGBI. I S. 1554. 
Sucht man nun nach dem Erfolg dieser Bemühungen, so scheinen diesbezügliche Erfahrungen und vor allem fortlaufende Beiträge in Medien und wissenschaftlichen Untersuchungen eher auf eine kontinuierliche Zunahme des Steuerwiderstandes durch Versuche, die Besteuerung um jeden Preis zu vermeiden, hinzuweisen, als auf die durch Betriebsprüfungen angestrebte Verbesserung der Steuerehrlichkeit. Auch hohe Ansprüche an ein Amnestiegesetz für die Jahre 1986 und 1987 erfülten nicht die Erwartungen einer Verringerung der Hinterzichungen bei den Einkünften aus Kapitalvermögen. Ein derzeit vom Bundesfinanzministerium zur Beschlußfassung vorgelegter Entwurf eines "Gesetzes zur Bekämpfung des Mißbrauches und zur Bereinigung des Steuerrechts" und die bereits erwähnte "Mitteilungsverordnung" vom 7. September 1993 zu $\S 93$ a AO scheinen die Skepsis amtlich zu bestätigen. Bereits gegen Ende der 50er Jahre beklagte der Kommentator der Abgabenordnung, Armin Spitaler, daß die Versuche zur Steuervermeidung eine sporlicher Betătigung vergleichbare Beschäftigung geworden seien. ${ }^{201}$ Die Situation hat sich seither nicht verändert.

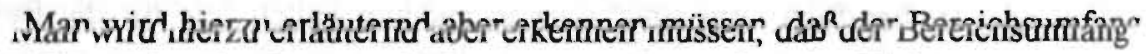
der Kontrollen der Steueraufsicht stets von dem geltenden Einkommensteuerrecht bestimmt wurde. Das heißt, die Betriebsprüfung überprüft nur Sachverhalte, "die für die Besteuenung von Bedeutung sind". ${ }^{202}$ Ihrer Bestimmung gemäß überprüft sie also nicht die Steuerehrlichkeit von Personen, sondern die richtige Erfassung und Beurteilung steuerbarer Vorgänge. Bezuiglich der bereits mehrfach angeführten Versuche zur legalen Vermeidung der Besteuerung als Folge des dualen Einkommensbegriffs kann aber auch die noch so perfektionierte Kontrolldichte der Steueraufsicht nur dort registrierende Funktionen ausüben, wo sie von Gesetzes wegen Zugang hat. Bereiche, für die keine Verpflichtung zu Aufzeichnungen bzw. zur Buchführung bestehen, unterliegen nur in besonders gelagerten Ausnalumefällen einer Prüfung. Mit anderen Worten: Nichtsteuerbare Vorgänge sollen und können mithin von der Betriebsprüfung gar nicht erfaßt werden. Nicht die steuerliche Leistungsfähigkeit von Steuerbürgern steht also im Mittelpunkt des Interesses der Betriebsprüfung, sondern der durch rechtsstaatliche Privatautonomie und nach Ausübung der steuerlichen Gestaltungsfreiheiten verbliebene steuerbare Teil der wirtschaftlichen Aktivitäten der Steuerpflichtigen. Oft ist es weniger als der "halbe

201 Zur Mitteilungsverordnung siehe: Der Steuerzahler 11/1993, S. 187. Viele Zeitschriften, die gern vorgeben, die Interessen "des Steuerzahlers" zu vertreten, zeigen in ihrer Beurteilung der Verordnung, daß sie auf Seiten derjenigen stehen, die an einer lastengerechten und gesetzmalBigen Besteuerung wenig Gefallen finden und daher Kontrollen in jeder Form ablehnen.

${ }^{202} \S 2$ Abs. 3 BpO vom 17.12.1987, BGBI. I, S. 802; im Text der BpO wird heute "die richtige Ermittlung und Beurteilung der steuerlich bedeutsamen Sachverhalte" vorgeschrieben. 
Steuerbürger", der der Besteuerung unterworfen wird. Ja, oft lebt der Geprüfte seit Jahren sogar recht üppig mit stattlichen rück- und vortragsfahigen Verlusten. So verfolgt die Betriebsprüfung steuerliche Vorgänge gegebenenfalls durch Kontrollmitteilungen zwar bis in die jeweilige konkrete Veranlagung im ESt-Bescheid des Betroffenen; für eine Prüfung des Steuerpflichtigen, insoweit er nicht unternehmerisch, sondern nur vermögensverwaltend tätig wird, gibt es im Normalfall aber keine Grundlage. Soweit für die Vermögens- bzw. Privatsphäre eines Steuerbürgers keine Aufzeichnungs- oder Buchführungsverpflichtungen bestehen und kein konkreter steuerstrafrechtlicher Anlaß hierzu vorliegt, findet eine Außenprüfung nicht statt. Die Finanzverwaltung muß darauf vertrauen, daß der Steuerbürger seinen Mitwirkungspflichten bezüglich der Erfassung eventuell steuerbarer Vorgănge in der Privatsphăre in seiner Einkommensteuererklärung ordnungsmäßig nachkommt. Für eine amtiche Überprüfung durch Stichproben fehlt es an einer rechtlichen Grundlage. Und: Der Steuerpflichtige neigt dazu, den Umfang nicht steuerbarer Zuflüsse stark zu überschătzen, da er in seiner rechtlichen Beurteilung sehr großzügig verfăhrt.

Gerade die Grauzone steuerbarer Einkünfte aus Kapitalvermögen, aus Spekulationsgeschäften mit beweglichen Wirtschaftsgütern, z. B. Effekten, und aus sonstigen Leistungen, z. B. Börsenoptionen, wird daher von der lästigen Einrichtung einer amtlichen Prüfung der Regel nach verschont. Dabei sind Fälle, in denen steuerbare Spekulationsgewinne und steuerpflichtige Überschüsse aus sonstigen Leistungen in sehr beträchtlicher Höhe unversteuert vorkommen, gar nicht so selten, wie bei Steuerberatern und an Bankschaltern bekannt ist. Aber auch der Finanzverwaltung ist dies geläufig. Die früher zitierte Feststellung Robert Meyers zu den Schwachstellen der Systematik des preußischen EStG gelten in verschiedenen Hinsichten heute noch. Mit wachsendern Wohlstand hat sich die Tragweite sogar vervielfacht.

\section{d) Die Fortentwicklung zum heutigen Gesetzesvollzug bei der Einkommensbesteuerung}

Nach dem erzwungen Rücktritt und gewaltsamen Tod Erzbergers wurde durch das neue Reichseinkommensteuergesetz vom 10. August 1925 wieder auf die Systematik des preußischen EStG von 1891 zurückgegriffen.

Der seit 1925 bis heute weiter geltende dualistische Einkommensbegriff bringt es mit sich, daß - zivilrechtlich beurteilt - gleichartige Geschäftsvorfalle bei Anwendung steuerrechtlicher Kriterien infolge abweichender Tatbestandsmerkmale zu ganz verschiedenen Folgewirkungen führen können. Es kann 
sich bei gleichartigen Vorgängen - gewissermaßen je nach steuerlicher Verpackung - um steuerbare oder nichtsteuerbare Sachverhalte handeln. Rechtsgeschäftliche Privatautonomie und steuerrechtliche Gestaltungsfreiheit lassen daher nach Einschätzung der Folgewirkungen intelligente Abstimmungen von geschäftlichen Maßnahmen zu.

Das im Einkommensteuerrecht seit 1925 auf die Einkunftsarten bezogene unterschiedlich definierte Besteuerungsgut führte dazu, daß folgende Gestaltungsempfehlungen bei den Gewinneinkunftsarten einen kolossalen Anreiz. auszuüben vermochten, da sie eine steuerfreie Vermögensbildung erlaubten. Dies gilt bis heute:

Wertzuwăchse von Sachgütern müssen jeweils in der Privat- oder Vermögenssphăre, zu der auch die Einkunftsquellen gehören, dagegen Vermögensgegenstănde mit vermutetem Risiko eines Wertverlustes in der Betriebs- oder Einkommenssphäre angesiedelt werden. Anschaffungskosten für Vermögensgegenstănde mit erwarteter Wertsteigerung, die daher im Privatvermögen verbleiben, sollten möglichst aus betrieblichen Mitteln bestritten werden. Aufwendungen mủssen, soweit vertretbar, als Betriebsausgaben die steuerbaren Einnahmen schmälern. So wurden und werden bis heute in der Betriebsoder Einkommensspháre Schulden aufgenommen, um auf Umwegen in der Privatsphäre Vermögensgegenstände mit Aussicht auf Wertzuwächse anzuschaffen, was auch bei bankmäßiger Finanzierung keine Probleme bereiten muß. Natürlich können die Vermögensgegenstände, sofern erforderlich, wiederum - und dies gegebenenfalls unter Einschaltung von Angehörigen oder Nahestehenden - an den Betrieb vermietet werden, ohne daß eine Einbringung in den Betrieb erfolgt.

Durch Befolgung dieser Richtlinien wurde es seit 1925 bei hoher progressiver Steuerbelastung möglich, Vermögensmehrungen zu erzielen, die bei Bedarf jeweils steuerfrei realisiert werden können. Jedenfalls erfolgte auf diese Weise bis heute der Aufbau von Vermögen wesentlich schneller, als durch mühsames Zusammensparen versteuerter Gewinne. Diese Möglichkeiten führten bereits zur Zeit der Geltung des preußischen EStG 1891 unter dem Stichwort "Konjunkturengewinne" zu streitigen Erörterungen. Letztlich war bereits in Preußen die Steuerbelastung der Gewinne recht spürbar, denn zu der Einkommensteuer von höchstens $4 \%$ kamen die Gemeindezuschläge noch mit bis zu $420 \%$ hinzu, so daß eine Gesamtbelastung von ca. $21 \%$ entstehen konnte. Darüber hinaus war eventuell noch die Gewerbesteuer zu berücksichtigen. So wird verständlich, daß der typischen Trennung von Vermögens- oder Privatsphäre und Einkommenssphäre mit wachsender Einsicht in die Zusammenhănge mehr und mehr Bedeutung zukam. Diese Tendenz wurde mit dem all- 
gemeinen Wirtschaftswachstum und der Entstehung großer Vermögen noch verstärkt. Die hier auftretende legale Form der Steuervermeidung hat bereits Fuisting 1903 in einer Rückbesinnung als Systemschwächen beklagt. Befriedigende Reformvorschläge wußte er in seinen Empfehlungen jedoch nicht vorzutragen. ${ }^{203}$ Allgemein gilt seit 1925 wiederum: Die Privatsphäre ist der Bereich, in dem eine schnelle steuerfreie Vermögensmehrung möglich ist. Steuerbürger mit Gewinneinkünften müssen ihre Geschäftsvorgănge entsprechend gestalten. In dieser Hinsicht sind Steuerbürger mit Überschußeinkünften privilegiert, wenn sich dies auch erst bei höheren Einkünften als Folge der Progression auswirken mag.

Naturgemäß haben Gesetzgeber und Finanzverwaltung seit 1925 durch amtliche Richtlinien bzw. Gesetzesnovellierungen versucht, diese Form der als ungerechtfertigt empfundenen Steuervermeidung bei den Gewinneinkünften in oft spitzfindigen Bestimmungen einzudämmen. Das führte dann zu komplizierten - und oft wiederum umgehbaren - amtlichen Richtlinien über "notwendiges" bzw. "gewillkürtes" Betriebsvermögen, ${ }^{204}$ über den Wertansatz bei Einbringung und Entnahme von Wirtschaftsgütern, ${ }^{205}$ über die Entstehung von Gewinnen bei der Veräußerung von Anteilen "wesentlich" Beteiligter an Kapitalgesellschaften, sofern diese zu einem Privatvermögen gehören, ${ }^{206}$ etc. Bei dem letzteren Problembereich wurde bereits im EStG 1925 eine Regelung gefunden, die bis heute fortgilt. So wird eine wesentliche Beteiligung dann unterstellt, wenn der "Veräußerer allein oder mit seinen Angehörigen an der Gesellschaft zu mehr als $25 \%$ unmittelbar oder mittelbar ... innerhalb der letzten zehn Jahre beteiligt war". ${ }^{207}$ Für den Begriff der Angehörigen wurde dabei auf die RAO zurückgegriffen. ${ }^{208} \mathrm{Daß}$ die Wirkungen dieser Ermittlungsvorschrift, die in Wirklichkeit das Besteuerungsgut als Folge der Normierung des Besteuerungsgegenstandes überhaupt erst festlegt, durch geeignete Verträge mit Personen, die nach Abgabenrecht nicht als verwandt gelten - Verlobte gehören dazu, ob auch Lebensgefährten, mag, da nicht im Gesetz erwăhnt,

\footnotetext{
${ }^{203}$ Fiusting, B. (1903), S. 232, S. 281; ders. (1906), Entwurf..., Sp. 1170, insbes. Sp. 1173. Im Grunde stellte Fuisting das preuB. EStG 1891 aber wegen der teilweisen Öbernahme unvereinbarlicher tragender Gesichtspunkte der Schmollerschen Besteuerungsidee infrage.

${ }^{204}$ Siche etwa Abschn. 14 EStR 1965.

${ }^{209}$ Siche etwa Abschn. 14 Abs. I EStR 1965. Die Veranlagungsvorschriften des Verwaltungsrechts sind auf Grundlage der Finanzrechtsprechung im Lauf der Zeit sehr umfangreich und spitzfindig geworden. Die zugrundeliegenden Urteile suchen den Grundgedanken der Lastenverteilung nach dem Gesetz zu gewahrleisten.

206 $\$ 17$ Abs. 1 EStG 1934, die Vorschrift wurde inzwischen mehrfach der allgemeinen Rechtsentwicklung angepa $B$, blieb aber im Sinngehalt bestehen.

$\$ 30$ Abs, 3 EStG 1925.

2as $\$ 47$ Abs, 1 Ziff. 2 und 3 RAO 1919.
} 
zumindest umstritten sein - umgangen werden kann, muß nur angedeutet werden. ${ }^{209}$ Die hier entstehende Grauzone kann sich als Goldgrube erweisen, an der sich auch wendige Steuerberater und Rechtsanwälte Schürfrechte an den Bergrechten der Mandanten sichem dürfen. Voraussetzung steuerfreier Realisierung der Wertzuwächse von Anteilen an Kapital- aber auch an Personengesellschaften ist, daß dieselben zu der Privat- oder Vermögenssphäre des Steuerbürgers gehören und keine mitunternehmerischen Rechte beinhalten, so daß ein Veräußerungsvorgang sich als Maßnahme der reinen Vermögensverwaltung darstellt. So können sich rechtzeitige Entnahmen aus dem und Einlagen in das Unternehmen vorteilhaft auswirken. Hier bieten sich interessante Gestaltungen durch die Trennung von blo $\beta$ verwaltenden Besitzgemeinschaften und Betriebsgesellschaften an. Eine Fülle von amtlichen Richtlinien sucht die mőglichen Steuervermeidungen einzudämmen.

Johannes Popitz als Schöpfer des EStG 1925 und Enno Becker als dessen führender Kommentator und Vordenker der systematischen Grundlagen der Vorschriften glaubten, durch die im Gesetz durch einen Enumerativkatalog gegebene Definition des als Einkommen bezeichneten Besteuerungsgutes der Realităt besser gerecht zu werden. Darin folgten sie den Auffassungen Wagners und Fuistings. Die Beurteilung der Folgen einer vermeintlich "richtigen", der Leistungsfahigkeit des Steuerpflichtigen entsprechenden Ermittlung der Bemessungsgrundlage durch Bestandsvergleich bzw. als Überschuß der Einnahmen über die Werbungskosten war für sie von nachrangiger Bedeutung gegenüber der richtigen Regelung der sachlich vorgegebenen Zusammenhänge, die von der jeweiligen Einkunftsart typisierend vorbestimmt wurde. Eine andere Deutung lassen viele Ausführungen von Popitz zur Einkommensteuer trotz widersprüchlicher Passagen nicht zu, zumal ihm die Klagen über die Folgen der an einem dualen Einkommensbegriff ausgerichteten Systematik des preußischen EStG 1891 bekannt sein mußten. Auch die acht Jahre währenden streitigen Verhandlungen um die Systematik des württembergischen EStG von 1903, in denen die Kritik an dem preußischen Gesetz von dem Berichterstatter des Ausschusses, und Vertrauten Erzbergers vehement vertreten wurde, ${ }^{210}$ können Popitz nicht entgangen sein, da im "Finanzarchiv" mehrfach darüber

209 Die standig verbreitete Meinung. Eheleute seien insgesant steuerlich privilegiert, bedarf der Relativierung. Gestaltungsmőglichkeiten vermōgen bei Berücksichtigung der der Öffentlichkeit unbekannt bleibenden einschrănkenden Ermittlungsvorschriften zur Verhinderung von Mißbrăuchen dị von Vertretern neuerer Lebensformen gem verbreiteten Vorurteile geradezu auf den Kopf zu stellen. Hier werden oft eigensüchtige Interessen unter der Tamfarbe der Gerechtigkeit verfolgt.

210 Pistorius, T. (1904), S. 68; zu Grober siche Epstein, K. (1959), S. 16, S. 461; Bachem, K (1929), S. 422: Grobber war als Landgerichtsrat in Stuttgart Mitglied des Württembergischen Landta. ges, seit 1895 gewalhlter Vorsitzender des Ausschusses fur die Steuerreform, Mitglied des Reichstages und langjăhriges Vorstandsmitgliedl bzw. Fraktionsfuhrer der Deutschen Zentrumspartei. 
berichtet worden war. Dennoch glaubte Popitz in seinem berïhmt gewordenen Aufsatz über die Einkommensteuer an eine Besteuerung nach der Leistungsfahigkeit, wobei ihm Systematik und Vollzug des Gesetzes als allein von der Einkunftsart vorbestimmt erschienen.

Daher führte man 1925 auch für die Einkünfte aus Land- und Forstwirtschaft und aus selbstăndiger Arbeit den sogenannten "eingeschränkten Bestandsvergleich" ein, der erst 1971 beseitigt wurde. ${ }^{211}$ Erst nachdem die fortlaufende Aussparung von exorbitanten, nicht steuerbaren Vermögensmehrungen bei Einzelverảußerungen von parzellierten landwirtschaftlichen Großflächen in der Năhe von Großstådten von der Einkommensteuer, gelegentlich von geschäftstüchtigen Landwirten noch durch intelligente Gestaltungen maximiert, unüberhörbares öffentliches Ärgernis erregte, stellte der wissenschaftliche Beirat beim Bundesfinanzministerium 1967 plötzlich als neuesie Erkenntnis fest, daB diese Bestimmung einer Besteuerung nach der Leistungsfahigkeit widerspreche und angepaßt werden sollte. ${ }^{212}$

Der in den 20er Jahren eingeführten amtlichen Betriebsprüfung kommt gewiß bis heute eine wichtige Funktion für die Gewinnung neuer Erkenntnisse über Betriebsführung, Betriebsvergleiche und Abrechnungswesen zu und sie dient dadurch der Gleichmäßigkeit der Besteuerung. Auch kann ein von ihr insbesondere durch Kontrollmitteilungen ausgehender Zwang zur Steuerehrlichkeit kaum in Abrede gestellt werden. Die der Steueraufsicht zuzurechnende überwachende Tätigkeit erstreckt sich in der Regel aber infolge der dualen Systematik des EStG aus den dargestellten Gründen ausschließlich auf das sogenannte Markteinkommen, das der Leistungsfahigkeit der Zensiten nach Schmollers Beitrag von 1863 nun einmal nicht genügen kann.

Mit wachsendem Wohlstand wurde diese Beschrănkung der Steueraufsicht auf das Markteinkornmen und die damit einhergehende Erschwerung einer nachhaltigen Kontrolle steuerbarer Vorgänge außerhalb der rein benuflichen Betätigung der Steuerbürger von der Finanzverwaltung in den Notzeiten der

311 § 12 Abs. 1 Satz 2 EStG 1925; $\S 4$ Abs. 1 Satz 5 EStG 1934; 84 Abs. 1 Satz 5 EStG 1949: Satz 5 wurde gestrichen durch StÄndG 1971 vom 10.8.1971 (BGBI. I' S. 1266) mit Wirkung ab 1.1.1971. Gegen den Umstand, daß durch Parzellierungen einfachen Ackerlandes in der Umgebung von Großstădten fortwăhrend völlig steuerfrei gewaltige Vermōgen entstanden, ist vor 1969 ' selten bffentliche Kritik gệbl worden. Gegen Ende der 60 er Jahre stieB jedoch in der Offentlichkeit die von Fachleuten vertretene These von der ESt als einer nach der Leistungsfahigkeit organisierten Abgabeform angesichts hoher steuerfreier Vermōgensbildungen zunehmenci auf Verărgerung.

212 Wissenschaftlicher Beirat beim BMF (1967), Gutachten ... vom 11.2.1967, \$. 24. Der Beirat hat zwar die bei Gewinnermittlung vorgesehene Ausnahmeregelung fur den Ansatz von "Grund und Boden" für nicht nach $\S 5$ EStG buchfühungspflichtige Steuerzahler nicht ausdrücklich erwâhnt. Er trat aber für eine uneingeschränkte Besteuerung realisierter Vermōgensmehrungen ein. Vom Gesetzgeber wurde dies dann für Steuerpflichtige der Einkunftsarten 1 - 3 verwirklicht. 
Weltwirtschaftskrise als unerträglich beurteilt. So gelang es der Verwaltung 1931 im Rahmen der Notverordnungen durchzusetzen, was infolge des fehlenden allgemeinen Verständnisses im Reichstag wohl kaum eine Mehrheit gefunden hătte: Eine wesentliche Ergänzung der Reichsabgabenordnung von 1919 durch Erweiterung der Aufzeichnungspflichten, die nunmehr unter bestimmten Umständen unabhängig von dem Vorliegen steuerbarer Vorgänge auch die reine Privatsphäre der Steuerbürger prüfbar machte. ${ }^{213}$ Diese Vorschrift war geeignet, die ursprüngliche Idee Enno Beckers, Steuerehrlichkeit zu erzwingen, entscheidend zu unterstützen. Die neuen Bestimmungen wurden, nachdem sie Gesetzeskraft erlangt hatten, jedenfalls von den betroffenen Steuerpflichtigen - nach konkreten Kenntnissen des Verfassers - zumeist auch ordnungsmäßig befolgt. ${ }^{214}$ Die Finanzverwaltung hat von den ihr gegebenen neuen Möglichkeiten jedoch später nach 1945 keinerlei Gebrauch mehr gemacht, obgleich die Bestimmungen zu den Bestandteilen der Abgabenordnung gehörten, dic als Recht der Länder und dann des Bundes nach 1945 weiterhin Geltung hatten. ${ }^{215}$ In die Abgabenordnung von 1977 wurden die Vorschriften dann nicht mehr aufgenommen.

Nach der erwähnten "Verordnung des Reichspräsidenten gegen die Kapitalund Steuerflucht" vom 18. Juli 1931 wurde die gesetzliche Aufzeichnungspflicht so erweitert, daß die Finanzverwaltung die Steueraufsicht in die Privalund Vermögenssphäre ausdehnen konnte. ohne daß hierzu betriebliche Vorgănge berührt sein mußten. Auch Vorgänge, die nur die Möglichkeit zu steuerbaren Einnahmen aus Überschußeinkünften gewährten, konnten nun routinemäßig überwacht bzw. überprüft werden. Das war ein systemfremdes novum. Sogar steuerfreie Zuflüsse durften nun die Steueraufsicht interessieren,

${ }^{213}$ § 11 der VO des Reichspralsidenten gegen die Kapital- und Steuerflucht vom 18.7.1931 (RGBI. IS. 373); hierzu: VO zur Durchfuthrung des \$160 Abs. 2 RAO (Aufzeichnungs VO) vorn 24.3.1932. in: RGB! $1 \mathrm{~S} .165$.

$2 ! 4$ Der Autor hat konkrete Erfahrungen mil der Erledigung dieser besonderen Aufzeichnungspflichten ab 1937. Er assistierte während seinet Schulzeit einem leitenden Mitarbeiter einer überregionalen deutschen Gralbank, der für mehrere große Vermögensinhaber. đie auch steuerlich geprüt wurden. diese Aufzeichrungen fỉhrte.

215 Als der Autō den Auftrag zui steuerlichen Betreuung eines sehr vermōgenden Mandanten ab 1968 übernahm, suchte er sich wegen der Fohrung der Aufzeichnungen gem. $\S 160$ Abs. 2 RAO infolge einiger auftretender Auslegungsfragen mit dem Referatsleiter der zuständigen OFD abzustimmen. Das war nicht mōglich. obgleich es sich um eine der größ̣ten Aufsichtşbehörđẹn dieser Art der BRD handelte. Weder Hauptsachbearbeiter noch Referassleiter kannten die Bestimmung. Der Hinweis des Autors auf die Vorschrift versetzte sie in Erstaunen. obgleich im Bereich der DFD die Bestimmungen zweifellos auf viele große Vermögensinhaber anzuwenden waren. Auch đem später im Rahmen der Außenprüung zustandigen Leiter der KonzemBP waren die Vorschriften $\S 160$ Abs. 2 RAO unbekannt, obgleich es sich um geltende Bestimmungen des Abgabenrechts handelte. Die ordnungsmäbig gefuhuten Aufzeichnungen blieben überflüssig. 
sofern die gesetzlichen Voraussetzungen vorlagen. ${ }^{216}$ Nach der als $\$ 160$ Abs. 2 RAO aufgenommenen Ergănzung wurden ab 1932 nămlich Steuerpflichtige "mit Reineinkünften, die eine gewisse vom Reichsminister der Finanzen zu bestimmende Grenze überschritten", verpflichtet, "Einnahmen und Ausgaben fortlaufend aufzuzeichnen und alljährlich eine Zusammenstellung über ihr Vermögen anzufertigen". In $\$ 2$ der hierzu ergangenen "Aufzeichnungsverordnung" wurde sodann im einzelnen vorgeschrieben, daß alle Steuerpflichtigen mit "Reineinkünften" von über RM 100.000,-- ab dem Kalenderjahr 1932 betroffen waren. Dieser Betrag entsprach in den Jahren um 1930 sehr hohen Bezügen, was vom Gesetzgeber der Notverordnung als Grund für eine eventuell notwendige steuerliche Öberwachung der Privat- oder Vermögenssphäre beurteilt wurde. ${ }^{217}$

Nach $\S 7$ der Durchfuhrungsverordnung zu $\S 160$ Abs. 2 RAO umfaßte die Verpflichtung ausdrücklich auch "Einnahmen, die der Steuerpflicht nicht unterliegen (Beispiel: Einmalige Vermőgensanfalle $-\S 6$ Abs. 3 des EStG)" und sie bezog Personen, die zusammenveranlagt wurden, ebenso ein. ${ }^{218}$

Die "Aufzeichnungsverordnung" zu $\S 160$ Abs. 2 RAO 1931 hatte die den Finanzämtern obliegende Steueraufsicht den wirtschaftlichen Verhältnissen und den daraus resultierenden zeitgemäßen Erfordernissen angepaßt. So ermöglichte sie auch eine glaubwürdige Anwendung der aus dem sächsischen EStG 1874/78 in das Reichseinkommensteuergesetz 1925 als $\S 49$ und ab 1934 als $\S 48$ übernommenen Vorschrift über die Besteuerung nach dem Verbrauch, wenn dieser erkennbar als Ausdruck einer Selbsteinschätzung der Leistungsfähigkeit dienen konnte und die nach den amtlichen Ermittlungsvorschriften errechnete Bemessungsgrundlage wesentlich niedriger lag. ${ }^{219}$ Die Steueraufsicht wurde auf diese Weise überhaupt erst in die Lage versetzi, Unterlagen über Vorgănge in der Privatsphäre einzusehen, die Aufschlüsse uber eventuell steuerbare Einkünfte aus Kapitalvermögen, aus Spekulationsgeschăften oder aus sonstigen Leistungen gewährten. Insoweit waren die relevanten Bereiche der steuerlichen Grauzone nunmehr für die Finanzverwaltung, routinemäßig überwachbar geworden. Auf Einhaltung dieser Vorschriften wurde. jedoch nach 1945 von der Finanzverwaltung kein Wert mehr gelegt. Mehr noch: Die Bestimmungen der Aufzeichnungsverordnung blieben in der Fi-

216 Aufzeichnungspflichtig war jeder Steuerbürger, der ab 1930 in einer oder mehreren Einkunfts. arten den Betrag von 100.000,- Reichsmark uberschritt. Für die Zeitumstände war das ein relativ sehr hoher Betrag, der nach 1949 hătte angepaßi werden können.

$217 \S 7$ der AufzeichnungsVO zu $\S 160$ Abs. 2 RAO.

21 $\$ 7$ Abs. 2 Ziff. 2 der AufzeichnungVO zu $\S 160$ Abs, 2 RAO.

a1 Hierzu: $\S 49$ EStG 1925; siehe: Entstehungsgeschichte, Begründung und Inhalt des $\$ 49$ EStG 1925, in: Strutz, G. (1930), Anm. 1 bis 5 zu $\$ 49$ EStG 1925. 
nanzverwaltung meist unbekannt. Dieser Umstand zeigte Systematik. Die Vorschrift war und blieb in der "deutschen Type" der Einkommensbesteuerung ein nicht integrierbarer Fremdkörper.

Folgendes kam hinzu: Als nach 1945 die Finanzverwaltung der Länder aus den noch bestehenden Institutionen der Reichsfinanzverwaltung neu aufgebaut wurde, sind die Reichsabgabenordnung und das diese ergänzende Steueranpassungsgesetz vom 16. Oktober 1934 als weiterhin geltend einheitlich bestätigt worden. ${ }^{220}$ Durch einen gemeinsamen Erlaß der Länderfinanzminister zum Schutz des Vertrauenszustandes in den deutschen Kapitalmarkt wurde am 2. August 1949 die Einschaltung von Banken zum Zweck der allgemeinen Steueraufsicht aber stark eingeschränkt. ${ }^{221}$ Zwar behielt das Finanzamt nach $\S$ 177 AO 1919 bzw. § 175 AO 1931 auch nach diesem Erlaß die Befugnis, von Kreditinstituten ebenso, wie von anderen nicht unmittelbar beteiligten Dritten Auskünfte zu steuerlich bedeutsamen Sachverhalten zu verlangen. Dies mußte jedoch unter strenger Beachtung formaler rechtsstaatlicher Gesichtspunkte und in einer Weise erfolgen, die der Empfindlichkeit des Kapitalmarktes gerecht werden sollte. Jedenfalls durften bei Prüfung einer Bank keine Kontrollmitteilungen über Konten der Bankkunden ausgefertigt werden. Der von Enno Becker angestrebte Zwang zur Steuerehrlichkeit hat durch den Bankenerlaß von 1949 eine Einschrănkung erfahren, die die Privat- oder Vennögenssphäre der Steuerbürger praktisch von jeglicher Steueraufsicht ausnahm und nur in Fällen konkreter, beachtlicher Verdachtsgründe von der Steuerfahndung durchbrochen werden konnte. Diese Entwicklung ist dann 1977 in der reformierten Abgabenordnung fortgesetzt worden. Mehr noch: Die Tendenz zur steuerlichen Überwachung der nicht von Betriebsprüfungen abgedeckten Bereiche wurde für die Finanzverwaltung weiter erschwert. Zwar wurde in $\$ 193 \mathrm{AO} 1977$ die "Auskunftspflicht der Beteiligten und anderer Personen" zureichend normiert und mit rechtsstaatlichen Prinzipien abgestimmt. Durch Einfügung des $\S 30$ a AO erhielt jedoch 1986 der inhaltlich erweiterte Regelungsgehalt des bisherigen Bankenerlasses sogar Gesetzeskraft. Sofern die Finanzverwaltung keine konkreten Hinweise hat, daß "für die Besteuerung erhebliche Verhältnisse" vorliegen, "die der Aufklärung bedürfen", kann obendrein nun "e contrario" aus dem Gesetz geschlossen werden, daß

\footnotetext{
RAO 1970, S. 371
}

$221 \mathrm{Vgl}$. Bankeneriaß vom 2.8.1949, in: DStZB 49. S. 242. Der Eriaß verbot des Finanzbehộden im Steueraufsichtsverfaturen. von Banken einmalige oder periodische Mitteilungen aber Konten nach Art und Hōhe zu verlangen. Es handelte sich um eine bloße Selbstbeschrănkung, die bei Vorliegen der Tatbestandsmerkmale des $\$ 109$ RAO entfiel. Tipke spricht vom Bankenerlaß bzw. seiner heute gultigen Fortsetzung in $\$ 93$ a AO als, von einer "Magna Charta der Steuerhinterziehung". Tipke, K (1989), Zinsbesteuerung ..., S. 157; hierzu auch: Mattern, G./Me/3mer, K., (1968) Reichsabgabenordnung, Bem. $1149 \mathrm{zu} \S 175$ RAO. 
gemäß $\S 193$ Abs. 2 Ziff. 2 AO 1977 eine Außenprüfung unzulässig ist. Nach $\S \S 196,197$ AO 1977 ist ohnehin eine Prüfungsanordnung und ebenso der Umfang der Prüfung dern Steuerbürger schriftlich bekannt zu geben, wobei gegen die Festsetzung des Prüfungsbereichs ein Rechtsbehelf gemäß $\$ 349$ AO gegeben ist und der Klageweg obendrein noch offensteht. ${ }^{222}$ Das vermag die eventuelle Vollziehung des Verwaltungsaktes für lange Zeit hinauszuschieben, wenn nicht gar zu verhindern. Ähnlich hatte sich bereits das umfängliche formale Beanstandungsverfahren bei der Veranlagung zur preußischen Einkommensteuer - wie Meisel beklagte - ausgewirkt.

Erst wenn bei der Veranlagung oder anläßlich einer Betriebsprüfung das Vorhandensein grőßerer Vermögen erkennbar wird, die mit den amtsseitig vorliegenden Besteuerungsunterlagen auf keine Weise in Einklang zu bringen sind, kann das Finanzamt heute zur Beseitigung des Verdachts einer Steuerverkürzung die Erörtenung des Sachverhalts mit dem Steuerpflichtigen zum Zweck der richtigen Ermittlung der Bemessungsgrundlagen einleiten.

Dabei können dann im Fall des Fehlens von Unterlagen Schătzungen unvermeidlich werden. Aber erst wenn Anzeichen dafür vorliegen, die den konkreten Verdacht einer Steuerstraftat erkennen lassen, kann ein Strafverfahren eröffnet und - sofern zur Aufklärung erforderlich - die Steuerfahndung eingeschaltet werden. Dieser ist dann gegebenenfalls auch das Eindringen in die Privatsphảre gestattet.

Der BFH hat Schätzungen der Bemessungsgrundlage nach anerkannten Methoden gebilligt.

Im Ermittlungsverfahren bleibt es vorerst zumeist bei der Aufforderung zur Abgabe von Vermögensteuererklärungen für die betroffenen Jahre durch die gemäß $\S 149$ AO unverfangliche Zusendung der dafür vorgesehenen Formulare. Gegebenenfalls werden sodann berichtigte Einkommensteuererklärungen für fünf bzw. zehn verflossene Jahre einverlangt, was insbesondere in Todesfallen bei den Erben erhebliche Unruhe zu erzeugen vermag.

Sofern von dem Steuerpflichtigen in den amtlichen Erörterungen keine überzeugenden Unterlagen für den fraglichen Vermögenszuwachs beizubringen sind, muß das steuerbare Einkommen für die betroffenen Jahre dann nachträglich durch Schätzung ermittelt werden. Hierzu wurden aus der Erfahrung zwei Verfahren entwickelt, die als "Geldverkehrsrechnung" (GVR) bzw. "Vermögenszuwachsrechnung" (VZR) von der Finanzverwaltung angewandt werden und vom BFH gebilligt wurden. ${ }^{223}$ Sie erlauben eine Einkünfteverpro-

\footnotetext{
272 Vgl. $\$ 5$ Abs. 1 BpO und $\$ 5$ Abs. 2 BpO vom 17.12.1987, in: BGBL. I S. 802.

${ }^{22}$ Handwörterbuch des Steuerrechts (1981), Bd. 2. S. 1177 ; hierzu: Korn. K. (1981), S. 4023.
} 
bung mit Hilfe einer sogenannten "Lebenshaltungsgleichung", die im Ergebnis mit einer "Einnahmen-Ausgaben-Deckungsrechnung" in etwa übereinstimmt.

Die VZR entspricht dem von Gustav Schmoller 1862 skizzierten Einkommensbegriff. Die GVR ist der Einnahmen-Ausgabenrechnung nach dem Quellenprinzip der Einkünfteermittlung nachgezeichnet.

Die VZR wirft nach Hinzufügungen und Abzügen dann als Ergebnis den Betrag aus, der hätte versteuert werden müssen.

Die GVR erfaßt nur Einnahmen und Ausgaben. Sie vermag auf diese Weise einen anderen Einblick in die Entstehung des Vermögens zu gewähren, gelangt aber nach den entsprechenden Korrekturen zu demselben Resultat. ${ }^{224}$ Beide Berechnungsarten können sich ergänzen und bestätigen. Sie erlauben eine Schătzung des steuerbaren Teils der erfolgten wundersamen Vermögensmehrung. Für Strafverfahren sind die Ergebnisse im übrigen aber nur sehr eingeschränkt verwendbar.

Letztlich dienen die Verfahren den Steuerpflichtigen oft zum Nachweis einer bekḷggten überhōhten Zuschătzung durch đie Finanzverwaltung.

Nun sind seit vielen Jahren die allgemeinen Einkommen einschließlich der Lobne stark angestiegen und zugleich haben sich die Lebenshaltungskosten entsprechend angepaßt. Der Tarif des Einkommensteuerrechts und vor allem der Grundfreibetrag bei Anwendung des Tarifs wurden in derselben Zeit nicht wesentlich verändert. Ein Ergebnis dieser Entwicklung war das starke Auseinanderfallen von Existenzminimum und Grundfreibetrag des Einkommensteuertarifs. Das Bundesverfassungsgericht hat in einem diesbezüglichen Klageverfahren am 25. September 1992 für Recht erkannt, daß der Grundfreibetrag für jeden Steuerpflichtigen das Existenzminimum abdecken und der Höhe der Sozialhilfesătze entsprechen muß. ${ }^{225}$ Seither orientiert die Finanzverwaltung aus guten Gründen den hierzu neu eingeführten Begriff der "Erwerbseinkünfte", die nach dem Richterspruch bis zur Höhe des Existenzminimums steuerfrei bleiben müssen, an dem von Gustav Schmoller 1862 skizzierten Einkommensbegriff, für den sich heute allgemein der Terminus "Reinvermögenszugangstheorie" durchgesetzt hat. Als "Erwerbseinkünfte" sind danach alle für den Lebensunterhalt des Steuerpflichtigen verwendbaren geldwerten Zugånge einschließlich der "steuerfreien Einnahmen und Einkommensteile, die zur Deckung des existenznotwendigen Bedarfes verwendet werden kön-

224 wie Anm. 223, S. 1178.

22. BVerfG Beschluß vom 25.9.1992, in: BVerfG 93, S. 153. 
nen", also unabhăngig von ihrer steuerlichen Behandlung zu berücksichtigen. $^{226}$

Auch in diesem Fall ist der Gesetzgeber aber den Grundmustern der von Meisel sogenannten "deutschen Steuertype" treugeblieben. In einem amtlichen Enumerativkatalog wurden Tatbestandsmerkmale festgelegt, welche Zuflüsse bei Ermittlung der "Erwerbseinkünfte" zu berücksichtigen sind. Der Praxis bleibt auf diese Weise wiederum die Möglichkeit, Konstruktionen zu finden, die im. Enumerativkatalog nicht vorgesehen sind und die somit das Ausschöpfen des vollen Grundfreibetrages problemlos ermöglichen. ${ }^{227}$

Auch in der Ausarbeitung dieses komplizierten Regelungsgefugges folgt die Verwaltung also wiederum den von Meisel heftig kritisierten charakteristischen Grundgedanken der "deutschen Steuertype" durch die Festlegung eines Enumerativkatalogs zu berücksichtigender Wertzugănge anstatt einer Aufzăhlung von Zugängen, die als Ausnahme von der Regel nicht zu berücksichtigen sind.

Der Steuerbürger ist im übrigen zwar verpflichtet, eine Steuererklärung abzugeben, in der er versichert, daß diese wahrheitsgemäß erstellt wurde. Tatsăchlich wird die Richtigkeit der Erklärung aber durch die Mitteilungsverordnung vom 7. September 1993 im einzelnen indirekt erzwungen. Nicht das Vertrauen in die Steuerehrlichkeit der Zensiten bei Berechtigung der Behörde zu strengen Prüfungen und drohenden hohen Strafen im Fall des Vertrauensmißbrauchs durch die Abgabe falscher Erklärungen, also ein Appell an die gewissenhafte Mitwirkung des Steuerpflichtigen im gemeinsamen Interesse aller Bürger, ist hier die eigentliche Grundlage der Veranlagungstătigkeit, sondern der Zwang, durch die Festlegung von Mitwirkungspflichten Dritter, aber dies nur, sofern es sich nicht um Kreditinstitute oder bankähnliche öffentlich-rechtliche Einrichtungen handelt. Dabei wird - wie wir gesehen haben - aber eine Überprüfung der Richtigkeit der Angaben durch gestrenge Nachschau bei dem Steuerbürger selbst völlig vernachlässigt, wie es bereits für die Veranlagung zur klassifizierten Einkommensteuer bis 1891 und für das Besteuerungssystem nach 1891 in Preußen typisch war. Hier kommt der Steuererklärung nur die Funktion eines unter vielen Hilfsmitteln zu. So wird der Behörde wiederum Unmögliches abverlangt, nämlich die richtige Ermittlung der Bemessungsgrundlage für die Einkommensbesteuerung nach dem Amts-

\footnotetext{
226 wie Anm. 225. S. 152, S. 171

227 Das hierzu als Anlage zu Abschn. 185 b EStR erteilte Schreiben des BMF betr. Anwendung \$32 d EStG vom 26.3.1993 erstreckt sich aber vier doppelspaltig eng bedruckte Seiten. Wiederum wird versucht, MiBbräuche durch abschließende Aufzählung der Möglichkeiten zu verhindern, was nie recht möglich erscheint.
} 
ermittlungsgrundsatz durch Erteilung des gesetzlich vorgeschriebenen Bescheides. Der dem im deutschen Strafrecht als "Inquisitionsmaxime" bekannten Prinzip der "Untersuchung von richterlichen Amtes wegen" für das Steuerrecht nachgebildete Amtsermittlungsgrundsatz ist als Rechtsinstitut im Steuerrecht aber ungeeignet, da die Voraussetzungen für seine Ausübung in der dargestellten Weise eingeschränkt werden.

In dem zuletzt angeführte Zusammenhang sind im übrigen wegen der auftretenden, von den sich ausschließenden Einkommensbegriffen verursachten Differenzen demnächst dem Praktiker noch unlösbar erscheinende soziale Probleme zu enwarten, sobald erst kleinere lohnsteuerpflichtige Einkommensbezieher im Wege der Veranlagung von Gesetzes wegen zu Nachzahlungen aufgefordert werden müssen. Ein später als zu niedrig errechneter Lohnsteuereinbehalt läßt sich nämlich bei dieser Regelung in vielen Fällen nicht vermeiden. Schwierige Verteilungskămpfe sind hierdurch vorprogrammiert.

Der hohe Steuerwiderstand im Bereich der Geltung der deutschen Einkommensbesteuerung wird auf der Grundlage der vorstehenden Feststellungen verständlich.

e) Fehlentwicklungen in der deutschen Einkommensbesteuerung durch das Zusammenwirken von Gesetz und Gesetzesvollzug

Das an zwei sich ausschließenden Einkommensbegriffen ausgerichtete preußische und später reichsdeutsche Einkommensteuergesetz hat von vornherein dem für die zuträgliche Erfüllung ihrer Mitwirkungspflichten erforderlichen Vertrauenszustand der Steuerbürger, wie Fuisting bereits beklagte. im Wege gestanden. Dieser setzt letztlich eine einheitliche, verständliche und allgemein akzeptierte teleologische Orientierung des Gesetzes voraus. Der Vollzug des Gesetzes, mit dem der Steuerbürger unmittelbar in Berührung kommt, muß diesen Vertrauenszustand dann durch eine erkennbar zweckmâBige Verfolgung der systemtragenden Besteuerungsidee unterstützen. Dabei gilt für das formale Recht, wie Fuisting festhielt, was Schmoller gelegentlich aus seiner Erfahrung als Historiker des Besteuenungswesens feststellte, was aber im preußischen EStG von 1891 nicht gewăhr!eistet war: "Die Masse der Menschen wollen die materielle Ungerechtigkeit of lieber ertragen als die formelle; sie sind zufrieden, wenn sie klare, einfache Gesetze haben, über deren Anwendung nicht gestritten werden kann, deren buchstăbliche Ausführung Jedem gleiches Recht sichert; ...". ${ }^{228}$ Die Verpflichtung der Verwaltung

${ }^{228}$ Schmoller, G., zitiert nach Gerlach, O. (1902), S. 787. 
zur gesetzmäßigen Veranlagung der Steuerbürger bei fehlender Deklarationspflicht in Preußen und das der Behörde auferlegte Verbot des für die Betroffenen lästigen Eindringens in die Privatsphäre haben vor 1891 und die Verpflichtung der Finanzverwaltung zur amtlichen Ermittlung des Sachverhalts nach einer verwirrenden zugrundeliegenden durchbrochenen Besteuerungsidee, dazu die unzureichenden Rechte der Behörde zur amtlichen Überprüfung der steuererheblichen Tatbestandsmerkmale, und dies alles bei einem völlig unzureichenden strafrechtlichen Sanktionsmechanismus, haben nach 1891 eine Besteuerung nach der Leistungsfähigkeit unmöglich gemacht. Nach 1925 ist man im Deutschen Reich nach einer kurzen Zwischenphase, in der die im Württembergischen Abgeordnetenhaus um 1900 erörterte Kritik an dem preußischen EStG 1891 für die Erzbergersche Einkommensteuerreform von 1920 bestimmend wurde, dennoch wieder zu dem ursprünglichen System des preußischen EStG von 1891 zurückgekehrt.

Es mag, wie aus den Ausführungen an anderer Stelle hervorgeht, angesichts der unerträglichen Finanznot des Staates der Zeit nach dem Weltkrieg gewichtige Gründe für diesen Schritt gegeben haben, dem Vertrauen der Öffentlichkeit in die nach fortlaufenden Zusicherungen angeblich angestrebte Besteuenung nach der Leistungsfähigkeit, verstanden in einem üblichen Wortsinn, konnte dieser Schritt jedenfalls, insbesondere dann, wenn man die Organisation des Vollzuges der Besteuerung mit einbezog, nicht dienen.

Der seit dieser Zeit in Deutschland entstandene Steuerwiderstand spiegelt noch heute diese Umstände wider und hat sich inzwischen in der Bundesrepublik auf einem Stand eingependelt, der kaum noch steigerungsfähig erscheint. Gewiß ist es verständlich, daß völlig unabhängig von dem jeweiligen Steuersystem niemand ohne Widerstand auf Kaufkraft verzichten möchte, um diese dem Staat zu übertragen. Daß inzwischen jedoch auch Kaufkraftverluste hingenommen werden, nur um Steuerzahlungen zu vermeiden, mit anderen Worten, daß Steuerpflichtige sogar bereit sind, eine Schlechterstellung zu erleiden, um Steuerzahlungen zu entgehen, ist ein eigenartiges Phänomen, das besondere Aufmerksamkeit verdient.

Das Bestreben, Steuerzahlungen zu vermeiden, ist inzwischen in der Bundesrepublik so ausgeufert, daß von rationalem Verhalten in vielen Făllen nicht mehr gesprochen werden kann.

Zur Erläuterung mag hier folgendes dienen: Wohl jeder im steuerberatenden Beruf Tätige macht heute Erfahrungen mit Mandanten, die unbedingt Anteile an steuersparenden geschlossenen Investmentfonds erwerben wollen, um die hierdurch gewährten Abzüge von der steuerlichen Bemessungsgrundlage für Steuerersparnisse zu nutzen. Das ist verständlich. Aber dies wollen Steuer- 
pflichtige gelegentlich sogar dann vorgesehen wissen, wenn sie hohe Darlehen mit unkalkulierbaren Risiken aufnehmen müssen und sich rein rechnungsmäBig gar kein sinnvolles wirtschaftliches Interesse erkennen läßt.

Gerade qualifizierte Fachkräfte mit Hochschulausbildung neigen heute offenbar zu derartigem Verhalten, und zwar auch dann, wenn ihr zu versteuerndes Einkommen unter $100.000,--$ DM liegt, obgleich sich der Erwerb wegen der geringeren Tarifprogression nicht mehr rechnet. Argumenten gegenüber zeigen sie dann Verständnislosigkeit. Träger großer geschlossener Investmentfonds machen aus diesem letztlich irrationalen Verhalten überaus einträgliche Geschäfte, indem sie in ihren Werbeprospekten ausgiebig darauf eingehen, wieviel Steuern erspart werden können, aber kaum darlegen, welche Voraussetzungen gegeben sein müssen, damit der später oftunals vorerst unverkäufliche Fondsanteil ein zumindest ausgeglichenes Ergebnis verspricht. Dabei kommt ihnen entgegen, daß der Kreis potentieller Erwerber in den letzten Jahren mit wachsendem Wohlstand außergewöhnlich zugenommen hat.

Das sich hier an legalen Steuervermeidungen zeigende, rational nicht auflösbare Verhalten kann als Anhalt dafür gelten, wie groß erst der Anteil der illegalen Steuervermeidung, dessen kleinere Teilklasse in der Öffentlichkeit als "Schwarzmarkt" bezeichnet wird, sein mag. In Schătzungen von kompetenter Seite wird der Umfang des "Schwarzmarktes" in der Bundesrepublik derzeit auf ca. $12 \%$ des Bruttosozialproduktes, das heißt, auf ca. $387 \mathrm{Mrd}$. DM jâhrlich beziffert. ${ }^{229} \mathrm{Im}$ übrigen verbreiten sämtliche Medien in der Bundesrepublik Deutschland derzeit ein Klima, in dem das Zahlen von Steuern als vermeidbares Übel dargestellt wird. Selbst einflußreiche Personen aus Wirtschaft und Politik lassen die Steuerhinterziehung, gelegentlich wie ein sportliches Ereignis in einem Zweikampf mit dem Finanzamt erscheinen. Gewinner ist der, der sich nicht erwischen läßt.

Ein impressionistisches Beispiel für das irrationale Bestreben Steuern zu sparen, in dem sich die offentliche Einstellung zu spiegeln vernag, soll nachfolgend skizziert werden:

Als im Jahr 1982 das steuerliche Privileg der Gemeinnützigkeit der gewerkschaftseigenen Wohnungsbaugesellschaft "Neue Heimat" wegen des, Verdachts von Verstößen gegen strafbewehrte Vorschriften der Abgabenordnung und insbesondere des Gemeinnützigkeitsrechts ( $\$ \S 51 \mathrm{ff} \mathrm{AO}$ ) zu Ermittlungstătigkeiten der Staatsanwaltschaft führte, wurde unwidersprochen von einem weit verbreiteten Hamburger Nachrichtenmagazin veröffentlicht, daß unter anderen der fuhrende "Gewerkschaftsbankier" und Vorstandsvorsitzende des gewerk-

229 DSTG (1992), S. 8. Die Zahlen bezichen sich auf Feststellungen des Jahres 1992. 
schaftseigenen überregionalen Bankinstituts die steuerbegünstigten Chancen der Vermögensbildung in Berlin "am gründlichsten genutzt hatte". ${ }^{230}$ So hatte er sich nach unwidersprochen gebliebenen Angaben des Magazins im Jahr 1980 durch Enwerb von Anteilen in Höhe von insgesamt 1,8 Mio. DM an Berliner Abschreibungsgesellschaften beteiligt. In einem infolge der Vorgänge ausgestrahlten Interview des Zweiten Deutschen Fernsehens erläuterte der "Gewerkschaftsbankier", der oft "der Abs der Gewerkschaften" genannt wurde, und dessen Bezüge als Vorstandsvorsitzender einer der sechs deutschen Großbanken wohl über $800.000,--$ DM jährlich betragen haben müssen, daß ihm für das Jahr 1980 Einkommensteuern in Höhe von 7.500,-- DM entstanden seien "und das waren noch 7.500,-- DM zuviel". ${ }^{231}$ Die Zeichnung eines Anteils, der letztlich sogar diesen geringen Steuerrestbetrag in Vermogen wandelt, macht von einer abwägenden rechnerischen Beurteilung her keinen Sinn. Es ist auch kaum anzunehmen, daß der Gewerkschaftsbankier, der lange Zeit eine leitende Stellung bei der Deutschen Bundesbank innehatte, zur Zeit vorherrschender rezessiver Tendenzen eine bevorstehende inflationäre Entwicklung erwarten konnte und sich dagegen absichern wollte.

Einstellung und Verhalten des wegen seiner herausgehobenen Stellung im offentlichen Leben wohlbekannten Gewerkschaftsbankiers - Walter Hesselbach war Vorsitzender vieler gemeinnütziger Gesellschaften und Stiftungen - wurden in den Medien nicht etwa im Zusammenhang mit der für Gutsituierte gebotenen Möglichkeit, Steuern in Vermögen zu wandeln, kritisiert. Dies erschien wohl als völlig normal und akzeptabel. Kritisiert wurde im Magazin und in anderen Medien nur die Filzokratie, die darin zum Ausdruck kam, daß Gewerkschaftsfunktionäre und nahestehende Politiker sich die Filetstücke des Berliner Wiederaufbaues zu Vorzugsbedingungen wie Beute untereinander aufgeteilt hatten ${ }^{232}$ Beklagt wurde auch die eigenartige Rolle, die eine den Gewerkschaften gehörende gemeinnützige Gesellschaft dabei spielte.

Der Rechtsschutz des ehrlichen kleinen Steuerzahlers, der infolge dieser steuerbegünstigten Vorgänge, die durchweg in der ungeprüften Privatsphäre von finanziell überaus gutsituierten Bürgern angesiedelt sind, immer stärker zur Abgabenkasse gebeten wird, ist zwar gelegentlich beklagt worden; andere Gesichtspunkte haben jedoch stets die Beachtung der Öffentlichkeit beherrscht und dem Steuerwiderstand weitere Nahrung gegeben.

\footnotetext{
230 Der Spiegel, 36. Jg., Nr. 7 vom 15.2.1982, S. 99.

231. Die Aussage erfolgte in einem persônlichen Interview zu den Vorgängen im Zweiten Deutschen Fernsehen.

${ }^{232}$ Der Spiegel, 36. Jg. Nr. 7 vom 15.2.1982, S. 101.
} 
So wurden fortlaufend die Einführung diverser höherer Freibeträge, Werbungskostenpauschalen und ebenso eine Anhebung der Progression durch Ergänzungsabgaben, Stabilitätszuschläge etc. erörtert. Auch die Angemessenheit der Höhe des Arbeitnehmerfreibetrages - als Kompensat für die Wohltaten der Gestaltungsfreiheiten bei den Gewinneinkünften eingeführt - war gelegentlich Gegenstand der Diskussion. Dabei spielen bis heute die mit der Vorstellung von dem sogenannten "gläsernen Portemonnaie" lohnsteuerpflichtiger Steuerbürger einhergehenden Bewertungen eine wichtige Rolle. Die damit verbundenen Überzeugungen stellen jedoch ohne Berücksichtigung der Besteuerungswirklichkeit interessenbedingte Vorurteile dar. Merkwürdigerweise begegnet man noch heute sogar bei Fachleuten der Auffassung, das deutsche Einkommensteuerrecht sei als Klassensteuerrecht zu beurteilen, da privilegierte Gewinneinkünfte benachteiligten Überschußeinkünften gegenüberständen. ${ }^{233}$ Die Wirklichkeit zeigt dagegen ein eher verwirrendes Bild, da die Auswirkungen des Gesetzesvollzuges hierbei vernachlässigt werden. Eine Unterscheidung zwischen Steuerpflichtigen, die wegen der Höhe ihrer Einkünfte die entstehende Steuerschuld ohne liquide Belastung in voller Höhe in Vermögen umwandeln können, und denjenigen, denen dies infolge des niedrigeren tariflichen Steuerzugriffs verwehrt ist, erscheint ein für die Einteilung nach Merkmalen heute wichtigeres Kriterium der Typenbildung zu sein. Jedenfalls eignet sich diese Gliederung für die Erörterung wichtiger sozialer Fragen.

Da einflußreiche Steuerrechtler noch heute den Standpunkt vertreten, daß die Auslegung der Artikel 13 ff des Grundgesetzes der Bundesrepublik gebiete, die Privatsphäre der Steuerbürger unabhängig von den Auswirkungen der Maßnahmen von steuerlichen Prüfungen und sogar Eingriffen überhaupt abzuschirmen, mag die derzeitige, als problematisch zu beurteilende Entwicklung wohl noch länger Bestand haben. Offenbar fallt es ihnen schwer, die sozialtechnologischen Konsequenzen ihrer in juristischer Hinsicht schlüssigen Argumente zu berücksichtigen. So ist es nur allzu verständlich, daß ihnen von interessierten Kreisen gern höchste unbestrittene Sachkompetenz bescheinigt wird. $^{234}$

Der Umfang der durch Eigentümlichkeiten von Gesetz und Gesetzesvollzug begünstigten Gruppe von Steuerpflichtigen mit zunehmendem Wohlstand ist erheblich gewachsen. Nach dem Ergebnis des neuesten Prüfungsberichtes des

${ }^{233}$ Upmeier, W. (1970), S. 117, S. 111, spricht von einer "Denaturierung" der Besteuerungsformen. zu neuen "Klassensteuern". Der Untersuchung Upmeiers mangeln praktische Kenntnisse über die Veraulagung. Daher ist das Ergebnis nur von theoretischem Wert. Dies ist dem Autor von Bediensteten der Finanzverwaltung auch vorgehalten worden.

${ }^{24}$ Hierzu: Kirchhof, P. (1988), S. F. 29; Kirchhof ist Richter am BVerfG. 
Landesrechnungshofes des Landes Rheinland-Pfalz haben zum Beispiel inzwischen mehr als $12 \%$ der 4.089 Mitarbeiter des Zweiten Deutschen Fernsehens Bezüge von über $120.000,--$ DM jährlich ${ }^{235}$ Nach der Steuerstatistik gehörten 1986 aber weniger als $6,67 \%$ aller Steuerpflichtigen insgesamt zu dieser Gruppe. ${ }^{236}$ Die Meinungsbildner der Medien gehören schwerpunktmäßig zur Gruppe der von der Ausgestaltung des geltenden Steuersystems Begünstigten. Bei einer selten gewordenen sachlichen Beurteilung desselben werden sie von eigenen Interessen beeinträchtigt. Daß die Vermoggensbildung aus Steuermitteln für Steuerbürger mit Einkünften aus nichtselbständiger Arbeit, also solche mit dem sogenannten "gläsernen Portemonnaie", die nach den vorstehenden Ausführungen keinerlei steuerlicher Uberwachung unterworfen sind, problemloser zu bewerkstelligen ist, wird wohl obendrein nach den früheren Ausführungen verståndlich erscheinen. Eine fehlende Kapitalertragsteuer auf festverzinsliche Wertstellungen verschiedenster Art war obendrein bis vor kurzer Zeit ein starker Anreiz zur Steuerhinterziehung. Auch heute gilt dies noch fur Steuerbürger mit hohem steuerpflichtigen Einkommen wegen des für ihre Verhăltnisse zu niedrigen Einbehalts von 30\% der Ertrăgnisse. Wie wir sahen, ist dabei der finanzielle Eigennutz lăngst nicht mehr der einzige, wenn vielleicht auch noch der wichtigste Bestimmungsgnund für Steuerhinterziehungen. Praktiker erkennen seit langem bei ihren Mandanten "eine vorhandene Lust an der Verkürzung" als einer Art sportlicher Betätigung, zumal das Risiko einer Aufdeckung äußerst gering ist. "Wir müssen davon ausgehen, daß in der Regel jeder Steuerbürger Steuern hinterzieht, so berichtete kürzlich ein Fachanwalt für Steuerrecht im "Betriebs-Berater". 237

Die Höhe der bei Banken gehaltenen privaten Festgeldkonten vermochte zeitweise sogar die Einhaltung des Zielkorridors für die Geldmengenregulierung durch die Währungspolitik der Deutschen Bundesbank empfindlich zu stören. Im Hintergrund der Erscheinung stand die hohe Verzinsung kurzfristiger Geldmittel, die unter anderen Umständen von der Möglichkeit zu fast

23s Die Relation wurde nach Mitteilungen in der Presse im Prüfungsbericht des Landesrechnungshofes des ! Landes Rheinland-Pfalz beanstandet, s. "Bild am Sonntag" v. 28.11.1993, S. 14, und v. 23. 10.1994, S. 22.

236 Die Ziffern wurden errechnet aus den Daten des Statistischen Jahrbuchs für die BRD fur 1993, S. 566. Die Angaben entsprechen der letzten aufgearbeiteten Steuerstatistik, also des Jahres 1986.

23? Streck, M. (1984), S. 2205. Diese Feststellungen Strecks, die bei wertfreier Betrachtung von allen Berufstrăgern bestaltigt werden muB, führte zu erheblichen Verärgerungen. Die FAZ sprach gar am 31.10.1984 von der "gröBten Diffamierung des deutschen Volkes". 
risikoloser Hinterziehung der entstandenen Einkommensteuer durch private Sparer noch gefordert wurde. ${ }^{238}$

In vielen Beiträgen von Nationalökonomen und Finanzwissenschaftlern ist darauf hingewiesen worden, daß eine auf die Besteuerung des Zensiten nach der Leistungsfähigkeit hin ausgerichtete Einkommensbesteuerung der nachhaltigen Mitwirkung der Steuerpflichtigen bedarf. Das sächsische EStG 1874/ 78 wurde darauf ausgerichtet, den Steuerpflichtigen zunehmend zur richtigen steuerlichen Erfassung des Sachverhalts in seiner Fassion zu veranlassen, um dadurch das Vertrauen in eine vorherrschende Verteilungsgerechtigkeit zu unterstützen.

Die gesetzlich vorgesehene Verpflichtung zur Abgabe von Deklarationen war hier ein wichtiger Teil der angestrebten verantwortlichen Mitwirkung. Die Fassion war amtlicherseits bei der Veranlagung auch entsprechend zu werten. In Preußen wurde trotz großen Widerstands im Landtag 1891 die Fassionspflicht aus dem săchsischen Muster zwar übernommen, alle maßgeblichen Entscheidungen zu der Veranlagung wurden jedoch der Behörde übertragen. Diese hatte die Pflicht, wie ein Gericht für und wider den Zensiten zu ermitteln. Die Veranlagung wurde daher, der preußischen Tradition entsprechend, zumeist unter eingriffsrechtlichen Gesichtspunkten gesehen. Die Ermittlungspflicht verursachte nach allgemeiner Bewertung, auch nach 1891 noch die ständige Sorge eines unerwünschten Eindringens der Behörde in die Privatsphäre der Steuerbürger. Das ist im Grunde bis heute so geblieben.

Der Schutz der Privatsphăre vor möglichen mißbräuchlichen Eingriffen erhielt in Preußen daher jeweils Priorität vor den wichtigen Mitwirkungspflichten. Der Einkommensteuererklärung wurde hier deshalb nie die ihr zukommende zentrale Bedeutung beigemessen. Man betonte stets die Funktion der Behörde bei der Veranlagung, die Kenntnisse voraussetzt, die dem Steuerpflichtigen mangeln. Der Lernfahigkeit der Zensiten traute man - anders als in Sachsen - wenig zu. Was Fuisting noch ernsthaft geglaubt hat, ist heute für führende Kreise längst zu einem Argument zur Rechtfertigung eigener Interessen entartet.

Erst die große Finanznot von 1919 setzte nach Kriegsende neue Schwerpunkte, die aber bald wieder in Vergessenheit gerieten. Nun suchte man die Steuerehrlichkeit durch umfassende Maßnahmen einer systematischen Steuer= aufsicht zu erzwingen.

2s8 Deutsche Bundesbank Geschätsbericht 1993, S. 68 - S. 71; desgl. 1994, S. 71: Deutsche Bundesbank Monatsbericht Februar 1994, S. 11 u. S. 24; hierzu: Kölnische Rundschau v. 17.3.1994, S. 5; FAZ v. 22.1.1994. S. 17. 
Der Finanzminister Erzberger glaubte 1919, ein neu zu schaffendes Reichsabgabenrecht könne gegenüber den im Grunde gar nicht finanzierbaren Kriegsfolgelasten zu einer festen Klammer fortentwickelt werden, die die notleidenden Lănder Deutschlands zu einem als Solidargemeinschaft gedachten Deutschen Reich zusammenbinde. Ein neuartiger vertikaler Finanzausgleich sollte dabei die Bedürfnisse der Länder abdecken. Die auf Grundlage der in Preußen gemachten negativen Erfahrungen nach dem SchmollerHerrmannschen Prinzip reformierte Einkommensteuer sollte dabei als wichtigste Steuerart neben der Umsatzsteuer die Heranziehung der Steuerpflichtigen nach ihrer jeweiligen Leistungsfahigkeit sicherstellen.

K.onservative Interessen, die bereits der Übernahme des sãchsischen Musters der Einkommensbesteuerung entgegengestanden hatten und für dessen nur eingeschränkte Vorbildfunktion 1891 in Preußen und 1903 in Württemberg sorgten, führten zusammen mit dem politischen Feldzug des vormaligen Leiters des Reichsschatz- und Reichsinnenamtes Karl Helfferich zum Sturz Erzbergers. Die Steuerrechtswissenschaft stand nach der Beseitigung Erzbergers noch in den Denktraditionen Fuistings und die Finanzwissenschaft wurde von den Schülern Adolph Wagners und Friedrich J. Neumanns beherrscht. So kam es $1925 \mathrm{zu}$ der erneuten Reform des Einkommensteuerrechts, wobei wieder auf das alte dualistische System des preußischen EStG von 1891 zurückgegriffen wurde. Der Parteifreund und langjährige Kollege von Helfferich im Reichsschatzamt, Otto von Schlieben, setzte als Finanzminister das Gesetz im Parlament dann durch.

Bis zum Jahr 1934 wurde dieses zu einer beeindruckenden begrifflichen Klarheit ausgebaut. Die zum großen Teil aus dem Privatrecht übernommenen Rechtsfiguren und Termini erhielten nunmehr ihre bis heute gültigen spezifischen Begriffsinhalte und wurden dabei von den bürgerlich-rechtlichen Verwendungen für die andersartigen steuerlichen Zwecke abgegrenzt. Strenge Definitionen von Steuergegenstand und TatbestandsmäBigkeit fanden Eingang in die Diskussion steuerrechtlicher Regelungen.

Der dual konzipierte Einkommensbegriff des bis heute geltenden, kontinuierlich weiterentwickelten Einkommensteuerrechts hat zu langwieriger Erörterung von Auslegungsdifferenzen, zu gesetzlichen Regelungen und spitzfindigen Erlassen zur Sicherstellung einer zureichenden Erfassung dessen geführt, was allgemein als Einkommen verstanden und somit als Besteuerungsgut beurteilt wurde und welcher Einkunftsart die einzelnen Partialen zuzurechnen seien. Diese Zurechnung bestimmt nämlich bis heute gegebenenfalls nicht nur den Umfang des Besteuerungsgutes, sondern auch, ob zusătzlich Umsatzund/oder Gewerbesteuer entstanden ist. 
Die Kompliziertheit des deutschen Einkommensteuerrechts wurde zu einem guten Teil von diesen Ausgangsbedingungen verursacht. Darüber haben wir ausführlich berichtet. Allein, wir müssen festhalten, daß das deutsche Einkommensteuerrecht nur für diejenigen ein "Chaos", "Dschungel", "Dickicht" oder "Irrgarten" ist, dem der Werdegang fremd blieb. Die verborgene innere Ordnung zeigt sich, sobald man der Entstehungsgeschichte nachgeht und die beiden konkurrierenden Baupläne nachvollzieht, die als tragende Elemente dienen. Dann werden die verwirrenden Konturen des Bauwerkes in ihren Zusarnmenhängen erkennbar. Dann zeigen sich auch Eignung und Schwachstellen des Regelungssystems in einem neuartigen Licht. Entsprechend wechseln auch die Bewertungen mit Änderung der Zielvorgabe, für die eine geeignete Problemlösung gesucht wird. Denn das deutsche Einkommensteuerrecht ist, wie wir gesehen haben, durch die Verschmelzung von zwei Bauplänen sehr vielseitig verwendbar.

Wer nach Reformen ruf, sollte sich vorher darüber klar werden, welche konkreten Probleme das Gesetz meistern soll. Er sollte sich dann abwägend

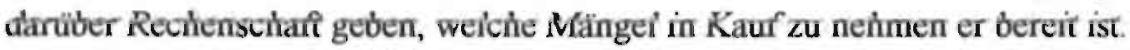

Steuerrechtler scheinen an derartigem sozialtechnologischen Vorgehen wenig Gefallen zu finden, da sie auf ein einheitliches Normengebäude fixiert sind.

Eine weitere Quelle für Komplikationen sind die vielen von der Systematik zugelassenen nichtfiskalischen, unterschiedlichsten politischen Zielen dienenden Lenkungsnormen, die die Ermittlungsvorschriften inzwischen abändern, sofern bestimmte erwünschte Tatbestandsmerkmale im Sachverhalt vorliegẹn und die seit 1949 die Gesetzessystematik zunehmend überwuchern.

So hatte von den Erzbergerschen Reformen von 1919/1920 nur die Reichsabgabenordnung Bestand. Deren Systematik wurde spãter mehrfach ergänzt. Die Abgabenordnung von 1977 hat die Grundgedanken dann übernommen, in neuer Gliederung ausgebaut und mit den Anforderungen, die die Verwendung der elektronischen Datenverarbeitung bei der Veranlagung mit sich brachte, abgestimmt.

Der ursprünglich von der Reichsabgabenordnung erwartete Zwang zur Steuerehrlichkeit konnte sich aberr nur sehr eingeschränkt auswirken, da die Erzbergersche Steuerreform infolge des auf das preubische System zuruickorientierten EStG 1925 halbiert wurde. Die Steueraufsicht erfaßt daher mit wenigen Ausnahmen, wie wir gesehen haben, bis heute nur das Markteinkommen der Zensiten und auch dieses nur eingeschränkt. 
In vielen Abhandlungen wurde seit der Einführung der Einkommensteuer unter Verarbeitung umfangreichen empirischen Materials dargelegt, daß es fir eine allgemein befriedigende Lösung der aktiven Erfullung der Mitwirkungspflichten durch die Zensiten bedarf. Empirische Untersuchungen haben auch gezeigt, daß bei einen Einbau der Steuerbürger in die verantwortiche Veranlagungstătigkeit der Steuerwiderstand nachläbt.

Die von Franz Meisel 1911, 1914 und dann 1925 herausgestellten Măngel an der von ihm sogenannten "deutschen Type" der Einkommensbesteuerung sind trotz des weitgehenden Ausbaues der Vollzugsvorschriften durch Festlegung der Pflichten der Zensiten und dritter Personen zur Mitwirkung, durch Einsatz der Steueraufsicht und durch Bestimmungen zum Steuerstrafrecht bis heute nur unvollkommen beseitigt worden. Der duale Aufbau des Einkommensbegriffs setzte hier die dargestellten und infolge des vorgegebenen $\mathrm{Zu}$ sammenhanges schwer überwindbaren Hürden durch die strenge Trennung von Vermögens- und Einkommenssphäre.

Die entstandene Kompliziertheit der Bestimmungen hat letztlich zu einer unverantwortlichen Belastung der Finanzverwaltung gefürt, die darin zum Ausdruck kommt, daß die Veranlagungen nicht mehr in Übereinstimmung mit den gesetzlichen Vorschriften erfolgen kőnnen. Wegen der Überforderung der Behörden kann auch eine befriedigende Steueraufsicht, sieht man von deren dargestellten, ohnehin sehr eingeschränkten Möglichkeiten einmal ab, kaum noch erfolgen. Die turnusmäßigen Betriebsprüfungen mußten daher inzwischen bereits stark eingeschränkt werden. Den in den Finanzămtern zustăndigen Sachbearbeitern stehen für eine Steuerveranlagung of im Durchschnitt nur 30 Minuten, selten länger als drei Stunden zur Verfugung. ${ }^{239}$ Das reicht für die von Gesetzes wegen nach $\S 88$ AO vorgeschriebene Prüfung und Beurteilung von Sachverhalt und Tatbestandsmerkmalen bei weitem nicht mehr aus.

Die Finanzgerichte vermögen die Rückstände, die einer Bearbeitungszeit von etwa fünf Jahren entsprechen, nicht mehr abzubauen. ${ }^{240}$ Die Steuerstrafsachenstellen sind inzwischen derart überlastet, daß zwischen der Aufdeckung. einer Steuerstraftat und deren konkreter Bearbeitung durch die Strafsachenstelle im Bereich einer großen Oberfinanzdirektion nach Erfahrungen des

\footnotetext{
23 Weingarten, J. (1993), S. 130; Tipke, K./Lang. J. (1991), Steuerrecht ..., S. 685. Die hier wiedergegebenen Zahlen werden nach Feststellungen des Autors aus Räcksprachen mit Sachgebietsleitern in groben Ảmtern im Köln Raum noch erheblich aberschritten.

200 Der Autor bezieht sich auf eigene Erfahrungen, die durch die amtliche Statistik bestätigt werden. 
Verfassers allein bereits eine Zeitspanne von über drei Jahren verstreicht. ${ }^{24 \mid}$ Von einer Präventivwirkung der Strafe kann unter diesen Umständen nicht mehr gesprochen werden.

Die Folge ist die ständige Sorge der ehrlichen Steuerbürger, von unehrlichen Mitbürgern übervorteilt zu werden, so daß letztendlich auch sie zu Fehlverhalten verleitet werden. Ein Kölner Fachanwalt für Steuerrecht berichtete kürzlich von seinem Eindruck, "daß viele Bürger im Wege der Hinterziehung ihre kleine, höchst private Abrechnung mit dem Staat für erfahrene bürokratische, gesetzliche oder rechtgesprochene Unbilligkeit oder Ungerechtigkeit vornehmen". ${ }^{242}$ Er glaubt, derartigem "Gegensteuern gegen Staatsverdrossenheit" sogar noch einen positiven Aspekt für das Staatsbewußtsein abgewinnen zu sollen. Setzt sich beim Bürger aber erst einmal der Eindruck fest, "Hinterziehung entwickele sich zum Volkssport, mag auch der Rechtschaffene nicht länger beiscite stehen": "Steuerhinterziehung blüht, wo die Gesellschaft sie toleriert", ${ }^{243}$ so Vito Tanzi. Vor eben dieser Entwicklung hatte Meisel stets gewarnt.

Andererseits, so zeigen neuere empirische Forschungen in den USA, "scheinen die meisten Bürger von sich aus ehrlich zu sein". ${ }^{244}$

Nach Franz Meisel war die notwendige Voraussetzung einer erstrebenswerten Steuerkultur ein Zusammenwirken mehrerer Faktoren: Das Einkommensteuergesetz muß für die Steuerpflichtigen verständlich und überzeugend sein und soll nicht nur formalen juristischen Ansprüchen genügen, der Gesetzesvollzug muß zweckmäßig auf die gesetzmäßige Erfassung des Besteuerungsgutes ausgerichtet sein; es muß letztlich durch geeignete Kontrollinstrumente sichergestellt sein, daß keine Benachteiligung der ehrlichen Steuerbürger statfindet, indem ein strenger Sanktionsmechanismus in Form eines wirksamen Steuerstrafrechts die Einhaltung dieses Zieles gewährleistet. ${ }^{245}$ Bereits frühe Befürworter der Einkommensteuer haben darauf hingewiesen, daß die aktive Mitwirkung der Steuerbürger für eine befriedigende Einkommensbesteuerung, unterstützt von einem nachhaltigen Sanktionsmechanismus, un-

241 Der Autor bezieht sich auf mehrere konkrete Vorgänge, deren Bearbeitung durch die Strafsachenstellen seit Qber zwei Jahren seit Entdeckung noch nicht aufgegriffen wurde.

202 Streck, M. (1984), S. 220 S.

24s Streck, M. (1984), S. 2205; Wirtschaftswoche Nr. 38 vom 17.9.1993. S. 48.

244 Wirtschaftswoche Nr. 38 vom 17.9.1993, S. 48. Die nachfolgenden Anmerkungen geben Ergebnisse einer internationalen Tagung von Finanzwissenschaftlem in Berlin im Jahr 1993 wider: International Institute of Public Finance (IIPF), 49. Congress Berlin, 23. - 26.8.1993.

24s Meisel, F. (1911), S. 330. 
verzichtbar ist. ${ }^{246}$ Ein Appell an das Verantwortungsgefühl der Steuerbürger erschien ihnen unvermeidlich. Der Erfolg des sächsischen Musters weist bereits in diese Richtung. Die Bevormundung des Bürgers, der nach der Uberzeugung Fuistings der gesetzmäßigen Erledigung seiner Mitwirkungspflichten nicht gewachsen sein konnte, aber gleichwohl seine eigennützigen Interessen zur Steuervermeidung vorzüglich zu verfolgen wußte, zusammen mit einem ausufernden spitzfindigen Beanstandungsverfahren, mangelhaften Kontrollmöglichkeiten der Verwaltung und einem unzweckmäßigen und unwirksamen Steuerstrafrecht haben zu der beklagten Fehlentwicklung der "preußischen Type" der Einkommensbesteuerung geführt. Ähnlich verhält es sich mit der spăteren "deutschen Type".

$\mathrm{Da}$ die deutsche Einkommensbesteuerung eine schnelle Kapitalbildung aus Steuermitteln erlaubte und heute noch erlaubt und in extremen Situationen von volkswirtschaftlichen Gesichtspunkten aus völlig anders zu beurteilen sein mag, als dies in diesem Zusammenhang geschieht, kann hier unberücksichtigt bleiben, da dem Gedanken an anderer Stelle ausgiebig nachgegangen wird.

Wenn die Finanzverwaltung ihrer Verpflichtung zu einer gesetzmaßBigen Veranlagung nicht mehr mit der notwendigen Sorgfalt nachkommen kann, muß der erkennbaren Fehlentwicklung durch eine Neuorganisation des Verfahrens gegengesteuert werden.

Da die Verwaltung heute faktisch von der Entwicklung ohnehin dazu gezwungen wird, ungeprüft nach eingereichten Steuererklärungen zu veranlagen, sobald diesen ein Mindestmaß an Plausibilităt zukommt, könnte der Vollzug des Gesetzes in der Weise umgestellt werden, daß der Steuerpflichtige sich gleich selbstveranlagt. Auf diese Weise könnten Sachbearbeiter in der Verwalfung, deren Tătigkeit bisher vornehmlich der ungeprüten Übertragung der von den Pflichtigen erklärten Angaben in Computerprogramme diente, für nachhaltige Prüfungstätigkeiten eingesetzt werden. Die Steueraufsicht könnte - ausgebaut und personalmäßig aufgestockt - gezielt andere Aufgaben übernehmen. Auch das Steuerstrafrecht könnte durch eine bessere Ausstattung mit Sachbearbeitern eine tatsächliche Präventivwirkung zum Schutz des ehrlichen Steuerbürgers entfalten. Die Ermittlungstätigkeit, die Feststellung der entstandenen Steuerschuld und deren gleichzeitige Fălligstellung und Tilgung würden so in die Verantwortlichkeit der Steuerbürger verlegt. Diesen gegenüber könnte die Finanzverwaltung sich auf eine wachsame Steueraufsicht durch Wahrnehmung von Prüfungspflichten zum Schutz der Allgemeinheit konzen-

\footnotetext{
is Vocke, W. (1887), S. 485; Schmoller, G. (1871), S. 136. Schmoller hielt aus den dargestellten Grînden 1871 für Sachsen eine Obergangslosung für angebracht. Meisel, F. (1911), S. 373.
} 
trieren. In den USA wird diese Form der Veranlagung seit vielen Jahren erfolgreich betrieben.

Nur durchschnittlich $1 \%$ der Steuerveranlagungen werden in den USA genau geprüft. ${ }^{247}$ Zusammen mit einer gut ausgebauten, auf Erfahrungen aufruhenden Rasterfahndung und sehr streng gehandhabten Strafen für ungesetzliches Verhalten führt dies in den USA zu einem befriedigenden Ergebnis der Selbstveranlagung und damit zum Erfolg des Vollzuges der Besteuerung. ${ }^{248}$

In einem weiteren Abschnitt wollen wir diesen Gedanken, der in der Bundesrepublik Deutschland bereits um 1960 kurz erörtert wurde, ${ }^{249}$ erneut zur Diskussion stellen. Denn nachdem eine Neuorganisation des Veranlagungsverfahrens durch Einführung der Selbstveranlagung von einem Gutachterausschuß im Jahr 1951, desgleichen vom Präsidenten des Bundesrechnungshofs als Bundesbeauftragtem für Wirtschaftlichkeit in der Verwaltung und auch vom Bund Deutscher Steuerbeamten 1959 vergeblich empfohlen worden ist, ${ }^{250}$ gelangten die Erörterungen nach 1962 schnell in Vergessenheit.

6. Unpraktikable Anforderungen an den heutigen Gesetzesvollzug die Selbstveranlagung der Steuerpflichtigen als Ausweg aus einem Dilemma

\section{a) Der Amtsermittlungsgrundsatz und die Besteuerungswirklichkeit}

In $\S 88 \mathrm{AO} 1977$ wird bestimmt, daß die Finanzbehörde den steuererheblichen Sachverhalt "von Amts wegen" ermittelt. Diese hat hierzu auch "Art und Umfang der Ermittlungen" zu bestimmen und ist "an das Vorbringen und an die Beweisanträge der Beteiligten ... nicht gebunden". Vor allem hat die Behörde "alle für den Einzelfall bedeutsamen, auch die für die Beteiligten ginnstigen Umstände zu beruicksichtigen". In $§ 90 \mathrm{AO}$ ist den Beteiligten hierzu eine Pflicht zur "Mitwirkung bei der Ermittlung des Sachverhaltes" auferlegt, die die "Pflicht der Behörde zur Aufklänung des Sachverhaltes von Amts wegen ... ergänzen soll". Diese Vorschriften entsprechen dem althergebrachten Grundsatz der "deutschen Type" der Einkommensbesteuerung, nach der die Erklärung eines Zensiten nur als ein "Hilfsmittel" unter vielen anderen Infor-

\footnotetext{
247 Wirtschaftswoche Nr. 38 vom 17.9.1993, S. 48.

24 wie Anm. 246.

249 Hartmann, J. (1967), S. 52.

${ }^{250}$ Bund Deutscher Steuerbeamten (1959), S. 4. Der Prăsident des Bundesrechnungshofes als Bundesbeauftragter für Wirtschaftlichkeit in der Verwaltung. Bundestags-Drucksache 1518, 3. Wahlpenode, S. 137. Fur weitere Fundstellen siche Hartmann, J. (1967), S. 20.
} 
mationen bei der Ermittlung der Bemessungsgrundlage durch die Finanzbehōrde nach dem "Amtsermittlungsgrundsatz" dienen soll.

Dieser Untersuchungsgnundsatz wurde der in das deutsche Strafverfahren eingegangenen und dasselbe bestimmenden "Inquisitionsmaxime" nachgebildet. $^{251}$ Wegen des Grundsatzes, daß kein Bürger verpflichtet sein kann, Erklärungen abzugeben, die ihn selbst strafweise belasten könnten, mußte diese Verfahrensweise aber von vornherein im Steuerrecht zu Schwierigkeiten führen. Es mußte nämlich nun streng zwischen dem Ermittlungsverfahren zur Bestimmung der steuerlichen Bemessungsgnundlage und der Ermittlung zur Aufklärung einer Steuerstraftat differenziert werden, da die Mitwirkungspflichten eine klare Grenzziehung benötigen. Der Amtsermittlungsgrundsatz läßt jedoch eine befriedigende Lösung der Differenzen nicht zu, da die Behörde im Ermittlungsverfahiren stets auf Mitwirkungspflichten der Steuerbürger bestehen muß, dessen Ergebnis dieselbe Behörde dann gegebenenfalls gegen den Zensiten zu strafweisem Vorgehen verpflichtet. ${ }^{252}$ Die beiden Verfahren, die einander widersprechende Pflichten bzw. Rechte des Bürgers mit sich bringen, lassen sich nur in der Theorie klar voneinander trennen. Sie bleiben in der Praxis unlösbar miteinander verquickt. Harmlos beginnende Ermittlungen der Finanzverwaltung, beispielsweise anläßlich einer Betriebsprüfung, können daher fast übergangslos und von allen Beteiligten - einschließlich der Betriebsprüfer - so gut wie unbemerkt zu problematischen Teilen von Steuerstrafverfahren werden. ${ }^{253}$

Der derzeitige Ablauf des Veranlagungsverfahrens ist daher geeignet, die Beurteilung der Behördentätigkeit in der Öffentlichkeit als ungenehmen und gefahrbelasteten Eingriff in die Privatsphäre zu verstărken und jedenfalls tiefes Miß̈trauen zu erzeugen.

Steuerberater sind stăndig gehalten, ihre Mandanten auf die Gefahren und den Rollenwechsel beim Übergang vom steuerlichen zum steuerstrafrechtlichen Ermitulungsverfahren aufnerksam zu machen. ${ }^{254}$ Letztlich hat jeder

\footnotetext{
29i Wirschaftswoche Nr. 38 v. 17.9.1993, S. 48.

292 Ein Verwertungsverbot bezüglich der durch Außenprufungen und andere Ermittlungsmaßnahmen der Finanzbehörde gewonnene Erkenntnisse kann nür geitend gemacht werden, wenn die Informationen auf rechtswidrige Weise erlangte Tatsachenkenntnisse oder Ergebnisse von Beweiserhebungen darstellen, siehe: Urbar, J. (1989), S. 1037.

${ }^{23}$ Die Tatsache, daß Zwangsmittel gegen den Zensiten im Ermittlungsverfahren unzulässig, sind, sobald das Strafverfahren in derselben Sache erōffnet wurde, ändert an dem Zusammenhang nichts, siche hierzu $\S 393$ Abs. 1 AO; Streck, M. (1979), S. 4. Die Mitwirkungspflicht im Ermittlungsverfahren bleibt bestehen, mögen der Verwaltung auch der Einsatz von Zwangsmitteln verwehrt sein.

${ }^{24}$ Nur im Strafiverfahren lebt das Recht der Aussageverweigerung auf, da der Beschuldigte grundsitzlich in keiner Weise verpflichtet sein kann, an seiner Oberfuhrung aktiv mitzuwirken, Peters, K. (1985), S. 207. Der Beschuldigte hat einen Anspruch darauf, uberfuhrt zu werden.
} 
Mandant Anspruch auf Erläuterung seiner rechtlichen Stellung, dies gilt zu seinem Schutz gerade dann, wenn er dem Berater erkennbar steuerunehrlich ist.

Die so in der Offentlichkeit erzeugte Einstellung verdrängt daher leicht die Einschätzung der Finanzämter als Institution für die Verteilung der gemeinsamen Lasten nach dem gesetzlich festgelegten, an der Leistungsfähigkeit des Bürgers orientierten Schlüssel, eine Ausrichtung, die Gustav Schmoller 1863 empfahl und die der Entwicklung der Einkommensteuer im 19. Jahrhundert zugrunde liegen sollte.

Appelle der Behörde zur aktiven Mitwirkung der Steuerbürger können diesen nach landläufiger Meinung wie versteckte Fallen zur Erzielung höherer Steuereinnahmen erscheinen. Die Beurteilung des Steuerrechts als Eingriffsrecht und das Interesse am Schutz vor staatlicher Willkür finden überzeugende Begründungen.

Mehr noch: Der Behörde obliegt bei der Veranlagungstätigkeit im Rahmen der ihr zugewiesenen Ermittlung der steuerlichen Bemessungsgrundlage nach geltendem Abgabenrecht sogar eine in $\S 89$ AO 1977 normierte "Fürsorgepflicht" gegenüber den Steuerbürgern. In deren Interesse hat sie danach die "Berichtigung von Erklărungen oder Anträgen anzuregen", "wenn diese offensichtlich nur versehentlich oder aus Unkenntnis unterblieben, unrichtig abgegeben oder gestellt worden sind". Sie hat darüber hinaus "Auskünfte über die den Beteiligten ... zustehenden Rechte und die ihnen obliegenden Pflichten zu geben". Die hier festgelegte Stellung der Finanzbehörde erinnert an die Aufgabe der Obrigkeit im angehenden 19. Jahrhundert, für die dem Untertan zwangsweise verordnete Förderung des Wohlstandes bemüht zu sein, wie dies etwa im Josephinismus besonders typisch zum Ausdruck gelangte. ${ }^{255}$

Es ist unübersehbar, daß die Finanzverwaltung diesen Bestimmungen bereits lange Zeit vor 1976, als die reformierte Abgabenordnung beschlossen wurde, gar nicht mehr entsprechen konnte und auch "Einschränkungen" nach den "Grundsätzen von Zumutbarkeit und Verhältnismäßigkeit", die vom Ausschußbericht des Bundestages als Begrenzung der Fürsorgepflicht erwähnt wurden, hieran nichts zu ändern vermögen.

Nicht einmal die gesetzlich gebotene Überprüfung der Einkommensteuererklärungen kann heute amtsseitig routinemäBig noch durchgeführt werden und sie erfolgt in der Regel auch nicht mehr. Nur eine oberflăchliche Kontrolle

$255 \mathrm{Vgl}$. AusschuBbericht zu $\S \S 88,89$ AO, abgedr. In: Mittelsteiner, K.-H./Schaumburg, H. (1976), S. 118. 
nach offen erkennbaren Plausibilitătsmăngeln wird - und dies auch nur noch gelegentlich - vorgenommen.

Die Ergebnisse sind oft für den korrekt arbeitenden Steuerberater deprimierend. Er muß sich von seinen Mandanten sagen lassen, er vernachlăssige deren Interesse, weil er zu gestrenge, vom Finanzamt gar nicht erwartete Maßstăbe anlege.

Hierzu kommt: Mittelstăndische Betriebe können im Durchschnitt nur noch alle 9,5 Jahre, Kleinbetriebe alle 19,3 Jahre und Kleinstbetriebe nur noch alle 50 Jahre von einer Betriebsprüfung durchleuchtet werden, so daß dem Finanzamt nicht bekanntgewordene steuererhebliche Tatbestandsmerkmale nur ausnahmsweise und verspätet zu berichtigten Veranlagungen führen können. ${ }^{256}$ Obendrein läßt die Qualităt der Betriebsprüfungen zum Vorteil der Steuerpflichtigen zunehmend Zweifel aufkommen, ob das eingesetzte Personal noch über ausreichende Qualifikationen verfügen mag. "Da die Inhaber (von Betrieben, d.V.) das wissen, können zum Beispiel Gastwirte und Handwerker ihre Steuern selber bestimmen", so die Erfahrung der Finanzbeamten nach Klagen des Vorsitzenden der Deutschen Steuer-Gewerkschaft vom November 1993. ${ }^{257}$ Diese Institution schätzt im übrigen, "daß dem deutschen Staat allein 1992 durch die dargestellte Entwicklung Steuerausfälle von 130 Mrd. DM entstanden seien. ${ }^{258}$ Sollte diese Schätzung richtig sein - dem Autor erscheint sie überzogen -, so wurden 1992 ganze 39,15\% des Aufkommens der zur Einkommensteuer zu rechnenden Abgaben infolge des ungeeigneten Zusammenwirkens von Gesetz und Gesetzesvollzug zumindest vorläufig verkürzt. Dies würde dem Anteil entsprechen, den Meisel 1911 und 1914 in seinen Ausführungen zur preußischen Gesetzestechnik durch Hochrechnungen als Ausfall einkalkulierte.

\section{b) Ansätze zu einer Reform der Veranlagung zur Einkommensteuer}

Wenn die Deutsche Steuer-Gewerkschaft bereits seit 1976 und 1986 offen von einem unlösbaren "Dilemma" der Finanzverwaltung spricht, da diese ihren gesetzlichen Aufgaben in keiner Weise mehr nachkommen könne. so enthălt diese Beurteilung keine Übertreibung. ${ }^{259}$

\footnotetext{
26 DSTG (1993), Heft 9.

DST D (1993), Heft 9.

${ }^{25}$ DSTG (1992), S. 2, S. 8.

299 DSTG (1986), S. 62.
} 
Die Entwicklung konnte allerdings seit vielen Jahren vorhergesehen werden. Es gehört jedoch zu den Eigentümlichkeiten der Finanzwissenschaft und ebenso der durch Fuisting begründeten Steuerrechtswissenschaft, daß der Vollzug der Einkommensteuergesetze bis heute gröblich vernachlässigt wurde. Das beklagte bereits Franz Meisel für die praktische Entwicklung als verhängnisvoll. Hehre Prinzipien der Besteuerung, begriffliche Festlegungen, gesetzessprachliche Zusammenhänge, die widerspruchsfreie Vereinbarkeit steuerlicher Vorschriften mit dem übrigen Normengefüge und den Verfassungsbestimmungen sind für die gesamten Steuerwissenschaften stets von größerem Interesse gewesen, als die gleichermaßen wichtigen konkreten Ausgestaltungen der Gesetzestexte und deren jeweilige praktische Auswirkungen. Dies gilt etwa um nur ein Beispiel zu nennen - für die billigen, weil zinslosen Langzeitkredite, die ein am Rechtsstaatsgedanken orientiertes perfektioniertes Veranlagungsverfahren großen Steuerschuldnern früher ständig gewährte, ebenso, wie für die um Jahre hinter der Zeit hereilenden Nachzahlungen nach endgültiger rechtskräftiger Veranlagung. Das allerdings interessierte jeweils nur Praktiker, die sich über viele von Hochschullehrern und Richtern vertretene spitzfindige Thesen von einer angeblichen Besteuerung nach der Leistungsfähigkeit bei Vergleich mit der Besteuerungswirklichkeit ohnehin zu wundern vermochten.

Sogar dann, wenn der Begriff der Praktikabilität von Vorschriften von Steuerrechtslehrern erörtert wird, sind damit zumeist rein begriffliche Zusammenhänge angesprochen, nicht aber die Regelungen, die Steuerberater und Veranlagungsbeamte in Finanzämtern zu beachten haben und deren Konsequenzen, nämlich eine unzweckmaßige und uneffiziente, nicht mehr zeitgemäße Veranlagungspraxis, die obendrein den Grundgedanken zu ihrer Rechtfertigung nicht entsprechen kann: eine Besteuerung der Bürger nach ihrer jeweiligen Leistungsfăhigkeit zu ermöglichen.

Daher ist es auch zu verstehen, daß noch heute mit nur unwesentlich verăndertem Personalbestand nach einem Veranlagungsverfahren mit einer "spezifischen Behördenmentalität" gearbeitet wird, welches vor 75 Jahren unter Finanzminister Erzberger aus dessen Erfahrungen mit dem preußischen EStG entwickelt wurde und das seinerzeit gewil als sehr fortschrittlich gelten konnte.

Aber die Steuereinnahmen haben sich allein in den letzten 45 Jahren mehr als verzehnfacht. Erhebung und Überwachung der Einkommensteuer erfolgen dennoch heute mit unwesentlich verändertem Personalbestand. Die Reform der Abgabenordnung im Jahr 1977 diente im wesentlichen der Überarbeitung und Abstimmung der Besteuerung mit den Errungenschaften der elektronischen Datenerfassung. Sie blieb Flickwerk, da die hergebrachten Verfahren als 
solche nicht in Frage gestellt wurden. Trotz tiefgreifender struktureller Verănderungen der Wirtschaft und vor allem eines nach dem letzten Krieg geradezu revolutionierenden Einsatzes der gesamten Besteuenung für nichtfiskalische Zwecke, der weit über das hinausgeht, was von der sogenannten "fiscal policy" der 50er Jahre als sogenaunte Globalsteuerung der Wirtschaft empfohlen wurde, ist es in dieser Zeit nicht zu Veränderungen am System gekommen.

Der wirtschaftliche Aufschwung nach 1950 hătte jedoch eine grundlegende Reform der Verwaltungsorganisation nach neuartigen Gesichtspunkten erfordert, schon um dem unausweichlich wachsenden Arbeitsanfall bei der Besteuerung zu entsprechen und ebenso um - wie wir im Laufe der Abhandlung gesehen haben - den Anforderungen an eine zeitgemäße und effektive Steueraufsicht im Interesse der Gleichmäßigkeit der Besteuerung in einem weitergehenden eigentlichen Sinn zu genügen. Gerade der wachsende nichtfiskalische Einsatz des Steuerrechts mußte eine Überprüfung des Verfahrens und eventuelle Anpassungen empfehlen.

Diese Feststellungen sind keineswegs neuartig. In Warnungen ist frühzeitig von Sachkundigen auf die Schwerfalligkeit des Veranlagungsverfahrens, die daraus resultierende Ungleichmäßigkeit der Besteuerung bei im Grunde gleichen Sachverhalten und viele unerwünschte Auswirkungen auf Unternehmens- und Steuerpolitik hingewiesen worden. Vor die Entscheidung gestellt, "durch peinlich genaue Anwendung der Bestimmungen den gesamten Geschäftsgang (der Verwaltung, d.V.) zu blockieren oder lieber gelegentlich fünf gerade sein zu lassen und dafür einigermaßen der Arbeitslast Herr zu werden", hat die Finanzverwaltung sich unter dem Druck der Ereignisse stets für das letztere entscheiden müssen, so stellte Schmölders bereits 1951 resignierend fest. ${ }^{260}$

Bereits im Sommer 1951, zu einer Zeit also, in der der deutsche Wiederaufbau nach dem Krieg einsetzte und der Neuaufbau der Behörden Änderungen leichter zuließ, wurde in dem "Hansen-Musgrave-Report" vom 24. September 1951 durch eine amerikanische Studiengruppe zur Vereinfachung der Verwaltung $^{261}$ die grundsätzliche Anwendungsmöglichkeit der Selbstveranlagung im deutschen Veranlagungsverfahren erörtert und als Ergebnis eine völlige Umstellung des Gesetzesvollzuges empfohlen. In den USA wurde eben zu dieser Zeit die Selbstveranlagung im Jahr 1954 eingeführt. ${ }^{262}$

${ }^{260}$ Schmolders, G. (1951), S. 121.

201 Hansen, A. H./ Musgrave, R. A., ECA-Team on Fiscal Problems of Germany, Bericht vom 24.9.1951, S. 364, zitiert nach Hartmann, J. (1967), S. 20, Anm. 24.

${ }^{262}$ Debatin, H. (1957), S. 484. 
Es bot sich somit damals eine gute Chance zur Verfolgung der Ergebnisse für einen Neuaufbau mit vergleichbarer Fortschrittlichkeit in Deutschland. Der Ausschußbericht einer "amtlichen Kommission zur Prüfung von Fragen der Organisation und Vereinfachung der Finanzverwaltung" sprach sich dann 1959 für eine grundsătzliche Überprüfung des vorhandenen deutschen Systems der Veranlagung aus. ${ }^{263}$ Der Bund Deutscher Steuerbeamten, der Vorläufer der Deutschen Steuer-Gewerkschaft, kam 1959 mit konkreten Vorschlägen zu demselben Ergebnis. ${ }^{264}$ An weiteren Vorschlägen und Anregungen hat es in den späteren 50er Jahren, als sich das bis heute gültige hergebrachte System verfestigte, nicht gefehlt.

In einer Denkschrift vom Juni 1959 hat der Bund Deutscher Steuerbeamten auf Grundlage des amerikanischen Selbstveranlagungsverfahrens und der inzwischen damit gemachten Erfahrungen einen Forderungskatalog mit neun Positionen zur Reform der Veranlagungstätigkeit vorgelegt. Als wichtigste Neuerungen waren darin die Einführung der Selbstveranlagung mit festen Abgabefristen und gleichzeitigen Fälligkeiten für Steuerabschlußzahlungen, Verjährung nacn Betriebsprürungen (spätestens nach đrei Jatren), Einfütrung einer verbindlichen Auskunftspflicht der Behörde und Intensivierung der Betriebsprufungsdienste durch die Übernahme der auf diese Weise freiwerdenden Mitarbeiter vorgesehen. ${ }^{265}$ Von einer Reform nach diesen Gesichtspunkten glaubte man unter anderen Vorteilen eine wirtschaftlichere Verwaltungstätigkeit, einen rationaleren Einsatz des Personals der Finanzbehörden, eine Erhöhung der Rechtssicherheit und damit Erleichterung unternehmerischer Dispositionen, eine zeitnahere Abwicklung der Steuerzahlungen und vor allem eine "Versachlichung des Spannungsverhältnisses" zwischen Fiskus und Steuerzahler infolge der vorgesehenen bankmäßigen Abwicklung der falligen Nachzahlungen erwarten zu kø̈nnen. ${ }^{266}$ Aber auch für die Verwendbarkeit der Steuer als konjunkturpolitisches Instrument und zur wirtschaftspolitischen Feinsteuerung håtte eine Reform unter diesen Gesichtspunkten erhebliche Vorteile durch jeweils zeitnahe Gestaltung der Steuerzahlungen und damit bessere Beherrschbarkeit der Steuerungsmechanismen mit sich gebracht.

Nachdem verschiedene Beiträge von fachkundiger Seite und auch der Präsident des Bundesrechnungshofs als "Bundesbeauftragter für Wirtschaftlichkeit

\footnotetext{
263 Institut "Finanzen und Steuern" (1954), Grundlagen und Moglichkeiten einer organischen Finanz- und Steuerreform, H 30 der Schriftenreihe Bd. 1, S. 70.

204 Bund Deutscher Steuerbeamten (1959); hierzu auch die eingehende Erörterung der vorgebrachten kritischen Argumente bei Hartmann, J. (1967), S. 23.

${ }^{269}$ Bund Deutscher Steuerbeamten (1959), S. 4.

${ }^{266}$ Bund Deutscher Steuerbeamten (1959), S. 6; Hartmann, J. (1967), S. 52.
} 
in der Verwaltung" sich an einer Überprüfung des Veranlagungssystems beteiligt und sich für die Einführung der Selbstveranlagung ausgesprochen hatte, fand der Gedanke vorübergehend Eingang in die öffentliche Diskussion. ${ }^{267}$ Einige Fachzeitschriften berichteten über Organisation. Ausgestaltung und Ergebnisse der Selbstveranlagung in den USA. ${ }^{268}$

Die Erörterungen führten đazu, daB in den Jahren 1960 und 1961 in zehn Finanzämtern des Landes Niedersachsen ein erster Schritt in Richtung auf die Einführung der Selbstveranlagung gewagt wurde ${ }^{269}$ Probeweise wurden die Steuerpflichtigen aufgefordert, durch eine Selbstberechnung die für sie zutreffende Bemessungsgrundlage zu ermitteln. Zur Unterstützung konnten sie in Zweifelsfallen auf eingerichtete Hilfsstellen in den Finanzämtern zurückgreifen. Die Teilnahme an dem Versuch war freiwillig. Die Festsetzung der Steuer als Verwaltungsakt durch Erteilung des Bescheides verblieb bei der Verwaltung. ${ }^{270}$ Entgegen vielen Vorurteilen stellte sich als Ergebnis heraus, daß die Einfühnung der Selbstberechnung für alle Beteiligten vorteilhaft war. Daher konnte man wohl davon ausgehen, daß einer möglichen Weiterfuhnung zur Selbstveranlagung von Seiten der Steuerwissenschaften und der Öffentlichkeit zumindest größere Aufmerksamkeit gewidmet werden würde.

Die Neuartigkeit begegnete jedoch Hemmschwellen, die eine Neuorganisation und erforderliche Reformen belasten mußten.

Die vom Bund der Steuerzahler vertretene These von der drohenden Überforderung der Zensiten infolge mangelhafter steuerrechtlicher Kenntnisse hatte sich nicht bestătigt. ${ }^{271}$ Vor allem die Warnung vor einer unzumutbaren zusätzlichen Belastung der Steuerbürger mit Mehrarbeiten, die sie im Grunde zu "Hilfsarbeitern des Fiskus" herabwürdigen, fand spăter in der Offentlichkeit dennoch zunehmend Resonanz. ${ }^{272}$ Tatsächlich sanken die Fehlerquoten der Selbstberechnungen bereits im zweiten Jahr der Probeläufe ganz entscheidend. Die freiwillige Teilnahme der Steuerbürger stieg sogar auf fast $90 \%$ an. Da im Durchschnitt 48,19\% der Steuerpflichtigen von Beratern vertreten wurden, ergab sich für diese Gruppe keinerlei Probleme. Alle Berufsträger fertigen

\footnotetext{
Vgl. Bemerkungen des Bundesrechnungshofes zu der Bundeshaushaltsrechnung fur das Rechnungsjahr 1956 (einschließlich Vermőggensrechnung), in: Deutscher Bundestag, 3. Wahlperiode, Drucksache 1518 vom 10.12.1959, S. 137.

204 Debatin, H. (1957), S. 484; Bund der Steuerzahler. Der Steuerzahler (1961) S. 89; Beske, S. (1962), S. 375.

${ }^{259}$ Hartmann, J. (1967), S. 24; Beske, S. (1962), S. 375.

Beske, S. (1962), S. 375.

${ }^{271}$ Beske, S. (1962), S. 377; Hartmann, J. (1967), S. 60.

27 Bund der Steuerzahler (1961): Der Steuerzahler, S. 90.
} 
heute üblicherweise für jeden Mandanten ohnehin mit der Steuererklärung eine Ergebnisrechnung.

Von Seiten der für die Veranlagung zuständigen Finanzbehörden las man denn 1961 auch von ausnahmsloser Befürwortung einer Beibehaltung des als Experiment gelaufenen Verfahrens. Bei den teilnehmenden Angehörigen der steuerberatenden Berufe erfuhr man von Vorteilen sowohl für Zensiten, als auch für die beteiligten Finanzämter und von einem allgemein befriedigenden positiven Ergebnis. ${ }^{273}$

In einer empirisch fundierten Untersuchung des finanzwissenschaftlichen Forschungsinstituts der Universität zu Köln suchte der Autor unter dem Eindruck der Ergebnisse der Probeläufe in Niedersachsen 1967 dem Einfluß der Selbstveranlagung auf Staatsbewußtsein, Steuermoral und Steuermentalität nachzugehen. ${ }^{274}$ Er glaubte, infolge der besseren Informiertheit der Zensiten über die steuerrechtlichen Vorschriften im Falle der Einführung der Selbstveranlagung sogar von einer zu erwartenden "Versachlichung des Spannungsverhältnisses" zwischen Steuerbürger und Finanzbehörde ausgehen zu können. Der Autor war selbst als Steuerberater seit mehreren Jahren eigenverantwortlich in einer großeren Steuerberatungspraxis tätig, also sachkundig. Von einer Neuorganisation des Vollzuges durch Übernahme der Selbstveranlagung erwartete er mehr Steuergerechtigkeit im Vergleich mit dem veralteten System, dessen Mängel, wie er glaubte, der Öffentlichkeit "in den Grundzügen" bekannt seien. ${ }^{275} \mathrm{Er}$ glaubte jedoch nach den anläßlich seiner Untersuchung gesammelten Erfahrungen nicht daran, daß die Selbstveranlagung in der Bundesrepublik trotz aller erkennbaren Vorteile in absehbarer Zeit gegen die ihr abgeneigten Grundeinstellungen, gegen die Interessenvertretung der Verbände und vor allem gegen die verfestigte vorherrschende typische Beamtenmentalitât in den Behörden durchgesetzt werden könne. ${ }^{276}$ Diese Feststellung sollte sich schnell bewahrheiten.

\section{c) Die US-amerikanische Selbstveranlagung zur Einkammensteuer aus der Sicht der Bundesrepublik Deutschland im Jahr 1994}

Bereits 1957 ist "die amerikanische Steuerverwaltung und das Besteuenungsverfahren" in den USA aus dem Blickwinkel des deutschen Behörden-

\footnotetext{
${ }^{279}$ Beske, S. (1962), S. 377.

${ }^{274}$ Hartmann, J. (1967), S. 47.

273 Hartmann, J. (1967), S. 48.

${ }^{276}$ Hartmann, J. (1967), S. 52.
} 
aufbaus in dem bekannten Fachorgan "Steuer und Wirtschaft" eingehend dargestellt worden. ${ }^{277}$ Bereits zu dieser Zeit zeigte sich nămlich in der Bundesrepublik Deutschland deutlich die Notwendigkeit einer Entlastung der von den Folgen des Wirtschaftsaufschwungs überforderten Finanzämter. Von einer umfassenden Mechanisierung und modernen technischen Ausstattung der Verwaltung versprach man sich zu dieser Zeit noch die erforderliche Erleichterung. Aus dem Bericht ergab sich jedoch, daß die "wirkungsvolle Arbeit der amerikanischen Bundessteuerverwaltung" keineswegs einer großzügigen Mechanisierung als "Wesensgrundlage" zu verdanken war. Vielmehr unterstützte das moderne technische Gerăt nur einen vorgegebenen neuartigen Verfahrensgang durch dessen Rationalisierung und Beschleunigung. "Kernstück des amerikanischen Besteuerungsverfahrens ist seit der Reform von 1954 der Grundsatz der Selbstveranlagung", so fuhrte der damalige Regienungsassessor Helmuth Debatin nach einem Studienaufenthalt in den USA aus. ${ }^{278}$

Nach dem Bericht hatte der Steuerpflichtige in dem neuen System zur Erleichterung der Verwaltungstätigkeit nicht nur seine Steuerschuld selbsi zu ermitteln, sondern auch mit Abgabe der Steuererklärung die errechnete Steuerschuld oder Nachzahlung sofort zu begleichen. Charakteristisch für das reformierte Verfahren in den USA waren nach Darstellung Debatins

1. die starke Aufgliederung der Zustanndigkeiten nach reinen Funktionsgesichtspunkten,

2. die durch verschiedene Regelungen gewährleistete Rechtssicherheit und der sehr ernstgenommene Vertrauensschutz der Zensiten,

3. die zeitgerechte Sicherstellung der laufenden Steuereingänge,

4. der Grundsatz der Selbstveranlagung,

5. die Verzinsung im Geldverkehr zwischen Staat und Sieuerbürger,

6. ein System hoher Zuschläge und Nebenstrafen für Versăumnisse und Ordnungswidrigkeiten und ein strenges, Steuerstrafrecht,

7. die materielle Prüfung der Selbstveranlagung erst nach Abgabe der Erklărung und Tilgung der Steuerschuld,

8. die bevorzugte Förderung gütlicher Einigungen zwischen Verwaltung und Steuerpflichtigen in Form vertraglicher Absprachen,

9. eine moderne technische Ausstattung zur Unterstützung der Verwaltungstătigkeit dort, wo dies zweckmäßig erschien. ${ }^{279}$

mebatin, H. (1957), Sp. 484.
Debatin, H. (1957), Sp. 490.
Debatin, H. (1957), Sp. 498. 
Eigentliches Ziel von Organisation und Ausstattung war die Erleichterung und Beschleunigung der Verwaltungsarbeit, die ausschließlich nach Zweckmäßigkeitsgesichtspunkten ausgerichtet worden war. ${ }^{280}$

Tatsächlich hatte der Steuerpflichtige in den USA nach Darstellung Debatins ein in Deutschland völlig unbekanntes Ausmaß von Mitwirkungspflichten bei der Besteuerung zu erfüllen. Zur Vermeidung sehr empfindlicher Nachteile war er von Gesetzes wegen zur pünktlichen, korrekten und verantwortungsbewußten Erledigung sehr lästiger Pflichten gehalten, die aber, wie er wußte, alle Bürger ausnahmslos in gleicher Weise treffen.

Wie Debatin berichtete, schloß diese Mehrbelastung keineswegs aus, daß jeweils Steuervorteile wahrgenommen werden konnten, daß von Seiten der Finanzverwaltung der Vertrauensschutz beachtet wurde, daß die Rechtssicherheit respektiert und alle rechtsstaatlichen Ausgestaltungen für die Steuerbürger gewăhrleistet blieben. ${ }^{281}$

Als erste Bearbeitungsstelle der eingehenden Einkommensteuererklärungen dienen seiv 1954 in den USA sogenannte "Service Centers" als "Dreh- und Angelpunkt" des Besteuerungsverfahrens. ${ }^{282}$ Hier bestimmt High Tech seit 1954 bis heute das Verfahren und hier wird noch heute mit Hilfe ausgefeilter Computerprogramme die Selbstveranlagung der Zensiten auf ihre Plausibilităt hin überprüft. ${ }^{283}$ Dabei werden, wie aus Berichten des Jahres 1987 hervorgeht, automatisch Verprobungen mit Kontrollmitteilungen, von denen jährlich weit mehr als 1 Mrd. beim Internal Revenue Service (IRS) eingehen, vorgenommen. ${ }^{284}$ Diese Kontrollmitteilungen betreffen Informationen über größere Kontenbewegungen und Zinsbelege von Banken und Meldungen von anderen Verwaltungen, wie etwa der Sozialversicherung. Für Sozialversicherung und Besteuerung wurden den Bürgern identische Ordnungsnummern zugeteilt, so dab steuererhebliche Informationen wechselseitig für Überprüfungen unmittelbar abrufbar sind. Datenträgerschutz und Steuergeheimnis werden jedoch von der Finanzverwaltung streng gewahrt. ${ }^{285}$

Sofern eine Steuererklärung nicht plausibel erscheint oder sogar offene Widersprüche auftreten, versucht die Verwaltung die Abweichungen in Zusammenarbeit mit dem Steuerpflichtigen zu bereinigen. Falls dies brieflich

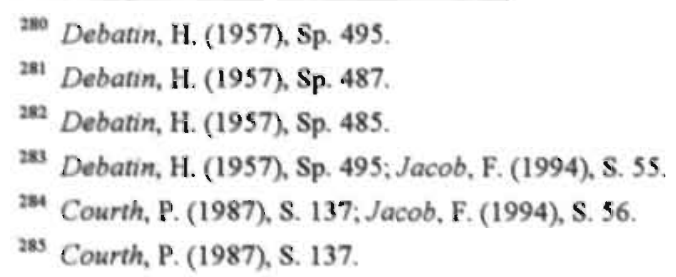


(correspondence audit), durch Vorladung an Amtsstelle (office audit) oder durch eine Betriebsprüfung vor Ort (field audit) nicht zufriedenstellend gelingt, wird der Vorgang an das übergeordnete "District Office" abgegeben. ${ }^{286}$ Hier befassen sich dann in Zusammenarbeit hochqualifizierte Fachleute, wie geschulte Betriebsprufer, Buchfühungsspezialisten, Steuerberater, Wirtschaftsprüfer und Rechtsanwälte, die mit modernster Technologie ausgestattet sind, mit dem Fall. Auch hier wird vordringlich versucht, mit dem Steuerpflichtigen zu einer befriedigenden Einigung zu gelangen. Es gilt seit 1954 die Richtlinie, "daß das gute Verhältnis zwischen dem Steuerpflichtigen und der Steuerverwaltung als eine Grundvoraussetzung für die reibungslose und wirkungsvolle Arbeit im Besteuerungsverfahren angesehen werden muß. Steuerverwaltung und Steuerpflichtiger dürfen sich nicht als Gegner gegenübertreten, sondern sollen bei aller Wahrung der gegensätzlichen Auffassungen gemeinsam auf das Ziel einer zutreffenden Feststellung der Steuerlast hinarbeiten" ${ }^{287}$ Nicht eine perfektionierte Subsumierbarkeit aller Merkmale des einzelnen Besteuerungsvorgangs unter die Gesamtheit des hierarchisch gefügten Rechtsnormengebäudes ist das Ziel der Verwaltungstätigkeit, sondern eine überzeugende Lastenverteilung.

Streitige Auseinandersetzungen werden daher zügig vornehmlich nach wirtschaftlichen Kriterien beurteilt und so abgewickelt, daß schnell Rechtssicherheit gegeben ist. ${ }^{288}$ Dabei bleiben alle uns geläufigen rechtsstaatlichen Gesichtspunkte bei der Besteuenung gewährleistet. ${ }^{289}$

$\mathrm{Zu}$ dem Bundessteuergesetz (Internal Revenue Code, IRC) sind jeweils "Regulations", der Intention nach als deren verbindliche Auslegungen, und außerdem "Rulings" als Einzelfallentscheidungen der Verwaltung neben "Court Decisions" als Urteile der jeweils zuständigen Gerichte zu berücksichtigen ${ }^{290}$ Daneben gibt es noch die an Einzeladressaten gerichteten fallbezogenen "letter rulings", Stellungnahmen zu allgemeinen Rechtsfragen als "re-

296 Courth, P. (1987), S. 137; Debatin, H. (1957), Sp. 484; Barnett, J. S., S. 351; Yudkin, L. (1971), S. 17, S. 92.

ar Debatin, H. (1957), Sp. 488.

2 a Auch Tipke stellte nach Studium der US-Verhalltnisse 1992 fest, daß das Gesprăch mit dem Steuerpflichtigen in den vorgesehenen "office audits" sich in den USA bewhihr, Tipke, K. (1992), GleichmäBigkeit ..., S. 130. Hervorzuheben ist, daB Tipke die futalen Mängel des praktischen Vollzuges der Einkommensbesteuerung zutreffend widergibt und kritisiert, s. Tipke, K. (1986), UngleichmàBigkeit ..., S. 601; ders. (1989), Die rechtliche Misere ..., S. 157; ders. (1990), Ober Steuergesetzgebung ..., S. 309. Insoweit sich aus Tipkes Ausführungen aberhaupt konkrete Abhilfen herleiten lassen, reichen diese jedoch ohne eine abgestimmte Reform des Institutionengefüges für wesentliche Verânderungen der Verhăltnisse nicht aus.

\footnotetext{
${ }^{2 n}$ Debatin, H. (1957), Sp. 488.

${ }^{200}$ Barnett, J. S., S. 351
} 
venue rulings" und "determination letters" als Stellungnahmen eines Bezirkdirektors zur Rechtsanwendung auf einen konkreten Sachverhalt. ${ }^{291}$ Im übrigen gehen Vertrauensschutz und Beratungsbereitschaft der Verwaltung sehr weit. Sie werden höher bewertet, als die unbedingte Durchsetzung eines gesetzlichen Steueranspruchs. Nach dem Institut des "Closing Agreement" können sich Finanzverwaltung und Steuerpflichtiger in einem schriftlichen Vertrag sogar dahingehend binden, "für einen bestimmten Tatbestand, der auch eine erst geplante wirtschaftliche Maßnahme betreffen kann, eine bestimmte Auslegungs- und Rechtsauffassung gelten zu lassen". ${ }^{292}$ Allein für die Bearbeitung regelmäßiger Auskunftsantrăge, die im übrigen den veröffentlichten Verwaltungsentscheidungen des IRS dann zumeist zugrunde liegen, waren 1980 bei der Hauptverwaltung 700 qualifizierte Mitarbeiter beschäftigt. ${ }^{293}$

Im Vergleich hierzu sollte als Beispiel erwähnt werden, daß im allgemeinen Steuerrecht ebenso, wie in der Praxis der Finanzverwaltung der Bundesrepublik Deutschland das Institut der verbindlichen Auskünfte bis heute völlig unzureichend geregelt wurde, so daß die Rechtssicherheit trotz vieler wohlklingender Ausführungen inhaltlich in dieser Hinsicht unterentwickelt geblieben ist. ${ }^{294}$ Die in einem Schreiben des BMF an die nachgeordneten Behörden vorgesehenen "Auskünfte mit Bindungswirkung nach Treu und Glauben"295 sind in so viele spitzfindige juristische Kautelen eingebunden, daß man von praktischer Wertlosigkeit sprechen kann, da es der Bearbeitung vorausgehend sogar der Erteilung einer Ermessensentscheidung zur Abwăgung der Bedeutung des Interesses des Fragestellers bedarf. ${ }^{296}$ Der Referent im BMF kommentiert diese Wendung wie folgt: "Leitgedanke für die Ausübung des Ermessens muß stets sein, daß die knappen Ressourcen der Finanzverwaltung bei der Erteilung von Auskünften den Fällen gewidmet werden sollen, die es verdie-

\footnotetext{
291 Walz, W. R. (1982), S. 381.

${ }^{292}$ Debatin, H. (1957), Sp. 488.

${ }^{293}$ Barnett, J. S., S. 351; Courth, P. (1987), S. 139.
}

${ }^{294}$ Fur USA vgl. Barnett, J. S., S. 351; Courth, P., S. 139; Debatin, H. (1957), Sp. 488, Sp. 492 Die in $\$ 89$ AO der Verwaltung auferlegte allgenneine Fursorgepflicht bzw. die in $\$ 204$ normierte eingeschränkte Auskunftspiflicht entsprechen den Bedünfnissen des: Wirtschaftslebens an Rechtssicherheit in keiner Weise. Es fand sich aber bei den Beratungen der AO-Reform keine Mehrheit für eine gesetzliche Regelung der "verbindlichen Auskunt" der Verwaltung. Unklarheiten sollten jeweils, so die Mehrheit des Ausschusses, im ErlaBwege geregelt werden, vgl. Mittelsteiner, K. H./Schaumburg. H. (1976), S. 5.

${ }^{299}$ BMF-Schreiben vorn 24.6.1987 - IV A 5 - \$ 0430 - 9/87 - in: BStBI. I S 474. Zur Kommenticrung vgl. Krabbe, H., S. 4913 .

${ }^{296}$ Krabbe, H., S. 49115. 
nen". ${ }^{297}$ Rechtssicherheit vermag eine derartig fragwürdige Regelung gewiB nicht zu gewährleisten.

$\mathrm{Zu}$ erwähnen sind noch die strengen Bestimmungen in den USA bei Verletzung der allen auferlegten steuerlichen Pflichten. Hier sind empfindliche "civil penalties" vorgesehen, die Strafzuschläge von $5 \%$ bis $50 \%$ der Steuersumme anordnen ${ }^{298}$ Steuerdelikte mit betrügerischer Absicht können sogar mit hohen Gefängnisstrafen belegt werden. ${ }^{299}$

Aber selbst in Steuerstrafverfahren kann wirtschaftliche Zweckmäßigkeit unter Umständen Priorităt erhalten. ${ }^{300}$

Diese Verwaltungseinrichtungen und Verfahrensmöglichkeiten der USEinkommensbesteuerung werden, wie sich aus neueren Berichten ergibt, im internationalen Vergleich als effizient beurteilt ${ }^{301}$ und sie haben gewiß einen erheblichen Anteil an dem hohen Ansehen, das der IRS nach Umfragen bei den Bürgern der USA genieBt. Eine große Mehrheit der Steuerpflichtigen bestătigt nach Umfrageergebnissen, daß die Behörde ein "faire" Besteuerungspraxis gewährleiste. ${ }^{302}$ "Die Aufklärung der Steuerpflichtigen, die Wahrung des Vertrauensschutzes und der Sicherheit in der Erfüllung der steuerlichen Pflichten sind nicht weniger zum Ziel der Finanzverwaltung erhoben, als die Durchsetzung des Steueranspruches", so hielt Debatin bereits 1957 fest. $^{303}$ Daran hat sich nach neueren Berichten von Fachleuten im Vergleich mit der Bundesrepublik Deutschland nichts wesentliches verändert. Einen mit den hiesigen Verhältnissen vergleichbaren Steuerwiderstand gibt es offenbar heute in den USA nicht. Die in Deutschland unvermeidbaren hohen Bearbeitungsrückstände sind in den USA unbekannt. ${ }^{304}$

Die aktive Beteiligung der Steuerpflichtigen bei der Erfüllung der steuerlichen Pflichten schließt keineswegs aus, daß "Steuervorteile, die sich aus den gesetzlichen Vorschriften ergeben, wahrgenommen und mit aller Beharrlich-

\footnotetext{
${ }^{297}$ Krabbe, H., S. 4915.

29. Barnett, J. S., S. 351; Debatin, H. (1957), Sp. 493; Yudkin, L., S. 61.

${ }^{290}$ Debatin, H. (1957), Sp. 492; Barnett, J. S., S. 351; Yudkin, L., S. 70.

${ }^{300}$ Courth, P., S. 137

${ }^{301}$ Courth, P., S. 137.

${ }^{302}$ Courth, P., S. 137

${ }^{303}$ Debatin, H. (1957), Sp. 488.

${ }^{104}$ Debatin, H. (1957), Sp. 488. Die Zahlung des durch Selbstveranlagung ermittelten Steuerbetrages hat der Steuerpllichtige sofort mit Abgabe der Erklärung auszugleichen. Diese Regelung entspricht den Bestimmungen für die deutsche Umsatzsteuer seit deren Einfuhrung. GröBere Schwierigkeiten treten nicht auf.
} 
keit verfochten werden". ${ }^{305}$ Aber Steuerbürger und Finanzverwaltung verstehen sich in den USA nicht als verfeindete Gegner. Der Steuerbürger ist sich klar darüber, daß gesetzliche Vorschriften vollzogen werden, die bei aller möglichen Hărte im Einzelfall jedenfalls alle Bürger gleichmäßig treffen. Das vermag offenbar die Steuerpflichtigen zu befrieden. Allerdings kann auch die gute Organisation des IRS die Steuerkriminalität nicht unterdrücken. Die Steuerausfalle wurden im Jahr 1986 auf 100 Mrd. Dollar geschätzt, das waren $11 \%$ der gesamten Steuereinnahmen von 916 Mrd. Dollar. Die Vergleichsziffer in der Bundesrepublik Deutschland lag mehr als doppelt so hoch. ${ }^{306}$ Die hohe Steuerehrlichkeit in den USA wird durch ein System strenger Prüfungen unterstützt. Dabei sucht die Behörde jeweils dasjenige Auswahlprinzip anzuwenden, das am wirkungsvollsten für einen ungeschmälerten Steuereingang sorgt. ${ }^{307}$ Auch Stichproben nach Zufallsauswahl spielen eine Rolle. Hierfür sind die Service Centers zuständig. Zumeist sind jedoch Verdachtsmomente und Erklärungsinhalte für die Auswahl der Prüffalle von Bedeutung. ${ }^{308}$ Hohe Strafen üben eine angestrebte Präventivwirkung aus.

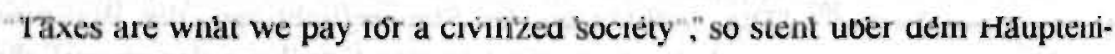
gang des IRS in Washington D. C.. Nach Umfragen gibt diese Aussage heute ebenso die Einstellung einer großen Mehrheit der US-Steuerbürger wider. ${ }^{309}$ Obgleich dic US-Einkommensteuer auch nach der letzten Reform der Kompliziertheit des deutschen EStG nicht wesentlich nachsteht, ist diese Mehrheit auch heute noch überzeugt, daß die Besteuerungspraxis "fair" sei. ${ }^{310}$

Die gern seit der Zeit Fuistings als Grund für die Beibehaltung der mit dem Amtsermittlungsgrundsatz kombinierten deutschen Fremdveranlagung verwendete Rechtfertigungsthese von einer angeblich unabänderlich mangelhaften Gesetzeskenntnis der Zensiten wurde in den USA jedenfalls nicht bestätigt. Unüberbrückbare Schwierigkeiten mit der Selbstveranlagung sind ausgeblicben. Die Selbstveranlagung hat sich nach allgemeiner Überzeugung bewährt. ${ }^{311}$

Fragt man sich, was dieser Gesetzesvollzug den Steuerzahler letztlich kostet, so ergibt sich folgendes: Der IRS beschäftigte 1987110.000 feste Mitarbeiter.

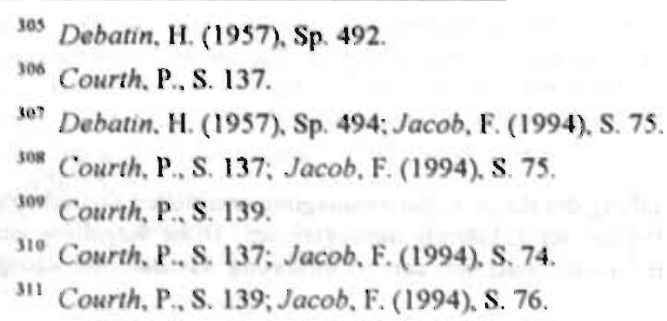


zu denen noch 30.000 Teilzeitkräfte für Stoßizeiten hinzukommen. ${ }^{3 / 2}$ Viele der Beschăftigten in den als Eingangsstellen für die Erklärung dienenden Service Centers sind oftmals angelernte Kräfte. Eine besondere Ausbildung für die Angehörigen der Steuerverwaltung gibt es im übrigen nicht. Es fehlt auch an einem einheitlichen Berufsbild. Das heißt, daß die Mitarbeiter aus allen möglichen Berufssparten stammen. In den District Offices findet sich allerdings eine große Zahl hochqualifizierter Absolventen von fürenden Universităten und besonderen Fachhochschulen. Um Lebensstellungen handelt es sich zumeist bei diesen Beschäftigungen nicht. Viele Mitarbeiter üben die Tatigkeit nur vorübergehend aus und machen sich nach einiger Zeit selbstăndig.

Laufbahnbeamte, die den deutschen Verhältnissen entsprechen, gibt es in der IRS nur wenige. Die Honorierung der Tătigkeit bei dem IRS ist im übrigen, an deutschen Verhältnissen gemessen, wenig attraktiv. ${ }^{313}$

So mag es von Interesse sein zu erfahren, daß die US-Finanzbehörde mit diesem Personalstand von 110.000 festen Mitarbeiter, also einem Mitarbeiterstab, der den Verhältnissen in Deutschland etwa entspricht, ein vielfaches des deutschen Steuervolumens vereinnahmt, rechtlich qualifiziert abwickelt, verwaltet und verausgabt. Es handelt sich gewiB um eine überaus effektive Behörde, aber ihr Schlankheitsgrad ist verglichen damit noch beeindruckender.

Im Jahr 1980 waren in den USA insgesamt etwa 140 Mio. Veranlagungen zu bearbeiten. Das ist mehr als das siebenfache der zu dieser Zeit in Deutschland durchzuführenden Veranlagungen eines Jahres. Damals hatte der IRS 89.000 Civil-Service-Angestellte, von denen 28.500 Angestellte Prüfungsaufgaben erledigten ${ }^{314}$ Dabei erfolgen die Steuerfestsetzungen und -zahlungen in den USA zeitnah. Wesentliche Rückstände bestehen nur, insoweit es sich um streitbefangene Vorgănge handelt. ${ }^{315}$ Die Verwaltung ist angewiesen, die Selbstberechnung des Steuerpflichtigen vorerst auch zu respektieren, wenn umstrittene Rechtsfragen, zu denen Vercinbarungen ex post nicht möglich sind, auftreten. Erst nach gerichtlicher Klärung kann eine obsiegende hőhere. Steuerfestsetzung durch die Behörde zum Zuge kommen. Das in Deutschland mögliche Aussetzungsverfahren muß hier systemfremd bleiben. ${ }^{316}$

\footnotetext{
${ }^{312}$ Courth, P., S. 137; s.a. Jacob, F. (1994), S. 74.

313 Courth, P., S. 138; Jacob, F. (1994), S. 74.

${ }^{314}$ Vgl. Walz, W. R. (1982), Steuerverwaltungsanordnung .... S. 381: Courth. P.. S. 137.

"1ts Barnett, J. S., S. 351: Debatin, H. (1957), Sp. 496: Jacob, F. (1994), S. 75.

Bgs. $\mathrm{Vgl}$. $361 \mathrm{Abs}, 2 \mathrm{AO}$
} 
Die US-Steuerverwaltung - vergleichbares gilt für Kanada und Australien ${ }^{317}$ vermag auf diese Weise einer sehr viel höheren Arbeitsbelastung zu entsprechen, ohne in einen Zustand zu geraten, der oftmals als Chaos bezeichnet wird, allgemeine Unzufriedenheit erzeugt und die deutsche Besteuenung in den Augen der Öfentlichkeit in Mißkredit bringt.

In Untersuchungen der Materie ist daher oftmals von Experten für die Bundesrepublik der Übergang zur Selbstveranlagung empfohlen worden. Eine derartige Reform würde gewiß viele von der heutigen fragwürdigen Veranlagungstätigkeit verursachte Schwachstellen in der Einkommensbesteuenung beseitigen.

Nachdem die in Niedersachsen 1960 und 1961 probeweise durchgeführten Versuche mit der Selbstberechnung der steuerlichen Bemessungsgrundlage durch die Steuerpflichtigen abgeschlossen waren, erbaten im Jahr 1962 Mitglieder des Finanzausschusses des deutschen Bundestages von der Regienung eine wertende Stellungnahme zu der Möglichkeit der Einführung der Selbstveranlagung.

Die Antwort des zuständigen Staatssekretärs lief darauf hinaus, daß ein Übergang die grundlegende Änderung des in der Abgabenordnung normierten Verfahrensrechts und daß die Vermeidung von drohenden Steuerausfaillen durch Übernahme des US-Musters "strengere Ordnungsbestimmungen .... die dem deutschen Recht fremd sind ..." und "zahlreiche Steuer- und Strafzuschläge" sowie eine "besonders strenge Ahndung von Steuervergehen" nötig machen werde. ${ }^{318}$ Er verwies auf höhere Kosten für die erforderliche Steuerberatung und stellte infrage, ob eine Entlastung der Verwaltung durch eine Umstellung überhaupt erzielt werden könne. ${ }^{319}$

Nach dieser offiziellen Verlautbarung der Bundesregierung im Jahr 1962 ist das Thema weder von Steuerwissenschaftlern, noch von Politikern oder der Finanzverwaltung nochmals offentlich diskutiert worden. Es war gestorben.

Der Gesetzesvollzug als solcher, der für Franz Meisel 1911 das problematische Glied in der preußischen und später "deutschen Type" der Einkommensbesteuerung darstellte, ist auch in den verschiedenen Gutachten der wissenschaftlichen Beiräte des Finanzministeriums nicht wieder ausführlich angesprochen worden. Als zu der Anpassung der Abgabenordnung an die fortschreitende Entwicklung im Rahmen der Steuerreform um 1970 in dem hierzu gebildeten Arbeitskreis die Frage einer Neuordnung der Veranlagung erörtert

\footnotetext{
317 Bos, R. W. (1988); ders. (1989), S. 267.

$318 \mathrm{Vgl}$. Deutscher Bundestag, 4. Wahlperiode, Drucksache IV 342, S. 2.

319 Wie Anm. 317.
} 
wurde, entschied man sich für das Institut der "Steuerfestsetzung unter Vorbehalt der Nachprüfung". Ein nach Fallgruppen der Steuerpflichtigen gebildeter, jeweils unterschiedlicher Prüfungsmechanismus sollte fortan der Verwaltung erlauben, das gesetzlich gebotene Ermittlungsverfahren vor Rechtskraft des Bescheides innerhalb von vier Jahren nachzuholen. ${ }^{320}$ Die Regelung wurde sogleich als Verstoß gegen verfassungsmäßig normierte Grundsătze heftig umstritten und brachte jedenfalls für die Veranlagung und die Besteuerungspraxis keine der dringend erwarteten Entlastungen. ${ }^{321}$

Die Veranlagung ist bis heute auf diesem Stand verblieben. Die Feststellung der Bemessungsgrundlage durch die Behörde nach dem Amtsermittlungsgrundsatz wurde beibehalten. Wenn eine Steuerreform gefordert wird, so verbindet sich damit bis heute zumeist die Forderung nach Beseitigung aller oder einzelner nichtfiskalischer Lenkungsnormen, nach Einführung oder Änderung von Pauschalierungen, Typisierungen, Schematisierungen, Erhebungsformen, Tarifgestaltungen und ähnliches mehr. ${ }^{322}$

Der vorhandene Gesetzesvollzug als solcher, der naturgemäß praktische Kenntnisse voraussetzt, wird weder von Wissenschaftlern, noch von Politikern oder den Leitern der Finanzverwaltung infrage gestellt. In den USA ist dies grundsătzlich anders, dort wird der Vollzug stets praxisnah in die Gesetzgebung eingebunden. Dies gilt insbesondere dann, wenn Reformworhaben erörtert werden.

Franz Meisel hielt 1911 fest, daß die Einkommensbesteuerung Preußens sehr zum Schaden des ihr zugrundeliegenden Gedankens in eine bedenkliche abwegige Richtung geraten sei. Die Wegegabel der fehlerhaften Entwicklung der "preußischen Type" der Einkommensbesteuerung, die später zur "deutschen Type" fortgeschrieben wurde, sah er in dem von Fuisting nach rechtsstaatlichen Gesichtspunkten perfektionierten "Beanstandungsverfahren" im Rahmen der amtlichen Veranlagung. Dies war eine Folge des Umstands. daß die Einkommensbesteuerung stets als Eingriffsrecht beurteilt wurde.

\footnotetext{
${ }^{320}$ Koch, K. (1971), S. 80, S. 85; auch: Mittelsteiner, K. H./Schaumburg, H. (1976), Begründung des Regierungsentwurfs zu $§ 164$ AO, S. 219.

321 Die Kritik an den GNOFĀ-Richtlinian sucht deren Rechtswidrigkeit herauszustellen, da sie mit dem. Amtsermittlungsgrundsatz des $\S 88 \mathrm{AO}$ unvereinbar seien. Für einen Oberblick und Fundstellen zu der Kritik vgl. Felix, G. (1980), S. 3678.

322 Die bisher vorgebrachten Reformivorschlăge von der sogenannten "organischen Steuerreform" des Jahres 1949 bis zu dem Symposium "Einsparungen durch einfaches Steuerrecht und effiziente Steuererhebung" vom 28.2.1994 beinhalten stets nur Änderungen an dem bestehenden System. Auch der neueste Entwurf von J. Lang bewegt sich im wesentlichen in den vorgegebenen Bahnen, Schmölders, G. (1953); auch: Spitaler, A. (1953), S. 689; Gesellschaft zur Förderung der Entbürokratisierung (1984) und (1994); Lang, J. (1993); Findling, M. (1992), S. 90; Muscheid, J., S. 16.
} 
Amtsermittlungsgrundsatz, ein perfektioniertes Beanstandungsverfahren, strenge Einhaltung rechtstaatlicher Prinzipien und das preußische, an der Quellentheorie orientierte Einkommensteuergesetz ohne genügende Kontrollrechte der Verwaltung und einen die Richtigkeit abgegebener Erklärungen stützenden Sanktionsmechanismus überforderte nach seiner Ansicht den Steuerbürger bezüglich der von ihm einzubringenden Mitwirkung bei der Ermittlung der richtigen Bemessungsgrundlage. Damit wurde eine überzeugende Lastenverteilung verfehlt.

Das sächsische EStG 1874/78 hatte für Preußen als Blaupause gedient. Es war an der Hermann-Schmollerschen Definition von Leistungsfähigkeit als Maßstab für den Einkommensbegriff ausgerichtet worden. Es hatte eine andere, nämlich an wirtschaftlichen Gesichtspunkten orientierte Ausrichtung erhalten.

Der fruhere Referent für die sächsische Einkommensteuerreform 1874/78 und spätere Senatspräsident am sächsischen Oberverwaltungsgericht Paul Wachler reagierte daher 1912 prompt auf eine von dem frustrierten Leiter preußischer Veranlagungskommissionen wiederholte und durch viele konkrete Beispiele belegte Kritik Meisels an der preußischen Einkommensbesteuenung. Er verwies auf den besseren, weil nach wirtschaftlichen Gesichtspunkten aufgebauten Gesetzesvollzug in seinem Heimatland Sachsen. Die dortigen Beamten, so führte er aus, seien, anders als in Preußen, nicht juristisch, sondern wirtschaftlich ausgebildet und die Ermittlung der Bemessungsgrundlage erfolge in Zweifelsfällen nach Erörterung mit den Pflichtigen und nach ökonomischen Gesichtspunkten.

Ähnliche organisatorische Grundgedanken für eine Reform des amtlichen Ermittlungsverfahrens, wie sie hier zum Ausdruck gelangen, scheint neuerdings Klaus Tipke zu vertreten, wenn er die amerikanische Einrichtung des "office audits" oder "office examination" nebst weitgehenden Kontrollrechten für die Bundesrepublik als beispielhaft anführt. Freilich gehen die Reformforderungen Tipkes nach diesseitiger Auffassung nicht weit genug. ${ }^{323}$

Ein dem Mißbrauch von Eingriffen des Staates zum Schutz des Bürgers vor einem stăndig drohenden Fiskalismus dienendes Rechtsinstitut, das vom Steu-

123 Tipke, K. (1992), GleichmaBigkeit ..., S. 130, geht nicht auf die vollig andere Rolle der US. Finanzbehörde im Veranlagungsverfahren ein, nàmlich, daB die "office audits" im Regelfall Kontrollfunktionen erfullen und in der Regel nicht von Amts wegen die Aufgabe wahrzunehmen haben, Bemessungsgrundlagen zu ermitteln. Diese Verpflichtung kann sich jeweils ergeben. Durch Zufallsaus. wahl ausgefilterte Praffalle dienen im abrigen auch der Ermittlung von Erfahrungswerten, die unserth Richtsatzsammungen entsprechen. In einem "Taxpayer Compliance Measurement Program" werden für den Steuerbürger - ggf. sehr lästig - Daten für die Überwachung des allgemeinen Steuergehorsams erarbeitet; hierzu: Jacob, F. (1994), S. 75. 
erpflichtigen zum eigenen Vorteil gefahrlos durch provoziertes Ausufern des amtlichen Beanstandungsverfahrens mifbraucht werden und obendrein gar nicht garantieren konnte, daß die Behörde im Regelfall die Bemessungsgrundlage tiberhaupt richtig feststellte, da dazu die Mitwirkung eines aufrichtigen Steuerpflichtigen unersetzbar war, hat es in Sachsen bis zur Schaffung des Reichseinkommensteuergesetzes nicht gegeben. Klagen über Behördenwillkür sind dennoch für Sachsen bis 1919 weder in den Entscheidungssammlungen des Oberverwaltungsgerichts in Staatssteuersachen, noch in Fachzeitschriften nachweisbar.

Nach den in Preußen geltenden Maßstäben war die bereits erwähnte 1916 von Waldecker geübte Kritik, daß in Sachsen der Personenrechtsschutz gegenüber Preußen in steuerlicher Hinsicht zurückgeblieben sei, formell vielleicht berechtigt. Sachsen erkaufte sich jedoch mit dieser Regelung der Priorităten nach wirtschaftlichen Gesichtspunkten einen zügigen und zur allgemeinen Zufriedenheit arbeitenden Gesetzesvollzug zur Einkommensteuer. Das sächsische Steuersystem basierte auf dem Grundsatz der richtigen Steuerdeklaration durch den Steuerpflichtigen. Es bedurfte zur Sicherstellung der Bürger vor Übervorteilungen eines ausgefeilten Kontrollapparates und gestrenger Strafvorschriften. Die in den USA auf Grundlage der Selbstveranlagung organisierte Einkommensteuer kann als Fortentwicklung einer Besteuenungstechnik gesehen werden, die von der den Verhandlungen des săchsischen Landtages 1872 zugrundeliegenden Besteuerungsidee eingeleitet wurde.

Die Kritik Meisels an der preußischen Einkommensbesteuerung lăuft auf die von Cicero überlieferte Wendung hinaus, die auch noch für den heutigen $\mathrm{Ge}-$ setzesvollzug in Deutschland vielfach von Bedeutung ist: Summum jus summa injuria. Die Masse der mittleren und kleineren Steuerzahler hat die Zeche letztlich auszugleichen. Hier findet der Steuerwiderstand nămlich die wenigsten Ansatzpunkte.

\section{d) Denktraditionen als Hemmnisse für einen reformierten Gesetzesvollzug}

Die um 1960 zumeist von Experten wirtschaftlicher Fachrichtungen stammenden Empfehlungen, zur Entlastung der Finanzverwaltung die Selbstveranlagung zur Einkommensbesteuerung einzuführen, haben in der Offentlichkeit keine weitere Resonanz gefunden. Sie sind inzwischen sogar völlig in Vergessenheit geraten, obgleich allgemein bekannt ist, daß die Finanzärnter die Arbeitslast nicht mehr zu bewältigen und bei der Veranlagungstätigkeit den gesetzlichen Vorschriften auch bei Anlegung großzügiger Maßstäbe nicht mehr zu entsprechen vermögen. 
Die entstandene Situation begünstigt, wie wir wiederholt erfuhren, kleine Teilmengen der etwa 28 Mio. Steuerpflichtigen in der Bundesrepublik Deutschland. Es sind dies diejenigen, die es verstehen, die Schwachstellen von Gesetz und Gesetzesvollzug geschickt für sich auszunutzen. Die potentiellen Kritiker des Zustandes sind zumeist mit den Nutznießern der Verhältnisse identisch, was einem Vertrauensverhältnis nicht förderlich sein kann.

Waren dies bis vor einigen Jahren zumeist Bürger mit höheren Einkommen, so haben daher inzwischen auch kleinere Einkommensempfänger nachgezogen und helfen sich gegen Übervorteilung durch dieser Art Selbstjustiz.

Die große Masse der Steuerbürger muß jedenfalls nach wie vor an einen ordnungsmäßigen Vollzug der letztlich auch zu ihrem eigenen Schutz geschaffenen Gesetze interessiert sein. Es ist kaum zu bezweifeln, daß diese Einstellung durch den Einsatz von Medien vermittelbar ist. Die Steuerbehörde der USA, der IRS, gibt für diese Erkenntnis ein gutes Beispiel. Für dergleichen Versuche fehlen in Deutschland jedoch vorerst die sachlichen Voraussetzungen. Für die USA gilt jedenfalls, daB erst umfassende öffentliche Aufklänungstătigkeiten die unbestreitbar hohe Funktionsfähigkeit des dortigen "Systems, millionenfacher Selbstveranlagungen" von "fast furchteinflößenden Dimensionen" gewăhrleistet. ${ }^{324}$

Wenn eine Diskussion der Selbstveranlagung aus der Erörterung um die Entlastung der Verwaltung zugunsten von bloßem, ständig vermehrtem Flickwerk an Symptomen mit begrenzter Reichweite heute in Deutschland verschwunden ist, so mag hierfür die mangelnde Aufgeschlossenheit kleinerer, aber sehr einflußreicher Gesellschaftsgruppen mitverantwortlich sein. Diese Gruppen scheuen oft aus Voreingenommenheiten eine ihnen im einzelnen noch unbekannte Umwälzung der vorgesehenen Funktionen - einschließlich ihrer eigenen - als Mitarbeiter bei Behörden, als Benufsträger im steuerbera* tenden Benuf oder als Steuerzahler. Dies gilt naturgemäß auch für eine empfehlenswerte Neuorganisation, die eine rechtsstaatlich durchstrukturierte moderne Industriegesellschaft in Kürze vermutlich gar nicht mehr wird vermeiden können, wenn kultivierte, mit dem "ordre publique" abgestimmte steueriche Verhältnisse aufrechterhalten bleiben sollen.

Eine Umstellung der bisherigen Fremdveranlagung durch den Fiskus auf eine Selbstveranlagung kann man dabei durchaus als Endstufe einer Entwicklung der Einkommensbesteuenung sehen, die von dem sächsischen EStG 1874/78 eingeleitet wurde. Hier hatte man seit 1872 im Landtag nach einer Neuordnung der Besteuerung gesucht, die eine gerechtere Verteilung der La-

324 Walz, W. R. (1982). S. 381. 
sten des Gemeinwesens auf die Steuerbürger versprach. Der "Selbsteinschätzung" der Zensiten wurde in den Verhandlungen des Landtages ein hoher Stellenwert beigemessen. Man erwartete, daß es die Steuerpflichtigen in $\mathrm{Zu}$ kunft lernen würden, sich jährlich verantwortlich Rechenschaft über ihr erzieltes Jahreseinkommen als Bemessungsgrundlage ihrer Beitragsverpflichtungen abzulegen. Das Einkommensteuergesetz, das in der Öffentlichkeit nach wirtschaftlichen Kriterien beurteilt wurde, übertrug dem Bürger mit der sogenannten "Selbsteinschätzung" die entscheidende Rolle bei der Lastenverteilung. Das war mit einem Vertrauensvorschuß verbunden. Der Staat sollte ihn daher zugleich vor Übervorteilungen durch den steuerunehrlichen Defraudanten vermittels eines gestrengen Kontroll- und Sanktionsmechanismus' schützen. Diese Gesichtspunkte ergaben im ganzen gesehen eine schlüssige Regelungsstruktur des Gesetzes. Im übrigen fügten sich Gesetz und Vollzug in die bestehende Rechtsordnung ein, indem Öffentlichkeit, Finanzverwaltung bzw. Gerichte zwischen den gesetzlichen Prioritäten der Steuervorschriften und der übrigen Rechtsordnung unter Berücksichtigung der Auswirkungen eine die Allgemeinheit befriedigende Balance schufen.

Das preußische EStG 1891 war in dieser Hinsicht keine Fortentwicklung eines såchsischen Entwurfes. Aus dem wirtschaftslenkenden Kameralstaat des 18. Jahrhunderts war hier nach den Befreiungskriegen ein sich direkter wirtschaftspolitischer Eingriffe enthaltender liberaler Rechtsstaat des 19. Jahrhunderts geworden. Dieser Entwicklung folgte "die Veränderung der alten kameralistischen Ausbildung durch eine rein juristische Vorbildung" der Beamtenschaft ${ }^{325}$ Der für die Einkommensbesteuerung zuständige preußische Landrat war ursprünglich ein "Organ der Landstände gewesen, die das Steuerbewilligungsrecht besaßen" ${ }^{326}$ Er unterstand bis 1919 noch der inneren Verwaltung. "Bei dieser für Preußen typischen Verwaltungsstruktur wurde kein sonderliches Bedürfnis nach einer abgetrennten Finanzbeamtenlaufbahn laut" ${ }^{327}$ Die Ausbildung endete mit der Befähigung zum Richteramt, wobei eine viermonatige Referendarzeit in der Finanzabteilung des Regierungspräsidenten, der für die direkten Staatssteuern als Vertreter des Innenministeriums zuständig war, die notwendige Fachqualifikation verlieh. Nach der Reichsgründung 1871 wurde Preußen dann "Schrittmacher des Juristenprivilegs" für Beamte der Finanzverwaltung. ${ }^{328}$

\footnotetext{
323 Pausch, A. (1976), 250. Jahre ..., S. 116.

${ }^{326}$ Pausch, A. (1976), 250 Jahre .... S. 63, S. 192, Anm 96 mit Fundstellen; von der Groeben, K. (1975), S. 517.

${ }^{2}$ Pausch, A. (1976), 250 Jahre ..., S. 115.
${ }^{39}$ Pausch, A. (1976), 250 Jahre .... S. 113.
} 
Der einflußreiche Staatsrechtslehrer Rudolf Gneist sah in dieser juristischen Ausbildung eine Garantie für die spätere strenge Beachtung von Gesetz und Recht vor persönlicher Behördenwillkür, eine Garantie für rechtliche Verfahren, "wie sie im Privatrecht zum Schutz der Person und des Eigentums errungen worden waren". ${ }^{329}$ Gerade dem Studium des Privatrechts kam daher Priorităt zu.

Die Zuordnung der Besteuerung zur inneren Verwaltung hatte naturgemäß weitreichende Konsequenzen für viele Änderungen des preußischen EStG 1891 gegenüber der sächsischen Mustervorlage, so etwa auch bei den strafrechtlichen Bestimmungen, da es sich um Verwaltungsstrafrecht handelte. ${ }^{330}$

Nach dem Zusammenbruch des Kaiserreichs mit der Übertragung der Steuerverwaltungshoheit auf das Reich in der Erzbergerschen Finanzrefom blieben naturgemaß wesentliche Strukturelemente erhalten.

Das Einkommensteuergesetz war in Preußen nicht erst seit Fuisting und Wagner als Eingriffsrecht beurteilt worden. Der für Wagner wichtige Umverteilungsgesichtspunkt sah ohnehin eine Besteuerung unabhängig von einer erforderlichen Lastenverteilung nach den jeweils geltenden epochalen Entwicklungsgesetzen vor. ${ }^{331}$ Der scharfsinnige Bernhard Fuisting hat mit seinen Gesetzesinitiativen und Beitrăgen zur Gesetzesauslegung einen ständigen Kampf gegen Gefahren geführt, die er in einem angeblich fortwährend drohenden "Fiskalismus" befurchtete. Meisel, Michaelis und andere zeigten, daß Fuisting einen Kampf gegen Windmühlen führte. ${ }^{332}$ Gelehrige Steuerbürger wußten die dadurch entstandenen Schwachstellen im Gesetz fachkundig geschickt im eigenen Interesse zu nutzen.

Das Steuerrecht suchte, seiner zunehmenden Bedeutung entsprechend, seit Fuisting allgemeine Anerkennung als neue rechtsdogmatische Disziplin, wobei dem Versuch einer Rechtfertigung der Normen aus zugnundeliegenden, unmittelbar einsichtigen "sachgerechten" letzten Prinzipien bei einigen Vertretern heute eine besondere Rolle zukommt. Die Bestimmungen des Steuerrechts sollen danach mehr sein, als eine zweckmäßige Sozialtechnologie zur Lastenverteilung, was das såchsische EStG 1874/78 nur hatte sein wollen. Nur so ist der Nachdruck zu verstehen, der bis heute der Herausarbeitung von "Fundamentalprinzipien" und der nachhaltigen Abstimmung steuerrechtlicher

\footnotetext{
329 Pausch, A (1976), 250 Jahre ..., S. 115.

${ }^{330}$ Schneider, V. (1987), S. 44, S. 54. Bestraft wurde nicht die Schådigung des Fiscus oder der Allgemeinheit, sondern die Nichtbeachtung van Vorschritten.

$33 !$ Wagner, A. (1890), S. 372.

${ }^{332}$ Meisel, F. (1911), S. 353; ders. (1914), S. 154; Michaelis (1912), S. 83; Meyer, R. (1903), s. 26.
} 
Bestimmungen mit dem übrigen Normengefüge zu einem einheitlichen Systerngebåude von Juristen zugeordnet wird. Die konkreten sozialen Auswirkungen der Normen, insbesondere die zu bericksichtigenden Vollzugsvorschriften und die Konsequenzen des Gesetzes in sozialtechnologischer Hinsicht - zugegebenermaßen für Juristen lăstige Problemstellungen, auf die Franz Meisel schonungslos aufmerksam machte, - treten in ihrer Bedeutung zurück und werden heute überhaupt erst wahrgenommen, seitdem die öffentliche Kritik sich vernehmbar artikuliert.

Einrichtungen, Verwaltungspraxis, Ausbildung und Laufbahnstruktur der Finanzverwaltung wurden, unabhängig von gelegentlicher Kritik, von der allgemeinen Entwicklung bestimmt.

Ein Öbergang zur Selbstveranlagung würde eine völlige Neuorganisation der Finanzverwaltung mit sich bringen. Eine Ändenung von Ausbildung und Personalstruktur wären erforderlich, da neben der juristischen andere Qualifikationen erforderlich werden und an Bedeutung gewinnen.

So zeigte sich die Delegation der Deutschen Steuer-Gewerkschaft anläßlich des Besuches ihrer Präsidialmitglieder bei dem IRS im Jahr 1987 unmittelbar nach der letzten US-Steuerreform von dem Aufbau und der deutschen Verhăltnissen weit überlegenen Effizienz nach dem veröffentlichten Bericht zwar tief beeindruckt. Der Umstand aber, daß es bei dem IRS fast keine Laufbahnbeamte und viele nur verhältnismäßig gering dotiente Besoldungsstufen gibt und das System mit geringer Personalausstattung und verhalltnismäbig wenigen hochqualifizierten Mitarbeitern gefahren werden kann, dămpfte erkennbar die im übrigen positive Beurteilung. ${ }^{333}$

Tatsächlich wird der Übergang zur Selbstveranlagung in der Deutschen Steuer-Gewerkschaft gar nicht mehr diskutiert, obgleich ihr ehemaliger Vor* șitzender in einem ausfuhrlichen Gutachten des Berufsverbandes, das 1959 an den Präsidenten des Deutschen Bundestages mit der Bitte um Weiterleitung an den Finanzausschuß versendet wurde, ${ }^{334}$ vor der kommenden Entwicklung wamend, dringend zu diesem Schritt unter Auflistung konkreter Richtlinien geraten hatte. Heute sieht diese Berufsorganisation die Lösung der anstehenden Probleme zwar zu Recht in einer Ausweitung und Verbesserung der steuerlichen Betriebsprüfung. die historisch gewordene Struktur der Veranlagung

\footnotetext{
330 Courth, P., S. 138.

${ }^{134}$ Bund Deutscher Steuerbeamten (1959): Die Eingabe an den Deutschen Bundestag fuhrte von 21 Abgeordneten zus sechs konkreten Fragen an die Bundesregierung. Diese Abgeordneten waren zumeist Mitglieder des Finanzausschusses, vgl.: Deutscher Bundestag, 4. Wahlperiode, Drucksache IB/393. Die Antwort durch Staatssekretăr Hettlage fur die Regierung vom 23.6.1962 war äußenst negativ, vgl. Drucksache IV/432.
} 
soll jedoch offenbar dabei erhalten bleiben. Ein Übergang würde letztlich neuartige Laufbahnen mit hohen disziplinübergreifenden Qualifikationen erfordern. Diese Problemlösung wird heute nicht einmal mehr erörtert. Das ist bedauerlich.

Ein Übergang würde auch an die in Finanzverwaltung und Gerichtswesen tätigen Juristen abgewandelte Anforderungen stellen. Die Umstellung mag in den USA einfacher vor sich gegangen sein, da dort die Ausbildung der Juristen ohnehin - historisch so entstanden - eher auf das Berufsziel des freiberuflichen Anwalts und insbesondere des wirtschaftlich tätigen Steueranwalts ausgerichtet war. ${ }^{335}$ In Deutschland hat jedoch bis heute die Richterlaufbahn infolge der anderen Entwicklung das nur von wenigen erreichbare Ziel der Ausbildung gebildet. ${ }^{336}$

Die Rechtssicherheit ist eine der wichtigsten Vorbedingungen unseres hochentwickelten, aber sehr empfindlichen modernen Industriegefüges. Zur Rechtsanwendung reichen daher heute notwendig abstrakte Gesetzesdefinitionen und die theoretisch erlernte einfache Subsumtion der Tatbestandsmerkmale des Sachverhalts unter die Gesetzesnormen ohne Berücksichtigung von Zusatzkriterien nicht mehr aus. Aus der Entscheidungsnot entwickelt sich daher ein wachsender Bedarf an Zusatzkriterien und auf diese Weise unvermeidbares "Fallrecht" neben dem abstrakten Normengefüge, das unter anderem aus "gesellschaftlich vorherrschenden Normalitätsvorstellungen" und "richterrechtlichen Quellen" gespeist wird. ${ }^{33}$ ?

Da jeder Fall zur Vermeidung von Willkür nach einer allgemeinen Regel entschieden werden muß, die für alle gleichen Vorgänge zu gleichen Rechtsfolgen führt, ist ein ständiges Anknüpfen an "erheblich gewordene Fallentscheidungen" unumgănglich. ${ }^{338}$ Der allmählich vor sich gehende Wandel gesellschaftlicher Werte bringt obendrein noch einen schleichenden Rechtsprechungswandel mit sich. Ohne Berücksichtigung sozialtechnologischer Gesichtspunkte wird eine allgemeine Befriedung schwieriger.

Dies alles muß bei einem Systemwandel Erwägung finden. Es werden sich hohe Anforderungen an die für eine notwendige einheitliche Anwendung der Steuergesetze zuständige Finanzbehörde ergeben. Denn "ein System millionenfacher Selbstveranlagung (kann) nur dann einigermaßen zuverlässig funk-

33 Risschemeyer, D., S. 103.

336 Raschemeyer, D., S. 102, S. 139. S. 225 Anm. 2, S. 175, diese Ausrichtung der Ausbildung ist ein Ergebnis der Vorherrschaft Preußens ab dem 19. Jahrhundert.

337 Walz, W. R. (1986), S. 30.

338 Walz, W. R. (1986), S. 36, S. 41. 
tionieren, wenn die Steuerpflichtigen, ohne das Ergebnis langwieriger Finanzgerichtsprozesse abwarten zu müssen, im voraus über den Standpunkt der Verwaltung möglichst verbindlich, umfassend und detailliert informiert sind". ${ }^{339}$ Die US-Besteuerungswirklichkeit zeigt jedenfalls, daß das Problem zufriedenstellend lösbar ist. Es scheint jedoch ein anderes Problemlósungsverhalten erforderlich, das die derzeitigen Vorschläge in Deutschland vermissen lassen.

Ein Übergang wird hier völlig neue Regelungen vorsehen müssen, deren Einfulhrung erhebliche Verantwortung mit sich bringt. Welchen Wert der Richtlinienkompetenz der Verwaltung hier beizumessen ist und welchen Stellenwert nachgeordnetes, verwaltungsgeschaffenes Recht einnehmen soll, wird positiv geregelt werden müssen. Eine derartige Balance zwischen der über den Vollzugsapparat verfügenden und sachkompetenten mächtigen Exekutive und der mit rechtlichem Übergewicht ausgestatteten Legislative wird sich dabei jeweils neu einpendeln müssen.

Es ist nach diesen Ausführungen verständlich, daß die Finanzverwaltung in der Frage eines Überganges, der letztlich politisch vertreten werden muß, große Zurückhaltung übt. Im Jahr 1969 wurde die Frage der Selbstveranlagung von dem Leiter der Steuerabteilung im Bundesfinanzministerium letztmalig als Lősungsmöglichkeit noch kurz erwähnt. ${ }^{340}$

Wenn auch etwa der Bund der Steuerzahler, der nach seiner Zielbestimmung die gemeinsamen Interessen aller Steuerzahler vertritt, zu Reformempfehlungen in dieser Richtung schweigt, so mag dies darin seinen Grund finden, daß hier zumeist die unmittelbaren Interessen eines gut situierten selbstăndigen Mittelstandes verfolgt werden.

Bereits 1962 kamen aus dieser Richtung Warnungen, der Steuerbürger dürfe nicht zum "Büttel des Staates" werden. Das ist unvermeidlich, belastet aber alle Bürger gleichermaßen. Die Bewertung ist gewiß willkürlich.

Für den Verband der steuerberatenden Berufe gilt vergleichbares.

Im übrigen hat es sich der Staatssekretär 1962 im Deutschen Bundestag wohl zu leicht gemacht, wenn er den Eindruck zu erwecken suchte, daß ein Ôbergang zur Selbstveranlagung keine Änderungen des Berufsrechts der Steuerberater empfehlenswert mache. ${ }^{341}$

\footnotetext{
13 Walz, W. R. (1982), Steuerverwaltungsanordnungen ..., S. 381

500 Koch, K. (1971), S. 84. Koch erwăhnt zwar nur "neue Vorschriften aber die Selbstberechnung der Steuer". Dieser würde jedoch bei Anmeldung der Steuerschuld der Charakter einer Steuerfestsetzung unter dem Vorbehalt der Nachprufung zukommen.

${ }^{3}$ Deutscher Bundestag, 4. Wahlperiode, Drucksache IV/432, S. 2, Antwort zu Frage Nr. 5
} 
Das amerikanische Berufsrecht kennt hier strengere strafrechtliche Vorschriften, die die Einhaltung der Bestimmungen für die gesetzmäßige Anwendung steuerlicher Anordnungen bei der Selbstveranlagung absichern und dem deutschen Berufsrecht fremd sind. ${ }^{342}$ Das auch für Berufsträger steuerberatender Berufe gleichmaßßig geltende allgemeine Steuerstrafrecht vermag heute entgegen gelegentlich erzeugter gegenteiliger Eindrücke keinen nachhaltigen Einfluß zur Verbesserung der Steuermoral mehr zu bewirken. ${ }^{343}$

Auch in diesem Punkt .kann sich die soziale Bedeutung eines unvoreingenommenen Problemlösungsverhaltens zeigen. Die unterstützende Mitwirkung der sleuerberatenden Berufe ist für eine Verringerung des Steuerwiderstandes und dic Verbesserung der Stcuermoral zur Erziclung einer fairen Besteuerung der Bürger als Ergebnis einer zweckentsprechenden Gesetzgebung von erheblichem Einfluß.

42. Walz, W. R. (1981), S. 4334, S. 4339, S. 4336, für viele Nachlässigkeiten werden "civil penalties" angedroht. Es mulssen jałtrlich von den Berufsträgern persöraliche und berufliche Angaben an die Finanzverwaltung gemachl werden. Die steuerberatenden Benufe haben als Mittler zwischen Steuer. pllichtigen und Staat höhere Pflichten gegenûber der Allgemeinheit, als Rechtsanwalte. Auch der berufsethische Kodex des American Institute of Certified Public Accountants ist strenger, als die beruflichen Kammervorschriften in der BRD. Die vergleichbaren strafrechtlichen Vorschriften des IRC werden offenbar auch strenger gehandhabt, als dies in der BRD geschicht.

sus Streck, M. (1984), S. 2205, S. 2208; Dickopf, J. (1990), S. 175 u. a. In der Regel hat der steuerliche Berater, anders als in den USA, nach den Bestimmungen, deren Auslegung und der eingefahronen Handhabung in der BIRD gegenuber der Finanzbehörde keine Garantenpflichı zur Abwendung eines Verkürzungserfolges. Er steht in keiner Treuepflicht gegenüber der Finanzverwaltung. 


\section{Die mit dem wachsenden Einsatz der Einkommensteuer zu nichtfiskalischen Zwecken verbundenen gesellschaftspolitischen Interessen und die zu erwartenden Verteilungskämpfe}

Der Einsatz der Einkommensbesteuerung zu verschiedenartigen nichtfiskalischen Zwecken wurde stets kontrovers diskutiert. Bei Beurteilung der gefuhrten Auseinandersetzungen ist zu berücksichtigen, daß die Besteuerung zu allen Zeiten und auch über längere Perioden hinweg sogar mit zeitweise relativ hohen Beträgen der Förderung jeweiliger politischer Prioritäten, also nichtfiskalischen Zwecken gedient hat. ${ }^{1}$ Es handelt sich somit nicht um ein ungewöhnliches Phänomen.

Neuartig ist nur das außergewöhnlich hohe Ausmaß der steuerlichen Förderung, der Einbau der Fördermaßnahmen an den verschiedensten Stellen des Steuerrechts, insbesondere in den Ermittlungsvorschriften, sowie die systematische Einordnung des Einkommensteuerrechts in das wirtschaftspolitische Instrumentarium zur globalen und - mehr noch - zur sektoralen Steuerung des Wirtschaftsablaufs. Die Fördermaßnahmen verstecken sich dabei "unter der Tarnfarbe von Normen des Steuerrechts" und die gesamte Abwicklung von Subventionsentscheidungen, für die im Grunde Fachbehörden zuständig sein müßten, wird zusätzlich der Finanzverwaltung übertragen.

In den bisherigen Ausführungen wurde versucht, die Entstehung und Systematik der steuerlichen Fördermaßnahmen im Zusammenhang mit dem Normengefüge des Einkommensteuerrechts und dessen Vollzuges darzustellen, die Interessenlage des einzelnen Steuerbürgers offenzulegen und die problematischen Auswirkungen auf den wachsenden Steuerwiderstand und die Belastung der Verwaltung zu skizzieren und deren objektive Grenzen aufzuzeigen.

Zum besseren Verstândnis der jeweils behandelten Fachbereiche schien es erforderlich, die Darstellung von unterschiedlichen Aufgabenstellungen und damit Wertungen ausgehen zu lassen. So konnten die steuerlichen Regelungen einmal unter dem Gesichtspunkt einer allgemein als gerecht empfundenen

'Meyer, D. (1977); Timm, H. (1968); Schmidt, D. (1926), S. 14. 
Lastenverteilung dargestellt und beurteilt werden; ebenso konnten dann im Kontrast dazu die gesamtwirtschaftlichen Erfordernisse den Blick in eine andere Richtung lenken, nämlich diejenige volkswirtschaftlicher Notwendigkeiten. Abschließend konnten dann die einem instrumentalen Einsatz des Einkommensteuerrechts gezogenen Grenzen erörtert werden.

Die von Gustav Schmoller 1863 vorgetragene Besteuerungsidee fügte sich in seine liberalen sozialpolitischen Vorstellungen ein. Sie war ein früher Teil seiner Sozialpolitik, die auf einen Abbau der Klassenspaltung abzielte. Der aus Schmollers Besteuerungsidee entwickelte gesetzliche Steuergegenstand für die Einkommensteuer wurde an dem 1863 empfohlenen Maßstab für die Leistungsfahigkeit eines Steuerbürgers ausgerichtet. Steuervergünstigungen konnten als Fremdkörper in der Systematik des sächsischen EStG 1874/78 nicht integriert werden.

Adolph Wagner verfolgte ein vergleichbares Ziel. Jedoch kam dem Staat in seinem Konzept eine andere Bedeutung $\mathrm{zu}^{2}$ Der von ihm mitentwickelte gesetzliche Steuergegenstand des preußischen EStG 1891 legte im einzelnen fest, welche Wertezuflüsse als steuerbare Einkommenspartiale zum Einkommen zu rechnen waren und somit die steuerliche Leistungsfähigkeit des Steuerpflichtigen bestimmten. Das Einkommensteuerrecht wurde von ihm von vornherein als Eingriffsrecht verstanden und lie $B$ entsprechende zeitgemäße Änderungen der einzelnen Vorschriften, aber auch deren Auslegung und derjenigen der Vollzugsbestimmungen zu. Letztlich wurden die Begriffsinhalte nach Wagner ohnehin von den epochalen Entwicklungsgesetzen jeweils unterschiedlich bestimmt. ${ }^{3}$ Sie konnten daher einer zeitgemäßen Umverteilung des Einkommens genügen. Die Systematik ließ fast beliebige Steuervergünstigungen in der "preußischen Type" der Einkommensteuer zu.

Eine Erörterung der gesellschaftspolitischen Interessen, die sich mit dem heute geltenden Einkommensteuerrecht verbinden, würde sehr unterschiedlich wertende Standpunkte berücksichtigen müssen.

Rechtswissenschafter sehen das Steuerrecht unter Gesichtspunkten ihrer Ausbildung. Sie vermissen daher die Konturen einer strengen Rechtsdogmatik. ${ }^{4}$ Durch eine Beseitigung der Lenkungsnormen glauben viele Juristen heute den entscheidenden Teil der Măngel des Einkommensteuerrechts heilen zu

\footnotetext{
${ }^{2}$ Heilmann, M. (1980), S. 26 ff, Thier, E. (1930) S. 29 ff, S. 50 ff, Wagner. A. (1887); Finanzwis" senschaft .... S. 37 ff u. S. 675 ff.

${ }^{3}$ Wagner, A. (1880), Finanzwissenschaft ... S. 292; ders. (1890) Finanzwissenschaft ... S. 367, S. 386 u. a.

4 Tipke, K. (1993), Die Steuerrechtsordnung, S. 101; Vogel, K. (1993) S. 1121, u. a.
} 
kōnnen. ${ }^{5}$ Andere Gruppierungen glauben jedoch, daß ein Verzicht auf nichtfiskalische Normen im Einkommensteuerrecht nicht erfolgen darf. ${ }^{6}$ Auch eine Vereinfachung des Steuerrechts, so glauben sie, müsse auf andere Weise erreicht werden. ${ }^{7}$ Die langfristig zu erwartenden sozial- und gesellschaftspolitischen Folgen des geltenden Einkommensteuerrechts haben bis heute noch keine zureichende Aufmerksamkeit gefunden.

Der Autor möchte nachfolgend zur Skizzienung der weiteren gesellschaftspolitischen Entwicklung einige ihm wichtig erscheinende Standpunkte in kurzen Darstellungen ohne eigene Kommentienung auflisten. Vollstăndigkeit wird dabei nicht angestrebt.

Der Autor trägt, indem er in fünf Rollen schlüpft. Beurteilungen des geltenden Einkommensteuerrechts, von berufsspezifischen Gesichtspunkten des Steuerrechtswissenschaftlers, des Sozialpolitikers, des Nationalökonomen, des Vertreters der Finanzverwaltung und des Soziologen ausgehend, vor. Dabei erfordert das Verstăndnis für die beiden letzten Rollen ein stärkeres Eindringen in den historischen Ablauf. Es müssen einige Wiederholungen in Kauf genommen werden.

\section{Thesen des Steuerrechtswissenschaftlers}

Der Steuerrechtswissenschaftler bemängelt und fordert folgendes:

1. Das Einkommensteuerrecht der Gegenwart zerfallt in zwei Hauptnormgruppen: $^{8}$

a) Fiskalzwecknormen zur Abdeckung des Haushaltsbedarfs.

b) Sozialzwecknormen im weitesten Sinne, mit denen sozialpolitisch, wirtschaftspolitisch oder sonst politisch gelenkt oder interveniert wird.

2. Wăhrend Fiskalzwecknormen ex definitione zur Erzielung von Einnahmen an dem Leistungsfähigkeitsprinzip als "Gerechtigkeitsregel" sind, haben Lenkungsnormen, die sich unter der "Tarnfarbe von Normen des

\footnotetext{
Tipke, K. (1993), Die Steuerrechtsordnung, S. 364 u.a.; Beschlusse des 57 . Deutschen JuristenLages, Mainz, 1988, in: NJW 1988, S. 3005.

Strauß, F. J. (1969), S. 103, S. 113 u. a.; Birk, D. (1983): Das Leistungsflahigkeitsprinzip ..., S. 332 u.a.; Neumark, F. (1961), Wirtschafts- und Finanzprobleme, S. 279

Strank, F. J. (1969), S. 178; Uelner, A. (1977) S. 123; ders.(1985) S. 191; ders. (1988) S. N

26; Uelner empfiehlt die Beibehaltung des Systems und vorsichtigen Abbau der Subventionsnormen.

"Tipke, K. (1993), Die Steuerrechtsordnung, S. 119; Vogel, K. (1993) \$. 1123.

Tipke, K. (1993), Die Steuerrechtsordnung S. 122 u. S. 478.

29 Hansea
} 
Steuerrechts verstecken" ${ }^{10}$, den "Effekt einer Subvention oder Prämie, eingekleidet in das Korsett steuerlicher Normen". "Im Grunde verkörpern sie nicht Steuerrecht, sondern vor allem Wirtschafts- und Sozialrecht"."

3. Das geltende Steuerrecht kann wegen der Einbindung zahlloser Lenkungsnormen als "Steuerchaos, Steuerdschungel, Steuerdickicht, Steuerirrgarten, Steuerlabyrinth" oder kurz "Steuerkonglomerat" ${ }^{n 12}$ bezeichnet werden. Dieser sogenannte "Steuerinterventionismus" muß durch die Forderung nach "sachgerechten Regeln" für die Aufnahme von versteckten Subventionen als Norm durch deren Prüfung auf Eignung nach Zweckmäßigkeit, Erfordernis und Verhältnismäßigkeit eingedämmt werden. ${ }^{13}$

4. Für das Steuerrecht muß ebenso, wie für die gesamte Rechtsordnung gelten: "Richtiges" oder "gerechtes" Recht besteht aus "konsequenten, sachgerechten Regeln". ${ }^{14}$ Diese setzen Regelhaftigkeit voraus, die aber heute weitgehend vermißt wird. Für das Steuerrecht und speziell für das Einkommensteuerrecht muß das "Leistungsfăhigkeitsprinzip" als "sachgerechtes Fundamentalprinzip" bestimmend werden. ${ }^{15}$ Alle Vorschriften des Einkommensteuerrechts müssen diesem Prinzip entsprechen.

5. Das Einkommensteuerrecht muß durchgängig neu an dem von Schanz fortentwickelten sogenannten "Reinvermögenszugangsprinzip" ausgerichtet werden. ${ }^{16}$

6. Steuervergünstigungen sind grundsätzlich ungerechtfertigt, weil sie Gerechtigkeit und Gleichmäßigkeit der Besteuerung verletzen. "Zur Verwirklichung von Lastengleichheit und Vereinfachung sind Steuervergünstigungen und steuerliche Sonderregelungen zu streichen", so das knappe Beratungsergebnis des 57. Deutschen Juristentages von 1988. ${ }^{17}$

7. Eine einheitliche und konsequente Orientierung der Normen des Einkommensteuerrechts an dem "Fundamentalprinzip der Leistungsfähigkeit beseitigt vorhandene Verstöße gegen die Gleichmäßigkeit der Besteuerung"

\footnotetext{
${ }^{10}$ Zirelsheger. H. (1985), S. 202.

"Tipke, K. (1993), Die Steuerrechtsordnung S. 364, S. 122

12 Tipke, K. (1971), S. 2.

13 Tipke, K. (1988), Über "richtiges Steuerrecht ..." S. 274; ders. (1989) Über Steuervergünstigungen.... S. 186, insbes. S. 190 u.a.

14 Tipke, K. (1988), Über "richtiges Steuerrecht ..." S. 264: ders. (1993) Die Steuerrechtsordnung.
} S. 284, S. 288 , S. 296 u. a.

15 Tipke. K. (1993), Die Steuerrechtsordnung. S. 112.

16 Schanz, G. (1896), S. 28: Tipke, K. (1993), Die Steuerrechtsordnung, S. 565.

17 57. Deutscher Juristentag, Mainz, 1988, s. NJW 1988, S. 3006. 
und wăre daher dem "Nutzen aller Beteiligten" forderlich. Nur auf diese Weise kōnnen die dem heute gültigen Einkommensteuerrecht innewohnenden gravierenden Fehlentwicklungen geheilt werden. ${ }^{18}$

8. Das Einkommensteuerrecht muß vereinfacht werden. Es kann nicht mehr schulmäßig als Lehrstoff für Studierende vermittelt werden. ${ }^{19}$ Ursăchlich hierfur ist die Aufnahme der zahllosen Lenkungsnormen an verschiedenen Stellen der Vorschriftensystematik. Eine Beseitigung aller Lenkungsvorschriften wird auch der Fordenung nach Vereinfachung genügen.

\section{Thesen des Sozialpolitikers}

Der Sozialpolitiker trăgt zu dem Problemkreis vor:

1. Die Einlassung von Steuerrechtlern ist oftmals ein Plädoyer für die Schaffung einer einheitlichen "Dogmatik des Einkommensteuerrechts", die, in eine "steuerliche Gesamtdogmatik" eingebunden, eine umfassende Systematisierung des geltenden Steuerrechts ermöglichen soll. ${ }^{20}$ Auf diese Weise soll das gesamte hierarchisch angelegte Rechtsnormengefuge zu einer übersichtlichen Einheit verbunden werden. So sollen Widerspruchsfreiheit, geistige Ordnung, Kohärenz, begriffliche Klarheit und - nicht zuletzt - einfache Übersichtlichkeit als bestimmende Orientierungspunkte gewährleistet sein. Steuerrechtler leiten aus diesen rein formalen Ordnungsprinzipien und einer Reihe weiterer formaler Postulate her, daß Lenkungsnormen für Steuervergünstigungen beseitigt werden müssen, da sie einem "richtigen" oder "gerechten" Steuerrecht im Wege stehen. ${ }^{21}$

2. Offenbar beriicksichtigen die Vertreter dieser Auffassung - oftmạls futhrende Steuerrechtslehrer - aber nicht genügend die Fragwürdigkeit ihres, Răsonnements. Diese besteht darin. daß Termini, wie "Leistungsfahigkeit", "sachgerechte Regelhaftigkeit̂", "Gleichmäßigkeit", "Gerechtigkeit" und viele andere, die als "undefinierte Rechtsbegriffe" zu bezeichnen sind, als Prinzipien oder gar "Fundamentalprinzip der Besteuerung" zu Auswahlgesichtspunkten für eine allgemein erwünschte, gelegentlich sogar als "richtig" oder "wissenschaftlich" bezeichnete Ausgestaltung der Steuernormen verwendet werden. Zwar erwähnt ein führender Vertreter dieser Richtung gelegentiich

\footnotetext{
"Tipke, K. (1988), Ober "richtiges Steuerrecht", neuerlich vorsichtige Einschrânkungen, s. ders. (1989), S. 181

I9 Tipke, K. (1988), Die Situation ... S. 865.

* Tipke, K. (1993), Die Steuerrechtsordnung. S. 14.

2t Tipke, K. (1988), Ober "richtiges ...". S. 262; ders. (1988) Die Situation ..., S. 878, S. 883 u. a.
} 
diesen Umstand, beruhigt sich aber damit, daß er keine besseren Prinzipien kenne, die ein gleiches Makel nicht aufweisen. ${ }^{22}$

Da er aber die Notwendigkeit einer inhaltlich konkreten Definition der verwendeten Prinzipien oder Postulate nicht sieht und eine Bestimmung des Inhalts auch gar nicht versucht, bleiben die verwendeten Termini Begriffe seiner Erlebnissprache. Sie eignen sich nicht zum interpersonellen Informationsaustausch. ${ }^{23}$ Wer sie undefiniert benutzt, muß sich vorhalten lassen, nicht über konkrete Sachverhalte zu reden, da die Gesprăchspartner affektgeladene Synonynna so verwenden, als sprächen sie über denselben Gegenstand. Tatsächlich werden aber Gefühle ausgetauscht. Undefinierte Rechtsbegriffe können nicht informationshaltige Instrumente der Objektsprache sein. Daher war es auch möglich, daß sich bereits die klassischen Vertreter der Quellentheorie der Einkünfte, Adolph Wagner und Bernhard Fuisting, als engagierte Anhänger zu einem Einkommensteuerrecht bekannten, das streng an der Leistungsfähigkeit der Steuerbürger orientiert sein sollte, was sie im preußischen EStG 1891 verwirklicht glaubten. Fuisting beklagte sogar die aus dem sächsischen Muster übernommenen Abweichungen vom Quellenprinzip als Durchbrechung dieser sachgerechten Regelhaftigkeit der Besteuerung nach der Leistungsfähigkeit. ${ }^{24}$

3. Auch die Argumentationsweise vieler Juristen ist eigentümlich: In der steuerrechtspolitischen Rechtfertigung einer "richtigen" oder "gerechten" Steuerrechtsordnung wird den zugrundeliegenden Prinzipien oder Postulaten nämlich eine eigenartige Rolle zugewiesen. Da es sich jeweils um unbestimmte, weil undefinierte Begriffe handelt, die sehr unterschiedliche Inhalte haben können, sind sie als Grundlage für die angeführte Ausmerzung unvereinbarlicher Steuerrechtsnormen ungeeignet. Dabei ist die steuertheoretische Diskussion für den Laien verwirrend, da sie sich in zwei Bereichen abspielt. Einmal streitet man um die Bedeutung der Prinzipien und ebenso um deren inhaltliche Auslegung. Dabei herrscht zumeist Einigkeit darüber, daß vieldeutige, weil undefinierte, inhaltsleere Formeln (Leerformeln), wie "Leistungsfähigkeit". "Gleichmăßigkeit", "Gerechtigkeit" und andere mehr den gültigen Besteuerungsnormen zugrunde liegen sollen. Diese Termini werden daher als Postulate dem Räsonnement vorangestellt. Ein konkreter empirisch aufgewiesener Gehalt wird den Postulaten aber nicht gegeben. Eine eindeutige Bedeutung kann daher, so sollte man meinen, a priori aus ihnen auch nicht erschlossen werden. Dennoch wird jeweils mit diesen Postulaten oder Prinzipien so ver-

${ }^{22}$ Tipke, K. (1988), Dber "richtiges ...", S. 272.

2s Kelsen, H. (1953), S. 23; Topitsch, E. (1960), S. 262; Frank, P. (1952), S. 65; Arndt. H.W. (1981), S. 20 u. S. 36.

24 Fristing, B. (1896), S. 480. 
fahren, als ob sie einen konkreten Gehalt hătten und man verweist dann auf die rechtspolitischen Konsequenzen für eine Reform - in unserem Fall - des Einkommensteuerrechts. Hier sollen alle Lenkungsnormen entfernt werden, da sie mit den undefinierten Prinzipien nicht vereinbar seien.

Im Grunde wird in die Prinzipien alles hineininterpretiert, was man gern aus ihnen erschließen möchte. Es handelt sich bei dieser Vorgehensweise um eine "petitio principii" im Sinne der klassischen Logik des Philosophen aus Stagyros. Die von Gunnar Myrdal 1932 für die Kritik an der Finanzlehre erarbeitete Feststellung gilt für Vertreter der vorgetragenen Auffassungen heute noch: "Die höchsten Principien haben ein besonderes Interesse deswegen, weil sie es sind, die den nachgeordneten Deutungen den Schein wissenschaftlicher Objektivităt geben". ${ }^{25}$ Je allgemeiner und damit vieldeutiger sie sind, desto eher muß sich im übrigen jeder mit ihnen identifizieren.

Die skizzierte Vorgehensweise wurde 1932 von Myrdal als "in der wirtschaftspolitischen Doktrinbildung vorherrschend" und für die Finanzlehre typisch kritisiert ${ }^{26}$ In gleicher Weise kann 1993 die entsprechende Begründung einer Steuerrechtsordnung trotz vieler Erkenntnisse über die Zusammenhẳnge des Normensystems kritisiert werden.

4. Ohne empirische Untersuchungen über die Wirkungen eines konkreten Normengefüges oder einzelner darin integrierter Bestimmungen ist ein Urteil über dessen Zweckmäßigkeit nicht möglich. Dabei kommt auch dem Gesetzesvollzug eine gleichhohe Bedeutung zu.

5. Das Steuerrecht ist nach den seit 1949 gemachten Erfahrungen ein nützliches und ebenso ein legitimes Lenkungsinstrument der Wirtschafts- und Sozialpolitik geworden. Nach dem neuen Abgabenrecht ist der Einsatz des Steuerrechts für nichtfiskalische Zwecke auch zulässig. Das Einkommensteuerrecht dient auf diese Weise zugleich anders nicht erzielbaren wirtschaftlichen oder sozialen Zwecken.

6. Lenkungsnormen dienen vorgegebenen sozialen Zwecken zur Verbesserung der sozialen Zustände. Eine Rechtsinstitution läßt sich nicht allein abschließend aus der Tatsache beurteilen, daß sie bestimmten formalen Kriterien genügt oder mit ihnen vereinbar ist.

Unentbehrlich ist jeweils eine begleitende Kontrolle, zu welchen Ergebnissen die Verwendung von Lenkungsnormen führ,, indem man sie unter sozial-

\footnotetext{
${ }^{20}$ Myrdal, G. (1963), S. 153.

"Myrdal, G. (1963), S. 153.
} 
technologischen Gesichtspunkten bezüglich der von ihr provozierten Konsequenzen beurteilt.

7. Normengefüge und die zugehörigen Vollzugsvorschriften sind als soziale Institutionen zur dauerhaften gleichartigen Lösung konkreter massenhaft auftretender Vorgänge, wie Karl Popper gelegentlich zeigt, mit Maschinen vergleichbar. ${ }^{27}$ Bei Verwendung eines für das Leben der Gemeinschaft zweckmäßigen instrumentalen Gesichtspunktes gleicht der Steuerrechtswissenschaftler trotz Anerkenntnis aller Unterschiedlichkeiten durchaus einem Ingenieur, hier einem Sozialingenieur, der die Institution wie eine Maschine auf wissenschaftlicher Grundlage konstruiert, umkonstruiert oder gar anders in das hierarchisch geordnete Normengefüge einpaßt oder mit der als "ordre publique ${ }^{\mathrm{B}}$ verstandenen übergreifenden Sozialordnung abstimmt. Die Maschine muß geeignet sein, ohne Schäden durch sozial unverträgliche Ergebnisse den Massenanforderungen zu genügen. Der Ingenieur ist gehalten, die Produktionsergebnisse zu überwachen, den Ausschuß statistisch zu erfassen, um ihn jeweils Korrekturen an der Maschinenkonstruktion zugrunde zu legen. Versäumt er dies, macht er sich gegebenenfalls schadenersatzpflichtig. Er darf sich nicht einfach zurücklehnen und ständig von einer Verbesserung der Konstruktion träumen, ohne das Ergebnis derselben zu verproben und die Resultate $\mathrm{zu}$ begutachten.

8. Die Behauptung, die Kompliziertheit des Einkommensteuerrechts mache dasselbe heute als Lehrstoff ungeeignet, ist eine einseitige Übertreibung. Die Realität lehrt, daß es trotz erheblicher Kompliziertheit noch vermittelbar ist. Anderenfalls wären Steuerberater und Rechtsanwälte nicht mehr in der Lage, ihrem Beruf nachzugehen, und ebenso könnten die Finanzämter keine Veranlagungen mehr durchführen. $\mathrm{Daß}$ man das Einkommensteuerrecht in bezug auf seine innere Ordnung nur leicht verstăndlich darstellen kann, wenn man seine Entstehungsgeschichte kennt, ist richtig.

9. Eine Beseitigung der beklagten Mängel- des Einkommensteuerrechts sollte durch Revision der Lenkungsnormen, der Pauschalen, Typisierungen und des Tarifs nach sozialen Gesichtspunkten erfolgen.

\section{Thesen des Volkswirts und Finanzwissenschaftlers}

Volkswirt und Finanzwissenschaftler mögen den Einsatz des Einkommensteuerrechts als Instrument politischer Zielvorstellungen folgendermaßen beurteilen:

27 Albert, H. (1976), S. 179; Popper, K. (1971), S. 58, S. 73, S. 122 u.a. 
1. Nach der klassisch-orthodoxen Wirtschafts- und Finanztheorie verbinden sich mit Steuern grundsätzlich kapitalhemmende Wirkungen. Entsprechend führte nach dieser Auffassung, der man heute noch in Fachkreisen begegnet, eine Ausdehnung der Staatstătigkeit, die höhere Steuereinnahmen erfordert, grundsătzlich zu einer unproduktiven Verwendung volkswirtschaftlichen Kapitals. Jedenfalls besteht nach dieser Lehrmeinung eine Gesetzmä@igkeit der Art, daß höhere Steuern stets mit verringerter Kapitalbildung verbunden sind. ${ }^{28}$ Nur langsan bildete sich die Auffassung, daß vernittels steuerpolitischer Maßnahmen Kapitalbildung sogar gefördert werden kann. Die Steuer ist nach überwiegender Überzeugung heute ein machtvolles Instrument einer modernen Finanz- und Wirtschaftspolitik geworden. Aber zumeist beschränkt sich diese Auffassung, die in den späten 60er Jahren aufkam, auf die Beiträge der Steuerpolitik zur sogenannten "Globalsteuenung" der Wirtschaft, die zu dieser Zeit gesetzlich geregelt wurde. ${ }^{29}$

2. Grundsätzlich bekennt sich die Bundesrepublik Deutschland zu einer marktwirtschaftlich organisierten Wettbewerbswirtschaft. Dies wurde zwar nicht in der Verfassung, aber im Gesetz gegen Wettbewerbsbeschränkungen, im Außిenwirtschaftsgesetz, im Sachverståndigengesetz und im Stabilitătsund Wachstumsgesetz verbindlich festgeschrieben. ${ }^{30}$ Im Falle einer konkreten Ergănzungsbedürttigkeit der Marktwirtschaft wegen globaler, sektoraler oder einzelner sonstiger sozialer Disharmonien, bei denen die Selbstregulierungskrăfte versagen, engen diese Vorschriften erforderliche Eingriffe des Gesetzgebers zur Aufrechterhaltung einer konkurrenzwirtschaftlichen Ordnung stark ein. Die Maßnahmen müssen nämlich grundsätzlich in marktkonformer Weise erfolgen und die marktwirtschaftliche Rechenhaftigkeit des Preisgefuges mit seiner Signalfunktion für die Steuerung des gesamten Wirtschaftsablaufs muß dabei aus guten Gründen erhalten bleiben. Diese Bestimmungen kanalisieren die Empfehlungen von Volkswirten und Finanzwissenschaftlern und verhindern systemwidrige Eingriffe in einen sich selbst regulierenden Wirtschaftsablauf. $^{31}$

3. Die dargestellten Regulienungen bringen es mit sich, daß Subventionen in Form von Finanzhilfen und Steuervergünstigungen heute nicht mehr prinzi-

\footnotetext{
a Neumark, F. (1953), in: Albrecht, S. 56; Beitrăge von B. Harms u. G. Stolper, in: Colm, G.Neisser, H. (1930), S. 383 u. S. 390; Stolper (1929), S. 1462.

3 Pagenkopf. H. (1969), S. 9; Steinberg, W. (1969), S. 24: Neumark, F. (1969), S. 100; ders. (1970), Grundsaltze gerechter ..., S. 282: ders. (1961), Finanzprobleme .... S. 216.

${ }^{10}$ Gesetz gegen Wettbewerbsbeschrănkungen, in: BGBI. I, 1957, S. 1081; Außenwirtschaftsgesetz. in: BGBI. L. 1961, S. 481: Sachverständigengesetz, in: BGBI. L. 1963, S. 685; Stabilităts- und Wachstumsgesetz, in: BGBI. L., 1967. S. 582.

"von Arnim, H. H. (1983), S. 727
} 
piell verworfen werden können, sobald sie den Anforderungen an Marktkonformität genügen. Es müssen nur befriedigende Markt und Wettbewerbsverhältnisse gegeben sein, wenn ein sinnvoller Einsatz steuerpolitischer Eingriffe erfolgen soll. ${ }^{32} \mathrm{Da}$ Steuervergünstigungen infolge der für den Laien gegebenen Undurchdringlichkeit der Zusammenhänge kaum auf politischen Widerstand stoßen, besteht nach allgemeiner Überzeugung aber eine ständige Gefahr, daß die Einfühnung von steuerlichen Anreizen durch Abgabenvergünstigungen "zum Einfalltor für unkontrollierten Interesseneinfluß" wird, ohne daß die Zweckmäßigkeit der Maßnahme vor Beschlußfassung genügend geprüft wurde. ${ }^{33}$ Volkswirte und Finanzwissenschaftler warnen daher nachhaltig vor unübersehbaren, später nicht mehr revidierbaren Folgen bei Anlegung unbedachter Maßstäbe. ${ }^{34}$

4. Steuervergünstigungen und Finanzhilfen dürfen zur Vermeidung von Mißbräuchen und Fehlinvestitionen infolge verfälschter, da nicht marktgerechter Preis-/ Kostenverhältnisse daher von Gesetzes wegen nur für begrenzle Zeitspannen und nur zur Unterstützung konkret anzugebender Ziele eingefühn werden. Sie müssen daher tumusmäßig von der Regierung in einem Subventionsbericht mit näheren Angaben über Geltungsdauer und fortbestehendes Erfordernis aufgelistet werden. ${ }^{35}$

5. Nach den übereinstimmenden Auffassungen von führenden Nationalökonomen und Finanzwissenschaftlern ist heute ein Wandel der Staatsfinanzierung geboten. Der Steuerstaat habe seinen Kulminationspunkt überschrilten, ${ }^{36}$ so hört man. Die Ausgabenbeschlüsse der Parlamente waren in den verflossenen Zeitrăumen infolge voller öffentlicher Kassen von "ideologischem Überschwang" und dadurch "ausgelöster Begehrlichkeit" gekennzeichnet. Heute ist ein Sanierungsprogramm, das den Steuerstaat angesichts wachsender Staatsverschuldung funktionsfähig hält, gefragt. Als Lösungsvorschlag soll das Steuersystem "rationaler" ausgestaltet werden, so heißt es. Dazu sollen die Einebnung von "loopholes", zunehmende Pauschalierungen, Besteuerung der "capital-gains", ungeschmälerte Besteuerung von Versorgungsbezügen und andere Maßnahmen mehr beitragen. Bestimmungen, die einer gleichmäßigen Steuerbelastung im Wege stehen, sollen neben weiteren Vorschlägen überprüf

\footnotetext{
32 von Arnim, H. H. (1983), S. 742.

33 von Arnim, H. H. (1983), S. 742.

34 Schmölders, Q. (1970), Finanzpolitik, S. 233.

3s $\$ 12$ des Gesetzes zur Förderung der Stabilitåt und des Wachstums der. Wirtschaft (StWG) vom! 8.6 .67 .

${ }^{36}$ Hedtkamp、 G., Krise des Steuerstaates, in: Hansmeyer, K. H. (1983), S. 20.

37 ders., S. 31.
} 
werden ${ }^{38}$ Regelungen, die anläßlich sămtlicher Steuerreformen der Vergangenheit zusammen mit einem rationalen, an der Leistungsfähigkeit der Bürger orientierten Steuersystem ultimativ gefordert wurden, machten zumeist Gebrauch von mehr oder weniger unbestimmten, weil undefinierten Rechtsbegriffen. Wie mit Gebetsmühlen werden wiederum, wie bereits früher, auch von Finanzwissenschaftlern genăhrte hohe, nicht erfüllbare Ansprüche an Reformen eingefordert. Jedenfalls sind Haushaltsmittel für große Transferleistungen und Finanzhilfen heute nicht mehr verfügbar. ${ }^{39}$

6. Nationalökonomen haben sich, ebenso wie Finanzwissenschaftler, aus den eingangs genannten Gründen mit den gesamtwirtschaftlichen Konsequenzen der verschiedenen Steuervergünstigungen nur unzulänglich befaßt. "Anreize als Alternativen wirtschaftspolitischer Steuerung" ${ }^{40}$ in Form massiver Steuervergünstigungen sind infolge der liberalen Traditionen in der Geschichte dieser Wissenschaften nie nachhaltig erörtert und daher immer der sachkundigen Finanzverwaltung und den Praktikern in Verhandlungen der Parlamentsausschüsse überlassen worden. ${ }^{41}$ Politiker und Verwaltung haben den ihnen überlassenen weiten Gestaltungsspielraum, wie es scheint, bisher im Interesse der Allgemeinheit erfolgreich zu nutzen verstanden. Daß steuerliche Anreize gegebenenfalls den Haushalt gar nicht belasten, sondern infolge der ausgelösten allgemeinen Belebung der Wirtschaft unter dem Strich sogar die Steuereinnahmen mehren können, ist zwar Praktikern bekannt, wurde aber bisher von Wissenschaftlern nicht aufgegriffen. Hier herrscht Nachholbedarf. Der von Wissenschaftlern gern betonte Verweis auf die erforderliche Marktkonformität von Subventionen und die stetig wiederholten Forderungen nach Kompatibilität von Steuervergünstigungen mit den in der Verfassung festgeschriebenen Grundrechten wie Gerechtigkeit, Freiheit, Eigentumsgarantie, Sozialbindung, allgemeine Wohlfahrtsentwicklung etc. etc. sind formale Gesichtspunkte geblieben. Sie reichen als Prüfungskriterien für die Rechtfertigung von zulässigen Eingriffen nicht aus. Von großer Wichtigkeit für die Allgerneinheit wären heute Erkenntnisse darüber, welche gestaltbaren Voraussetzungen erforderlich und welcher Art Steuervergünstigungen geeignet sind, in Zeiten sozialer Not, vergleichbar den Umständen nach dem letzten Krieg, einen wirtschaftlichen Aufbau in Gang zu setzen oder jedenfalls zu fordern. Auf diese Weise könnten heute Planungen zum Ausbau der Infrastruktur, die

\footnotetext{
18 ders., S. 21.

is ders., S. 16.

40 von Arnim, H. H. (1983), S. 738; Hansmeyer, K.H. (1969), Subventionen als wirtschaftspolitisches Instrument, in: Recktenwald, H. C. (1969), S. 323; s. Kapitel K, Anm. 67 u. 68.

"Hierzu: Findling, M. (1992), S. 64, die hier unterstellten Motive sind einseitig und nicht belegt.
} 
in den neuen Bundesländern das Nadelöhr für Investitionen darstellt, verbessert und die Folgen der dortigen Arbeitslosigkeit gemindert werden. Steuervergünstigungen, die in Zeiten sozialer Not Mangelerscheinungen zu lindern vermögen, lassen die Frage zurücktreten, ob die Besteuerung den formalen Anforderungen an Gerechtigkeit, Gleichmäßigkeit, Vorausschaubarkeit, Einheit der Rechtsordnung etc. entspricht, solange die Maßnahmen marktkonform sind und alle Bürger von der eingeleiteten Wohlstandsmehrung gleichermaßen profitieren. Die Prioritäten müssen verschoben werden.

7. Die Bürger haben letztlich ein Recht darauf, daß Politiker und Verwaltung alles daransetzen, den ihnen überlassenen Gestaltungsrahmen zur Wohlstandsforderung des Gemeinwesens auch durch den Einsatz steuerlicher Anreize auszuschöpfen, insoweit die vier gesamtwirtschaftlichen Ziele des Gesetzes zur Förderung der Stabilität und des Wachstums der Wirtschaft (StWG) gewährieistet bleiben und dic Vorschriften der Rechtsordnung Berücksichtigung finden. Ideologische Voreingenommenheiten von Seiten der Wissenschaft müssen in außergewöhnlichen Zeiten zurückstehen. Vordringlich ist die Erarbeitung konkreter Erkenntnisse, die uns zur Konstruktion geeigneter Institutionen für die Förderung eines wirtschaftlichen Aufschwungs befähigen. Dazu gehört jedenfalls auch die geeignete Verwendung steuerlicher Anreize. $\mathrm{DaB}$ dabei unerwïnschte Folgewirkungen Berücksichtigung finden müssen, ist gewiß richtig. Erst ihre Kenntnis ermöglicht eine abgewogene Beschlußfassung. Dogmatisch vorbestimmte Einengungen des Erkenntnisinteresses können der Aufgabe der politischen Wissenschaften, die Grundlagen für die Gestaltung gesellschaftlicher Verhalltnisse nach allgemein akzeptablen Zielvorstellungen aufzubereiten, nicht entsprechen.

8. Die Einkommensteuer ist längst Teil der pretialen Lenkung der Wirtschaft geworden. Man mag dies begrüßen oder nicht. Die Vorschriften des Einkommensteuerrechts wirken wie elektronische Umwandler. Verstärker und Verteiler der Prozeßvorgänge. Zur rationalen Steuerung der Wirtschaft ist es daher unumgănglich, die jeweilige Wirkungsweise der Vorschriften zu ergründen und kritisch zu begleiten, soll die gesellschaftliche Entwicklung beherrschbar bleiben.

9. Eine neutrale Besteuerung in dem Sinne, daß die relative Einkommensund Vermögensverteilung der Wirtschaftssubjekte von ihr unverändert bleibt. gibt es nicht. ${ }^{42}$

10. Unabhăngig davon, ob fiskalische oder außerfiskalische Ziele verfolgt werden, ist die Steuerpolitik stets als Teil der Wirtschaftspolitik zu beurteilen.

${ }^{42}$ Mann, F. K. (1937), S. 343. 
11. Die Geschichte hat gezeigt, daß eine unkontrollierte Konkurrenzwirtschaft Tendenzen in sich trăgt, sich selbst zu zerstören. Die Aufrechterhaltung einer marktwirtschaftlichen, sich selbst steuernden Wirtschaftsordnung kann heute durch einen geeigneten Einsatz der Steuerpolitik erleichtert werden. ${ }^{43}$ Was für die Aufrechterhaltung gilt, muß erst recht für deren Aufbau gelten.

12. Die bisher übliche Einteilung in abzulehnende dirigistische bzw. notwendige interventionistische Maßnahmen der Steuerpolitik wird den vielfaltigen Anforderungen der modernen Wirtschaftsgestaltung nicht mehr gerecht. ${ }^{44}$ Eine differenzierende Betrachtung der einzelnen Maßnahmen in bezug auf ihre Wirkungen ist angezeigt.

\section{Darstellung der Entwicklung und Rechtfertigung der Steuerpolitik durch die Finanzbehörde}

Ein für die Besteuerung verantwortlicher leitender Finanzbeamter wird zur Rechtfertigung der vielfaltigen Inanspruchnahme des Besteuerungswesens für fachfremde Aufgaben auf die historische Entwicklung aufmerksam machen. Er mag folgende Beurteilung der geltenden Einkommensbesteuerung beitragen:

1. Die seit 1949 kontinuierliche Steigerung des Aufkommens der Einkommensteuer und ihr obendrein erhöhter Stellenwert innerhalb der gesamten Steuereinnahmen zeigen eindrucksvoll, daß von einem "Niedergang" dieser Besteuerungsart und von einer unvermeidbaren "Neuordnung des deutschen Einkommensteuerrechts" ${ }^{\mathrm{45}}$ bis heute bei Anlegung realistischer Maßstabe undifferenziert nicht gesprochen werden kann. Nach einer Umfrage des EMNID-Instituts von 1993 sind heute 84\% der Steuerzahler sogar davon überzeugt, daß ihre Steuererklärung vom Finanzamt "korrekt" bearbeitet wird. Von einem "wachsenden Grad der Unzuträglichkeiten", die "von breiten Wahlermassen nicht mehr hingenommen wird" - ein Eindruck, der von vielen Steuerjuristen, von ausgewiesenen Fachleuten, von Politikern und vor allem von den Meinungsmachern in den Medien mit plausibel klingenden Argumenten erzeugt und wachgehalten wird - kann schlechterdings nicht gesprochen wer-

\footnotetext{
${ }^{4}$ Hansmeyer. K.-H. (1969), Subventionen ..., S. 323.

4 Ansltze zu dieser Denkweise finden sich bereits bei F. Neumark (1952), S. 586 u. S. 593; ders. (1961), Wirtschafts- und Finanzprobleme .... S. 131, S. 147, S. 281.

"Hierzu: Raupach, A. (1985).
} 
den. ${ }^{46}$ Mit dieser Feststellung soll aber nicht der Eindruck erweckt werden, umfassende Reformen seien derzeit nicht geboten.

2. Die unterschiedlichen, im 19. Jahrhundert entstandenen Einkommensteuergesetze der Länder konnten 1919 nach dem verlorenen Krieg und dem Ende des Kaiserreichs den gegebenen Anforderungen schon wegen der angehäuften Folgelasten nicht mehr genügen. Das unter Verantwortung von Matthias Erzberger durchgesetzte REStG 1920 diente nach dem Zusammenbruch der Notwendigkeit einer Verteilung der drückenden Lasten nach Gesichtspunkten der Leistungsfahigkeit und der Verklammenung der Lănder durch die Zielvorstellung einer solidarischen Haftung aller Bürger des Deutschen Reichs. ${ }^{47}$ Das den Auffassungen der katholischen Soziallehre der Zentrumspartei Württembergs nahestehende, nach der Hermann-Schmollerschen Besteuerungsidee gefertigte REStG 1920 mußte den von unerfüllbaren Reparationsforderungen und sonstigen Kriegsfolgen belasteten Wiederaufbau des Deutschen Reichs nicht nur infolge der hohen erforderlichen Steuersätze, sondern auch wegen der Unmöglichkeit, mehr als die laufend notwendige Ersatzinvestition gewinnmindernd abzusetzen, bei fehiendem Kapitaimarkt abwurgen. ${ }^{10}$ Hinzu kam die inflationäre Entwicklung der Zeit bis 1924.

3. Johannes Popitz als Staatssekretår und der Reichsfinanzminister Otto von Schlieben, vormals Kollege des ersteren als Abteilungsleiter im Finanzministerium, schufen und setzten 1925 ein geändertes Reichseinkommensteuergesetz im Reichstag durch, das wieder auf die Systematik des beiden wohlvertrauten preußischen EStG von 1891 zurückgriff. Bevor Popitz in das Reichsschatzamt eintrat, war er seit 1912 bei dem preußischen Oberverwaltungsgericht in Staatssteuersachen tätig gewesen. ${ }^{49}$ Er kannte die Schwachstellen des preußischen EStG, eine gerechte Lastenverteilung zu bewirken, aber auch dessen in der preußischen Tradition angelegte Eignung. steuerfrei eine zügige Kapitalbildung zu ermbglichen. Auf die grundsätzliche Kritik Franz Meisels an dem preußischen EStG 1891 und dessen Vollzug hat er sich gelegentlich bezogen. ${ }^{50}$ Daher losste sich das Popitz'sche Reformgesetz von den "dogmatischen Vorgaben der Theorien und legte einen pragmatisch techni-

\footnotetext{
46. Hierzu: Bund der Steuerzahler NW, Nachrichten Nordrhein-Westfalen, 36. Jg., Heft 12/93, S, 1.

47 Erzberger, M. (1919), S. 3. Auch diesen Gedanken hat. Erzberger vermutlich von. Schmoller nbernommen, der "das Band des Einzelnen .... mit dem ... Staatsmittelpunkt" ebenso durch die Steuer geknupft wissen wollte: Schmoller, G. (1863), S. 57.

48 Hoffmann, A. (1921), S. 1.

49 Grabower, R. (1954), S. 316

se Popitz, J. (1928), Finanzrecht .... S. 50; s. a. Krohn, C. D. (1974), S. 148, S. 179.
} 
schen Einkommensbegriff zugrunde","5! der jeweils wirtschaftspolitischen Zweckmäßigkeiten Raum ließs.

4. Auf der für die Wirtschaftspolitik der Weimarer Zeit wichtigen Tagung der Friedrich List-Gesellschaft vom 26. bis 30. Oktober 1929 fürte Popitz zu dern Thema "Kapitalbildung und Steuersystem" vor dem anwesenden Kreis von renommierten Gelehrten, einflußreichen Staatsmännern, Wirtschaftspolitikern und Wirtschaftsführern aus, daß die Einkommensbesteuerung genötigt sei, Prioritäten zu setzen, die gegebenenfalls im allgemeinen Interesse der Kapitalbildung als unentbehrlichem Hilfsmittel zum Wiederaufbau des Deutschen Reichs den Forderungen nach Gerechtigkeit zuwiderlaufen. ${ }^{52}$ Vorsichtig wandte er sich damit gegen die Tendenz in den Verhandlungen aller anwesenden führenden Finanzwissenschaftler und Nationalökonomen. ${ }^{53} \mathrm{Er}$ warnte davor, durch Reformpläne mit Änderungen des Steuersystems und Tariferleichterungen, die "sich gewiß wunderschön schriftstellerisch ausarbeiten und drucken" ließen, ${ }^{54}$ eine Verbesserung der Engpässe zu erwarten. Damit richtete er sich behutsam, aber unüberhörbar gegen den "Finanzplan", den Gustav Stolper 1929 im "Deutschen Volkswirt" vorgetragen hatte und der die Diskussion bestimmte. ${ }^{55}$ Stolper erwartete von einer Erhöhung des Grundfreibetrages und der Rückführung des höchsten Tarifsatzes der Einkommensteuer von $40 \%$ auf $25 \%$ und von konkreten Maßnahmen auf der Ausgabenseite des Haushalts eine Erhöhung der Kapitalbildung und eine Belebung der Wirtschaft. ${ }^{56}$ Auf Grundlage seiner hohen Sachkenntnis nach langjăhriger Tătigkeit im Besteuerungswesen skizzierte Popitz vorsichtig eine andere Diagnose und entsprechend eine andere Therapie. Er hielt die Steuerflucht für das gröBte Hemmnis der Entwicklung. Die notleidende Kapitalbildung konnte man nach seinen Andeutungen nur verbessern, wenn die höheren Einkommensbezieher, denen nach seiner Kenntnis Steuervermeidung und gar Steuerhinterziehung leicht möglich waren und die dies auch ständig in Verbindung mit Steuerflucht praktizierten, wieder dazu gewonnen werden könnten, in den eigenen Betrieben ohne Zwischenschaltung des Kapitalmarktes zu investieren und auf diese Weise die Wirtschaft zu beleben. ${ }^{57}$ Popitz regte daher behutsam an, gerade die höheren Einkommensbezieher durch steuerliche Erleichterun-

\footnotetext{
31 Walz, W. R. (1986), S. 39.

52 Colm, G./Neisser, H. (1930), Bd. 2, S. 9 u. S. 148; Dieckmann, H., S. 105.

s3 Colm, G./Neisser, H. (1930), Bd. 1, S. 390.

s4 Colm, G./Neisser, H. (1930), Bd. 2, S. 149.

ss Stolper, G. (1929), Ein Finanzplan, S. 1399; Dieckmann, H., S. 92, S. 109

so Colm, G./Neisser, H. (1930), Bd. 1 S. 390 ff, S. 394.

"Colm, G./Neisser, H. (1930), Bd. 1, S. 103 ff, S. 107.
} 
gen von der Steuerflucht abzuhalten und zu Investitionen in Deutschland zu bewegen. ${ }^{58}$ Anders als das REStG 1920 ließ das von Popitz durch Rückbesinnung auf das preußische EStG 1891 umgestellte Gesetz von 1925 die Einfügung geeigneter Vorschriften zur steuerlichen Begünstigung von Investitionen problemlos zu. Das war in der Tradition der preußischen Einkommensbesteuerung ohnehin so angelegt.

5. Obwohl der Dawes-Plan vom Jahr 1929 eine Entlastung von dem unmittelbaren Druck der Reparationsverpflichtungen mit sich brachte ${ }^{59}$ und auf der Tagung in Bad Eilsen daher sofortige radikale Steuersenkungen gefordert wurden, ${ }^{60}$ suchte Popitz die hohen Erwartungen an eine durch diese Maßnahme $z u$ erzielende Verbesserung der Kapitalbildung zu dämpfen. ${ }^{61}$ Er erklärte, $\mathrm{da}$ ß̊m Reichsfinanzministerium Plăne entwickelt würden, die zur richtigen Zeit mit taktischem Geschick im Parlament eingebracht werden sollten ${ }^{62}$ Offensichtlich beurteilte Popitz das "Steuerwesen als ein Mittel staatlicher Wirtschaftslenkung". Maßnahmen auf der Ausgabenseite des Haushalts, von dem er als einem "Verschiebebahnhof" sprach, waren ihm ebenso ein wichtiges, aber eher nachrangiges Hilfsmittel. ${ }^{63}$ Eine Steuerreform mußte für ihn vorrangıg "Steuersenkung und Steuerumbau" in geeigneter Weise miteinander vereinigen, um die Kapitalbildung anzuregen. ${ }^{64} \mathrm{Er}$ wollte die Einkommensteuer für die höheren Einkommen in einer Weise gesenkt wissen, die zu einer wirtschaftichen Belebung anregen mußte. Dabei wollte er der Stärkung der Wirtschaftskraft des Reiches und nicht einseitig der steuerlichen Gerechtigkeil Prioritat beigelegt wissen. ${ }^{65}$ Konkrete Maßnahmen beurteilte er vornehmlich unter dem Gesichtspunkt der Zweckmäßigkeit zur Verfolgung eben dieses Ziels. Austrocknung der Steuerflucht durch Förderung der Selbstfinanzierung erhielt so einen hohen Stellenwert. Der höchste Tarifsatz der Einkommensteuer von $40 \%$ wurde fortan nicht gesenkt. ${ }^{66}$ Nach Rücktritt von Popitz und Hilferding zu Ende 1929 wurde er im Jahr 1934 sogar noch auf 50\% erhöht. $^{67}$

\footnotetext{
${ }^{58}$ Colm, G./Neisser, H., Bd. 1, S. 107; hierzu auch S. 386; Dieckmann, H., S. II 1.

"Stolper, G. (1929), Der Young-Plan, S. 1251; auch: Spindler, J. (1965), S. 148.

${ }^{60}$ Colm, G./Neisser, H. (1930), Bd. 1. S. 394.

61 Colm, G./Neisser, H. (1930), Bd. 2. S. 147

22 Colm, G./Neisser, H. (1930)., Bd. 2, S. 154.

as Colm, G./Neisser, H. (1930), Bd. 2, S. 153; Dieckmann, H., S. 111.

a Colm, G./Neisser, H. (1930), Bd. 1. S. 108

a* Colm, G./Neisser. H. (1930), Bd. 1. S. 148

65. \$5 EStG v. 10.8.25. RGBI. 1. S. 200.

$67 \S 32$ i. V. m. Anlage 1 zu § 32 EStG v. 16.10.34. RGBI. I, S. 1023.
} 
6. Zur Zeit der großen Weltwirtschaftskrise zeigte sich gegen Ende 1931 nicht nur, daß die Reparationsverpflichtungen vom Deutschen Reich auch nach den Erleichterungen des Dawes- und Young-Planes gar nicht einzuhalten waren. Die Notlage der öffentlichen Kassen machten unübersehbar, daß die Staatsfinanzen nur über eine Wiederbelebung der Volkswirtschaft, also eine "Anti-Deflationspolitik", erreichbar war. ${ }^{68}$ Die gesamte Finanzpolitik wurde nun auf Erfordernisse der Wirtschaftspolitik ausgerichtet. Zu Beginn erfolgte dies ohne Einschaltung des Parlaments durch sogenannte Notverordnungen des Reichspräsidenten gemäß Artikel 48 Abs. 2 der Reichsverfassung, ${ }^{69}$ später auf Grundlage des Ermăchtigungsgesetzes vom 24. März $1933 .^{70} \mathrm{Zu}$ den steuerpolitischen Regelungen hatte Popitz gewiß noch die Weichen gestellt. Nicht nur die Ausgabenseite des Haushalts wurde durch Ausgabe von Steuergutscheinen für die Schaffung von Arbeitsplătzen, durch Zinsvergütungsscheine bei Durchführung von Baumaßnahmen, durch Arbeitsschatzanweisungen, durch Ausgabe von Wechseln mit Rediskontzusagen im Straßenbau etc. in die Konjunkturförderung eingeplant; auch die Steuerpolitik wurde systematisch und zunehmend zur Entlastung des Arbeitsmarktes eingesetzt. ${ }^{71}$ Die von Popitz geschaffene Gestaltung des EStG 1925 zeigte jetzt die ihr innewohnenden wirtschaftspolitischen Verwendungsmöglichkeiten. Ein Gesetz über Steuererleichterungen vom 15. Juli 1933 sah einen Einkommensteuernachlaß von $10 \%$ der Aufwendungen für bestimmte Instandsetzungen und Ergänzungen an Betriebsgebäuden innerhalb festgelegter Fristen vor. ${ }^{72}$ Ein Gesetz vom 1. Juni 1933 ließ den Abzug von Ersatzbeschaffungen in Landwirtschaft und Gewerbe als Betriebsausgaben zu. Dann wurden Einkünfte aus Vermietung und Verpachtung von neugeschaffenen Kleinwohnungen in Eigenheimen für lange Zeit steueibefreit. ${ }^{73}$ Auch ein neugeschaffenes Gemeinnützigkeitsrecht wurde in den Dienst der Entlastung des Arbeitsmarktes gestellt. In dem "konzentrierten Angriff" gegen die Arbeitslosigkeit "von den verschiedensten

\footnotetext{
Terhalle, F. (1950), S. 313.

"Terhalle, F. (1950), S. 310; Notverordnung v. 4.9.32 (Steuergutscheine). S. 315

Gesetz zur Behebung der Not von Volk und Reich v. 24.3.33. RGBI. I, S. 141; Terhalle (1950),

"Gesetz zur Verminderung der Arbeitslosigkeit v. 1.6.33 (RGBI. L, S. 323 ff), darin Abschnitt II
} mit weitergehender Steuerfreiheit für Ersatzbeschaffungen, Anschaffungen und Herstellung, abweichend von § 16 EStG für 1933 - 1935, als Betriebsausgaben (RGBI. I S. 324 u. S. 1073). Die Notverordunung, vom 1.12.30 enthielt sowohl Zuschlāge zur ESt ab 1931, als auch Steuervergunnstigungen für den Bau von Kleinwohnungen und die Anerkennung als gemeinnutziger Wohnungsunternehmen (RGBBI. I 1930. S. 527 f u. S. 593); Mann, F. K./Nipperdey, H. C. (1933).

₹ 1 Gesetz ûber Steuererleichterungen v. 15.7 .33 (RGBI. I, S. 491) mit Vorschriften ( $\$ \S 2$ f) âber Steuerfreiheit von einmaligen Zuwendungen an Arbeitnehmer und für neue Unternehmen.

Gesetz betreffend die Steuerbefreiung neuerrichteter Wohngebăude v. 15,7.33. RGBI. I S. 493 i.

V. m. RGBI. I 1930. S. 517. S. 582. 
Seiten" kam der Steuerpolitik eine zentrale Rolle zu. ${ }^{74}$ Dabei stand der seit 1932 beibehaltene höchste Steuersatz von $50 \%$, der nach den Auffassungen des sachkundigen Gremiums auf der Tagung der Friedrich List-Gesellschaft über "Kapitalbildung und Steuersystem" bereits bei $40 \%$ als Hemmnis der Wirtschaftsbelebung beurteilt worden war, dem Konjunkturaufschwung nicht im Wege. ${ }^{75}$ Der auf 50\% angehobene Tarif konnte das Interesse von Investoren sogar erhöhen. Die Auffassung von Popitz, daß eine steuerliche Begünstigung der Selbstfinanzienung zur Belebung der Wirtschaft eingesetzt werden könnte, hat sich dann bestätigt. Nicht ein niedriger Tarif war unbedingt wichtig, sondern - wie Popitz richtig unterstellt hatte - ein angemessener Tarif, gekoppelt mit hohen Steuervergünstigungen für Steuerpflichtige mit hohen Einkünften, die geeignet waren, zur Steuerersparnis durch Investitionen anzuregen, war entscheidend.

7. Als die Militărregierung Deutschland 1945 zur eigenen Entlastung dem "Vereinigten Wirtschaftsgebiet" der westlichen Zonen durch eine geordnete und leistungsfahige Finanzwirtschaft eine neue tragfähige Grundlage verschaffen wollte, führte sie die von einer sachgerechten ZweckmäBigkeit bestimmte frühere Steuerpolitik fort. Zum Direktor der Verwaltung der Finanzen des "Vereinigten Wirtschaftsgebietes" wurde der frühere langjährige Mitarbeiter im Reichsfinanzministerium, Alfred Hartmann, ernannt. Hartmann war seit 1925 als Ministerialrat in der Steuerabteilung tảtig, bis er 1935 aus politischen Gründen aus dem Ministerium ausschied. ${ }^{76}$ Unter Hartmann, der nach Gründung der Bundesrepublik Deutschland als Staatssekretär im Bundesfinanzministerium weiter zuständig war, wurde an die Tradition dieser Behörde zur Weimarer Zeit wieder angeknüpft. ${ }^{77}$ Der Präsident des Wirtschaftsrates, Erich Kohler, begribte das EStG vom 20. April 1949 zwar als ein deutsches Gesetz; ${ }^{78}$ der aus Wissenschaftlern und Politikern bestehende Finanzpolitische Beirat der Verwaltung für Finanzen wurde jedoch nie zu den Entwürfen gehör. ${ }^{79}$ In diesem Gremium fand das Gesetz denn auch starke Kritik.

\footnotetext{
${ }^{34}$ Terhalle, F. (1950), S. 315.

7 Colm, G./Neisser H. (1930), Bd. 1, S. 390, S. 394.

${ }^{76}$ s. Stichwort A. Hartmann, in: Wer ist wer?, Hrsg. W. Habel, Berlin 1951, 3. 218.
}

7 Die steuerlichen Vergünstigungen des EStG ab 1948 gleichen den Maßnahmen zum Wiederaufbau ab 1932, s. hierzu Fischer, C. (1949), Sp. 579; s, auch: Dreißig, W. (1984), S. 189.

7 Fischer, C. (1949), Sp. 586.

${ }^{79}$ Hierzu: Fischer, C. (1949), Sp. 581 ff, insbes. Sp. 588; s. wörtl. Berichte u. Drucksachen des Wirtschaftsrates des Vereinizten Wirtschaftsgebietes 1947 - 1949, hrsg. v. Institut für Zeitgeschichte, Bd. 3, $23-40$, Vollversammlung S. 1453 ff u. Bd. 5 Drucksachen $638-1182 \mathrm{Nr}$. 974, München 1977 . 
Der von der Militărregierung Deutschland als oberste Regierungsgewalı vorerst auf $95 \%$ festgesetzte Höchstsatz des Einkommensteuertarifs wurde bis zur Beendigung des Besatzungsstatuts infolge des Vetorechts der Alliierten Hohen Kommission nach Gründung der Bundesrepublik trotz aller entgegenstehenden Appelle nicht gesenkt. ${ }^{80}$ Zur Ankurbelung der Wirtschaft, an der die Besatzungsmacht und nach Gründung der Bundesrepublik die Alliierte Hohe Kommission höchștes Interesse bekundeten, waren in das geltende Einkommensteuergesetz Steuervergünstigungen für kapitalbildende Investitionen eingefügt worden. ${ }^{81}$ Diese Bestimmungen wurden dann nach Gründung der Bundesrepublik infolge des sich zeigenden Erfolgs trotz scharfer Gegnerschaft seitens führender Volkswirte und Finanzwissenschaftler in den Folgejahren beibehalten. ${ }^{82}$ Erst nach Wiederherstellung der vollen Beschlußsouverănităt des Deutschen Bundestages nach Gültigkeit des sogenannten "Generalvertrages" vorn 26. Mai 1952 wurde der höchste Steuertarif auf $80 \%$ und spater auf $55 \%$ herabgesetzt. ${ }^{83}$ Seit dieser Zeit ist er jedoch nie unter $53 \%$ gesenkt worden. Im Zusammenhang mit hohen Steuervergünstigungen hat er die wirtschaftspolitischen Wirkungen der Lenkungsnormen jeweils erheblich verstärkt. Hohe Steuervergünstigungen haben zusammen mit hohen Einkommensteuertarifen bis heute den Wiederaufbau der Bundesrepublik Deutschland forciert.

8. Die Einkommensteuer hat in der in Deutschland gefundenen Ausgestaltung nicht nur Flexibilität und dazu die Fähigkeit bewiesen, tiefe Krisen mit völliger Umgestaltung der Wirtschaftsordnung zu überstehen, sie hat im Grunde dreimal, nämlich nach 1919, dann nach 1932 und vermehrt nach 1945 eine entscheidende Rolle beim Wiederaufbau eines kriegszerstörten Landes bzw. bei Ingangsetzung der Konjunktur gespielt. ${ }^{84}$ Vergleichbares gilt heute für die Zeit seit der Wiedervereinigung der Bundesrepublik Deutschland mit

\footnotetext{
${ }^{\text {10 }}$ Hierzu: Anlage zu $\$ 32$ EStG v. 22.6.48, Beilage 4 zu Gesetz- und VOBI. des Vereinigten Wirtschaftsgebietes, Jg. 48, S. 2, hier S. 14; Alliierte Hohe Kommission für Deutschland. Der Rat. Schr. v. 21.4.50. Obersetzung in: Verhandlungen des Deutschen Bundestages, 1. Wahlperiode, Drucksache Nr. 854.

n Zweites Gesetz zur vorläufigen Neuordnung von Steuern v. 20.4.49, ESt u. KSt, GesBl. d. Verwaltung d. Vereinigten Wirtschaftsgebietes, Jg. 1949, S. 69, hier S. 70. Dieses Gesetz wird ven W Dreißig als der "Paukenschlag" der Vergünstigungspolitik bezeichnet (1984). S. 192.

"Verhandlungen des Deutschen Bundestages, 1. Wahlperiode, Stenograph. Berichte Bd. 2, S. 798 , S. 811, S. 1400 u.a.: Schmölders, G. (1953): Organische ..., S.58, S. 68. S. 412 .

B BGBL. I 1953, S. 834 u. Gesetz zur Neuordnung von Steuern v: 16.12.54, BGBI. I S. 373, hier 4

Ein qualifizierter Wirtschaftsberichterstatter gibt der Finanzierung des Wiederaufbaus durch Steuervergünstigungen die entscheidende Rolle: Zischka, A. (1977), S. 519; ähnliches ergibt sich für Ortieb, H.-D., auch wenn er die Konsequenzen beklagt, (1974), S. 122.
} 
der ehemaligen Deutschen Demokratischen Republik. ${ }^{85}$ Das ist gewiß nicht nur auf die Gesetzessystematik zurückzuführen, sondern gleichermaßen ein Ergebnis des vorgeschriebenen Gesetzesvollzuges und der dazu von der Verwaltung jeweils eingebrachten Prioritäten. Die einzelnen Maßnahmen entsprachen den gegebenen politischen Notwendigkeiten. Sie waren Lösungsbeiträge der Finanzverwaltung zu konkreten Problemen der Zeit.

9. Das primăre Ziel der Besteuerung in einem aus Steuern finanzierten Staatswesen ist es, das für die gesetzlich bestimmten Haushaltsausgaben erforderliche Steueraufkommen sicherzustellen. Die Gewährleistung dieser zentralen Funktion erfordert beim Aufbau des Gesetzes und der Festlegung des Besteuerungsgegenstandes zuverlässige Grundlagen und die Berücksichtigung pragmatischer Gesichtspunkte, die eine praktische und verläßliche Umsetzung der Vorschriften garantieren. Darüber hinaus hat die Einkommensbesteuerung seit 1931 zunehmend wirtschafts- und weitere politische Funktionen übernehmen müssen. Auch in dieser Hinsicht bedurfte es immer wieder einer realistischen Abwägung und Abstimmung von Zweck, Mitteln und Nebenwirkungen der Eingriffe. Die in langjährigen Erfantrungen entwickelte Sachkunde der Finanzbehörden hat auch dabei als Grundlage für viele Experimente gedient. Aus den Steuerwissenschaften kam hierzu keine Hilfestellung. Die von den Steuerwissenschaften entwickelten Lehren über den Zusammenhang zwischen Besteuenung und Kapitalbildung und die daraus hergeleiteten praktischen Empfehlungen $^{86}$ konnten nach 1929 bzw. nach 1945 angesichts der großen Enge des Kapitalmarktes nicht weiterhelfen. Erst die in der Praxis der Finanzverwaltung erdachte Kombination hoher Steuern zugleich mit Einführung geeigneter Steuervergünstigungen brachte eine Meisterung der vorhandenen Engpåsse. Daß díese Problemlösung von Steuerwissenschaftlern und Nationalökonomen auch später nie unter den Gesichtspunkten eines gelungenen Experiments zureichend untersucht wurde. zeigt die Schwierigkeiten, mit der wertfreie Forschung gegen herrschende Meinungen in den Sozialwissenschaften stets zu kămpfen hat. Bereits Max Weber wußte dies 1912 zu beklagen.

10. Die Finanzverwaltung hat sich seit 1919 ständig mit weitreichenden und umfassenden Problemlösungen für verworrene Haushaltsverhältnisse bei politisch vorgegebener Machtverteilung auseinandersetzen müssen. Wissenschaftler neigen dazu, ihre steuerrechtspolitischen Überzeugungen als Ausfluß eines

\footnotetext{
Das Fördergebietsgesetz. - Gesetz aber Sonderabschreibungen und Abzugsbetrăge im Förderge biet, in letyer Fassung vom 23.9.93. das dem ursprünglichen Gesetz, zum Abbau von Hemmnissen bet Investitionen in der DDR einschl. Berlin-Ost folgte. entspricht dem 1949 vorgegebenen Schema BGBI. I 1990. S. 1143 bzw. 1 1993, S. 1655

86 Uelner. A. (1977), S. 125 f. Raupach, A. (1985), Bd. 1. S. 176 u. S. 235; ders. in: Verhandlunt gen des 57. Deutschen Juristentages, Mainz. 1988, S. N 10.
} 
allgemeinverbindlichen Sachverstandes zu beurteilen. In das, was sie als "sachgerechte Regelhaftigkeit" bezeichnen, gehen in ihre Ausfuihrungen unbewußt nicht wenige Voreingenommenheiten ein. Da in den demokratisch vorbestimmten Beschlußgremien widerstreitende Interessen ausgetragen werden, können oft Lehrmeinungen mit kryptonormativen Versatzstücken und unprăzisen Begriffen in der Diskussion zwar als Gesichtspunkt eine wichtige kritische Funktion übernehmen, jedoch letztlich keine konkrete Wirkung ausüben. Sie vermögen den politischen Anfordenungen der Praxis nicht zu genügen, da sie den in den Beschlußkörpern der Ausschüsse artikulierten Interessen zuwiderlaufen oder unerwünschte Nebenwirkungen erwarten lassen. Ein gleichermaßen sachkundiges und kritisches Gremium wie in den Finanzausschüssen der Parlamente findet sich in Universitäten nicht. ${ }^{87}$ Besteuerungsideen ohne Überzeugungskraft haben dort schon deshalb nur geringe Chancen, weil von den Behördenleitern vor Beschlußfassung eine von sachkundiger Erfahrung und nicht reiner Denkleistung getragene verantwortliche Stellungnahme erwartet wird.

11. Sowohl in den Lehren der klassischen Nationalökonomie, als auch der Finanzwissenschaften wurden Steuern als Folgen gesetzlich festgelegter Merkmale im Sachverhalt behandelt. Die "Steuerausweichung" war das Indiz einer fehlsamen, jedenfalls unzweckmäßigen steuerpolitischen Gestaltung, deren Ziel die Einhaltung der Neutralităt des Abgabewesens gegenüber den sich frei entwickelnden Marktvorgängen hatte sein sollen. Die Entwicklung hat diese einem marktwirtschaftlichen Liberalismus zuzurechnende Vorstellung inzwischen zurücktreten lassen. ${ }^{88}$

Die Erfordernisse des modernen Steuerstaates in seiner Ausgestaltung zum Sozialstaat haben dazu geführt, daß die Steuerpolitik den Bürger heute nicht mehr einseitig als einen zu respektierenden Steuerzahler betrachtet, sondern gleichermaßen als einen "potentiellen Träger staatlich erwünschter Verhaltensweisen" ${ }^{89}$ Durch zahlreiche steuerliche Prämien werden zielentsprechende Verhaltensänderungen belohnt, unerwünschte dagegen bestraft. Sobald die Marktsignale wegen Anpassungsschwierigkeiten das zur Aufrechterhaltung marktwirtschaftlicher Entwicklungen erwünschte Verhalten nicht zu erzeugen vermögen, werden Verhaltensänderungen durch eine Füle steuerlicher Maß-

\footnotetext{
" Matthâus-Meier, I. (1985) in: Raupach, S. 199; Uelner, A. (1977), S. 123, das Beispiel Uelners bezicht sich auf Hallers Beiträge von 1964 und deren praktische Bedeutung. Die Behauptung, in Ausschüssen herrsche Besitzstandsdenken vor, ist eine willk0rliche Bewertung. s. Uelner (1988). S. N

" Schmolders, G. (1968), Der Staatsbürger ..., S. 137.
} 14 
nahmen veranlaßt. Verborgene Lenkungsnormen durchziehen als Ausnahms: regelungen das gesamte Steuersystem.

Als im Jahr 1949 Ansătze zu dieser Entwicklung deutlich wurden, warnte Günther Schmölders mit anderen vor unkalkulierbaren unerwünschten Lang. zeitfolgen. 1968 konnte er jedoch nicht umhin zuzugeben, daß der Einbar systemfremder Steuervergünstigungen - er nannte die Abschreibungsfreiheitêt der $\S \S 7$ a bis 7 d EStG - "unbestreitbar zum Wiederaufbau der deutschen Wirtschaft beigetragen hat. ${ }^{190}$ Tatsächlich hat die Einspannung des "Staats. bürgers als Material politischer Gestaltungen, die sich der Steuer lediglich als Vehikel ihrer wechselnden Kommandos bedient", ${ }^{21}$ erst die Global- und Feinsteuerung der Wirtschaft unter Umständen ermöglicht, die früher als schicksalhaft und unbeherrschbar dem Zufall überlassen bleiben mußten und unverschuldete Not und Elend mit sich bringen konnten.

12. $\mathrm{Zu}$ der Frage, ob die Verwaltung für die unerwünschten Folgen dieser Entwicklung verantwortlich zu machen ist, mag folgendes vorgetragen we:den:

Es hat sich so ergeben, daß die Lenkungsinstrumente, die im Verborgenen ohne großeren Widerstand in Parlamenten leicht durchsetzbar waren, ausuferten und das Steuerrecht mit immer weitergehenden sachfremden Avifgaben belasteten. Frühe Warnungen finden nun eine Bestătigung. Das Steuerrecht wird heute sogar für repressive Zwecke verwendet, indem etwa mißliebige Druckwerke trotz der Verfassungsgarantien des Art. 5 GG durch erhöhte Steuern behindert werden, ${ }^{92}$ oder wenn die etablierten Kirchen durch ihren Einfluß erreichen, daß störende Glaubens- und Religionsgemeinschaften trotz des in Art. 4 GG vorgeschriebenen Schutzes der "Glaubens- und Bekenntnisfreiheit von Minderheiten" durch Verwehrung der Anerkennung als gemeinnitzig im Sinne der $\$ \S 51 \mathrm{ff} A O$ und durch eine geeignete enge Auslegung der

9o Schmolders, G. (1968), Der Staatsbürger .... S. 137.

a Schmōlders, G. (1968), Der Staatsbụnger ..., S. 138.

${ }^{92}$ Gem. Schreiben des BMF in der letzten Fassung vom 16,11.93 gilt der in $\S 12$ Abs. $2 \mathrm{Nr} .1$ u. 2 UStG vorgesehene ermäBigte Steuersatz nicht für Waren des Buchhandels, die aufgrund des Gesetzes uber jugendgefahrdende Schriften von der Bundesprüfstelle in eine Liste aufgenommen werden. Infolge eines gesetzlich 1978 neu geregelten großzügigen Antragsverfahrens werden seither auch politisch und aubenpolitisch ungenehme Schriften, etwa von Flüchtlingsverbalnden, indiziert. Da der Bescheid der Bundesprüfstelle wie ein Grundlagenbescheid ( $\$ 361$ Abs. $1 \mathrm{AO})$ zu behandeln ist, tritt für die Finanzverwaltung eine nicht aussetzbare Bindungswirkung ein. Der Beschluß des BVerfG wom 11.1.1994 (NJW 94, S. 1781) zeigt, daB 15 Jahre Beschwer bis zur Aufhebung eines Verwaltung" aktes vergingen. 
Buchhaltungs- und Aufzeichnungsvorschriften bis zur Auflösung benachteiligi werden. ${ }^{93}$

Schuldzuweisungen an die Behördenleiter der Finanzverwaltung wegen der vielen inzwischen integrierten Lenkungsnormen gehen aber fehl. Finanzausschüsse und Parlamente sind souveräne Beschlußkörper, in deren Beratungen zwar Mitglieder der Verwaltung die Sachkunde der Behörde einbringen, aber nicht entscheiden können. Die Vorstellung, die Bürokratie könne mehr als Empfehlungen beitragen, ist unhaltbar. ${ }^{94}$ Es kann nicht die Aufgabe der Finanzverwaltung in einem demokratisch geordneten Staatsgefuge sein. Regelungsziele der Steuerpolitik zu bestimmen.

13. $\mathrm{Zu}$ der Frage, ob die Finanzverwaltung zu einer Verringerung der Lenkungsnormen beitragen kann, ist folgendes zu sagen:

Die Überfrachtung, des Einkommensteuerrechts mit sachfremden Vorschriften zur Ermittlung der steuerlichen Bemessungsgrundlage hat inzwischen zu einer Belastung geführt, die die Gesetzmäßigkeit der amtlichen Veranlagungstătigkeit behindert. ${ }^{95}$ Nach allgemeiner Überzeugung kann ein befriedigender Zustand nur durch die rigorose Beseitigung eines Großteils der Lenkungsnormen des Einkommensteuerrechts wiederhergestellt werden. Die von vielen Experten beschworene und von allen Medien verbreitete Einigkeit in der Diagnose vermochte bisher jedoch nicht zur Einigkeit in der Sache zu führen, nämlich daniber, auf welche nichtfiskalischen Normen im Einkommensteuerrecht konkret verzichtet werden solle. Nicht wenige Fachleute glauben offenbar, eine geeignete impressionistische Darstellung problematischer Vơrgănge und Zustände führe automatisch zu einer Genesung. ${ }^{96}$ Hierzu sind jedoch überzeugende neue Gestaltungsgesichtspunkte und ein allgemeiner Konsens erforderlich. Beides ist nicht in Sicht. Die Forderung, nichtfiskalische Normen

93 Hierzu: Urt. d. Hess. FG v. 28.10.82 IV 303/79 u. 4K4132\%/86 v.13.12.90; BFH-Beschlosse IR305/82 v.11.12.85 u. I B 16/91 v.16.10.91; ebenso Urt. FG Köln 1K359/85 v.23.11.88 u. BFH. Beschl. II R 44/89. Gegen beide Verfahren wurde Verfassungsbeschwerde eingelegt. Es handelt sich um die Anerkennung der Vereinigungskirche und deren Jugendorganisation als gemeinnôtzig. Die Gruppe ist in allen westlichen Staaten als neue Religion anerkannt. Zu einigen Einzelheiten s. Low, K. (1993).

"Nelner, A. (1985), Bd. 1, S. 177, S. 182, S. 185 u.a.; ders. 1977, S. 121.

15 Jenetzka, J. (1982), S. 274; hierzu: Mitteilungsblatt der Steuerberaterkammer Köln Nr. 4 v. 6.6.93, S. 3: Steuerchaos in Deutschland, ähnlich: Der Steuerzahler (1993).

\footnotetext{
"In zahllosen Veranstaltungen wird ein angebliches "Steuerchaos" als "Klimastörer" beklagt. Die "Normenflut" und eine unzumutbare Komplizierung als Grund für Staatsverdrossenheit wird für alles Negative verantwortlich gemacht. obgleich diese Diskussion so alt wie die Besteuenung ist. In einer gemeinnätzigen "Gesellschaft zur Förderung der Entbürokratisierung e.V." tragen Interessenverbănde venstindliche Ânderungswünsche vor. Bundes- und Verfassungsrichter empfehlen eine Vereinfachung des Rechtsgebietes durch Abschaffung aller Lenkungsnormen. hierzu: Ges. Z Förderung - (1984). Tagungsbericht v.9.11.84; ders. Symposium v. 28.2.94; Strempel, D. (1987); Isensee, J. (1985)
} 
grundsätzlich als Fremdkörper aus dem Einkommensteuerrecht zu entfernen, kann obendrein kurzfristig nicht realisiert werden. ${ }^{97}$ Derartige Forderungen gleichen der Empfehlung, das Skalpell wegen zunehmender Mißerfolge durch unsachgemaßßen Gebrauch aus dem Operationssaal zu entfernen.

14. Viele für die gesetzmaßige Durchführung der Veranlagungstätigkeit zu. ständige Mitarbeiter der Finanzverwaltung sind überzeugt, daß die Einführung der Selbstveranlagung durch die Steuerpflichtigen in Verbindung mit wirksameren Kontrollrechten der Verwaltung und einer Reform des Steuerstrafrechts die erforderliche Entlastung der Verwaltung herbeiführen würde. ${ }^{58}$ Wer Steuervergünstigungen in Anspruch nimmt - so die Meinung vieler Fachleute ; hat sich durchweg mit der Gesetzesmaterie vertraut gemacht und ist zumeist beraten. Die beklagte Kompliziertheit des Einkommensteuerrechts behindent weniger den Steuerbürger, als die Veranlagungsbehörde bei Wahrnehmung ihrer gesetzlich vorgeschriebenen Verpflichtungen.

15. Die neueste Entwicklung hat nun eine Wende gebracht, die zu Ändenungen der Einkommensbesteuenung in der Bundesrepublik von noch unüberset. barer Tragweite führen kann. Hierzu soll nachfolgend Stellung, genommen werden:

Durch Beschluß des Ersten Senats vom 25. September 1992 hat das Bundesverfassungsgericht für Recht erkannt, daß der in der Tarifvorschrift des geltenden EStG enthaltene sogenannte Grundfreibetrag ( $\$ 32$ a Abs. 1 Ziff. 1 ESIG) spätestens seit 1978 verfassungswidrig sei, weil er nicht gewährleistet, daß "dem Steuerpflichtigen nach Erfüllung seiner Einkommensteuerschuld von seinem Erworbenen soviel verbleiben, als er zur Bestreitung seines notwendigen Lebensunterhaltes und ... desjenigen seiner Familie bedarf (Existenzminimum)". ${ }^{99}$ Das Gericht hat dem Gesetzgeber auferlegt, bis 1996 verfassungskonforme Neuregelungen zu schaffen. Dabei suchte das Gericht, ausgehend vom geltenden Einkommensbegriff, für die Bestimmung des Existenzminimums unter Berïcksichtigung der Vorschriften des Sozialhilfegesetzes einen neuen Terminus "Erwerbsbezüge" festzulegen, der einen Maßstab für die Făhigkeit ergibt, den "notwendigen Lebensunterhalt aus eigenen Krăften

\section{S. 189.}

${ }^{97}$ Zitzelsberger, H. (1985), S. 204; Tipke, K. (1989) Öber Steuervergünstigungen .... S. 186, hia

${ }^{97}$ Diese Auffassung vertreten zumeist die Mitarbeiter der Finanzverwaltung, die unmittelbar in der Veranlagung tâtig sind.

${ }^{99}$ Entscheidungen des BVerfG v.25.9.92, 87. Bd. Tabingen 1993, S. 153. Die nachfolgenden Aw" fuhrungen zu diesem Problemkreis entsprechen dem Stand vor Tatigwerden des Gesetzgebers zu Ende 1993. 
und Mitteln, vor allem aus eigenem Einkommen und Vermögen" zu bestreiten, wie es im Sozialhilfegesetz (SHG) heißt. ${ }^{100}$

16. Aus der Sicht der Finanzbehörden ist dazu folgendes zu sagen: Seit Geltung des Bundessozialhilfegesetzes vom 30. Juni 1961 haben diejenigen Bürger, deren "notwendiger Lebensunterhalt" im Sinne von § 12 SHG nicht erreicht wird, einen in $\S 4$ SHG gewährten Rechtsanspruch auf Auffullung ihrer Unterhaltsmittel gemăß $\S 11$ SHG auf die Hohe des in $\S 22$ SHG bestimmten "Regelbedarfes". Diesen Anspruch können auch Einkommensteuerpflichtige geltend machen, da das SHG subsidiăren Charakter hat. ${ }^{101}$ Für die Zukunft soll dennoch nach dem Spruch des Gerichts als Folge einer unterstellten Bindung des einkommensteuerlichen Girundfreibetrages an die Regelsătze des SHG für die betroffenen Personen keine Einkommensteuer mehr entstehen. Die von den Gemeinden betriebene Verwaltung der Sozialhilfe ${ }^{102}$ wird dann um diese Fälle nur unwesentlich entlastet. Die Finanzämter werden dagegen zusätzliche Veranlagungen unter Berücksichtigung von Gesichtspunkten des SHG durchführen müssen. Der Begriff der "Enwerbsbezüge" umfaßt dabei einen nicht abgeschlossenen beispielhaften Katalog anzurechnender Unterhaltsmittel. ${ }^{103}$ Die Finanzämter werden zusălzzlich erheblich belastet: denn auch kleine Lohnsteuerpflichtige, bei denen bisher eine Veranlagung entfiel, werden schon ab 1993 zur Abwehr von Mißbrăuchen veranlagt werden müssen. ${ }^{104} \mathrm{Ob}$ die für die Sozialhilfe zustăndigen Gemeindebehörden überhaupt entlastet werden, muß fraglich erscheinen. Viele bisherige Sozialhilfeempfänger bleiben zur Ergånzung ihres Lebensunterhalts berechtigt. Die Finanzverwaltung andererseits wird personalintensive Veranlagungen durchführen müssen, die für Massenverfahren ungeeignet sind. Völlig neuartige Kontrollen und Prüfungen werden wegen möglicher mißbräuchlicher Inanspruchnahme unvermeidlich. Rechtsbehelfs- und Rechtsmittelverfahren vor Finanzbehörden und Finanzgerichten werden anschwellen und Verwaltungsgerichte nur teilentlasten. Nach den Ausfuhnungen des Verfassungsgerichts ist der neuaruige, an dem "Hermann-Schmollerschen" Einkommensbegriff anknūpfende Begriff der "Erwerbsbezüge" als Maßstab für die anrechenbare eigene Leistungsfähigkeit vorab bei Veranlagungen aller Grenzfa!le zu be-

\footnotetext{
$100 \$ 11$ Abs. 1 SHG. v. 30.6 .61 i. d. F. v. 20.1.87. BGBl. I. S. 400.

101 Bundessozialhilfegesetz mit Durchführungsverordnungen und Erlăuterungen von B. Schulte. Munchen 1988, S. 32

${ }^{102}$ Ders.: BSHG..., S. 21 , s. $\$ \S 96$.

${ }^{105}$ Definition in $\$ 32 \mathrm{~d}$ Abs. 1 EStG in der fur 1993 geltenden Fassung.

It: Als Konsequenz des Urteils hat $\S 46$ Abs. 2 EStG ab 1993 durch Ziff. 7 eine zweizeilige Einfugung erhalten, die wegen komplizierter Zusatztabellen auf den neuen $\$ 61$ EStG mit einer Linge von 41 Zeilen verweist.
} 
rücksichtigen. Bei Steuerpflichtigen mit höheren Einkünften mag es dann bei den bisherigen Regelungen bleiben. Jedenfalls wird aber wegen der Erhöhung des Grundfreibetrages eine starke Anhebung der Tarifprogression unvermeidlich werden, da Einbußen von Einnahmen der wichtigsten Geldquelle des Sozialstaates für die Umverteilung ausgeglichen werden müssen. ${ }^{105}$ Dabei ist zu berücksichtigen, daß die höhere Steuerbelastung vornehmlich Steuerpflichtige der mittleren und unteren Einkommensgruppen beschwert. Daß dic Haushaltslage drohende Einnahmeausfälle selbst bei Berücksichtigung der Empfehlungen des Gerichts, überflüssige, nichtfiskalische Normen im Einkommensteuergesetz abzubauen, nicht verkraften kann, ist allgemein bekannt. Ein schneller Abbau gesetzlich gewährter Subventionen ist nicht möglich.

Noch gravierender erscheint der Umstand, daß der Gesamtzusammenhang des Einkommensteuerrechts ohne Neuordnung ab 1996 nicht mehr widerspruchsfrei gewährleistet erscheint.

Das wurde bisher noch nicht ernsthaft erörtert. Zu Recht machte kürzlich in dem Organ der Bundessteuerberaterkammer ein leitender Mitarbeiter des Bundesfinanzministeriums warnend darauf aufmerksam: "Man braucht kein Prophet zu sein, um vorauszusagen, daß bei der mit Wirkung ab 1996 notwendigen gesetzlichen Neuregelung der Bereich 'Erwerbsbezüge' die schwierigsten Fragen aufwirft, die möglicherweise nur über eine Neudefinition des steuerrechtlichen Einkommensbegriffes gelöst werden können". ${ }^{106}$ Das kann das Ende eines Einkommensteuergesetzes bedeuten, das seit der Wirksamkeit von Popitz Gesichtspunkten der Gerechtigkeit gegenüber wirtschaftspolitischer Effizienz Nachrang einräumte und eine Besteuerung nach der Leistungsfähigkeit vernachlässigte, dafür aber für das Gemeinwesen vorteilhafte wirtschaftspolitische Eingriffe erlaubte. Der Begriff "Erwerbsbezüge", nach dem sich der Beginn des Steuerzugriffs richten soll, wird sich kaum mit dem geltenden dualistischen Einkommensbegriff vereinbaren lassen. $\mathrm{Ob}$ damit höherer Gerechtigkeit gedient wird, muß sich erst noch in den Auswirkungen zeigen.

17. Das Verfassungsgericht wurde zu seinem Urteilsspruch nach Verfahrensaussetzung gemäß Art. 100 Abs. I GG von drei Finanzgerichten zur Entscheidung über die Frage der Verfassungsmäßigkeit des Grundfreibetrages

105 Woring, S. (1992), S. 9162; im übrigen ermöglicht das Urteil ìm Zusarmenhang mit dem gettenden EStG erhebliche Steuervermeidungen bei wohthabenden Familien, die ihre Verhăltnisse optimal gestałten kọnnen. Bei Uniersiellung eines Existenzmninimums von DM 10.500 , - für Nichterwerbstâtige bleiben bei einer fünfoöpfigen. Familie DM 52.500,- pro Jahr steuerfrei.

${ }^{106}$ Rendels, H. J. (1993), S. 893, insbes. S. 895. 
angerufen. ${ }^{107}$ Die drei Klăger fühlten sich durch den nicht den Regelsătzen des SHG entsprechenden Höhe des Grundfreibetrages beschwert. Sie hielten die ihnen entstandenen Einkommensteuern für verfassungswidrig. Pikanterweise betrugen die zu versteuernden Einkommen von zwei Klägern ca, DM $120,000,00$ bzw. DM 135,000,00. Der dritte Kläger ist Professor für betriebliche Steuerlehre. ${ }^{108}$ Als notleidend und hilfsbedürftig im Sinne von $\$ 22$ SHG wird man wohl keinen der Kläger bezeichnen können. Im Hintergrund der Klagen stand die Frage, ob sich auch Steuerpflichtige mit hohen Einkünften darauf berufen können, daß der Grundfreibetrag wegen Abweichens vom Existenzminimum verfassungswidrig und die Steuerlast daher auch bei ihnen zu mindern ist. Tipke hat die Frage auf die Formel gebracht "Existenzminimum auch für Reiche?". ${ }^{109}$ Das Verfassungsgericht hat für die Beurteilung dieser Frage als bedeutsam herausgestellt, daß die deutsche Einkommensteuer "traditionell nur das verfügbare Einkommen (gemeint ist nach Abzug des notwendigen Lebensunterhalts, d. V.) belastet" und "die zur Finanzierung des existentiellen Bedarfs benötigten Einnahmen in der einen oder anderen Form von der Besteuerung frei(stellt)" ${ }^{110}$ Es sucht offenbar diese unterstellte Tradition zur Beurteilung des heute geltenden deutschen Einkommensteuerrechts heranzuziehen. Eine ähnliche Auslegung der Entstehungsgeschichte des deutschen Einkommensteuerrechts unterstellte das Finanzgericht Münster in seinem Urteil vom 1. Februar 1991. ${ }^{111}$ In dem Beschluß vom 25. September 1992 verweist der Verfassungsgerichtshof zum Nachweis auf das preußische Einkommensteuergesetz vom 1. Mai 1851, indem er ausführt, daß die klassifizierte Einkommensteuer nur von denjenigen Bürgern erhoben wurde, deren Jahreseinkommen 1.000 Taler überschritt $(\$ 16)^{112}$ Dabei übersieht das Gericht aber, daß die Klassensteuer als Teil der Einkommensteuer ohne Eingangsfreibetrag bei Einkommen bis zur Höhe von 1.000 Talern erhoben wurde $(\$ \S 7$ bis 9). ${ }^{113}$ In dem preußischen Einkommensteuergesetz von 1873 wurden dann die untersten Stufen wegen der Aufwendigkeit der Erfassung abgeschmolzen, so

107 FG Münster, VorlagebeschluB vom 1.2.91 16K936/90E, in: EFG 1991, S. 253; Niedersâchs. FG, Vorlagebeschlu B v. 15.1.91 DX 427 u.437/90, in: EFG 91, S. 260 ff, FG des Saarlandes, VorlagebeschluB v.19.3.91, $1 \mathrm{~K} 84 / 91$, in: EFG 91 , S. 330.

\footnotetext{
19 Bilsdorfer, P. (1992), S. 1421. Bildsdorfer ist Richter am zuständigen FG.

195 Tipke, K. (1990), Einkommensteuerliches Existenzminimum .... \$. 349.

110 Entscheidung des BVerfG v.25.9.92, S. 155.

III Entscheidung, FG Mûnster v.1.2.91, 16K936/90 E, in: EFG 91, S.253.

112 Entscheidungen d. BVerfG (wie Anm. 108), S. 156.

III $\$ 9$ i. V. m. $\$ 7$ Gesetz betreffend die Einfuhrung einer Klassen- und klassifizirten Einkommensteuer v.1.5.1851, in: Gesetz-Sammlung für die. Königl.-PreuB.Staaten 1851, Nr. 12, S. 193, hier S. 195.
} 
daß die Klassensteuer mit weiterhin 12 Stufen erst bei 140 Talern einsetzte. ${ }^{114}$ Im übrigen bestimmte in Preußen das Haushaltseinkommen die Bemessungsgrundlage, während in Sachsen und anderen Ländern auf das Einkommen einer Person abgestellt wurde. ${ }^{115}$ Ein ähnliches Bild vermitteln die Gesetze der übrigen deutschen Bundesländer bis zum Ende des Kaiserreichs. ${ }^{116}$ Sie zeigten 1879 im einzelnen - einem Flickenteppich gleich - unterschiedlichste Regelungen. Die These des Verfassungsgerichts bestätigen sie nicht. Verschiedene Länder kannten um 1880 keine Eingangsstufe. Andere setzten sie in einer Höhe von 300 Mark bis 600 Mark fest. Das blieb so bis 1920. Entscheidend waren stets die Erfordernisse des Haushalts und verwaltungsmäßige Schwierigkeiten bei dem Vollzug von Kleinstbeträgen. ${ }^{117}$ Denn die vorherrschende Meinung verschaffte den Tarifbestimmungen eine früh beginnende Proportionalzone mit Zugriffen von $3 \%$ bis $5 \%$, die für die kleinen Einkommen bis auf $0,02 \%$ gemindert wurde (Sachsen, Gesetz vom 22. Dezember $1874,{ }^{118}$ im Gesetz vom 2. Juli 1878, das der preußischen Reform von 1891 als Vorbild diente, wurden daraus 0,13\%). ${ }^{119}$ Als die Mitglieder des Vereins für Socialpolitik sich ab 1872 für eine Milderung der mit der Industrialisienung einhergehenden anpassungsbedingten Not breiter Schichten durch Eintreten für eine soziale Ausgestaltung des gesamten Institutionengefüges einsetzten, gab es nur ein von Land zu Land unterschiedliches uneffektives Armenrecht. ${ }^{120}$ Sie suchten daher das Schicksal der Hilfsbedürttigen in jeder Weise zu verbessern. Die Verteilung der Steuerlast nach der Leistungsfähigkeit war eines der frühen Programmpunkte. ${ }^{121}$ Sie sollte durch eine proportionale und degressive und spater auch progressive Tarifgestaltung erfolgen. Weiterhin forderte man Regelungen als Gemeinnützigkeitsvorschriften und Steuerbegünstigung von Kleinwohnungen, soziale Hilfskassen, Kündigungsschutzbestimmungen, Arbeiterschutz- und neuartiges Tarifrecht für Arbeitnehmer, staatliche Vergünstigungen für "offentliche Leihhäuser" und Sparkassen etc., um den "standard of life" - so Gustav Schmoller bereits 1864 - der Minderbemittelten zu he-

$114 \$ 7$ Gesetz wegen Abünderung des Gesetzes v. 1.5.1851 betreffend die Einführung einer Klas. sen- und klassifizierten Einkommensteuer v. 25.5.1873, in: Gesetz-Samml. f.d. Kgl-PreuB.Staaten 1873, Nr. 16. v. 4.6.1873, S. 213, hier S. 215.

115 wie Anna. 111, \$. 196.

${ }^{116}$ Helft, E. (1908), S. 130, hier S. 210 ,

117 Burkart, K. (1879), S. 8.

$118 \$ 15$ salchs. EStG 1874, S. 475.

49 \& 17 preuB. EStG v. 24.6.1891, S. 175, hier S. 183.

${ }^{120}$ Laum. B. (1923). S. 954; s. auch Schmoller, G. (1902), S. 8.

12) Verhandlungen der dritten Generalversammlung des Vereins: fur Socialpolitik arn 10., 11. und 12. Oktober 1875, in: Schriften des Vereins .... XI. Bd, Leipzig 1875, S. 15. 
ben. ${ }^{122}$ Die Gedanken fanden bald Eingang in alle Bereiche der Gesetzgebung. Soweit die Haushaltslage es jeweils erlaubte und es okonomisch zweckmäßig erschien, wurden in den Einkommensteuergesetzen zusätzlich zu der starken Steuerdegression die oben erwähnten untersten Stufen als tarifliche Grundfreibetrăge eingeführt. In Preußen wurde der aus der Literatur übernommene Begriff des Existenzminimums dabei metaphorisch in den Erörterungen des Landtags nach 1883 verwendet. ${ }^{123}$ Damit wurde der Ausgangsbetrag der untersten Steuerstufe bezeichnet, die dann 1891 von vormals 420 Mark auf 900 Mark für den Haushaltungsvorstand, einschließlich der mit diesem nach dem Gesetz zusammenveranlagten Angehörigen, angehoben wurde. Die Steuerdegression wurde dabei auf $0.6 \%$ abgesenkt. Nach Hans Herzfeld hätte eine von Wagner und anderen geforderte höhere Eingangsstufe aus Haushaltsgründen mit Bestimmtheit in den Verhandlungen des Landtags zu höheren indirekten Steuern geführt, was Miquel und ebenso Wagner nicht wünschenswert erschien. ${ }^{124}$ Die stärkere anteilmäßige Steuerentlastung der unteren Einkommen ließ sich - wie auch Wagner darlegte - bei Berücksichtigung der Erfordernisse des Haushalts weder durch degressive Tarifgestaltung, noch - wegen der Unmöglichkeit, indirekte Steuern zu berücksichtigen - durch weitere Erhöhung des Eingangsbetrages erreichen. Eine völlige Freistellung der untersten Gruppen blieb im übrigen schon wegen des Gleichheitsgebotes stets umstritten. ${ }^{125}$ Darüber hinaus hătte das Verfassungsgericht vielleicht berücksichtigen solllen, daß eine flüchtige Lektüre der Bestimmungen geeignet ist, einen fehlerhaften Eindruck von der Lastenverteilung zu erzeugen. Der Schmoller nahestehende Ignaz Jastrow kritisierte 1893 in den Preußischen Jahrbüchern, daß die zu den Miquelschen Steuerreformen zählende Gemeinde-Einkommensteuer gegebenenfalls Zuschläge festlegen durfte, die die Degression der Staatssteuer durch eine Progression nach unten, also durch stärkere Belastung der Armen glatt aufheben konnte. Dabei betrugen die Zuschläge oftmals ein Mehraches der Staatssteuer.

18. Zu der Urteilsbegründung des Verfassungsgerichts ist daher festzuhalten, daß - anders, als das Gericht unterstellt - die Entwicklung der Einkommensteuer im 19. Jahrhundert kein Regelungsziel kannte. die Eingangsstufen des Einkommensteuertarifs auf die Höhe des Existenzminimums festzulegen. Einzelne Autoren haben dies zwar gefordert, die Auffassungen blieben jedoch

\footnotetext{
122 Schmoller, G. (1864), S. 524, S. 538 ff u. ders. (1865), S. 552.

12 Herzfeld, H. (1937), Bd. 1, S, 477.

124 Ders., Bd. 2, S. 216 f, S. 227 f, S. 232.

125 Wagner. A. (1890), S. 402. S. 447. Der Versuch, die Höhe der anfallenden indirekten Steuern mit dem Einkommen ins Verhalltnis zu setzen, ist nie recht gelungen; s. Helft, E. (1908), S. 214.
} 
umstritten, das Existenzminimum obendrein unterschiedlich definiert. ${ }^{126}$ So glaubten einflußreiche Autoren, auch Steuerzahlungen gehörten zum notwendigen Existenzminimum, da niemand ohne Staat leben könne. ${ }^{127}$ Grundfreibeträge in den Gesetzen waren zur Vereinfachung des Vollzuges und zur Entlastung der minderbemittelten Steuerpflichtigen vorgesehen. Im übrigen waren ein verbessertes und vereinheitlichtes Armenrecht und die Angehörigen im Falle von Hilfsbedürftigkeit zuständig. ${ }^{128}$

Im 20. Jahrhundert wurden dann die Ansätze zur Sozialpolitik zu einem systematisch aufgebauten umfassenden, dem Bürger Rechtsansprüche gewährenden sozialen Netz gefügt, das die Bedeutung der hilfsweisen sozialen Einfügungen in verschiedene Einzelgesetze aufhob oder jedenfalls zurückdrängte. $^{129}$ So konnte auf das Wohnungsgemeinnützigkeitsrecht nach Einführung des Wohngeldgesetzes verzichtet werden. ${ }^{130}$ Die Steuerbegünstigungen der Sparkassen wurde mit der steuerlichen Fördenung der Sparleistungen kleiner Sparer überflüssig und beseitigt ${ }^{131}$. Die Tarifbestimmungen des Arbeitsrechts haben heute ebenso veränderte Regelungsziele erhalten, seitdem nicht mehr die Garantie des Existenzminimums des Avbeitnehmers Prioritat hat. ${ }^{132}$ Das

${ }^{126}$ Vocke, W. (1894), S. 180. Der Abzug des standesgemãBen Unterhalts als Existenzminimum war das Regelungsziel zur Jahrhundertmitte; siehe: Biersack. H. L. (1950), S. 22, S. 36, S. 39, S. 149. Ähnliche Auffassungen finden sich bei Rau und Roscher. Erst Hermann und dann Schmoller haben damit gebrochen. Schmoller vertrat 1863 den Standpunkt, daB die gesamte Steuerzahlung eines Steuerpflichtigen einschl. der indirekten Steuem einer der Leistungsfahigkeit proportionalen Lastenverteilung, entsprechen sollte, Schmoller, G. (1863), S. S.

${ }^{127}$ Cohn, G. (1889), S. 275. Cohn war ein einflußreicher Nationalōkonom und Mitglied des Vereins furr Socialpolitik; hierzu: Schanz, G. (1923), S. 911. Schanz nennt Rottek, Gneist, Nasse, Cohn und Held als Gegner der Steuerfreiheit, Schanz gibt deren Meinung nur unvollkommen wieder. Auch das oftmals mit der Aufnahme in Steuerregister verbundene Wahlrecht spielte hier eine Rolle. s. Helft, E. (1908), S. 216: siehe auch: Moll, W. (1918), S. 93. "Jeder Arbeiter ist zugleich Bürger und soll ... auch durch das Steuerzahlen dies empfinden" so Schmoller (1863), S. 37. Er sah in der Pflicht Einkommensteuer zu zahlen "das Band des Einzelnen ... mit dem ... Staatsmittelpunkt" (S. 57). Er forderte daher "zwar Erleichterung aber keine Steuerfreiheit des Existenzminimums" (S. 83).

128 Wagner, A. (1890), S. 404.

${ }^{129}$ Hierzu: Lampert, H. (1988), S. 283. Das BSHG hat das Armenpflegerecht des 19. Jahrhunderts und die Soziaifürsorge abgelöst. Die Sozialhilfe ist mit Rechtsanspruch des Bûrgers ausgestattet. der Schlubstein des Systems sozialer Sichenung.

${ }^{130}$ Die steuerliche Beganstigung des Baues von Kleinwohnungen und eines gemeinnützigen Wohnungswesens war seit 1864 eine oftmals vorgetragene Forderung Schmollers, s. hierzu: Hansen, R. (1993), S. 176, Annm. 212. Die im Zuge von Maßnahmen zur Konjunkturförderung als Teil der ersten Notverordnung des Reichspräsidenten erlassenen Bestimmungen über die "Gemeinnützigkeil von Wohnungsuntemchmen" (RGBI. I 1930, S. 530 A) wurde inzwischen im Steuerreformgesetz 1990 (BGBI. I v.2.8.88. S.1093, BStBI. 88, Teil I. S. 105, hier S. 110) beseitigt; hierzu: Hansen, R. (1993), S.177.

i3) Koschorreck, W., S. 256.

${ }^{132}$ Der Schutz des Arbeitnelumers wurde inzwischen in einer Folle von Einzelbestimmungen in den verschiedensten Gesetzen sichergestellt (Z.B. Gewerbeordnung. KündigungsschutzG, ZivilprozeBordnung. $\mathrm{BGB}$, Konkursordnung. ArbeitsforderungsG u. a.) Die Bestimmungen sorgen für Sicherstellung 
Einkommensteuerrecht hat die Grundfreibeträge als Bestandteil der Tarifprogression beibehalten. Es hat im übrigen an Bedeutung gewonnen, indem es zu der wichtigsten Einnahmequelle für die Finanzierung des Sozialstaats aufrückte und heute obendrein schwer entbehrliche Funktionen als Instrument der allgemeinen Wirtschaftspolitik übernahm.

Die Erwartungen der drei Kläger, deren Verfahren dem Beschluß des Bundesverfassungsgerichtes vom 25. September 1992 zugrundelagen, wurden dennoch in wesentlichen Punkten erfüllt. Das Gericht bestătigte, daß ein höheres, von den Vorgaben des Bundessozialhilfegesetzes bestimmtes Existenzminimum bei Ermittlung der Einkommensteuer steuerfrei zu belassen ist. Das Urteil überläßt aber - wie es scheint - dabei dem Gesetzgeber die Entscheidung darüber, ob der Abzug sogenannter "unvermeidbarer Privatausgaben" als Positionen der Einkommensverwendung von der Bemessungsgrundlage oder, wie bisher, von der Steuerschuld als Folge der Tarifbestimmungen vorzunehmen ist. ${ }^{133} \mathrm{Im}$ letzteren Fall betrăgt die Steuerersparnis dann gleichmäßig für alle Steuerpflichtigen bei Ansalz des gültigen Grundfreibetrages nach den heutigen Tarifvorschriften DM 1.067,--. Bei Abzug von der Bemessungsgrundlage würde die Steuerminderung dagegen nur in der Eingangsstufe DM 1.067,-ausmachen. Bei steigendem Einkommen würde sie dann in der höchsten Progressionsstufe auf das 2,79-fache dieses Betrages anwachsen. Diese letztere Regelung wird von der großen Mehrheit der Steuerjuristen als "aus der Natur der Sache folgend", also als "richtig" gefordert. ${ }^{134}$ Zur Begründung dieser von rechtsdogmatischer Vorgehensweise bestimmten Lehre wird vorgetragen, die progressive Entlastungswirkung ergebe sich als "systemnotwendige Kehrseite" oder als "sachgerechter Reflex"135 eines progressiven Tarifs. "Der Abzug eines Grundfreibetrages von der Bemessungsgrundlage", so heißt es bei einem fuhrenden Steuerrechtler, "ist keine Steuervergünstigung, keine Sozialleistung sondern der Ausdruck reduzierter steuerlicher Leistungsfähigkeit, dem die Reduktion der Bemessungsgrundlage durch Abzüge (Freibeträge) Rechnung trăgt". ${ }^{136}$ Tatsăchlich zeigt die Rechtsprechung des Bundesverfassungsgerichts zu dieser Frage widersprüchliche Beurteilungen. Daher konnte Tipke zu der

\footnotetext{
angemessener Lohne, evtl. durch Konkursausfallgeld u. subsidiär durch eingreifende Sozıalhılte; hıera: Lampert, H. (1988), S.135.

133 Das BVerfG weist dem Gesetzgeber, wie es scheint, in dieser Frage einen Gestaltungsspielraum zu; s. BVerfG-Urt. v.25.9.92, in: Entscheidungen .... (1993), 87. Bd., S. 169/170.

13 Auch Tipke vertritt diesen Standpunkt, wobei Widerspruche zu den Ausfuhrungen in Tipke, K (1993), Die Steuerrechtsordnung, S. 687, aufzutreten scheinen. Anderer Auffassung sind Giloy, J. (1986), Lehner, M. (1985), Schneider, D. (1984 u. 1993).

us Tipke, K. (1993), Die Steuerrechtsordnung, S. 687.

136 wie Anm. 135.
} 
Feststellung gelangen, daß sich das Gericht der Auffassung der Steuerrechtswissenschaft angeschlossen habe. ${ }^{137}$ Die Steuerjuristen vertreten mit einer Ausnahme diese Beurteilung, die inzwischen durch Beschluß des 57. Deutschen Juristentages sogar quasioffizielle Bedeutung erhielt. ${ }^{138}$ Eine Folge dieser Regelung wäre, daß die Beurteilung wieder derjenigen vieler Autoren zur Mitte des 19. Jahrhunderts vor Gründung des Vereins für Socialpolitik nahe käme. Von ihnen wurde gefordert, bei Ermittlung des steuerpflichtigen "ReinEinkommens" den standesgemäßen Unterhalt abzuziehen. ${ }^{139}$ Mit dieser Auffassung hatte sich bereits 1863 Schmoller ablehnend auseinandergesetzt, zumal für ihn auch der Verbrauch als Maßstab für die Leistungsfähigkeit eines Steuerbürgers bei Aufteilung der Lasten des Gemeinwesens infrage kam. ${ }^{140} \mathrm{Er}$ definierte Einkommen für diese Zwecke als den Wert alles dessen, was ein Bürger in einem Zeitabschnitt für seine umfassenden Bedürfnisse aufwenden kann, ohne sein Vermögen anzugreifen. Entlastungen für notwendige Privatausgaben aus sozialen Gründen gehörten für ihn in die Tarifvorschriften.

Indem das Verfassungsgericht der Einkommensteuer Funktionen zuweist, für die eine neuartige Systematik erforderlich wird, erschwert es die Wahrnehmung der Obliegenheiten, in die sie infolge einer von der Entwicklung diktierten Aufgabenverteilung hineingewachsen ist. Es ergibt sich die Frage, ob das Bundesverfassungsgericht die dem Beschluß vom 25. September 1992 zugrunde liegenden Gesetzesregelungen unter anderen Gesichtspunkten auf ihre Vereinbarkeit mit höherrangigen Erfordernissen der Gesellschaft hätte prüfen müssen. $\mathrm{Daß}$ eine andere Beurteilung der Vereinbarkeit der hergebrachten Grundfreibeträge des Einkommensteuerrechts mit Verfassungsbestimmungen widerspruchsfrei möglich war, haben das Finanzgericht Köln, der Bundesfinanzhof und ein führender Fachautor zu vergleichbaren Vorgängen schlüssig nachgewiesen. ${ }^{\text {(4I }}$

137 Tipke, K. (1993), Die Stenerrechtsordnung. S. 688.

138 Abgedr. in NJW 1988, S. 2998, Verhandlungen des 57. Dt. Juristentages, Sitzungsberichte Sektion N, S. 214

139 Biersack, H.-L. (1850), S. 150 ff, s. Auseinandersetzungen mit den Begriffen Roh- und Reineinkommen in: Schmoller, G. (1863), S. 2, S. 26, S. 45.

140 Schmoller, G. (1863), S. 54, S. 76, S. 78: "Die Gesamtsumme, welche der Einzelne an verschiedenen. Steuern zahit, soll ungefahr seinem Einkommen entsprechen, nicht, die einzelne Steuer; sondem das Gesamtsystern soll sein MaB am Einkonnmen haben. Der nothwendige Lebensbedarf is! etwas vollkommen Relatives und je nachdem man ihn fasst, ist in keinem Stand und in keiner wirthschaflichen Klasse ein großer Dberschuß aber dea notwendigen Lebensbedarf vorhanden" (S.80)"Wir verlangen nicht verschiedene Behandlung des nothwendigen und des freien Einkommens, sondem nur eine bilitige Anlage des ganzen Steuersystems, weiche bei niederen Einkommen einige Erleichterung bis zur Möglichkeit der Erreichung von freien Einkommen gewalhri" (S. 83).

${ }^{141}$ FG Kóln U. v. 14.7.88 \$K424/88, in: EFG 1988, S.581; BFH U. v. 8.6.90 III R 14-16/90, in: BStB1. II 1990, S. 969: Tipke, K. (1990), Einkommensteuerliches Existenzminimum .... S. 350, letzter 


\section{Der gesellschaftspolitische Hintergrund bei Entstehung der Einkommensteuer und die Beurteilung der neueren Entwicklung durch den Soziologen}

Der Soziologe mag zur Analyse der sozialpolitischen Auswirkungen des geltenden Einkommensteuerrechts bei Berücksichtigung der Entstehungsgeschichte folgendes beitragen:

1. Die Einführung und Neugestaltung der Einkommensteuer war einer der ersten Verhandlungsgegenstände des im Jahr 1872 begründeten Vereins für Socialpolitik. ${ }^{142}$ Bei den Mitgliedern herrschte 1875 Einigkeit darüber, daß höhere Steuergerechtigkeit durch Berücksichtigung der Leistungsfähigkeit der Steuerbürger vermittels addierter Erfassungen der Wertzugănge und Berücksichtigung des Vermögens in einer einheitlichen Bemessungsgnundlage durch eine progressive Ausgestaltung des Tarifs bei Rücksichtnahme auf die sozialen Verhältnisse der Pflichtigen den Maßstab für die Verteilung der Steuerlast bestimmen müsse. ${ }^{143}$

Die von Schmoller 1863 beigetragene Besteuerungsidee bestimmte seit 1872 die Reformerörterungen in der Zweiten Kammer des săchsischen Landtags und die Berichterstattung in den Fachzeitschriften. ${ }^{144}$ Die Besteuerungsidee Schmollers hatte sich von der aus dem Denken der nachklassischen Ökonomie fortgeführten Begriffswelt gelöst. ${ }^{145}$ Schmoller hatte die Ermittlung des Einkommens an die Grundgedanken der bewährten realitătsnahen kaufmănnischen Rechnungslegung angelehnt. Die Definition ließ sich im übrigen zu einer praktikablen Meßvorschrift ausgestalten. Diese wird im Grunde von jedern steuerlichen oder wirtschaftichen Betriebsprüfer noch heute für verschiedene wirtschaftlich und auch amtliche Zwecke verwendet. ${ }^{146}$ Bei seiner Definition des Einkommens- und Vermögensbegriffs hat Max Weber über 40 Jahre spãter einen ähnlichen Weg beschritten, wenn er beide Größen mit sẹ-

Abs:; Tipkes Ausführungen enthalter mit spitteren Stellungnahmer, Widerspruche, die nicht auflossbar zu sein scheinen.

${ }^{142}$ Verhandlungen der dritten Generalversammlung des Vereins für Socialpolitik vom 10., 11. und 12. Oktober 1875, in: Schriften des Vereins .... Bd. IX; s. auch: Boese, F., S. 23 u. S. 305.

10 Beiträge und Beschlüsse in Verhandlungen der dritten Generalversammlung, S. is.

14 Kônigl.-Săchs. Landtags-Acten von đen Jahren 1871/72. Beilage zur dritten Abtheilung, die Berichte der Zweiten Kammer enthaltend, 3. Bd. 1873, S. 435; hierzu auch Fundstellen in: Hansen, R. (1990), S. 14 u. S. 53.

is Schmoller, G. (1863), S. 26.

us Zur Schătzung von Besteuerungsgrundlagen gemẳ §̧ 162 AO kommt der Vermógenszuwachs. rechnung große Bedeutung zu. Deren Schema wurde bisher stets hőchstrichterlich anerkannt. Zur Prüfung der Plausibilităt von Vorgängen der Rechnungslegung wird sie im gesamten Abrechnungswesen verwendet, hierzu: BFH U. v. 8.11.1990, in: BStBI. II, S. 268; s. auch: NWB, Fach 17, S. 1174. 
nem Machtbegriff als "Chance" in Verbindung brachte. In Webers soziologischen Beitrăgen ist Einkommen "derjenige in Geld geschätzte Betrag", der als "Zugang" der "insgesamt verfügbaren Güter und Chancen ... während einer Periode zur Verwendung verfügbar" ${ }^{147}$ ist. Max Weber und Gustav Schmoller richteten gleichermaßen ihre besondere Aufmerksamkeit auf die Machtverteilung in der Gesellschaft, die der Klassenspaltung zugrunde lag.

2. Wenn das sächsische EStG 1874/78, das erklärtermaßen der Schmollerschen Besteuerungsidee folgte, nicht auf größere Kritik und starren Steuerwiderstand stie $\beta,{ }^{148}$ so wird das nicht zuletzt an dem allgemein überzeugenden Einkommensbegriff und dem damit abgestimmten Vollzug gelegen haben. Anders verlief die Entwicklung in Preußen. ${ }^{149}$ Sowohl das EStG 1891, als auch die dazu erteilten Vollzugsvorschriften folgten nicht wirtschaftlichen Sachverhalten, sondern streng formalistisch definierten Merkmalen. So wurde für die Steuerbarkeit eines Sachverhalts nicht auf die Bereicherung des Steuerpflichtigen als dem wirtschaftlichem Vorgang, sondern formal auf das Merkmal des Zuflusses als Ertrag aus einer in dem Enumerativkatalog des Gesetzes auf́geführten Quelle, also auf das "Woher" als Tatbestandsvorausselzung entscheidender Wert gelegt. ${ }^{150}$ Der einflußreiche Berliner Finanzwissenschaftler Adolph Wagner betrieb Nationalökonomie und Finanzwissenschaft als dogmatische Wissenschaften nach Art der Jurisprudenz. ${ }^{151}$ Die Begriffe "dogmatisch" und "theoretisch" verwendete er gern als Synonyma. ${ }^{152}$ Er bekannte sich zu der Methodenlehre Carl Mengers und behandelte praktische Fragen durchweg durch rein begriffliche Erörterungen bei Verwendung von unterstellten letzten, unmittelbar als wahr erkennbaren, heute sogenannten

147 Weber, M. (1985), S. 45.

148 Gensel, J. (1875), S. 499; Bliher (1913), S. $620 \mathrm{ft}$, Böhmert, V., S. 38; Ministerielle Denkschrift ... (1898), S. 382; von Nostiz, H.; Hoffmann, A.; Wachler, P. (1903): Ein fünfundzwanzigiahriges ..., S. 508; Wachler, P. (1903): Erfahrungen .... S. 147 bzw. S. 312; Wachler, P. (1912): Moral ..., S. 353; sogar der Mitbegrander der sozialdemokratischen Arbeiterpartei August. Bebel erklärte als Mitglied des Lanưtages nach melujuahriger Wirksamkeit des săchs. EStG 1874/78. nach Angaben von Bohmert und Gense! Zustimmung und Zufriedenheit, s. Bohmert. V., S. 40; Gensel, J., S. 502.

149 Schanz, G. (1896), S. 1; Meyer, R. (1901): S. 99 u. S. 141; Meyer, R. (1903), S. 125 - 127; Justus (Pseudonym), S. 61 u. S. 68; Delbrilck, H. (1909), S. 166; Schmoller, G.: Anmerkung zu Behrnauer. F. (1910), S. 675; Meisel F. (1911), S. 330 und (1914), S. 144; Mrozek, A (1909), S. 259 u. (1910), S. 101; Michaelis (1912). S. 65 und (1916), S. 289; Buck, L. (1916):, S. 44, 57, 70, 82; Moll, W. (1918), S. 16, 20, 77, 99.

${ }^{150}$ Fuisting, B. (1902), S. 110.

${ }^{191}$ Hasbach, W. (1885), S. 180; die Kritik an Sax bezieht sich ebenso auf C. Menger und A. Wag. ner, dies ergibe sich aus vielen Textstellen; Hasbach, W. (1895), S. 797, Anm. 2, Wagner, A. (1886), S. 198 ff, Hasbach, W. (1887), S. 587, dieser Aufsatz richtete sich gegen Wagner, hierzu: Hansen, R. (1990), S. 24, S. 58.

${ }^{152}$ Hasbach, W. (1895), S. 797, Anm. 2. 
Fundamentalprinzipien. ${ }^{153}$ Diese letzteren wurden von ihm als vorgegebene Erkenntnisse der empirischen Realität verwendet und konnten undefiniert bleiben. Eben aus diesen Gründen wurden seine Veröffentlichungen zur Finanzwissenschaft, die ob ihrer strengen begrifflichen Sprachregelung für die Steuerrechtswissenschaft später große Bedeutung erlangten, vom Standpunkt nationalökonomischer Erkenntnis aus von Gustav Schmoller und Wilhelm Hasbach kritisiert. ${ }^{154}$ Hierbei handelte es sich um konkrete Vorgănge des sogenannten Methodenstreits in der deutschen Nationalökonomie um 1885, in der nach allgemeiner Überzeugung die Gegner Schmollers als überlegene Wissenschaftler galten. ${ }^{155}$ Tatsăchlich hat sich Wagner dann in Fragen der Steuerpolitik, die zum preußischen EStG 1891 fürte, durchgesetzt. Das gegen Wagner gerichtete erklärte alternative Ziel Schmollers, Finanzwissenschaft und Nationalökonomie als "Sozialwissenschaft" zu betreiben und das Deduzieren politischer Konsequenzen aus Prinzipien nach Machart einer traditionellen, überholten dogmatischen Wissenschaftslehre durch eine modernere Form wissenschaftlich geleiteter Politik als auf überprübarer Erfahrung aufruhender Sozialtechnologien zu ersetzen, hat in den Steuerwissenschaften jedenfalls bis heute nicht recht Fuß fassen können. ${ }^{156}$

3. Aus der Hermann-Schmollerschen Konzeption des Einkommensbegriffs leitete der Schüler Schmollers, Georg Schanz, dann 1896 unter Verwendung von Gesichtspunkten des săchsischen Musters seine Kritik an der das erklärte Ziel einer Besteuerung nach der Leistungsfähigkeit verfehlenden preußischen Einkommensbesteuerung her. ${ }^{157}$ Man nennt seither den als Ergebnis seiner Abhandlung entwickelten Maßstab "Reinvermögenszugangstheorie" des Einkommens. ${ }^{158}$ Anders als für Wagner hatten bei Schanz nach dem Rezept

\footnotetext{
191 Wagner, A. (1886), S. 197; Wagner, A. (1890), S. 299; Wagner, A. (1892), S. 186; Wagner A. (1885), S. 258

154 Schm. Jb. (1890), S. 709; Hasbach, W. (1887), S. 587

195 hierzu: Hansen, R. (1993), S. 111; die historischen Umstände der Auseinandersetzungen behandelt in: Lindenlaub, D. (1967), S. 96.

156 hierzu: Schmoller, G. (1882), Rezension von Schōnberg Handbuch der politischen Oekonomic, in: Schm. Jb. (1882), S. 1379; Erwiderung (Antikritik) A. Wagners in: (1883), S. 263. Wagner verteidigte hier das Handbuch und distanziert sich von Schmollers erklärtem Ziel, die politische Ókonomie in einen Zweig der Sozialwissenschaften umzuwandeln.

157 Schanz, G. (1896), S. 47. Der von Schanz zitierte Abschnitt aus der Rede des Generalsteuerdiroktors Burghart als Regierungskommissar im PreuBischen Landtag vom 13.2.1891 zur Rechtfertigang einer Besteuerung des Vermőgenszuganges entsprach inhaltlich sogar in den Formulienungen den Ausführungen, die der săchsische Regierungskommissar Dr. Diller am 12.2.1878 im dortigen Landtag Zur Ausgestaltung des sachsischen EStG als Grundgedanken ausgefuhrt hatte. Was in Sachsen die Abgeordneten zu aberzeugen vermochte, blieb in Preußen ohne Erfolg. Hierzu Fundstellen in: Hansen, R. (1990), S. 30, S. 63, Anm. 134 .

Is: Schanz, G. (1896), S. 23 
Schmollers empirisch-historische Studien der Wirkungen steuerlicher Maßsnahmen im Vordergrund des Interesses gestanden und nicht Prinzipien einer "richtigen" Besteuerung. ${ }^{159}$

4. Das preußische EStG 1891 hatte zwar das sächsische Gesetz und die damit gemachten Erfahrungen als Muster verwendet. ${ }^{160}$ Es folgte jedoch den von Wagner stammenden völlig anderen wissenschaftstheoretischen und methodischen Grundgedanken. Charakteristisch für die von der rechtsdogmatischen Argumentation bestimmten und streng an Begriffen orientierte Ausgestaltung war, daß in den Begründungszusammenhang aufgenommene Prinzipien eine wichtige Funktion erfülten. ${ }^{161}$ Sie waren in einem jeweils entwickelten Ableitungszusammenhang die ausschließliche Rechtfertigungsinstanz fur die "Richtigkeit" von Gesetzesbestimmungen, denen normative Qualität zukam. Das preußische EStG 1891 ist in systematischer Hinsicht eine Fortentwicklung der Ertragsbesteuerung durch Berücksichtigung des Inhabers der Erträge und dessen persönlicher Verhältnisse geworden. ${ }^{162}$ Der Einkommensbegriff wurde dabei wie etymologisch, der Zeit entsprechend vorgegeben, verwendet. Das damit bezeichnete Einkommen galt für Wagner, Fuisting und maßgebliche Steuerrechtler bis heute - oftmals beteuert - als bester Indikator der Leistungsfähigkeit eines Steuerbürgers. ${ }^{163}$ Es bezog sich im Grundsatz auf die Früchte im Gesetz enumerativ aufgezählter, in der Regel für den Markt produzierender Quellen. Die richtige Ermittlung des Besteuerungsgutes setzte die strenge begriffliche Abgrenzung der Begriffe wie "Einkommen" von "Vermögenszugang" voraus, wobei zum Einkommen nur die Früchte aus einer bestehenden Quelle und zum Vermögen die Substanz der Quellen inclusive deren Veränderungen rechneten. ${ }^{164}$ Schanz bezeichnete die von ihm als sinnentfremdende Begriffsspielerei mit weitreichenden Folgen beurteilte

159 Schanz, G. (1890), Schanz war ein Schuler Schmollers. Er hatte in Strabburg studiert. Schanz G. (1928), S. 14, S. 18. Schmollers Lehren, die Geschichte wie ein Experiment durch vergleichende Forschung zur Gewinnung und Bestatigung von RegelmäBigkeiten der sozialen Realităt zu verwenden. haben offenbar die Methodenauffassung von Schanz bestimml. Die umfangreichen historischen Studien von Schanz und die theoretische Durchdringung der Erfahrungen mit der Besteuerung in der Schweiz im 19. Jahrhundert sind ein eindrucksvolles Ergebnis dieser Forschungsrichtung zur Gewinnung nomologischer Erkenntnisse.

${ }^{100}$ Wagner, A. (1899), S. 107; ders. (1891), S. 51; hierzu: Jastrow, J. (1891), S. 744.

161 Wagner, A. (1880), S. 220; ders. (1890), S. 292; hierzu auch: Heidrich, P., S. 40.

162 Fuisting. B. (1902), S. 133; (1903), S. 2; hierzu: Bredt, V., S. 31

${ }^{163}$ Fuisting, B. (1902), S. 89 ff, Wagner. A. (1890), S. 323 u. S. 442: ahhnlich heute noch: Tipla. K. (1993) Die Steuerrechtsordnung. S. 560.

${ }^{104}$ hierzu: Schanz, G. (1896), S. 54; Fuisting, B. (1902), S. 109, S. 133 ff: Wagner. A. (1880), S. 249 ; Wagner, A. (1890), 3. 324. 
Denkweise und die aus den Grundannahmen entwickelte Veranlagungstătigkeit 1891 als "Haare spalten". ${ }^{165}$

5. Der Ausgleich der Klassenspaltung war für Gustav Schmoller der zentrale Gesichtspunkt seiner gesamten Forschungstätigkeit. Die sozialen Differenzen zur Mitte des 19. Jahrhunderts brachte er in ursächlichen Zusammenhang mit der Entwicklung von Arbeitsteilung, Einkommensverteilung und Vermögensschichtung. ${ }^{166}$ Der Gestaltung geeigneter, Feindlichkeiten mildernder Institutionen galten seine sozialpolitischen Aktivitäten, wobei der Entwicklung von Einkommensverteilung und Vermögensschichtung entsprechende Bedeutung zur Überwindung der Klassenspaltung zukam. ${ }^{167}$ Die Überzeugung, daß es sich bei diesem Ziel um das wichtigste Anliegen der Wirtschaftspolitik handele und dies auch die Gesichtspunkte für die zugrundeliegende Nationalökonomie bestimmen müsse, ging soweit, daß Schmoller die Beurteilung volkswirtschaftlicher Literatur oft von der Frage abhängig machte, ob der Autor die Bedeutung von Einkommens- und Vermögensschichtung erkannt habe. ${ }^{168}$ Bereits 1874 hatte er beklagt, daß die Resultate der Besteuerung von Einkommen und Vermögen ein stärkeres Wachstum der Lebensumstände der bessergestellten Steuerzahler gegenüber den Minderbemittelten auswiesen. ${ }^{169}$ Durch eine Fülle neuartiger sozialer Institutionen, die von der Einführung einer gerechteren Einkommensbesteuerung bis zu Bestimmungen zu Tarifvertrags-, Arbeitsvertrags-, Kündigungsschutz-, Versicherungsschutzrechten, reformiertem Armenrecht etc. etc. reichten, wollte er eine innere Befriedung der Gesellschaft bewirkt sehen. Hierzu machte er die Schriftenrcihe des Vereins für Socialpolitik zu einem Diskussionsforum für soziale Reformen, indem deren Beiträge alle wichtigen anstehenden gesellschaftspolitischen Fragen - von verschiedensten Gesichtspunkten aus erörtert - theoretisch und praxisnah bearbeiteten. Ziel dieser Publikationen war es in der Sprache Schmollers. "gleichsam mit der Fackel der Erkenntnis denen voran(zu)leuchten, die als Staatsmănner und Beamte, als Partei und Klassenführer, als Beherrscher der öffentlichen Meinung direkt Politik machen wollen". ${ }^{170}$

\footnotetext{
is Schanz, G. (1896), S. 57.

is Lindenlaub, D. (1967), S. 274; Hansen, R. (1993), S. 163.

in Lindenlaub, D. (1969), S. 274; Hansen, R. (1993), S. 137; Schmoller, G. (1904), 2. Aufl.

1923, S. 1065; Schmoller, G. (1918), S. 157, S. 622.

is Schmoller, G. (1900), S. 122; Lindenlaub, D. (1969), S. 274.

160 Schmoller, G. (1874), S. 131. S. 173: Schmoller befaßte sich 1895 wiederum mit dieser Frage. in: Schm. J. S. 1067.

Schmoller, G. (1912), S. 1.
} 
6. Öffentliche Kritik und vor allem die konkreten Beschwerden Hans Delbrücks über die Auswirkungen der preußischen Einkommensbesteuerung in den "Preußischen Jahrbüchern" von $1909^{171}$ führten dazu, daß Schmoller dieses Thema in dem Organ des Vereins zur Zeit nachlassender sozialpolitischer Reaktion und wachsender Gegnerschaft in einer jüngeren Generation erneut zur Diskussion stellte. ${ }^{172}$ Letztlich konnte die Kritik Delbrücks gerade zu dieser Zeit zunehmender Opposition zur Sozialpolitik die Sorge verstärken, daß die Einkommensbesteuerung in Preußen den verteilungspolitischen Zielvorgaben entgegenstehe und damit eine Fortentwicklung der Sozialreform gefahrde. Schmoller brachte daher im Organ des Vereins für Socialpolitik 1910 die Replik eines leitenden Finanzbeamten aus der "Konservativen Monatsschrift" zum Abdruck, in der dieser die preußische Besteuerungspraxis gegen Delbrücks Thesen von dem amtlichen rechtsdogmatischen Standpunkt aus rechtfertigte. ${ }^{173} \mathrm{Daß}$ er die Kritik Delbrücks voll teile und nur zu einer sachlichen Erörterung anregen wolle, machte er dabei in einer längeren Fußnote deutlich. ${ }^{174}$ Bereits im nåchsten Heft des "Jahrbuchs" veröffentlichte Schmoller daher 1911 zwei längere Aufsătze, die man heute den Disziplinen Rechtssoziologie und Rechtstatsachenforschung zuordnen würde. ${ }^{175}$ Die damit einsetzende Erörtenung der Zusammenhänge zwischen Gesetzesnormen und deren Umsetzung in der Realităt wird denn auch heute als Anbeginn dieser die Gesetzgebung kritisch begleitenden Wissenschaftssparten angeführt. ${ }^{176}$ Ihnen rechnet man die wichtige Funktion zu, durch Vermittlung von Einsichten in die quasigesetzlichen Zusammenhänge der sozialen Realităt auf das Rechtsbewußtsein der Offentlichkeit und damit auf die Gesetzgebung einen korrigierenden Einfluß auszuüben. ${ }^{177}$ Durch die Aufnahme eines Aufsatzes mit dem Titel "Die Erforschung des lebenden Rechts" gab Schmoller Eugen Ehrlich die Plattform, die dann bereits 1912 zur Übernahme eines Referates auf dem 31 . Deutschen Juristentag und fortan zu lebhafter Diskussion seiner Thesen fuhr-

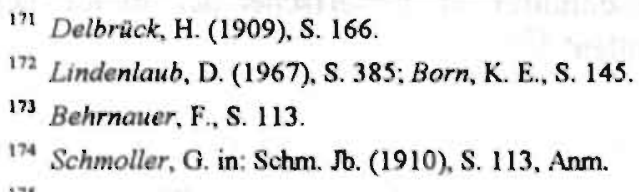

175 Der Begriff "Rechtstatsachenforschung" wurde erstmals 1914 von A NußBaum für eine neue Disziplin geprägt, die der "Prüfung der sozialen, politischen und sonstigen Wirkung" von Rechtsnormen dienen sollte: Nußbaum, A (1914). Neuaufl. 1968, S. 57, S. 67. Die von Nußbaum gesuchte Abgrenzung von der Rechtssoziologie, zu der man die Vertreter der sogenannten "Freirechtsschule" (Ehrlich, Kornfeld, Kantorowicz u. a.) rechnete, hat nur historische Bedeutung. Die Abgrenzung erscheint heute künstlich und ohne systematische Bedeutung. Hierzu: Raiser. T., S. 12, S. 18: Rehbinder, M. (1993), S. 1; Rohl, K. (1987), S. 105; Zippelius, R. (1991), S. 53; Rehbinder, M. 1989), S 64; Opp, K. D. (1973), S. 127.

\footnotetext{
${ }^{176}$ Rehbinder, M. (1986), S. 29.

177 Strempel, D.(1984), S. 195, S. 198; Nancke, W. (1972), S. 26, S. 41, S. 61; Raiser, T., S. 18
} 
te. ${ }^{178}$ Weiterhin ließ Schmoller in demselben Heft den provozierenden Aufsatz von Franz Meisel mit dem Titel "Moral und Technik bei der Veranlagung der preußischen Einkommensteuer" abdrucken, der danach in hoher Auflage als Broschüre erschien und bis heute grundsätzliche Bedeutung behalten hat. ${ }^{179}$ In dieser Abhandlung zeigte der zum Steuerrechtler ausgebildete damalige hohe österreichische Finanzbeamte vermittels einer Analyse der Veranlagungsergebnisse die Differenzen zwischen den mit dem preußischen EStG 1891 geweckten Erwartungen an gerechtere Lastenverteilungen und den tatsächlichen Auswirkungen. Da das System des preußischen Gesetzes inzwischen auch in Österreich und in weiteren Ländern übernommen worden war, hatte die Kritik Meisels an dem Auseinanderfallen von Anspruch und Wirklichkeit eine aktuelle Grundlage. Aus den Ausführungen Meisels und den durch sie ausgelösten weiteren Beiträgen verschiedener Fachleute konnte man entnehmen, daß das preußische EStG 1891 tatsächlich keine Verteilung der Steuerlast nach einer im üblichen Sinn verstandenen Leistungsfăhigkeit bewirkte, sondern eher geeignet war, größere Kapitalansammlungen und umfangreiche Investitionen auf Kosten der kleinen Steuerzahler zu begünstigen. ${ }^{180}$ Dies entsprach den Feststellungen, die der Mitarbeiter Schmollers, Karl Oldenberg, 1893 im "Jahrbuch" als Charakteristik der Wirkungen der preußischen Besteuerung für die Zeit vor 1891 getroffen hatte. ${ }^{181}$ Meisel hielt später fest, was er als den "Irrtum der Einkommensteuer des preußischen Typs" bezeichnete: "Die Technik der preußischen Einkommensteuer blieb in den wichtigen Mitteln die primitive der Vorgängerin, der klassifizierten Einkommensteuer". ${ }^{182}$ Auch das preußische EStG 1891 paßte, nach den Resultaten der Veranlagun-

17" Ehrlich, E. (1911), S. 129; ders. (1913, Wiederabdruck 1967): Gutachten uber die Frage "Was kann geschehen, um bei der Ausbildung (vor und nach Abschluß des Universitătsstudiums) das Verstlindnis des Juristen für psychologische, wirtschaftliche und soziale Fragen in erhöhtem Maße fördern?" Siehe hierzu die Kritik der Schriften Ehrlichs und von Kantorowicz durch H. Kelsen und die Erwiderungen Ehrlichs in: Kelsen, H. (1915), S. 839; Ehrlich, E. (1916), S. 844; Kelsens Replik auf S. 851; Ehrlichs Replik (1917) auf S. 609 und Kelsens SchluBwort S. 610. A. Ross stellte spater heraus, daß die frühen theoretischen Irrtüner der Richtung um Ehrlich der Preis war, "den das Leben fur den praktischen Erfolg fordert", Ross, A. (1929), S. 188.

\footnotetext{
17 Meisel, F. (1911), S. 285 , unnittelbar nach diesem Aufsatz erschien unter Bezugnahme auf den inzwischen in Form einer Broschüre verbreiteten und weithin erörterten Beitrag unter dem Himweis auf diesen der gleiche Titel aus der Feder des preußischen Regierungsbeamten im höheren Finanzdienst, Michaelis, der die Thesen Meisels durch Verarbeitung amtlichen Materials aus langjăhriger Erfahrung in der Veranlagungstatigkeit und vor allem als Vorsitzender von Berufungskommissionen voll bestatig. te und sogar ergânzte. Auch diese Abhandlung, die 1912 im halbamtlichen Verwaltungsarchiv erschien, wurde im selben Jahr ebenso von Duncker \& Humblot als Broschüre verbreitet, da großes offentliches Interesse an dem Streitgegenstand bestand. Hierzu: Michaelis (1913) in: Verwaltungsarchiv, Bd. 21, S. 486 .

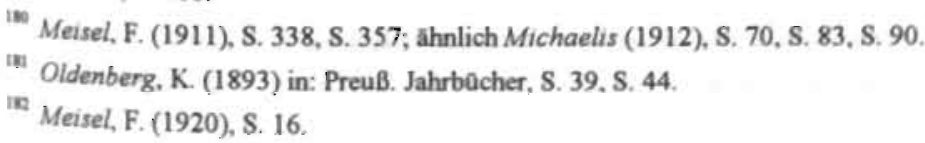


gen beurteilt, nicht in das Konzept der Sozialreform. Nur die Begüterten konnten mit dem System zufrieden sein. Das Gesetz wirkte weiterhin als konservativer Stabilisator und ermöglichte infolge der durch geeignete Gestaltungen erzielbaren Entlastungen im übrigen, wie sich zeigte, beliebigen Gruppen, sich gegenseitig unter Hinweis auf ausgewiesene allzu niedrige Veranlagungsergebnisse Steuerunehrlichkeit vorzuwerfen. ${ }^{183}$

7. Die Reform der Einkommensteuer war bei Gründung des Vereins für Socialpolitik im Jahr 1872 eines der vordringlichen Ziele gewesen. ${ }^{184}$ Die Bestrebungen der im "Verein" wirkenden sogenannten "Kathedersozialisten" blieb fortan vielen, zumeist konservativen Gruppierungen ein Dorn im Auge. Dafür waren materielle Interessen gewiß ein wichtiges, aber nicht das einzige Motiv. Auch abweichende politische Leitbilder sorgten für Verschiedenartigkeit der Ziele. Waren die Kathedersozialisten der ersten Stunde noch am Leitbild des sozialen Ausgleichs, der sozialen Gerechtigkeit, interessiert, so lósten dann zu Beginn des 20. Jahrhunderts andere Zielvorstellungen einer jüngeren Generation, etwa "die Ankurbelung der Wirtschaft", der "Aufstieg der Arbeiterklasse" oder streng liberale Konzepte diese von der Zeit diktiente einseitige Orientierung ab. ${ }^{185}$ Die Kathedersozialisten hatten zur Jahrhunderwende wesentliche Ziele, wie die Arbeiterversicherungs- und -schutzgesetzgebung, gegen repressiven Druck erreicht und durchgesetzt. Sie gerieten mit ihren Bemühungen zur Fortfuihrung der Sozialreformen zur Jahrhundertwende in eine Verteidigungshaltung. ${ }^{186}$ Für eine jüngere Generation von Mitgliedern, die sich durchaus noch zu den Zielen der Sozialreform bekannten, trat nun der

183 von Gerlach, H. (1910), S. 48; ders. (1923), S. 27. Die Ausführungen Gerlachs zeigten starke politische Voreingenommenheiten. Sie sind geeignet, die Thesen Behrnauers zu bestătigen, daß die Veranlagungen in der Regel in völliger Übereinstimmung mit den Gesetzesvorschriften erfolgten. So war nicht das Verhalten Bismarcks. der sich steuerlich von einem renommierten Berliner Bankier vertreten ließ, fragwüdig, das EStG war, wie weithin bekannt, ungeeignet. Hierzu: Behrnaner, F. (1910), S. 1586 u. S. 1609: Delbruck, H. (1909), S. 176; Michaelis (1912). S. 75; Historiker suchen offenbar gern nach Bestätigungen ihrer historisch-ideologischen Voreingenommenheiten. Infolge mangelnder Sachkenntnisse vermögen sie die Darstellungen exponierter Politiker nicht kritisch zu wârdi. gen. Hiezzu auch: Hitt, P.-C. (1986), S. 194 u. S. 286; ders. (1973) zur Qualifikation des preuflischen Landrats als Leiter der Veranlagungsbehörde des Innenministerium; aueh: von Delbrück, C. (1917), 8 12: Paksch, A (1976), S. 117. Zur anderen Ausbildung der Finanzbeamten in Sachsen im Vergieich zu Preußen: Wachler, P. (1912), S. 353. Die Differenzen in der Ausbildung blieben in der Offentlich. keit unbekannt, s. Pausch, A (1976), S. 116; s. a. Euck. L. (1916), S. 70.

Iit Bereits auf der zweiten Generalversammlung sollte nach dem Votum von G. F. Knapp im Aus. schuß des Vereins für Socialpolitik das als dringlich beurteilte Steuerthema auf der Tagesordnung stohen. Wegen des Schwierigkeitsgrades und der Notwendigkeit der Vorbereitung wurde es als Verhand. lungsgegenstand auf die dritte Tagung verschoben. Es wurden drei Gutachten in Auftrag gegeben. Boese, F. (1939), S. 15.

18 Lindenlaub, D. (1967), S. 439; Hansen, R. (1993), S. 154; Born. K. E. (1985), S. 146.

${ }^{186}$ Lindenlaub, D. (1967), S. 439; Hansen, R. (1993), S. 154; Born, K. E. (1985), S. 146; die Heftigkeit der Auseinandersetzung zeigt: Ehrenberg, R. (1910), S. 72. 
einseitig politische Charakter des Vereins stärker hervor. ${ }^{187}$ Das Schlagwort von der "Voraussetzungslosigkeit der Wissenschaft" kam auf. In einem grundlegenden Aufsatz hat Max Weber 1904 die wissenschaftliche Unverbindlichkeit von Werturteilen herausgearbeitet. ${ }^{188} \mathrm{Er}$ hat dabei zwischen Wertungen des Wissenschaftlers bei der Auswahl seiner Aufgabenstellungen und Wertungen desselben im Aussagenzusammenhang seiner Forschungen unterschieden, wobei er die ersteren als unvermeidbar und zulässig und nur die letzteren als unzulässig ausgab. ${ }^{189}$ Die jüngeren Mitglieder des Vereins betonten nunmehr zunehmend wohl zu Recht, daß vielerlei Aufgabenstellungen als politisch vorgegebene Ziele ebenso Interesse verdienten wie diejenigen, die konservative Mitglieder im Interesse von Sozialreformen verfolgten. ${ }^{190}$ Die Forderungen nach einem Ausgleich der Klassen stand für sie - methodologisch richtig gesehen - auf gleicher Stufe mit Klassen- und Parteiinteressenstandpunkten. Eine einflußreiche Gruppe begann sogar, die Fortführung der Sozialpolitik zu bekämpfen. Sie wollte die Gesetzgebung zur Sozialpolitik vor 1890 als endgültigen idealen Maßstab gegen weitere sozialpolitische Eingriffe festgeschrieben wissen. Der Begründer und Herausgeber der "Zeitschrift für Sozialwissenschaft", Julius Wolf, stellte in einem einleitenden Aufsatz 1898 heraus, "daß der Verein für Socialpolitik von seinem Einfluß und Nimbus einbüße, ... wenn die von ihm vertretenen Ziele aufhören. für weite Kreise als Erkenntnisse, als Ergebnisse wirklich wissenschaftlicher Forschung zu gelten". ${ }^{191}$ Dieses Urteil traf gewiß für viele Anhänger zu. Wolf suchte dann fortan durch einen rigorosen Einsatz seiner Zeitschrift mit einer Gruppe von Gelehrten dieses Ziel zu erreichen, wobei einzelne Autoren auch nicht vor Schmăhungen und Verunglimpfungen der Personen Schmoller und Hasbach zurückschreckten. ${ }^{192}$ Letztlich ging es um eine Beendigung der Sozialpolitik und Hinwendung zu stärkerer Förderung wirtschaftlicher Interessen. ${ }^{193}$ Tatsächlich hatte Schmoller sich seit 1872 stets zu einer die Klassen versöhnenden Sozialpolitik bekannt. Er hatte dieses Bekenntnis aber nie - anders als etwa Wagner - als vorgegebene wissenschaftliche Erkenntnis eingestuft. Im

\footnotetext{
th Lindenlaub, D. (1967), S. 440; auch: Tonnies, F. (1912), S. 6.

tin Weber, M. (1904), S. 22; ders. S. 27 und S. 54. Noch 1895 war für Max Weber die nationale Macht der selbstverständliche Leitstern der Wirtschaftspolitik gewesen, Herkner, H. (1912), S. 5, Anm 2.

I5 Weber, M. (1904), S. 54; hierzu: Albert, H. (1967), S. 246; ders. (1971), S. 200.

${ }^{100}$ Lindenlaub, D. (1967), S. 441.

1ต Wolf, J. (1898), S. 4, S. 89, S. 249, S. 352, S. 407.

in von Below. G. (1904/5), S. 145 , S. 221 , S. 304, S. 367 , S. 451 , S. 654, S. 684 , S. 710 , S. 787 ; den. (1905), S. 137, S. 267; daß hier tiefergehende weltanschauliche Umwalzungen zugrundeliegen, wird skizziert in: Hansen, R. (1990), S. 48: ders. (1993), S. 111

193 Lindenlaub, D. (1969), S. 277; Ehrenberg, R. (1904), S. 32; Born, K. E. (1985), S. 146.
} 
Gegenteil hatte seine Auffassung bereits frühzeitig in etwa der von Max We. ber erst nach 1900 entwickelten Lehre entsprochen. ${ }^{194}$ Der Vorsitzende der Deutschen Gesellschaft für Soziologie, einer Gründung jüngerer Wissenschaffler zur Förderung wertfreier ungebundener Forschung, bestätigte Schmoller ausdrücklich 1912 offentlich, daß die Forschungsbeiträge des "Vereins" zur Vorbereitung von Sozialreformen zwar einseitig zweckgerichtet, aber inhalllich stets wertfrei und objektiv überprüfbar waren. ${ }^{195}$ Die große politische Wirksamkeit des Vereins für Socialpolitik und die Reputation Schmollers konnte in der Öffentlichkeit jedoch, nachdem erste Erfolge sich eingestell hatten, andere Eindrücke erwecken. Als um 1910 neue wirtschaftspolitische Gesichtspunkte als gleichwertig in den Vordergrund der Diskussion gerückl wurden und für sie sogar um Priorităt geworben wurde, suchte Schmoller zur Fortführung der Sozialpolitik ihrer Bedeutung einen höheren vorzugswürdigen Rang beizumessen. Unter dem Druck seiner Gegner suchte er durch kurze Einschübe in seinen Methodenaufsatz von 1892 für die dritte Auflage des "Handwörterbuchs der Staatswissenschaften" von 1911 im Widerspruch zu den sonstigen Ausführungen in derselben Abhandlung und seinem gesamten Lebenswerk den Wertungen und Interessen einer Mehrheit einen gewissen Grad von Allgemeinverbindlichkeit zuzusprechen. Im "Jahrbuch" erschienen nach 1911 dann theoretische Aufsätze verschiedener Gelehrter, die diesen Standpunkt, dem Schmollers eigene Methodenlehre im Grunde widersprach, vertraten. $^{196}$

Zur selben Zeit wurden die im Zuge der Industrialisierung entstandenen großen Vermögensdifferenzen öffentlich erörtert. Nun wurde durch Schmollers Veröffentlichungstätigkeit, empirisch überprüfbar belegt, offenkundig, daß das preußische EStG zu grundlegender systematischer Kritik Anlaß gab. Die Korrektur der 1891 geschaffenen, maßgeblich von Adolph Wagner konzipierten Systematik eines der wichtigsten Verhandlungsgegenstände unmittelbar nach Gründung des "Vereins" war gefragt. Aus rechtsdogmatischen Gründen hatte Adolph Wagner die Erfassung von "Conjunkturgewinnen" und sonstigen "unverdienten" Vermögensmehrungen stets außerhalb des EStG in besonderen

194 Lindenlaub, D. (1967), S. 436; Hansen, R. (1993), S. 153.

193 Tönnies, F. (1912), \$. 6.

196 Herkner, H. (1912), S. 1; Köhler, W. (1912), S. 396; ders. (1914), S. 431; Engländer, 0 (1914), S. 397; Köhler, W. (1915), S. 17; Spranger, E. (1914), S. 33. Die von Schmoller dem ursprünglichen Text von 1890 für die dritte Auflage des HdSt von 1911 gefertigten Ergănzungen zu seinem Methodenaufsatz lassen sich geschlossen verfolgen in: Skalweit, H. (1949), S. 74; S. 77, Anmt 6 zu S. 30. Zu Schmollers Einstellung zur Werturteilsfrage und der ab 1910 erfolgten Verunsicherung siche Herkner, H. (1912), S. 2. 
Gesetzen gefordert. ${ }^{197}$ Die Konsequenzen waren für jedermann erkennbar. Nun wurde sein Gedankengut zur Grundlage der Forderungen nach Einführung einer "Wertzuwachssteuer" verwendet. ${ }^{198}$ Die von Wagner stammende rechtsdogmatische Gestaltung des preußischen EStG 1891 hat sich fortan in dern gleichen Tempo verfestigt, mit dem die von Schmoller vertretenen Grundgedanken zur Sozialpolitik zunehmend verblabten. Daß im Werturteilsstreit angeblich Gustav Schmoller unterlegen ist, gehört seither zu den Gemeinplätzen der Disziplin. Der Vorwurf mangelnder Wertfreiheit wurde zum beliebten Instrument zur Ablehnung fremder mißliebiger wissenschaftlicher Beitrăge. ${ }^{199}$ An den kryptonormativen Aussagen Wagners, Brentanos, Neumanns, Cohns, Sombarts und vieler der jüngeren Kollegenschaft hat die Disziplin jedoch nie Anstoß genommen. ${ }^{200}$ Der fachkundige Soziologe ahnt die hier dem steuerlichen Laien unerkennbar verborgenen Interessenkonflikte.

Die von Juristen spăter weiter ausgearbeitete, letztlich von Wagner stammende, von Prinzipien ausgehende rechtsdogmatische Vorgehensweise übernahm mit kurzer Unterbrechung nach 1919 die Herrschaft über die weitere Gestaltung und Auslegung des Einkommensteuerrechts. Meisel bedauerte 1920 diese Entwicklung: "Um die Jahrhundertwende ist die deutsche Finanzwissenschaft nach einer kurzen herrlichen Blüteperiode mitten im vollen Wachstum plötzlich stehen geblieben", ${ }^{201}$ so hören wir. Und: "Die Steuer-

197 Wagner, A. (1890), S. 566; siehe auch Fundstellen in: Hansen, R. (1990), S. 27; Bauckner, A. (1919), S. 27, S. 29, S. 148; Keller, K. (1907), S. 214; Bundsmann, E. (1912), S. 32, S. 39, S. 59; Pausch, A. (1973), S. 306; auch: Wagner A. (1878), S. 16, S. 21, S. 25.

190 Wagner wurde in Labands Deutscher Jurisien-Zeitung 1910 als "Bannertragger" einer neugeschaffenen und beschlossenen Wertzuwachssteuer gelnbt. Siehe Deutsche Juristen-Zeitung (1910), Sp. 519; hierzi: Bauckner, A. (1919), S. 27, S. 29.

199 Ein eindrucksvolles Beispiel fur diese aggressive Verwendung des Postulats der Werturteilsfreiheit und der Aburteilung fremder unerwünschter Lehren bieten die Aktivitaten Sombarts, der seine marxistischen Lehren für richtig hielt, weil sie "kein Gran Ethik" enthielten. Der ethische Futurismus des ganzen Systems von Marx wurde von ihm abbergangen. Lindenlaub, D. (1967), S. 438.

200 Stavenhagen, G. (1969), S. 204; Schneider, E. (1970), S. 294; S. 509, S. 514; Montaner, A. (1967), S. 354; Ott, A. Winkel, H. (1985), S. 230; Pribram, K. (1992), S. 437, insbes. S. 439. Weber beklagte sofort nach der von ihm eigens hierfur begrindeten Deutschen Gesellschaft für Soziologie, dab es selbst den Mitgliedern nicht gelingen wollte, wertfreie Wissenschaft zu praktizieren und nicht nur zu fordern. Er zog sich daher von der Leitung der Gesellschaft zurück. Dabei bekannten sich nur

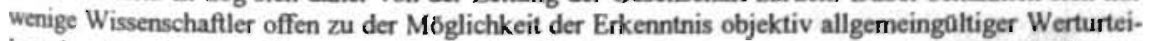
le, wie etwa Justrow, Spranger, Engländer, Herkner, Wagner und andere. Schmollers Wissenschaftsauffassung, wie er sie 1892 in dem Methodenaufsatz für das HdSt festhiclt, lię Werturteile nicht als wissenschaftliche Erkenntnisse zu: Schmoller, G. (1993), S. 549. Die für die dritte Auflage von 1911 gemachten Zusaltze verunklarten seine Auffassungen, da er keine ursprünglichen Textstellen tilgte, siche Skalweit, A. (1949), S. 74; hierzu. Wagner, A. 1892), S. 144, S. 159, S. 164; Wagner gibt hier die theoretische Grundlage für die Nationalökonomie als ein normatives System nach Art der Rechtsdogmtik; siehe auch: Koch, W. (1963), S. 38.

$2 n$ Meisel, F. (1920) Das Strafrecht ..., S. 35. 
technik, ihre Lehren und die Erkenntnis dieser Materie sind im System ganz vernachlăssigt worden." 202

Franz Meisel, Wilhelm Gerloff - und ähnliches deutet Fritz Stier-Somlo an waren der Überzeugung, daß die von Wagner befürwortete und dann um 1911 als soziales Heilmittel schließlich eingeführte heftig umstrittene, nicht zweckmäßige, aber systemkonforme Wertzuwachssteuer zu einem "Prüfstein gewisser Aufgaben der Steuertheorie zu einer tiefgehenden Kritik der Steuersystematik hătte benutzt werden können". ${ }^{203}$ Dem stand jedoch nun, nachdem den Beiträgen Schmollers nicht mehr das ursprüngliche Gewicht zukam, die von Wagner geschaffene, längst eingefahrene Systematik im Wege.

8. Das Wertfreiheitspostulat ist schnell von einer einflußreichen großen Gruppe um den Begründer der "Zeitschrift für Sozialwissenschaft", Julius Wolf, die bekannten Nationalokonomen Richard Ehrenberg. Ludwig Pohle, Andreas Voigt und andere, zur Aburteilung der Wissenschaftlichkeit der Lehren der "Kathedersozialisten" und zu dem heftigen Kampf gegen deren Bemühungen zur Fortentwicklung der Sozialpolitik verwendet worden. ${ }^{204}$ Ähnlich wie 1872 bot die Kritik an der preußischen Einkommensteuer mit den aufkommenden Forderungen nach besserer Erfassung der mit der Industrialisierung einhergehenden hohen Gewinne durch die auf Anregungen Wagners zurückgehende neuartige Wertzuwachsbesteuerung Zündstoff für Interessenkonflikte. ${ }^{205}$ Zudem hatten verschiedene Länder inzwischen das preußische Steuersystem kopiert und interessierten sich für die sozialpolitischen Errungenschaften im Deutschen Reich. Systematischen Reformvorschlägen für soziale Institutionen fehlte nun bald die aus Einsicht in die Notwendigkeit gespeiste innere Stoßkraf, die die Aufbruchstimmung von 1872 getragen hatte. Dem Versuch Schmollers, die Schwachstellen des preußischen EStG durch theoretische Verarbeitung der Veranlagungsergebnisse zum Gegenstand einer wissenschaftlichen Erörterung zu machen, war kein Erfolg beschieden. Eine von Meisel geforderte sozialere Ausgestaltung der Einkommensteuer war nicht durchzusetzen. Der zugrundeliegenden Methodenauffassung Wagners hatte Schmoller vom Standpunkt der Sozialwissenschaften aus in vielen Rezensionen seine Kritik gewidmet. ${ }^{206}$ Das einem theoretischen Essentialismus verhaf-

\footnotetext{
202 ders., S. 35.

2013 Jers. (1920/21), S. 487; Gerloff, W. (1913), S. 401.

${ }^{204}$ Ehrenberg, R. (1904), S. 14. S. 27 u. a; ders. (1910), S. 72 u. a; hierzu auch; Borm, K. E. (1985), S. 145.

${ }^{209}$ Ehrenberg. R. (1909), S. I. insbes. S. 16.

206 Schmoller, G. (11882), Rezension des Handbuches der politische Oekonomie in Schm. Jo. (1882), S. 249, hier S. 251, wo er feststellt, daB die "alte dogmatische Systematik sich vollends uberlebt" habe Auf Seite 352 kritisiert er daher das von Wagner fortgefuhrte "Rau'sche System". Ähnliche
} 
tete Methodenkonzept Wagners bestimmte - von Prinzipien ausgehend - jeweils das Einkommen als Summe der einzelnen durch spitzfindige Tatbestandsmerkmale gekennzeichneten, in einem Enumerativkatalog aufgezăhlten Einkünfte. Vom Gesichtspunkt der Rechtsdogmatik aus war das konsequent. Aber der zugrundeliegende dogmatische Essentialismus ließ eine Kritik des Systems und dessen Anpassung nach den Veranlagungsergebnissen als regulativer Instanz nicht zu. Erst unübersehbare Fehlleistungen veranlaßten spăter unter dem Gesichtspunkt einer "richtigen" Besteuerung im Sinne der Prinzipien Erweiterungen des Enumerativkatalogs bzw. Ergänzungen der normierten Tatbestandsmerkmale bzw. zusätzliche Steuerarten zur Auslösung der Steuer.

Bis heute ist das System so geblieben, ohne infrage gestellt zu werden. Die konkrete Veranlagungstătigkeit ist noch als Subsumtionsmechanerie darstellbar. Die rechtsdogmatisch festgelegte Vorgehensweise garantiert die richtige Besteuerung. ${ }^{207}$

Für die von Schmoller konzipierte Richtung war der Kontrolle der Veranlagungsergebnisse an der sozialen Realităt eine Korrekturfunktion für Gesetzesănderungen zugekommen. Die sozialen Institutionen, zu denen das Steuerrecht zählte, sollten nach Gesichtspunkten der Zweckmäßigkeit gestaltet werden. Die Tătigkeit des Gesetzgebers gleicht der des konstruierenden Maschineningenieurs, so etwa dachte der heute als Begründer der Rechtssoziologie bezeichnete Eugen Ehrlich, dem Schmollers 1911 in seinem "Jahrbuch" Gehör verschaffte. ${ }^{208}$ Für Ehrlich war es Sache der Gesetze. Techniken für Problemlösungen bereit zu halten. "In diesem Sinne ist Gesetzgebung, Jurisprudenz, Rechtspflege angewandte Gesellschaftswissenschaft", ${ }^{209}$ so fuhrte er aus. So ist es nicht verwunderlich, daß der Richtung um Ehrlich auf dem 1. Soziologentag von 1911 infolge unglücklicher Formulierungen ebenso global das Postulat der Werturteilsfreiheit entgegengehalten wurde, wie Schmoller ${ }^{210}$ Es ging dabei weniger darum, wertfreie Wissenschaft zu unterstützen, als weltanschaulich ungeliebte Richtungen zu bekämpfen.

\footnotetext{
Kritik Schmollers in: Schmoller, G. (1890), Rezension von Wagners. Finanzwissenschaf, in: Schm. Jb. (1890), S. 709. Hierher gehören auch die Rezensionen von Schmollers engem Mitarbeiter W. Hasbach, siehe: Schm. Jb. (1895), S. 783; (1887) S. 587. Wagner wuBte die Differenzen richtig zu konkretisieren. Siehe: Wagner A. (1883), S. 199, S. 209, S. 216, S. 226, S. 229, S. 231. S. 239, S. 245; weitere Fundstellen: Hansen, R. (1990), S. 59; ders. (1993), S. 124.

${ }_{77}^{207}$ Buck, L. (1916), S. 44, S. 57, S. 62, S. 70, S. 82 u. a.; Moll, W. (1918), S. 15, S. 53, S. 63, S.

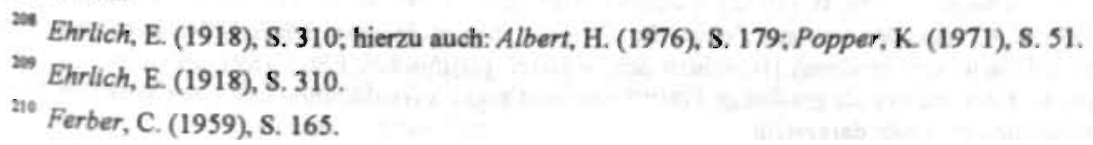


9. Für das aus Prinzipien entwickelte Steuersystem herrschte bei Wagner die Auffassung vor, daß das, was in der Dogmatik richtig sei, auch in der Praxis richtig sein müsse. Empirische Erkenntnisse über die Besteuerungswirklichkeit dienten somit nur als Material für die Gestaltung der Tatbestandsmerkmale zur Garantie richtiger Anwendung der Prinzipien. Der von Schmoller fortentwickelte Gedanke, den Reinvermögenszugang als Maßstab für Leistungsfahigkeit eines Steuerbürgers einzuführen und damit als Bemessungsgrundlage festzulegen, war im preußischen EStG zu einer bloßen Ermittlungsvorschrift für eine Einkunftsart denaturiert. Meisel bemängelte 1920, daß das System seit der Jahrhundertwende nicht mehr grundsätzlich in Frage gestellt wurde und daß Steuerjuristen seit dieser Zeit die Leitung der Fortentwicklung des Steuerrechts in ihre Regie übernahmen. ${ }^{211}$ Erkennbaren Fehlleistungen wurde fortan begegnet, indem der Katalog steuerbarer Vorgänge um weitere Tatbestandsmerkmale bis dahin nicht erfaßter Sachverhalte erweitert wurde bzw. Freibeträge, Freigrenzen oder Abzüge bei Ermittlung der Bemessungsgrundlage oder bei den Tarifvorschriften eingefüht, verändert oder wieder abgeschafft wurden. Regelungen, die infolge neuartiger Beurteilungen oder sozialer Entwicklungen als lückenhaft erkannt worden waren, sind jeweils durch Erweiterungen der Gesetzesvorschriften angepaßt worden.

10. So kommt es, daß das deutsche Einkommensteuerrecht noch heute zumeist als Ergebnis einer gradlinigen und sachgerechten Fortentwicklung eines auf die Besteuenung nach der Leistungsfahigkeit ausgerichteten rechtsdogmatischen Systems beurteilt wird, ${ }^{212}$ das 1891 in Preußen entstanden und nur kurzfristig 1919 eine Unterbrechung erfahren hat, Die Besteuerungsidee Adolph Wagners hat es ermöglicht, vermittels methodischer Denkoperationen Entscheidungen für die weitere Gesetzgebung, aber auch konkrete Rechtsregeln für Einzelfalle zu entwickeln, die in widerspruchsfreier Übereinstimmung mit den generell normierten Wertungen abgeleitet wurden. Dazu wurde der Sinngehalt der Gesetzesgebote fortlaufend genauer festgelegt und weiter präzisiert. Auf diese Weise hat die rechtsdogmatische Fortentwicklung des preuBischen EStG zu einer modernen Rechtsdisziplin innerhalb des öffentlichen Schuldrechts als eigenständigem Gegenstand des Staats- und Verwaltungsrechts durch Klärung der Begriffe und Abgrenzung derselben vom Zivilrecht. geführt, wie es uns heute gelăufig ist. $\mathrm{Zu}$ Ende der sogenannten "goldenen

${ }^{211}$ Meisel, F. (1920), S. 35.

${ }^{212}$ Kirchhof, P./Söhn, H. (1992), § 2 EStG, Rdnr. 240; Bayer, H.-W. (1991), \$. 333; Großfeld, B. (1981), S. 43. Aus den werigen Zeilen, die Großfeld' dem săchsischen ESIG 1874/78 widmet, ergibt. sich, daß es in verschiedenen Hinsichten dem spăteren preußischen EStG 189\| uberlegen war. Dennoch wird das letztere als gradlinige Fortfuhrung, und sogar' Vervollkommnung einer kontinuierlichen Entwicklung bis heute dargestelle. 
zwanziger Jahre" des deutschen Steuerrechts, in denen diese Arbeit im wesentlichen geleistet wurde, ist dann auch die Grundlage für die nach 1949 in Gang gesetzte nachhaltige verfassungsrechtliche Einbindung des gesamten Steuerrechts gelegt worden. ${ }^{213}$

11. Bereits zu Ende der Geltung der Weimarer Verfassung hatte das Einkommensteuerrecht zusätzlich wirtschaftspolitische Zielsetzungen übernommen. Nach 1949 wurde dieser Einsatz stark ausgedehnt. Was 1949 ausdrücklich nur vorlăufigen Charakter haben sollte, ${ }^{214}$ wurde dann sogar noch verstärkt und bis heute beibehalten. Die empirischen Konsequenzen der steuerrechtlichen Bestimmungen sind seit der Kritik Meisels in den Hintergrund getreten. Weitgehend herrschte die Ansicht vor, daß das, was rechtsdogmatisch richtig sei, einer empirischen Kontrolle der ZweckmäBigkeit nicht bedürfe. Bald wurden dem EStG dann die Bestimmungen integriert, die als sogenannte Lenkungsnormen wirtschaftspolitischen Zielen dienten und die sich dennoch in die fortentwickelte Systematik problemlos eingliedern ließen. Seitdem Lenkungsnormen in der Tarnfarbe von Fiskalzwecknormen zunehmende Bedeutung erhielten, haben Steuerrechtswissenschaftler wieder die ursprünglichen Inhalte der Steuerrechtsdogmatik in den Vordergrund gerückt. ${ }^{215}$ Von führenden Steuerjuristen wird heute "Steuerrechtswissenschaft als Steuergerechtigkeitswissenschaft" beurteilt, ${ }^{216}$ wobei diese letztere "die hinter den positiv gesetzlichen Regelungen verborgenen Zielsetzungen, Wertungen und Sachgesetzlichkeiten aufdecken" und systematische Verknüpfungen offenlegen soll. ${ }^{217}$ Auf diese Weise glauben sie, eine Steuerrechtsordnung schaffen zu können, die "Lastengerechtigkeit" erreichbar macht. ${ }^{218}$ Das Einkommen, so heißt es, sei ein "besonderer Maßstab steuerlicher Leistungsfahigkeit", 219 Der Einkommensbegriff bleibt bei den Vertretern dieser Richtung aber stets unde-

21. Hierzu: Kirchhof, P. (1983), S. 357, insbes. S. 363; Henning, F.-W. (1973), S. 293; Kruse, H. W. (1973), S. 278.

\footnotetext{
${ }^{214}$ Dreißig. W. (1984), S. 198.
}

213 Die Ursprünge ciner deutschen Einkommensteuer fuhren auf das Steuerkonzept des FreihermI vom Stein vom 28.9.1806 zurūck. Von den Forderungen der französischen Revolution beeinfluBit, nachı englischem Muster entworfen, sollte jeder Burger nach seinem Vermögen, d. h. nach dem, was er vermag, zu den Kosten des erwarteten Krieges gegen Napoleon beitragen. Hierzu siehe: Grabower, R. (1932), S. 215; Greim-Kuczewski, P. (1989), S. 13; Anonym (1848), S. 180, S. 185, S. 202; Hansen, R. (1990), S. 5 .

216 Vogel, K. (1993), S. 1121, S. 11.23; Tipke, K. (1980); ders. (1981) Steuergerechtigkeit ..., S. 295; ders. (1993) Die Steuerrechtsordnung. S. 277; ders. (1988) Ober "richtiges; ...". S. 269; Lang. J.
(1987), S. 9.

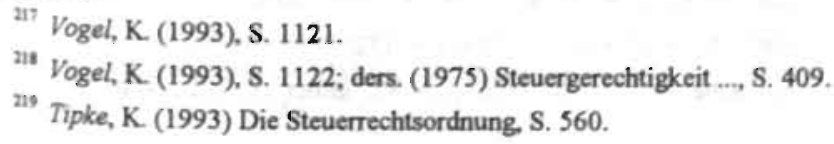


finiert. ${ }^{220}$ Es muß daher der Eindruck entstehen, es handele sich bei der Verwendung um den Begriffsinhalt der Umgangssprache. Zur Korrektur einer zunehmenden inhaltlichen Verwässerung der Rechtsdogmatik durch sachfremden Zwecken dienende Lenkungsnormen wird die Steuerrechtsordnung heute mit "Prinzipien formaler Rechtsstaatlichkeit" ${ }^{1221}$ in Zusammenhang gebracht und als deren Grundlage das "Prinzip der Besteuerung nach der Leistungsfahigkeit" als "Fundamentalprinzip"222 erkannt. Dabei wird dasselbe als Erkenntnis "richtiger", also auf "Sachgesetzlichkeit" beruhender Lastenverteilung ausgegeben. ${ }^{223}$

12. Die Konsequenzen des Úmstandes, daß die Begriffe "Einkommen" und "Leistungsfahigkeit" nicht definiert werden, mag hier unerörtert bleiben. Sie bezeichnen ein grobes Spektrum inhaltlich unterschiedlicher Gestaltungsmöglichkeiten. ${ }^{224}$ Ebenso wichtig erscheint die bei vielen Steuerrechtlern vorherrschende Überzeugung von der Erkenntnis "sachgerechter Prinzipien" und der "Sachgerechtigkeit" als unmittelbarer Rechtsquelle. ${ }^{225}$ Diese Auffassung setzt voraus, daß das Steuerrecht auf reinen Vernunftseinsichten und nicht etwa auf voluntaristischen Quellen beruht. Dabei handelt es sich um Prinzipien normativen Innalts, die die Steuerrechtswissenschaft als dogmatische Disziplin in ein

${ }^{220}$ Zwar bestätigt Tipke (1993), Die Steuerrechtsordnung, S. 560, daß es einen "richtigen Einkommensbegriff als solchen" nicht gibt, dieser sei am "Leistungsfahigkeitsprinzip" auszurichten, das aber wegen seiner Unbestimmtheit "Spielraum bei der Bestimmung des Einkommens als Bemessungsgrundlage" zulasse. Eine lastengerechte Bestimunung der Bemessungsgrundlage in einem Sachgesetzlichkeiten entsprechenden Steuersystem grenzen nach dieser Auffassung den richtigen Einkommensbegriff ein. De facto verbleiben jedoch große Differenzen, Die wiederholten Hinweise Tipkes auf "Erkenuntnisse" in Urteilen des BVerfG mőgen für Richter und Rechtsvertreter bindend sein. Sie sind es nicht für den Wissenschaftler. Schneider, D. (1984), S. 360, sieht in dem Gebrauch, den Tipke und andere von dem Begriff "Leistungstahigkeit" machen, zu Recht eine geschickte Erschleichung von willkürlichen Wertungen, die der Rechtfertigung der Umverteilung dienen, aber wissenschaftliche Objektivitât vortäuschen sollen.

${ }^{221}$ Tipke, K. (1993), Die Steuerrechtsordnung, S. 135.

222 ders., S. 283 i. V. m. S. 478 und S. 560.

223 Wis fest Tipke an die Möglichkeit glaubt, eine allgemein verhindliche lastengerechte Steuer. rechtsordnung erkenunen zu können, zeigt, sein Vorschlag zum Abschluß eines "Sachlichkeitsabkommens" der Parteien zur Ausschaltung "systemfremder" stërender Zwänge im geltenden Steuerrecht (S. 1513). Welche Gestaltungen inhaltlich Tipke auch mit seinen Begriffen konkret verbinden mag, so plädiert er jedenfalls für eine Beschränkung der Gestaltungsfreiheit der Politik, die letztlich fur das Gerneinwohl verantwortlich ist. Zur Kritik hierzu: Manthäus-Maier, I. (1985), Diskussionsbeitrag in: Raupach, A, S. 199. Tipke glaubt im ubbrigen nicht, daß "Steuergerechtigkeit und Steuereffizienz auseinanderfallen" mûssen (S. 280), "Gerechtigkeitsdefizite" der Marktwirtschaft will er nicht durch die Steuerrechtsordnung aufgefangen sehen (S. 281). Tipkes "Steuerrechtsordnung" trägt utopische Zige. Daraus ergibt sich ihre kritische Bedeutung. Zur kritischen Bedeutung von Utopien für den gesellschaftlichen Fortschritt siehe: Engelhardt, W. W. (1969), S. 660, S. 665.

${ }^{224}$ Hierzu: Arndt, H.-W. (1981), S. 18; Myrdal, G. (1963), S. 152.

225 Zur Kritik dieser Lehren siehe: Bobbio, N. (1965), S. 87, insbes. S. 102; auch: Albert, H. (1978), S. 65, S. 75. 
System widerspruchsfreier Wertungen im Detail umzusetzen sucht. Im Hintergrund dieser Wertungen aus der "Natur der Sache" steht eine philosophische Ontologie in Form der Wertungsjurisprudenz, ${ }^{226}$ die nach "richtigen" Regelungen und zureichenden Begründungen forscht. Die gelegentliche Bezugnahme auf Ergebnisse empirischer Forschung führt dabei nicht zu Änderungen von Rechtsinhalten im Normengefüge, sondern zu sprachlichen KIärungen und jeweils eleganteren Formulierungen bei unveränderten Grundwertungen und zur Darstellung von Anwendungsbeispielen.

Ein einflußreicher Steuerrechtswissenschaftler beruft sich ausdrücklich für verschiedenste Regelungen von weitreichender Bedeutung auf Erkenntnisse der "Sachgerechtigkeit". "Steuern sind nur 'gerecht'-fertigt, wenn sie gerecht sind .... wenn sie eine Bemessungsgrundlage liefern, die unter Berücksichtigung der steuerlichen Gesamtordnung sachgerecht bestimmt, welchen Anteil seines Gewinnes das Unternehmen als Steuer abzufuhren hat", so Klaus Tipke. ${ }^{227}$ Der sachgerechte Bestimmungsgrund für die Lastenverteilung ist danach die persönliche Leistungsfahigkeit des Besteuerten. Aus den als Erkenntnisse ausgegebenen Prinzipien folgert Tipke die Beschrảnkung des Systems auf́ Fiskalzwecknormen, die Orientienung desselben an dem Reinvermögenszugangsprinzip, die Einschränkung der Besteuerung auf das Markteinkommen, die Einführung von Freibeträgen, Abzügen für Sonderausgaben, die Begren= zung der Besteuerung auf das frei verfügbare Nettoeinkommen und anderes mehr. ${ }^{228}$ Tipke glaubt offenbar sogar, unterschiedliche Grade der Leistungsfâhigkeit ohne Angabe der hierzu verwendeten Meßvorschrift objektiv verbindlich erkennen zu können. ${ }^{229}$ Ein anderer Steuerrechtswissenschaftler lehnt

${ }^{226}$ Kaufmann, A (1982). S. 18. S. 44, S. 55; auch: Muller, M., in: Kaufmann, A. (1982), S. 461.

${ }^{277}$ Tipke, K. (1993) Die Steuerrechtsordnung, S. 534; Vogel, K. (1993), S. 1123.

228 Tipke, K. (1993) Die Stcuerrechtsordnung, S. 135. Tipke glaubt, daß eine Befolgung der aus sogenannten "Fundamentalprinzipien" hergeleiteten "Subprinzipien" und deren Zusammenbindung zu einem "Prinzipiensystem" (S. 283) die "Steuergerechtigkeit in Theorie und Praxis" garantiere. Das "Leistungsfahigske,itsprinzip" wird dabei als "Fundamentalprinzip sozial gerechter Besteuerung" vorgestellt (\$. 469). Die verschiedenen Begriffe werden von ihm in dem Sprachsystem in einen spitzfindigen Zusammenhang der Sub- und Koordination gebracht und zu einern rechtsdogmatischen System verknuppt. Durch je nach Bedarf eingeschleuste weitere Prinzipien wird dann das zu versteuende Einkommen als "geeigneter Maß̉stab steuerlicher Leistungsfahigkeit" (S. 500) entwickelt. "Praktikabilitătsprinzip" und "Nettopsinzip", beide nicht näher konkret definiert oder umrissen (S. 370 bzw. S. 591), spielen bei der Herleitung des zu versteuemden Einkommens eine wichtige regulierende Funktion. Die von Tipke aus "sachgerechten Prinzipien" rechtsdogmatisch entwickelte Steuerrechtsordnung stellt sich als ein aufwendiges Sprachsystem dar, das zur Rechtfertigung inhaltlich sehr unterschiedlicher, sich ausschließender Lastenverteilungen geeignet ist und dessen objektiv verbindlicher Charakter als problematisch bezeichnet werden muB.

23 Tipke unterscheidet gelegentlich eine "wahre" von einer "unwahren" Bemessungsgrundlage zur Einkommensbesteuerung als Maßstab der Leistungsfahigkeit. "Wenn aber eine Gruppe von Steuerpllichtigen auf der Grundlage einer wahren, die andere auf der Grundlage einer unwahren Bemes. sungsgrundlage und eines unwahren Tarifes besteuert wird, so liegt darin eine Verletzung des Gleich- 
Reformvorschläge ohne sachliche Erörterung mit der Begründung ab, daß einem Autor mit fehlender beruflicher Qualifikation als Steuerjurist grundsätzlich die Fähigkeit fehle, rezensierbare Beiträge zu dem Thema zu liefern. ${ }^{230}$ Die objektive Wahrheit der Wertungen, die derartigen Beiträgen zugrunde liegt, wird jeweils durch die Autorität der Vertreter belegt. Die Notwendigkeit, die konkreten Implikationen und sachlichen Auswirkungen dieser Form juristischer Argumentation mit Hilfe sozialwissenschaftlicher Arbeitsweisen zu prüfen, wird trotz gegenteiliger Beteuerungen zumeist nicht mit Nachdruck verfolgt. ${ }^{231}$

13. Zwar wird von führenden Steuerjuristen die Beseitigung aller Lenkungsnormen infolge mangelnder Sachgerechtigkeit gefordert, die weitreichenden wirtschaftlichen Konsequenzen einer Beseitigung werden - wenn überhaupt jedoch nur angedeutet. ${ }^{232}$ Eine Beschränkung der Beseitigung nur auf unzweckmaßßige Lenkungsnormen wird gelegentlich eingeräumt, aber nicht konkretisiert. $^{233}$ Auch die geforderte Neuorganisation des Systems der Einkommensbesteuerung nach dem Reinvermögenszugangsprinzip wird nicht konkret bezüglich der Auswirkungen erörtert und im übrigen sofort durch eine $\mathrm{Be}$ schränkung der Steuerbarkeit auf das Markteinkommen entwertet, wobei dem Begriff der "Praktikabilität" eine eigentümliche Rolle zur Rechtfertigung eigener Voreingenommenheiten zugewiesen wird. ${ }^{234}$ Die wirtschaftliche Bedeutung der verschiedenen, durch die Tarnfarbe der Steuernormen als Subventionen verborgen bleibenden Steuervergünstigungen wird nicht untersucht. Daß den Lenkungsnormen nach den seit 1949 gemachten Erfahrungen erhebliche Bedeutung für die allgemeine Wohlstandsmehrung zukommen kann, ist ein Forschungsgesichtspunkt, der gewiß den Rahmen rechtsdogmatischer Untersuchungen sprengt. Demgegenüber muß aber gefragt werden, worin konkret der Vorteil eines rein nach dieser Art Sachgerechtigkeit organisierten Einkommensteuersystems liegen mag. Die steuerjuristischen Berater des Gesetzgebers glauben "im Buche der Natur zu lesen", dabei interpretieren sie es

heitsgrundsatzes, nămlich eine gemessen an der Leistungsflihigkeit ungleiche Besteuerung". Als Wahrheitskriterien dienen Tipke offenbar "Erkenntnisse" in Gerichtsurteilen und Stellungnahmen der Mehrheit đer Steuerjuristen, Tipke, K. (1990) Einkommensteuerliches Existenuminimum ..., S. 349: siehe auch: Pezzer, H.J. (1989), S. 224.

${ }^{230}$ Lang, J. (1986), S. 502, S. 504.

${ }^{231}$ Naucke, W. (1972), S. 42; Raiser. T. (1987), S. 14: Reformforderungen beruhen zumeist auf rechtsdogrnatischen Begrindungen ohne sozialwissenschaftliche Absicherung

${ }^{212}$ Tipke, K. (1993), Die Steuerrechtsordnung, S. 127, S. 361. S. 371; ders. (1988), Ober "richtiges ...", S. 272; Lang, J. (1987), S. 28.

23s Tipke, K. (1989), Ober Steuervergûnstigungen .... S. 188; Zitzelsberger, H. (1985), s. 204: Tipke, K. (1988), Ober "richtiges ..." S 274

24 Tipke, K. (1993), Die Steuerrechtsordnung, S. 500; Ihnlich: Uelner, A. (1988), S. N 17 
nur. ${ }^{235}$ Bevor er sich seinen Handlungsspielraum einengen läßt, sollte der Gesetzgeber weitere Dolmetscher zur Auslegung der Texte beiziehen. Im übrigen vertreten einflußreiche Nationalökonomen gegenüber Rechtswissenschaftlern völlig abweichende Vorstellungen von einer den Handlungsspielraum der Politik als vorgegebene Ordnung einschränkenden "Natur der Sache", auf die sie sich gleichermaß̉en beziehen. Darin kommt der den Interventionsstaat eingrenzenden Privatautonomie eine besondere tragende Rolle zu. Die Interventionen des Rechtsstaates und dessen Sozialbindungen werden von ihnen als Abweichungen von einer natürlich vorgegebenen Ordnung für Vorgänge verantwortlich gemacht, die allgemein als Fehlleistungen beurteilt werden. ${ }^{236}$ Als eigentümlich muß erwähnt werden, daß maßgebliche Steuerjuristen die Probleme des Gesetzesvollzuges fortlaufend als unwichtig vernachlässigen. Bereits Meisel suchte 1911 in Schmollers "Jahrbuch" darauf aufmerksam zu machen, daß die Organisation des Gesetzesvollzuges die Zweckerfullung des Steuergesetzes vereiteln könne und in Preußen auch tatsächlich behinderie. Dieses Problem wird bis heute von zuständiger Seite kaum sachdienlich erörtert. ${ }^{237}$ Der derzeitig desolate Zustand der deutschen Finanzverwaltung findet hier seine wichtigste Ursache. Die Interessenlage hat gelegentliche Kritik abgewürgt. Eine Verbesserung der Situation läßt sich angesichts der gewachsenen unübersichtlichen Menge von normabweichenden Steuervergünstigungen und Ergănzungen heute nur noch durch eine völlige Umsiellung des Vollzuges zur Selbstveranlagung durch die Steuerpflichtigen erreichen. Der Einsatz moderner Computertechnik, die Móglichkeiten zur Speichenung und Verarbeitung großer Informationsmengen und die damit gegebenen Möglichkeiten moderner Ausrüstungen zur routinemäßigen schnellen Überprüfung nach Gesichtspunkten der Plausibilität machen eine Reform der Veranlagungstătigkeiten ohnehin empfehlenswert. Hierzu müßten für die Finanzverwaltung aber neue Schwerpunkte der Organisation gesetzt werden. ${ }^{238}$ Trotz entsprechender weitsichtiger Empfehlungen ist eine Anregung des Bundesrechnungshofes im

\footnotetext{
23 Bobbio, N. (1965), S. 95

S. 368 .

27. Meisel, F. (1914), S. 152; ders. (1911), S. 334, S. 359; âhnlich: Michaelis (1912), S. 87, S. 96; Meisel, F. (1920), S. 16.

2ง Die Möglichkeiten des Einsatzes der modernen Technik zur Vereinfachung und Verbesserung. der Effizienz der Verwaltungstätigkeit werden als Grundlage für eine reformierte rechtliche Ausgestaltung des Besteuerungsverfahrens bisher nicht gesehen. Eine Umstellung des Vollzugs der Veranlagung zusammen mit der Anwendung von Plausibilitätsprüfungen vermittels Computereinsatz nach US. amerikanischem Muster kőnnte erhebliche Entlastungen mit sich bringen. Die auftretenden Rechtsfragen im Zusammenhang mit den Bestimmungen des Datenschutzes bedürfen der Erồrterung der Harmonisierung von Technik und Recht mit den Bedurfnissen des modernen Industriestaates. Die Proble-
} 
Jahr 1960 nie von Steuerjuristen aufgegriffen worden. Die Beispiele lassen sich belicbig vermehren. ${ }^{239}$

14. Der Dogmatik des Steuerrechts ist zwar die empirische Überprüfung der Ergebnisse und Verbesserungen der Besteuerung für erforderliche Korrekturen der Gesetzesvorschriften fremd; dennoch dient erstere bei vielen Vertretern der Disziplin de lege ferrenda als Grundlage für Forderungen und Empfehiungen. Noch heute verfahrt man nach dem Satz, daß, was in der Dogmatik richtig sei, auch für die Praxis bestimmend sein müsse. Steuergesetze entstehen stets im Spannungsfeld widerstreitender Interessen zur Regelung heterogener Sachverhalte. Bei Beurteilung der Institutionen darf das nicht übersehen werden. Die einzelnen Bestimmungen führen dann zu Ergebnissen, die gegenüber der eingeforderten Sachgerechtigkeit anderer Ordnungssysteme abgewogen werden müssen. Hinzu kommt, daß Begriffe wie "Gerechtigkeit", "Sachgerechtigkeit", "Leistungsfähigkeit", "Praktikabilität", "Einkommen" und andere als unbestimmte Rechtsbegriffe mit höchst unterschiedlichen Inhalten verwendet werden, so daß zumeist Uneinigkeit in bezug auf den Gehalt bei gleichen verwendeten Worthülsen verborgen bleibt. So vermögen höchst unterschiedliche subjektive Wertungen den Anschein äußerlicher Objektivität zu erhalten. In der Politik mag dies als übliches Mimikry zulässig sein.

15. Die Nebenfolgen steuerrechtlicher Eingriffe können sehr verschiedenartige und weitgehende, zu Zielkonflikten führende Konsequenzen zeitigen. Verteilungskämpfe drohen, wenn das von den nachklassischen Nationalökonomen geprägte Schlagwort von den "unverdienten" Vermögensmehrungen von Wagner zur Begründung steuerlicher Zugriffe verwendet - das Verständnis für den Einsatz von wirtschaftpolitisch zweckmäßigen Vergünstigungsnormen im Einkommensteuerrecht verdrängt.

Als im Jahr 1968 das Ergebnis eines im Auftrag des Bundesministeriums fur Arbeit und Sozialordnung erstellten Forschungsgutachtens zu dem Ergebnis gelangte, daß in der Bundesrepublik Deutschland zum 1. Januar 1960305.000 Haushalte, das waren $1.7 \%$ der Bevölkerung. $35 \%$ des gesamten Volksvermó-

me werden offenbar noch gar nicht in ihrer Bedeutung gewürdigt. Siehe hierzu: Lukes, R. (1985) in: Kongress-Versffentlichungen der Hanns-Martin-Schleyer-Stiftung. 18. Bd., S. 40

219 Hierzu: Hartmann, J. (1967), S. 10. S. 14 und dort angefuhrte Fundstellen; Jenetzki, J. (1982), S. 278, S. 282, beklagte die Verstandnislosigkeit der Fühnungsstäbe der Finanzverwaltung für die praktischen Probleme der Veranlagung. Er empfahl dringend die Berücksichtigung der Ergebnisse der Hauptsachgebietsleiterkonferenzen der Oberfinanzdirektionen an in den Fürungsebenen der Ministerien, auch: Weingarten, J. (1993), S. 139, S. 261 u. a. 
gens besaßen ${ }^{240}$ und daß eben diesen 1,7\% der Bevölkerung 70\% des Eigentums an den gewerblichen Unternehmen gehörten, ${ }^{241}$ regte sich beachtliche Unzufriedenheit. Eine neuere Untersuchung steht noch aus. Es besteht aber kein Grund, sich über das zu erwartende Ergebnis falsche Vorstellungen zu machen. ${ }^{242}$ Nach fast 20 jähriger Wirksamkeit der als soziale Marktwirtschaft bezeichneten Wirtschaftsordnung vermochten diese statistischen Berechnungen 1968 Unruhe zu erzeugen. Gewiß waren zehn Jahre steuerlicher Begünstigungen der Selbstfinanzierung mit diesem Ergebnis in Zusammenhang zu bringen. Das Auseinanderklaffen von Erwartungen der Öffentlichkeit mit den Ergebnissen der Ermittlung führte zu starken sozialen Spannungen und zu überhöhten Lohnforderungen, die dann wiederum wesentlich durch komplizierte steuerliche Begünstigungen der Vermögensbildung benachteiligter Gruppen aufgefangen wurden. ${ }^{243}$ Etwa zu dieser Zeit setzte bei Steuerjuristen der Wandel darüber ein, was unter einer von Sachgerechtigkeit bestimmten Besteuerung nach der Leistungsfahigkeit zu verstehen sei. Die Begriffsinhalte entfernten sich nun zunehmend von den Inhalten, die etwa Wagner, Fuisting. Behrnauer, Waldecker, Bredt und andere als eine sachgerechte Besteuerung nach der Leistungsfähigkeit und damit Erkenntnissen von der "Natur der Sache" entsprechend unterstellt hatten. ${ }^{244}$ Inzwischen haben dennoch die Be-

${ }^{200}$ Krelle, W. u. a. (1968), S. 368, S. 379. Nach Auskunt des Sachbearbeiters des Deutschen Instituts für Wirtschaftsforschung in Berlin wurde eine Untersuchung vergleichbarer Art nach 1968 nach dessen Kenntnis nicht mehr durchgeführt.

${ }^{24}$ Krelle, W. u. a. (1968), S. 381.

${ }^{212}$ Nach Siebke nahm die Konzentration des Produktivvermögens in wenigen Händen zwischen 1960, auf welches Datum die Untersuchung abstellte, und 1966 erheblich zu; hierzu: Willgerodt, H. (1971), S. 408.

${ }^{20}$ Im Anschluß an die in der Ōffentlichkeit aufsehenerregenden Ergebnisse der Untersuchungen Krelles, Siebkes und Schmacks suchten insbesondere Vertreter einer marktwirtschaftlichen Organisation des Wirtschaftsgefüges nach Maßnahmen, die die Ergebnisse der Untersuchungen aber die Vermógensstreuung für die Zukunft neutralisieren kōnnten. Es wurden Zielprojektionen entwickelt und vermoggenspolitische Pläne entworfen und offentlich erörtert. Zahlreiche Vorschläge der aberbetrieblichen und betrieblichen Gewinnbeteiligung von Arbeitnehmern wurden nach 1969 ebenso diskutiert, wie Investitionsverfahren miteinander verglichen und die Vor- und Nachteile gegeneinander abgewogen wurden. Als brauchbare Maßnahmen empfahlen sich schlieBlich Steuervergünstigungen und Primien für kleinere Steuerzahler als Anreiz zur Bildung von Ersparnissen. Daß steuerliche Maßnahmen zum Rückgrat der unerwînschten Konsequenzen der Fördenung der Selbstfinanzienung entgegensteuemden Vermōgenspolitik der năchsten Zeit wurden, ist in den Darstellungen nie genügend gewardigt worden. Selbst in einschlägigen Abhandlungen zur Vermögenspolitik wird das Steuerrecht als irrelevant übergangen. Hierzu etwa: Weißer, G. (1961), S. 163; auch: Willgerodt, H. (1971), S. 407; obwohl bei Willgerodt Steuervergûnstigungen und Prämien die tragende Rolle bei der Vermögensbildung zukommt, werden die Probleme auf wenigen Seiten als untergeordnet abgehandelt.

im Die von Wagner geschaffene Dogmatik der Einkommensbesteuerung setzte die Lehren Rau's fort. Danach war das Einkommen nach herkömmlicher Auslegung des Begriffs der richtige Maßstab fur eine Besteuerung nach der Leistungsfahigkeit. Wertzuwachsgewinne erhöhten somit die LeistungsAlhigkeit nicht. Thre Erfassung, bei der Einkommensteuer blieb für Wagner und Fusting eine Verlegenheitslösung, mochte die Regelung auch zweckmäBig erscheinen. Hierzu: Bredt, V. (1912), S. 29, \$. 63; Hansen, R. (1990), \$. 26, S. 62. GroBe Wertzuwalchse führten um 1909 in Preußen und im 
stimmungen des herkömmlichen Einkommensteuerrechts weiterhin mit Priorität wirtschaftspolitischen Zwecken durch Förderung politisch erwünschten bzw. seit 1990 zur Erleichterung der Wiedervereinigung begünstigten Verhaltens dienen müssen. Daß die steuerliche Förderung regelmäßig die Vermōgensbildung der Steuerbürger mit höheren Einkünften, der Progression des Steuertarifs entsprechend, höher begünstigte, ist nun einmal die sozialpolitische Crux dieses offensichtlich sehr wirksamen, vielleicht sogar heute für einen befriedigenden Wirtschaftsablauf oftmals unentbehrlichen neuen Instruments der Wirtschaftspolitik. ${ }^{245}$ Die Konsequenz müßte sein, daß dieser Art Vergünstigungsnormen genau konkretisiert und nur befristet gewährt werden und eine begleitende statistische Überwachung der Ergebnisse stattindet. $^{246} 1985$ warnte der Soziologe Florian Tennstedt auf Grundlage von Untersuchungen vor einer "offenen Spaltung des Sozialstaates", für die er Ansätze zII erkennen glaubte: "In einer solchen Spaltung koexistieren 'Reichtumi' (Sperrung vom Autor) von etwa drei Vierteln der Gesellschaft mit der Verarmung eines Viertels". ${ }^{247}$ Eine weitere Feststellung Tennstedts lautet: "Anders als in der Weltwirtschaftskrise geht gesellschaftliche Verarmung nicht mehr Hand in Hand damit, daß auch der gesellschaftliche Reichtum erheblich schmilzt". ${ }^{248}$ Die Spaltung droht gewissermaßen zu erstarren. Daß das Einkommensteuerrecht diese Entwicklung bei intelligenter Ausnutzung der gegebenen Vergünstigungen geradezu provoziert, wird gern verdrängt. Das mag verständlich sein, gehören doch die potentiellen Kritiker und die für die Gesetzgebung zuständigen Minderheiten gleichermaßen zu den Begünstigten. Gustav Schmoller hatte aus diesen Gründen sein "Jahrbuch" 1910 durch Eröffnung der Diskussion über die Wirkungen des preußischen EStG in den Dienst der Aufgabe gestellt, das soziale Gewissen einflußreicher Minderheiten

Deutschen Reich zu einer intensiven offentlichen Diskussion. Ähnliche Vorgänge zeigten sich um 1970. Der Wissenschafliche Beirat beim Bundesrninisterium der Finanzen setzte sich angesichts ungewöhnlicher nicht steuerbarer VerăuBerungsgewinne 1967 für eine gleichmäßige Besteuenung von VerăuBerungsvorgăngen ein (Gutachten 1967, S. 23). Nun wurden die Konsequenzen der "dualistischen Einkunfteermittlung" als systemfremd bemalngelt: Tipke, K. (1973), S. 391 . Tipke zeigte fortan wenig Verstilndnis für den Umstand, daß die hōchstrichterliche Finanzrechtsprechung sich dem "dictum des Gesetzgebers" verpflichtet fühlte. Er gab dem Begriff der Leistungsfähigkeit zeitgemilb gewandelte Inhalte, denen er seither einen verfassungsmäBigen Hintergrund zu verschaffen sucht, s. Tipke. K. (1993), Die Steuerrechtsordnung. S. 47, S. 277; Vogel, K. (1975), S. 409.

245 Ortlieb, H.-D. (1974), S. 126; Zischka, A. (1966), S. 536; Oldenberg, K. (1893), S. 99; ders. (1893), S. 44. Die in die Ausfuhrungen einfließende unterschiedliche Bewertung zeigi die vorhandenen Zielkonflikte.

${ }^{246} \S 12$ des Gesetzes von Stabilital und. Wachstum schreibt eine umfassende Berichterstattung uber Finanzhilfen und Steuervergûnstigungen als Instrument der Wintschafts- und Gesellschaftspolitik vor. Diese müssen den Zielvorgaben des $\$$ I StabG genügen. denen die hier angesprochenen vermógenspolitischen Fragen fremd sind.

24) Tennstedt, F. (1985), S. 15.
${ }^{248}$ Tennstedr, F. (1985), S. 16. 
in der Gesellschaft durch Vermittlung von Informationen für sozialpolitische Zielsetzungen zu gewinnen und zu beeinflussen. Im "Jahrbuch" betonte er dies 1912 nochmals. ${ }^{249}$

16. Auch in einem demokratisch organisierten Gemeinwesen sind es nicht "die Regelungsbedürfnisse selbst", nicht "Interessen, der Volksgeist oder Produktionsverhältnisse, die den Gesetzgeber in Gang setzen", sondern "Personen und Personengruppen. Minderheiten also" ${ }^{250}$ Zur Fertigung eines zweckmäßigen, den zeitgemäßen Rechtsvorstellungen entsprechenden Gesetzes müssen umfassende Informationen über Fakten und Meinungen Berücksichtigung finden. Der Ministerialbürokratie kommt dabei die Aufgabe zu, mit Hilfe der in der Behörde angesammelten Fachkenntnisse durch Einbindung der Interessenverbände, Einholung von Auskünften durch Beteiligte und Betroffene und Einflußnahme auf Abgeordnete und Parteien in Entwürfen eine geeignete, letztlich zumeist richtungsweisende Verhandlungsgrundlage $\mathrm{zu}$ schaffen. ${ }^{251}$ Das gibt der Verwaltung ohne Zweifel ein starkes Übergewicht bei der Gesetzgebung: Einseitigkeiten der Tatsachendarstellung und vor allem deren Bewertung und durch eingeschränkte Sachkenntnis bedingte Parteilichkeit können fast unvermeidlich Einzug halten ${ }^{252}$ Hier ist eine wissenschaftliche Rechtstatsachenforschung angesichts mangelbehafteter Informationsquellen, die auf die Bedürfnisse des gesamten Gemeinwesens ausgerichtet sein sollten, für notwendige Korrekturen heute unverzichtbar. Für die in Gesetzen formulierten generellen Regelungen kann nach interessierenden Gesichtspunkten aufbereitetes statistisches Material Bedeutung erhalten. Die laufende periodische Kontrolle, ob das Gesetz in der Realität geeignet umgesetzt wurde, ob es in die vorgesehene Richtung wirkt und welche unbeabsichtigten Nebenfolgen sich einstellen, mag für verbessernde Novellierungen hilfreich sein. ${ }^{253}$ Die ständig zunehmende Kompliziertheit der gesetzlichen Regelungen auf allen Gebieten führt heute unter anderen Umständen zu neuen Formen der Übervorteilung Hilfloser, zu bisher unbekannten Erscheinungsformen von Armut und neuartigen Ungerechtigkeiten und nicht zuletzt zu mißbräuchlicher Inanspruchnahme sozialer Errungenschaften. ${ }^{254}$ Die Ergänzung der Rechtsdogmatik durch eine begleitende finanzwissenschaftliche Forschung in Form von Rechtstatsachenforschung und deren rechtssoziologischer Verarbeitung ist daher heute ver-

\footnotetext{
20 Schmoller, G. (1912), S. 1.

${ }^{200}$ Rehbinder, M. (1993), S. 247

${ }^{21}$ Rehbinder, M. (1993), S. 251; Strempel, D. (1984), S. 195; Naucke, W. (1972), S. 26, S. 55

${ }^{32}$ Rehbinder, M. (1993), \&. 251.

${ }^{23}$ Rehbinder, M. (1993), S. 260.

${ }^{24}$ Rehbinder. M. (1993), S. 33; Zippelius, R. (1991), S. 53; Hansen, R. (1993), S. 179
} 
stärkt geboten. ${ }^{255}$ Ziel muß es sein, das soziale Ordnungsgefuge an einem. allgemein erträglichen Ablauf des Soziallebens nach legitimen Rechtsnormen so auszurichten, "daß eine wirksame Garantie für die Rechtlichkeit der Macht" ${ }^{256}$ geschaffen wird, wie der Rechtssoziologe Rehbinder festhält. Im übrigen ist gerade für das Steuerrecht zu bedenken, daß auch in Demokratien "Legislative ein Handeln von organisierten Minderheiten ist", ${ }^{257}$ wobei infolge der fehlenden Kompetenz und nicht zuletzt des mangelnden Interesses der Staatsbürger eine aktive Beteiligung an den hochkomplizierten öffentlichen Angelegenheiten weder erreichbar erscheint, noch wünschenswert sein mag. Weder Parlamentsausschüsse noch Plenum sind die eigentlichen Inhaltgeber und Formpräger" ${ }^{\text {258 }}$ des Steuerrechts. "Doch sollten Transparenz und Publizităt des Minderheitenhandelns dafür sorgen, daß dieses Handeln tatsächlich und nicht nur der Rechtskonstruktion nach demokratisch legitimiert ist ..."259 Dazu ist die rechtssoziologische Durchdringung von Gesetzesvorhaben und Begleitung der Gesetzeswirklichkeit erforderlich. Die heute vorherrschenden rechtsdogmatischen Beiträge zum Steuerrecht müssen dringend durch rechts-

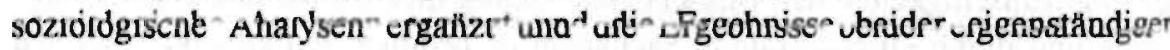
Disziplinen in Balance gebracht werden. Erst dann wird es möglich werden, die Lastenverteilung von Rechtssetzungen bei Abwägung vorhergesagter Nebenfolgen und nach Kenntnisnahme unerwarteter Ergebnisse "verantwortungsethisch nach ihren Folgen zu beurteilen", wie dies kürzlich von Dieter Schneider in einer kritischen Besprechung des Urteils des Bundesverfassungsgerichts zum Existenzminimum bei Steuerjuristen vermißt wurde. ${ }^{260}$

Bereits 1966 beklagte Neumark, daß "gradlinig apodiktische Formulierungen des Rechtstheoretikers" gelegentlich in Rechtsbegriffen dazu herhalten müssen, "auftretende Antinomien" zu verstärken, während es sinnvoller wäre, sie "in moralisch einwandfreier Weise zu überwinden". Er zeigte sich verwundert, "wie es dem Juristen moglich ist, ohne genaue umfassende Kenntnis des von ihm zu beurteilenden Gegenstandes verbindliche Regeln ... aufzustellen". ${ }^{26 i}$

17. Die Einkommensteuer hat mit der starken Erhöhung der Steuersătze im Zeitablauf zunehmend die Funktion übernonnmen, als Umwandlervorrichtung

\footnotetext{
25s. Naucke, W. (1972), S. 42: Strempel, D. (1984), S. 195; Raiser, T. (1987), S. 18.

${ }^{256}$ Rehbinder, M. (1971), S. 194.

257 Rehbinder, M. (1993), S. 262.

258. Eichenberger, K. (1982), S. 29: Rehbinder, M. (1993), S. 262.

25s. Rehbinder, M. (1993), S. 262.

Siegel, T./Schneider, D. (1994), S. 603, S. 604.

${ }^{261}$ Newmark, F. (1966), S. 476
} 
zu dienen. Sie ändert das marktwirtschaftliche Belohnungssystem und dessen Signalwirkungen für die Produktion und Dienstleistungen regulierenden Steuenungsprozesse in erwünschter Weise ab. Hohe Steuerprogression und zeitliche Verlagenung von Abschreibungen als Betriebsausgaben sind unter anderen die erfolgreichsten Bedienungshebel. Ihr Einsatz war bisher angesichts umwälzender politischer und sozialer Umstürze jedenfalls von Erfolg begleitet. Nach einer befriedigenden Lōsung der drängendsten Aufgaben durch den auf diese Weise forcierten Wiederaufbau der Bundesrepublik Deutschland wurden viele Regelungen trotz der veränderten Umstände beibehalten. Sie sind inzwischen mit Veränderung der Bedürfnisse allgemein in die Kritik geraten und werden oftmals sogar als mißbräuchlich abgeurteilt. Offensichtlich erscheinen sie vielen als zeitlich überholt. Dennoch wird ein Bedürfnis nach steuerlicher Begünstigung von Investitionen inzwischen allgemein anerkannt.

In einem neuartigen Entwurf eines Einkommensteuergesetzes hat ein Steuerurist versucht, den sich artikulierenden Differenzen gerecht zu werden. ${ }^{262}$ Die vorgelegte Systematik soll als Radikalkur den "Mißbrauch des Steuerrechts als Vehikel der Wirtschaftslenkung"263 verhindern und dennoch durch steuerliche Förderung marktwirtschaftlich vernünftige Lösungen einer notwendigen Investition ermöglichen. Zwar ist der Musterentwurf als "Steuergesetzbuch für eine östliche Republik", ${ }^{264}$ also als Exportartikel gefertigt. Lang zielt jedoch auf sein Heimatland, dessen Einkommensbesteuerung er zum Teil für "entartet" hält, da sie "gegenüber ökonomischen Entscheidungen nicht mehr neutral wirkt" ${ }^{\text {265 }}$ und dem er jedenfalls "Reformunfähigkeit" ${ }^{266}$ vorwirft. Lang glaubt sich mit seinem Entwurf nicht auf "Neuland" zu bewegen, da "die verschiedenen Konzepte und Wirkungen einer sogenannten konsumorientierten Einkommensbesteuerung hinreichend erforscht sind" ${ }^{267}$ Es scheint Lang wichtig, daß durch seine Systematik den bisher als Katalysatoren eines erwünschten Investitionsbooms dienenden "Sonderabschreibungsgesellschaften und anderen Steuersparmodellen ... der Năhrboden entzogen" wird. ${ }^{268}$ Er verweist darauf, daß viele Steuerzahler, von suggerierten Steuervorteilen geblen-

\footnotetext{
262 Lang, J. (1993). Der Entwurí soll den gemachten Auflagen entsprechend Rechtsstaatlichkeit, Einfachheit und administrative Effizien\%, fiskalische Ergiebigkeit, Harmonisierbarkeit in der EU garantieren und Investitions-, Spar- und Umweltfreundlichkeit fordern (S. 3).

2ss Lang, J. (1993), S. 6.

24 Lang. J. (1993), S. 3, S. 7.

265 Lang, J. (1993), S. 53.

266 Lang, J. (1993), S. 57.

267 Lang, J. (19913), S. 53. Dali es sich nur jeweils um Modellstudien und nicht um empirische Untersuchungen handelt, muB wohl erwähnt werden.

26a Lang, J. (1993), S. 56.
} 
det, Anteile an Verlustzuweisungsgesellschaften zeichneten, die schließlich sogar zu Konkursen führten. ${ }^{269}$ Dieses Argument wird von der Statistik jedoch entwertet. Bei auftretenden Schwierigkeiten wurden Investitionen fast immer oft mir anderen Eigentümern - abgeschlossen und das Gemeinwohl somit durch den Abschluß gefördert. Außerdem waren nicht nur zu diesem Zweck begründete Abschreibungsgesellschaften Träger steuerlich forcierter Investitionen; jeder Bürger konnte an den Förderungsmaßnahmen teilhaben. Das geschah auch in großem Umfang. Wenn Lang in seinem Entwurf nicht mehr der Privatautonomie, sondern staatlich lizensierten Sparinstituten durch steuerliche Förderung das Monopol für Entscheidungen über die Finanzienung erwünschter Investitionen gewährt sehen will, so kann er sich nicht auf gesicherte Erkenntnisse dafür berufen. Die größten verlustreichen Abschreibungsgesellschaften mit Sanierungsbedarf waren in Berlin. Sie wurden öffentlichrechtlich kontrolliert, gefordert und sogar von staatlichen Landesbanken betreut.

Jedenfalls ist der Entwurf eine wichtige Diskussionsbasis für eine mögliche Fortentwicklung der Einkommensbesteuerung.

Nach Lang soll zugleich mit der Abschaffung aller Steuervergünstigungen jeder Bürger fortan nur noch das sogenannte "disponible" Einkommen ${ }^{270}$ als Nettoüberschuß der ungekürzten Erwerbsbezüge über erwerbsrelevante Werbungskosten, existenznotwendige Konsumausgaben für Familie und Unterhaltsverpflichtungen gegenüber Abhängigen versteuern. Die Steuerbelastung soll so am "aktuellen Konsum orientiert" ${ }^{\text {271 }}$ werden. Dabei soll die Einkommensteuer nur das für den nicht existenznotwendigen Konsum "disponible" Einkommen des Bürgers erfassen. Dieses ergibt sich nach einem Abzug aller Aufwendungen für Investitionen, für Altersvorsorge. Versicherungen, Hausoder Wertpapiererwerbe, Sparbildungen verschiedenster Art etc., etc. bei Ermittlung der steuerlichen Bernessungsgrundlage. Die Bildung von Ersparnissen und Investitionen bleiben somit, da nicht der Konsumsphäre zugehörig, von der Besteuerung ausgenommen. Erst aus diesen Ersparnissen resultierende Erträge werden bei Zufluß an den Begünstigten als steuerbar erfaßt. Ebenso müssen Erträge aus jeglichem Vermögen, aber auch Verkaufserlöse von geldwerten Sachen und Rechten jeder Art. die vorher die steuerliche Bemessungsgrundlage minderten, bei Rückfluß in die Privatsphäre des Steuerpflichtigen und zwar stets in voller Höhe - der Besteuerung unterworfen werden.

\footnotetext{
269 Lang, J. (1993), S. 56; auch: Tipke, K. (1988), S. 878.

270 Der Spiegel. Das Deutsche Nachrichten-Magazin, Nr. 20 vom 16.5.1994, S. 112.

27. Lang, J. (1993), S. 104.
} 
Zur Durchfühnung dieser Gestaltung sollen staatlich besonders überprïfte und privilegierte Institute ${ }^{272}$ auf "qualifizierten Konten"273 "qualifizierte Vermögensanlagen ${ }^{\prime 274}$ verwalten dürfen, über deren Wertezu- und -abfluß durch Ersparnisbildung bzw. Verbrauch durch die Kunden Bescheinigungen auszustellen sind. Der Saldo zwischen Ersparnisbildung der Kunden bzw. Rückfluß an die Kunden auf diesem "qualifizierten Konto"275 ist dann jăhrlich bei der Ermittlung der steuerlichen Bemessungsgrundlage in den "Gesamtbetrag der Welteinkünfte ${ }^{m 276}$ einzustellen und der Tarifbesteuerung zu unterwerfen.

Der als "einfaches System aus einem Guß"277 begrüßte Entwurf läßt den Einsatz. der Einkommensteuer zur sektoralen wirtschaftspolitischen Steuerung der Volkswirtschaft dem Konzept nach nicht mehr zu. Die Aufgaben werden verlagert. Privilegierte staatlich genehmigte Sparinstitute des Entwurfs sind als marktwirtschaftlich organisierte Kapitalsammelstellen für den Großteil der Investitionsvorgänge vorgesehen. Sie sollen nunmehr die Aufgaben der bisherigen, an den einzelnen Steuerbürger gerichteten Lenkungsnormen des EStG übernehmen.

Zu dem Gesetzesentwurf mag folgendes ausgeführt werden: Der Vorschlag berücksichtigt, daß Investitionsbedürfnisse, die bei Aufrechterhaltung einer marktwirtschaftlichen Gesamtordnung im allgemeinen Interesse liegend, einer Förderung bedürfen, auch in der Zukunft verbleiben werden. Das marktwirtschaftiichen Gesichtspunkten verpflichtete privilegierte Sparinstitut wird aber den Anforderungen ohne gesetzliche dirigistische Sonderregelungen im einzelnen nicht entsprechen können.

Das Gebiet der ehemaligen DDR wirkt heute auf einen Besucher wie eine einzige große Baustelle. Vereinzelte notleidende Investitionen fallen kaum ins Gewicht. Die Aufbauleistungen sind das Ergebnis der Steuervergünstigungen des Fördergebietsgesetzes, der angekündigten erhōhten Tarifbelastungen des EStG und weiterer gezielter steuerlicher Maßnahmen. ${ }^{278}$ Die schwerfallige Geschäftspolitik von privilegierten Instituten mit der erforderlichen Finanzierung und Abwicklung von Einzelobjekten hătte dieses Ergebnis ohne überhộhte staatliche Förderungen kaum aufzuweisen. Allerdings verlangte hier auch

\footnotetext{
${ }^{272}$ Lang, J. (1993), S. 221 (\$ 832 des Entwurfs).

${ }^{273}$ Lang. J. (1993), S. 221 ( $\$ 833$ des Entwurfs).

274 Lang. J. (1993), S. 144 ( 123 des Entwurfs).

275 Lang, J. (1993), S. 134 (§ 109 Abs. 3 i. V. m. $\S 105$ Abs. 2 Ziff. 3 des Entwurfs).

2\% Lang, J. (1993), S. 149 (§ 135 des Entwurfs).

27 Der Spiegel, S. 112.

Zu nennen sind Investitionszuschûsse und -zulagen (BGBI. I 1993 S. 165; BStBI. 1 1993 S.
} 
eine einmalige historische Aufgabenstellung Problemlösungen besonderer Art, mögen die Folgeerscheinungen sich über viele Jahre hinziehen.

$\mathrm{Da}$ nach dem Entwurf nur die Aufwendungen des Steuerbürgers für den "disponiblen" Konsum besteuert werden sollen, stellt sich die Frage, welche Móglichkeiten sich für die bei Ermittlung der Bemessungsgrundlage abzugsfahigen Aufwendungen im Falle von Selbstfinanzierungen ergeben.

Hier sind letztlich nach wie vor zusätzliche, Investitionen anregende steuerliche Begünstigungen unter dem Druck von Notwendigkeiten - und sei es im Erlaßwege oder aufgrund einer Ermåchtigungsvorschrift - zu erwarten. Die Privatautonomie wird hier schnell ein kaum verriegelbares Einfallstor für intelligente, weil steuerfreie und übertragbare, gegebenenfalls mit besonderen Vergünstigungen gekoppelte Vermögensakkumulationen schaffende Gestaltungen finden. Dabei führt der Entwurf dazu, daß nunmehr ausschließlich diejenigen Steuerbürger begünstigt sind, die als Inhaber von Unternehmen oder Eigentümer geeigneter Objekte Selbstfinanzierung überhaupt betreiben kőnnen. Die Hobhe der Begünstigung würde wie bisher mit der Hobhe der ausgelösten Steuerprogression wachsen.

Die geweckte Erwartung. daß das von Lang entworfene Steuerkonzept einfacher und gerechter als das geltende sein soll, erweckt beim Praktiker Bedenken. $^{279}$

Schwerwiegende Konsequenzen des Entwurfs müssen den Soziologen interessieren:

Bisher hatten als Folge der Lenkungsnormen steuerlich berücksichtigungsfähige Investitionen in Form von Sonderabschreibungen als Steuervergünstigungen Ausnahmecharakter. Sie wurden im Gesetz jeweils nur zeitbegrenzt vorgesehen, da sie letztlich im Grunde allgemein als Verfalschung der Ermittlungsvorschriften beurteilt wurden. Sie wurden denn auch seit 1949 jeweils vorgesehen, zeitlich limitiert, verändert, abgeschafft, wieder eingeführt, in ihrem Geltungsbereich zeitlich und răumlich eingeschränkt etc, etc. Ständig blieben sie im Gespräch der politischen Gruppierungen ein Zankapfel. Wegen dieses Ausnahmecharakters und der Beurteilung der Steuervergünstigungen als verborgene Subventionen mußte gemäß $\$ 12$ des Gesetzes zur Förderung der Stabilität und des Wachstums der Wirtschaft ${ }^{280}$ im Rhythmus von zwei Jahren in einem offentlich stets streitig diskutierten Subventionsbericht umfassend von der jeweiligen Regierung Rechenschaft abgelegt werden. Es stellt

${ }^{279}$ Lang, J. (1993), S. 104. Auf die mit der Finanzierung langlebiger Gebrauchsguter auftretenden Probleme kantı hier nicht eingegangen werdet.

${ }^{200}$ BGBI. I 1967, S. 383 
sich somit die Frage, ob der vorliegende Entwurf nicht die erkennbaren Mängel des bisherigen Systems zur Steuerung, der Wirtschaft durch Steuervergùnstigungen mit verstärkter Abgabenbelastung der mittleren und unteren Einkommensgruppen wesentlich verstärkt und obendrein sogar zementiert. Ein neuartiges privilegiertes halbamtliches Bankinstitut stellt wegen seiner bürokratischen Schwerfalligkeit die Wirkungseffizienz in Frage. Da aus problematischen Ausnahmen der Steuervergünstigung nach dem Entwurf die Regel wird, entfallt die Erörterung in einem Subventionsbericht. Den Hinweis auf eine bloße Aufschiebung der Versteuerung lăngstens bis zum Tod des Steuerpflichtigen wird der Verweis auf die großen Gestaltungsmöglichkeiten der Privatautonomie entschärfen. Letztlich verläßt diese Ausgestaltung der Einkommensbesteuerung den Grundgedanken der Schmollerschen, als Vermögenszugangstheorie bezeichneten Besteuerungsidee. Steuerfrei entstehende hohe Vermögen können als Machtpositionen durch die damit verbundenen Gestaltungsmöglichkeiten, etwa von Dispositionen über Investitionen und Betriebsausgaben zu unübersehbaren, kaum kontrollierbaren und schwer auflösbaren Begünstigungen von Bürgern mit hohen Einkünften, auf Kosten der Abgabenhöhe mittlerer und kleinerer Steuerzahler führen.

18. Daß eine hohe Tarifprogression der Einkommensteuer in Verbindung mit wirtschaftspolitisch hohen zweckgebundenen Abzugspositionen zur Ermittlung der steuerlichen Bemessungsgnundlage bei Vorliegen weiterer normierter Umstände wohlstandsfördernd wirken kann, kann schlechterdings nicht mehr bezweifelt werden. Die Bedeutung dieser wichtigen Zusammenhänge hat in der Wissenschaft bislang nicht genügend Aufmerksamkeit gefunden.

Die fortlaufend von vielen Fachleuten vorgetragene These, eine hohe Steuerbelastung werde große, für eine Volkswirtschaft schädliche Vermögensverlagerung der Reichen verursachen, ist in dieser Allgemeinheit jedenfalls widerlegt ${ }^{281}$ Das Gegenteil kann richtig sein, mag es auch absurd erscheinen.

Sofern es Steuerpflichtigen möglich ist, vermittels der Besteuerungsnormen und der Veranlagungspraxis Steuern in Vermögen zu verwandeln und das in zunehmendem Ausmaß bei höherem Einkommen, zeichnet sich ein eigentümliches Zusammenspiel der Interessen in der Gesellschaft ab. Die aus sozialen Gründen übliche Forderung nach höherer Besteuerung der Reichen vermag den Interessen eben dieser kleinen Gruppe von etwa 5\% der Bevölkerung zu entsprechen. Mag der Wohlstand der Allgemeinheit als Folge gezielter Inve-

231 Hamer, E. (1994), Besserverdienende - Wie der Staat sie auspreBt, in: Welt am Sonntag vom 6.2.94, S. 46. Hamer ist Leiter des Mittelstandsinstituts in Niedersachsen. Die Auswirkungen des Steuersystems werden von ihm nur eingeschränkt berocksichtigt. 
stitionsförderungen auch steigen, so geschieht dies jedenfalls in hohem Maß zu Lasten erhöhter Steuerzahlungen der mittleren und kleineren Einkommensempfänger, denen ein Ausweichen durch Steuervermeidung versperrt ist. Die Vermögensverteilung wird auf diese Weise zunehmend kopflastig und vermag unerwünschte Langzeitwirkungen zu zeitigen. Ein soeben veranstalteter "Armenkongress" der zuständigen Verbände der Bundesrepublik hat wegen des allgemein hohen Lebensstandards wenig Aufmerksamkeit gefunden. Die inzwischen veröffentlichen Zahlen über die Zunahme der Anzahl von Sozialhilfeempfängern bei steigendem Wohlstand und steigenden Ansprüchen bedürfen jedenfalls gesteigerter Aufmerksamkeit.

Eine kritische Erörterung dieser Fragen, die ein Grundanliegen der Einführung einer modernen Einkommensteuer in Deutschland im 19. Jahrhundert berühren, sollte geboten erscheinen. Übersehbare Folgewirkungen verlangen ständig nach Berücksichtigung. Auch bei Beurteilung der Eignung als "Exportartikel" ${ }^{282}$ sollte dieser Gesichtspunkt nicht übersehen werden.

282 Tipke, K. (1990), Steuergesetzgebung ..., S. 309. 


\section{N. Ergebnis: Eignung und Grenzen der aus unterschiedlichen und einander ausschließenden Besteuerungsideen entwickelten Einkommensbesteuerung der Bundesrepublik Deutschland}

Die eigenartige Verschlingung von zwei auf die Nationalökonomen Adolph Wagner und Gustav Schmoller zurückführbare, sich gegenseitig ausschließende Besteuerungsideen hat die tragenden Grundgedanken des deutschen Einkommensteuerrechts maßgeblich bestimmt. Dieser dualistische Aufbau hat dem deutschen Einkornmensteuerrecht die Fähigkeit verliehen, die unterschiedlichsten politischen Systeme zu überleben und dabei für verschiedenartige soziale und wirtschaftspolitische Anforderungen ein geeignetes, vielfältig ausgestaltbares Rahmengefüge zur Verfügung zu stellen.

Bei dem Aufbau der neuen Bundesländer und ihrer wirtschaftlichen Eingliederung in die Bundesrepublik kann sich wiederum dic vielseitige Eignung des Gesetzeswerkes zeigen.

Die Möglichkeit zu einem nachhaltigen instrumentalen Einsatz, zur Lösung von vordringlichen sozialen und politischen Anliegen bei der Wiedervereinigung ist in dem Rahmengefüge des geltenden Einkommensteuerrechts zureichend angelegt.

Diese Tauglichkeit muß jedoch mit der allgemeinen Forderung der von vielen Steuerrechtlem als sogenanntes "Fundamentalprinzip der Besteuenung nach der Leistungsfahigkeit" - der Idee der Steuergerechtigkeit in einem inhaltlich verstandenen Sinn - in höchst pragmatischer Weise jeweils in ein Gleichgewicht gebracht werden. Die Besteuerung nach der Leistungsfähigkeit und der instrumentale Einsatz des Steuerrechts zur Verfolgung nichtfiskalischer Zwecke sind gleichermaßen heute unverzichtbare Prinzipien steuerrechtlicher Gestaltungen im Abgabewesen. Die Verfolgung des einen Zieles schließt jedoch die gleichzeitige Vereinbarkeit mit den anderen Anforderungen aus. Die Entscheidung über die Rangordnung der Prinzipien und die konkrete Ausgestaltung des Steuerrechts kann nicht von den die sachlichen Konsequenzen aufzeigenden Wissenschaftlern, sondern nur von verantwortlichen Politikern bei Abwägung der Folgen mit Augenmaß für den Einzelfall getroffen werden. 
Dem Aufbau des deutschen Einkommensteuergesetzes liegen nun einmal, wie wir der Entstehungsgeschichte entnommen haben, zwei unterschiedliche Baupläne zugrunde. Es gab zwei Architekten mit sehr verschiedenartigen Grundauffassungen. Das heute noch geltende EStG erhielt daher von vornherein keine einheitliche Statik. Als das Bauwerk 1925 errichtet wurde, ließ man offen, ob die von Schmoller stammende Blaupause vorrangig bestimmend sein sollte, wobei - wie im săchsischen EStG 1874/78 - aus Gründen der Praktikabilităt Vereinfachungen der Ermittlungsvorschriften und gar begrenzte Abweichungen von der Grundregel vorzusehen seien. Der Gesetzgeber wollte sich aber auch nicht auf die von Wagner stammende Systematik des preußischen EStG 1891 festlegen lassen, dem nur Ausnahmevorschriften für die Ermittlung der Bemessungsgrundlage bei den Einkunftsarten eins bis drei eingefügt wurden. Die wirtschaftliche Entwicklung sollte für die endgültige Fertigstellung des Bauwerkes nach den Erfordernissen des Lebens selbst bestimmend sein, so etwa laßt sich die Beurteilung Enno Beckers aus dem Jahr 1925 referieren.'

Finanzgerichte, aber auch Verfassungsgerichte haben sich seither schwergetan, offen gelassene Lücken im Bauplan zu schließen. Steuernormen sind auch staatliches Eingriffsrecht. Entscheidungen auf Grundlage von Analogieschlüssen sind daher nach vielfach vertretenen Rechtsauffassungen nur insoweit möglich, als Einigkeit in bezug auf den Bauplan - die zugrundeliegende Regel - besteht.

Bei Zweifeln ist nach diesem Verständnis auf das "dictum" des Gesetzgebers allein abzustellen. Das hat eben weitreichende Konsequenzen.

Eine Konsequenz dieses Umstandes ist der Grad an Kompliziertheit des heute geltenden Einkommensteuerrechts. Dies ist aber eine Folgewirkung. die - wie es scheint - ein hochindustrialisiertes und nach rechtsstaatlichen Gesichtspunkten ausgerichtetes Gemeinwesen unvermeidlich belastet.

Eine weitere Konsequenz dieser Zusammenhänge ist der Umstand, daß einige der das Steuerrecht betreffenden Instrumente einer modernen Wirtschaftspolitik zu höchst unerwünschten gesellschaftspolitischen Zuständen führen kônnen. Zielkonflikte bedürfen daher auf Grundlage dessen, was die eigentliche Aufgabe von Finanzwissenschaftlern sein müßte, nämlich der Erforschung von Wirkungen alternativer Besteuerungen auf Einkommens- und Vermögensverteilung, heute ständiger Aufmerksamkeit.

Für Gustav Schmoller sollte ein nicht auf den formalen begrifflichen Aufbau des Systems abstellender, von der Sprachregelung unabhängiger, nach reinen

\footnotetext{
'Becker, E. (1940), S. 1 .
} 
Zweckmäßigkeitsgesichtspunkten definierter Einkommensbegriff als Bemessungsgrundlage für die Besteuerung dienen. Vereinfachend formuliert sollte alles, was ein Steuerpflichtiger in einem Besteuenungsabschnitt verbrauchen kann, ohne sein Vermögen anzugreifen, als Kriterium für die Leistungsfahigkeit der zentrale, von Zeitentwicklungen unabhängige Orientierungsgesichtspunkt für die Ermittlung des Steuerbeitrages sein.

$\mathrm{Da}$ es für Schmoller einen erkennbaren "richtigen" Einkommensbegriff nicht gab, wir also stets auf konventionelle Festsetzungen angewiesen bleiben, kam seiner Definition auch nur Bedeutung als systemtragender leitender Gesichtspunkt zu. Auch andere Orientierungen verlangten nach seinen Ausführungen Berücksichtigung und die Vorrangigkeit war dann jeweils zu prüfen. ${ }^{2}$

Der Beitrag Wagners zur Reform war die Systematik der später sogenannten "deutschen Type" des Einkommensteuerrechts, die noch heute das Grundmuster für die Besteuerung nach dern Einkommen vorzeichnet. Diese gibt dabei weitgehend Raum für interventionistische und dirigistische Eingriffe nach zeitgemäßen wirtschafts- und sozialpolitischen Erfordernissen. Wagners stark begrifflich orientierte Ausrichtung der Bestimmungen sollte die Besteuerung nach einer von sozialen Kriterien festgelegten Leistungsfähigkeit ermóglichen. Nach seiner Vorstellung mußte ein "richtiger" Einkommensbegriff der Entwicklung der Zeit, also dem Übergang von der "staatsbürgerlich liberalen" zu der anstehenden "sozialen Epoche" entsprechen und vom Wissenschaftler erkannt und vorwegnehmend herausgearbeitet werden. In jeder Epoche, war für Wagner nämlich das ihr eigene "richtige" Besteuerungsrecht angelegt. Zweckmäßigkeitsgesichtspunkte bei der Festlegung der Begriffe waren nach Wagner daher nur zu berücksichtigen, soweit sie den Gang der in der Realităt angelegten Entwicklung - zu seiner Zeit den Weg zur sozialen Epoche - forderten, ein Ubergang. den zu erkennen Wagner für sich zu Lebzeiten beanspruchte. ${ }^{3}$ Die aus diesen Vorstellungen fortentwickelte Besteuenungsidee fir

\footnotetext{
2 Schmoller, G. (1863), S. 2, S. 69; ders. (1871, S. 137 a). Den sächsischen Regierungsentwurf von 1871 (s. Landtags-Acten von den Jahren 1871/1873. Erste Abtheilung, Zweiter Band, S. 214) beurteilte Schmoller nur als Obergangsregelung positiv (1871, S. 136). So wurde das Gutachten Schmollers von dem zustăndigen Ausschuß̉ des silchsischen Landtages auch verstanden (s. Landtags-Acten von den Jahren 1871/1872. Beilage zur dritten Abtheilung die Berichte der zweiten Kammer enthaltend, Dritter Band, S. 369). Die Ëinfuhrung đer ESt als einziger đirekter Abgabe lehnte Schmoller ab (1863, S. 54, S. 63, S. 83); ders. (1871, S. 136 b). Ohne die erhōhten ausbildungsmäBigen Voraussetzungen bei Einfuhrung der ESt befürchtete Schmoller, daß die Praxis infolge der notwendig komplizierten Ausgestaltung zu einer Begünstigung der Reichen auf Kosten von Mittelstand und Armen bei der Lastenverteilung entarten könne (1871. S. 137 a). Die ESt sollte nach Schmollers Bestimmung im Steuersystem eine Ergånzungsfunktion zur Herstellung von Steuergerechtigkeit wahmehmen. Sie sollte die Gesamtbelastung des Steuerbürgers mit Steuern in Proportion zu seiner Leistungsflahigkeit bewir. ken. Daher betonte er den zur zweckmäBigen Gestaltung, vorauszusetzenden Ausbildungsstand (1871. S. 138 a).
}

Wagner, A. (1887), S. 121. 
die Einkommensteuer bestimmt noch heute als sogenannte "deutsche Type" das Rahmengefüge unseres Einkommensteuerrechts. Die Wagnersche Besteuerungsidee vermag als systemtragendes Prinzip den Anforderungen an die wichtigste Abgabenart unseres Besteuerungswesens heute allein aber nicht zu genügen.

Für beide Gelehrte war das Steuerrecht ein - wenn auch unterschiedlich konzipiertes - Instrument für sozialpolitische Zielvorstellungen. Die Reform zu einem modernen System war bereits Gegenstand der Diskussionen auf den ersten Tagungen des von Schmoller und Wagner 1872 begründeten "Vereins für Socialpolitik".

Von einer Besteuenung nach der Leistungsfähigkeit kann nach der Sprachregelung des Alltags in der Besteuerungswirklichkeit des Einkommensteuerrechts der Bundesrepublik Deutschland heutzutage nur noch sehr eingeschränkt gesprochen werden. Das ist keine neue Erkenntnis. Aber sie verlangt nach Konsequenzen durch fortlaufende Berücksichtigung der Schmollerschen Gesichtspunkte bei weiterer Ausgestaltung und Ergänzung des steuerlichen Normengefüges.

Wegen der einseitig nichtfiskalischen Ausgestaltung hat sich zum Beispiel das Unterhaltsrecht in der Bundesrepublik schon seit längerer Zeit von dem Einkommensteuerrecht gelöst und eigene Begriffe zur Bestimmung der Leistungsfähigkeit entwickeln müssen.

Die mit der Entstehung des modernen deutschen Einkommensteuerrechts in zeitlichem Zusammenhang stehenden Lehren von Gustav Schmoller und Adolph Wagner zentrierten um eine Versöhnung der Klassenspaltung durch Einebnung der mit der Industrialisierung einhergehenden wachsenden ungleichen Einkommens- und Vermögensverteilung und deren sozialen Folgewirkungen.

Die moderne Industriegesellschaft, in der wir leben, benötigt offenbar infolge der rechtsstaatlichen Organisation unseres Gemeinwesens ein Steuerrecht, das, vielfältigen Ansprüchen gleichermaßen gerecht werden muß. Parlamentarische Mehrheiten beschließen Steuertatbestände, die nach Auslegung durch Verwaltung und Rechtsprechung Unsicherheiten mit sich bringen und oft keinen einheitlichen Architektenplan mehr erkennen lassen. Oftmals tragen auch Steuergesetze heute bereits "Geburtsfehler des Kompromisses als Regelwidrigkeit in sich". Das bringen "Ausgaben- und Anspruchsdemokratie" ${ }^{14}$ mit sich. Ein an monolithisch ausgestalteter Regelhaftigkeit orientiertes Einkommensteuerrecht kann den modernen Anfordenungen dabei nicht mehr gerecht

4 Felix, G. (1982), in: Tipke, K. (1982), S. 134. 
werden. Es muß ein Wunschtraum einiger Steuerrechtslehrer bleiben, mag man diesen Umstand auch allgemein beklagen. Ohne die stăndige Rückbesinnung auf die von Schmoller konzipierte Besteuerungsidee als einem unter anderen wichtigen regelhaft systemtragenden Grundprinzip wird ein modernes Einkommensteuerrecht jedoch heute und für die Zukunft nicht auskommen können. Anders hatte Gustav Schmoller seinen eigenen Beitrag auch nicht beurteilt.

$\mathrm{DaB}$ die abnehmende Praktikabilität der Steuernormen nicht nur die Finanzverwaltung belastet, sondern empfindliche Rückwirkungen auf die Steuergerechtigkeit und den ausgelösten Steuerwiderstand veranlaßt, muß erwähnt werden. Hier liegen Begrenzungen einer zumeist verborgen bleibenden instrumentalen Verwendung des Steuerrechts für wirtschafts- und sozialpolitische Zwecke, die nicht übersehen werden dürfen.

Vordringlich stellt sich unaufschiebbar das Erfordernis, den Gesetzesvollzug durch ein reformiertes Veranlagungsverfahren neu zu ordnen. Der durch die Kompliziertheit der offenbar nur schwer verzichtbaren modernen finanzpolitischen Steuerungsmechanismen verursachte hohe Arbeitsanfall in den Finanzämtern erfordert eine vorausplanende Abstimmung von Gesetzesregelungen und Gesetzesvollzug. Ohne eine Neuorganisation des Abgabenrechts, die das Zusammenwirken der Steuerbürger mit der Finanzverwaltung fördert, kann die Einkommensteuer die ihr gegenüber anderen Abgaben nachgesagten Eigenschaften, einer gerechteren Lastenverteilung zu dienen, nicht verwirklichen. Ohne ständige strenge Kontrollen und ein angepaßtes Steuerstrafrecht, das die allgemeine Beachtung der Gesetzesvorschriften glaubhaft macht, wird man in Zukunft die heute beklagten Mißstände in der deutschen Einkommensbesteuenung nicht abzustellen vermögen. Dies hat bereits Franz Meisei 1911 festgehalten.

Bei Berücksichtigung der noch nicht übersehbaren Konsequenzen des Urteils des Bundesverfassungsgerichts vom 25. September 1992 wird der Gesetzgeber vorerst prüfen müssen, ob er auf den Einsatz des Einkommensteuerrechts als Instrument der Wirtschaftspolitik in Zukunft wird verzichten können.

So bestimmen Adolph Wagners vor etwa 100 Jahren gefertigte Beiträge das Rahmengefüge und die Besteuerungsidee Gustav Schmollers 130 Jahre nach ihrer Niederschrift noch heute die wesentlichen Gesichtspunkte für korrigierende Eingriffe in die tatsăchliche Besteuerụng und̆ - was zumeist vernachlăssigt wird - auch in die korrigierende Auslegung der Gesetzesvorschriften durch die Finanzgerichtsbarkeit der Bundesrepublik Deutschland. 


\title{
Anlagen
}

\author{
Anlage 1 \\ Einkommensteuergesetz vom 2. Juli 1878 \\ in: Gesetz- und Verordnungsblatt fur das Königreich Sachsen vom Jahre 1878.
}

S. 134

\section{$\S 15$ Abs. 1}

Für die Berechnung und Schătzung des steuerpflichtigen Einkornmens sind im Allgemeinen folgende Grundsătze zu beachten:

1. Als Einkommen gilt die Summe aller in Geld oder Geldeswerth bestehenden Einnahmen der einzelnen Beitragspflichtigen mit Einschluß des Mietwerthes der Wohnung im eigenen Hause oder sonstiger freier Wohnung, sowie des Werthes der zum Haushalt verbrauchten Erzeugnisse der eigenen Wirthschaft und des eigenen Gewerbebetriebs, abzuglich der auf Erlangung, Sicherung und Erhaltung dieser Einnahmen verwandten Ausgaben, sowie etwaiger Schuldzinsen, auch sofern diese nicht zu den eben bezeichneten Ausgaben gehoren.

2. Außerordentliche Einnahmen durch Erbschaften und ähnliche Erwerbungen gelten jedoch nicht als steuerpflichtiges Einkommen, sondern als Vermehrung des Stammvermögens, sie kommen daher ebenso, wie Verminderungen des letzteren - vorbehältlich der Bestimmung in \$ 21, Punkt 1 - nur insofern in Bericksichtigung, als die Erträgnisse des Vernögens dadurch vermehrt oder vermindert werden.

\section{$\S 15$ Abs. 6}

Ist das Einkommen einer Person, welche innerhalb Landes eine eigene Haushaltung hat, geringer als die Summe, welche sie zur Bestreitung des Unterhaltes für sich und die von ihr unterhaltenen Personen oder freiwillig an Andere gewährten Unterstützungen aufwendet, so kann diese Summe, soweit nicht die in $\S 13$, Abs. 2 angefuluten Verhaltnisse vorliegen, als Betrag des Einkommens angenommen werden. Bezieht dieselbe jedoch nachweislich Einkünfte, welche nach den Bestimmungen in $\$ 5, \mathrm{Abs} .1$ und in $\$ 6$ unter 4 und 5 bei Berechnung des steuerpflichtigen Einkommens außer Betracht zu bleiben haben, so sind diese Einküntte von dem vorstehender Bestimmung gemaäß festgestellten Einkommensbetrage in Abzug zu bringen.

$\$ 17$

Im Einzelnen sind bei Einschătzung des Einkommens folgende Hauptquellen zu unterscheiden: 
a) Verpachtung von Grundstacken, Vermiethung von Gebaluden oder Benutzung derselben zur eigenen Wohnung, Betrieb der Land- oder Forstwirthschaft auf eigenen Grundstücken;

b) Capitalzinsen, Renten, Apanagen, Dividenden von Actien oder Kuxen, Naturalgefalle, Auszüge und andere Gerechtsame;

c) Bekleidung einer ausschließlich oder zum Theile mit festem Gehalte oder Lohne verbundenen amtlichen oder sonstigen Stellung, ingleichen der Bezug von Pension oder Wartegeld;

d) Handel, Gewerbe, einschließlich des Betriebs der Landwirthschaft auf fremden Grundstacken und jede andere Enwerbsthătigkeit.

\section{$\$ 21$ Abs. 1}

Für die Berechnung und Schătzung der in $\$ 17$ unter $\mathrm{d}$ erwähnten Arten des Einkommens gilt insbesondere Folgendes:

1. Beim Handel und Gewerbebetrieb ist der Reingewinn nach den Grundsatzen zu berechnen, wie solche für die Inventur und Bilanz durch das Handelsgesetzbuch vorgeschrieben sind und sonst dem Gebrauche eines ordentlichen Kaufmanns entsprechen, insbesondere gilt dies vom Zuwachs und andererseits von der Abnutzung des Anlagecapitals, sowie von Forderungen und Schulden und deren Zinsen. Im Uebrigen leiden die in $§ 15$ aufgestellten allgemeinen Grundsatze auch hier Anwendung.

Instruction zum Einkommensteuergesetz vom 2. Juli 1878 in: Gesetz- und Verordnungsblatt für das Königreich Sachsen 1878, Seite 561

\$64 der "Instruction" zum EStG 1878 vom 7.12.1878 lautete:

Bei Gewerbetreibenden, welche nicht Kaufeute im Sinne des Handelsgesetzbuchs sind, bildet der Erlös aus den von ihnen gewährten Leistungen und veräußerten Waaren, sowie aus etwaigen Nebennutrungen den Rohertrag ihres Gewerbebetriebs, von welchem der Preis der zum Behufe des Gewerbebetriebs angeschafften Stoffe und Waaren, die Löhne der Angestellten und Arbeiter und alle sonstigen, durch das Geschăft hervorgerufenen Kosten und Lasten, einschließlich der Versicherungskosten, zu Feststellung des gewerblichen Einkommens in Abrechnung zu bringen sind. 


\section{Anlage 2}

Einkommensteuergesetz vom 24. Juni 1891

in: Gesetz=Sammlung fur die Preußischen Stanten vom 7. Juli 1891, Seite 178

\section{7}

Als Einkommen gelten die gesamten Jahreseinkunfte der Steuerpflichtigen in Geld und Geldeswerth aus:

1. Kapitalvermögen,

2. Grundvermögen, Pachtungen und Miethen, einschließlich des Miethwertes der Wohnung im eigenen Hause,

3. Handel und Gewerbe einschließlich des Bergbaues,

4. Gewinn bringender Beschaftigung sowie aus Rechten auf periodische Hebungen und Vortheile irgendwelcher Art ...

\section{$\S 8$}

Außerordentliche Einnahmen aus Erbschaften, Schenkungen, Lebensversicherungen, aus dem nicht gewerbsmaßßig oder zu Spekulationszwecken unternommenen Verkauf von Grundstucken und ahnliche Erwerbungen getten nicht als steuerpflichtiges Einkommen; sondern als Vermehrung des Stammvermoggens und kommen ebenso wie Verminderungen des Stammvermogens nur insoweit in Betracht, als die Erträge des Letzteren dadurch vermehrt oder vermindert werden.

\section{$\$ 14$}

Das Einkommen aus Handel und Gewerbe einschließlich des Bergbaues besteht in dem in der Gemaßheit der allgemeinen Grundsatze $(\$ \S 6-11)$ ermittelten Geschäftsgewinne. Mit dieser Maßgabe ist der Reingewinn aus dem Handel und Gewerbebetriebe nach den Grundsätzen zu berechnen, wie solche fur die Inventur und die Bilanz das Allgemeine Deutsche Handelsgesetzbuch vorgeschrieben sind und sonst dem Gebrauche eines ordentlichen Kaufmannes entsprechen ...

Die $\$ \$ 9$ und 10 preuß. EStG 1891 regelten die Ernittlung der Einkünfte als Oberschuß der Einnahmen ( $\$ 10)$ uber die Ausgaben ( $\$ 9)$.

$\$ 9$

1. Von dem Einkommen $(\$ 7)$ sind in Abzug zu bringen:

1. die zur Enwerbung, Sicherung und Erhaltung des Einkommens verwendeten Ausgaben, einschließlich auch der unter den Kommunalabgaben begriffenen Deichlasten. 


\section{Anlage 3}

Einkommensteuergesetz Vom 29. Mïrz 1920

in: Reichs=Gesetzblatt 1920, Nr. 57, Seite 359

\section{$\S 4$}

Soweit in diesem Gesetze nichts anderes vorgeschrieben ist (\$12), unterliegt der Steuer der Gesamtbetrag der in Geld oder Geldeswert bestehenden Einktinfte nach Abzug der im $\S 13$ genannten Betruge (steuerbares Einkommen).

\section{$\$ 5$}

Zum steuerbaren Einkommen gehorren Einkünte aus, Grundbesitz, aus Gewerbebetrieb, aus Kapitalvermögen und aus Arbeit sowie sonstige Einnahmen ohne Racksicht darauf, ob es sich um einmalige oder wiederkehrende Einkunfte handelt oder aus welchem rechtlichen oder tatsăchlichen Grunde sie dem Steuerpflichtigen zugeflossen sind. 


\section{Anlage 4}

Einkommensteuergesetz. Vom 10. August 1925

in: Reichsgesetzblatt 1925, Teil I vom 25.8.1925

\section{$\$ 6$}

(1) Der Besteuerung des Einkommens nach diesem Gesetz unterliegen nur: 1....

\section{$\$ 7$}

(1) Zur Steuer wird das Einkommen herangezogen, das der Steuerpflichtige innerhalb des Steuerabschnitts $(\$ 10)$ bezogen hat $(\$ 11)$.

(2) Als Einkommen gilt:

1. bei Einkünften der im $\S 6$ Abs. 1 Nr. 1 bis 3 bezeichneten Art der Gewinn ( $\$$ 12, 3);

2. bei Einkunften der im $\$ 6$ Abs. 1 Nr. 4 bis 8 bezeichneten Art der Uberschuß der Einnahmen ( $\$ 14$ ) uber die Ausgaben ( $\$ 15$ bis 17).

(3) Treffen bei einem Steuerpflichtigen mehrere Einkommensarten zusammen oder hat er Einkünfte derselben Art aus mehreren Betrieben oder hat er Ausgaben ( $\S 15$ ), die bei keiner einzelnen Einkommensart abgesetzt werden kőnnen, so ist das Einkommen durch Zusammenrechnung und Ausgleich der bei der gesonderten Ermittlung gewonnenen Ergebnisse zu berechnen. 


\section{Anlage 5}

\section{Gesetz zur Verminderung der Arbeitslosigkeit. Vom 1. Juni 1933}

in: Reichsgesetzblatt, Teil I, Nr. 60, vom 2.6.1933, S. 323

Abschnitt II, Steuerfreiheit für Ersatzbeschaffungen:

Bei der Ermittlung des Gewinns für die Einkommensteuer, Körperschaftsteuer und Gewerbesteuer gilt abweichend vom $\$ 16$ des. Einkommenstewergesetzes fur die Steuerabschnitte, die nach dem 30 . Juni 1933 und vor dem 1. Janur 1935 enden, das folgende:

Aufwendungen für die Anschaffung oder Herstellung von Maschinen, Gerăten und ăhnlichen Gegenständen des gewerblichen oder landwirtschaftlichen Anlagekapitals kōnnen im Steuerabschnitt der Anschaffung oder Herstellung voll abgezogen werden, wenn die folgenden vier Voraussetrongen gegeben sind:

1. Der neue Gegenstand muß inländisches Erzeugnis sein;

2. Der Steuerpflichtige muß den neuen Gegenstand nach dem 30. Juni 1933 und vor dem 1. Januar 1935 angeschaff oder hergestellt haben;

3. Der neue Gegenstand muß einen bisher dem Betrieb dienenden gleichartigen Gegegenstand ersetzen;

4. Es muß sichergestellt sein, daß die Verwendung des neuen Gegenstandes nicht zu einer Minderbeschaftigung von Arbeitnehmern im Betrieb des Steuerpflichtigen fuhrt.

Das Gesetz war von den zustăndigen Finanzämtern großzagig auszulegen. Der Steuerplichtige hatte eine Erklarung aber die Vernichtung, Verkußerung oder Verschrottung des ersetzten alten Gegenstandes auf amtlichen Vordrucken (RGBI. I 1933, S. 1073 - S. 1075) abzugeben. Die Voraussetrang des Abzuges der vollen Anschaffungsoder Herstellungskosten als Ausnahme zu \& 16 EStG 1925 war jedoch auch erfulit, wenn auf amtlichern Vordruck eine "Anzeige ubber die Belassung alter Gegenstănde im Betrieb als Aushilfegegenstande" (RGBI. I 1933, S. 1072, s. "Vordruck 1" als Anlage 5 a) zu den Besteuerungsakten gegeben uurde. Diese Verwaltungsanweisung ermöglichte dem Steuerpflichtigen, die hohe Steuervergunstigung fur Ersatzbeschaffungen zu einer Vergunstigung fur Erweiterungsinvestitionen unzufunktionieren, was die große. Auswirkung der befristeten Vorschrift erklärt. Hinzu kommt die weite Auslegung des Begriffs "Gegenstand" in Zivilrecht und der gewallurte zweijahrige Verlustvortrag, s. hierzu StW 1933, Sp. 769. 


\section{Anlage 5 a}

1072

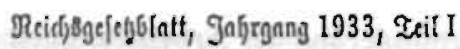

\section{Borbrud 1}

\section{Inzeige über die Gela)lung alter (Segenftände im Betrieb als IUsbilfegegenftände}

\section{Gteuerfreibeit für Grjabbefdaffungen}

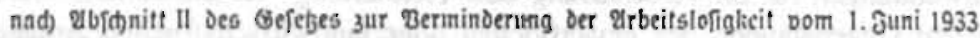

(Reitbogejetybl. 1 8, 323, 324)

ฆn

Das Finanzamt

in

1. $\frac{\text { Id) }}{\mathrm{agit}}$ in etgititl(-)

aII von ier gituma

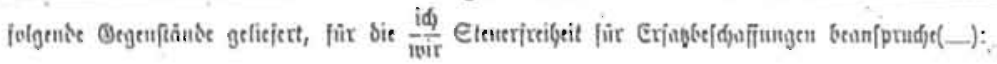

\section{(Oendint Tngebern)}

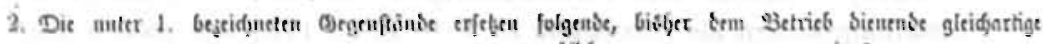

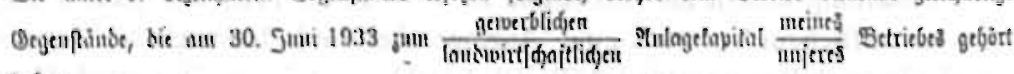
Lyalin:

\section{(Neunase Wuataber!)}

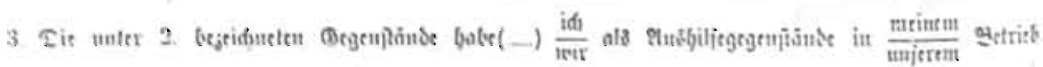

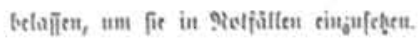

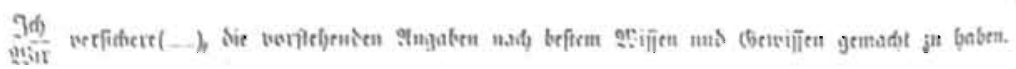




\section{Anlage 6}

\section{Fördergebietsgesetz}

- Gesetz uber Sonderabschreibungen und Abzugsbeträge im Fördergebiet vom 23. September 1993 (BGBI. IS. 1655)

\section{§ I Anspruchsberechtigter, Fördergebiet}

(1) Für begünstigte Investitionen im Sinne der $\$ \$ 2$ und 3, die im Fördergebiet durchgefuhrt werden, kỏnnen Steuerpflichtige Sonderabschreibungen nach $\$ 4$ oder Gewinnabzige nach $\S 5$ vornehmen oder Rücklagen nach $\S 6$ bilden. Bei Personengesellschaften und Gemeinschaften tritt an die Stelle des Steuerpflichtigen die Gesellschaft oder Gemeinschaft.

(2) Fördergebiet sind die Länder Berlin, Brandenburg, Mecklenburg-Vorpommern, Sachsen, Sachsen-Anhalt und Thüringen nach dem Gebietsstand vom 3. Oktober 1990.

\section{$\S 2$ Bewegliche Wirtschaftsgüter des Anlagevernnögens}

Begunstigt sind die Anschaffung und die Herstellung von abnutzbaren beweglichen Wirtschaftsgütern des Anlagevermögens sowie nachtrăgliche Herstellungsarbeiten an abnutzbaren beweglichen Wirtschaftsgutern des Anlagevermőgens, die

1. keine Luffahrzeuge sind,

2. mindestens 3 Jahre nach ihrer Anschaffung oder Herstellung zum Anlagevermogen einer Betriebsstătte des Steuerpflichtigen im Fördergebiet gehören und wathrend dieser Zeit in einer solchen Betriebsstätte verbleiben und

3. in jedem Jahr des in Nummer 2 genannten Zeitraums vom Steuerpflichtigen zu nicht mehr als 10 vom Hundert privat genutzt werden.

\section{\$3 Baumaßnahmen}

Begünstigt sind die Anschaffung und die Herstellung von abnutzbaren unbeweglichen Wirtschaftsgütern sowie Modernisierungsmaßnahmen und andere nachtrăgliche Herstellungsarbeiten an abnutzbaren unbeweglichen Wirtschaftsgatern. Die Anschaffung eines abnutzbaren unbeweglichen Wirtschaftsguts ist nur begunstigt, wenn

1. Das Wirtschaftsgut bis zum Ende des Jahres der Fertigstellung angeschafft worden ist und für das Wirtschaftsgut weder Absetzungen für Abnutzung nach \& 7 Abs. 5 des Einkommensteuergesetzes noch erhöhte Absetzungen oder Sonderabschreibungen in Anspruch genommen worden sind oder

2. das Wirtschaftsgut beim Erwerber zu einem Betriebsvermögen gehört, nach dem. Jahr der Fertigstellung und

a) vor dem 1. Januar 1994 angeschafft worden ist oder

b) nach dem 31. Dezember 1993 angeschafft. worden ist und mindestens funf Jahre nach seiner Anschaffung zu eigenbetrieblichen $Z$ wecken verwendet. wird oder 
3. das Wirtschaftsgut nach dem Jahr der Fertigstellung und aufgrund eines nach dem 31. Dezember 1991 rechtswirksam abgeschlossenen obligatorischen Vertrags oder gleichstehenden Rechtsakts angeschaff worden ist, soweit Modemisierungsmaßnahmen und andere nachtragliche Herstellungskosten nach dem Abschluß dieses Vertrags oder Rechtsakts durchgefuthrt worden sind.

\section{\$ 4 Sonderabschreibungen}

(1) Die Sonderabschreibungen betragen bis zu 50 vom Hundert der Anschaffungsoder Herstellungskosten der angeschaffen oder hergestellten Wirtschaftsguter oder der Herstellungskosten, die fur die nachträglichen Herstellungsarbeiten aufgewendet worden sind, oder der Anschaffungskosten, die auf Modernisierungsmaßnahmen und andere nachträgliche Herstellungsarbeiten im Sinne des $\$ 3$ Satz 2 Nr. 3 entfallen. Sie können im Jahr đer Anschaffung oder Herstellung oder Beendigung der nachtrăglichen Herstellungsarbeiten und in den nachfolgenden vier Jahren in Anspruch genommen werden. In den Fallen des $\$ 3$ Satz 2 Nr. 3 tritt an die Stelle des Jahres der Anschaffung das Jahr der Beendigung der nachtralglichen Herstellungsarbeiten.

(2) Die Sonderabschreibungen nach Absatz 1 können bereits für Anzahlungen auf Anschaffungskosten und fur Teilherstellungskosten in Anspruch genommen werden.

(3) Bei Herstellungskosten, die für nachträgliche Herstellungsarbeiten im Sinne des \$ 3 Satz. 1 aufgewendet worden sind, und bei Anschaffungskosten, die auf Modernisierungsmaßnahmen und andere nachtrăgliche Herstellungsarbeiten im Sinne des $§ 3$ Satz $2 \mathrm{Nr} .3$ entfallen, ist der Restwert von dem auf das Jahr der Inanspruchnahme der insgesamt zulässigen Sonderabschreibungen folgenden Jahr an, spätestens vom fünften auf das Jahr der Beendigung der Hersteliungsarbeiten folgenden Jahr an, bis zum Ende des neunten Jahres nach dem Jahr der Beendigung der Herstellungsarbeiten in gleichen Jahresbetragen abzusetzen.

\section{$\$ 5$ Gewinnabzug}

Land- und Forstwirte, deren Gewinn nach $\S 13 \mathrm{a}$ des Einkommensteuergesetzes zu ermitteln ist, kőnnen im Wirtschaftsjahr der Anschaffung oder Herstellung oder Beendigung der nachträglichen Herstellungsarbeiten 25 vom Hundert der Anschaffungsoder Herstellungskosten der angeschafften oder hergestellten Wirtschaftsguter oder der Herstellungskosten, die für die nachträglichen Herstellungsarbeiten aufgewendet worden sind, vom Gewinn abziehen. Die abzugsfahigen Betrige dürfen insgesamt 4000 Deutsche Markt nicht abersteigen und nicht zu einem Verlust aus Land- und Forstwirtschaft fuhren. $\$ 7 \mathrm{a} / \mathrm{Abs} .5$ des Einkommensteuergesetzes gilt entsprechend.

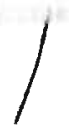




\section{Anlage 7}

\section{Geschlossene Immobilienfonds. Jahrbundertgeschenk oder Zeitbombe? Wie trennen Sie die Spreu vom Weizen?}

\section{Was ist eigentlich ein geschlossener Immobilienfonds?}

Grundsătzlich gibt es zwei Immobilienfondsarten: den geschlossenen Immobilienfonds und den offenen Immobilienfonds. Gemeinsam haben beide Fondsarten die Investition in die Immobilie und die Transformation des Produktes Immobilie in ein Finanzdienstleistungsprodukt. LosgröBentransformation ("Großhandelseffekt"), Auswahl der Imnobilien, Verwaltung und den Service rund un die Immobilie werden von beiden Fonds angeboten.

Aus Anlegersicht haben die Fonds jedoch kaum Gemeinsamkeiten. Offene Immobilienfonds sind Kapitalanlegegesellschaften, deren Geschaftstatigkeiten per Gesetz (KAGG) strikt geregelt sind. Vielfach handelt es sich um Bankentöchter. Tátigkeit, Chancen und Risiken sind mit einem Aktienfonds zu vergleichen. Zielgruppe ist der Kleinanleger. Ein Einstieg ist ab 100 DM moglich. Anteile können laufend gekauf und auch zuruackgegeben werden. Der Preis der Anteile wird regelmäßig errechnet. Der Anleger wird kein Bauherr. Das Fondsvermogen ist variabel. Das Immobilien-Portfolio wird laufend ergänzt oder umgestaltet. Ober $30 \%$ des Geldes sind meist sowieso in Wertpapieren angelegt. Die lanfristige Durchschnittsrendite liegt bei knapp $7 \%$. Steuereffekte sind vernachlässigbar. In den vergangenen Jahren erwiesen sich die offenen Fonds im Renditevergleich allerdings als erstklassige Anlagen. Letztes Jahr hatten sie einen Mittelzufluß von 14,6 Mrd. DM, nach 6 Mrd. DM im Vorjahr. Dieses Jahr dürtte es etwas ruhiger ablaufen. Fazit: Der offene Immobilienfonds ist kein echtes Immobilieninvestment, sondern eine Kapitalanlage mit begrenzter Chance und Risikoposition.

Vollig anders der geschlossene Immobilienfonds: Hier ist nichts geregelt. Den Rahmen stellt lediglich das allgemeine Gesetzeswerk. Einheitliche Definitionen gibt es nicht. Vorab: Beim geschlossenen Immobilienfonds trifft der Anleger eine echte Immobilienentscheidung.

Die wichtigsten Kriterien des geschlossenen Immobilienfonds im Oberblick: Der Anleger wird Bauherr und kann alle daraus resultierenden Steuervorteile erhalten. Langfristig trăgt er mit seinem Anteil Chance und Risiko dieser konkreten Immobilieninvestition. Lediglich die Anfangsrisiken federt der Emittent hăufig ab. Die Mindestzeichnungssumme liegt zwischen 10.000 und 200.000 DM. In der Mehrzahl der Falle hat der Anleger Einkunfte aus Vermietung und Verpachtung. Fur die Geseilschaftsanteile besteht kein geregelter Markt. Die zugewiesenen Verluste kann der Anleger mit anderen Einkunftsarten verrechnen. Das Fonds-Management nimmt dem Anieger den gesanten Verwaltungsaufwand der Immobilie bis hin zur steuerlichen Abwicklung ab. Der typische Ablauf ist so: Ein Entwickler/Developer sieht ein Grundstuck. Er sichert sich die Rechte an dem Grundstuck, schlimmstenfalls sogar durch Kauf. Dann baut seine Phantasie ein LuftschloB und er sichert sich das Baurecht. Gezielt sucht er sich 
einen Fonds-Initiator, der ihm das Grundstuck zum Preis des Schlosses abkauft. Der Initiator wiederum fotografiert das Luftschloß, schneidet es in kleine Scheibchen und macht daraus einen Prospekt. Banken, freie Anlageberater oder auch "Strukkis" (Strukturvertriebe) suchen dann den Anleger, der das Projekt kauft und mit der Immobilie leben muß. Die Argumentationskette Steuer, Rentabilităt und Immobiliensicherheit funktioniert dabei immer. Sobald das zum Bau benotigte Kapital in Form von Eigenkapital und Fremdkapital zusammengesammelt ist, wird der Fonds geschlosssen.

Nach der Objektart werden geschlossene Immobilienfonds differenziert nach Gewerbefonds, die ablicherweise Bürogebăude, Einkaufszentren oder Hotels erstellen, und Wohnungsbaufonds. Der Wohnungsfonds hat im Moment noch eine untergeordnete, aber zunehmende Bedeutung. Seit die Flaute auf den Buromärkten absehbar ist, denken immer mehr Emittenten uber Wohnungsbaufonds nach. Wenn die Sonder-Afa 1997 auslăuft, dürfte nach unseren aktuellen Marktrecherchen der Wohnungsfonds erheblich an Bedeutung gewinnen. Die weiteren Spielarten des geschlossenen Immobilienfonds sind neben dem Normalfall, in dem dem Anleger das Immobilienprojekt bekannt ist, der "blind pool", bei dem zunăchst das Fondskapital zusammengesammelt wird und dann erst Objekte nach in der Regel vorher festgelegten Kriterien erworben werden und der Immobilien-Leasing-Fonds.

Welche Steuereffekte gibt es? Wieso gibt es Ausschüttungen trotz hoher Verluste? Die Immobilie, vor allem die Wohnimmobilie, ist das steingewordene SteuerParadoxon. Das sind Investitionen, die sich nur unter steuerlichen Gesichtspunkten lohnen. Bei Gewerbeimmobilien kann es positive Ausnahmen geben. Unter Beruck-. sichtigung der notwendigen zusatzlichen Fondskosten dörten sie jedoch sehr selten sein. Die Steuer alleine ist kompliziert genug, um jeden Nichtprofi aus dem Rennen zu werfen. Der Anleger in seinem geschlossenen Immobilienfonds wird Bauherr. Damit sind alle einkommensabhăngien und vermögensabhängige Steuern betroffen. Steuereffekte treten bei EE-Steuem immer dann ein, wenn steuerlich Kosten anfallen, die nicht zu Zahlungen führen. Der Effekt bei vermoggensabhängigen Steuern (Vermögen-, Erbschaft-, Schenkungsteuer) liegt an der Koppelung am Einheitswert.

Einkommensteuer: Die meisten geschlossenen Immobilienfonds in der Rechtsform der KG (Kommanditgesellschaft) bieten Verlustawweisungen zwischen $35 \%$ und knapp $100 \%$ des eingesetzten Eigenkapitals an. Bei BGB-Gesellschaften liegen die ablichen Verlustzuweisungen bei höherer Haftung bis zu $200 \%$ des eingesetzten Eigenkapitals. Diese Verlustzuweisungen fallen üblicherweise in den ersten 2 bis 3 Jahren des Fonds an. Die Verluste können bei den Anlegern mit Einkünften aus anderen Einkunftserten verrechnet werden. Die tatsăchliche Steuerersparnis hăngt also von ihrem persőnlichen Steuersatz ab. Als Faustregel gilt, daß sich eine Fondsbeteiligung nur damn lohnt, wenn mindestens $40 \%$ der gesamten Verlustzuweisungen an Steuern gespart werden können. Für einen klassischen Durchschnittsverdiener ist der geschlossene Immobilienfonds damit aberhaupt nichts und selbst gutverdienende Angestellte mit Familie, eigenem Hauschen, Arbeitszimmer und lăngeren Arfahrtsweg müssen da schon mit spitzem Bleistift rechnen. Bei vielen Vertriebsgruppen setzt die Akquisitionsebene aber schon deutlich tiefer an. 
Wie Sie an Ihr Geld kommen: Das Betriebsfinanzant, das für die Fondsgesellschaft zustăndig ist, ermittelt einheitliche Grundlagen für die Besteuerung. Die Ergebnisse zzugl. etwaiger sonstiger Werbungskosten teilt das Betriebsfinanzamt den einzelnen Wohnsitzinanzämtern der Anleger mit.

Die Hōhe der Steuervorteile in der Investitionsphase hängt von Art und Standort des Objektes und der Innenfinanzierung der Fondsgesellschaft ab. Und hier setzt das "Jahrhundertgeschenk" des Fördergebietsgesetzes für die neuen Bundeslinder an. 50\% der Herstellungskosten können, beliebig verteilt auf die ersten 5 Jahre, als Kosten angesetzt werden. Hinzu kommen die "normalen" Anlaufverluste der Investitionsphase, bevor die Mieteinnahmen fließen. Nach den reinen Ost-Fonds kommen immer mehr Kombinationsfonds, die eine relativ hohe Rendite aus vermieteten Westobjekten und laufender Abschreibung mit den Anfangsverlusten eines Ostobjektes kombinieren, an den Markt. Die Hôhe der Anfangsverluste ist uber die Innenfinanzierung von der Gesellschaft relativ frei gestaltbar. Bei einem Fondsvolumen von 100, Herstellungskosten von 80 und $50 \%$ Afa gemaß Fordergebietsgesetz ergibt sich eine Verlustzuweisung (ohne Berincksichtigung der anderen Steuereffekte) bei einem reinen Eigenkapitalfonds von ca. $40 \%$, einem üblichen Fonds mit der Halfte Fremdkapital in der Fondsgesellschaft von $80 \%$ und bei einem Fonds mit $75 \%$ Innenfinanzierung von $160 \%$ immer bezogen auf das eingesetzte Eigenkapital. Bei KG-Modellen ist die Verlustzuweisung auf höchstens $100 \%$ des Eigenkapitals beschränkt. Bei KG's kỏnnen Sie also mehr als die Hälfte ( $53 \%$ + Kirchensteuereffekt) und bei BGB-Gesellschaften praktisch das ganze eingesetzte Kapital vom Finanzamt zuruckerhalten. Über Zwischenfinanzierungen kann das auch zeitlich entsprechend gesteuert werden. Bei teilweiser Fremdfinanzierung der Beteiligung sind hierauf entfallende Zinsen noch einmal abzugsfahige laufende Werbungskosten. Diese Finanzierung muß jedoch eng mit der Fondsgesellschaft thres Steuerberaters abgestimmt werden. Voraussetzung für die Anerkennung der Verlustzuweisung ist die steuerliche Gewinnerzielungsabsicht. Insofern muß irgendwann in der Laufzeit des Investments sowohl in der Gesellschaft als auch beim Anleger ein steuerlicher Totalüberschuß erzielt werden. Die Fondskonstruktionen sind entsprechend ausgelegt. Eine hohe Fremdfinanzierung des Anteils kann jedoch fur den Anleger verhindern, daß jemals der notwendige steuerliche Totaluberschuß rechnerisch erzielt wird. In diesem Moment ist sein Investment Liebhaberei und die Steuereffekte entfallen bzw. müssen zurickgezahlt werden. Das gleiche Risikg gilt bei einem schnellen Verkauf der Anteile. Auch hier keine langfristige Gewinnerzielungsabsicht.

Vermōgensteuer/Erbschaftsteuer/Schenkungsteuer: Auch bei den vermögensabhängigen Steuem ergeben sich Vorteile. Die Vermögensteuer errechnet sich nicht nach dem Verkehrswert, sondern um einen erhöhten Einheitswert. Der vermögensteuerliche Wert liegt in der Regel bei 20 bis $30 \%$ des Verkehrswertes einer Immobilie. Ober die Fremdfinanzierung kann sich sogar ein negativer Vermögenswert ergeben. Derzeit liegt der Steuersatz bei $0,5 \%$. Ab Januar wird er auf $1 \%$ erhöht. In der Zukunft ist davon auszugehen, daß der Vermögensteuereffekt sinken wird, da eine Lösung zur Problematik der Ungleichbehandlung von Geldvermögen und Realvermőgen đurch das Bundesverfassungsgericht ansteht. Besonders interessant ist der Einheitswerteffekt. auch bei Erbschaftsteuer. Der Effekt ist der gleiche, nus die Steuersătze sind unterschiedlich. Ober den Fonds kann Vermögen erbschaftsteuerfrei oder sogar noch mit 
einem negativen Wert, der noch Platz für andere Assets läßt, vererbt werden. Dies macht z. B. auch Zweitmarktanteile fur altere Anleger interessant. Bei der Schenkung sind die Effekte abgeschwächt. Negative Werte können sich nicht ergeben. Der Schenkungsteuerwert ist nur niedriger.

Aus: Der Platow Brief Spezial, November 1994, S. 1 bis 2, S. 5 bis 6. 


\section{Anlage 8}

Haushaltspline von Berlin (West) 1962 - 1974

Jahr Ordentliche Haushalte insgesamt Reine Ist-Ausgaben

Mio DM

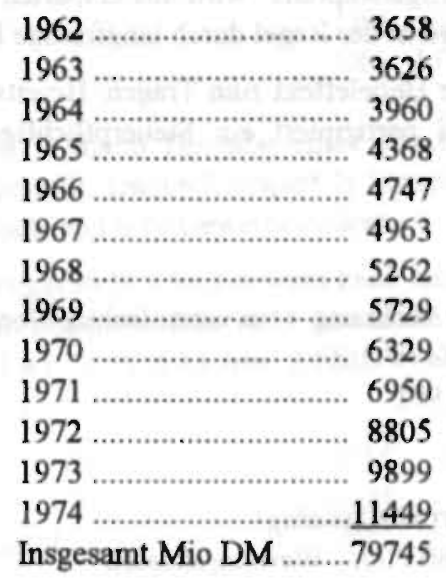

Fundstellen:

Statistisches Landesamt Berlin

Statistisches Jahrbuch 1964 S. 312 ff, 1965 S. 284 ff, 1966 S. 291 ff, 1967 S. 264 ff, 1968 S. 270 ff, 1969 S. 262 ff, 1970 S. 294 ff, 1971 S. 348 f, 1972 S. 364 ff, 1973 S. 366 ff, 1974 S. $352 \mathrm{ff}$. 


\section{Anlage 9}

\section{Der "Hebeleffekt" bei Erzielung von Überschüssen zwischen Verkauf und Kauf einer Wohnung}

Kernpunkt bei der steuerbegünstigten Kapitalanlage ist der sogenannte "Hebeleffekt". Der Anleger zahlt keinen oder nur einen geringen Teil seiner Investitionen selbst. Der Rest des "Eigenkapitals" wird aus ersparten Steuern bezahlt. Das erforderliche Fremdkapital wird in der Regel durch langfristige Bankdarlehen finanziert.

Hier kommt nun der Hebeleffekt zum Tragen: Bereits mit nur einigen Tausend DM "echtem"' Eigenkapital partizipiert ein Steuerpflichtiger voll am Wertzuwachs der gesamten Investition.

Beispiel: Erwerb einer Wohnung (ein vereinfachter Überblick)

Kauf einer Wohnung 1991

Gesamtinvestitio

Eigenkapital (20\%)

Werbungskosten (sofort abzugsfahig)

Steuervorteil aus DM 80.000,-- Werbungskosten

bei $50 \%$ Steuerbelastung

Eigenkapitaleinsatz netto

Verkaufspreis der Wohnung 1993
DM. 350.000,-

DM 70.000,-

DM $80.000,-$

DM 40.000,--

DM $\quad 30.000,-$

DM 400.000,--

Ergebnis:

1. Die Steuerersparnis von DM 40.000,-- netto (steuerfrei) verdient.

2. Den Wertuwachs von DM $50.000,-$ steuerfrei realisiert, da Immobilien aus Privatvermogen nach zwei Jahren steuerfrei weiterverkauft werden können.

Die Hebelwirkung: Der Steuerpflichtige hat mit DM 30.000,-- tatsächlichem Eigenkapital nach drei Jahren DM $90.000,-$ steuerfrei erlost, also eine Rendite von $300 \%$ enzielt. 


\section{Anlage 10}

Die schiffahrtsfremde Kapitalgesellschaft B grindet mit dem Kaufmann A eine Reederei in Form einer GmbH mit einem Stammkapital von DM 20.000,--, an dem B mit DM 18.000,- und A mit DM 2.000,- beteiligt ist. Die Reederei plant den Neubau eines Schiffes in Gestehungswert von 1 Mio DM. Die Finanzierung ist wie folgt vorgesehen:

$50 \%$ offentliche Mittel

$50 \%$ eigene Mittel

\begin{tabular}{lr} 
DM & $500.000,--$ \\
DM & $500.000,-$ \\
\hline DM & $1.000 .000,-$
\end{tabular}

Die eigenen Mittel werden von B durch Hingabe eines Zuschusses in Höhe von DM 500.000,- zur Verfuggung gestellt. Dadurch erspart B Steuern in Hobe von rund DM $330.000,-$ ( $60 \%$ Korperschaft- und $6 \%$ Gewerbesteuer).

Das Schiff wird Ende 1952 fertiggestellt. Die Reederei kann nach $\S 7$ d Abs. 1 EStG im Jahr der Fertigstellung und im folgenden Jahr je $15 \%$ auf die um den Zuschuß gekürzten Herstellungskosten ( $\$ 11$ a i. V. m. § 11 Abs. 2 EStDV) absetzen:

$\begin{array}{ll}\text { 1951: } 15 \% \text { von DM } 500.000,-- & = \\ \text { 1952: } 15 \% \text { von DM } 500.000,- & \text { DM 75.000,- } \\ \text { in den Jahren } 1951 \text { und } 1952 \text { gesant } & \text { DM 75.000,- }\end{array}$

Daneben kann die GmbH für die Jahre 1951 und 1952 die normalen Absetzungen nach $\S 7$ EStG und u. U. auch die Sonderabschreibungen nach $\$ 7$ a EStG in Anspruch nehmen, die hier aber unberucksichtigt bleiben sollen. Fur die folgenden Jahre bemessen sich die Absetzungen gemaß $§ 7 \mathrm{EStG}$ nach dem Buchwert am 31.12.1952 und der Restnutzungsdauer.

Die Abschreibungen in den Jahren 1951 und 1952 kônnen mit den Erträgen der ersten Betriebsjahre des Schiffes kompensiert werden und ermöglichen damit die Bildung zeitlich zusătzlichen Kapitals in diesen Jahren. Es ergibt sich somit für B folgende Gegenuberstellung:

Ausgaben 1951:

Einzahlung der Kapitaleinlage

Hingabe des Zuschusses nach $\$ 7 \mathrm{~d}$ Abs. 2

\begin{tabular}{lr} 
DM & $18.000,-$ \\
DM & $500.000,-$ \\
\hline DM & $518.000,-$
\end{tabular}

Steuerersparnis 1951:

$66 \%$ von DM $500.000,-$ (Zuschuß) . J.

Effektiver Aufwand

$\begin{array}{ll}\text { DM } & 330.000 \text { - } \\ \text { DM } & 188.000,-\end{array}$


Mit diesem Aufwand von DM 188.000,-- erzielte B in zwei Jahren bis Ende 1952. eine Reederei-Beteiligung von rund DM 603.000,--, nämlich:

Kapitaleinlage

$90 \%$ des Zuschusses von DM $500.000,-$ -

$90 \%$ der Kapitalbildung 1951/1952.

\begin{tabular}{lr} 
DM & $18.000,-$ \\
DM & $450.000,--$ \\
DM & $135.000,--$ \\
\hline DM & $603.000,-$
\end{tabular}




\section{Anlage 11}

\section{Der Begriff der Abschreibungs- oder Verlustruweisungsgesellschaft und Darstellung der sogenannten "Hebelwirkung"}

Unter Abschreibungs- oder Verlustzuweisungsgesellschaft versteht man den gesellschaftlichen Zusammenschluß von (Privat-)Personen, der dem Zweck dient, durch mitunternehmerische Beteiligung an einem Wirtschaftsunternehmen hohe Buchverluste aufgrund der Ausnutzung von Steuerverganstigungen in Form von Sonder- abschreibungen, Bewertungsabschlägen oder steuerfreien Rücklagen oder durch Anwendung der allgemeinen steuerrechtlichen Vorschriften uber die Ermittlung des Gewinns bzw, des Uberschusses der Einnahmen über die Ausgaben zu erzielen. Diese Verluste werden gemäß $\S 15$ Abs. I Satz 2 EStG den Gesellschaftern anteilig zuge- wiesen und kōnnen gemä̊ § 2 Abs. 2 EStG mit anderen positiven Einkünften des Gesellschafters verrechnet werden. Sie fuhren somit zu einer Senkung des steuer- pflichtigen Einkommens des Gesellschafters und daraus folgend zu einer Verringerung der Einkommensteuerschuld.

Der Veriust ist von folgenden Faktoren abhăngig:

Investition,

Abschreibungsvorschrift,

Eigenkapital,

Fremdkapital.

Zwei vereinfachte Zahlenbeispiele sollen die Wirkungsweisen der möglichen Gestaltungen zeigen:

\section{Beispiel 1:}

Begünstigte Investition

Sonderabschreibung $50 \%$ gemä

\$4 Fördergebietsgesetz

Eigenkapital $20 \%$

Fremdkapital $80 \%$

Abschreibung, bezogen auf Eigenkapital

Abschreibungsquote $250 \%$

DM $1.000 .000,-$

\begin{tabular}{ll} 
DM & $500.000,-$ \\
DM & $200.000,-$ \\
DM & $800.000,-$ \\
DM & $500.000_{--}$ \\
\hline DM & $200.000,-$
\end{tabular}

Es wird angenommen, die Gesellschaft habe 2 Gesellschafter, die Mitunternehmer sind, und von denen jeder eine Einlage von DM 100.000,- erbracht hat. Beide Gesellschafter befinden sich in der höchsten steuerlichen Progressionsstufe von derzeit $55 \%$.

Die Rechnung fur den einzelnen Gesellschafter sieht dann so aus:

Einlage

Anteiliger Verlust
DM 100,000,-

DM $250.000,-$ 
Minderung der Steuerschuld aus der

Verrechnung des Verlustes aus der

Beteiligung mit anderen Einkünften

( $55 \%$ von DM $250.000,-$ )

DM $137.500,--$

Liquiditatsuberschuß

DM 37.500,-

Im vorliegenden Fall ist die Steuerersparnis des Gesellschafters aus seiner Beteiligung also so hoch, daß er nicht nur letztere aus der Steuerersparnis tinanziert, sondern daruber hinaus noch einen Liquiditätsūberschuß von DM 37.500,- erzielt hat.

\section{Beispiel 2:}

Investition

Sonderabschreibung

Eigenkapital $60 \%$

Fremdkapital $40 \%$

DM $1.000 .000,-$

Abschreibung, bezogen auf Eigerkapital

DM $500.000,-$

DM $600.000,--$

DM 400.000,--

DM $500.000,-$

DM $600.000,--$

Abschreibungsquote $83,33 \%$

Die Gesellschaft hat gegenuber Beispiel 1 nun eine höhere Eigenkapitalfinanzierung, die durch Eintritt von vier weiteren Gesellschaftern mit einer Einlage von DM $100.000,--$ entstanden ist.

Die Rechnung fur einen einzelnen Gesellschafter sieht nun so aus:

Einlage

DM 100.000,--

Anteiliger Verlust

DM 83.333,-

Minderung der Steuerschuld

DM 45.833,-

effektiver Eigeneinsatz für die

Beteiligung

DM 54.167,-

Der Gesellschafter finanziert in diesem Fall seine Beteiligung nicht voll aus Steuermitteln, er muß noch DM 54.167,- aus seinem zu versteuernden Einkommen dazulegen.

In Erweiterung der o. a. Definition der Abschreibungsgesellschaft kann gesagt werden, daß die Kombination der vier Faktoren immer mit dem Ziel erfolgt, die Verlustzuweisung des Anlegers in dem Jahr bzw. in den Jahren, in denen er seine Einlage erbringt, so hoch zu gestalten, daß bei Unterstellung des Höchststeuersatzes bei dem Gesellschafter die Finanzierung der Einlage voll aus Steuermitteln möglich ist und der Gesellschafter u. U. sogar noch einen zusătzlichen Liquiditătsvorteil erreicht.

Hierbei ist zu berücksichtigen, daß Verluste seit vielen Jahren im Regelfall (mit Ausnahmen) auf die Höhe der Haftung des Gesellschafters für Schulden der Gesellschaft begrenzt sind ( $\$ 15$ a und $\$ 21$ Abs. 1 Satz. 2 EStG). Soweit Verluste nicht berücksichtigt werden können, mindern sie die Gewinne spăterer Jahre. 


\section{Anlage 12}

\section{Berechnungsbeispiel I für eine Beteiligung am Immobilienfonds Ostdeutschland}

Persornliche Daten des Anlegers: ledig, Kirchensteuer 9\%,

Zu versteuerndes Einkommen:

Steuersumme ohne Fondsbeteiligung

DM $\quad 90.000,-$

DM 28.585,-

Ergebnisse der Beteiligung in der Investitionsphase:

Beteiligungshöhe

Grenzsteuersatz der Beteiligung

Steuerliches Ergebnis der Beteiligung

Daraus resultierende Steuerersparnis

Bruttoinvestitionsbetrag incl. Agio

Nettoinvestitionsbetrag

$\begin{array}{lr}\text { DM } & 10.000,- \\ & 45,30 \% \\ \text { DM } & 15.300,- \\ \text { DM } & 6.931,- \\ \text { DM } & 10.500,- \\ \text { DM } & 3.569,-\end{array}$

Laufende Erträge der Beteiligung während der Vermietungsphase:

$\begin{array}{llll}\text { Ausschüttung 1994 } & \text { DM 125,-- } & \text { Rendite } & 3,50 \% \\ \text { Ausschuttung 1995 } & \text { DM 250,-- } & \text { Rendite } & 7,01 \% \\ \text { Ausschüttung 1996 } & \text { DM 275,-- } & \text { Rendite } & 7,71 \% \\ \text { Ausschüttung 1997 und Folgejahre } & \text { DM 300,-- } & \text { Rendite } & 8,41 \%\end{array}$

(bezogen auf Nettoinvestiton)

Zusătzlich zu den Ausschüttungen entfallt auf die Beteiligung eine anteilige Tilgung (Entschuldung des fondsinternen Kredits) in folgender Höhe:
1994
DM 95,-
Renditen incl. Tilgung und Ausschüttungen
$6,18 \%$
1995
DM 196,-
1996
DM 207,-
$13,51 \%$
1997
DM 219,-
$14,53 \%$

weiter ansteigend in den Folgejahren.

Einige Angaben zur möglichen Wertentwicklung des Fondsanteils:

Norninalwert der Beteiligung

Anteiliger Immobilienwert incl. Fondskredit

Nettoaufwand für diesen Immobilienbestand

bzw. in Prozent
DM

DM

DM
$10.000,-$ 23.637,--

$3.569,-$ $15,1 \%$

D. h.: Ein Wertanstieg der Gesamtimmobilie um z. B. $10 \%$ bewirkt einen Wertanstieg des eingesetrten Kapitals um $66,2 \%$.

Solche Wertzuwächse sind in der Regel steuerfrei (im Privatbereich bei Beachtung der entsprechenden Vorschriften) 


\section{Anlage 13}

Berechnungsbeispiel II für eine Beteiligung am Immobilienfonds Ostdeutschland

Personliche Daten des Anlegers: verheiratet, Kirchensteuer 9\%.

Zu. versteuemdes Einkommen:

DM 350.000 ,-

Steuersumme ohne Fondsbeteiligung:

DM $152.399,-$

Ergebnisse der Beteiligung in der Investitionsphase:

Beteiligungshởhe

DM 10.000

Grenzsteuersatz der Beteiligung

Steuerliches Ergebnis der Beteiligung

Daraus resultierende Steuererspamis

I. DM

$56,77 \%$

Bruttoinvestitionsbetrag incl. Agio

DM

$152.998,-$

Nettoinvestitionsbetrag

DM

86.857,-

DM $105.000,-$ 18.143,--

Laufende Erträge der Beteiligung während der Vermietungsphase:
Ausschattung 1994
DM 1.250,-
Rendite
$6,89 \%$
Ausschattung 1995
DM 2.500,--
Rendite
$13,78 \%$
Ausschattung 1996
DM 2.750,-
Rendite
$15,16 \%$
Ausschuttung 1997 und Folgejahre
DM $3.000,-$
Rendite
$16,54 \%$

Zusătzlich zu den Ausschuttungen entfallt auf die Beteiligung eine anteilige Tilgung (Entschuldung des fondsinternen Kredits) in folgender Hobe:
1994
DM 955,-- Renditen incl. Tilgung und Ausschüttungen
$12,15 \%$
1995
DM 1.962,--
$24,59 \%$
1996
DM 2.071,--
$26,57 \%$
1997
DM 2.186,--
$28,59 \%$

weiter ansteigend in den Folgejahren.

Einige Angaben zur mőglichen Wertentwicklung des Fondsanteils:

Nominalwert der Beteiligung

DM

$100.000,-$

Anteiliger Immobilienwert incl. Fondskredit

DM

$236.369,-$

Nettoaufwand für diesen Immobilienbestand

DM

18.143,-

bzw. in Prozent

$7,7 \%$

D. h.: Ein Wertanstieg der Gesamtimmobilie um z. B. $10 \%$ bewirkt einen Wertanstieg des eingesetzten Kapitals um $130.3 \%$.

Solche Wertruwăchse sind in der Regel steuerfrei (im Privatbereich bei Beachtung der entsprechenden Vorschriften). 


\section{DS-FONDS NR.38}

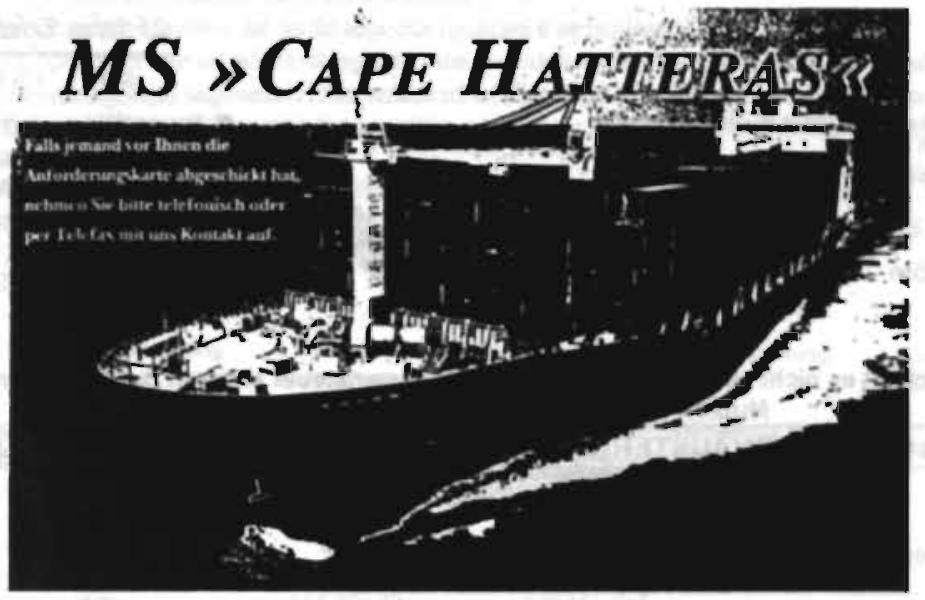

- $115.7 \%$ stcuerliche linlusizuneisung auf die Beleiligung (daron $10,7^{\circ}$ h nerrechembare Verlust)

- 3120 - steuerliche Verlust:anceisung auf die Finzahlung in 1994 bri Inanspruchualime des zuischenfinanzienungsangeboles der DS-Fondserncaltung Dr. Pelers $\mathrm{GmbH}$

- $7 \%$ siruerfreie .iusschüttung bereils ab 1995

- Bis zu $81 \%$ Kápitalrürkfluß in dem erslen 5 Jahren

- Ilenurragende . Iarktchanren fur dic Conlainerschiffalort

- Modemes Containerschiff mit niedrigen Betriebskosten

- Gesicherte Beschäfligung durch 2jahlinge Feskcharier za USS 10.500,pro Tag $\approx$ isl. Profit-Sharing

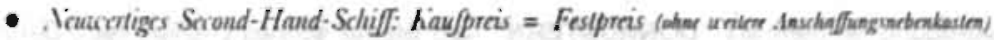

- Eiflahnes Sichiffs- und Fondsmanagement

- Haflungsbeschränkung durch Kommanditbeleiligung

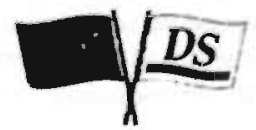

DS.FONDSVERWALTUNG DR.PETERS G-M.B.H 


\section{Anlage 15 \\ Gernot Busch \\ Berliner Straße 60 40822 Mettmann}

Gemot Busch - Beriner Stra00 60. 60222 Mottmann Persônfich

Herf Peginald Hansen

Hirzstr. 1

50937 Köln
Telefon (0 21 04) 76078 Telefax (0 2104$) 82753$ Mobil (01 72) 211200 ?

\section{5 gafue Evfafoung seit 1969}

- Investitlonsvermittlung

- Vermögenskonzepte

- Steuergünstige Anlegen

- USA-Rendite-Aniagen

\section{Dezember 1994} DB

Noch ist es nlcht zu splt, Ihre gezahlte E.Inkommensteuer alnnvoll zu investieren! Nutzen Sle lhre Chancn. Hendeln Sle letzil

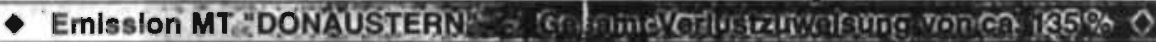
thre Verlustzuweisung fur 1994 be fragt aut thre Einzahlung ca. $236 \%$

Sehr geehrter Herr Hansen,

das Interesse an Schiffsbeteiligungen ist weiter gestiegen, und lch freue mich, Ihnen noch zum Jahresende den MT "DONAUSTERN" aus dem Emissionshaus G H F mit exzellenten Eckdaten anbieten zu können. Es handelt sich hier um einen ertahrenen Partner mit einer hervorragenden Leistungsbilanz.

Eine Beteilligung an dem MT "DONAUSTERN" bedeutel Sonderabschreibung und hohe Rendite. Nachstehend die besonderen Verleile aus der Sichl eines Anlegers:

ca. $473 \%$ Vorlustzuwolsung 1994 aucthes a

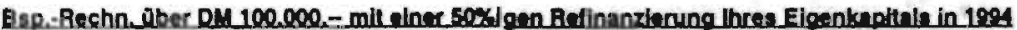
Darlehensrückzahlung in vier gleichen Paten, beginnendi ami 10.12.1996 bis 10.12.1999 jeweils DM 12.500,(zusâtzlich angefallene Zìnsen) Ihre erste Eigenkapitalrate betrigt nur DM 30.000,thie zweite Eigenkapitairate von DM 15.000,-- wird aut Wunsch bis zum 10.06.1995 zinelos vorfinanziert Ihr Llquidilisgewinnn betrigt som/t DM 62.500,-1 (oel hochssier Sieverprogression in 1994)

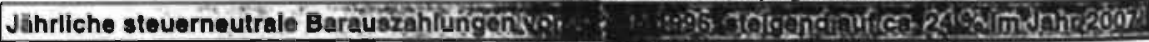

Prognositizierter MittelrúckluB im Jahre 2007 nach Steuem ca. 237.059 DM

Die Beteiligung an dem MT "DONAUSTERN" ivird wieder schnell plaziert sein. Darum wãre es emplehlenswert, bei Interesse eine unverbindliche Resenvierung vorzunehmen. Die Annahme ertolgt in der Reihenfolge des Eingangs.

Bitto rufen Sie mich hierzu an!

Für Fücklragen stehe ich gerne zu lhrer Vertügung und verbleibe

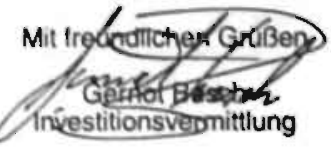

Gultig ist allein der Ermissionsprospelt. der lûr' Sie abrutbereit vorliegt!

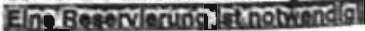

Für die meisten Steuerzahler ist die Mark weniger sls to Ptennig wert. Wollen Sie des nicht für sich indern?

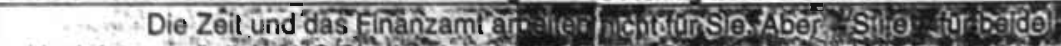

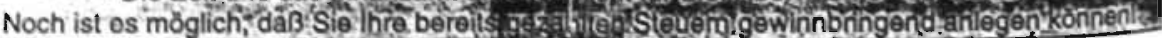




\section{Anlage 16}

\section{Musterberechnung}

Für eine Betziligung in Köhe von 100.000, - DM zzgl. $5 \%$ Agio.

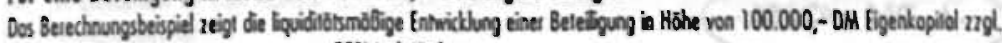
$5 \%$ hig bei einem Spithensteversot von $55 \%$ ind. Fuchenstever.

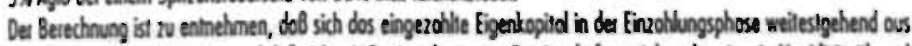

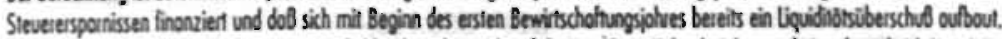

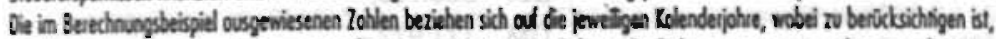

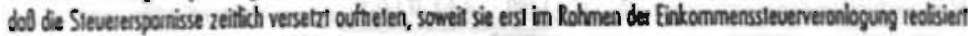
weden.

Die Reolisierung der prognosfizierten Steveetersponisse setri rorous, dob die duch dis: Velustzuweisungen kompensienten

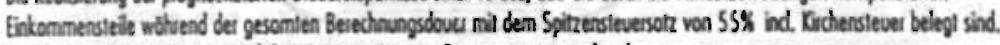
Die Steveressponis retringet sich bei einem getingeren Sleversot? enkpicchend.

\begin{tabular}{|c|c|c|c|c|c|}
\hline \multirow[t]{2}{*}{ Jaht } & $\begin{array}{l}\text { Einzahlung } \\
\text { ind. Agio }\end{array}$ & $\begin{array}{l}\text { Vertual- } \\
\text { zuwelsung }\end{array}$ & $\begin{array}{c}\text { Slevererepamis bel } \\
\text { 55\% Progression } \\
\text { (1992 mil sa\%) }\end{array}$ & Ausschorlung & $\begin{array}{l}\text { kumulione } \\
\text { Llquiditan }\end{array}$ \\
\hline & OM & DM & DM & DM & OM \\
\hline 1992 & $35.000 \mathrm{DM}$ & $68.229 \mathrm{DM}$ & $39.573 \mathrm{DM}$ & .1 & $4.573 \mathrm{DM}$ \\
\hline 1993 & $50.000 \mathrm{DM}$ & $113.330 \mathrm{DM}$ & $62.332 \mathrm{DM}$ & .1 & $16.904 \mathrm{DM}$ \\
\hline 1994. & $10.000 \mathrm{DM}$ & $4.757 \mathrm{DM}$ & $2.616 \mathrm{DM}$ &.$l$ & $0.521 \mathrm{OM}$ \\
\hline 1995 & $5.000 \mathrm{OM}$ & $4.359 \mathrm{DM}$ & $2.397 \mathrm{DM}$ &.$t$. & 6.918 DM \\
\hline 1896 & $5.000 \mathrm{DM}$ & $4.078 \mathrm{DM}$ & $2.243 \mathrm{DM}$ &.$t$. & $4,161 \mathrm{DH}$ \\
\hline \multicolumn{2}{|c|}{ Zmischensummo: } & $194.753 \mathrm{DM}$ & $109.161 \mathrm{DM}$ & & \\
\hline 1097 & .1. & 3.767 DW & $2.072 \mathrm{DM}$ & $1.000 \mathrm{Cm}$ & $7.2330 \mathrm{DM}$ \\
\hline 1998 & 1. & $3.394 \mathrm{DM}$ & $1.067 \mathrm{DM}$ & $1.000 \mathrm{OM}$ & $10.100 \mathrm{DM}$ \\
\hline 1009 & .1. & $1.171 \mathrm{DM}$ & $64 \mathrm{OM}$ & $1.000 \mathrm{DM}$ & $11.744 \mathrm{DM}$ \\
\hline 2000 &.$t$. & $763 \mathrm{OM}$ & $420 \mathrm{DM}$ & $1.000 \mathrm{DM}$ & $13.1631 \mathrm{DM}$ \\
\hline 2001. & $t$. & $346 \mathrm{DM}$ & $190 \mathrm{OM}$ & $1.000 \mathrm{DM}$ & $14.354 \mathrm{DM}$ \\
\hline 2002 & $f$ & $-96 \mathrm{DM}$ & $.53 \mathrm{DM}$ & $1.000 \mathrm{DM}$ & $15.3011 \mathrm{DM}$ \\
\hline 2003 & $t$. & $.578 \mathrm{DH}$ & $-318 \mathrm{DM}$ & $1.000 \mathrm{DM}$ & $15.9813 \mathrm{DM}$ \\
\hline .2004 & 1. & $5.527 \mathrm{DM}$ & $3.040 \mathrm{DMH}$ & $1.000 \mathrm{DM}$ & $20.0231 \mathrm{DM}$ \\
\hline \multicolumn{2}{|c|}{ Zwischensumnoe: } & $209.047 \mathrm{DM}$ & $117.023 \mathrm{DM}$ & $8.000 \mathrm{OM}$ & \\
\hline 2005 & .1 & $-2.2450 \mathrm{DH}$ & $-1235 \mathrm{DM}$ & $2.5000 \mathrm{M}$ & $21.2800 \mathrm{OM}$ \\
\hline 2006 & .1. & $-2.651 \mathrm{DM}$ & $-1.458 \mathrm{DM}$ & $2.750 \mathrm{OM}$ & $22.580 \mathrm{DM}$ \\
\hline 2007 & .1 & $-3.040 \mathrm{DM}$ & $-1.677 \mathrm{DM}$ & $3.000 \mathrm{DM}$ & $23.903 \mathrm{OM}$ \\
\hline 2008 & .. & $-3.454 \mathrm{OM}$ & $.1 .000 \mathrm{DM}$ & $3.250 \mathrm{DM}$ & $25.253 \mathrm{DM}$ \\
\hline 2009 & it. & $-3.912 \mathrm{OM}$ & $-2.152 \mathrm{DM}$ & $3.500 \mathrm{OM}$ & $26.602 \mathrm{DM}$ \\
\hline 2010 & $i$ & $-4.332 \mathrm{DM}$ & $-2343 \mathrm{OM}$ & $3.750 \mathrm{DM}$ & $27.068 \mathrm{DM}$ \\
\hline 2011 & .1. & $-4.760 \mathrm{DM}$ & $-2.610 \mathrm{DM}$ & $4.000 \mathrm{DM}$ & $20.351 \mathrm{DM}$ \\
\hline 2012 & .1 & $-5.212 \mathrm{DM}$ & $-2.067 \mathrm{DM}$ & $4250 \mathrm{DM}$ & $30.734 \mathrm{OM}$ \\
\hline 2013 & .1. & $-5.581 \mathrm{DM}$ & $-3.059 \mathrm{DM}$ & $4.500 \mathrm{DM}$ & $32.176 \mathrm{OM}$ \\
\hline
\end{tabular}

\section{Anmerkung:}

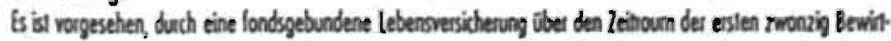

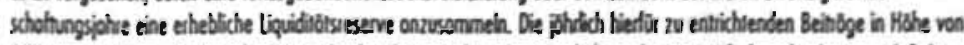

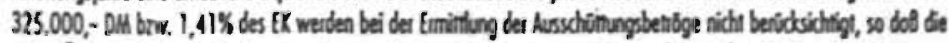

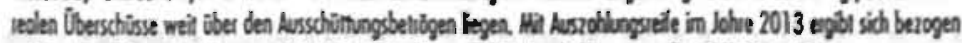

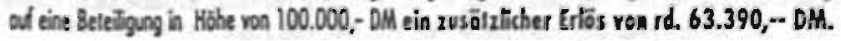




\section{Anlage 17}

\section{Auf einen Blick:}

1. DM 47.250,-

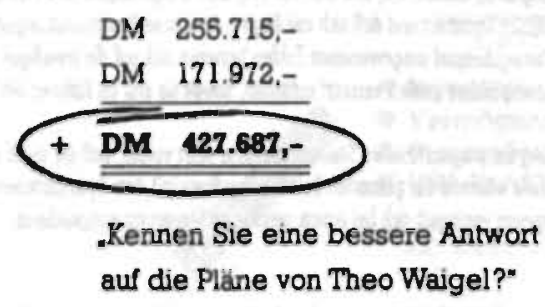

In der Bauphase tnanziert der Fickus thre Beteiligung mit DM 57.750,- Sie investieren aus der eigenen Thasche per Saldo ledighich DM 47.250.-

Aufgrund der laufonden Ausschütungen plus Liquidilatrreserven baut sich das von thnen eingesetzio Kapital nicht nur aul DM -,- ab, sondem fuhrt bis Ende 2014 zu oinem therschus van DM 203.465,(DM 255.715,- I. DM 47.250,-), nachvollziehber im Prospeka (liquiditatsborectunung).

\section{Vorhuberang:}

Würde die Kinik Ende 2014 nur zum 8,06 tachen der dann gulligen Jahresmiete verkauf, ergabe sich, zusaltr-

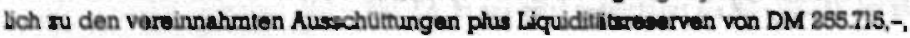




\section{Unverbindliches Berechnungsbeispiel:}

Die neue Fachklinik für Anschlusheilbehandlung und Rehabilitation von Erkankungen der Bewegungsorgane entsteht auf einem kostbaren, ca. $13.000 \mathrm{~m}^{2}$ groBen Parkgrundstick, in Bad Lie benstein/Thünngen Bad Liebenstein ist das alteste und grobte Heilbad Thüringens und blickt auf eine mehr als 300 jahrige Kurtradition zuruck.

Die Konzeption erfolgt in der Rechtsform der KG $(V+$ V), also ohne Fremdmittelhaftung

Der Gesamtaufwand von DM 61,5 Mio, setzt sich aus DM 19,6 Mio. Kommundit- und DM 41,9 Mio. Fremdkapital bzw. stlle Beteiligung zusammen. Bezogen aul das Kommanditkapilal entstehen in 1993/94 Buch. Verluste in Hohe von $164 \%$. Davon sind $105 \%$ solort verrechentuar und 5990 ausgleichsfahig bis; 2002.

Unterstellt wurde eine Spitzensteuerbelastung von $55 \%$, inklusive Kirchensteuer. Pro DM. 100.000,Kommanditkapital betràgt die Wertquote 0,5102\%. Verbindlich ist der Emissionsprospekt.

\begin{tabular}{|c|c|c|c|c|c|c|}
\hline \multirow[b]{2}{*}{$\begin{array}{l}1993 \text { (DM 60.000,-- + DM 5.000,--Agio) } \\
1994\end{array}$} & \multicolumn{2}{|c|}{$\begin{array}{l}\text { Einzalung } \\
\text { Eigenlapital }\end{array}$} & & & \multicolumn{2}{|c|}{$\begin{array}{l}\text { Sonderafa und } \\
\text { Werbungskoster }\end{array}$} \\
\hline & $\begin{array}{l}\text { DM } \\
\text { DM }\end{array}$ & $\begin{array}{l}65.000,- \\
40.000,-\end{array}$ & & & $\begin{array}{l}\mathrm{DM} \\
\mathrm{DM}\end{array}$ & $\begin{array}{l}65.000 \\
40.000\end{array}$ \\
\hline & $\mathrm{DM}$ & $105.000,-$ & x $100 \%$ & $=$ & DM & 105.000 \\
\hline Steuerersparnis aus DM 105.000.- & $\underline{D M}$ & $57.750,-$ & 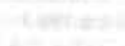 & & & \\
\hline Investition In der Beuphase & $\underline{\mathbf{D M}}$ & $1250,-$ & & & & \\
\hline
\end{tabular}

\begin{tabular}{|c|c|c|c|c|c|c|c|}
\hline \multirow[b]{2}{*}{1995} & \multicolumn{3}{|c|}{ Ausschititungen } & \multicolumn{2}{|c|}{$\begin{array}{l}\text { zusatzlicbe } \\
\text { Liquiditä }\end{array}$} & \multicolumn{2}{|l|}{ total } \\
\hline & DM & & & DM & $5.982,-$ & DMI & $5.982,-$ \\
\hline $\begin{array}{l}1996 \\
1997\end{array}$ & DM & $7.000-$ & 1. & DM & $838,-$ & DMI & $6.162,-$ \\
\hline $\begin{array}{l}1997 \\
1998\end{array}$ & DM & $\begin{array}{l}7.000 \text {-- } \\
7.000-\end{array}$ & 1 & $\begin{array}{l}\mathrm{DM} \\
\mathrm{DM}\end{array}$ & $\begin{array}{l}884,- \\
450-\end{array}$ & DMI & $\begin{array}{l}0.136,- \\
6.550-\end{array}$ \\
\hline 1999 & $\mathrm{DM}$ & 7.000 & & DM & $\begin{array}{l}\text { 150.- } \\
201,-=\end{array}$ & DMI & $1.201,=$ \\
\hline 2000 & $\mathrm{DM}$ & 2.000 - & & DM & $888,=$ & $\overline{\mathrm{DM}}$ & $7.888,-$ \\
\hline 20 & $\mathrm{DM}$ & $7.000-$ & & DM & $1.589,-=$ & DMI & $8.589,-$ \\
\hline 20 & DM & 7.000 - & & DM & $2.354,-$ & DMI & $9.334=$ \\
\hline 3 & DM & $2.000^{3}-$ & & DM & $3.160,-$ & DM & $10.160-$ \\
\hline 4 & $D M$ & $7.000,-$ & & DM & $3.885 .-$ & DM & 10.985,- \\
\hline 005 & $D M$ & $7.000_{1}-$ & & DM & $4.879,-$ & DM & 11.879 \\
\hline 006 & $D M$ & $1.000,-$ & & DM & E.820,- & DM & $12.820,-$ \\
\hline 2007 & $\mathrm{DM}$ & $1.000,-$ & & DM & $10.374-$ & DM & $17.374 .-$ \\
\hline & $\mathrm{DM}$ & $1.000_{2}^{-}$ & & DM & $11.430,-$ & $\mathrm{DM}$ & $18.430,-$ \\
\hline & DM & $7.000,-$ & & DM & 12.632 - & DM: & $19.632,-$ \\
\hline & DN & $2.000,-$ & & DM & $13.892,-$ & DM & $20.892, \cdots$ \\
\hline & D) & $7.000,-$ & & DM & $15.212,-$ & $\mathrm{DM}$ & $22.212-$ \\
\hline & D) & $7.000,-$ & & $\mathrm{DM}$ & 16.596,- & DM & $23.596,-$ \\
\hline & DN & $7.000,-$ & & DM & 18.045,- & DM & $25.045,-$ \\
\hline & D! & $7.000,-$ & $f$ & DM & $2.172,-$ & DM & 4.828,- \\
\hline
\end{tabular}

Insschüttungen plas Uqudditätsreserven ble zum Jahr 2014

+ DM255.711,-* 


\section{Anlage 18}

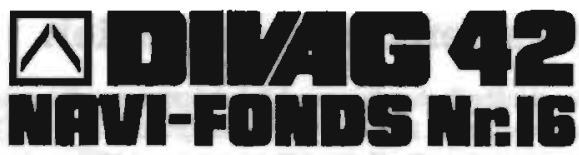

\section{Berechnungs-Beispiele}

Steuerliche Netto-Überechussrechnung für den Anleger

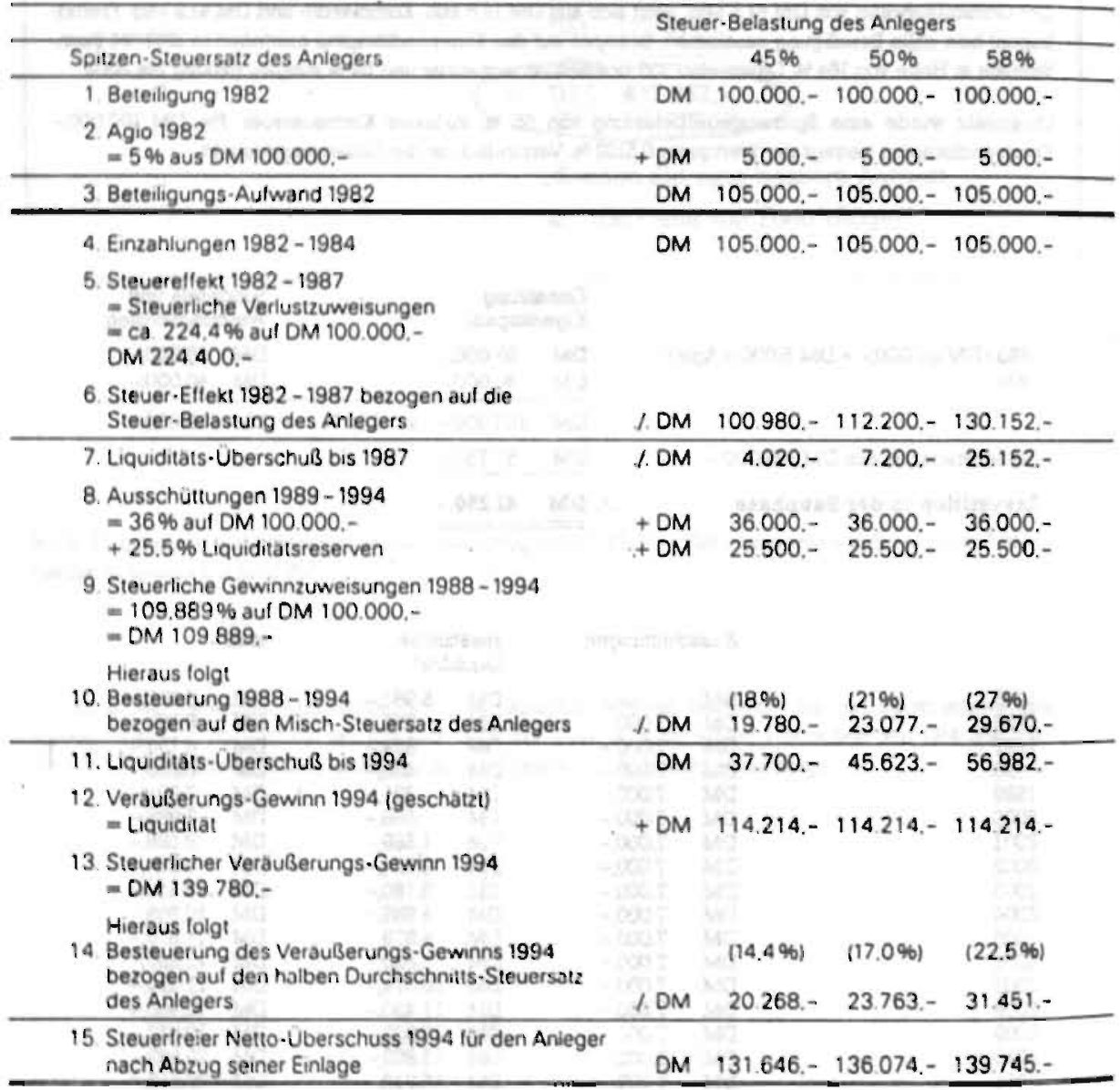




\section{Anlage 19}

\section{Der offentlich geforderte soziale wohnungsbau Berlin - Ein Überblick -}

L. Crundiagen des offentlich geforderten sozialen wohnungsbaus Berlin

\section{1. cesecxesregelung}

\section{a) Noschraibungsgrundiage}

Nach i 14 a (1) BerlinkC ionnen im sazulen Wohnungsbau im

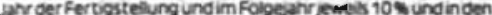
ych anschiedenden 10 Jahren pewels 3 t dor Herstelungs costen ernont aogeschreben werden

b) Ubergangsregelung zo if 15 a Einkommensteuer gesetz

Cema3 52 ADS 21 Satz $2 \mathrm{Nr}$. 3 und Sutz $3 \mathrm{Nr}$. 2 EstC besteht fur Verluste, die im sozivien Wohnungsbov entstehen eine Aus. cohmeregelung zu 515 a EStC. Bs 1989 konnen diese Veruste den Kommanditstenin der tatslchlichentstehenden Hohe ru gerechnet werden

c) Ausrahmeregetung zu 15 a Einkommanstever. gesetr

Cemalo 15 a BerinfC komen auch nach 1990 venuste in ione der erhonten Abseczungen nach if 14 a t11 BerinfC den An legern zugewesen werden

Dis Crundlipe des Angebotes basiert somit ouf elner Cestrzesregelung und nicht auf husnutrung einer Cosetresucke.

2. De Bürgschaft des Landes Berfin fur de bHydochek stelt ene hochrangige Aoscherung der Cesamtfinanzierung dar.

3. Absitherung der Wirtschafelichkeit und der Louidicht enes Bauvorhabens ourch das forderungssystem Die Wohnungsoaukredicanstat wBo - ene Anstalt des Offent. Ichen Rechts und Organ der staatichen wohnungspoltili finansert for einen Zeitraum von 15 jahren de offerens $\mathrm{zw}$ schen der gesetalich festgeiegten sozialmete und der Kosten mete ourch Auhwendungshifen $2 / 3$ der Aufwendungshilfen werden als veriorene Zuschusse gewahre Das verbielcence $1 / 3$ ats Aufwendungsdariehen weiches jedoch bistur planmiligen Rüd

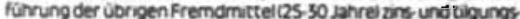
fres st Eine Anschlubforderung für die Zeit nach dern 15-jänngen Forderungszetraum ist vom Senv? vorgesehen
4. im zuge der Bewligung des Bavorhubens werden durch die wair umfangreiche technische und wirtschaftliche Prüfungen ourchgefuhre

5. De Aussage der wax, dab in den vergangenen 30 Jahren alle Bau. vorhaben des ren piftendich geforderten sozialen wohnungs baus berlin. Writschaftilch gesund und voll vermietiot snd. basiert im wesentichen auf diesen ver aufgefonrten crund agen.

C. Darúber ninaus ist aufgrund der rechtichen Cestaltung die Kar. tung auf de Elinlage beschrankt - ene Nachschuboflicht sit in acdem Falle ausgeschiossen. Die Einlage wird ie nach Pro. gressonsstufe voll aus stevermittein erbracht, somit ohne Egencagitalaufwand. Hyoothekenverpfichtungen werden von cem Anleger nicht ubernommen

7. Die vermietung der Objekte st aufgrund der vom Senat ausge vecenen Dringlichiteitsucherne fur Sokalmeter und der Meter nachlrage gewahrieistet.

1. Wirtschaftilehes/steuerilches Ergebnit - dargestelit am Beispiel einer Beteligung von Das 100.000 ,- -

1. Die coen genannten Crundiagen (Punkte 1-7hermogichen folgen den Effett

Vom Wohnsitz-Finarzamt in den offentich geforderten sozivien Wohnungsbau Berin sinnvoll verlagerte Stevergeider

2. Das Berechnungsbeispiel zeigt dal durch die Betelloung al en sich aufbavender erheblicher Liquidicatsiberschul ourch ersoarnisse und Barausschüttungen erzieit wird. und

bien interessanter, auch veraderbarer immoblenantel erwor. ben wird

3. Das Fazik der erisuterten Forderungsnalinahmen und der recht. ichen Cestaltung ist eine Verdinsung verlagerter stevem. - e rach Progressionsstufe ohne jeglichen igapitaleinsati.

Derechnungsbeisples fur eine Betelligung von DM 100.000,-

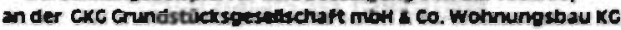

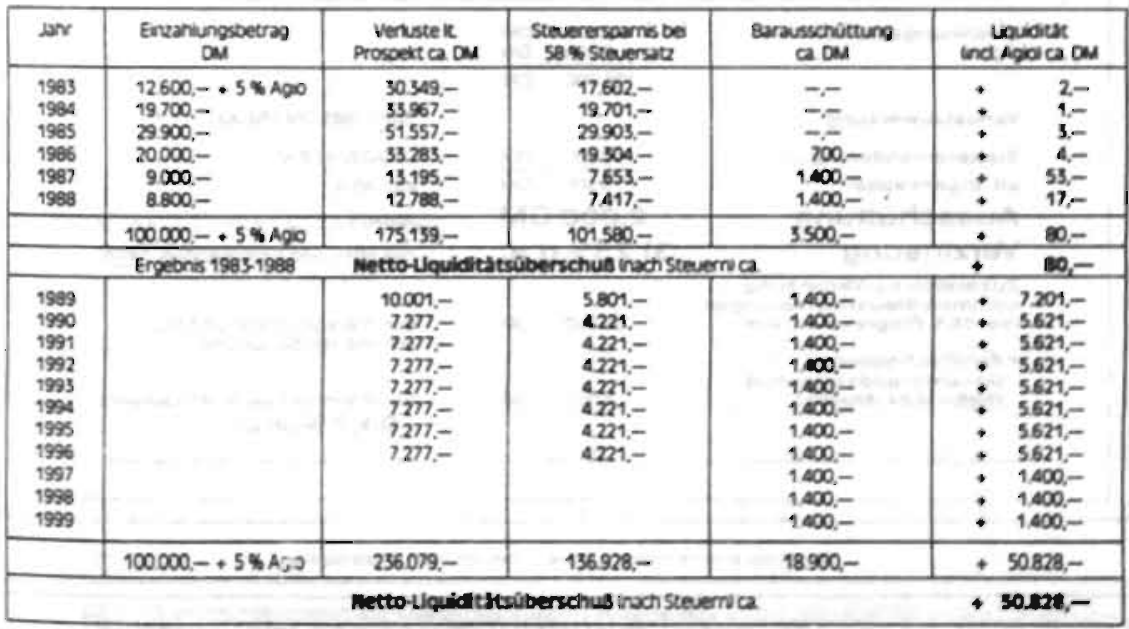

Das alles ist mit dc $n$ politischen Stahs Derlins entartiar - Beritn braucht inre Unterstútrungl certh braucht jede wohnung! 


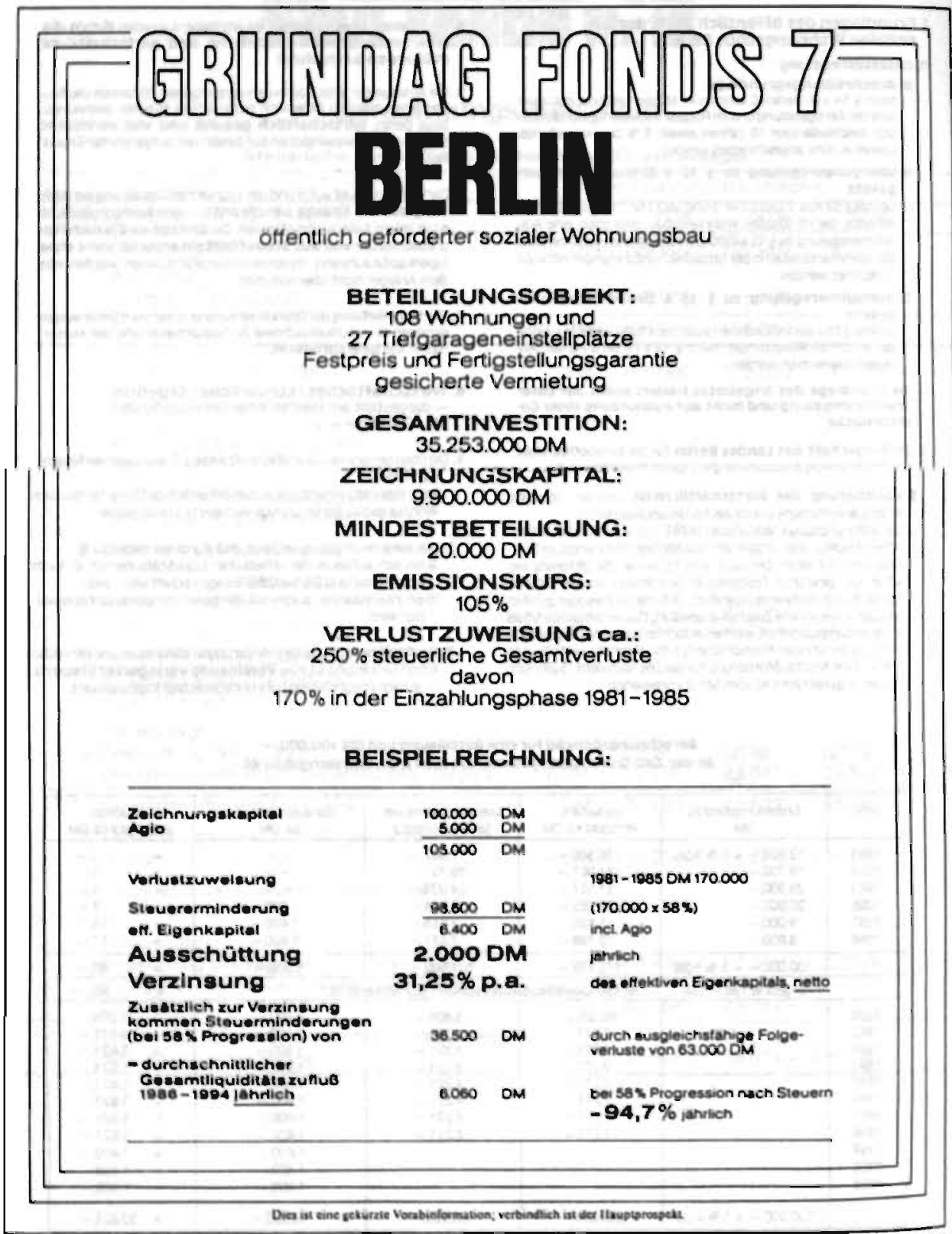

Ihr Gesprächspartner Di: $\mathbf{R}$ Vos! (0201) 783091

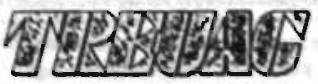

Treuhand Aktiengesellschan
Treuag AG

Bismarckstrabe 69

4300 Essen 1

Telefon (0201) 783091 


\section{Anlage 21 .}

IERECHAUNGS-

BEISPIEL

B ...ohne Refinanzierung Bareinlage II fur eine Rommanditeinlnge ia Hähe von 160.000 DM

Bareinlage J: DM 100.000,- 2xgl. 5\% Agio Bareinlage II: DM $60.000,-$
Sicutrat:

\section{IMTLSTITIONSPHASE}

1. 1993

a) Eigenkagital incl. $58 \mathrm{AgiO}$

b) Vertustruweisung

c) daraus resultierender Sieuervorteil

6) Eigeniapitaleinsatz nach Sievern

2. 1991

a) Eigeniapital

b) Verlustumetisung

c) daraus resultierender Stevervorteil

G) Eigeniapituleinsalz nach Stevern
97.124 DM

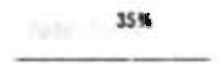

125.000

63.402 DM

3. tatsachlleher Eisenkapitaleinsalz (1993-1998)

108.816
3596

33.993

91.007

40.000

4ox

50\%

Ss.4.

125.000

125.000

125.000

48.562

53.411

86.151

71.582

76.438

40000

2.191

17.901

40.000

40.000

34เก!

31.701

5.129

14.639

K1.73h

76.7II

100.790

\section{I]. IEWIRTSCHATTUNCSPHASE IQUS-2001}

1. Summe der Entnahmen

2. Durchschnittlicher Liquiditatsüberschus p.a. (15 Jahre)

1. berogen auf den tauschlichen Eigenkapitaleinutz (L.3.)

A. Steverbel. Gewinn 1995-2009

$125.213 \mathrm{DM}$

5. Ergebnis nach Steuern

6. Durchschnitt. Oberschul nach Steuern p.a.

7. Entspricht einem Ertrag vor Sievern p.e. von

$\begin{array}{rr}197.001 & 137.000 \\ 5,71 \% & 5,71 \% \\ 1.39 \% & 9,06 \% \\ 4.175 & 50.415 \\ 92.825 & 86.515 \\ 6.14 & 5.768 \\ 1.521 & 2.613\end{array}$

$137,000 \quad 137.060$

$5,71 \%$

$10,7310110,91 \%$

$0.106 \quad 69.417$

7.89 67.589

49264506

$9.152 \quad 10.012$

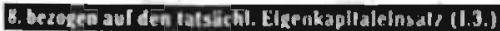

\section{WERTENTWICKLUNGSEETIMCHTUNG}

bel einem angenommenen, Wert de, Objektes

Lade 200 s zur 13 -fachen Jahresmiete

1. Anteiliger VeräuBerungserlös

356.229

356.229

356.229

356.229

2. abrgl, Kreditvaluta

113.069

113.069

113.069

113.069

3. abzgl. Steverzahlungen (II.4.)

44.175

50.485

63.106

69.817

4. agli. Entnahmen

137.000

[37.000

137.000

137.000

5. ugl. Liquiditätsreserve anteilig

4.997

4.997

4.997

4.997

\section{Erebais nach steuera}




\section{Anlage 21 b \\ ...mit Reflnanzlerung Barelnlage II für else Kommanditeinlage in Hobe voo $160.000 \mathrm{DM}$ \\ Bareinlage L: DM $100.000,-22 g$ L. 5* Aglo Bareinlate II: DM 60.000 ,-}

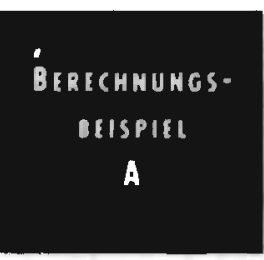

Steueraniz

35\%

$40 \%$

$50 \%$

मा

i. INVESTITIONSPMASE

I. 1994

a) Eigenkapiral incl. 5.4 Agio

b) Verlustruweisung:

105.124 DM

65.000

65.000

65.000

65)

c) daraus resulticrender Steuenorteil

36.793

42.049

20.207

22.951

52.562

12.438

ราม

2. 1944

a) Eigenhapitai

b) Verlustruweisun:

40.000

40.000

10.000

a.

C) daraus resultierender Steuenorteil

$67.402 \mathrm{DM}$

d) Eigenikapitaleinsatz nach Sievern

23.591

16.409

26.961

13.039

33.701

6.298

nim

20

HI

35990

18.737

IDIII

\section{DEWIRTSCRATUNGSPHASE I095-2009}

1. Summe der Ausachüllungen

2. Durchschniltticher Liquiditatsübernchus p.a. (15 Jahre)

3. Bezogen auf den batsàchlichen Eigenkagitaitimaiz (1.3.)

$\begin{array}{rr}59.000 & 59.000 \\ 3,234 & 3,93 \% \\ 1.04 & 10,90 \% \\ & \\ 22.41 & 26.104 \\ 36.159 & 32.896 \\ 2.411 & 2.193 \\ 3.705 & 3.655\end{array}$

59.000

$3,93 \%$

20,934

59.0

4. Sieverbel. Gevrinin 1998-2009

abrügl. Veriusle 1995-1997

$65260 \mathrm{DM}$

$0,93 \times$

32.530

26.370

1.758

3.516

7. Entspriche einem Enchus war Steuern p. von

8.315

10.165

$18,76 \%$

B. hezogen auf den tatsachl. Eisenkapilaleinsatz (1.3.)

Sleuerait

35x

$40 \mathrm{~s}$

504

55

\section{WERTENTWICKLUNGSEETRACKTUNG}

\section{bel elwein angenommenen Wert des Oyjektes}

Exde 2009 aur is-faches Jahreinlele
1. Anteiliger Verliußerungserlōs
2. abzgl. Kreditvaluta
3. abzgl. Steuerahiungen (11.4.)
1. rzgl. Aussehuitungen
5. zzgl. Liquiditătsreserve anteilig

356.229

356.229

356220

162.689

162.688

162.688

162.68

22.841

26. 104

32.630

35.893

59.000

4.997

59.000

59.000

59.000

4.997

4.997

4.95:

\section{Brsehnis nach Steuern}

237.697

231.734

224.908

221105

7. bei einem tatsăchl. Eigenkapitaleinsatz (1.3.) von

4.616

35.990

18.737

10.111 
Anlage 22

A A C ISCHE

Y C E I N S A A K A G

Zentralbereich Privatkunden

\section{Vereinsbank}

\author{
Müschen, 18.11.94/V \\ Rundschreiben Nr. 314
}

2 i.

PKD-Nr. 27

Beteiligungsarigubot an einem Flugzeug-Leasingfonds

Lufthansa Leasing GmbH \& Co. Charlie-Echo KG-Fondsgesellschaft -

Initiatoren/ debis Aviation Leasing $\mathrm{GinbH}$, Stuttgart

Prospekcherauszeber: Fondsverwaltungssgesellschaft Allgemeine Leasing mbH, Grünwald

Leasinzobiekt: Flugzeug des Typ Airbus A 340 - 300, das am 06, 12.1994 von der Fondsgesellscheft gekauft und an die Lufthansa verieast wird

Bei dem Airbus A 340 - 300 handelt es sich um eine der jûngster, Entwicklungen innerhallb der Airtus-Produktfamilic. Für den ersten seit 20 Jahren vỗig neu konstruierten Langstreckenjet konnte Airbus tndustric auf umfangriche Erfahrungen aus den bisherigen Ajrbusprogrammen aurückgreifen.

Leasingeeberi Lufthansa Leasing GmbH \& Co. Chartie-Echo KG, Grünwald

Leasinenehmer: Deutsche Lufthansa AG, Koln

Leasingvertrag: Laufzeit von 8,5 Jahren. Er sicht eine Haftpflicht-, Kasko- und eine Kriegsrisikoversicheruag vor.

Sigherheit der Sämtliche Kosten und Risiken im Zusammenhang mit der Halterschaft und Beteiliguns dem Betrieb des: Flugzeugs werden fur die Dayer des Leasingvertrages vor der Lofthansa getragen. Die in der internaionsjen Luffishr ablichen Versicherningeo werdea durch die Lufthansa abgeschlossen.

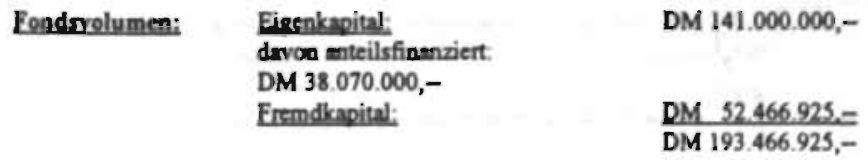

Plnzierungsearantic: Die Daimler-Benz InterServices (debis) AG, Berlin, garantient die Plaxierung des erforderlichen Eigenkapitals.

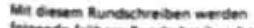

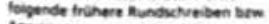
Anstinugen pepenstandien. 
VeriluBerungserlos: Nach Ablauf des Leasingsvertrages hat der Leasingnehmer eine Einmal zahlung von DM 118,24 Mio. (66 \% des ursprünglichen Flugzeugpreises) zu leisten. Damit werden neben dem auf die Anleger entfallenden Anteil an dieser Einmal zahlung saimtliche noch ausstehenden Fremdmittel einschlieBlich der Anteilsfinanzienung zurûckgefuhrt. Danach wird das Flugzeug verwertet, wobei die Lufthansa ein Ankaufsrecht zum Marktwert hat.

Einkunftsarr:

Einkunnte aus Gewerbebetrieb gemal \$ $\$ 15$ EStG

Mindestbeteiligun \& DM $150.000,-$ brw. durch 10.000 teilbare höhere Beträge

\section{Zahlune:} (ohne Agio)
$73 \%$ des Eigenkapitals durch Abbuchung der Fondsgesellschaft am 23.11.1994,

$27 \%$ des Kapitalanteils werden aber Namensschuldverschreibungen der Anleger finanzien (Auftrag und Vollmacht an die Fondsgesellschaft, damit der Betrag aufgenomnen und die Schuldverschreibung begeben werden kann).

\section{Rendite nach \\ Steuern: (Orenzaloverasta v. $53 \%$ \% \\ Solidarituruschles: von 7,3 4, ab 1999 sowie ind. Verbulerengerericas?$$
\text { - }
$$

$9,6 \%$ auf das jeweils gebundene Kapital (interne Zinsfulmethode)

von ca $4,8 \%(1995)$ auf ca. $5,3 \%$ (2002) steigend (Gesamteinlage)

\begin{tabular}{l}
. Verlustzuweisungen: \\
\hline (insgesamt ca $88 \%$ \\
bzw ca. $118 \%$ )
\end{tabular}

bzw ca. $118 \%$ )

Treuhandkem=

ca $27 \%$ bzw ca. $37 \%$ fur 1994

ca. $27 \%$ bzw. ca. $37 \%$ fur 1995

ca. $17 \%$ bzw. ca $23 \%$ fur 1996

ca. $11 \%$ bzw. ca $14 \%$ fur 1997

ca $5 \%$ bzw ca $7 \%$ fur 1998

ca $1 \%$ bzw. ca. $2 \%$ fur 1999

(bezogen auf die Gesamteinlage, bzw. Eigenkapitaleinlage von $73 \%$ )

manditis $/$ Direks.

beteilizuns:

Eintragung ins Treuhandregister oder dirckt ins Handelsregister

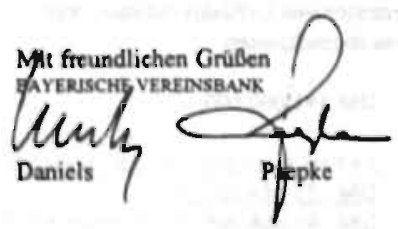


Anlage 23

IA TEISC H E

VERIINSBANK AG

\section{Vereinsbank}

Immobilien-Leasing-Fonds

Beteiligung an der HETTA VerwaltungspesellschaftrmbH + Co. Vermietungs KG

\section{Mindestzeichnungsbetrag DM 1 Mio}

Mindesteinlage

Fremdfinanzierung

DM 1 Mio (Bareinlage) $=43,51 \%$

DM 1,3 Mio $=56,49 \%$

(In Ausnahmefâllen jeweils die Hälfte; ist mit Herm Gerathewohl MUC/ -3809 abzustimmen)

Objekt ist ein Dienstleistungszentrum mit Büro- und Ladenflâchen in Jena.

Generalübernehmer ist die Jenoptk Bauentwicklung $\mathrm{GmbH}$.

Leasingnehmer ist die Jenoptik $\mathrm{GmbH}$, Jena, die zu $100 \%$ dem Land Thüringen gehôrt. Geschättstührer ist Dr. Lothar Spăth.

Steuerliche Verlustzuweisungen

$$
\begin{aligned}
& 1994=144,55 \% \\
& 1996=10,43 \% \\
& 1996=9,80 \% \\
& 1997=9.73 \%
\end{aligned}
$$

Weitere Verlustzuweisungen für die Folgejahre,

\section{Gesamt 234,15\%}

Die Verluste aus der Betelligung kônnen vom Gesamtbetrag der übrigen Einkünfte in 1994 abgezogen werden. Die den Gesamtbettag übersteigenden Verlusta kōnnen gemẳ $510 \mathrm{~d}$ EStG wahtweise auf die beiden Vorjahre verteilt werden; evtl. dann noch verbleibende Verluste lassen sich auf die Folgejahre vortragen.

Autgrund der hohen Verlustzuweisungen lälìt diese steuerorientierte Konzeption nur geringe Ausschüttunger zu.

Zins und Tilgung werden vom Leasingnehmer bezahlit. Das Zinsănderungesrisiko trăgt auch der Leasingnehmer.

Bei einem Steuersatz von $53 \%$ ergibt sich eine Rendite von $18,87 \%$ nach Steuem.

Die Bindung des Eigenkapitals betrăgt nur 5 Jahre.

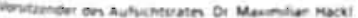

Wovinamiginder

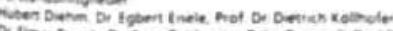

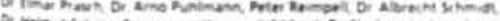

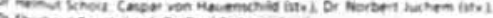

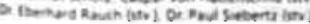

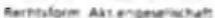

bes Mureten

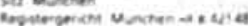




\section{Vereinsbank}

Immobilien-Leasing-Fonds
Beteillgungen der HETTA Verwaltungsoesellschaft mbH + Co. Vermietungs KG

$$
-2-
$$

Ausschütungen

von $0,1 \%$ tür 1998 steigend aut

$2,1 \%$ tür 2005

3,3 \% tûr 2010

$5.5 \%$ tûr 2015

$11,5 \%$ îr 2020

$20,5 \%$ tür 2025

Die Ausschüttungen reichen für die Steuerzahlungen in den jeweiligen Jahren aus.

Die durchschnittliche Ausschüttung für die Jahre 1998 - 2025 beträgt ca. 6,5\%, bezogen cut die Bareinlage (ohne Verdubenungsgewinn)

Für Rũckfragen wie fûr Kundengespr tche stehen Ithnen die Herren Paepke, Tel: 089 / 3884-8811, Korb, -8143 , und Gerathewohl, -3809 , gerne zur Vertügung. 


\section{Anlage 24}

\section{BEISPISL YOPTEIIEISPRETEIUCINC}

Berechnung dor Vortellhohigkelt einer Leteiligung an dem Oblekt Fetnnarner Strabe 6, 13353 Eerlin

\begin{tabular}{|c|c|c|c|c|c|}
\hline \multicolumn{6}{|c|}{ Wotriligung: DM 100.000,00+5\% Agle } \\
\hline lon & $\begin{array}{l}\text { Einzahlung } \\
\text { DM }\end{array}$ & $\begin{array}{l}\text { Sieverliche } \\
\text { Verluste } \\
\text { ca. DM }\end{array}$ & $\begin{array}{l}\text { Stever } \\
\text { erspornis bei } \\
55 \% \text {. }\end{array}$ & $\begin{array}{l}\text { Auhrond "'/ } \\
\text { Etrog } \\
\text { co. DM }\end{array}$ & $\begin{array}{l}\text { Liquidinats } \\
\text { Uberschuo } \\
\text { ca: DM }\end{array}$ \\
\hline 99 & $30,000,00$ & $-79.970,00$ & $43.984,00$ & 0,00 & $13.984,00$ \\
\hline \multirow[t]{2}{*}{904} & $75,000,00$ & $-111.005,00$ & $61.053,00$ & 0,00 & $-13.947,00$ \\
\hline & $105,000,00$ & & 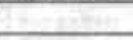 & & 37,00 \\
\hline 199 & 0,00 & $-55.137,00$ & 32531,00 & $-18.212,00$ & $14.319,00$ \\
\hline$\overline{P B}$ & 0,00 & $-28.544, \infty)$ & $16.841,00$ & $-16.451, \infty$ & 390,00 \\
\hline$M$ & 0,00 & $-27.937,00$ & $16,483,00$ & $-16.161,00$ & 322,00 \\
\hline Ma & 0,00 & $-27,301,00$ & $16.108,00$ & $-15.862,00$ & 246,00 \\
\hline 1909 & 0,00 & $-26.635,00$ & $15.715,00$ & $-15.555,00$ & 160,00 \\
\hline 200 & 0,00 & $-25,936,00$ & $15.303,00$ & $-15.238,00$ & 65,00 \\
\hline 200 & 0,00 & $-25,203,00$ & $14.870,00$ & $-14.911,00$ & $-4 i, 00$ \\
\hline 2002 & 0,00 & $-24.435,00$ & $14.417,00$ & $-14576,00$ & $-159,00$ \\
\hline \multirow[t]{2}{*}{2003} & 0,00 & $-23,627,00$ & $13.940,00$ & $-14.229,00$ & $-289,00$ \\
\hline & 105000,00 & $-455.730,00$ & $261.245,00$ & $-1.41 .195,00$ & $15.050,00$ \\
\hline
\end{tabular}

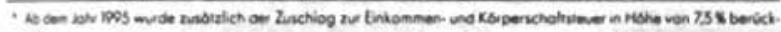
uckigh

- Mers abagl Zinuen Tilgung und brwohungsiosien.

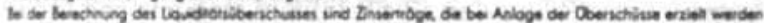
ismen netu bericlsichrigt

\section{Lڤteillgungsmögltchkeiren}

De Mindestbeteligungssumme sollte eine Eigenkopitaleinzohlung von DN1 50.000,00 nicht munchreilen. Hohere Zeichnungsberröge sind möglich, müssen aber durch DM 5.000,00 ohne fest tellbor sein.

\begin{tabular}{|c|c|c|c|c|c|}
\hline \multirow[t]{2}{*}{ Beneilgung } & Anteiliger & \multicolumn{2}{|c|}{ Dorlehen IA } & \multicolumn{2}{|c|}{ Dorlehen $1 \mathrm{~B}$} \\
\hline & Autwond & netto & brutho & netho & brutho \\
\hline DM & DM & DM & DM & DM & DM \\
\hline 52500,00 & $209.482,00$ & $63.020,00$ & $70.089,00$ & $93.366,00$ & $103.741,00$ \\
\hline 63000,00 & $251,371,00$ & $76,342,00$ & $84,825,00$ & $112.037,00$ & $124,186,00$ \\
\hline $84,000,00$ & $335.167,00$ & $101.792,00$ & $113,103,00$ & $149,386,00$ & $165.985,00$ \\
\hline 105000,00 & $418.966,00$ & $127.242,00$ & $141.379,00$ & $186.735, \infty 0$ & $207.483,00$ \\
\hline
\end{tabular}

\section{Intwicklung der Fromdfinanzierung und wirschaftich Uberlegung rur Betoiligung}

Duch die butende Tilgung verringent sich die volutierende Fremdiminelbelostung.

Si betrogr bei einem, tigeniopital von DM 100,000,00

\begin{tabular}{|c|c|c|}
\hline on 3112,1998 & $\begin{array}{c}\text { Darlehen IA } \\
\text { DM 135,084,00 }\end{array}$ & $\begin{array}{l}\text { Dorlehen } 18 \\
\text { DM 193.382,00 } \\
\end{array}$ \\
\hline on 3112.2004 & $\begin{array}{l}\text { Dorlehen IA } \\
\text { DM } 122550,00\end{array}$ & $\begin{array}{c}\text { Dorlehen } 18 \\
\text { DM } 164.008,00 \\
\end{array}$ \\
\hline \multicolumn{3}{|c|}{ De Belasung $e^{2} \mathrm{~m}^{2}$ betrog!: } \\
\hline on 31.2 .1998 & DM 3516,00 & \\
\hline on 31.2 .2004 & DM $3.067,02$ & \\
\hline
\end{tabular}

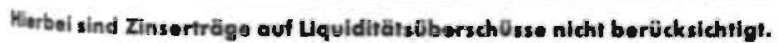


Anlage 25

\section{DAS ANGEBOt AUf DEN PUNKT GEBRACHT...}

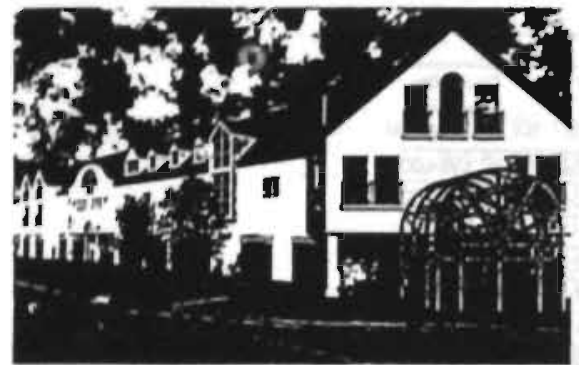

Beispielrechnum einer Kommanditeinlage von DM 160.000,Barainlage I DM 100,000,- mzl. $5 \%$ Aglo

Bareinlage II (refinanziert) DM $60.000,-^{\prime \prime}$

\section{Steversata $55 x$}

I. Invertitionaphase 1903 blu 1994 Eigenkapital incl. Agio lBareinlage If

a) Verlustrumeisung DM 172.526,

04105.000 -

Steuerersparnis bieraus

OM 94.889.-

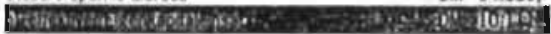

II. Bewirtschaftungsphase 1995 bis 2009 (15 Jahre)

a) Ausschüthungen DM 59.000,-

Durchschnittliche Ausschûftung bezocen auf den eflektiven Kapitaleinsatz (I. b) 38.98

b) Stevern auf positive Einhünfte aus der Betelifguns. DM 35.893c) Uberschud OM 23.107.-

Durchschnittlicher jahrlicher Oberschud

aach Stevern, bezogen aul den

effehtiven Kaptaleinsatz (Ib)

$15,2 \times$

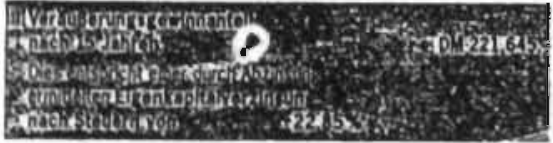

1) Der Kapitaldienst fír die Finanzierung der Bareinlage if wed von der Geiellschalt erbracht.

2) Bei einem angenommenen Verbuberungserlos im jahr 2009 zum 13-lachea der Jahresmiete abzüglich der Resthreditvaluta und Steverzahlungen zzel. Ausschütfung und Liquiditatsreserve. bej der Lage Unmittelbar in geografischen Mitteipunit is bu Durrenberg. einer ehemaligen und rukünfligen Karstat s ca. 14,000 Einwohnern. Das geplante Verwaltungszentha te Stadt ist nur wenige Gehminuten von dem ca. $14.000 \mathrm{~m}^{\prime} \mathrm{r}$ te Grundstuck entlernt. Hier entsteht ein Ẹinkauls und bes leistungszentrum mit is Wohnungen. Aul ca. 9200 ? Gewerbeflache werden Praxen, Buros, ein Supermark Drogeriemarkt und verschiedene kleinere Laden, Wars ast Dienstleistungen des taglichen Bedaris anbieten. Die fris stellung des 1. Bauabschnittes ist für Ende 1993 und der 2 ba abschnitt im Marn 1994 vorgesehen.

bei der Finanzierung Ca. DM 23,9 Mio. Eigenkapital linct. 58 iy und ein Grundschulddarlehen von Ca. DM. 19,9 E (zag. Damnum ").

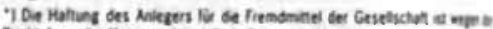

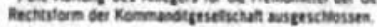

bei der wirtschaftlichen Sicherheit $\mathrm{Ca} .75 \%$ der prospeitert Mieten sind bei der Prospektherausgabe durch entsorectes Vertrige unterlegt. Alle Mietvereinbarungen erhalien in Koppelung der Miethóhe' an den jeweiligen Lebenshatap kostenindex brw. Staffeimietvereinbarungen. Die Ladentione sind 2.T. an bundesweit tatize Filialisten vermietet.

bel den Steuervorteilen Werbungskosten in der Investitonstare 1993 bis 1994 von $\mathrm{Ca}, 172 \%$ bezogen aut de nonivel Bareinlage bei Inanspruchnahme einer Telifinanzierung bes fap kapitals, fohne Refinanzierung betragh die Verlusiasa ca. 100,48 . Eintrag aul die Lohnsteuerkarte und Redubens: der Einkommensteuervorauszahlung ist möglich.

beil der Wirtschaftlichkeit $29,7 \%$ Ausschuttung: stegend $\mathrm{k}$ $69.2 \%$ im Jahr 2009 bezogen aut die tatsachich encestial Bareinlage lbei hochster Steuerprogression).

ber den Partnern Uber DM 2.5 Mrd. vermitteltes und nuesters: Kapital sowie eine uneingeschrankt positive Lesturgatas: sprechen fur sich.

..be) der Beteiligung Die Mindestbeteiligung (Barenlage D beis DM $30.000,-z z \mathrm{gl}$. 58 Agio (nomineli).

Dieses Kurzerpose enthall werbliche Aussagen. Verbindich fur tert ho lageentscheidung ist ausscniteblich der ausfuhriche Emssionsorosgek Nerve: 
Anlage 26

\section{Investieren in Berlin-Neukölln!}

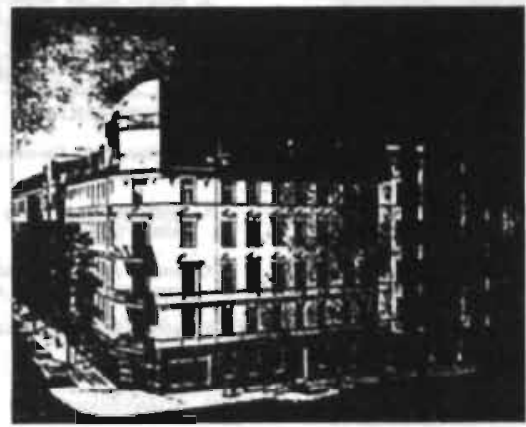

In der Karl-Marx-Strabe 272, der Houpigeschäftsstrabe im Berliner Bezirk Heukollin, wird mit einem, Gesamtinvessifionsvofumen von DM 36 Mio. tin Geschäfts., Büro- und Wiohnhous mit tiner Brultonurzlläche von $2.9 \$ 5 \mathrm{gm}$ atrichtes. Dos Bouvorhoben beinhaltet dos Neubouvorhaben sowie den Dachgeschobausbav des zugehörigen und bereits modernisierten Altbeus. Die Boustelle ist bereits aingerichtet, die Baugrube ausgehoben. Die Fertigstellung des Bauvorhabens ist zum Ende 1994 garantiert. Aư einen Blick die Eckdaten dieses geschlossenen Immobilienfonds:

\section{$50 \%$ Sonderobschreibung nach dem Fördergebietsgeselz} ca. $240 \%$ Verlostzuwelsung ouf das Zoichnungskapilal 5-jährige Mieigarantlo 


\section{Anlage 27}

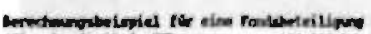

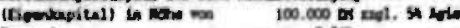
hrowent: $0, \mathbf{M}$

\begin{tabular}{|c|c|c|c|c|}
\hline Resernati & 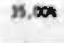 & $0, \infty$ & 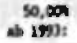 & $\begin{array}{l}91,00 \\
95,000\end{array}$ \\
\hline
\end{tabular}

\section{Imeatitianghe}

\section{1 1\%2}

\begin{tabular}{|c|c|c|c|c|c|}
\hline $\begin{array}{l}\Delta \\
\text { c) }\end{array}$ & 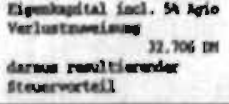 & 4.000 & 0.000 & $\infty, \infty \infty$ & 0.000 \\
\hline 4 & $\begin{array}{l}\text { Eiombayiteleinata } \\
\text { nurb staters }\end{array}$ & 23.531 & 2.916 & 2.J.41 & $2.3 \mathrm{st}$ \\
\hline \multicolumn{6}{|c|}{ 2. 1953} \\
\hline ii & Diombaital & 6.000 & 6.000 & 8.000 & 65.000 \\
\hline c) & 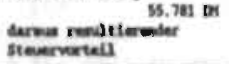 & 19.523 & 2..น & n.m & 10.600 \\
\hline & nats stamm & $13.4 n$ & 40 & n.140 & M.320 \\
\hline
\end{tabular}

3. 1996

1) Digentapital

b) Verilustriationa

e) daraud retaltieredet $\begin{array}{lllll}\text { Stevervarteil } & \text { 2.45 } & 2.059 & 3.512 & 3.46\end{array}$

d) Diventapitaleinatx

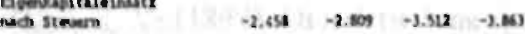

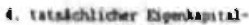
einsata (3992-1994)

13.572 $66.7 \% \quad 37.265$ S1.ns

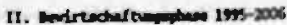

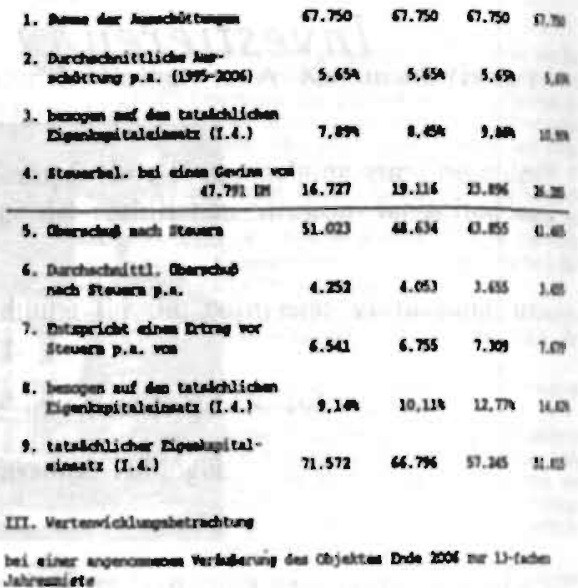

\begin{tabular}{|c|c|c|c|c|}
\hline steverues & 15,00 n & $\infty 0.000$ & 50,000 & 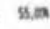 \\
\hline 1. Anteilifor Verbiberunguerlib & $2 n .561$ & $226.54 r$ & $26.36 !$ & 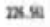 \\
\hline 2. mol. Laschatrowen & 67.750 & $67.7 \times 0$ & 67.750 & n. $\mathrm{m}$ \\
\hline 3. Waol. Rretitvelues & 66.406 & 6.65 & 4. $\cos$ & H. \\
\hline A. ahagl. Steverzatlurpen & 16.727 & 19.116 & v.tw & $x: z$ \\
\hline 3. Terrschab nuch stevern & 212.178 & 2ot. 2ty & 204.010 & alla \\
\hline 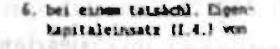 & $n .5 n 2$ & 4.7\% & 57.285 & st en \\
\hline
\end{tabular}

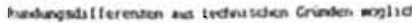

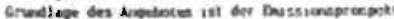




\section{Anlage 28}

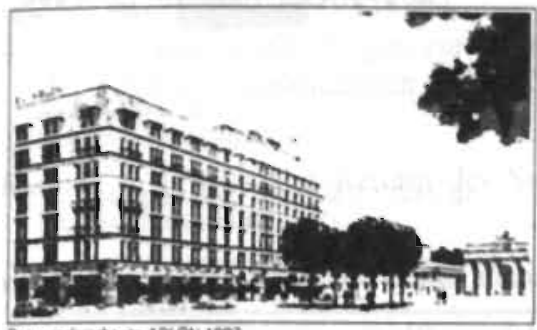

Das neclererbate ADLON 199 ?

\section{Die Fondsgesellschaft}

- Lagdeld Hotel Adion

FUNDUS FONDS 31 KG

- 435000000 ,- DM Fonds. volumen ragl Ago

\section{- 425000 000,- DM Eigen.} kaptakEmissionskapital zrgl Agio

- Rechtsform vermogensver. waltende Kornmandigesell. schatt mit Einkinften aus Vermietung und Verpachtung

- Beteligung als Direkt- oder Treuhandiommanditst. Treuhandes st eine Steuer. beratungrgesellschaft

- De Haftung des Gesel. shatters of aut seine linlage beschrank?

\section{Die Beteiligung}

- Mindestbeteligung 50 000-DM zagt 5\% Agio

- De Geseilschafter der Fonds-XG werden Minglieder im exklusven ADLON-CLUB Mit de ADLON-Club-Cand konnen die Mitglieder im ADLON und allen KempinsiarHotels weitweit wertvolle Sonderlestungen und Vorrugsbehandiungen in Amoruch nehmen

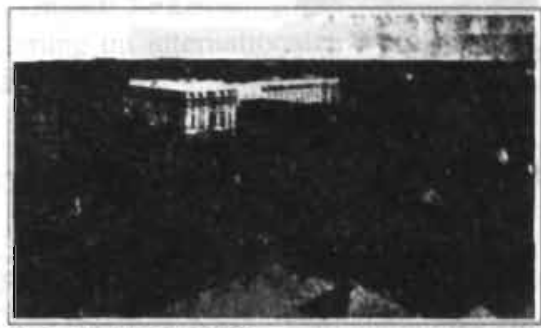

Der Pomer Rati ine ADCO, $199 \mathrm{y}$

\section{Der Pachtvertrag}

\section{Die Rentabilităt}

\section{- 20 iahre festlautzeit ab Fervgstellung und Uber nume}

- 10 iahre Verlangerungs. option fur den Pachter

- 16.9 Mio DM anianglicre fahresoacht $z$ gi. Must nach einem pachtiresen laht indevert mat $60 \%$ fur oen Hotelberech und 80 s sur Tefoarage und Liden

- plis zisatipacht in Abhanggket vom Hote betrebsergebns

egentumertreundiche Nepenkosten. und instand. maltungregelungen
- Antanguvsischuttung 4\$ DA. - beginnend 1996 (mitantedigy

- durch sowige Sonder. abschretoung und weitere Werbungskosten attraktive Steuerersparnis bei der Einkommenstever und geningeres figenkapital dadurch Emohung der Rentabilitat

- Rusatich Steuerent. lastungseffekte bei der Vermogen, Erbschaft. und Schenkungsteuer: dadurch weitere tithohung der Rentabititat

- Werbungsiosten a $38.45 \%$ verteilt we folgt $21.34 \mathrm{~s}$ ant 1995 17.115 and 1996

- ergot bezogen aul die tinzatilung von $100 \%$ in 1995 21,34 und rusatrliche Wer. bungu osten won $17.11 \mathrm{~s}$ oer Beteligung on 1996 ohne Kaprailenzahiung 
Anlage 29

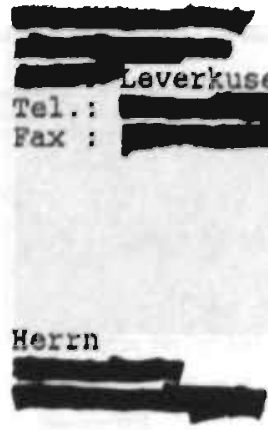

53175 BONN

Wirtschaftilchkeitsberechnung

\section{Sehr geehrter Herr}

nach unserem Telefonat vom 29.06.19915 ubbersende ich Ihnen zu Ihrer Information die wirtschaftlichkeitsberechnung des objektes;

Es handelt sich hier um ein 2 - Familianlandhaus mit 2 voneinander unsbhlingigen Wohneinheiten, die sleh steuerlich und bei. der Mieteinnahme positiv bemerkbar machen.

Um ein zahlenbeispiel darzustellen, habe ich Innen das objekt whthrend der Bauzeit und in der vermietungsphase berechnet.

Wie Sie aus den Berechnung und dem beigefugten Angebot der Lebensversicherung ersehen ist der Uberschuß in der Vermietungsphase so hoch, daß sie bei der angebotenen Tilgungsaussetzung in 13 Jahren. das Haus bezahlt haben, ohne selbst einen Beitrag von Ihren Nettogehalt zu leisten, wobei hier zu. Ihrer sicherheit eine Mietgarantie vereinbart ist.

Selbst die steuerersparnis in der Bauphase ist so hoch, da/3 Sie keinerlei Eigenkapital einsetzen müssen und noch ein tberschuß nach der Erbringung des Bigenkapitals vorhanden ist.

Bei Rückfragen stehe ich Ihnen gerne unter der $0 . g$. Telefonnummer zur Verfügung.

Ich melde mich am 01.07.1995 wahrend der Geschaftszeit bei Ihnen.

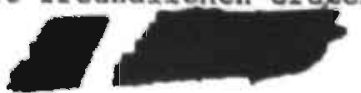


Kunde: Herr

Grundstūcksanteil

Gebaudeherstellungskosten

Gesamtkosten incl. Stellplatz + Garage
Objekt: 2-Familienlandhaus,

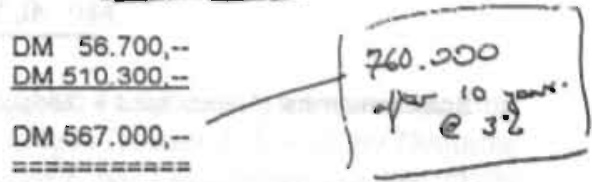

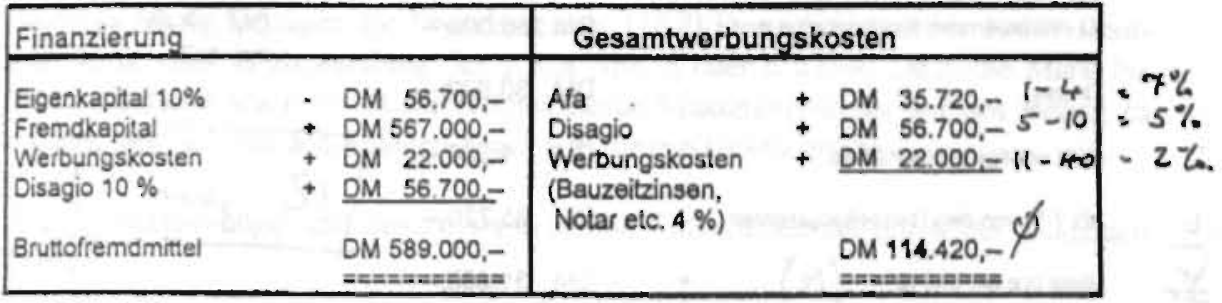

Finanzierungskonditionen: 5,25\% Zinsen $९ 0 \%$ Auszahlung 5 Jahre Festschreibung

\section{Erwerbsphase}

Werbungskosten gesamt

Werbungskostenautteilung

1995 DM 280.000,-- Einkommen Sp Steuern alt

DM 57.210,- Werbungskosten

DM 202.790,-- Einkommen nach
Werbungskosten
1995

1996
DM 114.421,-

DM 57.210,-

DM 57.210,-

DM 98.037,-.

incl. S.Z.

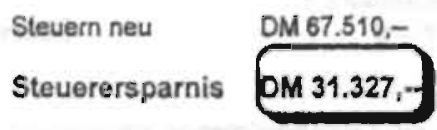

1996 DM 260.000,- Einkommeǹ Sp Steuern alt

DM 98.937,-

OM 57.210,- Werbungskosten

incl. $\mathbf{S . Z}$

DM 202.790,-- Einkommen nach

Werbungskosten

Stevern neu

Steuerersparnis

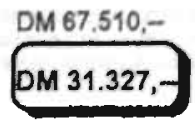

Gesamtsteuerersparnis

Egenkapital

OberschuBnach Erbringung des Eigenkapitals

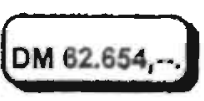

DM 56.700,Can pinance
DM 5.954,-- 


\section{Vermietungsphase}

\section{Bruttofremdmittel (Fremdkapital + Disagio) $\quad$ DM 589.000,--}

Botrag Steuern

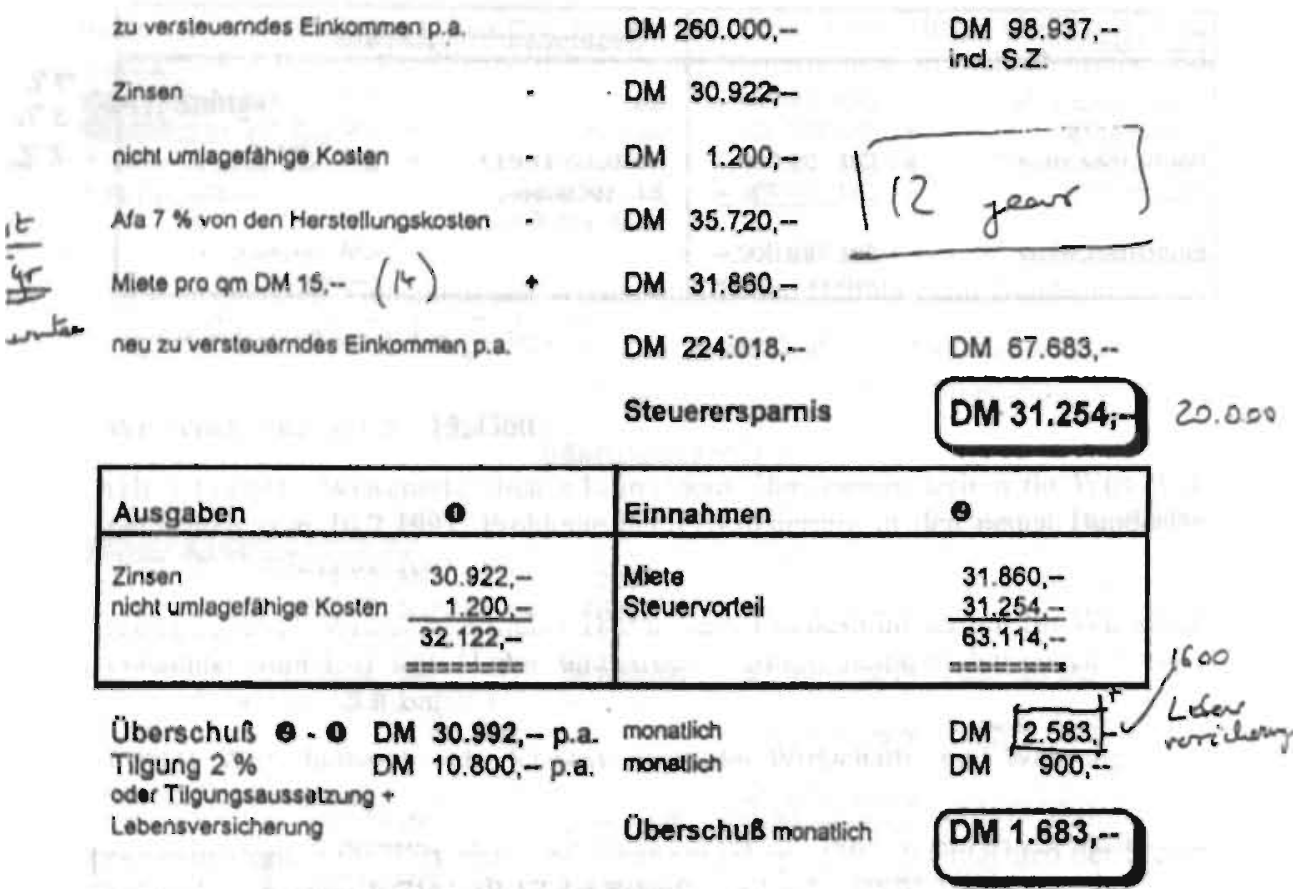

Es wird emplohlen eine Lebensversicherung abzuschließen, un die Stevervorteillo uber die Dauer des Darlehensvartrages in voller Holhe zu erhalten.

$$
\text { * }
$$

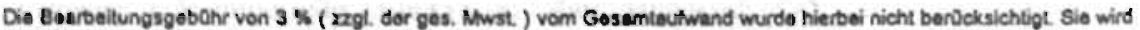
nech Nolarvertrug innertialls vor, 14 Tagen Iflig. .

Ala Angaben und Berechnungan wurden mit duBerster Sorgfalt zusammengestolit. Aus starndesrochtlichen Gründen weisen wir darauf hin, daל es sich nicht um pine stouediche Beratumg, sondem um eine Wirtschaftlichkeitsberechnung handelt, die zum Teil aul' Kundenangaben berulu und insolem die Richtigkeil nicht garantiert werden kann.

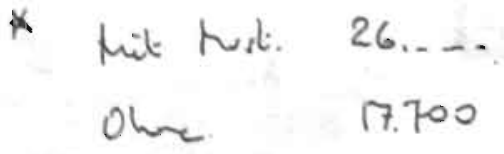




\section{Anlage 30}

§ 32 d EStG 1990 i. d. F. vom 23. Juni 1993

in: BGBI. I 1993, S. 944.

(1) Die festzusetzende Einkommensteuer ( $\$ 2$ Abs. 6) auf das zu versteuernde Einkommen betrăgt 0 Deutsche Mark bei Enwerbsbezugen (Absatz 2) bis 11069 Deutsche Mark und bei Anwendung des § 32a Abs. 5 oder 6 bei Erwerbsbezugen bis 22139 Deutsche Mark. Betragen die Erwerbsbezuge 11070 Deutsche Mark bis 13607 Deutsche Mark und bei Anwendung des § 32a Abs. 5 oder 622140 Deutsche Mark bis 27215 Deutsche Mark, so ist die festzusetzende Einkommensteuer auf den Betrag zu mildern, der sich aus den Anlagen 4 und 5 zu diesem Gesetz ergibt.

(2) Erwerbsbezuge sind das zu versteuernde Einkommen zuzuglich der folgenden Beträge:

(Hier folgt eine Aufzăhlung von 10 Positionen. Insoweit die relevanten Vorgănge nicht bereits aus der ESt-Erklärung des Steuerbärgers hervorgehen, sind die notwendigen Angaben in einer hierfur entwickelten Anlage E einzutragen, um eine Entlastung wegen niedrigen Erwerbseinkommens zu bewirken, - s. hierzu Anlage 31 -.) 


\section{Anlage 31}

Name und Vorname

Stevernummet

Anlage E

\section{zur Einkommensteuerenklärung}

Bette beschten Sle die Hinwesse auf der Ruckspite.

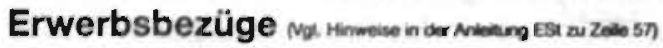

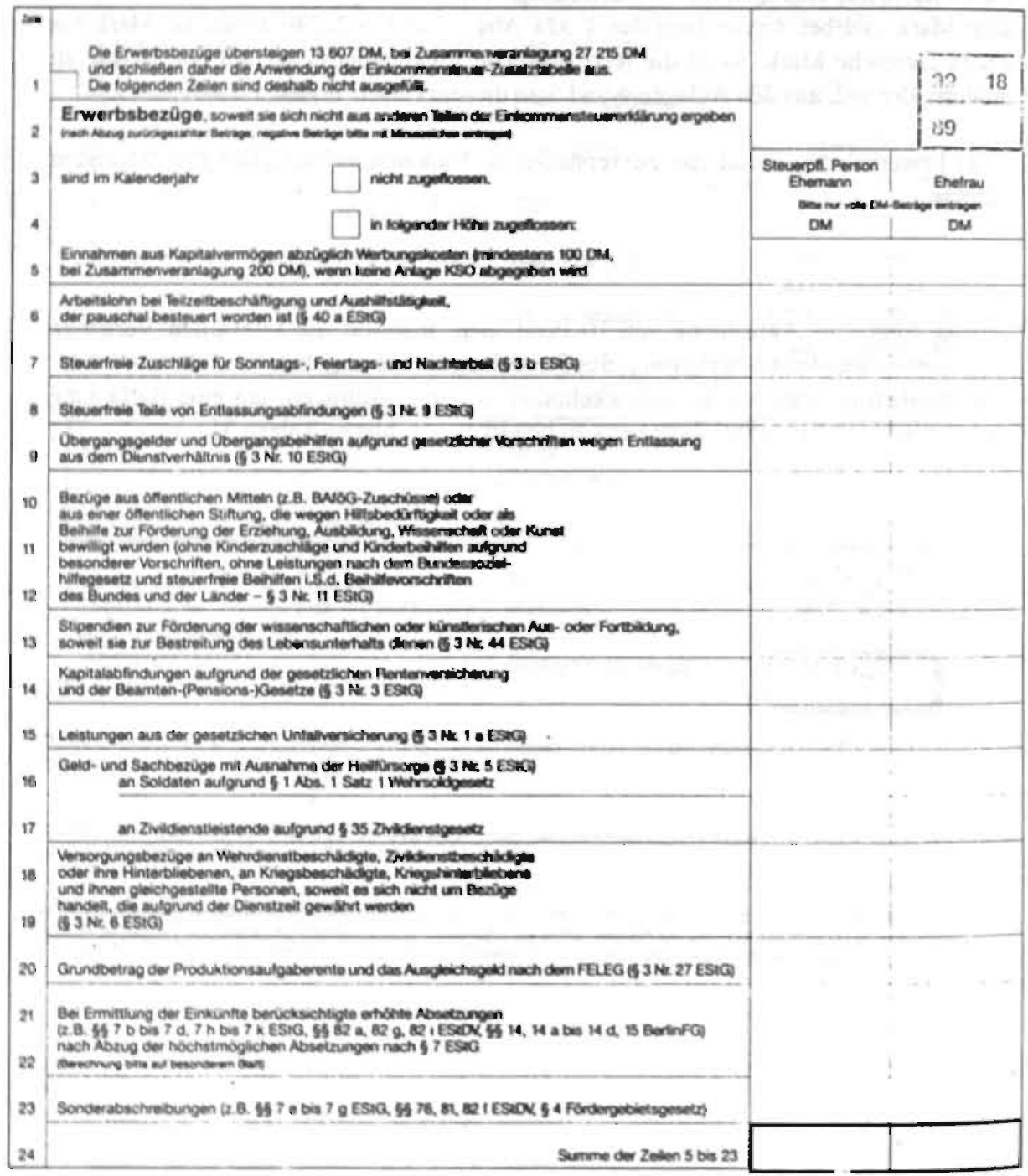




\section{Literaturverzeichnis}

"A" (anonym) (1920): Gerichtstage uber Erzberger, 19. Januar bis 12. Mărz 1920, Berlin.

Abgabenordnung 1992, Finanzgerichtsordnung. Handbuch des steuerlichen Verwalltungs- und Verfahrensrechts (= Schriften des deutschen wissenschaftlichen Steuerinstituts der Steuerberater und Stenerbevollmächtigten e. V.), München.

Abs, H.-J. (1980): Erfolgreiche Vermögensbildung in der Bundesrepublik, in: Kannengießer, W. (Hrsg.), S. 19

Änderungen des Einkommensteuergesetzes, des Berlinförderungsgesetzes und des Zonenrandforrderungsgesetzes durch das Steueründerungsgesetz 1991 (StÄndG 1991) vom 24.6.1991, in: BGBI. I S. 1322.

Albach, H./Beckmann, M. (1970): Zur Reform der direkten Steuern, Wiesbaden.

Alber, J. (1984): Versorgungsklassen im Wohlfahrtsstaat. Oberlegungen und Daten zur Situation in der Bundesrepublik, in: R. Lepsius (Hrsg.): Kölner Zeitschrift für Soziologie und Sozialpsychologie, 36. Jg., S. 225.

Albers, W. (1952): Soziale Sicherheit durch individuelle Vorsorge oder durch kollektive Maßnahmen?, in: Zeitschrift für die gesamte Staatswissenschaft, 108. Bd., Tubingen, S. 68.

- (1957/58): Die Berücksichtigung der Leistungsfahigkeit in der deutschen Einkommensteuer. Eine: Auseinandersetzung mit dem Beschluß des Bundesverfassungsgerichts zur Ehegattenbesteuerung und dem Regierungsentwurf zur Ānderung steuerlicher Vorschriften vorn 7. Mărz 1958, Finanzarchiv 18, S. 423.

- (1988): Steuerreserven in der deutschen Einkommensteuer, in: Finanzarchiv, Bd. 46, S. 172.

- (1989): Der Lastenausgleich. Rackblick: und Beurteilung, in: Finanzarchiv, N.F., Bd. 47, S. 272.

Albert, H. (1961): Die Problematik der okonomischen Perspektiven, in: Zeitschrift fur die gesamte Staatswissenschaft, 117. Bd. Tubingen, S. 438.

- (1967): Marktsoziologie und Entscheidungslogik, Neuwied.

- (1968): Sozialwissenschaft und politische Praxis. Bemerkungen zu Lompes Analyse des Problems der wissenschaftlichen Beratung der Politik, in: Archiv für Rechtsund Sozialphilosophie, Wiesbaden, S. 247.

- (1969): Traktat aber kritische Vernunft, 2. Aufl., Tabingen. 
- (1971): Theorie und Praxis. Max Weber und das Problem der Wertfreiheit, in: Albert, H./Topitsch, E.: Werturteilsstreit, Darmstadt.

- (1972): Erkenntnis und Recht. Die Jurisprudenz im Lichte des Kritizismus, in: H. Albert/N. Luhmann,W. Maihofer/O. Weinberger (Hrsg.): Rechtstheorie als Grund. lagenwissenschaft der Rechtswissenschaft, Dusseldorf, S. 80.

- (1972): Normativismus oder Sozialtechnologie? Bemerkungen zu Eike von Savignys Kritik, in: H. Albert/N. Luhmann/W. Maihofer/O. Weinberger (Hrsg.): Rechtstheorie als Grundlagenwissenschaft der Rechtswissenschaft, Düsseldorf, S. 109.

- (1976): Aufklärung und Steuerung, Hamburg.

- (1978): Traktat uber rationale Praxis, Tubingen.

Albert, H./Luhmann, N./Maihofer, W./Weinberger, O. (Hrsg.): Rechtstheorie als Grundlagenwissenschaft.

Albert, H./Topitsch, E. (Hrsg.) (1971): Werturteilsstreit, Darmstadt.

Albrecht, G. (1938): Gustav Schmollers Beitrag zur allgemeinen Steuerlehre, in: Schmollers Jahrbuch fur Gesetzgebung, Verwaltung und Volkswirtschaft im Deutschen Reich, 62. Jg., Leipzig.

Albrecht, G.IAmdt, H. (Hrsg.) (1953): Kapitalbildung und Kapitalverwendung. Verhandiungen auf der Tagung in Salzburg, Oktober 1952 (= Schriften des Vereins für Sozialpolitik.

Albrod, P. (1978): Zweifelsfragen zur einkommensteuerlichen Behandlung eines Liebhabereibetriebs, in: Deutsches Steuerrecht, Heft 19, S. 545.

Allgemeine Encyclopädie der Wissenschaften und Künste (1838), Leipzig.

Allgemeine deutsche Real-Encyclopädie fưr gebildete Stände (Conversations-Lexikon).

Allgemeine deutsche Real-Encyclopádie fur die gebildeten Stânde. ConversationsLexikon, (1852) Zehnte, verbesserte und vermehrte Auflage, Leipzig.

Allgemeines Landrecht für die Preußischen Staaten von 1794, hrsg. H. Hattenhauer, Frankfurt/M., 1970.

Altmann, S. P./Ashley, C. und andere (Hrsg.) (1908): Die Entwicklung der deutschen Volkswirtschaftslehre im neunzehnten Jahrhundert. Gustav Schmoller zur siebenzigsten Wiederkehr seines Geburtstages, 24. Juni 1908, 1. Teil, Leipzig.

Amerikanische Steuerreform (I) u. (II), Bericht des Stabs des gemischten Finanzausschusses des amerikanischen Repråsentantenhauses und des Senats, der die Steuerreformvorschläge analysiert, welche anlaßlich von Hearings, die vom 25,-27.9.1984 stattfanden, vom Haushaltsausschuß des Repräsentantenhauses zu erwägen waren, abers. Von W. E. Weisflog, in: Steuer und Wirtschaft $2 / 1985$, S. 160 u. 3/1985 S. 247.

Amonn, A. (1949:) Gerechtigkeit und Zweckmaßigkeit der Besteuerung, in: Probleme der offentlichen Finanzen und der Wăhrung. Festgabe furr Eugen Grossmann, Z0rich, S. 3. 
Andel, N. (1969): Zum Gesetz uber Maßnahmen zur außenwirtschaftlichen Absicherung, in: Finanz-Archiv, N. F., Bd. 28, Tabingen, S.401.

- (1970): Subventionen als Instrument des finanzwirtschaftlichen Interventionismus, Tubingen.

- (1980): Einkommensteuer, Handbuch der Finanzwissenschaft, 3. Aufl., Bd. 2, Tubingen, S. 331 .

- (1980): Einkornmensteuer, in: Handbuch der Finanzwissenschaft, Bd. II, Tubingen, S. 331 .

- (1987): Eine insgesarnt begrußenswerte Tarifanpassung, Zeitgespräch: Die "Große Steuerreform 1990", Wirtschaftsdienst IV, S. 171.

Anderson, V. (1965): Grundsatze ordnungsgemäßer Bilanzierung in der Rechtsprechung der Finanzgerichte, Heidelberg.

Andreae, C.-A./Keuschnigg, C. (1991): Einkommensteuerreform in Öterreich und der Bundesrepublik Deutschland, in: Steuerliche Vierteljahresschrift, Heft 2, S. 234.

Anhang zum Gesetz Nr. 64 zur vorlăufigen Neuordnung von Steuern vom 22.6.1948, in: Beilage zum Gesetz- und Verordnungsblatt des Wirtschaftsrates.

Anonym (1848): Die Vermögens- oder Einkommensteuer als Grundlage des Steuerwesens der Zukunft, in: Deutsche Vierteljahrs Schrift, 1. Heft, Stuttgart und Tubingen.

anonym (von einem Fachmann) (1906): Praktischer Steuerreklamant und Ratgeber für steuerzahlende Bürger nebst einem Anhang mit Mustereingaben aller Art, Einkommens- und Vermögensberechnungen, sowie vielen Formularen für Steuererklârungen, Reklamationen etc. und Notizen. Zum Gebrauch fur 5 Jahre eingerichtet. 2. Auflage. Bearbeitet nach dem neuen Einkommensteuer-Gesetz vom 19. Juni 1906., Mülheim a. d. Ruhr.

Anweisungen des Finanzministers zur Ausfuhrung des Einkommensteuergesetzes vom 24.6.1891 vom 5.8.1891, in: Gesetz-Sammlung, S. 175 (\$ 85 Abs. 1)

Archiv für Kuiturgeschichte: s. Goetz, W. (Hrsg.).

Amdt, H.W. (1981): Steuerliche Leistungsfahigkeit und Verfassungsrecht, in: J. Damrau/A. Kraft/W. Fürst (Hrsg.): Festschrift für Otto Mohl zum 70. Geburtstag 10. Oktober 1981, Stuttgart, S. 17.

- (1993): Existenzminimum und Einkommensteuerrecht, in Steuerliche Vierteljahresschrift, Heft 3, Herne, S. 1 - 11.

von Amim, H. H.(1977): Steuergesetzgebung aus der Sicht des Steuerzahlers, in: Steuer und Wirtschaft 3, S. 252.

- (1977): Gemeinwohl und Gruppeninteressen. Die Durchsetzungsschwäche allgemeiner Interessen in der pluralistischen Demokratie. Ein Beitrag zu verfassungsrechtlichen Grundfragen der Wirtschaftsordnung, Frankfurt/M.

- (1983): Alternativen wirtschaftspolitischer Steuerung, Anreize oder Gebote, in: K. H. Hansmeyer (Hrsg.): Staatsfinanzierung im Wandel, S. 727.

- (1984): Staatslehre der Bundeșrepublik Deutschland, München. 
- (1991): Möglichkeiten privatwirtischaftlich geplanter, finanzierter bzw. betriebener Infrastrukturvorhaben des Bundes im Verkehrsbereich innerhalb der verfassungs. und haushaltsrechtslichen Ordnung der Bundesrepublik Deutschland nach dem Beitritt der neuen Lănder. Eilgutachten für das Bundesministerium der Finanzen, Speyer.

von Amim, H. H./Litmann, K. (Hrsg.) (1983): Finanzpolitik im Umbruch: Zur Konsolidierung offentlicher Haushalte, Vorträge und Diskussionsbeiträge der 51. Staatswissenschaftlichen Fortbildungstagung 1983 der Hochschule für Verwaltungswissenschaften Speyer, Berlin.

von Amim, H. H./Klages, H. (Hrsg.) (1986): Probleme der staatlichen Steuerung und Fehlsteuerung in đer Bundesrepublik Deutschland, Vorträge und Diskussionsbeitráge der 54. Staatswissenschaftlichen Fortbildungstagung 1986 der Hochschule für Verwaltungswissenschaften Speyer, Schriftenreihe Band 101.

Assmann, E. (1989): Rechte und Mitwirkungspflichten beinn Erstellen von Geldverkehrs- bzw. Vermögenszuwachsrechnungen, in: Der Betrieb, S. 851.

- (1989): Die Geldverkehrsrechnung in der Außenprufungspraxis, in: Die Steuerliche Betriebsprufung, S. 252, S. 269 und (1990), S. 1.

Atkinson, A. B./Stiglitz J. E. (1980): Lectures on Public Economics, Maidenhead, Berkshire.

Ault, H. J. (1978): Möglichkeiten und Grenzen der Obertragung von Einkunttsquellen nach amerikanischem Steuerrecht, in: K. Tipke (Hrsg.): Ubertragung von Einkunftsquellen im Steuerrecht, Köln.

- (1980): Steuern in den USA, in: Hörstmann F. u. a. (Hrsg.), Steuerberater-Jahrbuch 1979/80, Köln, S. 512.

Ausfuhrungsanweisung zum Einkommensteuergesetz vom 19.6.1906 vom 25.7.1906, Amtliche Ausgabe, Berlin 1906.

Bach, S. (1991): Die Perspektiven des Leistungsfahigkeitsprinzips im gegenwärtigen Steuerrecht, in: Steuer und Wirtschaft 2, S. 116.

Bachem, K. (1929): Vorgeschichte, Geschichte und Politik der Deutschen Zentrumspartei, 6. Bd. (1931): 8. Bd., Köln.

Backhaus, J. (1991): Gemeinsamer Nenner. Die Gerichte stutzen sich bei ihren Entscheidungen immer häufiger auch auf ökonomische Argumente, in: WirtschaftsWoche, Nr. 10, S. 149.

- (1991): Systemwandel und Reform in östlichen Wirtschaften, Marburg 1991.

Badura, P. (1989): Die Verantwortung des Gesetzgebers, in: Jahrbuch für Rechtssoziologie und Rechtstheorie, Bd. 14, S. 246.

Ball, K. (1925): Steuerrecht und Privatrecht, in: Steuer und Wirtschaft, IV. Jg., Nr. 2, Stuttgart, Sp. 177.

- (1927): Organisationsprobleme der Finanzverwaltung. Ein Beitrag zur Verwaltungslehre, in: Vierteljahresschrift für Steuer- und Finanzrecht, 1. Jg., S. 523. 
- (1932): Zur Typisierungstheorie des Reichsfinanzhofs, in: Deutsche Steuer-Zeitung, XXI. Jg., S. 424.

Bank-Lexikon. Handwörterbuch für das Geld-, Bank- und Börsenwesen, 10. vollst. überarb. und erw. Aufl..

Bareis, H. P. (1986): Konzept für Schuldzinsenabzug, in: Steuer und Wirtschaft 2, S.117.

Bamelt, J. S. (1980): Die US-Bundessteuerverwaltung, in: DStR, S. 351.

Barth, K. (1953): Die Entwicklung des deutschen Bilanzrechts und der auf ihm beruhenden Bilanzauffassungen, handelsrechtlich und steuerrechtlich, Band I. Handelsrechtlich. Stuttgart.

- (1955): Die Entwicklung des deutsche Bilanzrechts und die ihm zugrundeliegenden Bilanzauffassungen handelsrechtlich und steuerrechtlich, Band II Steuerrecht, Stuttgart.

- (1970): Die betriebliche Besteuerung im Rahmen der gegenwärtigen Finanz- und Steuerpolitik, in: Der Betrieb, Nr. 47, S. 2189.

- (1973): Tendenzen zur Gesetzgebung in der rechtsprechenden Tâtigkeit des obersten Finanzgerichts, in: Finanzarchiv, S. 277.

Bauckner, A. (1919): Die Wertzuwachsbesteuerung in Deutschland, Diss., Würzburg.

- (1921): Der privatwirtschaftliche Einkommensbegriff, Munchen.

Bauer, E. (1925): Erzberger, Bilder aus seinem Leben und Wirken, Kämpfen und Leiden, Ludwigsburg.

- (1992): Neue Chancen für Investmentfonds. Das neue Investmentfondsgesetz, in: Zeitschrift für das gesamte Bank- und Börsenwesen, Wien, S 972

Baumdicker, G. (1984): Zur einkommensteuerrechtlichen Behandlung sog. hăuslicher Arbeitszimmer, in: Deutsches Steuerrecht, 22. Jg., Nr. 5, S. 129.

Bayer, H. W. (1975): Das System des Steuerrechts, in: Betriebs-Berater, Heft 13, S. 569.

- (1983): 175 Jahre Deutsches Einkommensteuerrecht, in: Finanz-Rundschau, 38. (65.) Jg., 4. Heft, Köln.

- (1983): Zum Systemgedanken des deutschen Einkommensteuerrechts, in: FinanzRundschau, 38. (65) Jg., Nr. 5, S. 105.

- (1988): Die Erwerbstatigkeit - der Steuergegenstand des Einkommensteuerrechts. Zugleich ein Beitrag zur Lehre vom Stufenbau des Steuertatbestandes, in: BetriebsBerater, 1. Teil in Heft 1, S. 1, 2. Teil in Heft 3, S.141, 3. Teil in Heft 4, S. 213.

- (1989): Der Bundesfinanzhof und das Steuerrecht, in: Juristen Zeitung, 44. Jg., Heft 12, S. 1095.

- (1991): 100 Jahre modernes preußisch-deutsches Einkommensteuerrecht 24.6.1891 -24.6.1991, in: Finanz-Rundschau Nr. 12, S. 333. 
- (1991): Der Mensch, sein Leben, sein Einkommen und das Einkommensteuerrecht. Thomas Oppermann zum 60. Geburtstag, in: Betriebs-Berater, Teil 1, Heft 7, S. 421, Teil 2 Heft 8, S. 517.

- (1992): Grundbegriffe des Steuerrechts. Eine Einfuhrung für Studenten der Rechtsund Wirtschaftswissenschaften, 4. völlig uberarbeitete und erweiterte Aufl.

Bebel, A. (1914): Aus meinem Leben, Stuttgart.

Becker, E. (1921): Die Reichsabgabenordnung vom 13. Dezember 1919 nebst Ausfuhnungsverordnungen. Erlauterte Handausgabe, Berlin.

- (1924): Zur Auslegung der Steuergesetze, in: Steuer und Wirtschaft, III. Jg., Nr. 2, Stuttgart, Sp. 146.

- (1925): Die neuen Steuergesetzentwürfe. Einführung, in: Steuer und Wirtschaft, IV. Jg., Nr. 3, Stuttgart, Sp. 353.

- (1925): Die neuen Steuergesetze, in: Steuer und Wirtschaft, IV. Jg., Nr. 9, Stuttgart, Sp. 1370.

- (1925): Rechtsnot und Rechtsschutz, in Steuer und Wirtschaft, IV. Jg., Sp. 547.

- (1926): Grundfragen aus den neuen Steuergesetzen, in: Steuer und Wirtschaft, V. Jg., Nr. 18, Stuttgart, Sp. 525.

- (1926): Reform der Reichsabgabenordnung? in: Deutsche Juristen-Zeitung, Heft 1, Sp. 20.

- (1927): Der Rechtsschutz in Steuersachen, in: Steuer und Wirtschaft, VI. Jg., Nr. 7, Stuttgart, Sp. 189.

- (1927): Zur Rechtsprechung. 5. Einkommensteuer, in: Steuer und Wirtschaft, 6. Jg., Sp. 1037.

- (1927): Grundfragen aus den neuen Steuergesetzen. Das Einkommensteuergesetz in der Rechtsprechung des Reichsfinanzhofs, in: Steuer und Wirtschaft, 6. Jg.: Sp. 383.

- (1927): Rundschau zur Rechtsprechung, in: Steuer und Wirtschaft, 6. Jg., Sp. 705.

- (1928): Handkommentar der Reichssteuergesetze (Besitz- und Verkehrssteuem), II Das Einkommensteuergesetz vom 10. August 1925, Stuttgart.

- (1928): Zur Rechtsprechung. 2. Einkommensteuer, in: Steuer und Wirtschaft, ?. Jg., Bd. I, Sp. 823

- (1929): Handkommentar der Reichssteuergesetze 1925, Teil II. Das Einkommensteuergesetz, Stuttgart.

- (1931): Zur wirtschaftlichen Einstellung der Rechtsprechung des Reichsfinanzhofs, in: H. Großmann (Hrsg.): Festschrift zum zehnjăhrigen Bestehen des SteuerInstituts an der Handels-Hochschule Leipzig, Berlin, S. 24

- (1932): Zur Rechtsprechung. A. Einkommensteuergesetz, in: Steuer und Wirtschaft, 11. Jg., Bd. 1, Sp. 805. 
- (1934): Zur Rechtsprechung. A. Zur Reichsabgabenordnung. Allgemeines Steuerrecht, in: Steuer und Wirtschaft, 13. Jg., Sp. 201.

- (1934): Steuerrecht und Privatrecht. Das Steuerrecht als selbstandiger Teil eines einheitlichen deutschen Rechts, in: Steuer und Wirtschaft, Sp. 299.

- (1935): Zum neuen Einkommensteuergesetz, in: Steuer und Wirtschaft, Teil I, 14. Jg., Sp. 1.

- (1935): Erlăuterungen zur Rechtsprechung. A. Einkommensteuergesetz, in: Steuer und Wirtschaft, 14. Jg. Sp. 779.

- (1936): Erlăuterungen zur Rechtsprechung. A. Allgemeines Steuerrecht. AO. Einkommensteuergesetz, in: Steuer und Wirtschaft, 15. Jg., Bd. 1, Sp. 513.

- (1937): Die Einheitlichkeit des deutschen Steuerrechts, in: Steuer und Wirtschaft, 16. Jg., Sp. 705.

- (1940): Die Grundlagen der Einkommensteuer, München/Berlin.

Becker, E./Dom, H./Hensel, A./Popitz, J./Lion, M. (Hrsg.) (1930): Die steuerliche Gleichheit vor dem Gesetz. Vorwort der Herausgeber zum vorliegenden Sonderheft, in: Vierteljahresschrift fur Steuer- und Finanzrecht, IV, S. 323.

Becker, E(rich) (1933): Deutsche Überseeschiffahrt (= Salz, A. (Hrsg.): Heidelberger Studien aus dern Institut fur Sozial- und Staatswissenschaften, Bd. III, Heft 4).

von Beckerath, E. (1912): Die preuBische Klassensteuer und die Geschichte ihrer Reform bis 1851 (Staats- und sozialwissenschaftliche Forschungen), hrsg. von G. Schmoller u. M. Sering, Heft 163, München und Leipzig.

- (1952): Die neuere Geschichte der deutschen Finanzwissenschaft. \& 1: Die Finanzwissenschaft in den ersten sechs Jahrzehnten des 19. Jahrhunderts. \& 2: Die Systeme der Finanzwissenschaft und die gleichzeitige monographische Literatur, in: Handbuch der Finanzwissenschaft, 1. Bd., Tubingen, S. 424.

von Beckerath, E./Meyer, F. W.IMüller-Armack, A. (Hrsg.) (1957): Wirtschaftsfragen der freien Welt. Zum 60. Geburtstag von Bundeswirtschaftsminister Ludwig Erhard, Frankfurt/M.

Begründung zum Entwurf eines Einkommensteuergesetzes vom 10.8.1925/ 19.12. 1925/26.2.1926 vom 23.4.1925, in: Finanzarchiv, 43. Jg., 1. Bd., S. 1906.

Behmauer, F. (1910): Der Streit uber die Steuerhinterziehungen in Preußen, in: Konservative Monatsschrift, 67. Jg., 2. Halbjahresbd., S. 675 - 805, S. 788; und (1910) in: Jahrbuch für Gesetzgebung, Verwaltung, und Volkswirthschaft im Deutschen Reich, 34. Jg., Leipzig, S. 113.

Beichelt, B./Bievert, B.IDaviter, J./ Schmölders, G./Strümpel, B. (1969): Steuernorm und Steuerwirklichkeit, Bd. II, Steuermentalităt und Steuermoral in Großbritannien, Frankreich, Italien und Spanien, Opladen 1969.

Beichelt, B. (1990): Funktion und Arbeitsweise des Finanzausschusses des Deutschen Bundestages, in: Deutsche Steuer-Zeitung, 78. Jg., Nr. 9, S. 213. 
Beisse, H. (1976): Grenzen der Gesetzesauslegung im Steuerrecht, in: Deutsches Steuerrecht, 14. Jg., Nr. 7, S. 176

- (1981): Auslegung, in: Handworterbuch des Steuerrechts, Munchen, 1. Bd., S. 134.

- (1984): Zum Verhalltnis von Bilanzrecht und Betriebswirtschaftslehre, in: Steuer und Wirtschaft $1, \mathrm{~S} .1$.

Bekanntmachung der neuen Fassung des Einkommensteuergesetzes vom 10.8.1949, in: Gesetzblatt der Verwaltung des Vereinigten Wirtschaftsgebietes, Nr. 31 vom 27.8.1949, S. 266

Bekanntmachung der Neufassung des Einkommensteuergesetzes vom 28.12.1950, in: BGBL. INr. 1, S. I.

Beker, M. (1978): Steuerrecht und Wirtschaftsordnung, 1. Aufl., Baden-Baden.

von Below, G. (1904) und (1905): Zur Wurdigung der historischen Schule der National-Okonomie, in: Zeitschritt fur Sozialwissenschaft, 3. u. 4. Jg.

Bericht der außerordentlichen Deputation der zweiten Kammer fur die Steuerreform. frage nber das Königliche Dekret Nr. 49 vom 8.2.1874, eingegangen am 2.5.1874, Săchs. Landtagsacten 1873/74, Berichte der 2. Kammer, Bd. I.

Bericht der IV. Kommission des Reichstags aber den Entwurf eines Gesetzes gegen die gemeingefahrlichen Bestrebungen der Sozialdemokratie (Vgl. "Annalen" $1878 \mathrm{~S}$. 989), in: Annalen des Deutschen Reichs, S. 27.

Bericht der Sachverstăndigenkommission für die Vereinfachung der Verwaltung beim Bundesministerium des Inneren, Bonn 1960.

Beske, S. (1962): Die Selbstberechnung der Einkommensteuer. Zum Versuch der Finanzïnter Celle und Stadthagen, in: Deutsche Steuerzeitung A, Nr. 24, S. 375.

Best, M. (1991): Die Gewinn- und Uberschußerzielungsabsicht als konstituierendes Merkmal der steuerbaren Tatigkeit, Diss. jur., Augsburg.

Beutel, F. K. (1971): Die Experimentelle Rechtswissenschaft, Möglichkeiten eines neuen Zweiges der Sozialwissenschaft, Berlin.

von Bibra, Th. (1952): Die Einkommensteuer in deutschen Lăndern bis 1918 und die volkswirtschaftliche Bedeutung dieser Steuer. Diss. phil., Erlangen.

Bickel, W. (1949): Die Steuer als Instrument des Einkommens- und Vermögensausgleichs. Eine dogmenhistorische Betrachtung, in: Probleme der offentlichen Finanzen und der Wahrung. Festgabe für Eugen Grossmann, Zürich, S. 15.

Biedenkopf, K.: (1985): Reform des Steuer- und des Sozialsystems, in: SteuerberaterJahrbuch S. 28.

- (1995): Emeuerung der Ordnungspolitik, in: Ludwig-Erhard-Stiftung (Hrsg.): Wirtschaftsordnung als Aufgabe. Zum 100. Geburtstag von Franz Böhm, Bonn.

Biergans, E./Stockinger, R. (1982): Zum Einkommensbegriff und zur persōnlichen Zurechnung von Einkünften im Einkommensteuerrecht (I), in: Finanz-Rundschau, 37. (64.) Jg., Heft 1, S. $1=7$; (II) in: Heft 2, S. 25. 
Biergans, E./Wasmer, C. (1985): Zum Tatbestand der Besteuerung und zum Leistungsfahigkeitsbegriff in der Einkommensteter, in: FinanzRundschau, Ni. 3, 40. (67.) Jg., S. 57.

Biersack, H. L. (1850): Ober Besteuerung, ihre Grundsătze und ihre Ausfulhrung, Frankfurt/M.

von Bilinski, L. (1876): Die Stellung der Vermögens- und Verkehrssteuern im Steuersysteme, in: G. Hirth (Hrsg.): Annalen des Deutschen Reichs, S. 719.

Bilsdorfer, P. (1992): Die Entscheidung des Bundesverfassungsgerichts zu den Grundfreibeträgen - Einladung zum Erlaß verfassungswidriger Gesetze?, in: Stenerbriefe, Heft 24, Freiburg, S. 1416.

Birk, D. (1983): Das Leistungsfähigkeitsprinzip als Maßstab der Steuernormen. Ein Beitrag zu den Grundfragen des Verhalltnisses Steuerrecht und Verfassungsrecht. Steuerwissenschaft Bd. 13, Köln.

- (1983): Zum Stand der Theoriediskussion in der Steuerrechtswissenschaft. Erwiderung zu Walter Leisner, Von der Leistung zur Leistungsfahigkeit - die soziale Nivellierung, in: Steuer und Wirtschaft 4, S. 293.

- (1989): Gleichheit und Gesetzmăßigkeit der Besteuerung. Zum Stellenwert zweier Grundprinzipien in der Steuerreform 1990, in: Steuer und Wirtschaft, 66. Jg., Nr. 3, S. 212 .

- (Hrsg.) (1989): Die Situation der Finanzgerichtsbarkeit. Münsteraner Symposion, Köln.

Bimbaum, K. (1872): Ober die Anwendbarkeit der Einkommensteuer und Steuerreformen uberhaupt, in: Georgika. Sammlung von Abhandlungen und Vorträgen für Landwirthe, Hrsg. K. Bimbaum, Bd. 3, 1. Heft, Leipzig.

Birtel, T. (1981): Das Ferienhaus in Spanien und die Liebhaberei, in: Deutsches Steuerrecht, Heft 23, S. 671.

Blaich, F. (1976): Die Grundsătze nationalsozialistischer Steuerpolitik und ihre Verwirklichung, in: Henning, T. W. (Hrsg.): Probleme nationalsozialistischer Wirtschaftspolitik, Berlin, S. 99.

Bleek, W. (1972): Von der Kameralausbildung zum Juristenprivileg. Studium, Prufung und Ausbildung der hơheren Beamten des allgemeinen Verwaltungsdienstes in Deutschland im 18. und 19. Jahrhundert, Berlin.

Blencke, H. (1979): Gestaltungsfreiheit im Steuerrecht und ihre Grenzen, Herne.

Bley, H. (1994): Leistungen der Sozialhilfe, in: Neue WirtschaftsBriefe, Heft 10, Fach 27, S. 4211 .

Blüher (ohne Vorname) (1913): Die Verwaltung der direkten Steuern im Königreich Sachsen, in: Deutsche Juristen-Zeitung, XVIII. Jg., Berlin.

Blum, W. (1969): Einfuhrung elektronischer Datenverarbeitung in die Finanzverwaltung des Landes Rheinland-Pfalz, in: Die Verwaltung, Bd. 2, S. 235. 
Blumenstein, E. (1930): Der Grundsatz der Gieichheit vor dem Gesetz im schweizerischen Steuerrecht, in: Vierteljahresschrift fur Steuer- und Finanzrecht, 4. Jg., Berlin, S. 323.

Blumers, W. (1987): Grenzen der Sachaufkläungspflicht in Steuererklărungen, in: Der Betrieb, Heft 16, S. 807.

Bobbio, N. (1965): Ober den Begrift der "Natur der Sache", in: A. Kaufmann (Hrsg.): Die ontologische Begrundung des Rechts, Darmstadt.

Bohm, F. (1933): Wettbewerb und Monopolkampf. Eine Untersuchung zur Frage des wirtschaftlichen Kampfrechts und zur Frage der rechtlichen Struktur der geltenden Wirtschaftsordnung, Berlin.

- (1946): Die Bedeutung der Wirtschaftsordnung für die politische Verfassung, in Suddeutsche Juristen-Zeitung, Nr. I, S. 141.

- (1948): Das Reichsgericht und die Kartelle, in: Ordo, 1. Bd., S. 197.

- (1950): Wirtschaftsordnung und Staatsverfassung, Túbingen.

- (1960): Reden und Schriften, Karlsruhe.

- (1961): Demokratie und okonomische Macht, in: Kartelle und Monopole im modernen Recht, Hrsg.: Institut für ausländisches und internationales Wirtschaftsrecht an der Johann-Wolfgang-Goethe-Universität, Frankfurt/M., Karlsruhe, Bd. 1, S. 3

- (1966): Privatrechtsgesellschaft und Marktwirtschaft, in: Ordo, Bd. XVII, S. 75.

Bohmert, V. (1898): Die Verteilung des Einkommens in Preußen und Sachsen, Dresden.

- (1891): Resultate der sächsischen Einkommensteuer von 1875 - 1884, in: Zeitschrift des Konnigl.-Sächs. Bureaus, 31. Jg., Dresden.

- (1891): Die săchsische Einkommensteuerstatistik von 1879 bis 1888, in: Zeitschrift des Königl.-Sächsischen Statistischen Bureaus, 35. Jg., Dresden.

Bolke, P. (1973): Geschăfte mit Berlin, München.

Börsen-Enquete-Kommission. Statistische Anlagen, Berlin 1893.

Boese, F. (1939): Geschichte des Vereins fur Sozialpolitik 1872 - 1932, Berlin.

Boesler, F. (1941): Stand und Aufgaben der Finanzgeschichtsforschung, in: Schmollers Jahrbuch für Gesetzgebung, Verwaltung und Volkswirtschaft im Deutschen Reiche, 65. Jg., 1. Halbband, S. 137.

Bottger, H. (1914): Kapitalauswanderung und Steuerhinterziehung, in: Deutsche Steuer-Zeitung, Jg. II. 1913-1914, Frankfurt/M., S. 52.

Bordewin, A. (1989): Leasingverträge in Handels- und Steuerbilanz, in: NWB, Fach 17, S. 975 .

Borm, K. E. (1985): Wirtschafts- und Sozialgeschichte des Deutschen Kaiserreichs $1867 / 71-1914$, Stuttgart. 
Bos, R.-W. (1988): Die Steuererklărung im internationalen Vergleich - BR Deutschland, Großbritannien, USA, Kanada, Australien -, Diss. jur., Köln.

- (1989): Ausgewăhlte Fragen zur Steuererklărung im internationalen Vergleich BR Deutschland, Großbritannien, USA, Kanada, Australien, in: Steuer und Wirtschaft, S. 267.

Bossart, A. (1872): Zur Reform des Systems der direkten Steuem in Preußen und Deutschland, Hannover.

von Bosse, H. A. (1890): Die Gemeindebesteuerung in Sachsen, Leipzig

Braeutigam, H. (1955/56): Wettbewerbsordnung - Steuerreform - Nationalbudget, in: Finanzarchiv, N. F., Bd. 16, Tubingen, S.81.

Brandenburg, H. B. (1985): Nießbratch an Privatgrundstūcken, Betriebsgrundstucken und Kapitalvermögen, Herne.

Brandenburg, H. B.IPetzold, R. (1984): Nießbrauch an Grundstucken des Privatvermögens, Betriebsvermögens und an Kapitalvermögen. Anpassung bestehender Verträge zum 31.3.1985, Gestaltungen für die Zukunft. Als Manuskript gedruckt, Herne.

- (1992): Liebhaberei aus Vermietung und Verpachtung, in: Neue WirtschaftsBriefe, F. 3, S. 8399.

Brandis, P. (1987): Einkommen als Rechtsbegriff, in: Steuer und Wirtschaft 4, S. 289.

- (1990): Drittaufwand als Aufwand des Steuerpflichtigen?, in: Steuer und Wirtschaft 1, S. 57.

Bredt, J. V. (1912): Die Besteuerung nach der Leistungsfăhigkeit. Ein Beitrag zur Systematik und Reform der direkten Steuern in Preußen und dem Reiche, Leipzig.

Brell, K.-H. (1957): Zur Problematik der progressiven Einkommensbesteuerung. Eine Antikritik zu F. A. Hayeks "Ungerechtigkeit der Steuerprogression" und C. Föhls "Kritik der progressiven Einkommensbesteuerung", Diss. rer. pol., Frankfur/M.

Brentano, L. (1931): Mein Leben im Kampf um die soziale Entwicklung Deutschlands, Jena.

Brinkmann, C. (1937): Gustav Schmoller und die Volkswirtschaftslehre, Stuttgart.

Brinkmann, J. A. (1982): Tatbestandsmåßigkeit der Besteuerung und formeller Gesetzesbegriff, Köln.

Brockhaus Enzyklopädie, 17. vōllig neubearbeitete Auflage des Großen Brockhaus, Wiesbaden 1972

Brüggemeier, G. (1982): "Wirtschaftsordnung und Staatsverfassung" - "Mischverfassung des demokratischen Interventionskapitalismus" - "Verfassungstheorie des Sozialstaates". Drei Modelle der Verflechtung von Staat und Wirtschaft? - Eine Problemskizze, in: Jahrbuch fur Rechtssoziologie und Rechtstheorie, darin: Rechtsformen der Verflechtung von Staat und. Wirtschaft, Bd. 8, S. 60 .

Brimmerhoff, D. (1996), Finanzwissenschaft, 7. Aufl., Munchen. 
Brunner, G. (1988): Gedanken uber Hans Kelsen und das Ostrecht, in: Festschrift der Rechtswissenschaftlichen Fakultăt zur 600-Jahr-Feier der Universităt zu Köln, Köln, S. 647.

Buchanan, J. M./Tollison, R. D./Tullock, G. (Eds.) (1980): Toward a Theorie of the Rent-Seeking Society. College Station: Texas.

Buchanan, J. M./Tullock, G. (1971): The Calculus of Consent, Ann Arbor, 4. Aufl., deutsch in: H. P. Widmaier (Hrsg.) (1974), S. 67.

Buchenberger, A. (1902): Finanzpolitik und Staatshaushalt im GroBherzogtum Baden in den Jahren 1850 - 1900. Zugleich ein Beitrag zur deutschen Finanzpolitik, Heidelberg.

Buck, L. (1909): Zui Besteuerung des land- und forstwirtschaftlichen Vermögens in Preussen (Novelle vom 26. Mai 1909), in: Finanz-Archiv, 26. Jg, 2. Bd., S.349.

- (1909): Die. Novelle zum preußischen Einkommensteuergesetz vom 19.6.1906 im Lichte der Rechtsprechung, in: Finanzarchiv, 26. Bd., S. 813.

- (1911): Die: weitere EntwickJung der Einkommen- und Vermögensbesteuerung in Preussen, in: Finanz-Archiv, 28. Jg., 1. Bd., S. 45, Stuttgart und Berlin.

- (1913): Der objektive Ertragswert als Bewertungsgrundlage der Vermōgensbesteuerung Preußens in der Rechtsprechung, des preussischen Oberverwaltungsgerichts, in: Finanz-Archiv, Stuttgart, S. 48.

- (1916): Die Besteuerung der Kriegsgewinne, in: Finanz-Archiv, 33. Jg., S. 1., Stuttgart.

- (1919): Zur Frage der Neuorganisation der Verwaltung der direkten Steuem in Preussen, in: Finanz-Archiv, 36. Jg., 2. Bd., S. 1.

Biahler, O. (1925): Die englische Einkommensteuer. Thr heutiger Stand und ihre Handhabung im Vergleich mir der deutschen Einkommensbesteuerung nebst Oberblick. uber das ganze englische Steuersystem, Berlin.

- (1927): Allgemeines Steuerrecht, Berlin.

- (1950): Die Ziele der organischen Steuerreform, in: Steuerberater-Jahrbuch 1949, Koln, S. 19.

- (1953): Steuerrecht, Bd. I, Allgemeines Steuerrecht, München.

- (1954): Popitz als Jurist, in: Finanz-Rundschau 23, S. 526.

Buschgen, H. E. (1967): Das Leasing als betriebswirtschaftliche Finanzierungsalternative, in: Der Betrieb, S. 473.

Bisschgen, H. E./Engenzinger, T. (1993): Privatwirtschaftliche Finanzienung und Erstellung von Verkehrsinfrastruktur-Investitionen, Frankfurt.

Bund der Steuerzahler (ohne Autorenangabe:) (1961): Sich selbst veranlagen, in: Der Steuerzahler, Mitgliederzeitschrift des Bundes der Steuerzahler, Juni 1961, S. 89.

Bund Deutscher Steuerbeamten (Hrsg.) (1970): Fünfzig Jahre deutsche Steuerfachverwaltung, Dusseldorf: 
- (1959): Vorschlăge zur Finanz- und Steuerreform, Schreiben an den Prăsidenten des Deutschen Bundestages, Juni 1959.

Bundesfinanzhof (1954): Urteil vom 9.6.1953 I 34/53 S, in: Sammlung der Entscheidungen des BFH, Bonn 1954.

- (1965): Urteil vom 27.8.1964 IV 204/62 U, in: Sammlung der Entscheidungen des BFH, Bonn 1965.

- (1969): Urteil vom 9.8.1968 VI R 220/66, in: BStB1 II, S. 6.

Bundes-Gesetzblatt des Norddeutschen Bundes (1870).

Bundesgesetzblatt, Jahrgănge 1949 und 1950, Hrsg. vom Bundesminister der Justiz, Bonn.

Bundesminister der Finanzen (Hrsg.): Zweiter Bericht aber die Automation der Steuerverwaltungen der Bundesländer, Deutscher Bundestag, 5. Wahlperiode, Drs. V/2749 vom 15. März 1968.

- (1966): Bericht uber die Entwicklung der sichtbaren und unsichtbaren Finanzhilfen des Bundes für die Jahre 1964 bis 1966, in: Drs. V/931.

- (Hrsg.) (1980): Geschäftsordnung für die Finanzämter (FAGO) nebst Ergänzungsbestimmungen, Nachdruck.

Bundesministerium der Finanzen (Hrsg.) (1964): Untersuchung zum Einkommensteuerrecht unter besonderer Berücksichtigung textkritischer, rechtssystematischer und verfassungsrechtlicher Gesichtspunkte, Bericht der Einkommensteuerkommission. Schriftenreihe des Bundesministeriums der Finanzen, Heft 7, Bonn.

- (Hrsg.) (1967): Gutachten zur Reform der direkten Steuern (Einkomrnensteuer, Körperschaftsteuer, Vermógensteuer und Erbschaftsteuer, erstattet vorn Wissenschaftlichen Beirat beim Bundesministerium der Finanzen, Schriftenreihe des Bundesministeriums der Finanzen, Heft 9.

- (Hrsg.) (1969): Von der Reichsschatzkammer zum Bundesfinanzministerium. Geschichte, Leistungen und Aufgaben eines zentralen Staatsorganes, bearb. von A. Pausch, Bonn.

- (Hrsg.) (1974): Der Wissenschaftliche Beirat beim Bundesministerium der Finanzen. Entschließungen, Stellungnahmen und Gutachten 1949 - 1973, Tübingen.

- (Hrsg.) (1987): Finanzbericht 1988, Bonn.

- (Hrsg.) (1988): Finanzbericht 1989, Bonn.

- (Hrsg.) (1988): Der Wissenschaftliche Beirat beim Bundesministerium der Finanzen, Gutachten und Stellungnahmen 1974 - 1987, Tubingen.

- (Hrsg.) (1991): Finanzbericht 1991, Bonn.

- (Hrsg.) (1991): Finanzbericht 1992, Bonn.

- (Hrsg.) (1992): Finanzbericht 1993, Bonn. 
- (Hrsg.): Bericht der Bundesregienung uber die Entwicklung der Finanzhilfen des Bundes und der Steuerverganstigungen fur die Jahre 1989 bis 1992 (Dreizehnter Subventionsbericht), Bonn.

- (Hrsg.) (1993): Stellungnahme des Wissenschaftlichen Beirats beim Bundesministerium der Finanzen zum Standortsicherungsgesetz, in: BMF Dokumentation 2/93.

- (Hrsg.) (1993): Entwicklung des Steueraufkommens und Oberlegungen zur Steuerschaltzung 1993, in: Finanzbericht 1993, Bonn, S. 96.

Bundesminister fur Jugend, Familie, Frauen und Gesundheit (Hrsg.) (1988): Wissenschaftlicher Beirat, Familienpolitik nach der Steuerreform, in: Schriftenreihe, Bd. 241, Stuttgant.

Bundesminister fur Wirtschaft (1991): Lohn- und Arbeitsmarktprobleme in den neuen Bundesländern, in: Bundesanzeiger Nr. 153, Jg. 43.

Bundesministerium fur Wirtschaft (1985): Steuerpolitik unter gesamtwirtschaftìichen Gesichtspunkten. Gutachten des Wissenschaftlichen Beirats beim Bundesministerium fur Wirtschaft, Studien-Reihe 49.

- (Hrsg.), (1950 bis 1990): Der Wissenschaftliche Beirat beim Bundesministerium fur Wirtschaft, Bănde í bis 13, Gottingen.

- (Hrsg.) (1991): Wissenschaftlicher Beirat beim Bundesministerium für Wirtschaft, Gutachten vom 16.2.1991, Probleme der Privatisierung in den neuen Bundesländern, in: Bundesanzeiger v. 16.3.1991, Nr. 53, S. 1873.

- (Hrsg.) (1991): Wissenschaftlicher Beirat beim Bundesministerium für Wirtschaft, Gutachten vom 15.7.1991, Lohn- und Arbeitsmarktprobleme in den neuen Bundesländern, in: Bundesanzeiger v. 17.8.1991, S. 5550.

- (1992): Wirtschaftspolitische Konsequenzen der Wirtschafts- und Wăhrungsunion, in: BMWi Studienreihe, $\mathrm{Nr}$. 79.

Bundesministerium fitr Wirtschaft und Finanzen (Hrsg.) (197I): Gutachten der Steuerreformkommission 1971, Heft 17 der Schrittenreihe des BMF, Bonn.

Bundesregierung (1975): Dritter Bericht uber die Automatisierung in den Steuerverwaltungen der Länder. Unterrichtung durch die Bundesregierung, Deutscher Bundestag/ 7. Wahlperiode, Drucksache 7/4406 vom 4.12.1975.

- (1987): Bericht der Bundesregierung aber die Entwicklung der Finanzhilfen des Bundes und der Steuervergunstigungen für die Jahre 1985 bis 1988 gemäß $\S 12$ des Gesetzes zur Förderung der Stabilităt und des Wachstums der Wirtschaft (StWG) vom 8. Juni 1967 (Elfter Subventionsbericht), in: Bundesrat Drucksache 530/87 vom 25.11.87.

Bundesverfassungsgericht (1974): Beschluß des Ersten Senats vom 17. Juli 1974 - 1 BvR. 51 160, 285/69, i BvL 16, 18, 26/72, in: Entscheidungen des Bundesverfassungsgerichts.

- (1987): Urteil des Ersten Senats vom 10.2.1987 - BvL 18/81 und 20/82, in: Entscheidungen des Bundesverfassungsgerichts, Tubingen 1987. 
- (1992): Beschluß des Ersten Senats vom 23.9.1992, 1 BvR 720/90, in: Entscheidungen des Bundesverfassungsgerichts, Tubingen 1993.

Bundesversamulung der Bundesrepublik Deutschland, Bericht uber die 1. Sitzung, Bonn, Montag, den 12. September 1949.

Bundsmann, E. (1912): Der Wertzuwachs an Liegenschaften und seine Besteuerung, Innsbruck.

Bunzel, G. (1903): Die Beziehungen der politischen Oekonomie zu den anderen Sozialwissenschaften, in: J. Conrad (Hrsg.): Jahrbuicher fur Nationalōkonomie und Staltistik, III. Folge, 26. Bd., S. 433.

Buob, H. (1977): Ein Beitrag zur steuerlichen Beurteilung von VerlustzuweisungsGesellschaften, in: Deutsche Steuer-Gewerkschaft (Hrsg.): Steuerwarte, 50. Jg., Dusseldorf, S. 125.

Burger, R. (1919): Entwicklung der Idee der Einkommensteuer und der Einkommensteuergesetzgebung in Deutschland, Diss. phil., Erlangen.

Burkart, K. (1874): Die Reform der directen Steuem, in: G. Hirth (Hrsg.): Annalen des Deutschen Reichs, Sp. 1681.

- (1876): Die bestehenden Einkommensteuern. Eine vergleichende Darstellung, im Auftrage des deutschen Steuer-Reformvereins bearbeitet, in: G. Hirth (Hrsg.): Annalen des Deutschen Reichs, S. 21 - 50, S. 682.

- (1877): Die bestehenden Einkommensteuern. Eine vergleichende Darstellung, im Auftrage des deutschen Steuer-Reformvereins bearbeitet, in: G. Hirth (Hrsg.): Annalen des Deutschen Reichs, Teil I, S. 219 - 227, (1879): Teil II in: Annalen des Deutschen Reichs 1879, S. 1.

- (1886): Zur sog. Meldeangabe bei der Veranlagung der persőnlichen Steuern in: Finanz-Archiv, 3. Jg., Stuttgart, S. 86.

Burmester, G. (1993): Begriff und Funktion des Steuergutes im Steuerrecht. Zur Bedeutung der Steuerguter für eine inner- und interstaatlich sachgerechte Steuerordnung, in: Steuer und Wirtschaft, Heft 3, S. 221.

Busch, U./Schrnidt, H. (1991): Theoretische Probleme der Transformation planwirtschaftlicher in marktwirtschaftliche Systeme, in: Backhaus, J. (Hrsg.): Systemwandel und Reform in ostlichen Wirtschaften, Marburg.

Canaris, C.-IW. (1993): Funktion, Struktur und Falsifikation juristischer Theorien, in: Juristen-Zeitung, Nr. 8, 48. Jg., S. 377.

Carl, D./Klos, J. (1993): Die neue Kontrollmitteilungsverordnung zu $\S 93 \mathrm{a} \mathrm{AO}$, in: Neue Wirtschafts Briefe, Fach 2, S. 6051.

Cash. Das exklusive Kapitalanlage-Magazin, Hamburg.

Cerutti (ohne. Vorname) (1931): Ein Beitrag zur Gleichheit vor dem Steuergesetz, in: H. Großmann (Hrsg.): Festschrift zum zehnjăhrigen Bestehen des Steuer-Instituts an der Handels-Hochschule Leipzig, Berlin, S. 46.

Chambers's Encyclopaedia (1950), New Edition, Vol. VII, London. 
Clemm, N. (1980): Das Berliner Modell - Gesetzeskonformer Weg oder Subventionsbetrug? in: Der Betrieb, Heft 14, S. 657.

Cołn, G. (1885): Grundlegung der Nationalökonomie. Ein Lesebuch für Studirende, Stuttgart.

- (1889): System der Finanzwissenschaft. Ein Lesebuch für Studirende, Stuttgart.

- (1891): Die Preußische Steuerreform, in: Jahrbücher für Nationalökonomie und Statistik, 3. Folge, Bd. 56, S. 20., Jena.

- (1908): Charakterzuge des amerikanischen Steuerwesens, in: G. Schmoller (Hrsg.): Jahrbuch für Gesetzgebung, Verwaltung und Volkswirtschaft im Deutschen Reich, 32. Jg., Leipzig, S. 1.

- (1911): Die Einkommensteuer in den Vereinigten Staaten von Amerika, in: Jahrbuch für Gesetzgebung, Verwaltung und Volkswirtschaft im Deutschen Reich, N.F., Hrsg. G. Schmoller, Heft 3, Leipzig, S. 1.

Colm, G./Neisser, H. (Hrsg.) (1930): Kapitalbildung und Steuersystem, in: Veröffentlichungen der Friedrich List-Gesellschaft e. V., 3. Bd.

Conrad, J. (1871): Die Revision der Gesetzgebung uber die direkten Steuern in Sachsen, in: Jahrbücher fur Nationalokonomie und Statistik, Bd. 16, Jena, S. 429.

- (1873): Die Revision der Gesetzgebung uber die direkten Steuern in Sachsen, in: Jahrbucher fur Nationalokonomie und Statistik, Bd. 20, Jena, S. 227.

- (1875): Das Königlich Sächsische Einkommensteuergesetz vom 22.12.1874, in: Jahrbücher für Nationalökonomie und Statistik, 24. Bd., Jena, S. 279.

- (1879): Die neueste Entwicklung der Steuergesetzgebung in Sachsen, in: Jahrbücher fur Nationalokonomie und Statistik, Bd. 32, S. 445.

Conversations-Lexicon, Neue Folge (1824), Leipzig.

Conze, A. G. (1966): Abgabenordnung und Finanzgerichtsordnung, in: Finanz-Rundschau 7, S. 130.

Castede, J. (1977): Mitunternehnerschaft und Betriebsaufspaltung bei der $\mathrm{GmbH}$ \& Still. Dogmatische und methodische Probleme des einkommensteueriichen Dualismus, in: Steuer und Wirtschaft 3, S. 208.

- (1978): Zentrale Fragen zum Steuerrecht gewerblicher A.bschreibungsgesellschaften, in: Steuer und Wirtschaft 1, S. 23.

Courth, P. (1987): Nur wenig Anlaß zur Euphorie, DStG studierte US-Steuerreform vor Ort, in: Die Steuer-Gewerkschaft, S. 137.

Cramer, K (1934): Wilhelm Hermanns Bedeutung für die Lehre vom Wert, Preis und Einkommen, Diss. Köln.

Crezelius, G. (1981): Verkappte Analogien in der Finanzrechtsprechung, in: Steuer und Wirtschaft 2, S. 117. 
- (1985): Das Verhăltnis des Steuerrechts zum Zivilrecht, in: Steuer und Studium, 6. Jg., Nr. 6, S. 162.

Czok, K. (Hrsg.) (1989): Geschichte Sachsens, Weimar.

Dalton, H. (1946): Principles of Public Finance, 7. ed., London.

Dann, W. (1987): Grußwort des Präsidenten der Bundessteuerberaterkarnmer, in: 25 Jahre Steuerberatungsgesetz, Deutsches Steuerrecht, 25.Jg., Beilage zu Nr. 3, S. I.

- (1993): Steuerchaos in Deutschland? in: Steuerberaterkammer Köln (Hrsg.): Mitteilungsblatt 4-6/1993, Köln, S. 3.

Das große Conversations-Lexicon fûr die gebilideten Stände (1840), Hildburghausen.

Das große Conversations-Lexicon für die gebildeten Stände (1846), Hildburghausen.

Das Staats-Lexikon. Enzyklopådie der sărntlichen Staatswissenschaften für alle Stände.

Daviter, J./Könke, J./Graf Schwerin, O. (1969): Steuernorm und Steuerwirklichkeit, Bd. 1, Steuertechnik und Steuerpraxis in Frankreich, Großbritannien, Italien und Deutschland, Opladen.

Debatin, H. (1957): Die Steuerverwaltung und das Besteuerungsverfahren der USA, in: Steuer und Wirtschaft, S. 484.

- (1988): Quellensteuer - ein trojanisches Pferd, Frankfurter Allgemeine Zeitung Nr. 19 vom 23.1.1988, S. 13.

Deklaration des Kriegsschuldenreglements, d. d. 23. Februar 1808, die abgeănderten Besteuerungsgrundsătze für die Haupt- und Residenzstadt Königsberg betreffend, 22. Mărz 1810, in: Sammlung der für die Königlich Preußischen Staaten erschienenen Gesetze und Verordnungen von 1806 bis 27. Oktober 1810, Berlin 1822.

von Delbrick, C. (1917): Die Ausbildung fiur den höheren Verwaltungsdienst in PreuBen, Jena.

Delbrück, H. (Hrsg.): Preußische Jahrbacher, Berlin.

Delbrück, H. (1891): Die Preußische Einkommensteuer-Reform 189| und der Bochumer Steuerprozess von 1891, in: Preußische Jahrbûcher, Bd. 68, S. 135.

- (1909): Volksvermögen und Steuerdeklarationen. Nachlaß-Steuer, in: Preußische Jahrbücher, Bd. 136, Berlin, S. 166.

- (1909/1910): Politische Korrespondenz, in: Preußische Jahrbucher, Bde. 134 - 138, S. a. Frhr: von Liebig, E. (1910): 139. Bd., S. 113.

- (1910): Die Regierung, die Parteien, die Finanzen, in: Preußische Jahrbacher, Bd. 139, Berlin, S. 379.

Der Platow Brief Spezial: Geschlossene Immobilienfonds. Jahrhundertgeschenk oder Zeitbombe? Wie trennen Sie die Spreu vom Weizen? November 1994, Frankfurt/Main.

Der Spiegel. Das Deutsche Nachrichten-Magazin, Hamburg.

Der Steuerzahler. Mitgliederzeitschrift des Bundes der Steuerzahler, Dusseldorf. 
Deutsche Bundesbank (1979): Zur Berücksichtigung der Geldentwertung bei der Besteuerung von Einkunften aus Kapitalvermögen. Gutachten der Deutschen Bundesbank vom 22. September 1977 für das Bundesverfassungsgericht, Monatsbericht 8/1979, S. 20.

- Geschäftsberichte.

- Monatsberichte.

Deutsche Reichsabgabenordnung vom 13.12.1919, in: RGBI. 1919, S. 1993.

Deutsche Steuer-Gewerkschaft (ohne Autorenangabe) (1986): Das Dilernma offengelegi. Bericht zur Lage der Steuerverwaltung, in: Die Steuer-Gewerkschaft, Mai 1986, S. 62.

- (1992): Protokoll über die Pressekonferenz des DSTG-Bundesvorsitzenden Erhard Geyer am 19.11.1992 (Bundespressekonferenz).

- (1993): Personallage in den Steuerverwaltungen der alten Länder im Haushaltsjahr 1991, in: Info, Nr. 1/93.

Deutsche Steuer-Zeitung, Jahrgang II. 1913 - 1914, Frankfurt/M.

- Jahrgang III. 1914 - 1915, Frankfurt/M.

Deutscher Bundestag (1949): Schreiben vom 21. April 1950: Alliierte Hohe Kommission für Deutschland. Der Rat. An den Kanzler der Bundesrepublik Deutschland, betr. Das Gesetz zur Änderung des Einkommensteuergesetzes und des Körperschaftsteuergesetzes, in: Drucksache Nr. 854, 1. Wahlperiode.

- (1950): Mündlicher Bericht des Ausschusses fur Finanz- und Steuerfragen (II. Ausschuß) uber den Entwurf eines Gesetzes uber die Finanzverwaltung, in: Drucksache Nr. 888.

- (1950): Stenographische Berichte, Bd. 2 und 3, in: Verhandlungen des Deutschen Bundestages, I. Wahlperiode 1949.

- (1954): Stenographische Berichte, Bd. 19, in: Verhandlungen des Deutschen Bundestages, 2. Wahlperiode, Bonn.

- (1962): Kleine Anfrage vom 11.5.1962 betr. Selbstberechnung der Einkommen- und Kärperschaftsteuer und Selbstveranlagung zu diesen Steuern, in: Bundestagsdrucksache IV/393.

- (1962): Antwort des Bundesministers der Finanzen vom 23.5.1962 auf die kleine Anfrage vom 11.5.1962, in: Bundestagsdrucksache IV/432.

- (1971): Steuerliche Bewertungsfreiheit (Sonderabschreibungen im Bereich der Deutschen Luftfahrt, in: Drucksache VI/1677.

- (1975): Bericht der Bundesregierung über die Entwicklung der Finanzhilfen des Bundes und der Steuervergünstigungen für die Jahre 1973 bis 1976 gemäß $\S 12$ des Gesetzes zur Förderung der Stabilităt und des Wachstums der Wirtschaft (StWG) vom 8. Juni 1967 (Funfter Subventionsbericht), in: Drucksache 7/4203 vom 22.10.75. 
- (1980): Gesetzentwurf der Bundesregierung. Entwurf eines Gesetzes zur Änderung und Vereinfachung des Einkommenteuergesetzes und anderer Gesetze, in: Drucksa-che $8 / 3688$ v. 21.02 .80 .

- (1980): Entwurf eines Gesetzes zur Änderung und Vereinfachung des Einkommensteuergesetzes und anderer Gesetze. (VII. Abschnitt und $\$ 48$ EStG), Dritte Beschlußempfehlung und Dritter Bericht des Finanzausschusses (7. Ausschuß), in: Drucksache 8/4007.

- (1986): Bericht der Bundesregierung uber die Entwicklung der Finanzhilfen und Steuervergünstigungen des Bundes in der Zeit von 1966 bis 1982, in: Drucksache $10 / 352$.

- (1993): Obersicht uber die Entwicklung der Finanzhilfen des Bundes in den Jahren 1989 bis 1992 (Subventionsbericht 1993), in: Drs. 12/1525.

- (1993): Steuerpolitik an den gesamtwirtschaftlichen Erfordernissen ausrichten, in: Drs. 12/4330, S. 16 - 17.

- (1993): Jahreswirtschaftsbericht 1993 der Bundesregierung, in: Drs.12/4330.

Deutscher Industrie- und Handelstag (Hrsg.) (1982): Gewerbesteuer auf neuem Kurs, Măngel beseitigen, Vorteile erhalten, DIHT 201, Bonn, I. Juni 1981.

- (Hrsg.) (1987): Gemeinsame Erklärung des BDI und des DIHT zu den Eckpunkten der Steuerreform, DIHT-Meinung, Bonn, S .63.

Deutsches Doppelsteuergesetz vom 22.3.1909, in: RGBI. Nr. 16, S. 332.

Deutsches Reichseinkommensteuergesetz vom 29.3.1920, in: RGBI. 1920, Nr. 57, S. 359 .

Deutsches Reichseinkommensteuergesetz vom 29.3.1920 unter Bericksichtigung der Abănderungsgesetze vom 24.3.1921, 11.7.1921 und 20.12.1921, in: RGBI. 1920, S. 428; RGB1. 1921, S. 313, S. 845, S. 1580.

Deutsches Reichsgesetz zur Oberleitung der Einkommensteuer und Körperschaftsteuer in das regelmåßige Veranlagungsverfahren (Steueruberleitungsgesetz) vom 29.5.1925.

Dickopf, J. (1990): Steuerberatung und steuerstrafrechtliche Risiken. Eine Untersuchung unter besonderer Berlicksichtigung der Steuerdeklarationsberatung, Diss, rer. pol., Köln.

Dictionary of National Biography (1885), Ed. by L. Stephen, London.

Die Personalbesteuerung. Gutachten auf Veranlassung der Eisenacher Versammlung zur Besprechung der sozialen Frage (= Schriften des Vereins für Socialpolitik, Bd. 3), Leipzig 1873.

Die preußischen Steuergesetzentwürfe von 1892, nebst Denkschrift und Begrundung (ohne Autorenangabe), Berlin 1892.

Die Steuerreform in Preußen (ohne Autorenangabe) (1894), in: Annalen des Deutschen Reichs, Jg. 1894, München, S. 63. 
Dieckmann, H. (1960): Johannes Popitz. Entwicklung und Wirksamkeit in der Zeit der Weimarer Republik (= Studien zur europäischen Geschichte aus dem FriedrichMeinecke-Institut der Freien Universităt Berlin, Bd. IV), Berlin.

Diefenbach, F. (1923): Armengesetzgebung und Armenpolizei in Deutschland, in: Handwörterbuch der Staatswissenschaften, 1. Bd., S. 967.

Diehl, K. (1924), in: Die Volkswirtschaftslehre der Gegenwart in Selbstdarstellungen, Hrsg. F. Meiner, Leipzig, S. 59.

- (1929): Zur neuesten Entwicklung der Lehre vom Einkommen und Ertrag, in: Schmollers Jahrbuch, 53. Jg., II. Halbbd., S. 901.

Diemer, A. (Hrsg.) (1977): Die Struktur wissenschafticher Revolutionen und die Geschichte der Wissenschaften. Symposion der Gesellschaft für Wissenschaftsgeschichte anlaßlich ihres zehnjährigen Bestehens 8.-10. Mai 1975 in Münster.

Dietzel, H. (1919): Englische und preußische Steuerveranlagung. Ein Vergleich des englischen mit dem preußischen System der Einkommensbesteuerung (Quellenprinzip contra Empfangerprinzip), in: Schriften des Vereins fur Socialpolitik, 157. Bd., hrsg. von H. Herkner, München und Leipzig.

van Dijk, J. E. A. M. (1978): Möglichkeiten und Ubertragung von Einkunftsquellen im niederlândischen Steuerrecht, in: K. Tipke (Hrsg.): Öbertragung von Einkunftsquellen im Steuerrecht, Köln, S, 167.

Doring, D./Spahn, P. B. (Hrsg.) (1991): Steuerreform als gesellschaftspolitische Aufgabe der neunziger Jahre, Berlin.

Donath, R. (1991): Die Betriebsaufspaltung, Steuerliche Grundlagenprobleme. Ausgewählte Fragen des Gesellschafts- und Konzernrechts, Heidelberg.

Donch, U. (1994): Jagd auf Besserverdiener. Höhere Steuern auf Einkommen, Vermögen und Erbschaft drohen. Besonders betroffen: Leistungstrăger - die sogenannten Besserverdiener, in: Focus. Das moderne Nachrichtenmagazin, Heft 15, S. 192.

Dom, H. (1933): Von Finanzen und Steuern einst und jetzt, zugleich eine Besprechung des Grabower'schen Buches "Preußens Stewern vor und nach den Befreiungskriegen", in: Steuer und Wirtschaft, 12. Jg., Stuttgart, Sp. 1.

Domfeld, R. (1974): Negatives Kapitalkonto, Abflußprinzip und Verlustbegrenzung bei vermögensverwaltenden Kommanditgesellschaften, in: Der Betrieb, Heft 50, S. 2373.

- (1976): Steuerliche Behandlung von Vermittlungsprovisionen, Aufgeldern und Konzeptionskosten bei Gesellschaften, die mit Verlustzuweisungen werden, in: Der Betrieb, Nr. 38, S. 1786.

Dreier, H. (1993): Hans Kelsen (1881-1973): "Jurist des Jahrhunderts"?, in: H. Heinrichs/H. Franzki/K. Schmalz/M. Stolleis (Hrsg.): Deutsche Juristen judischer Herkunft, München, S. 705.

Dreißig, W, (1984): Steuerpolitik im Zusammenhang mit der Wāhrungsrefom, in: W. A. S. Koch//H.-G. Petersen (Hrsg.): Staat, Steuern und Finanzausgleich. Probleme nationaler und internationaler Finanzwirtschaften im zeitlichen Wandel. 
Dröge (ohne Vorname) (1908): Die "Einkommensquelle", in: Preußisches Verwaltungs-Blatt, 29. Jg., S. 46.

Droste (ohne Vorname) (1897): Zur Auslegung des $\S 14$ des Einkommensteuergesetzes vom 24. Juni 1891, in: Verwaltungsarchiv, 5. Bd., Berlin, S. 543.

Dziadkowski, D. (1981): Kindergeld und Besteuerung nach der Leistungsfahigkeit, in: Betriebs-Berater, Beilage 9 zu Heft 24, S. 1.

- (1985): Plädoyer für einen transparenten und realitaatsbezogenen ("bürgernahen") Einkommensteuertarif, in: Betriebs-Berater, Beilage 9 zu Heft 15, 1. Hj.

- (1986): Grundfreibetrag und Einkommensteuertarif, in: FinanzRundschau, Heft 19, S. 504.

Eberhard (ohne Vorname) (1971): Zur großen Steuerreform. Vortrag, gehalten auf der Mitgliederversammlung des Instituts "Finanzen und Steuern" am 28. April 1971 in Bonn.

Ebnet, O. (1978): Die Besteuerung des Wertzuwachses. Ein theoretischer Ansatz im Rahmen der Einkommensbesteuenung, in: P. Eichhorn/P. Friedrich (Hrsg.): Schriften zur offentilichen Verwaitung und offentlichen Wirtschaft, Baden-Baden.

Eckhardt, W. (1962): Das Steuerrecht und die Einheit der Rechtsordnung, in: Steuerberater-Jahrbuch 1961/62, S. 77.

von Eheberg, K. T. (1909): Finanzwissenschaft, 10. verb. und stark verm. Aufl, Leipzig.

- (1911): Finanzwissenschaft, 11. Aufl. Leipzig, und: (1920): 14. und 15. Aufl., Leipzig; und alle weiteren Auflagen.

Ehlers, H. (1978): Durchsuchung - Beschlagnahme - Bankgeheimnis, in: BetriebsBerater, Heft 30, S. 1513.

Ehrenberg, R. (1904): Sozialreformer und Unternehmer, Jena.

- (1909): Die Katheder-Sozialisten und die Reichs-Finanzreform, Berlin.

- (1910): Terrorismus in der Wirtschafts-Wissenschaft, Berlin.

Ehrlich, E. (1911): Die Erforschung des lebenden Rechts, in: Jahrbuch für Gesetzgebung, Verwalitung und Volkswirtschaft im Deutschen Reich, 35. Jg., Leipzig, S. 129 .

- (1913): Grundlegung der Soziologie des Rechts, 1. Aufl., Berlin; 2. Aufl. 1929; 3. Aufl. 1967; 4. Aufl. 1989.

- (1916): Entgegnung, in: E. Jaffé (Hrsg.): Archiv furr Sozialwissenschaft und Sozialpolitik, Tubingen, 41. Bd., S. 844.

- (1918): Die juristische Logik, 1. Aufl., Wien; 2. Aufl. Tubingen 1925; Neudruck der 2. Aufl., Aalen 1966.

- (1922): Die Gesellschaft, der Staat und ihre Ordnung: in: E. Blankenburg u.a. (1992): Zeitschrift für Rechts-Soziologie, Jg. 13, Heft 1, S. 3. 
- (1967): Recht und Leben, Gesammelte Schriften zur Rechtstatsachenforschung und zur Freirechtslehre, Hrsg. von M. Rehbinder, Berlin.

Ehrlicher, W. (1968): Wandlung der Steuerordnung, in: Finanzarchiv, N. F., Bd. 27, S. 49.

Einkommensteuer, in: Handwörterbuch der Staats-Wissenschaften, 47. u. 48. Lieferung, Jena 1926.

Einkommensteuer-Durchführungsverordnung (EStDV 1949) vom 2.6.1949, in: Gesetzblatt der Verwaltung des Vereinigten Wirtschaftsgebietes, Nr. 22 vom 14.7.1949, S. 109.

Einkommensteuergesetz vom 22.12.1874, in: Gesetz- und Verordnungsblatt für das Königreich Sachsen, 24. Stück vom Jahre 1874, S. 471.

Einkommensteuergesetz vom 2.7.1878, in: Gesetz- und Verordnungsblatt fur das K0nigreich Sachsen, 1. bis 19. Stück, S. 129.

Einkommensteuergesetz vom 10.8.1925, in: RGBI. I Nr. 39, S. 189.

Einkommensteuergesetz (EStG) vom 16.10.1934, in: RGB1. I Nr. 119, S. 1005.

Einkommensteuergesetz (EStG 1939) vom 27.2.1939, in: RGBI. INr. 35, S. 297.

Einkommensteuergesetz (EStG 1951) vom 17.1.1952, in: BGBI. I Nr. 3, S. 33.

Einkommensteuergesetz (EStG 1953) vom 15.9.1953, in; BGBI. I Nr. 61 v. 19.9.1953, S. 1355 sowie alle weiteren Einkommensteuergesetze bis 1995.

Eichenberger, K./Novak, R./Kioepfer, M. (1982): Gesetzgebung im Rechtsstaat. Berichte und Diskussionen auf der Tagung der Vereinigung der Deutschen Staatsrechtslehrer in Trier vom 30.9. - 3.10.1981, in: Veröffentlichungen der Vereinigung der Deutschen Staatsrechtslehrer, Heft 40, Berlin/New York.

Eisele, P./Zimmermann, R. (Hrsg.) (1989): Steuerrecht im Wandel. Festschrift zum Bestehen der Fachhochschule für Finanzen Baden-Württemberg, Stuttgart.

Ellwein, Th. (1973): Formierte Verwaltung - Autoritäre Herrschaft in einer parlamentarischen Demokratie, in: Steffani, W. (Hrsg.), S. 48.

- (1983): Das Regierungssystem der Bundesrepublik Deutschland, 5. neubearb. Aufl., Opladen.

Elster, L. (1885): Die Jahresversammlung des Vereins für Socialpolitik im Oktober 1884, in: Jahrbuch fur Gesetzgebung und Verwaltung im Deutschen Reich, Leipzig. S. 285 .

Encyclopaedia Britannica, Dictionary of Arts and Sciences (1771), Edinburgh.

Encyclopaedia Britannica, Dictionary of Arts, Sciences and General Literature, 9. Ed, Vol. XXIII, Edinburgh.

Encyclopaedia Britannica (1973), Vol. 12, Chicago u. a.

Engel, D. (1974): Die Risiken einer Beteiligung an Verlustzuweisungskommanditgesellschaften, in: Die Wirtschaftsprufung, 27. Jg., Nr. 4, S. 101. 
Engel, E. (1875): Die Klassen- und klassificierte Einkommenstener und die Einkommensvertheilung im preussischen Staat in den Jahren 1852 bis 1872, in: Zeitschrift des Kóniglich Preussischen Statistischen Bureaus, 15. Jg., Berlin, S. 105.

von Engelhardt, D. (1979): Historisches Bewußtsein in der Naturwissenschaft von der Aufklărung bis zum Positivismus, München.

Engelhardt, W. W. (1969): Utopien als Problem der Wirtschaftswissenschaft, in: Zeitschrift fur die gesamte Staatswissenschaft, 125. Bd., Tubingen.

Engisch, K. (1935): Die Einheit der Rechtsordnung, Heidelberg.

- (1977): Einfuhrung in das juristische Denken, Stuttgart.

Engländer, O. (1914): Die Erkenntnis der Sittlich-Richtigen und die Nationalokonomie, in: Schmollers Jahrbuch für Gesetzgebung, Verwaltung und Volkswirtschaft im Deutschen Reiche, 38. Jg., 3. Heft, Leipzig, S. 397.

Entscheidungen des Bundesverfassungsgerichts, 26. Bd., Tübingen 1970.

Entscheidungen des Königlich Preußischen Oberverwaltungsgerichts in Staatssteuersachen, 4. Band, Berlin 1894; 4. Band 1896; 5. Band 1897; 7. Band 1899; 1. Band 1898; 8. Band 1900; 10. Band 1903; 11. Band 1904; 12. Band 1906; 13. Band 1909.

Entscheidungen Reichsgericht in Strafsachen, 7. Bd. 1883;29. Bd. 1897; 30. Bd. 1898; 31. Bd., 1899; 40. Bd. 1908; 41. Bd. 1909; 42. Bd. 1909

Entwurf eines Gesetzes die Einfühung einer allgemeinen Einkommensteuer in Baden betreffend v. 8.12.1883, in: Reg.Blatt 1848 Nr. LI, S. 279.

Entwurf eines Gesetzes betreffend Ergänzung und Abänderung einiger Bestimmungen uber Erhebung der auf das Einkommen gelegten direkten Kommunalabgaben vom 18.2.1884, in: Stenographische Berichte, Haus der Abgeordneten, Aktenstacke Nr 103 und 104 , S. 145.

Entwurf eines Einkommensteuergesetzes vom 3.11.1890, in: Finanz-Archiv, 2. Bd., S. 243, dazu Begriundung in: Finanz-Archiv, 2. Bd., S. 263.

Enzyklopådisches Lexikon für das Geld-, Bạk- und Börsenwesen, 3. Aufl., Frankfurt/A. $1967 / 68$.

Epstein, K. (1959): Matthias Erzberger and the Dilemma of German Democracy, Princeton, New Jersey.

Erard, B./Feinstein J. S. (1993): The Role of Mora! Sentiments and Audit Perceptions in Tax Compliance. Referat anl. $49^{\text {th }}$ Congress International Institute of Public Finance (IIPF), Berlin.

Erhard, L./Muller-Armack, A. (Hrsg.) (1972): Soziale Marktwirtschaft, Ordnung der Zukunft; Manifest '72, Frankfurt.

Erhard, L. (1975): Franz Bohms Einfluß auf die Politik, in: Sauermann, H./ Mestmăcker, E. J. (Hrsg.): Wirtschaftsordnung und Staatsverfassung. Festschrift für Franz Böhm zum 80. Geburtstag, Tubingen.

Erstes Gesetz zur Förderung des Kapitalmarkts vom 15.12.1952, in: BGBI. I Nr. 53, v. 16.12.1952, S. 793 . 
Erstes Gesetz zur Neuordnung des Geldwesens (Wăhrungsgesetz) vom 21.6.1948, in: Verordnungsblatt fur die Britische Zone, Nr. 27, Hamburg.

Erträge der Einkommensteuer im Königreich Sachsen, in: Annalen des Deutschen Reichs, Jg. 1879, S 1066.

Enberger, M. (1903): Die württembergische Steuerreform, in: Historisch-politische Blatter für das katholische Deutschland, 1. Heft, München, S. 380.

- (1904): Die Reichsfinanzreform, in: F. Binder/G. Jochner (Hrsg.): Historischpolitische Blätter, 130. Bd. 1. Heft, München, S. 685.

- (1919): Reden zur Neuordnung des deutschen Finanzwesens, Berlin.

Eschenburg, T. (1973): Matthias Erzberger Der große Mann des Parlamentarismus und der Finanzreform, München.

vam Essen, U. (1993): Tarifliche Änderungen bei der Einkommensbesteuenung durch das Standortsicherungsgesetz und das Geselz zur Umsetzung des fóderalen Konsolidierungsprogramms, in: Neue Wirtschafts Briefe, F. 3b, S. 4469.

Eucken, W. (1948): Das ordnungspolitische Problem, in: Ordo, 1. Bd., S. 56.

- (1948): Die soziale Frage, in: Synopsis, Alfred Weber, 30. VII 1868 - 30. VII 1948, Heidelberg, S. 111.

- (1950): Grundlagen der Nationalökonomie, 6. Aufl., Berlin.

Evans, E. L. (1981): The German Center Party 1870 - 1933, Southem Illinois University Press.

Evers, R. (1925): Der Entwurf des Gesetzes zur Ueberleitung der Einkommensteuer und Körperschafısteuer in das regelmäßige Verfahren (Steueruberleitungsgesetz), in: Steuer und Wirtschaft, 4. Jg., Sp. 375.

Evert, G. (1902): Socialstatistische Streifzüge durch die Materialien der Veranlagung zur Staatseinkommensteuer in Preussen von 1892 bis 1901, in: Zeitschrift des Kōniglich Preussischen Statistischen Bureaus, 42. Jg., Berlin, S. 245.

von Eynem, E. (1889): Zur Reform der direkten Steuern in Preußen. Gegen die Selbstdeklaration, Barmen.

Falk, L. (1962): Die Steuergesetzgebung in der offentlichen Kritik, in: SteuerberaterJahrbuch 1961/62, Koln, S. 27.

Feit, A. (1987): Entlastung der Finanzgerichte und Beschleunigung der Prozesse durch den 'Amtsrichter' in Steuersachen, in: Handelsblatt, Nr. 107 vom 5./6. 6.1987, S. 4.

Feldstein, M. (1976): On the Theory of Tax Reform. Journal of Public Economics, 6, S 77.

Felix, G. (1958): Praktikabilitătserwăgungen als Auslegungsgrundsatz im Steuerrecht, in: ders. (Hrsg.): Von der Auslegung und Anwendung der Steuergesetze, Stuttgart, 3. 124.

- (1965): Landwirtschaftliche Betătigung als Liebhaberei, in: Deutsche Steuer-Zeitung A, Nr. 21, S. 327 
- (1968): Bilanzierung von Leasing-Verträgen uber Immobilien beim Mieter, in: Betriebs-Berater, S. 196.

- (1979): Zur Zulässigkeit von Verwaltungsanweisungen uber die Nichtanwendung von Urteilen des Bundesfinamzhofs, in: Steuer und Wirtschaft, 56. Jg., Nr. 1, S. 65.

- (1980): Zum gesetzlichen Verbot, die Steuer zu umgehen, in: KÖSDI, Heft 1/80, S. 3606 .

- (1980): Neuorganisation der Finanzämter - Stellungnahmen und Chronik, in: KOSDI $3 / 80$, S. 3678.

- (1981): Ringsherum Rentenbetrug, in: KOSDI, Heft 1/81, S. 4009.

- (1981): Der Steufa-Berater im Richter-Talar oder An den Grenzen der Fachschriftstellerei aktiver Richter, in: KÖSDI, Heft 1/81, S. 4033.

- (1981): Einkommensteuer, in: Handwörterbuch des Steuerrechts, 1. Bd., 2. Aufl., München und Bonn, S. 394.

- (1990): Erwartungen des Mittelstandes an ein Steuersystem der neunziger Jahre, in: Deutsche Steuer-Zeitung 8, S. 184.

- (1990): Die Wende in der Einkommensteuer - Konsequenzen fur die Steuerberatung. Deutsche Steuer-Zeitung 19, S. 471.

Ferber, C. (1965): Der Werturteilsstreit 1909/1959. Versuch einer wissenschaftlichen Interpretation, in: E. Topitsch (Hrsg.): Logik der Sozialwissenschaften, Koln.

Fernow, A. (1891): Wie schätze ich mich ein? Ein allgemein verstăndlicher Ueberblick über die fur den Steuerpflichtigen wichtigsten Bestimmungen des neuen Einkommensteuergesetzes vom 24. Juni 1891, Frankfurt/Oder.

- (1892): Bin ich richtig eingeschátzt oder soll ich Berufung einlegen? Eine Anleitung für den Steuerpflichtigen zur Prüfung der Richtigkeit seiner Einkommensteuerveranlagung und zugleich eine Belehrung aber die zulässigen Rechtsmittel, Frankfurt/Oder.

Festschrift fur Eugen Schmalenbach (1933). Gewidmet von Schalem und vom Verlag, Leipzig.

Figge, H. (1990): Strategien von Leasinggesellschaften im EG-Binnenmarkt, in: E. Büschgen (Hrsg.) (1990): Der Finanzdienstleistungsmarkt in der Europäischen Gemeinschaft, Frankfurt/.

Findling, M. (1992): Die politische Ôkonomie der Steuerreform. Eine Untersuchung der politischen Grenzen von Steuerreformen unter besonderer Berücksichtigung der Steuerreform 1990. Diss. rer. pol.

Fischer, C. (1948): Der erste Schritt zur deutschen Steuerreform, in: Steuer und Wirtschaft, Sp. 511.

- (1949): Der zweite Schritt zur deutschen Steuerreform, in: Steuer und Wirtschaft, Sp. 579. 
Fischer, P. (1992): Innere Unabhăngigkeit und Fiskalinteresse, in: Deutsche Richterzeitung 12/92, S. 446.

- (1994): Die wirtschaftiche Betrachtungsweise, in: Neue WirtschaftsBriefe, Fach 2. S. 6143, Herne.

Fischer, R. (Hirsg.) (193I): Archiv für das Revisions- und Treuhandwesen, 27. Jg, Leipzig.

Flamig, C. (1984): Standort und Zukunft des steuerberatenden Berufs - Anforderungsprofile und Leistungsangebote, in: Deutsche Steuer-Zeitung, 72. Jg., Nr. 11, S. 263.

Focus, Das modeme Nachrichtenmagazin, München.

Fördergebietsgesetz. Gesetz uber Sonderabschreibungen und Abzugsbeträge im Fơrdergebiet vom 24.6.1991, in: BGBl. I S. 1331.

Fördergebietsgesetz. Gesetz über Sonderabschreibungen und Abzugsbeträge im Fördergebiet vom 23.9.1993, in: BGBI. IS. 1655.

Folkers, C./Pollak, H./Timm, H. (1987): Wandlungen der Besteuerung, Hrsg. K. Hău* ser, Berlin (= Schriften des Vereins für Socialpolitik, N.F., Bd. 160).

Folkers, C. (1988): Wer wird durch Steuervergünstigungen eigentlich begünstigt? Zu. einem Problem der materiellen Steuerinzidenz, in: Finanzarchiv, N.F., Bd. 46, S. 214.

Forschungsinstitut der Konrad-Adenauer-Stiftung (1991): Wahlergebnisse der Bundesrepublik Deutschland und in den Bundeslăndern 1946 - 1991 - insgesamt nach Alter und Geschlecht -, Stand Februar 1991, Bonn.

Forsthoff, E. (1943): Deutsche Gesichte von 1918 bis 1938 in Dokumenten, 3. Aufl., Stuttgart.

- (1977): Begriff und Wesen des sozialen Rechtsstaats.

Frank, P. (1952): Wahrheit, - relativ oder absolut, Zürich.

Franke, S. F. (1981): Entwicklung und Begründung der Einkommensbesteuerung, Darmsiadi.

- (1984): Zur politischen Funktion konsensmobilisierender Formeln in der parlamentarischen Demokratie: Das Beispiel des Leistungsfahigkeitsprinzips, in: Steuer und Wirtschaft 1, S. 32.

- (1990): Ókonomische und politische Beurteilung von Öko-Steuern, in: Steuer und Wirtschaft 3, S. 217.

Frankfurter Institut für wirtschaftspolitische Forschung (1983): Vorschläge zu einer "kleinen" Steuerreform (= Schriftenreihe Bd. 2), Frankfurt.

- (1986): Bürgersteuer. Ein Entwurf einer Neuordnung von direkten Steuern und Sozialleistungen (= Schriftenreihe Bd. 11), Frankfurt.

Franz, C. (1988): Einkommensbegriffe im Steuer- und Sozialrecht, in: Steuer und Wirtschaft 1,S. 17. 
Freye, G./Görlich, W.(1960): Steuerbegünstigte Kapitalanlage im Sozialen Wohnungsbau Berlin, Berlin.

Friauf, K. H. (1967): Sondersteuern als verfassungsrechtes Mittel zur Eindämmung des Strassen-Güterverkehrs?, in: Der Betriebs-Berater, Heft 33, 22. Jg., S. 1345.

- (1978): Möglichkeiten und Grenzen der Rechtsfortbildung im Steuerrecht, in: Tipke, K. (1982): Grenzen der Rechtsfortbildung durch Rechtsprechung und Verwaltungsvorschriften im Steuerrecht, S. 53.

- (1989): Verfassungsrechtliche Anforderungen an die Gesetzgebung aber die Steuern vom Einkommen und vom Ertrag, in: Steuerrecht und Verfassungsrecht (= Veroffentlichungen der Deutschen Steuerjuristischen Gesellschaft e. V., Bd. 12,) Köln.

Friauf, K. H./Hansmeyer, K.-H. u. a. (Hrsg.) (1971): Geleitwort der Herausgeber, in: Steuer und Wirtschaft, 1. (48). Jg. Nr. 1, S. 1.

Fricke, D. (1977): Die "heimlichen Steuererhöhungen", in: Steuer und Wirtschaft 3, S. 243.

Fricke, R. (1934): Die Problematik der direkten Einkommensbesteuerung als Grundlage künftiger Finanzreform. Eine Auseinandersetzung mit Adolf Lampe, in: Finanzarchiv, N. F., Bd. 2, S. 393.

Friedberg, R. (1878): Zur Theorie der Stempelsteuern, in: Jahrbücher für Nationalökonomie und Statistik, Bd. 31, Jena.

- (1897): Die franzōsische Einkommensteuer-Reform, in: Verwaltungsarchiv, 5. Bd., Berlin, S. 329.

- (1903): Über Spekulationsgeschäfte und deren Stellung im Einkommensteuegesetz vom 24.6.1891, in: Verwaltungsarchiv, 11. Bd., Berlin.

Fritsch, B. (1956): New Deal, in: Handwörterbuch der Sozialwissenschaften, Bd. 5.

Fuisting, B. (1891): Das Preußische Einkommensteuergesetz vom 24. Juni 1891 und die Ausführungsanweisung vom 5. August 1891 mit Erlāuterungen, Berlin.

- (1892): Das Preußische Einkommensteuergesetz vom 24. Juni 1891 und die Ausfuhrungsanweisung vom 5. August 1891 mit Erlăuterungen und einer Einileitung. Die geschichtliche Entwick]ung des Preußischen Steuersystems und systematische Dar. stellung der Einkommensteuer, Berlin.

- (1893): Die Preußische Gewerbesteuer in ihrer geschichtlichen Entwicklung und künttigen Verfassung, in: Verwaltungsarchiv, Zeitschrift fur Verwaltungsrecht und Verwaltungsgerichtsbarkeit, 1. Bd., Berlin.

- (1894): Das Preußische Einkommensteuergesetz vom 24. Juni 1891 und die Ausfuhrungsanweisung vom 5. August 1891 mit Erlāuterungen, Dritte umgearbeitete Auflage, Berlin.

- (1894): Die geschichtliche Entwicklung des Preußischen Steuersystems und systematische Darstellung der Einkommensteuer, Berlin.

- (1896): Der Rechtsschutz bei der Einkommensbesteuerung in Preußen, in: Verwaltungsarchiv, 4. Bd., Berlin, S. 293. 
- (1902): Die Grundzage der Steuerlehre, Berlin.

- (1902): Die Preußischen direkten Steuern. Grundzuge der Steuerlehre. 4. Band, Berlin.

- (1903): Die Einkommensbesteuerung der Zukunft in Anknuppfung an das Preußische Einkommensteuergesetz, Berlin.

- (1903): Die Reformbedurftigkeit des preussischen Einkommensteuergesetzes, in: Deutsche Juristen-Zeitung, VIII. Jg., Nr. 10, S. 229; Nr. 12, S. 281; Nr. 16/17, S. $380 ;$ Nr. 18, S. 409.

- (1905): Die Preußischen direkten Steuern, 2. Bd., Kommentar zum Ergănzungssteuergesetze, 2. Aufl., Berlin.

- (1906): Zur Besteuerung der Spekulationsgewinne nach dem preuß. Einkommensteuergesetze, in: Deutsche Juristen-Zeitung, XI. Jg., Nr. 21, Sp. 1170.

- (1906): Der Entwurf der Novelle zum preußischen Einkommensteuergesetz, in: Finanzpolitische Zeit- und Streitfragen, hrsg. von B. Fuisting, Heft 1 und Heft 2, Berlin.

- (1915): Einkommensteuergesetz. Nach dem Tode des Verfassers bearb. von Dr. jur. Strutz, Erste Halfte, Berlin.

Gaddum, J. W. (1986): Steuerreform: einfach und gerecht! Für ein besseres Einkommensteuerrecht, Stuttgart.

- (1986): Ist die US-Steuerreform ein Modell für die Bundesrepublik Deutschland?, Deutsche Steuer-Zeitung 9, S. 211.

Gäfgen, G. (1961): Die kurzfristige Diagnose von Inflationsursachen, in: Zeitschrift fur die gesamte Staatswissenschaft, 117. Bd., Tubingen, S. 468.

Gärtner, C. F. (1849): Versuche und Beobachtungen über die Bastarderzeugung im Pflanzenreich. Mit Hinweisen auf die ähnlichen Erscheinungen im Thierreiche, Stuttgart.

Gärtner, F. W. (1898): Ueber den Einkommensbegriff, in: Finanz-Archiv, XV. Jg., S. 31.

Gareis, C. (1879): Das Sozialistengesetz im Reichstag, in: Annalen des deutschen. Reichs, Leipzig.

Gattermann, H. H. (1985/86): Marktwirtschaftliche Steuerpolitik - Notwendigkeit und Chancen einer Neuordnung der Einkommen- und Körperschaftsteuer, Steuerberater Jahrbuch, S. 49.

- (1988): Aufgaben und Arbeitsstil des Finanzausschusses, in: Steuer und Wirtschaft, 65. Jg., Nr. 2, S. 170.

Gayl, K. (1905): Stadtische Finanzpolitik, in: Verwaltungsarchiv, Berlin, S. 33.

Geiger, W. (1934): Miquel und die preußische Steuerreform 1890/93, Diss. rer. pol., Tubingen. 
Geimer, R. (1988): Der Anwendungserlaß zur Abgabenordnung bei der Außenprufung, in: Die steuerliche Betriebsprufung, S. 133.

Geiss L./Wendt, J. (Hrsg.) (1973): Deutschland in der Weltpolitik des 19. und 20. Jahrhunderts. Fritz Fischer zum 65. Geburtstag, Dusseldorf.

Gemperli, A. (1923): Finanztheoretischer und finanzpolitischer Einkommensbegriff, Diss., Freiburg.

Gensel, J. (1873): Wie ist unsere bestehende directe Personalbesteuerung im Sinne der Gerechtigkeit und einer richtigen Wördigung der wirthschaftlichen Interessen am zweckmäßigsten zu reformieren?, in: Die Personalbesteuerung. Gutachten auf Veranlassung er Eisenacher Versammling zur Besprechung der sozialen Fragen (= Schriften des Vereins für Socialpolitik, 3. Bd)., Leipzig, S. 39.

- (1874): Die Steuerreform im Königreich Sachsen, in: G. Hirth (Hrsg.): Annalen des Deutschen Reichs, Sp. 1373.

- (1875): Die Steuerreform im Königreich Sachsen. Verhandlungen des Landtags 1873/74, in: G. Hirth (Hrsg.): Annalen des Deutschen Reichs, Sp. 1519.

- (1885): Die sắchsische Einkommensteuer in ihrer praktischen Anwendung, in: J. Conrad (Hrsg.): Jahrbücher fur Nationalókonomie und Statistik, N.F., 10. Bd., S. 489.

von Gerlach, H. (1910): Meine Erlebnisse in der Preußischen Verwaltung, Berlin.

- (1923): Erinnerungen eines Junkers, Berlin.

Gerlach, O. (1902): Zehn Jahre Rechtsprechung des Oberverwaltungsgerichts in Staatssteuersachen, in: Preußisches Verwaltungs-Blatt, Wochenschrift für Verwaltung und Verwaltungsrechtspflege in Preußen, 23. Jg., S. 785.

- (1905): Gemeindesteuerrecht, Dresden.

- (1906): Zur Reform der preußischen Einkommensteuer, in: Verwaltungsarchiv, Zeitschrift fur Verwaltungsrecht und Verwaltungsgerichtsbarkeit, hrsg. von $\mathrm{M}$. Schultzenstein und A. Keil, Bd. 14, Berlin, S. 429.

- (1908): Geschichte der Finanzwissenschaft unter besonderer Berücksichtigung der Lehre vom Verhältnis zwischen Volkswirtschaft, Staat und Finanzen, in: Festgabe für Gustav Schmoller zum 70. Geburtstag, Bd. I u. II, Berlin.

Gerloff, W. (1908): Verbrauch und Verbrauchsbelastung kleiner und mittlerer Einkommen in Deutschland um die Wende des 19. Jahrhunderts. Eine Konsum- und finanzstatistische Studie, in: Jahrbücher für Nationalokonomie und Statistik, III. Folge, 35 . Band, Jena.

- (1909). Beiträge zur Reichsfinanzreform, in: Jahrbücher fur Nationalókonomie und Statistik, III. Folge, 37. Bd., Jena.

- (1910): Verănderungen der Bevölkerungsgliederung in der kapitalistischen Wirtschaft, Berlin. 
- (1913): Finanz- und Zollpolitik des Deutschen Reiches nebst ihren Beziehungen zu Landes- und Gemeindefinanzen von der Gründung des Norddeutschen Bundes bis zur Gegenwart, Jena.

- (1913): Die Wertzuwachssteuer in Literatur und Gesetzgebung, in: Schmollers Jahrbuch, 37. Jg., S. 1485.

- (1927): Zur Geschichte der Entwicklung der Personalbesteuerung in Preussen, in: Zeitschrift fur die gesamte Staatswissenschaft, 82, Bd., 2. Heft, S. 384.

Gerstein, E. (1970): Die Frage der Vereinbarkeit der Besteuerung nach dem Verbrauch mit dem mit dem allgemeinen Gleichheitssatz (Art. 3 Abs. 11 GG), Diss. jur, Münster.

Gesellschaft zur Förderung der Entbürokratisierung e.V., Bonn (Hrsg.) (1984): Steuerreform durch Steuervereinfachung, Tagungsbericht vom 9. November 1984 über die gemeinsame Tagung des Präsidiums des Bundes der Steuerzahler e. V. und der Gesellschaft zur Förderung der Entbürokratisierung.

- (Hrsg.) (1994): Einsparungen durch einfaches Steuerrecht und effiziente Steuererhebung, Bericht aber das Symposium am 28. Februar 1994 der GFE und der Bundessteuerberaterkammer.

Gesetz, betreffend die Einfuhrung einer Klassen- und klassifizirten Einkommensteuer vom 1.5.1851, in: Gesetz-Sammlung für die Königlichen Preußischen Staaten 1851, Nr. 12, S. 193.

Gesetz, betreffend die Ergănzung des Einkommensteuergesetzes vom 30.12.1916, in: Preußische Gesetzsammlung 1917, Nr. 1, S. 1.

Gesetz, betreffend die Kommanditgesellschaften auf Aktien und die Aktiengesellschaften vom 18.7.1884, in: R.G.Bl. 1884, Nr. 22, S. 123.

Gesetzblatt der Verwaltung des vereinigten Wirtschaftsgebietes 1949.

Gesetz Nr. 64 zur vorlaufigen Neuordnung von Steuergesetzen vom 22.6.1948, in: Verordnungsblatt firr die britische Zone. Amtliches Organ zur Verkindung von Rechtsverordnungen der Zentralverwaltungen, Nr. 31, Hamburg.

Gesetz-Sammlung futr die K.oniglichen Preußischen Staaten 1842, 1851, 1861, 1873, Berlin.

Gesetz uber Darlehen zum Bau und Erwerb von Handelsschiffen vom 27.9.1950, in BGBI. Jg. 1950, S. 684.

Gesetz uber den vorlăufigen Aufbau der Wirtschaftsverwaltung des Vereinigten Wirtschaftsgebietes (amerikanisches und britisches Besatzungsgebiet in Deutschland (Öberleitungsgesetz) vom 9.8.1947, in: Gesetz- und Verordnungsblatt des Zweizonen-Wirtschaftsrates, Nr. 1, S. 1.

Gesetz über die Aktiengesellschaften vom 9.11.1843, in: Gesetz-Sammlung für die K.oniglich-Preußischen Staaten 1843, Nr. 31, S. 341.

Gesetz über die Steuerfreiheit einer Wohnungsbauanleihe der Kreditanstalt fur Wiederaufbau vom 10.8.1949, in: Gesetzblatt der Verwaltung des Vereinigten Wirtschaftsgebietes, Nr. 30, S. 1. 
Gesetz- und Verordnungsblatt des Wirtschaftsrates des Vereinigten Wirtschaftsrates (Amerikanisches und Britisches Besatzungsgebiet in Deutschland, Jg. 1947.

Gesetz- und Verordnungsblatt für das Königreich Sachsen vom Jahre 1874. 1. bis 24. Stück; vom Jahre 1878 1. bis 18. Stück, Dresden.

Gesetz zu dem Vertrag vom 31. August 1990 zwischen der Bundesrepublik Deutschland und der Deutschen Demokratischen Republik ober die Herstellung der Einheii Deutschlands - Einigungsvertragsgesetz - und der Vereinbarung vom 18. September 1990 vom 23.9.1990, in: BGBl. II, S. 885.

Gesetz zum Abbau von Hemmnissen bei Investitionen in der Deutschen Demokratischen Republik einschließlich Berlin (Ost) (DDR-IG) vom 26.6.1990, in: BGBI. I, S. 1143.

Gesetz zur Änderung des Einkommensteuergesetzes vom 1.2.1938, in: RGB1. I, S. 99

Gesetz zur Änderung des Einkommensteuergesetzes und des Körperschaftsteuergesetzes vom 29.4.1950, in: BGBll. Nr. 17, S. 95.

Gesetz zur Änderung und Ergänzung des Einkommensteuergesetzes vom 19.5.1953, in: BGBI. I, S. 222.

Gesetz zur Ändenung steuerliche Vorschriften und zur Sicherung der Haushaltfuhrung vom 24.6.1953, in: BGBI. I, S. 413.

Gesetz zur Förderung der Stabilităt und des Wachstums der Wirtschaft vom 8.6.1967, in: BGBI. I.

Gesetz zur Förderung der Wirtschaft von GroB-Berlin (West) vom 7.3.1950 sowie alle dazu ergangenen Ergănzungs- und Änderungsvorschriften, in: C. Hecker (1982), Abschreibungsgesellschaften in Berlin (West) Köln.

Gesetz zur Neuordnung von Steuern vom 16.12.1954, in: BGBI. I, S. 373.

Gesetz zur Regelung offener Vermōgensfragen vom 28.9.1990, in: BGBI. II, S. 1159.

Gesetz zur Uimsetzung des Föderalen Konsolidierungsprogramms (FKPG) vom 23.6.1993, in: BGBI. I, S. 944.

Gesetz zur Verminderung der Arbeitslosigkeit. Vom 1. Juli 1933, in: RGBI. INr. 60 v. 2.6.1933, S. 323.

Geyer, E. (1949): Steuerpolitik und Konjunkturpolitik, in: Probleme der offentlichen Finanzen und der Wăhrung. Festgabe für Eugen Grossmann, Zürich, S. 68.

Geyler, F. (1931): Steuer, Besteuerung und Steuertatbestand als Grundbegriffe des Doppelbesteuerungsrechts, in: Festschrift zum zehnjăhrigen Bestehen des SteuerInstituts an der Handels-Hochschule Leipzig, Berlin, S. 62.

Giering, H.-P. (1972): Die stille Gesellschaft im Einkommen- und Gewerbesteuerrecht, Diss. rer. pol., Mainz.

Giersch, H. (1977): Konjunktur- und Wachstumspolitik in der offenen Wirtschaft. Allgemeine Wirtschaftspolitik, Zweiter Band, Wiesbaden.

Giloy, J. (1978). Vieldeutige Einkommensbegriffe, Herne. 
- (1986): Ist der Grundfreibetrag im Einkommensteuertarif wirklich entbehrlich?, in: FinanzRundschau 3, S.56.

- (1989): Reform der Unternehmensbesteuenung, Deutsche Steuerzeitung, 22, S. 547.

- (1991): Zur künftigen Besteuerung der Kapitalerträge, in: Finanz-Rundschau 16, S. 482.

Gischler, E. (1955): Das Einkommen als Ausdruck der steuerlichen Leistungsfahigkeit, Diss. rer. pol., Köln.

Glaser, J. (1883): Handbuch des Strafprozesses, 1. Bd., Leipzig.

Goetz, W. (1938) (Hrsg.): Der Briefwechsel Gustav Schmoller mit Lujo Brentano, in: Archiv fur Kulturgeschichte, XXVIII Bd., Weimar, S. 316; (1939), XXIX Bd., S. 147; (1941), S. 142.

Goldscheid, R. (1928): Steuerverwendung und Interessenpolitik, in: W, Lotz (Hrsg.): Finanzwissenschaftliche Untersuchungen (= Schriften des Vereins für Sozialpolitik, 174. Bd.), S. 8, München und Leipzig.

Gosch, D. (1990): Vermōgensverwaltung statt gewerblichen Grundstückhandels dank Realteilung? Zugleich Anmerkungen zum BFH-Urteil vom 22.3.1990, IV R 23/88, in: Deutsches Steuerrecht 19, S. 585.

Gotthardt, G. (1917): Kriegsfragen der Steuerpolitik, in: Annalen des Deutschen Reichs, München, S. 274.

Grabein, M. (1895): Beiträge zur Geschichte der Lehre von der Steuerprogression, in: Finanzarchiv, 12. Jg., 2. Bd., S. 1

Grabower, R. (1927): Die Buch- und Betriebsprufung im Ausland, in: Steuer und Wirtschaft, VI. Jg., Sp. 813.

- (1931): Die steuerliche Buch- und Betriebsprufung im Ausland, in: Steuer und Wirtschaft, Bd. I, X. Jg, Sp. 1241.

- (1932): Preußens Steuern vor und nach den Befreiungskriegen, Berlin.

- (1932): Die Stellung der Buch- und Betriebsprufung im Steuerwesen, in: Paul Deutsch (Hrsg.): Festgabe für Hermann Grossmann zum 60. Geburtstag am 5. Oktober 1932 .

- (1933): Die ethische Betrachtungsweise im Steuerrecht, in: Steuer und Wirtschaft, 12. Jg., Sp. 49.

- (1953): Steuerliches Prufungswesen, in: W. Gerloff/F. Neumark (Hrsg.): Handbuch der Finanzwissenschaft, 2. Aufl., Tubingen.

- (1954): Persōnliche Erinnerungen an Johannes Popitz, in: Finanz-Rundschau 23, S. 516

- (1956): Zur steuerlichen Betriebsprufung (Zugleich eine Besprechung des Buches von Arnulf Gnam "Die Betriebsprufung", Stuttgart 1955), in: Steuer und Wirtschaft I, Sp. 605. 
- (1959): Zur ethischen Betrachtungsweise im Abgabenrecht, in: Steuer und Wirtschaft, Teil 1, Sp. 561.

- (1962): Bismarck und die Steuem. Zugleich ein Beitrag zur Lehre von der Tradition im Steuerwesen, in: Finanzarchiv, N.F. Bd. 22, S. 377 - 461, Tubingen.

- (1963): Enno Becker und die Betriebsprufung, in: Steuer und Wirtschaft, Sp. 39.

Graepel, P. H. (1978): Carl Friedrich von Gărtner (1772 - 1850), Familie - Leben Werk. Ein Beitrag zur Geschichte der Sexualtheorie und der Bastarderzeugung im Pflanzenreich, Diss. Marburg.

Grätzer, R. (1884): Zur Geschichte der preußischen Einkommens- und Klassensteuer, Berlin.

Grau, W. (1929): Einkommensteuer und Kapitalbidlung, in: Der Deutsche Volkswirt, S. 239.

Greim-Kuczewski, P. (1989): Die preußische Klassen- und Einkommensteuergesetzgebung im 19. Jahrhundert, Köln.

Grimmer, K./Lenk, K. (1978): Datenverarbeitung und Rationalisierung in der Steuerverwaltung. Ein Projektbericht, in: C. Böhret (Hrsg.): Verwaltungsreformen und Politische Wissenschaft, Baden-Baden, S. 141.

von der Groeben, K. (1975): Die Verwaltung der direkten Steuem in Preußen, in: Die Verwaltung, Zeitschrift für Verwaltungswissenschaft, 8. Bd., S. 512.

Groh, M. (1984): Gewinnerzielungsabsicht und Mitunternehmerschaft. Anmerkungen zum Beschluß des Großen Senats des BFH vom 25.6.1984 GrS 4/82, in: Der Betrieb, Heft 47, S. 2424.

Große, Th. (1990): Probleme bei der Geburt von Steuerbescheiden. Ober das interne Entstehen und die ordnungsmåßige Bekanntgabe von Steuerbescheiden, in: Deutsche Steuer-Zeitung, 78. Jg., Nr. 13 - 14, S. 348.

Grossekettler, H. (1987): Der Beitrag der Freiburger Schule zur Theorie der Gestaltung von Wirtschaftssystemen, Münster.

- (1995): Franz Bōhm als Protagonist einer ökonomischen Theorie der Gesetzgebungslehre, 1. vorl. Fassung, Manuskript.

Großfeld, B. (1981): Die Einkommensteuer. Geschichtliche Grundlage und rechtsvergleichender Ansatz. in: Recht und Staat in Geschichte und Gegenwart. Eine Sammlung von Vorträgen und Schriften aus dem Gebiet der gesamten Staatswissenschaften, Bd. 504/505, Tubingen.

Grin, W. H. (1994): Der Clan der Steuer-Haie, Berlin/Frankfurt.

Gumpel, H. J. (1989): Die Grundprobleme der Personengesellschaft aus der Sicht des Steuerrechts der Vereinigten Staaten, in: K. H. Friauf (Hrsg.): Steuerrecht und Verfassungsrecht, Ko.ln.

Guth, F. (1869): Die Lehre vom Einkommen in dessen Gesammtzweigen. Aus dem Standpunkte der Nationalōkonomie nach einer selbststăndigen theoretisch-practischen Anschauung, Prag. 
Gutmann, G. (1976): Die Wirtschaftsverfassung der Bundesrepublik Deutschland, Stuttgart.

Hackmann, J. (1986): Analyseprobleme einer Erörterung der Einkommensqualität unrealisierter Wertsteigerungen, in: Finanzarchiv, N.F., Bd. 44, S. 241.

Hainser, K. (1966): Das dritte Reich und der zweite Weltkrieg, in: Stolper, G. u. a.: Deutsche Wirtschaft seit 1870, 2. Aufl., Tubingen, S. 147.

- (1975): Abriß der geschichtlichen Entwicklung der offentlichen Finanzwirtschaft, in: Handbuch der Finanzwissenschaft, 3. Aufl., Tübingen, S. 44.

- (1991): Adolph Wagner - Leben und Werk, in: Wagner, A. (1991) FaksimileAusgabe der Grundlegung der politischen Oekonomie, Dusseldorf, im Manuskript eingesehen.

- (1993): Ausgleichsforderungen und Währungsreform. Stationen der Bankgeschichte, Beilage zum Geschäftsbericht 1992 der BHF-Bank, Frankfurt.

Hagedom, W. (1987): Vorteile und Mängel der geplanten Steuerreform - Aus der Sicht von Gewerkschaften, ifo-Schnelldienst 16-17, S. 15.

$H a h n$, H. (1980): Gleichheit und Gleichartigkeit im Steuerrecht. Einige Bemerkungen zu den Zweitwohnungsteuerurteilen des Bundesverfassungsgerichts, in: Deutsches Steuerrecht, Heft 8, S. 215.

- (1984): Die Grundsătze der Gesetzmäßigkeit der Besteuerung und der Tatbestandsmaßigkeit der Besteuerung in rechtsvergleichender Sicht, Berlin.

Halfar, B. (1991): Einhundert Jahre moderne Einkommensteuer. Bericht über die Tagung des Instituts für Finanz- und Steuerrecht der Universität Osnabrück am 24.6.1991, in: Steuer und Wirtschaft 4, S. 397.

Haller, H. (1971): Steuerreform, in: Steuerberater-Jahrbuch 1970/71, Köln, S. 15.

Haller, H./Kullmer, L./Shoup, C. S./Timm, H. (Hrsg.) (1970): Theorie und Praxis des finanzpolitischen Interventionismus. Fritz Neumark zum 70. Geburtstag, Tubingen.

Haller, H./Recktenwald, H. C. (Hrsg.) (1969): Finanz- und Geldpolitik im Umbruch, Mainz.

Hamacher, R. (1985): Der Bankenerlaß als ermessensgerechte Handhabung von Ermittlungsbefugnissen der Finanzbehörden, in: Der Betrieb, 38. Jg., Nr. 35, S. 1807.

Hamann, A. (1952): Wirtschaftslenkung durch Steuern, in: Der Betriebs-Berater, 7. Jg., Heft 34, S. 953.

Hamburger Einkommensteuergesetz vom 9.1.1914, in: Finanz-Archiv, 32. Jg., 1. Bd., 1915.

Hamburger Wertzuwachssteuergesetz vom 12.10.1908.

Hamel, H. (1994): Soziale Marktwirtschaft: Anspruch und. Realităt eines ordnungspolitischen Konzepts, in: Klein, W./Paraskewopoulos, S./Winter, H. (1994): Festschrift für Gernot Gutmann zum 65. Geburtstag, Berlin, S. 109.

Hamm, F. (1908): Zur Grundlegung und Geschichte der Steuermoral, Trier. 
Hampe, P. (Hrsg.) (1989): Wahrungsreform und Soziale Marktwirtschaft. Rückblicke und Ausblicke, Munchen.

Handbuch der Politischen Oekonomie (1882), Hrsg. Dr. G. von Schönberg, 1. Aufl., Tübingen; 4. Aufl. (1897).

Handbuch des Bank-, Geld- und Borsenwesens der Schweiz, Thun 1964.

Handwörterbuch der Betriebswirtschaft, 4. völlig neu gestaltete Aufl., Stuttgart 1976.

Handwörterbuch der Sozialwissenschaften, zugleich Neuauflage des Handwörterbuch der Staatswissenschaften, Stuttgart/Tübingen/Góttingen 1959.

Handwörterbuch der Staatswissenschaften, Jena.

Handwörterbuch des Steuerrechts unter Einschluß von Betriebswirtschaftlicher Steuerlehre, Finanzrecht, Finanzwissenschaft, 2., neubearbeitete und erweiterte Auflage, München und Bonn 1981.

Handwörterbuch des Steuerrechts und der Steuerwissensehaft (1981), 2. Aufl, München.

Handwörterbuch der Volkswirthschaftslehre, Leipzig 1866.

Hansen, A. H./Musgrave, R. A. (1951): ECA Team on Fiscal Problems of Germany, Bericht vom 24.9.51, S. 364.

Hansen, R. (1968): Der Methodenstreit in den Sozialwissenschaften zwischen Gustav Schmoller und Karl Menger, seine wissenschaftshistorische und wissenschaftstheoretische Bedeutung, in: A. Diemer (Hrsg.): Beitrage zur Entwicklung der Wissenschaftstheorie im 19. Jahrhundert (= Studien zur Wissenschaftstheorie, Bd. 1), Meisenheim am Glan.

- (1990): Gustav Schmollers Beitrag zur allgemeinen Steuerlehre, in: B. Strümpel (Hrsg.): Beiträge zur Wirtschaftswissenschaft in Berlin, Geschichte und Gegenwart $(=$ Wissenschaft und Stadt, Publikationen der Freien Universităt Berlin aus Anlaß der 750-Jahr-Feier Berlins, Bd. 14), Berlin.

- (1993): Gustav Schmoller und die Sozialpolitik von heute, in: J. G. Backhaus (Hrsg.): Gustav Schmoller und die Probleme von heute (= Volkswirtschaftliche Schriften, Heft 430), Berlin, S. 111.

Hansmeyer, K.-H. (1963): Subventionen in der Bundesrepublik Deutschland, Berlin.

- (1973): Abbau von Subventionen. Ein finanzpolitischer Evergreen, Wirtschaftsdienst III, S. 125.

- (1979): Umbau des Steuersystems, Berlin.

- (Hrsg.) (1983): Staatsfinanzierung im Wandel. Verhandlungen auf der Jahrestagung des Vereins furr Socialpolitik Gesellschaft fur Wirtschafts- und Sozialwissenschaften in Köln (= Schriften des Vereins für Socialpolitik, N.F. Bd. 134, Berlin.

- (1984): Die Steuerreformdiskussion 1984, WISU 10, S. 477.

Hansmeyer, K.-H./Bretschneider, U. (1988): Die Finanzpolitik der Bundesrepublik Deutschland 1983 - 1986, in: Finanzarchiv, Bd. 46, Nr. 3, S. 465. 
Hansmeyer, K.-H./Mackscheidt, K. (1977): Finanzpsychologie, in: Handbuch der Finanzwissenschaft, Bd. 1, Tübingen, S. 553.

Hardach, K. (1976): Wirtschaftsgeschichte Deutschlands im 20. Jahrhundert, Göt. tingen.

Harden, M. (Hrsg.) (1894): Vom Steuerzahlen, in: Die Zukunft, 6. Bd., Berlin

Hardes, H.-D./Rahmeyer, F./Schmid, A. (1990): Volkswirtschaftslehre. Eine problemorientierte Einfuhrung, 17. aktualisierte Auflage, Tübingen.

Harder, N. (1990): Die Sonstige Leistung im Einkommensteuerrecht, Diss. jur., Tubingen.

Hartmann, J. (1967): Reform des Veranlagungsverfahrens durch Selbstberechnung der Steuer. Dargestellt an den Versuchen zur Selbstberechnung im Lande Niedersachsen, in: Finanzwissenschaftliche Forschungsarbeiten, hrsg. von G. Schmölders, N. F., Heft 35 , Berlin.

Hartz, W. (1956): Die Auslegung von Steuergesetzen. Inhalt und Grenzen der wirtschaftichen Betrachtungsweise, Herne.

- (1965): Mehr Rechtssicherheit im Steuerrecht. Ziele - Wege - Grenzen, in: Thoma, G. u. a. (Hrsg.) Steuerberater-Jahrbuch 1965/66, Köln, S. 75.

- (1972): Einkommensteuer, in: Handwörterbuch des Steuerrechts, 1. Bd., 1. Aufl., München und Bonn.

- (1975): Zeitpunkt der Auswirkung der Verlustzuweisungen von Abschreibungsgesellschaften und Bauherrengemeinschaften auf die Einkommensteuer ihrer Gesellschafter, iñ: Der Betrięb. Heft 21, S. 947.

Hasbach, W. (1885): Ein Beitrag zur Methodologie der Nationalokkonomie, in: Jahrbuch fur Gesetzgebung, Verwaltung und Volkswirthschaft im Deutschen Reich, 9. $\mathrm{Jg}$, 1. Heft, 173.

- (1887): Ueber eine andere Gestaltung des Studiums der Wirthschaftswissenschaften, in: Jahrbuch fur Gesetzgebung, Verwaltung und Volkswirthschaft im Deutschen Reich, 11. Jg., Leipzig, S. 163.

- (1890): Die allgemeinen philosophischen Grundlagen der von Francois Quesnay und Adam Smith begrundeten politischen OKonomie, Leipzig.

- (1891): Untersuchungen uber Adam Smith und die Entwicklung der politischen Okonomie, Leipzig.

- (1895): Zur Geschichte des Methodenstreites in der politischen Okonomie, in: Jahrbuch für Gesetzgebung, Verwaltung und Volkswirthschaft im Deutschen Reich, 19. Jg., Leipzig, S.53; S. 78 .

- (1906): Diehls Erlāuterungen zu Ricardos Grundgesetzen, in: Jahrbuch fùr Gesetzgebung, Verwaltung und. Volkswirtschaft im Deutschen Reich, 30. Jg., Leipzig, S. 375 .

Hasselblatt, W. B. (1952): Einkommen und Produktion, in: Zeitschrift für die gesamte Staatswissenschaft, 108. Bd., Tübingen, S. 101. 
Hauptergebnisse der Einkommensteuer-Veranlagung furr 1893/94 in Preussen, in: Finanz-Archiv, 11. Jg. 1894, S. 172.

Hechter, M./Opp., K.-D./Wippler, R. (Ed.) (1990): Social Institutions. Their Emergence, Maintenance and Effects, Berlin/New York.

von Heckel, M. (1890): Die Einkonmensteuer und die Schuldzinsen. Ein Beitrag zur Reform der deutschen Einkommensteuern, Leipzig.

- (1907): Lehrbuch der Finanzwissenschaft, Erster Band, Leipzig.

- (1911): Lehrbuch der Finanzwissenschaft, Zweiter Band, Leipzig.

Hecker, C. (1982): Abschreibungsgesellschaften in Berlin (West). Untersuchung uber wirtschaftliche und rechtliche Wirkungen von Personengesellschaften in der Rechtsform der GmbH \& Co. KG und der AG \& Co. KG, Köln.

Heeckt, H./Stender, H. (1954): Der Wiederaufbau der deutschen Handelsflotte. Kieler Studien. Forschungsberichte des instituts für Weltwirtschaft an der Universitât Kiel $(=$ Weltwirtschaftliches Archiv, Zeitschrift des Instituts für Weltwirtschaft an der Universităt Kiel), Hrsg. F. Baade.

Hegemann, W. (1977): Neuorganisation der Finanzämter, in: Die Steuergewerkschaft in Nordrhein-Westfalen, 18. Jg., Nr. 4, S. 1.

Heidrich, P. (1929): Die Lehre von den obersten Steuerprinzipien. Ein Beitrag zur Theorie der offentlichen Wirtschaft, Jena.

Heilmann, M. (1980): Adolph Wagner - Ein deutscher Nationalökonom im Urteil der Zeit. Probleme seiner biographischen und theoriegeschichtlichen Würdigungen im Lichte neuer Quellen, Frankfurt (= Campus-Forschung, Bd. 160), S. 21 und 25.

Heinitz, E. (1920): Die Rechtsanwaltschaft bei den Finanzgerichten, in: Festgabe für Dr. jur. H. c. Otto Liebmann, den Begrinder, Verleger, Schriftleiter und Herausgeber der Deutschen Juristen-Zeitung, Berlin, S. 219.

Heiß, C. (1893): Die großen Einkommen in Deutschland, in: Annalen des Deutschen Reichs, S. 1.

Held, A. (1872): Die Einkommensteuer. Finanzwissenschaftliche Studien zur Reform der directen Steuern in Deutschland, Bonn.

Heldrich, A. (1993): Eugen Ehrlich (1862-1922) Begrunder der Rechtssoziologie, in: H. Heinrichs/H. Franzki/K. Schmalz/M. Stolleis (Hrsg.): Deutsche Juristen jüdischer Herkunft, München.

Helft, E. (1908): Beiträge zur Frage der technischen Ausgestaltung der deutschen Einkommenbesteuerung, in: Annalen des Deutschen Reichs, München, S. 130.

Henke, J. (1981): Economic Reconstruction in Europe: The Reintegration of Western Germany. Report on the Relevant Historical Material in the Bundesarchiv, in: Zeitschrift für die gesamte Staatswissenschaft 137, S. 469.

Henkel, H. (1968): Strafverfahrènsrecht, 2. Aufl., Stuttgart.

Hennemann, G. (1959): Naturphilosophie im 19. Jahrhundert, Freiburg. 
Henning, F.-W. (1973): Fünfzig Jahrgãnge Steuer und Wirtschaft - Probleme des Steuerwesens vor dem realgeschichtlichen Hintergrund, in: Steuer und Wirtschaft 4, S. 288.

Henrich, L. (1888): Die Reform der direkten Steuern, insbesondere die Einführung der Selbsteinschatzung in Preußen. Ein Mahnwort an die preußischen Landtagswähler, Bierlin.

Hensel, A (1928): Die Entwicklung des deutschen Steuerrechts durch die Gesetzgebung vom September 1926 bis August 1928, in: Zum 35. Deutschen Juristentag, in: Steuer und Wirtschaft, 7. Jg., Bd. 1, Sp. 821.

- (1930): Verfassungsrechtliche Bindungen des Steuergesetzgebers, Besteuerung nach der Leistungsfthigkeit - Gleichheit vor dem Gesetz, in: Vierteljahresschrift für Steuer- und Finanzrecht, 4. Jg., S. 441.

- (1932): Die Auskunftspflichten Dritter (insbesondere der Bankinstitute) im Rahmen des \$201 AO. (n. F.), in: Steuer und Wirtschaft, Jg. XI, Sp. 1347.

Herden, C./Gmach, G. (1988): Die Entwicklung des Steuerrechts, in Neue Juristische Wochenschrift, Heft 33, S. 2008.

Herkoner, H. (1912): Der Kampf un das sittliche Werturteil in der Nationalökonomie, in: Jahrbuch fur Gesetzgebung, Verwaltung und Volkswirtschaft im Deutschen Reich, 36. Jg., S. 1.

Hermann, F. B. W. (1832): Staatswirthschaftliche Untersuchungen uber Vermögen, Wirthschaft, Productivitat der Arbeiten, Kapital, Preis, Gewinn, Einkommen und Verbrauch, Manchen.

- (1870): Staatswirthschaftliche Untersuchungen, München.

Hermann, S. (1988): Anshize zu einer Integration von Steuer- und Sozialsystem (= Finanzwissenschaftliches Arbeitspapier Nr. 16 VWL I und VWL II, Universitất Gießen.

Hermann, H. J. (1989): Einkommensteuerrechtliche Fragen der Gestaltung geschlossener Immobilienfonds, in: StuW, S. 97.

Herzfeld (1938): Johannes von Miquel. Sein Anteil am Ausbau des Deutschen Reiches bis zur Jahrhundertwende. Band II: Konservative Wendung und staatsmännisches Wirken 1884 - 1901, Detmold.

Herzig, N./Schiffers, J. (1989): Neuregelung der Besteuenung von Veraußerungsgewinnen, in: Der Betrieb, 42. Jg., Heft 49, S. 2441.

Herzog, R. (1985): Leitlinien und Entwicklungstendenzen der Rechtsprechung des Bundesverfassungsgerichts in Steuerfragen, in: Steuerberater-Jahrbuch, S. 27.

- (1988): Der Weg zum Bundesverfassungsgericht. Das Verhältnis zwischen Verfassungsgerichtsbarkeit und Steuergerichtşbarkeit, in: Deutsche Steuer-Zeitung, 76. Jg., Ni. 12, S. 287.

Hessler, H.D. (1983). Theorie \& Politik der Personalsteuern. Eine Kritik ihrer Ein kommens- und Vermōgensbegriffe, Habilitationsschrift, Köln. 
Hill, H. (1978): Steuerreform als Chance zur Verbesserung der Steuergesetzgebung, in: Zeitschrift fur Gesetzgebung, 2. Jg., S. 238.

Hill, J. A. (1892): Prussian Income Tax: in: The Quarterly Journal of Economics, Vol. VI, Boston.

- (1894): The Prussian Business Tax, in: The Quarterly Journal of Economics, Vol. VIII, Boston.

Hintze, O. (1896): Preußische Reformbestrebungen vor 1806, in: Historische Zeitschrift, N.F., Bd. 40, München und Leipzig.

Hirsch, H. (1968): Wirtschaftliches Prinzip und offentliches Interesse als Leitideen des Steuersystems, in: Finanzarchiv, N.F., Bd. 27, Tubingen, S. 5.

Hirth, G. (1874): Matricularbeiträge oder Reichs-Einkommensteuer? Bericht über die Eisenacher Versammlung am 11. October 1874, in: G. Hirth (Hrsg.): Annalen des Deutschen Reichs, Sp. 115.

- (1874): Die Reichs-Einkommensteuer und ihre Gegner, in: G. Hirth (Hrsg.): Annalen des Deutschen Reichs, Sp. 987.

- (1875): Aus den Gutachten des Vereins für Socialpolitik. Materialien zu einer Reichs-Einkommensteuer, in: G. Hirth (Hrsg.): Annalen des Deutschen Reichs, Sp. 979.

- (1875): Das souverăne Gesetz der Preisbildung. Ein Beitrag zur Kritik der Einkommensvertheilung und zur Lehre von der Steuerprogression, in: G. Hirth (Hrsg.): Annalen des Deutschen Reichs, Sp. 1265.

- (1879): Die direkte Steuer ein aberwundener Standpunkt, in: G. Hirth (Hrsg.): Annalen des Deutschen Reichs, S. 153.

Hock, W. (1960): Deutscher Antikapitalismus. Der ideologische Kampf gegen die freie Wirtschaft im Zeichen der großen Krise, Frankfurt/M

von Hock, C. (1863): Die offentlichen Abgaben und Schulden, Stuttgart.

Hoeth, P. (1956): Schiffbaufinanzierung mit 7d-Mitteln, in: Hansa, Zeitschrift für Schiffahrt, Schiffbau, Hafen, 93. Jg., Hamburg, S. 1272 - 1276; S. $1492-1493 ;$ S. $1566-1570$.

Hoffmann, A. (1906): Die direkten Staatssteuern im Königreich Sachsen. Mit besonderer Berücksichtigung der allgemeinen Eỉnkommensteuer, Leipzig.

- (1921): Der Gerechtigkeitsgedanke in der Reichseinkommensteuer, in: Zeitschrift für Sozialwissenschaft, N.F., Bd. XII, S. I.

Hoffmann, W. (1951): Aktivierung der Schiffahrtsfinanzierung, in: Hansa, Zeitschrift für Schiffahrt, Schiffbau, Hafen, Hamburg, S. 961.

Hoffmann, W. G./Müller, J. H. (1959): Das deutsche Volkseinkommen 1851 - 1957, Tubingen.

Hollerbach, A. (1988): Zu Leben und Werk Franz Bơhms, in: Freiburger Universitătsblätter, H. 102, Bd. 27, S. 81. 
Hopfenmüller, T. (1962): Zur Mißachtung von Tatbestandsmerkmalen, in: Steuerberater-Jahrbuch 1961/62, Köln.

Hopt, K. (1975): Was ist von den Sozialwissenschaften fur die Rechtsanwendung zu erwarten?, in: Juristenzeitung, 30 . Jg., Heft $11 / 12, \mathrm{~S} .341$.

Horst, H. (1978): Die GNOFÄ schaffen ernste Probleme fur eine gerechte Besteuerung, in: Die Steuerberatung, 21. Jg., Nr. 11, S. 251.

Howard, H. (1873): Landwirthschaftliche Rentabilităts-Berechnungen mit Rücksicht auf Brauchbarkeit doppelter Buchhaltung in der Landwirthschaft, Leipzig.

- (1889): Wie hat sich der Landwirt zur progressiven Einkommensteuer zu verhalten? Leipzig.

Hubschmann/Hepp/Spitaler (Hrsg.) (1993): Kommentar zur Abgabenordnung und. Finanzgerichtsordnung, 9. Aufl., Köln.

Huncke, E. (1905): Die Entwicklung von Einkommensteuer und Einkommen in England in den letzten zwanzig Jahren, in: Finanz-Archiv, 22. Jg., 1. Bd., S. 138.

ifo-Institut fur Wirtschaftsforschung e. V., München, (Hrsg.) (1988): Subventionen, Probleme der Abgrenzung und Erfassung.

Inhulser, C. H. P. (1897): Aus der englischen Steuerpraxis, in: Finanz-Archiv, 14. Jg., 1. Bd., S. 358.

- (1925): Die englischen Finanzvoranschlăge für das Jahr 1925/26, in: Finanzarchiv, 42. Jg., S. 119.

Institut Finanzen und Steuern (1954/1955): Grundlagen und Moglichkeiten einer organischen Finanz- und Steuerreform, Schriftenreihe des Instituts, Heft 30, Bd. 1 und 2, Bonn.

- (1957): Grundlagen und Möglichkeiten einer organischen Finanz- und Steuerreform III, Schriftenreihe des Instituts, Heft 30, Bd. 3, Bonn.

- (1966): Die Groß̉e Finanzreform, Schriftenreihe des Instituts, Heft 80, Bonn.

- (1968) Subventionen - Begriff und Beurteilungsmaßstăbe, Brief 101.

- (1971): Zur Steuerreform. Brief 125, Bonn.

- (1971): Zur Steuerreform. Die Vermögensteuer, Heft 100, Band 1, Bonn.

- (1982): Modell fir die Ablosung der Gewerbesteuer durch einen Gemeindeanteil an der Umsatzsteuer, Brief 211 , Bonn.

- (1983): Heimliche Steuererhōhungen. Belastungswirkungen machen Einkommen= steuertarifreform notwendig. Brief 227, Bonn.

- (1985); Einkommensbegriff und Einkommensermittlung in den Transfergesetzen, Bonn.

Institut für Steuerrecht an der Universităt zu Köln (1949): Bonner Steuertagung 9.-11 Juni 1949, in: Steuer und Wirtschaft, Sp. 737. 
Institut fur Zeitgeschichte/Deutscher Bundestag, Wissenschaftliche Dienste (Hirsg.) (1977): Wörtliche Berichte und Drucksachen des Wirtschaftsrates des Vereinigten Wirtschaftsgebietes 1947 - 1949, Bd. 3 und Bd. 5, München u. Wien.

Instruction zum Einkommensteuergesetz vorn 2.7.1878, in: Gesetz- und Verordnungsblatt für das Königreich Sachsen, 18. Stück vom Jahre 1878, S. 522.

International Encyclopedia of the Social Sciences (1968), Vol. 15, USA.

Investitionszulagengesetz vom 24.6.1991, in: BGBI. I, S. 1333.

Investitionszulagengesetz vom 23.9.1993, in: BGBI. I, S. 1651.

Imgang, W. (1988): Steuerhinterziehung durch Abweichung von der Auffassung der Finanzverwaltung oder höchstrichterlicher Rechtsprechung?, in: Der Betrieb, Heft 15, S 781 .

Isensee, J. (1968): Subsidiaritatsprinzip und Verfassungsrecht (= Schriften zum Offentlichen Recht, Bd. 80, Berlin.

- (1975): Die typisierende Verwaltung. Gesetzesvollzug im Massenverfahren am Beispiel der typisierenden Betrachtungsweise des Steuerrechts, Berlin.

- (1977): Steuerstaat als Staatsform, in: R. Sto̊dterNW. Thieme (Hrsg.): Festschrift für Hans-Peter Ipsen zum siebzigsten Geburtstag, Tubingen, S. 409.

- (1985): Mehr Recht durch weniger Gesetze? in: Zeitschrift fur Rechtspolitik, 18. Jg., München, S. 139.

Isensee, J./Kirchhof, P. (Hrsg.) (1987): Handbuch des Staatsrechts der Bundesrepublik Deutschland, Bd. I: Grundlagen von Staat und Verfassung, Heidelberg 1987.

Issing, O. (1993): Aristoteles - (auch) ein Nationalökonom? in: Aristoteles und seine "Politik". Vademecum zu einem Klassiker des antiken Wirtschaftsdenkens, Dusseldorf, S. 95.

Jacob, K. (1994): Taxes are what we pay for a civilized society, in: Die SteuerGewerkschaft, 43. Jg., Heft. 5, S. 55 und Heft 6 S. 74.

Jäger, J. W. (1974): Die Entwicklung des Rechtsmittelverfahrens des Steuerrechts vom 18. Jahrhundert bis zum Erlass der Finanzgerichtsordnung vom 6.10.1965, Diss. jur., Marburg.

Jahrbuch für Gesetzgebung, Verwaltung und Volkswirtschaft im Deutschen Reich, Hrsg. Gustav Schmoller, Leipzig.

Jahn, J./Senglaub, K. (1985): Geschichte der Biologie. Theorien, Methoden, Institutionen, Kurzbiographien, Jena.

Jahrmarkt, M. (1973): Zur betriebswirtschaftlichen, steuerlichen und gesellschaftspolitischen Problematik von "Verlustbeteiligungen" an Abschreibungsgesellschaften, in: K. Oettle (Hrsg.): Steuerlast und Unternehmungspolitik. Kuno Barth zum fünfundsechszigsten Geburtstag, Stuttgart.

Jahrmarkt, M./Bareis, H. P. (1981): Abschreibungsgesellschaft, in: Handwörterbuch des Steuerrechts, 1. Bd., S. 31. 
Jansen, R./Hoffmann, M. (1977): Der Nießbrauch im Zivil- und Steuerrecht, Herne.

Jansen, R./Wrede, F. (1981): Renten, Raten, Dauernde Lasten, Herne.

Janssen, B. (1990): Die Umsatzsteuer als Verkehr- und/oder Verbrauchsteuer, in: Deutsche Steuer-Zeitung, Nr. 1-2, S. 35.

- (1991): Zur Gerechtigkeit in der Familienbesteuerung in Theorie und Praxis, in: Deutsche Steuer-Zeitung, Nr. 1-2, S. 13.

- (1991): Totalreform des Steuersystems?, in: Deutsche Steuer-Zeitung, Nr. 19, S. 593.

- (1991): Familienbesteuerung. Steuergerechtigkeit und Steuerreform. in: Deutsche Steuer-Zeitung, Nr. 23, S. 719.

Jastrow, J. (1891): Die Selbsteinschätzung und die geistige Arbeit. Ein Beitrag zur Erlăuterung des Preufischen Einkommensteuer-Gesetzes vom 24. Juni 1891, in: Volkswirtschaftliche Zeitfragen 103, Berlin.

- (1891): Zur Selbsteinschätzung in Preußen. Beiträge zur Erlăuterung der Ministerialanweisung vom 5. August 1891, in: Jahrbucher für Nationalökonomie und Statistik, 3. F, 2. Bd., S. 730.

- (1893): Der Abschluß der preußischen Steuerreform, in: Preußische Jahrbücher, 73. Bd., S. 363.

Jecht, H. (1948), Probleme der Einkommensteuerreform, Göttingen.

- (1955/56): Die Bundessteuerreform 1954, kritischer Ruckblick auf ihre wichtigsten Ergebnisse, Finanzarchiv 16, S. 31.

- (1957): Uber einige Entwicklungstendenzen und Probleme des westdeutschen Kapitalmarktes, in: Beckerath, E.Meyer, F. W./Müller-Armack, A.: Wirtschaftsfragen der freien Welt. Zum 60. Geburtstag von Bundeswirtschaftsminister Ludwig Erhard, Frankfurt/M., S. 420.

- (1959/60): Der Problemkreis "Besteuerung und Wirtschaftspolitik" in der deutschen Finanzwissenschaftlichen Literatur, in: Finanzarchiv, N.F., Bd. 20, S. 5.

Jehner, I. (1988): Der gesetzliche Gegensatz als systematische Grundlage der Einkommensbesteuenung, in: Deutsches Steuerrecht, 26. Jg., Nr. 9, S. 267.

- (1990): Des Kaisers neue Kleider. Zum bewußten Verzicht auf Gerechtigkeit im Einkommensteuergesetz und in der zu ihm ergehenden Rechtsprechung, in: Deutsches Steuerrecht, 28. Jg., Nr. 1-2, S. 6.

Jenaische Allgemeine Literatur-Zeitung (1813), Jg. 10, Bd. 1.

Jenetzky, J. (1978): System und Entwicklung des materiellen Steuerrechts in der wissenschaftlichen Literatur des Kameralismus von 1680 - 1840, Berlin.

- (1982): Die Misere der Steuerverwaltung. Ober die Wirklichkeit der Steueranwendung durch die Steuerbehörden, in: Steuer und Wirtschaft, 59. Jg., Nr. 3, S. 273. 
- (1982): Diskussionsbeitrag, in: K. Tipke (Hrsg.): Grenzen der Rechtsfortbildung durch Rechtsprechung und Verwaltungsvorschriften im Steuerrecht, Köln, S. 363.

Joecks, W./Richter, H./Schmider, K.-H. (1986): Praxis der Steuerbegunstigten Kapitalanlagen, Bd. XVI: Gesetz zur Neuregelung der steuerrechtlichen Förderung des selbstgenutzten Wohneigentums, Änderungen im Zwischenmietverhalltnis, Strafrechtliche Risiken durch den Tatbestand des Kapitalbetrugs, Köln.

Jonas, B. (1983): Steuermoral verbessert? Zur Notwendigkeit der Verstärkung der Betriebsprüungsdienste, in: Deutsches Steuerrecht, 21. Jg., Nr. 11, S. 321.

Jostock, P. (1943): Uber den Umfang des der Besteuerung entgehenden Einkommens. Ein Beitrag zur Volkseinkommenstatistik, in: Weltwirtschaftliches Archiv, Bd. 57 1943 I, Jena.

Jürgens, G. (1976): Zum 25jährigen Bestehen der Bundesfinanzakademie. Entwicklung - Aufgaben - Arbeitsweise, in: Deutsche Steuer-Zeitung A, Nr. 10, S. 172.

Justus, J. (Pseudonym) (1897): Die preuss. Steuerreform und die Reichseinkommensteuer, in: Finanzarchiv, 14. Jg., 2. Bcl., Stultgart, S. 58.

Kärger, K. (1890): Die Sachsengăngerei - Auf Grund persönlicher Ermittlungen und efaticticher Frhehungen, Rerlin

Kannengießer, W. (Hrsg.) (1980): Forum Vermögensbildung, Kapitalbildung, Krisenvorbeugung, Köln.

Kapp, R. (1986): Gespaltener Rechtsschutz in Steuersachen? in: FinanzRundschau 3, S. 57.

Karl-Bräuer-Institut des Bundes der Steuerzahler (1971): Der Weg zu einem zeitgemäßen Steuersystem, Wiesbaden.

- (1975): Zur Reform der Gemeindesteuern, Wiesbaden.

- (1984): Ein Vorschlag zur Reform des Lohn- und Einkommensteuertarifs, Heft 56, Wiesbaden.

Kappe, H. (1976): Verluste aus Abschreibungsbeteiligungen und vorläufiger Rechtsschutz, in: Betriebs-Berater, Heft 10, S. 457.

Kauper, W. (1974): Das Verhăltnis der Bevőlkerung zur Rechtspflege, in: Jahrbuch für Rechtssoziologie und Rechtstheorie, Bd. 4, Düsseldorf, S. 555.

Kaufmann, A. (Hrsg.) (1965): Die Onthologische Begrundung des Rechts, Darmstadt.

- (1975): Durch Naturrecht und Rechtspositivismus zur juristischen Hermeneutik, in: Juristenzeitung, Nr. 11/12, S.337.

- (1982): Analogie und "Natur der Sache". Zugleich ein Beitrag zur Lehre vom Typus, Heidelberg.

Kausemann, E.-P. (1983): Möglichkeiten einer Integration von Steuer- und Transfersystem (= Reihe Wirtschaftswissenschaften, Bd. 290), Frankfurt/M.

Kelber, M. (1933): Die abgeleiteten Einkommen, in: Jahrbucher für Nationalôkonomie und Statistik, 138. Bd., S. 161. 
Keller, K. (1909): Die Besteuerung der Gebäude und Baustellen, insbesondere die Wertzuwachssteuer, 2. vermehrte Aufl., Berlin.

Keller, T. (1968): Merkliche oder unmerkliche Steuern?, in: Finanzarchiv, N.F., Bd. 27, Tübingen, S. 110.

Kellner, F. S. (1928): Der steuerrechtliche Begriff des Einkommens unter besonderer Berücksichtigung des Reichseinkommensteuergesetzes von 1925, Diss. jur., Erlangen.

Kelsen, H. (1912): Zur Soziologie des Rechtes. Kritische Betrachtungen, in: Archiv fur Sozialwissenschaft und Sozialpolitik, 34. Bd, Tubingen, S. 601.

- (1915): Eine Grundlegung der Rechtssoziologie, in: E. Jaffé (Hrsg.): Archiv für Sozialwissenschaft und Sozialpolitik, 39. Bd. Tübingen, S. 839.

- (1953): Was ist Gerechtigkeit?, Wien.

- (1960): Reine Rechtslehre. Mit einem Anhang: Das Problem der Gerechtigkeit, Wien.

Kempkens, J. (1917); Konjunkturgewinn, in: Annalen des Deutschen Reichs, München, S. 257.

Keynes, J. M. (1933): Nationale Selbstgenugsamkeit, in: Schm. Jb., 57. Jg., S. 561.

Kilius, J. (1973): Schiffahrtsbeteiligungen, in: Radler. A./Raupach, A., S. 245.

Kimminich, O. (1986): Das Eigentum in der Spannung zwischen Freiheit und Sozial. bindung, in: Jahrbuch firr Rechtssoziologie und Rechtstheorie, darin: Persönlichkeit, Familie, Eigentum, S. 336.

Kirchgässner, G. (1984): Optimale Wirtschaftspolitik und die Erzeugung politisch okonomischer Konjunkturzyklen, Königstein/Ts.

- (1985): Die Entwicklung der Einkommensteuerprogression in der Bundesrepublik Deutschland, Finanzarchiv 43, S. 328.

Kirchhof, G. (1973): Subventionen als Instrument der Lenkung und Koordinierung, Berlini.

Kirchhof, P. (1975): Das Hervorbringen von Normen und sonstigem Recht durch die Finanzbehörden, in: Steuer und Wirtschaft 4, S. 357.

- (1977): Verwalten durch "mittelbares" Einwirken, Berlin

- (1982): Steuergerechtigkeit und sozialstaatliche Geldleistungen, in: Juristenzeitung, 37. Jg., Nr. 9, Tubingen, S. 305.

- (1983): Albert Hensel, Forscher eines rechtsstaatlich gebundenen, systematischen Steuerrechts, in: Steuer und Wirtschaft 4/1983, S. 357.

- (1984): Steuergleichheit, in: Steuer und Wirtschaft 4, S. 297.

- (1985): Der verfassungsrechtliche Auftrag zur Besteuerung nach der finanziellen Leistungsfahigkeit, in: Steuer und Wirtschaft 4, S. 320. 
- (1988): Empfiehlt es sich, das Einkommensteuerrecht zur Beseitigung von Ungleichbehandlungen und zur Vereinfachung neu zu ordnen? Gutachien $F$ für den 57. Deutschen Juristentag, in: Verhandlungen des siebenundfünfzigsten Deutschen Juristentages, Mainz 1988, Bd. 1, München.

- (Hrsg.) (1991): Der offene Finanz- und Steuerstaat, Heidelberg.

- (1994): Rechtsstaatliche Anforderungen an den Rechtsschutz in Sieuersachen, in: Trzaskalik, C. (Hrsg.): Der Rechtsschutz in Steuersachen, Köln, S. 17.

Kirchhof, P./Söhn, H. (1992): Einkommensteuergesetz. Kommentar, Heidelberg.

Kirsch, L. (1887): Das kameralistische Studium im Grossherzogtum Baden, zugleich unter Angabe der bezüglich der Ausbildung für den Finanzdienst in Preussen, Bayern, Sachsen, Wurttemberg, Hessen und in Elsass-Lothringen bestehenden Vorschriften, in: Finanz-Archiv, 4. Jg., Stuttgart, S. 57.

Kitterer, B. H. J. (1990): Investieren in den neuen Bundesländern, Bonn.

Kittner, M. (Hrsg.) (1993): Gewerkschaftsjahrbuch 1993, Köln.

Kleedehn, B. (1996): Neue Finanzierungsformen für offentliche Haushalte, in: Mitteilungen und Berichte Nĩ. 22 des Forschungsinstituts für Leasing an der Universitât zu Köln, zitiert nach einem Vortrag vom 29.11.1995.

Klein, F. (1957/58): Bundesverfassungsgericht und Ehegattenbesteuerung, Finanzarchiv 18, S. 236.

- (1985): Die Belastung des Bundesfinanzhofs und Möglichkeiten zu seiner Ent-lastung, in: R. Curtius-Hartung u.a. (Hrsg.): Steuerberater-Jahrbuch 1984/85, Köln, S. 21 .

- (1986): Steuerreform und Steuervereinfachung - vordringliche Aufgabe in der năchsten Legislaturperiode, in: Zeitschrift für Gesetzgebung, 1. Jg., S. 245.

- (1986): Lexikon des Rechts. Steuer- und Finanzrecht.

- (1987): Ehe und Familie im Steuerrecht als verfassungsrechtliches Problem, in: W. Fürst/R. Herzog/D. C. Umbach (Hrsg.): Festschrift für Wolfgang Zeidler, Berlin, S. 773.

- (1988): 70 Jahre Reichsfinanzhof/Bundesfinarizhof, in: Deutsches Steuerrecht, 26. Jg., Nr. 19, S. 591.

Klein, F(riedrich) (1953/54): Steuerwesen und Rechtsordnung, in: Finanzarchiv, N.F., Bd. 14, Tübingen, S. 1.

- (1959/60): Grundgesetz und Steuerreformen, in: Finanzarchiv, N. F., Bd, 20, T0bingen, S. 115.

Kleinwächter, F. (1888): Die geplante Reform der rechts- und staatswissenschaftlichen Studien in Oesterreich, in: Jahrbuch furr Gesetzgebung, Verwaltung und Volkswirthschaft im Deutschen Reich, 12. Jg., Leipzig, S. 123.

- (1896): Das Einkommen und seine Verteilung, Leipzig.

- (1902): Lehrbuch der Nationalōkonomie, Leipzig. 
- (1922): Lehrbuch der Finanzwissenschaft, Leipzig.

Klöckner, K. (1993): Steuerfreistellung des Existenzminimums beim Lohnsteuerabzug 1993, in: Neue WirtschaftsBriefe, F. 6, S. 3493.

Klos, J. (1986): Steuerfahndung im Rechtsstaat. Bemerkungen zu Mösbauer, DStz. 1986, 339, in: Deutsche Steuer-Zeitung, 74. Jg., Nr. 20, S. 505.

Kobelt, H. (1984): Wirtschaftsstatistik fur Studium und Praxis mit einer Sammlung statistischer Tabellen, Bad Homburg vor der Hobhe.

Koch, K. (1970): 50 Jahre Reichsabgabenordnung, in: Deutsche Steuer-Zeitung, Ausgabe A, Nr. 1, S. 7.

- (1971): Zur AO-Reform, in Steuerberater-Jahrbuch 1970/71, Köln, S. 67.

Koch, K.IScholtz, R.-D. (1993) (Hrrsg.): Abgabenordnung 1977, 4. Aufl., Köln.

Koch, P./Haag, J. (1968): Die Rechtsnatur des Leasing-Vertrages, in: Betriebs-Berater, S. 93.

Koch, W. (1963): Das Verhaltnis zwischen gesellschaftlicher und steuerlicher Gerechtigkeit bei Adolph Wagner, in: Finanzarchiv, NF 23, Heft 1, S. 36.

Köhler, H. (1964): Lebenserinnerungen des Politikers und Staatsmannes 1878 - 1949 , Stuttgart.

Kohler, W. (1912): Die wissenschaftlichen Ergebnisse des Soziologentages, in: Jahrbuch fur Gesetzgebung, Verwaltung und Volkswirtschaft in Deutschen Reich, 36. Jg., S.383.

- (1914): Die Ergebnisse des zweiten deutschen Soziologentages, in: Schmollers Jahrbuch fuir Gesetzgebung, Verwaltung und Volkswirtschaft im Deutschen Reiche, 38. Jg., 1. Heft, S. 415.

- (1915): Die Objektivitalt. Untersuchungen uber die logische Struktur des Werturteils, in: Schmollers Jahrbuch filr Gesetzgebung, Verwaltung und Volkswirtschaft im Deutschen Reiche, 39. Jg., 1. Heft, S. 17.

Koenig, G. (1885): Die Meldeangabe bei der Veranlagung der persönlichen Steuern, in: Finanz-A.rchiv, 2. Jg., Stuttgart, S. 47.

Kŏnigl. săchsisches Ergănzungssteuergesetz vom 2.7.1902, in: Gesetz- und Verordnungsblatt für das Königreich Sachsen, S. 259.

Königl. săchsisches Ergănzungsstẹuergesetz vom 2. Juli 1902 auf. Grund der Novelle vom 21.4.1906.

Konnigl. Săchs. Finanzministerium (Hrsg.) (1893): Mittheilungen aus der Verwaltung der direkten Steuern im Kōnigreiche Sachsen, Bd. IV, Dresden.

Konigl. săchsisches Gesetz, betr. die Abänderung des Einkommensteuergesetzes vom 24. Juni 1900 vom 1.7.1902, in: Gesetz- und Verordnungsblatt für das Kōnigreich Sachsen, S. 257.

Kooniglich-sächsische Landtags-Acten von den Jahren 1871/72. Beilage zur dritten Abtheilung, die Berichte der zweiten Kammer enthaltend, 3. Bd., Dresden. 
Köppe, H. (1903): Der Wert der Wohnung im eigenen Hause vom Standpunkte der Einkommensbesteuerung, in: Finanz-Archiv, 20. Jg., S. 26.

- (1906): Ist die Wertzuwachssteuer uberwalzbar? in; Finanz-Archiv, 23. Jg., S. 1.

- (1909): Die Aufgaben der Reichsfinanzreform und die ihr drohenden Gefahren, vom finanz- und sozialpolitischen Standpunkte, in: Annalen des Deutschen Reichs, München, S. 1.

- (1910): Das Schicksal der Reichszuwachssteuer, in: Annalen des Deutschen Reichs, Munchen, S. $670 ;$ S. 721.

Kohl, H./Kubler, F./Walz, R./ Wüstrich, W. (1974): Abschreibungsgesellschaften, Kapitalmarkteffizienz und Publizitătszwang - Plădoyer fưr ein Vermögensanlagegesetz, in: Zeitschrift fur das gesamte Handelsrecht und Wirtschaftsrecht, 138. Bd., Stuttgart, S. 1.

Kongreß Junge Juristen und Wirtschaft, Wandlungen in Technik und Wirtschaft als Herausforderung des Rechts 1984, Berlin, West, Hrsg. R. Scholz (1985), Köln.

Konlarski, L. (1984): Einkommen als Maßstab steuerlicher Leistungsfahigkeit. Ein betriebswirtschaftlicher Beitrag zum Problem einer leistungsfahigkeitsăquivalenten Einkommensermittlung, $(=$ Hochschulschriften zur Betriebswirtschaftslehre, Bd. 28), Herne

Koppe (1928): Buch- und BP und Reichstag, in: Deutsche Steuer-Zeitung, S. 406; (1929), S. 218; (1930), S. 283.

Korff, H. C. (1953): Anwendung und Grenzen des $\S 7$ d EStG. im Kalenderjahr 1952, in: Hansa, Zeitschrift für Schiffahrt, Schiffbau, Hafen, Hamburg, S. 260.

Kom, K. (1981): Steuerprufungen mit Vermögenszuwachs- und Geldverkehrsrechnung, in: KÖSDI, Heft 1/81, S. 4023.

Kom, K./Streck, M. (1980): Praxis und Falle der Steuergestaltung, in: KOSDI, Heft $1 / 80$, S. 3585.

Komfeld, G. (1913): Der sozialpolitische: Nebenzweck in der Besteuerung, Diss. Erlangen.

Koschorreck, W. (1968): Zur Geschichte der Steuerprivilegien der Sparkassen und Kreditgenossenschaften, in: Finanzarchiv, N.F., Bd. 28, S. 253.

Koulis, J. (1948): Soziale Gestaltung der Besteuerung oder volkswirtschaftliche Steuerpolitik? Tubingen.

Krabbe, H. (1987): Verbindliche Auskunft im Steuerrecht, in: Neue WirtschaftsBriefe, Herne, Heft 44, Fach 2, S. 4913.

- (1989): Nochmals: Zum Gesetz über die strafbefreiende Erklärung, in: Deutsches Steuerrecht, 27. Jg., Nr. 3, S. 68.

Kraft, M. (1908): Die Lehre von den Produktionsfaktoren, in: Annalen des Deutschen Reichs, München, S. 707. 
Kramer, H.-H. (1970): Die Entwicklung der preussischen Steuerverfassung im 19. Jahrhundert, Diss. jur., München.

Kramer, J.-D. (1980): Grundzige des US-amerikanischen Steuerrechts. Ein Seminar der Bundesfinanzakademie, in: Deutsches Steuerrecht, 18. Jg., Nr. 1, S. 348

Krause, K. P. (1993): Bürgergeld und Bürgersteuer, in: Frankfurter Allgemeines Zeitung vom 9.10 .1993$, S. 11 .

Krause, P. (1992): Der Beitrag der Sozialwissenschaft zur Sozialpolitik, in: Juristenzeitung, Heft 17, S. 845.

Kreile, R. (1976): Wege und Irrwege der Abschreibungsgesellschaften, in: Deutsches Steuerrecht, Heft 10, S. 282.

- (1977): Die Steuergesetzgebung in der Bundesrepublik Deutschland aus der Sicht des Parlamentariers, in: Steuer und Wirtschaft, 54. Jg., Nr. 1, S. 1.

Krelle, W. (1955/56): Zur Wirkung der progressiven Einkommensbesteuerung, in: Finanzarchiv, N.F., Bd. 16, Tübingen, S.22.

Krelle, W.SSchunck, J/Siebke, J. (Bearb.) (1968): Uberbetriebliche Ertragsbeteiligung der Arbeitnehmer. Mit einer Untersuchung über die Vermögensstruktur der Bundesrepublik Deutschland, Bd. I und Bd. II, Tubingen.

Kreussler, H. (1968): Der allgemeine Gleichheitssatz als Schranke für den Subventionsgesetzgeber unter besonderer Berüksichtigung von wirtschaftspolitischen Differenzierungszielen, Berlin

Kriele, M. (1963): Kriterien der Gerechtigkeit, Berlin

- (1979): Recht und praktische Vernunft, Gottingen

- (1984): Gesetzestreue und Gerechtigkeit in der richterlichen Rechtsfindung, in: Deutsche Richter-Zeitung, 62. Jg., S. 226.

Kries, C. G. (1855): Ergebnisse der preussischen Einkommensteuer und Vorschläge zu inrer Verbesserung, in: Zeitschrift fur die gesammte Staatswissenschaft, 11. Jg., 3. u. 4. Heft, S, 361, Tubingen.

- (1894): Grundzüge ind Ergebnisse der englischen Einkommensteuer, in: Zeitschrift für die gesammte Staatswissenschaft, 10. Jg., S. 199 - 245 u. S. 497 - 551, Tübingen.

Krischausky, D. (1988): Besteuerung der Zinseinkünfte privater Haushalte. Diss. rer. pol., Köln.

Kröncke, C. (1804): Das Steuerwesen nach seiner Natur und seinen Wirkungen untersucht, Darmstadt und Gießen.

Krohn, C. D. (1974): Stabilisierung und okonomische Interessen, in: Fischer, F. (Hrsg.), Studien zur modernen Geschichte, Dusseldorf.

- (1981): Wirtschaftstheorien als politische Interessen. Die akademische Nationalokonomie in Deutschland 1918 - 1933, Frankfurt/M. 
Kronberger Kreis (1983): Vorschlăge zu einer kleinen Steuerreform, in: Kronberger Kreis 1984, S. 81.

- (1984): Mehr Mut zum Markt, Handlungsaufforderungen, Zusammenfassung der Schriften des Kronberger Kreises, Bd. 1, hrsg. vom Frankfurter Institut für Wirtschaftspolitische Forschung e. V., Bad Homburg.

- (1986): Bürgersteuer - Entwurf einer Neuordnung von direkten Stenern und Sozialleistungen, Schriftenreihe des Frankfurter Instituts fur Wirtschaftspolitische Forschung e. V., Bd. 11, Bad Homburg.

- (1989): Reform der Unternehmensbesteuerung, Schriftenreihe des Frankfurter Instituts fur Wirtschaftspolitische Forschung e. V., Bd. 18, Frankfurt.

Kriliger, H. (1966): Die Bestimmungen des Eigentumsinhaltes (Art. 14 Abs. I S. 2 GG), in: Hamburger Festschrift für Friedrich Schack zu seinem 80. Geburtstag am 1.10.1966, Hamburg, S. 71.

Krïger, W. (1911): Zwanzig Jahre aus Hamburg Finanz- und Steuerwesen 1889 1909, in: Annalen des Deutschen Reichs, Munchen und Berlin, S. 46.

Kruse, H. W. (1959): Ober Gewohnheitsrecht, in: Steuer und Wirtschaft, 36. Jg., Sp. 209.

- (1973): Fünfzig Jahugănge Steuer und Wirtschaft - Ein Ausschnitt aus der Geschichte des Steuerrechts, in: Steuer und Wirtschaft 4/1973, S. 273.

- (1979): Steuerumgehung zwischen Steuervermeidung und Steuerhinterziehung, in: Steuerberater-Jahrbuch $1978 / 79$, S. $443-460$.

- (1980): Grundfragen der Liebhaberei, in: Steuer und Wirtschaft 3, S. 226.

- (1985): Über Pflichtabfuhrungen und Steuern der Deutschen Demokratischen Republik, in: Steuer und Wirtschaft 4, S. 356.

- (1990): Ober die GleichmaßBigkeit der Besteuerung, Steuer und Wirtschaft 4, S. 322.

Küng, E.: Die Subventionen in nationalökonomischer Beleuchtung, in: Jahrbuch fur Nationalökonomie und Statistik, Bd. 149.

Küster, E. (1983): Das Steuerstrafrecht aus der Sicht der Steuerfahndung, in: G. Kohlhammer (Hrsg.): Strafverfolgung und Strafverteidigung im Steuerstrafrecht, Köln.

Kuhrt, D. (1976): "Volkswirtschaftlich besonders forderungswürdig" im Investitionszulagengesetz, in: Der Betrieb, Nr. 28, S. 1305.

Kumpf, J. H. (1991): Hans Delbrück: Die Preußische Einkommensteuer-Reform 1891 und der Bochumer Steuerprozeß von 1891, versehen mit Anmerkungen und einem historischen Kommentar, in: Steuerliche Vierteljahresschrift, S. 180.

- (1993): Zum 30. Todestag von Armin Spitaler, in: Steuerliche Vierteljahresschrift, Heft 3, Herne, S. 261.

Kupfer, G. (1993): Grenzbereich zwischen Einkünfteerzielung und Liebhaberei, in: KOSDI $1 / 93$, S. 9212.

Laband, P./Hamm, O./Heinitz, E. (Hrsg.): Deutsche Juristen-Zeitung, Berlin 
Lakatos, I.Musgrave, A. (Hrsg.) (1974): Kritik und Erkenntnisfortschritt. Abhandlungen des Internationalen Kolloquiums über die Philosophie der Wissenschaft, London 1965, Band 4, Braunschweig.

Lampe, A. (1928): Die wirtschaftlichen Voraussetzungen der nichtfiskalischen Steuergestaltung insbesondere der Steuerbegunstigung, in: $\mathrm{H}$. Taschemacher (Hrsg.): Festgabe fur Georg Schanz zum 75. Geburtstag 12. März. 1928, Bd. 1, S. 172.

- (1934): Verteidigung der Einkommensteuer, in: Finanzarchiv, N. F., Bd. 2, S. 619

- (1934): Reine Theorie der Finanzreform, in: Finanzarchiv N. F., Bd. 2, S. 218.

Lampert, H. (1988): Die Wirtschafts- und Sozialordnung der Bundesrepublik Deutschland, 9. aberarb. Aufl., Minnchen.

Lang, J. (1974): Systematisierung der Steuervergünstigungen, Diss., Köln.

- (1981): Liebhaberei im Einkommensteuerrecht, in: Steuer und Wirtschaft 3, S. 223.

- (1983): Familienbesteuerung. Zur Tendenzwende der Verfassungsrechtsprechung durch das Urteil des Bundesverfassungsgerichts vom 3.11.1992 und zur Reform der Familienbesteuerung, Steuer und Wirtschatt 2, S. 103.

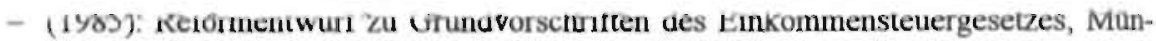
steraner Symposium, Bd. 2, Köln.

- (1985): Klaus Tipke sechzig Jahre, in: Steuer und Wirtschaft 4, S. 301.

- (1986): Einkommensteuerreform: Einfach und gerecht! in: FinanzRundschau, Nr. 19, 41. (68.) Jg., S.501.

- (1987): Die einfache und gerechte Einkommensteuer. Ziele, Chancen und Aufgaben einer Fundamentalreform, in: Schriftenreihe Rechtsordnung und Steuerwesen, hrsg. v. B. Knobbe-Keuk, Bd. 7, Köln.

- (1987): Gemeinnutzigkeitsabhängige Steuervergünstigungen. Ein Grundsatzthema zum Abbau von Steuersubventionen, in: Steuer und Wirtschaft 3, Sp. 220.

- (1988): Bemessungsgnundlage der Einkommensteuer. Rechtssystematische Grundlagen steuerlicher Leistungsfahigkeit im deutschen Einkommensteuerrecht, Habilitationsschrift 1981, Köln.

- (1989): Reform der Unternehmensbesteuerung, in: Steuer und Wirtschaft. 1, S. 3.

- (1990): Verfassungsrechtliche Gewahhrleistung des Familienexistenzminimums im Steuer- und Kindergeldrecht. $\mathrm{Zu}$ den Beschlüssen des Bundesverfassungsgerichts vom 25.5.1990 und vom 12.6.1990, in: Steuer und Wirtschaft 4, S. 331.

- (1990): Reform der Unternehmensbesteuerung auf dem Weg zum europäischen Binnenmarkt und zur deutschen Einheit, in: Steuer und Wirtschaft 2, S. 107.

- (1991): Heinrich Wilhelm Kruse sechzig Jahre, in: Steuer und Wirtschaft, Nr. 3/1991, S. 205 .

- (1993): Entwurf eines Steuergesetzbuchs für mittel- und osteuropăische Staaten, (= Schriftenreihe des Bundesministeriums der Finanzen), Bonn. 
Langer, K. (1952): Steuerersparnisse bei Investitionen in der Schiffahrt, in: Der Wirtschaftsprufer, Zeitschrift für das deutsche Prafungs- und Bilanzwesen, 5. Jg., S. 33.

- (1952): Steuerbegünstigtes Sparen mit fremden Mitteln, in: Die Wirtschaftsprüfung, Betriebswirtschaftliches Archiv und Fachorgan für das wirtschaftliche Prufungsund Treuhandwesen/Mitteilungsblatt der Prüfenden sowie der Wirtschafts- und Steuerberatenden Berufe, Jg. 5, S. 15.

Larenz, K. (1975): Methodenlehre der Rechtswissenschaft, 3. Aufl., Berlin u.a; (1991): 6. Aufl., Berlin u. a.

Latsch, W. (1986): Der Bankenerlaß aus der Sicht der steuerlichen Betriebsprüung/ Außenprüfung, in: Die steuerliche Betriebsprüfung, 26. Jg., Nr. 6, S. $121-127$ und Nr. 7, S. 145.

Laufenburger, H. (1956): Die Einkommensbesteuerung, in: Handbuch der Finanzwissenschaft, Hrsg. W. Gerloff und F. Neumark, Bd. 2, 2. völlig neubearb. Aufl., S. 447, Tubingen.

Laum (ohne Vorname) (1923): Geschichte der offentlichen Armenpflege, in: Handwōrterbuch der Staatswissenschaften, 1. Bd., Jena, S. 938.

Lehmann, M. (1901): Der Ursprung der preußischen Einkommensteuer, in: Preußische Jahurbücher, Bd. 103, S. 1.

Lehmann, M. (1990): Gesamthandskonzept und Erbauseinandersetzung. Die bisherigen einkommensteuerrechtlichen Folgen und der Vorlagebeschluß des VIII. Senats vom 18. 10.1988 an den Großen Senat des BFH, in: Finanz-Rundschau 9, S. 265.

Lehner, M. (1986): Abzug des Grundfreibetrages von der Bemessungsgrundlage oder von der Steuerschuld? in: Steuer und Wirtschaft 1, Sp. 58.

Leibfried, S./Tennstedt, F. (Hrsg.) (1985): Politik der Armut und die Spaltung des Sozialstaats, 1- Aufl., Frankfurt.

Leidel, H. (1964): Die Begrundung der Reichsfinanzverwaltung, Diss. Erfurt.

Leingortner, W. (1979): Zur Liebhaberei im Einkornmensteuerrecht, in: FinanzRundschau, 34. (61.) Jg., Nr. 5, S. 105 .

- (1985): Negative Einkünfte aus Liebhaberei nach bisheriger Rechtsprechung ind nichtsteuerbare Einkünfte nach dern Beschluß GrS 4/82 - Was hat sich gealndert?, in: Deutsches Steuerrecht, Heft 5, S. $13 \mathrm{i}$.

Leisner, W. (1983): Von der Leistung zur Leistungsfahigkeit - die soziale Nivellierung. Ein Beitrag wider das Leistungsfahigkeitsprinzip, in: Steuer und Wirtschaft 2, S. 97.

Leitner, F. (1907): Die Verteilung des Einkommens in Österreich, Wien.

Lexikon für das Geld-, Bank und Börsenwesen, 3. Aufl., Frankfurt/M.

Leuckart v. Weißdorf, H. (1911): Entwicklung und Ergebnisse der Wertzuwachsbesteuerung im Kőnigreich Sachsen, Diss. phil., Borna-Leipzig. 
- (1914): Das Verbot des Verkehrs der Stănde mit anderen Behörden als dem Ge. samtministerium, nach \& 133 der Sãchsischen Verfassungskunde, Diss. jur, BornaLeipzig.

von Liebig, E. (1910): Der Betrag der Feuerversicherungswerte in Deutschland, in: $\mathrm{H}$. Delbruck (Hrsg.): Preußische Jahurbacher, 139. Bd., Berlin, S. 108.

Liebmann, O. (1910) (Hrsg.): Festgabe der Deutschen Juristen-Zeitung 1810 - 1910 zur Jahrhundertfeier der Friedrich-Wilhelms-Universităt zu Berlin.

Limbach, J. (1973): Die rechtliche Erheblichkeit gesellschaftlicher Unwissenheit, in: Jahrbuch für Rechtssoziologie und Rechtstheorie, Bd. 3, Duisseldorf, S. 307.

Lindenlaub, D. (1967): Richtungskämpfe im Verein für Sozialpolitik, Wiesbaden.

- (1969): Firmengeschichte und Sozialpolitik. Zur Wissenschaftsgeschichte der Nationalokonomie in Deutschland vor dem Ersten Weltkrieg, in: K.-H. Manegold. Wissenschaft, Wirtschaft und Technik, Studien zur Geschichte, Wilhelm Treue zum 60. Geburtstag, München.

Linker, J. (1934): Subjektive: und objektive Tendenzen in der Einkommensbesteuenung, Diss. phil., Berlin.

Linzbach, P. (1984): Der Werdegang der preussischen Einkommensteuer unter Berucksichtigung ihrer kausalen Entwicklungsfaktoren. Ein Beitrag zur Theorie der Durchsetzbarkeit der Einkommensteuer, in: Europäische Hochschulschriften, Reihe V: Volks- und Betriebswirtschaft, Bd. 503, Frankfurt u. a. O.

Lion, M. (1925): Die Abschlußzahlungen vor dem Forum der Rechtswissenschaft, in: Steuer und Wirtschaft, 4. Jg., Sp. 1535.

- (1928): Der Einkommensbegriff nach dem Bilanzsteuerrecht und die Schanzsche Einkommenstheorie, in: H. Teschemacher (Hrsg.): Beiträge zur Finanzwissenschaft, Bd. II, Festgabe für Georg von Schanz zum 75. Geburtstag 12. Mărz 1928, Tubingen.

Lipps, W. (1977): Bedenkliche Sonderrechtsbildungen gegen "A.bschreibungsgesellschafter", in: Betriebs-Berater, Heft 1, S. 5.

- (1979): Zur Strafbarkeit des sogenannten "Berliner Modells", in: Betriebs-Berater, Heft 24, S. $1235-1239$.

Littmann, K. (1971): Ein Valet dem Leistungsfahigkeitsprinzip, in: H. Haller u. a (Hrsg.), S. 113

- (1977): Problemstellung und Methoden der heutigen Finanzwissenschaft, in: Handbuch der Finanzwissenschaft, 3. Aufl., Bd. 1, S. 99.

- (1984): Von Reform keine Spur, in: Wirtschaftswoche 38, S. 74.

- (1985): Steuerreform statt Tarifanpassung, Wirtschaftspolitische Kolloquien der Adolf-Weber-Stiftung, Berlin.

- (1985): Das Elend der Gewerbesteuerreform, in: H. Hanusch/K. W. Roskamp/ J Wiseman (Hrsg.), S. 223. 
- (1987): Bittere Klagen mit falschen Zahlen. Die Steuerlast der Unternehmen ist nicht so hoch wie behauptet wird, in: Die Zeit vom 20.2.1987.

- (1987): Durchmarsch ohne klares Ziel. Beim Abbau von Steuersubventionen fehit dem Finanzminister die Linie, in: Die Zeit vom 23.10.1987, S.31.

- (1987): Die Steuerlast der Unternehmen. Positives und Kritisches zu einem Orientierungspunkt der Steuerpolitik. Vortrag der Klaus-Dieter-Arndt-Stiftung am 17.9.1987 im Wissenschaftszentrum, in: Schriftenreihe der Klaus-Dieter-ArndtStiftung, Heft 11, Bonn.

Lófler, O, (1924): Der Buchprüfungsdienst der Reichsfinanzverwaitung, in: E. Schmalenbach (Hrsg.): Zeitschrift für Handelswissenschaftliche Forschung, Leipzig, S. 193

Low , K. (1993): Von Hexen und Hexenjägern. Die Moonies und die Glaubensfreiheit, Baierbrunn (Selbstverlag).

Lohmeyer, H. (1976): Die Straf- und Bußgeldvorschriften der AO 1977, in: Deutsche Steuer-Zeitung A, Nr. 13, S. 239.

Lorenz, E. (1977): Zur Struktur des internationalen Privatrechts. Ein Beitrag zur Reformdiskussion, Berlin.

Lorenz, K.-P. (1977): Die neue Ausbildungs- und Prüfungsordnung für die Steuerbeamten, in: Deutsche Steuer-Zeitung A, S. 384.

Loritz, K.-G. (1986): Die systemgerechte Einkommensteuer - ein unerreichbares Ziel?, in: Steuer und Wirtschaft 1, S. 9.

- Das Grundgesetz und die Grenzen der Besteuerung, in: Neue Juristische Wochenschrift, Heft $1 / 2, \mathrm{~S}$. 1 .

Loss, L. (1967): Der Schutz der Kapitalanleger, in: Zeitschrift fûr das gesamte Handelsrecht und Wirtschaftsrecht, Stuttgart, S. 197.

Lotz, W. (1912): Beitraige zur Literaturgeschichte des steueffeien Existenzminimums. Eine Bentham-Studie, in: Archiv für Sozialwissenschaft und Sozialpolitik, 34. Bd., S. 498 .

- (1917): Finanzwissenschaft, Tubingen.

- (Hrsg.) (1929): Kapitalbildung und Besteuenung, in: Schriften des Vereins furr Socialpolitik, 174. Bd., Leipzig.

- (1931): Finanzwissenschaft, 2. Aufl., Tubingen.

Luchterhandt, H. F. (1973): Luftfahrtbeteiligungen, in: Radler, A./Raupach, A., S. 269.

Luckan, E./Schacht, K. (1970): Glāubigerschutz, Publizităt und Haftung. Dargestellt am Beispiel der Behandlung von Gesellschafterdarlehen im Referentenentwurf eines GmbH-Gesetzes, in: Der Betrieb, Jg. 23, Heft 32, S. 1449.

Ludwig Erhard-Stiftung (Hrsg.) (1985): Recht und Gesittung in einer freien Gesellschaft. Zur Erinnerung an Franz Böhm aus Anlaß des 90. Geburtstages, Bonn. 
- (1995): Wirtschaftsordnung als Aufgabe. Zum 100. Geburtstag von Franz Böhm, Bonn.

Maaßen, K. (1957): Vereinbarungen mit dem Finanzamt - Thre Zulässigkeit und Wirkung, in: Finanz-Rundschau, 12. Jg., Nr. 11, S. 244.

- (1959): Regelungen mit dem Finanzamt. Auskünte, Zusagen und Vereinbarungen im Steuerrecht, Köln.

Maatz (ohne Vorname) (1897): Bilanzgewinn und Einkommen, in: Verwaltungsarchiv, 5. Bd., Berlin, S.373.

- (1905): Ertrag und Einkommen im Bürgerlichen Gesetzbuche, in: Verwaltungsarchiv, 13. Bd. Berlin, S. 309.

- (1906): Die Novelle zum preußischen Einkommensteuer- und Ergănzungssteuergesetz, in: Finanz-Archiv, 23. Jg., 2. Bd. S. 116.

- (1909): Die preußische Einkommen- und Ergănzungssteuernovelle von 1909, in: Finanz-Archiv, 26. Jg., 2. Bd., S. 341.

Mackenroth, G. (1934): Deutsche Industriepolitik 1933, in: Jahrbücher fur Nationalokonomie und Statistik, Bd. 140, S. 54.

Mader, L. (1988): Experimentelle Gesetzgebung, in: Jahrbuch für Rechtssoziologie und Rechtstheorie, darin: Gesetzgebungstheorie und Rechtspolitik, Bd. 13, S. 211.

Madje, A. (1950): Steuerbegunstigte Kapitalbildung, in: Der Betrieb, 3. Jg. Nr. 18.

Mamroth, K. (1890): Geschichte der Preußischen Staats-Besteuerung im 19. Jahrhundert. Mit Rucksicht auf Volks-- und Staatswirtschaft, Finanzverfassung und Finanzverwaltung. 1. Teil, Leipzig.

Mann, H. (1987): Theorie und Politik der Steuerreform in der Demokratie, (= Hohenheimer Volkswirtschaftliche Schriften) Frankfurt/M.

Mann F. K. (1929): Bemerkungen zur Fruhgeschichte der allgemeinen Steuerlehre, in: Schmollers Jahrbuch, 53. Jg., Leipzig.

- (1934): Beiträge zur Steuersoziologie, in: Finanzarchiv, N. F., Bd. 2, S. 218, Tubingen.

- (1937): Steuerpolitische Ideale. Vergleichende Studien zur Geschichte der okonomischen und politischen Ideen und ihres Wirkens in der offentlichen Meinung 1600 - 1935, in: Finanzwissenschaftliche Forschungen, hrsg. von F. K. Mann, Heft 5, Jena.

- (1952): Geschichte der angelsăchsischen Finanzwissenschaft, in: Handbuch der Finanzwissenschaft, 1. Bd., Tubingen, S. 460.

- (1959): Finanztheorie und Finanzsoziologie, Gottingen.

- (1971): Die drei Finanzwissenschaften, in: Finanzarchiv, N. F., Bd. 30, S. 1.

- (1975): Abriß einer Geschichte der Finanzwissenschaft, in: Handbuch der Finanzwissenschaft, 3. Aufl., Tubingen, S. 77. 
Mann, F. K./Nipperdey, C.-H. (1933): Steuergutscheine und Tariflockerung. Vollstăndiger Kommentar zur Notverordnung des Reichspräsidenten zur Belebung der Wirtschaft vom 4.9.1933, Berlin.

Marcinowski, F. (1893): Aus der Praxis der Verwaltung der direkten Steuem, in: Verwaltungsarchiv, 1. Bd., Berlin, S. 213.

- (1894): Die Ermäßigung endgultig veranlagter Staats- und Einkommensteuer, in: Verwaltungsarchiv, 2. Bd., Berlin, S. 520 .

Martens, J. (1981): Neuorganisation der Finanzămter - Neufassung der GNOFÄ, in: KOSDI, Heft 4, S. 4146.

- (1989): Sozialrechtsnormen im Steuerrecht, in: Steuerliche Vierteljahresschrift, 1. Jg., S. 199.

Marx, F. J. (1990): Steuervermeidende Sachgestaltungen mittels zivilrechtlicher Vermögenssonderung. Zur Abfolge von Aktionen der Steuerptlichtigen und Reaktionen von Finanzverwaltung, Rechtsprechung und Gesetzgebung, in: Steuer und Wirtschaft 2, S. 151 .

Mathiak, W. (1975): Die Einkünfleverprobung mit Hilfe der Lebenshaltungsgleichung (Vermögenszuwachsrechnung und Geldverkehrsrechnung), in: Steuer und Wirtschaft, S. 30.

Mattem, G./Me/3mer, K. (Hrsg.) (1968): Reichsabgabenordnung. Mit Nebengesetzen einschließlich Steuerberatungsrecht, Bonn.

Matthäu.s-Meier, I. (1989): Eine aufkommensneutrale Umstrukturierung des Steuersystems ist notwendig, Zeitgespräch, Wirtschaftsdienst V, S. 226.

Mauz, F. (1935): Geschichte der preußischen Einkommensteuer bis zur Reform im Jahre 1891, Diss. rer. pol., Tubingen.

May, R. E. (1899): Das Verhältnis des Verbrauches der Massen zu demjenigen der "kleinen Leute", der Wohlhabenden und Reichen und die Marxistische Doktrin, in: Jahrbuch fitr Gesetzgebung, Verwaltung und Volkswirtschaft im Deutschen Reich, 23. Jg., Leipzig, S. 27!

- (1903): Das deutsche Volkseinkommen im Jahr 1900, im ganzen und im Gesamteinkommen aber und unter 3.000 Mark, verglichen mit dem Volkseinkommen des Jahres 1895 und die Lohnsteigerungen in den Jahren 1896 - 1900, in: Schmollers Jahrbuch, 27. Jg., S. 195.

- (1903): Der Anteil der Arbeiter, der Angestellten und der Selbstăndigen am deutschen Volkseinkommen des Jahres 1900, die Zahl der in jeder dieser Gruppen Erwerbstätigen und der von ihnen Emảhrten, und das Verhăitnis zwischen Einkommen und Familienentfaltung, in: Schmollers Jahrbuch, 27. Jg., S. 521, S. 889.

- (1909): Das deutsche Volkseinkommen und der Zuwachs des deutschen Volksvermögens im Jahre 1907, in: Schmollers Jahrbuch, 33. Jg., S. 1459.

- (1909): Volksvermōgen und Steuerdeklaration, in: Preußische Jahrbächer, 138. Bd., S. 95; hierzu Dellbrück, H., S. 372, S. 559. 
- (1910): Das Hamburger Volkseinkomnen im Jahre 1907, in: Schmollers Jahrbuch, 34. Jg., S. 319.

von Maydell, B. (1987): Zur Reform unseres Sozialrechts. Notwendigkeit und Hindernisse, in: W. FürstR. Herzog/D. C. Umbach (Hrsg.): Festschrift fur Wolfgang Zeidler, Bdl, 1, Berlin, S. 673.

Mayer-Maly, T. (1989): Privatautonomie und Selbstveranwortung, in: Jahrbuch furr Rechtssoziologie und Rechtstheorie, darin: Verantwortlichkeit im Recht, Bd. 14, S. 268.

von Mayr, G. (1904): Zur Reform der Einkommensbesteuerung, in: Verwaltungsarchiv, 12. Bd., Berlin, S. 191.

(1919): Die neueste Umgestaltung der bayerischen direkten Besteuerung, in: Zeitschrift fur die gesamte Staatswissenschaft, Túbingen, S. 27.

Mecklenburgisches Einkommensteuergesetz vom 6.5.1913, in: Reg.-Bl. f. d. Grofherzogt. Mecklenburg-Schwerin, Nr. 24, S. 121.

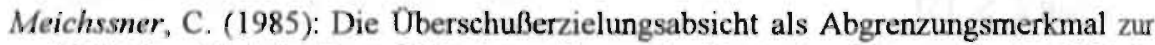
Liebhaberei bei den Immobilieninvestitionen, in: Deutsches Steuerrecht, Heft 21, S. 647.

Meier, A. (1984) Die Bekămpfung der Steuerhinterziehung in der Schweiz. Georg Schanz' "Die Steuern der Schweiz" und die Gegenwart, in. Finanzarchiv, 42. Jg., S. 490 ,

Meilicke, H. (1979): "Liebhaberei" im Einkommensteuerrecht - ein Lieblingskind richterlicher Gesetzgebung, in: Finanz-Rundschan, 34.(61.)Jg., Nr. 14, S. 337.

- (1984): Wird das Steuterstrafrecht fur die Stenerpraxis zum russischen Roulette ? in: Betriebs-Berater, 30. Jg., Heft 30, S. 1885.

Meincke, J. P. (1988): Empfiehlt es sich, das Einkommensteuerrecht zur Beseitigung von Ungleichbehandlungen und zur Vereinfachung neu zu ordnen?, in: Der Betrieb, Heft 37, S. 1869.

- (1990): Die sog. umgekehrte Maßgeblichkeit der Handelsbilanz für die Steuerbilanz aus rechtswissenschaftlicher Sicht, in: Steuer und Wirtschaft 1/1990, S. 15.

Meinecke, F. (1922): Drei Generationen deutscher Gelehrtenpolitikio, in: HZ, Bd. 125, S. 251.

Meisel, F. (1888): Unrecht und Zwang im Finanzwesen, in: Finanz-Archiv, 5. Jg. Stuttgart.

- (1902): Das Strafrecht der österreichischen Einkommensteuer, in: Finanz-Archiv, 19. Jg., S 491 .

- (1911): Moral und Technik bei der Veranlagung der preußischen Einkommensteuer, in: Jahrbuch für Gesetzgebung, Verwaltung und Volkswirtschaft im Deutschen Reich, hrsg. von G. Schmoller, 35. Jg., 1. Heft, Leipzig.

- (1914): Wahrheit und Fiskalismus bei der Veranlagung der modernen Einkommensteuer, in: Finanz-Archiv, 31. Jg., 2. Halbbd., Berlin, S. 144. 
- (1918): Stand und Wert der deutschen Finanzwissenschaft, in: Schmollers Jahrbuch, 42. Jg., Heft 3 u. 4, Leipzig.

- (1919/1920): Wo steht die Deutsche Finanzwissenschaft?, in K. Bücher (Hrsg.): Zeitschrift für die gesamte Staatswissenschaft, 74. und 75. Jg., Tabingen, S. 361, S. 461, S. 54

- (1920): Das Strafrecht der Reichsabgabenordnung, sein Prinzip und seine Technik, Stuttgart.

- (1925): Britische und deutsche Einkommensteuer. Ihre Moral und ihre Technik, Tübingen.

- (1926): Geschichte der deutschen Finanzwissenschaft im 19. Jahrhundert bis zur Gegenwart, in: Handbuch der Finanzwissenschaft, 1. Bd., Tubingen.

- (neubearbeitet von W. Gerloff): Steuertechnik, in: Handbuch der Finanzwissenschaft, 2. Bd., 2. Aufl., Tubingen 1956, S. 357.

Mellerowicz, K. (1963): Eine neuartige Form des Immobilien-Investment, in: Zeitschrift fur Betriebswirtschaft, 33. Jg., Wiesbaden, S. 179.

Menck, T. (1991): Die Steuerreform im Osten Europas - Zu einer Konferenz der OECD, in: Finanz-Rundschau 6, S. 161.

Menger, C. (1883): Untersuchungen uber die Methode der Socialwissenschaften und der Politischen Oekonomie insbesondere, Leipzig.

- (1889): Grundzuge einer Klassifikation der Wirtschaftswissenschaften, in: Jahrbücher für Nationalökonomie und Statistik, N. F., Bd. XIX, S. 465.

Merkenich, K. (1982): Die unterschiedlichen Arten der Einkünfteermittlung im deutschen Einkommensteuerrecht, Schriften zum Steuerrecht, Bd, 24, Berlin.

Merzbacher, F. (1973): Das Wesen der Steuer und die historischen Ansătze des deutschen Steuerrechts, Stuttgart.

Messmer, K. (1981): 'Steuergerechtigkeit' durch Normenflut, offene und verdeckte Subventionen und Entlastung der Finanzgerichtsbarkeit, in: Betriebs-Berater, Beilage 1/1981 zu Nr. 4.

Mestmacker, E. J. (1984): Recht und ökonomisches Gesetz, 2. Aufl, Baden-Baden.

Metz (ohne Vorname) (1935): Zur Frage der fehlerhaften Verwaltungsakte (unter besonderer Berucksichtigung der Verhalltnisse in der Finanzverwaltung), in: Steuer und Wirtschaft, 14. Jg., Sp. 429.

Metzger, U./Weingarten, J. (1989): Einkommensteuer und Einkommensteuerverwaltung in Deutschland. Ein historischer und verwaltungswissenschaftlicher Öberblick, Opladen.

Meyer, D. (1977): Entwicklung und Motive der nichtfiskalischen (insbesondere der wirtschaftspolitisch orientierten) Besteuerung in Deutschland auf der Ebene des Zentralstaates von 1871 bis. 1969, Diss. rer. pol., Munster. 
Meyer, H. (1906): Ein Ueberblick über die französischen Einkommensteuerprojekte nach Annahme der Resolution vom 10. Februar 1887, in: Finanz-Archiv, 23. Jg., S. 13.

Meyer, R. (1884): Die Principien der gerechten Besteuerung in der neueren Finanzwissenschaft, Berlin.

- (1887): Das Wesen des Einkommens, Berlin.

- (1892): Einkommen, in: Handwörterbuch der Staatswissenschaften, 1. Aufl., Jena.

- (1901): Das Zeitverhăltnis zwischen der Steuer und dem Einkommen und seinen Theilen. Ein Beitrag zum österreichischen Steuerrechte und zur Lehre vom Einkommen, Wien.

- (1903): Rezension von B. Fuisting: Die Grundzuge der Steuerlehre, in: Zeitschrift für Volkswirtschaft, Sozialpolitik und Verwaltung, 12. Bd., Wien und Leipzig.

Meyers Konversations=Lexikon. Funfte, gänzlich neubearbeitete Auflage (1894), Fonfter Band, Leipzig und Wien.

Michaelis (ohne Vorname) (1912): Moral und Technik bei der Veranlagung der preuBischen Einkommensteuer, in: Verwaltungsarchiv, 20. Bd, Berlin, S. 65.

- (1916): Uber direkte Steuem und deren Verwaltung in Preußen, in: Preußisches Verwaltungs-Blatt, 37. Jg., Nr. 1, S. 289.

Milatz, J. E. (1986): Die "tatsăchliche Verständigung" im Steuerrecht, in: Die Information uber Steuer und Wirtschaft, 40. Jg., Freiburg, S. 300.

Mill, J. St. (1921): Grundsătze der politischen Ökonomie, 2. Bd. Jena.

Ministerielle Denkschrift vom 30. April 1901, betreffend die Wiederaufnahme der Reform der direkten Staatssteuern in Württemberg, in: Finanzarchiv, 18. Jg., S. 862.

Ministerielle Denkschrift betreffend die Fortführung der Steuerreform in Württemberg Vom 19. März 1909, in: Finanz-Archiv, Tubingen, S. 394.

Mirbt; H. (1927): Beiträge zur Lehre vom Steuerschuldverhåltnis, in: Finanz-Archiv, 44. Jg., Tubingen, $\mathrm{S}$. 1 .

Mirre (1927): Die Bonner Vortrăge über die Zusammenhănge zwischen Steuern und Betriebswirtschaft, in: Steuer und Wirtschatt, 6. Jg., Sp. 1034.

Mischler, E. (1907): Die Verteilung des Einkommens in Österreich. Rezension des Titels von Friedrich Leitner, in: Göttingische gelehrte Anzeigen, 169. Jg., 2. Bd., S. 955 , Berlin.

Mitschke, J. (1975): Trivialarithmetik der Staatsbürgersteuer. Eine Replik auf Dieter Schneiders Rezension "Staatsbürgersteuer - ein Schildbürgerstreich", in: Steuer und Wirtschaft 1, S. 69.

- (1976): Ober die Eignung von Einkommen, Konsum und Vermögen als Bemessungsgrundlagen der direkten Besteuerung. Eine meßtechnische Analyse, Berlin.

- (1995): Bürgergeld für mehr Arbeitsplătze, in: FAZ v. 16.12.1995, S. 17. 
Mitteilungen aus der Verwaltung der direkten Steuern im preußischen Staate. Statistik der preußischen Einkommensteuer-Veranlagung für das Steuerjahr 1907, Berlin 1907.

Mittheilungen aus der Verwaltung der direkten Steuern im Koonigreich Sachsen (1870 ff), Dresden.

Mittheilungen über die Verhandlungen des Landtages im Königreich Sachsen 1871 bis 1878.

Mittelsteiner, K. H./Schaumburg, H. (Hrsg.) (1976): Abgabenordnung 1977, Materialien, Köln.

Mittmann, V. (1985): Die Überspannung des Werbungskostenbegriffs - ein Hindernis für die Erzielung von Einkünften aus Vermietung und Verpachtung, in Deutsches Steuerrecht, Heft 4, S. 99.

Model (ohne Vorname) (1923): Zur Frage der Vereinfachung des Reichssteuerwesens, in: Deutsche Juristen-Zeitung, Heft 13/14, Sp. 397.

Möhle, F. (1949): Betriebswirtschaft oder Steuerpolitik? in: Die Wirtschaftsprufung, Stuttgart, Stuttgart, Nr. 7, 2. Jg., S. 289.

Móller, A. (1969): Fünfzig Jahre Reichsabgabenordnung. Bulletin des Presse- und Informationsamtes der Bundesregierung, Nז. 147, S. 1249.

- (1971): Reichsfinanzminister Matthias Erzberger und sein Reformwerk (= Informationshefte des Bundesministeriums für Wirtschaft und Finanzen, Heft 7), Bonn.

Möller, H(ans) (1989): Die Währungsreform von 1948 und die Wiederherstellung marktwirtschaftlicher Verhältnisse, in: Hampe, R. (Hrsg.), Währungsreform und Soziale Marktwirtschaft, München.

Moeller, H. (1949): Schacht als Geld- und Finanzpolitiker, in: Finanzarchiv, N. F., Bd. 11, Tubingen, S. 733.

Mösbauer, H. (1975): Das Steuerrecht - Auf der Suche nach dem System, in: Deutsches Steuerrecht, Heft 24, S. 679.

- (1986): Steuerfahndung im Rechtsstaat, in: Deutsche Steuer-Zeitung, 74. Jg., Nr. 14, S. 339.

Möschel, W. (1985): Das Kartellgesetz heute - aus ordoliberaler Sicht, in: Ludwig-Erhard-Stiftung (Hrsg.): Recht und Gesittung in einer freien. Gesellschaft. Zur Erinnerung an Franz Bohm aus Anlaß des 90. Geburtstages, Bonn.

- (1995): Herausforderung an die Wettbewerbspolitik, in: Ludwig-Erhard-Stiftung (Hrsg.): Wirtschaftsordnung als Aufgabe. Zum 100. Geburtstag von Franz Bohm, Bonn.

Molitor, B. (1995): Wirtschaftspolitik, München.

Moll, B. (1915): Nationalōkonomie und Politik, in: Annalen des Deutschen Reichs, München, S. 689. 
- (1924): Probleme der Finanzwissenschaft. Methodologische und finanztheoretische Untersuchungen, Leipzig.

- (1930): Lehrbuch der Finanzwissenschaft, Berlin.

Moll, W. (1911): Entstehung und Ziele der Einkommensbesteuerung. Eine rechtsgeschichtliche und rechtsvergleichende Untersuchung, Berlin.

- (1912): Zur Reform des Einkommensteuergesetzes, in: Preußisches VerwaltungsBlatt, 33. Jg., S. 275.

- (1914): Einkommensbesteuerung nach der Vergangenheit? in: Preußisches Verwaltungs-Blatt, 34., Jg. S. 384.

- (1917): Kriegsănderung des preußischen Einkommensteuergesetzes (Antrag Schweckendieck), in: Finanz-Archiv, 34. Bd., S. 289.

- (1918): Zur Veredelung der preussischen Einkommensteuer, in: Finanz-Archiv, 35. Jg., S. 1 .

Mondorf (1950): "Siebener-Gruppe" und dritte Steuerreform, in: Der Betrieb, Nr. 19, S. 222 .

Montaner, A. (1967) (Hrsg.): Geschichte der Volkswirtschaftslehre, K.oln.

Morand, C.-A. (1988): Die Erfordemisse der Gesetzgebungsinethodik und des Verfassungsrechts im Hinblick auf die Gestaltung der Rechtsvorschriften, in: Jahrbuch fur Rechtssoziologie und Rechtstheorie, Bd. 13, S. 11.

Mrozek, A. (1909): Die Mangel der Veranlagung zur Einkommensteuer und Vorschläge zu ihrer Beseitigung, in: Preußische Jahrbucher, 136. Bd., Berlin, S. 259.

- (1910): Zur Reform der Preußischen Finanzverwaltung, in: Preußische Jahrbucher, 139. Bd., Berlin, S. 101

Muhlbauer, D. (1973): Ånderung der Rechtsprechung des Bundesfinanzhofes zum negativen Kapitalkonto eines Kommanditisten?, in: Der Betriebs-Berater, Heft. 22, S. 1018.

Miller-Amack, A. (1948): Wirtschaftslenkung und Marktwirtschaft, Hamburg.

- (1949): Das Grundproblem unserer Wirtschaftspolitik: Ruckkehr zur Marktwirtschaft, in: Finanzarchiv, N. F., Bd. 11, Tobingen, S. 57.

- (1956): Soziale Marktwirtschaft, in: Handwörterbuch der Sozialwissenschaften, 9. Bd., S. 390.

- (1966): Wirtschaftsordnung und Wirtschaftspolitik, Freiburg/Br.

- (1975): Fortschreibung der Sozialen Marktwirtschaft, in: Wirtschaftsordnung und Staatsverfassung, Festschrift für Franz Böhm, Tubingen, S. 449.

- (1981): Der humane Gehalt der Sozialen Marktwirtschaft, in: ders.: Genealogie der Sozialen Marktwirtschaft, 2. Aufl., Bern, S. 167.

Mundorf, H. (1989): Einmalige Gutmütigkeit im Umgang mit Steuersündern bei der Amnestie, in: Handelsblatt Nr. 5 v. $6 . / 7.1 .89$, S. 2. 
Munkes, H. (1973): Verlustzuweisung allein macht KG-Anteile noch nicht zur rentablen Kapitalanlage, in: Wertpapier, Zeitschrift für Kapitalanlage, S. 858.

Murhard, K. (1834): Theorie und Politik der Besteuerung. Ein Handbuch für Staatsgelehrte, Volksvertreter und Geschăftsmănner, Göttingen.

Muscheid, J. (1986): Die Steuerpolitik in der Bundesrepublik Deutschland 1949 . 1982, Berlin.

Musgrave, P. (1990): International Coordination Problems of Substituting Consumption for Income Taxation, in: M. Rose (Hrsg.), S. 453.

Musgrave R. A. (1974): Finanztheorie, 3. Aufl., Tübingen.

- (1981): Leviathan Cometh - or Does He?, in: H. F. Ladd/T. N. Tideman (Eds.), S. 77.

- (1985): Die, offentlichen Finanzen in Theorie und Praxis, Bd. 2.

- (1988): Wicksell und die Geburt der modernen Finanztheorie, in: Vademecum zu einem anregenden Klassiker der ökonomischen Wissenschaft (= Recktenwald, H C./Engels, W./Hax, H./Hayek von, F. A. (Hrsg.): Die Handelsblatt-Bibliothek, Düsseldorf.

Muuss, H. (1975): AO-Reform, in: Sieuerkongress-Report 1975, München, S. 117.

Freiherr von Myrbach, F. (1898): Die Reform der direkten Steuer in Osterreich. Die Personaleinkommensteuer, in: Schmollers Jahrbuch, 22. Jg., S. 799.

Myrdal, G. (1963): Das politische Element in der nationalökonomischen Doktrinbildung, bearb. von M. Schuler, Hannover.

Nasse, E. (1854): Ueber die Reformen in britischen Steuerwesen seit der Wiedereinfuhrung der Einkommensteuer durch Sir Robert Peel, in: Zeitschrift für die gesammte Staatswissenschaft, 10. Jg., Tubingen, S. 48.

- (1871): Die preußische Finanz- und Ministerkrisis im Jahre 1810 und Hardenberg's Finanzplan, in: Historische Zeitschrift, 13. Jg., 26. Bd., 3. Heft, Munchen, S. 282

- (1873): Ueber die Reform der Personalbesteuerung. Beantwortung der vom Ausschusse der Eisenacher Versammlung gestellten Fragen, in: Die Personalbesteuerung. Gutachten auf Veranlassung der Eisenacher Versammlung zur Besprechung der socialen Frage (= Schriften des Vereins fur Socialpolitik, 3. Bd., Leipzig, S. 1 .

Nassen, P. (1933): Geld schafft Arbeit, in: Der deutsche Volkswirt, 7. Jg., S. 1410.

Naucke, W. (1972): Ober die juristische Relevanz der Sozialwissenschaften, Frankfurt.

Naucke, W./Trappe, P. (1970): Rechtssoziologie und Rechtspraxis, Neuwied/Berlin.

Nebe, H. (1972): Steuerfinanzierte Vermögensbildung durch Verlustzuweisungen? Möglichkeiten und Gefahren der Beteiligung an steuersparenden Anlageobjekten, in: Deutsches Steuerrecht, Heft 13, S. 391.

Neckels, P. (1994): Zur Notwendigkeit eines mißbrauchssicheren Steuerrechts und effektiver Kontrollen im Steuerverfahrensrecht. Eine Betrachtung zu den Konse- 
quenzen des Zinsurteils des Bundesverfassungsgerichts vom 27. Juni 1991, in: Die Steuerwarte, S. 10.

Neumann, F. J. (1874): Die progressive Einkommensteuer im Staats- und Gemeindehaushalt. Gutachten über Personalbesteuerung, auf Veranlassung des Vereins fur Socialpolitik (= Schriften des Vereins fur Socialpolitik, 8. Bd.), Leipzig.

- (1877): Die Kommunalsteuerfrage (= Schriften des Vereins für Socialpolitik), Bd XII, Leipzig.

- (1880): Die Steuer nach der Steuerfahigkeit. Ein Beitrag zur Kritik und Geschichte der Lehren von der Besteuerung. Theil I, in: Jahrbucher fur Nationalokonomie und Statistik, N. F., 1. Bd., S. 511 .

- (1881): Die Steuer nach der Steuerfahigkeit. Ein Beitrag zur Kritik und Geschichte der Lehren von der Besteuerung. Theil IJ, in: Jahrbacher fur Nationalökonomie und Statistik, N. F., 2. Bd., S 455.

- (1882): Schwebende Finanzfragen, in: Jahrbuch fitr Gesetzgebung, Verwaltung und Volkswirtschaft im Deutschen Reich, N. F., 6. Jg., S. 143.

- (1887): Die Wehrsteuer. Beiträge zur Erkenntnis und Beurteilung dieser Steuer, in: Finanz-Archiv, 4. Jg., 109.

- (1889): Grundlagen der Volkswirtschaftslehre, Tubingen.

- (1896): Die persönlichen Steuern vom Einkommen, Tübingen.

Neumark, F. (1947): Theorie und Praxis der modernen Einkommensbesteuerung, Bern.

- (1949): Internationale: Entwicklungstendenzen auf dem Gebiete der Einkommensbesteuerung, in: Wirtschaftsarchiv, Bd. 63, S. 1 .

- (1952): Antinomien interventionistischer Wirtschaftspolitik und Möglichkeiten ihrer Oberwindung, in: Zeitschrift fiur die gesamte Staatswissenschaft, 108. Bd., Tubingen, S. 577.

- (1953): Gnundsätzliches zur "Großen Siteuerreform". Vortrag gehalten auf der vom Zentralverband deutscher Konsumgenossenschaften e. V. im JagdschloB Niederwald bei Rüdesheim am 23. und 24. Oktober 1953 veranstalteten Asbeitstagung, Hamburg.

- (1955/56): Alte und neue Probleme der Finanzwissenschaft, in: Finanzarchiv, N. F., Bd. 16, S. 1 .

- (1957): Interventionistische und dirigistische Steuerpolitik, in: Beckerath, E./Meyer, F.Muller-Armack, A. (Hrsg.): Wirtschaftsfragen der freien Welt. Zum 60. Geburtstag von Bundeswirtschaftsminister Ludwig Erhard, Frankfurt/M., S. 450.

- (1959): Wo steht die "Fiscal Policy" heute?, in: Finanzarchiv, Bd. 19, S. 47.

- (1961): Wirtschafts- und Finanzprobleme des Interventionsstaates, Tubingen.

- (1961): Steuerpolitik in der Oberflussgesellschaft, Berlin.

- (1963): Lassalles Steuer-Streitschrift, 1863 - 1963, in: Finanzarchiv, S. 66. 
- (1966): Wirtschaftsordnung, Steuerrecht und Steuerwirklichkeit. Bemerkungen zu einer Schrift von K. H. Friauf, in: Finanz-Archiv, N. F., Bd. 25, Tubingen, S. 476.

- (1969): Zur Problematik einer Steigerung der Effizienz fiskalpolitischer Instrumente des Stabilitătsgesetzes, in: Finanz-Archiv, N. F., Bd. 28, S. 100.

- (1970): Grundsătze gerechter und okonomisch rationaler Steuerpolitik, Tubingen.

- (1970): Grundsătze der Besteuerung in Vergangenheit und Gegenwart, 2. Aufl., Wiesbaden.

- (1970): Ausgabenpolitische Maßnahmen zur Verringerung von Wachstumsschwankungen, in: Grundsătze der Besteuerung in Vergangenheit und Gegenwart, 2. Aufl, Wiesbaden.

- (1972): Die Hundesteuer ist pure Willkuir. Ein Gutachten uber die Hundesteuer in der Bundesrepublik, Hamburg.

- (1976): Zur Finanzgeschichte der Weimarer Republik, in: Finanz-Archiv, N. F., Bd. 35, S. 551 .

- (1977): Finanzieller und politischer Bankrott eines Staates, in: Finanz-Archiv, N. F., Bd. 35, S. 497.

- (1981): Grundsătzliche Betrachtungen über die Grenzen der Besteuerung, ifoSchnelldienst $16 / 17$, S. 8.

- (1982): Betrachtungen zur steuerrechtlichen Liebhaberei, in: Finanzarchiv, N. F, Bd. 40 , S. 150.

- (1984): Hundert Jahre "Finanzarchiv", in Finanzarchiv, N. F., Tübingen, S. 385.

- (1986): Der Aufstieg der Einkommensteuer. Entstehung und Entwicklung der direkten Besteuenung, in: Mit dem Zehnten fing es an. Eine Kulturgeschichte der Steuer, hrsg. von U. Schult, München, S. 232.

- (1986): Wandlungen der Ansichten ûber Moral in Politik und Wirtschaft. Vortrag, gehalten anläßich der Jahresversammilung der Gesellschaft zur Förderung der finanzwissenschaftlichen Forschung e. V., K.oln, am 21.1.1986 in der Universitat zu Köln, in: Sonderveröffentlichung Nr. 12, Finanzwissenschaftliches Forschungsinstitut an der Universităt zu Kōln.

- (1989): Die Steuerrechtswissenschaft - Orientierungsmaßstab für die Steuerpolitik?, in: 40 Jahre Deutsche Steuer-Gewerkschaft, Bonn.

Nevermann, K. (1993): Justiz und Steuerumgehung. Ein kritischer Vergleich der Haltung der Dritten Gewalt zu kreativer steuerlicher Gestaltung in Großbritannien und Deutschland, Berlin.

Nickl, W. (1989): Das steuerrechtliche Sachverstăndigengutachten im Unterhaltsprozeß, in: Neue Juristische Wochenschrift, Heft 34, S. 2091.

Nicolaysen, G. (1966): Eigentumsgarantie und vermögenswerte subjektive offentliche Rechte, in: Hamburger Festschrift für Friedrich Schack zu seinem 80. Geburtstag am 1.10.1966, Hamburg, S. 107. 
Nieland, H. (1990): Der Einfluß des § 30 a AO auf die Besteuerung von Kapitalanlagen bei Banken, in: Deutsche Steuer-Zeitung Nr. 8, S. 192.

Niemann (ohne Vorname) (1910): Bodenspekulation und Wohnungsreform, in: Konservative Monatsschrift, 67. Jg., 2. Halbjahresband, Berlin.

Nipperdey, H. C. (1961): Soziale Marktwirtschaft und Grundgesetz, Berlin.

Nörr, K. W. (1995): Franz Böhm, ein Wegbereiter des Privatrechtsgedankens, in: Ludwig-Erhard-Stiftung (Hrsg.): Wirtschaftsordnung als Aufgabe. Zum 100. Geburtstag von Franz Bŏhm, Bonn.

Noll, P. (1972): Von der Rechtsprechungswissenschaft zur Gesetzgebungswissenschaft, in: H. Albert/N. Luhmann/W. Maihofer/O. Weinberger (Hrsg.): Rechtstheorie als Grund!agenwissenschaft der Rechtswissenschaft, Düsseldorf, S. 524.

Nothhardl, J. (1901): Zur Lehre vom Steuerfreien Existenzminimum, in: Finanzarchiv, 57. Jg., S. 115.

Nordenskjold, E. (1926): Die Geschichte der Biologie. Ein Úberblick, Jena.

von Nostitz, H. (1903): Grundzige der Staatssteuem im Königreich Sachsen, Jena.

- (1904): Die projektierte Neuordnung des Gemeindesteuerwesens im Königreich Sachsen, in: Finanz-Archiv, 21. Jg., S. 342.

- Novelle zum Preussischen Einkommensteuergesetz vom 19. Juni 1906 betr. Abänderung des $\$ 23$ vom 18.6.1907.

Nußbaum, A. (1914): Die Rechtstatsachenforschung. Programmschriften und praktische Beispiele, ausgew. u. eingel. v. M. Rehbinder, Berlin, neu abgedr. Berlin 1968.

Oeconomische Encyclopädie oder allgemeines System der Land- Haus- und StaatsWirthschaft in alphabetischer Ordnung (1777), Zehenter Theil, Berlin.

Dermann, J. (1950): Die Einkommensteuer 1949, in: Steuerberater-Jahrbuch 1949, Koln, S. 25.

Osterreichisches Gesetz, betreffend die direkten Personalsteuem vom 25.10.1896, in: Reichsgesetzbl. Stuck 84, S. 673.

Oettle, K. (Hrsg.) (1971): Steuerlast und Unternehmungspolitik. Kuno Barth zum fünfundsechzigsten Geburtstag, Stuttgart.

Offerhaus, K. (1984): Zur Analogie im. Steuerrecht, in: Betriebs-Berater, 39. Jg., Nr. 16, S. 993.

Oldenberg, K. (1893): Ober sociale Steuerpolitik, in: Jahrbuch für Gesetzgebung, Verwaltung und Volkswirtschaft im Deutschen Reich, 17. Jg., Leipzig, S. 93.

- (1893): Ober sociale Steuerpolitik, in: Preußische Jahrbucher, 73. Bd., S 38 (aus Schmollers Jahrbuch fur Gesetzgebung ..., Bd. 17, abernommen und theilweise vom Verfasser umgearbeitet).

Opp, K.-D. (1973): Soziologie im Recht, Reinbek. 
- (1983): Die Entstehung sozialer Normen. Ein Integrationsversuch soziologischer, sozialpsychologischer und ôkonomischer Erklärungen, Tübingen.

Ordnung betreffend die Erhebung einer Gemeindesteuer bei dem Erwerbe und bei der Verăusserung von Grundstacken und Rechten im Bezirke der Stadt Liegnitz vom 13.2.1907.

Ordnung fur die Erhebung der Wertzuwachssteuer beim Umsatz von Grundstucken in der Gemeinde Pankow bei Berlin vom 7.8.1906.

Ordo. Jahrbuch für die Ordnung von Wirtschaft und Gesellschaft, Stuttgart.

Ortlieb, H.-D. (1974): Glanz undi Elend des deutschen Wirtschaftswunders, München.

Ossenbühl, F. (1987): Der Eigentumsschutz sozialrechtlicher Positionen in der Rechtsprechung des Bundesverfassungsgerichts, Eine Zwischenbilanz, in: W. Forst/ R. Herzog/D. C. Umbach (Hrsg.): Festschrift für Wolfgang Zeidler, Bd. 1, S. 625.

Ott, A. E./Winkel, H. (1985): Geschichte der theoretischen Volkswirtschaftslehre, Göttingen.

Otte, R. (1994): Von der Regierung ist nichts, von der Opposition nichts Gutes zu erwarten, in: Welt am Sonntag, Nr. 17 v. 24.4.94, S. 40.

Pagenkopf, H. (1969): Wirtschaft und Finanzpolitik, in: Institut "Finanzen und Steuern e. V.", Wirtschaft und Politik, Bonn, S. 5.

Pahlke, J. (1969): Steuerpolitische Grundsatzfragen. Kritische Bemerkungen zum Gutachten des Wissenschaftlichen Beirats beim Bundesministerium der Finanzen zur Reform der direkten Steuem, in: Finanzarchiv, Bd. 28, Túbingen, S. 42.

Papier, H.-J. (1973): Die finanzrechtlichen Gesetzesvorbehalte und das grundgesetzliche Demokratieprinzip, Berlin.

Paraskewopoulos, S. (1976): Sozialordnung, in: Gutmann, G./Klein, W./Paraskewopoulos, S./Winter, H.: Die Wirtschaftsverfassung der Bundesrepublik Deutschland, Stuttgart, S. 200.

- (1994): Sozialpolitik in der Sozialen Marktwirtschaft der Bundesrepublik Deutschland, in: Klein, W./Paraskewopoulos, S./Winter, H. (Hrsg.): Soziale Marktwirtschaft. Ein Modell für Europa. Festschrift für Gernot Gutmann zum 60. Geburtstag, Berlin, S. 187.

Patschke, H. (1957): Scheitert der Rechtsstaat?, in: Der Betriebs-Berater, Heft 8, S. $265-271$.

Paulick, H. (1954): Der Grundsatz der Gleichmäßigkeit der Besteuerung - sein Inhalt und seine Grenzen, in: A. Spitaler (Hrsg.): Probleme des Finanz- und Steuerrechts. Festschrift für Ottmar Bühler, Köln, S. 121.

- (1964): Gedanken zur Bilanzbundeltheorie, in: Finanz-Rundschau, 19. (46.) Jg., Nr. 14, S. 294.

- (1970): Die wirtschaftspolitische Lenkungsfunktion des Steuerrechts und ihre verfassungsmäßigen Grenzen, in: Haller, H./Kullmer, L./Shoup, S./Timm, H. (Hrsg.), S. 204. 
Paus, B. (1991): Verfassungswidrige Zinsbesteuerung. Anmerkungen zur Entscheidung des Bundesverfassungsgerichts vom 27. Juni 19912 BvR 1493/89, in: Deutsche Steuer-Zeitung 20, S. 618.

Pausch, A. (1964): Johannes von Miquel. Sein Leben und Werk, in: Wegbereiter des Steuerrechts, hisg, von W. Hartz, Bd. 1, Stuttgart.

- (1965): Matthias Erzberger. Sein Leben und Werk, in: Wegbereiter des Steuerrechts, hrsg. von W. Hartz, Bd. 2, Stuttgart.

- (1973): Zur Geschichte der Besteuerung des Bodenwertzuwachses, in: Steuer und Wirtschaft, S. 306.

- (1973): Rolf Grabower und die Steuerwissenschaften. Und: Rolf Grabowers Veroffentlichungen von 1905 bis 1963, in: Steuer und Wirtschaft 2, S. 189.

- (1973): Zollkommissar Adam Smith und seine Vorleistungen für die europalische Integration, in: Zeitschrift fitr Zolle und Verbrauchsteuem, Nr. 6, S.161.

- (1976): Steuerverweigerung in Bonn und Siegburg - Anno 1848/49, in: Deutsches Steuerrecht, 14. Jg., München, S. 684.

- (1976): Die Steuerreform unter Stein-Hardenberg. Eine Sonderausstellung der Bundesfinanzakademie, in: Deutsche Steuer-Zeitung A, Nr. 3, Bonn, S. 46.

- (1976): Finanzbeamte als Mitgestalter der Kameral-, Finanz- und Steuerwissenschaften, in: Deutsche Steuerzeitung A, Nr. 10, S. 181.

- (1976): No Taxation without Representation. Betrachtungen zur "Steuertaufe" der der USA, in: Deutsche Steuer-Zeitung A, Nr. 13, S. 235.

- (1976): 200 Jahre "Steuer-Bibel" des Finanzbeamten Adam Smith, in: Deutsche Steuer-Zeitung A, Nr. 16, S. 303.

- (1976): 250 Jahre Fachausbildung für den höheren Finanzdienst in Deutschland, in: Im Dienste der Gleichmäßigkeit der Besteuenung, hrsg. vom Bundesministerium der Finanzen, Bonn.

- (1977): Die Geschichte der steuerberatenden Berufe im deutschen Kaiserreich von 1871 bis 1918, in: Die Steuerberatung, 20. Jg., 8. Heft, Bonn, S. $179-184$.

- (1978): Grillparzer im Finanzdienst. Ein Berufsbild des Dichters mit Selbstzeugnissen und Arbeitsbeispielen, 2. Aufl., Köln.

- (1979): Von der Miquelschen Steuerreform zur Betriebsprüfung. Zu einer Aus. stellung der Bundesfinanzakademie, in: Steuer und Wirtschaft, 56. (9.) Jg., S. 365.

- (1979): Von der Reichssteueraufsicht zur Bundesbetriebsprüfung. Betrachtungen zum 100. Geburtstag des ehem. Reichsschatzamtes, in: Deutsche Steuer-Zeitung A, Nr. 16, S. 299.

- (1979). Von der Steuerbilanz zur Handelsbilanz - geschichtlich betrachtet, in: Deutsche Steuer-Zeitung A, Nr. 4, S. 59. 
- (1979): Internationale Steuergeschichte im Aufwind Neue Ausstellung der Bundesfinanzakademie in Wien, in: Deutsche Steuer-Zeitung A, Nr. 20, S. 386.

- (1979): Rund um Beethevens Steuererklârung von 1818, in: Deutsche SteuerZeitung A, Nr. 21, S. 408.

- (1979): Von der Einkommensteuer zur Deklarationsberatung, in: Finanz-Rundschau, Nr. 18, 34. (61.) Jg., S. 441.

- (1982): Ausgewahlte Beitrage zur Finanzgeschichte, hrsg. vom Bundesministerium der Finanzen - Bundesfinanzakademie -, Bonn/Siegburg.

- (1982): Mehr Steuergerechtigkeit mit Hilfe der Bibel?, in: Steuer und Wirtschaft Nr. 2, S. 101.

- (1983): Zum Grabower-Gedenkjahr 1983, in: Deutsche Steuer-Zeitung, Nr. 10, S. 206.

- (1983): Zum 50. Todestag von Albert Hensel, in: Deutsche Steuer-Zeitung Nr. 21, S. 445 .

- (1985): Im Konflikt mit dern Steuerpositivismus. Johannes Popitz zwischen gesetzlichem Unrecht und abergesetzlichem Recht, in: Steuer und Wirtschaft 1, S. 54.

- (1987): Fritz Reinhardt als Mahnung. Ein Steuerfachmann im Dienste Hitlers, in: Der Steuerberater, Heft 11, S. 349.

- (1992): Persőnlichkeiten der Steuerkultur. Steuergeschichte in Lebensbildern von Johannes von Miquel bis Arnim Spitaler, Herne.

Pausch, A./Kumpf, J. H. (1986): Illustrierte Geschichte des steuerberatenden Berufes, 2. Aufl., Köln.

Pechman, J. A. (1985): Über den amerikanischen Steuerreformplan, in: Steuer und Wirtschaft 3, S. 267.

Peffekoven, R. (1980): Persōnliche allgemeine Ausgabensteuer, in: Handbuch der Finanzwissenschaft, Bd. II, Tubingen.

Pehl, S. (1962): Steuerpolitik in der Bundesrepublik Deutschland, D0sseldorf.

Penndorf, B. (1913): Geschichte der Buchhaltung in Deutschland, Leipzig.

Peters, H. R. (1995): Wirtschaftspolitik, München.

Pfleiderer, O. (1934): Steuersystem und volkswirtschaftlicher Kreislauf. Kritische Anmerkungen zu Adolf Lampes "Reiner Theorie der Finanzreform", in: Finanzarchiv, N. F., Bd. 2, S. 419.

Pflugfelder, P. (1984): Das Analogieverbot im Steuerrecht, in: Steuer und Studium, 5. Jg., Nr. 10, S. 290.

Peres, W. (1963): Die Steuerhinterziehung im Spiegel der Rechtsprechung. Die Entscheidungspraxis des Amts- und des Landgerichts Koln von 1950 bis 1959, in: G. Schmőlders (Hrsg.): Finanzwissenschaftliche Forschungsarbeiten, N. F., Heft 27, Berlin. 
Pesch, H. (1924) in: Die Volkswirtschaftslehre der Gegenwart in Selbstdarstellungen, Hrsg. F. Meiner, Leipzig, S. 191.

Pezzer, H.-J. (1987): Verfassungsrechtliche Perspektiven der Familienbesteuerung, in: W. Furst/R. Herzog/D. C. Umbach (Hrsg.): Festschrift für Wolfgang Zeidler, Berlin, S. 757.

- (1989): Familienbesteuerung und Grundgesetz, in: Steuer und Wirtschaft 3, S. 219.

von Philippovich, E. (1921): Grundriß der Politischen Oekonomie, 16. Aufl., Tubingen.

Pietsch, R. (1986): Von den Werbungskosten zu der Gewinnerzielungsabsicht eines Mitunternehmers, in: W. Schlutius (Hrsg.): Gesellschaften und Gesellschafter im Steuerrecht, Bonn, S. 171.

Pißel/Koppe (1927): Das Einkommensteuergesetz vom 10. August 1925 mit Aus- und Durchfuhringsbestimmungen (= Die Steuerkommentare der Praxis, Bd. I), Berlin.

von Pistorius, T. (1898): Minist. Denkschrift, die Weiterführung der Reform der direkt. Steuem in Sachsen, in: Finanz-Archiv, 15. Jg., 1. Bd, S. 407.

- (Hrsg.) (1903): Gesetz betreffend die Einkommensteuer für das Königreich Württemberg vom 8. August 1903 nebst Ausfuhrungsbestimmungen und einen Anhang enthaltend Fassionsbeispiele, Ravensburg.

- (1904): Die württembergische Steuerreform, in: Finanz-Archiv, 21. Jg., S. 1 - 114

- (1910): Vermögensteuer und Landwirtschaft mit besonderer Berücksichtigung der wïrttembergischen Verhältnisse, in: Finanz-Archiv, 27. Jg., Stuttgart, S. 1 - 57.

- (1913): Gesetz betreffend die Einkommensteuer für das Konigreich Württemberg vom 8. August 1903, 3. vermehrte Auflage, Ravensburg.

- (1919); Unser Steuerrecht. Eine Vortragsreihe, Stuttgart.

- (1919): Steuer oder Ertragsanteil?, Jena.

- (1920): Die deutsche Finanzwirtschaft und der Ausweg aus der Not, Stuttgart.

- (1924): Die Einkommensteuerluge, in: Steuer und Wirtschaft, III. Jg., Nr. 11, Sp. 1285 .

- (1927): Rucksichtsteuer und Zwecksteuer, in: Zeitschrift für die gesamte Staatswissenschaft, S. 575 .

- (1928): Allgemeines Steuerrecht einschließlich der Geschichte des deutschen Steuerrechts, den verfassungsmaßigen Grundlagen des geltenden Reichssteuerrechts mit Finanzausgleichsgesetz, Reichsbewertungsgesetz und Reichsabgabenordnung, in: ders.: Unser Steuerrecht Eine Vortragsreihe in drei Teilen (im Manuskript gedruckte akademische Vorlesung), 1. Teil, Bd. I, 2. völlig neubearb. Auflage, Stuttgart.

von Pistorius, T./Winschmann (1925): Die neuen Steuergesetze, in: Juristische Wochenschrift, 54. Jg., Heft 18, Leipzig, S. 1953. 
Platter, J. (1875): Der Kapitalgewinn bei Ad. Smith, in: Jahrbucher für Nationalôkonomie und Statistik, 24. Bd., S. 313.

Plener, E. (1903): Rezension von R. Meyer. Das Zeitverhăltuis zwischen der Steuer und dem Einkommen und seinen Teilen, in: Zeitschrift für Volkswirtschaft, Sozialpolitik und Verwaltung, 12. Bd., Wien und Leipzig.

Pohmer, D. (1988): Einige Bemerkungen zu Inhalt und Bedeutung des Leistungsfahigkeitsprinzips, in: Finanzarchiv 46, S. 135.

- (1993): Die Steuern als Instrument der Staatsfinanzierung oder Wirtschaftslenkung? Steuerpolitik im Spannungsfeld widerstreitender Ziele, in: DStZ, 81. Jg., S. 577.

Pohmer, D./Jurke, G. (1984): Zu Geschichte und Bedeutung des Leistungsfahigkeitsprinzips unter besonderer Berücksichtigung der Beiträge im Finanzarchiv und der Entwicklung der deutschen Einkommensbesteuerung, in: Finanzarchiv.

Pollack, F. (1911), Das Finanzdelikt als Verwaltungsdelikt. Sein Wesen und seine Durchbildung, Breslau.

Pool, K. E. (1957/58): The Impact of Erosion of the Personal Income Tax on Economic Stability, in: Finanzarchiv, N. F., Bd. 18, Tubingen, S. 44.

Popitz, J. (1919): Das Gesetz ubber die Reichsfinanzverwaltung, in: Deutsche JuristenZeitung, 24. Jg., Nr. 19/20, S. 778.

- (1920): Finanzmilitarismus?, in: Festgabe für Dr. jur. h. c. Otto Liebmann, Berlin, S. 232.

- (1925): Die neuen Steuergesetzentwürfe. Vorfragen zur Steuerreform, in: Deutsche Juristen-Zeitung, 30. Jg., Heft 5, Sp. 361.

- (1925): Die neuen Steuergesetze, in: Deutsche Juristen-Zeitung, 30. Jg., Heft 18 , Sp. 1357.

- (1926): Einkommensteuer. Geschichte und geltendes Recht, in: Handworterbuch der Staatswissenschaften, 3. Bd., 4. Aufl, Jena, S. 437.

- (1928): Reformvorschlāge fur das Ausbildungs- und Berechtigungswesen im hoheren Staatsdienst, in: Deutsche Juristen-Zeitung, 33. Jg., Heft 1, Sp. 17.

- (1928): Finanzrecht und Finanzwissenschaft, in: H. Taschemacher (Hrsg.): Festgabe zum 75. Geburtstag von Georg Schanz, Bd. 1, Tubingen.

- (1930): Der wirtschaftende Mensch als Steuerzahler, in: Vierteljahresschrift furr Steuer und Finanzrecht, 4. Jg., Berlin, S. 1.

Popper, K. (1971): Das Elend des Historizismus, 3. Aufl., Tubingen.

Pott, H.-M. (1979): Die Fahrung von Verlustunternehmen als verdeckte Gewinnausschüttung - Zur Ergebnissaldierung zwischen Gewinn- und Verlustunternehmen, in: Steuer und Wirtschaft 4, S. 321.

Preussischer Gesetzentwurf wegen einer Ergănzungssteuer vom 2.11.1892, in: FinanzArchiv, 10. Jg., 1893. 
Preußisches Verwaltungs-Blatt. Wochenschrift für Verwaltung und Verwaltungsrechtspflege in Preußen (1907/08), 29. Jg; (1909/10): 31. Jg.; (1910/11): 32. Jg., Berlin.

Preußisches Einkommensteuergesetz vom 24.6.1891, in: Gesetz-Sammlung für die Königl. Preuß. Staaten, Nr. 19, S. 175.

Preussisches Einkommensteuergesetz vom 19.6.1906, in: Gesetzsamml. Nr. 30, S. 260.

Preussisches Ergänzungssteuergesetz vom 19.6.1906, in: Preuss. Gesetzsamml. Nr. 30, S. 294.

Preussisches Gesetz, betr. die Abănderung des Einkommensteuergesetzes und des Ergănzungssteuergesetzes vom 26.5.1909, in: Preuss. Gesetzsammlung, S. 349.

Pribram, K. (1992): Die deutschen historischen Schulen, in: Geschichte des ökonomischen Denkens, ubers. von $\mathrm{H}$. Brihmann, Frankfurt.

- (1992): Geschichte des olkonomischen Denkens, 1. Bd., Frankfurt/M.

Priddat, B. P. (1992): Der nur halbe Smith: Modernisierungsschwierigkeiten der deutschen Nationalokonomie im 19. Jahrhundert, in: Jahrbuch für Wirtschaftsgeschichte $2 / 1992$, S. 147.

Puchta, G. F. (1856): Pandekten, 8. Aufl, Leipzig.

Radler, A J./Raupach, A. (1973): Handbuch der steuerbegünstigten Kapitalanlagen, Koln.

Raiser, T. (1987): Rechtssoziologie. Ein Lehrbuch, Frankfurt/M.

Rau, K. H. (1855): Grundsatze der Volkswirthschaftslehre, 6. vermehrte und verbesserte Ausgabe, Leipzig und Heidelberg.

- (1855): Lehrbuch der politischen Oekonomie. Erster Band Volkswirthschaftslehre. Grundsatze der Volkswirthschaftslehre, 6. Ausg., Leipzig.

- (1863): Lehrbuch der politischen Oekonomie. Erster Band Volkswirthaschaftslehre. Grundsalze der Volkswirthschaftslehre, 7. Ausgabe, Leipzig und Heidelberg.

- (1864): Lehrbuch der politischen Dekonomie. Dritter Band. Erste Abtheilung. Grundsatze der Finanzwissenschaft, Erste Abtheilung, 5. vermehrte und verbesserte Ausgabe, Leipzig und Heidelberg.

- (1865): Lehrbuch der politischen Oekonomie. Dritter Band. Zweite Abtheilung. Grundsatze der Finanzwissenschaft, 5. vermehrte und verbesserte Ausgabe, Leipzig und Heidelberg.

Raupach, A. (1985): Der Niedergang des deutschen Einkommensteuerrechts - Móglichkeitenkeiten der Neubesinnung, in: A. Raupach/K. Tipke/A. Velner (1985): Niedergang oder Neuordnung des deutschen Einkommensteuerrechts? Münsteraner Symposion Bd. I, Koln, S. 15.

Raupach, A./Tipke, K./Uelner, A. (1985): Niedergang oder Neuordinung des deutschen Einkommensteuerrechts? Münsteraner Symposion Bd. I, Köln.

Rechtsgnundsătze des $\mathrm{Kgl}$. Săchs. Oberverwaltungsgerichts. Bearbeitet von Dr. Paul Wachler und Dr. E. Naundorff, 1. Bd. Leipzig 1905, 2. Bd. Leipzig 1907. 
Rechts-Lexikon, hrsg. vom Staatsverlag der Deutschen Demokratischen Republik, Berlin.

Recktenwald, H. C. (Hrsg.) (1965): Lebensbilder großer Nationalökonomen, Köln/ Berlin.

- (Hrsg.) (1969): Finanztheorie, Köln.

- (Hrsg.) (1969): Finanzpolitik, Koln.

Reden und Ansprachen gehalten am 24. Juni 1908 bei der Feier zu Schmollers 70. Geburtstag (nach stenographischer Aufnahme).

Reglement, das Kriegs-Schulden-Wesen der Provinz, Ostpreußen und Litthauen und der Stadt Kōnigsberg insbesondere betreffend vom 23. Februar 1808, in: Sammlung der fibr die Konniglich Preußischen Staaten erschienenen Gesetze und Verordnungen von 1806 bis zumn 27sten Oktober 1810, Berlin 1822.

Rehbinder, M. (1970): Die Rechtstatsachenforschung im Schnittpunkt von Rechtssoziologie und soziologischer Jurisprudenz, in: R. Lautmann/W. Maihofer/H. Schelsky (Hrsg.): Die Funktion des Rechts in der modernen Gesellschaft, Bielefeld.

- (1971): Einfithrung in die Rechtssoziologie. Ein Textbuch fur Studenten der Rechtswissenschaft, Frankfurt/M.

- (1986): Die Begrundung der Rechtssoziologie durch Eugen Ehrlich, Berlin.

- (1989): Rechtssoziologie, 2. völlig neubearb. Aufl., Berlin/New York.

Reichsabgabenordnung mit Finanzgerichtsordnung, Steuerberatungsgesetz und allen Nebengesetzen einschließlich landesrechtlicher Bestimmungen, 35, neubearb. Auflage, Stand vom 1. November 1970, Munchen 1970.

Reichseinkommensteuergesetzentwurf vorn 29.11.1919, Begrundung, in: Finanzarchiv, 37. Jg., S. 235.

Reichsgerichtshof (1890): Urteil vom 29.5.1889, Rep. V. 64/89, in: RGZ 24, Leipzig 1890.

Reichs-Geselablatt ab 1874, Berlin

Reinach, H. (1925): Steuerrundschau. Gesetze und Verordnungen. Die Offenlegung der Steuerlisten und der Buchprifungsdienst, in: Steuer und Wirtschaft, IV. Jg., Stuttgart, Sp. 1157.

Reinhardi, F. (1936): Die neuen Steuergesetze, Berlin.

- (1943): Liebhaberei und Einkommensteuer, in: Deutsche Steuer-Zeitung, Jg. IX (XXXII), Nr. $41 / 42$.

Reiß, W. (1986): Einkunftsart und Einkunftsermittlung fur die Gesellschafter einer vermögensverwaltenden Gesamthandsgesellschaft, in: W. Schlutius (Hrsg.): Gesellschaften und Gesellschafter im Steuerrecht, Bonn.

Rendels, H. J. (1993): Der steuerliche Beitrag zum Föderalen Konsolidierungsprogramm, in: Deutsches Steuerrecht, 31. Jg., Heft 25, S. 893. 
Reuss, F. K. (1963): Fiscal Policy for Growth without Inflation. The German Experiment, The Goucher College Series, Baltimore/USA.

Richter, H./Boveleth, K.-H. (1991): Die neue steuerliche Förderung des Wohnungsbaus, 3. Aufl., Köln.

Rieker, H. (1994): Auf dem Rücken der Besserverdienenden, in: Rheinischer Merkur, Wochenzeitung für Politik, Wirtschaft, Kultur. Christ und Welt, 49. Jg., Nr. 16 v. 22.4.94, S. 11 .

Riesser (ohne Vorname) (1920): Die Verordnung uber Maßnahmen gegen die Kapitalflucht vom 24. Oktober 1919, in: Festgabe furr Dr. jur. h. c. Otto Liebmann, Berlin, S. 242.

Ritschl, H. (1930): Die Wandlungen des deutschen Steuersystems von 1913 bis 1928 in ihrem Einfluß auf die Kapitalbidlung, in: Kapitalbildung und Steuersystem, Berlin.

- (1953): Die große Steuerreform, Hamburg.

Ritter, G. A. (1983): Sozialversicherung in Deutschland und England. Ein Vergleich, München.

- (1987): Soziale Sicherheit in Deutschland und Großbritannien von der Mitte des 19. Jahrhunderts bis zum Ersten Weltkrieg. Ein Vergleich, in: Geschichte und Gesellschaft, Bd. 13, Göttingen, S. 137.

Ritter, W. (1989): Reform der Unternehmensbesteuerung aus der Sicht der Wirtschaft, in: Steuer und Wirtschatt 4, S. 319.

Róhl, K. F. (1987): Rechtssoziologie. Ein Lehrbuch, Köln u.a.

Rolle, H. (1973): Abschreibungsobjekte gehoren auf den Prüftand, in: Wertpapier, Zeitschrift für Kapitalanlage, S. 894.

Ropke, W. (1965): Wort und Wirkung, Ludwigsburg.

Roesler, H. (1868): Die Lehre vom Einkommen, in: Jahrbucher für Nationalökonomie und Statistik, 10. Bd., Jena, S. 302.

- (1872): Öber die Beziehungen zwischen Volkswirthschaftslehre und Rechtswissenschaft in Deutschland, in: G. Hirth (Hrsg.): Annalen des Deutsches Reiches, Sp. 509 .

- (1875): Uber die GesetzmäBigkeit der volkswirthschaftlichen Erscheinungen, in: G. Hirth (Hrsg.): Annalen des Deutschen Reichs, Sp. 1 - 42, Sp. 259.

Roßler, G. (1988): Zur Schătzung wegen Nichtabgabe der Steuererklărungen, in: Deutsche Steuer-Zeitung, 76. Jg., Nr. 8, S. 199.

Rogowsky, J. (1953): Zur Finanzierung des Wiederaufbaues der Seeschiffahrt unter besonderer Berucksichtigung der Selbstfinanzierung, in: Hansa, Zeitschrift für Schiffahrt, Schiffbau, Hafen, Hamburg, S. 642, S. 793.

- (1954): Die Wiederaufbaufinanzierung der Seeschiffahrtsbetriebe, Diss. rer. pol,, Köln. 
Roscher, W. (1871): Zum Gesetzentwurf über die directe Besteuerung im Königreich Sachsen, Leipzig, (handschriftlich 1.10.1871), in: Acta, die Reform der directen Steuern betreffend, vom Jahre 1871, Actenstuck. A 54, Vol. 2, Staatsarchiv Dresden.

- (1874): Geschichte der National-Oekonomik in Deutschland, München.

- (1886): Systern der Finanzwissenschaft, Stuttgart.

- (1889): Systemı der Finanzwissenschaft, Dritte vermehrte und verbesserte Auflage, Stuttgart.

Rose, G. (1976): Was heißt und zu welchem Ende studiert man Steuerwissenschaften, in: Deutsche Steuer-Zeitung A, S. 174.

- (1980): Besteuerung nach Wahl. Probleme aus der Existenz steuerlicher Rechtswahlmōglichkeiten, Grundsătze fur ihre Ausnutzung, in: F. Hörstmann u.a. (Hrsg.): Steuerberater-Jahrbuch 1979/80, Köln, S. 49.

Rose, M. (1989): Argumente zu einer 'konsumorientierten Neuordnung des Steuersystems, in: Steuer und Wirtschaft, 66. Jg., Nr. 2, S. 191.

- (1990): Konsumorientierte Neuordnung des Steuersystems, in: StuW, S. 88.

- (Hrsg.) (1990): Heidelberg Congress on Taxing Consumption. Proceedings of the International Congress on Taxing Consumption. Held at Heidelberg, June 28 - 30, Heidelberg.

Ross, A. (1929): Theorie der Rechtsquellen. Ein Beitrag zur Theorie des positiven Rechts auf Grundlage dogmenhistorischer Untersuchungen, Leipzig und Wien.

Roth, K. (1958): Die öffentlichen Abgaben und die Eigentumsgarantie im Bonner Grundgesetz, Heidelberg.

Rubner, H. (1978): Adolph Wagner. Briefe, Dokumente, Augenzeugenberichte. 1851 bis 1917 , Berlin.

Rueff, J. (1953): Naturliche Erklärung eines Wunders, in Hunold, A. (Hrsg.): Wirtschaft ohne Wunder, Erlenbach-Zürich, S. 204.

Rürup, B. (1989): Rucknahme der Quellensteuer: Eine Fehlentscheidung, in: Wirtschaftsdienst 7, S. 334.

Russchemeyer, D. (1976): Juristen in Deutschland und in den USA. Eine vergleichende Untersuchung von Anwaltschaft und Gesellschaft, Stuttgart.

Rüstow, A. (1953): Soziale Marktwirtschaft als Gegenprogramm gegen Kommunismus und Bolschewismus, in: Hunold, A. (Hrsg.): Wirtschaft ohne Wunder, ErlenbachZürich, S. 97.

Rüthers, B. (1987): Warum wir nicht genau wissen, was "Gerechtigkeit" ist, in: W. Fürst/R. Herzog/D. C. Umbach. (Hrsg.): Festschrift für Wolfgang Zeidler, Berlin, S. 19.

Ruppe, H. G. (1978): Möglichkeiten und Grenzen der Ubertragung von Einkunftsquellen als Problem der Zurechnung von Einkanften, in: K. Tipke (Hrsg.): Obertragung von Einkunftsquellen im Steuerrecht, Köln. 
Ruppel, A. (1984): Das echte, das unechte und das papierne Zweifamilienhaus, in: Deutsche Steuer-Zeitung 11, S. 274.

Saage, G. (1973): Die Prufung von Börsenprospekten, Beteiligungsangeboten und Gewinnprognosen. in: Der Betrieb, Heft 10, S. 485.

Sachs, J. (1875): Geschichte der Botanik vom 16. Jahrhundert bis 1860, München.

Sachs, M. (1993): Rezension K. Tipke, Die Steuerrechtsordnung, in: Steuerliche Vierteljahresschrift, Heft 3, S. 283.

Sachsen-Altenburgisches Gesetz, die Feststellung der Zahl der jăhrlichen Erhebung einer Ergănzungssteuer betreffend vom 20.6.1902, in: Finanz-Archiv, 20. Jg., S. 291.

Sachverstăndigenrat zur Begutachtung der gesamtwirtschaftlichen Entwicklung, Jahresgutachten 1982/83, 1983/84, 1985/86, 1986/87, 1987/88, 1988/89,1990/91.

- Sondergutachten 1982, Bundestags-Drucksache 9/2118, 1985.

Săchsisches Einkommensteuergesetz vom 24.7.1900, in: Gesetz- und Verordnungsblatt für das Königreich Sachsen, S. 502.

Salin, E. (1933): Von den Wandlungen des Staatswesens und der Wirtschaftsordnung, in: Wirtschaft und Staat, S. 192.

Sammlung der Entscheidungen und Gutachten des Reichsfinanzhofs (1928), 22. Bd., München.

Sammlung der Entscheidungen und Gutachten des Bundesfinanzhofs (1952), 25, Bd., Bonn.

Sammlung der Entscheidungen des Bundesfinanzhofs (1968), 93. Bd; (1972): 106 Bd. Bonn.

Sammlung der für die Königlichen Preußischen Staaten erschienenen Gesetze und Verordntingen von 1806 bis zum 27sten Oktober 1810 (1822), Berlin.

Samuelson, P. A. (1977): Thoughts on Profit-Sharing, in: Zeitschrift für die gesamte Staatswissenschaft, Special-Issue, Tubingen.

- (1988): Wicksells Werk und Persönlichkeit - Eine kritische Analyse in moderner Sicht, in: Vademecum zu einem anregenden Klassiker der okonomischen Wissenschaft (= Recktenwald, H. C./Enge!s, W./Hax, H./von. Hayek, F. A. (Hrsg.): Die Handelsblatt-Bibliothek "Klassiker der Nationalokonomie", Dusseldorf.

Sandelin, B. (1988): Ober Wicksells Vita und Person, in: Vademecum zu einem anregenden Klassiker der okonomischen Wissenschaft (= Recktenwald, H. C./Engels, W./Hax, H./von Hayek, F. A. (Hrsg.): Die Handelsblatt-Bibliothek "Klassiker der Nationalökonomie", Dosseldorf.

Sattler, C. (1894): Der preussische Staatshaushalt von 1886-93, in: Finanz-Archiv, S. 178.

Sauer, O. (1991): Entwicklung der Außenprufung zur rechtsstaatlich verfaßten Institution, in: Die steuerliche Betriebsprufung, S. 217, S. 241. 
Sauermann, H./Mestmäcker, E. J. (1975): Wirtschaftsordnung und Staatsverfassung. Festschrift für Franz Böhm zum 80. Geburtstag, Tubingen.

von Savigny, E. (1972): Die Jurisprudenz im Schatten des Empirismus, Polemische Anmerkungen zu Hans Albert: Erkenntnis und Recht, in: H. Albert/N. Luhmann/W. Maihofer/O. Weinberger (Hrsg.): Rechtstheorie als Grundlagenwissenschaft der Rechtswissenschaft, Düsseldorf, S.97.

- (1972): Die Phausnahme und die Phregel, oder Was die Logik im Recht nicht leisten will, in: H. Albert/N. Luhmann/W. Maihofer/O. Weinberger (Hrsg.): Rechtstheorie als Grundlagenwissenschaft der Rechtswissenschaft, Düsseldorf, S. 231.

Sax, E. (1887): Grundlegung der theoretischen Staatswirthschaft, Wien.

Schacht, H. (1953): 76 Jahrte meines Lebens, Bad Worishofen.

- (1968): 1933. Wie eine Demokratie stirbt, Dusseldorf.

Schäfle, A. (1861): Mensch und Gut in der Volkswirthschaft oder der ethisch-anthropologische und der chrematistische Standpunkt in der Nationalökonomie, mit besonderer Rücksicht auf die Grundprincipien der Steuerlehre, in: Deutsche Vierteljahrs-Schrift, 24. Jg., Stuttgart, S. 232.

- (1880): Die Grundsätze der Steuerpolitik und die schwebenden Finanzfragen Deutschlands und Oesterreichs, Tubingen.

- (1895): Die Steuern. Allgemeiner Teil. (= Hand- und Lehrbuch der Staatswissenschaften in selbständigen Bänden, Leipzig.

Schanz, G. (1887): Buchbesprechung: Dr. W. Vocke, Die Abgaben, Auflagen und die Steuer vom Standpunkte der Geschichte und der Sittlichkeit, Stuttgart, in: FinanzArchiv, 4. Jg., S. 500.

- (1890): Die Steuern der Schweiz, In ihrer Entwicklung seit Beginn des 19. Jahrhunderts, 1. Bd., Stuttgart.

- (1892): Existenzminimum und seine Steuerfreiheit, in: Handwörterbuch der Staatswissenschaften, 1. Aufl., Bd. III; 2. Aufl. (1900), Bd. III; 4. Aufl. (1926), Bd. III.

- (1895): Die Novelle zum săchsischen Einkommensteuergesetz vom 2. Juli 1878 vom 10. Mărz 1894, in: Finanz-Archiv, 12. Jg., S. 751.

- (1896): Der Einkommensbegriff und die Einkommensteuergesetze, in: Finanzarchiv, 13. Jg., S. 1.

- (1900): Das bayrische Ertragssteuersystem und seine Entwicklung, in: FinanzArchiv, 17. Jg., S. 25.

- (1903): Die săchsische Steuerreform vom Jahre 1902, in: Finanz-Archiv, 20. Jg., Stuttgart, S. 234.

- (1907): Die Novelle vom 21. April 1906 zum sächsischen Vermőgenssteuergesetz vom 2. Juli 1902, in: Finanz-Archiv, 24. Jg., S. 269.

- (1922): Die Abänderungsgesetze vom 24. Mărz, 11. Juli u. 20. Dezember 1921 zum Reichseinkommensteuergesetz v. 29. Mărz 1920, in: Finanz-Archiv, S. 119. 
- (1922): Der privatwirtschaftliche Einkommensbegriff, in: Finanz-Archiv, 39. Jg., S. 107.

- (1923): Existenzminimum und scine Steuerfreiheit, in: Handwörterbuch der Staatswissenschaften, 4. Aufl., Bd. III.

- (1928): Selbstbiographie, in: Finanzarchiv, N. F., 1. Bd., Stuttgart, S. 13.

Scharpf, F. W. (1974): Politische Durchsetzbarkeit innerer Reformen, Kommission fur wirtschaftlichen und sozialen Wandel 28, Göttingen.

von Scheel, H. (1872): Deutsche Literatur zur sozialen Frage aus den Jahren 1871 und 1872 (Besprechung), in: Jahrbucher fur Nationalokonomie und Statistik, 19. Bd., Jena, S. 213.

Schelcher, W. (Hrsg.) (1903): Fischers Zeitschrift fur Praxis und Gesetzgebung der Verwaltung, 26. Bd.; (1907) 30. Bd., Leipzig.

Schellenberger, H. (1985): Der Bundesfinanzhof-Beschluß vom 25.6.1984 GrS 4/82 Folgen und Forderungen, in: Deutsches Steuerrecht, Heft 6, S. 163.

Schick, W. (1985): Die Ausbildung zur "unbeschränkten Hilfeleistung in Steuersachen" in verfassungsrechtlicher Sicht, in: Steuer und Wirtschaft 2, S. 172.

Sehiffer, E. (1919): Die neuen Reichs-Steuervorlagen, in: Deutsche Juristen-Zeitung, 24. Jg. Heft 13-14 u. Heft 17-18.

Schlanwitz, W. (Hrsg.) (1966): Der Bund als Finanzier. ERP-Sondervermögen, Sondervermögen futr berufliche Leistungsiofrderung, Bad Godesberg.

Schlecht, O. (1995): Franz B8hm: Wissenschaftler und Politiker, in: Ludwig-ErhardStiftung (Hrsg.): Wirtschaftsordnung als Aufgabe. Zum 100. Geburtstag von Franz Bôhm, Bonn.

Schlenther (ohne Vorname) (1905): Zum § 81 des Einkommensteuergesetzes, in: Verwaltungsarchiv, 13. Bd., Berlin, S. 355.

Schmalenbach, E. (Hrsg.): Zeitschrif fur Handelswissenschaftliche Forschung, Leipzig.

Schmid, A. (1977): Die 'Neuorganisation der Finanzamter und Neuordnung des Besteuerungsverfahrens' - Abkehr vom Grundsatz der Gesetzmäßigkeit der Verwaltung (Art. 20 Abs. 3 GG)?, in: Finanz-Rundschau, 59. Jg. Nr. 12, S. 295.

- (1978): Rechisschutz gegen GNOFÄ und deren Folgen für den Steuerbürger, in: Der Betrieb, 31. Jg., Nr. 4, S. 174.

Schmidt, D. (1926): Nichtfiskalische Zwecke der Besteuerung. Ein Beitrag zur Steuertheorie und Steuerpolitik, Tubingen.

Schmidt, G./Treiber, H. (1975): Bürokratie und Politik. Zur Struktur und Funktion der Ministerialbürokratie in der Bundesrepublik Deutschland, München.

Schmidt, H./Frank, U./Muller-Rohr, I. (1985): Kritische Bemerkungen zum System des Kinderlastenausgleichs - zugleich ein Vorschlag zur Neugestaltung der gesetzlichen Rentenversicherung, in: Finanzarchiv 43, S. 28. 
Schmidt, K. (1962): Zur Reform der Unternehmensbesteuerung, in: Finanzarchiv 22, S. 35.

- (1971/72): Renaissance der Opfertheorien? Zur okonomischen Sinngebung politischer Entscheidungen, in: Finanzarchiv, Bd. 30, Tabingen.

- (1980): Grundprobleme der Besteuerung, in: Handbuch der Finanzwissenschaft Bd. 2, 3. Aufl., S. 120 .

- (1986): Răumliche Wirkungen von Gemeindesteuerreformvorschlägen. Gutachten im Auftrag des Bundesverbandes der Deutschen Industrie e. V., Kőln, ifo-Studien zur Finanzpolitik, Nr. 35, München.

- (1988): Notizen zur Steuerreform. Was geschehen wird und was nötig ist, in: Finanzarchiv 46, S. 193.

Schmidt, L. (1978): Möglichkeiten und Grenzen der Übertragung von Einkunftsquellen von. Eltern auf Kinder, in: K. Tipke (Hrsg.): Obertragung von Einkunftsquellen im Steuerrecht, Köln, S. 41.

- (1979): In den Grenzbereichen von Betriebsaufgabe, Betriebsverpachtung, Betriebsaufspaltung und Mitunternehmerschaft, in: DStR, S. 671, S. 699.

- (Hrsg.) (1984): Einkommensteuergesetz, 3. Aufl., Munchen.

- (1994): Einkommensteuergesetz Kommentar, 13. Aufl, München.

Schmidt-Liebig, A. (1977): Der Gewerbebetriebsbegriff der $\$ \S 2$ I Ziff. 2, 15 I EStG, in: Steuer und Wirtschaft 4, S. 302.

Schmólders, G. (1949): Um ein rationales Steuersystem, in: Finanzarchiv, N. F., Bd. 11, S. 479.

- (1949): Entwicklung und Wandlung der Körperschaftsteuer. Ein kritischer Beitrag zur Reform der Betriebsbesteuenung, in: Steuer und Wirtschaft, Teil I, S. 904.

- (1950): Steuersystem und Wettbewerbsordnung, in: Ordo. Jahrbuch fur die Ordnung von Wirtschaft und Gesellschaft, Band 3., Stuttgart, S. 135.

- (1951/52): Finarzpsychologie, in: Finanzarchiv, N. F., Bd. 13, Tubingen.

- (1953): Finanzpolitik und internationaler Kapitalmarkt, in: Steuer und Wirtschaft, 30. Jg., Sp. 633.

- (1953): Wandlungen in Sinn und Wesen der Besteuerung, in: Steuer und Wirtschaft, 30. Jg., Sp. 249.

- (1953): Organische Steuerreform. Grundlagen, Vorarbeiten, Gesetzentwürfe, Berlin und Frankfurt.

- (1953/54): Die Notwendigkeit der organischen Steuerreform, in: Finanzarchiv, N. F., Bd. 14, S. 21 .

- (1954): Johannes Popitz zum Gedenken, in: Steuer und Wirtschaft, Teil I, Sp. 706. 
- (1957/58): Der Grundsatz der Budgetpublizitat. Ein Kapitel Finanzpsychologie, in: Finanzarchiv, N. F., Bd. 18, S. 193.

- (1959): Zu Geschichte und Bedeutung des Leistungsfähigkeitsprinzips unter besonderer Berucksichtigung der Beiträge im Finanzarchiv und der Entwicklung der deutschen Einkommensbesteuerung, in Finanzarchiv, S. 445.

- (1959/60): "Unmerkliche" Steuern, in: Finanzarchiv, N. F., Bd. 20, S. 23.

- (1960): Der Fehlende Einkommensbegriff, in Steuer und Wirtschaft, Sp. 75.

- (1961): Der Wettbewerbsgedanke im Bereich der Steuer- und Finanzpolitik, in Kartelle und Monopole im modemen Recht, Hrsg.: Institut für ausländisches und internationales Wirtschaftsrecht an der Johann-Wolfgang-Goethe-Universităt, Frankfurt/M., Karlsruhe, Bd. 2, S. 495.

- (1963): Das Gerechtigkeitspostulat in der Besteuerung, in: Finanzarchiv N. F., Bd. 23, Tubingen, S. 53.

- (1964): Staatsburgerliche Gesinnung und Steuermoral. Die Verantwortung des Gesetzgebers, in: Finanzwissenschaft und Finanzpolitik, hrsg. von F. Schäfer, Tubingen, S. 285.

- (1965): Allgemeine Steuerlehre, 4. uberarb. u. erg. Auflage, Berlin.

- (1965): Das Selbstbild der Verbände, in: Schriften des Vereins furr Socialpolitik, Bd. 38, Berlin.

- (1968): Der Staatsbürger als Steuerzahler. Verwandlungen des Menschenbildes in Finanzwissenschaft und Steuerpraxis, in: Finanzarchiv, N. F., Bd. 27, Tubingen, S. 121 .

- (1970): Finanzpolitik, 3. Aufl., Berlin.

- (1970): Finanz- und Steuerpsychologie, erw. Neuauflage von: Das Irrationale in der offentlichen Finanzwirtschaft, Hamburg.

- (1970): Die Steuer als Instrument der Wirtschaftspolitik, in: Haller, H/Kullmer, L./Shoup, S /Timm, H. (Hrsg.): Theorie und Praxis des finanzpolitischen Interventionismus. Fritz Neumark zum 70. Geburtstag, Tubingen, S. 253.

- (1981): Finanz- und Steuerpsychologie, in: Handwörterbuch der Wirtschaftswissenschaften, Bd. 3, Stuttigart, S. 121.

Schmolders, G./Hansmeyer, K.-H. (1980): Allgemeine Steuerlehre, 5. Aufl., Berlin.

Schmoolders, G./Wóhe, G./Buchholz, E. H. (1976): Der Bürger als Objekt der staatlichen Finanzpolitik. Festschriit für Willy Haubrichs zum 65. Geburtstag, Bad Worishofen.

Schmoller, G. (1863): Die Lehre vom Einkommen in ihrem Zusammenhang mit den Grundprincipien der Steuerlehre, in: Zeitschrift für die gesamte Staatswissenschaft, 19. Jg., Tubingen, S. 1.

- (1864): Die Arbeiterfrage, in: Preußische Jahrbacher, 14. Bd. und (1865) 15. Bd. 
- (1871): Einige Bemerkungen zu dem Entwurf eines Gesetzes uber die directe Besteuerung im Kōnigreich Sachsen (handschriftlich), Halle 9.10.1871, in: Acta, die Reform der directen Steuern betreffend, vom Jahre 1872, Actenstilck A 54, Vol. 2, Bl. 136 ff, Staatsarchiv Dresden.

- (1872): Arbeitseinstellung und Gewerkvereine, Referat auf der Eisenacher Versammlung vom 6. und 7. Oktober uber die sociale Frage, Jena.

- (1874): Ober einige Grundfragen des Rechts und der Volkswirtschaft. Ein offenes Sendschreiben an Herm Professor Dr. Heinrich von Treitschke, in Jahrbucher für Nationaloekonomie und Statistik, in: Jahrbücher furr Nationaloekonomie und Statistik, 23. Bd., S. 225 und 24. Bd., S. 81.

- (1877): Die Epochen der preußischen Finanzpolitik, in: Jahrbuch für Gesetzgebung, Verwaltung und Volkswirtschaft im Deutschen Reich, S. 33.

- (1881): Theorie und Praxis der deutschen Steuerreform in Reich, Staat und Gemeinde, in: Jahrbuch fur Gesetzgebung, Verwaltung und Volkswirtschaft im Deutschen Reich, Leipzig, S. 42.1.

- (1881): Gerechtigkeit in der Volkswirtschaft, in: Schmollers Jahrbuch, S. 19.

- (1883): Zur Methodologie der Staats- und Sozialwissenschaften, in: Schmoliers Jahrbuch, 7. Jg., S. 975.

- (1893): Einleitung zu den Statistischen Anlagen der Börsen-Enquete-Kommission, Berlin.

- (1894): Volkswirtschaft, Volkswirtschaftslehre und ihre: Methode, in: Handwörterbuch der Staatswissenschaften, 1. Aufl., 6. Bd., Jena, S. 527.

- (1905): Das Verhăltnis der Kartelle zum Staat, in: Schmollers Jahrbuch, 29. Jg., S. 1459.

- (1908): Reden und Ansprachen gehalteñ am 24.6.1908 bei der Feier von Schmollers 70. Geburtstag (als Manuskript).

- (1911): Volkswirtschaft, Volkswirtschaftslehre und ihre Methode, in: Handwörterbuch der Staatswissenschaften, 3. Aufl., 6. Bd., Jena, S. 426.

- (1895): Die Einkommensverteilung in alter und neuer Zeit, in: Jahrbuch fur Gesetzgebung, Verwaltung und Volkswirtschaft im Deutschen Reich, Leiprig, S. 1.

- (1898): Die Epochen der preußischen Finanzpolitik bis zur Grundung des deutschen Reiches, in: ders.: Unnisse und Untersuchungen zur Verfassungs-, Verwaltungsund Wirtschaftsgeschichte, Leipzig, S. 104.

- (1898): Ueber einige Grundfragen der Socialpolitik, in: Historisch-politische Blattter für das katholische Deutschland, 2. Bd., S. 885.

- (1902): Entstehung, Wesen und Bedeutung der neueren Armenpflege, in: Sitzungsberichte der Kōniglich-Preußischen Akademie der Wissenschaften zu Berlin vom 31.7.1902. 
- (1905): Zum 70. Geburtstag von Adolph Wagner. Zwei Ansprachen, in: Schmollers Jahrbuch, 29. Jg., S. 5.

- (1909): Historische Betrachtungen uber Staatenbildung und Finanzentwicklung, in: Jahrbuch fur Gesetzgebung, Verwaltung und Volkswirtschaft im Deutschen Reich, hrsg. von G. Schmoller, 33. Jg., 1. Heft, Leipzig, S. 1.

- (1912): Zwei Bernerkungen uber den Verein für Sozialpolitik, in: Jahrbuch für Gesetzgebung, Verwaltung und Volkswirtschaft im Deutsche Reich, 36. Jg., München und Leipzig, S. 1.

- (1913): Charakterbilder, Leipzig.

- (1918): Meine Heilbronner Jugendjahre, in: Von Schwäbischer Scholle, Kalender Schwabische Literatur und Kunst, Heilbronn.

- (1921): Preußische Verfassungs-, Verwaltungs- und Finanzgeschichte, Berlin.

- (Hrsg.) Jahrbuch fur Gesetzgebung, Verwaltung und Volkswirtschaft im Deutschen Reich, Leipzig.

- Grundriß der Allgemeinen Volkswirtschafts!ehre, 2. Aufl., Leipzig.

Schneider, D. (1971): Eine Reform der steuerlichen Gewinnermittlung? Anmerkungen zum Teil "Gewinnermittlung" des Gutachtens der Steuerreformkommission. 1971, in: Steuer und Wirtschaft 4, S, 326.

- (1974): "Staatsbürgersteuer" - ein Schildbürgerstreich, in: Steuer und Wirtschaft 4, S. 369.

- (1975): Sind Steuervergünstigungen günstig? in: Steuerberater-Jahrbuch 1974/75, S. 395.

- (1976): Realisationsprinzip und Einkommensbegriff, in: Bilanzfragen, J. Baetge/A. Moxter/D. Schneider (Hrsg.): Festschrift zum 65. Geburtstag von Ulrich Leffson, Dusseldorf, S. 101.

- (1979): BezugsgröBen steuerlicher Leistungsfähigkeit und Vernögensbesteuerung, in: Finanzarchiv 37, S. 26.

- (1983): Geschichte betriebswirtschaftlicher Theorie. Allgemeine Betriebswirtschaftslehre für das Hauptstudium, München.

- (1984): Leistungsfahigkeitsprinzip und Abzug von der Bemessungsgrundlage, in: Steuer und Wirtschatt 4, S, 356.

- (1985): Steuergerechtigkeit durch Regelungen gegen Steuervermeidung - ein "Gefangenendilemma" des Steuerrechts, in: Steuer und Wirtschaft 4, S. 345.

- (1986): Verbesserung der Allokation durch Besteuerung unrealisierter Vermōgenswertanderungen?, in: Finanzarchiv N. F., Bd. 44, S. 224.

- (1987): Allgemeine Betriebswirtschaftslehre, 3. neu bearbeitete und erweiterte Aufl., München. 
- (1988): Wider leichtfertige Steuerbelastungsvergleiche, in: Die Wirtschaftsprufung, S. 281.

- (1989): Der Einkommensbegriff und die Einkommensteuerrechtsprechung, in: Finanzarchiv, N. F., Bd. 47, S. 407.

Schneider, E. (1970): Einfuhrung in die Wirtschaftstheorie, IV. Teil, 1. u. 2. Bd., 3. Aufl., Tubingen.

Schneider, P. (1938): Die Entwicklung des sozialen Gedankens in der preußischen Einkommensteuergesetzgebung bis zur Miquelschen Reform von 1891, D0sseldorf.

Schmeider, V. (1978): Die historische Entwicklung des Straftatbestandes der Steuerhinterziehung, Diss. jur., Koln.

Schoeck, H. (1974): Der Neid und die Gesellschaft, 4. Aufl., Freiburg.

von Scholz, A. (Hrsg.) (1922): Erlebnisse und Gespräche mit Bismarck, Stuttgart und Berlin.

Schreiber, R. (1972): Probleme rechtswissenschaftlicher Systembildung, in: H. Albert/N. LuhmannWW. Maihofer/O. Weinberger (Hrsg.): Rechtstheorie als Grundlagenwissenschaft der Rechtswissenschaft, S. 289.

Schröder, K.-W. (1985): Der Einkommensbegrift des § 2 EStG, in: Steuer und Studium, 6. Jg., Nr. 1, S. 10.

Schroedter, P./Schroedter, G. (Hrsg.) (1951): Im Blickfeld Dank an den Steuerzahler, in: Hansa, Zeitschrift für Schiffahrt, Schiffbau, Hafen, 88. Jg., Nr. 42, Hamburg.

- (Hrsg.) (1951): Erträge, Schulden und Investierungen der Handelsschiftahrt, in: Hansa, Zeitschrift für Schiffahrt, Schiffbau, Hafen, 88. Jg., Nr. 42, Hamburg, S. 1512 .

- (Hrsg.) (1952): Neugründungen in der Schiffahrt, in: Hansa, Zeitschrift für Schifffahrt, Schiffbau, Haferi, Hamburg, S. 141.

- (Hrsg.) (1955): Zur Jahreswende 1954/1955, in: Hansa, Zeitschrift fur Schiffahrt, Schiffbau, Hafen, 92. Jg., Nr. 1/3, Hamburg.

- (Hrsg.) (1956): Im Blickfeld: 20. Mill. BRT Neubauaufträge, in: Hansa, Zeitschrift für Schiffahrt, Schiffbau, Hafen, 93. Jg., Nr. 29/30, Hamburg.

Schünemann, B. (1989): Die Zinsamnestie - Totgeburt oder Schlußstein der Steuerreform in: Steuerliche Vierteljahresschrift, 1. Jg.

Schütte, C. (1993): Mündige Mogler. Die Steuerzahler, meinen Ôkonomen, sind viel ehrlicher, als die meisten Politiker glauben, in: WirtschaftsWoche Nr. 38.

Schuhmann, H. (1994): Liebhaberei im Einkommensteuerrecht. Neuere Rechtsprechung des BFH, in: Die steuerliche Betriebsprufung, S. 245.

Schulte, B./Trenk-Hinterberger, P. (Hrsg.) (1988): Bundessozialhilfegesetz (BSHG) mit Durchfuhrungsverordnungen und Erlâuterungen, München. 
Schultz, B. (1952): Das Steueraufkommen ais Maßstab, in: Zeitschrift für die gesamte Staatswissenschaft, 108. Bd., Tübingen, S. 295.

Schulz, G. (1980): Steuerberatungslehre in den Vereinigten Staaten von Amerika und der Bundesrepublik Deutschland (= Schriftenreihe "Besteuerung der Unternehmung", Bd. 10) Wiesbaden.

Schulz, M. (1990): Grundfragen des Aufbaus und der Aufgaben der Finianzverwaltung in der DDR, in: Deutsches Steuerrecht, 28. Jg., Nr. 10, S. 306.

Schulz, U. (Hrsg.) (1986): Mit dem Zehnten fing es an. Eine Kulturgeschichte der Steuer, München.

Schulze-Osterloh, J. (1989): Steuerliche Hauptprobleme der Abschreibungsgesellschaften und ihrer Gesellschafter, insbesondere das negative Kapitalkonto, in: K.H. Friauf (Hrsg.): Steuerrecht und Verfassungsrecht, Köln.

Schulze zur Wiesche, D. (1979): Vereinbanungen unter Familienangehörigen und ihre steuerlichen Folgen, Köln.

Schumacher, H. (1928): Wagner, Adolph, in: Deutsches Biographisches Jahrbuch, hrsg. vom Verbande der Deutschen Akademien, Uberleitungsband II: 1917 - 1920, S. 173 .

Schumpeter, J. A. (1914): Epochen der Dogmen- und Methodengeschichte, in: Grundriß der Sozialökonomik, 1. Abteilung, Wirtschaft und Wirtschaftswissenschaft, Tü. bingen.

- (1929): Was vermag die Finanzreform, in: Der Deutsche Volkswirt, 4. Jg., S. 75.

- (1929/30): Okonomie und Soziologie der Einkommensteuer, in: Der deutsche Volkswirt. Zeitschrift furr Politik und Wirtschaft, 4. Jg., Nr. 12/13, S. 380.

- (1930): Wenn die Finanzreform mißlingt, in: Der Deutsche Volkswirt, S. 695.

- (1965): Geschichte der ökonomischen Analyse, Gottingen.

Schuppert, G. F. (1987): Verfassungsrechtliche Prufungsmaßstäbe bei der verfassungsrechtlichen Bindungen des Steuerrechts, in: W. Fürst/R. Herzog/D. C. Umbach (Hrsg.): Festschrift fur Wolfgang Zeidler, Berlin, S. 691.

Schuster, E. (1926): Das Einkommen. Eine kritische Untersuchung, Tubingen.

- (1961): Einkommen, in: Handwörterbuch der Sozialwissenschaften, 3. Band, Titbingen, S. 53.

Schwandt (ohne Vorname) (1932): Das fiskalische Prinzip bei Ariwendung der Steuergesetze, in: Deutsche Juristen-Zeitung, Heft 11, Sp. 717.

Schwark, E. (1973): Neues "Maklergesetz" bietet besseren Anlegerschutz, in: Wertpapier, Zeitschrift fitr Kapitalanlage, S. 145.

Schweigert, E. (1970): Die Finanzverwaltung Westdeutschlands in der Zeit vom Ende des 2. Weltkriegs bis zu ihrer Neuordnung durch das Grundgesetz, Bonn. 
Schwerin von Krosigk, Graf L. (1974): Staatsbankrott. Die Geschichte der Finanzpolitik des Deutschen Reiches von 1920 bis 1945, geschrieben vom letzten Reichsfinanzminister, Frankfurt.

- (1977): Memoiren, Stuttgart.

Seckel, C. (1978): Die Steuerhinterziehung ( $\$ 370$ AO 1977), in: F. Geerds (Hrsg.): Kriminalwissenschaftliche Abhandlungen, Bd. 10, Lubeck.

Seithel, R. (1985): Einkommensteuerrechtliche Behandlung des NieBbrauchs und anderer Nutzungsrechte bei Einkunften aus Vermietung und Verpachtung und aus Kapitalvermögen. Zm Schreiben des Bundesministers der Finanzen vom 15.11.1984 und vom 23.11.1983, Hamburg.

Seligman, E. R. A. (1921): The Income Tax. A study of the history, theory and pratice of income taxation at home and abroad, 2. verm. Aufl., New York.

- (1926): Geschichte der Finanzwissenschaft außerhalb Deutschlands, insbesondere seit Beginn des 19. Jahrhunderts, in: Handbuch der Finanzwissenschaft, 1. Bd., T1bingen.

- (1927): Die Lehre von der Steueruberwălzung, Hrsg. K. Brăuer, Jena.

Sevin, L. (1912): Ein Vorschlag zur Reichsbesitzsteuer, in: Jahrbuch fur Gesetzgebung, Verwaltung und Volkswirtschaft im Deutschen Reich, 36. Jg., S. 113.

Shoup, C. S. (1957/58): Ricardo and Taxation, in: Finanzarchiv, Bd. 18, Tubingen.

- (1970): Tax Reform, in: Theorie und Praxis des finanzpolitischen Interventionismus, Fritz Neumark zum 70 . Geburtstag, Tübingen.

- (1984): The Schanz Concept of Income and the United States Federal Income Tax, in: Finanzarchiv, N.F., 42. Jg., S. 433.

Siegel, T. (1985): Eigen- oder Fremdfinanzierung und steuerlicher Schuldzinsenabzug. Zur Schuldzinsenzuordnung in der neueren Rechtsprechung des Bundesfinanzhofs, in: Steuer und Wirtschaft 3, S. 207.

Siegel, T./Schneider, D. (1994): Existenzminimum und Familienlastenausgleich: Ein Problem der Reform des Einkommensteuerrechts, in: Deutsches Steuerrecht, 32. Jg., Heft 17, S. 597.

Sieghart, R. (1897): Die Steuerreform in Österreich, in: Finanz-Archiv, 14. Jg., S. 1.

Simon, H. V. (1898): Die Bilanzen der Aktiengesellschaft und der Kommanditgesellschaften auf Aktien, Berlin.

Sinn, G./Sinn, H. W. (1993): Kaltstart. Volkswirtschaftiche Aspekte der deutschen Vereinigung, 3. Aufl. Tubingen.

Sinn, H.-W. (1991): Verteilen statt verkaufen, in: WirtschaftsWoche Nr. 5, S. 78.

Skalweit, A. (Hrsg.) (1949): Gustav von Schmoller. Die Volkswirtschaft, die Volkswirtschaftslehre und ihre Methode (1893), in: Sozialōkonomische Texte, Heft $16 / 17$. 
Smith, A. (1789): Der Wohlstand der Nationen. Eine Untersuchung seiner Natur und seiner Ursachen. An Inquiry into the Nature an causes of the Wealth of Nations, 5. Aufl., London.

Soffing, G. (1978): Möglichkeiten und Grenzen der Öbertragung von Einkunftsquellen durch Bestellung eines unentgeltlichen Nießbrauchs fur Familienangehörige, in: Tipke, K.: Obertragung von Einkunftsquellen im Steuerrecht, hrsg. im Auftrag der Deutschen Steuerjuristischen Gesellschaft e. V., Köln.

- (1981): Der Nießbrauch - eine selbstăndige Einkunftsquelle, in: Deutsche SteuerZeitung, 69. Jg., S. 199.

Soffing, G./Felix, G./Carle, D./Kom, K. (1981): Nießbrauch in Steuer und Recht. Manuskript zur Tagung vom 22,-29.6.1981.

Sön, H. (Hrsg.) (1980): Die Abgrenzung der Betriebs- oder Berufssphäre von der Privatsphäre im Einkommensteuerrecht, Köln.

Söhn, H. (1988): Verfassungsrechtliche Aspekte der Besteuerung nach der subjektiven Leistungsfahigkeit im Einkommensteuerrecht: Zum persőnlichen Existenzminimum, in: Finanzarchiv 46, S. 154.

Soetbeer, A (1879): Umfang und Vertheilung des Volks-Einkommens im Preussischen Staate 1872 - 1878, Leipzig.

- (1889): Volkseinkommen im Preussischen Staate, 1876 - 1888, in: Jahrbücher für Nationalokonomie und Statistik, N. F., Bd. XVIII, S. 415.

von Sparre, K. (1848): Die allgemeine Einkommensteuer als einzig gerechte direkte A.bgabe, aus Theorie und Erfahrung nachgewiesen, Gießen.

- (1852): Die allgemeine und die partielle Einkommensteuer, als direkte Abgaben, 2. Aufl., Marburg.

Speich, G. (1993): Liebhaberei im Steuerrecht, in: Neue WirtschaftsBriefe, Herne, Fach 3, S. 8481.

Spiethoff, A. (Hrsg.): Schmollers Jahrbuch fur Gesetzgebung, Verwaltung und Volkswirtschaft im Deutschen Reiche, Leipzig.

Spindler von, J. (1965): Reparationen, in: Handbuch der Finanzwissenschaft, 4. Bd. Tubingen, S. 136.

Spitaler, A. (1953): Die organische Steuerreform. Würdigung des Berichts des Wissenschaftlichen Beirats beim Bundesministerium der Finanzen zur organischen Steuerreform und der Abhandlung von Schmölders zum gleichen Gegenstand, in: Steuer und Wirtschaft, Teil I, Sp. 689.

- (1956): Der Notschrei der Steuerbeamtenschaft, in: Finanz-Rundschau, 11. Jg., S. 253.

- (1959): Wandlungen im Steuerrecht, in: Steuerberater-Jahrbuch 1958/59, S. 379.

- (1960): Enno Becker und die gegenwarrtige Steuerrechtswissenschaft, in: Steuer und Wirtschaft, 37. Jg., Teil 1, Sp. 21. 
- (1962): Der maßvolle Gesetzesvollzug im Steuerrecht, in: Steuerberater-Jahrbuch $1961 / 62$, Köln, S. 461.

Sponheimer, J. (11928): Treuhandgesellschaften, in: H. Nicklisch (Hrsg.): Handwörterbuch der Betriebswirtschaft, 5. Bd., Stuttgart, S. 419.

Spranger, E. (1914): Die Stellung der Werturteile in der Nationalokonomie, in: Schmollers Jahrbuch furr Gesetzgebung, Verwaltung und Volkswirtschaft im Deutschen Reiche, 38 . Jg., 1. Heft, S. 33.

Staatslexikon. Recht, Wirtschaft, Gesellschaft (1960), hrsg. von der Gorres-Gesellschaft, Bd. 5, Freiburg.

Ständige Deputation des Deutschen Juristentages (Hrsg.) (1988): Verhandlungen des siebenundfünfzigsten Deutschen Juristentages, Mainz, 1988, München.

- (Hrsg.) (1988): Empfiehlt es sich, das Einkommensteuerrecht zur Beseitigung von Ungleichbehandlungen und zur Vereinfachung neu zu ordnen? (= Verhandlungen des siebenundfìnfzigsten Deutschen Juristentages) Bd. II, Teil N.

Stahl, R. (1990): Orientierungen fur Zeugen im Besteuerungs- und Steuerstrafverfahren, in: KÖDI, Heft 5/90, S. 8074.

- (1991): Grenzfalle von Mitwirkungspflichten im Besteuerungs- und Steuerstrafverfahren, in: KÖDI, S. 8360.

Statistik der preußischen Einkommensteuer-Veranlagung für das Jahr 1899 und der Ergänzungssteuer-Veranlagung fur die Jahre $189 / 1901$, in: Mittheilungen aus der Verwaltung der direkten Steuern im preußischen Staate, Berlin 1899.

Statistisches Bundesamt (Hrsg.) (1952): Statistisches Jahrbuch für die Bundesrepublik Deutschland: Wichtigste Einnahmen aus Bundes-, Landes- und Gemeindesteuern in den Rechnungsjahren 1948 - 1950 nach Ländern.

- (1959): Statistisches Jahrbuch für die Bundesrepublik Deutschland: Vorlăufige Ergebnisse der Einkommensteuerveranlagung für 1950, S. 424 - 425.

- (1984): Statistisches Jahrbuch für die Bundesrepublik Deutschland: Einkommensteuer 1980, S. 449.

- (1987): Statistisches Jahrbuch für die Bundesrepublik Deutschland: Einkommensteuer 1983, S $452-453$.

- (1989): Ausgewählte Ergebnisse der Lohnsteuerstatistik 1983, S. 448; Ausgewahlte Ergebnisse der Einkommensteuerstatistik: 1983, S. 449.

- (1992): Statistisches Jahrbuch fur die Bundesrepublik Deutschland.

- (1992): Ausgewăhlte Ergebnisse der Lohnsteuerstatistik 1986, S. 545.

- (1992): Ausgewăhilte Ergebnisse der Einkommensteuerstatistik 1986, S. 546.

- (1992): Ausgewăhlte Ergebnisse der Körperschaftsteuerstatistik 1986, S. 547.

- (1992): Personal der offentlichen Haushalte am 30.6.1991, S. 540.

- (1993): Statistisches Jahrbuch für die Bundesrepublik Deutschland. 
- (1993): Ausgewăhlte Ergebnisse der Einkoramensteuerstatistik 1986, S. 566.

- (1993): Ausgewählte Ergebnisse der Körperschaftsteuerstatistik 1986, S. 567.

Stavenhagen, G. (1969): Geschichte der Wirtschaftstheorie, Gottingen.

Stechele, J. (1910): Der Stand der bayerischen Steuerreform, in: Annalen des Deutschen Reichs, Jg. 1910, S. 120.

Steffani, W. (Hrsg.) (1973): Parlamentarismus ohne Transparenz, Bd. 3, Opladen.

von Stein, L. (1884): Zur Geschichte der deutschen Finanzwissenschaft im 17. Jahrhundert, in: Finanz-Archiv, 1. Jg., 1. Heft, Stuttgart, S. 315.

- (1886): Lehrbuch der Finanzwissenschaft. Zweiter Theil. Die Finanzverwaltung Europas. Mit specieller Vergleichung Englands, Frankreichs, Deutschlands, Oesterreichs, Italiens, Rußlands und anderer Länder. Zweite Abtheilung. Die einzelnen Steuern und ihre Systeme, Funfte, neubearbeitete Auflage, Leipzig.

Steinberg, C.: Die Anforderungen an eine neuzeitliche Staatsvermögensrechnung und die Vermögensrechnung des Bundes, Diss. jur, Köln.

Steinberg, W. (1962): Aktuelle Fragen des Korperschaftssteuerrechts, in: Steuerberater-Jahrbuch 1961/62, S. 213.

- (1969): Wirtschaft und Steuerpolitik, in: Institut "Finanzen und Steuem e.V." (Hrsg.): Wirtschaft und Politik, Heft 93, Bonn, S. 20.

- (1988): Die höchstrichterliche Finanzrechtsprechung zu der Frage des Verhăltnisses des Steuerrechts zum zivilen Recht, in: Deutsche Steuer-Zeitung, 76. Jg., Nr. 21, S. 523.

Stengbein, W. (1897): Strafgesetzgebung in Steuersachen, in: Deutsche Juristen-Zeitung, S. 233.

Stenographische Berichte aber die Verhandlungen des preußischen Hauses der Abgeordneten, 32. Sitzung am 13.2.1891.

Stenografische Berichte ober die Verhandlungen. Haus der Abgeordneten (1883 ff). Nebst Anlagen, Berlin.

Stephan, R. (1985): Der zweite Nießbrauchserlaß, in: Beilage Nr. 3 zu Der Betrieb.

Stem, E. (1926): James Mill als Anhănger der Steuerprogression. Eine Fussnote zur finanzwissenschaftlichen Dogmengeschichte, in: Finanz-Archiv, 43. Bd., S. 133.

Stem, K./Schmidt-Bleibtreu, B. (Hrsg.) (1990): Verträge und Rechtsakte zur Deutschen Einheit, Band 1: Staatsvertrag zur Wăhrungs-, Wirtschafts- und Sozialunion mit Vertragsgesetz, Begrindungen und Materialien, Munchen.

Steuergerechtigkeit durch Vereinfachung - keine Utopie. Blaubuch zum Blaubuch zur Lage der Steuerverwaltungen der Länder. Hrsg.: Deutsche Steuer-Gewerkschaft, Dusseldorf 1978.

StiemSomlo, Fritz (1932): Der Streit der Fakultăten. Aus den Anfängen des Steuerrechts an der Universităt Köln; Stier-Somlo contra Schmalenbach. Schreiben vom. 
2.2.1932 an den Dekan der Rechtswissenschaftlichen Fakultăt, in: Steuer und Wirtschaft (Dokumente) 3/1987, S. 287.

Stolper, G. (1929): Der Young-Plan II, in: Der deutsche Volkswirt, Zeitschrift für Politik und Wirtschaft, 3. Jg. 2. Halbbd., S. 1251.

- (1929): Ein Finanzplan, in: Der deutsche Volkswirt, Zeitschrift für Politik und Wirtschaft, Teil I S. 1287 - 1290; Teil II S. 1323 - 1326; Teil III S. 1363 -1369; Teil IV S. 1399 - 1401; Teil V S. 1462 - 1467; Teil VI S. 1495 - 1497; Teil VIII S. 1559 -1562; Teil LX S. $1623-1627$.

Stoltenberg, G. (1987): Aufgaben der Finanz- und Steuerpolitik in der 11. Wahlperiode, in: Steuerberater KongreB Report, S. 23.

Stolz, W. (1983): Die Vermietung der Fassade zu Werbezwecken durch einen nichtbilanzierenden Hauseigentumer, in: Finanz-Rundschau 10, S. 235.

Strassl, A. (1977): Die Auswirkungen der Neuorganisation der Finanzămter auf die Steuerpflichtigen und ihre Berater, in: Deutsches Steuerrecht, 15. Jg., Nr. 6, S. 147.

Strauß, F.J. (1969): Finanzpolitik - Theorie und Wirklichkeit, Frankfurt/M.

Streck, M. (1979): Der Eingriff der Steuerfahndung, Praktische Hinweise zur Verteidigung, Köln.

- (1979): Schlagkrafttig und entpersönlicht. Verhaltensmafregeln furr den Umgang mit neu organisierten Finanzämtern, in: Wirtschaftswoche Special 6/79.

- (1983): Das Recht des Verhältnisses von Steuer- und Strafverfahren, in: G. Kohlmann (Hrsg.): Strafverfolgung und Strafverteidigung im Steuerstrafrecht, Köln.

- (1984): Der Steuerhinterzieher als Mandant. Vortrag auf dem Deutschen Steuerberatertag 1984 in Stuttgart, in: Betriebs-Berater, 39. Jg., Nr. 35/36, S. 2205.

- (1986): Der Steuerstreit, Rechtsschutz im Steuerrecht und Steuerstrafrecht, Bd. 3, Köln.

Streck, M./Rainer, T. (1980): Liebhaberei, in: KOSDI 2/80, S. 3638.

- (1989): Briefwechsel zur Abschaffung der mit Steuerreformgesetz 1990 eingefürr ten Kapitalertragsteuer, in: Steuer und Wirtschaft 3/1989, S. 280.

Streissler, E. (1990): Die Wurzeln der "Ōsterreichischen Schule" der Nationalökonomie in der deutschen Wirtschaftswissenschaft des 19. Jahrhunderts, in: Anzeiger der phil.-hist. Klasse der Ôsterreichischen Akademie der Wissenschaften, 126. Jg., S. 169.

Streit, M. E. (1991): Theorie der Wirtschaftspolitik, Düsseldorf.

Strempel, D. (1983): Altemativen in der Ziviljustiz. Bericht über Erfahrungen und neue Perspektiven in den USA als Anstoß für die weitere Entwicklung in der Bundesrepublik, in: Deutsche Richter-Zeitung, S. 86.

- (1983): Alternativen in der Ziviljustiz. Gerichtliche und außergerichtliche Streitbeilegung in Japan im Vergleich zur Bundesrepublik Deutschland, in: JuristenZeitung, S. 596. 
- (1984): Rechtstatsachenforschung und Rechtspolitik, in: Zeitschrift für Rechtspolitik, Heft 8, S. 195.

- (Hrsg.) (1987): Mehr Recht durch weniger Gesetze? Beiträge eines Forums des Bundesministers der Justiz zur Problematik der Verrechtlichung, Königswinter.

Strohner, K. (1988): Die Bürgersteuer. Entwurf des Kronberger Kreises zur Neuordnung von direkten Steuern und Sozialleistungen, in: Finanz-Rundschau, 70. Jg., Nr. 16, S. 434.

Strimpel, B. (1966): Sozioókonomischer Wandel und die Durchsetzbarkeit der Besteuerung in: Finanzarchiv, N. F., Bd. 25, Tubingen, S. 442.

- (1966). Steuermoral und Steuerwiderstand der deutschen Selbstāndigen. Ein Beitrag zur Lehre von den Steuerwirkungen, Opladen.

- (1968): Steuersystem und wirtschaftliche Entwicklung. Funktion und Technik der Personalbesteuerung im soziookonomischen Wandel, Tubingen.

Strunz, W. (1980): Schwerpunkt bei der Prufung von Steuererklänungen durch die Amtsprufstellen der Finanzämter, in: Deutsches Steuerrecht, 18. Jg., Nr. 21, S. 621.

Strutz, G. (1893): Der österreichische Gesetzentwurf, betr. die direkten Personalsteuern, in: G. Hirth (Hrsg.): Annalen des Deutschen Reichs, S. 108.

- (1894): Die Preußische Steuerreform, in: Annalen des Deutschen Reichs, München, S. 207 - 238; und S. 405 - 409.

- (1897): Die Steuerreform in Warttemberg und Baden, in: Verwaltungsarchiv, 5. Bd., Berlin, S. 480.

- Rezension von Fuisting, B.: Grundzuge", in: Verwaltungsarchiv, 11. Jg., S. 475.

- (1908): Bernhard Fuisting, in: Preußisches Verwaltungs=Blatt, Jg. 29, Nr. 22, S. 425.

- (1912): Der Gesetzentwurf betr. Abănderung des Einkommen- und Ergănzungssteuergesetzes, in: Deutsche Juristen-Zeitung, 17. Jg., Nr. 4, S. 244.

- (1912): Die Neuordnung der direkten Stantssteuern in Preußen, Berlin.

- (1915): Einkommensteuergesetz, Achte verănderte und vermehrte Auflage, Berlin.

- (1916): Die Besteuerung der Kriegsgewinne, Stuttgart.

- (1917): Das Preußische Einkommensteuergesetz vom 24. Juni 1891 in der Fassung der Bekanntmachung vom 19. Juni 1906 nebst Ausfuhrungsbestimmungen 5. Aufl., Zweiter Abdruck mit weiteren Nachtraigen und dem Gesetz vom 8. Juli 1916, Berlin.

- (1922): Grundbegriffe des Steuerwesens, Berlin.

- (1924): Die Regelung der Einkommen-, Körperschafts- und Vermögensteuer für 1923 und 1924, in: Steuer und Wirtschaft, 3. Jg., Sp. 1. 
- (1925): Der Entwurf eines Einkommensteuergesetzes, in: Steuer und Wirtschaft, 4. Jg., Sp. 409.

- (1925): Das neue Einkommensteuergesetz, in: Steuer und Wirtschaft, 4. Jg., Sp. 1395 .

- (1927): Die Besteuerung nach dem Verbrauch, in: Steuer und Wirtschaft, 6. Jg., Stuttgart, Sp. 721.

- (1928): Die: Entwickjung des Steuerrechtsschutzes, in: Beitrăge zur Finanzwissenschaft, Bd. 2, Tubingen, S. 223.

- (1930): Kommentar zum Einkommensteuergesetz 1925, Berlin.

Stubbe, H. (1963): Kurze Geschichte der Genetik bis zur Wiederentdeckung der Vererbungslehre Gregor Mendels, Jena.

Stubmann, P. (1902): Die Reform der sächsischen Steuern, in: Annalen des Deutschen Reichs, Munchen, S. 793.

Stucken, R. (1961): Wagner, Adolph, in: Handwörterbuch der Sozialwissenschaften, 11. Bd., S. 470.

Surrey, S. S. (1981): Steueranreize als ein Instrument der staatlichen Politik, in: Steuer und Wirtschaft, S. 359.

Tabacovici, N. (1913:) Die Statistik der Einkommensverteilung mit besonderer Rucksicht auf das Königreich Sachsen, Leipzig.

Tanzer, M. (1981): Das 'Analogieverbot' im Steuerrecht, in: Steuer und Wirtschaft, 58. Jg., Nr. 3, S. 201.

Tanzi, V. (ed.) (1982): The Underground Economy in The United States and Abroad, Massachussetts/Toronto.

Terhalle, F. (1952): Geschichte der deutschen offentlichen Finanzwirtschaft vom Beginn des 19. Jahrhunderts bis zum Schlusse des 2. Weltkrieges, in: Handwörterbuch der Finanzwissenschan, Bd. 1, 2. Aufl., S. 273.

- (1955/56): Wilhelm Gerloff+, in: Finanzarchiv, N. F., Bd. 16, Tutbingen, S. 16.

Teschemacher, H. (1912): Die Einkommensteuer und die Revolution in Preußen. Eine finanzwissenschaftliche und allgemeingeschichtliche Studie uber das preußische Einkommensteuerprojekt von 1847, Tubingen.

- (1927): Die Einkommensteuer, in: Handbuch der Finanzwissenschaft, 2. Bd, 1. Aufl., Tubingen, S. 65.

- (Hisg.) (1928): Festgabe für Georg von Schanz zum 75. Geburtstag 12. Mărz 1928, Band I und Band II (= Beiträge zur Finanzwissensichaft), Tubingen.

- (Hrsg.) (1933): Finarzarchiv, Neue Folge, Band 1, Tubingen.

Theisen, M. R. (1990): Enno Becker: "Die Girundlagen der Einkommensteuer" (1940) Erkenntnisse und Perspektiven aus der Sicht des Jahres 1990, in: Steuer und Wirtschaft 2, S. 130 . 
Thiel, J. (1986): Steuerliche Betriebsprufung im Rechtsstaat - Tipkes Engagement fur die Außenprufung. Von der Untersuchung der Rechtsgrundlagen der Betriebsprüfung im Jahi 1968 zur Neukommentierung der $\$ \S 193$ ff AO im Tipke/Kruse 1986, in: Steuer und Wirtschaft 1, S. 1.

Thieme, L. (1960): Verbrauchsbesteuerung? in: Finanzrundschau, S. 539.

Thier, E. (1930): Rodbertus, Lasalle, Adolph Wagner. Ein Reitrag zur Theorie und Geschichte des deutschen Staatssozialismus, Leipzig.

Thimme, A. (1954); Hans Delbrilck als Kritiker der wilhelminischen Epoche, Düsseldorf.

Thoma, G. (1971): Einige grundsătzliche Gedanken zur Reform der AO, in: Steuerberater-Jahrbuch, Kőln, S. 59.

Thudichum, F. (1892): Juristen-Deutsch, in: Annalen des Deutschen Reichs, S. 126.

Tiemeyer, J. (1969): Zur Methodenfrage der Rechtssoziologie. Ober die wissenschaftstheoretische Möglichkeit, die Rechtssoziologie wie eine Naturwissenschaft zu betreiben, Berlin.

Timm, H. (1961): Das Gesetz der wachsenden Staatsausgaben, in: Finanzarchiv, N. F. Bd. 21, Heft 2.

- (1968): Bemerkungen zur wirtschaftspolitisch orientierten nichtfiskalischen Besteuenung, in: Finanzarchiv, N. F., Bd. 27, Tubingen, S. 87.

Tipke, K. (1965): An den Grenzen der Rechtssicherheit im Steuerverfahrensrecht, in: Bundeskammer der Steuerbevollmăchtigten (Hrsg.): Steuer-Kongreß-Report 1965, Munchen/Berlin, S. 204.

- (1967): In dubio pro fisco?, in: Bundeskammer der Steuerbevollmăchtigten (Hrsg.): Steuer-Kongreß-Report 1967, München, S. 39.

- (1968): Steuerliche Betriebsprifung im Rechtsstaat, Minchen.

- (1969): Reformbedurftiges allgemeines Abgabenrecht, in: Steuerberater-Jahrbuch 1968/69, S. 69.

- (1969): Funfzig Jahre Reichsabgabenordnung, in: Archiv des offentlichen Rechts, 94. Bd., Tübingen, S. 224.

- (1971): Steuerrecht - Chaos, Konglomerat oder System?, in Steuer und Wirtschaft, 48, S. 2.

- (1971): Reformbedürttiges allgemeines Steuerrecht, in: Steuerberater-Jahrbuch $1971 / 72$, S. 70.

- (1972): Steuerrechtswissenschaft und Steuersystem, in: K. Vogel/K. Tipke (Hrsg.): Verfassung, Verwaltung, Finanzen. Festschrift fur Gerhard Wacke zum 70. Geburtstag, Koln.

- (1972): An den Grenzen der Steuerberatung: Steuervermeidung, Steuerumgehung, Steuerhinterziehung, in: Steuerberater-Jahrbuch 1972/73, Koln, S. 508. 
- (1973): Die Dualistische Einkünfteermittlung nach dem Einkommensteuergesetz, Entstehung, Motivation und Berechtigung, in: Festschrift fur Heinz Paulick zum 65. Geburtstag 9. Mai, Köln.

- (1974): Das Bundesverfassungsgericht zum Nettoprinzip. Zum BVerfG-Beschluß vom 7.11.1972, in: Steuer und Wirtschaft 1, S. 84.

- (1974): Grundstücksverăußerungen im Steuerrecht. Gewerbebetrieb oder Vermögensverwaltung. Rechtsgutachten, Köln.

- (1975): Steuerrechtswissenschaft und Steuerrechtsprechung, in: Deutsche SteuerZeitung A, Nr. 19-20, S. 406.

- (1976): Die Steuergesetzgebung in der Bundesrepublik Deutschland aus der Sicht des Steuerrechtswissenschaftlers - Kritik und Verbessenungsvorschläge, in: Steuer und Wirtschaft, 53. (6.) Jg., S. 293.

- (1976): Ober die Misere der Steuergesetzgebung, in: G. Schmolders/G.Wohe/ E. H Buchholz (Hrsg.): Der Bürger als Objekt der staatlichen Finanzpolitik, Bad Wörishofen.

- (Hrsg.) (1978): Obertragung von Einkunftsquellen im Steuerrecht, hrsg. im Auftrag der Deutschen Steuerjuristischen Gesellschaft e. V., Koln.

- (1978): Die Grundprobleme der Personengesellschaft im Steuerrecht. Zum Thema der Wiener Jahrestagung der Deutschen Steuerjuristischen Gesellschaft, in: Steuer und Wirtschaft, 55.(8.) Jg., Nr. 3, S. 193.

- (1979): Schaukeln - Gaukeln - Finassieren, in: Wirtschaftswoche Special, S. 76.

- (1979): Zur Abgrenzung der Betriebs- oder Berufssphäre von der Privatsphăre im Einkommensteuerrecht, in: Steuer und Wirtschaft, Nr. 3, S. 193.

- (1980): Über Steuergerechtigkeit in Steuergesetzgebung, Steuerverwaltung und Steuergerichtsbarkeit. Vom politischen Schlagwort zum Rechtsbegriff und zur praktischen Anwendung, in: Stener und Wirtschaft 4, S. 281

- (1981): Rechtsetzung durch Steuergerichte und Steuerverwaltungsbehörden? In: Steuer und Wirtschaft, 58. Jg., Nr. 3, S. 189.

- (1981): Steuergerechtigkeit in Theorie und Praxis. Vom politischen Schlagwort zum. Rechtsbegriff und zur praktischen Anwendung, Köln

- (1981): Rechtsetzung durch Steuergerichte und Steuerverwaltungsbehörden? in: Steuer und Wirtschaft Nr. 3, S. 189.

- (Hrsg.) (1982): Grenzen der Rechtsfortbildung durch Rechtsprechung und Verwaltungsvorschriften im Steuerrecht, Köln.

- (1983): Über "erwirtschaftete" Einkünfte und Einkünfteerzielungsabsicht, in: Finanz Rundschau 23, S. 580.

- (1983): Uber Steuergesetzgebung und parlamentarische Demokratie. Zu F. A. von Hayeks: Recht, Gesetzgebung und Freiheit, in: Steuer und Wirtschaft, 60. Jg., Nr. 1, S. 1 . 
- (1983): Plădoyer fur ein neues Steuerrecht. Referat auf dem 10. Steuergewerkschaftstag der DStG (Auszug), in: Die Steuer-Gewerkschaft, Nr. 6, S. 76.

- (1983): Gerechte Steuern, geordnete Besteuenung. Festvortrag gehalten auf dem 10. Steuer-Gewerkschaftstag in Hannover am 3. Mai 1983. Hrsg. Deutsche Steuer-Gewerkschaft, Bonn.

- (1985): Regelgebundenes Steuerrecht, in: Finanz-Rundschau, Nr. 740. (67.) Jg., S. 169.

- (1985): Von der Unordnung zur Neuordnung des Einkommensteuerrechts, in: Raupach u. a. (Hrsg.): Niedergang oder Neuordnung des deutschen Einkommensteuerrechts? Münsteraner Symposion Bd. I, Köln, S. 133.

- (1985): Forum: Das Einkommens als zentraler Begriff des offentlichen Schuldrechts, in: Juristische Schulung, 25. Jg., Heft 5, S. 345.

- (1986): Einkommensteuer-Fundamentalreform - Notwendigkeiten und Möglichkeiten zum Vorbild des amerikanischen Reformverfahrens, in: Steuer und Wirtschaft 2, S. 150 .

- (1986): Ober Steuervereinfachung und Staatsverdrossenheit. Referat auf dem Deutschen Steuerberatertag 1986 in Hannover, in: Deutscher Steuerberatertag 1986, Protokoll, Bonn.

- (1986): UngleichmäBigkeit der Besteuerung, in: Betriebs-Berater, 41. Jg., Nr. 10, S. 601.

- (1987): Uber Steuerreform und Steuergerechtigkeit, in: W. Fürst/R. Herzog/ D. C. Umbach (Hrsg.): Festschrift fur Wolfgang Zeidler, Berlin, S. 717.

- (1987): Der Streit der Fakultăten. Aus den Anfängen des Steuerrechts an der Universitát Köln: Stier-Somlo contra Schmalenbach, in: Steuer und Wirtschaft 3, S. 287.

- (1988): Fundamentalrevision des Einkornmensteuerrechts, in: Neue Juristische Wochenschrift, Heft 34, S. 2090.

- (1988): Ober "richtiges Steuerrecht", in: Steuer und Wirtschaft 3, S. 262.

- (1988): Die Situation des Steuenrechts im Jubiläumsjahr 1988, in: Festschrift der Rechtswissenschaftichen Fakultat zur 600-Jahr-Feier der Universităt zu Köln, Koln, S. 865.

- (1989): Die rechtliche Misere der Zinsbesteuerung, in: Betriebs-Berater 3, S. 157.

- (1989): Lehren aus der Steuerreform 1990, in: Steuer und Wirtschaft 4, S. 291.

- (1989): Ober Steuervergunstigungen - Abbautheoretische Uberlegungen, in: FinanzRundschau, 71. Jg., Nr. 7, S. 186.

- (1990): Einkunftsarten-Kăstchendenken versus Systemdenken. Zugleich Besprechung des BFH-Urteils v. 12.1.1990 - VI R 29/86, BStBI. II 1990, 423. 
- (1990): Ober Steuergesetzgebung und Verfassungsgerichtsbarkeit. Von der Euphorie uber die Resignation zu neuer Hoffinung, in: Steuer und Wirtschaft 4, S. 308.

- (1990): Einkommensteuerliches Existenzminimum auch furr Reiche?, in: FinanzRundschau, 72. Jg., Nr. 12, S. 349.

- (1991): Die Entwicklung von. Forschung und Lehre im Steuerrecht, in: Steuer und Wirtschaft 3, S. 210 .

- (1991): Konsequenzen aus dem Zinssteuer-Urteil des Bundesverfassungsgerichts, in: Finanz-Rundschau 16, S. 480.

- (1992): Gleichmāßigkeit der Steuerrechtsanwendung. Ein Postulat im Interesse der Solidargemeinschaft der Steuerzahler, in: $\mathrm{H}$. Vogelsang (Hrsg.), Perspektiven der Finanzverwaltung, Koln, S. 95.

- (1993): Die Steuerrechtsorủnung, 3 Bde., Köln.

- (1993): Steuerlegislative unter Verfassungsdruck, in: Steuer und Wirtschaft, Heft 1, S. 8.

- (1993): Von der formalen zur materialen Tatbestandslehre, in. Steuer und Wirtschaft, Heft 2.

Tipke, K./Kruse W. (1989): Abgabenordnung, Finanzgerichtsordnung, Kommentar zur AO 1977 und FGO, Bd. I.

Tipke, K./Lang, J. (1984): Zur Reform der Familienbesteuerung. Stellungnahme gegenüber der Kommission "Familienlastenausgleich" der CDU/CSU-Bundestagsfralktion, in: Steuer und Wirtschaft 2, S. 127.

- (1993): Steuerrecht. Ein systematischer Grundriß, 14. Aufl, Köln, und sämtliche vorherigen Auflagen.

Tönnies, F. (1912): Die neuesten Angriffe gegen den Verein für Sozialpolitik. Brief an Gustav Schmoller, in: Jahrbuch fur Gesetzgebung, Verwaltung und Volkswirtschaft im Deutschen Reich.

- (1918): Adolph Wagner, in: Deutsche Rundschau, Bd. 174, Berlin, S. 107.

Topitsch, E. (1960): Uber Leerformeln. Zw Pragmatik des Sprachgebrauches in Philosophie und politischer Theorie, in: Topitsch, E., Probleme der Wissenschaftstheorie, Festschrift für Victor Kraft, Wien, S. 233.

Trapp, P. (1926): Zur Reform des Steuerstrafrechts, in: Steuer und Wirtschaft, Sp. 863, Sp. 1032.

Troeger, H. (1953): Allgemeines zur Steuerreform, in: Zur grofen Steuerreform. Vortrag gehalten auf der vom Zentralverband deutscher Konsumgenossenschaften e.V. im Jagdschloß Niederwald bei Rudesheim am 23. und 24. Oktober 1953 veranstalteten Arbeitstagung, Hamburg.

- (Hrsg.) (1954): Diskussionsbeiträge des Arbeitsausschusses fur die Große Steuerreform. Ein Bericht an den Finanzausschuß des Bundesrates, Stuttgart. 
- (Hrsg.) (1954): Diskussionsbeiträge des Arbeitsausschusses des Bundesrates, Stuttgart.

- (Hrsg.) (1958): Denkschrift zur Verbesserung der Einkommensbesteuerung 1958, Stuttgart.

Obersicht uber die in 1975 veroffentlichten Erlasse der Finanzverwaltung zu steuerbegünstigten Kapitalanlagen, in Betriebs-Berater, Heft 10 v. 10.4.1976.

Uelner, A. (1977): Die Steuergesetzgebung in der Bundesrepublik Deutschland aus der Sicht des Ministerialbeamten, in: Deutsches Steuerrecht, Heft 5, S. 119.

- (1979): Wunderwaffen ohne Pulver, in: Wirtschaftswoche Special Steuer, S. 93.

- (1985): Ober Niedergang oder Neuordnung des deutschen Einkommensteuerrechts aus der Sicht der Gesetzgebungspraxis, in: K. Raupach/K. Tipke/A. Uelner (1985): Niedergang oder Neuordnung des deutschen Einkommensteuerrechts?, Münsteraner Symposion, Bd. I, S. 175.

- (1988): Ober die Notwendigkeit einer Reform des Einkommensteuerrechts. Referat zu den Verhandlungen des Siebenundfunfzigsten Deutschen Juristentages, Mainz, in: Sitzungsberichte Bd. 2, S. N 9.

- (1995): Steuergerechtigkeit zur Neukonzeption des einkommensteuerrechtlichen Familienlastenausgleichs, in: Stimme der Familie, 42. Jg., Heft 4/5, S. 2.

Ulmer, E. (1986): Steuervermeidung, Steuerumgehung, Steuerhinterziehung, in: Deutsche Steuer-Zeitung, 74, Jg., Nr. 12, S. 292.

Umpfenbach, K. (1859): Lehrbuch der Finanzwissenschaft, Erlangen.

Upmeier, W. (1972): Die netıe "Klassensteuer". Die Verselbstăndigung der Besteuerung nach Einkommensarten, dargestellt an der gesonderten Besteuerung der Einkünfte aus nichtselbstandiger Arbeit. Zum Postulat der Gleichmäßigkeit der Besteuerung, Diss. rer. pol., Kōln.

Urban, J (1989): Steuerrechtliche Verwertungsverbote, in: Neue WirtschaftsBriefe, Herne, Fach 17, S. 1037.

Verbalnde der Deutschen Akademien (Hrsg.) (1928): Deutsches Biographisches Jahrbuch, Uberleitungsband II: 1917 - 1920, Berlin und Leipzig.

Vereinbarung zwișchen der Bundesrepublik Deutschland und der Deutschen Demokratischen Republik zur Durchfithrung und Auslegung des am 31. August 1990 in Berlin unterzeichneten Vertrages zwischen der Bundesrepublik Deutschland und der Deutschen Demokratischen. Republik uber die Herstellung der Einheit Deutschlands - Einigungsvertrag - vom 18.9.1990, in: BGBl. II S. 1239.

Verfassung der Deutschen Demokratischen Republik vom 6. April 1968, in: GBIDDR I vom 9.4.1968, S. 199.

Verhandlungen der beiden Hăuser des preußischen Landtages. Haus der Abgeordneten. 15. Legislaturperiode, II. Session, Berlin 1883/84, Anlagen Bd. 4, Aktenstück 290.

Verhandlungen der dritten Generalversammlung des Vereins für Socialpolitik am I0., 11. und 12. Oktober 1875 (= Schriften des Vereins fur Socialpolitik, Bd. 11), S. 15. 
Verhandlungen der verfassungsgebenden Deutschen Nationalversammlung, Band 340. Anlagen zu den Stenographischen Berichten, Berlin 1920.

Verhandlungen des Deutschen Bundestages, Stenographische Berichte, 1. Wahlperiode 1949.

Verhandlungen des ZweiunddreiBigsten Deutschen Juristentags (Bamberg), Berlin und Leipzig 1922.

Verhandlungen des Dieiunddreißigsten Deutschen Juristentags (Heidelberg), Berlin und Leipzig 1925.

Verhandlungen des Siebenundfünfzigsten Deutschen Juristentags (Mainz) 1988.

Verordnung des Reichsministers der Finanzen zur Ausführung des $\$ 59$ a) des Einkommensteuergesetzes vom 25.7.1921, in: Zentralbl. furr das Deutsche Reich 1921, S. 658 .

Verordnung des Reichspräsidenten zur Sicherung von Wirtschaft und Finanzen vom 1.12.1930, in: RGBI. I Nr. 47, S. 517.

Verordnung, die Ausfuhrung des Einkommensteuergesetzes vom 2. Juli 1878 betreffend, vom 11.10.1878, in: Gesetz- und Verordnungsblatt fir das Konigreich Sachsen, 13. Stack vom Jahre 1878, S. 225.

Vertrag über die Schaffung einer Währungs-, Wirtschafts- und Sozialunion zwischen der Bundesrepublik Deutschland und der Deutschen Demokratischen Republik vom 18.5.1990, in: BGBI. II S. 537.

Vertrag zwischen der Bundesrepublik Deutschland und der Deutschen Demokratischen Republik uber die Herstellung der Einheit Deutschlands - Einigungsvertrag - vom 31.8.1990, in: BGBI. II, S. 889 .

Vietor und die "sogenannten reichen Leute". Wie die Manager der Neuen Heimat in Berlin Geschaffte machen (ohne Autorenangabe) (1982): in: Der Spiegel, Nr. 7, 36. Jg., Hamburg, S. 98.

Vocke, W. (1866): Geschichte der Steuem des britischen Reichs. Ein finanzgeschichtlicher Versuch, Leipzig.

- (1887): Die Abgaben, Auflagen und die Steuer vom Standpunkte der Geschichte und der Sittlichkeit, Stuttgart.

- (1890): Die Idee der Steuer in der Geschichte, in: Finanz-Archiv, 7. Jg., Stuttgart.

- (1892): Steuerobjekt und Realsteuer, in: Finanz-Archiv, 9. Jg., Stuttgart, S. 1.

- (1894): Die Grundzuge der Finanzwissenschaft, Einfuhrung in das Studium der Finanzwissenschaft, Leipzig.

Vogel, E. H. (1910): Die theoretischen Grundlagen der Vermōgensbesitzsteuer im Systeme der Ertrags- und Einkommensbesteuerung, in: Finanz-Archiv, 27. Jg., S. 81.

- (1911): Robert Meyer und sein Wirken auf dem Gebiete der Finanzwissenschaft, in: Finanz-Archiv, 32. Jg., S. 76. 
- (1912): Die Aufgaben der Sozialpolitik in der Steuergesetzgebung, in: Archiv furr Sozialwissenschaft und Sozialpolitik, 34. Bd., Tubingen.

- (1929): Grundsatzliches zur theoretischen Frage "nichtfiskalischer Zwecksetzung" in der Besteuenung, in: Finanz-Archiv, 46. Jg.

Vogel, H. (1969): Probleme einer modernen Finanzpolitik, in: Der Betriebs-Berater, Heft 7, 24. Jg.

- (1975): Zur Einschrinkung der Verlustzuweisungen an Kornmanditisten bei Vermietung und Verpachtung, in: Der Betrieb, Heft 12, S. 518.

Vogel, J. (1975): 25 Jahre Rechtsprechung des Bundesfinanzhofs, in: Deutsche SteuerZeitung A, Heft 23, S. 451.

Vogel, K. (1962): Verwaltungsrecht und Allgemeines Abgabenrechte, in: Deutsches Verwaltungs-Blatt, S. 435.

- (1975): Steuergerechtigkeit und soziale; Gestaltung, in: Deutsche Steuer-Zeitung A, Ni. 19-20, S. 409.

- (1977): Die Besonderheit des Steuerrechts, in: Deutsche Steuer-Zeitung A, Nr. 1-2, S. 5 .

- (1983): Verbot des Verlustausgleichs für bestimmte ausländische Verluste. Der neue $\$ 2$ a des Einkommensteuergesetzes, in: Betriebs-Berater, Heft 3, S. 180.

- (1984): Zwangslaufige Aufwendungen - besonders Unterhaltsaufwendungen - mússen realitatsgerecht abziehbar sein. Das BVerfG verschärft seine Rechtsprechung zum Verfassungsprinzip der Leistungsfahigkeit, in: Steuer und Wirtschaft 3, S. 197.

- (1984): Laudatio auf die Investitionshilfeabgabe, in: Steuer und Wirtschaft 2, S. 166.

- (1987): Begrenzung von Subventionen durch iluren Zweck, in: W. Fürst/ R. Herzog/D. C. Umbach (Hrsg.): Festschrift für Wolfgang Zeidler, Bd. 1, Berlin, S. 539.

- (1987): Der Finanz- und Steuerstaat, in: Handbuch des Staatsrechts der Bundesrepublik. Deutschland, Bd. 1, Heidelberg, S. 1151.

- (1993): Stenerrechtswissenschaft als Steuergerechtigkeitswissenschaft, in: JuristenZeitung, 48. Jg., Heft 23, S. 1121.

Vogel, K./Tipke, K. (Hrsg.) (1972): Verfassung, Verwaltung, Finanzen, Festschirift für Gerhard Wacke zum 70. Geburtstag, Köln.

Vogelsang, H. (Hrsg.) (1992): Perspektiven der Finanzverwaltung. Analysen und Prognosen im Spiegel von Wissenschaft und Praxis, Köln.

Voigt, A. (1951): Betrachtungen zur Verkehrsentwicklung in der Deutschen Bundesrepublik im Jahre 1950 und Ausblick auf 1951, in: Hansa, Zeitschrift für Schiffahrt, Schiffbau, Hafen, Hamburg, S. 293.

Wachler, P. (1902): Das Koniglich-Sachsische Oberverwaltungsgericht in Dresden, in: Deutsche Juristen-Zeitung, 7. Jg., S. 194. 
- (1903): Erfahrungen und Wünsche aus der Rechtsprechung des Oberverwaltungsgerichts in Abgabensachen, in: W. Schelcher (Hrsg.): Fischers Zeitschrift fur Praxis und Gesetzgebung der Verwaltung, Bd. 25, S. 147 u. Bd. 26, S. 312 .

- (1903): Ein funfundzwanzigjahriges Gesetzesjubilăum, in: Deutsche Juristen-Zeitung, VIII. Jg., S. 508.

- (1912): Moral und Technik bei der Veranlagung der preufischen Einkommensteuer, in: Verwaltungsarchiv, 20. Bd., Berlin, S. 353.

- (1912): Das Kōniglich Săchsische Einkommensteuergesetz vom 24. Juli 1900 in der Fassung der Gesetze vom 1. Juli 1902 und vom 15. Juni 1908 nebst Ausfulhrungsverordnung und Instruktion, 3. Aufl., Leipzig.

Wachler, P./Naundorff, E. (1905): Rechtsgrundsătze des Kgl. Săchs. Oberverwaltungsgerichts, 1. Band, Leipzig.

Wacke, G. (1966/67): Verfassungsrecht und Steuerrecht. Das Finanz- und Steuerrecht als Bestandteil der Verfassungsordnung, in: Steuerberater-Jahrbuch 1966/67, Koln, S. 75 .

Wacker, H. W. (1986): Expansion steuerwissenschaftlicher Studiengănge in den USA mit betriebswirtschaftlichem Spezialdiplom (Master of Taxation), in: Steuer und Wirtschaft 3, S. 269.

Wagner, A. (1875/76): Allgemeine oder theoretische Volkswirthschaftslehre. Mit Benutzung von Rau's Grundsaitzen der Volkswirthschaftslehre. Zugleich als 9. Ausgabe der Rau'schen Volkswirthschaftslehre, Theil I, Grundlegung, Leipzig und Heidelberg.

- (1876): Allgemeine oder theoretische Volkswirtschaftslehre. Erster Theil. Lehrbuch der politischen Oekonomie. Erster Band. Leipzig und Heidelberg.

- (1876): Lehrbuch der politischen Oekonomie von Karl-Heinrich Rau, 1. Bd., Leipzig und (1879), Leipzig.

- (1878): Referat über die Communalsteuerfrage, in: Verhandlungen der 5. Generaiversammlung des Vereins für Socialpolitik (= Schriften des Vereins für Socialpolitik), Bd. 14, Leipzig.

- (1879): Allgemeine oder theoretische Volkswirthschaftslehse. Erster Theil. Grundlegung, Leipzig.

- (1880): Finanzwissenschaft. Zweiter Theil. Gebuhren und allgemeine Steuerlehre (= Lehrbuch der politischen Oekonomie. Sechster Band), Leipzig und Heidelberg.

- (1882): Specielle Steuerlehre. I. Theil. Die sogenannten directen Steuern, insbeson-

- dere die Ertrags-, Personal-, Einkommen- und Vermōgensteuern, in: G. Schōnberg (Hrsg.): Handbuch der politischen Oekonomie, Zweiter Band, Tübingen, S. 247.

- (1885): Die sogenannten directen Steuern, insbesondere die Ertrags-, Personal-, Einkonmen- und Vermögenssteuern, in: G. Schönberg (Hrsg.): Handbuch der Politischen Oekonomie, 2. stark verm. Aufl., 3. Bd., Tubingen, S. 175. 
- (1886): Systematische Nationalókonomie, in: Jahrbücher für Nationalókonomie und Statistik, N. F., 12. Bd. Jena, S. 197.

- (1887): Finanzwissenschaft und Staatsozialismus, in: Zeitschrif f d ges. Staatswiss., 43. Jg., S. 37 und S. 675.

- (1890): Lehr- und Handbuch der politischen Oekonomie, Vierte Hauptabteilung: Finanzwissenschaft, Zweiter Theil: Theorie der Besteuenung, Gebührenlehre und allgemeine Steuerlehre, 2. Aufl., Leipzig.

- (1891): Die Reform der direkten Staatsbesteuerung in Preussen im Jahre 1891, in: Finanz-Archiv, 8. Jg., 2. Bd., Stuttgart, S. 551.

- (1891): Die Reform der direkten Staatsbesteuerung in Preussen im Jahre 1891, in: Finanz-Archiv, 8. Jg., S. 551

- (1892): Úber soziale Finanz- und Steuerpolitik, in: Archiv für Soziale Gesetzgebung und Statistik, 4. Bd.

- (1892): Grundlegung der politische Oekonomie, 3. Aufl., 1. Theil, Grundlagen der Volkswirthschaft, 1. Halbbd., Leipzig.

- (1894): Grundlegung der politischen Oekonomie, 3. Aufl., Zweiter Theil. Volkswirtschaft und Recht, besonders Vermögensrecht oder Freiheit und Eigenthum in volkswirthschaftlicher Betrachtung, Buch 1 - 3, Leipzig.

- (1896): Finanzwissenschaft. Ergänzungsheft zum dritten Theil: Specielle Steuerlehre, Leipzig.

- (1897): Direkte und indirekte Steuern in deт Finanzwissenschaft, in: G. von Schönberg (Hrsg.): Handbuch der Politischen Oekonomie, 4. Aufl., 3. Bd., 1. Halbband (Finanzwissenschaft), Tubingen.

- (1897): Finanzwissenschaft. Grundriß zu der Universităts-Vorlesung. Manuskript gedruckt. Oktober 1897.

- (1899): Finanzwissenschaft. Vierter Theil. Specielle Steuerlehre. (Praxis der Besteuerung). Die deutsche Besteuerung des 19. Jahrhundert. (Staats- und Communalbesteuerung.), 1. Halbbd. Preussen, Sachsen, Baiern, Württemberg, Leipzig.

- (1901): Die deutsche Besteuenung des 19. Jahrhunderts. Staats-, Communal- und Reichsbesteuerung, in: ders.: Finanzwissenschaft (= Lehr- und Handbuch der politischen Oekonomie, bearb. und hrsg. von A. Wagner, 4. Hauptabtheilung, 4. Theil, Leipzig.

- (1904): Zur Methodik der Statistik des Volkseinkommens und Volksvermögens. Mit besonderer Berücksichtigung der Steuerstatistik, in: Zeitschrift des Königlich Preussischen Statistischen Bureaus, 44. Jg., Berlin, S 41.

- (1910): Steuergeschichte vom Altertum bis zur Gegenwart, in: ders.: Finanzwissenschaft (= Lehr und Handbuch der politischen Oekonomie, bearb. und hrsg. von A. Wagner, 4. Hauptabtheilung, 3. Theil, 1. Buch, 2. Aufl., Leipzig. 
- (1910): Steuergeschichte vom Altertum bis zur Gegenwart, in: ders: Finanzwissenschaft (= Lehr- und Handbuch der politischen Oekonomie, bearb. und hrsg. Von A. Wagner, 4. Hauptabtheilung, 3. Theil, 1. Buch), 2. Aufl., Leipzig.

Wagner, F. W. (1990): Die umgekehrte Maßgeblichkeit der Handelsbilanz für die Steuerbilanz. Eine Analyse ihrer ökonomischen Wirkungen, in: Steuer und Wirtschaft 1, S. 3.

Wagner, F. W./Wangler, C. (1992): Kombizins-Anleihen - Eine Finanzinnovation als Steuersparmodell, in: Der Betrieb, 45. Jg., Heft 48.

Wagner, P. (1969): Leasing als Geschăftsbesorgung, in: Betriebs-Berater, S. 109.

Wagner, R. E. (1966): Pressure Groups and Political Entrepreneurs, Papers on NonMarket-Decision-Making 1, S. 161

Wagner, W. (1979): Aus der Arbeit des Steuergesetzgebers, in: Steuer und Wirtschaft 3, S. 287.

Wagner (ohne Vorname), (Referendar) (1916): Die Beweisaufnahme des Steuerbeanstandungs- und Rechtsmittelverfahrens im Preuß. Einkommen-Steuer-Gesetz, insbesondere die Büchervorlage, in: Deutsche Steuer-Zeitung, IV. Jg., 1915/16, Berlin S. 32 .

Walb, E. (1933): Zur Dogmengeschichte der Bilanz, 1861 - 1919, in: Festschrift für Eugen Schmalenbach, Leipzig, S. 1.

Waldecker, L. (1913): Oberfinanzrat Meisel und die preussische Einkommensteuerstatistik. Eine Erwiderung an Hand der hessischen Veranlagungsergebnisse, in: Finanz-Archiv, 30. Jg., Stuttgart, S. 53 - 95; und: (1917): 34. Jg., S. 155.

- (1917): Finanz- und Steuerrecht als juristische Disziplin, in: Finanz-Archiv 33. Jg., Stuttgart, S. 155.

- (1918): Rechtsfriede und Güteverfahren auf dem Gebiete des offentlichen, insbesondere des Einkommensteuerrechts, in: Annalen des Deutschen Reichs, S. 83.

- (1925): Steuerrecht oder Fiskalismus?, in: Finanz-Archiv, 42. Jg., Stuttgart, S. 69.

- (1928): Steuerrecht und Rechtsstaat, in: Öfentlichrechtliche Abhandlungen, Heft. 1, Berlin.

Walden, P. (1983): Eigenverbrauch und Arbeitgeberverbrauch. Steuersystematische Oberlegungen zur Frage der Steuerbarkeit von Zuwendungen an Arbeitnehmer im Umsatzsteuerrecht, in: Betriebs-Berater, Heft 11, S. 693.

Wallich, H. (1955): Triebkraffte des deutschen Wiederaufstiegs, Frankfurt/M.

von Wallis, H. (1975): Grundfragen der Einkommensbesteuerung, in: Finanz-Rundschau, Heft 14, S. 334.

Walz, W. R. (1980): Steuergerechtigkeit und Rechtsanwendung. Grundlinien einer relativ autonomen Steuerrechtsdogmatik, Hamburg.

- (1980): Empfiehlt sich eine rechtsformunabhăngige Besteuerung der Unternehmen? Gutachten F für den 53. Deutschen Juristentag, München 
- (1981): Steuerberatung in den USA - Einige berufsrechtliche Probleme, in: KOSDI, Heft 9/81, S. 4330.

- (1982): Richterliche Rechtsfindung im Steuerrecht der USA, in: Steuer und Wirtschaft, Nr. 1, S. 1.

- (1982): Steuerverwaltungsanordnungen im Bundessteuerrecht der Vereinigten Staaten, in: Steuer und Wirtschaft 4, S. 381.

- (1986): Steuerrechtliches Case Law oder Dictum des Gesetzgebers?, in: Steuer und Wirtschaft 1, S. 21

Walzer, K. (1986): Hauptgriunde fur die Wahl einer Besteuerung nach dem Leistungsfahigkeitsprinzip, in: Steuer und Wirtschaft 3, S. 201.

Wanner, E. (1987): Der einkommensteuerrechtliche Zurechnungszusammenhang steuerbarer Wertabgănge. Ein Beitrag zu einer kausalen Veranlassungstheorie im Einkommen-Steuerrecht, in: Steuer und Wirtschaft 4, S. 302.

Wassermeyer, F. (1979): Die Obertragung von Einkunftsquellen zwischen nahestehenden Personen. Ein Beitrag zu den Sachgesetzlichkeiten im Steuerrecht, in: Steuer und Wirtschaft 3, S. 209

- (1982): Das Erfordernis objektiver und subjektiver Tatbestandsmerkmale in der ertragsteuerlichen Rechtsprechung des BFH, in: Steuer und Wirtschaft 3, S. 352.

- (1983): Erfahrungen mit dem Außensteuergesetz von 1972, in: K.-H. Hansmeyer (Hrsg.): Staatsfinanzierung im Wandel, S. 573.

Watrin, C. (1988): Alfred Müller-Armack (1901 - 1978), in: Henning, F. W. (Hrsg.): Volkswirte und Sozialwissenschaftler, Köln.

- (1990): Prämissen gesamtdeutscher Wirtschaftspolitik, Referat vom 9.11.1990, ausgewahlte Vorträge $\mathrm{Nr}$. 12, BKU.

= (1993): Germany's Economic Unification Two Years Later, in: AICS Seminar Papers, No. 4. Washington, D. C

- (1994): Ordnungs- und wirtschaftspolitische Grundlagen Sozialer Marktwirtschaft, in: Klein, W./Paraskewopoulos, S./Winter, H.: Soziale Marktwirtschaft. Ein Modell für Europa. Festschrift fur Gernot Gutmann zum 65. Geburtstag, Berlin, S. 9.

Weber, M. (1904): Die Objektivitat sozialwissenschaftlicher und sozialpolitischer Erkenntnis, in: Archiv fur Sozialwissenschaft und Sozialpolitik, 19. Bd., Tubingen, S. 22.

- (1985 hrsg. von J. Winckelmann) Wirtschaft und Gesellschaft, 5. Aufl., Tubingen.

Weber-Grellet, H. (1991): Auf den Schultern von Larenz: Demokratisch-rechtsstaatliche Rechtsanwendung und Rechtsfortbildung im Steuerrecht, in: Deutsches Steuerrechi, Heft 14-15, München, S. 438.

- (1992): Wo beginnt die Grenze zur "Liebhaberei", Teil I, in: Deutsches Steuerrecht, Heft 17, S. 56I, Teil II, Heft 18 
- (1993): Die Bedeutung der Rechtsnatur des Steuerrechts für dessen Anwendung und Auslegung, in: Steuer und Wirtschaft, Heft 2.

Wegner, J. (1968): Das Berliner Abschreibungswunder, in: Der Betriebs-Berater, Heft $34, \mathrm{~S}, 1422$.

Wehler, H.U. (Hrsg.) (1966): Moderne deutsche Sozialgeschichte, Köln/Berlin.

Weingarten, J. (1993): Finanzverwaltung und Gesetzesvollzug, Opladen.

Weisflog, W. E. (1982): Öber Auslegung und Rechtsfortbildung im britischen Steuerrecht in: Steuer und Wirtschaft 2, S. 136.

- (1983): Die konsumbasierte oder Mittelfluß-Einkommensteuer von W. D. Andrews, in: Steuer und Wirtschaft 4, S. 337.

- (1987): Britische Steuerreform. Das amerikanische "Reformvorbild" und die britischen Reformaussichten, in: Steuer und Wirtschaft 2, S. 156.

Weiß, E. (1972): Die Neuorganisation der Finanzămter und des Besteuerungsverfahrens unter Berücksichtigung ihrer Auswirkungen auf die steuerberatenden Berufe, in: Bundeskammer der Steuerbevollmăchtigten (Hrsg.), Steuer-Kongress-Report.

Weissenbom, H. (1907): Zum Begrifî der Einkommensquelie im Sinne des $\S 9$ des Einkommensteuergesetzes vom 19.6.06, in: Preußisches Verwaltungsblatt, 28. Jg., Berlin, S. 705.

Weisser, G. (1949): Leitsätze zur Ordnung der Wirtschaft nach der Wăhrungssanierung, in: Finanzarchiv, N. F, Bd. 11, Tubingen, S. 429.

- (1961): Vermögen und Vermögenspolitik, in Handwörterbuch der Sozialwissenschaft, Bd. 11, S. 163.

Weißler, A. (1905): Geschichte der Rechtsanwaltschaft, Leipzig.

Welter , R. (1980): Die Besteuenung von Renten aus der gesetzlichen Rentenversicherung $(\$ 22 \mathrm{Nr}$. 1 Buchst. a EStG) und das Gleichbehandlungsgebot (Art. 3 Abs. I GG), in: Steuer und Wirtschaft 4, S. 332.

Wendt, R. (1988): Empfiehlt es sich, das Einkommensteuerrechi zur Beseitigung yon Ungleichbehandlung und zur Vereinfachung neu zu ordnen?, in: Die Offentliche Verwaltung, 41. Jg., Nr. 17, S. 710.

Werenberg, W. (1866): Der gegenwărtige Stand der Steuerreformfrage in Deutschland, in: Preußische Jahrbücher, 17. Bd. S. 303.

Wemer, W. (1919): Steuermoral und Sparkassen, in: Finanz-Archiv, 36. Jg., Bd. 2, S. 539.

Wersing, B. (1983): Investitionsforderung durch Verlustzuweisungen und ihre Beurteilung, Diss. rer. pol., Düsseldorf.

Weyermann, M. (1910): Die Ueberwalzungsfrage bei der Wertzuwachssteuer, in: Annalen des Deutschen Reichs, S. 881 . 
- (1912): Die Reichszuwachssteuer von sozialpolitischen Gesichtspunkten, in: Jahrbuch fur Gesetzgebung, Verwaltung und Volkswirtschaft im Deutschen Reich, 36. Jg., S. 283 ,

Wicksell, K. (1895): Finanztheoretische Untersuchungen nebst Darstellung und Kritik des Steuerwesens Schwedens, Jena.

Widmung, s. Liebmann, O. (Hrsg.).

Wieland, J. (1987): Steuerliche Wohneigentumsforderung, Finanzverfassung und Gleichheitssat2, in: W. Fürst/R. Herzog/D. C. Umbach (Hrsg.): Festschrift für Wolfgang Zeidler, Berlin, S. 735.

Wilding, A. (1893:) Laiengedanken uber Steuern, in: M. Harden (Hrsg.): Die Zukunft, 5. Bd., Berlin.

Wilke, G. (1921): Die Entwicklung der Theorie des staatlichen Steuersystems in der deutschen Finanzwissenschaft des 19. Jahrhunderts, in: Finanz-Archiv, 38. Jg., Stuttgart, S. 1.

Willgerodt, H. (1980): Kapital- und Vermögensbildung. Ordnungspolitische Konsequenzen, in: Kannengießer, W. (Hrsg.), S. 37.

- (1984): Staatliche Hilfen in einer Marktwirtschaft, in: Zeitschrift fur Wirtschaftspolitik, 33. Jg., S. 59.

- (1985): Die Sachlogik der Wirtschaft in Spiegel des Rechts, in: Ludwig-ErhardStiftung (Hrsg.): Recht und Gesittung in einer freien Gesellschaft. Zur Erinnerung an Franz Bohm aus Anlaß des 90. Geburtstages, Bonn.

Willgerodt, H./Bartel, K./Schillert, U. (1971): Vernōgen für Alle, (= Schriftenreihe der Ludwig-Erhard-Stiftung), Bd. 2, Dusseldorf.

von Wilmowski, B. (1915): Das preußische Einkommensteuergesetz vom 24.6.1891 in der Fassung der Abănderungsgesetze vom 19.6.1906, vom 18.6.1907 und $16.5 .1909,3$. Aufl., Breslau.

Wirminghaus, A. (1891): Die Ergebnisse der Konkursstatistik, in: Jahrbucher für Nationalökonomie und Statistik, Jena.

Wimer, J. (1990): Enno Becker, Schöpfer der Reichsabgabenordnung, in: Steuer und Wirtschaft 1, S. 74 .

WirtschaftsWoche, Pflichtblatt der Wertpapierborse in Frankfurt und Dusseldorf, Dusseldorf, (Zeitschrift).

Witt, P.-C. (1970): Die Finanzpolitik des Deutschen Reichs von 1903 bis 1913. Eine Studie zur Innenpolitik des Wilhelminischen Deutschland, Labeck/Hamburg.

- (1973): Der preußische Landrat als Steuerbeamter 1891 - 1918. Bemerkungen zur politischen und sozialen Funktion des deutschen Beamtentums, in: Deutschland in der Weltpolitik des 19. und 20. Jahrhunderts, hrsg. von I. Geiss und B. J. Wendt, Düsseldorf, S. 205 - 219; auch veroffentl. in: Preussen in der deutschen Geschichte, hrsg. von D. Blasius (= Neue Wissenschaftliche Bibliothek) Geschichte, 111, hrsg. von H.U. Wehler, Königstein/Ts. 1980, S. 293. 
- (1986): Patriotische Gabe und Brotwucher, in: U. Schulz (Hrsg.): Mit dem Zehnten fing es an, München.

Witthoeft (ohne Vorname) (1893): Die Besteuerung der Spekulations-Gewinne durch das Einkommensteuergesetz vom 24. Juni 1891, in: Verwaltungsarchiv, 1. Bd., S. 297.

Wittmann, R. (1993): Besteuerung des Markteinkommens - Grundlinien einer freiheitsschonenden Besteuerung, in: Steuer und Wirtschaft, Heft 1, S. 33.

Witmeben, A. (1961): Was hat Vorrang: Rechtssicherheit oder GleichmäBigkeit der Besteuerung?, in: Steuerberater-Jahrbuch 1960/61, Köln, S. 37.

Wittschewski (ohne Vomame) (1911): Die steuerliche Belastung in deutschen Volk, in: Annalen des Deutschen Reichs, S. 393.

Wöhe, G. (1975): Steuern als Mittel der Wirtschaftspolitik, in: Steuerkongress-Report 1975, München, S. 169.

- (1981): Leasing, in: Handwörterbuch des Steuerrechts, S. 953.

Woemer, L. (1975): Die neuere Rechtsprechung des Bundesfinanzhofs zur Einkommensbesteuenung von Gesellschaftern einer Personengesellschaft, in Betriebs-Berater, Heft 14, S. 645.

- (1978): Die Steuerrechtsprechung zwischen Gesetzeskonkretisierung, Gesetzesfortbildung und Gesetzeskorrektur, in: Tipke, K.: Grenzen der Rechtsfortbildung durch Rechtsprechung und Verwaltungsvorschriften in Steuerrecht.

- (1992): Verfassungsrecht und Methodenlehre im Steuerrecht. Auf den Spuren von Heinrich Beisse, in: Finanz-Rundschau Nr. 8, S. 226.

Wohnungswirtschaftlicher Fachausschuß des Instituts der Wirtschaftsprufer in Deutschland e.V. (1990): Grundsătze ordnungsmäßiger Durchführung von Prospektprufungen, in: WFA, 7. Erg.-Lfg.

Wolf, E. (1953): Probleme der Wiederbelebung des Kapitalmarktes, in: Albrecht, G./ Amdt, H. (Hrsg.): Kapitalbidlung und Kapitalverwendung.

Wolf, J. (1898): Illusionisten und Realisten in der Nationalokkonomie, in: Zeitschrift für Sozialwissenschaft, 1. Jg., Berlin, S. 4, S. 89, S. 249, S. 352, S. 407.

Wolff von Amerongen, O. (1975): Bundesfinanzhof und Wirtschaft, in Deutsche Steuer-Zeitung A, Nr. 19-20, S. 415.

Woll, A. (1992): Wirtschaftspolitik, Munchen.

Wollny, P. (1981): Veranlagung, in: Handwörterbuch des Steuerrechts, 2. Bd., 2. Aufl., München, S. 1489.

Woring, S. (1992): Zur Steuerfreistellung des Existenzminimums durch das Bundesverfassungsgericht, in: KOSDI 11/92, S. 9162.

Wueller, P. H. (1938): Concepts of taxable Income I and II, in: Political Science Quarterly, Vol. 53. 
Wurttembergisches Gesetz, betr. die Einkommensteuer vom 8.8.1903, in: RGBl. Nr. 23, S. 261.

Yudkin, L. (1971): A Legal Structure for Effective Income Tax Administration, International Tax Program, Harvard Law School, Cambridge.

Zarden (ohne Vorname) (1923): Der Entwurf eines Gesetzes über die Berücksichtigung der Geldentwertung in den Steuergesetzen, in: Deutsche Juristen-Zeitung, Heft 3/4, S. 74 .

- (1923): Das Gesetz uber die Berucksichtigung der Geldentwertung in den Steuergesetzen, in: Deutsche Juristen-Zeitung, Heft 7/8, S. 202.

Zeidler, W. (1985), Verfassungsrechtliche Fragen zur Besteuerung von Familien- und Alterseinkommen, in: Steuer und Wirtschaft 1, S. 1.

Zeitschrift des Königlich-Săchsischen Statistischen Bureaus (1889), 35. Jg., Dresden.

Zeitschrift fur das gesamte Kreditwesen (1972).

Zeitschrift fur die gesamte Staatswissenschaft, Tubingen.

Zeitschrift fur Wirtschaftspolitik, Köln.

Zeppermick, R. (1973/74): Die Bedeutung der Finanz- und Sozialpolitik fur die Einkommensverteilung, in: FA, N. F., Bd. 32, S. 425.

- (1986): Transfer-Einkommen und Einkommensverteilung, Berlin.

Ziegler, G. (1955): Subventionen in der Marktwirtschaft, Diss. rer. pol., Köln.

Zimmermann, H. (Hrsg.) (1987): Die Zukunft der Staatsfinamzierung, Stuttgart.

Zippelius, R. (1991): Grundbegriffe der Rechts- und Staatssoziologie, 2. neubearb. Aufl, München.

Zischka, A. (1966): War es ein Wunder? Zwei Jahrzehnte deutschen Wiederaufstiegs, Hamburg.

Zitzelsberger, H. (1985): Öber die Schwierigkeiten mit dem Abbau von Steuersubventionen in: Steuer und Wirtschaft 3, S. 197.

Znber, B. (1987): Die US-amerikanische Einkommensteuerreform 1986, in: WiSt Wirtschaftswissenschaftliches Studium, 16. Jg., Heft 6, S. 299.

Zweigert, E. (1891): Das Einkommensteuergesetz für die Preußische Monarchie vom 24. Juni 1891. Textausgabe mit Einleitung, Anmerkungen und Sachregister, nebst einem Anhang enthaltend die Gesetze betr. Erwerbung und Verlust der Bundes- und Staatsangehōrigkeit, betr. Beseitigung der Doppelbesteuerung, das Nothkommunalstener-Gesetz, das Wahl-Gesetz sowie das Formular für die Steuer-Erklărungen und den Steuer-Tarif, Essen.

Zweites Gesetz zur vorlăufigen Neuordnung von Steuern vom 20.4.1949, in: Gesetzblatt der Verwaltung des Vereinigten Wirtschaftsgebietes, Nr. 15, S. 69.

Zwick, M. (Hrsg.) (1994): Einmal arm, immer arm? Neue Befunde zur Armut in Deutschland, Frankfurt/M. 
Zybon, A. (1971): Ober die Fragwürdigkeit des Steuergeheimnisses. Ein. Beitrag zur Bekămpfung der Wirtschaftskriminalităt sowie zur Reform der Abgabenordnung und des Strafgesetzbuches, in: Zeitschrift für Betriebswirtschaft, 41. Jg., Wiesbaden, S. 85.

- (1973): Die Publikums-KG, in: Betriebswirtschaftliche Forschung und Praxis, 25. Jg., Herne/Berlin, S. 418. 


\section{Namenregister}

Abs, H. J. 336, 411

Addington, H. 212

Adenauer, K. 301

Agatz, G. 301

Albert, H. 44, 454, 487, 491, 494

Albrecht, A. 132

Albrecht, G. 127, 309

Albrecht, S. 455

Althoff, F. 222

Altmann, P. 216

Andel, N. 320

Anonym 493

Aristoteles 200

Andt, H. 127, 132, 309

Andt, H. W. 452, 494

Amim, H. H. von 297, 319, 320, 455, 456,457

Assmann, E. 116

Bachem, K. 400

Backhaus, J. 127, 129

Ball, K. 106

Ballerstedt, K. 238

Bareis, H. P. 314

Barnett, J. S. 431, 432, 433, 435

Barth, K. 26, 40, 41, 52, 53, 64, 69, 197', $373,380,381,382,385$

Bauckner, A. 71, 202, 221, 489

Baumgarten, E. 192

Baur, F. ! 14

Bayer, H. W. 33, 82, 94, 109, 170, 370, 492

Bebel, A. 363, 386

Becker, E. 26, 101, 103, 106, 108, 109 , $116,118,126,391,392,393,394,400$, 402,510

Becker, Erich 308

Beckerath, E. von $49,50,310$

Behmauer, F. 29, 31, 32, 84, 87, 93, 115 , $224,345,355,480,484$

Beichelt, B. 60

Beisse, H. 106
Bellow, G. von 199,487

Berger, P. A. 336

Beske, S. 427,428

Biedenkopf, K. 256

Biergans, E. 99, 103

Biermann, E. 189

Biersack, H.-L. 327, 476, 478

Bilsdorfer, P. 334, 473

Birk, D. 449

Blaich, F. 233

Bleek, W. 50, 366

Blencke, H. 111, 112, 116

Blücher, F. 132, 301

Blther 29, 60, 63, 65, 67, 104, 356, 363, 367,480

Blum, R. 369

Bobbio, N. 494, 497

Boese, F. 57, 100, 202, 216, 217

Böger, M. 314

Bohm, F. 247, 250, 251, 252, 253, 254

Bohmer, R. 177

Bohmert, V. 23, 29, 67, 95, 222, 356, $359,363,366,367,385,480$

Bohnen, A. 192

Bölke, P. 282, 289

Biordewin, A. 149, 150

Born, K. E. 484, 486, 487, 490

Bos, R. W. 436

Bosse, H. R. von, 29, 368:

Brandenberg, B. 113, 120

Biredt, V. 23, 31, 43, 73, 91, 225, 371, $383,482,499$

Brentano, L. 180, 182, 200, 489'

Brestel, H. 283

Broemel 40, 41

Brümmerhoff; D. 320

Buck, L. 29, 32, 63, 78, 83, 85, 88, 92, $93,108,115,368,372,385,388,480$, 486,491

Bugge, G. 192

Bundsmann, E. 489

Buob, H. 321 
Burkart, K. 29, 385, 474

Burghart, K. 24, 72, 207, 371, 481

Busch, U. 270

Busschgen, H. E. 319

Büssgen, H. R. 302, 303, 306

Cohn, G. 325, 476, 489

Colm, G. 122, 139, 455, 461, 462, 464

Conrad, J. 23, 28, 56, 60, 67, 68, 100, 183

Costede, J. 289, 314

Courth, P. 430, 431, 432, 433, 434, 435, 443

Cuno, 81

Czok, K. 386

Däke, K. H. 124, 130

Dalton, H. 166

Debatin, H. 425, 427, 429, 430, 431, $432,433,434,435$

Delbrück, C. von $50,63,82,356,486$

Delbruck, H. 29, 30, 31, 32, 43, 54, 55, $56,81,82,84,92,93,95,96,103,214$, $222,356,372,480,484,486$

Dewitz. 225, 226

Dickopf, J. 446

Dieckmann, H. 461

Diehl, K. 69, 182, 385

Döllerer, G. 238:

Donath, R. 111

Dreißig, W. 131, 132, 141, 277, 464, 465,493

Drōge $84,85,88$

Droste $32,42,88,382$

Droysen, J. G. 199, 200

Ehrenberg, R. 487, 490

Ehritich, E. 484, 485, 491

Eichenberger, K. 502

Elbrächter 298

Engelhardt, W. W. 494

Engels, T. 170

Engländer, O. 488, 489

Epstein, K. 102, 388, 400

Ergenzinger, T. 319.

Erhard, L. 140, 246, 250, 253, 301

Erzberger, M. 69, 99, 100, 102, 103, 386, $388,389,390,392,393,397,415,424$, 460

Eschenburg, A. 102
Eucken, W. 197, 247, 251, 253, 254

F.R. 140

Falk, L. 239, 255, 261

Falthauser, K. 177, 178

Felix, G. 45, 111, 114, 119, 121, 122, $330,437,512$

Ferber, C. 491

Figge, H. 159

Findling, M. 128, 236, 437, 457

Fischer, C. 132, 464

Fischer, F. 64

Fleischer, E. 313

Flitner, A. 199

Forsthoff, E. 17, 23i, 233

Frank, P. 452

Franke, S. F. 236

Fredersdorf, H. 345

Friauf, K.-H. 121

Friedberg, R. 85, 88, 209

Friedemann, J. 262, 281, 3 !6

Fritsch, B. 138

Fuisting, B. 18, 23, 24, 26, 30, 31, 32, $33,34,36,37,39,40,41,42,43,44$, $53,57,59,70,71,72,73,74,76,77$, $78,79,80,81,82,83,84,85,86,88$, $89,90,91,92,94,97,98,100,103$, $104,114,115,121,129,212,225,239$. $325,367,370,371,372,373,374,375$, $378,380,382,387,389,393,399,408$, $434,452,480,482,499$

Fusangel, J. 54, 55

Gaddum, W. 320

Gareis, C. 386

Gärtner, C. F. 189, 190, 191, 192

Gauß, C.-F. 199

Geiger, K. 171, 239, 255

Geiger, W. 181

Geimer, R. 110, 116

Gemperli, A. 73, 212

Gensel, J. 23, 24, 28, 29, 56, 57, 60, 61, $67,70,71,100,104,204,207,216$, $220,359,360,361,363,480$

Gerlach, H. von 87

Gerlach, O. 37, 72, 408, 486

Gerloff, W. 31, 43, 127, 227, 387, 490

Gerstein, E. 107

Geyer, E. 338

Giersch, H. 320 
Giloy, J. 477

Gneist, H. R. von 100, 325, 442, 476

Goetz, W. 182, 200

Goldschmidt, L. 40, 41

Grabower, R. 48, 103, 181, 182, 391, $392,394,460,493$

Graepel, H. 190, 191

Grätzer, R. 49

Grau, W. 127

Greim-Kuczewski, P. 25, 48, 49, 50, 344, 493

Groeben, K. von der 441

Gröber, A. 102, 388, 389, 400

Grossekettler, H. 246, 251, 253

GroBfeld, B. 19, 47, 48, 50, 51, 54, 69, 492

Grün, W. H. 130

Gutenberg, E. 238

Gutmann, G. 234

Habel, W. 464

Halfar, B. 18, 33

Hamel, H. 232, 234, 242

Hamer, E. 507

Hamm, W. 243

Hanesch, W. 177

Hampe, P. 274

Hansen, A. H.425

Hansen, R. 23, 27, 31, 33, 43, 64, 69, 71, $72,73,90,91,99,173,174,179,180$, $183,185,188,189,190,191,192,195$, $198,199,202,207,209,215,218,224$, $241,330,357,370,371,387,476,479$, $480,481,483,486,487,488,489,491$, $493,499,501$

Hansmeyer, K. H. 297, 298, 299, 456, 457,459

Hardach, K. 139, 141

Harden, M. 29, 54

Harms, B. 455

Hurtmann, A. 464

Hartmann, J. $345,420,425,426,427$, 428,498

Hartz, W. 165

Hasbach, W. 90, 182, 193, 195, 204, 218, $251,330,480,481,491$

Hatscheck, J. 100

Hăuser, K. 219, 233, 266, 267, 285

Heckel, M. 209, 210, 217
Hecker, C. 136, 165, 289, 290, 291, 292, 293, 294, 341, 347

Hedtkamp, G. 456, 457

Heeckt, H. 308

Heidrich, P. 482

Heilmann, M. 188, 201, 218, 448

Heiß, C. 56,68

Held, A. 48, 49, 50, 51, 53, 55, 56, 57 , $90,202,207,209,325,476$

Helft, E. 325, 327, 328, 474, 476

Hempel, C. G. 192

Hennemann, G. 190, 199

Henning, F. W. 102, 106, 233, 493

Henrich, L. 53, 54, 56, 60, 67

Hensel, A.103, 125

Herkner, H. 487, 488, 489

Hemann, F. B. W. 21, 66, 198, 476

Herrmann, H. J. 143

Herzfeld, H. 96, 181, 183, 218, 219, 220, 221,475

Hesselbach, W. 411

Hill, J. A. 49

Hirsch, H. J. 225, 330

Hirth, G. 29

Hock, W. 233

Hoeth, P. 301, 302, 303

Hoffmann, A. 29, 56, 86, 205, 359, 369, $386,387,390,460,480$

Hoffmann, H. L. 227

Hoffmann, J. G. 50

Hoffmann, W. G. 56, 68

Hollerbach, A. 250

Howard, H. 64, 68, 84

Hueck, A. 314

Humboldt, W. von 199,200

Isensee, J. 17, 469

Jacob, F. 430, 434, 435, 438

Jäger, K. 318

Jäger, W. 37

Jahn, J. 189

Jansen, R. 104, 113, 114, 1117

Janssen, B. 18

Jastrow, J. 61, 63, 107, 482, 489

Jecht, H. 237, 307

Jehl, H. W. 157, 158

Jehner, H. 35, 36, 1.07

Jenetzky, J. 242, 339, 344, 345, 350, 351, $352,353,354,469,498$ 
Jostock, P. 95

Jürgensen, H. 318

Justus (Pseudonym) 32, 60, 80, 82, 88, 222,480

Kantorowicz, H. 484, 485

Kappe, H. 262

Kărger, K. 56

Kaufmann, A. 495

Kelber, M. 74

Keller, K. 489

Kellner, F. 69

Kelsen, H. 122, 452,485

Keynes, J. M. 233

Kirchhof, G. 69, 70, 304

Kirchhof, P. 94, 101, 105, 109, 174, 213, $214,236,320,321,326,335,412,492$, 493

Kirsch, L. 63, 65, 104, 367

Kitterer, B. H. J. 264, 266, 271

Kittner, M. 275, 285

Kleedehn, B. 319

Kleinwaichter, F. 98

Klock, C. 227

Knapp, G. F. 57, 486

Koch, K. 437, 445

Koch, W. 489

Köhler, W, 488

Koppe 395

Korff, H. C. 303

Korn, K. 405

Komfeld, G. 90, 484

Koschorreck, W. 476

Krabbe, H. 432, 433

Keile, R. 145, 290

Krelle, W. 259, 499

Kries, C. G. 28

Krohn, C. D. 99, 233, 390, 460

Kruse, H. W. 493

Kuhne 5!

Kuhn, T. S. 191

Kummer, J. 331

Kumpf, H. 54

Kupfer, G. 109

Laband, P. 58

Lambsdorff, Graf O. 324

Lammsfuß/Rinne 117

Lampe, A. 17

Lampert, H. 173, 476, 477
Lang, J. 18, 44, 45, 94, 99, 101, 105, $109,117,126,215,335,337,339,354$, $391,417,437,493,496,503,504,505$, 506

Langer, K. 302

Larenz, K. 45

Laum, B. 474

Lavoisier, A. L. de 189, 192

Lehmann, M. 47

Lehner, M. 477

Leidel, H. 102

Leitner, F. 98

Lentze 225

Liebmann, O. 184, 186, 194, 197

Liebknecht, W. 363

Lindenlaub, D. 174, 179, 182, 183, 185, $188,227,481,483,484,486,487,488$, 489

Linzbach, P. 48, 50, 53, 344

Lipps, W. 262, 283

List, F. 227

Littmann, E. 238

Lodermann, W. 313

Loffler, O. 392

Loss, L. 292

Lotz, W. 122

Löw, K. 469

Luckau, E. 292

Lukes, R. 498

Maatz $32,87,93,385$

Maatzen 88

Mackenroth, G. 139

Malchus, C. A. von 227

Mamroth, K. von 47, 48

Manke, K. 345

Mann, F. K. 458, 463

Marx, K. 489

Mataja, V. S. 98

Mattem G. 110,404

Matthăus-Meier, I. 347, 467, 494

Matthōfer, H. 311

Maunz, T. 106

Mauz, F. 50, 53, 72, 181, 382

May, R. E. 78, 93, 95, 96, 222

Mayr, E. 189

Mayr, G, von 82

Meinecke, F. 195

Meinhold, W. 298 
Meisel, F. 29, 30, 31, 32, 33, 43, 55, 58, $69,79,80,81,86,87,88,93,94,95$, $96,97,98,102,108,110,122,123$, $184,214,224,225,226,227,228,344$, $345,355,356,366,367,368,372,376$, $377,383,384,385,388,389,394,407$, $417,418,419,437,438,439,442,480$, $485,489,490,492,497,513$

Mellerowicz, K. 142, 143, 155, 279, 280

Mendel, G. 190

Menger, C. 98, 183, 185, 186, 193, 197 . $202,218,480$

Meßmer, K. 110, 404

Mestmäcker, E. J. 256

Metzger, U. 176, 344, 345

Meyer, D. 447

Meyer, R. 43, 58, 79, 85, 98, 103, 376, $378,380,397,442,480$

Michaelis $29,30,31,32,43,63,79,80$, $81,82,86,88,93,98,103,214,366$, $367,372,384,385,442,480,485,486$, 497

Mill, J. St. 199, 358

Miquell, J von $23,27,33,40,41,69,71$, $72,169,214,215,219,220,227,357$, 366

Mischler, E. 98

Mitschke, J. 323, 324

Molitor, B. 320

Moll, W. 25, 29, 31, 32, 55, 81, 82, 88, $93,103,366,371,378,385,476,480$, 491

Moller, H. 266, 274, 285

Montaner, A. 489

Mrozek, A. 29, 30, 31, 32, 39, 43, 80, 81 , $82,86,88,384,385,480$

Malles, J. H. 56, 68

Muller-Armack, A. 172, 173, 238, 239, $246,247,253,254,256,258,298,310$

Murhard, K. 327

Muscheid, J. 132, 133, 234, 235, 236, 277,437

Musgrave, R. A. 425

Myrbach, F, von 206

Myrdal, G. 122, 215, 453

Napp-Zinn, A. F. 311

Nasse, E. 181, 325, 476

Nassen, P. 140

Naucke, W. 484, 496, 501, 502
Naundorf, E. 63

Neckels, P. 108

Neißer, H. 122, 139, 455, 461, 462, 464

Neumann, F. J. 86, 91, 197, 216, 387, $389,390,415,489$

Neumark, F. 99, 110, 127, 132, 239, 250, $256,257,298,310,311,387,380,449$, $455,459,502$

Nevermann, K. 92, 214

Nicklisch, H. 64

Nipperdey, H. 256, 463

Nordenskjöld, E. 189

Nörr, W. K. 250, 252, 253, 254

Nostitz, H. von $29,56,359,480$

Nothhardt, J. 325

Nußbaum, A. 484

Oettle, K. 238

Oldag, A. 161

Oldenberg, K. 96, 223, 228, 237, 485, 500

Opp, K. D. 484

Ortlieb, H. D. $140,177,465,500$

Ott, A. E. 489

\section{Pagel 199}

Pagenkopf, H. 45.5

Paraskewopoulos, S. 232, 234, 241, 243

Paulick, H. 257, 258

Paulus, H. 149

Pausch, A. 40, 50, 63, 64, 76, 96, 100, $102,116,183,186,221,227,233,356$, $365,366,380,388,391,441,442,486$, 489

Pehl, G. 174

Penzlin, H. 311

Peres, W. 375

Pesch, H. 183

Peters, H. R. 320

Peters, K. 421

Pezzer, H.-J. 496

Petzold, R. 120

Pfleiderer, O. 274

Pistorius, T. 58, 102, 380, 388, 389, 400

Platter, J. 24

Pohle, L. 490

Pohmer, D. 320

Pollack, F. 79, 88

Popitz, J. 17, 27, 99, 400, 401, 460, 462, 463 
Popper, K. 454, 491

Pribram, K. 489

Prion, W. 64

Promberger, B. 114

Puchta, G. F. 75

Ridler, A. J. 143, 148, 314

Rainer, T. 109

Raiser, T. 484, 496, 502

Ranke, L. von 199, 200

Rau, K. H. $24,31,34,62,72,73,82$, $181,183,187,202,208,210,212,216$, $217,357,476,499$

Raupach, A. 142, 148, 314, 352, 459, $466,467,494$

Recktenwaid, H. C. 457

Rehbinder, M. 484, 501, 502

Reinhardt, F. 109, 233

Reinsch, R. 98

Rendels, H. J. 329, 472

Reuss, F. G. 255

Ritschl, H. 99, 105, 122, 127

Rittershausen, H. 140

Roesler, H. 62, 74, 198

Rỏhl, K. 484

Rōpke, W. 231, 232, 234

Rogowsky, J. 300, 302, 303

Rohde 88

Roscher, W. 189, 358, 476

Rose, G. 28

Rose, M. 127, 176

Ross, A. 485

Rothacker, E. 199

Rottek, K. von 325,476

Rubner, H. 71, 180, 182, 187, 194, 220, 222

Rueff, J. 231, 232, 234

Ruppe, H. G. 121

Rüschemeyer, D. 444

Rüstow, A. 231, 234

Ruthers, B. 330

Saage, G. 292

Sachs, J. 189

Salin, E. 233

Sauer, 0. 116

Sax, E. 480

Schacht, H. 140

Schaffrath, W. 369
Schanz, G. 29, 30, 32, 34, 69, 70, 91, 96 , $97,98,99,197,213,216,219,220$, $222,325,378,381,385,386,389,450$, $480,481,482,483$

Scheel, $H$. von 186

Schelcher, W. 24, 63, 67

Schelling, F. W. J. 189, 191

Schelver, F. J. 191

Schlauwitz, W. 304

Schlecht, O. 296

Schlieben, O. von $27,99,415$

Schmacks $499^{\circ}$

Schmalenbach, E. 64, 238

Schmidt, D. 447

Schmidt, L. 1I1, 124

Schmitt, K. 140

Schmölders, G. 17, 26, 28, 101, 107, $127,132,239,249,258,307,310,345$, $425,437,456,465,467,468$

Schmoller, G. 21, 22, 23, 27, 28, 29, 31, $32,39,43,44,57,59,62,63,66,67$, $69,72,73,81,82,83,84,85,86,87$, $90,93,94,96,97,99,102,129,169$. $173,174,180,181,182,183,184,185$, $186,188,189,190,191,192,193,194$, $195,196,197,198,200,201,203,204$. $205,206,207,208,210,214,215,218$, $219,222,223,225,226,227,241,249$, $251,325,330,335,356,357,358,359$, $360,362,363,364,381,385,388,389$, $406,408,419,448,460,474,475,476$, $478,479,480,481,482,483,484,488$, $489,490,491,492,501,509,510,511$, $5,12,513$

Schnadel, G. 301

Schneider, D. 283, 477, 494, 502

Schneider, E. 489

Schneider, P. 90

Schneider, V. 79, 442

Schönberg, G. 180, 188:

Scholz, A. von $33,72,181,219,249$

Scholz, R. 330

Schröder, B. 314

Schuhmann, H. 109

Schuller, A. 243

Schutte, C. 127

Schulte, B. 471

Schulze zur Wiesche, D. 104, 113, 117

Schumpeter, J. 17, 127, 209

Schweckendieck 103 
Schweigert, E. 131

Schwerin von Krosigk, Graf L. 138, 233

Seebohm, H. C. 301, 302, 307

Seithel, R. 113, 118, 120

Seligman, E. P. A. 215

Senglaub, K. 189

Shoup, C. S. 349

Siebert, H. 324

Siebke, J. 259, 499

Siegel, T. 502

Sieghart, R. 98

Simon, H. 183

Sinn, G./Sinn, H. W. 109, 270, 271, 272, 273,285

Skalweit, H. 488, 489

Smith, A. 24, 47, 62, 73, 74, 227

Soetbeer, A. 23

Soffing, G. 104, 116, 119, 122

Söhn, H. 69, 70, 105

Sombart, 233, 489

Spindler, J. 462

Spitaler, A. 132, 239, 249, 307, 342, 345, 392,437

Spranger, E. 488,489

Staudinger, J. von 114

Stavenhagen, G. 489

Steinberg, W. 455

Stender, H. 308

Stenglein, W, 375

Stephan, R. 120

Stieda, W. 180

Stier-Somlo, F. 490

Stockinger, R. 99, 103

Stödter, R. 301

Siolper, G. 17, 127, 233, 455, 461

Strauß, F. J. 449

Streck, M. 36, 109, 110, 124, 171, 413, $418,42 i, 446$

Strecker, T. 301

Streißler, E. 215

Strempel, D. 469, 484, 502

Strickroth, G. 240,298

Strumpel, B. 55

Strutz, G. $37,39,58,70,71,76,77,78$, $80,82,84,85,86,88,89,90,91,92$, $94,100,103,108,114,115,225,380$, 393,403

Stubbe, H. 189

Stucken, R. 182

Student, D. 177
Tabacovici, N. 68

Tanzi, V. 418

Tennstedt, F. 500

Terhalle, F. 125, 233, 463, 464

Teschemacher, H. 51, 52

Theisen, M. R. 33

Thieme, L. 107, 241

Thier, E. 448

Timm, H. 447

Tipke, K. 18, 26, 33, 35, 36, 44, 69, 94, $100,101,102,106,107,108,109,110$, $112,115,121,122,125,126,170,174$, $175,215,229,321,326,328,339,342$, $344,354,384,391,417,431,438,448$, $449,450,451,452,473,477,478,479$, $481,482,493,494,495,496,500,504$, 508,512

Tonnies, F. 200, 217, 227, 487, 488

Topitsch, E. 122, 452

Trapp, P. 103

Treitschke, H. von 184, 199

Tróger, H. 307

Uelner, A. 262, 322, 338, 347, 449, 466, $467,469,496$

Uhlmann, R. 305, 316

Upmeier, W. 412

Urban, J. 42 l

Vielain, H. 330

Vocke, W. 30, 55, 222, 356, 357, 358, $359,419,476$

Vogel, H. 99, 376

Vogel, K . 102, 174, 448, 493, 495, 500

Voigt, A. 490

Vorländer, K. 218

Wachler, P. 24, 29, 31, 32, 37, 38, 39, $58,59,60,61,63,65,67,70,79,88$, $104,115,356,367,368,380,381,384$, $385,386,438,480,486$

Wagner, A. 24, 25, 30, 31, 32, 34, 36, $43,54,68,69,71,72,73,76,79,82$, $83,85,86,90,91,94,95,96,99,100$, $109,121,129,180,181,182,183,186$, $187,188,193,194,195,197,198,199$, $200,201,202,203,204,208,209,210$, $211,212,213,214,215,216,217,219$, $220,221,223,224,225,226,227,241$. 
$242,330,357,359,362,363,365,370$, $372,382,383,387,389,390,415,442$, $448,452,475,476,480,481,482,489$, $490,491,499,509,510,511,512,513$ Wagner, R. 199

Walb, E. 41, 52

Waldecker, L. 31, 32, 43, 59, 86, 123 , $129,184,345,355,366,368,369,387$. 390

Wallich, H. 235

Walz, W. R. 46, 48, 122, 432, 435, 440, $444,445,446,461$

Wardenbach, H. 313

Watrin, C. 234, 259, 320

Weber, M. 192, 466, 480, 487, 489

Weber-Grellet, H. 45, 109

Weidenfeld, U. 330

Weingarten, J. 176, 339, 342, 343, 344, $345,346,417,498$

Weiss, E. 345

Weißenborn, H. $84,85,88,375$

Weißer, G. 499

Weißler, A. 369

Wendt, R. 111

Wessels, T. 127, 297

Whewell, W. 189, 192, 196, 199

Wiede, F. 104, 117

Wieser, F. von 98

Wilbrandt, R. 83

Wilding, Graf A. $29,56,60,67,68$

Wilke, G, 73, 208

Willgerodt, H. 253, 259, 320, 336, 497, 499

Wilmowski 88

Winkel, H. 489

Witt, P. C. $50,115,356,486$

Witthoeft 85

Woerner, L. 121

Wōhe, G. 278, 296, 347

Wolf, E. 127

Wolf, J. 227, 487

Wolf, K. 190

Wolf-Doetlinchem, L. 330

Woll, A. 320

Woring, S. 331, 472

Yudkin, L. 431, 433

Zeppernick, R. 322

Ziegler, G. 297
Zippelius, R. 484, 501

Zischka, A. 136, 234, 465, 500

Zitzelsberger, H. 126, 170, 450, 470

Zwick, M. 336

Zybon, A. 142, 281, 282, 314 



\section{Lebenslauf}

Am 16. November 1919 wurde ich als dritter Sohn des Bankiers Albert Bernhard Hansen und seiner Ehefrau Mary Claire, geb. de la MontaigneSelwyn, in Köln geboren. Meine Mutter war die Tochter eines britischen Geographen und Naturforschers und wurde in Philadelphia/USA geboren. Nach dem Ende des 1. Weltkrieges verzogen meine Eltern im Jahr 1919 nach Deutschland. Mein Vater wurde dann Bankier in Berlin und spăter zusătzlich Landwirt in Blumenow/Mecklenburg-Strelitz.

Nach bestandenem Abitur am 13. Mărz 1938 an dem Humanistischen Gymnasium in Neustrelitz/Mecklenburg-Strelitz wurde ich zur Ableistung der halbjährigen Pflichtleistung zum Reichsarbeitsdienst einberufen. Danach begann ich im Oktober 1938 ein Studium der Ingenieurwissenschaften durch eine halbjährige Praktikantentätigkeit bei der Firma AEG AG in Berlin. Zum Sommersemester 1939 wurde ich an der Technischen Hochschule Berlin immatrikuliert, wohin ich nach kurzer Einberufung zum Wehrdienst mit Kriegsbeginn auf Antrag hin zum Studium freigestellt wurde.

Nach erfolgreich bestandener Diplom-Vorprufung wurde ich kurz vor Antritt der Prüfung zum Diplom-Ingenieur im Sommer 1942 endgültig zur reichsdeutschen Wehrmacht einberufen. Ich gelangte zum Einsatz bei der Infanterie in Rußland und geriet nach mehrfachen Verwundungen in der Slowakei in russische und nach gelungener Flucht in US-amerikanische Kriegsgefangenschaft.

Da ich nach Ende des 2. Weltkrieges nicht mehr auf unseren Besitz, das Landgut Blumenow zurückkehren konnte, suchte ich einen neuen Wohnsitz in meiner Geburtsstadt Köln.

Von Juli 1945 bis zum Jahr 1949 war ich leitender Angestellter der Britischen Militărregierung von Köln-Bonn. Ich schied auf eigenen Wunsch aus und wurde Geschäftsführer einer großen Kölner Vermögensverwaltungsfirma.

Da das Vermögen meiner Familie in Berlin vernichtet, das Gut Blumenow/Mecklenburg enteignet und das Auslandsvermögen meiner Eltern sequestriert und verwirtschaftet worden war, mußte ich fortan zur Erfüllung meines 
Wunsches, politische Wissenschaften zu studieren, ständig einer Berufstätigkeit nachgehen.

1949 wurde ich an der Universităt zu Köln in der Wirtschafts- und Sozialwissenschaftlichen Fakultăt zum Studium eingeschrieben. Ich studierte neben Nationalökonomie und Betriebswirtschaftslehre ebenso systematisch Philosophic, Historie, Rechtswissenschaften, Bankbetriebslehre, Soziologie, Sozialpolitik, Steuerrecht sowie Revisions- und Treuhandwesen. Im Jahr 1958 bestand ich das Examen als Diplom-Volkswirt, 1959 dasselbe als DiplomKaufmann und danach noch Zusatzprüfungen in Treuhandwesen und Steuerrecht.

Mein Studium habe ich durch stăndige Beratungstätigkeit finanziert. Im Jahr 1959 bestand ich vor der Oberfinanzdirektion Köln die amtliche Prüfung für die Befugnis zur geschäftsmäßigen Steuerberatung. Seit dieser Zeit betreibe ich selbstăndig eine eigene Steuerberatungspraxis.

Nebenberuflich war ich seit 1967 bis 1983 ständig als freiberuflicher Dozent an der Volkshochschule K.öln und anderen Einrichtungen der Erwachsenenbildung tätig.

Auch nach Beendigung meines Studiums habe ich stets die Verbindung zur Universität zu Köln durch kontinuierlichen Besuch vieler Seminarveranstaltungen verschiedener Fakuitäten aufrecht erhalten.

Meine besonderen Interessen richten sich bis heute auf die praktische Bedeutung der Lehren der im 19. Jahrhundert herausragenden Gelehrten Gustav von Schmoller, Carl Menger, Adolph Wagner und anderer. Aus diesem Grund und wegen einer früheren wissenschaftlichen Veröffentlichung wurde ich im Jahr 1988 gebeten, das Referat über den Rektor der Berliner Universităt von 1897, Gustav von Schmoller, als Beitrag der Freien Universităt Berlin zu den 750Jahr-Feiern der Stadt Berlin zu halten.

Ich bin verheiratet mit Marlis, geb. Wimber, und habe drei erwachsene Kinder, einen Schwiegersohn und zwei Enkelkinder. 

ISSN $0505-9372$

ISBN 3-428-08507-8 